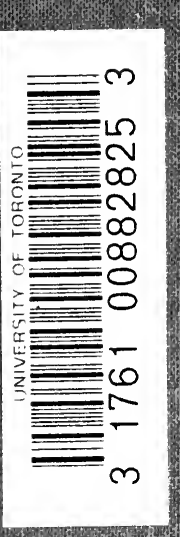

$y^{4} x^{4}$

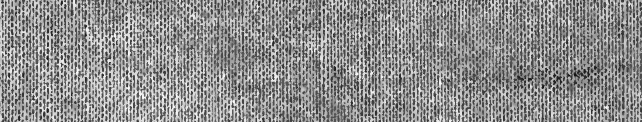
4 


$$
\text { - }
$$





\section{KRITIK DER \\ ÖFFENTLICHEN MEINUNG \\ VON

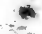

\section{FERDINAND TÖNNIES}

III

(2) $\rightarrow$ II

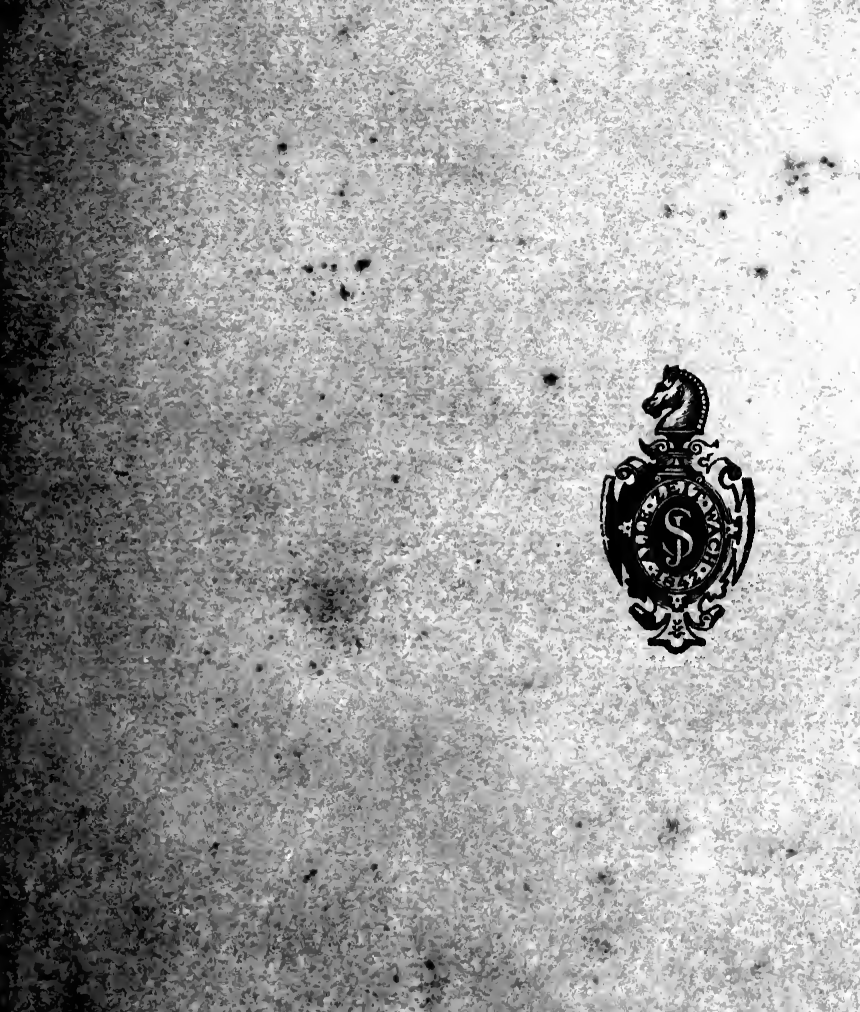

BERLIN

VERYAG VON JULIUS SPRINGER 1922 



\title{
KRITIK DER
}

\section{ÖFFENTLICHEN MEINUNG}

VON

\author{
FERDINAND TÖNNIES
}

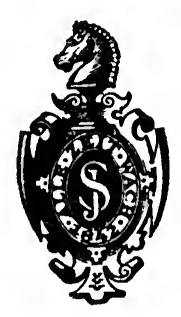

BERLIN

VERLAG VON JULIUS SPRINGER 


\section{Verfasser von:}

Gemeinschaft und Gesellschaft. Grundbegriffe der reinen Soziologie.

Vierte und fünfte Auflage. Berlin, Karl Curtius. 1922.

Der englische Staat und der deutsche Staat.

Eine Studie. Viertes Tausend. Daselbst 1917.

Philosophische Terminologie in psychologisch=soziologischer Ansicht.

Daselbst 1906.

Thomas Hobbes der Mann und der Denker.

$Z_{\text {weite }}$ Auflage von Hobbes' Leben und Lehre. Stuttgart, Fr. Frommanns Verlag 1912.

Marx' Leben und Lehre.

Berlin, Verlag für Sozialwissenschaft. 1921.

27.4.56 Die Sitte. 〈Die Gesellschaft Band XXV.〉

Frankfurt a. M., Rütten \& Loening. 1909.

Die Entwicklung der sozialen Frage bis zum Weltkriege. 〈Sammlung Göschen.) Dritte Auflage. Berlin, Vereinigung wissenschaftlicher Verleger. 1919.

Englische Weltpolitik in englischer Beleuchtung.

Fünftes und sechstes Tausend. Berlin, Julius Springer. 1915.

Deutschlands Platz an der Sonne.

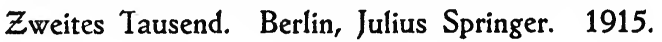

Weltkrieg und Völkerrecht.

Erstes bis drittes Tausend. Berlin, S. Fischer. 1917.

Die Schuldfrage.

Rußlands Urheberschaft nach Zeugnissen aus dem Jahre 1914.

Drittes und viertes Tausend. Berlin, Georg Stilke. 1919.

Alle Rechte, insbesondere das der ubersetzung in fremde Sprachen, vorbehalten.

Copyright 1922 by Julius Springer in Berlin. 


\section{DEM ANDENKEN \\ MEI NES F R U N D E S \\ KARL ROTHE \\ 〈1848-1921〉}

WEIL. GROSSH. SÄCHSISCHEN STAATSMINISTERS

EHREN-DOCTORS DER 4 FAKULTÄTEN DER UNIVERSITÄT JENA

Vus tis tain....

$$
\begin{aligned}
& \text { inum 18. Bhing } 1926 \\
& \text { trains } y / \mu \text {. }
\end{aligned}
$$


„Die öffentliche Meinung verdient daher eben so geachtet als verachtet $z u$ werden, dieses nach ihrem konkreten Bewußtsein und Außerung, jenes nach ihrer wesentlichen Grundlage, die, mehr oder weniger getrübt, in jenes Konkrete nur scheint."

He ge 1 


\section{Vorwort.}

Am I. März I907 wurde mir vom Herrn Verlagsbuchhändler und Schriftsteller O. HAERING - der angesehene Verlag ist seitdem auf die Firma JULIUS SPRINGER übergegangen - der Antrag gestellt, ein Werk über die öffentliche Meinung zu verfassen. Herr HAERING machte mich auf das damals neue Buch von GABRIEL TARDE "L'opinion et la foule" aufmerksam; ihn habe Herr Professor GeORG JELLINEK darauf hingewiesen. Ich schätzte seit vielen Jahren TARDE S Schriften hoch, wußte aber auch, $\mathrm{da} ß$ unsere wissenschaftlichen Voraussetzungen, insbesondere die soziologischen, ziemlich weit voneinander entfernt waren; Herr HAERING selber sprach die Ansicht aus, ein deutsches Buch über die öffentliche Meinung müsse anders gestaltet sein. Ich willigte ein, ein solches zu verfassen; den Gegenstand hatte ich schon in meiner Schrift "Gemeinschaft und Gesellschaft" (I887) zu berühren gewagt, indem ich den Begriff der öffentlichen Meinung in meine Lehre vom sozialen Willen aufnahm. Meine Zurüstungen zu dem Werke waren während der nächsten Jahre durch vermehrte akademische Tätigkeit, die der Statistik und Sozialökonomik galt, dann zumal durch den Weltkrieg und die Pflichten, die er auch dem Gelehrten auferlegte, gehemmt worden. Dennoch begann ich im Jahre 1915, das Werk zu schreiben, und habe seitdem bis zum Herbst I92I darin fortgefahren, wenngleich mehrmals durch größere und kleinere Arbeiten, die aus den Nöten der Zeit entsprangen, Unterbrechungen eingetreten sind. $\mathrm{Z} \mathfrak{u}$ diesen Arbeiten rechne ich auch das kleine Buch ",MarX' Leben und Lehre“ (Jena I92I).

Eine furchtbare Wendung menschlicher Geschicke liegt zwischen jener Zeit, da ich zuerst an das Thema heranging, und dem heutigen Tage. Die Bedeutung der öffentlichen Meinung ist in Wirklichkeit und noch mehr in der Schätzung, die ihr zuteil zu werden pflegt, unermeßlich gewachsen. Diese Schätzung freilich ist schon seit dem Ausbruch der großen französischen Revolution so bedeutend gewesen, daß, auch abgesehen von der periodischen Presse, die mehr und mehr das Selbstbewußtsein gewonnen hat, ihre Trägerin zu sein, die Literatur der öffentlichen Meinung, d. i. die Gesamtheit der Lehren und Theorien, die über sie ans Licht getreten sind, in Deutschland und in anderen Ländern - neuerdings besonders in den Vereinigten Staaten - einen großen Umfang gewonnen hat. Die Entwicklungs- 
geschichte dieser Meinungen über die öffentliche Meinung bietet ein nicht geringes Interesse dar, und war von mir bestimmt, das letzte Buch dieses Werkes zu bilden. Bald erschien mir aber der Stoff zu groß, ich habe ihn darum einem besonderen Werke, das als Anhang des gegenwärtigen ihm bald folgen soll, vorbehalten. Es ist ein Stück Geistesgeschichte, das in diesen Reflexen sich darstellt; insbesondere wird man eine Abbildung der politischen Geschichte Europas und seiner Ableger seit der großen Revolution darin erkennen.

Auch nach Ausscheidung dieses Stoffes blieb die Aufgabe groß und schwer. In keinem Augenblick habe ich dies verkannt, niemals habe ich mir zugetraut, sie in vollem Umfange lösen zu können. Was ich mir vorsetzen durfte und zu leisten vermochte, war eine begriffliche Klärung des Gedankens über eine so wichtige soziologische Tatsache und Erscheinung. Darum habe ich meinem Werke den Titel „Kritik der öffentlichen Meinung" gegeben. Er bedeutet, daß der Sprachgebrauch geprüft und geläutert werden sollte, daß ich in einem bestimmt umrissenen Sinne den Begriff der öffentlichen Meinung zu gestalten mir vorgenommen hatte. Es erschien mir vor allem als notwendig, von der öffentlichen Meinung als einem Konglomerat mannigfacher und widersprechender Ansichten, Wünsche und Absichten die Offentliche Meinung als einheitliche Potenz, als Ausdruck gemeinsamen Willens $z u$ unterscheiden, und ich freute mich zu entdecken und darauf hinweisen zu können, daß ich mit dieser wichtigen Unterscheidung nicht ohne Vorgänger war.

Ferner hielt ich für geboten, die Offentliche Meinung in ihrem historisch bedeutsamen und politisch maßgebenden Sinne von den beliebigen öffentlichen Meinungen abzuheben, die zwar einheitlich, aber von eingeschränkter, teils lokaler, teils unpolitischer Bedeutung überall im sozialen Leben sich geltend machen.

Endlich lege ich ganz besonderes Gewicht auf die von mir getroffene Unterscheidung von Aggregatzuständen der öffentlichen Meinung, deren Sinn und Wert unmittelbar einleuchtend sein dürfte.

$\mathrm{Da}$ alle 3 Unterscheidungen für eine kritische Theorie der öffentlichen Meinung bedeutsam, ja notwendig sind, ist die These, an deren Behauptung mir vor allem gelegen ist.

Für wichtig halte ich auch die Scheidung des Begriffs der öffentlichen Meinung (und der Offentlichen Meinung) vom Begriffe der Volksstimmung und Volksgefühle. Daß ich diese nicht zuerst gefunden oder aufgestellt habe, wird in mehreren Stücken des in Aussicht genommenen Anhangsbandes über die Literatur der öffentlichen Meinung offenbar werden. Hier verweise ich nur auf eine Bestätigung durch den bekannten amerikanischen Soziologen GIDDINGS 
(Elements of sociology p. 155f.), die mit den Worten beginnt: ,Kein Irrtum ist gewöhnlicher als derjenige, der Volksstimmungen (popular beliefs) mit den sozialen Urteilen verwechselt, welche die echte öffentliche Meinung bilden (constitute)."

Durch das Buch hindurch geht ferner die keineswegs neue Deutung der Meinung als Willens, der öffentlichen Meinung als einer Form des'sozialen Willens. Bei dem Versuche, sie in die Lehre von dessen Gesamtformen einzugliedern, habe ich mich an das Schema gehalten, wie es in "Gemeinschaft und Gesellschaft" vorliegt, und erlaube mir, darauf aufmerksam zu machen, daß dieses Werk eben in vierter und fünfter Auflage (Verlag von KARL CURTIUS) erscheint. Das enge und nahe Verhältnis, einerseits der Abhängigkeit und Verwandtschaft, andererseits des Widerspruchs und Gegensatzes zur „Religion" als einer Gesamtform des sozialen Willens, ist ein Hauptmerkmal dieses Schemas und also ein Hauptstïck meiner Lehre von der öffentlichen Meinung. Als solches wird es nur richtig verstanden und gewürdigt werden von denen, die auch in diesem Gebiete die Bedingungen eines streng begrifflichen und kritisch-logischen, oder dialektischen Denkens kennen und anerkennen. Daß dies nicht bei allen Gelehrten des Faches vorausgesetzt werden darf, weiß jeder, der mit dem Schrifttum im Felde der Sozialwissenschaften hinlänglich vertraut ist.

Der größere Teil meines Buches stellt aber solche Anforderungen nicht an den Leser. In diesem größeren Teile werden Anwendungen der Lehre gegeben, die auch ohne theoretische Subtilitäten sich verstehen lassen, und Beispiele für die Bedeutung und Macht der öffentlichen Meinung im Staatsleben, die diese Abschnitte als einen Gang durch die neuere und besonders die neueste Geschichte erscheinen lassen, in deren Zerrïttungen und Neubildungen wir mitten inne stehen. Ich habe in diesen Abschnitten die öffentliche Meinung angenommen, wie sie sich gibt, nämlich vorzugsweise als die öffentliche Meinung des Tages und als die Richterin in öffentlichen, zumal politischen Angelegenheiten, die sie zu sein in Anspruch nimmt. Eben in diesen Anwendungen, im schwankenden Ubergang in den Sprachgebrauch, muß das erwähnte Verhältnis zur Religion zutage treten, und ich habe nicht versäumt, an manchen Stellen darauf hinzuweisen. Gemeinsam mit der Religion ist der Offentlichen Meinung - das ist ein Punkt, den ich mit Nachdruck betone - die nach innen verbindende $\mathrm{Kraft}$ und der verpflichtende Wille, der sich oft als sittliche Entrüstung und Unduldsamkeit gegen Andersdenkende äußert. $\mathrm{Da}$ diese Neigungen auch die Öffentliche Meinung bezeichnen, ist ihr bisher noch kaum in Selbsterkenntnis bewußt 
geworden und zwar wohl darum nicht, weil ihr Wollen und ihre Macht in dieser Hinsicht noch auf wenig Widerstand gestoßen ist. Darauf hinzuweisen, halte ich für ein Verdienst dieser meiner Schrift. Seit John StuarT MILIS berühmtem Büchlein "On Liberty", das HeINRICH von TREITSCHKE zu seiner Rede über die Freiheit (I86I) veranlaßte, ist es davon stille geworden.

Viele Leser, hoffe ich, werden mit mir einverstanden sein, daß ich das Buch nicht durch einen Troß von Anmerkungen belastet habe. Die unerläßlichen Zitate habe ich in den Text aufgenommen und halte dies für ersprießlicher. Durch die Ausscheidung des literarhistorischen Teiles habe ich mir Hinweise auf ähnliche oder anders gerichtete Urteile anderer Autoren im allgemeinen erspart.

Anstatt die lästigen Bemerkungen ,Sperrdruck von mir" $\mathfrak{u}$. dgl. einzuschalten, habe ich seit lange begonnen, zitierte Stellen, die ich hervorheben will, obgleich sie in der Vorlage der Hervorhebung entbehren, nicht nur gesperrt setzen zu lassen, sondern zugleich in Asterisken einzuschließen. Da ich bisher keine Nachfolge gefunden habe, so muß ich immer von neuem darauf aufmerksam machen.

Das Namen- und Sachverzeichnis ist mit Sorgfalt von meiner Tochter Franziska angefertigt worden, die auch durch Korrektur des Satzes sich um das Buch verdient gemacht hat.

$\mathrm{Da} ß$ der Verlag dem Buche, trotz der so schwierigen Verhältnisse dieser Zeit, ein gefälliges Aussehen zu geben gewußt hat, wird der Leser mit dem Verfasser dankbar anerkennen.

Kie1, Ostern I922.

FERdinand TONNIES. 


\title{
Inhaltsverzeichnis.
}

\author{
Erstes Buch. \\ Begriff und Theorie der öffentlichen Meinung.
}

\author{
I. Kapitel. Meinen und Meinung.
}

Erster Abschnitt. Grundbegriffe . . . . . . . . . . . . .

I. Etymologie 3. - 2. Wahrnehmen 3. - 3. Denken 4. - 4. Erkennen und Wissen 5. - 5. Meinen 6.

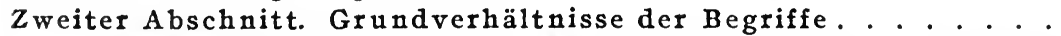
6. Meinen und Wollen (I) 7. - 7. Meinen und Wollen (II) 8. - 8. Meinen und Wollen (III) 9. - 9. Meinen und Wollen (IV) Io. - Io. Meinen und Wollen (V) I I. - I I. Begriff der Meinung I2. - I2. Meinen und Glauben I3. - I3. Glauben und Meinen I4. - I4. Der Glaube 15. - I5. Glaube als Pflicht 15. - I6. Glaube und Wahn I6. - I7. Glaube und Wille I6.

Dritter Abschnitt. Verhältnisse $z$ ur Wissenschaft . . . . . . . 18. Wesenwille und Kürwille I8. - r9. Begriffe, Glauben und Meinen I9. - 20. Wissen und Meinen 20. - 21. Kampf zwischen Glauben und Wissen 21. - 22. Streit zwischen Religion und Wissenschaft 22. - 23. Erlaubte und verbotene Meinungsäußerung 22. - 24. Aggregatzustände der Meinung 23. - 25. Wille in der Meinung 25.

\section{Kapitel. Gemeinsame Meinungen.}

Erster Abschnitt. Bedingungen der Gemeinsamkeit . . . . . . 1. Wahrscheinlichkeit der Ưbereinstimmung 25. - 2. Die Schwierigkeit der Sache 26. - 3. Lebensbedingungen 27. - 4. Tieferer Gegensatz 30. Differenzierung 31. - 5. Meinungen und Meinungsäußerungen 32. 6. Wahlen und Abstimmungen 35. - 7. Führung 37. - 8. Meinungen als Pflichten 39. - 9. Gemeinsame Meinung - gemeinsamer Wille 4I. Io. Verbindende Meinungen 43. - Ir. Úbereinstimmung und Nötigung 44. $Z_{w}$ eiter Abschnitt. Rationale und irrationale Formen des gemeinsamen Willens.................... I2. Beschlu $B$ und Beschlüsse 46. - I3. Sinn von Beschlüssen über Meinungen 50. - I4. Analogien des Beschlusses 51. - 15. Parallele von Brauch und BeschluB 53. - I6. Begriff der Lehre 55. - I7. Die richtigen Meinungen 58. - I8. Begriff und Lehre 60. - 19. Das Schlagwort 62. 20. Formen des Kollektivwillens. A. Eintracht - Sitte - Religion 66. 2I. B. Konvention - Gesetzgebung - öffentliche Meinung 70.

Dritter Abschnitt. Anwendung für öffentliche Meinung . . . . 22. Offentliche Meinung und Propaganda 77. - 23. Verhältnisse der sozialen Willensformen zueinander 80 .

\section{Kapitel. Offentliche Meinung.}

Erster Abschnitt. Das öffentliche Wesen . . . . . . . . . . I. Meinungsäußerung 8 I. - 2. Zeichen 8 r. - 3. Publikum 82. - 4. Das große Publikum 84. - 5. Stumme und laute Zeichen 86. - 6. Mitteilung 87. - 7. Schriftsteller 88. - 8. Denker 89. - 9. Meinungskämpfe 89. ro. Der Buchdruck 90. - I I. Zeitungen 9 I. 


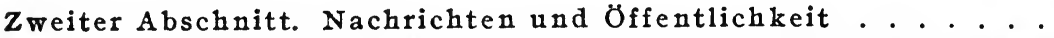
12. Gemeinschaft und Überlieferung 9r. - 13. Gesellschaft und Mitteilung 92. - I4. Staatsnachrichten 94. - I5. Handelsnachrichten 95. 16. Das Bedürfnis der Nachrichten 96. - I7. Verbreitung 97. - I8. Fälschung 97. - I9. Nachrichten und Meinungen 99. - 20. Erörterung 99.

Dritter Abschnitt. Öffentliches Leben und Parteiung . . . . . 2I. Öffentlichkeit roo. - 22. Öffentlichkeit im Mittelalter roo. - 23. Theologie ror. - 24. Die Fakultäten ror. - 25. Das öffentliche Leben ro3. 26. Meinung und Selbsterhaltung 104. - 27. Meinungen und Interessen 106. - 28. Parteien (I) ro8. - Parteien (II) I I2. - 30. Parteien (III) II4. - 31. Zusammenhänge II5. - 32. Kreuzungen (II6).

Vierter Abschnitt. Kampf und Freiheit. . . . . . . . . 33. Soziale Gegensätze II7. - 34. Öffentliches Meinen r21. - 35. Soziale Kämpfe 122. - 36. Gewissensfreiheit 124. - 37. Preßfreiheit 125. 38. Redefreiheit 126. - 39. Neubürgerliche Herrschaft 128. - 40. Öffentliche Meinung und eine öfentliche Meinung 129.

IV. Kapitel. Offentliche Meinung und die Offentliche Meinung.

Erster Abschnitt. Entstehung und Charakter der Öfentlichen Meinung . . . . . . . . . . . . . . . . . . . . I. Sprachgebrauch und Begriffe r3r. - 2. Die Analogie der Versammlung 133. - 3. Die Grenzen der Hörweite 135. - 4. Die Presse 136. 5. Aggregatzustände der Öffentlichen Meinung 137. - 6. Verallgemeinerung einer Teilmeinung r39. - 7. Kämpfe um die Öffentliche Meinung I4I.

Zweiter Abschnitt. Näheres über politische Kämpfe . . . . . 8. Regierung und Presse 147. - 9. Die Defensive 151. - ro. Cäsaristische Methoden 152. - Ir. Die Öffentliche Meinung als Regierung 155. 12. Staatsmänner und die Öffentliche Meinung 157. - I3. BISMARCKs Ansicht 164. - 14. Konservative und reformative Parteiung 165. 15. Orthodoxe und heterodoxe Meinungen 174. - 16. Öffentliche Meinung beiderlei Sinnes im Verhältnis zur Presse 177 .

Dritter Abschnitt. Vulgäre Erscheinung der Öffentlichen Meinung 17. Öffentliche Meinung und das Zeitungsgeschäft 178. - 18. Korruption 182. - 19. Unabhängige Presse und Öffentliche Meinung 183. 20. Zusammenhang mit den Aggregatzuständen der Öffentlichen Meinung 187.

Vierter Abschnitt. Höhere Erscheinungen der Öffentlichen Meinung . . . . . . . . . . . . . . . . . . . . . . . . . 21. Ausdrucksformen und Ausdrucksmittel der öffentlichen Meinung nach W. BAUER 189. - 22. Ergänzungen 195. - 23. Rückwirkungen Mache - Analogien der Religion 199. - 24. Verbindung, Verpflichtung 203. - 25. Führer der Öffentlichen Meinung 206.

Zweites Buch.

\section{Empirische Beobachtungen und Anwendungen.}

\section{Kapitel. Die Offentliche Meinung und ihre Merkmale.}

Erster Abschnitt. Soziologische Zusammenhänge der Öffentlichen Meinung . . . . . . . . . . . . . . . . . . r. Die Formen des sozialen Willens 219. - 2. Die Entwicklung der sozialen Willensformen 220. - 3. Zusammenhänge 221. - 4. Unterschiede der Individuen 222. - 5. Sekundäre Unterschiede 223. - 6. Die Richtung auf Gesellschaft 224. - 7. Individuelle Anlagen 226. 
$Z_{\text {weiter Abschnitt. Soziologische Wechselwirkungen }}$ 8. Anwendung auf die Öffentliche Meinung 228. - 9. Religion und Öffentliche Meinung 229. - ro. Gemeinsame und unterscheidende Merkmale 235. - Ir. Moral der Religion und Moral der Offentlichen Meinung 236. - 12. Ordnung, Recht, Moral 239. - 13. Empirische Merkmale der ephemeren Öffentlichen Meinung 245. - I4. Gefühlspolitik der Öffentlichen Meinung 253.

\section{Kapitel. Allgemeine Inhalte der offentlichen Meinung in ihren neuzeitlichen} Gestaltungen.

Erster Abschnitt. Das soziale und ökonomische Gebiet . . . $25^{8}$ r. In der festen Öffentlichen Meinung 258. - 2. In der flüssigen Öffentlichen Meinung 262. - 3. In der luftartigen Öffentlichen Meinung 264 .

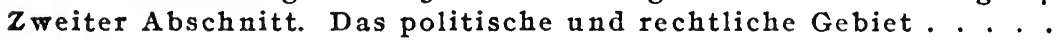
4. In der festen Öffentlichen Meinung 268. - 5. In der flüssigen Öffentlichen Meinung 27r. - 6. In der luftartigen Offentlichen Meinung 276.

Dritter Abschnitt. Das geistige und sittliche Gebiet ...... 7. In der festen Öffentlichen Meinung 279. - 8. In der flüssigen Öffentlichen Meinung 287. - 9. In der luftförmigen Öffentlichen Meinung 29r.

Vierter Abschnitt. Urteile der Moralphilosophen über die allgemeinen Inhalte . . . . . . . . . . . . . . . . . . . 10. HobBes, LOCRE, MANDEviLLE, Helvetius, SMirh 293. - Ir. Neuere Moralphilosophen 297.

\section{Kapitel. Macht und Machtfaktoren der Offentlichen Meinung.}

Erster Abschnitt. Die Macht. ............... r. Neuerungen 299. - 2. Das Moment der Öffentlichen Meinung 301. 3. Verhältnis zur Kîrche um die Wende der Neuzeit 302. - 4. Die Wucherfrage 306. - 5. Kirche und Staat 309.

Zweiter Abschnitt. Die Machtfaktoren . . . . . . . . . 6. Übergänge der Aggregatzustände 3II. - 7. Eindrücke 314. -8 . Debatte 317. - 9. Staatsreden, Gespräche, Briefe 318.

VIII. Kapitel. Die offentliche Meinung als Faktor des Staatslebens.

Erster Abschnitt. Die Öffentliche Meinung in Amerika ..... r. Die Anerkennung der Tatsache 321. - 2. Vereinigte Staaten 322. 3. Die Organe der Öffentlichen Meinung in Amerika 324. - 4. Faktoren der Öffentlichen Meinung 326. - 5. Einfluß von Klassen 327. - 6. Wirksamkeit 328. - 7. Mehrheit und Menge 33r. - 8. Schätzung der Öffentlichen Meinung 33r. - 9. Kritik (I) 334. - ro. Kritik (II) 335. Ir. Kritik (III) 340. - I2. Andere Auffassungen - OSTROGoRSKI 345. - 13. Andere Zeugnisse 35r. - I4. Amerikanische Ansicht 353. 15. Schlußfolgerungen 355. - 16. Nachträge zu BRYCE 359.

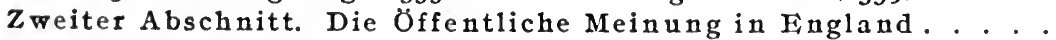
17. Grundzüge 362. - 18. Reformbill - Freihandel 366. - 19. Die Offentliche Meinung im neuesten England 372.

Dritter Abschnitt. Die Öffentliche Meinungim französischen Staat 20. NeCKER und die große Revolution 374. - MIRABEAU, SiEyìs u. a. 378. - 22. GeORg Forster 385. - 23. Frau voN StaËI, 388. - 24. NiEBUHR, TOCQUEVILLE, ANTON SPRINGer 392. - 25. Die Öffentliche Meinung Frankreichs in neuester Zeit 396. - 26. Die Friedensbedingungen I871 398. - 27. Exkurs 401 .

Vierter Abschnitt. Die Offentliche Meinung im deutschen State 28. Allgemeines 40r. - 29. PERTHes über die deutsche Staatsgesinnung 407. - 30. Wirkungen der Revolution, Freiherr vom STEIN 4 IO. - 
31. Die Öffentliche Meinung bis I 848 , die Burschenschaft 4 I5. -32 . Die Paulskirche 418. - 33. Preußens Revolution 424. - 34. Die Reaktion, Bismarcks Kampf gegen die Öffentliche Meinung 428. - 35. Die Öffentliche Meinung unter WILHELM II. 434.

\section{Drittes Buch.}

\section{Besondere Fälle der Öffentlichen Meinung.}

IX. Kapitel. Die Offentliche Meinung und die soziale Frage.

Erster Abschnitt. Das allgemeine Verhältnis . . . . . . . . .

I. Grundlagen 439. - 2. Sozialistische Lehren 44r. - 3. Der Handel 444.

Zweiter Abschnitt. Die besonderen Probleme.......... 4. Das Koalitionsrecht 447. - 5. Das Genossenschaftswesen 455.

Dritter Abschnitt. Verhältnis zur Sozialdemokratie und Arbeiterbewegung . . . . . . . . . . . . . . . . . 462

6. Die Sozialdemokratie 462. - 7. Wandlungen der Öffentlichen Meinung 472. - 8. Der Sozialismus in anderen Ländern 479. - 9. Streiks und Aussperrungen 490. - Io. Veränderungen des Urteils 500.

X. Kapitel. Die Offentliche Meinung und der Weltkrieg.

Erster Abschnitt. Vor dem Weltkriege . . . . . . . . . .

I. Vor dem Weltkriege in Deutschland 504. - 2. Vor dem Weltkriege in England 510. - Vor dem Weltkriege in Frankreich 525. - 4. Vor dem Weltkriege in Rußland 530. - 5. Vor dem Weltkriege in anderen Ländern 539.

Zweiter Abschnitt. Die Öffentliche Meinung während des Weltkrieges . . . . . . . . . . . . . . . . .

6. Im allgemeinen 544. - 7. In Deutschland während des Weltkrieges 546.

- 8. In England während des Weltkrieges 550. - 9. Frankreich während des Weltkrieges 555 . - 10. Rußland während des Weltkrieges $55^{8}$.

Dritter Abschnitt. Die Öffentliche Meinung nach dem Weltkriege II. Im allgemeinen und in Deutschland 559. - I2. In Frankreich 565. 13. In England 566. - I4. In den übrigen Ländern 568.

XI. Kapitel. Die Zukunft der Offentlichen Meinung.

I. Verhältnis zur Religion 569. - 2. Mögliche Entwicklungen 572. 3. Die Reform der Presse 574.

Namenverzeichnis . . . . . . . . . . . . . . . 576

Sachverzeichnis . . . . . . . . . . . . . . . . 580

\section{Berichtigung.}

Seite 17 , Zeile 6 von unten: wirklich statt wörtlich.

Seite 500, Zeile 9 von unten: Bötticher statt Böttiger. 
Erstes Buch

\section{Begriff und Theorie der öffentlichen Meinung}




\section{Kapite1. \\ Meinen und Meinung.}

\section{Erster Abschnitt. Grundbegriffe.}

I. (Etymologie.) Die Wörter gehen auf eine Wurzel zurück, die im Sanskrit die einfache Form man in der Bedeutung "bewußt sein" hat - auch ein Verbum manyatê, das den Sinn des Denkens, Meinens trägt, gibt es in dieser alten priesterlichen Sprache. In der griechischen und der lateinischen Sprache gibt es viele Wörter, die aus der gleichen Wurzel stammen. Und der Ursinn dieser Wurzel wird sogleich klar, wenn uns aus diesen Sprachen andere Wörter entgegentreten, denen die Bedeutung des Bleibens, Beharrens innewohnt. Denn die Wurzeln sind (nach Fick, S. I $^{6} 6^{1}$ )) identisch. Und die Bedeutungen begegnen einander in den Wörtern, die Gedächtnis, Erinnerung bedeuten: lat.

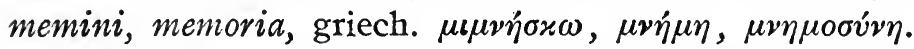

Die Beharrung ist Grundbegriff der Naturwissenschaften und sollte in gleicher Weise von den Geisteswissenschaften aufgenommen werden. $\mathrm{DaB}$ auch Bewegung (nicht von selber in Ruhe übergeht, sondern) in gleicher Richtung, mit gleicher Geschwindigkeit bleibt, sofern sie nicht durch eine ihr äußere Kraft abgelenkt oder gehem:mt oder beschleunigt wird, ist die Erkenntnis, woraus GaLILEI die Hauptgesetze der Mechanik abgeleitet hat.

Analog ist die Tendenz des Beharrens der Empfindung. Denn sie ist eine Folgerung aus der Tatsache des Lebens selber, das ohne Empfindung nicht ist und im Mannigfachen der Empfindungen sich äußert. Darum ist schon manchesmal Gedächtnis (Mneme) für eine Funktion der Materie erklärt worden und auch den lebenden Elementarorganismen (den "Zellen«) von Naturforschern Gedächtnis zugeschrieben worden. In der Tat, wie wir alles Geistige in den Raum werfen, um es zu begreifen, so können wir nicht umhin, uns auch das Beharren der Empfindung als fortgesetzte Bewegung in einer geraden Linie vorzustellen, wenn wir auch wissen, daß es ein Gleichnis ist.

2. (Wahrnehmen.) Allerdings ist keine Wahrnehmung erklärbar, ohne daß Gedächtnis mitwirkend gedacht wird. Niemand glaubt noch, daß die Gegenstände selber auf einer passiven Fläche - des Geistes oder speziell des Sinnesorgans - mehr oder minder ähnlich sich abbilden. Sondern die Seele und ihre Organe sind immer

1) Vergleichendes Wörterbuch der indog. Sprache. 2. Aufl.

Tönnies, Kritik. 
tätig: als die »innere« oder subjektive Wirklichkeit des lebendigen Leibes. Andere Dinge - oder psychologisch verstanden andere Seelen - stehen ihnen gegenüber und in Wechselwirkung mit ihnen. Aber jede Empfindung ist Tätigkeit und aus vielen Empfindungen eines Sinnes gestaltet der Sinn die Wahrnehmung, insbesondere schafft der Gesichtssinn aus der Mannigfaltigkeit von Lichtempfindungen und ihren Widerständen das »Bild " des Gegenstandes. Auch das Bild ist nichts anderes als eine Tätigkeit, die Wahrnehmung selber, und das Beharren des Bildes ist zugleich die Möglichkeit und Wahrscheinlichkeit seiner erneuten Schaffung (der »Reproduktion«). Es wird "geweckt» durch 》Reize» - innere oder äußere - ; es kann geweckt werden, weil es noch lebt. Das Zusammenwirken des Gesichts mit dem Tastsinn bildet die Bilder der Wahrnehmung, die als Vorstellungen aufwachen. Wirksame Reize erlangen die größte Bedeutung als Zeichen, deren Wahrnehmung das Wiederauftauchen schlummernder Vorstellungen erleichtert. Da treten dann die Wahrnehmungen des Gehörs hinzu, die Auffassungen von "Lautbildern*, die als Zeichen wirken und mit den Vorstellungen Gefühle auslösen. Darin beruht die menschliche Sprache, und in der menschlichen Sprache das menschliche Denken.

3. (Denken.) Denken ist die schwerste, verwickeltste, bedeutendste psychische Tätigkeit.

Alle seelische Tätigkeit ist wesentlich Verbindung und Trennung von Elementen (der Empfindung, Wahrnehmung, Vorstellung oder der Gefühle), Zusammensetzung (Synthese) und Auflösung (Analyse), Bejahung und Verneinung ihres Zusammenseins, ihrer Zusammengehörigkeit, ihrer Einheit.

Alle seelische Tätigkeit kann als "Leiden", als etwas Passives aufgefaßt werden, auch das Denken. "Es denkt in mir»: die Vorstellungen, durch Lautbilder erregt, kommen und gehen, verbinden sich und trennen sich, nehmen ihren Lauf, hemmen und fördern, verlangsamen und beschleunigen einander. In Wahrheit ist der Begriff der Tätigkeit notwendig, um die Unterschiede zwischen verschiedenen Arten seelischer Bewegungen zu bezeichnen; sie sind mehr empfangend, leidend ("passiv«) oder mehr wirkend, bildend, erzeugend ("aktiv«): so hebt vom Gefühl als der wesentlichen Begleiterscheinung oder vielmehr "Innenseite" des vegetativen Lebens die gesamte animalische Tätigkeit sich ab, zu der auch das ganze Gebiet der Empfindung gehört: vom nackten Empfinden ebenso das Wahrnehmen, vom Wahrnehmen das Vorstellen, vom Vorstellen das Denken. Das Zunehmen des Tätigseins pflegt als Zunahme des "Bewußtseins» verstanden $\mathrm{zu}$ werden, und die be- 
wußtesten" Tätigkeiten gelten als Tätigkeiten des "Willens». In Wahrheit handelt es sich um eine kontinuierliche Skala, auf der man Stufen (》Grade«) abzeichnen kann, um die Höhe des Bewußtseins zu messen; es sind Grade der Helligkeit, in denen "die Seele" sich selbst beleuchtet oder, wie man es auch nennen kann, ihrer, und der ihr entsprechenden leiblichen Tätigkeiten bewußt »wird».

Denken, insofern es das Urteil in sich enthält, ist Verbinden oder Trennen von Vorstellungen. Als solches ist es den anderen seelischen Tätigkeiten um so näher verwandt, je mehr diese deutlich unterschiedene Elemente verbinden oder trennen. Das $₫$ Erkennen ist die allgemeine Funktion.

4. (Erkennen und Wissen.) Das Wort serkennen s hat ebenso wie "kennen" und "wissen" eine Beziehung auf die Vorstellung des wirklich Seienden und Wahren. Wenn ich von jemandem aussage: er oder sie skennt» das Buch, das Gedicht, das Schauspiel, so versteht es sich von selbst, daß damit zugleich das Dasein des Buches, des Gedichts, des Schauspiels ausgesagt wird; ebenso wie mit der Aussage: er oder sie "weiß», daß BISMARCK I8I5 geboren wurde, NAPOLEON I82I gestorben ist, es sich versteht, daß die Wirklichkeit dieser Geschehnisse behauptet wird. Alle solchen Sätze lassen sich in die zwei Urteile auflösen: I. Die Sache $\mathrm{x}$ ist vorhanden, oder das Ereignis y ist geschehen; 2. NN besitzt »die Kenntnis» dieser Sache oder dieses Ereignisses, what" sie in seinem "Bewußtsein". Beide Urteile können irrig sein, das zweite unabhängig vom ersten. Wenn aber das erste irrig ist, so verliert das andere seinen Sinn. Ebenso ist die Bedeutung des Wortes ser kennen". „Nachdem ich den Fremden lange betrachtet hatte, erkan nte ich ihn endlich“ - d. h. I. ,,es war (oder ist) mein Jugendfreund $A^{\prime \prime}$, und 2. ich erwarb die Kenntnis dieser Tatsache, ich empfing sie in meinem "Bewußtsein". „Ich erkannte, da $B$ ich mich auf einem falschen Wege befand", d.h., I. der Weg, auf dem ich mich befand, war ein unrichtiger Weg; 2. ich wurde dessen ninne , ich gewahrte diese Tatsache. (Zeitwörter, wie wahrnehmen, gewahren haben eben dieselbe Beziehung auf das Wahre oder Wirkliche.) Da das Erwerben immer der Prozeß eines Werdens ist, so wird das Wesen des Erkennens gut ausgedrückt durch ein griechisches Wort wie $\gamma \iota \gamma \nu \omega \sigma \varkappa \omega$, lateinische wie cognosco, scisco; denn die auf sco lautenden Derivate bezeichnen alle, wie cresco, ein Wachsen und Werden.

Die Sprachen ermangeln aber der Wörter, die geeignet wären, die Tätigkeit des Erkennens ohne Beziehung auf ihren Gegenstand (als wahren oder wirklichen) zu bezeichnen. Wenn ausgesagt wird, jemand glaube oder meine zu wissen (eine Sache oder eine Person zu 
"kennen«), ja er sei überzeugt, sei völlig sicher und gewiß, so versteht man immer, daß n ur eine Tatsache von subjektivem Charakter ausgesagt wird; es ist nicht im mindesten darin enthalten, daß der Gegenstand wirklich vorhanden oder wirklich so beschaffen, daß das Ereignis wirklich geschehen sei; so wenig, als wenn einfach gesagt wird: er glaubt, er meint, er ist uiberzeugt, daß ... In gleicher Weise kann man freilich auch sagen: er glaubt (oder meint oder ist überzeugt) zu erkennen, aber da ist ein Unterschied vorhanden. Wenn ich $z u$ wissen glaube (z. B. daß NN heute in Berlin verweilt), so kann mein Irrtum (ebenso die Richtigkeit meiner Meinung) sich auf die angeblich gewußte Sache beziehen (NN ist heute nicht in Berlin) oder aber obgleich die Tatsache richtig ist, so irre ich doch, wenn ich sie zu "wissen " glaube; in Wahrheit habe ich sie nur erraten oder vermutet. Eine Tatsache kann auf verschiedene Weise psychisch besessen werden: das Gefühl der Gewißheit und Sicherheit, womit sie besessen wird, kann der Wirklichkeit entsprechen, es kann aber auch trügerisch sein: in Wahrheit ist man gar nicht sicher und gewiß, wie sich z. B. herausstellt, wenn ein anderer dagegen streitet. Hingegen, wenn ich zu erkennen glaube, so ist nur der eine Irrtum möglich: was ich zu erkennen glaube, das ist nicht. Eine Tatsache kann nicht auf verschiedene Arten psychisch erworben werden. Wenn sie ist und erworben wird, so ist die Erwerbung immer Erkenntnis, ob nun die Erkenntnis durch Wahrnehmung oder durch Denken erworben wird.

Daher kann man auch, ohne gegen die Sprache Gewalt zu üben, das Erkennen gleichsam neutral auffassen - die Beziehung auf den Inhalt als wirklichen abstreifen und nur die Tätigkeit als solche bezeichnen, die also das Gemeinsame des.Wahrnehmens und Denkens in sich schließt, insofern als beide darauf abzielen, Kenntnis zu erwerben. Beharren von Empfindungen und Vorstellungen, also was als Gedächtnis verstanden wird, ist die Voraussetzung beider. Und das Beharren ist auch das Wesen des Meinens. Sobald als eine Vorstellung die Form eines Urteils annimmt, ist sie Meinung. Eine Vorstellung nimmt aber die Form eines Urteils an, wenn sie aus zerlegbaren Elementen besteht: deren Verknüpfung oder Auseinanderhaltung ist das Urteil.

5. (Meinen.) Daher ist Meinen und Denken einerlei, wie auch der Sprachgebrauch beide Wörter zu verwechseln pflegt. Als Denken aber wird im flüssigen Zustande aufgefaßt, was als Meinen gleichsam im geronnenen Zustande sich darstellt. Denken ist ein eigentliches Tätigkeitswort. Meinen ist es nur der Form nach, seinem Inhalte nach zeigt es ein Haben, ein Besitzen an, es ist perfektisch; 
Meinen, soviel wie "die Meinung haben " oder hegen, der Ansicht sein, sich das Urteil gebildet haben, zu dem Schlusse gekommen sein. So auch im Lateinischen: opinari $=$ in opinione esse. Im Althochdeutschen gehörte $\operatorname{man}=$ ich meine zu den Zeitwörtern, die trotz der präsentischen Bedeutung auch die Form des Perfektums hatten, den sogenannten Praeterito-Praesentia, die aber unrichtig so genannt werden: „Da das Perfektum kein Tempus der Vergangenheit war, sondern nur den Zustand des Vollendet- und Fertigseins bezeichnete, so begreift man leicht, daß, wenn die zugehörigen Präsensformen außer Gebrauch kamen ... das Perfektum ganz wie ein Präsens empfunden wurde." (Wilmanns, Deutsche Grammatik, 3. Abt., I. H., S. 93.) Treffender noch bezeichnet WestPhal, (Deutsche Grammatik S. 235) das Perfektum seinem ursprünglichen Wesen nach, als ein durch Wurzelreduplikation erweitertes Präsens, und seiner Bedeutung nach als ein zunächst die Gegenwart bezeichnendes Tempus, ,aber diese Gegenwart ist keine dauernde Gegenwart wie beim Präsens, sondern eine vollendete" - besser: sie ist keine fließende, werdende, sondern eine feste, geronnene, vollendete Gegenwart.

$\mathrm{Zu}$ dieser perfektischen Bedeutung des Meinens paßt nun vortrefflich der Ursinn des Beharrens und Bleibens. Wird dieses wiederum als Tätigkeit gedacht, so ist es das Festhalten, was psychologisch zum Besitz gehört, sofern der Besitz als zu dem besitzenden Wesen gehörig, als ein Stück von ihm empfunden wird. So wollen wir das Meinen des Menschen begreifen als ein Festhalten seines geistigen Besitzes; das Wort "Hegen» dürfte diesen Sinn gut ausdrücken.

\section{$Z$ weiter Abschnitt. Grundverhältnisse der Begriffe.}

6. (Meinen und Wollen, I.) In Wahrheit erkennt man leicht, daß das Meinen der Menschen mit ihrem seelischen Wesen, also mit ihrem Wesen-Willen, aufs innigste zusammenhängt. Wie und weil das Denken abhängig ist vom Wünschen und Begehren, von Hoffnung und Furcht, vom Trachten und Streben.

Etymologisch ist der Zusammenhang sichtbar im lateinischen Worte opinio, das in alle romanischen Sprachen und ins Englische

g egangen ist. Denn hier liegt die Wurzel op-wie in optare, optimum, zugrunde, und als Urbedeutung wird Erwartung, Hoffnung angegeben. Darin kommt zum Ausdruck, da $\beta$ der Mensch leicht für wahr hält, was ihm willkommen ist, insbesondere sein Urteil über das Zukünftige bestimmen läßt durch seine Hoffnung: Dem steht freilich gegenüber, daB umgekehrt auch die Furcht Meinungen bewirkt, da $\mathrm{B}$ gerade das Schlimme gern und leicht geglaubt wird; 
daß es "Pessimisten " gibt, die immer "schwarz" sehen, also von der Zukunft nichts Gutes erwarten, meinen, daß es immer abwärts gehe usw. Indessen diese negative Seite zeigt das seltnere Bild; es ist die Ansicht des Alters gegen die Ansicht der Jugend, und die Ansicht der Jugend ist die des Lebens, die Ansicht der Werdenden und Wollenden; in ihrem Sinne ist gesagt worden: ,der Lebende hat immer recht". $\mathrm{DaB}$ dies positive Verhältnis überwiegt, spricht sich auch in dem bekannten Satze aus ,der Wunsch ist der Vater des Gedankens". Dieser Satz hat aber auch eine allgemeinere Wahrheit. Auch die Furcht enthält Wünsche; wenn sie trübe Meinungen hervorbringt, so bleibt der Wunsch dahinter verborgen (oder tritt auch hervor), dem drohenden Ubel vorzubeugen, die Gefahr abzuwenden, der Wunsch, rechtzeitig zu warnen, in der Regel auch der Wunsch, daß es doch anders kommen möge; wenngleich diesem der Wunsch, recht $\mathrm{zu}$ haben und recht $\mathrm{zu}$ behalten, in einigem Maße entgegenwirkt. Die Furcht selber ist keine Ausnahme von der Regel, daß die lebenbejahenden Gefühle das Wesen der Seele sind; aber sie zeigt die Seele unter einem äußeren Druck - im Zustande der „Depression * -, der die Wünsche beklemmt und verengert, während sie, von solchem Drucke befreit, also ihrer eigenen Natur folgend, sich ausdehnen und heben. Wenn also der Wunsch immer den Gedanken erzeugt, so können doch die so beklommenen und verengerten Wünsche nur verkrüppelte Kinder hervorbringen, die in der Vorstellung die Gestalt von Gespenstern anstatt von heiteren guten Genien annehmen. Aber der "Wille zum Leben « arbeitet auch alsbald daran, die Dämonen zu »versöhnen «, ihnen ein freundlicheres Ansehen oder wenigstens einen freundlicheren - Namen zu geben $(\varepsilon \dot{v} \varphi \eta \mu \varepsilon \tilde{\imath})$.

7. (Meinen und Wollen, II.) Nun aber ist das Meinen auch selber ein Wollen. Wenn das Meinen zunächst ein Haben, einen Besitz anzeigt - wie das Wollen selber, das Wissen und Können -, so ist dieser Besitz etwas Lebendes, was sich nach außen hin geltend macht, was sich wehrt; indem es ruht, enthält es doch die Tendenzen zur Bewegung in sich; indem es gegenwärtig ist, hat es seine Richtung in die Zukunft. Beim Wollen selber liegt dies am klarsten zutage; in den Sprachen neigt Wollen zum Ubergang in die Bedeutung der Zukunft. Aber wie das Gegenwärtige immer "schwanger" mit der Zukunft geht (nach LEIBNIz' Ausspruch), so ist auch gegenwärtiges Meinen soviel wie zukünftiges Meinen - eine Tendenz der Bewegung, die zu beharren sucht und, insofern sie beharrt, Widerstand überwindet. Eine Meinung haben ist gleich eine Meinung behaupten. Meinen selber ist "Behaupten eines Satzes, eines Urteils; ist das Meinen unbestimmt, mit $Z$ weifeln vermischt, so ist die 
Verteidigung der »eingenommenen Stellung" schwach; wenn gar kein Streben vorhanden ist, sie zu halten, so ist auch die Meinung nicht mehr vorhanden.

8. (Meinen und Wollen, III.) Die deutsche Sprache tut diese Beziehungen offen kund, wenn "meinen" auch gebraucht wird für "eine Meinung sagen «, "aussprechen«. Aber nach weit überwiegendem Gebrauch bedeutet Meinung vielmehr, was unausgesprochen, heimlich und verborgen ist, was zwar zuweilen offenbart wird, oft aber auch nur erraten und gedeutet werden kann. "Was meint er? welches ist die eigentliche Meinung des Redners? - und in diesem Sinne ist das Meinen schlechthin dem "Wollen " gleich, das immer der einzelnen Seele angehört, weil es ganz und gar in Gedanken besteht, ein Zustand von Spannkräften, der nur stückweise und teilweise in Handlungen und Reden sich entladet. Darum, owas meint er ? $=$ was will er damit sagen? und allgemein: Meinung = Absicht. Im Grrmmschen Deutschen Wörterbuch ist dies die allererste Bedeutung: Meinen, im Sinne haben, mit etwas durch Wort, Bild, Gebärde usw., geäußertem bezeichnen, andeuten, sagen wollen. Daraus folgt dann, daß insbesondere Worte etwas »meinen", d. h., bedeuten (eng1. meaning) und es geht daraus leicht ein Gegensatz zwischen dem wirklichen und dem scheinbaren Sinn von Worten, wie von anderen Zeichen des Gedankens und Willens hervor. Was ein Wort meint $\mathrm{d}$. $h$. bedeutet, ist eine objektive Tatsache und ist das, was in der Regel die Menschen meinen, wenn sie das Wort gebrauchen; was aber in einem gegebenen Falle der einzelne Mensch "meint", wenn er das Wort gebraucht, ist vielleicht etwas ganz anderes; er kann auch das Gegenteil meinen, und diese seine Meinung durch den Ton der Ironie andeuten, oder aber gar nicht andeuten, sondern schlechthin verbergen (um zu täuschen). So wird denn auch Meinen das Wort für Gesinnung, für Wohlwollen oder Ubelwollen. Daraus entwickelt sich, indem der positive, bejahende Sinn in den Vordergrund tritt, meinen = lieben: „Freiheit die ich meine, die mein Herz erfüllt."

So ist denn die gewöhnliche rein intellektuelle Wortbedeutung des Meinens und der Meinung durch Abschwächung und Verblassen entstanden, wie die Grammatiker sagen; logisch möchten wir es lieber als eine Verallgemeinerung auffassen, die sich in einem einzelnen Sinn fixiert, eben dem des Vorstellens und (unausgesprochenen) Urteilens „oft mit dem Beisinn des Ungewissen oder Schwankenden“" (HEYNE, Deutsches Wörterbuch, sub.v.), womit denn auf synonymische Wörter hingewiesen wird. Auch ADELUNG hatte "Meinen "erklärt als Dafürhalten, Urteilen, ohne zu entscheiden, ob das Urteil wahr ist oder 
nicht (vg1. LothaR Bucher, Der Parlamentarismus ${ }^{2}$, S. 245, Stuttgart I88I).

9. (Meinen und Wollen, IV.) Den lateinischen Wörtern opinio, opinari, opiniosus usw. wohnt die intellektuelle Bedeutung viel ausschließender bei, obgleich sie etymologisch, wie schon angedeutet wurde, an den Zusammenhang mit Wünschen erinnern. Auch sie gehen aber in einen Willenssinn über, wenn die Meinung ein bejahendes oder verneinendes, günstiges oder ungünstiges Urteil, insbesondere über Menschen und ihren Wert, in sich enthält, und dies ist ein Feld von weiter Fläche. Es gibt ein bene aut male opinari über Menschen wie über Sachen; jemand kommt in eine opinio, das bedeutet in einen "Verdacht", wenn der Inhalt der opinio etwas ist; was Menschen "verdacht" zu werden pflegt. Opinio wird dadurch gleich dem "Ruf", und da der bejahende Sinn immer den Vorrang hat, vorzugsweise = bona existimatio, fama, gloria, und diese Bedeutung einer. "guten Meinung" als eines günstigen Urteils ist vorzugsweise ins mittelalterliche und neuere Latein übergegangen. So ist von Leuten die Rede quos morum et honestatis commendat Opinio (welche der Ruf ihres Charakters und ihrer Ehrenhaftigkeit empfiehlt), und es sollen solche als Beamte erwählt werden, qui essent bonae opinionis et vitae (die guter Meinung - d.h. guten Rufes - und Lebenswandels seien). Auch in den romanischen Sprachen spielt diese Bedeutung, z. B. im Französischen, die bonne ou mavvaise aber auch opinion allein im bejahenden Sinne, eine große Rolle, die das Meinen als ein geistiges Wägen und Schätzen erscheinen läßt. So ist auch im Englischen (nach MURRAY, $A$ nerw english dictionary) opinion = what one thinks of a person or thing; estimation, or an estimate, of character, quality or value; dann aber auch "speziell" = good, high or favourable estimate; esteeme, wozu aber bemerkt wird, $\mathrm{da} B$ der heutige Sprachgebrauch dies nur mit negativen oder mit Beiwörtern, wie great, zulasse. Eine andere Sonderbedeutung, die sich im Englischen entwickelt hat, macht aus der opinion den favourable estimate of oneself or of one's oren abilities - im Sinne von Dünkel oder im Sinne von Selbstvertrauen. So wird dann aber auch Opinion = Ruf: ,What is thought of one by others; the estimation (esp. good estimation) in which one stands $i$. e. standing; reputation, repute, character, credit (of being so and so, or of possessing some quality). In den eigentlichen romanischen Sprachen nimmt die opinion (franz.), opinione (ital.), opinión (castellan. = span.), opinião (portug.) diesen charakteristischen Sinn des "Rufes" und "Ansehens" auf ausgesprochene Weise an. Am deutlichsten tritt der Willenscharakter des Meinens im Vorurteil zutage, sei es für oder wider eine Person 
oder Personengruppe, eine Sache oder einen Komplex von Sachen; wo das Wort andeutet, daß das Urteil nicht erst nach Prüfung, Beobachtung, Untersuchung gebildet wurde, sondern vorher feststeht, auf Grund irgendwelcher Eindrücke, am ehesten sinnlicher, von denen daher auch metaphorisch in diesem Sinne gesprochen wird (man kann solche und solche Menschen "nicht riechen "; »er ist nicht mein Geschmack «); in dem Worte ist ferner ausgesprochen, da $B$ aus der Neigung oder Abneigung das Urteil, die Meinung entspringt.

ro. (Meinen und Wollen, V.) Allen jenen (romanischen) Sprachen fehlt ein Zeitwort, das der opinion, wie das deutsche meinen der Meinung entspricht. Es gibt zwar opiner (franz.), opine (eng1.), opinar (span. u. port.), opinare (ital.), aber alle haben die Vorzugsbedeutung angenommen, welche wir aus dem Ursinne des "Meinens" als Ausnahme entwickelten: "Eine Meinung äußern, kundgeben, sagen«, daher auch sein Urteil, seine Stimme »abgeben». Wenig geübt und altertümlich gefärbt ist dagegen der Gebrauch dieser Wörter im Sinne von meinen, glauben, denken usw. Wohl aber wird in diesen Sprachen ausgedrückt, was im Deutschen als »der Meinung (der Ansicht u. dg1.) sein " gleichfalls bekannt genug ist, so »to be of opinion ", "je ne suis pas de votre opinion", usw., wodurch der zuständliche Sinn des Meinens betont wird. Das mehr flüssige »meinen « wird dagegen am meisten durch Ausdrücke wiedergegeben, die diesem »denken" - z. B. to think, penser, pensare usw. - oder "glauben« entsprechen: Believe, croyer, credere usw. Merkwürdig ist nun zu beobachten, daß auch im Deutschen das "meinen", wenigstens in der ersten Person singul. praes. (»ich meine«) vorzugsweise den Sinn gewonnen hat, "ich will sagen ", engl. "I mean to say", während man nicht gern seine "Ansicht», sein "Urteil" durch »ich meine, daß«, als eine »bloße Meinung" ausspricht. Der Stolz des Meinenden scheint sich dagegen zu wehren, ein Wort von so leichter Art darauf anzuwenden. Es will und soll volltönender zur Geltung kommen: "Ich bin der Meinung, daß ...", "meine Meinung geht dahin", oder man sagt lieber: Meiner Meinung nach - womit angedeutet wird, daß meine Meinung Gewicht habe, daß sie Anspruch auf Beachtung mache; sonst wird lieber die "feste Úberzeugung « unterstrichen. Anders, wenn die zweite oder die dritte Person gebraucht wird, obschon auch hier die Bedeutung leicht in "sagen wollen" hinübergleitet. Als Ausdruck für das bloß intellektuelle Verhältnis zu Dingen und Tatsachen ist das "Meinen " zwar nicht immer, aber sehr oft mit einem leichten Makel behaftet, daher es gern mit "man «, mit "die Leute $u$. dgl. verbunden wird und die Bedeutung in die des "Ver neinens« hinübergleitet. „Menen (Menin) liggt in Flandern" 
ein weitverbreitetes niederdeutsches Sprichwort, das Geringschätzung ausdrücken will. So klingt auch »Meinen Sie?» leicht etwas verächtlich. Nach LACTANTIUS wäre OPINIO in Gestalt einer jungen Weibsperson mit einem kühnen Gesichte und unbeständigen Gebärden abgebildet worden (ZEDLER, Lexicon universale I740). Nur wenn die Sache als wesentlich zweifelhaft hingestellt wird, oder doch Unwissenheit darüber als entschuldbar, ja vielleicht eine (scheinbar begründete) Meinung schon als verdienstvoll gelten darf, dann wird wohl mit »ich meine» eine subjektive Schätzung geltend gemacht; z. B. bei Zahlenangaben u. dg1. Auch sonst, wenn die Bescheidenheit als solche sich aussprechen will. Diese Bemerkungen greifen der synonymischen Unterscheidung vor.

II. (Begriff der Meinung.) Wenn wir begrifflich die Meinung untersuchen wollen, so müssen wir uns an den Sinn halten, den sie mit den entsprechenden Wörtern der lateinischen und der romanischen Sprachen gemein hat: dieser Sinn ist der intellektualistische, den wir darum auch für das deutsche Zeitwort meinen in den Vordergrund stellen, der Sinn also, den die anderen Sprachen in der Regel durch Wörter anzeigen, die "denken, glauben, vermuten" bedeuten.

Dabei werden wir aber, was durch die vorausgegangenen sprachlichen Erörterungen bestätigt wird, in Erinnerung behalten und dahin zusammenfassen, daß alles Denken und Meinen in einem dreifachen Verhältnisse zum Wünschen und Wollen oder schlechthin zu den Gefühlen steht: I. es geht zum großen Teil daraus hervor, ist immer dadurch mitbedingt, es drückt Gefühle aus; 2. eben deshalb, und zum Teil infolge davon, hat es auch Gefühlsbetonung, Gefühlsbedeutung, es ist "Wollen" und "Nichtwollen" als Bejahung und Verneinung, als günstiges und abgünstiges Urteil. 3. es ist wesentlich perfektisch wie das Wollen: Meinen = eine Meinung haben, sich ein Urteil gebildet haben, wie Wollen = beschlossen haben, sich vorgenommen haben. Wie aber alles Haben und Besitzen die Seele bindet, so auch das Meinen und Wollen, und zwar auf zwiefache Art: I. Es bewirkt unmittelbar das Werden, die zukünftigen Meinungen und Entschlüsse - wie aus jedem Zustande, wenn die Anstöße erfolgen, bestimmte Bewegungen erfolgen; 2. es wirkt auch gegen widerstrebende Gedanken und Neigungen als Nöti gung - vermittelst des Gedächtnisses; man erinnert sich dessen, was man seigentlich" meint, "eigentlich" will, und dies genügt oft schwächeren Antrieben gegenüber sogar regelmäßig - um den Gedanken und um dem Willen eine bestimmte, die normale Richtung $z u$ geben. So bindet und regelt die feste Uberzeugung, aber auch der feste Wille, der Grundsatz das Handeln, wenigstens des charak- 
terfesten Menschen, von dem allein man wohl sagt, daß er peine Meinung hat", einen Willen hat. In diesem Sinne rühmt man wohl, daß ein Mann »den Mut seiner Meinung " habe, und der Erwerb einer Meinung, mehr noch die "Bildung" einer eigenen Meinung wird als eine Leistung vorgestellt, also als eine willkürliche Tätigkeit, die eine Mühewaltung in sich einschließt, und eine gewisse Zeit kostet.

12. (Meinen und Glauben.) Um nun die Bedeutung, worin wir Meinung und Opinio verstehen wollen, festzulegen und abzugrenzen, ist es geboten, an die synonymische Unterscheidung anzuknüpfen, wie sie durch den Sprachgebrauch überliefert wird. Am nächsten liegt da die Vergleichung der deutschen Wörter "Meinen " und "Glauben«. In WEIGANDs Wörterbuch der deutschen Synonymen wird Meinen erklärt als: Dafürhalten mit dem Bewußtsein der Ungewißheit seines Urteils, ob es wahr sei oder nicht. Hingegen "glauben" bedeute seiner $A b s t a m m u n g$ gemä $B$ eigentlich »sich beifällig hinneigen, vertrauend hingeben", wie z. B. in "gläubig"; daher: aus Gemütsneigung dafürhalten, wobei aber natürlich die Wahrheit des Gegenstandes unausgemacht ist. Besonders aber bedeute das Wort "glauben" weiter: dafürhalten aus Vertrauen auf andere, d. i. im Vertrauen auf andere, deren Zeugnis u. dgl. eine Aufstellung oder Wahrheit beifällig annehmen ... Diese letzte ist nun offenbar die ursprüngliche und wesentliche Bedeutung. Denn ihr liegt zugrunde, wie dem Worte selber, die Wurzel $l u b=$ Willigsein und Gutheißen, wie in goth. lubains, Hoffnung, lubo, Liebe, in erlauben, Urlaub. Demnach heißt glauben eigentlich jemandem glauben, eine Beziehung, die für das Meinen nicht möglich ist. Der eine sagt es, der andere glaubt es. Er glaubt ihm, dem Redenden. Am ehesten und leichtesten, wenn er denkt, daß dieser es weiß, es "wissen muß*. Er glaubt daher auch mit dem Gefühle der Gewißheit. Wenn das Meinen (nach KANT) etwas aus objektiven, aber mit Bewußtsein unzureichenden Gründen für wahr halten ist; wenn das Schwankende und Unzulängliche in der Bedeutung des Wortes liegt und oft betont wird (Grimmsches Wörterbuch, sub. v.), so ist für das Glauben der nächste Grund immer subjektiv, zugleich aber neigt das Gefühl zur Gewißheit, daher zur Festigkeit des Vertrauens, und das Glauben kommt dem Uberzeugtsein nahe. Das entsprechende lateinische Wort credere gehört zu $\operatorname{cor}(d)=\mathrm{Herz}$; das Glauben ist Sache des Herzens, das Meinen des Kopfes. So ist der religiöse Sinn des Glaubens unmittelbar verständlich. Wie an die Götter, so wird an die Menschen, denen man in Pflichten verbunden ist, zumal wenn sie wie die Götter Verehrung und Gehorsam in Anspruch nehmen, geglaubt. Glaube und 
Treue sind innig verwandt; das gleiche lateinische Wort »fides * drückt den (religiösen) Glauben und die Treue aus. Und in deutscher Sprache ist das Vertrauen fast gleichbedeutend mit dem Glauben an Personen. Der Glaube ist mit Zuversicht verbunden; ja der Apostel verkündet ihn - nach LUTHERs Verdolmetschung - als eine gewisse Zuversicht.

I3. (Glauben und Meinen.) So schließt denn Glauben seinem rechten Sinne nach den $Z$ weifel aus; er ist ganze und einheitliche Hingebung an die Person oder die Sache. Die Seele ist mit sich einig, auch in gewöhnlichen und weltlichen Dingen, wo immer das Wort durch das Wort Vertrauen ersetzt werden kann; der Glaube wird dann auch als fest und als vollkommen bezeichnet.

Hingegen das Meinen, wenn es scharf und deutlich vom Glauben unterschieden wird, gibt sich selber als eine Ansicht, es will persönlich und individuell sein; es wird leicht mit dem Bewußtsein ausgesprochen, daß es möglicherweise irrig sei, oft will nur für sich der Meinende die Gewißheit betonen, nicht daß es (objektiv) gewiß, sondern daß er (subjektiv) der Sache gewi $\beta$ - oder doch beinahe gewi $B$ - sei, weil er sich selbst, seinem Denken und Schließen, seinem Rechnen (putare heißt eigentlich »rechnen") vertraut, aber er weiß auch, da $B$ in Rechnungen sich Irrtümer einschleichen, $d a ß$ man allzuoft fehlerhafte Schliisse zieht. Darum behält er sich vor, die Rechnung nachzuprüfen (zu »revidieren«), und wenn er einen Fehler entdeckt, ihn zu tilgen; ja er kann das auch anderen überlassen. Wenn er nicht aus Eigensinn und Trotz in seinem Irrtum beharrt, so wird er die als irrig erkannte Meinung »aufgeben" und einer anderen Meinung "zuneigen", oder sogar alsbald eine solche »annehmen", die frühere mit einer neuen 》vertauschen". Mancher wechselt seine Meinungen rasch und oft, wie denn auch keineswegs die Meinungen, die einer "hegt", auch nur in der Regel auf eigenem Denken (Schließen, Rechnen) beruhen; vielmehr ist eine sehr häufige Erscheinung, daß der Meinende die Gründe für seine Meinungen gar nicht kennt, oder doch nur eine unbestimmte "Ahnung" davon hat; er nimmt die Meinung an, die über den Gegenstand "geläufig" ist, die Meinung der großen Menge. - Das Subjektive und Unverbindliche wird scharf betont in Wendungen, wie 》das ist Meinungssache». In dem englischen Bericht über die mißglückte Dardanellenexpedition heißt es am Schlusse (die Kommission versucht, das Gesicht der Urheber zu wahren), die Sache habe doch wichtige politische Vorteile gehabt. „Ob diese Vorteile die damit verbundenen Verluste an Menschenleben und Finanz wert waren, ist Meinungssache, und muß das immer bleiben." (cf. The National Review, April I9I7.) 
14. (Der Glaube.) Es ist merkwürdig, daß wir im Deutschen keinen Plural von "Glaube» bilden können. Wir müssen zu 》Glaubensmeinungen ", „Glaubensvorstellungen«, "Glaubenssätzen" oder »Glaubenslehren" unsere Zuflucht nehmen. Ebensowenig gibt es eine Pluralform von fides oder vom englischen faith, dem franz. foi. ఎDer» Glaube setzt sich als der echte und wahre, als der allein richtige und "allein seligmachende" anderem Glauben entgegen, der für ihn nichts ist als eine Summe von irrigen und verderblichen Meinungen; diese sind nicht "beglaubigt « durch gültige höhere Autorität, durch die göttliche »Offenbarung《, durch die Übereinstimmung der Völker, oder sogar durch die Vernunft, was alles (insbesondere) von dem Gottesglauben behauptet wird. Die freien Meinungen sind gegenüber dem offenbarten und offenbaren Glauben, dem gültigen und bewährten Dogma, willkürlich ergriffene Meinungen, die der Vorwitz der Mei-

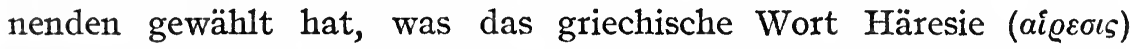
ausdrückt. Sogar im neueren Sprachgebrauch und in einem Gebiete, das dem des religiösen Glaubens fernliegt: „The question" (des handelspolitischen Verhältnisses zwischen Großbritannien und Irland) ,was especially difficult in days when Free Trade, now an orthodox dogma was yet but an heretical opinion." (Die Frage war besonders schwierig zu einer Zeit als der Freihandel, jetzt ein orthodoxes Dogma, noch bloß eine ketzerische Meinung war): HoLLAND, Imperium et Libertas, p. I98 (Lond. Igor).

I5. (Glaube als Pflicht.) Darum wird der Glaube ganz regelmäßig, was eine bloße Meinung schwerer wird, in der Vorstellung der Gläubigen eine Pflicht; ja, wird als solche mit dem Gewande der Notwendigkeit und Selbstverständlichkeit bekleidet. Der Gottesgläubige meint, dem Gotte selber, an den er glaubt, es schuldig zu sein und ihn zu ehren dadurch, daß er ihm glaubt und vertraut, daß er a n ihn glaubt. Aus den Reden des Priesters, oder aus heiligen Büchern, glaubt er die Stimme des Gottes selber, der sich »offenbare«, zu vernehmen. Darum ist es eine Beleidigung dieses Gottes, nicht an ihn zu glauben, etwa gar sein Dasein zu leugnen; es ist nicht ein bloßer Irrtum - für den Gläubigen ist das Dasein seiner Gottheit so offenbar, als ob sie ihm leibhaftig gegenwärtig wäre; jezuweilen fühlt er auch des Anblicks oder doch der Nähe und Mitteilung, in Zuständen der Verzückung, im Traum usw., sich völlig sicher - sondern die Gottesleugnung ist eine Bosheit, ein Frevel, ein Verbrechen, das die schwerste Strafe, die Todesstrafe verdient. So erlebt man auch im Kriege, $\mathrm{da} B$ der Zweifel an der Güte und Gerechtigkeit der eigenen Sache, d. h. der Sache des eigenen Landes und Staates, ebenso aber der Zweifel am Siege, oder gar die Meinung, daß der Feind siegen werde, 
als Zeichen abscheulicher Gesinnung empfunden und als eine Art von Verrat gebrandmarkt, daß wohl auch die Kundgebung einer solchen Meinung mit schweren Strafen belegt wird. An die Güte der vaterländischen Sache und an ihren endlichen Erfolg zu glauben wird für Pflicht gehalten. Damit berühren sich die - tiefer unten zu erörternden - Merkmale der "öffentlichen" Meinung.

I6. (Glaube und Wahn.) Hingegen ist für den Ungläubigen der Gläubige in einem "Wahn" befangen; und so für jeden Religiösen derjenige, der einem a nderen religiösen Glauben zugetan ist. Ein Wahn ist nicht ein bloßer Irrtum, wie er auch dem Gesunden und richtig Denkenden begegnet; sondern etwas Krankhaftes und Verrücktes, dem Rausche oder dem Traume verwandt, daher auch dem Zustande des dichterischen Menschen vergleichbar, der die Gebilde seiner Phantasie anschaut, aber dem Wahnsinnigen vergleichbar, weil er diese Gebilde für wirkliche Gegenstände hält. Ein Wort, das unsere Sprache anwendet, um einen Glauben als töricht, grundlos, in Unwissenheit und Gedankenlosigkeit beruhend, zu brandmarken, ist das Wort "Aberglaube«. Für den Freidenker ist aller religiöse Glaube mehr oder weniger Aberglaube, ebenso für den Gläubigen jeder andere religiöse Glaube, außer in den Bestandteilen, die er mit dem eigenen gemein hat. Es gibt aber auch eine Vorstellung vom Aberglauben, die einen allgemeineren Sinn hat, der eben dadurch sich enger begrenzt: der religiös nicht geheiligte Glaube an natürliche oder übernatürliche Zusammenhänge zwischen Erscheinungen, Ereignissen, Handlungen, die keinen erkennbaren und für die Vernunft keinen wahrscheinlichen Zusammenhang haben, z. B. zwischen dem Anblick einer Katze und irgendwelchem herannahendem Unglück, dem Sichtbarwerden eines Kometen und dem Ausbruch eines Krieges, oder gewisser Handlungen, etwa des dreimaligen Klopfens unter einen Tisch und der Abwehr möglichen Unheils. In Wahrheit stellt der Aberglaube dieses Sinnes Reste des bei allen Völkern ursprünglichen Glaubens an die Allgegenwart von Geistern und Dämonen dar, folglich zumeist Überlebsel vergangener Religionen, die von einer neuen Religion überschattet und als Aberglaube in den Bann getan wurden. In klassischer Form hat der Philosoph Thomas HobBes die Wahrheit ausgedrückt: „Furcht vor unsichtbarer Macht, die der Geist frei ersonnen oder auf Grund von Erzählungen, die von Staats wegen gestattet werden, sich eingebildet hat, ist Religion; von solchen, die nicht gestattet wurden, Aberglaube" (Leviathan, I, 6).

I7. (Glaube und Wille.) Das Wesen des Glaubens wurde hier am religiösen und ihm verwandten Volksglauben erläutert, weil diese 
Arten es am schärfsten ausgeprägt in sich enthalten. Es zeigt sich aber auch in anderen Gebieten, wo immer eine zumeist mit dem Gefühle der Ehrfurcht und der Andacht verbundene Vorstellungsmasse auf einen Gegenstand, eine Person, eine Idee oder ein Ideal sich sammelt, als Uberzeugung von deren Wert, Güte, Größe, Zukunft, Sieg, als Vertrauen, das nicht sowohl auf Überlegungen, Gedanken, Folgerungen, als auf ungeteilter Hingebung der Seele beruht. So ist Glaube mit Liebe und mit Ehrfurcht verwandt, er ist selber eine Art der Verehrung, er drückt sich im Kultus, d. i. in liebevoller Pflege aus; Glaube, Liebe, Hoffnung verbindet die christliche Denkungsart als "die theologischen Tugenden " miteinander.

Es ergibt sich leicht, wie das Glauben und der Glaube im menschlichen Willen angelegt und enthalten sind; wenn man nämlich als Willen den Geist versteht, aus dem das einzelne Wollen hervorgeht, als Wollen aber die gesamte Bereitschaft zu gewissen Tätigkeiten; nicht sowohl die Entschließung, als das Entschlossen-sein, darum aber auch das Geneigtsein und das Gewohntsein, insofern als beide dem Zu-etwas-Entschlossensein verwandt sind und nahekommen, also auch vorauszugehen pflegen. Wie durch Neigung (»Gefallen«) und Gewohnheit, so ist durch "Gedächtnis» die Seele mit Dingen und Personen »verbunden«; aus Gedächtnissen aber bestehen Dankbarkeit, Liebe, Treue und alle diese Gefühle und Stimmungen faßt Glaube in sich zusammen. So darf auch Glaube als eine Art des Wesen willens erklärt und bestimmt werden. Aber auch wenn das Glauben rein intellektuell verstanden wird (als Fürwahrhalten von Tatsachen oder von Urteilen), so steht es zum Wünschen und Wollen im gleichen dreifachen Verhältnisse, wie sonst das Denken und Meinen gefunden wurde (S. I2): I. Es geht daraus hervor, ist dadurch mitbedingt; 2. es ist selber Bejahung und Verneinung, hat Gefühlsbetonung und Gefühlsbedeutung; 3. auch das Glauben ist perfektisch: s. v. a. den Glauben hegen, zu dem Glauben gekommen sein, aber auch »sich zu dem Glauben bekehrt, ihn angenommen haben«, "im Glauben stehen». In Wahrheit gleicht der Sprachgebrauch den Unterschied von Meinen und Glauben (in diesem Sinne) aus, aber gerade in der zweiten Beziehung bleibt ein synonymischer Unterschied bemerkenswert. Wenn Meinen das im Sinne haben bedeutet, daher das «sagen wollen " (die eigentliche Meinung), den wörtlichen Gedanken im Gegensatz zu der Erscheinung in Worten, so nimmt Glauben daran keinen Teil; es hält vielmehr seine intellektuelle Bedeutung fest - man glaubt, was man sagt (oder man glaubt es nicht), das ist ein inneres Verhältnis zur Sache und betrifft nicht die Ausdrucksweise, da kann allerdings Meinen für Glauben eingesetzt werden, aber nicht umgekehrt: für 
"was meint er damit" kann man nicht sagen, "was glaubt er damit«; dem Meinen liegt die Bedeutung der "Absicht" ganz nahe, dem Glauben bleibt diese fern. Wir werden diese Beobachtung festhalten, wenn wir nunmehr versuchen, den Unterschied in begriffliche Formen zu gießen. Dabei tritt die Frage des Sprachgebrauchs in den Hintergrund. Begriffliche Unterscheidungen müssen, wenn sie als Zeichen der Begriffe gangbare Wörter gebrauchen, an den Sprachgebrauch sich anlehnen, können aber nicht von ihm abhängig gemacht werden, weil er schwankend und unbegrifflich ist, sondern müssen auf ihren eigenen Füßen stehen, darum auch oft besondere Sprachschuhe ihren Füßen anziehen.

\section{Dritter Abschnitt. Verhältnisse zur Wissenschaft.}

I8. (Wesenwille und Kürwille.) Ich beziehe mich hier auf meine Unterscheidung der Begriffe Wesenwille und Kürwille (Willkür). Auch dies ist nicht eine Unterscheidung, wie sie gewöhnlich verstanden wird: als ob in der Erfahrung die Dinge nebeneinander lägen und nun getrennt werden sollten. Für die Begriffe ist es gleichgültig, ob so etwas wie bloßer Wesenwille und bloße Willkür in der Erfahrung überhaupt vorkomme oder nicht. Die Begriffe werden verfertigt als Geräte, um die Erfahrung anzufassen, sie zu »begreifen«, und das Begreifen ist Auflösung, die nur durch Denken geschehen kann, wo auch der Stoff nur im Denken gegeben ist. Vergleichbar ist das Verfahren der chemischen Analyse: wie es nicht einiges Wasser gibt, das Wasserstoff, einiges, das Sauerstoff ist, so gibt es nicht einigen Willen der Wesenwille, einigen, der Kürwille wäre; sondern in allem Willen ist Wesenwille und Kürwille enthalten und verbunden. Hier hört aber die Analogie auf; nicht nur gibt es sehr verschiedene Verhältnisse der Mischung, sondern wir können auch nicht umhin, einigen in der Erfahrung gegebenen Willen wegen dieser Verschiedenheit Wesenwillen, anderen Kürwillen zu nennen; lieber freilich werden wir Ausdrücke darauf anwenden, die nicht zugleich eine rein begriffliche Bedeutung erhaiten haben, die also ganz und gar bestimmt sind, den empirischen Willen als solchen $z u$ bezeichnen, je nachdem er mehr dem einen oder mehr dem anderen »Idealtypus« entspricht. Ferner ist zu erinnern, daß auch die Motive des Denkens in Gefühlen (Neigungen, Abneigungen usw.) wurzeln, daß also, wenn Kürwille als »Denken", sofern darin das Wollen enthalten ist, bestimmt wird, die empirischen Ausdrücke des Kürwillens immer durch die empirischen Ausdrücke des Wesenwillens bedingt und von ihnen abhängig erscheinen werden, mithin nicht sowohl ihnen koordiniert, als (wenigstens zugleich) ihnen 
subordiniert erscheinen müssen. Wesenwille ist also (empirisch) das Allgemeine, Kürwille (empirisch) das Besondere. Glauben und Meinen verhalten sich zueinander wie Wesenwille und Kürwille. Das will sagen: Die synthetischen Begriffe von Glauben und Meinen lassen sich auf die zweckmäßigste Art so gestalten; im empirischen Ausdruck ist Glauben das Allgemeine, Meinen das Besondere.

19. (Begriffe, Glauben und Meinen.) Glauben ist Sache des Gemütes, Meinen des Denkens; wie schon ausgesprochen ward, daß Glauben dem Herzen, Meinen dem Kopfe angehöre. Glauben ist weiblich betont, Meinen ist männlich betont. Glauben wurzelt in der Phantasie, Meinen im Verstande. "Kindlicher" Glaube; aber "man bildet sich eine Meinung — - »man«, d. i. der gereifte Mensch. Glaube gilt oft auch dem Unwahrscheinlichsten, ja dem ఎUnmöglichen" (credo quia absurdum, verum quoniam impossibile); die Meinung will, wenn sie nicht das Wahre erreichen kann, wenigstens das Wahrscheinliche, das Wahrscheinlichere und das Wahrscheinlichste treffen.

Den hierdurch bezeichneten bedeutsamen Unterschied und Gegensatz möge noch folgende Betrachtung erläutern.

Alle denkfähigen Menschen haben und hegen gewisse "Ansichten " über sogenannte göttliche und sogenannte menschliche Dinge, über Vorgänge der Natur und des Kulturlebens, vergangene, gegenwärtige, zukünftige; mehr oder minder bestimmte, mehr oder weniger feste und entschiedene "Ansichten". Wenn diese Ansichten »Meinungen" genannt werden, so ist in dieser Benennung eine Hindeutung auf ihre Mannigfaltigkeit und Verschiedenheit, daher auch auf ihre Subjektivität enthalten, und also darauf, daß sie vielfach einander widerstreiten und entgegengesetzt sind, zum guten Teil einander ausschließen, so $\mathrm{da} B$ von den entgegengesetzten nur die eine "richtig * sein kann, während die andere sfalsch « sein muß, wenn nicht etwa beide unrichtig sind. Mit diesen Prädikaten be urteilen wir die Meinungen, indem wir gleichsam einen Maßstab an sie anlegen, den Maßstab des Richtigen, der wie eine mathematische gerade Linie gedacht wird, daher seinem Wesen nach ein wissenschaftlicher Begriff ist. Richtig nennt jeder die Meinung, die nach seiner Meinung mit den Tatsachen ibereinstimmt; insoweit ist es nur ein anderer Ausdruck dafür, daß er die Meinung billigt oder sie »teilt«. Aber alle denkenden Menschen urteilen, da $B$ es wirkliche Tatsachen gibt, die jeder erkennen und anerkennen muB, weil er sie ssieht «; und in der Tat gibt es keine verschiedenen Meinungen darüber, ob die Sonne, der Mond und die Sterne sind, in dem gewöhnlichen Sinne, in dem das Sein verstanden zu werden pflegt. In ähnlicher Weise gibt es 
eine weitgehende Übereinstimmung unter den Menschen über Dasein, Wirklichkeit, Wahrheit, Tatsächlichkeit von Vorgängen, Zusammenhängen, Ursachen und Wirkungen, so $\mathrm{da} B$ an diesen Übereinstimmungen die Richtigkeit einer Meinung gemessen werden kann. Oder es ist wenigstens Übereinstimmung über die Bedingungen des richtigen Denkens und Erkennens vorhanden, dann kann sichtbar gemacht, gezeigt, bewiesen werden, daß eine Meinung richtig ist, für richtig gelten $\mathrm{mu} B$, oder das Gegenteil: kraft logischer Nötigung. Aber wir wissen, daß diese Übereinstimmung nur innerhalb enger Grenzen allgemein ist; und auch wenn Einigkeit über gewisse Sätze vorhanden, so werden sie doch in abweichender Weise ausgelegt, und am häufigsten werden dabei die Wörter selber in verschiedenem Sinne gebraucht und verstanden.

20. (Wissen und Meinen.) Daher ist Ubereinstimmung am ehesten zu erzielen, wo die Bedeutung der Wörter feststeht; wie die der Zah1wörter - so daß das "Rechnen " vorbildlich geworden ist für das Denken überhaupt, und die Gewißheit des Satzes $2 \times 2=4$ sich der Gewißheit sinnenfälliger Erkenntnis - z. B. des Daseins der Sonne - an die Seite stellt. Aus dem Zusammenfluß dieser beiden Quellen: der sinnlichen Wahrnehmung und der Einigkeit über die Bedeutung von Wörtern, gehen die Meinungen hervor, die wir als "Wissen" bezeichnen, mit einem vielsagenden Worte, wie schon (unter 4, S. 5) dahin bedeutet wurde: wenn wir von jemandem aussagen, er wisse, da $B$ ..., so enthalte dies Urteil: I. Es ist so (z. B., "der Knabe weiß, daß es fünf Erdteile gibt«; es gibt fünf Erdteile) und 2. er kennt diese Tatsache, d. h. er »hat《 oder »besitzt» die Kenntnis davon; mit anderen Worten, er meint es und es ist auch so, er hat die richtige Meinung (ő@ๆ̀̀ $\delta o ́ \xi \alpha)$.

Dazu kommt aber noch, und zwar besonders, wenn der Redende von sich selber das Wissen aussagt (»ich weiß«), die Betonung des Gefühls der subjektiven Gewißheit und Sicherheit, des Freiseins von jedem $Z$ weifel, des mit sich einig-seins. In diesem Sinne aber begegnet und berührt sich das Wissen mit dem festen Glauben; auch der Glaubende, zumal der religiös Gläubige, ist ja (subjektiv) seiner Sache gewiß, wie sehr auch andere daran zweifein mögen. Auch er hält den Irrtum für ausgeschlossen, er ist überzeugt, $\mathrm{da} B$ alle, die anders glauben, Irrende sind; er spricht ausdrücklich von seiner Glaubensgewi 3 heit. Fragt man, worauf er diese Gewißheit gründe, so verweigert er entweder, unter Behauptung der objektiven Gewißheit, die Antwort, oder er beruft sich auf Beweise, die der Form nach wissenschaftlichen Beweisen ähnlich sehen - so wird z. B. gar manches "aus der Schrift» bewiesen - oder endlich er 
macht eine besondere Erkenntnisquelle geltend, sei es eine innere Stimme oder eine äußere angeblich historische Tatsache, wie die "Offenbarung», die den Menschen durch einen Gott zuteil geworden sei. Die Wirklichkeit dieser Tatsache ist selber Sache des Glaubens, und dieser Glaube bedarf wieder der scheinbar wissenschaftlichen oder der unwissenschaftlichen Stützen. Am sichersten aber fühlt sich jeder Glaube, wenn er sich als Tugend behauptet und den $Z$ weifel als Frevel brandmarken kann; dies kann er wiederum am leichtesten mit gutem Gewissen tun, wenn der Gläubige den eigenen Zweifel als abscheulich und verwerflich erkennt und darum in seiner Seele getötet hat; oder doch in unablässigem, qualvollem Kampfe mit ihnen lebt; wenn also die Pflicht des Glaubens ihm ebenso feststeht, wie "den Anderen«. Für das wissenschaftliche Meinen und Glauben ist vor allem bezeichnend, $\mathrm{da} B$ es nur aus Gründen für wahr gehalten sein will; damit steht aber scheinbar in Widerspruch, daß es in sehr vielen Fällen ausdrücklich bedeutet vfür wahrscheinlich halten\&; indessen eben dies ist das Unterscheidende des kritisch-behutsamen wissenschaftlichen Urteils. Diese Behutsamkeit ist die allgemeine, darum ist der $Z_{\text {weifel }}$ oft die besondere Pflicht des wissenschaftlichen Menschen.

2r. (Kampf zwischen Glauben und Wissen.) Wenn man von der subjektiven Seite absieht, so stellen sich sowohl alle Glaubensmeinungen, als alle wissenschaftlichen "Ansichten" als 》Meinungen " dar, die wir auf ihre Gründe, also auf ihre Richtigkeit oder doch wie später zu erörtern - auf ihre »Wahrscheinlichkeit» prüfen können. Wir können aber auch auf diese Prüfung verzichten, wenn wir lediglich ihren Widerstreit und Kampf ins Auge fassen.

Da tritt uns denn vor allem ein großer Kampf entgegen, der als Kampf zwischen Glauben und Wissen bezeichnet zu werden pflegt, richtiger Kampf zwischen Religion und Wissen schaft heißen sollte; weil diese die autoritativen sozialen Kräfte sind, welche die Meinungen der Menschen in sich enthalten und bestimmen.

Dieser Kampf ist in der Entwicklung der Kulturvölker von tiefgehender Bedeutung; eine Begleiterscheinung des Fortganges von überwiegend ländlichen $\mathrm{zu}$ überwiegend städtischen Lebensformen, Sitten, Denkweisen; der großen Wandlung des sozialen Geistes von Gemeinschaft zu Gesellschaft.

Dieser Kampf ist auch ein Kampf zwischen weiblichem Gemüt und männlichem Verstande, zwischen Gefühl und Gedanken - dort naive Deutung natürlicher Vorgänge durch Beziehung auf übernatürliche Urheber, hier kritische Untersuchung der natürlichen Kräfte, Feststellung der Regeln, denen sie unterworfen sind, also 
der Regelmäßigkeit, mit der sie sich ereignen, daraus erschlossener Notwendigkeit und "Gesetzmäßigkeit», dort vertrauensvolle Hinnahme überlieferter Berichte über wunderbare Erscheinungen, hier nüchterne Prüfung der Glaubwürdigkeit solcher Zeugnisse, der inneren Wahrscheinlichkeit berichteter angeblicher Tatsachen; ihre Messung an den wissenschaftlichen Begriffen der "Naturgesetzer.

22. (Streit zwischen Religion und Wissenschaft.) Aber das reine und strenge wissenschaftliche Denken ist in allen bisherigen Erfahrungen nur als die Sache weniger, zumeist mit Mißfallen und Mißtrauen betrachteter Individuen aufgetreten. In die Wirklichkeit tritt der Kampf zwischen Religion und Wissenschaft vielmehr wenigstens vorzugsweise - als ein Streit zwischen verschiedenen Religionsparteien, die also jedesmal beide an der Religion Anteil haben, aber auch beide an Wissenschaft teilhaben, so jedoch, daB die eine mehr und stärker das Wesen der Religion zum Ausdruck bringt, die andere mehr in die Richtung der Wissenschaft deutet.

Hier liegt zugrunde, da $\mathrm{B}$ ein bestimmter religiöser Glaube zur sittlichen Pflicht gemacht worden ist, ja die Geltung eines Gesetzes erlangt hat, zumal wenn eine organisierte Körperschaft, eine "Kirche«, ihn vertritt und deckt als den "rechten Glauben, den nicht $\mathrm{zu}$ hegen als hassenswert und schandbar, nicht $\mathrm{zu}$ bekennen als verdächtig hingestellt wird, so $\mathrm{da} \beta$ es zum Verbrechen wird, Andersgläubigkeit öffentlich kundzugeben.

Je mehr aber dieses öffentliche Kundgeben das eigentlich Verbotene wird, um so mehr gewinnt auch das öffentliche Bekennen an Wert, und kann durchaus zur Hauptsache werden, so daB nicht sowohl erwartet wird, daß man einen gültigen - zum Gesetz erhobenen - Glauben hege, als da $B$ man ihn sbekenner, d. i. ihn vertrete und verteidige oder wenigstens ihm nicht widerspreche. Diese Forderung richtet sich naturgemä $B$ vorzugsweise an diejenigen Personen, die förmlich und amtlich dazu bestellt sind, gewisse Glaubensmeinungen geltend zu machen, in Geltung zu erhalten und zu schützen: die Priester einer religiösen Gemeinde oder Kirche.

23. (Erlaubte und verbotene Meinungsäußerung.) Das empirische Staatsleben ist erfüllt von religiösen Elementen und in höchst bedeutenden historischen Erscheinungen sind Kirche und Staat, oder, wie wir sachlich treffender sagen mögen, geistliche und weltliche Gewalt unlöslich ineinander verschlungen. Die weltliche Gewalt stiitzt sich auf die geistliche, weil auch sie geglaubt werden, weil sie ihren Halt in den Meinungen und Gesinnungen der Menschen gewinnen oder bewahren will. Darum scheint sie ins Schwanken zu geraten, wenn die Meinungen von der Religion, oder doch von dieser 
die weltliche Gewalt unterstützenden Religion abtrünnig werden, wenn der Zweifel wuchert oder gar der Unglaube vorherrschend wird. Aus diesem Grunde pflegt von den Vertretern des Staates, oder doch der jeweiligen Regierung, großer Wert darauf gelegt zu werden, daß solche gefährliche oder geradezu für verderblich gehaltene Meinungen, wenn sie einmal vorhanden sind (und oft von ihnen selber geteilt werden), doch so wenig als möglich offenbar werden, daß sie geheim bleiben. Wenn man die Meinungen selbst nicht unterdrücken kann, so will man doch ihre Äußerungen und also ihre Verbreitung hemmen. Der praktische Staatsmann erkennt bald, daß Gedanken, also auch Meinungen und Glaubensvorstellungen, nicht erzwungen werden können, wenn man auch stark auf sie zu wirken, sie zu hemmen oder zu fördern vermag. In diesem Verstande gilt dann die Denkweise ihrem Wesen nach als "frei« ("Gedanken sind zollfrei»). Aber das Aussprechen von Gedanken und Ansichten, zumal das öffentliche, vollends also die bewußte planmäßige Verbreitung solcher (Propaganda, Agitation) - das sind freie Handlungen, die man mit Erfolg gebieten und verbieten kann. Und zwar ist die negative Wirkung, die Hemmung dúrch Verbote, immer diejenige, die am nächsten liegt, wo es sich darum handelt, vermeintlichen oder wirklichen Schädlichkeiten zu wehren. Und in Wahrheit ist eine öffentlich kundgegebene Meinung eine andere Sache als eine Meinung, die im Freundeskreise ausgesprochen, oder gar nur im stillen gehegt wird. Jene will wirken, will Eindruck machen, anerkannt werden, Beifall finden, sich durchsetzen und zur Geltung bringen. Sie ist eine Waffe, die mit mehr oder weniger Geschick und Erfolg geschwungen wird. Auch wenn die Meinung selber, die Ansicht, als etwas bloß Intellektuelles verstanden wird, und es bleibt, solange als sie unter Genossen - Fachgenossen, Berufsgenossen, Standesgenossen - mitgeteilt wird, so ist doch immer hinter ihr eine Gesinnung, eine bestimmte Art zu denken, ein Streben und Wollen, das daraus hervorgeht und zumeist um Teilnahme, ja um Kampfgenossenschaft wirbt; eben dies ist nun bei anderen willkommen oder unwillkommen, es wird geliebt oder gehaßt, ist ihnen selten gleichgültig; wenn es nicht das "richtige«, anerkannte, gute ist, so wird es im günstigsten Falle geduldet, d. h. im Grunde unwillig ertragen, so $\mathrm{da} B$ die Träger solcher Irrmeinungen irgendwie dafür büßen müssen, auch wenn man sie nicht unmittelbar unterdrücken kann oder will.

24. (Aggregatzustände der Meinung.) Als Aggregatzustände der Meinung, deren Begriff hier auch Glaubensmeinungen umfassen möge, verstehe ich das $\mathrm{MaB}$, worin der Mensch, in seiner Ansicht oder Uberzeugung, "mit sich einig" ist oder geworden ist; je vollkommener 
diese Ưbereinstimmung in seinem Gemüte, um so unerschütterlicher ist sein Glaube oder seine Meinung; je mangelhafter, um so unsicherer fühlt er sich, sein Glaube ist schwankend, er kämpft mit dem Zweifel, er glaubt, aber er betet zugleich "Herr, hilf meinem Unglauben«. Er ist in Unruhe und Bewegung: wie man jenen Seelenzustand oft felsenfest nennt, so kann man diesen mit einem Flusse oder sogar mit dem Zustande der Gase vergleichen. Der Glaube befindet sich eher in jenem, die Meinung eher in diesem Zustande. Denn die Meinung gibt sich selber als ungewiß, ist oft mit dem $Z$ weifel verbunden, verhehlt nicht ihre »Subjektivität«. Der flüssige Zustand ist der vorherrschende im menschlichen Denken, denn er ist es, der dem a nimalischen Leben und seiner Bedingtheit durch die Tätigkeiten der Sinnesorgane am meisten entspricht, nämlich den Bedürfnissen des täglichen Lebens, der Bewegung und Arbeit zu ihrer Befriedigung, der Mischung von sinnlichen Wahrnehmungen und auf Gedächtnis beruhenden Vorstellungen und Einbildungen, zugleich aber der Gewohnheit des Beharrens in den einmal befahrenen Geleisen der Denkungsart, und der Bequemlichkeit des Vertrauens auf das Vorgesagte und Vorgeschriebene, des Nachahmens und Nachsprechens. Indem die Erregungen der Leidenschaft, des Strebens nnd Bedenkens, also des $Z$ weifels, daraus entweichen, geht dieser Zustand in den festen über, und wird als solcher ein Element des vegetativen Lebens, der Mensch ist erfüllt und durchdrungen von seiner Überzeugung, der Glaube ist ihm in Fleisch und Blut (vin succum et sanguinem《) übergegangen, ist ganz und gar mit ihm verwachsen*, daher gibt er ihm etwas von der Ruhe« und seligkeit des pflanzlichen Lebens, wie sie auch an kleinen Kindern gepriesen wird, und der kindliche Glaube, die heilige Einfalt sollen diese in sich gesättigte Harmonie des Gemütes bezeichnen, die dem vegetativen Wesen der Frau mehr als dem animalischen Wesen des Mannes gemäß ist. Auf der anderen Seite ist das, was den Menschen als Menschen heraushebt, die Mentalität, das eigene freie Denken und Philosophieren etwas, was mit dem Zweifel beginnt und oft auch endet; hier ist die sich selber als subjektiv gebende, vorsichtig tastende, erwägende und sich selbst bedingende wissenschaftliche Meinung, die, auf Kritik beruhend, nicht zum 》Dogma erstarren will, zu Hause; sie kann allerdings tropfbar flüssig werden, d. h. eine Gestalt annehmen, in der sie in das Gefäß eines Systems gegossen zu werden taugt, sie kann endlich auch in eine feste Uberzeugung sich verhärten und so wiederum dem selbstsicheren Glauben ähnlich werden; aber das ist ihrer Natur, d. i. dem Charakter, der sie auszeichnet, insofern zuwider, als der rechte $\gg$ Denker» immer neuen 
Erfahrungen und neuen Gründen zugänglich bleiben will; dieser wird daher immer beflissen sein, seine Meinungen und Ansichten »im Flusse zu erhalten*, er wird sich gegen den Dogmatismus wehren und nicht müde werden, auch seine sfestgewurzelten Anschauungen" nachzuprüfen; wenn er sie von sich zu lösen vermag, so wird er sie auch vüber Bord werfen«, um »vorwärts* zu kommen, denn daran ist ihm alles gelegen, wie dem Schiffer, der auf seinen bestimmten Hafen lossteuert.

25. (Wille in der Meinung.) Meinung ist auch insofern dem Wollen verwandt, als in diesem die gleichen Aggregatzustände unterscheidbar sind. Wir sprechen von festen Vorsätzen und Entschlïssen, schlechthin vom festen Willen, und wissen, daß hingegen das meiste Wollen lose und locker ist, daß zumeist die Menschen leicht "wankend " gemacht werden durch Verführung oder Bestechung, daß sie andererseits sehr oft schwanken und unstät hin und her flattern; die auf innere Entzweiung hinweisenden Ausdrücke (zweifeln, dubitare) werden vom Wollen wie vom Meinen gebraucht. In beidem ist es manchem Menschen immer, jedem zuweilen schwer, "mit sich einig zu werden«. Diese innere Einmütigkeit und Festigkeit hat aber viele Grade, und je nach ihrer Stärke verschiedene Dauerhaftigkeit; sie kann sich in Eigensinn verhärten und jeder Widerlegung, jedem Rat, jedem Bedenken, jeder Warnung unzugänglich sein, aber in der Regel ist sie ein lockeres Gefiige, das durch Einfliisse jeder Art leicht zersetzbar ist. Von dieser flüchtigen, leicht beweglichen Art ist auch das Denken und Meinen, wie es dem künstlerischen Genius eigen ist, der die tiefe Anschauungsfähigkeit und Unmittelbarkeit des Weibes mit der männlichen $Z$ wecksicherheit und Vernunftkraft in sich vereinigt. Hingegen bei der großen Menge überwiegt die Oberflächlichkeit des Denkens und die Erregbarkeit durch Gefühle und Leidenschaften, die Stimmung, wovon die sonst wenig begründeten Meinungen abhängig sind; diese wirbeln empor wie die Luftblasen in einem Kessel, der mit siedendem Wasser gefüllt ist.

\section{Kapite1.}

\section{Gemeinsame Meinungen.}

\section{Erster Abschnitt. Bedingungen der Gemeinsamkeit.}

I. (Wahrscheinlichkeiten der Übereinstimmung.) $\mathrm{DaB}$ zwei oder mehrere Menschen über eine Sache wirklich einer "Meinung" sind, erscheint um so mehr als bemerkenswert, weil um so weniger wahr- 
scheinlich, A. je schwieriger, verwickelter, undurchsichtiger die Sache ist; B. je mannigfacher die Menschen nach ihren individuellen und sozialen Lebensbedingungen, Bedürfnissen und Interessen sind; C. je mehr insbesondere die einzelnen, die zu urteilen fähig und willens sein mögen, teils nach ihrer Begabung, teils in ihrer Denkungsart und in ihrem Gefühlsleben verschiedene Individuen sind, je mehr also jeder durch seine Entwicklung und Bildung sich differenziert hat. Die Umkehrungen ergeben sich von selbst. Mithin ist der Dissens um so wahrscheinlicher, je mehr alle drei Schwierigkeiten zusammentreffen und zusammenwirken.

2. (A. Die Schwierigkeit der Sache.) Nicht immer, aber in der Regel wird derjenige, der eine Sache versteht, sie zu beurteilen fähig ist, eine andere "Ansicht darüber haben als der "Laie" (wenn dieser iberhaupt eine solche sich gebildet hat); und zwar - wiederum nicht immer, aber in der Regel - die richtigere Ansicht. Aber je schwieriger, verwickelter, undurchsichtiger die Sache, um so eher werden auch Kundige, etwa sogar gleich intelligente und gleich unterrichtete Personen verschieden urteilen, abweichende Meinungen hegen. Ein Beispiel gewähren die ärztlichen Diagnosen. Dafür sind aber auch Regeln der Erkenntnis - der Differentialdiagnose - ausgebildet, die als bindend anerkannt und befolgt $z u$ werden pflegen. Die Fälle sind, je schwieriger und verwickelter, um so seltener. Die Ausdrucksweise, welche Ärzte und Laien unterscheidet, ist der alten Unterscheidung von Geistlichen (Klerus) und Laien nachgebildet. Von jeher erschien es gegeben, daß über die göttlichen Dinge, über Geheimnisse der Offenbarung, über theologisch-metaphysische Begriffe, nur der Geweihte, der die Fragen "von Grund aus studiert» hat, "ein Urteil habe». Eben da aber, zumal solange und sofern nicht eine bindende Entscheidung in Gestalt eines Dogma vorliegt, war und ist das Gebiet des Auseinandermeinens (dis-putare) und daraus entspringenden leidenschaftlichen Streites, der den "furor theologorums verrufen gemacht hat. Nächst der theologischen Fakultät ist die der Juristen am meisten mit historischer Würde angetan. Auch ist die Unterscheidung der Gelehrten und Lehrer (Doctores) von den Laien im Gebiete der "Jurisprudenz fast ebenso tief eingebürgert wie in der "Gottesgelahrtheit . Ebenso ist aber hier auch das Feld endloser Kontroversen und Disputationen zwischen den Gelehrten selber. Die "Advokaten haben von jeher in dem Rufe gestanden, fähig zu sein, das Weiße als Schwarz, wie das Schwarze als Weiß erscheinen zu machen. Sie machen notwendigerweise entgegengesetzte Meinungen geltend, wenn dem einen die Sache des Klägers, dem anderen die des Verklagten $z \mathfrak{u}$ vertreten obliegt, oder wenn der eine 
das Amt des Anklägers, der andere das des Verteidigers hat; ob sie die entsprechende Meinung auch hegen, ist nicht von wesentlicher Bedeutung; sehr oft wird sie aber den Anforderungen sich anpassen. Und so kommen wir auf die Unterscheidung zurück: das Hegen und Gestalten einer Meinung ist Sache des Wesenwillens, das Kundgeben aber möglicherweise Sache eines davon abweichenden, ja ihm zuwideren Kürwillens, der sich aber auch eine Meinung "bilden" kann. So kann auch in bezug auf eine schwierige Frage, wenn mehrere siibereinstimmen«, der eine sich ein Urteil gebildet haben und die Ansicht, deren Gründe er kennt, wirklich hegen; die übrigen aber sie nur äußern, indem sie sie gläubig" nachsprechen. Man folgt und unterwirft sich den Autoritäten«. Man unterdrückt den Widerspruch, sei es im Bewußtsein, daß man zum Urteilen nicht berufen sei, oder aus Scheu vor Mißbilligung und schlimmeren Folgen; am ehesten, wenn man sich nicht der Meinung einzelner, die etwa auch insgemein noch unbekannt ist, sondern der einmütigen und kundbaren Meinung vieler - wie auch immer diese entstanden sein möge gegenüber findet. Und durch Schweigen erscheint man selber als Zustimmender, wird dem Chore, dessen Stimmen vernehmbar geworden sind, zugerechnet. Also bildet in jeder Gruppe, in jedem Kreise sich eine möfentliche Meinung, und tritt zutage nach außen und nach innen; es ist regelmäßig die Meinung der Autoritäten innerhalb der Gruppe oder des Kreises, der die übrigen Mitglieder sich unterordnen; je mehr die Autorität anerkannt ist, je mehr Ansehen sie gewinnt, um so williger, also rascher, leichter und regelmäßiger vollzieht sich diese Anpassung. Die Übergänge vom bloßen Nachsprechen zum Nachmeinen sind leicht und häufig. Und es läßt sich hier auch das Gesetz der Beharrung feststellen, indem die Nachmeinungen noch an Autoritäten sich halten, die im engeren Kreise der $\$$ Sachverständigen" schon keine mehr sind, oder deren Ansichten doch in dem bezüglichen Punkte so stark angefochten werden, daß ihnen keine wahre "Geltung" mehr zugesprochen werden kann. Ubrigens wirkt ähnlich wie das Ansehen und die Autorität eines Führers die bloße Nähe des und noch mehr der Anderen, der Genossen, Kameraden, Nachbarn, aber auch die bloße körperliche Nähe von Versammelten und sich Versammelnden, die einander anstecken und ihre vorhandenen Gefühle gegenseitig steigern, eben dadurch auch ihre Meinungen und Wirkungen einander mitteilen: das Wirken der $₫$ Menge $"$ auf den einzelnen ${ }^{1}$ ).

3. (B. Lebensbedingungen.) Wenn in begrenzter Weise die Eirwartung recht behält, da $B$ auch in schwierigen Fragen die Kundigen

1) Vgl. "Die große Menge und das Volk“ (F. T.), Schmolrers J ahrbuch XLIV, 2. 
einer Meinung sind, so gilt in leichteren um so mehr, daß gleichartige Lebensverhältnisse gleichartige Meinungen bedingen, da $B$ mithin, je mehr jene auseinandergehen, um so mehr auch diese verschieden sind. Dies läßt sich schon beobachten an der verschiedenen Denkungsart von Alten und Jungen, von Männern und Frauen, von starken und schwachen Individuen; will sagen, daß die Alten, die Jungen, die Männer, die Frauen, die Starken, die Schwachen je in vielen Stücken ähnliche, oft die gleichen Gesinnungen und Meinungen zu haben pflegen. Ganz analog stehen sich die Schichten innerhalb eines Volkes gegenüber: Den Alten entspricht die ländliche, den Jungen die städtische, daher insonderheit die großstädtische Schicht; den Männern die weltliche kriegerische, den Frauen die geistliche (darum friedlichere) Adelsschicht, den Starken die Reichen, den Schwachen die Armen. Überall gehen gemeinsame Meinungen aus gemeinsamer Lebenslage, gemeinsamem Stande, gemeinsamer Klassenzugehörigkeit und Berufsart hervor. Mehr als der Wohnort wirkt die Beschäftigung, die Art der Erwerbung des Unterhalts, am meisten der Besitz und die Freiheit gegenüber dem Mangel an beiden. Zufriedenheit mit dem eigenen Lose ergibt andere Meinungen über den bestehenden öffentlichen Zustand als Unzufriedenheit mit dem eigenen Lose. Herren werden eher zufrieden sein mit der geltenden Ordnung, als Diener. Weltliche Herren werden die Meinung vertreten, daß die geistlichen, diese hingegen, da $B$ die weltlichen Herren an zweiter Stelle stehen sollten und sich zu viel anmaßen. Landleute meinen in der Regel, daß sie von den Städtern Übervorteilung durch betrügerischen Handel und unehrliches Schwatzen zu gewärtigen haben, Städter, daß die Bauern roh und einfältig sind, also durch Bildung verbessert werden müssen, oder aber, sie seien schlau und hinterlistig, nur auf ihren Vorteil bedacht, engherzig und höheren Gesichtspunkten unzugänglich. Und so gilt in großem Umfange, daß gleiche Meinungen Ausdruck gleicher, verschiedene Ausdruck verschiedener Belange (Interessen) sind, also die Meinungskämpfe zum großen Teile Standes- und Klassenkämpfe ausdrücken. Kampf und Krieg selber bringen notwendigerweise gleiche oder doch ähnliche Meinungen bei den Kampfgenossen, verschiedene und entgegengesetzte bei den Feinden hervor. In der Regel meint jede Partei, $\mathrm{da} B$ sie siegen werde, oder auch, da $B$ sie wertvoller, besser sei als die Gegner, daß ihre Sache die gerechte Sache sei usw. Der Zusammenschluß in Gefahr und Entschlossenheit durch Furcht und Sorge, der sich im Heere verkörpert, wirkt auch auf die Meinungen vereinigend. - Als Meinungskämpfe sind (wie mehrfach betont wurde) die religiösen von überragender Bedeutung. Sie haben oft ganze 
Staaten und Völker gegeneinander aufgebracht, sind aber vorzugsweise innervolkliche Kämpfe. In groben Umrissen betrachtet entsprechen sie hauptsächlich dem Gegensatz ländlicher und städtischer Denkweise, also ebensolcher Angelegenheiten. Das Christentum kämpfte um Dasein und Herrschaft als Glaube von Städtern, indem es in die Lücken eingedrungen war, die der städtische Unglaube da gelassen hatte, wo sonst die alten Götter verehrt wurden. Die Heiden werden noch heute in den romanischen und in den slavischen Sprachen danach benannt, daß es die Landbewohner waren, die diesen alten Göttern treu blieben (paganus-paien, altslov.-russ.: poganu). Heute ist ein umgekehrtes Verhältnis entstanden, nachdem die christlichen Gottheiten selber alt geworden sind. Sie haben ihre Heimstätten noch auf dem Lande; in den Städten, besonders den großen, keimt zwar mancher "Glaube neu», aber weit überwiegend herrscht (zumal in den führenden Schichten) der Unglaube als Denkungsart, die im Vertrauen auf Wissenschaft und ihre Ergebnisse beruht. Schon die freiere Glaubensgesinnung, die sich in der Reformation Bahn brach, hatte in den Städten ihren Mutterschoß. Neuerdings warnten römischkatholische Gelehrte davor, daß ihre Religion zur "Paganenreligion* herabsinke. Der liberale Protestantismus ist wiederum in den Städten mehr zu Hause als auf dem Lande, in großen mehr als in kleinen Städten. Mit den religiösen Streitigkeiten hängen die politischen innig zusammen. $\mathrm{DaB}$ das Land im großen und ganzen konservativ, die Stadt hingegen mutativ gesinnt ist, rührt zu einem Teil daher, $\mathrm{da} B$ der geistliche Einfluß dort viel stärker wirkt; aber seinen tieferen Grund hat es in der verschiedenen Art der Tätigkeit und Arbeit und der Lebensweise, also des Zusammenlebens. Die des Landes ist ebenso verhältnismäßig ruhig und stätig, vom Kreislauf der Natur abhängig, wie die der Städte auf Bewegung und Verkehr angewiesen und in viel höherem Grade durch menschliches Wollen und Denken bedingt ist. Dies gilt besonders vom Ackerbau dort, schon von der handwerklichen Tätigkeit hier, die daher eine freiere Art der Religiosität begünstigt, aber auch, wie vollends der gewerbsmäßige Handel, rechnendes Denken und kritisches Forschen hervorruft, beide den überlieferten Vorstellungen gefährlich. Ferner bewirkt schon das dichtere Wohnen häufigere Gespräche und lebhafteres Denken, heftigere Empfindungen; daher auch Unzufriedenheit und Unruhe festere Wurzel faßt, rascher sich ausbreitet, leichter sich entladet. Je mehr die Dörfer in den Verkehr und Austausch hineingezogen werden, um so mehr werden sie den Städten in dieser Hinsicht ähnlich. - Der weltliche Adel findet sich, schon durch seinen kriegerischen Beruf und die Leitung öffentlicher Angelegenheiten, 
die ihm in Verbindung damit ehemals oblag, noch heute oft zufällt, eher auf Neuerungen und Anpassungen hingewiesen als die Geistlichkeit, die andererseits aber - zumal als unerblicher Stand, und die niedere -, weniger beflissen, ihre Herrschaft zum Familienvorteil auszunutzen, stärkere Fühlung mit den Bedürfnissen, Nöten und Unzufriedenheiten des gemeinen Volkes zu behalten pflegt. Bei den Aristokraten ist doch die konservative Denkungsart in bezug auf ihre Herrlichkeit und Würde natürlich. Meinungsverschiedenheiten zwischen wetteifernden Gruppen herrschenden Schichten werden immerhin leicht entstehen; am tiefsten werden sie in Eifersüchten beruhen, aber nicht ausschließlich darin und in ausschließenden Belangen; auch die Grundsätze und Regeln des Denkens werden zumeist verschieden sein.

4. (Tieferer Gegensatz.) Tiefer aber und allgemeiner als diese Gegensätze ist - wie von neuem betont werden muß - der Gegensatz zwischen herrschender und beherrschter Klasse, zwischen den Hohen und den Niederen, den Reichen und den Armen, den Gebildeten und den Ungebildeten - wenn auch diese Ausdrücke für einen und denselben Gegensatz sich etwas voneinander unterscheiden und die Gruppenbildungen in jedem sich etwas verschieben. Demnach bilden sich auch gemeinsame und gleiche, oder doch ähnliche Meinungen, hüben und drüben. Auch dieser Gegensatz erscheint am häufigsten in religiösem Gewande. So ist die christliche Kirchengeschichte erfüllt von den Tatsachen, daß das gedrückte Volk sich enger zusammenschließt in der Meinung, da $B$ dieser Welt Ende und die Wiederkunft des Herrn herannahe, und daß die Gottlosen - das sind die Herren - ihren Lohn dahin haben. Es hilft diesen nicht, $\mathrm{da} B$ sie in die Kirche gehen und dem Zauber der Sakramente sich hingeben; ihre weltliche Gesinnung, auch die ihrer Priester, verrät sich in ihrem üppigen, sündhaften Lebenswandel, wovor den 》Heiligen « schaudert. Hingegen die Herren lächeln und lästern über den Irrwahn des armen Volkes, der Schwarmgeister und "Stillen im Lande", über ihre einfältigen Vorstellungen und törichten Reden. Zum Glauben jener gehört als wesentliches Stück die Heiligkeit der Obrigkeit und des Eigentums, also auch die Scheidung der Stände und die höhere Würde des Herrenstandes, insbesondere auch der Priesterschaft. In neuerer Zeit wirken zwar diese Anschauungen noch fort, aber mehr, wenigstens in den höchstentwickelten Gesellschaften, wird von beiden Seiten mit wissenschaftlichen Meinungen und Gründen gestritten. Dazwischen liegt in breiter Masse, da $\beta$ die Herrschenden auf Religion, die Beherrschten auf Wissenschaft sich stützen, wenn auch zunächst meistens auf Wissenschaft, die religiös verbrämt ist. Dies ist der in den neueren Zeiten überwiegende Streit zwischen konser- 
vativer und liberaler "Weltanschauung», und dieser läßt uns immer wieder bemerken, daß der Kampf und seine Not, wie nach außen, so nach innen, vereinend auch auf die Meinungen wirken, sei es zum Angriff (der Offensive), sei es zur Verteidigung (der Defensive); nur daß zum Angriff immer diejenigen am meisten geneigt sind, die sich bedrückt fühlen; daß aber auch die Schwächeren am meisten sich auf Zusammenschluß und Verbindung hingewiesen finden, um dadurch, was ihnen sonst an Kampfmitteln fehlt, zu ersetzen.

5. (C. Differenzierung.) Dazu kommt, daß die große Menge leichter sich auf gewisse Meinungen einigt, als die Gebildeten, weil diese schon als solche in ihren Ansichten weiter auseinandergehen: der Dünkel des Besserwissens, die Lust am Widerspruch machen sich hier ebenso geltend, wie die wirklich überlegene Einsicht, der Wettstreit höherer Erkenntnis, vermehrter Erfahrung, reiferen Denkens. Diese Momente machen sich stärker geltend als in der großen Menge, die mehr durch elementare Gefühle und entsprechende Meinungen bestimmt wird, daher leichter durch solche sich leiten läßt. Überdies beharren am wenigsten in der herrschenden Schicht die Gruppen: einerseits ihrer die Vorherrschaft einander mißgönnender, um den ersten Platz streitender Teile, andererseits Gruppen, die noch unter den Resten ihres ehemals gedrückten Standes, da sie selber zu den Beherrschten gehörten, leiden, und sich vielfach noch als solche fühlen, daher mit den wirklich und noch Beherrschten sympathisieren. Die Differenzierung des Einzelnen macht sich überhaupt zunächst als unsozialer Faktor erkennbar: der Eigensinn und der Dünkel des Besserwissens macht „Einspänner", die sich in keine Schablone fügen wollen. Andererseits machen aber solche Eigenschaften, wenn sie mit wirklicher Úberlegenheit, mit dem Besitze äußerer Hilfsmittel, mit Beredsamkeit und Leutseligkeit verbunden sind, für die Führerrolle um so geeigneter; zumal den, der davon überzeugt ist, $d a ß$ er dazu berufen sei, der sich etwa gar als Werkzeug einer übersinnlichen Macht, also als inspiriert und gottbegnadet fühlt; der zugleich etwa den Ehrgeiz hegt, selber als ein gottähnliches Wesen verehrt, angebetet $\mathrm{zu}$ werden, oder endlich gar in dem Wahne lebt, ein solches Wesen zu sein. Er wird seine Meinungen und Vorstellungen als die allein wahren, ihm geoffenbarten, mit Eifer und Enthusiasmus verkünden, er wird begeisterte Jünger um sich scharen, die seine Botschaft als Heilswahrheit verkünden, und nach seinem Tode die allein seligmachende Lehre in alle Lande zu tragen für ihre heilige Pflicht halten; um so mehr mit unwiderstehlicher Begeisterung und gerechtem Zorn, wenn der Meister als Blutzeuge seiner Wahrheit gefallen ist. Den dankbarsten Boden wird immer eine Lehre finden, 
die Befreiung von Knechtschaft und Qual, Erlösung von drückenden Banden, Erlassung drohender Strafen, und hingegen dauernde Wohlfahrt, himmlische Freuden, ewige Seligkeit dem Gläubigen in Aussicht'stellt; ob nun die Glïckseligkeit in diesem oder in jenem Leben, ob für die individuelle Seele als ihre Fortdauer, oder für die Kinder, Enkel und späte Nachkommen versprochen werde. Für den Führer aber, den Propheten, ist die Hauptsache, weil Hauptursache seines Erfolges, daß er mit dem Glauben an seine Lehre, seine Predigt, den Glauben a n sich verbindet, ja er kann jenen eher entbehren als diesen. Damit verbindet sich dann, um ihn zu ïberleben, der Glaube seiner Jünger an ihn, eines engen, aber durch sich selber, durch Propaganda, durch Vererbung und durch äußere Umstände, die den nährenden Mutterboden darbieten, sich erweiternden Kreises. So erzeugt sich immer neu der Ursprung aller sozial wirksamen oder ethischen Religion: die Vergötterung von Menschen, lebenden und vollends verstorbenen, wozu die naive Gefühls- und Denkungsart, also die der großen Menge, immer geneigt ist. Ihnen gegenuiber erscheinen dann die Ungläubigen als von bösem Willen gegen ihren Gott oder Propheten, also auch gegen sie selber, erfüllt, die ihm zu dienen und seinen Namen zu verkünden für Pflicht halten.

6. (Meinungen und Meinungsäußerungen.) Die Tatsache, daß zwei oder mehrere Menschen die gleiche Meinung hegen, 》einer Ansicht sind, ", muß also streng von der Tatsache unterschieden werden, $\mathrm{da} B$ sie die gleiche Meinung kundgeben, vertreten, zumal wenn diese Kundgebung und Vertretung öffentlich geschieht. Naturgemäß, und der großen Masse nach, erfolgt die Kundgebung allerdings »spontan «: der Mensch hat, unter gewissen Umständen, den natürlichen Drang und das Verlangen, seine Meinung zu sagen, wenngleich zumeist nur in engem Kreise, also nicht eben öffentlich; die stärkste Anregung dazu gibt das Vernehmen der Meinung eines anderen oder anderer; das Bedürfnis tritt hervor, ihr Beifall und Zustimmung zu geben, oder ihr Widerspruch entgegenzusetzen, eine a nde re Meinung auszusprechen. Übrigens aber bestimmt die Stärke der Hegung (die Intensität) einer Meinung den Wunsch, sie kundzutun. "Wess das Herz voll ist, dess geht der Mund über", gilt auch für Meinungen. IIch glaube, darum rede ich " - den Glauben zu bekennen, sich mutig und ohne Scheu $z \mathbf{u}$ ih $\mathrm{m} z \mathrm{u}$ bekennen, wird als Pflichtgebot empfunden und aufgestellt. Die Gedanken, mit denen die Menschen sich beschäftigen, sind freilich zum größten Teile die Angelegenheiten ihres täglichen Lebens, also ihre Arbeit und ihre Obliegenheiten, vergangene, gegenwärtige und zukünftige, Sorgen und Hoffnungen in bezug auf sich selber und ihre Angehörigen, daher auch die Bedeutung äußerer 
Umstände dafür, z. B. des Wetters, das zumal für die ländlichen und hauswirtschaftlichen Arbeiten so wichtig ist. Man spricht darïber und stauscht seine Meinungen aus«. Uber "gutes" oder "schlechtes" Wetter pflegt man gleicher Meinung zu sein, solange nur an Angenehmes oder Unangenehmes dabei gedacht wird, aber nicht mehr, wenn die Nützlichkeit in Frage kommt; so heißt der Landwirt etwa den strömenden Regen willkommen, der für andere, z. B. Wanderer, "scheußlich" ist. Derartig gibt es manche "Meinungsverschiedenheiten «. Vielfach wird aber das Aussprechen einer gewissen Meinung, wenigstens einer bestimmt gearteten Meinung, gewohnheitlich, und die (innere) Meinung selber wird durch die Übung des Aussprechens befestigt. Der eine neigt mehr zu Hoffnungen, der andere mehr zu Befürchtungen, die Meinungen sind mehr oder minder heiter ("optimistisch"), oder mehr oder minder düster ("pessimistisch«). Ferner kann die Bildung einer Meinung, und deren Kundgebung, eine Sache des Berufes und Gewerbes, oder (noch allgemeiner) eine gestellte Aufgabe sein, also pflichtmäßig erfolgen: das Fällen eines Urteils durch den Richter, Aussprechen der Diagnose durch den Arzt, die Abgabe einer Gutachtens durch den Sachverständigen, die Entscheidung über Vormarsch oder Rückzug durch den Feldherrn. In allen solchen Fällen wird selten Grund vorhanden sein zu bezweifeln, $\mathrm{da} B$ die ausgesprochene Meinung die wahre Meinung dessen sei, der sie ausspricht. Dagegen wird fast immer, von vielen oder von wenigen, mit größerer oder geringerer Heftigkeit, bestritten, daß die Meinung richtig sei. Meinung ruft Gegenmeinung, Bejahung ruft Verneinung hervor. Aber das Aussprechen einer Meinung kann sich auch von seinem natürlichen Zusammenhang mit der Meinung selber losreißen, es kann in bestimmter Absicht, zu bestimmtem Zwecke geschehen, ohne daß die Meinung wirklich gehegt wird. Die Kundgebung wird vorgestellt und gedacht als ein zweckmäßiges Mittel. Man will etwas dadurch erreichen, weil man weiß oder wenigstens glaubt, $\mathrm{da} B$ etwas dadurch erreicht werden kann. Am deutlichsten tritt dies zutage beim Tauschen, also dem Kaufen und Verkaufen. Es gilt beim Tauschgegner eine Meinung zu erregen, die ihn veranlasse, weniger zu fordern, mehr zu geben; etwa die Meinung, daß ein anderer (ein Mitbewerber) herannahe, der von derselben Sache mehr gebe oder für dieselbe Sache weniger fordere: allgemein, da $B$ man leicht das Nachgefragte billiger bekomme, daß die nachgefragte Sache minderwertig sei usw. Das einfache Mittel ist: diese Meinung selber aussprechen, als ob man sie hege, auch wenn man sie nicht hegt; oder sie mit größerer Bestimmtheit aussprechen, als man sie hegt, ihrem Aggregatzustand größere Festigkeit zuschreiben, als er besitzt. Die 
Freiheit des Denkenden, Uberlegenden betätigt sich in der bewußten Wahl der Worte, die geeignet scheinen, eine bestimmte Wirkung zu erzielen, also auch eine bestimmte Meinung zu erwecken; aber auch in den Tönen, mit denen das Sprechen der Worte begleitet wird. Hier öffnet sich das ganze Gebiet des Kürwillens als Lüge, als Verstellung, als Heuchelei, aber alle diese Ausdrücke bezeichnen äußerste Fälle, z. B. die Lüge: daß etwas gesagt wird, obgleich der Redende weiß, $\mathrm{da} B$ es nicht wahr ist, die Verstellung: $\mathrm{da} B$ man die Geberden und Worte (etwa) des Traurigen, die Heuchelei: daß man (etwa) die des Frommen und Rechtschaffenen anwendet, um dadurch Vorstellungen und Meinungen in der Seele des anderen zu erregen, von denen man sich Vorteil verspricht. Die feinere und leichtere Unwahrhaftigkeit, an die wir hier denken, ist unendlich viel häufiger: weil eben Meinung selber ein leichtes und flüchtiges Element ist, wenigstens in ihrem gewöhnlichen luftartigen Aggregatzustande. Man hegt etwa eine Meinung, aber sie ist eben "nur» eine Meinung, es mag sich auch anders verhalten, und man glaubt vielleicht, seine Meinung selber zu ändern, wenn man sich bewogen fühlt, eine andere Meinung auszusprechen oder sonst kundzutun; noch häufiger ist die absichtliche "Übertreibung", die oft um so weniger auffällt, weil sie auch ohne bestimmte Absicht alltäglich ist und, wenn auch als solche erkannt, doch ihre Wirkung tut. Sie geht bis zum rücksichtlosesten Mißbrauch der Sprache. Gleich jeder freien Handlung kann aber die Meinungsäußerung einer beweglichen Sache ähnlich werden, iiber die man verfügt, die man beliebig, aber als Vernünftiger mit Bedacht, ja mit Berechnung anwendet, als ein brauchbares Gerät. Die Meinungsäußerung wird dadurch selber einer käuflichen und verkäuflichen Sache ähnlich, und ebenso kann ihre Hergabe erzwungen werden. Alle anderen Mittel, die zur Hergabe einer Sache zu bewegen geeignet sind, als Uberredung, Schmeichelei, Versprechen künftiger Vorteile, Bitten, Drohungen, Befehle, finden auch auf Meinungsäußerungen Anwendung. Dabei kann es sich aber immer noch darum handeln, zur Äußerung der wirklichen Meinung zu veranlassen, wenn auch dem Veranlassenden es gleichgültig ist, ob und wie echt die Meinungsäußerung sei. Der Veranlaßte aber fühlt sich, wenn ihm die Äußerung abgenötigt ist, um so weniger »frei« und "verantwortlich" dafür, d. h. er empfindet und denkt die "Tat《 nicht schlechthin als seine eigene; am wenigsten natürlich, wenn er sich wirklich gezwungen fand, so zu handeln. Die unausgesprochene Meinung bleibt dann die seine (er »behält sie für sich«), aber der Ausdruck einer entgegengesetzten, vielleicht von ihm verabscheuten Meinung wird empfunden als die Handlung des anderen, des Zwingers; wie man keinen 
wesentlichen Unterschied findet, ob der Räuber mir die Uhr aus der Tasche reißt oder durch Vorhaltung einer geladenen Pistole mich nötigt, sie selber herauszunehmen und ihm zu übergeben - ob der Eroberer fremdes Land einfach wegnimmt und sich aneignet, oder durch Hungerblockade den Eigentuimerstaat zwingt, es in der Form eines $"$ Friedensvertrages abzutreten. Frei hingegen fühle ich mich, wenn ich die Sache zu meinem Nutzen gebrauche, daher auch, wenn ich sie freiwillig hingebe, um etwas dafür einzutauschen, was mir eben besser gefällt, oder wovon ich mir mehr Nutzen verspreche. Daher ist das Verkaufen der Meinungsäußerung, ebenso wie ihre Anwendung zum eigenen Nutzen, Betätigung der persönlichen Freiheit. Die Anwendung zum eigenen Nutzen kann auch in bewußter Weise mit Äußerung der eigenen Meinung geschehen: nur die Art der Äußerung, ihr Ton und ihre Form, mögen etwa verraten, daß sie in bestimmter Absicht geschieht. Aber die Feilbietung und "Veräußerung" macht unmittelbar die eigene Meinung zur fremden, wie jede Ware als Ware niemandem gehört, sondern dem beliebigen Käufer, und vollends Geld, als die umläufigste Ware, keinen Herrn hat, sondern jedem zufällt, der es erwirbt.

7. (Wahlen und Abstimmungen.) Wenn also die Schwierigkeit der Sache nicht jedem gestattet, eine eigene Meinung zu hegen, sich ein Urteil zu bilden, so hindert sie doch niemanden, eine Meinung kundzugeben, sei es, daß er sie wirklich, auf die Autorität eines anderen hin, den er für kundig und urteilsfähig hält, annimmt, und somit als seine eigene, wenn auch nicht selbstgebildete Meinung kundgibt, sei es, daß er sie, auf ebensolche Autorität hin, aber zugleich aus anderen Gründen, $z \mathbf{u}$ irgendwelchen $Z$ wecken ausspricht, ohne sie innerlich anzunehmen, oder endlich, daß er ausschließlich um eines äußeren $Z$ weckes willen sie kundgibt, und davon ist der äußerste Fall der, daß diese Kundgebung ein Gegenstand des Tausches, eine verkäufliche Sache für ihn wird, gleichgültig, ob die Meinung wirklich gehegt wird, angenommen ist, oder ob sogar die entgegengesetzte gehegt wird oder angenommen ist. Sehr deutlich wird dies bei Wahlen und Abstimmungen. Die Menge der Unkundigen wird als "Stimmvieh", wie man sich derb ausdrückt, „zur Urne getrieben«; in der Regel wird es sich hier nicht einmal um schwierige Sachen handeln, wenigstens scheint es eine leichte und einfache Sache zu sein, zu entscheiden, welche Partei »rechthabe - sie wird, vor allem Denken, durch das Gefühl entschieden, und zwar durch ein so elementares Gefühl wie das: hie die Guten - hie die Bösen; man entscheidet sich natürlich für die Guten wider die Bösen, sogar 
wenn etwa gut ganz bewußt gedeutet wird = für mich, für meine Angelegenheiten und Wünsche günstig, böse als das Gegenteil. Ubrigens aber wirken auch hier Beispiel und Úberredung, also die Autorität der "Führer" dahin, daß eine Parteimeinung angenommen und als solche durch Abstimmung kundgetan wird, sie bewirken auch, daß dies "gedankenlos " geschieht, oder in irgendwelcher der Sache fremden Absicht, z. B. in der Hoffnung, durch die Stimmabgabe (zumal wenn sie öffentlich geschieht) die Gunst anderer und dadurch eine vorteilhafte Stellung zu erhalten; endlich tritt an die Stelle der Úberredung, die sich schon leicht betrügerischer Mittel bedient, die unmittelbare Bestechung, sei es durch Geld oder durch Versprechungen (von Geld oder Ehren oder anderen Vorteilen). So kommen auf mannigfache Weise die großen übereinstimmenden Meinungsäußerungen der Parteien zustande, die in öffentlichen Wahlen vorliegen. Etwas anders ist die gemeinsame gleiche Abstimmung einer Partei - der Mitglieder einer "Fraktion" - innerhalb einer Körperschaft, wenn es sich um die Annahme oder Ablehnung einer "Vorlage« handelt. In der Regel ist hier die Aufgabe einfach, als eine logische Subsumtion: z. B. ,,alle Gesetze, wodurch die Freiheit der Individuen vermehrt und erweitert wird, sind gut (schlecht); der vorliegende Gesetzentwurf ist ein solcher; folglich muß er angenommen (abgelehnt) werden". Die Mitglieder der Fraktion sind in den Grundsätzen einig, hegen also uiber diese die gleiche Meinung: so wird wenigstens angenommen, und dann scheint es als notwendig oder doch höchst wahrscheinlich zu folgen, $\mathrm{da} ß$ sie im gleichen Sinne abstimmen werden; eben darum wird es ihnen aber auch zur Pflicht gemacht; wer es nicht tut, erscheint als ein Abtrïnniger, wohl gar als ein Verräter, seine Treue zum "Programm" der Partei als zweifelhaft, und wenn einer seine vin diesem Punkte abweichende《 oder "auf anderen Schlußfolgerungen beruhende» persönliche Überzeugung geltend macht, so wird verlangt, daß er diese "zum Opfer bringe", daß er also seine Parteitreue auch durch eine Abstimmung, die seiner Úberzeugung zuwider sei, bekunde. Nicht selten wird dabei auch der "Fraktionszwang" ausgeiibt, so daß der Dissentierende nur die Wahl hat: gegen seine Uberzeugung zu stimmen oder auszuscheiden aus dem Verbande und fortan ein "Wilder" zu sein, wenn er nicht in einer anderen Gruppe Aufnahme findet. Andererseits können nun aber auch und werden, bei gewichtigen Entscheidungen oft, von innen und von außen - auch von außerhalb des Hauses - Einfliusse zur Geltung gebracht, entweder die eigene Überzeugung oder die Parteitreue, oder sogar die Willensmeinung einer ganzen Fraktion $z u$ erschüttern, und auch diese Einflüsse sind mannigfach abgestuft, zwischen sachlichen, ob- 
jektiv-wissenschaftlichen Vorstellungen und grober Korruption durch angebotene Reichtümer oder Ehrenstellen.

8. (Führung.) Ferner aber macht sich die Errscheinung geltend, daß, je schwieriger die Sache, je gleichartiger die Lebensverhältnisse, je größer die Menge, um so mehr sind jedesmal die Wenigen, die führenden und maßgebenden Personen, ob sie Kundige gegenüber den Laien sind oder nicht, in der Lage, ihre Meinung so kundzugeben, $\mathrm{da} B$ sie als die Meinung der Vielen gelten kann: sei es I. weil diese dem Urteil der Wenigen sich unterwerfen, es durch ihren Beifall oder wenigstens durch Schweigen a nerkennen; oder 2. weil die Wenigen gleichsam als die Advokaten die Sache der Vielen führen, so daß sie deren unartikulierten Empfindungen und Bedürfnissen Sprache verleihen und sogar für sie zu reden scheinen, wenn viele a nders empfinden und denken; endlich 3. weil durch Reden und andere Mittel der Wenigen Gefühle in der Menge erregt werden, selbst wenn die entsprechenden Gedanken und Meinungen unverstanden bleiben. In alledem tritt die Führerschaft der Meinung uns entgegen, die im sozialen Leben von starker und mannigfacher Bedeutung ist. Sie kann auch bestehen, obgleich die Führer selber etwas anderes sagen, also $\mathrm{zu}$ meinen scheinen, als sie wirklich meinen; und wenn in diesem Falle auch die geführte Menge nur einem unbestimmten Gefühle Ausdruck gibt, so ist es denkbar, da $\beta$ eine große Meinungskundgabe stattfindet, an der nichts echt ist, außer der Stimmung der großen Masse, die etwa von Zorn, $\mathrm{Haß}$ und Rachsucht erfüllt, auf Zerstörung und Vernichtung gerichtet ist. - Immer liegt den Führern der Meinung ob, die geführte Menge in ihrer, d. i. in der von ihnen gewohnheitsmäßig kundgegebenen Meinung zu erhalten oder sie dafür zu gewinnen, dazu zu »bekehren«. Das hauptsächliche Mittel dafür ist die Rede, wenn es zu bekehren gilt, als Überredung, sonst zur Befestigung, Bestärkung, Ermutigung in der Meinung, die als richtige und wahre empfohlen wird. Aber die Rede ist nicht das einzige Mittel; auch Handlungen des Führers machen den Anspruch, als Beweise der von ihm vertretenen Meinung zu gelten. Um so eher gelten sie dafür, je mehr sie Verwunderung und Bewunderung erregen - Wundertaten und Heldentaten. Sie setzen sich in den Gemütern fest ("imponieren"), sie überzeugen. Und so entfaltet durch Reden und durch Taten die Persönlich keit ihren Machtzauber (ihr »Prestige oder "Charisma«), auch auf die Meinungen magnetisch, "suggestiv" wirkend. Und breiter noch, zuweilen tiefer, pflanzt das durch Schrift und Druck verbreitete Wort sich fort, sei es mit dem Einfluß einer Persönlichkeit, oder auch ohne diesen. Hier muß an das erinnert werden, was vorher über Mitteilung, Offentlichkeit, Autorität, aus- 
gesprochen wurde. Und am lebendigsten beleuchtet wird die gesamte Führerschaft der Meinungen wiederum durch die Ausbreitung der Gla ubensmeinungen, wo der Führer ein Prophet, ein Prediger, Zauberer und Priester ist, und die gläubige Menge an ihn glaubt, darum auch an den Gott, der, wie er meint und sagt, in ihm wohnt und ihn erfüllt, und folglich andere Meinungen, die er vertritt, annimmt; oder aber sie glaubt an ihn, weil er diesen Gott und diese Meinungen predigt, und der Glaube an ihn wirkt dann bestätigend auf diese zurück. Das Predigen von Glaubenssätzen, das Verkünden eines Gottes als des einzigen und allein wahren Gottes, und des Heils, das der Glaube an ihn bringe, ist aber eine ziemlich junge Erscheinung in der Geschichte der Meinungen. Ehemals erschien es natürlich, daß jeder Volksstamm seine, ja jede Stadt ihre heimischen, ererbten Götter pflege, und bei den Griechen hat nur die Begeisterung, mit der einzelne schwärmerische Kulte gelehrt wurden und wohl gar sich aufzwangen, etwas der Mission Ähnliches an sich. Im Orient ist die Stiftung von Religionen zu Hause, und die christliche Mission hat an der buddhistischen einen entfernten, am Proselytenmachen des Judentums einen unmittelbaren Vorgänger, wie an dem des Islâm einen bedeutenden Nachfolger. Allen gemeinsam ist, daß sie in einer einzigen Gottheit oder - wie der Buddha - in einer einzigen Weisheit Schutz, Rettung, Hilfe und was sonst die Menschen von ihren Göttern erwarten und erbitten, gelegen sein lassen, zugleich mit der Wendung dabei, daß es viel mehr auf das Heil der Seele als auf das des Leibes ankomme. Hierin liegt schon ein gewisser Zusammenhang mit wissenschaftlicher Denkweise, der den älteren Religionen wesentlich fremd bleibt, wenn auch in ihrem Schoße deren Anfänge von Priesterschaften und in Geheimlehren gepflegt werden. Die "Theologie freilich, die sich auf übernatürliche Erkenntnisquellen oder auf Offenbarungen beruft, ist durch diese Methode im Gegensatz und Widerspruch zur wirklichen Wissenschaft; aber sie ist in ihrem Ziele mit dieser verwandt, insofern als das Ziel objektive, d. i. allgemein - für alle Menschen gültige Wahrheit sein will. Darum müssen alle Menschen, denen sie zugänglich gemacht ist, sie auch anerkennen, namentlich alle, die durch einen Zauberakt (das Sakrament der Taufe) die Gnadengabe empfangen haben, wodurch ihnen gleichsam die Augen geöffnet sind. Folglich kann die Weigerung und das Anhängen an anderen Meinungen (die Heterodoxie) nur auf Verhärtung des Herzens, auf Verstocktheit, also auf Bosheit, beruhen und ist Sünde, und zwar eine unverzeihliche Todsünde - die Häresie, deren Name bedeuten soll, daß sie aus freiem Willen, der von seiner göttlichen Bestimmung abirrte, erwählt worden ist. Wie die Wahrheit göttlichen Ursprungs 
ist, so hat beim Atheismus und der Ketzerei ohne $Z$ weifel der arge Teufel die Hand im Spiele. Also wird die logische Nötigung zur Bejahung und Zustimmung, die der wissenschaftliche Beweis in Anspruch nimmt - der seinerseits wieder auf den Augenschein, d. i. auf die Gleichheit der menschlichen Wahrnehmungsorgane zurückgeht - in eine sittliche Notwendigkeit und Pflicht erhöht. Wenn solche Pflicht nicht unmittelbar erzwungen werden kann, so wird doch die Behörde, welche, sei es aus eigener Überzeugung, sei es um ihrer anderen Zwecke willen, die Beobachtung dieser Pflicht durchsetzen will, nicht nur den Widerspruch, zumal die öffentliche Kundgebung des $*$ Unglaubens», zu verbieten und zu verhindern vermögen, sie wird auch die Zeichen des Glaubens - z. B. Empfang der Sakramente, Teilnahme an Feiern - erzwingen oder wenigstens einen starken Druck in Richtung darauf ausüben können, um sie pflichtmäßig und gewohnheitmäßig $z u$ machen. So wird in bezug auf Glaubensmeinungen eine äußere Einigkeit bewirkt, die in der Regel so gedeutet wird, als ob der Schluß vom äußeren Schein auf innere Wirklichkeit ohne weiteres zulässig und richtig wäre; während höchstens das Nichtwidersprechen auch ein inneres ist, z. B. in der Masse des gläubigen Volkes gegen unverstandene und ihm schlechthin unverständliche Glaubenslehren.

9. (Meinungen als Pflichten.) In Wirklichkeit ist die Zugehörigkeit zu einer Religion, zu einem Bekenntnis oder $z u$ einem sektirerischen Glauben ebenso bedingt, wenn diese Glaubensmeinungen auf allgemeine Gültigkeit Anspruch machen, als wenn sie es nicht tun und nichts anderes sein wollen als die Verehrung der angestammten, einheimischen, örtlichen Götter. Bedingt nämlich in erster Linie durch den Familiengeist und Gemeindegeist, wie sie als Wunsch und Wille der Eltern sich ausprägen, daß ihr eigener Glaube auf ihre Kinder, der Lehrer und Meister, da $B$ er auf ihre Jünger übergehe; daher gleichsam angeboren und ererbt, heranwachsend durch frïhe Gewöhnung und frühe Unterweisung, gepflegt und erhalten eben durch jenen Gemeinwillen, der Gehorsam verlangt und aufnötigt, wenigstens als Schweigen und Erfüllung der Formen, d. i. Kundgebung äußerer Zeichen der Verehrung und teilnehmenden Stimmung. Es können aber auch diese Zeichen scheinbarer Gläubigkeit verschwinden, und nur die äußere, etwa durch Zahlung von Kirchensteuern dargetane, vielleicht auch durch das Geschehenlassen gewisser Zeremonien sich bewährende Zugehörigkeit zu einer Religionsgesellschaft wie zu einem beliebigen und zufälligen Vereine übrigbleiben. In diesem Sinne kann dann auch die Religion oder Konfession leicht gewechselt werden. Übertritte aus der einen in die andere finden statt. $\mathrm{Zu}$ - 
weilen werden dafür Gebärden und Getue, oder wenigstens das Aussprechen von Formeln, einer wirklichen Sinnesveränderung oder Bekehrung erfordert; in vereinzelten Fällen mag diese "Bekehrung" wirklich stattfinden. Auch wenn nichts dergleichen der Fall war, so wird doch oft eine Vertretung und Verteidigung der "neuen Meinungen" eintreten, als ob sie aus Überzeugung angenommen wären. Dahin wirkt teils das Schamgefühl, da man wei $B$, da $B$ der Religionswechsel um äußerer $Z$ wecke willen (aus Kürwillen) von den früheren Freunden und sogar von vielen anderen gemißbilligt wird, das eigene Gewissen auch wohl an dieser Mißbilligung teilnimmt, teils der Druck der neuen Umgebung, die ohnehin dem Neuling zu mißtrauen geneigt ist; diesem Druck, der durch eigene Einbildung erhöht wird, ist es zumeist zuzuschreiben, $\mathrm{da} B$ die "Konvertiten« oft die älteren Gläubigen im Eifer ïbertreffen, ja die heftigsten Fanatiker werden. Wahrscheinlicher ist dies freilich, wenn eine wirkliche „Bekehrung" und neugewonnene Überzeugung zugrunde liegt, wie solches besonders bei Frauen durch innere Seelenschicksale und äußere Einflüsse nicht selten bewirkt wird.

Ähnlich, wenn auch in verringertem Maßstabe, wie mit religiösen, verhält es sich mit anderen Meinungen, am meisten ähnlich mit politischen Parteimeinungen, die auch (wie wir oft bemerken) mit den religiösen stark zusammenhängen, selbst wo sie im Gegensatz zu ihnen sich entwickeln. In einigem Maße wird, wenigstens heute, der Mensch auch in diese hineingeboren oder doch hineinerzogen. Sie werden zur Pflicht gemacht, und zum mindesten der Schein gewisser Meinungen $m u ß$ aufrecht erhalten werden. Die Äußerung gar mancher Meinungen ist in gewissen Kreisen, insbesondere in der "guten Gesellschaft", "verpönt", - im günstigsten Falle wird sie als exzentrisch belächelt oder gar komisch gefunden und verlacht, so lange als sie noch wegen des Alters oder der Lebensstellung des Andersdenkenden ungefährlich scheint. Dann wird wohl auch die Äußerung als ein bloßes Spiel mit Gedanken und Worten hingenommen und geduldet (oft ist sie auch nichts anderes); daß ein wohlerzogener junger Mann wirklich solche "gräßlichen Ansichten" hege, wird für unmöglich gehalten. Die Ansichten, d. h. die zur Schau getragenen, gehören zur Kleidung. Gut angezogen sein und gute Gesinnungen haben wenn die Gelegenheit es erfordert, kundgeben - gehört beides zur Schicklichkeit, zum Anstande, oder wie man im I8. Jahrhundert sagte, dem "Wohlstande«. Aber wie die Art sich zu kleiden, die Form der Kravatte oder des Hutes, so richten auch die Meinungen sich nach der Mode; in gewissen "Modifikationen", - und die Mode läßt hier ihre Gesetzmäßigkeit deutlicher erkennen, als in bezug auf 
Kleidertrachten. Im einen wie im andern Gebiete wirkt, neben dem Beduirfnis der Abwechslung, das Beispiel, das Vorbild "maßgebender" Personen viel; aber die Mode in den Meinungen ist außerdem durch den Gang der Ereignisse, insbesondere (in den politischen Meinungen) durch den der politischen Ereignisse in hohem Grade mitbestimmt. Innerhalb gewisser Grenzen ist also der Wechsel der Meinungen nicht nur gesellschaftlich erlaubt, sondern geboten. Man will und darf so wenig in veralteten Ansichten wie in verjährter Kleidermode einhergehen. Ubrigens aber hat auch die wirkliche Veränderung von Grundmeinungen, also der Wechsel der Partei, im allgemeinen nicht so große Bedeutung, wie der Wechsel der Religion. Dort wie hier werden Bekehrte, „Proselyten" willkommen geheißen, wenn auch zuweilen mit geheimem, zuweilen sogar mit offenem Mißtrauen, aufgenommen. Im Grunde und von den aufrichtigsten Anhängern eines religiösen oder politischen Bekenntnisses wird die unechte Bekehrung verabscheut; oft aber ist die Echtheit gleichgültig, wenn es sich darum handelt, daß einer für eine Sache zu reden, und besonders zu schreiben, fähig und willens ist. Überall steht eben die Handlung, die aus Kürwillen geschieht, mit derjenigen des Wesenwillens in Wettbewerb und übertrifft sie oft in der Wirkung. Der besondere Eifer der Bekehrten wird bei politischen wie bei religiösen "Renegaten (wie sie vom Standpunkte ihrer früheren Genossen heißen) bemerkt; sie hassen oft ihre früheren Meinungen oder tragen wenigstens solchen $\mathrm{Haß}$ zur Schau.

10. (Gemeinsame Meinung - gemeinsamer Wille.) Wie es für die individuellen Meinungen festgestellt wurde, so ist auch für die sozialen Meinungen der Zusammenhang mit dem Willen mannigfach und tief. Wir fanden (vgl. S. Io) ein dreifaches Verhältnis vom Denken und Meinen zum Wünschen und Wollen, oder schlechthin zu den Gefühlen: I. Es gehe daraus hervor, sei immer dadurch mitbedingt, es drücke Gefühle aus; 2. eben darum und zum Teil infolgedavon, habe es auch Gefühlsbetonung, Gefühlsbedeutung, es sei "Wollen" und "Nichtwollen" als Bejahung und Verneinung, als günstiges und abgünstiges Urteil (Werturteil - Vorurteil); 3. es sei wesentlich perfektisch wie das Wollen: Meinen = eine Meinung haben, sich ein Urteil gebildet haben, wie Wollen = beschlossen haben, sich vorgenommen haben. - Betrachten wir dies dreifache Verhältnis an den gemeinsamen Meinungen. I. Alles, was über Bedingtheit der Meinungen durch Lebensumstände und gemeinsame Interessen gesagt wurde, läuft dahin zusammen, daß das Meinen aus Gefühlen hervorgeht, Gefühle ausdrückt. In offenbarster und schlagender Weise tritt es uns entgegen, wenn wir das Verhalten des 
Menschen in einem Kriege beobachten. Die Meinung, daß das eigene Land siegen werde, drückt hier unmittelbar den Wunsch aus, daß es siegen möge, und dieser Wunsch ist von der "Liebe zum Vaterlande» untrennbar. Aber sogar innerhalb dieser Einigkeit macht sich noch die Verschiedenheit der Lebensgefühle geltend. Die Frauen und die Alten sind eher zum Verzagen, zu Furcht und Sorge, daher auch zum $Z$ weifel und zu weniger hoffnungsvollen Meinungen geneigt, die Männer und die Jungen sind mehr von Gewißheit und Zuversicht erfüllt, ihre Meinungen sind "optimistischer", die der andern "pessimistischer". Ebenso verhalten sich in einigem Maße die Besitzenden, Genießenden, zumal die eben Reichwerdenden zu den Armen, Arbeitbedrückten, vollends den eben Verarmenden. Ebenso macht sich der Gegensatz zwischen dem mehr kriegerisch gesinnten, oft auch unter dem Kriege weniger leidenden "Land « und den Städten, zumal großen Städten, von denen das Umgekehrte gilt, bemerkbar; und entsprechenderweise zwischen den verschiedenen Schichten des Volkes. Sodann aber macht sich in gleichem Sinne die »persönliche Gleichung«: Gesundheit, Temperament, Stimmung überall geltend. So wirkt dann auch wieder die Gesamtheit der Meinungen, Denkungsart, Weltanschauung, also auch was in dieser Hinsicht den Menschen gemeinsam ist, auf die Einzelmeinung, z. B. uiber den Ausgang und die Folgen des Krieges, zurück. 2. Daß gemeinsame Meinungen gemeinsame Bejahungen und Verneinungen enthalten, ist an allen Parteimeinungen sehr deutlich, religiösen wie politischen. Sie besagen nicht nur, daß die gegnerischen Meinungen irrig und falsch, vielleicht sogar töricht und verderblich sind, sondern sie schwärzen in der Regel die Gegner selber als schlechte Menschen, im günstigsten Falle als arme verirrte Schafe, an. Aber sie enthalten auch unmittelbar bejahenden Wunsch und Willen; in den Meinungen kristallisieren sich Forderungen, die Meinung, daß etwas gut oder böse, richtig oder falsch sei, bedeutet das Verlangen, daß es eingeführt oder abgeschafft, vermehrt oder vermindert, verstärkt oder "abgebaut" werde, wenn auch etwa eingeräumt wird, da $ß$ es nicht augenblicklich geschehen könne, nicht überstürzt werden dürfe. 3. Auch das soziale Meinen ist perfektisch, es ist das Ergebnis von Überlegungen und Erfahrungen, wie das soziale Wollen, und eben dadurch oft mit diesem identisch. So bildet Meinen und Wollen einer Schicht, einer Klasse, und in der Folge einer Partei, aus verworrenen Gedanken und Bestrebungen, die in vielfachen Widersprüchen zueinander standen, als abgeklärte Denkweise und Gesinnung sich heraus; gewisse »Grundsätze treten als wesentliche und notwendige, als Lebensbedingungen hervor. Und so hat das Meinen als ein fertiggewordener Zustand 
Wirkungen bei jeder "Gruppe», der es gemeinsam ist, die den Wirkungen entsprechen, die es beim Einzelmenschen hat, nämlich: I. Es bestimmt das Werden, die zukünftigen, einzelnen Meinungen gehen aus der einmal feststehenden Gesamtmeinung hervor, sie lassen sich daraus erschließen: man weiß z. B. wie eine religiöse oder politische oder auf welchem Gebiete auch immer sich betätigende Partei über eine neu auftauchende Einzel-»Frage« urteilen wird, wenn man die Grundsätze, die Haupt- und Grundmeinungen der Partei kennt. 2. Diese üben aber auch eine bestimmende, nötigende Wirkung aus gegen widerstrebende, schwankende, abzuweichen geneigte Meinungen der einzelnen Personen, die der Gruppe oder Partei angehören.

II. (Verbindende Meinungen.) Wir finden also in der gemeinsamen Meinung als solcher, insofern als sie gemäß dem Willen derer, die sie gebildet haben und (der Voraussetzung nach) fortwährend tragen, gemeinsam sein und verbinden soll, ein gemeinsames Wollen von der Art, wie alles gemeinsame - soziale - Wollen ist, indem es verbindlich, verpflichtend, befehlend und verbietend, fördernd oder hemmend auf die Einzelnen, die Mit-Wollenden, die Mit-Glieder wirkt, eben dadurch auch die Wirkung nach außen hin sicherer und stärker macht. Es ist das gleiche Verhältnis und die gleiche Wirkung, von altersher bekannt, wenn der Staat seinen Bürgern Gesetze gibt und seine Kraft einsetzt um deren Befolgung zu erwirken, Übertretungen zu wehren. Wiederum ist dieser Sachverhalt in seinem Wesen nicht davon verschieden, daß ein einzelner Mensch, ein Herr, vielen als seinen Dienern oder Untertanen befiehlt und durch Zwang wie andere Mittel (»Zuckerbrot und Peitsche») eine solche Menge in seinem Gehorsam zusammenhält. Auch da ist es möglich, daß die Vielen, oder doch ihre Mehrzahl, gutwillig und freiwillig sich der Person des Herren unterordnen, ja sogar in seinem Willen ihren eigenen Gesamtwillen wiedererkennen. Dadurch, daß jeder Einzelne, der zu einer Gruppe gehört, den tatsächlichen Zustand dieser Gruppe, vermöge dessen sie ein irgendwie ausgesprochenes Gebot oder Verbot als ihren Willen gelten läßt, von sich aus bejaht, wird für ihn, und somit für alle Mitglieder, dieser tatsächliche Zustand ein rechtmäßiger Zustand; das Dasein der Gruppe selber, symbolisiert durch ihren Namen, wird als ein Dasein im Rechte empfunden und gedacht. Ebenso wird es für weitere Kreise in die Rechtssphäre erhoben dadurch, daß diese es kennen lernen und anerkennen. Im gleichen Sinne ist aber auch der Inhalt des Willens einer Gruppe - eines Bundes, eines Vereins geltendes Recht für die Mitglieder dieser Gruppe, insofern als es gedacht wird als auf dem übereinstimmenden Willen aller beruhend, und in den Formen, die diesem übereinstimmenden Willen gemä $B$ 
sind, beschlossen und kundgegeben. Dieser ausgesprochene Wille einer rechtmäßig eingesetzten - vkonstituierten" - Gruppe ist nun ein besonderer Fall der allgemeineren Erscheinung, daB überhaupt der verbundene Wille mehrerer, also auch etwa nur zweier Personen, für diese mehreren gültig, also verbindlich "ist", d. i. von ihnen selber dafür gehalten, als solcher anerkannt wird. Daher muß immer diese allgemeine Betrachtung zugrunde gelegt werden, wie es in den folgenden Ausführungen geschieht.

12. (Übereinstimmung und Nōtigung.) Ein allgemeines Problem, worin das einer "öffentlichen Meinung", also auch der öffentlichen Meinung eingeschlossen liegt, ist also die Gemeinsamkeit und Übereinstimmung mehrerer Menschen überhaupt in ihren Meinungen oder "Ansichten*, mithin auch in ihren Glaubensvorstellungen, Weltanschauungen, sittlichen Grundsätzen usw. Wir betrachten hier wie früher die Vorstellungen der Menschen als Ausdruck ihrer Gefühle oder sogar ihres bewußten auf $Z$ wecke und Mittel gerichteten Wollens. Darum ist auf gemeinsame Gefühle und gemeinsames Wollen zurückzugehen, um - wenigstens in gewissem Umfange - gemeinsame Meinungen zu erklären.

Gemeinsamkeit wird hier nicht nach dem losen Sprachgebrauch verstanden, wonach zwei Menschen oder Gegenständen gemeinsam ist, was der eine hat und der andere auch hat, - sondern wir denken an Gefühle usw., die zugleich Ausdruck einer Verbundenheit zwischen Menschen sind, und diese Verbundenheit mitbedingen. Die Verbundenheiten und positiven Verhältnisse sind (nach meinen Begriffen) von gemeinschaftlicher oder gesellschaftlicher Art, oder doch mehr in die eine oder mehr in die andere Richtung weisend. Gemeinschaft wurzelt im Wesenwillen, der das Denken in sich enthält, gleichsam aus sich entläßt, so daß auch Verhältnisse und Verbindungen, die um ihrer Zweckmäßigkeit willen gewollt werden, noch von gemeinschaftlicher Art sein können. Erst an dem Punkte, wo das Denken frei wird und sein Mittel scharf unterscheidet vom $Z_{w e c k}$ ja - im typischen Falle - es mit Widerwillen will, da hebt sich begrifflich der Bereich des Kürwillens vom Bereiche des Wesenwillens ab und setzt sich ihm entgegen.

Danach ist auch gemeinsamer Wesenwille und gemeinsamer Kürwille $\mathrm{zu}$ unterscheiden; mithin auch gemeinsame Meinungen, sofern sie im einen oder im anderen wurzeln oder doch damit zusammenhängen.

Ein besonderes Gebiet des gemeinsamen Wollens ist aber dasjenige, wodurch das Einzelwollen gebunden wird, das als I m perativ ihm gegenübersteht. Ein solches gemeinsames Wollen bestimmt im 
allgemeinen die Handlungen der Einzelnen, mögen die Handelnden ihres Gehorsams gegen den gemeinsamen Willen sich bewußt sein oder nicht, mögen sie den gemeinsamen Willen als solchen kennen oder nicht. Die Handlung ist aber hier in einem sehr weiten Sinne $z u$ verstehen. Auch das verstehbare Sprechen als Gebrauch einer Sprache ist in diesem Sinne eine Handlung. In den Bedeutungen der Wörter und in den Regeln der Sprache drückt sich ein gemeinsamer Wille aus. Auch das Denken und Meinen ist in diesem Sinne ein Handeln. Daß das Aussprechen von Gedanken, die Meinungsäußerung als vfreie Handlung gerechnet wird, ist man gewohnt. Hingegen scheint das Denken selber und das Für-wahr-halten, weil unwillkürlich, der Wirkung von Geboten und Verboten entzogen zu sein. In Wahrheit ist es nicht unmittelbar von Entschlüssen und Vorsätzen abhängig, daher auch nicht, gleich einer freien Handlung sonst, durch Hoffnung und durch Furcht unmittelbar bedingt, als die Gefühle, welche ein fremder Wille, mithin auch ein Gesamtwille, einzuflößen vermag. Aber diese bezeichnen wohl die am meisten auffallende, aber keineswegs die einzige Art des Einflusses eines Willens auf den anderen, insbesondere nicht eines gemeinsamen Willens auf Gefühle und Denkungsart des Einzelnen, der innerhalb des Bereiches dieses gemeinsamen Willens steht. Vielmehr ist es eine ganz regelmäßige Erscheinung, daß das Denken eines Menschen, wie es durch seine gesamte Umgebung, durch die Atmosphäre bedingt wird, worin das Denken lebt, durch die Nahrung, die es täglich und stündlich empfängt, so ganz besonders sich richtet und sich fügt nach den Ausdrücken des sozialen Willens, den es kennt und anerkennt, wovon es sich getragen fühlt: des »Geistes ", worin sein eigener Geist beruht. Die Grenze zwischen Denken und Reden, Meinung und Meinungsäußerung ist in der Regel eine fließende Grenze; die Äußerung, vollends die gewohnheitsmäßige und etwa berufsmäßige Äußerung wirkt zurück auf Glauben und Meinung und also auf die Denkungsart. Es kann nicht mit Erfolg befohlen oder verboten werden, so und so zu denken, solche und solche Sätze zu glauben, die und die Meinungen zu hegen - aber es kann ge- und verboten werden, die entsprechenden Anschauungen kundzugeben, zumal sie öffentlich auszusprechen, sie durch die Schrift und den Druck zu verbreiten, andere dazu zu überreden oder davon zu überzeugen, kurz, werbend dafür einzutreten (zu "agitieren"). Wenn das Gebotene zuerst mit Widerstreben getan, das Verbotene mit Groll unterlassen wird, so findet doch hier wie in allen Fällen von Druck und Hemmung zumeist eine Anpassung und Anbequemung statt: die Gedanken fügen sich dem Druck. Die gehemmten Meinungen, sofern sie nicht gleichzeitig 
von anderen Seiten gefördert werden, erlahmen und treten in den Hintergrund des Bewußtseins zurück. Ubung erleichtert auch hier die Bewegung, Gewohnheit beschleunigt das Wiedererwachen schlummernder Gedanken. Umgekehrt: bei mangelnder Übung stellen die Vorstellungen sich mühsam her, ungewohnte Gedankengänge erlöschen allmählich, auch solche, die einmal mit Liebe, ja mit Leidenschaft gepflegt wurden.

Einige der hier betrachteten Vorgänge sind des öfteren erörtert worden, als Wirkungen des Volksgeistes. Daß Rede- und Denkweise der Menschen, wie durch Erziehung und Lehre, so durch unzählige sich anhäufende Einflüsse ihrer Mitmenschen, insbesondere ihrer Alters- und Geschlechtsgenossen, ihrer Standes- und Berufsgenossen, ihrer Glaubens- and Parteigenossen ursächlich mitbestimmt werden, ist eine offenbare Tatsache und hat längst dahin geführt, daß man unter dem Namen der Völkerpsychologie und der Sozialpsychologie die Gesamtheit dieser Erscheinungen $\mathrm{zu}$ erforschen begonnen hat. Die gegenwärtige Untersuchung will sie alle in den Brennpunkt des sozialen Willens bringen. Dieser aber wird nicht nur von seinen elementaren gefühlsmäßigen Formen bis hinauf $\mathrm{zu}$ den gedankenmäßigsten Formen entwickelt, sondern überdies unter die Kunstbegriffe des Wesenwillens als des Willens, der das Denken in sich enthält, und des Kürwillens, als des Denkens, das den Willen bildet, gebracht, und nach diesen Schematen sind auch die folgenden Begriffe entworfen.

\section{Zweiter Abschnitt. Rationale und irrationale Formen gemeinsamen Willens.}

I3. (Beschluß und Beschlüsse.) Man kann gemeinsamen Willen und gemeinsames Wollen I. als unmittelbaren Gegenstand der Erkenntnis verstehen und auffassen: die Tatsache, daß mehrere miteinander einig sind, a) in ihrem Vorhaben, in Verfolgung eines Zweckes, in einem Entschlusse, einer Bereitschaft, und zwar muß das Wollen wie alles eigentliche Wollen als ein freies, nicht als ein Sollen, gedacht werden; es kann aber, b) bei jedem Beteiligten zu einem Sollen werden, dann erstreckt sich das gemeinsame Wollen auch auf das Sollen - wie auch der Einzelne sich selbst nötigen, ja sich zwingen kann, und ,wer sich nicht selbst befiehlt, bleibt stets ein Knecht" das Wollen nimmt also den Charakter des Imperatives an, der Folge, Gehorsam, Anpassung in Anspruch nimmt. Als solcher oder als Komplex von Imperativen kann aber 2. das gemeinsame Wollen und der gemeinsame Wille ferner begriffen werden, insofern es (und er) für die gemeinsam Wollenden, also die Subjekte des Willens 
selber, Gegenstand ihres Wollens, mithin ihres Denkens ist; also für die Theorie ein mittelbarer Gegenstand der Erkenntnis. Auf die einfachste und klarste Weise geschieht dies Heraussetzen des gemeinsamen Denkens und Wollens in der Form des "Beschlusses», den mehrere für sich zusammen, wie jeder Mensch für sich allein, "fassen" kann. Ein gemeinsamer Beschluß heißt: I. Wir wollen tun; 2. jeder von uns soll folglich tun - die beiden Sätze fallen hier zusammen, der erste schließt den zweiten in sich ein. Hier wird zunächst an etwas Einzelnes gedacht, z. B. die Männer eines Stammes beschließen, einen Einfall ins Nachbargebiet zu unternehmen, oder: eine Anzahl von Freunden beschließt, einen Ausflug zu machen, ein Fest zu feiern, oder einen Toten $z u$ bestatten. Es kann aber auch die "Entschließung (Resolution), z. B. einer Volksversammlung, einen bloßen Wunsch, eine Forderung oder etwa einen an die Nichterfüllung des Verlangens sich anknüpfenden Vorsatz ausdrücken, ohne daß der Einzelne, der zufällig zugegen ist, dadurch zu einem Tun oder Unterlassen veranlaßt werden soll; 3. kann der Beschluß mehrerer dahin gehen, $\mathrm{da} \mathrm{B}$ sie einen Verein, einen Klub, eine Verbindung, Gesellschaft oder Gemeinschaft, Bund, Genossenschaft oder welchem Namen immer - in jedem Falle eine beschlußfähige Einheit aus sich bilden, gründen oder stiften wollen, die also eben durch diesen gemeinsamen Willen und Schöpfungsakt, mithin zunächst für Willen und Gedanken dieser Schöpfer, ein gleichsam objektives - der Unterscheidung halber wird man besser sagen: ein ejektives - Dasein gewinnt ${ }^{1}$ ). Eine beschlußfähige Einheit heißt, daß ein auf bestimmte Weise, in vorgesehener und vorgeschriebener Form, entstandener Beschlu $B$ einer oder mehrerer Personen als Beschluß der Einheit oder Gesamtheit gelten soll - am einfachsten und nächsten "gilt» dafür, was wirklich ein Beschluß aller ist, aber ein leichterer Weg wird gesucht und gefunden, indem I. eine Anzahl, die in bestimmter vorgeschriebener Form zusammenkommt, oder sogar ein Einzelner, der bestimmte vorgeschriebene Formen beobachtet, als die Gesamtheit darstellend gedacht wird, also wiederum dafür gilt, und indem 2. dieser Versammlung die Befugnis verliehen wird, auch dann Beschlüsse zu fassen, wenn nicht alle ihre Mitglieder anwesend sind, oder sogar dem Einzelnen im Namen aller und endlich 3. sogar, wenn die Anwesenden nicht einig sind, sondern nur eine Mehrheit einig ist oder wird, so da $B$ der Beschluß dieser (sei es einfacher oder größerer) Mehrheit als Beschluß der

1) Als Ejekte schlıg etwa im Jahre 1880 der englische Mathematiker und Philosoph K. G. Clifford vor, die nur für das Denken vorhandenen Gegenstände des inneren Sinnes zu bezeichnen. Diese gute terminologische Neuerung hat gleich mancher anderen keine Beachtung, geschweige Nachfolge gefunden. 
Versammlung gilt, mit der Folge, daß solcher Beschluß alle bindet. Auf diese Weise erhält der Verein oder wie das "Ding" sonst benannt werden mag, eine Ordnung oder "Verfassung" als Komplex bindender Regeln. Wenn im idealen Falle »alle» einig sind, nicht nur den Verein (oder dg1.) zu wollen, sondern auch solche und solche Verfassung dieses. Vereins, so kann doch eine stillschweigende oder ausdrückliche Einigkeit auch dahin gehen, schon die Beschlüsse über diese Verfassung einer Versammlung so anheim zu geben, daß diese nach ihren Regeln und auf Grund einer Mehrheit, diese Beschlüsse faßt. - Ein Beschluß macht sich eben dadurch geltend, daß er "gefaßt " wird, $d . h$. in Worte gefaßt wird, die erkennbar und verstehbar sind, weil dies die Bedingung dafür, daß man sich danach richte, ihn befolge. Sein objektives (ejektives) Dasein wird aber dadurch noch verstärkt, daß er schriftlich niedergelegt wird und also eine bleibende Gestalt empfängt, an die jeder, insbesondere also wer ihn ausführen und ihm gehorchen soll, sich halten kann und soll. 4. Die gemeinsamen Beschlüsse Vieler, mithin auch die ihnen gleichwertig geltenden Beschlïsse einer Versammlung (oder einer einzigen Person) können aber auch dahin gehen, daß die Mitglieder der Gesamtheit oder des Vereins, nicht einmal, sondern regelmäßig, wenigstens unter gewissen Voraussetzungen immer, bestimmte Tätigkeiten tun oder unterlassen sollen. Es ist die Verallgemeinerung von 3. Denn schon Herstellung einer Verfassung bedeutet, da $B$ die Mitglieder die in den vorgeschriebenen Formen gefaßten Beschlüsse anerkennen, also nach ihnen fortwährend sich richten und den Widerstand dagegen dauernd unterlassen wollen und sollen. Hier aber handelt es sich etwa um gewisse zu wiederholende Leistungen (Mitgliedsbeiträge), um dauernde und regelmäßige Unterlassungen, z. B. feindseligen Handelns der Mitglieder gegeneinander, kurz darum, daß sie nach bestimmten Beschlüssen der Gesamtheit (oder solchen einer oder mehrerer dafür ausgelesener Personen) als für bestimmte gleichartig wiederkehrende Fälle gültigen sich richten sollen, so daß ein gewisses Verhalten als ein für allemal richtig oder rechtmäßig, ein entgegengerichtetes als unrichtig und unrechtmäßig gleichsam abgestempelt wird. 5. Darum gehen ferner solche Beschlüsse als "Satzungen" dahin, Recht zu setzen, d.h. für Richtersprüche die Richtschnur - die Normen - zu geben, mithin allgemein zu bestimmen wie a) in Streit- und Zweifelsfällen; b) in Fällen der gewollten Verletzung des Rechts durch den Richter, der dafür bestallt wird, geurteilt, entschieden werden soll. Also beziehen sich 6 . die Beschlüsse und folglich die Normen darauf, daß (nicht alle, sondern) bestimmte einzelne Mitglieder des Vereins, bestimmte Tätigkeiten 
tun oder unterlassen sollen, als Diener oder Beamte der Gesamtheit. 7. Ferner aber können die gemeinsamen Beschlüsse (oder die der dazu erlesenen - delegierten - Personen) auch dahin gehen, festzustellen, was als wahr, welche Meinungen oder Glaubenssätze als richtig gelten sollen. Der Zusammenhang mit den Rechtsnormen ist hier offenbar. Die Nötigung scheint aber weniger natürlich. Es wird geleugnet, da $\beta$ es Gegenstand eines Beschlusses und überhaupt einer Willensentschließung sein könne, daß man so oder so $\mathrm{d}$ e $\mathrm{n} \mathrm{ke} \mathrm{n}$, dies oder jenes für richtig halten, an dies oder jenes glauben wolle oder solle. Denn alles derartige - so wird in uiberzeugender Weise geltend gemacht - sei "unwillkürlich" und auf keine Art dem Belieben oder der Absicht zugänglich. Auf Grund dieser Ansicht ist viel gesprochen, geschrieben und gehandelt worden, sie hat eine historische Bedeutung. Aber, auch wenn man die entgegengesetzte Ansicht nicht ausdrücklich verteidigt, so wird doch unablässig auf Grund einer solchen gehandelt, aber auch geschrieben und gesprochen. Ein gewisses Denken, Meinen, Glauben wird gefordert, zur Pflicht gemacht; ein abweichendes oder gar widersprechendes gemißbilligt und mit Verachtung, Entrüstung, nicht selten auch mit unmittelbaren Schädigungen geahndet. Freilich nur, wenn es offenbar wird, wenn es zutage tritt, denn nur dadurch setzt es sich der Erkenntnis, also auch der Verurteilung aus. Daher scheint es, daß nicht das Denken selber, nicht die Meinung, sondern nur die Meinungsäußerung gemeint und getroffen wird durch Vorschriften und Sanktionen in bezug auf das Denken, Meinen, Glauben. Die Meinungsäußerung ist allerdings Gegenstand des Wollens und Nichtwollens; man kan n, wenn man will, die Kundgebung jedes Gedankens unterdrücken, kann seine Meinung "für sich behalten«, man kann auch, wenn dies zu schwer wird, die Kundgabe auf einen engen verborgenen und vertrauten Kreis beschränken und wenigstens der öffentlichen Mitteilung sich enthalten. Folglich kann man auch für sich selber beschließen, dies zu tun, und wird es beschließen, wenn es als nützlich und gut erscheint. So können mehrere beschließen, auch in diesem Sinne gemeinsam sich zu verhalten; sie können folglich auch beschließen, daß jeder von ihnen, der nicht nach dieser Vorschrift sich richten werde, vollends, daß jeder außerhalb ihrer, der dagegen verstoße, Tadel, Verfolgung und andere ihm unerwünschte Folgen $\mathrm{zu}$ gewärtigen haben solle. In Wahrheit kann nur dies der unmittelbare und eigentliche Sinn eines Beschlusses sein, da $B$ diese oder jene Lehre für richtig gehalten werden soll, oder $\mathrm{da} B$ dies oder jenes die Wahrheit sei. Indessen schon der einzelne Mensch für sich selber kann auf seine Gedanken und seine Denkungsart durch freiwillige 
Handlungen einwirken, indem er z. B. gewisse Bücher oder Zeitungen liest, gewisse Versammlungen besucht, einem Lehrer folgt und seinen Worten lauscht, ja auch dadurch, daß er um eines Zweckes willen seine Meinungen nachprüft ("einer Revision unterzieht«), dem Zweifel "Raum gibt", und - sei es von Furcht oder von Hoffnung geleitet, die Äußerung gewisser Meinungen, die er hegt, unterläßt oder doch beschränkt: durch alle solche freiwillige Tätigkeiten kann er allerdings seine Gedanken sin andere Bahnen lenken «, ja er kann ihnen auch inneres Schweigen gebieten, und wenn dies anfangs zumeist keinen oder doch geringen Erfolg haben mag, so wird doch hier wie überall die Wiederholung wirken, die neuen Geleise werden durch Wiederholung fahrbarer werden, die Gedanken, Schlußfolgerungen, Urteile werden an die bisher ungewohnten und unerwünschten Bahnen sich gewöhnen. Das Interesse, und somit der Wille, wirkt auch auf das Gebiet des 》Unwillkürlichen*. Insbesondere wirkt das Tun und Handeln auf das Denken, also auch auf das Meinen, zurück. Dazu kommt dann die allmähliche Wirkung des Verbotes, der Mißbilligung und die entgegengesetzte der Billigung und Förderung auf das Gemüt des durchschnittlichen Menschen. Diese Wirkungen sind allgemein, wie auch immer der gemeinsame maßgebende Wille, daß so oder so gedacht und nicht gedacht werden solle, zutage trete. Unter allen Umständen ist es gefährlich, wenn nicht unmittelbar mit Unannehmlichkeiten verbunden oder sogar schädlich, »anders« zu denken. Und wenn man die Gedaǹken eines anderen nicht lesen kann, wenn die Äußerungen trügerisch sind, eben weil vom freien Willen abhängig, wenn verbotene Meinungen unterdrückt und sogar oft durch entgegengesetzte Reden ausdrücklich verleugnet werden - mancher stimmt lebhaft in das Verdammungsurteil über Ansichten ein, die er selber hegt - so kann gleichwohl der Verdacht entstehen und Nahrung finden, daß einer die richtigen (sagen wir die beschlossenen) Ansichten nicht habe, daß seine Gesinnung nicht tauge, da $\beta$ er etwa sogar böse sei und arges im Schilde führe gegen »uns», gegen »unsere Sache», unseren Glauben, gegen den Staat oder die Kirche. Der Argwohn der Gläubigen oder sonst Gutgesinnten spürt nach Zeichen und findet sie, trotz der zur Schau getragenen Zeichen des Gegenteils - in Gebärden, in Lebensweise, Umgang, unwillkürlichen Ausdrücken von Gemütsbewegungen, im Mangel an der gehörigen Wärmeim Tone und in der Form seiner Beteuerungen des richtigen Glaubens und der guten Gesinnung; in der Mattigkeit seines Tadels und der ungenügenden Entrüstung über die Andersdenkenden.

I4. (Sinn von Beschlüssen über Meinungen.) So hat es allerdings einen Sinn, daß beschlossen wird: dies ist die Wahrheit, ist die echte 
Lehre, dies soll als richtig gelten. In der Regel mag die Mehrheit, zuweilen mögen alle, wirklich das festgesetzte für die Wahrheit halten, aber da $B$ auch die Dissentierenden sich unterwerfen, ist nur ein Ausdruck des Grundsatzes: es $\mathrm{m} u ß$ entschieden sein, was als richtig und gut gelten, was Kurs haben« soll, es kann nicht Beliebiges gedacht und gesagt werden, denn abweichende Meinungen sind die Saaten des Aufruhrs, Einigkeit im Glauben und in der Denkungsart ist notwendig für die Selbsterhaltung einer Gemeinde, eines Volkes, eines Staates ... Wenn daher der Wille der Verbundenen zunächst darauf gerichtet ist, da $B$ solche und solche Wahrheit bekannt werde, $\mathrm{da} B$ jedenfalls $Z$ weifel daran oder gar wfreches Leugnungen nicht slaut werden", so ist er doch nur befriedigt, wenn er auch die Gedanken und Gefühle beherrscht, nur dadurch wird die Sicherheit gegeben, da $B$ nicht anders gerichtete Gedanken erstarken und durchbrechen, wenn sie das Ubergewicht bekommen. Sie erstarken aber durch Vermehrung, also durch Ausbreitung unter mehreren Menschen, besonders durch Mitteilung an die für das Neue empfängliche, dem Eindringen von Gefühlen leicht zugängliche J ugend; sie erstarken ferner, wie alles Wollen - und jede Gesinnung erkennt sich bald als ein Wollen - dadurch, daß die Gleichgesinnten sich vereinen und ihre vereinten Kräfte zweckmäßig verteilen, »organisieren«. So bilden sich innerhalb eines Vereines, einer Genossenschaft, des Staates und der Kirche, Parteien, Fraktionen, Cliquen, die mit dem Ganzen, dem sie angehören, wie gegeneinander in Konflikt geraten können, und dies erfüllt sich leicht.

15. (Analogien des Beschlusses.) Nach Art eines Beschlusses, einer Satzung, eines Gesetzes kann nun jeder gemeinsame Wille in sich und in seinen Wirkungen gedacht werden, und dieses Denken wird durch Beziehung auf die einfache rationale Form erleichtert. Ihr stehen die als irrationale - negativ - begreifbaren Formen gegenüber; ich bezeichne sie als Formen des sozialen Wesenwillens. Im Wesenwillen unterscheide ich Gefallen, Gewohnheit, Gedächtnis; im sozialen Wesenwillen Verständnis, Brauch, Glaube. Die Zentralbegriffe sind Gewohnheit und Brauch; sie sind auch unserem Bewußtsein am meisten geläufig. Aber sie werden in der Regel nur als objektive Tatsachen begriffen, und im Anschlu $B$ daran als Regeln, Normen, Gesetze oder Vorschriften, nach denen Schreiben und anderes Tun und Treiben sich richtet. Sie sind aber auch subjektive Wirklichkeit, sind Wille und nur dadurch werden sie Regeln und Normen. Jenes Gefühl, wodurch das Fremde angeeignet, das Unwillkommene ertragbar oder sogar angenehm wird, das Liebe immer lieber und unentbehrlich, geht aus den Wirkungen der Wiederholung und Übung 
hervor, die das Ertragen, das Bejahen, das Wollen erleichtert, den Gedanken ihre Wege bahnt, Lustgefühle und Wünsche befördert, wie sie Muskeln und Nerven stärkt, Widerstände und Reibungen überwindet, widrige Gefühle der Unlust glättet und abstumpft, insofern sie nicht durch fortwirkende Ursachen verstärkt und erneuert werden (wie Zahnschmerzen). Wie Gewohnheit das tägliche Leben, das Benehmen, das Verhalten, aber auch die Handlungsweise und die Denkungsart des Menschen beherrscht, so die soziale Gewohnheit, der Brauch das gemeinsame Leben, das gemeinsame Handeln und auch die gemeinsame Denkweise. Aber vorzugsweise ist es das Handeln, worin Gewohnheit und Brauch herrschen. Die Willensform, welche im individuellen Betragen, wie in der Geselligkeit, im familiären Zusammenleben, überall wo das geschieht, was als sselbstverständlich" empfunden und gedacht wird, ihre Geltung hat, ist unmittelbarerer Ausdruck des Wesenwillens. Ich nenne sie individuell das Gefallen, sozial das Verständnis. Wiederum die Willensform, der die Denkungsart, wie sehr sie auch durch Gefallen und Gewohnheit, durch Verständnis und Brauch mitbestimmt wird, als ihrem eigenen Wesenwillen unterliegt, nenne ich Gedächtnis und Glaube - das ist ein Komplex erworbener Vorstellungen und Urteile, woran die Seele des Einzelnen, wie die Seele der Gemeinschaft hängt, die als wahr und als heilsam gelten, als heilig und ehrwürdig geliebt und gepflegt werden.

Wenn der Wille der Verbundenen zunächst darauf gerichtet ist, $\mathrm{da} B$ solche und solche Wahrheit oder eigentlich der Glaube daran, offen bekannt werde - daß die Bekenner ihm treu seien -, daß jedenfalls $Z$ weifel oder gar Leugnungen nicht slaut werden«, so ist er doch nur befriedigt, wenn er auch die Gedanken beherrscht, nur dadurch wird die Sicherheit gegeben, daß nicht andersgerichtete Gedanken erstarken und durchbrechen, wenn sie das Übergewicht bekommen.

Zugrunde gelegt wurde die Vorstellung, daß der »Beschluß» die normale Form der rationalen Willenseinigung sei. Mit ihr konkurrieren aber sogleich 2 andere Formen: eine, die gleichsam vor, und eine die gleichsam nach ihr vorhanden gedacht wird. Anstatt des Beschlusses, der in der Idee die künstliche Samtperson voraussetzt, kann auch jede Abmachung zwischen zweien oder mehreren Personen, die Form des Vertrages haben, der aus gegenseitiger Versprechung besteht: hier wird nicht jene Einheit der Person, sondern eine bloße Aneinanderfügung (Addition) der mehreren Willen aneinander vorausgesetzt. Sie können gleichwohl den Gegenstand der Abmachung, das was sie wollen, objektivieren, gleichsam aus sich 
herausheben, aber sie objektivieren nicht sich selber als Subjekte dieses Wollens. Offenbar ist ein Beschluß per universos (anstatt per majora) - wenn nicht Beschlußfähigkeit einer Körperschaft vorausgesetzt ist - eine Übergangsform dahin von der bloßen vertragsmäßigen Úbereinkunft oder Abrede.

Es gibt aber eine dritte Form der Einigung und rationalen Übereinstimmung, die gleichsam nach und über der Form des Beschlusses liegt. Mehrere kommen in ihren Ansichten überein - sie treffen sich, und werden über eine Formulierung dieser Ansichten dadurch miteinander einig, daß entweder alle eine identische Lehrmeinung aussprechen - was möglich, aber unwahrscheinlich ist - oder daß einer - etwa auch mehrere, die schon dem einen anhangen - eine Formel dafür gefunden hat, der alle ihre Zustimmung, ihren Beifall geben. Naturgemä $\beta$ wendet sich diese Form vorzugsweise auf das Gebiet des Geistigen und Moralischen an, weil es dieser Form leichter zugänglich ist als dem Beschluß, der in der Regel schon die Uberzeugung einer Mehrheit von der Richtigkeit der Ansichten voraussetzt, denen der Beschluß oder die Satzung Gültigkeit verleihen will. Andererseits wird das Gebiet der bloßen sozialen Ordnung und.Verfassung, daher das bloße Dasein einer beschlußfähigen "Körperschaft immer zuletzt auf die elementare Willenseinigung durch Vertrag oder Verabredung zurückgehen, so daß sich Vertrag: Ordnung wie Satzung: Recht und wie Lehrsatz: Moral verhalten wird; wo Satzung den Beschlu $B$ bedeutet, der eine Handlungsweise als dem sozialen Willen gemäß oder widersprechend setzt; und Lehrsatz ein allgemeiner Ausdruck ist für eine auf Gründe sich stützende und in einem Kreise angenommene Theorie der richtigen Denkungsart.

16. (Parallele von Brauch und Beschluß.) Alle diese Entstehungsarten sind gleichsam mechanische: die Willenseinigungen werden gemacht um bestimmter $Z$ wecke willen, die sie bewirken sollen. Dies leuchtet in bezug auf den Lehrsatz am wenigsten ein, und gilt auch nicht, sofern er als Wahrheit gedacht und verstanden wird. Etwas anderes ist es, wenn es eine programmatische Formel ist, auf die man sich einigt, um damit zu wirken, zu agitieren, also um Anhänger zu gewinnen, und dies ist eine häufige und wichtige Erscheinung des öffentlichen Lebens.

Es ist aber auch denkbar und wirklich, daß die Einigkeit, Einmütigkeit, Harmonie von Natur und im Keime schon vorhanden war, $\mathrm{da} B$ sie aus dem Keime wächst und sich entfaltet, also ein gleichsam organisches Dasein hat. Gleichwie in der Einzelseele nicht immer ein Widerstreit der Gefühle und Gedanken vorausgesetzt wird, von dem dann das Mitsicheinigwerden, die Absicht und der Entschluß sich 
abheben, sondern vieles, und um so mehr, je mehr der Mensch in einfachen und regelmäßigen Zuständen sich bewegt, aus spontanem Antrieb, aus Gewohnheit und unmittelbar aus einem herrschenden Gefühl und Gedanken hervorgeht - so gibt es auch eine soziale Seele, deren Zellkern ich als "Verständnis " bezeichne, die im Brauch sich mannigfach betätigt, und im gemeinsamen Gla uben sich erhält und sich fortsetzt. Auf Verständnis beruhen alle ursprünglichen und einfachen Formen des Zusammenlebens, sie gelten als natürlich und durch sich selbst verständlich; der Brauch regelt die gemeinsame Arbeit wie das gemeinsame Vergnügen, den Werktag und den Feiertag, der Glaube stellt fest, was geschehen soll, weil es immer so gehalten wurde, und namentlich um die Gunst der ungesehenen Geister sich zu erhalten oder wiederzugewinnen.

Auch durch Verständnis, durch Brauch, durch Glaube, steht wie durch Beschlïsse und Satzungen fest, was in der allgemeinen sozialen Ordnung, in Recht, in Moral eines gegebenen Kreises gilt. Es sind Vorschriften darin enthalten, nach denen teils alle, teils erlesene Einzelne sich richten sollen. Z. B. der Gerichtsbrauch bindet den Richter, der Brauch in Ehrenhändeln den Ritter, den Offizier und Studenten, der Zunftbrauch den Handwerker. Die Macht der Gewohnheit im individuellen Leben ist bekannt: sie beruht $I$. darauf, $\mathrm{da} B$ der gewohnte Weg der Weg des geringsten Widerstandes oder des kleinsten Kraftmaßes ist, also der leichteste Weg, wie Úbung alle Tätigkeit erleichtert; 2. auf der Identität des menschlichen Subjektes, also dem Beharren seiner Neigungen und Dispositionen, die auf gleichartige Reize in gleichartiger Weise antworten. Die analoge Ursache der Macht des Brauches, mithin der Úberlieferung, des Herkommens im sozialen Leben liegt in dem Kontinuum der Übung, das wiederum durch die Nachahmung bedingt ist, vermöge deren ein gleichartiges Tun sich fortsetzt und sich erhält. Für das Gefühl ist es das Leichteste, Bequemste, Gefälligste, daher erscheint es auch dem Denken als das Natürliche und Vernünftige, bisher Geübtes zu wiederholen, und den »alten Brauch « zu ehren, wie die alten Leute und die Vorfahren, die ihn überliefert haben.

Der Brauch kommt in allen seinen Wirkungen einem Beschlusse oder Beschlüssen gleich. Diese Wirkungen sind nämlich: I. wir wollen das und das tun, so und so handeln, weil wir es für notwendig, für geboten halten; 2. wir wollen, daß alle, die zu uns gehören, das und das tun, so und so handeln; 3. wir wollen zusammen einen Bund, einen Verein oder dgl. bilden, uns als Mitglieder dieser Körperschaft denken und empfinden. Die Begründung dieser Körperschaft wird hier etwa den Vorfahren zugeschrieben, die dadurch in eine mythische 
Verklärung kommen, oder sogar auf Götter und Heroen zurückgeführt. Aber auch vermöge des Brauchs, wie vermöge beschlossener Satzung, kann eine Verfassung gelten, daher der Willensentschluß einer Person oder mehrerer gleich dem gemeinsamen Willen aller; 4. vollends hat der Brauch zum Inhalt, da $\mathrm{B}$ alle, die einer Gruppe oder einem Bunde angehören, regelmäßig und unter gewissen Voraussetzungen immer gewisse Leistungen vollbringen, gewisse Handlungen unterlassen sollen. Z. B. herrschen bei allen Stämmen und Völkern gewisse Formen zur Begehung einer Hochzeit, eines Leichenbegängnisses, die mit peinlicher Sorgfalt eingehalten werden, weil der Brauch es so will, und gewisse Arten des Benehmens, die bei einem Volke üblich sind, gelten bei anderen als ungehörig, weil es »des Landes nicht der Brauch ; 5. gleichwie durch beschlossene Satzung, wird durch Brauch Recht gesetzt, nämlich die Regel der Streitentscheidung durch einen anerkannten Richter, und der Gegenwirkung gegen gewollten Bruch des Friedens. Der Brauch kann auch, 6. gleich einer Satzung bestimmen, wie bestimmte einzelne Mitglieder, namentlich wie die Führer als Hüter des Brauchs, sich verhalten, was sie tun und was sie unterlassen sollen. Endlich 7. erstreckt sich der Brauch auch auf das, was als wahr und richtig gilt, was geglaubt werden soll. So ist charakteristisch für den Brauch die Vorschrift gewisser Worte und Redewendungen, die bei bestimmter Gelegenheit gebraucht und gesprochen werden müssen. Aber auch die Meinungen über das, was sittlich erlaubt und verboten sei, insbesondere iiber Anstand und Schicklichkeit, sind in weitem Umfange, zumal in engeren Kreisen, von der sozialen Gewohnheit, also dem Brauch, abhängig. Man weiß, was üblich und herkömmlich ist, nicht nur zu tun, sondern auch $\mathrm{zu}$ denken, insbesondere $\mathrm{zu}$ billigen und $\mathrm{zu}$ mißbilligen, und man richtet sich danach. Diese Richtung wird durch den Brauch in der Regel ohne Druck bewirkt, ja der Einzelne fühlt sich in dem Brauche - seines Landes, seines Standes, seiner Verbindung und Genossenschaft - meistens heimisch und wohl, wie im Gebrauche seiner Muttersprache, er tut also gern, was der Brauch von ihm fordert, er stellt auch seine Denkungsart danach ein, ohne Hemmung zu empfinden. Aber er weiß gleichwohl, da $B$ der Brauch ein Imperativ ist, $\mathrm{da} B$ er gebieterisch von ihm heischt, nicht nur so und so zu handeln, sondern auch die dazugehörige Gesinnung zu hegen, daß also auch die Hüter des Brauches den Verletzer und den, der etwa gar eine Verachtung des walten und ehrwürdigen Brauches zur Schau tragen oder dazu aufwiegeln sollte, zu strafen berechtigt und verpflichtet sind.

17. (Der Begriff der Lehre.) In diesem Zusammenhange kommen wir auf den schwierigsten und zugleich den wichtigsten Punkt für 
die hier vorgetragene Theorie der sozialen Willensformen. Wenn der soziale Wille sowohl gemeinschaftlicher als gesellschaftlicher Art unterschieden wurde, je nachdem er sich a) auf das soziale Verhalten schlechthin, auf allgemeine Betätigung bezieht; $b$ ) sofern auf besondere Handlungen und Unterlassungen, zumal solche - denn sie sind sonst auch in a) eingeschlossen -, die als gemeinsame und gleichartige Handlungen und Unterlassungen einer verbundenen (»organisierten «) Gesamtheit - einer Verbindung, eines Vereines - sich darstellen; c) sofern er im Denken, im Für-wahr-halten, also im Glauben oder Meinen der einzelnen Menschen, die einer, wenn auch nur geistig und sittlich verbundenen Gesamtheit angehören, sich offenbart so hat der Begriff der Lehre wie der Begriff des (sozialen) Glaubens im dritten dieser Gebiete seine eigentümliche Sphäre. Ein herrschender sozialer Glaube und eine herrschende Lehre wollen, daß die Angehörigen des Kreises oder der Gruppe, worin sie herrschen, auf eine bestimmte - ihnen vorgeschriebene - Art denken und urteilen, daß sie das glauben und für wahr halten, was der Glaube, was die Lehre als wahr oder als richtig behaupten, sei es an sich, oder in Absicht auf einen bestimmten Zweck, z. B. das Heil der Seele oder die Hebung des Wohlstandes. Und zwar unterscheiden wir hier als sozialen Glauben vorzugsweise die Behauptung von "Wahrheiten", die als schlechthin gültig in Anspruch genommen werden, wie das Dasein von Göttern, von guten und bösen Engeln, die Wahrheit gewisser wunderbarer Begebenheiten und Offenbarungen; wenn auch "Heilswahrheiten", daran hängen, die sich durch die Glückseligkeit in einem jenseitigen Leben empfehlen. Hingegen soll der Begriff der Lehre hier sich wesentlich beziehen auf soziale $Z$ weckmäßigkeiten, auch wenn diese in das Gewand von Richtigkeiten, z. B. ethischer Lehrsätze gekleidet sind; der "Glaube» der Individuen verwandelt sich ihnen gegenüber in die "Anerkennung", die als innere auch die Meinung, ja im günstigsten Falle die Uberzeugung von ihrer Richtigkeit bedeutet. Die äußere Anerkennung fließt daraus am leichtesten und sichersten; auf sie eben zielt die "L,ehre als sozialer Wille; für diesen Willen ist es nicht unerläßlich und schlechthin notwendig, $\mathrm{da} B$ die Lehre als wahr erkannt oder auch nur für wahr und richtig gehalten werde, $d a ß$ sie in nere Zustimmung finde, sondern, daß sie gelte und als geltend sich behaupte, also daß man ihr wenigstens äußerlich sich unterwerfe und etwanigen inneren Widerspruch schweigen lasse. Man soll im kundgegebenen Meinen, in der Meinungsäußerung als Handlung und in entsprechenden anderen Handlungen sich nach ihr richten, also keinesfalls sie angreifen und anfechten, keine Zweifel äußern, nicht als Andersdenkender erscheinen. 
Dieser soziale Wille ist uns am meisten geläufig und bekannt als Religion, insbesondere in der Gestaltung der "Kirche« als ihres Willensträgers. Aber erst die neueren, höheren Religionen, insbesondere die christliche, machen in dieser Weise mit ihren Ansprüchen an den Gedanken ihrer Bekenner sich ausschließender und schärfer geltend; während die älteren, wenigstens in ihren älteren Zuständen, den Glauben als etwas Selbstverständliches voraussetzen, und nur Opferhandlungen, Teilnahme an Festen, rituelle Lebensweise $u$. dgl. verlangen (wie denn in der Reduktion wiederum heute eine "Landeskirche" mit Kirchenbesuch und Empfang der Sakramente, ja sogar mit Zulassung kirchlicher Teilnahme an gewissen feierlichen Handlungen vufrieden « ist). Nun ist die christliche Religion (in minderem Grade auch der Buddhismus und der Islam) von Lehren erfüllt - als - Dogma* haben sie ihre große historische Macht entfaltet, diese Dogmen wollen und sollen geglaubt werden, sie enthalten angeblich die Heilstatsachen, aus denen die Gewißheit der ewigen Seligkeit entsprießt, und „extra ecclesiam nulla salus".

Nicht jeder Verein ist in der Lage seinen Mitgliedern ein so hohes Gut wie die ewige Seligkeit anzubieten oder zu versprechen, aber mancher bietet Vorteile und Annehmlichkeiten von anderer Art, die in der Regel auch wer jener mit Zuversicht gewiß zu sein glaubt, zu schätzen weiß; insbesondere bietet die weltliche Gewalt - oder, als Verein gedacht, der Staat - Schutz und Sicherheit für das leibliche Leben, für die Gesundheit und die Habe der Person und der Familie; Schutz auch für ideelle Güter, wie die Ehre, die persönliche Freiheit und die erworbenen Rechte. Wer diese Vorteile genießen will, muß auch bereit sein, Opfer dafür zu bringen, unter Umständen die Gefahr auf sich nehmen, um dieser Güter willen, die auch für seine Freunde und für seine Nachkommen ihren Wert behalten sollen, für seine Person solche Güter einbüßen zu müssen. $Z u$ dieser Entsagung wird nur in dem Maße der Mensch gewillt sein, als er von dem Werte der Sache, für die er solche Opfer bringen soll, überzeugt ist, und er wird in der Regel in dem Maße davon überzeugt sein, als er darüber belehrt worden ist. Jeder Verein, der einen höheren Wert für sich in Anspruch nimmt, bedarf der Lehre, die zu seinen Gunsten wirken muß, der Lehre, die seine Vortrefflichkeit darstellt oder in nüchterner Weise seinen Nutzen beweisen will. Die Lehre kann sich, gleich einer religiösen Lehre, vorzugsweise an die Gefühle wenden und an die Gläubigkeit: also Pietät und Dankbarkeit, Liebe und Begeisterung in Anspruch nehmen; oder sie kann auf Verstand und Einsicht rechnen, und dies ist, was die wis se n sch a f t li che Lehre näher bezeichnet: als wissenschaftliche Lehre aber erfüllt die Lehre ihren Begriff. 
18. (Die richtigen Meinungen.) Gleich einem religiösen muß auch jeder selbständige politische Verband wünschen, daß seine Mitglieder ihm auch mit ihren Seelen, ihren Gesinnungen zugetan seien, daß sie ihn bejahen; der Wille zum Gehorsam soll sich offenbaren oder wenigstens nicht die Abneigung dagegen. Meinungen lassen auf Gesinnungen schließen, aus den Meinungsäußerungen wird die innere Meinung entnommen oder wenigstens vermutet: darum gelten überall gewisse Meinungen als die richtigen Meinungen, als diejenigen, die der Verband, der Bund verlangen muß, die der Gesamtheit, dem Ganzen zum Heile sind, teils unmittelbar, weil sie eben seinen Wert aussprechen, teils einer Satzung gemäß, wenn sie als gültige verkündet wurden, teils endlich, weil die beglaubigte - voffizielle» - Lehre sie als solche behauptet oder ihre Geltung durchzusetzen beflissen ist. Solche Lehre ist für jeden Verband um so mehr notwendig, je mehr er nach einem bestimmten Ziele strebt und seine Mitglieder zu diesem Streben anregen und ermutigen, also auch Opfer dafür zu bringen bewegen will. Den wesentlichen Inhalt der Lehre wird dann nicht sowohl der unmittelbare Nutzen, den der Verein gewährt, oder seine ideellen Vorzüge ausmachen, als vielmehr der Wert des Zieles, dessen Erreichung als Zweck der Vereinigung und des Zusammenwirkens vorgestellt wird, seien es materielle oder ideelle Gïter, die »des Schweißes der Edlen wert» zu sein scheinen; als solche muß die Lehre sie darstellen, wenn sie nicht etwa von selber jedem als solche einleuchten, wie dem Mitglied einer Räuberbande oder eines räuberischen Soldatentrupps die lockende Beute. Auch ist eine Rede, die etwa ein derartiges Ziel in gliihenden Farben darstellt und die Gemüter zum Eifer anstachelt, als solche noch keine Lehre, so wenig als etwa der »Prospekt einer gegründeten Aktiengesellschaft, der einen ungeheueren Gewinn in Aussicht stellt, um zum Erwerben der Aktien anzuregen. Wohl können in solchem Prospekt und solcher Rede Lehren enthalten sein, deren Wahrheit behauptet wird: die Allgemeinheit muß als Merkmal hinzutreten. Und weil materielle Güter unmittelbar das sinnliche Begehren reizen, weil aber nicht nur religiöse, sondern auch moralische und ästhetische Lehren vielfach das sinnliche Begehren als unedel und häßlich erscheinen lassen, so $\mathrm{da} B$ viele Menschen sich seiner zu schämen geneigt sind - so stellt sich eine Lehre, die das Streben nach einer Beute anfeuern soll, leicht die Aufgabe, dies nackte Begehren zu verhüllen; sie umkleidet die rohen materiellen Ziele mit dem Gewande eines sittlichen Gutes. Die Absicht versteht sich leicht: das Gewissen wird beschwichtigt oder sogar verwandelt, nämlich aus einem bösen oder doch zweifelnden wird ein gutes oder doch getrostes gemacht. Das ist eine Kunst, auf 
die das Gerät der Lehre zugeschnitten werden muß; naturgemä $\beta$ eignen sich religiöse Lehren ganz vorzüglich dazu. Der Beifall der Götter veredelt jedes Vorhaben, der fromme $Z$ weck heiligt fast jedes Mittel. Diese veredelnde Tätigkeit kann aber durchaus in gutem Glauben geschehen und das ist das ursprüngliche naive Verhältnis der Religion zur Politik; je mehr aber die wirklichen politischen $Z$ wecke klar zutage treten, je mehr andererseits die naive Gläubigkeit schwächer wird, um so mehr macht die Absichtlichkeit und innere Unwahrhaftigkeit sich bemerkbar: so, wenn die englische Geistlichkeit die Ausbreitung des Christentums für den eigentlichen $Z$ weck der britischen Welteroberung und ihrer skrupellosen Angriffskriege ausgibt.

Der gute Glaube des modernen Bewußtseins ist mehr wissenschaftlich als religiös gefärbt. Das wissenschaftliche Denken selber bleibt freilich lange, und steht auch heute noch, in mancher Hinsicht unter dem Einfluß religiöser Denkungsart. Auch hat religiöse immer gegen religiöse Denkungsart gestritten: kirchliche gegen ketzerische, evangelische gegen katholische, kalvinische gegen lutherische, pietistische und rationalistische gegen orthodoxe, gestritten; und jede vertrat, wenn nicht Kirchen und geistliche Herrschaften, so Sekten und Gemeinden oder doch Schulen und Bekenntnisse. Jedoch treten in den neueren Jahrhunderten alle diese Streitigkeiten zurück gegen den gewaltigen Gegensatz von "Glauben und Wissen" oder von Theologie und (weltlicher) Wissenschaft, in welchem Kampfe bisher jene - wenn auch mit Unterbrechungen - immer mehr von ihrem Gebiet verloren, diese immer mehr gewonnen hat. Wissenschaftliche Lehren sind als solche sicherer vor dem Verdacht als religiöse Lehren, wenn diese objektive Wahrheiten in Anspruch nehmen, aus anderen Beweggründen $z u$ entspringen als solchen der Erkenntnis; auch wenn etwa hinter dem Streben nach Wahrheit Feindseligkeit gegen die Kirche oder die Theologie sich verbergen mag. Der Widerspruch gegen diese Mächte und gegen die von ihr vertretenen oder befohlenen Ansichten ist in jenen Lehren notwendig enthalten, sofern sie Vorstellungen, die auf dem Schein, auf dem Trug der Sinne oder auf den Täuschungen und Ausschweifungen der Einbildungskraft beruhen, durch solche der Vernunft und des Gedankens verdrängen und ersetzen wollen. Auch hier freilich hat der Irrtum einen weiten Spielraum. Was auf der Oberfläche als vernünftig und wahr erscheint, kann von einer tieferen Ansicht als durchaus unzulänglich verworfen werden und unter Umständen sogar zugunsten jener ursprünglichen Sinnes- und naiven Phantasievorstellungen. Andererseits aber erstreckt sich jener Widerspruch weiter als auf das Gebiet, wo die vernünftige Rechnung und richtige Beobachtung den scheinbaren Er- 
fahrungen und Wahngebilden siegreich begegnen kann. Er erstreckt sich auf die Anschauungen und Gedanken über das Gute und Böse, über Gerechtigkeit und Ungerechtigkeit, über das in sozialem und politischem Sinn Heilsame und Verderbliche. Hier handelt es sich in der Hauptsache nicht mehr um beweisbare Lehren, sondern um Behauptungen, die aus einer veränderten Einstellung des Willens zu den Problemen des Lebens hervorgehen. Indessen folgt diese Veränderung zum guten Teil aus der anderen Weltanschauung, die Einstellung ist auf wissenschaftlichem Grunde anders als auf religiösem Grunde. Uberall ist ein starker, wenn auch nicht immer bewußt werdender Zusammenhang zwischen Lebensverhältnissen und Weltanschauung, also auch zwischen Bedürfnissen, Wünschen, Interessen einerseits, Ansichten über das Richtige und Gute andererseits. Die Grundherren denken anders als die Kaufleute, die Bauern anders als die Handwerker, die Lohnarbeiter anders als die Unternehmer. In jeder Schicht, in jeder Klasse bilden sich Gruppen von Vorstellungen und Gedanken - eine Ideologie - aus, die in bestimmten Lehren, welche behauptet und verteidigt werden, sich zusammenfaßt.

I9. (Begriff und Lehre.) Als das psychologische Äquivalent der Lehre faßt die gegenwärtige Theorie den "Begriff", nämlich als die mentale Form des individuellen Kürwillens. Um diesem Begriff des Begriffes gerecht zu werden, muß er - unabhängig vom Sprachgebrauch - gefaßt werden als $\mu \eta \chi \alpha \nu \eta$, als ein bewußt gebildetes und ergriffenes Mittel für einen bestimmten, von ihm durchaus verschiedenen und getrennten $Z$ weck. Solcher $Z$ weck ist die Erkenntnis des Zusammenhanges der oder einer Wirklichkeit. Der vollkommene Begriff ist der mathematische Begriff. Der Begriff der Linie bedeutet etwas Unwirkliches, aber er ist in höchstem Grade zweckmäßig, ja schlechthin notwendig als Mittel, um Entfernungen zwischen wirklichen Gegenständen $\mathrm{zu}$ vergleichen, nämlich $\mathrm{zu}$ messen. So denken wir die Lehre oder Lehrmeinung als ein Mittel, über dessen Wert Mehrere sich geeinigt haben in dem Entschluß, diese Lehre für wahr zu halten oder wenigstens gelten $\mathrm{zu}$ lassen, ihr nicht $\mathrm{zu}$ widersprechen, vielmehr sie zu vertreten und $\mathrm{zu}$ fördern, auf ihre Ausbreitung und Bekräftigung bedacht $z \mathfrak{u}$ sein. Welchem $Z$ wecke aber soll dies Mittel dienen? Jedenfalls einem Zwecke, der den Mehreren gemeinsam ist. Ein solcher kann auch das Erkennen sein, und dann ist die Lehre vom Begriff nicht wesentlich verschieden. Unter den vielen anderen Zwecken aber, die von Vielen gemeinsam verfolgt werden, hebe ich die Wirkung auf den Staat, nämlich vorzugsweise auf die gesetzgebende Gewalt, heraus. Die Vielen wollen etwas erreichen, was ihnen gemeinsam wertvoll ist, oder etwas verhindern, was ihnen ge- 
meinsam schädlich oder gefährlich erscheint. Sie wollen an der politischen Macht Anteil haben oder sogar die ganze politische Macht für sich erobern. Als notwendig, um dies Ziel zu erreichen, erkennen sie, Anhänger für ihre Lehre zu werben; denn diese Lehre enthält ihren Willen, ihre Wünsche, ihre Forderungen, ihr Programm. Wenn die Lehre geglaubt wird, wie ein Evangelium, so macht das ihren Erfolg um so wahrscheinlicher: sie entzündet dann den Eifer, die Begeisterung, den Fanatismus. Solche Lehre ist dann von einem religiösen Glauben nur durch ihren Inhalt verschieden. Aber leicht wird eben durch den Inhalt auch die Form des psychologischen Verhaltens abgeändert, wenn es sich nämlich um Gegenstände handelt, die der Phantasie wenig Nahrung geben und nur verstanden werden wollen, nämlich erkannt werden als dem Interesse desjenigen dienlich, um dessen Anhängerschaft geworben wird. In den politischen Kämpfen, zumal den Wahlkämpfen, die heute alle Länder erfüllen, sind es zum größten Teil solche Gegenstände, die vorgetragen und in Rede oder Schrift "breitgetreten" werden. In bestimmten Lehren, die auf wissenschaftliche Geltung Anspruch machen, werden sie verallgemeinert. Eine solche Lehre war und ist die Lehre des Naturrechts oder Vernunftrechts, die Freiheit und Gleichheit aller Menschen als eine ursprüngliche, darum auch allein normale und innerlich notwendige Tatsache behauptet. Mehrere andere Lehren wurden teils daraus abgeleitet, teils im Zusammenhange damit begründet; so die Forderung der Gewissens- oder Religionsfreiheit, der Preßfreiheit, der Schwurgerichte und anderer Laiengerichte, des mündlichen und öffentlichen Gerichtsverfahrens, die Forderung geschriebener Verfassungen und gewählter Volksvertretungen, die des allgemeinen gleichen Wahlrechts, insbesondere endlich die der Teilnahme von Frauen an politischen Wahlen, der Frauen-Emanzipation überhaupt. Diese Lehren des Liberalismus sind, obgleich immer bekämpft, mehr und mehr siegreich geworden. Die Überzeugung von ihrer Richtigkeit und ihrem Werte ist zu gleicher Zeit gerade in den neubürgerlichen Kreisen, denen sie ursprïnglich als Ausdruck ihres Willens dienten, schwach geworden. Erhalten hat sie sich mehr im Kleinbürgertum und Proletariat, die Lehren selber werden aber in dem sehr bewußt geführten Klassenkainpf gegen die "Bourgeoisie als Kampfmittel und Waffen gebraucht, wozu sie um so tauglicher sind, weil ihnen die bekämpfte Klasse die grundsätzliche Anerkennung und Geltung nicht versagen kann. In diesem Sinne betrachten wir die "Lehre» als Gegenstand einer äußeren Einigung und gleichsam Verabredung. Der eigentliche Glaube kann herabgesetzt, ja ganz entbehrlich werden, wenn an seine Stelle die Meinung und Erkenntnis des Wertes oder 
Nutzens der Lehrsätze tritt, für die man um Anhang wirbt und die man zur Geltung zu bringen sich bemüht. Treffend hat der Jesuit LESSIUS gesagt: Aliud est credere, aliud judicare esse credendum. Hinzuzufügen ist: je mehr die Uberzeugung fest und stark, daß es notwendig sei, zu glauben, um so mehr wird das Glauben selber entbehrlich. Es mag immer mit jener Überzeugung verbunden bleiben und gleichsam ihren Hintergrund bilden; aber es ist nicht mehr wesentlich, man darf davon absehen. Dennoch kann die Verbreitung in der Form geschehen, daß eine Wahrheit behauptet und begründet wird, und $\mathrm{da} B$ viele, vielleicht die meisten, an diese Wahrheit gla uben. Den Begriff der Lehre in diesem soziologischen Sinne bestimmen wir gleichwohl durch die bewußte Vertretung und Geltendmachung, die ihr zuteil wird von denen, die ihre Bedeutung und ihren Wert als den Wert einer Waffe - erkennen und in dieser Anerkennung miteinander einig sind, weil sie sich darïber geeinigt haben. Dies tritt am deutlichsten zutage, wenn solcher Einigung eine Beratung vorhergegangen ist, wie es zum Beispiel geschieht, wenn die Häupter einer Partei über das Programm der Partei in Beratung treten. Es handelt sich für sie darum, die zweckmäßigste Form, den geeignetsten Ausdruck eines gemeinsamen Bewußtseins, d. i. eines gemeinsamen Interesses und Willens $z \mathfrak{u}$ finden. Man einigt sich auf eine Formel man rechnet damit, daß die Formel eine packende Gewalt bewähren werde; man faßt die Quintessenz des Gedankens, der in die Welt gesetzt werden soll, in ein Schlagwort zusammen.

20. (Das Schlagwort.) W. BAUER ${ }^{1}$ ) unterscheidet bei allen "Schlagwörtern", die „aus dem herkömmlichen Sprachschatz stammen“", ein sachlich-logisches und ein emotionales "Stadium" ihres Daseins. Ich würde lieber sagen: das Schlagwort wirkt zu gleicher Zeit auf Verstand und Willen derer, die es empfangen und in sich aufnehmen. Bei oberflächlicher und schwacher Wirkung auf den Verstand kann doch die Wirkung auf den Willen sehr stark sein und ist es oft, indem Assoziationen von Ideen ausgelöst werden, die in hohem Grade gefühlsbetont sind. Der Übergang in ein emotionales "Stadium" vollzieht sich dann mit blitzhafter Geschwindigkeit: das Schlagwort »elektrisiert«. BAUER weiß aber auch, daß Schlagwörter für einige „zum bewußt angewandten Agitationsmittel" werden, und weil die Menge nur in Bildern denken könne, so sei das Schlagwort die einzig richtige Sprache, worin man $\mathrm{zu}$ ihr sprechen müsse ...

Die einzig richtige? Das dürfte nicht allgemein und immer gelten! Aber wer die Kraft des Schlagwortes kennt, wird sie zu seinem Vorteil

1) "Das Schlagwort als sozialpsychische und geistesgeschichtliche Erscheinung“" Histor. Zeitschrift, Bd. I22, H. 2, S. 212-223. 
Gemeinsame MeINungen. - Rationale und IRRationale Formen usw. 63

gebrauchen wollen, wenn er auf seinen Vorteil bedacht ist. Dieser Vorteil mag der bloße rednerische oder schriftstellerische Erfolg sein, selber teils seiner selbst wegen, teils als "Weg zur Macht erwünscht und erstrebt; öfter wird es sich unmittelbar um einen sozialen Erfolg handeln, sei es der Wahlerfolg einer Partei, oder ein noch handgreiflicheres Interesse materieller Art; auch ideelle $Z$ wecke können damit verbunden sein, können sogar für sich allein ins Auge gefaßt werden. Immer kann es als seltene Ausnahme betrachtet werden, daß jemand zu einem $Z$ wecke redet oder schreibt, der ausschließlich sein eigener ist. Auch wenn etwa ihm nur an seinem Lohn oder Sold gelegen ist, so hat doch das, was er sagt, einen anderen $Z$ weck, und indem er redet oder schreibt, wirkt er für diesen $Z$ weck, der vielleicht ihm selber gleichgültig (oder sogar zuwider), jedenfalls aber der Zweck irgendeines, in der Regel Zweck mehrerer Menschen ist. Diese mehreren bilden eine Gruppe, eine Clique, einen Stand oder eine Klasse, eine Schicht oder eine Partei - möge diese Menge mehr oder weniger fest organisiert sein. Je fester sie organisiert ist, um so stärker wird ihr einheitliches Bewußtsein - Denken und Wollen - nach außen hin in die Erscheinung treten. Um so mehr verfolgt eine solche Gesamtheit eine bestimmte »Politik», d. h., sie setzt sich planmäßig ihre Ziele und richtet nach diesen Zielen und Plänen ihren Willen, ihre Handlungsweise. Folglich werden ihre Kundgebungen aus unabsichtlichen absichtliche, sie werden durch Kürwillen bestimmt. Nun werde vorausgesetzt, daß solche Kundgebungen eine Lehre vertreten, daß sie »das» oder doch »ein « Publikum darüber belehren wollen, was ihm nützlich und heilsam sei, für oder wider welche Gesetzgebung es eintreten solle, und da $B$ dafür allgemeine Grund sätze aufgestellt und mit Gründen geltend gemacht werden - so haben wir ein regelmäßiges Ereignis des politischen Parteilebens und Parteikampfes vor uns: dazu gehört das Schlagwort, worin die Lehre und Botschaft zusammengedrängt, zusammengefaßt wird, die Formel, worauf die Häupter sich einigen als ein geeignetes Mittel, ihre Meinungen, d. i. ihren Willen in die Menge zu tragen und ihm Anhänger zu werben. Die zündende Kraft, die das Schlagwort darin bewährt, $\mathrm{da} B$ es in ein emotionelles Stadium« eintritt, gewinnt es eben d urch die "Agitation ", nämlich durch das Pathos der Betonung, der Wiederholung, der Erschütterung. Darum ist es ein so gewaltiges Mittel, um Stimmungen zu erregen, Gefühle zu entflammen, Entschlüsse hervorzurufen. Aber nicht das einzige Mittel. Es wirkt nur im $\mathrm{Zu}$ sammenhange mit bestimmten Vorstellungen und Behauptungen über Tatsachen: gegenwärtige, vergangene und zukünftige; im Staatsleben also im Rahmen einer gesamten politischen Denkungsart. So 
etwa jenes Schlagwort »Freiheit « in seinen Anwendungen auf Gewissen, auf Presse, auf Handel und Gewerbe. Es empfiehlt sich durch: a) Hinweisungen auf die Schäden, die aus dem Mangel der Freiheit, aus Knechtung, Knebelung, $Z$ wang, Schutzzoll sich ergeben: diese werden anschaulich und glaubhaft gemacht durch Beispiele aus gegenwärtigen und vergangenen Zuständen. Da individuelle Freiheiten aller Art immer im Interesse des Zusammenlebens beschränkt worden sind und werden mußten, so ist es leicht, die Vergangenheit in das trübe Licht der Sklaverei zu setzen und die Vorstellung der Freiheit mit der Vorstellung des Fortschritts zu verknüpfen, einer Vorstellung von ebenso angenehmer Art: wenn $\gg$ Freiheit» das Gefühl des frei Atmens, des Aufatmens, der Erleichterung in sich schließt und als Gegenteil von Druck, Bindung, Beklommenheit willkommen ist, so "Fortschritt» mit der allgemeinen Empfindung des Besserwerdens, des Wachstums, der Aufwärtsentwicklung. Wie könnte man Freiheit und Fortschritt nicht lieben und loben? So wirkt denn auch die Hinweisung auf ein sfreies Land", auf seine Macht und sein Gedeihen; auf ein fortschreitendes Land, das mit sich und seinen Zuständen, seinen Einrichtungen zufrieden ist und vor inneren Unruhen, Aufständen, Bürgerkriegen sicher. Die sozialde mokratische Lehre wirkt gleichfalls mit dem Begriff und Schlagwort "Freiheit " und steigert dessen Bedeutung dadurch, daß sie (mehr als der Liberalismus es heute noch kann) die Sache als Ziel des Strebens, als etwas zu Eroberndes im Gegensatz zur bestehenden "Lohnsklaverei" darstellt. Stärkere Schlagkraft hat aber für sie der Begriff der Gerechtigkeit und die sittliche Entrüstung, die der Vorstellung gilt, daß der Arbeiter unzureichenden Lohn erhalte, während es reiche Müßiggänger gibt, die von arbeitlosem Einkommen, dem Ertrage fremder Arbeit, überfließen. Schlagwort-Sentenzen wie „Eigentum ist Diebstahl", „das Eigentum ist Fremdtum geworden", drücken diese Empörung aus. Die marxistische Lehre vom historisch notwendigen Siege erhöht Kampflust und Mut im Klassenkampfe, wie schon die Idee eines bedeutungsvollen Kampfes für eine bessere Zukunft den Gemeinsinn (die "Solidarität«) und den Willen zur Aufopferung nebst verwandten kriegerischen Tugenden erzieht. Die konserva tive n Lehren wenden sich noch unmittelbarer an die Gefühle, namentlich an so starke tiefgewurzelte Gefühle, wie die Anhänglichkeit an gewohnte Verhältnisse und Vorstellungen, wie die Ehrfurcht vor dem Heiligen und Geheimnisvollen und ganz besonders die Furcht vor dem göttlichen Zorn, aber auch Hoffnung und Vertrauen auf Gunst und Hilfe der unsichtbaren Mächte. Diese Lehren daher, angewandt auf politische Verhältnisse, warnen vor dem Frevel, dem 
Abfall und der Empörung gegen die "gottgewollte Ordnung und klagen die Revolution als Teufelswerk an, zumal wenn sie gegen das "geweihte Haupt « eines Monarchen sich richtet, der "von Gottes Gnaden"seines Amtes waltet. Aber je moderner diese Lehren sind, um so mehr wenden sie sich auch an die Einsicht, an die Vernunft, also an die Erkenntnis des Nutzens, an das Interesse. So liegt es nahe, den Wert eines $\mathrm{r}$ uhigen, ungestörten Zustandes ("Quieta non movere«) hervorzuheben, so empfiehlt sich die Zusammenfassung der gesamten Würde und Macht des Staates in ei ner natürlichen Person als "Vernunft-Monarchismus«, so wird etwa von JOSEPH DE MAISTRE die Notwendigkeit eines höchsten Friedensrichters zugunsten der Einheit der Christenheit, zuletzt also der Menschheit, unter dem Papste, verwertet, wie schon DANTE und andere große Autoren des Mittelalters in einer solchen Einheit unter Papst und Kaiser die Erfüllung des natürlichen und göttlichen Rechtes sahen. Naturgemäß hängen Lehren politischer Art mit Weltanschauungslehren zusammen, teils durch innere Verwandtschaft, teils durch bloße Uberlieferung; aber diese Zusammenhänge sind, wenn auch häufig und wahrscheinlich, keineswegs notwendig. TOCQUEVILLE wunderte sich, da er in Frankreich fast immer den Geist der Religion und den Geist der Freiheit in entgegengesetzter Richtung gehen sehe, diese in den Vereinigten Staaten so innig miteinander verbunden und miteinander auf dem gleichen Boden herrschen zu sehen. In der Tat sind sehr verschiedene Kombinationen von Lehren möglich, aber mehr oder weniger wahrscheinlich. Es finden Anziehungen und Abstoßungen statt, und je stärker eine Lehre oder der hinter ihr wirksame Wille, das sie belebende Interesse ist, um so eher vermag sie auch entgegenstrebende, ja feindliche Elemente an sich zu ziehen und zu beherrschen. Um Lehren sammeln sich die Volksbewegungen für oder wider eine Sache, immer mit einem bestimmten, mehr oder minder idealen Ziele; dazu gehören auch religiöse Bewegungen, mit denen sehr oft auch solche rationalen Charakters innig verwandt sind und zusanmenhängen: Bewegungen ökonomischer, politischer oder moralischer Art, die letzteren am ehesten von religiösen Bewegungen abstammend und ihnen ähnlich. Alle suchen in neuerer Zeit mehr und mehr auf wissenschaftliche Beweisgründe für die Güte ihrer Sache sich zu stützen, sogar streng religiöse Bewegungen, wie die der Christian Science, vollends andere mystagogische, wie die der Spiritisten, Theosophen, Anthroposophen usw. Alle werben mit solchen Gründen um die Gunst des Publikums, ja sie kämpfen und streben danach, diese ganz für sich zu gewinnen, was selten gelingt. 


\section{1. (Formen des Kollektivwillens, A. Eintracht-Sitte-Religion.)} Ich betrachte nunmehr die zusammengesetzten oder höheren Formen eines gemeinsamen Willens, die ich zur Unterscheidung von den (einfachen) Formen des sozialen Willens Formen des Kollektivwillens nenne.

Die allgemeinste Form des Ausdrucks eines ge meinschaft lichen Kollektivwillens bezeichne ich als - psychologische - Eintracht. Sie ist, als solche subjektive Form, das Gesamtverständnis einer verbundenen Gruppe, zuhöchst eines Volkes und (der Idee nach) des Menschheitvolkes über das, was ihm für sein Zusammenleben notwendig, ersprießlich und gut, oder schädlich und verderblich ist. Sie wehrt also vor allem der Zwietracht, gebietet Zusammenhalten, inneren Frieden, heischt daher Unterordnung unter gegebene Führerschaft, regelmäßig also der Jüngeren unter die Älteren, zumeist der Frauen unter die Männer, in manchen und wichtigen Bezügen aber der Männer unter die Frauen, allgemein: der Unkundigen unter die Kundigen, der Nichtwissenden unter die Wissenden, also der Unerfahrenen unter die Erfahrenen, der Kinder unter die Eltern, des Schülers unter den Meister, des Knechtes unter den Herrn, der Magd unter die Hausfrau; des Kriegers unter den Hauptmann, des Hauptmanns unter den General, des Generals unter den König oder Oberbefehlshaber; des Laien unter den Priester und Gelehrten, des Priesters unter den Bischof, des Bischofs unter den Erzbischof, des Erzbischofs unter den Heiligen Vater. - Wir finden den Geist der Eintracht am ehesten und leichtesten wirksam in kleinen und engen Verhältnissen des Zusammenlebens, er ist am meisten charakteristisch - wenn auch noch so oft getrübt - für die Familie, und zwar noch mehr für die um einen häuslichen Herd vereinigte (obgleich die nahen Berührungen um so mehr Gelegenheiten und Anlässe der Zwietracht darbieten), als für die zerstreute, die leicht, auch ohne durch Zwietracht zerrüttet $z u$ werden, sich auseinanderlebt. Nicht in gleicher Stärke, aber immer noch höchst bedeutsam, waltet der Geist der Eintracht in der Dorfgemeinde, wo jeder den anderen kennt, der Nachbar dem Nachbarn beisteht, wo die Nebenordnung mehr als Unterordnung die Regel ist. Schwieriger und künstlicher als die bisher betrachteten Unterordnungen sind schon diejenige des Bauern unter den Grundherrn und Edelmann oder den Beamten, unter den geistlichen Herrn, wenn er ihm nicht zugleich als Nachbar vertraut und beliebt ist, oder unter den Fürsten, der geistliche und weltliche Würde in seiner Person vereinigt - während andererseits die Höhe des Ranges, sofern sie durch sozialen Willen festgestellt ist, zur demütigen Unterordnung geneigter macht. 
Gemeinsame MEINUNGEN. - RATTONALE UND IRRATtonale Formen USW. 67

Das größere und ummauerte Dorf, woraus die Stadt erwächst, wenn sie nicht als Gesamtheit von Dörfern entsteht, schwächt bei seinen Einwohnern den Willen zur Unterordnung, sofern er nicht noch in den älteren und allgemeineren Verhältnissen der Verwandtschaft und Nachbarschaft beruht und von diesen sich herleitet. Dagegen tritt stärker auf das Bewußtsein der Zusammengehörigkeit und ihres Wertes, das Bewußtsein des Bürgers und Mitbürgers, der seine Stadt wie seinen häuslichen Herd schützt und verteidigt. Darum ist auch die ständische Unterordnung hier noch schwieriger, unwahrscheinlicher, nimmt mehr Überwindung in Anspruch, weil mit Bildung und Wohlstand das Selbstbewußtsein gesteigert, die Neigung zur Ehrfurcht und Gläubigkeit also schwächer, die wirklichen Uberlegenheiten der Ranghöheren teils vermindert, teils durch Überlegenheiten der Rangniederen, die ihrer Künste kundig, in ihrem Fache tüchtig sind, ausgeglichen werden; weil auch das allgemeine Zusammenleben minder auf persönliche Bekanntschaften und, soweit dies der Fall, mehr auf gelegentliche, oberflächliche als auf dauernde und innerliche angewiesen ist. Die Menschen isolieren sich um so mehr gegeneinander, je mehr sie sich häufen und jeder seinem Geschäfte nachgeht, um den anderen nur im Wege des Tausches und der Verträge zu begegnen: er kennt sie als Mitbewerber und Tauschgegner, günstigen Falles als Kunden und Geschäftsfreunde. Diese Tendenzen vollenden sich um so mehr, je stärker die Stadt als Großstadt, Handelsstadt, Hafenstadt, Weltstadt sich entwickelt, in welchen Gebilden am wenigsten noch ursprüngliche Eintracht $\mathrm{zu}$ suchen ist.

Wie das natürliche Gefallen des einzelnen Menschen: daß er mit sich einig ist in Lust oder Unlust an Mitmenschen, Dingen, Tätigkeiten, Zuständen, in Gewohnheit niederschlägt, indem die häufige Wiederholung, die Ubung und Erfahrung, die vertrautere Bekanntschaft, Erregungen dämpft, alle Bewegungen, Strebungen und Widerstrebungen in bezug auf die Mitmenschen erleichtert und beschleunigt, Beziehungen und Verbindungen befestigt - ebenso verhält sich Verständnis zu Brauch, Eintracht zu Sitte. Volkssitte, Landessitte, Standessitte beruht in Volkseintracht (Landeseintracht, Standeseintracht), und wirkt mannigfach auf sie zurück. Stärker als Eintracht tritt Sitte gebietend auf, nämlich als verpflichtender Gemeinwille, wie etwa am deutlichsten in Verehrung der Toten: in den letzten Ehren, die ihnen gegeben werden, in Bekränzung und Pflege der Grabstätten, Errichten von Gedenksteinen u. dgl. sich offenbart, weshalb ich (Die Sitte, S. 2I) den Totenkult die Sitte der Sitten genannt habe. $\mathrm{DaB}$ Gewohnheit, Brauch, Sitte als Imperative - Geund Verbote - sich geltend machen, ist eine psychologische Tat- 
sache, die in bezug auf Gewohnheit oft erklärt worden ist. Sie beruht darin, da $\mathrm{B}$ das Gewohnte angenehm ist; es ist aber angenehm, insofern es als natürlich und notwendig empfunden und gedacht wird, und dies ist um so mehr der Fall, je mehr es in das Gemeingefühl, den psychischen Lebensstrom - den ich, sofern er auf Mitmenschen, Dinge, Verhältnisse sich bezieht, Gefallen nenne - übergegangen ist. Und dies bewirkt die Häufigkeit der Wiederholung einer Tätigkeit wie eines Eindruckes (der selber Tätigkeit ist), weil sie die Bahnen glättet und erweitert, die Reibungen abschwächt, also auch die Anstrengungen, den Aufwand an Energie, der zu solcher Tätigkeit erfordert wird, vermindert; es ist das Gesetz der Sparsamkeit (der "Ökonomie»), was die Seele beherrscht und das Leben bedingt; die Bewegung erfolgt in der Richtung des geringsten Kraftmaßes oder der leichtesten Arbeit; intellektual-psychologisch heißt das: es bildet sich die Vorstellung von dem Richtigen, dem Guten, nicht mehr allein aus dem Gefallen heraus, sondern auch aus der Gewohnheit, bald auch gegen das unmittelbar Gefallende, weil das Gewohnte in einer besonderen Weise, mittelbar, gefällt und gewollt wird; für die Erkenntnis gehört das Gewohnte als Stück oder Teil zu einem Ganzen, wird innerhalb dessen als natürlich und notwendig empfunden und gedacht: an dem Ganzen fehlt etwas, es ist eine Lücke vorhanden, wenn das Gewohnte nicht da ist - das Mißfallen daran ist gleichartig mit dem Mißfallen an Disharmonie in Tönen, Farben, Urteilen. Darum fordert sozusagen das Gewohnte sein Recht, es wird zum Maß, zur Richtschnur, zur Norm; die Wörter Regel und regelmäßig bezeichnen den Übergang der Vorstellung des Gewohnten, Häufigen zu der des Geheischten, Seinsollenden, die eine unermeßliche Bedeutung im Leben des Einzelnen wie im sozialen Leben hat. Im sozialen Leben ist es der Bratuch und als Gesamtausdruck die Sitte, die so als maßgebende Macht auftritt. Sie bestätigt und befestigt die natürliche, ursprüngliche, von selbst verständliche Ordnung, also Über-, Unter- und Nebenordnungen, wie sie aus den gegebenen Beziehungen und Verhältnissen sich ergeben; sie bewirkt aber auch, daß gewohnte Ordnung, selbst wenn sie davon abweicht, als natürlich und notwendig erscheine. Wie Gewohnheit eine zweite Natur und als Gesinnung eine erhöhte Natur, so ist Sitte gleich der Eintracht in zweiter Potenz. So erwächst aus der Sitte das Recht, das als Gewohnheitsrecht ein allmählich verstärktes und vermehrtes Gebilde des Volksgeistes ist. Wie die alte Sitte bessere Sitte und um so ehrwürdiger, so ist in einer gemeinschaftlichen Kultur auch das alte Recht besseres Recht, gutes Recht, richtiges Recht auch für das objektive Recht galt im »Mittelalter «das Alter als wichtigste Grundeigenschaft (F. KERN, Historische Zeitschrift, 3. F., 24. Bd., 
Geireinsame Meinungen. - Rationale und irRationale Formen usw. 69

I. H., S. 3) und die zweite wesentliche Eigenschaft des Rechtes, daß es gut sei, ist mit jener »eng verschwistert, fast zusammenfallend" (das. S. 6). Recht wird aber die Sitte durch den Richter; sie bindet den Richter und macht ihm zur Pflicht, so zu richten, wie es dem Herkommen gemä $B$ ist, wie es die Vorfahren für recht und billig gehalten haben. Es sei denn, daß die Götter, die höher sind als die Vorfahren, oder daß der Gott, aus dem alles Gute und also auch das Recht sich herleitet, anderes erlaubt oder sogar heischt. Hier tritt die dritte der Potenzen ein, die das soziale Leben regeln und bestimmen.

Im individuellen Geiste ist es der Gedanke, das Urteil, die Erinnerung - als Kraft und Fähigkeit das Gedächtnis: mit Gewohnheit unlösbar zusammenhängend, unmerklich daraus hervorgehend, gelangt es doch zu selbständiger Wirkung vermöge der Erfahrung, die selber der Gewohnheit gleichartig ist. Erfahrung lehrt oft, daß das aus Impulsen hervorgehende, oft auch, daß das gewohnte Handeln Schmerzen und Schaden im Gefolge hat; Gedächtnis schreibt daher vor, es zu vermeiden; Gedächtnis macht auch, da $B$ das Ungewohnte, ja das ursprünglich Mißfallende in seinem Werte erkannt wird. Das Denken ist für den Menschen die höchste Instanz, die Erkenntnis ist für sein Wollen der Leitstern, daher Gedächtnis selber ein allgemeiner Wille, ein maßgebender Wille. Und sein Gesamtausdruck ist das Gewissen - organisches Bewußtsein dessen, was an und für sich gut und böse, daher zu erstreben und zu fliehen, wie auch immer es sich zum Gewohnten oder Ungewohnten, zum unmittelbar Gefallenden oder Mißfallenden verhalte. Ein analoger Gesamtausdruck des sozialen Willens ist Religion, die, in Sitte und Eintracht beruhend, auf beide gestaltend, umgestaltend zurückwirkt. Religion ist hier nicht, oder doch nicht zunächst, gemeint als eine Gesamtheit von Vorstellungen und Gedanken, die sich auf unsichtbare, zumeist nach Art von Menschen gedachte Wesen beziehen, denen übernatürliche Kräfte und Wirkungen auf die Natur zugeschrieben werden, Wesen, die man erzürnen und kränken, aber auch versöhnen und gnädig stimmen kann, die man anfleht, denen Dank gebührt; sondern Religion wird verstanden als der gemeinsame und verbindliche Wille einer Gemeinde, eines Volkes oder einer unbestimmten Menge von Menschen, ein Wille, dessen unmittelbarer Gegenstand ist, jene vorgestellten Wesen zu ehren, ihnen zu dienen, also auch sie zu versöhnen und gnädig zu stimmen, zu ihnen zu beten und ihnen für ihre Gunst zu danken, also ihnen Opfergaben darzubringen und ihre vorgestellten Wünsche, Befehle, Gebote zu erfüllen. Diese sind Gesetze, denen man gehorchen soll und will - heilige, ewige, unverbrüchliche Gesetze, nicht durch Menschen hergestellt, also auch durch Menschen zer- 
störbar, sondern selber göttlichen Wesens, göttlichen Rechtes, also ïber menschliche Schwachheit erhaben. Sie erheben sich sogar über das, was durch Eintracht und durch Sitte festgesetzt ist, wenn sie auch zumeist sich daran anschmiegen und es bestätigen: Natur und Herkommen werden auch von den Göttern geachtet, die selber ihr Dasein und ihre Heiligkeit diesen noch fester begründeten Mächten verdanken. Ihr eigentümliches Gebilde ist die Moral, wie das der Eintracht die Ordnung des täglichen, häuslichen, wirtschaftlichen Lebens, das der Sitte das Recht des Bodens und der Landesgenossen, welches der Richter $\mathrm{zu}$ finden und $\mathrm{zu}$ erkennen hat. Auch Religion spricht da mit: sie heiligt die natürliche Ordnung wie das Recht, das Ursprüngliche, Uralte, ist auch das, was die Götter wollen, sie sprechen durch den Mund des Hausvaters, des Heerführers, wie durch den Mund des Richters, wenn auch am meisten und unmittelbarsten durch den ihres Stellvertreters, des Priesters, dessen Amt mit jeder anderen Führerrolle verbunden sein kann, aber mehr oder minder, je nach anderen Beschaffenheiten des Kulturzustandes, alle an Würde und Bedeutung überragt. Die Götter - und also die Priester - wollen gleich anderen Lebewesen, zuerst und vor allem, sich, sie wollen erkannt, geglaubt, anerkannt werden, wollen auch gefürchtet werden als mächtig, übermächtig, allmächtig - Furcht und Ehrfurcht zu erregen ist Vorbedingung für die Erlangung des beständigen treuen Gehorsams, den sie für ihre Gebote in Anspruch nehmen, und für Erlangung der Opfergaben, die daraus fließen. Aus dem Wert, den sie auf die richtigen angemessenen Gefühle legen muß, folgt unmittelbar die Schätzung des richtigen Denkens, des richtigen Glaubens. Dieser versteht sich zunächst schlechthin von selbst, er wird aber durch altes Herkommen, Überlieferung, Sitte gestärkt, befestigt, vertieft und endlich sogar begründet, erklärt, wahrscheinlich gemacht: es entsteht eine Lehre und Wissenschaft von den göttlichen Dingen die Theologie - worin der Gott selber sich offenbart, deren Kenntnis er daher seinen geweihten Dienern zur Pflicht macht. Lehrsätze, die das Dasein und Walten der Gottheit behaupten und beschreiben, werden wie Lehrsätze der Mathematik bewiesen, obschon zugleich der grundlose, vertrauende Glaube geheischt wird. Die Religion stellt immer die Frömmigkeit an die Spitze ihrer moralischen Vorschriften, und nur in ihrem Glauben läßt sie die wahren Tugenden gedeihen.

22. (Formen des Kollektivwillens, B. Konvention - Gesetzgebung Öffentliche Meinung.) In der Erfahrung ist keine Gesittung anzutreffen, deren positives, friedliches, also soziales Wesen nicht durch diese großen, die Gefühle und Gedanken beherrschenden Mächte gemeinsamen und verbindenden Willens: Eintracht, Sitte, Religion, 
ausgedrückt und erfüllt würde. Aber dieselben Mächte sind wie alles Lebende, fortwährenden Widerständen, Störungen, Anfechtungen ausgesetzt, sie können nur im Kampfe sich behaupten, vor allem im Kampfe gegen $Z$ wietracht, Un-Sitte - wenn als solche der Abfall vom Hergebrachten verstanden wird - Unglauben, antisoziale Mächte, die sie unablässig bedrohen. Aus und neben diesen Mächten setzen sich aber auch besondere neue soziale Gebilde, Willensgebilde, die in gleicher Richtung wie Eintracht, Sitte, Religion wirken wollen, sie abzuändern und zu ersetzen fähig sind und sich anheischig machen und in Wahrheit denselben kollektiven Willen in rationaler Verschiebung - Kürwille anstatt Wesenwille - darstellen. Denn sie entspringen der zerteilenden, auflösenden Vernunft und dem zweckmäßigen Denken, das im menschlichen Individuum den Kürwillen begründet. Auch sie wollen das Gebahren, das Handeln, das Denken des Einzelnen beschränken, bestimmen, bedingen, wollen Ordnung, Recht, Moral schaffen, treten also in Wettbewerb mit jenen älteren, gemeinschaftlichen, im sozialen Wesenwillen beruhenden Kräften und sind ihnen in bezug auf äußere Wirkungen weit überlegen. Sie bleiben aber zugleich von ihnen abhängig: wenn wir sie begrifflich bestimmen mögen und müssen, als ob sie ganz und gar auf eigenen Füßen zu stehen und für sich allein das soziale Leben $\mathrm{zu}$ beherrschen vermöchten, so sind sie in der Erscheinung nur erfaßbar als Bewegungen und Entwicklungen von Eintracht, Sitte, Religion her, als immer durch sie mitbedingt, als ihre Verneinungen, die doch von ihnen getragen bleiben. Wir stellen sie zunächst in Begriffen dar als I. Konvention, 2. Gesetzgebung, 3. Offentliche Meinung.

Wenn die Großräumigkeit - um diesen Begriff von EMMERICH SCHUBER $T^{1}$ ) zu entlehnen - alles Gemeinschaftliche gefährdet und erschwert, so ist in dem mannigfachen und zerstreuten Nebeneinanderleben der großen Stadt, wie der weit ausgebreiteten Nation, wenig Eintracht zu erwarten. Wettbewerb und Wettstreben entwickeln sich, die Verallgemeinerung des Tausches erregt Tauschgegnerschaften, Verträge werden leicht strittig, der Handelsegoismus bildet sich aus, das materielle Interesse tritt in den Vordergrund und wird auch maßgebend für neue und besondere Verbindungen der Menschen und Menschengruppen, Stände und Schichten, ganze Klassen grenzen sich schärfer gegeneinander $a b$, der Stände- und Klassenkampf entspinnt sich zwischen ihnen. Zuvörderst aber ist es die obere, die herrschende Klasse, die sich als solche versammelt und konsolidiert und, da sie schon aus bewußteren, ausgeprägteren Individuen besteht, ihr gemeinsames Interesse erkennt und zur Geltung bringt.

1) Kultur und Volkswirtschaft. Heidelberg 1918. 
Sie bedarf eines Kriteriums der Zugehörigkeit $\mathrm{zu}$ ihr, ein solches ist zunächst etwa der Geburtsadel, der Patriziat oder der geistliche Herrenstand, je mehr aber die Klasse sich erweitert, um so mehr macht sie andere Kennzeichen notwendig: die Kleidung, die Sprechund Redeweise, das Benehmen, die Umgangsformen, einen gewissen Schliff der wissenschaftlichen Bildung - lauter Merkmale, die mit der Gemeinschaft der Sprache, insbesondere der heimatlichen Mundart, der Landessitte und auch der Religion nicht notwendig verbunden sind. Die Bedeutung dieser Gemeinsamkeiten tritt daher zurück: in der "Gese11schaft « ist man mit seinesgleichen zusammen, auch wenn diese sonst Fremde und ihrer eigenen Volkssitte entfremdet sind, auch wenn sie einer anderen, sonst vielleicht verabscheuten, Religion angehören oder die Religion uiberhaupt verleugnen. Bis dahin gibt es aber manche $Z$ wischenstufen: der Schein der richtigen und also der gleichen Religion kann auch für die Gesellschaft von hohem Werte sein und als Kennzeichen der Güte gelten; ebenso können die gesellschaftlichen Formen der Landessitte bedeutende Elemente entlehnen und Anpassungen an den Brauch, wie er nun einmal festgesetzt ist, verlangen. Maßgebend ist jedenfalls das gesellschaftliche Belieben, die stillschweigende oder ausdrückliche Übereinkunft, die "Konvention ". Wie die Konvention in dem sozusagen häuslichen am meisten im höfischen - Kreise der Gesellschaft ein gesittetes, anständiges, feines, also unanstößiges und rücksichtsvolles Betragen fordert, so verlangt sie in der kommerziellen Gesellschaft auch den guten Verkehrswillen, der sich in Einhaltung von Versprechungen, "Kulanz«, d. h. flüssiger Gefälligkeit, insbesondere der Gegenleistung und Promptheit, d. h. rascher Beförderung und Erfü̈llung kundgibt. Das alles verträgt sich sehr gut mit vollkommener Fremdheit und Gleichgiltigkeit gegen das wirkliche Wohl und Wehe des anderen. So setzt auch die Artigkeit und Höflichkeit, das korrekte Benehmen, ja die scheinbare Herzlichkeit und innige Teilnahme, wo die Formen solcher Art vorgeschrieben sind, durchaus keine freundliche Gesinnung voraus, kann sogar mit feindseliger verbunden sein. Alle Regeln dieser Art wollen aber zunächst zwar in dem engeren Kreise der (guten oder kommerziellen oder bürgerlichen) Gesellschaft beobachtet werden, nehmen aber ihrem Wesen nach allgemeine Gültigkeit in Anspruch. Besonders charakteristisch ist in dieser Hinsicht das eigentümliche Gebilde der Konvention: die Mode. Sie will schlechthin maßgebend sein und gelte $n$; was ihr gemäß ist, was sie diktiert, behauptet schön, elegant, zeitgemäß, richtig, ja wahr zu sein - und doch schnürt sich der Kreis derer, die sie genau beobachten und genau kennen, als solcher von der großen Menge, vom Pöbel ab, darum 
nennt R. VON JHERING sie die unausgesetzt von neuem aufgeführte, weil stets von neuem niedergerissene Schranke, durch welche die vornehme Welt insbesondere von der mittleren Region der Gesellschaft (denn die untere sei von vornherein ausgeschieden) sich abzusperren ringe. Die Satzungen der Mode erstrecken sich auf das ganze Gebiet des äußeren Betragens, der Handlungen und der Denkweisen, aber das äußere Betragen unterliegt ihnen in der am wenigsten eingeschränkten Weise. Dazu gehört auch die Art sich zu kleiden, und weil hier die Neuheit das ist, was am meisten auszeichnet, und weil zur allgemeinen Standeseitelkeit die weibliche Eitelkeit hinzukommt, so ergehen sich in der weiblichen Kleidung die "Launen" der Mode am freiesten, so daß der Wechsel selber zum Gebot wird. Aber zum Wesen der Mode, nach deren wissenschaftlichem Begriff, gehört ihre Wandelbarkeit und Launenhaftigkeit nicht, sie kann auch dauernde Formen - wenigstens für "Herren « - annehmen, wie es etwa die Vorschrift des schwarzen Frackes als Festgewandes (in England ausschließlich als Abendkleid) seit mehr als einem Jahrhundert geworden ist, wenn auch der Schnitt der Mode unterliegt; aber zumeist unterscheidet allerdings der häufige Wechsel, das Streben nach Neuheit, die Mode von der Sitte - die ebenfalls charakteristisch in "Trachten « der Kleidung sich geltend macht - , denn die Sitte ist um so mehr Sitte, je mehr sie altüberliefertes Herkommen darstellt; die Mode ist um so mehr Mode, je mehr sie den allerneuesten Geschmack wiedergibt und also als "Laune" auftritt. Gleichwie von den Launen der Mode, so spricht man von gesellschaftlichen und in gleichen Sinne von "konventionellen" L üge n: die Verabredung und Einigung über das, was gegenseitig und gemeinsam nützlich, ist notwendig gleichgültig gegen Wahrheit und Unwahrheit dessen, was sie gelten lassen will und behauptet, wird sich daher ohne Bedenken auch dazu verstehen, das gelten zu lassen, wovon sie, d. h. "man", weiß oder doch denkt, daß es unwahr und unrichtig ist; das Richtige im Sinne des Zweckmäßigen überwindet das Richtige im Sinne des Wahren und Wirklichen. - Durch Konvention geregelt, daher vielfach der Mode unterworfen, ist im Zustande der "Gesellschaft" wesentlich die gesamte Ordnung des I,ebens, wozu die Formen des "täglichen Lebens« gehören, und insbesondere die des geselligen Zusammenlebens und Verkehrens, das ganz eigentlich vom einträchtigen in Familie und Freundschaft zum konventionellen der großen Welt - der Höfe, der Salons, des Kosmopolitismus sich entwickelt. Eine andere - allgemeinere und wesenhaftere - Seite des täglichen Lebens gesellschaftlicher Art stellt aber das wirtschaftliche Leben dar, insofern als es im Austausch und Feilschen des Marktes besteht, und seine höchste Steigerung im kapitalistischen Waren- 
und Geldhandel wie in der kapitalistischen Waren- und Diensteproduktion erfährt. Hier ist in Konvention gegründet die gesamte Eigentumsordnung und die Regeln für ihre Veränderungen, die Usancen des Handels, die Assoziation der gemeinsamen und einander bekämpfenden Interessen. Aber nächst der allgemeinen Ordnung wird auch das darin beruhende Recht und die von beiden abhängige Moral in vielen Stücken konventionell». Sitte und Religion erstarren in der Konvention, indem sich die Formen von den Inhalten scheiden und von der Konvention aufgenommen werden, die gegen die Inhalte gleichgültig ist und sie absterben läßt. Im System des gesellschaftlichen Rechtes ist es alles Recht, das nicht durch Gesetzgebung und hinter ihr wirksamen $Z$ wang bestimmt wird, also das Staatsrecht die rationalistische Theorie vom Staatsvertrag, wie sie HobBes entworfen hat, als eines Vertrages zwischen Individuen, durch RouSSEAU vergröbert - und das Völkerrecht, wo die Stelle der souveränen Individuen durch souveräne Staaten vertreten wird. Im System der gesellschaftlichen Moral ist zunächst die »kleine« Moral, die der Umgangsformen mit den Gesetzen der Höflichkeit schon, als zur Ordnung des täglichen und geselligen Lebens gehörig, vorweggenommen. Es gibt aber in der gesellschaftlich geltenden und anerkannten "größeren" Moral, ein bedeutendes Gebiet, das an diese kleine Moral angrenzt und wie sie wesentlich durch Konvention bestimmt wird nämlich die Regeln des sogenannten Ehrenkodex, die ihrem ganzen Zuschnitt nach auf die Ausschließlichkeit der höheren gesellschaftlichen Schichten berechnet sind und mit der "Standessitte" verwandt sind, aus der sie sich historisch entwickeln ${ }^{1}$ ).

Das Recht findet aber seine ausgesprochene gesellschaftliche Gestaltung durch den sozialen Willen, der, im »Staate" sich darstellend, als zielbewußte zweckmäßig gerichtete Gesetzgebung begriffen

1) In der englischen Wochenschrift „The New Statesman « war während des Weltkrieges (27. II. I915) ein Artikel zu lesen, der uiber "Scham" handelte. Es heißt darin: „Niemand, der durch Geschmacklosigkeit oder aus einem andern Grunde bewirkt, daß wir uns ihm überlegen fühlen, kann hoffen, unsere Schámempfindung zu erregen. Scheinbar wird das widerlegt, wenn man bemerkt, daß Leute, die auf ihresgleichen mit grenzenloser Verachtung blicken, gleichwohl sich schämen würden mit einem Kragen gesehen zu werden, dessen Form die öffentliche Meinung des Augenblickes nicht für sich hat. Aber dies bedeutet nur, dab öffentliche Meinung eine Sache ist, die Individuen, die das Publikum bilden, eine andere. Die Meinung unseres Nächsten als Individuums ist etwas, dem wir eine lange Nase machen mögen. Etwas ganz anderes, nämlich etwas weit bedeutenderes und furchtbareres ist seine Meinung, sofern er ein Repräsentant des Menschengeschlechts: als solcher wird er der ideale $\mathrm{Zu}$ schauer, und wenn uns mißlingt, dessen Billigung zu finden, so scheint das beinahe das schlimmste Utbel zu sein, das uns zustoßen kann ... Der ideale Zuschauer kann Gott, oder das Gewissen, oder das Vaterland, oder unsere Nachbarn, unsere Freunde, unsere Schule sein." 
wird, d. i. eine Gesetzgebung, die nach einem vorgestellten und vorgezeichneten Plane die sozialen Wechselbeziehungen regelt, also das Verhalten von Personen zu Personen und das Verhältnis der Personen zu Sachen im allgemeinen und für besondere Fälle festsetzt, also innerhalb des Verhältnisses der gesetzgebenden Faktoren seien es die Gesamtheiten selber oder deren Ausschüsse - zu den Individuen und deren Gruppen: das Personenrecht, das Sachenrecht und - als die am meisten charakteristische Gestalt - das Obligationenrecht so bestimmt, wie es der Gesetzgeber für die größte mögliche und so sehr als möglich dauernde Wohlfahrt "aller " für notwendig oder doch für ersprießlich erachtet. Der Gesetzgeber hat hier zunächst immer mit den ïberkommenen, in Sitte und Religion verwurzelten Einrichtungen und Begriffen sich auseinanderzusetzen, um so mehr dagegen zu kämpfen, je mehr er ausschließlich von jener Absicht auf Erfüllung eines $Z$ weckes sich leiten läßt - je mehr er mithin frei umgestaltender, ein "revolutionärer" Gesetzgeber ist. Je mehr die gemeinschaftlichen Willensmächte noch stark sind und ihre Kräfte anstrengen um sich zu wehren, um so mehr muß er sich ihnen anpassen und sich genügen lassen, das Recht, wie sie es geschaffen, umdeutend oder wettbewerbend abzuändern oder abzuschwächen; je mehr ihre Kräfte abnehmen, ihre Anstrengungen erlahmen, um so erfolgsicherer kann er umgestaltend, neuernd, revolutionierend, seinen Gedanken und Willen zur Geltung bringen; ob dieser von ihm vertretene soziale Wille - der Idee nach Wille einer Gesamtheit - in roher Wirklichkeit der Wille einer Minderheit oder einer Mehrheit ist; auch wo dem Schein und der Form nach eine Mehrheit, ist der gebildete Wille doch der Wille der Gebildeten, d. i. Weniger, aber er wird um so sicherer wirken, je mehr er eine Massenstimmung, Massenwünsche, Massenstrebungen hinter sich hat. In der Wirklichkeit unserer neueren Geschichte hat in diesem Sinne zuerst in großem Stile der fürstliche Absolutismus mit seinen Ratgebern und Kreaturen, seinen Generalen, Bischöfen, Günstlingen und Ministern, sich geltend gemacht; der Fürst als Repräsentant des Staatsgedankens, der seine Lebenszwecke und die seiner Dynastie mit den Lebensnotwendigkeiten des werdenden Staates und diese mit denen der sich entwickelnden Gesellschaft gleich erkennt und gleichsetzt. Die vom Staate und die von der Gesellschaft ausgehenden Strömungen steigern einander gegenseitig, weil sie in der Lösung gemeinschaftlicher Bande, also in Entfesselung der Individuen sich begegnen, sofern und so lange als sie nicht wider einander wirken, wie es mehr und mehr dadurch geschieht, da $B$ der Staat die Individuen zwar mbefreien", aber zugleich regulieren und beschneiden will, die Gesellschaft ihrerseits 
den Staat von sich abhängig erhalten und ihn, den Herrscher, beherrschen will. Der Staat steht selber in der Gesellschaft, durch sie bedingt und getragen, insbesondere der Finanzstaat durch seine Steuerzahler und durch seine Gläubiger, und je mehr die verwaltende, kapitalmächtige Klasse der Staatsbürger Einfluß auf ihn gewinnt und die gesetzgebende Gewalt sich anzueignen vermag, um so deutlicher wird der Staat zum Hüter einer Gesellschaftsordnung, die als schlechthin natürliche und notwendige sich darstellt, vor Vernunft und Wissenschaft gerechtfertigt, wenn auch von Eintracht, Sitte und Religion vielfach angeklagt, zuweilen verachtet. Teils aus der staatlich anerkannten Praxis des Lebens und der Rechtsprechung, teils durch unmittelbare Gesetzgebung, ist so das System des unbeschränkten Privateigentums und der vollkommenen Vertragsfreiheit erwachsen, das jedoch nur in fortwährendem Konflikt mit den überlieferten Lebensformen wie mit den Nöten der eigentumslosen großen Menge, deren der Staat sich niemals gänzlich erwehren kann, sein Dasein findet. In der bisherigen - neuzeitlichen - Erfahrung ist Gesetzgebung immer noch - wie es die gesellschaftlichen Abhängigkeiten fordern - unter dem Einflusse der oberen gesellschaftlichen Schichten, und zwar so, daß diese bald miteinander zusammen, bald auseinander und widereinander gehen, demnach auch - die des großen Grundeigentums, die des großen industriellen, die des großen Handelsund Finanzkapitals - mehr oder minder geneigt sind, mit den mittleren Schichten und sogar mit der großen besitzlosen Menge - dem Proletariat - sich zu verbünden und ihren Ansprïchen gerecht $z u$ werden; außer daß diese auch aus eigener Kraft gegen die vereinte Macht der oberen Schichten sich durchzusetzen versucht. Der Einfluß und Druck des Proletariats ist bekanntlich im Laufe des I9. Jahrhunderts, besonders in dessen letztem Drittel, durch eine "soziale" Gesetzgebung zutage getreten, vermöge deren der Staat die allgemeine Wohlfahrt gegen die Privateigentümer und ihre Gesellschaft zur Geltung zu bringen sich genötigt fand. Dies ist bisher fast ausschließlich in einem aus konservativen und liberalen Tèndenzen gemischten Sinne geschehen, während ein großer Gesamtversuch, die Gesellschaft und Volkswirtschaft nach sozialistisch-kommunistischen Gesichtspunkten zu gestalten, bisher - vielleicht zum Glücke eines solchen Versuches - nicht gemacht worden ist; wenn man nicht etwa das rohe Experiment einer Diktatur des Proletariats in Groß-Rußland so verstehen will, wo bekanntlich das Proletariat - insofern es vom Bauerntum unterschieden wird - der Zahl nach sehr schwach und in geistig-moralischer Entwicklung am meisten zurückgeblieben ist. Indessen ist die Idee einer solchen Gesetzgebung das, worin sich 
deren Begriff erst erfüllt; sie würde, historisch unbelastet, ausschließlich ihrem rationalen Zweckbewußtsein folgen und radikal vollenden, was in einigen Stücken der absolutistische, aber in seinen Spuren auch der liberale Staat begonnen hat: die Schaffung einer Eigentumsordnung, eines bürgerlichen Rechtes, und also eines sozialen Zustandes, worin die bisher überwiegend spontan erwachsene Gesellschaft wirklich, nach dem HEGEL,schen Worte, auf den Kopf, nämlich auf die Vernunft gestellt würde. Das Prinzip wäre: Ausschließung alles Gewinn erzielenden Privateigentums, Regelung der Güterherstellung ausschließlich nach den gemeinsamen Bedürfnissen und den Beduirfnissen der Einzelnen, Festsetzung und Normierung dieser Bedürfnisse.

Offentliche Meinung ist der geistigste Ausdruck des gleichen Gemeinwillens, der sich in Konvention und in Gesetzgebung dartut. Ihr Subjekt, das also der Gesellschaft und dem Staate als den Subjekten jener sich anreiht, mögen wir als »das Publikum» oder näher, sofern es sich um ein wissendes, gebildetes, unterrichtetes Publikum handelt, als die "Gelehrtenrepublik nach international, doch auch als die nationale geistige Elite iiber ein Land hin verstreut ist, aber in den Städten, zumal den Großstädten und Bildungsstätten, am liebsten in den Hauptstädten sich versammelt und verdichtet; sie wird auch als »die Intelligenz« oder »die Intellektuellen" nicht selten bezeichnet. Man kann sie füglich als eine ideelle Ratsversammlung verstehen, die durch ihre Beschlïsse Normen gibt, oder treffender - wie es in Wirklichkeit oft geschehen ist - als einen Gerichtshof, dessen Beschlüsse oder Erkenntnisse die ideelle Geltung von Richtersprüchen für sich in Anspruch nehmen und, obwohl ohne Beistand einer vollziehenden Gewalt, eine Macht und Kraft der Ehrung wie der Entehrung, der Emporhebung wie der Vernichtung, der Verherrlichung, wie der Verurteilung darstellen, aber auch als Freisprechungen, als Verschweigungen, Duldungen zwischen diesen Grenzen sich bewegen können. Diese Sprüche oder Erkenntnisse sind die öffentliche Meinung in ihrer flüchtigen - ephemeren - Gestalt, nach der sie in der Regel beurteilt owird.

\section{Dritter Abschnitt. Anwendung für öffentliche Meinung.}

23. (Öffentliche Meinung und Propaganda.) Ich schlicße num ebenso den Begriff der öffentlichen Meinung an den Begriff der Gesetzgebung an, wie den Begriff der Religion an den der Sitte, und betrachte die öffentliche Meinung als die rationalisierte Gestalt der Religion, insofern als beide Formen des geistigen und moralischen Kollektivwillens sind; der Begriff aber verhält sich zum Begriff der »Lehre» 
wie der Begriff der Religion zum Begriff des Glaubens, wird also als eine Ganzheit gedacht, worin die Einzelheit aufgeht wie die Einzelheit des Brauches in der Sitte, die Einzelheit der Satzung in der Gesetzgebung. So verstanden ist öffentliche Meinung die gemeinsame Denkungsart, der korporative Geist irgendwelcher Gruppe oder Verbindung, sofern sich deren Meinen auf Denken und Wissen, anstatt auf ungeprïften Vorstellungen, auf Glauben und Autorität aufbauen will, wie es zunächst und am einfachsten in Angelegenheiten des täglichen Lebens, des gemeinen Nutzens und der gemeinsamen und verbindenden Ideen einer sozialen Schicht, zumal einer solchen, die bewußter ihre Interessen wahrnimmt, in die Erscheinung tritt. Bestimmte Begriffe springen daraus hervor: so der Begriff der Ehre als des Wertes einer Person in der öffentlichen Meinung seines Standes, seiner Korporation, folglich auch die Begriffe der Standesehre, der Berufsehre, der Ehre einer Korporation oder einer Partei, als des gemeinsamen Wertes in der öffentlichen Meinung eines größeren Kreises: die Ehre ein gemeinsames Gut, daher Gegenstand gemeinsamen Interesses, aber zugleich Gegenstand des sittlichen Bewußtseins. Ist die Gruppe eine religiöse Gemeinde, ein Orden oder sonst ein Kreis, der sich durch ein mystisches Band verbunden fühlt, so ist ihre Ehre gemeinschaftlich und ganz im verbindenden Glauben und dessen Symbolen beschlossen; die Lehre entbindet sich vom Glauben, indem sie als Lehre bewußter wird und sich einerseits an Tatsachen, andererseits an allgemeinen Begriffen mißt. Die Ehre wird gesellschaftlich-konventionell, und die öffentliche Meinung der Gruppe bemißt ihre Ehrungen nach dem Schein, nach Beobachtung äußerer Formen, und vor allem nach dem Erfolge, also nach Glanz und Glück. In ausgesprochener Weise unterscheidet sich ferner die öffentliche Meinung jeder Gesamtheit, je nachdem sie nach innen oder nach außen sich richtet - nach innen ist sie etwa noch der Religion wesensverwandt, nach außen viel eher und ausschließlicher auf den - gemeinsamen - Nutzen, den Vorteil und Gewinn, den Erfolg, auf den Sieg im Kampfe oder Wettstreit abzielend. Im Kampfe wie in jeder Not entwickelt sich am leichtesten und raschesten der Gedanke, daß jedes. Mittel gut und redlich sei, das dem $Z$ wecke diene, $\mathrm{da} B$ der $Z$ weck die Mittel rechtfertige, also die Uberwindung aller Gewissensbedenken und die skrupellose Politik des freien und absoluten Kürwillens. Die Offentliche Meinung kämpft in diesem Sinne nicht nur mit, sie wird zum Vorkämpfer und muß sich verstärken, ihre Waffen schärfen und Anhänger zu gewinnen suchen, indem sie die eigene Sache, das eigene Interesse, als gleichzeitiges Interesse anderer, als gemeinsame Sache, wenn möglich als die Angelegenheit der Mensch- 
heit hinstellt und verkündet. Die objektive Wahrheit dessen, was ausgesagt wird, ist dabei ebenso gleichgültig wie die subjektive Wahrhaftigkeit jedenfalls zurücktritt vor der bewußten Verfolgung des Zieles, vor der agitatorischen Absicht. - Die Agitation der öffentlichen Meinung in großem Stil, die also einen Gedanken ohne Rücksicht auf seine Wahrheit und Richtigkeit auszubreiten bestimmt ist, wird neuerdings durch den Namen der "Propaganda ausgezeichnet, für den es charakteristisch ist, daß er der Praxis einer religiöskirchlichen Behörcle entlehnt wurde. Ein Autor, der in allen wesentlichen Stücken dem modernen Fortschritt zugetan ist und die demokratischen" Verfassungen mit vielen Beweisgründen verteidigt, nennt die unverantwortliche Macht in den Händen derer, die das Volk mit dem Stoffe versehen, den es, um Menschen und Maßregeln zu beurteilen, nötig habe, eine der großen Gefahren aller heutigen Demokratien. „Jenes Aussäen von Unwahrheiten, falschen Schlußfolgerungen, Anreizungen zu Gewalttat, das wir Propaganda zu nennen gelernt haben, ist ein mächtigerer Einfluß unter den Massen in großen Ländern geworden, als jemals der Demagoge war unter den kleinen Völkern früherer Tage" (BRYCE, Modern democracies II, 505). Und derselbe in dem Kapitel, das die Macht des Reichtums in der Politik darstellt: eine Form, worin sie sich fühlbar mache, scheine jeder Regelung zu spotten. „Das ist die Fabrikation (manufacture) öffentlicher Meinung. Eine Gruppe von reichen Leuten, die ein bestimmtes geschäftliches Projekt oder Klasseninteresse, sei es berechtigt oder gemeinschädlich, verfolgen, könne sich verbinden, um zu Gunsten ihres Interesses oder Projektes eine Propaganda in der Presse ins Werk zu setzen, teils durch Flugschriften und Bücher, teils dadurch, daß sie auf Zeitungen Einfluß gewinnen oder solche in ihren Dienst zwingen, so daß sie das Publikum mit Tatsachen und Beweisgründen nasführen, die ihren Plänen zugute kommen oder eine Partei fördern, deren Führer insgeheim für die Unterstützung solcher Pläne gewonnen sind. Eine solche Gruppe kann, durch ihre Herrschaft über die Presse, mit Eirfolg ihre Ansichten einem Publikum aufdringen, das leicht irregeführt wird, weil immer nur eine Seite des Falles unablässig und in geschickter Weise ihm vorgestellt wird, während entgegenstehende Erwägungen entweder totgeschwiegen oder niedergeschrien werden" (ib. 530). Und an früherer Stelle, wo die öffentliche Meinung in den Vereinigten Staaten betrachtet wird: „Die Kunst der Propaganda ist viel studiert worden in unserer Zeit und hat eine Vollkommenheit erreicht, die ihre Meister in den Stand setzt, durch geschicktes und emsiges Liefern falscher oder einseitiger Darstellungen diejenigen $z u$ täuschen und irrezuführen, die nicht 
die Mittel oder nicht die Zeit haben, sich selber über die Tatsachen zu vergewissern" (I, I75). Wir werden auf diese Zeugnisse in unserem letzten Kapitel - über die öffentliche Meinung im Weltkriege zurückzukommen Gelegenheit haben.

24. (Verhältnisse der sozialen Willensformen zueinander.) Alle Formen eines Kollektivwillens und eines sozialen Willens ïberhaupt sind einander verwandt und hängen miteinander zusammen. Sie haben alle miteinander gemein, daß sie auf die in ihnen enthaltenen Einzelwillen - die selber Willen irgendwelcher Gesamtheiten sein können - bestimmend einwirken, und zwar vorzugsweise hemmend, beschränkend, verwehrend. Die »Determinationen" sind vor allem "Negationen«. Sie verwehren die Eigenwilligkeit, beschränken die Freiheit. Darum werden auch ihre Gegenwirkungen gemieden und gefürchtet, die sehr mannigfach sind: von Mißbilligung, Tadel bis zu Ächtung, Verurteilung, Verbannung, schweren Leibes- und Lebensstrafen, Brandmarkung und Tötung: es sind die Mittel, durch welche der gemeinsame Wille seine Überlegenheit über den einzelnen Willen kundgibt und bewährt, wodurch er diesen seine Schwäche fühlen läßt, indem er die eigene Stärke behauptet. Wenn aber alle gleichartig wirken: so folgt daraus keineswegs, daß sie alle im gleichen Sinne wirken; oft ist es der Fall und in lebenswichtigen Bezügen, oft aber auch findet Widerspruch und Kampf zwischen den verschiedenen Formen statt, insbesondere zwischen den gemeinschaftlichen einer-, den gesellschaftlichen andererseits. Dieser Streit ist sogar der große historische Prozeß, der den Übergang der Kultur in die Zivilisation, der Gemeinschaft in Gesellschaft wesentlich bezeichnet. Insbesondere sind es die Formen des Kollektivwillens, die so einander ablösen und verdrängen: Konvention schiebt sich an die Stelle von Eintracht, Gesetzgebung von Sitte, Offentliche Meinung von Religion; die einen waren, die anderen werden die entscheidenden Mächte im sozialen Leben. Und zwar gehen und halten im allgemeinen die gemeinschaftlichen Formen zusammen und die gesellschaftlichen Formen zusammen, aber es kommen auch andere Verbindungen und Gegensätze vor, Widerstreit auch je zwischen gemeinschaftlichen und je zwischen gesellschaftlichen Formen des Kollektivwillens und des sozialen Willens überhaupt. Wenn wir nun hier die öffentliche Meinung ins Auge fassen, so wird zunächst ihr allgemeines Wesen erörtert werden, um alsdann die Öfentliche Meinung als spezifische Erscheinung davon abzuheben, und ihre Verhältnisse zu anderen Formen des Kollektivwillens, insbesondere zu Religion, zu untersuchen. 


\section{Kapitel. Öffentliche Meinung.}

\section{Erster Abschnitt. Das öffentliche Wesen.}

I. (Meinungsäußerung.) Es wurde auf den Widerspruch der Sprache aufmerksam gemacht, daß \#meinen " einerseits so viel als "denken" bedeuten will, also durchaus das Hegen eines Urteils, einer Absicht, andererseits geradezu ein abgekürzter Ausdruck ist für »eine Meinung (ein Urteil, eine Absicht) aussprechen", kundgeben; sie an einzelne Personen oder in engem Kreise oder öffentlich, "allen", dem Publikum, mitteilen.

So lange ich eine Meinung hege und die Worte, in denen ich sie ausdrücke, "im Busen bewahre", ist sie ganz mein eigen, oft mein Geheimnis: sei die Meinung eine Ansicht oder eine Absicht. Ich kann sie, ohne es gewollt zu haben, erkennbar werden lassen - unfreiwillige Zeichen, wenn sie richtig gedeutet werden, 》verraten « mich - oder aber ich will sie zu erkennen geben, ich mache Zeichen, von denen ich wünsche und in der Regel auch Grund habe zu vermuten, daß sie richtig gedeutet, daß sie "verstanden" werden. Erst mein eigenes Wollen verwandelt die innere Meinung in eine "Meinungsäußerung". Sie bedient sich der Zeichen, die als solche gegeben und empfangen werden.

2. (Zeichen.) Solche Zeichen sind I. stumme Zeichen. Ich kann unwillkürlich oder wollend durch Gebärden, als durch Neigen oder Schütteln des Kopfes und durch mannigfaches Mienenspiel, mit dem Munde und mit den Augen, durch Lachen und durch Weinen, ferner durch Bewegungen der Füße und Hände, besonders aber der Finger, meine Meinung ausdrücken, wollend freilich nur in beschränktem Maße; hauptsächlich um Zustimmung und Gegenstimmung zu einer schon kundgewordenen Meinung erkennbar zu machen, bedienen wir uns regelmäßig solcher Zeichen. Indessen bleiben Gebärdenund Zeichensprache immer, soweit sie verständlich sind, die allgemeinstverständlichen, daher dienen sie dem Stummen wie dem Fremdling, der sich als ein Stummer zu der ihm fremden Sprache verhält. Stumme Zeichen dieser Art sind auch Bildwerke und Abbildungen, insofern als auch sie geeignet sind, Gedanken und Meinungen zu erkennen zu geben und mitzuteilen; ja wir können alle stummen Zeichen als "Bilder * zusammen begreifen. Sie drücken daher auch die Gemiitsbewegungen aus, welche regelmäßig Zustimmung und Gegenstimmung begleiten, oft leidenschaftliche Gemütsbewegungen, als Freude, Pegeisterung, Bewunderung oder Arger, Zorn, Verachtung, Unwillen. - Ganz 
ebenso werden 2. die 1a uten Zeichen gebraucht: solche können mit den Bewegungen der Füße und Hände verbunden sein, als Trampeln, Scharren, Klatschen, wichtiger sind solche, die mit den Organen der Stimme und mit dem Munde gemacht werden, vom Schreien, Zischen, Jauchzen, Murren und unartikulierten Rufen bis zu den artikulierten Tönen der Zunge, d.i. Wörtern und also der »Sprache«. Innerhalb der Sprache wiederum findet der Fortgang von einzelnen Rufen, die Zustimmung oder Gegenstimmung bezeichnen mögen, zu Sätzen, die ein Urteil, also möglicherweise auch eine Meinung, meine Meinung«, ausdrücken, statt. Aus einem Satze wird eine zusammenhängende Folge von Sätzen, ein Zuspruch, eine Ansprache, eine Rede.

Wie Gebärden, Bilder, Geräusche, aber am vollkommensten Worte, Zeichen von Gefühlen und Gedanken, so ist die Schrift in ihren mannigfachen Gestaltungen Zeichen von Worten, also auch mittelbar von Gedachtem, Zeichen von Meinungen. Reden werden in Schriften niedergelegt, dann auch Gedankenfolgen, die weit über den Umfang einer möglichen Rede hinausgehen, Gedankenwerke. Reden und Schriften können auch bloß erzählen, Gesehenes, Gehörtes oder sonst Wahrgenommenes und Erlebtes berichten; mittelbar werden auch solche als Zeichen von Gedanken und Meinungen sich darstellen. Als stummes Zeichen von Worten ruft die Schrift in der Seele dessen, der sie versteht (lesen kann), Worte hervor, die er wiederum verstehen muß, damit die Schrift für ihn Sinn und Bedeutung habe. Die Gestalten der Schrift sind in der Regel öffentlich, zuweilen aber geheim und nur für denjenigen zugänglich, der den "Schlüssel " besitzt oder entdeckt.

Der Redner kann von Tausenden zu gleicher Zeit gehört werden; wenn er dieselbe Rede oft wiederholt, von Hunderttausenden. Er hat sein "Publikum». Aber der Schreibende hat unmittelbar dadurch, daß seine Schrift vervielfältigt wird, ein weit größeres mög liches Publikum, das Publikum der Lesenden. Der wirklich die Schrift Vernehmende ist oft nur ein einzelner Mensch, der Empfänger eines Briefes; wie denn auch das gesprochene Wort in unzähligen Fällen nur an einen Einzelnen oder doch an einen geschlossenen Kreis von Einzelnen sich richtet; wenn es aber nachher geschrieben und gedruckt wird, an Unzählige, an »das* Publikum.

3. (Publikum.) Das Publikum ist eine Menge von Menschen Männern und Frauen -, zunächst von solchen, die sich räumlich vereinen, z. B. im Theater; von Menschen sehr verschiedener Art, die aber miteinander gemein haben, daß die Gelegenheit, das Erwartete, das Interesse, sie zusammenführt oder zusammenhält. Das Publikum ist 
hör- und schaulustig, es will durch Gesehenes und Gehörtes - oder zu dessen Ersatz, Gelesenes, wie im Kinematographen-Theater unterhalten sein, durch Lustiges erheitert, durch Trauriges gerührt werden. Es kommt zusammen und geht wieder auseinander; immer ein anderes und in einigen Merkmalen, wenigstens an demselben Orte, immer dasselbe, am meisten nach Zahl und Größe verschieden. Das Theaterpublikum, eine besonders ausgeprägte Erscheinung des Publikums, will keine Meinungen empfangen, es will, wenigstens nicht unmittelbar, belehrt werden, noch weniger in Glaubens- oder anderen Meinungen bestärkt oder erschüttert werden; und doch hat auch das Schauspiel nicht selten dergleichen Wirkungen, und noch öfter geht dahin die Absicht des Dichters, der durch das Schauspiel auf die Menge wirken will. Heldentaten und Heldenleiden, in lebendigen Handlungen vorgeführt, begeistern und entsetzen; man erwärmt sich für die Idee, der das Leben des Helden geweiht ist, man bewundert ihn, man glaubt an ihn und an den Wert seiner Sache, man wird in der Meinung bestärkt, oder sie wird erst in den Seelen geweckt, da $B$ diese Sache, diese Idee edel und wertvoll sei, etwa auch, $\mathrm{da} B$ es als gro $B$ und nachahmenswert zu schätzen, für eine Idee, für diese Idee zu leben, zu leiden oder sogar sich aufzuopfern und zu sterben. Uberhaupt werden die moralischen Meinungen und Gefühle, die mit religiösem Glauben so vielfach und eng zusammenhängen, in Erregung gebracht, aufgewïhlt und erneuert, oder genährt und vertieft, am häufigsten in der schlichten und volkstümlichen Weise, da $B$ Laster und Bosheit bestraft, Tugend und Güte belohnt werden. Aber auch der Zweifel wird wachgerufen, der sittliche Ernst gelockert, indem, was sonst für schlecht gehalten wird, z. B. Liederlichkeit und Ehebruch, als etwas Alltägliches und etwa gar in den höheren, vorbildgebenden Lebenskreisen Leichtgenommenes, ja von einer vergnüglichen und anmutenden Seite in verführerischem Schimmer dargestellt wird. Näher noch trifft es ins Gebiet der eigentlichen Meinungen, wenn etwa der Freidenker nicht nur, im Gegensatz zum überlieferten Glauben, dem der Gottlose auch ein Verruchter ist, als edler Mensch, sondern in einem löblichen, ja ihn verherrlichenden Kampfe gegen die Vorurteile und Verfolgungen der Rechtgläubigen auf der Bühne erscheint. Oder wenn der Dichter einen edlen, von Begeisterung für das Wohl der Menschheit erfüllten Jüngling einem finsteren König gegenüberstellt und ihn in hinreißender Rede ausrufen läßt: „,Sire, geben Sie Gedankenfreiheit!" Am häufigsten begegnet in dieser Richtung, da $B$ das Theater dem Spott, dem sittlichen Unwillen, und also der Satire, gröberer und feinerer, dienstbar gemacht wird. Also bewirkt auch das Schanspiel die Ausbreitung, die Begünstigung oder 
Bekämpfung von Meinungen. Und wie das Schauspiel, so seine stummen Abarten: die alte Pantomime und ihre neue unter mannigfachen Namen auftretende Gestalt, der ebenso moderne wie unschöne »Kinematograph«.

4. (Das große Publikum.) Wenn also die Bühne, auch die falsche Bühne, ihr Publikum hat, so hat es jeder Redner, jeder Schriftsteller, hat es jede Zeitung. Aber davon verschieden denken wir, "das" Publikum, das "große " Publikum, die unbegrenzte Menge der Menschen, die ungeachtet ihrer Zerstreuung und endlosen Verschiedenheit möglicherweise in einem und gleichem Sinne denkt und urteilt; sie versammelt sich nicht, sie kann sich gar nicht versammeln, aber sie lebt und wirkt in unzähligen Kreisen, und sie kann sich vernehmbar machen, macht sich vernehmbar, wenn auch oft nur in dumpfem Grollen oder in heiserem Schreien, in höhnischem Lachen oder in trübem Wehklagen und, wie das Theaterpublikum, in Zeichen des Beifalls und Mißfallens, des Staunens und der Spannung. Seiner Idee nach besteht dies Publikum in bezug auf bestimmte Ereignisse und Arten von Ereignissen aus allen Menschen, die daran teilzunehmen, sie aufzunehmen, dariber zu urteilen fähig und willens, die dazu vorbereitet und bereit sind, die also ein gewisses $M a ß$ von Geschick und Bildung dazu haben - die "gebildete Welt». Sie urteilt uiber politische Begebenheiten, wie uiber solche des Kunstlebens, der Wissenschaft und Technik, über Entdeckungen und Erfindungen, über Persönlichkeiten, die in irgendeinem dieser Bereiche sich ausgezeichnet haben oder eben hervorragend sich zeigen; Voraussetzung ist, daß sie die Tatsachen, wenn auch nur oberflächlich, kennen gelernt hat, daß diese "bekannt" geworden sind, und dies kann plötzlich, wie mit einem Schlage, blitzartig geschehen, oder in allmählich sich erweiternden Kreisen; immer wird es in sehr verschiedenen Graden der Intensität wirken und in der Regel auch sehr verschiedene - nach Art und Stärke verschiedene - Gefühle, Affekte, Stimmungen auslösen. Heute - seit mehr als Ioo Jahren - geschieht das Bekanntwerden fast ausschließlich 'durch die Zeitungen, und das Publikum ist fast ausschließlich das Zeitungen lesende Publikum; längst vorher war es das lesende, aber weder das Lesen von Zeitungen noch von Büchern ist die notwe ndige Form des Kennenlernens von Begebenheiten und Neuigkeiten; auch durch bloßes Sehen und Hören können sie, wenn auch langsamer und mangelhafter, bekannt werden; durch fahrende Sänger, durch Händler und andere Reisende, durch die unmerklich schreitende Fortpflanzung des Gespräches, die geschäftige »Fama«; sodann durch Predigten, durch den Unterricht der Jugend. Frühzeitig aber sind auch verabredete 
Zeichen angewandt worden, wie Feuer auf den Bergen, die man als Urformen der Telegraphie beschrieben hat. So ist einst der Fall Trojas, so die Ermordung J ULIUS CAESARS, bekanntgeworden und mit Staunen und Entsetzen aufgenommen worden; so die Umseglung des Kaps, die Entdeckung Amerikas, der Tod Gustav Adolphs; alles was »die Welt" erschüttert hat, längst ehe es Zeitungen gab oder doch ehe sie gewirkt haben. Aber von dem Weltpublikum haben sich immer gar viele engere Publika unterschieden, in verschiedenen Graden der Teilnahme und Erregung; unterschieden zunächst nach Raum und nach Zeit. Die Ereignisse haben immer rascher und stärker gewirkt in engeren Kreisen und in näherer Zeit; mit beiden Entfernungen schwächt der Anteil sich ab, den das Publikum zu nehmen gewillt ist. Unterschieden auch nach Art der Bildung und folglich der Bereitschaft. Der Tod MozarTs wirkte zunächst auf die "musikalische", der KanTS auf die philosophische "Welt». Aber im Vordergrunde seiner gemeinsamen Interessen stehen für das "große« Publikum die wirtschaftlichen und die mit diesen eng zusammenhängenden politischen Angelegenheiten; jene werden unmittelbar zu politischen dadurch, daß sie das politische Denken und also die politischen Parteien aufregen; das große Publikum ist das politische Publikum, das weniger als jedes andere einen internationalen Charakter hat, melnr als jedes andere durch die Besonderheiten eines Staates oder Reiches bedingt wird, wohl aber in hohem Maße durch politisches Interesse, politische Bildung; aber die "Weltereignisse《 haben auch, und gewinnen immer mehr ein internationales Publikum. In jedem Sinne ist $\mathrm{d}$ as Publikum, wenn es nicht an einen bestimmten Raum, eine bestimmte Zeit gebunden gedacht wird, eine Idee von unbestimmbarer Weite und Dauer - auch insofern es durch das Merkmal allgemeiner oder besonderer, zumal politischer "Bildung « bezeichnet wird. Die Bildung ist ein historisches, auf Úberlieferung, L,ehre, Gespräch, Lektüre und Erfahrung beruhendes Gewächs vorzugsweise des städtischen Lebens, überhaupt aber der oberen reichen oder wenigstens wohlhabenden sozialen Schichten; Bildung und Besitz werden mit Grund zusammengenannt, so oft sie auch getrennt sind. Und zwar mehr das bewegliche Vermögen als der Grundbesitz führt zur Bildung hin, wird durch sie gefördert. Daher wird sie oft in höheren und höchsten, aristokratischen Kreisen, gering geschätzt, es sei denn, $\mathrm{da} B$ sie in religiösen Formen und Gestalten erscheine, die aber von fortschreitender Bildung mehr und mehr verneint werden; politische Bildung freilich verträgt sich eher mit diesen, ja steht oft in fruchtbarer Wechselwirkung mit ihnen, ebenso die ästhetisch-kunsthafte Bildung; aber die eigentlich typische Bildung ist die wissenschaft - 
liche Bildung, von deren Wesen und Stärke in einem gewissen Maße jene anderen Arten der Bildung abhängig $\operatorname{sind}^{\mathbf{1}}$ ). - Das große $\mathrm{Pu}$ blikum ist ein charakteristisches Gebilde der neueren Jahrhunderte. Der Verfasser des Anti-Macchiavel (der spätere FRIEDRICH D. GR.) kannte es schon. „Man weiß, in welchem Grade das Publikum neugierig ist, es ist ein Tier, das alles sieht, das alles hört und das alles verbreitet, was es gesehen und gehört hat." Er führt dann aus, daB Fürsten weit mehr als Private den Reden und Urteilen (aux raisonnements et aux jugements $d u$ monde) ausgesetzt sind. Sie seien wie die Sterne, auf die ein Volk von Astronomen seine Fernrohre richte. „,So wenig wie die Sonne ihre Flecken, so wenig können die großen Fürsten ihre Laster den Blicken entziehen (Examen du Prince de Macchiavel, S. I94.).

5. (Stumme und laute Zeichen.) Die lebendigsten Zeichen, durch die wir uns mitteilen, wirken zugleich auf Gesicht, Gehör und Phantasie. Aber die stummen Zeichen wirken vorzugsweise aufs Auge, die lauten aufs Ohr; der Lesende sieht sinnlich und geistig, er hört zugleich geistig; Sehenden wie Hörenden wirkt die ganze Masse gewesener Eindrücke mit, die als Erinnerungen schweben und berührt werden. Und durch neue wie alte Eindrücke wird das "Gemüt", werden die Gefühle, wird der Wille erregt. Sie machen sich beim Sehen am unmittelbarsten als Gefallen - Lust und Unlust - geltend, beim Hören überwiegend als Gewohnheit: denn Verstehen von Worten ist durchaus Sache der Ubung und Gewöhnung, und das Gewohnte, Verstandene, - ja das Gewohnte, wie das Klangvolle, feierlich Tönende, sogar wenn unverstanden, - wird gern gehört, Ungewohntes zumeist auch Unverstandenes, stößt auf Widerstand und Abneigung, findet "keinen Widerhall", gewohnte Gedankengänge werden leicht und in angenehmer Weise erneuert, sind willkommen, ungewohnte sind schwer verdaulich und werden abgelehnt. Beim Lesen endlich hängen sich die Gefühle ans Gedächtnis: denn hier ist die Seele sozusagen angewiesen auf den Schatz der erworbenen Vorstellungen und der "Phantasie die verstärkend, vergrößernd, erweiternd, immer mittätig ist. Geistig ist der Leser gegenwärtig in unbekannten Ländern, sieht und hört Verstorbene und Unbekannte wie im Traume,

1) Recht charakteristisch für das überreizte Selbstgefühl der städtischen Bildung ist die Äußerung Hernrich Hrines: „, Eine Handvoll J unker, die nichts gelernt haben als ein bißchen Roßtäuscherei, Volteschlagen, Becherspiel oder sonstige plumpe Schelmenstücke, womit man böchstens nur Bauern auf Jahrmärkten übertölpeln kann: diese wähnen damit ein ganzes Volk betören zu können, und zwar ein Volk, welches das Pulver erfunden hat, und die Buchdruckerei und die Kritik der reinen Vernunft." Politisches Glaubensbekenntnis oder Epistel an Deutschland (1832), S. 5, Ausg. 1848 . 
nimmt an erdichteten Ereignissen Anteil, als ob er sie erlebte, daher mit tätiger Freude oder leidendem Kummer, mit gespannter Erwartung und mit bitterer Enttäuschung mit Hoffnung und Furcht». Er verhält sich ähnlich wie der Zuschauer im Theater, aber bei diesem wird die Einbildungskraft unmittelbarer in Anspruch genommen und gefesselt, darum auch in rascherem Wechsel und mit stärkeren Erschütterungen; der Lesende kann, was ihn erregt, begeistert, gerührt hat, wieder und wieder lesen; er kann nach Belieben das Buch weglegen und seine Gedanken darin vertiefen. Der Zeitungleser findet fortwährend seine patriotischen oder parteiischen Gefühle aufgeregt; nicht selten packt ihn leidenschaftliche Wut, so daß er das zerknitterte Blatt in die Ecke wirft; zuweilen Begeisterung, daß er laut aufjauchzt. Der Gelehrte gibt in Büchern, die er liest, Beifall oder Mißfallen durch Striche, durch Ausrufungs- und Fragezeichen zu erkennen, die aber auch zur bloßen Erinnerung und Richtung der Aufmerksamkeit dienen mögen.

6. (Mitteilung.) Bild, Rede, Schrift wirken also, je für sich und in Verbundenheiten, als Geräte der Mitteilung. Das Publikum, wie es durch sie gebildet wird, ist nicht wie ein Theaterpublikum, zumeist in geschlossenem Raume zusammen (freilich kann auch ein Theaterpublikum unter freiem Himmel sich versammeln); am ehesten das Publikum der Rede, wie die Gemeinde in der Kirche, die Volksmenge in der politischen Versammlung. Jedes Publikum solcher Art ist zusammengekommen, zusammengelaufen, es stellt eine, wenn auch schwache, Einheit dar, die als solche durch Zeichen des Beifalls und Mißfallens, der Begeisterung oder des Abscheus, durch gemeinsame stille Andacht oder lauten Gesang, aber auch durch einmütige Beschlüsse und Entschlüsse ihre gemeinsamen Stimmungen, Meinungen, Wünsche, kundgibt. Anders ist das Publikum als zerstreute Menge: oft die unzusammenhängende oder doch nur unräumlich verbundene Mehrheit von Publika der ersten Art; öfter aber die bloße Vielheit von Individuen, die fähig und in irgendwelchem Maße willig sind, Mitteilungen zu empfangen und ihnen eine Stätte zu bereiten. Immerhin ist auch das zufällige Publikum verhältnismäßig selten stark -gemischt . Es pflegt dieselbe Sprache zu verstehen und zu sprechen, in der Regel auch aus gleichen sozialen Schichten zusammengesetzt zu sein. Daher auch die Stimmung zumeist einheitlich, z. B. in Volksversammlungen die Genossen der Partei des Redners, die ihn eben bestellt haben, um das zu vernchmen, was ihnen gefällt; oder es sind Vorkehrungen getroffen worden, um die Anhänger heranzuziehen, die Gegner abzuwehren und, wenn sie doch sich vernehmbar machen, ihre Stimmen zu töten. Es entstehen oft Zusammenstöße zwischen 
dem gebetenen und dem ungebetenen Publikum. Das versammelte Publikum ist in der Regel laut; dagegen das zerstreute Publikum der Leser seinem Wesen nach stumm, wenn auch oft Stimmen aus dem Publikum, aus dem "Leserkreis" sich vernehmbar machen.

7. (Schriftsteller.) Ein buntes, mannigfaches, zufälliges Publikum hat vorzüglich der Schriftsteller. Freilich, nur der Schriftsteller ersten Ranges - der aber durch Umstände, die den inneren Rang erhöhen, begünstigt sein mag - hat ein Publikum von menschenweiter Ausdehnung, das sich möglicherweise durch Jahrtausende fortpflanzt und vermehrt. In erster Linie als Dichter - wie sonst ein Künstler, dessen Werke, oder doch Bruchstücke davon, erhalten bleiben und, selber vunsterblich" zu den wechselnden Geschlechtern der Sterblichen reden. Auch in Dichtungen sind Meinungen enthalten: teils solche, die der Dichter mit seinen Zeitgenossen teilt, also auch Irrtümer über Welt, Götter und Menschen, teils auch besondere Meinungen, die er seinen Zeitgenossen mitteilen, durch die er sie etwa belehren oder bekehren will. Solche Meinungen pflegen weniger Ansichten als Gesinnungen zu sein, daher auch Parteigefühle, Parteistimmung, Parteileidenschaft: Artungen des Wünschens und Wollens, wie des Unwillens und der Empörung. Solche sind bestimmt, durch das lebendig beschwingte Wort, und etwa in Verbindung mit Bildern, abgebildeten Handlungen und Leiden, auf Zuhörer, Zuschauer, endlich auch auf Leser zu wirken, die Gefühle, Stimmungen, Leidenschaften mitzuteilen. Der dramatische Dichter vor allem hat solche Gewalt, aber auch der erzählende und der lyrische; insbesondere aber der didaktische und der moralisierende, daher auch der religiöse Dichter und Schriftsteller. Die Form der Dichtung ist nicht wesentlich; ja die ungebundene Rede ist auf den Verstand zu wirken mehr geeignet, und diese Wirkungen sind oft Bedingung für die Wirkungen aufs Gefühl. Eine besondere Gattung der Poesie (im weiteren Sinne) - die Satire - hat vorzüglich den Charakter, Meinungen auszudrücken und auf Meinungen wirken zu sollen; als dramatische Gattung ist ihr die Komödie verwandt. Sie will Gelächter erregen; und zwar wird sie gern kämpfend auftreten, also bekämpfte Meinungen, Menschen, Zustände »ins Lächerliche ziehen" - vertrauend darauf, daß die Lächerlichkeit schadet, ja »tötet«. Die Bosheit aber will töten, oder wenigstens tief verwunden und unschädlich machen; solche "Bosheit * kann aber auch und wird oft aus ehrlicher sittlicher Entrüstung entspringen und sich in Gutheit verwandeln, wenn sie böses Unkraut vertilgen hilft. - Eine Dichtung kann bestehen und auf späte Nachwelt kommen, obgleich die Stimmungen und Leidenschaften des 
Kampfes, dem sie entsprungen ist, vergessen sind oder nicht mehr verstanden werden; das Wesen der Kunst ist die edle Form, ihr Geist ist die Gestaltung. Das Allgemein-Menschliche spricht aus fernsten Zeiten zur empfänglichen Seele, um so mehr, wenn es einem verwandten Menschentum Ausdruck gibt, oder aber durch Glauben erhöhte Bedeutung gewinnt.

8. (Denker.) Unmittelbarer und förmlicher als Dichtungen sprechen die Werke der Denker und Forscher ihre Mein ungen aus: Meinungen, die sie begründen und durch Begründung empfehlen, mögen sie nun den sonst herrschenden Meinungen sich anschließen oder sich entgegensetzen. Und diese Meinungen kämpfen nicht nur immer um ihr Dasein, ihre Geltung; sie sind auch zumeist streitende Willensmeinungen für oder wider eine Sache, eine Idee, ein System, sei es der Weltanschauung oder der Regierung, daher auch für oder wider bestimmte mächtige Personen oder Parteien. Auch solche Meinungen überleben ihre Gelegenheiten. Schriften, die zur Verteidigung der griechischen oder römischen Religion verfaßt wurden, haben heute nur noch ein "historisches Interesse; sie finden keinen Widerhall. Fast nicht anders ist es mit der gesamten christlichen Polemik zwischen den Theologen verschiedener Schulen, der Orden, der Konfessionen und den Richtungen des Glaubens oder Unglaubens. Auch philosophischen Lehren und wissenschaftlichen Ansichten, deren Voraussetzungen erloschen sind, wird ein solches Veralten zuteil. Andere Meinungen wissenschaftlicher und philosophischer Art wirbeln einen Staub auf, der die Wege von Jahrzehnten, ja von Jahrhunderten erfüllt. Was allgemein geglaubt wurde, wird bezweifelt, widerlegt. Neues, Unerhörtes, bricht sich Bahn. Feste Überzeugungen werden erschüttert, Manchen gefällt das Neue, Andere erkennen es als richtig an, es bilden sich Parteien für und wider die sich darbietende Lehre, sie wird erörtert in Wort und Schrift, sie gewinnt ein Leben, das sich erhält und sich fortpflanzt, im Kampfe sich bewährt und sich behauptet; bis es untergeht.

9. (Meinungskämpfe.) Denn es ist - wie früher bedeutet - der Streit, der den Meinungen der Schriftsteller wie der Redner ihr Leben gibt. Die Rede und das Buch, die Flugschrift, der Zeitungsartikel, sind Waffen, mit denen im Kampfe der Weltanschauungen und Gedanken, wie im Kampfe der politischen Bestrebungen und Ansichten, gefochten wird.

Diese Kämpfe aber wechseln fortwährend ihren Inhalt. Den Kämpfen des Jahrhunderts, mehr noch denen des Jahrzehntes, des Jahres, aber am meisten denen der Woche, des Tages, heftet sich die brennende Anteilnahme der Zeitgenossen an. Hier zündet das Wort, 
das geredete wie das geschriebene, Redner und Schriftsteller machen ihre Meinungen geltend und breiten sie aus, Gehiulfen erstehen ihnen, die "Propaganda" für ihre "Ideen" machen, für "Agitation" und »Aufklärung《 werden Verbände organisiert, die ihre Finanzen haben, und ein großes Publikum erfüllt sich mit den empfangenen Gedanken. Die Kämpfe der Meinungen gehen von sachlichen Gegensätzen, als "Meinungsverschiedenheiten", in persönliche Feindschaften über, die Feindschaften der Gruppen, Bekenntnisse, Parteien von Worten zu Taten - von Verbal- zu Realinjurien -, endlich sogar zu organisiertem Kampfe mit Waffen, zu Aufruhr und Bürgerkrieg. Das Aussprechen einer Meinung enthält sehr oft ganz unmittelbar eine Kränkung des Andersmeinenden. Sein Verstand oder sein Charakter wird angezweifelt oder geradezu angeschwärzt, nicht selten sowohl Verstand als Charakter. Die entgegengesetzten Meinungen werden verabscheut und als ruchlos gebrandmarkt. Der Andersdenkende ist ein Scheusal; hat er früher etwa ähnlich gedacht, wie diejenigen, die nun über ihn richten, so ein "Verräter«.

ro. (Der Buchdruck.) Seit 4-50o Jahren ist in Europa die Mitteilung und Vervielfältigung von Bildern und Schriften allmählich bis ins Grenzenlose vermehrt und vergrößert worden durch den Druck der Bücher. Dieser hat nicht nur, anstatt der wenigen langsam durch Handschrift hergestellten Abschriftexemplare eines Buches, deren viele mechanisch und mit erhöhter Geschwindigkeit ins Dasein gerufen; er hat neben das massige, schwer bewegliche Buch, das vorzugsweise in stillen Klöstern oder etwa in Schlössern und Rathäusern aufbewahrt wurde, und zum größten Teile an dessen Stelle, das Buch des kleinen Formats, leicht tragbar, leicht versendbar, zur Ware tauglicher, geschaffen; aus diesem wiederum ist früh die Flugschrift später der gedruckte Brief, endlich die "Zeitung " in ihren mannigfachen Gestalten hervorgegangen, die von der Flugschrift durch das Merkmal der periodisch regelmäßigen Erscheinung scharf sich abhebt; ob nun die Periode Woche, Monat, Vierteljahr oder, wie im typischen Falle, der Tag ist, nach dem das 》Journal " benannt wird, dessen Name dann wiederum erweiterte Bedeutung gewinnt, während wir von Tageszeitungen, Tageblättern nur in einem engen Sinne sprechen können, der freilich auch bleibt, wenn die Zeitung mehr als einmal am Tage herauskommt und etwa in ein Morgen- ein Mittags- und ein Abendblatt zerfällt; die $Z$ wiefachheit von Morgen- und Abendblatt ist bisher die häufigste Form geblieben, dann wird noch Erstes und Zweites Morgenblatt unterschieden usw. Der romanische Name des Buchdrucks, die $*$ Presse», heftet sich an ihre flüchtigste und vergänglichste Form, die Zeitung. 
II. (Zeitungen.) Das Zeitungswesen, im I7. Jahrhundert entstanden und langsam gewachsen, ist schon im I8. mehr und mehr eine Macht des sozialen und politischen Lebens geworden, im I9. eine bedeutende, allgemein anerkannte, tief wirkende Macht, die $\$ 6 . "$ oder $» 7 . "$ Großmacht, wie man sie prahlend genannt hat; in ihrer furchtbaren Stärke vielleicht erst im gegenwärtigen (20.) Jahrhundert offenbar werdend. Denn die Zeitung ist nunmehr das vorzüglichste, brauchbarste und am meisten gebrauchte Mittel, Meinungen bekannt zu geben, geltend zu machen, öffentlich $\mathrm{zu}$ verkünden und $\mathrm{zu}$ verteidigen, gegnerische Meinungen anzugreifen, gehaßt und verachtet zu machen die Mehrheit von Zeitungen der Kampfplatz, auf dem der unablässige Krieg der Gedanken und Meinungen am heftigsten entbrennt und in heißen Flammen lodert. Zumal im politischen Streit entfaltet sich die ${ }^{2}$ Presse als eine Macht, die von Parteien und Regierungen mit mehr oder minder Geschicklichkeit und Energie gehandhabt wird, teils um Meinungen, Wünsche, Beschwerden und Gefühle aller Art auszudrücken, gegeneinander auszuspielen, teils um die Meinungen und Gefühle unbeteiligter oder minder beteiligter Zuschauer für sich zu gewinnen.

Denn die Streitenden suchen Sympathie und Beifall zu ihrer eigenen Ermutigung, suchen Bundesgenossen zu ihrer Hilfe; die Genossenschaft der Meinungen und Gefühle is t eine Hilfe gegen feindliche Meinungen und Gefühle und sie kann zu tätiger Hilfe werden, die moralische Unterstützung zu materieller Unterstützung, wenn nicht diese von Anfang an in jener enthalten ist.

\section{$Z$ weiter Abschnitt. Nachrichten und Offentlichkeit.}

12. (Gemeinschaft und Uberlieferung.) Dem begrifflichen Unterschiede von Gemeinschaft und Gesellschaft entspricht auch ein innerlicher Unterschied der vorherrschenden Mitteilung und Lehre.

In "Gemeinschaft" - um der Kürze halber so zu sagen - werden vorzugsweise gegebene, überlieferte Meinungen - Glaubenssätze, Dogmen - weiter überliefert; es ist in erster Linie die Unterweisung der Jugend, der die Älteren sich widmen: Väter und Mütter übergeben, was sie selber gelernt haben, ihren Kindern, Meister und Lehrer ihren Lehrlingen, Jüngern und Schülern Kunst und Wissen, zu deren beherrschender Kunde und Ausübung, und also zu weiterer Úberlieferung, diese sich entwickeln sollen. Und so verhält sich die gesamte Oberschicht, insonderheit aber der Priesterstand, zum Volke, zu den I Jaien, als "Lehrstand», der den Unmündigen gibt, was er ihnen für heilsam erachtet: der Priester, diese historisch am meisten bedeutende Gestalt des Lehrstandes - seinem eigenen oder wenigstens dem 
Glauben des Volkes gemäß - in beständiger Fühlung mit den überirdischen Mächten, die droben im Lichte wandeln oder auf einer Bergeshöhe wohnen oder allgegenwärtig sind und doch auf eine besondere Art in einem Brote oder einem Kelche, der mit heiligem Wein gefüllt ist, sich befinden und wirksam werden. Der höchste Geistliche zumal, der aber vielleicht mit dem weltlichen Herrscher in einer Person vereinigt ist, kennt den göttlichen Willen und weiß ihn richtig zu deuten; so steht er in der Meinung aller Gläubigen selber als ein höheres Wesen da, und - zum wenigsten, wenn sie ihres priesterlichen Amtes walten in minderer Weise auch alle, die die heiligen Weihen empfangen haben. Das Heilige ist das Allgemeine, der Geist, der die Glieder der Gemeinde verbinden soll, weil er einem jeden sich mitteilt und der Glaube daran ihm entgegenkommt. Das "Oben", die "Höhe», worin dieser Geist wohnt, ist in Wirklichkeit (d. i. dem Ursprunge der Vorstellung nach) die Stätte der Vorfahren, die immer als die früheren auch höher gedacht werden und von ihrer Erhabenheit allen jeweilig lebenden Würdenträgern etwas abgeben. Wie zu den Vorfahren die Väter, so verhalten sich zu den Göttern die Priester. - Denkbar ist jedoch, $\mathrm{da} B$ Gemeinschaft sich aller dieser mythologischen und theologischen Gewänder entkleidet, indem sie ihr eigenes Wesen erkennt und sich darauf besinnt: ein Fortschritt, der zur Erhaltung von Gemeinschaft um so mehr notwendig wird, je mehr Erkenntnis zunimmt und die Gebilde der Einbildungskraft durchschaut, um sie zu zerstören. In jeder Gemeinschaft also, sofern und solange als sie lebensfähig ist, verbindet ein solcher "Geist « des Zusammenwirkens und der gemeinsamen Ideale nicht nur die gleichzeitig und nebeneinander lebenden Menschen, sondern mehr noch die aufeinander folgenden, eben dadurch voneinander abhängigen Geschlechter.

13. (Gesellschaft und Mitteilung.) Anders in "Gesellschaft"; wenn wir durch diesen Begriff einen entgegengesetzten sozialen $\mathrm{Zu}$ stand und zwar den seinem Wesen nach rationalen oder doch nach Rationalität strebenden Zustand bezeichnen und daran messen. Hier fehlt - der Idee nach - die Tradition oder hat doch nur eine bedingte Geltung, weil sie vor der prüfenden Vernunft, der Kritik, sich rechtfertigen muß. Die Individuen stehen gleichberechtigt und mit gleichen Ansprüchen nebeneinander. Jeder kann den anderen belehren - wie wirklich und immer auch ein Kind einem Erwachsenen, auch seinem Vater, eine Neuigkeit, die es gehört, mitteilen, eine Begebenheit, die es erlebt, erzählen, ja auch eine Meinung äußern kann, die des Älteren und Überlegenen Meinung berichtigt. Auch die Mitteilung von Meinungen, die zur Annahme solcher Meinungen überreden will, wendet sich an das eigene Urteil des Angeredeten oder 
Lesers. Sie gibt dafür Gründe, die ihm einleuchten sollen, aber die er auch prüfen und verwerfen kann, sie versucht seine Gefühle und sein Denken zugunsten solcher Gründe zu stimmen. Autorität "von oben herab» wird hier der Natur der Sache nach nicht in Anspruch genommen, man bewegt sich in einer Ebene, der Ebene des Tausches und des gesellschaftlichen Verkehrs. Dazu neigt die schriftliche, vollends gedruckte Mitteilung und Belehrung an sich schon mehr als die mündliche; diese ist die ursprüngliche, natürliche, immer von neuem notwendige Form der Erziehung und des Unterrichts, sie bleibt auf eine bestimmte und begrenzte Zuhörerschaft wesentlich gerichtet. - Freilich kann sie mit dieser sich auf den FuB der Gleichheit stellen, ja, der Volksredner kann zum "Volke« als zu einem höheren von ihm verehrten Wesen sprechen; und doch behält er für die Menge, wenn er nur sagt, was sie hören mag, etwas vom Ansehen des Propheten. - Das Buch hingegen, überhaupt die "gedruckte Kolumne" - nach GOETHEs Ausdruck - wendet sich an die unbekannte, unbestimmte Menge; der Schriftsteller versucht wohl, indem er den »lieben Leser" anredet, oder an Lectorem bencvolum sich wendet - neuerdings ist es außer Übung gekommen - zu diesem Jemand ein näheres Verhältnis zu gewinnen, ein Verhältnis, das von Seite des Lesers Vertrauen, Achtung und Ehrfurcht oder wenigstens Bewunderung und Dankbarkeit, ja Entzücken darbietet, wenn es sich um ein "liebes" oder »schönes" oder gar heiliges Buch handelt, also um ein religiöses oder moralisches Erbauungsbuch oder ein dichterisches Kunstwerk. Ähnlich kann aber auch ein wissenschaftliches, insbesondere ein philosophisches Werk empfunden werden. Solchen Büchern wohnt immer eine gewisse Erhabenheit bei. Je niedriger die Seele des Lesers, desto eher läßt sie auch von einem gemeinen Buch, einem spannenden Roman sich imponieren und nimmt wohl gar die darin ausgesprochenen Ansichten als Offenbarungen, die aus der Höhe kommen, an. Wie nun aber, wenn wirklich geglaubt wird, da $B$ in der "Schrift" eine Offenbarung vorliegt, $\mathrm{da} B$ es eine heilige Schrift sei, verfaßt vom Propheten des einigen Gottes, oder eingegeben und dem Schreiber diktiert vom "heiligen Geist»? Hier erscheint das »Buch der Bücher" mit einer Würde bekleidet, die ihm selber einen göttlichen Charakter verleiht und es zum Symbol und Bindemittel der religiösen Gemeinschaft macht. So wird die "Bibel" als das unvergängliche Wort Gottes gedacht und nur durch Zusammenhang mit ihr, durch Beziehungen darauf, als Bestätigungen oder Vorauskündungen ihrer Wahrheit, als dichterische oder rednerische Verherrlichungen ihrer Gegenstände, vielleicht auch als Folien, um ihren Glanz desto heller leuchten zu machen, 
können andere Schriftwerke Wert gewinnen; hingegen werden Bücher entgegengerichteter Art als verderblich gebrandmarkt und verboten. Åhnliches wiederholt sich in der politischen Sphäre, wo die Regierungen und rechtgläubigen Denkweisen durch anerkannte Bücher ihr Ansehen behaupten und befestigen, und die ihnen feindlichen Gesinnungen auch in den Büchern, die solche ausprägen, verfolgen.

Immer behält das Buch etwas Intimes und bekleidet sich leicht zumal das »dicke Buch" - mit einer gewissen Erhabenheit, es scheint von oben herab zu seinem Leser zu sprechen; um so eher, je mehr es durch Alter geheiligt ist und als »unsterbliches Werk" seine Würde behauptet.

Auf eine glatte Fläche - ein gleiches "Niveau" - mit dem Leser stellt sich hingegen die Zeitung, deren Wesen wir hier in einem neuen Lichte betrachten. Sie geht durchaus in die Breite, will von der großen 》Öffentlichkeit « aufgenommen werden und in dieser wirken, nicht auf Grund persönlichen Ansehens oder anerkannter Würde, sondern als Sache, die von Unbekannten zu Unbekannten spricht und am sichersten Eindruck macht durch ihre regelmäßige Erneuerung, die das jedesmalige einzelne "Blatt" rasch veralten, bald vergessen werden läßt: am reinsten wirkt in diesem Sinne die A nony mität der Verfasser, die zur Folge hat, daß gar nicht ein gewisser Mensch, sondern eben 》die Zeitung z $z$ schreiben und geschrieben $z \mathfrak{u}$ haben scheint, wodurch das augenblickliche Ansehen zwar gesteigert wird, aber als rein sachliches; die Personen der wirklichen Schriftsteller sind zumeist gleichgültig und bleiben im Schatten. Seine eigene Meinung und die seiner Genossen in Bekenntnis, Interessen, Partei will der normale Zeitungsleser in "seiner" Zeitung ausgesprochen, verdeutlicht, bestätigt finden; um wiederum sich in seiner Meinung bestärken und ermutigen zu lassen.

I4. (Staatsnachrichten.) Die ursprüngliche Bedeutung, von der auch die "Zeitung" wie das "Nerespaper《 ihren Namen haben, ist durch die Veröffentlichung von Nachrichten gegeben; neue Nachrichten, die neuesten Nachrichten, lassen auch jetzt noch am begierigsten nach der Zeitung greifen; wenngleich es außerdem andere Weisen gibt, solche Nachrichten bekannt zu geben. Welche Nachrichten werden mit Spannung erwartet, mit Eifer aufgenommen? Nachrichten mannigfacher Art, aber zwei Gattungen stechen als weitaus die bedeutendsten hervor: I. Politische Nachrichten; 2. Handelsnachrichten. - Politische Nachrichten beziehen sich im schärfsten, am meisten aufregenden Falle auf Krieg oder Frieden, Gefahren oder günstige Aussichten in den Beziehungen des eigenen Staates zu anderen Staaten; oder aber auf innere Unruhen, Aufstände, Bürger- 
kriege - demnächst aber auch auf andere folgenreiche Erreignisse, wie Wahlkämpfe, Wahlentscheidungen, Verfassungskämpfe und Gesetzgebungen, die das Wohl und Wehe der Familien und Individuen auf Jahrzehnte hin bestimmen. Im Kriege handelt es sich um Niederlagen oder Siege, Gründe für Befürchtungen oder Gründe für Hoffnungen, Wahrscheinlichkeit des Fortganges oder Wahrscheinlichkeit des Friedens; im Frieden, außer um die Gefahren der Friedensstörungen, die fast fortwährend die Aufmerksamkeit in Anspruch nehmen, um andere Verhältnisse zwischen den Staaten und ihren Untertanen, namentlich die mannigfachen Verhältnisse des Verkehrs, also auch des Handels, die zu Zwisten und "Handelskriegen", zu Verhandlungen, zu Verträgen führen. Ferner aber treten die in ne re $n$ Angelegenheiten im Frieden mehr als im Kriege in den Vordergrund; die Nachrichten darüber beziehen sich in erster Linie auf Fragen des Rechtes, also der Gesetzgebung: Neuerungen, die erstrebt oder verabscheut werden; deren Wahrscheinlichkeit und vermutete - erhoffte oder gefürchtete - Wirkungen; daher der Ausfall der politischen Wahlen, insbesondere derjenigen für die größten und wichtigsten gesetzgebenden Körper, während der »Wahlbewegung " die Mutmaßungen - Hoffnungen und Befürchtungen -, als vollendete Tatsache dann die Neugier und das Bedürfnis zu wissen aufregt. Wird die Regierung siegen? wird sie gestürzt werden? Droht eine Umwälzung? Wohl gar Rebellion und Bürgerkrieg? Ist der Besitz in Gefahr? Haben die Armen Grund, Verbesserungen ihrer Lage zu erwarten? Furcht und Hoffnung sind gespannt, Aufregungen verbreiten sich mit den Nachrichten in die Weite. Aufmerksamkeit, zuweilen Aufsehen, erregen die öffentlich gehaltenen oder doch für öffentliche Mitteilung bestimmten Reden und Ansprachen der Staatsmänner und Parteiführer, innerhalb und außerhalb der gesetzgebenden Körperschaften.

15. (Handelsnachrichten.) Handelsnachrichten sind Nachrichten über den Stand der Märkte und also über die Aussichten des Geschäftes; alles dreht sich hier um die geforderten, gebotenen und wirklich gezahlten Preise von Waren aller Art, von Geld und Geldzeichen, Schuldtiteln und Besitztiteln, also „Wertpapieren" mannigfacher Art, deren Handel sich an gewissen Hauptplätzen in besonderen Räumen versammelt, in der "Effektenbörse», die wegen ihrer Weltbedeutung auch als Börse schlechthin verstanden wird. An diese Markt- und Börsenberichte knüpft sich keine bloße Neugier, selten auch eine rein geistige Teilnahme, sondern wesentlich das höchst materielle Interesse des Gewinnens oder Verlierens, und der Beweggrund des Handelns - Kaufens oder Verkaufens - wird daraus 
entnommen. Dies Interesse hebt und verschärft aber die Teilnahme an politischen Angelegenheiten; denn diese wirken fortwährend auf die Märkte, verbessern oder verschlechtern die Aussichten der Geschäfte; wie auch Naturereignisse - Wetter und Unwetter - wegen ihrer Wichtigkeit für den Ausfall von Ernten und wegen anderer Wirkungen auf die Bewegung der Preise beobachtet werden. So erfüllen sich wenigstens die großen Zeitungen - die das Wesen der Zeitung allein zum Ausdruck bringen - in ihrem "Handelsteil " mit Erörterungen dieser Art; es entstehen aber auch besondere Handels- und Börsenzeitungen, die sich ausschließlich diesen $Z$ wecken widmen, und in der Regel besonderen kommerziellen Interessen dienstbar gemacht werden.

r6. (Das Bedürfnis der Nachrichten.) Wer bedarf der Nachrichten, wer ist ihr Abnehmer? Für Staatsnachrichten offenbar am unmittelbarsten der Staatsmann, für Handelsnachrichten am unmittelbarsten der Kaufmann. Jeder von beiden ist Geschäftsmann, ihre Geschäfte haben miteinander gemein, daß sie Schaden vermeiden, Vorteil suchen wollen, und zwar wirken beide, wo ihre entwickelten Gestalten gegeben sind, als Vorsteher einer Sache, mit der ihr persönliches Wohl und Wehe, ihr Nutzen und ihre Ehre, eng verknüpft ist: der Staatsmann für seinen Staat, der Kaufmann für seine Firma, jener mehr auf Ehre, dieser mehr auf Nutzen hingewiesen. Aber ihre Geschäfte und Sorgen berühren einander vielfach; die finanziellen Bedürfnisse und Nöte des Staates müssen oft im Vordergrunde des staatsmännischen Denkens stehen, zumal, wenn es um auswärtige Angelegenheiten, um Machtfragen, also namentlich um die große Betätigung der Macht im Kriege sich handelt. Der Staat braucht seine Bank, um Geld zu erhalten, Geld zu machen; der Staatsmann braucht also die Verbindung mit der "hohen Finanz", d.h. mit Kaufleuten, die über ungeheure Mittel verfügen, sei es, $\mathrm{da} B$ sie diese selber flüssig haben oder in der Lage sind, sie zusammenzuziehen und in sich aufzusaugen. Ehemals - und noch heute in orientalischen Staatsverbänden wurden auch die Steuern durch Finanzmänner erhoben, die das Recht dazu durch regelmäßige Zahlung fester Summen von den Regierungen erworben ("gepachtet«) hatten. - Umgekehrt sind für den Kaufmann die Angelegenheiten des Staates unendlich wichtig, und nicht nur, wenn er mit dem Staate Geschäfte machen kann und will, Geldgeschäfte oder andere, unter denen die Lieferungsgeschäfte für kriegerische Bedürfnisse schon im Frieden, und um so mehr im Kriege, hervorragende gewinnreiche Bedeutung haben; nicht nur der eigene, sondern in Friedenszeiten sogar feindlich gesinnte Staaten sind für Stoffe und Geräte zu Angriff und Abwehr erwünschte Abnehmer 
und (in der Regel) gute Zahler. Auch für viele andere Waren, und zwar gerade für solche, die hohe Werte enthalten, ist die Handelspolitik, die Verkehrs- und demnächst die gesamte Wirtschaftspolitik des eigenen Staates und fremder Staaten von höchster Bedeutung; also für den Kaufmann, der durch ihren Absatz, und vielleicht mehr noch für den, der durch ihre Herstellung Gewinne zu erzielen beflissen ist.

I7. (Verbreitung.) Schon ehe es Zeitungen gab, waren der Staatsmann und der Kaufmann auf Nachrichten angewiesen, die sie durch Boten oder (öfter) durch Briefe empfingen: private und nicht selten geheime Nachrichten. Auch hat diese Art des Nachrichtenwesens ihre Notwendigkeit und Bedeutung nicht verloren. Neben den privaten Nachrichten und sie fast überwuchernd, ist das öffentliche Nachrichtenwesen gediehen; nachdem, wenigstens innerhalb der gesellschaftlichen Oberschicht, sozusagen jederman ein (dilettierender) Staatsmann, und nicht minder jederman ein (dilettierender) Kaufmann geworden ist, dient die Zeitung nicht nur zur Ergänzung privater Staats- und Handelsnachrichten, sondern vorzugsweise zur Verbreitung derjenigen, die für die Offentlichkeit bestimmt sind oder sich gewollter Verheimlichung entziehen. Sie dient ferner zur Bekanntmachung von allen Nachrichten, an deren Verbreitung Behörden oder einzelnen Personen gelegen ist; insbesondere wird sie für den Handel selber, zumal den Kleinhandel und Gelegenheitsverkäufe, wie auch für den Austausch von Nutzungen und Diensten, Organ der Vermittlung der Nachfrage und besonders des Angebots; ein gedruckter Marktplatz. - SombarT (Der moderne Kapitalismus ${ }^{2}$ II, I, S. 362) unterscheidet individuelle und kollektive Nachrichtenübermittlung, er könnte auch jene die private, diese die öffentliche nennen, wie er wirklich den Ausdruck "Nachrichtenpublikation" anwendet. Ganz verschieden davon ist (auch in SombarTs Darstellung) der öffentliche Dienst, den die Post ngleichsam als Kollektivbote für die Gesamtheit " der privaten Nachrichtenübermittlung leistet. Sie widmet sich aber nicht minder der öffentlichen Nachrichtenübermittlung und auch die private betrifft vorzugsweise, sofern die Briefe Schreibenden "öffentliche Personen", also Fürsten und andere Staatsmänner sind, "öffentliche Angelegenheiten". Man bemerkt, wie hier die verschiedenen Sinne des Wortes "öffentlich" aufeinander stoßen: gerade öffentliche Angelegenheiten und sie betreffende Nachrichten sind oft sehr "privat", d. h. geheim und vertraulich.

18. (Fälschung.) Nur ein Teil der Nachrichten, insbesondere der politischen, besteht aus wahren und richtigen Nachrichten. Sie werden gefälscht durch Irrtümer, Mißverständnisse, Nachlässigkeiten, aber auch, und zwar in hohem Maße, durch Absichten. Die Täuschung 
durch L üge ist hier, wie sonst im Verkehre der Menschen, ein Mittel für mannigfache $Z$ wecke. Am stärksten und deutlichsten treten diese im Kriege hervor. Hier ist ins Ungeheure und Gewaltsame gesteigert, was sonst in jedem Parteikampfe auch beobachtet wird. Es gilt: r. Die Feinde als Bösewichte darzustellen, sowohl den Kampfgenossen als den - neutralen - Zuschauern, ebenso hingegen die eigenen Handlungssweisen, Grundsätze, Ideen in hellem Lichte strahlen zu lassen. Der Feind - so verkündete die englische und französische Presse I9I4/I8 und verkündet es noch heute (I9I9/2I) immer von neuem hat den Krieg angezettelt, um zu erobern, um die Weltherrschaft zu gewinnen usw. „Wir kämpfen für die Freiheit, die Zivilisation, die Humanität, für die Rechte der kleinen Nationen." Um dies wahrscheinlicher zu machen als es für den, der etwas von geschichtlichen Tatsachen weiß, sein kann, werden Nachrichten gefärbt und auch geradeswegs erfunden. In späterem Zusammenhange wird dies näher erörtert werden. Es gilt ferner 2. die eigene Lage als möglichst günstig, die des Feindes als möglichst schlimm erscheinen zu lassen. Dafür sind Siegesnachrichten das einfachste, aber nicht das einzige Mittel. Der Feind ist dem Bankerott und der Hungersnot verfallen, Unruhen und Revolten finden statt, sein Herrscher oder der Thronfolger ist dem Tode nahe, oder hat Selbstmord begangen usw. Der Feind bittet, wenn auch noch nicht mit ausdrücklichen Worten, um Frieden. Bei »uns" herrscht ungebrochene Kriegslust und Siegeszuversicht. Wenn der Feind, obgleich siegreich, seine Geneigtheit kund gibt, in Friedensverhandlungen einzutreten, um den Kriegsgreueln ein Ende zu machen, so läßt sich vielleicht nicht glaubwürdig machen, daß es aus Schwäche geschehe; dann ist es unaufrichtig, eine böse List, eine Falle, in die hineinzuschlïpfen der Kluge sich hütet; zumal wenn er noch hofft und in Aussicht stellt, den Feind gänzlich zu vernichten.

Fälschung und Lüge haben auch ihre sehr bedeutenden Wirkungen im Gebicte der Handelsnachrichten. Politische Nachrichten werden zu Handelsnachrichten verwandt, um im Sinne des Käufers oder Verkäufers zu wirken. Man will verkaufen: so wünscht man Höhe der Preise (Hausse). Man will kaufen: so wünscht man Tiefe der Preise (Baisse). Auf beides kann mit Kunst und Künsten hingearbeitet werden. Es muß Stimmung gemacht werden. Genügen dazu wahre Nachrichten, gut; genügen sie nicht, so werden Gerüchte für Wahrheiten ausgegeben, unbedeutende Tatsachen durch Übertreibung in gewaltige verwandelt, oder endlich erschütternde Begebenheiten einfach erfunden. Als Börsenmanöver sind solche Nachrichten verrufen; sie werden aber zumeist auf anderen Wegen als durch Zei- 
tungen bekannt gemacht; längst durch private oder durch den Druck (gleich Zeitungen) verbreitete telegraphische Depeschen, neuerdings durch Fernsprecher, oder (innerhalb einer Börsenversammlung) auf dem veralteten Wege mündlicher Rede.

19. (Nachrichten und Meinungen.) Durch Nachrichten, wahre und unwahre, bilden sich Meinungen, richten sich danach, werden danach verändert. Wer aber die Meinung für sich hat, hat einen Bundesgenossen im Streite für seine Angelegenheiten; und wenn er schon Kampfgenossen hat, so ist deren Meinung in vielen Hinsichten für ihn wichtig: ihre Meinung von seiner Stärke und Tüchtigkeit, von den Leistungen des Gegners oder Konkurrenten, von ihren eigenen Aussichten auf Vorteil und Gewinn. Dies gilt für alle Arten des Kampfes und ist insonderheit wichtig für die Erkenntnis der politischen Parteikämpfe, die zum großen Teile mit Worten, gesprochenen und geschriebenen, also gedruckten, geführt werden. Auch für sie sind die Nachrichten, ist die Benutzung und oft die Entstellung der Nachrichten, von entscheidendem Werte. Die schiere Erfindung ist das einfachste, leichteste, aber auch das gefährlichste und auch sonst wohl in inneren Kämpfen mit einigem Widerstreben angewandte Mittel, um einen Gegner bloßzustellen und ihn mit Flecken behaftet erscheinen zu lassen, die allen mißfallen.

20. (Erörterung.) Aber hier, wie sonst in Kriegen, stellt sich die Aufgabe, unmittelbarer auf die Meinungen zu wirken, nämlich durch Meinungen selber: Rede und Schrift werden dazu bentitzt. Zu Büchern, Flugschriften, Bildern kommt als Mittel, das durch unablässige Wiederholung am wirksamsten wird, die Zeitung; in der Zeitung der Leitartikel. Den Nachrichten schließt die Erörterung sich an. Darin erfüllt sich die große Entwicklung der Zeitungen, da $B$ sie mehr und mehr außer Nachrichten Erörterungen bringen. Diese erst verleihen der Zeitung eine deutlich wahrnehmbare Farbe, denn daß die Nachrichten selber gefärbt sind, verfehlt seinen Zweck, wenn es leicht erkennbar ist. Nun erst wird sie eine "Tribüne» (und nimmt zuweilen diesen Namen an), indem sie zu der Menge ihrer Leser spricht, um auf sie Einfluß zu gewinnen, ihre Meinungen zu ernähren oder zu bekehren. Dies ist auch vorher durch Schauspiele, öffentliche Reden und Predigten, Bücher, Bilder, Flugschriften geschehen. Dringender, erregender, leichter und sicherer wirkt die Zeitung. Die Parteien, vornehmlich die politischen Parteien, bemächtigen sich ihrer. Die Regierungen wehren sich gegen die Kritik, die ihnen in Zeitungsartikeln entgegengetragen wird, teils durch Verbote, Zensur, amtliche Berichtigungen, teils durch Zeitungen, die sie selber in ihre Dienste nelimen oder begründen, oder erkaufen. Parteien 
kämpfen teils gegen die Regierung, die vielleicht mit der (oder einer) Gegenpartei sich deckt, teils allgemein gegen die anderen Parteien, durch die der Partei gehörigen oder doch sie unterstützenden Zeitungen.

Die Meinungen gewinnen einen erweiterten Absatz, einen größeren Markt. Sie stehen in der Offentlichkeit und gehen in der Offentlichkeit um.

\section{Dritter Abschnitt. Öfentliches Leben und Parteiung.}

2I. (Öffentlichkeit.) Die Öffentlichkeit ist ihrem allgemeinen Charakter nach mit jedem entwickelten politischen Leben verbunden. Daher zuerst in ausgeprägter Weise mit dem Leben der Städte. Sie hat ihren natürlichen Ort, wie der Austausch von Waren und Geld, auf der Straße (»in publico«), namentlich auf dem Marktplatze, sei es unter freiem Himmel, oder in geschlossenen Räımen, die für jeden zugänglich sind (Verkaufslauben, Markthallen, Bazare). Dennoch hat weder die antike Polis mit ihrer glanzvollen Kultur, noch hat die mittelalterliche Stadt, die ebenso an Kunstleben und an Kämpfen um die Macht in der Gemeinde reich war, Zeitungen gekannt. Sind ja auch ohne Buchdruckerkunst die Blütezeiten dieser Kulturen verlaufen, überhaupt, ohne $\mathrm{da} a$ die eigentlichen mechanischen Künste und die Wissenschaften, zumal die technologischen, jene erstaunlichen Fortschritte gemacht hätten, deren die neueren Jahrhunderte sich rühmen. Wenn es für die Funktion der Zeitung, Nachrichten $\mathrm{zu}$ vermitteln, andere Mittel und Wege gab, um wenigstens denen, die wichtige Geschäfte führten, solche Nachrichten zukommen zu lassen, so blieb hingegen der Austausch und Streit der Mein unge n vorzugsweise auf die Rednertribüne, die Kanzel und das Katheder angewiesen, neben welchen allerdings die eigentliche Literatur frühzeitig, zumal in den antiken Städten, sich erhob. Dazu kam im Mittelalter die Disputation (auf dem Katheder) und die Aufstellung von Thesen, die man öffentlich anschlug als Herausforderung, sie zu bestreiten, und Eirbieten, sie zu verteidigen. Wie solche Thesen an der Schwelle der Neuzeit, von einer kleinen Universitätsstadt aus, die damalige deutsche Welt und die gelehrte Welt auch jenseits ihrer Grenzen erschütterten, ist so merkwürdig wie bekannt; im Jahre rgI 7 hat sich ein Zeitalter dessen erinnert, das wiederum bis in seine Grundfesten erbebte.

22. (Öffentlichkeit im Mittelalter.) Ess gab eben für eine Gattung von Fragen und Erörterungen schon eine Öfentlichkeit, ein urteilendes Publikum: nämlich für die religiösen Fragen, die theologischen Erörterungen. Christliche Lehre und christlicher Glaube, waren das 
Erbteil der aufgelösten alten Kultur, und die Stadt Rom war der Mittelpunkt geblieben für den Erdkreis, soweit als das Ansehen des römischen Bischofs seinen Glanz verbreitete. Welt- und Klostergeistliche waren durch die römische Sprache verbunden und nahmen durch sie am Schatze heidnischen Wissens wie christlicher Dogmatik und Philosophie teil. Sie konnten sich untereinander und mit ihren Schülern unterreden, konnten also auch Meinungen geltend machen und vertreten, konnten miteinander streiten. Durch Reisen hatten sie Kunde voneinander und kamen zusammen, Briefe wurden befördert, Bücher abgeschrieben. Durch steigenden Handelsverkehr zu Wasser und zu Lande, wie durch Feldzüge und Fehden, wurden die Zusammenkünfte auch gelehrter Männer begünstigt. Beide Elemente hatten nie gefehlt; das "Mittelalter" ist eben nicht bloß Anfang und Entwicklung aus Ursprüngen, sondern zugleich Fortsetzung eines gesellschaftlich entwickelteren Zeitalters und starken öffentlichen Lebens: des weströmischen Reiches. Städte spielten von Anbeginn eine Rolle, wenigstens bis zu den Rändern des alten Reiches: und bis in die entlegensten Gegenden, in die Wildnis der Gebirge und in die Dickichte der Wälder trugen Klöster etwelche Bruchstücke und Denkmäler städtischer Künste und städtischer Bildung, die im sonnigen Hellas ihre Heimat hatten und in Rom gepflegt, aber auch verblüht und verkümmert waren.

23. (Theologie.) Das "Gezänk" der Theologen und theologischen Schulen oder Parteien stand durch viele Jahrhunderte - ïber das Mittelalter hinausreichend - im Brennpunkte des öffentlichen Interesses; naturgemä $B$, da dessen Träger fast ausschließlich Geistliche waren (nur die Fürsten und ihre Höfe nahmen zunächst, allmählich dann auch weitere Kreise des Adels und wohlhabenden Bürgertums, daran Anteil). Sie - die Theologen - stellten ein internationales gelehrtes Publikum dar.

Dieses hat sich teils erhalten - noch lebt die römische Kirche mit ihren Orden -, teils sich verdichtet und nationalisiert: auch für die geistliche Gelehrsamkeit sind die nationalen Sprachen in den Vordergrund getreten; ganz besonders aber hat es durch Spaltungen gelitten und die verschiedenen Bekenntuisse sprechen ihre eigene Sprache, haben je im eigenen Schoße zwar ihre Streitigkeiten, polemisieren aber verhältnismäßig wenig mehr gegeneinander. Das Publikum der einen ist gleichgültig gegen das Publikum der anderen.

24. (Die Fakultäten.) Die Universitäten und ihre Städte waren naturgemä $B$ die Schauplätze der theologischen Disputationen und literarischen Fehden. Starke innere Beziehungen zur Theologie hatte die Jurisprudenz: zumal das eine der "beiden Rechte", das geist- 
liche oder kanonische Recht, war ein bewaffneter Arm für sie. Die Fakultät der Rechtsgelehrten entwickelte ihre Dogmatik und ihre Kontroversen, gleich der theologischen. Die medizinische Fakultät hingegen, und vollends die jüngste, die Facultas Artium, hatten von vornherein einen lebhafteren Trieb zur Erforschung der Wahrheit wirklicher Tatsachen und Vorgänge. Ihre Streitfragen konnten weniger, oder gar nicht, durch Dialektik ausgemacht werden: man glaubte (und glaubt zumeist noch heute, irrigerweise) der starken und scharfen Begriffsbildung entraten zu können, wenn man nur beschreibt, was man beobachtet hat. Diese Wissenschaften rufen in erster Linie die Sinne als Zeugen auf und den auf Grund der Wahrnehmung urteilenden Verstand, anstatt übersinnlicher Offenbarung und vernünftelnder Unterscheidung der Begriffe von unwirklichen Dingen. So hängen sie auch mehr mit Entwicklung der jüngeren Städte, größeren Städte, Handelsstädte und Hauptstädte zusammen, wenigstens, wenn diese den Wert der wissenschaftlichen Erkenntnis ahnten und ihr eine Stätte boten, wie es mehr und mehr, teils durch reiche Handelsherren, teils durch Fürsten und ihre Höfe geschah. Der Handel und der Krieg bieten sich der Rationalisier ung wie von selber dar; beide verlangen Rechnung und Berechnung; mit ihnen das ganze ihnen dienende Verkehrswesen, besonders die Schiffahrt.

Wenn nun schon hinter theologischen Meinungsverschiedenheiten, obgleich oft nur mit Mühe, auseinandergehende soziale Schichten und ihre praktischen Bestrebungen sich erkennen lassen, so ist das viel eher und deutlicher bei den Streitigkeiten innerhalb der Juristenfakultät der Fall, zumal wenn sie sich auf die Gefilde des öffentlichen Rechtes begeben. Rein wissenschaftliche Streitigkeiten sind eher unter den zwei anderen, ihrer ganzen Richtung nach unmittelbarer wissenschaftlichen Fakultäten, zu erwarten. Aber auch in diese spielt mächtig der Gegensatz der Weitanschauungen hinein, die wieder mit Religion und Politik, daher auch mit dem allgemeinen sozialen Leben und seiner ökonomischen Innenseite, mannigfache und starke $\mathrm{Zu}$ sammenhänge darbieten. Vor allem wichtig ist in dieser Hinsicht der Kampf zwischen Theologie auf der einen Seite, den Naturwissenschaften, später auch den Geisteswissenschaften auf der anderen. Dort das überlieferte Landleben, die alte Zeit, die alten sozialen Schichten und Mächte; hier die neu emporkommende städtische, zumal neu- und großstädtische Menschheit mit ihrer aufgeklärten Denkungsart. Ähnlich, wenn auch schwächer, zeigen denselben Charakter und bieten dasselbe Interesse, Streitigkeiten zwischen Glauben und Glauben, zwischen Wissenschaft und Wissenschaft. 
Allerdings bleiben viele gelehrte Kontroversen, denen ein solches Interesse nicht beiwohnt; eben darum können sie auch keine öffe ntliche Teilnahme an sich ziehen und fesseln. Sie haben kein eigentliches Publikum, das mit Spannung dem Kampfe folgt, dem Sieger oder dem Liebling Beifall klatscht, den Gegner, zumal wenn er unterliegt, verlacht und verspottet. Sie stehen in keinem Verhältnis zum öffentlichen Leben.

25. (Das öffentliche Leben.) Das öffentliche I,eben besteht im Unterschiede vom Privatleben vorzugsweise im Verkehr und gemeinsamen Interesse solcher Personen, die einander persönlich unbekannt sind, aber durch Besitz gemeinsamer Sprache und anderer geistiger Güter, zumeist auch durch materielle Interessen miteinander zusammenhängen und verbunden sind. Daher entfaltet sich das öffentliche Leben mit dem Wachstum der Städte, es hat in der Großstadt seinen gegebenen Ort, wo nicht mehr der Marktplatz die Menschen oder wenigstens die Männer zu kommerziellen und politischen Geschäften einheitlich versammelt, sondern mannigfache Zusammenkünfte $\mathrm{zu}$ vieletlei $Z$ wecken, wenn auch gleichfalls vorzugsweise $z u$ kommerziellen und politischen, an verschiedenen Stellen, aber zumeist im Zentrum der Großstadt, stattfinden, und wo sodann der schriftliche Verkehr, neuerdings teilweise ersetzt durch fernsprecherischen, zum großen Teile an Stelle des persönlichen und unmittelbar mündlichen tritt.

Wie aber der Marktplatz zur Stadt, wie das Zentrum einer Großstadt (die City) zu ihrer Peripherie, so verhält sich die Großstadt als ganze zu einem Lande, zu ihrer Umgebung, zur Provinz: die große Handelsstadt vorwiegend in wirtschaftlicher, die große Hauptstadt vorwiegend in politischen Belangen, die "Weltstadt « in beiden zur Menschheit in unbestimmten Grenzen. Die Zentralisation gestaltet sich mithin um so vollkommener, wenn beide in einer Großstadt vereinigt sind, wie es cinerseits dadurch geschieht, daß eine große Handelsstadt zur Hauptstadt wird, andererseits, daß die Hauptstadt immer mehr auch das Geschäft an sich zieht und an sich fesselt; da $B$ endlich die Weltstadt beide in sich vereinigt.

Wesentlich bedingt aber ist die Verdichtung des mannigfachen Privatlebens in einem I,ande zu seinem öfentlichen I,eben durch Etleichterung und Steigerung des Verkehrs. Das Zusammenkommen der Personen, also die Versammlung zil politischen und kommerziellen Zwecken, wird dadurch begünstigt und vermehrt; bald gibt es auch Versammlungen zum Austausch der Mcinungen und - was mehr bedeutet - zum Verkünden und Geltendmachen gemeinsamer Meinungen und Entschlüsse: zum "Demonstrieren" einer Stimmung, 
besonders der Unzufriedenheit. Und alles das in Verbindung mit dem Transport von Sachen, also auch von Büchern und Schriften, von Briefen und Depeschen. Auf diesen Wegen werden auch die Meinungen mitgeteilt, gesprochene, geschriebene, gedruckte, telegraphierte. Eine planmäßige Propaganda dafür wird, wenn nicht zuerst möglich, so doch wahrscheinlicher und also häufiger organisiert. Die Agitation geschieht, um Waren »an den Mann« zu bringen, um Meinungen an den Mann zu bringen. Und allen diesen $Z$ wecken dient das Papier - auch in dem besonderen und verkürzten Sinne, den das Wort in der englischen Sprache angenommen hat, als die Zeitung. Sie ist, zum Teil schon durch die Färbung, die sie ihren Nachrichten gibt, durch deren Auswahl und Betonung, vollends aber durch ihre Leitartikel und Betrachtungen, gedruckte und insofern "öffentlich" werdende Meinung, die sich verstärken will dadurch, daß sie andere Meinungen bildet und für sich gewinnt.

26. (Meinung und Selbsterhaltung.) Schon der englische Philosoph THOMAS HoBBES, - er schrieb in einer politisch hocherregten Zeit, die aber kaum die ersten Anfänge des Zeitungwesens kennen lernte (I640-I660), - führt als einen überkommenen Ausspruch den Satz an, daB die Welt durch Meinungen regiert werde (The Elements of Law, P. I, Ch. I2. 6.). Er nennt den Satz in gewissem Sinne richtig, in dem Sinne nämlich, daß Wille den Meinungen folge, wie Handlung dem Willen. Die Meinungen aber, von denen Begehren und Furcht und darum das Wollen abhänge, sind für ihn die Meinungen von Lohn und Strafe, d.i. allgemein die Erwartung von Gutem oder Ublem - wodurch der Mensch von den intelligenten Tieren nicht wesentlich verschieden ist. Der Stolz des Menschen empört sich dagegen, er meint, Herr seiner Handlungen zu sein und als Denkender frei seine $Z$ wecke zu setzen. Das Gute und Böse glaubt er zu erkennen und auf Grund solcher Erkenntnis die Handlung frei zu wählen. Allerdings ist diese Vorstellung ein Schema, an dem wir die wirklichen Vorgänge in der Seele des Wollenden messen mögen. Um diese aber richtig zu verstehen, hat man noch andere Begriffe nötig, vor allem den des Selbsterhaltungstriebes, den SchopenHauEk als "Willen" der Vorstellung und dem Intellekt entgegengesetzt hat, und sogar als allgemeines Weltwesen, als das »Ding an sich" zu behaupten wagte. Richtig ist darin, daß das Verhalten der materiellen Substanz und das Verhalten der Seelen im letzten Grunde den gleichen Gesetzmäßigkeiten unterliegen, die in der Tendenz zu beharren ihren allgemeinsten Ausdruck haben. Diese Tendenz bedingt bei den organischen Wesen die Wehr gegen Vernichtung, das Streben nach Nahrung, die Arbeit der Erneuerung und Zeugung. Die Harmonie dieser drei Betätigungen 
bildet auch den Generalbaß im Leben des Menschen, durch sie bedingt ist das Spiel seiner mannigfachen Gefühle und Leidenschaften, daher sind auch die Anstrengungen seiner Sinne und seines Denkens davon abhängig. Eine philosophische Terminologie, die jene Urgründe "Willen" nennt und den Intellekt als davon wesentlich verschiedenes Organ (oder als »Diener «) solchen Willens darstellt, ist irreführend; es wäre denn, daß sie darauf Verzicht leistete, den Terminus "Wille* auch in dem Sinne zu gebrauchen, der im Sprachgebrauche vorherrscht und nur dem Menschen einen wirklichen Willen zuschreibt. Denn hier ist der Wille ganz und gar an das Denken gebunden, vom Denken erfüllt, sei es, daß er als "Wesenwille« begriffen werde, der das Denken in sich enthält, insofern als er Wille eines Vernunftwesens ist, oder als $₫$ Kürwille«, der nichts als Denken ist, wenn auch Denken, das »den Willen in sich enthält", d. i. auf zu wollende Mittel für erstrebte $Z$ wecke sich bezieht. Wille ist der Grund des Wollens und Wollen ist nicht eine Tätigkeit, sondern der (perfektische) $\mathrm{Zu}$ stand des "beschlossen habens", "sich vorgenommen habens", "entschlossen seins", "gesonnen seins", welchen Zustand unsere Sprache auch durch "gedenken « und - durch »meinen " ausdrückt. Dies Meinen und Gedenken ist durch anderes Meinen und Denken bedingt: jenes (das erstere) gehört dem Gebiete des "Willens" (nicht nur in jenem allgemeinen ScHOPENHAUERschen Sinne, sondern auch in dem besonderen Sinne, da es selber menschliches Wollen ist), dieses dem Gebiete des "Intellektes" an, aber wie die Worte identisch sind, so liegen die beiden Gebiete nicht nur dicht zusammen, sondern sind ineinander verwoben, sind in Wahrheit eine organische Einheit. Der Gedanke und die Meinung, daß etwas "gut« (nützlich, heilsam, ja auch schön und edel) sei, schließen, wenigstens sobald sie aus dem Gefüh1 entspringen - und davon können sie niemals völlig sich losreißen - die Bejahung und Hinneigung in sich ein, eben dadurch aber auch den Keim und Anfang eines "Wollens«, möge solcher Keim und Anfang nun Streben oder Wünschen oder Trieb oder Begehren genannt werden: immer ist dieser Willenskeim (Conat) der Anfang der Tätigkeit selber und zwar einer Bewegung zu dem Dinge hin, also einer Ausdehnung des eigenen und Annäherung an den fremden Körper. Ebenso verhält sich umgekehrt Gedanke und Meinung, da $B$ etwas "schlecht" (schädlich, übel, ja auch häßlich und ekelhaft) sei; sie sind, je mehr sie wahr und stark, um so inniger verbunden mit "Widerwillen«, Abneigung, Scheu, Zusammenziehung und Zurückziehung des eigenen Körpers, Ëntfernung von dem fremden Körper. In Wirklichkeit sind aber die Gefühle und Meinungen regelmäßig gemischt, so daß von mehreren Willenskeimen (Conaten) nur die 
stärksten, indem sie die schwächeren überwinden, in einem Willensakt, d. i. im Anfang und dem Versuch einer Tat, sich vollenden. Der Mensch vergleicht und ïberlegt: er sucht nicht das Gute, vielleicht ist es in unerreichbarer Ferne, sondern das Bessere, vielleicht (und gar oft) das kleinere von mehreren Übeln. Auf der einen Seite steht etwa: möglicher Tod und gewisse Schande - auf der anderen viel wahrscheinlicherer Tod und gewisse Ehre, oder doch Vermeidung der Schande. Wenn er jung ist, kräftig und mutig, so wählt er ohne Zaudern und Schwanken. Darum folgt aber auch nicht aus Einsicht und richtiger Meinung richtiges Wollen und Handeln, wenn der Antrieb dazu nicht stark genug ist. Video meliora proboque, deteriora sequor ,ich sehe den besseren Weg und billige ihn, den schlechteren abet gehe ich". Das will sagen: die Leidenschaft, die Begierde ist zu stark, ist stärker als »ich «, d.i. als meine Vernunft und Besonnenheit ${ }^{1}$ ). Bringen aber Leidenschaft und Begierde auch eine Meinung hervor, die mit ihnen übereinstimmt? Ja, wenigstens den stummen Embryo einer Meinung, den Gedanken etwa, es müsse sein, es müsse ein Ende gemacht werden, oder: er, der Täter, könne nicht mehr leben, ohne seine Rache genommen und genossen zu haben. Dies sogar im Falle eines unmittelbaren Handelns »im Affekt«, ohne Vorbedacht; vollends, wenn die Gelegenheit dazu erwartet, erhofft wird, und die Leidenschaft Zeit hat, sich in das gesamte Denken des von ihr Besessenen hineinzubohren.

27. (Meinungen und Interessen.) Es scheint unhaltbar, $z u$ behaupten, daß alle Meinungen durch Gefühle, Neigungen, Leidenschaften verursacht oder bedingt werden. Werden nicht wissenschaftliche Ansichten, historische Urteile, rein und ausschließlich durch Denken, durch »unbefangene " Prüfung der Tatsachen, richtige oder irrige Schlußfolgerungen bestimmt? Gewiß werden wir diese Idee als die eines vorgestellten möglichen Falles festhalten. Wissen wir doch, daß der echte Forscher und Denker nur von der einen Leidenschaft, dem einen Streben beseelt ist, die Wahrheit zu erkennen, Zusammenhänge und Ursachen der Dinge zu ergründen. Wenn ihm dies gelingt, so werden wir nicht sagen, seine Meinung werde durch seine Neigungen oder Wünsche bestimmt, sondern sie erscheint uns als allein von der Tatsache, vom Gegenstande, von der (»objektiven«) Wirklichkeit abhängig. Gewiß ist auch solche reine Erkenntnis und dadurch gewonnene Ansicht oder Meinung, von der Beschaffenheit, der Kraft und dem "Willen" der Erkenntnisorgane abhängig; wenn aber diese gut und stark sind, so ist der Erkennende "Mensch"

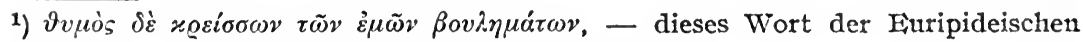
Medea ist das Original jenes lateinischen Spruches. 
schlechthin: seine Erkenntnis trägt den Charakter der Allgemeinheit und Notwendigkeit und also der Wissenschaft, oder wenigstens der Notwendigkeit, und also der (einzelnen und besonderen) Wahrheit. Aber wir wissen auch, daß die erkennenden Subjekte ihre »menschlichen Schwächen" haben. Die Ansichten oder Meinungen sind verschieden. Warum? Zum Teil offenbar wegen verschiedener Beschaffenheit der Erkenntnisorgane und Erkenntnismittel; aber zu einem weitaus größeren Teil infolge von verschiedenen Gefühlen, Gewohnheiten und von Gedanken und Ansichten, die selber wieder in Gefühlen und Gewohnheiten beruhen oder sonst durch die gesamte Lage, die Voraussetzungen und 》Vorurteile« des Subjektes gegebene Faktoren sind. Am leichtesten verständlich ist in dieser Hinsicht, daß die Ansichten über das Gute und Richtige weit voneinander abweichen; denn sie folgen aus den wesentlich verschiedenen Gefühlen der Individuen, nach denen sie zunächst nur eine Meinung hegen und oft genug eine irrige - über das, was ihnen, was einem jeglichen $\mathrm{für}$ sich zuträglich ist; aber es ist eine allgemein menschliche Neigung, eben dies für allgemein nïtzlich und gut $\mathrm{zu}$ erachten oder wenigstens dafür auszugeben. Unterstützt wird diese Neigung durch Wünsche und Anliegen, die eben davon einen Vorteil für den Wünschenden erwarten, da $B$ das für ihn Gute als im allgemeinen gut anerkannt werde; und solches »Interesse« übersetzt sich leicht und rasch in die Meinung, $\mathrm{ja}$ in einen - vielleicht schwärmerischen - Glauben, daß es wirklich schlechthin gut und richtig sei. Aufrichtige Meinung vermischt sich hier wie sonst nit interessierter Kundgebung oder wenigstens einer Hervorhebung und Betonung, höher und schärfer, als mit Aufrichtigkeit sich verträgt. Die wirkliche Meinung selber ist oft, auch wenn ihr Träger dessen nicht bewußt wird, mitbedingt durch Wetteifer und Eitelkeit, das Gefallen an neuen und neuesten, auffallenden und höchst besonderen Meinungen, die eine höhere oder tiefere als die gemeine Einsicht vermuten lassen. - Unterschied und Gegensatz der Meinungen macht sich in jeder Körperschaft geltend, worin gemeinsame Angelegenheiten beraten werden, zumal wenn die Körperschaft als Einheit einen Beschluß fassen soll; ebenso aber in dem größeren Kreise, der etwa als "Wählerschaft« die Zusammensetzung einer solchen Körperschaft mitbestimmen und also mittelbar auf dessen zukünftige Beratungen und Beschliisse einwirken soll und will. Ja, selbst wenn die letzten Entscheidungen nur von einer einzigen natürlichen Person, also in Staatsangelegenheiten von einem unumschränkten Monarchen, abhängen, so können sich die auseinandergehenden Meinungen geltend machen und mit allen verfügbaren Mitteln dahin streben, sein "Ohr»zu erreichen, seinen Willen zu be- 
stimmen. Naturgemäß bilden sich hier die "Parteien« am leichtesten in der räumlichen und in der geistigen $U \mathrm{mgebung}$, also um den Monarchen an seinem Hofe, und unter denen, die seinem Range am nächsten stehen, also im Adel und in der hohen Geistlichkeit.

28. (Parteien.) Übrigens aber sind Entstehung und Gliederung der Parteien und Parteimeinungen immer von dreifacher Art:

A. Die Partei der Herrscher und die Partei der Beherrschten oder die Partei des Regimentes und die Partei der Opposition: ein allgemeiner und notwendiger Gegensatz, insofern als das Regiment immer Menschen und Meinungen an sich fesselt, die unmittelbar oder mittelbar von ihm abhängig sind; als ihm alle diejenigen in der Regel zugetan sind, welche die Ruhe lieben und die Veränderung fürchten; als es oft mit einem Glanze von Heiligkeit und Würde umgeben ist, und daher an Glauben und Ehrfurcht seine Ansprüche machen kann; wenn auch schließlich nur der Machtzauber (das "Prestige«) des "Volkswillens" das ist, was noch diesen Eindruck machen kann, oder endlich die rohe Tatsache der gegenwärtigen Gewalt. Hingegen die Opposition wird sich immer bilden aus denen, die vom Regimente ausgeschlossen sind; zumal wenn sie durch die geltenden oder neu erlassenen Gesetze und Verordnungen sich bedrückt fühlen oder durch die Verwaltung unterdrückt werden; aus denen, die Neuerungen hold sind und selber durch neue Einrichtungen, neue Regierungen gehoben zu werden hoffen; die den Glauben und die Ehrfurcht vor den Regierenden nicht teilen, vielmehr deren menschliche Schwächen, Mängel und Laster, Torheiten und Irrtümer in grelle Beleuchtung zu setzen beflissen sind; die überzeugt sind, oder sich wenigstens den Anschein geben, es zu sein - weil es in ihrem Interesse liegt, die Überzeugung auszubreiten, - daß die Maßnahmen der Regierung dem allgemeinen Wohle nachteilig sind; die den "Volkswillen" für gefälscht halten oder ihn als Einfalt der Menge verspotten und als Minderheit der Tyrannei der Mehrheit sich widersetzen.

Hiermit ist der allgemeine Charakter eines Gegensatzes bezeichnet, der in mannigfachen Gestalten sich wiederholt. Seine große historische Ausprägung findet er in jedem Kampf und Streit zwischen herrschenden und beherrschten Schichten, Ständen oder Klassen; wobei zu gedenken ist, $\mathrm{da} B$ es innerhalb dieser Gegensätze gleichzeitig verschiedene Arten von Regierung, also auch verschiedene Arten von Opposition gibt. Auch wer zur herrschenden Schicht gehört, fühlt sich als Beherrschter, insofern als er vom Regimente ausgeschlossen ist, und er kann, um diesem Opposition zu machen, die Partei der beherrschten Schicht "nehmen", mit dieser "fraternisieren" und sich zu ihrem Führer aufwerfen. 
In der europäischen Geschichte der Neuzeit hat daher dieser Gegensatz seine weiteste Ausdehnung in dem Kampfe zwischen den mittelalterlichen Herrenständen (der Geistlichkeit nebst dem weltlichen Adel), und dem Bürgertum, insofern als dieses sich aus einem lokal bedingten in ein territoriales und nationales (den "dritten Stand «) verwandelt und sammelt; also anstatt einer Vielfachheit der Städte eine Einheit des Staates oder Reiches wird. Diese Bürgerlichkeit kämpft innerhalb der bischöflich regierten römischen Kirche, und innerhalb der ständisch regierten Staaten, gegen Geistlichkeit und Adel. Sie setzt damit den Kampf fort, den die städtischen Bürgerschaften, zum guten Teile siegreich, innerhalb ihrer Städte geführt hatten und weiter führen. Die historisch bedeutsamste Erscheinungsform dieses Kampfes, sofern er gegen die herrschende Geistlichkeit gerichtet war, ist die "Reformation «. In ihr vermischen und verbinden sich aber mit diesem Hauptgegensatze andere von minderer Tragweite: der Gegensatz der weltlichen gegen die geistliche Gewalt, des niederen gegen den hohen Adel, d. i. gegen die Landeshoheiten (in Deutschland); in anderen Ländern des Adels überhaupt, vornehmlich gerade des hohen Adels, gegen die Monarchie, so auch in Deutschland der Fürsten gegen den Kaiser; ebenso der niederen Geistlichkeit gegen die höhere, der niederen Bürgerschaften (der Gemeinde oder Zünfte) gegen die Geschlechter (den Patriziat) der Städte; endlich der armen großen Menge in Stadt und Land gegen die Reichen oder für reich Geltenden, d. i. die Kaufleute und Wucherer in größeren Städten, die Grundherren in ihren Schlössern, die Mönche und Nonnen in Klöstern und Stiften. Diese Bewegung geht durch die Jahrhunderte hindurch, vorzugsweise gegen den von der Kirche geforderten und verkündeten rechten Glauben als abweichende Meinung, "Häresie", gerichtet. Ihren allgemeinen und elementaren Ausdruck hat die Häresie als Leugnung der Heiligkeit der Kirche, Bestreitung der Notwendigkeit und des Wertes der Priesterschaften. In nächstem Zusammenhange damit steht die Anfechtung der "Sakramente als der Wunder- und Gnadenmittel, worüber die Kirche verfügt. Volkstümlich in einem Brennpunkte gesammelt tritt diese Anfechtung auf gegen die Taufe der neugeborenen Kinder, wenn auch - mit wenigen Ausnahmen - das Symbol behalten wird, als Form der Aufnahme in die Gemeinde der wahren Christen, die sich selber Priester sind und die baldige Wiederkunft des Herrn erwarten. Die stäuferische " und schwärmerische Bewegung ist die eigentliche Volksbewegung, lange vor der Reformation gärend, lange nach ihr in mancherlei Gestalten fortlebend. Denn die Reformation bildet neue Kirchen, wenn auch - schon durch ihre Vielheit - minder 
heilige, die auf Allgemeinheit keinen Anspruch machen, sondern als Landeskirchen dem Landesherrn - oder dem städtischen Rat gehorchen. Das neue Kirchenregiment ruft neue Opposition hervor. Diese empfängt ihre historisch bedeutendste Ausprägung in der Geschichte Großbritanniens, teils als Widerstand der mehr laienhaft organisierten presbyterianischen Kirche Schottlands gegen die bischöfliche Kirche von England, teils innerhalb dieser als bürgerliche Gesinnung der Puritaner und von der Kirche sich trennender (independenter) mannigfacher Sekten (der "Revolutionskirchen «). Die "puritanische Rebellion «spielte sich ab in dem Lande, dessen Kirche noch heute sich rïhmt die rechte katholische Kirche, wenn auch mit weltlichem Oberhaupt, geblieben $\mathrm{zu}$ sein. In anderen protestantischen Iändern ist die unmittelbare politische Bedeutung der Kritik, die gegen Kirche und Geistlichkeit gerichtet wird, schwach; sie bedingt einerseits rein kirchliche Parteibildung, andererseits führt sie zum inneren, hie und da auch äußeren Abfall vom kirchlichen Glaubenssystem, also zur Ausbreitung einer wissenschaftlichen und freigeistigen Denkweise. Die große Offensive des dritten Standes gegen Adel und Geistlichkeit erneut sich in welterschütternden Ereignissen durch die französische Staatsumwälzung, die nach schweren Unterbrechungen gerade ihren antikirchlichen Charakter bis an die Wende des 20. Jahrhunderts fortgesetzt und vollendet hat. In beiden großen Revolutionen aber - der englischen und der französischen - vermischt sich die Opposition gegen die beiden herrschenden Stände mit einer ganz anderen: derjenigen gegen das absolute Königtum oder gegen den modernen Staat, den dieses vordeutend darstellt, weil es ihn um seiner selbst willen aus sich entwickeln mußte (,Der Staat, das bin ich", dieser Ausspruch enthält nicht, wie er gewöhnlich verstanden wird, die Leugnung, sondern eher die Anerkennung und Behauptung des Staates). Hier steht das weltliche Regiment auf seinen eigenen Füßen und hat sich auch über die herrschenden Stände erhoben, ja diese Erhebung, also die Bekämpfung der Stände, ist ihm Hauptaufgabe der inneren Politik, denn es ist die Bekämpfung seiner Rivalen. Der Fürst ist daher, soweit als dieser $Z$ weck und dieses Interesse ihn leitet, natürlicher Bundesgenosse des dritten Standes. Ebenso sehr aber bedarf er, um seine Autorität zu befestigen, der ihm sozial viel näherstehenden Schichten, als seiner Stützen; eben darum macht er die Kirche so sehr als möglich zur Hofkirche (auch in Frankreich) und den Adel zum Hofadel; die Schaffung neuen Adels aus den Spitzen des dritten Standes ist eines der Mittel, die beiden Zwecke - Stützung auf die Aristokratie, Verbindung mit der Bürgerklasse - zu vereinen. Immer wird er nur Teile beider auf seiner Seite haben; denn die Masse 
der Untertanen, ob herrschgewohnt (wie der Adel) oder wenigstens bisher selbständig (wie ein städtisches Patriziat und sonst freie Bürgerschaften) wird sich durch Gesetzgebung und Verwaltung, zumal wenn sie nicht einmal scheinbar einen mitbestimmenden Einfluß darauf haben, leicht bedrückt fühlen, insbesondere durch Steuern und durch die Aufhebung oder Beschneidung ihrer herkömmlichen Rechte und Vorrechte (Privilegien). Das absolute Regiment eines Fürsten wird immer hauptsächlich durch seine eigene bewaffnete Macht sich behaupten müssen; wo diese fehlt oder zu gering ist, da wird er - bald gegenüber dem Adel, bald gegenüber dem dritten Stande - unterliegen; vollends wenn beide gegen ihn sich alliieren, wie die Lords und Gemeinen gegen JАКов II. Mit der "glorreichen « Revolution (I688) setzte in England - und bald in Großbritannien eine Oligarchie sich ein, in der die plutokratischen Teile des Adels und der jungen Bourgeoisie - Großhandel und Geldhandel - sich durch gegenseitige Einräumungen zusammenfanden; diese Oligarchie wird auch "Squirearchy "genannt, d.h. Herrschaft der Gutsherren, weil die politische Macht der großen Vermögen, auch der im Handel erworbenen, durch Grundbesitz als Macht über Land und Leute insbesondere über die Wähler - sich befestigt. Ihr gegenüber blieben dann als beherrschtes Volk I. die soziale Schicht dcr Pächter und die der Gewerbetreibenden, welche beide im I8. und vollends im I9. Jahrhundert in ihren Spitzen allmählich zu Reichtum gelangen, so da $B$ wenigstens die Industriellen demgemä $B$ auch politische Macht erobern, - in entscheidender Weise durch die Reformbill I830, aber schon drei Jahre früher auch durch Aufhebung der Test-Acte, die bis dahin alle Ämter, wie auch die parlamentarische Wählbarkeit, den Bekennern zur offiziellen Kirche vorbehalten hatte. Es blieb aber 2. die große Menge, aus der im I9. Jahrhundert die industrielle Arbeiterklasse, der sich die ländliche zögernd anschließt, mit eigenem Bewußtsein und eigenem Willen emportaucht. Nachdem also der Reichtum jeder Gattung Anteil am Regiment gewonnen hat, bleibt als natürliche Opposition der Untertanen nur die des Proletariats. Dieser Gegensatz ist nun gerade in Großbritannien und in allen parlamentarisch regierten Ländern strenge zu unterscheiden von dem Gegensatz zwischen der jeweilig am Ruder befindlichen Regierung und dem jeweilig win der Opposition « befindlichen Flïgel der herrschenden Schichten. In Rußland hat sich, infolge des gänzlichen Zusammenbruchs der bisher herrschenden - wenn auch seit I905 formell nicht mehr allein herrschenden - Monarchie, die Herrschaft einer proletarischen Minderheit aufgeworfen und bisher (I9I/I92I) sich zu behaupten vermocht. Da diesc als Diktatur auftritt, so ist 
eine öffentliche Opposition dagegen nicht möglich; auch die Kritik der Presse wird unterdrückt. In Deutschland war aus ähnlichen Ursachen ein ähnlicher Vorgang im November I9I8 erfolgt, der aber einige Monate später in ein erneutes Verfassungsleben auf breitester republikanisch-demokratischer Grundlage übergegangen ist. Dadurch ist der größte Teil der sozial herrschenden Schichten in die politische Opposition gedrängt worden. Ein ungewöhnlich starker Widerspruch zwischen sozialer Herrschaft und politischem Regiment ist zu Tage getreten. Das Wahre des Gegensatzes zwischen Regiment und Opposition läßt sich an diesem Falle um so reiner beobachten.

29. (Parteien II.) B. Entstehung und Gliederung der Parteien und Parteimeinungen richtet sich ferner nach dem Gegensatz des Erhaltenwollens und des Verändernwollens: die konservative Partei und - so wollen wir sie, um den Gegensatz in logischer Allgemeinheit auszudrücken, nennen - die mutative - bequemer sagen wir: die reformative - Partei; sofern aber die bestehende Ordnung, die eine Partei erhalten will, historisch zumeist sich in Bindungen darstellt, und insofern als die natürliche Richtung des Verändernwollens auf Befreiung von solchen Bindungen geht, so hatte sich die mutative und reformative Partei regelmäßig »freiheitlich «, "freisinnig «, »liberal « genannt. Und, insofern als der Parteienkampf der neuzeitlichen Jahrhunderte sich um Erhaltung oder Zerstörung der sozialen und politischen Ordnungen des Mittelalters bewegt hat und zum Teil noch bewegt, so deckt sich dieser Gegensatz mit dem unter A. erörterten zwischen den alten herrschenden Ständen und dem dritten Stande, oder genauer der aus ihm sich entwickelnden Bourgeoisie, die sich in England die "Mittelklasse " nennt. Indessen ist daraus im I9. Jahrhundert deutlich ein anderer Gegensatz herausgewachsen: derjenige nämlich, bei dem es sich um Erhaltung oder Zerstörung des gesamten Privatrechtes handelt, dessen wesentliche Einrichtungen, insbesondere die des Privateige nt u ms an Boden und Kapital, den alten und den neuen Zuständen, oder, was das Gleiche bedeutet, dem alten und dem neuen Herrentum gemeinsam sind, und folglich von den Vertretern beider emsig verteidigt werden, so daß sie eine verbundene konservative oder "Ordnungspartei « darstellen; wogegen dann die in diesem Sinne mutative Partei zuweilen a uch als \#liberal «weil sie Freiheit und Befreiung ("Emanzipation«) der jenes Privateigentums ermangelnden Klasse von den Fesseln, die es ihr aufgelegt hat, erstrebt - oder aber, und zwar genauer als "radikal " (weil sie das Drückende dieser Fesseln als Reste des sonst überwundenen "Feudalismus « betrachtet, die sie mit der Wurzel vertilgen will) öfter jedoch als "sozialistisch « oder "kommunistisch « (weil sie das 
Programm entfaltet, die Produktionsmittel zum gesellschaftlichen oder gemeinschaftlichen Eigentum zu machen) sich vorstellt. Insofern nun, als auch die Staatsregierung von der gemeinsamen Macht des alten und des neuen Herrentums getragen wird und also den natürlichen Beruf hat, die bestehende Eigentumsordnung aufrechtzuerhalten und zu schützen, so fällt dieser Gegensatz des Errhaltenwollens und des Verändernwollens wiederum mit dem unter A. allgemein behandelten von Herrschern und Beherrschten, Regiment und Opposition zusammen; näher aber im Staate mit demjenigen zwischen der Regierung, auch wenn diese abwechselnd den an der sozialen Herrschaft teilhabenden Parteien zu eigen ist, einerseits, der Untertanenschaft andererseits, insofern als diese hauptsächlich aus der großen Menge besteht, deren Vertreter von der Regierung dauernd ausgeschlossen bleiben, oder doch nicht die bestimmende Macht in ihr werden.

Für die historische Ansicht bleibt aber immer im Vordergrunde die universale Bedeutung des Kampfes zwischen konservativen alten, herkömmlichen, religiösen - und wiberalen « - als neuen, revolutionären, auf wissenschaftliches Denken sich stützenden Ideen; denn es ist der Kampf zwischen den Weltaltern, der Befreiungskampf der Neuzeit gegen das Mittelalter, und also die Entbindung der Neuzeit von ihrem Mutterschoße, die teilweise in schmerzloser, stiller Entwicklung sich vollzieht, aber stärker die Aufmerksamkeit des Beobachters auf sich zwingt durch die geräuschvollen Katastrophen und Krisen, worin die Gegensätze der sozialen Mächte, ihrer Interessen und ihrer Anschauungen aufeinanderplatzen. Hier erscheint durchaus der Kampf der Meinungen als ein Ausdruck des gesamten Lebensprozesses, der, von der Seite der alten Zustände (des Mittelalters) gesehen, wesentlich eine Auflösung und Zersetzung ist, hingegen von diesseits, d. i. von den neuen Zuständen (der Neuzeit) aus, Anfang und Fortschritt der wirklichen Kultur oder ihre Wiedergeburt und Erneuerung bedeutet, wenn auf das Altertum, das hinter der - Barbarei « des "finsteren «Mittelalters liegt, zurückgeschaut wird. Die deutsche Revolution (I9I8/I9) hat nun bewirkt, daß die sozialdemokratische Partei (nachdem Teile von ihr abgesplittert sind) wenn auch nicht die alleinherrschende, so doch zeitweilig die vorherrschende in den Regierungen des Reiches und der Einzelstaaten geworden ist. "Konservativ" und "Ordnungspartei « ist nun, was diese Staatsordnung erhalten will und damit zugleich sich anheischig macht, die Gesellschaftsordnung - wenn auch in besonnenem Fortschritt, allmählich - von Grund aus zu reformieren oder sogar zu revolutionieren. Ob dies Auseinanderklaffen von Staatsordnung 
und Gesellschaftsordnung in längerer Dauer sich zu erhalten vermöge, kann nur die Erfahrung lehren; das objektive Urteil wird es nicht als wahrscheinlich anzuerkennen vermögen.

Der Wille der Ethaltung und der Wille der Veränderung können eben, wie als Bejahung und Verneinung eines gegebenen politischen, so auch eines sozialen Zustandes einander gegenüberstehen. Und dies ist der allgemeine Begriff, worauf der Gegensatz zwischen besitzender, dadurch herrschender Klasse und besitzloser, auch bebeherrschter Klasse, zwischen Oberen und Unteren, Herren und Dienenden, Reichen und Armen, zwischen "Kapital und Arbeit sich bezieht. Auch diese Gegensätze durchziehen die Weltgeschichte, sie haben aber in den neueren Zeitläuften eine wachsende politische Partei-Bedeutung erlangt, die zuweilen als Kampf zwischen OrdnungsPartei (s. oben) und Umsturz-Partei bezeichnet wird, welches aber nur ein anderer Ausdruck ist für den Gegensatz zwischen konservativer und liberaler Parteiung, nur daß bei jenem mehr an Errhaltung und Veränderung des sozialen Zustandes, also des Privatrechts, bei diesem des politischen Zustandes, also des öffentlichen Rechtes gedacht wird.

30. (Parteien III.) C. Entstehung und Gliederung der Parteien und Parteimeinungen muß aber endlich auf den Gegensatz von Rechtgläubigen (Orthodoxen) und Andersgläubigen (Heterodoxen oder Ketzern) bezogen werden, welcher Gegensatz mit den beiden erörterten Gegensätzen sich vielfach berührt, aber doch seinen eigentümlichen Inhalt hat, und besonders auf das ganze Gebiet des geistigen und sittlichen Lebens und die es bestimmenden Denkweisen sich erstreckt. Er findet sich hier überall, wo eine bestimmte Art zu denken und zu urteilen, "Geltung " hat, daher in jedem geistig verbundenen Kreise die Schätzung dieses Kreises und seiner Denkungsart selber, die als Lebensbedingung der Gemeinschaft empfunden wird. Bei weitem die größte historische Bedeutung hat aber in dieser Hinsicht die Gemeinde von Kultgenossen mit ihrem Glauben an übernatürliche Zusammenhänge, an Götter und deren Eigenschaften gewonnen. Der Kampf der Meinungen ist hier um so bedeutender, da es nicht um Erhaltung oder Abschaffung einer Regierung, auch nicht um Erhaltung oder Veränderung von Staatseinrichtungen und Gesetzen, oder gar einer gesamten Gesellschafts-Ordnung, sondern um Erhaltung oder Beseitigung von "Glauben «selber sich handelt, indem solcher Glaube als ein heiliges teures Gut geschätzt wird, als seligmachend, ja alleinseligmachende "Heilswahrheit«, während er von seinen Gegnern als finsterer Irrwahn, törichter Aberglaube, als Hemmnis des Fortschrittes auf der Bahn menschheitlicher Ent- 
wicklung verachtet und gebrandmarkt wird. Wenn wir auch Glaubenssätze als Meinungen begreifen, so ist hier der Wert von Meinungen schlechthin in Frage gestellt. Meinungen, die sich als die richtigen behaupten, wollen auch die heilsamen Meinungen sein. Einen ungeheuren Vorteil haben aber hier die Meinungen, welche eine übernatürliche, "göttliche "Beglaubigung für sich in Anspruch nehmen, eben die als "richtig « verkündeten, als heilsam geweihten Meinungen.Auch in dieser Hinsicht ist die deutsche Revolution, unter der wir jetzt (I920) leben, vorzüglich merkwürdig und "paradox «. Denn sie hat die Ungläubigen, Freidenker, Juden, Dissidenten, Monisten, Konfessionslosen an die Spitze gebracht; ihre politischen und sozialistischen Meinungen hängen zumeist mit dem Bekenntnis zu einer wissenschaftlichen Denkungsart innig zusammen; sie bringen dies Bekenntnis, das längst innerhalb der gebildeten Schichten das herrschende ist, aber eben aus Scheu vor den politisch-sozialen Folgen und Folgerungen mehr oder minder verborgen gehalten wurde, an die Oberfläche und ans Tageslicht. Neue Dogmen fordern Bekenntnis, neue Ketzereien erregen Abscheu oder Hohn.

3r. (Zusammenhänge.) Diese 3 Gegensätze laufen übrigens, wie leicht erkennbar, in der Regel parallel miteinander, ja vermischen sich und fallen zusammen. Da ist die Partei der Regierung auch die Partei der Erhaltung bestehender Zustände, immer wenigstens der Erhaltung dieser Regierung, sehr leicht und oft dann auch dieser Regierungsform und also der bestehenden Verfassung, mithin auch der gesellschaftlichen Zustände, der "Gesellschaftsordnung ", worin sie beruht. Die Partei der Regierung ist ferner auch in manchen Beziehungen die Partei des rechten Glaubens: zunächst schon, weil eben der Glaube an die Regierung, ferner an die Regierungsform und Verfassung, zum richtigen Glauben gehört; sodann aber weil in der Regel der religiöse Glaube auch die bestehende Regierung deckt und sogar weiht. Der Zusammenhang zwischen »konservativer « und rechtgläubiger Denkungsart ist besonders stark und ursprünglich. Wer die bestehenden sozialen und politischen Verhältnisse zu erhalten wünscht, $\mathrm{muB}$ auch den herrschenden Glauben beschützen, sofern und so lange als er diese Verhältnisse heiligt; und die Rechtgläubigkeit ist als solche konservativ, wenigstens wenn sie als Kirche organisiert ist, für diese Kirche, für ihren Glauben und ihre Ordnungen. Uberhaupt aber hat sie ihre Stärke in der Uberlieferung, dem Herkommen, der Gewohnheit; ihre festeste Stütze in den Seelen ist die Pietät, die das heilig hält und pflegt, was die Väter und Vorfahren heilig gehalten und gepflegt haben. Die Götter selber, verklärte Abbilder der Väter und Vorfahren, werden als konservativ gedacht, nach Art 
alter und ehrwürdiger Männer und Frauen, die keine Veränderungen lieben. Darum sind der Natur der Sache nach die Priester, die den Willen der Götter deuten und erfüllen, ihren Dienst leiten sollen, ebenso gesinnt, wenigstens in bezug auf diesen Gottesdienst, der seine bestimmten Regeln hat, deren Veränderung gefährlich ist, weil er die Unzufriedenheit des Gottes erregen kann, der gleich einem berechtigten Menschen erwartet und verlangt, was ihm gewohnheitsmäßig zukommt: es ist seine Mindestforderung, mehr Gaben, mehr Gebet, mehr Preis und Dank wird er sich gefallen lassen und anerkennen, aber die Hauptsache ist, daß er nicht verkürzt werde, darum das peinliche Festhalten an den hergebrachten Riten und Förmlichkeiten (Zeremonien), das Mißfallen an Neuerungen (Misoneismus) in dieser Beziehung, und folglich überhaupt. Wenn aber die konservative und rechtgläubige Gesinnung der Herrschaft und dem Einfluß der Priester zugute kommt, so schärfen sie überhaupt Gehorsam als sittliche Pflicht ein: Gehorsam gegen Menschen, wie gegen Götter und ihre Stellvertreter, d. h. gegen Menschen als Stellvertreter der Götter. Die 3 Gegenparteien haben miteinander gemein, daß sie alle Parteien der Kritik und folglich möglicherweise, ja der Tendenz nach, der Verneinung sind. Freilich ist nicht notwendig, daß die Kritik und Verneinung einer Regierung auch Kritik und Verneinung politischer oder sogar sozialer Zustände in sich schließt, noch weniger, da $B$ sie auch Kritik des geltenden Glaubens, insbesondere in bezug auf die göttlichen Dinge sei. Aber leicht erstreckt sich doch die Stimmung der Kritik und der Geist der Verneinung von einem Gebiet auf die anderen. In dem $\mathrm{Maße}$ als eine Regierung zugleich die konservative Richtung vertritt, als sie für den richtigen Glauben Partei nimmt, wird auch die Opposition gegen diese Regierung dazu neigen, jene Richtung zu bekämpfen und den Glauben durch $Z$ weifel anzugreifen. Ebenso wird eine reformative Partei sich gegen die Regierung wenden müssen, die mit dem konservativen Interesse solidarisch ist; und sie wird, auch wenn sie sonst um die Glaubensmeinungen sich nicht bekümmert, die Orthodoxie, welche in das politische Gebiet übergreift, als ihren Gegner betrachten müssen. Endlich werden die Andersgläubigen und Gegner der Kirche auch eher als die Rechtgläubigen andere Einrichtungen, besonders also solche des Staates, anzufechten geneigt sein, und werden sich zur Opposition schlagen, sobald und sofern eine Regierung Staat und Kirche, "Thron und Altar « als solche, oder deren bestehenden Zustand verteidigt oder sogar für aller Mängel bar erklären möchte.

32. (Kreuzungen.) Möglich sind aber auch andere Kombinationen und Kreuzungen. Wir werden diese am leichtesten in historisch 
bekannten Fällen verstehen. $\mathrm{DaB}$ eine Regierung selber "reformativ «, ja revolutionär sein kann, lehrt zumal in neueren Zeiten gar manche Erfahrung; natürlich sind dann die konservativen Parteirichtungen in Opposition; sie werden aber alsdann auch leicht mutativ in bezug auf Staatsform und Verfassung, zumal wenn diese selber neu und durch gewaltsame Veränderungen herbeigeführt ist. Eine solche neuernde Regierung wird auch nicht leicht mit dem alten Glauben in gutem Verhältnis stehen; obschon es nicht unmöglich ist, da $B$ sie mit Errfolg dies gute Verhältnis erstrebt, um sich dadurch zu beglaubigen und ihre Autorität zu befestigen; wie NAPOLEON, als er sich durch den Papst als Kaiser der Franzosen krönen ließ. Jedenfalls kann die Opposition gegen eine Regierung auch von den Rechtgläubigen ausgehen; und wird sich regelmäßig einstellen, wenn die Regierung andere Wege geht, als diese für richtig halten; mithin auch wenn sie den Einfluß und das Herrschertum der rechtgläubigen Priester einzuschränken beflissen ist; und dazu wird sie sich genötigt sehen, um sich zu behaupten - wenn zwei Regierungen in Wettbewerb treten, werden sie nicht leicht, ohne daß eine das Übergewicht erhält, miteinander sich vertragen. Ferner wird auch die konservative Denkungsart sich von der rechtgläubigen trennen, wenn diese etwa soziale und politische Zustände, an deren Erhaltung jener gelegen ist, als dem Einflusse der Priester und der Kirche hinderlich, bestreitet oder aus moralischen Gründen anklagt. Solchen $Z$ wiespalt erzeugt neuerdings die soziale Frage. Die konservative Denkungsart will das bestehende Verhältnis zwischen Kapital und Arbeit, zumal zwischen Grundbesitz und Arbeit retten, die rechtgläubige muß sich, um ihr Ansehen bei den Arbeitern zu wahren oder wiederherzustellen, für Veränderungen interessieren, wodurch die Lage der Arbeiter gehoben, ihr Recht erweitert wird. Die rechtgläubige Denkungsart wird sich überhaupt mit jeder verbünden, die nicht in ausgesprochener und streitbarer Weise ihr entgegen ist. Dies gilt für sie in besonderer Weise, weil sie allein sich zumeist auf zu schwachen Füßen fühlt; sonst gilt es für jede Denkungsart gleichermaßen, sofern sie verteidigend oder angreifend sich ihren Gegnern gegenüber findet.

\section{Vierter Abschnitt. Kampf und Freiheit.}

33. (Soziale Gegensätze.) Die hier bezeichneten Gegensätze der Denkungsarten, die in den Parteibildungen niederschlagen, beruhen aber, in ihren großen historischen Gestalten, auf Gegensätzen des Lebens, die sich naturnotwendig entwickeln, und in der Erfahrung ausgeprägt vorliegen. Es sind die schon erwähnten oder doch angedeuteten, die wir hier resümieren: 
I. der Gegensatz der besitzenden und der besitzlosen Klassen, Gegensatz von Reich und Arm, von Kapital und Arbeit usw.; welcher Gegensatz sich historisch abwandelt, indem das Gebiet des wirtschaftlichen Lebens sich vergrößert und zugleich kommerzialisiert wird; übrigens ein Gegensatz, mit dem immer nationale und Rassengegensätze und entsprechende Gefühle des Widerwillens, Hasses, Neides sich verbinden.

2. der Gegensatz von Stadt und Land; Großstädten und »Provinz «;

3. der Gegensatz von Gebildeten und Volk.

Die Entsprechungen mit den Gegensätzen der Denkungsarten liegen klar zutage.

I. Die besitzenden Klassen haben in aller Regel die Regierung in den Händen, die besitzlosen sind die regierten und beherrschten. Dies ist das normale Verhältnis. Als Besitzlose müssen hier auch die Minderbesitzenden gelten. Die Bauern des Mittelalters und auch leibeigene Bauern der Neuzeit waren nicht besitzlos, aber ihr Besitztum war nicht nur geringer an Umfang als das der Herren, sondern zumeist auch geringeren Rechtes: Besitz als Herrschaft über Land gehörte mit der Herrschaft über Leute so natürlich und notwendig zusammen, wie die allmählich sich herausbildende und erhebende Landeshoheit mit den Rechten des Richters und Gesetzgebers für den "Untertanenverband «. Im Laufe des I9. Jahrhunderts hat sich mehr und mehr in den führenden Ländern ein Zustand herausgebildet, der dem massenhaften Kapital die Übermacht verleiht, so daß sogar der große Grundbesitz, wenn ohne massenhaftes Kapital, in Macht und Einfluß eingeschränkt wird. Dieser Zustand ist durch die Entwicklung großer Städte und großer Industrien bedingt. In ihm stehen einer verhältnismäßig kleinen Zahl überreicher Personen die großen Mengen derer gegenüber, die gänzlich oder zum größeren Teile durch ihre Arbeitskraft ihr Einkommen gewinnen, ohne an den Produktionsmitteln irgendwelchen Anteil zu haben oder doch ohne über solche wirksam verfügen zu können. Jene bestimmen im wesentlichen auch die Regierungen der Staaten. Freilich stehen dem zum guten Teile die Formen der Staatsverfassung entgegen, insofern als die Vorstellung der formalen Gleichheit, die das gesellschaftliche und wirtschaftliche Leben beherrscht, auch auf das politische Leben ausgedehnt ist, um der Arbeiterklasse die Vorstellung einzugeben, $\mathrm{da} B$ die jedesmalige Regierung auch auf ihrem Willen beruhe; wodurch sie aber wenigstens eine Handhabe gewinnt, um auf die Gesetzgebung für ihre $Z$ wecke und Interessen einzuwirken. Selbst wenn sie durch ihre Vertretungen Anteil am Regierungssystem gewinnt, so bleibt doch dieses wesentlich das Organ der auch sozial herrschenden Klasse; 
wenngleich die Idee des Staates als eines Gesamtkörpers, also die Idee des Gemeinwohls, auch in den Staatsdienern, die aus dieser Klasse hervorgehen, mächtig werden und den Bedürfnissen und Wünschen der großen Menge um des "Vaterlandes « willen, also zum Behuf der Erhaltung männlicher Wehrkraft, weiblicher Gebärkraft, entgegenkommend gerecht werden kann.

2. Der Gegensatz von Stadt und Land läuft historisch in einer großen Linie parallel mit dem der herrschenden und beherrschten Schicht, nämlich so lange als die ihrem Charakter nach überwiegend ländlichen Stände, die Geistlichkeit und der Adel dem »dritten " Stande (tiers état) gegenüberstehen, der seine soziale Kraft und Bedeutung vorzugsweise in den Städten entwickelt, so daß diese den Schoß der Opposition und Kritik darstellen, während der Bauernstand und die ländliche Arbeiterklasse teils politisch stumm und gleichgültig, teils als gehorsame Diener jenen herrschenden Ständen untertan bleiben, soweit sie nicht von den sozial maßgebenden Teilen des dritten Standes in deren Bewegungen mit fortgerissen werden, während jedoch zu Zeiten, und zumal so lange als ein entwickeltes städtisches Gesamtbewußtsein des dritten Standes noch nicht vorhanden ist, gerade die Bauern als dessen (auch zeitliche) Vorkämpfer auftreten, indem sie die festen Stellungen der Geistlichkeit und des Adels durch gewaltsame Angriffe erschüttern. - Der Unterschied und Streit konservativer und reformativer - oder sagen wir revolutionärer Parteiung beruht, wie gesagt, wesentlich in diesen gesellschaftlichen Verhältnissen, und erstreckt sich großen Teiles auf Gestaltung, daher auf Formen und Verfassung des Staates, so daß der konservativen Partei des Adels und der Geistlichkeit als waristokratischer " die *demokratische "des dritten Standes gegenübersteht. Der Gegensatz verschiebt sich aber, indem - iberwiegend in nerhalb der Städte und stadtähnlichen Bevölkerungszentren - jener neue gesellschaftliche Zwiespalt entsteht, derjenige zwischen den Vertretern des Kapitals auf der einen, den Vertretern der Arbeit auf der anderen Seite, wiederum ein Zwiespalt zwischen Reichen und Armen, den die Erscheinung begleitet, da $\beta$ auch das Land als verhältnismäßig arm gegenüber den durch Handel erworbenen Massenreichtümern der großen Städte sich darstellt. Wird aber das Land nach wie vor durch den alten Herrenstand vertreten, so gesellt sich ihm nunmehr das Kapital trotz aller Gegensätzlichkeit im erhaltenden Interesse für die "Grundlagen der Gesellschaftsordnung ", d. h. für das schrankenlose und unbedingte Privateigentum von Boden und Kapital gegen den "Umsturz «, also gegen mutative 'Tendenzen dieser Art: ein taktisches Verhältnis, das alsbald auch ins politische Gebiet überspringt und 
hier neue Parteibildungen bewirkt. Der tiefe Gegensatz zwischen dem Lande als konservativem und der Stadt, namentlich der Großstadt, als mutativem Element wird aber dadurch nicht aufgehoben.

3. Das Volk ist überwiegend gläubig, daher auch in einigem Maße immer rechtgläubig - teils seiner Anlage und der menschlichen Natur gemäß; teils aus der sich daraus entwickelnden Anhänglichkeit an Herkommen, Uberlieferung und Sitte; endlich aber, weil es die Lehre empfängt und annimmt, die ihm mitgeteilt wird, zumal soweit und so lange als diese seinen Neigungen entgegenkommt und sich anbequemt. Die Bildung hingegen ist skeptisch und zweifelnd, ja sie leugnet auf Grund des Wissens, d. i. der Beobachtung und Erfahrung von Tatsachen, wie der Schlußfolgerungen des Denkens, die angeblichen Glaubenswahrheiten. Nun bleibt der alte Herrenstand, der gewissermaßen vor dem Volke ist, in dieser Hinsicht mit ihm einig und verbunden; zumal der geistliche, weil er in dieser Verbindung die Wurzeln seiner Kraft und seines Einflusses hat. Die Bildung und Kultur jenes Standes ist in seinen höheren Schichten oft bedeutend und tief, nicht selten auch in den niederen, zumal unter den historisch jüngeren Gestalten des Christentums. Sie pflegt aber gerade dadurch volkstümlich zu sein, daß sie überwiegend kunsthaft und praktisch ist; auch in ihrer "Wissenschaft " an den volkstümlichen Glauben und dessen naturwüchsige Vorstellungen angelehnt und in beständiger Wechselwirkung damit stehend, nur zögernd und langsam sich von ihnen entfernend. Von jeder wissenschaftlich - vom Sinne wirklicher Wissenschaft - bestimmten Denkweise aus gesehen, bleibt sie daher in weitestem Umfange vollkommene Unwissenheit und oft auch entsprechende Roheit: man denke etwa an die Popen des vorthodoxen "Glaubens, oder an die Dunkelmänner vieler Klöster, oder an die bäuerlichen Kapläne romanischer Länder. Åhnlich verhält es sich mit dem weltlichen Adel, dessen historisches Wahrzeichen das Schwert ist, zugleich als Werkzeug seiner Berufstätigkeit und als Merkmal seiner Herrschgewalt, die aber mehr und mehr der Feder und des Lehrstandes, der sie führt, zu ihrer Ergänzung und Unterstïtzung bedarf. Schon sein starkes Interesse an Erhaltung der Herrschaft lehrt ihn, auch in geistlichen Dingen konservativ sein; und die gläubige Ehrfurcht des Volkes wird selber durch den Gottesdienst befestigt. Wenn wir dem Volke die Gebildeten gegenüberstellen, so wird damit die Kultur des Volkes nicht angefochten, noch weniger die seiner führenden Stände; aber das Besondere der wissenschaft lichen Bildung steht $\mathrm{zu}$ ihr in einem vielfachen, oft vernichtenden Gegensatze, nicht nur zu den religiösen Vorstellungen, in die alle ursprüngliche, zumal künstlerische Gemeinschaftstätigkeit einge- 
bettet ist. Die wissenschaftliche Bildung charakterisiert wesentlich den jüngeren, neuen Herrenstand, der zwar auch aus dem alten sich rekrutiert, aber seinen Hauptbestandteilen nach aus anderen Elementen hervorgeht, die in Städten und Industriezentren emporwachsen. Diese Bildung kann dann allerdings durch mannigfache Mittel - Schule, Literatur, Verkehr - über weitere und weitere Kreise sich ausbreiten, so daß es denkbar wäre, daß als Vertreter des Volkes im alten Sinne nur die bewußteren Betätiger seines Glaubens, also vorzüglich der alte Herrenstand, den materielle und ideelle Interessen an dessen Erhaltung binden, übrig bleiben; ein Zustand, von dem wir in einigen europäischen Ländern nicht mehr weit entfernt geblieben sind. Längst zuvor schon, und in verschiedenen Gestaltungen ist ein Gegensatz zwischen der offiziellen und künstlichen Religion, die auch in theologischer Wissenschaft ihre Stützpunkte sucht und, schon durch diese, mit der Wissenschaft überhaupt und der in ihr beruhenden Weltbildung Fühlung gewinnt, die auch zu den Merkmalen des priesterlichen Standes gehört, auf der einen Seite, der volkstümlichen Frömmigkeit, die gegen allen solchen Schmuck, als gegen irreligiöse Hoffart, mißtrauisch abgeneigt, mindestens gleichgültig ist, auf der anderen: zwischen der Kirche und der Sekte. Trotz dieses starken Gegensatzes verbinden sich die Geisteselemente der Sekte, weil sie, mehr städtischer Natur, in Industrie und Handel verankert sind, leichter als die der Kirche mit den spezifischen Elementen der spezifisch modernen, naturwissenschaftlichen und philosophischen Bildung.

34. (Öfentliches Meinen.) Die Entwicklung des Meinens ist in der Hauptsache Folge und Wirkung des Fortganges wissenschaftlicher Erkenntnis. Insbesondere gilt dies für die öffentlichen Kundgebungen des Meinens und für das öffentliche Meinen auch in dem Sinne, da $B$ es sich auf die öffentlichen Angelegenheiten vorzugsweise bezieht. Hier ist seine Tätigkeit in erster Linie Kritik; es entspringt also aus der Unzufriedenheit mit bestehenden Regierungen, mit überlieferten Zuständen, mit geltenden Glaubenslehren. Die Unzufriedenheit ist zunächst gefühlsmäßig, wird allmählich denkend und einsichtig; zunächst stumm und dumpf, wird allmählich laut und deutlich; zunächst zerstreut und ohnmächtig, wird allmählich zusammenhängend und organisiert.

Am unmittelbarsten beziehen sich Meinungen auf Glaubenslehren, sie sind hier in ihrem eigensten Gebiet. Glaubenslehren gibt es auch in politischen, ja in wissenschaftlichen Angelegenheiten selber. Typisch sind aber immer die religiösen Glaubenslehren. Und hier tritt es in der am meisten ausgeprägten Weise hervor, daß sie 
selber, daß die Gläubigen, und daß die Schützer des Glaubens abweichende Meinungen nicht nur bestreiten und widerlegen, sondern vielmehr und hauptsächlich deren Ausdruck und öffentliche Kundgabe verbieten, ja unter Strafe stellen. Dies gehört zum Wesen einer anerkannten und geltenden Religion, sofern sie mit politischer Macht verbunden ist. Zweifel an Dasein und Macht des von der Gemeinde verehrten Gottes ist Beleidigung des Gottes; es ist Sünde und Frevel, auch weil es eine unfromme "gottlose» Gesinnung verrät. Äußerungen von dieser Art werden nicht nur im Namen des Gottes rächend vergolten, auch der Gott selber wird den züchtigen, der in unwürdiger Weise über ihn spricht, wie den, der seine Gebote nicht achtet; und die Gotteslästerung erregt in der Gemeinde sittliche Entrüstung und Abscheu. Dies sind auch die Ursprünge der Verfolgung der Ketzerei, der häretischen, d. h. frei und frech, den Autoritäten zum Trotz, angenommener Meinungen. Ihr Ursprung und Anfang ist der Zweifel, der als solcher schon Auflehnung bedeutet, wo der Glaube Pflicht ist.

Die ganze Geistesgeschichte der Neuzeit ist erfüllt von den Kämpfen solcher neuen Meinungen gegen die überlieferten religiösen Glaubenslehren, indem sie diese I. bezweifeln und im Zusammenhange damit ihren moralischen Wert in Frage stellen; 2. unmittelbar anfechten, als unrichtig oder unwahrscheinlich und unglaubwürdig; 3. mittelbar ihre Voraussetzungen und Rücklagen zerstören und untergraben. Folglich auch erfüllt von Versuchen der Abwehr, und zwar der Abwehr, I. durch erneute Behauptung, Befestigung, verstärkte und mehr systematische Lehre; 2. durch Gründe und Reden als Apologetik; 3. durch gewaltsame Mittel der Mißbilligung und Unterdrückung.

35. (Soziale Kämpfe.) Mit den religiösen Glaubenslehren wird aber die gesamte soziale Ordnung, die in ihnen verankert ist, angegriffen und verteidigt.

Die gewaltsamen Mittel der Abwehr sind uns vorzüglich darum merkwürdig, weil sie die Meinungen verhindern, öffentlich zu werden (im ursprünglichen Sinne des Wortes). Die Ketzereien sollen nicht ans Licht des Tages treten, nicht verbreitet werden, man arbeitet der Gefahr entgegen, die in ihrer ansteckenden Kraft vermutet wird. Die gewaltsamen Mittel sind solche der Polizei und des Strafrechts. Die Kirche nimmt, soweit sie nicht selber darüber verfügt, den "weltlichen Arm « in Anspruch, um ihr zu helfen, die "Pest « verderblicher Meinungen auszurotten. Der Staat setzt zunächst sich gleich mit der Kirche oder hält doch für seine Pflicht, ihr zu helfen und zu dienen; sodann aber begegnet er auch Meinungen, die ihn unmittelbar zu bedrohen scheinen, sei es, daß sie seine Form oder seinen Inhalt 
in Frage stellen. In der Regel wird überdies die jeweilige Regierung des Staates, wie die jeweilige Regierung der Kirche und jeder anderen Körperschaft, den Staat oder die Kirche oder die Körperschaft angegriffen finden, wenn sie, die Regierung, angegriffen wird, mithin auch in Meinungen, die der Kritik und Opposition gegen die Regierung Ausdruck geben, eine Gefahr für den Staat, die Kirche usw. zu erblicken geneigt sein.

Es ergeben sich aus dieser Verdrängung der Kritiker und Gegner besondere Arten des Kampfes, sofern dieser nicht öffentlich, also mit unverhüllten Waffen geführt werden kann. Die Angreifer werden gleichsam nicht als Kriegführende anerkannt, es gibt kein Kriegsrecht ihnen gegenüber, sie werden als Rebellen behandelt. Mithin sind sie auf heimliche Führung des Streites angewiesen. Sie selber werden diese nur als eine Vorbereitung zukünftigen of fe ne n Kampfes betrachten, sie werden sich für diesen zu rüsten beflissen sein. Sich rüsten heißt: I. Streitkräfte sammeln. Der Ohnmächtige, Schwache, wird, wenn er sich zu wehren genötigt ist, oder bestimmte Ziele vor Augen hat, Bundesgenossen suchen; im Gedanken an die Zukunft, an sein und seiner Kampfgenossen Ausscheiden, wird er die Fortsetzung der Kampfarbeit durch frische Kräfte, durch Ersatzmannschaften ins Auge fassen. Um Bundesgenossen $\mathrm{zu}$ finden, sieht er sich a) unter seinesgleichen um; teils kennt er, teils lernt er Menschen kennen, die ähnlich wie er denken, weil sie ähnlich wie er leben und also unter ähnlichen Úbeln leiden, b) wenn er wei $B$, daß seine Gedanken und seine Denkungsart Andersgearteten und Andersbedingten als er selber ist, förderlich sein können, weil sie mit dem zusammentreffen (in allen oder einigen Stücken) was diese denken müssen, wenn sie auf Grund ihrer Lage zu denken beginnen und lernen, so wird er sich diesen nähern und sie für seine Ideen zu gewinnen suchen. Um Ersatzmannschaften zu sichern, ist der Kämpfer auf die $\mathrm{J}$ uge nd hingewiesen, er $\mathrm{muB}$ sie in seinem Sinne zu bilden und zu erziehen sich angelegen sein lassen. Zunächst und am leichtesten erfolgt die Fortpflanzung seiner Lehre im eigenen Familienkreise; darüber hinaus muß er Schule zu bilden beflissen sein; er wird Jünger um sich sammeln, die zu seinen Füßen sitzen und die Worte des Meisters andächtig empfangen. Die Jünger verehren ihn auch nach seinem Tode, seine Worte werden ihnen maßgebend, sie schwören wohl auf die Worte des Meisters (,in verba magistri"), sie gewinnen darin eine Autorität zur Ausgleichung ihrer eigenen Meinungsverschiedenheiten, sie bilden eine Gemeinde und gewinnen dadurch vermehrte Stärke. Wenn jede Kampfgenossenschaft ein enges und starkes Band um ihre Mitglieder knüpft, so ist das um so mehr der 
Fall bei einem Ringen Unterdrückter um ihr Befreiung; und wiederum um so mehr, je mehr die Ringenden an ihren zukünftigen Sieg gla u be n. Der Glaube daran aber wird mächtig verstärkt durch den Glauben an Personen, an lebende oder tote, menschliche oder göttliche Führer, Vorbilder, Verkünder. Und zum Glauben an einen Menschen, zum verbindenden Glauben, hilfts nichts so, wie die Erinnerung und Botschaft, daß dieser Mensch für die gemeinsame Sache gelitten, $\mathrm{da} B$ er dafür sein Leben gelassen hat, vollends, $\mathrm{da} B$ er wissend und wollend sich dafür aufgeopfert habe. Das Martyrium macht einen Eindruck, dessen Wirkung in Begeisterung und Liebe zutage tritt. Blutzeugen gelten auch als Zeugen der Wahrheit einer Lehre, der Glaube an ihre Heiligkeit oder gar Göttlichkeit verbindet die kämpfenden Scharen, belebt ihren Mut, beseelt sie mit Todesverachtung, zumal wenn der Glaube an ein anderes Leben nach dem Tode und an den Lohn der Tugend damit verbunden ist. So wird aus dem Kampfe gegen überlieferten Glauben und dessen Fesseln ein neuer Glaube, ein neues Bekenntnis mit neuen Fesseln.

36. (Gewissensfreiheit.) Die große "protestantische "Empörung wider die päpstliche Kirche hat so zur Bildung mannigfacher neuer Kirchen und Gemeinden geführt. Freilich bleiben diese in der Substanz des Glaubens an den göttlichen Erlöser und seinen Opfertod mit dem katholischen Glauben einig, und haben nur hin und wieder neuer Blutzeugen bedurft, um ihre Verbindungen zu kitten. Aber sie sind auch schwach und zersplittert geblieben und haben dem verneinenden wissenschaftlichen Denken keinen so nachhaltigen Widerstand wie die alte Kirche zu leisten vermocht, da sie vielmehr selber in wichtigen Bezügen sich darauf stiitzen wollten. Zunächst sind sie auch mit dem freien Denken einig in dem Verlangen nach Freiheit des "Gewissens «, also der Betätigung religiöser und etwa auch philosophischer Gesinnungen. Es sei denn, daß sie selber - die neuen Kirchen im Staate und durch den Staat eine herrschende Stellung gewinnen, wodurch ihnen dann die "Dissidenten " nicht wesentlich verschieden von Juden, Atheisten und anderen Nichtchristen erscheinen, so daß diese alle wieder im Verlangen nach Freiheit des Bekenntnisses geeinigt werden. Diese, als Religionsfreiheit oder Gewissensfreiheit, Glaubensfreiheit, fordert zunächst von der herrschenden Kirche und dem mit ihr mehr oder minder eng verbundenen Staate, Duld ung, geht aber weiter zur Forderung der Gleichheit und Gleichberechtigung der Religionen und Bekenntnisse, zunächst in ihrer Ausuibung und öffentlichen Vertretung, demnächst auch in bezug auf andere subjektive öffentliche Rechte (Befugnisse). Diese Freiheit aber erweitert sich zur Freiheit des "Denkens « und der "Wissenschaft «, d. h. der 
öffentlichen Äußerung beliebiger Meinungen; insbesondere der Vervielfältigung und öffentlichen Mitteilung von religiösen und politischen Ansichten, d. i. nach Ausbildung des Druckes und der Zeitungen, zur $\otimes$ Preßfreiheit «.

37. (PreBfreiheit.) Die historische Bedeutung der Preßfreiheit ist die Befreiung von der "Zensur «, insbesondere der vorherigen Prïfung von Druckschriften durch eine Behörde. In dieser Hinsicht, wie überhaupt in bezug auf Kundgebung von Meinungen, war der Freiheit immer am entschiedensten die Kirche entgegen, vor allen die mächtigste, die römisch-katholische. Der Staat tritt zunächst, wie auch sonst in gar manchen Stücken, in ihre Fußstapfen. Kirche wie Staat wollen sich selbst behaupten, daher wehren sich ihre Regierungen nach innen und nach außen gegen Angriffe und Anfechtungen. Aber in dieser Kampfstellung tritt auch ihre Verschiedenheit deutlich hervor. Die Kirche ist wesentlich ein geistig-moralischer Organismus: sie hat kein sichtbares Landgebiet $\mathrm{zu}$ verteidigen und will auch mit äußeren Waffen keins erobern; der innere Zusammenhalt, die Eintracht des Glaubens und Brauches, ist ihr Lebensgesetz. Der Staat ist wesentlich Macht und Gewalt. Die kriegerische Landesverteidigung ist sein notwendiger Bereich. Im Kriege spielt die Kundschaft eine höchst bedeutsame, oft eine entscheidende Rolle. Der Feind darf nicht wissen wie es um uns steht, was wir vorhaben, wie wir gerüstet sind. Um so mehr begehrt er es $\mathrm{zu}$ wissen, und wendet alle Mittel, die ihm zur Verfügung stehen, an, um es auszukundschaften. Das leichteste Spiel hat er, wenn unser eigenes Nachrichtenwesen ihm offen steht, sei es, daß es über die Grenze dringt, oder $\mathrm{da} B$ es dem Spion im eigenen Lande, die sonst verborgenen und geheimzuhaltenden Dinge ausplaudert. Also wird der kriegführende Staat das Nachrichtenwesen seines Landes aufmerksamer und scharfer Uberwachung zu unterwerfen sich genötigt finden. In dem Weltkriege, der seit 43 Monaten wütet, während dies geschrieben wird, haben alle Länder, die sonst mehr oder minder ausgedehnter Preßfreiheit sich erfreuten, aufs neue eine recht innige Bekanntschaft mit der "Zensur " zu machen Gelegenheit gehabt. So sehr das politische Publikum sonst in jedem Lande für die PreBfreiheit eingenommen war und sie als Errungenschaft der allgemeinen liberalen Bestrebungen und des Fortschritts zu preisen gewohnt war, so hat es doch überall, wenn auch mehr oder minder willig, mit der Kriegszensur sich abgefunden und ihre Notwendigkeit, wenigstens in bezug auf militärische Angelegenheiten, anerkannt. Naturgemä $B$ sind aber die Grenzen der militärischen Angelegenheiten fließend und die Zensur oder die ihr übergeordnete Behörde muß selber darüber richten, 
ob eine Nachricht, wenn sie verbreitet würde, die militärische Lage ungünstig beeinflussen könne: wo es sich um Sieg oder Niederlage, Leben oder Tod handelt, scheint die äußerste Vorsicht, auch wenn sie Außenstehenden als übermäßige Ängstlichkeit erscheint, schlechthin geboten. Wie die Ausübung jeder Macht zu ihrer Verstärkung und Ausdehnung reizt, so ist es auch in diesen Fällen geschehen, daß die Vorstellung der Gefährlichkeit sich rasch erweitert hat. Unvermeidlich ist ferner, $\mathrm{daB}$ die Zensur der Nachrichten auf die von ihnen schwer trennbaren Meinungen übergeht. Schon die Form einer Nachricht enthält sehr oft eine Meinung über ihren Inhalt. Aber jede Meinung über die Lage der Dinge kann als gefährlich erkannt werden. Jede kann als Ermutigung des Feindes, als Entmutigung der eigenen Landesbewohner wirken. Gar manche Meinung, auch wenn sie nur eine theoretische Ansicht oder Feststellung und Prüfung von Tatsachen sein will, kann beunruhigend wirken, und, wenn sie streitbar sich kundgibt, den "Burgfrieden « unterbrechen, wozu etwa die Parteien für die Dauer des Krieges sich verbunden haben. Daher erstreckt sich die Zensur auch auf Veröffentlichungen rein wissenschaftlicher Art, wenn sie fürchtet, daß dadurch Dinge bekannt werden, die geeignet sein möchten, die Stimmung in der Heimat oder sogar an der Front zu drücken. Vollends, wenn dies in Zeitungen geschieht, die jederman lesen und verstehen kann. Die Zeitungen müssen fortwährend ermahnt, belehrt, berichtigt, zuweilen verboten, wenn nicht als unheilbar unterdrückt werden nach diesen Maximen ist überall die Zensur verfahren und hat naturgemäß viele Kritik und Mißbilligung auf sich gezogen, wenn sie aber ein gut Teil selber zu hemmen in der Lage ist, indem sie ihm die Offentlichkeit versperrt, so daß in der Hauptsache nur die Volksvertretungskörperschaften als die Orte bleiben, worin die Unzufriedenheit laut werden kann. Aber auch ohne die Zensur behält sich jede Regierung das Recht vor, auf die Presse abwehrend und unterdrückend zu wirken, durch die sie ihr Ansehen, ihre Macht bedroht findet; sie wei $B$, da $B$ die Verbreitung friedlicher Worte friedliche Stimmungen erzeugt oder doch - was um so gefährlicher, wenn sie schon vorhanden sind - fördert, verstärkt und ermutigt.

38. (Redefreiheit.) Wenn eine bevorrechtete Redefreiheit derer, die als Gesetzgeber berufen sind, übrig bleibt, so ist im übrigen auch das sonst gewährte Recht, seine Meinung öffentlich auszusprechen, im Kriegszustande beschränkt. Die Beschränkungen gehen nicht so weit, wie etwa ehemals in Wien, als es von den Türken belagert wurde, da ein Maueranschlag »bei körperlicherStrafe verbot, von dem, was im Feldzuge sich ereignet habe, oder überhaupt von irgendeiner Staatsangelegenheit 


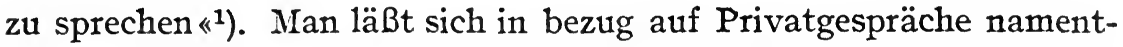
lich der Soldaten, an Warnungen genïgen. Aber die öffentliche Rede und wegen ihrer die Versammlungsfreiheit steht naturgemäß unter strenger Aufsicht. $\mathrm{Da} B$ darunter auch die in Verfassungen gewährleistete Freiheit der Wissenschaft und ihrer Lehre leiden muB, wenigstens soweit die Lehre in Druckschriften, zumal periodischen, geschieht, ist offenbar. So durfte - wohl in allen kriegführenden Ländern — von den zerstörenden Einflüssen des Krieges auf die Bevölkerung und ihre Bewegung öffentlich nicht geredet oder geschrieben werden. In Großbritannien durfte ein hervorragender Gelehrte, BERTRAND RUSSELL, weil er andere Meinungen als die vorgeschriebenen vertrat, innerhalb eines für gefährdet erklärten Bezirkes ïberhaupt nicht reden.

Diese jüngste Einschränkung der Offentlichkeit und besonders der Preßfreiheit hat, wie bekannt, auch die Folgen gehabt, die sie ehemals, wo sie auch in normalen Zeitläufen geschah, zu haben pflegte: r. Entstehung und Wachstum einer heimlichen Literatur und somit 2. Führung von Kämpfen, die sonst offen geführt wurden, in versteckter Form. Charakteristisch dafür war die Bildung einer sogenannten Vaterlandspartei, die angeblich eine Nichtpartei sein wollte, in Wirklichkeit eine ausgesprochen politische Parteigruppe war, die durch diesen Vorwand das Recht auf jenen Namen zu erwerben meinte. Vit Grund wird behauptet, daß die freie Erörterung und der offene Streit solche Unwahrhaftigkeiten nicht so leicht emporkommen läßt. Indessen ist hier nicht die Absicht, Vorteile und Nachteile des öffentlichen Wesens, der PreBfreiheit usw. zu erwägen. Vielmehr sollte die Kriegszensur und deren allgemeine Geltung uns lehren, daß veränderte Umstände veränderte Rechte und veränderte Ansichten bedingen; weshalb zu vermuten, da $B$ auch, wenn wir die Zensur mit allen ihr verwandten Hemmungen der geistigen Freiheit einem verflossenen Zeitalter zuschieben, dies Zeitalter starke Gründe für solche Einrichtungen gehabt hat, und zwar zum Teil schon darum, weil es sie zu haben glaubte; weil seine Herrscher von Geschlecht zu Geschlecht die Ansicht fortpflanzten, da $B$ solche Verbote und Uberwachungen zur Regierungskunst (der Ars gubernandi) gehörten. Wie in anderen Gebieten, so dürften auch in diesem die Kunstregeln durch Ubung und Eirfahrung entstehen und wachsen, wodurch freilich keineswegs ihre dauernde Richtigkeit bewiesen wird; vielmehr wirkt auch die "Routine " der bedachten Verbesserung entgegen.

Aber gewi $\beta$ und offenbar ist, da $B$ jede soziale Gesamtheit, in dem Maße als sie kämpfend sich zu wehren und zu erhalten genötigt,

\footnotetext{
$\left.{ }^{1}\right)$ Comte de Haussonville, Histoive de la réunion de la Lorraine avec la France III, 334. Ob und wiefern das Verbot wirksam gewesen sei, erfahren wir nicht.
} 
oder durch ihr Lebensgesetz sich zu vermehren und auszudehnen angetrieben wird, die Kritik aus ihrer eigenen Mitte nicht unbedingt dulden darf, also wenigstens sie in bestimmte Formen einschränken muß. Immer wird sie versuchen, abfälligen Meinungen als einem inneren Feinde $z \mathfrak{u}$ begegnen; die Frage ist nur, ob Unterdrückung und Erstickung der öffentlichen Kundgaben, das richtige Mittel ist, auch ob sie auf die Dauer gelingen kann. Daß sie immer wieder versucht wird, und oft mit Erfolg versucht wird, ist bekannt genug. $\mathrm{Daß}$ jede Regierung geneigt ist, sich und ihr System für wesentlich zusammengehörig mit dem Wohle des Ganzen - besonders also der Kirche, des Staates - zu halten, oder doch dafür auszugeben, stellt sie immer der Anfechtung bloß, daß diejenigen Meinungen, welche sie, die Regierung verneinen, doch mit günstigem Scheine für sich geltend machen können, daß sie das Gemeinwohl bejahen und es richtiger erkennen als die Regierung.

39. (Neubürgerliche Herrschaft.) Der ganze Kampf um Glaubensfreiheit, um Preßfreiheit und andere bürgerliche Freiheiten, der die letzten Jahrhunderte erfüllt, ist seinem eigentlichen Wesen nach Ausdruck des Ringens der neubürgerlichen, nationalbürgerlichen Klasse, welche als "die Gesellschaft " - oft auch als "das Volk" oder "die Nation " - sich einsetzt, um die Herrschaft, und zwar zunächst um Teilnahme an der Herrschaft der alten Stände und der diese einschränkenden Monarchie, mehr und mehr um die Allei n herrschaft. Insoweit als dieses Ziel erreicht wird, ist die herrschende Klasse naturgemä $B$ alsbald wieder beflissen, die von ihr beherrschte Klasse in Besitz und Genuß jener als allgemein und notwendig in Anspruch genommenen Freiheiten $z u$ hemmen und $z u$ verkürzen. Diese, die Arbeiterklasse, muß alsdann gegen sie aufs neue um die von ihr für sich, dem Worte nach aber für alle, errungenen Freiheiten streiten. Daraus geht deutlich hervor, daß es sich in Wahrheit immer um jenen allerersten Kampf zwischen den Parteien handelt, der unter A. (S. I08) als solcher zwischen Regiment und Kritik, zwischen Herrschenden und Beherrschten, bezeichnet wurde. - Wichtiger ist aber für die gegenwärtige Betrachtung, daß mit dem Erstarken und Steigen der neubürgerlichen Schicht auch ihre Gedanken erstarkt und gestiegen sind; sie hat vermocht, ihre Gedanken zu einem Gemeingut des politischen Publikums zu machen. Insofern also, als die gemeinsame Meinung dieses Publikums ihre Meinung, ihr Wille ist, so schlägt die neue herrschende Klasse sich selber ins Gesicht, wenn sie der beherrschten Klasse die bürgerlichen und politischen Freiheiten verkürzt, auf welche diese Anspruch macht. Sie gesteht dadurch ein, daß sie diese Freiheiten nur für sich begehrt hat und 
sie nur für sich angemessen erachtet, während sie sonst und als Grundsatz ihren Wert schlechthin behauptet hatte.

Anmerkung. Nachdem dies geschrieben war, hat eine große politische Umwälzung im Deutschen Reiche, wie in anderen Ländern, die bisher beherrschte Klasse zur herrschenden gemacht, wenn auch nicht zur unbedingt und allein herrschenden. Ein nicht geringer Teil derer, die ihr angehören, fühlt sich nach wie vor als beherrschte Schicht und wendet sich mit Ungestuim, ja mit heftiger Tatkraft gegen die neue Regierung, die jenen Revolutionären um so mehr verhaßt ist, weil sie die eigenen Grundsätze zu verraten scheint; hier ist es wiederum das Trachten nach einer Freiheit des Handelns und Redens, die gegen alle Gewalt sich wehrt, was am schwersten in den Gefühlen der Menge wiegt; während gleichzeitig der äußerste Flügel der Protestierenden gerade die unbedingte und rücksichtslose Gewaltausiubung (einer Minderheit) als Grundsatz verkündet und, wo sich Gelegenheit bietet, auch geltend macht - in ausgesprochenster Weise gerade gegen die Freiheit der Meinungsäußerung, die Pressefreiheit, weil sie in dem Gebrauch dieser Freiheit einen Ausdruck der gesellschaftlichen Macht der "Kapitalisten " erblickt, die sie um so mehr in ihren Lebensäußerungen unterdrücken will, je weniger sie in der Lage zu sein glaubt, sie unmittelbar niederzuzwingen.

40. (Öffentliche Meinung und e in e Öffentliche Meinung.) Sofern aber und so lange als die verschiedenen Schichten an PreBfreiheit und Redefreiheit Anteil haben oder aber die gezogenen Schranken zu durchbrechen wissen, so ergibt sich aus dieser gemeinsamen Freiheit der Meinungsäußerung unmittelbar eine Vielheit und Mannigfaltigkeit, aber auch Widerspruch und Streit der öffentlich ausgesprochenen Meinungen. Offentliche Meinung in diesem Sinne ist keineswegs einheitlich. Sie kann als Einheit aufgefaßt werden, indem sie als Gesamtheit des in die Erscheinung tretenden Denklebens einer Einheit, insbesondere der in einem Staate vereinigten Nation gedacht wird; gleichsam als die Einheit eines Gefäßes, worin sehr verschieden geartete Bestandteile vermischt angetroffen werden. Offentliche Meinung in diesem Sinne hat nur das wesentliche Merkmal, da $B$ sie ausgesprochen, kundgegeben wird, und zwar der "Allgemeinheit ", d. h. jedem beliebigen Hörer oder Leser kundgegeben wird, im Gegensatz I. gegen Meinung als etwas seiner Natur nach Inneres und Eigenes (Privates), aber auch 2. im Gegensatz zu der an bestimmte, bekannte Personen vertraulich kundgegebenen Meinung. Ist nun aber die so sich kundgebende Meinung die Meinung und das Urteil Vieler, ja einer Mehrheit, folglich - wenn deren Gewicht gleich dem der Mehrheit einer Versa m mlung geschätzt wird - als das einer Gesamtheit, 
eines Kreises, einer als Gemeinschaft oder als Gesellschaft verbundenen Einheit, so ist gegeben, was meine " offentliche Meinung genannt werden möge. Eine öffentliche Meinung ist also die im wesentlichen einmütige oder doch dafür geltende Meinung irgendeines Kreises, das geschlossene Urteil einer Gesamtheit, insbesondere wenn und sofern es bejahend oder verneinend, mit Beifall oder in abfälliger Weise, in Bewunderung und Ehrung oder in Verurteilung sich geltend macht. In diesem Sinne haben gerade kleine Orte, wenigstens Städte, eine öffentliche Meinung, deren Träger zunächst die »Honoratioren * sind, denen eine unbestimmte Menge derer, die zur "Gesellschaft *gehören wollen, sich anschließt. In diesem Sinne ist auch der Ausdruck in $\S \mathrm{r} 86$ des Deutschen Strafgesetzbuches (in den folgenden Paragraphen wiederholt) zu verstehen: „Wer in Beziehung auf einen anderen eine Tatsache behauptet oder verbreitet, welche denselben verächtlich zu machen oder in der öffentlichen Meinung herabzuwürdigen geeignet ist ..."1), denn die (eigentliche) Offentliche Meinung, in dem Sinne, den wir nachher ins Auge fassen, bekümmert sich um die Beleidigungen, die Hinz und Kunz einander zuschleudern, nicht. Sie wird nur aufgeregt, wenn der Beleidiger oder der Beleidigte, am ehesten wenn beide, hervorragende allgemein bekannte Personen oder Gesellschaften, vollends wenn die Beleidigung ein offenbarer Ausdruck heftiger Parteikämpfe, an denen die Öfentlichkeit gespannten Anteil nimmt, ist. Eine öffentliche Meinung kann man jedem offenen oder geschlossenen Kreise zuschreiben, der als solcher ein Gewicht für die ihm angehörigen Personen hat, so daß sie nach der in ihm vorherrschenden Meinung, die als einmütige um so stärker wird, ihr Betragen, auch ihre Meinungsäußerungen, richten; indem sie fürchten, Anstoß zu erregen und dagegen sich freuen und es genießen, wenn sie Zustimmung und Beifall finden, oder sogar als Helden und Häupter gefeiert und gepriesen werden. In jeder Gruppe, die nach innen soziale Wirkungen ausübt, hat sozusagen jeder Mitspieler sein Publikum, dem er gefallen oder wenigstens nicht mißfallen will. Es ergeben sich aber daraus viele Kollisionsfälle. Oft wird das Mißfallen eines Kreises in den Kauf genommen, um das Gefallen eines anderen zu finden; insbesondere der Beifall einer kleineren Gruppe verschmäht, wenn derjenige einer größeren winkt, derjenige einer nahen hintangesetzt, wenn derjenige einer entfernten erreichbar scheint ${ }^{2}$ ).

\footnotetext{
1) Nach Franks Kommentar zum StrG.ist ,"öffentliche Meinung im Sinne desGesetzes" „die Meinung eines größeren, individuell nicht bestimmten Teiles der Bevölkerung“.

2) BÖHM-BAwERK spricht von einer öffentlichen Meinung der Wissenschaft in der Times ist öfters von der »commercial public opinion « die Rede; hingegen sprechen S. u. B. WEBB von ,einer öffentlichen Meinung, die sich um 1867 unter den englischen Gewerkvereinen gebildet habe (History of Trade Unionism, p. 250).
} 
IV. Kapitel.

\section{ÖffentlicheMeinung und die ÖffentlicheMeinung.}

\section{Erster Abschnitt. Entstehung und Charakter der Offentlichen Meinung.}

I. (Sprachgebrauch und Begriffe.) Hier bleibe zunächst seine" öffentliche Meinung außerhalb der Betrachtung. Um so mehr ist daran gelegen, die öffentliche Meinung als äußere Gesamtheit widersprechender mannigfacher Meinungen, die öffentlich laut werden, und dagegen die Offentliche Meinung als einheitlich wirksame Kraft und Macht deutlich und scharf $\mathrm{zu}$ unterscheiden. Es wurde mehrmals auf das Widersprechende hingewiesen, daß "Meinen* einerseits so viel als Denken bedeutet, also durchaus das Hegen eines Urteils, einer Absicht oder Ansicht, andererseits geradezu ein abgekürzter Ausdruck ist für: eine Meinung (ein Urteil, eine Absicht oder Ansicht) aussprechen, kundgeben: sei es in vertrautem Kreise, in geschlossener Gesellschaft, oder öffentlich, sozusagen in offener, jedem zugänglicher Gesellschaft. Im Sprachgebrauch bedeutet öffentliche Meinung nicht nur die ausgesprochene, sondern die für die Offentlichkeit, das Publikum, die Allgemeinheit ausgesprochene und bestimm te Meinung. Aber diese Bedeutung vermischt sich eben im Sprachgebrauch mit der anderen, wonach die Allgemeinheit oder das "Publikum « zunächst oder wenigstens a uch als S ubjekt der Mein ungen gedacht wird: in diesem Sinne ist schon von den Meinungen und dem Gemeingut des politischen Publikums gesprochen worden. Der wissenschaftliche Gedanke muß diese Bedeutungen nicht nur auseinanderhalten, sondern die beiden ganz verschiedenen Begriffe daraus entwickeln, wie es hier geschieht, wenn wir die »unartikulierte" öffentliche Meinung getrennt von der artikulierten, »der " (eigentlichen) Offentlichen Meinung darstellen. Für beide Begriffe bleibt die öffentliche Kundgebung und die Beziehung auf öffentliche, d.i. in erster Linie politische Angelegenheiten wesentlich. Dort aber - bei öffentlicher Meinung - wird Allgemeinheit nur insofern mitgedacht als »alle" irgendwie am öffentlichen Kundgeben von Meinungen tätigen oder leidenden Anteil nehmen; hier dagegen, für die Offentliche Meinung ist das Subjekt eine wesentlich, insbesondere politisch, verbundene Gesamtheit, die darüber einig geworden ist, so zu meinen und zu urteilen, und die eben dadurch wie von selber der Offentlichkeit, dem öffentlichen Leben angehört. Damit berührt sich nahe ein starker Unterschied in der Bedeutung des Meinens selber. Dort hat es überwiegend einen Gedankensinn (intellektualistischen), hier überwiegend einen 
Willenssinn (voluntaristischen). Dort sind es die öffentlich kundgegebenen, allen sich mitteilenden Ansichten - mannigfach und bunt und einander widersprechend, ja leidenschaftlich bekämpfend -, Ansichten, hinter denen freilich die Wünsche und Bestrebungen, die Interessen von Gruppen und Einzelnen stehen, unterbewußt, bewußt und überbewußt; Ansichten, die auch regelmäßig zugleich Urteile, Verneinungen und Bejahungen sind. Hier aber ist die Offentliche Meinung wesentlich ein Wille, Wille im Urteil und durch das Urteil - das Urteil aber ist ein einheitlicher Akt -; mithin eine bewußte und ausgesprochene Willensform, nach Art des Beschlusses, den ein Gerichtshof oder sonst eine "beschlußfähige "Versammlung "faßt «, worauf sie sich einigt - Ausdruck des Willens einer Gesamtheit, die aber als Publikum oder Subjekt der Offentlichen Meinung nicht versammelt ist, außer im Geiste - in der Regel viel zu groß, um als Versammlung vorgestellt werden zu können ${ }^{1}$ ).

1) Nachdem ich schon seit etwa fünf Jahren die hier vorgelegte wichtige Unterscheidung gehegt und durchdacht hatte, fand ich in dem auch sonst schätzbaren Buche »Kultur und Presse von DR. EMiL LöbL (auch MAX WEBER rühmte es in seinem Berichte an die Deutsche Gesellschaft für Soziologie: Verhandlungen des ersten deutschen Soziologentages [Tübingen, Mohr I9II, S. 43], es sei auffallenderweise viel weniger gekannt als es verdiene) folgende Stelle: nachdem dargelegt worden, daß eine öffentliche Meinung außerhalb der Presse sowie im Gegensatze zur Presse entstehen, sich entwickeln und zur Macht werden könne. „Noch schwieriger wird das Problem dadurch, daß eine einheitliche öffentliche Meinung infolge der fortschreitenden Differenzierung und Zerklüftung des Parteiwesens immer seltener wird. Streng genommen kann von »der« öfentlichen Meinung nur in dem Falle gesprochen werden, wenn es eben eine ist, eine einzige, oder wenn wenigstens eine von den mehreren Meinungen die erdrückende Majorität für sich hat; in allen anderen Fällen hat man es mit mehreren verschiedenartigen öffentlichen Meinungen $z u$ tun" (S. 252f). Schon früher hatte ich die I5 Jahre später als LöBls Buch erschienene Schrift des im Kriege gefallenen HERBERT JORDAN, (angelegt als eine Doktor-Dissertation, aus seinem Nachlasse herausgegeben von Johannes Hohlfeld, Kamenz 1918) kennen gelernt. Darin heißt es (S.4): „,Der Begriff \#öffentliche Meinung ist eigentlich ein Widerspruch in sich selbst. Der Charakter des Einheitlichen - im Begriff des Hauptwortes - wird zerstört durch das Eigenschaftswort, denn dieses weist auf eine Vielheit von Menschen und damit von Meinungen hin. Wirklichen Sinn konnte diese Zusammensetzung bloß haben zu einer Zeit, wo das Volk noch eine ungebrochene Einheit in De $\backslash$ ken und Fühl ın darstellte, oder, wo doch, wie in der Romantik, der Begriff einer einheitlichen, auf den einzelnen Lebensgebieten zu entsprechender Ausformung gelangend n Volksseele allgemein geläufig und gebräuchlich war. In Wahrheit stellt die öffentliche Meinung (besonders wenn man den Begriff auf das rein Politische beschränkt) auf jeder höheren Entwicklungsstufe ein Spiel stetig und heftig miteinander ringender Gegensätze dar, die nur in den seltensten Augenblicken in der überflutenden Welle eines großen einheitlichen Gefühls untergehen. Diese Gegensätze gilt es hervorzusuchen und sie in ihrem gegenseitigen Kräfte- und Spannungsverhältnisse darzustellen." Man erkennt, wie der junge Gelehrte, der als wahrer Held sein Leben geopfert hat, mit der von LöBL bedeuteten Schwierigkeit ringt. Wiefern seine Auffassung berichtigt werden muß, wird sich aus dem, was im Texte mitgeteilt wird, ergeben. JORDAN nennt einen Begriff, was nur eine im Sprachgebrauch schwebende Vorstellung ist. 
2. (Die Analogie der Versammlung.) Zusammenhänge und Ủbergänge zwischen dem einen und dem anderen Sinne des Ausdruckes ’offentliche Meinung sind allerdings vorhanden. Auch eine Versammlung, die ja unter Umständen befugt ist oder doch das Recht in Anspruch nimmt, Gesetze für einen ganzen Staat zu geben, ist etwas anderes, indem sie beschließt und beschlossen hat, etwas anderes im Zustande der Beratung. Dort steht sie als ganze, als Gesamtheit, hinter dem Beschluß, weil (in der Regel) der Wille der Mehrheit der Anwesenden oder doch einer gewissen Anzahl (der beschlußfähigen Zahl) als Wille der Versammlung und als solcher oft zugleich als Wille einer größeren Gesamtheit, die durch diese Versammlung "vertreten * wird, gilt. Diese größere Gesamtheit - z. B. das in einem Staate vereinigte Volk - trägt gleichsam die ideelle Versammlung (z. B. den Reichstag oder Landtag), die sich in der realen Versammlung abbildet. Im Zustande der Beratung ist die reale Versammlung geteilt und zerrissen durch widerstreitende Meinungen und Reden. Die ideelle Versammlung und die hinter ihr stehende Gesamtheit warten gleichsam darauf, da $B$ die reale Versammlung zur Abstimmung schreite und also zu einem Beschlusse komme. Bis dahin wird der Gegenstand, die Vorlage, der Antrag, nach dem lateinischen Ausdruck wauseinandergeschlagen * (diskutiert), es findet die "Debatte "d.i. eine Art von Kampf und Streit in Worten, Gebärden, Beifalls- oder Mißfallensgeräuschen, zuweilen auch in Tätlichkeiten statt, wozu sich dann die Beschlußfassung als eine Art von Friedensschluß verhält, der gleich anderen Friedensschlüssen zuweilen aus dem entschiedenen Siege der einen Seite (hier der einen Meinung) hervorgeht, oft aber auch durch ein gegenseitiges Nachgeben zwischen Ansichten und Absichten, die einander sonst ausschließen und $\mathrm{zu}$ vernichten wünschen, - als "Kompromiß — - bedingt ist: sei es, daß eine geschlossene Mehrheit ihrerseits ein teilweises Nachgeben für richtig hielt, um die Minderheit nicht zu sehr zu kränken und zu drücken, vielmehr, anstatt ihre Vergeltung herauszufordern, sie zu beruhigen; sei es, daB eine Mehrheit in der Angelegenheit iiberhaupt nur durch gegenseitiges Nachgeben zwischen verschiedenen Meinungsgruppen zustande kommt, die insoweit sich einig werden, da $B$ sie gemeinsam den Widerstand der Minderheit zu überwinden fähig sind: in der Regel werden diese Gruppen auch sonst einander nahe stehen und eine Affinität zueinander haben, zuweilen aber wird die gemeinsame Gegner- und Feindschaft die heterogensten und sonst einander am meisten zuwideren Gruppen zu Bundesgenossen machen; gleichwie in der großen Politik. Die Personen der Beratung und der Beschlußfassung sind nicht notwendig und immer dieselben: manche nehmen 
an der Beratung teil, die an der BeschluBfassung nicht teilnehmen oder sich der Abstimmung enthalten, zuweilen haben auch einige zwar das Recht, mitzuraten, aber nicht das Recht "mitzutaten «, d.h. sie haben eine beratende, aber keine beschließende Stimme. - Man kann also öffentliche Meinung sowohl als »die" Offentliche Meinung mit einer Versammlung vergleichen, um dadurch ihr gegenseitiges Verhältnis zu erläutern; die beiden Vorstellungen werden so gleichsam auf einen Nenner gebracht, und dies ist für das begriffliche Denken wertvoll. Im Sprachgebra uch ist man des Unterschiedes sich nicht bewußt. Wohl aber wird tatsächlich bald von der öffentlichen Meinung als von etwas Unlebendigem (ich vergleiche sie einem Gefäß oder einem Mischkessel) gesprochen, worin mannigfache, miteinander unverträgliche Bestandteile sich zusammengegossen finden und in mehr oder minder heftige Gärung geraten; bald erscheint (im anderen Sinne) die Offentliche Meinung gleichsam als ein denkendes Wesen und als einheitliche Macht, ja wird oft als ein geheimnisvolles erhabenes und beinahe mythisches Wesen gepriesen, oder aber - von solchen, die sich durch diese Gottheit mißhandelt fühlen - angeklagt und gescholten.

Wenn wir hier die Analogie der beratenden und beschließenden Versammlung heranziehen, so bleiben wir der Unterschiede uns bewußt. Versammlungen, die $\mathrm{zu}$ beraten und $\mathrm{zu}$ beschließen vermögen, gibt es höchst mannigfache. Ich unterscheide Selbst-Versammlungen und gebotene Versammlungen, ungeordnete und geordnete, selbst sich ordnende und von außen geordnete, ungeordnet oder schon geordnet zusammenkommende, ideelle und reale Versammlungen (s. oben), wo die ideelle Versammlung eine Körperschaft bedeutet, insofern sie als deren durch einen Kollektivwillen bestellte Eirscheinungsform sich darstellt, sei es da $B$ diese Körperschaft ein selbständiges Dasein hat oder als Organ eines allgemeinen Willens und Verbandes gedacht wird. Die ideelle Versammlung kann als ein zeitlich bedingtes und begrenztes, sie kann aber auch als ein unzeitliches oder doch auf unbestimmte, ja ewige Dauer eingerichtetes Wesen gedacht werden; eine reale Versammlung, möge sie eine ideelle Versammlung darstellen oder nicht, nimmt einen bestimmten Raum ein und dauert eine gewisse Zeit, sie hat also ein materielles Dasein, auch wenn sie als eine Einheit sich geltend machen und zu diesem Behuf einen gemeinsamen Willen aus sich entwickeln will oder soll. In der Regel wird alsdann von ihrem äußeren und sichtbaren Dasein das innere und geistige dadurch unterschieden, daß sie förmlich meröffnet " und förmlich "geschlossen " wird. Jede Versammlung kann auch unter freiem Himmel stagen "; aber auch dann sind die $\mathrm{zu}$ ihr gehörigen Personen als solche erkennbar, sei es da $B$ sie lebendig mitwirken 
oder nur zuhören; in jedem Falle können aber auch die zur Mitwirkung Berechtigten besondere Merkmale oder Kennzeichen tragen, und wenn es sich um die berechtigten Mitglieder einer ideellen Versammlung handelt, so werden diese ihre Berechtigung nachweisen müssen, auch finden solche Versammlungen regelmäßig in ge schlossenem Raume, und nicht selten geheim - unter AusschluB der Offentlichkeit - statt. Offentliche Meinung entbehrt des bestimmten Raumes, der gewissen Zeit. Sie breitet sich nebelhaft aus, sie ist ganz und gar unsinnlicher Natur, nur durch Denken wahrnehmbar; dies Merkmal hat sie mit der ideellen Versammlung gemein, aber wie in einer realen Versammlung kommen in ihr viele gegenwärtige Menschen zu Worte, sie kann um so eher einer beratenden Versammlung verglichen werden, wenn in solcher Versammlung ein Durcheinander von Stimmen, von Tumult und Geschrei sich vernehmbar macht und den Präsidenten vermissen läßt, der in einer geordneten Ratsversammlung dem Zank und Streit seine Grenzen zieht, gewisse Ausdrücke rïgt und dem allzu frechen Redner das Wort entzieht. Jedoch ist auch die öffentliche Meinung, als Versammlung gedacht, nicht schlechthin ohne Geschäftsordnung: gewisse Anstandsregeln sollen gemä $B$ stillschweigender Verabredung beobachtet werden, wer diese konventionellen Vorschriften nicht beobachtet, macht sich in der Gesellschaft *unmöglich «, er wird aus ihr moralisch hinausgeworfen, wie unter Umständen ein Mitglied aus einer parlamentarischen Versammlung entfernt wird.

3. (Die Grenzen der Hörweite.) Die Offentlichkeit der öffentlichen Meinung ist an und für sich unbeschränkt. Wer in ihr das Wort nimmt, kann möglicherweise überall auf dem Erdenrund gehört werden und wird es zuweilen wirklich, wenn auch kaum jemals von allen (auch nur den erwachsenen) Menschen. In der Regel ist die Hörweite begrenzt I. durch die Sprache, in der er sich vernehmen läßt, 2. auch durch ein politisches Gebiet, innerhalb dessen der Gegenstand, auf den die "Rede" sich bezieht, seine Bedeutung ïberhaupt oder doch in der gegebenen Anwendung hat, 3. durch den Bildungsstand der Hörer oder Leser, der sie das Gehörte verstehen und überlegen läßt, 4. durch die Kraft der geistigen und moralischen „Stimme «: auf diese wirkt bedingend a) das Ansehen, das der »Redner " aus äußeren oder inneren Gründen genieBt, b) das Gewicht seiner Gründe, die Gewandtheit und Geschicklichkeit im Gebrauche von Schlagwörtern, erheiternden Wendungen und Witzen, rednerischen Figuren, Interesse und Aufsehen erregenden Mitteilungen und anderen die Aufmerksamkeit stachelnden und reizenden Mitteln, c) die L,eidenschaft, das Pathos, der "Brustton der Uberzeugung ", womit er seine 
Zuhörer oder Leser zu "packen « versteht, d) die Tatkraft und Rücksichtslosigkeit; womit er die wirksamste der rednerischen Figuren, die Wiederholung anzuwenden sich befleißigt und versteht. Die Hörweite ist ferner wesentlich begrenzt 5 . durch die schon vorhandene Anhängerschaft, also insbesondere die Glaubensgenossenschaft, Parteigenossenschaft, Berufsgenossenschaft und oft die Zugehörigkeit zu einer bestimmten Clique, einer Gruppe, einem Flügel, in nerhalb solcher Verbundenheiten; also auch durch das Ansehen und die anderen Momente, die das Gewicht einer Stimme insbesondere in einem solchen engeren Kreise bestimmen - dazu gehört vor allem eine anerkannte Führerrolle, aber auch der Glanz eines gefeierten Namens, der Machtzauber (Prestige), der von anerkannten Leistungen und von Erfolgen, die allen als erwünscht gelten, ausgeht; dies Moment macht sich in kleinen wie in großen Verbundenheiten unwiderstehlich geltend - es ist, was MAX WEBER neuerdings als Charisma beschrieben hat. Endlich 6. ist die Hörweite begrenzt durch die äußeren Mittel und Wege der Ausbreitung, also durch die Art des Vertriebes eines Buches, die Kapitalkraft, die Verbindungen, die Rührigkeit eines Verlages; insbesondere aber durch Art und Größe des Publikums, das eine periodische Druckschrift - Zeitschrift oder Zeitung - hat oder sich zu verschaffen weiß. Zum guten Teil ist dieser Grad der Offentlichkeit wiederum abhängig von der Zahl, der Kaufkraft, Opferwilligkeit und anderen Eigenschaften der Angehörigen einer Partei oder anderen Gruppe, aber auch andere Eigenschaften tragen zur Erweiterung des Publikums bei, so $\mathrm{da} B$ z. B. je bedeutender eine Zeitung, desto mehr sie auch außerhalb ihrer Parteikreise gelesen und beachtet wird.

4. (Die Presse.) Tatsächlich ist unter den Lebensbedingungen des gegenwärtigen Zeitalters nicht nur der Buchdruck ïberhaupt das wichtigste Mittel, wodurch sich Menschen in der öffentlichen Meinung gehört, verstanden, gewürdigt machen, sondern es ist besonders die periodische Presse, und als solche wiederum die Tagespresse, die in diesem Sinne »das« Organ der öffentlichen Meinung genannt zu werden pflegt und genannt zu werden verdient. Aber es ist ein großer Irrtum und ein typischer Fall des Mißverständnisses, das aus der gedankenlosen Unterwerfung unter den Sprachgebrauch so oft entspringt, wenn man darum die Presse als Organ der Offentlichen Meinung bezeichnet oder wohl gar als ihrem Wesen nach mit dieser identisch, was wiederum dahin ausgelegt zu werden pflegt, daß sie die Offentliche Meinung "mache" - obgleich hierin der entgegengesetzte Sinn des Satzes, der sie als deren "Organ" auffaßt, ausgesprochen wird. Mit der ,weitverbreiteten aber unberechtigten Identifizierung von Presse und 
öffentlicher Meinung" hat auch LöвL (Kultur und Presse, S. 253ff.) sich beschäftigt. Er trägt die genannte Auslegung vor, ohne zu bemerken, $\mathrm{da} ß$ sie doch etwas anderes ist als die gerügte Identifizierung. Die eine wie die andere will er mit dem Satze widerlegen, die Offentliche Meinung sei das Produkt aus zwei Faktoren: der eine sei die ursprüngliche lebendige Idee, der andere aber der "Verstärkungsmultiplikator «, diesen stelle regelmäßig, nicht ausnahmslos, die Presse dar. Es könne eine öffentliche Meinung außerhalb der Presse sowie im Gegensatze zur Presse entstehen, sich entwickeln und zur Macht werden. „Dem Propagator der Idee stehen auch andere Mittel der Verbreitung und Verstärkung seiner Idee zu Gebote, das Buch, die parlamentarische Tribüne, das Vereinsleben, Versammlungen, öffentliche Vorträge, gesellige $\mathrm{Zu}$ sammenkünfte, die unmittelbare stille Agitation von Mann zu Mann, und alle diese Mittel sind in jenen „Fällen erfolgreich zur Anwendung gelangt, in denen eine öffentliche Meinung ohne oder selbst gegen die gesamte Presse ins Leben gerufen wurde" (255). LöBL geht an den Folgerungen vorbei, die aus seiner längst vor mir gefundenen Unterscheidung "der * Offentlichen Meinung von der mannigfachen öffentlichen Meinung gewonnen werden müssen. Um diese zu begründen, muß zunächst eine tiefere Auffassung der Offentlichen Meinung hier eingeschoben werden.

5. (Aggregatzustände der Öffentlichen Meinung.) Ebenso wie bei der individuellen Meinung, sind bei der sozialen, der allgemeinen, der Offentlichen Meinung, verschiedene Aggregatzustände zu unterscheiden. Der Grad ihrer Festigkeit ist der Grad ihrer Einheitlichkeit. Auch im luftartigen Zustande kann sie als Einheit erscheinen I. wenn dieser Zustand gleichsam durch Verdunstung einer fester und inniger zusammenhängenden Einheit entsteht, also aus einem flüssigen oder unmittelbar einem festen Aggregatzustande hervorgeht. Die feste Offentliche Meinung gerät in Fluß, wenn ihr Bewegung zugeführt wird, und dies kann durch irgendwelche Wahrnehmung, irgendwelche Gedanken, irgendwelche Erfahrung geschehen, von der die Gesamtheit, die wir als Subjekt der Offentlichen Meinung vorstellen, ergriffen wird. Die feste Offentliche Meinung ist eine allgemeine unerschütterliche Uberzeugung des Publikums, das als Träger solcher Überzeugungen ein ganzes Volk oder einen noch weiteren Kreis der "zivilisierten Menschheit «vertritt. Solche Uberzeugungen gibt es nicht wenige, z. B. auf dem politischen Gebiete, da $B$ der Absolutismus oder die Autokratie eines Monarchen als Staatsform vom Ubel sei, oder auf dem rechtlichen, daß die peinliche Frage ("Folter ") als Beweismittel, und daß qualifizierte Todesstrafen als Strafmittel "barbarisch ", also verwerflich seien. Sie können in FluB geraten, wenn z. B. bekannt wird, daß eine Autokratie, deren 
Sturz die Offentliche Meinung mit Genugtuung wahrgenommen hat, unter dem Scheine des Konstitutionalismus mit Gewalt und Schrecken sich wiederherstellt, wie es in Rußland durch SToLyPIN geschah. Die Uberzeugung gewinnt dann an Leidenschaft, aber sie verliert an Festigkeit und Einheitlichkeit: die Ansicht, daß nichts als Scheinkonstitutionalismus und ungerechte Verfolgung der Revolutionäre vorliege, kann bestritten werden, sie wird aber durch die Opposition heftiger. Uber die allgemeinen Ideen ist die Einigkeit der Offentlichen Meinung am vollkommensten, wie sich schon im Affekt der Sprache kundgibt, die Wörter wie Tyrannei, Despotismus, Barbarei, oft auch Mittelalter u. dgl. mit dem Bann belegt; anders ist es schon, wenn die Frage entsteht: liegt hier Tyrannei, liegen mittelalterliche $Z$ ustände vor? und vollends, wenn etwas als verwerflich, verdammenswert erscheint und dafür ausgegeben wird, ohne sich einfach nach solchem Schema zu richten. Doch entsteht in solchen Fällen eine dunstartige Offentliche Meinung aus der flüssigen oder durch deren Vermittlung aus der festen. Dieser Dunst ist das, was gewöhnlich als die Offentliche Meinung verstanden wird, weil sie hier am auffallendsten, heftig und stürmisch, in die Erscheinung tritt. Hier wird aber auch ihr parteilicher Charakter offenbar. Sie beruht in der modernen Denkungsart, deren allgemeine Grundsätze den Parteien gemeinsam sind und kaum je bestritten werden; aber in Einzelheiten jeder Art gibt es nicht nur abweichende Meinungen, sondern ganze Gruppen und Parteien, die auch an hochgebildeten Männern und Frauen ihre Häupter haben, und an alten Vorstellungen und Vorstellungsweisen hängen, wenn auch ihre Stimmen in der Regel vielleicht übertönt werden. Denn in der Offentlichkeit ist eben das Neue, das Moderne, die aufgeklärte Denkungsart auch die stärkere und hat zumeist eine unwiderstehliche Kraft. Die Offentliche Meinung tritt immer mit dem Anspruch auf, maßgebend zu sein, sie heischt Zustimmung und macht wenigstens das Schweigen, das Unterlassen des Widerspruchs zur Pflicht. Mit mehr oder weniger Erfolg; je vollkommener der Erfolg, um so mehr bewährt sie sich als die Öffentliche Meinung, trotz des mehr oder minder zum Schweigen gebrachten Widerspruchs. Am klarsten tritt dies in Fragen hervor, die mit der Religion zusammenhängen. So ist die Theokratie und der Glaube, daß durch priesterliche Salbung ein König mit göttlichem Zauber angetan werde, in Europa so gut wie aufgegeben. Aber es gibt zweifellos in jedem Lande viele, auch sehr gebildete Personen, die wenigstens in ihrem König und etwa sogar in jedem Prinzen so etwas wie ein höheres, vom Himmel begnadetes Wesen verehren. Gleichwohl erhebt sich ein Sturm der Offentlichen Meinung, wenn ein König daraufhin eine überirdische Weisheit in Anspruch nimmt und Gehorsam für einen 
Befehl verlangt, weil ihm eine Eingebung von Gott $z u$ Teil geworden sei, die diesen Befehl heilige. Sogar, wenn der Befehl an und für sich nicht als unsinnig erscheint, wird die Offentliche Meinung doch mit vollkommener Zuversicht über diese Anmaßung den Stab brechen. Ebenso wird in Fällen, wo die Humanität, mit der im allgemeinen die Offentliche Meinung fest verbunden ist, in Frage steht, obschon die Anwendung streitig ist und manche Arten der Behandlung von Mitmenschen als "Humanitätsdusel « angeklagt werden, dennoch eine krasse In h u ma nität - etwa die Mißhandlung eines schwachsinnigen Soldaten durch seinen Vorgesetzten - von der Offentlichen Meinung mit anscheinender Einmütigkeit verurteilt werden, wenn man auch wei $B, \mathrm{da} B$ es viele gibt, die das Verhalten der Vorgesetzten unbedingt billigen, oder doch unter den gegebenen Umständen für gerechtfertigt halten.

6. (Verallgemeinerung einer Teilmeinung.) 2. Aber die luftartige Offentliche Meinung, die wir auch als die Offentliche Meinung des Tages verstehen mögen, entsteht auch auf andere Weise, nämlich dadurch, daß eine Teilmeinung sich ergänzt und verallgemeinert, und zwar eine Teilmeinung, die nicht an einer festen Offentlichen Meinung ihre Stütze hat, sondern vielmehr dieser entgegengerichtet ist. Sie erringt einen Sieg - etwa nur für den Augenblick, in einem bestimmten Zusammenhange und Bezuge. Diesem Siege, selbst, wenn er sich wiederholt, kann eine schwere und langwierige Niederlage folgen; es kann aber auch ein dauernder Sieg werden, und wird es am ehesten, wenn er in der Linie einer natürlichen, d. i. durch andere mächtige Faktoren geförderten Entwicklung liegt. So ist es im allgemeinen mit der religiösen, der bürgerlichen und der politischen Freiheit gewesen, um die aufgeklärte Denker und hinter ihnen die bürgerliche, aber auch die Arbeiterklasse seit etwa 400 Jahren mit langsam zunehmender Energie und wachsender Kühnheit gekämpft haben. Sie hatten zunächst die Offentliche Meinung, soweit diese durch das Herkommen, die Religion, die Macht des Herrenstandes gebildet und gebunden war, gegen sich. Diese Mächte waren z. B. im Deutschland nach den Befreiungskriegen wieder erstarkt durch den $\mathrm{HaB}$ gegen BONAPARTE und die große Enttäuschung der Revolution, die ihn emporgebracht hatte, durch den Widerwillen gegen die Schrecken und Verwüstungen, die sie nach sich zog, durch das Bedürfnis der Ruhe und die Iiebe zu den hergebrachten heimischen Institutionen, wiedererwachte Ehrfurcht vor den Landesvätern, dem Adel, der Kirche und allen Würdenträgern. Da trat die Juli-Revolution ein; die Kunde von der "großen Woche "breitete sich in deutschen Landen aus. „Die so lange niedergehaltenen Parteien der deutschen Oppo- 
sition atmeten fröhlich auf." Früher hatte TREITSCHKE, der sich so ausdrückt (D. G. IV, 35), schon auf ,die literarischen Vorboten einer neuen Zeit" aufmerksam gemacht: die Wissenschaft habe sich (I820 bis I830) mit wachsendem Eifer und Verständnis auf die großen Probleme des öffentlichen, des handelnden Lebens geworfen (III, 683), F. C. SchlosSER, der durchaus unpolitische Gelehrte, sei ein Wortführer der Offentlichen Meinung geworden (das. 697). Es war in der Tat ein Glück für den Liberalismus in Deutschland (wie auch in England, wo er um die parlamentarische Reform kämpfte), da $B$ der letzte Bourbonen-König in so grober Weise durch seine "Verordnungen " (die Ordonnances) die Öfentliche Meinung vor den Kopf stieß, die von einem ultramontan-reaktionären Regiment überall nichts wissen wollte und darum zunächst für die Umwälzung jenseits der Vogesen, dann auch für Belgien, für Polen und endlich auch in deutschen Gauen für die Vertreibung des Braunschweiger Herzogs, für den Verfassungskampf in Kurhessen, Partei ergriff und das hannöverische Staatsgrundgesetz von 1833 willkommen hieß, wie einst die konstitutionelle Charte Frankreichs von I8I4. Und wiederum war es, nur 4 Jahre später, ein Staatsstreich, der ,die halb entschlummerte öffentliche Meinung" wachrief und die Deutschen zwang, ihre, ,politische Leidenschaft wieder dem Vaterlande zuzuwenden" (TREITSCHKE das. 665) die Aufhebung jenes hannöverischen Staatsgrundgesetzes, das ,unzweifelhaft die bescheidenste unter den neuen norddeutschen Verfassungen" (das. S. I63) war, durch die Willkür eines neuen Königs. Die Handlungsweise der "Göttinger Sieben « fand in ganz Deutschland einen lange nachwirkenden Widerhall. „Mit Staunen verfolgte man im Ausland die einmütigen Äußerungen der öffentlichen Meinung des deutschen Bürgertums" (STERN, Geschichte Europas V, I24). Und wenn der französische Bürgerkönig es beklagt hat (das.), daß ERnSt August durch seinen Staatsstreich der demokratischen Partei so gefährliche Waffen in die Hand gegeben habe, so ist damit eben der Punkt getroffen, wo durch eine auffallende Begebenheit, insbesondere durch die Erregung menschlich-sittlicher Sympathie und Antipathie, eine Parteimeinung in die Offentliche Meinung übergeht, was allerdings für jene eine "Waffe «, also einen Vorteil in ihrem Kampfe darstellt. Dies ist eine allgemeine und sich oft wiederholende Erscheinung. Im Kampfe der Parteien ist es zuweilen ein erstrebtes und erreichtes Ziel, öfter aber ein ungewolltes, zufälliges Ereignis, das der einen Seite ein moralisches Ubergewicht gibt, das, auch wenn nur augenblicklich, doch tiefwirkende Folgen haben kann; und dies moralische Übergewicht ist der Beifall oder das Mißfallen der Öffentlichen Meinung. Gewolltes und Erreichtes - der Erfolg - kommt in erster Linie den 
einzelnen weithin sichtbaren Personen, also auch ihren Anhängern und der Partei, die sich um eine solche schart, zu gute. Der Zufall kann jedem helfen; aber der wahrscheinlichste Zufall ist der Fehler oder das Mißgeschick des Gegners, wozu einzelne Personen oft am meisten beitragen. So hat im Deutschen Reiche der letzten Epoche das Auftreten eines Mannes wie Herr von OLDENBURG-JANUSCHAU, so der Fall BRÜsEwITZ (die Taktlosigkeit und Brutalität eines Offiziers), so die ungeschickte, ja täppische Art, wie der Monarch sich die Freundschaft des englischen Philisters wiederzugewinnen suchte, so endlich die "Zabern-Affaire " - ein Ubergriff der Heeresgewalt über die Grenzen seines Rechtes - , alle diese "Fälle» schienen im Inlande wie vollends im begierig danach haschenden Auslande, denen Recht zu geben, die den Militarismus und das Junkertum anklagten, als ob sie die bürgerliche Freiheit in Deutschland zu nichte machten: die Offentliche Meinung war, wie immer, «schnell fertig mit dem Wort «und war insbesondere im Auslande, das der wirklichen Verhältnisse unkundig, durch die Scheinwerfer solcher Ereignisse sein Urteil gestalten oder vielmehr in seinen Vorurteilen sich bestärken läßt, verhängnisvoll; noch heute dienen sie, selbst für ziemlich einsichtige Schriftsteller britischer Zunge als Beweisstücke für die "Schuld " Kaiser Wilhelms und der deutschen Oberschicht am Weltkriege - freilich eine armselige Beweisführung, aber von der Art, wie sie vor dem "Gerichtshof der Offentlichen Meinung " alle Tage geführt wird, zumal wenn Ankläger und Richter mit gleicher Parteiblindheit geschlagen sind.

7. (Kämpfe um die Öffentliche Meinung.) Die unablässigen Kämpfe der Meinungen, die in der Arena der öffentlichen Meinung, also in der gesamten Literatur und in der Presse, wie auf allen anderen Gebieten des öffentlichen Lebens geführt werden, sind zum guten Teil Kämpfe um die Offentliche Meinung, und zwar am unmittelbarsten und häufigsten, insbesondere die der Tagespresse, um die luftartige Öffentliche Meinung des Augenblicks. Diese Kämpfe gliedern sich also nach den wesentlichen Unterschieden der Parteien, daher stehen in dauerndem oder immer sich wiederholendem Gegensatz, wie früher dargestellt:

A. Die Regierung und die Opposition,

B. Die konservative und die reformative Richtung,

C. Die rechtgläubige (orthodoxe) und die andersgläubige (heterodoxe) Richtung.

Wir betrachten diese Gegensätze hier wesentlich unter dem Gesichtspunkte des Verhältnisses einer herrschenden Macht und Richtung zur Opposition und Kritik, die ihr begegnet. 
A. Jede Regierung strebt, sich zu behaupten: nach außen mit dem Gemeinwesen oder Staat, an dessen Spitze sie steht, nach innen gegen die Widerstände, denen sie innerhalb der Regierten begegnet. Diese Widerstände werden regelmäßig um so heftiger sein, je mehr sie ihre Macht zu vergrößern und zu verstärken sich bemüht, je mehr sie dabei auf andere Mächte stößt und je mehr diese Mächte in ihren ursprünglichen oder erworbenen Rechten sich gekränkt fühlen. Denn jede Regierung stïtzt sich zwar in erster Linie auf die tatsächliche Gewalt, die sie besitzt, aber diese Gewalt selber will eine rechtmäßige Gewalt sein oder wenigstens werden, sie will als rechtmäßig gelten. Gelten d. h. dafür geachtet und geschätzt werden, also den Glauben oder die Meinung für sich haben.

Der moderne Staat hat sich in fortwährendem Gegensatz gegen die Einrichtungen und die herrschenden Stände des Mittelalters entwickelt. Vorbildlich geschah diese Entwicklung in freien Städten und zwar um so leichter, wenn sich hier als Träger des Staats der weltliche Herrenstand (der Patriziat) gegen den geistlichen geltend machte, aber auch, wenn die Bürgerschaft gegen beide sich erhob, die mit dem Glauben an sich selber eine ausreichende Gewähr ihrer Macht, auch gegenüber der großen Menge, besaß. Aber der hauptsächliche Träger des modernen Staats, der sich auf Land und Städte ausdehnt, ist der Monarch, der Fürst gewesen, zumeist beglaubigt durch Erbrecht, mehr aber durch Religion, die ihn in ein unsicheres Wechselverhältnis $\mathrm{zu}$ deren organisierter Macht, der Kirche setzte, auf die er sich stützen, die er aber zugleich beherrschen wollte. Oft, und in zunehmendem $\mathrm{MaBe}$, hatte er in diesem Kampfe auch die Religiosität eines guten Teiles seiner Untertanen, besonders der städtischen Bürger, auf seiner Seite, mit deren Interesse er zugleich gegen die Großen als seine Rivalen sich zu verbinden pflegte. Vor allem aber wirkte er durch den Machtzauber, das Prestige, die Pracht seiner Würde, seiner Person und seiner Umgebung, nach allen Richtungen, auf die Großen, die daran mehr und mehr Anteil gewannen und Geschmack fanden, auf das Volk, dem die Monarchie von altersher als erhaben und göttlich erscheint, und um so mehr sinnlich starken Eindruck zu machen, $\mathrm{zu}$ "imponieren " bestimmt ist, je mehr in ihm selber die Kunstpflege fortschreitet. MACHIAVELLI betrachtet im allgemeinen nur als die Aufgabe seines Principe, gegen den Ehrgeiz der Großen und gegen die Frechheit (insolenza) des Volkes zu kämpfen, aber den römischen Imperatoren sei als dritte Schwierigkeit entstanden, daß sie die Grausamkeit und Habsucht der Soldaten befriedigen mußten. Der Florentiner faßt noch nicht eine eigentliche Opposition und Kritik ins Auge, wie sie aus der wissenschaftlichen 
Bildung, schon unter dem Einflusse der Theologie, mehr und mehr durch Ausbreitung des literarischen Wesens hervorgeht. Solche gehört eben einer späteren Phase, der des eigentlichen fürstlichen Absolutismus an. Dieser behauptet sich, wie der Principe MacchiaVELIIS, durch Gewalt und durch List oder Staatsklugheit; und zur Staatsklugheit gehört die Begünstigung einer ihm günstigen Religiosität, wenn nicht seiner eigenen Göttlichkeit, so wenigstens einer solchen, die sein göttliches Recht anerkennt und behauptet; zur Gewalt gehört die Unterdrückung der Opposition und Kritik, und diese Unterdrückung gehört wirklich zum vorwaltenden System des Absolutismus. Sie gelingt immer nur in begrenzter Weise: teils scheitert sie offenbar, weil die gesamte geistig-moralische Entwicklung mächtiger ist, teils treibt sie die bekämpfte Feindseligkeit unter die Oberfläche und verschärft sie dadurch. Sofern sie aber wirksam ist, erleichtert sie dem Absolutismus, sich im Glauben des Volkes festzusetzen und zu erhalten. Ein kluger Fürst läßt sich aber daran nicht genügen; er will auch die Mein ungen für sich gewinnen, und hier tritt deren charakteristisches Merkmal zu Tage, da $B$ sie vorzugsweise auf das Nützliche gehen, also sofern die allge meine Meinung sich kundgibt und als die Offentliche Meinung zur Geltung gelangt, denkt sie an das Gemeinwohl, dessen Verfolgung dann der »aufgeklärte « Absolutismus für das höchste aller Staatsgesetze crklärt (Salus publica suprema lex esto). Die Wichtigkeit, daß diese Überzeugung im Volke, besonders natürlich unter den führenden und denkenden Geistern Wurzel schlage, hat die Staatskunst des fürstlichen Absolutismus frühzeitig erkannt. In Däne mark-Norwegen war 166o/65 durch einen Staatsstreich die unumschränkte Königsmacht als Verfassungsrecht festgelegt worden. Der dänische Historiker EDvard Holm führt aus, $\mathrm{da} B$ die Alleinherrscher in ihren Verordnungen und offenen Briefen den Stil beibehielten, worin die ständischen Könige z. B. GuSTAv ADOLF, zu ihren Reichstagen oder Ständeversammlungen zu reden pflegten: sie suchen mit Gründen darzutun, warum gerade das geschehen müsse, was sie gebieten, und sie wechseln ihren Ton je nach dem Gegenstande. Bald reden sie in religiösem Schwung, bald moralisieren sie über Verschwendung und Eitelkeit in einer Weise, die man aus Hol,BERGs Komödien kennt. Der Rede vom Wohl des Vaterlandes oder dem Bedürfnis der Untertanen begegnet man öfter, wenn neue Institutionen eingeführt werden, wenn Verordnungen ergehen, um Schwelgerei zu hemmen, das Armenwesen zu ordnen oder Manufakturen zu fördern usw. „Man sieht es leicht, es ist ein doppeltes Ziel, dem die Königsmacht durch diese Art sich ans Volk zu wenden, sich zu nähern strebte, auf der einen Seite: sich selbst der öffent - 
lichen Mein ung zu empfehlen, als vom Bewußtsein ihrer Pflichten und vom Eifer ihnen gerecht zu werden erfüllt, auf der anderen Seite an das eigene Gefühl der Untertanen für das Gemeinwohl zu appellieren als die sicherste Gewähr dafür, daß die Verordnungen durchgeführt werden können." Natürlich wendet sich auch diese Seite an den denkenden Teil der Untertanenschaft, in der es schon außer den Geistlichen Leute gab, die Bücher lasen, vor allem die Bürger, Rechtsgelehrte, Ärzte, Schulmeister der Hauptstadt und der lebhafteren Städte überhaupt. Es war also nicht, wie Roscher meint (Politik S. 285) erst zur Zeit JOSEPHS II., daß Gründe in den Gesetzen üblich wurden, „um auf die Meinung der gebildeten Welt zu wirken“. Deutsche Gelehrte unterscheiden in zeitlicher Folge den konfessionellen, den höfischen und den aufgeklärten Absolutismus. Die Einteilung ist logisch mangelhaft. Die erste und die dritte Form bezeichnen die geistige Sphäre, die sich im Laufe der Jahrhunderte von starrer Gläubigkeit zum Rationalismus verschob - im gesamten öffentlichen Leben und darum auch als Grundlage des Absolutismus. In der ersten Phase glaubte der Monarch im Namen Gottes zu regieren, in der anderen erkannte er, daB er nur im Namen des Staates solche Macht in Anspruch nehmen könne; dies wiederum bedeutete in letzter Linie: im Auftrage der bürgerlichen Gesellschaft oder des Volkes. Die theokratische Begründung wurde niemals aufgegeben, aber sie trat zurück, wie in der Staatswissenschaft selber. "Höfisch " ist der Absolutismus immer gewesen; will man eine besondere Phase $z$ wischen dem konfessionellen und dem aufgeklärten abgrenzen, so kann es nur um eine Übergangsform zwischen den beiden sich handeln, man wird sie füglich "theologisch-rational " nennen dürfen und dabei an Erscheinungen wie BosSUET und an den Pietismus des preußischen Soldatenkönigs denken. Ihm entspricht auch als die höhere Dienerschaft des Fürsten der Hof-Adel, den er selbst gestaltet und um sich sammelt als eine Gruppe, die zwischen der theologischen und der auf Bildung begründeten Aristokratie ihren Platz hat. Ein Element des Rationalismus ist aber von Anbeginn in der Absolutie des Fürstentums enthalten: es ist die Ratio status selber, von der sie bestrahlt wird. Dem entspricht es, daß der Fürst zwar seine geistige Stuitze zuerst und immer in hohem Maße im Klerus sucht, mehr und mehr aber nicht nur diesen für sich zurecht macht - sich anpaßt - , sondern auch, und zwar, um seine wachsenden finanziellen Bedürfnisse zu stillen, mit dem "dritten Stande" gemeine Sache macht und insonderheit die handeltreibende, zumal die dem Geldhandel ergebene Schicht, mehr und mehr aber auch die Unternehmer von AusfuhrIndustrien in sein Interesse zu ziehen beflissen ist. Die Entwicklung 
vom konfessionellen zum aufgeklärten Absolutismus ist zugleich die Entwicklung vom Klerus zur Bourgeoisie als der Hauptstuitze des Thrones - wo wir aber wiederum, wenn wir den Klerus als intellektuelle Potenz betrachten, auch aus dem Neu- und Staatsbürgertum diese herauszuheben Grund haben, und das ist in der Tat die Schicht der Intellektuellen, der Gebildeten, derer, die da lesen und schreiben (und zwar nicht nur in Mußestunden); immer je nach dem Grade ihrer Leistungsfähigkeit und ihrer wirklichen Leistungen: ist es dort vorzugsweise der hohe Klerus, der den Thron umgibt, so sind es auch notwendig die Höhergebildeten, die allmählich in die Stellen einrücken, und als Minister, Generale, hohe Beamte, Werkzeuge des fürstlichen Willens werden. In der höheren Bildung wiederum wetteifern, neben dem Anteil, den der Klerus selber daran hat, der Adel, zumal der jüngere und höfische und das städtische Bürgertum: Juristen, die aus allen 3 Schichten hervorgehen, an erster Stelle, als die notwendigen Gedankenträger des Staates; Kaufherren und Bankiers als gesellschaftliche Mächte: Heerführer des Geldes, das zum Kriegführen wie zum Friedeführen im Staate vorzugsweise notwendig; Ärzte, Apotheker, Mechaniker u. a. "Künstler " als Vertreter der neuen Naturwissenschaft und Technik, deren volkswirtschaftlichen und finanziellen Nutzen die Staatsmänner zu würdigen lernten; der weltliche Lehrerstand, der sich allmählich aus dem geistlichen Lehrstande herausschälte. Immer mußte das Bestreben des Fürsten dahin gehen, so viel als möglich, so wertvolles als möglich: dort von der geistlichen, hier von der weltlichen Intelligenz sich dienstbar zu machen und für die Regierung anzuwenden. In diesem Sinne wirkt er zugleich für die Religion und für die Bildung, so tief auch der zwischen beiden sich entwickelnde Gegensatz. Aber immer gelingt es ihm nur, Teile - und nicht immer die charaktervollsten und lebendig-wirksamsten Teile der Stände an sich zu fesseln; vielmehr zeichnen sie sich oft nur durch Geschmeidigkeit und Gesinnungslosigkeit aus, auch die gewandtesten und intelligentesten Hof- und Staatsdiener, während die Opposition des alten Herrenstandes immer rege bleibt und die Opposition des neuen immer kühner in den Vordergrund sich schiebt. Naturgemäß wirken beide Oppositionen oft zusammen, ja vermischen sich miteinander. Aber die neue ist die junge und wachsende, sie wird genährt von der zunehmenden I,esebildung, ihr kommt der Verkehr mit dem Auslande, wo auch die "freiesten " Schriften gedruckt werden, vorzugsweise zu statten. Sie ist der Ausfluß des modernen Geistes, des "Zeitgeistes «. Sie fühlt sich in der Offentlichkeit zu Hause, sie ergreift die neuen Mittel, um zu wirken, um sich bekannt, von sich reden zu machen. Sie geht in das Gespräch des 
Salons in Paris, des Kaffeehauses in London, in die Briefe, die von den Empfängern vielen mitgeteilt werden, in öffentliche Reden, wo sie möglich sind, daher zuweilen auch in die Predigten der Kanzelredner über. Offentliche Meinung und die Offentliche Meinung scheinen zusammenzufallen. Das war der Grund, warum in der Mitte des 18 . Jahrhunderts, als noch die französische Monarchie in ungebrochener Kraft dastand, gleichwohl - nach TOcQUEVILLE - die Schriftsteller ,allmählich zur höchsten politischen Macht gelangten" (L'ancien régime et la révolution p. 226). „Sie beschäftigten sich fortwährend mit Gegenständen, die auf die Regierung Bezug haben, es war dies sogar ihre hauptsächlichste Beschäftigung. Man hörte sie alle Tage über die Entstehung der Gesellschaften und deren ursprüngliche Formen, über die ursprünglichen Rechte der Bürger und die der Staatsgewalt, über die natürlichen und künstlichen Verhältnisse der Menschen zueinander, über das Irrige oder Rechtmäßige des Herkommens und über das Wesen der Gesetze selbst sprechen“ (ib.). „Alle glauben, $\mathrm{da} B$ es besser sei, einfache und leichtfaßliche, aus der Vernunft und der Natur abgeleitete Regeln an die Stelle der komplizierten traditionellen Normen treten $z \mathbf{u}$ lassen, welche die Gesellschaft ihres Zeitalters beherrschen" (227). Und, nachdem er ausgeführt hat, wie sich der Hang zu abstrakten und allgemeinen Regierungstheorien ausgebildet und gesteigert hatte, wie ihm in Frankreich das Gefühl aller derer entgegengekommen sei, die sich durch das Hergebrachte und Bestehende bedrückt und beeinträchtigt fanden, fährt er fort: „So vermummte sich jede öffentliche Aufregung in das Gewand der Philosophie, das politische Leben wurde auf solche Weise mit Gewalt in die Literatur gedrängt, und die Schriftsteller, $*_{\text {inde }} m$ sie die Leitung der Meinung in ihre Hände nahmen*, behaupteten eine Zeitlang die Stellung, die in freien Ländern die Parteiführer einzunehmen pflegen" (23I). Aber die Aufklärung gehörte nicht der Opposition allein; Fürsten und ihre Staatsmänner nahmen daran Teil, seinem Wesen nach war (wie gesagt) der Absolutismus vom Rationalismus erfüllt. Der aufgeklärte Absolutismus mußte dahin wirken, daß seine Vernünftigkeit gelehrt und anerkannt wurde. Er wollte Volkserzieher sein. Von oben her, darum am nächsten von den Hochschulen aus, sollte die Erkenntnis des Guten und Richtigen als ihrer wahren Glückseligkeit über alle Schichten der Untertanen sich ergießen. Indem der Fürst sich als Herr des Staates und Volkes fühlte, wurde er sich der Aufgabe bewußt, ihm zu dienen; und wodurch konnte er ihm anders dienen, als indem er durch Gesetze sein Wohl und durch Unterricht die Einsicht und das Verständnis dafür, was dem Einzelnen und der Gesamtheit ersprießlich sei, beförderte? Zur 
vernünftigen Staatsleitung gehörte auch, dem Untertan nicht nur zu gestatten, sondern ihn anzuregen, mit Bitten und Beschwerden dem Throne zu nahen, und so konnte ein aufgeklärter Staatsmann, TURGOT, schon I4 Jahre vor der Einberufung der Generalstände dem König von Frankreich raten, von der ganzen Nation jährlich eine repräsentative Versammlung wählen zu lassen, die freilich nicht mitregieren, aber doch ihre Meinung über wünschenswerte oder nicht wünschenswerte Gesetzgebung kundgeben sollte. „Dadurch würde die königliche Gewalt aufgeklärt werden, ohne gehemmt zu sein, *u nd die öfentliche Meinung wäre dann ohne alle Gefahr befriedigt*" (1. c. S. 235). Man kann sagen, es war der Irrtum, an dem der Absolutismus scheiterte: eine beratende Volksvertretung schien vom monarchischen Standpunkt immer als das Vernünftige, aber auch als das Außerste, was eingeräumt werden könne. Ebenso eine scharf begrenzte Preßfreiheit, die für den Absolutismus so viel hieB als: eine gemilderte Zensur. Der Herzog FrIEdRICH Christian von Augustenburg rühmt am 4. April I794 in einem Briefe an ScHILrFR, $\mathrm{da} B$ der Kronprinz (von Dänemark) die überzeugendsten Beweise allgemeiner Liebe und Achtung gegen die Regierung erhalte. „Es hat sich zugleich ein Gemeingeist geäußert, die natürliche Folge des bisherigen Regierungssystems, der ihn lehrt, wie sehr er auf die Unterstützung der Nation bauen kann, *solange die öffentliche Mei $\mathrm{n}$ ung ih m günstig ist*, und in der Tat sind dadurch die politischen Kräfte des Staates verdoppelt" (der damalige Kronprinz war Regent in Dänemark, Norwegen und den Herzogtümern).

\section{$Z$ weiter Abschnitt. Näheres über politische Kämpfe.}

8. (Regierung und Presse.) Auch eine moderne Regierung läßt, zumal in unruhigen Zeiten, niemals die Verbreitung beliebiger Meinungen in Rede und Schrift zu. Auch wenn sie etwa nur von dem Rechte, das gesetzlich auch jedem Privatmann zusteht, Gebrauch macht, so kann sie dies als Regierung in um so wirksamerer Weise tun, insbesondere also das Strafrecht gegen die Presse in Anwendung bringen. Aber in der Hauptsache begegnet sie der literarischen Opposition nicht mehr von oben herab mit der Zuchtrute, sondern zur ebenen Erde mit den gleichen Waffen der Worte und Gründe. Die Regierungen werden selber literarisch, sie begründen und handhaben ihre eigene Presse. Und zwar geschieht dies in mannigfacher Weise. I. Die gute, d. h. freundlich wirkende Presse wird gefördert, die schlechte, d.h. oppositionelle gehemmt. Förderung kann auf mannigfache Weise geschehen: a) materielle: durch geldliche Unterstützung, unmittelbare und mittelbare - z. B. Pflichtabonnements 
für Behörden, Ankauf und Verbreitung von Flugschriften; Erwerb eigener Zeitungen und Druckereien -, in den heutigen Staaten besitzt jedesmal die Regierung ihr besonderes amtliches Organ an einer Zeitung, wie in Frankreich das Journal officiel, in Preußen der »Staatsanzeiger " (später für das Deutsche Reich: Reichs- und Staatsanzeiger), in Großbritannien die Gazette - aber diese Zeitungen dienen zumeist nur amtlichen Bekanntmachungen; wenn sie außerdem Nachrichten bringen, so halten sich diese streng an Tatsachen, es fehlt ihnen die Würze der Unterhaltung. Will die Regierung ihre Ansichten zur Geltung bringen, so muß sie in Zeitungen sich vernehmen lassen, die wirklich und gern von einem großen Publikum gelesen werden: das aber sind Zeitungen der Parteien. Die Regierung, auch wenn sie nicht aus einer Partei oder einer Mischung von Parteien hervorgeht; muß sich eine Partei bilden, oder doch Parteien unterstiutzen, von denen sie einige Hilfe oder wenigstens Verständnis und Nachsicht erwarten darf; sie nützt sich selber und der Partei, wenn sie sich der Zeitungen dieser Partei bedient. „Was von Seiten des Monarchen (soll heißen : der Regierungen) in die Zeitungen gedruckt wird, nimmt sich nicht gut aus; denn die Macht soll handeln und nicht reden", meinte noch GoETHE ("Sprüche in Prosa «). Seither hat sich nicht nur die regelmäßige Beeinflussung der Presse zu einem fortwährend gebrauchten Instrument der Regierungen entwickelt, sondern es wird auch für notwendig gehalten, halbamtliche Zeitungen zu begründen oder käuflich zu erwerben, offiziöse - lithographierte oder gedruckte - Korrespondenzen herauszugeben und fortwährend Schriftsteller als Gehilfen der amtlichen Tätigkeit in Anspruch zu nehmen; besondere Preß-Åmter oder doch geschulte Beobachtungsstellen gehören $\mathrm{zu}$ jedem Auswärtigen Amt, und in jeder Botschaft und Gesandtschaft gehört die Beobachtung und, wo es nötig und möglich scheint, die ständige Fühlung mit der Presse des Landes, besonders der Hauptstadt, zu den Pflichten des Dienstes. Vorzugsweise wichtig ist die Verbindung mit den telegraphischen Agenturen, denen die Ausbreitung der neuesten Nachrichten in die "Welt" obliegt ${ }^{1}$ ): weil oft Form und Fassung einer Nachricht den Eindruck bestimmt, den sie auf das Publikum macht, so kann es im höchsten Staatsinteresse liegen, darauf einzuwirken, auch wenn es nur negativ geschieht, so daß der "alarmierende" Charakter einer Neuigkeit gedämpft wird. Jeder Regierung ist darum zu tun, die Offentliche Meinung auf ihrer Seite zu haben, also den Eindruck günstiger Nachrichten

1) ,Ein Netz von Vertretern dieser Organisationen ist über die ganze Erde ausgespannt und macht überall die öffentliche Meinung“. Bứcher, Unsere Sache und die Tagespresse, S. 2. 
zu erhöhen, ungünstiger abzuschwächen; aber um den gebildeten Leser zu gewinnen oder zu besänftigen, sind auch Erörterungen, Begrïndungen — Räsonnements" - erforderlich, und auch dafür kann eine Regierung vieles tun, daß ihre Gedankengänge ans Publikum herankommen und von ihm freundlich oder wenigstens nachsichtig aufgenommen werden. Sie hat dafür viele Mittel in der Hand: die förmlichen Begründungen der Gesetzentwürfe, die aber von wenigen gelesen werden, die Reden der Regierungsvertreter in den Parlamenten, die aber nur von den amtlichen und offiziösen Zeitungen im Wortlaut wiedergegeben werden, auch andere öffentliche Reden der verantwortlichen Männer, sofern solche für schicklich gehalten werden, dazu feierliche Kundgebungen der Staatsoberhäupter - aber die Ansicht GoETHES behält insofern Recht, als eine Regierung verhältnismäßig wenig durch Worte, aber sehr viel durch Taten vermag; nach diesen - und freilich auch nach Unterlassungen, die darin einbegriffen werden müssen, wird sie beurteilt, und oft genug falsch beurteilt, weil ihre wahren Absichten nicht erkannt und der Sinn eines Tuns oder Unterlassens oft mißdeutet wird; dazu kommt, daß die Offentliche Meinung zumeist geneigt ist, wenn sie aus anderen Gründen einer Regierung nicht wohl will, ihr auch die Schuld an Zuständen und Begebenheiten zuzuschreiben, die keine Regierung zu verhindern oder $\mathrm{zu}$ verbessern imstande wäre, denen eine andere vielleicht noch macht- und hilfloser gegenüberstände als die gerade auf der Bühne beobachteten Machthaber, die aber leicht für allmächtig gehalten und um so schonungsloser getadelt werden, wenn man sie gleichzeitig für töricht oder für böswillig hält oder sogar ihnen beide Eigenschaften zuschreibt - was natürlich auch geschehen kann, ohne daß es wirklich gemeint wird. Je freier die Presse und die öffentliche Rede - die aber auch erst durch die Presse ihren tausendfachen Widerhall erhält - um so weniger vermag eine Regierung unmittelbar gegen die Kritik und Opposition, die sie zu stürzen beflissen ist. Sie kann sie durch Strafanträge verfolgen, sie kann ihren Behörden und Beamten Weisungen erteilen, die bestimmt sind zur Abwehr, aber je mehr derartiges bekannt wird, um so mehr wirkt es ähnlich und oft nachteiliger auf die Offentliche Meinung als unmittelbarer Druck, der durch Präventivzensur, Verbote, Beschlagnahmen, Verwarnungen usw. geübt wird, - alles derartige lenkt die öffentliche Aufmerksamkeit auf den Verfolgten und dadurch auf die Sache, um derentwillen die Verfolgung geschieht; das schadet der Regierung nicht, wenn die Offentliche Meinung den Personen und den Sachen abgeneigt ist, es schadet um so mehr, wenn sie ihnen zugetan ist. Durch stille Gegenwirkungen, unabsichtliche Belehrungen, die nicht offenbar von ihr ausgehen, durch scheinbar von freier Uberzeugung 
getragenen Kampf wird eine Regierung in der Regel mehr zu ihren Gunsten bewirken. Nicht ohne guten Sinn bezeichnete eine offiziöse Zeitung sich als "freiwillig gouvernemental«: um eine Regierung, die wirklich viele freiwillige, nicht streberhafte, wenn möglich enthusiastische Helfer hat, ist es wohl bestellt. Ebenso sind ihr die freiwilligen, überzeugten, von einer Idee erfüllten und sich aufzuopfern willigen Gegner am gefährlichsten. Es ist der große Vorteil der Parteiregierungen gegenüber schweren Übeln, die ihr anhaften, daß sie I. solche Anhänger, 2. überhaupt einen festen und zuverlässigen Anhang hinter sich haben ${ }^{1}$ ). Dadurch besitzen sie auch einen gewissen Vorsprung in der Offentlichen Meinung, deren sorgsame Pflege wird ihnen erleichtert. Die einer solchen Regierung ergebene Presse wird zuweilen einen Eindruck von der Offentlichen Meinung hervorzurufen vermögen, der diese selber in der erwünschten Richtung verstärkt. Aber das vermag auch, und meistens mit größerem Erfolge, die Opposition und ihre Presse. Ohnehin wirkt die Verneinung stärker auf die Leidenschaften als die Bejahung. Sattheit stimmt zur Ruhe, Hunger zur Bewegung. In dieser Hinsicht verhält sich das Publikum des öffentlichen Lebens anders als das Theaterpublikum. Dieses ist im ganzen mehr zum Beifall als zum Zischen geneigt: es ist da seines Vergnügens halber, und auch eine mittelmäßige Aufführung eines schlechten Stückes macht der schaulustigen Menge Vergniigen, zuweilen genügt schon das Auftreten eines beliebten Schauspielers (oder einer -in), um eine heitere, sogar enthusiastische Stimmung hervorzurufen. Das politische Publikum fühlt sich hingegen durchweg leidend: die Regierung bedrückt es durch Steuern, legt ihm durch Gesetze neue lästige Verpflichtungen auf, ist ein sehr kostspieliger Apparat, dessen Nutzen ihm (dem Publiko) oft zweifelhaft ist; der Verdacht regt sich immer, daß "sie * - die an der Spitze stehenden - auf Kosten des Volkes sich bereichern, ïberhaupt, daß sie ihre Interessen oder höchstens die ihrer Partei im Auge haben, anstatt munserer", - und nun wird solcher Verdacht, wird solche Mißstimmung tagtäglich durch die Zeitung, die man liest und zuweilen vor Erregung und Empörung nicht zu Ende lesen mag, genährt, ja gemästet, sie schwellen an und gewinnen krankhaften Umfang die Krankheit wirkt ansteckend, die Unzufriedenheit breitet sich aus. In guten Zeiten findet solche Ausbreitung leicht ihre Grenzen: der Tag belehrt den Tag, bei materiellem Gedeihen schwillt der politische

1) Freilich, wenn die Regierung durch $»$ Koalition « gebildet ist, so kann die Anhängerschaft als ganze sehr unzuverlässig sein, indem ihre Teile zwar die entsprechende Partei unterstützen, nichts destoweniger aber der Regierung als solcher Opposition machen. Irebendiges Beispiel: Deutschland r920/2I. 
Unwille wieder $a b-$ aber in schlimmen Zeiten, Zeiten der Krise, der Hungersnot, der wachsenden Teuerung, der Fremdherrschaft -, nicht leicht wird ihnen gegenüber eine Regierung sich dauernd $\mathrm{zu}$ rechtfertigen und vor der Offentlichen Meinung sich zu halten vermögen. Sie kämpft dann einen ungleichen Kampf. Alle Mittel, durch die sie sonst überlegen ist, versagen einer Kritik und Opposition gegenüber, die in einer allgemeinen, sei es wesentlich ökonomischen oder wesentlich moralischen und politischen Unzufriedenheit ihre Wurzeln hat.

9. (Die Defensive.) Uberhaupt aber ist das ursprüngliche und in dem angezeigten Sinne immer natürliche Verhältnis, daß die Regierung - wir denken hier zunächst an diejenige eines Fürsten - der Opposition und Kritik gegenüber sich in der Defensive befindet. Ihres Amtes ist, $z \mathfrak{u}$ regieren, d. h. $z \mathbf{u}$ befehlen. Ihre allgemeinen Befehle sind Gesetze und Verordnungen. Wenn den Meinungen nicht freisteht, sich »öffentlich "insbesondere nicht in Schriften und Zeitungen, darüber, wenigstens nicht: dagegen sich $z u$ äußern, so können sie trotzdem auf mannigfache Weise sich "L,uft machen", von denen man einige doch auch als öffentliche Kundgebungen ansprechen wird, z. B. auffallenden Beifall, der bestimmten Reden im Theater zuteil wird, oder das tötliche Schweigen, womit etwa eine gebietende Persönlichkeit, vielleicht sogar der Kaiser oder König, öffentlich auftretend empfangen wird. Außerdem aber bleiben den Meinungen die heimlichen Wege ihrer Kundgebung und Ausbreitung, äußersten Falles die Verschwörung. In den neueren Staaten, die immer mehr der öffentlichen Meinung freien Lauf gelassen haben, unter dem Druck der Offentlichen Meinung selber, die PreBfreiheit und Redefreiheit forderte, ist die Gesetzgebung selber nicht mehr wesentlich Sache der Fürsten, ihrer Geheimen Räte und Regierungen, sondern - wenigstens förmlich - der Parlamente oder gesetzgebenden Körperschaften. Die Initiative freilich geht meistens von den Regierungen aus, auch dies erst, nachdem die Entwürfe im engeren Schoße beraten wurden, also auch auf Widerstand stoßen konnten; sie kommen daher zumeist gleichzeitig an die Offentlichkeit und an die Körperschaft, zuweilen früher an jene; dort wie hier werden sie beraten - gebilligt oder verworfen, im ganzen oder im einzelnen; das Parlament hat ständige und besonders erwählte Ausschüsse (Kommissionen) zur "Durchberatung *. Die Presse bemächtigt sich, teils unmittelbar, teils im Anschluß an diese Beratungen, des Gegenstandes - hier treten die Zeitungen und ihre Schriftsteller, dort die Redner - werster ", "zweiter ", "dritter " "Garnitur " - für und wider den Entwurf, daher in der Regel für und wider die Regierung auf. Zuweilen ist die Offentliche Meinung von vornherein so lebhaft für, öfter gegen einen Gesetzentwurf, daß ihre 
Stimme gleichsam die Stimmen der Redner wie die der Presse übertönt und da $B$ sie folglich deren Ton und Richtung bestimmt. Sonst aber handelt es sich für die Parteien um Bearbeitung der öffentlichen Meinung für oder wider, und also darum, ihr eine entschiedene Richtung, einen so sehr als möglich einheitlichen Ton zu geben, so daß eine Partei mit gutem Grunde behaupten kann, was sie oft ohne solchen, ja ohne guten Glauben, behauptet, die Offentliche Meinung wolle dies oder wolle jenes, wolle jenes oder dieses nicht. Wenn dies Streben Erfolg hat, wenn der Versuch gelingt, so handelt es sich in der Regel nur um einen luftigen Aggregatzustand der Öffentlichen Meinung, der sozusagen aus "nichts «, d. h. aus einem schlechthin diffusen Zustande gebildet wird, während in dem anderen Falle zumeist ein fester oder wenigstens flüssiger Aggregatzustand zugrunde liegt, der unter einem bestimmten Eindruck sozusagen schmilzt oder verdunstet. Wesentlich bedingend ist es, wie die Regierung selber in der öffentlichen Meinung dasteht: wird sie von d e r Offentlichen Meinung getragen, kann sie auf diese sich stützen? oder muß sie fortwährend nach ihr, vielleicht nach ihren "Launen ", d. h. rasch wechselnden, flüchtigen Stimmungen des Tages, sich richten? Mit Recht urteilt Constantin Frantz (Das europäische Gleichgewicht S. 388), um ein stabiles politisches Gleichgewicht zu erzielen, sei notwendig I. die Stuitze sittlicher Ideen, 2. daß die Unterlage, worauf die Stütze selbst ruht, so stark und fest wie möglich sei. „Die allerschlechteste Unterlage ist daher jedenfalls die sog. öffentliche Meinung, die sich nach dem Zeitungswind bewegt, und verloren ist jedes politische System, welches keinen anderen Halt hat als diese öffentliche Meinung. Oder es müßte zugleich ein so wirksames Bureau des öffentlichen Geistes besitzen, daß es sich die öffentliche Meinung selbst machen kann; in welchem Falle dann aber die Sache die wäre, daß es eigentlich doch nicht auf der öffentlichen Meinung, sondern auf sich selbst beruhte."

ro. (Cäsaristische Methoden.) Das letztere ist sichtlich sehr viel günstiger für ein politisches System, und jede Regierung strebt danach, solchen Halt zu gewinnen, wenn sie nicht ihn schon durch ihren Ursprung und ihr Wesen zu besitzen meint, und auch dann muß sie bemüht sein, ihn zu erhalten und zu befestigen, also den Anstürmen zu wehren, die dagegen gerichtet werden. Hier ist sogleich offenbar, welch ein ungemeiner Vorteil es für eine Regierung ist, wenn sie von der Religion ihre Gewähr und Heiligung empfängt, so lange als diese die Offentliche Meinung wesentlich bestimmt und aus sich hervorgehen läßt, oder der anders bedingten und gerichteten an Kraft und Autorität wesentlich überlegen ist. Auch wenn weder das eine noch das andere der Fall ist, kann doch eine religiöse Ehrfurcht nach- 
wirken, die entweder einer Institution oder einer Person oder beiden gezollt wird. Den modernen Regierungen, zumal den republikanischen, wird davon viel weniger zuteil als denjenigen der Monarchien, die noch das Vorrecht sich gerettet haben, nach eigenem Bedünken ihre Regierung zu ernennen; jene wollen in erster Linie auf eine Mehrheit sich stützen, wenigstens auf eine scheinbare und konventionell als solche geltende, wie die Regierung des Präsidenten in den Vereinigten Staaten, wenn sie aus einer Mehrheit der Elektoren, obschon zuweilen gegen eine Mehrheit des gesamten Volkes, hervorgeht. In der Regel, und so auch in der gegenwärtigen deutschen Republik, ist es eine Mehrheit der von der Gesamtheit des Volkes erwählten gesetzgebenden Körperschaft, woraus die Regierung hervorgeht und worauf sie sich zu stützen angewiesen ist, so lange bis dieser Stab bricht; die demokratische Denkungsart ist aber sonderlich - und gerade in der neuesten deutschen Revolution - beflissen gewesen, dahin zu wirken, daß diese Mehrheit so sehr als möglich eine Mehrheit des Volkes selber, der Wählerschaft, und zwar unter Vernichtung des sonst geltenden Vorrechtes der Männer, widerspiegele, indem freilich eine willkürlich gesetzte, aber so niedrig als zulässig schien, gesetzte Altersgrenze des Wahlrechtes bestimmt und eine "verhältnismäßige Vertretung angeordnet wurde. Im einzelnen Falle kann aber - und dies ist das letzte Wort der demokratischen Verfassungen - (und muß unter Umständen) die Entscheidung über ein Gesetz dem Volke selber anheimgegeben werden, so da $B$ es gleichsam wie eine Versammlung bejahend oder verneinend seinen Willen ausspricht. Das ist dann das "Referendum ", das "Plebiscit " oder der Volksentscheid, woraus aber auch eine unumschränkte Einherrschaft, "wenn's dem Volke so beliebt ", hervorgehen kann und tatsächlich hat die moderne Form dieser Herrschaft, der "Cäsarismus ", bekanntlich darin seine Stütze gesucht und zeitweilig gefunden: es ist der Zentralgedanke der idées Napoléoniennes. Mehrfach findet sich nun in der Literatur die Ansicht vertreten, das sei nun eben die Regierung durch die Öfentliche Meinung, diese erhalte ihren reinsten und echtesten Ausdruck durch das »Referendum \&. Diese Ansicht, die dem oberflächlichen Scheine abgewonnen wird, ist durchaus irrig. Im günstigsten Falle ist eine Volksabstimmung Ausdruck der Volksstimmung und Volksleidenschaft, aber auch das ist sie keineswegs immer. Zunächst machen regelmäßig vicle Individuen keinen Gebrauch von ihrem Rechte. Wahrscheinlich ist die Sache ihnen gleichgültig, oder sie sind tatsächlich verhindert oder sie meinen, auf ihre Stimme komme es nicht an, die Mehrheit werde ohnehin dafür oder dawider sein. Dann aber ist die Beteiligung und die Stimmabgabe im einen oder dem anderen Sinne keineswegs ein Beweis dafür, 
da $B$ dem Individuum die Sache nicht gleichgültig sei, noch weniger dafür, $\mathrm{da} B$ es aus eigener Überlegung für oder wider stimme, sondern mancher stimmt so einem anderen zu Gefallen, mancher, weil er von anderen überredet wurde, mancher, weil er sich irgendwelche Vorteile davon verspricht, die außerhalb der etwaigen Vorteile der Sache (die er vielleicht nicht einsieht oder nicht versteht) liegen, mancher, weil er durch Versprechungen bewogen, wenn nicht unmittelbar durch einen gewährten oder angebotenen Preis bestochen wurde. Gleichwohl möge man Grund haben, zu vermuten, daß in der Regel die wirkliche Volksstimmung mit unwiderstehlicher Gewalt zum Durchbruch komme. Aber die Volksstimmung ist nicht die Offentliche Meinung. Diese ist nach dem hier zugrunde gelegten und ferner zu begründenden Begriff das gemeinsame Urteil des gebildeten, insbesondere des politisch denkenden Publikums, das ich gleichsam kristallisiert vorstelle als die »Gelehrtenrepublik «. Die Offentliche Meinung hängt immer mit der Volksstimmung zusammen; sie steht in der Regel in stärkerer oder schwächerer Wechselwirkung mit ihr, aber sie kann auch sehr von ihr verschieden sein und geradezu im Gegensatze $z \mathfrak{u}$ ihr sich bewegen. So müssen bestimmte Gründe vorhanden sein, um die Vermutung $z u$ rechtfertigen, da $B$ in dem Ergebnis einer Volksabstimmung die Offentliche Meinung gleichsam eingeschlossen sei; wie andere bestimmte Gründe dieser Annahme entgegen sein, ja zu dem Schlusse führen mögen, daß die Offentliche Meinung ganz anderen Sinnes sei, also etwa mit der Minderheit gehe, und daß ihre Macht sich als stark genug erweisen werde, um diese Ansicht durchzusetzen, ja ihr vielleicht demnächst - wenn auch etwa erst nach Jahren - zum Siege zu verhelfen. Das Kranken- und Unfallversicherungsgesetz für die Schweiz, das durch eine Volksabstimmung vom 26. X. 1890 dem Grundgedanken nach angenommen war (56,6 der Stimmberechtigten, davon 42,7 bejahend), wurde daraufhin in einer Vorlage ausgearbeitet, die drei Jahre später sowohl vom Nationalrat als vom Ständerat fast einstimmig angenommen wurde: hier darf man vermuten, da $B$ die Offentliche Meinung auf die Entscheidung gedrückt hat, und diese war ohne Zweifel durch den Erfolg des deutschen Vorbildes und durch die Wirkungen, die es schon in anderen Staaten gehabt hatte, wesentlich bestimmt. Gleichwohl lehnte das Volk diese Vorlage am 20. V.I900 mit nahezu 342 gegen 148 Tausend Stimmen ab (65,9 der Stimmberechtigten, davon 46,0 verneinend). Zwölf Jahre später wurde eine neue Vorlage wieder dem Referendum unterworfen: es ergab die Annahme, wenn auch nicht mit großer Mehrheit (bei 63,0 Abstimmenden 34,3 für, 28,7 gegen), aber die Zahl der Zustimmenden hatte sich fast verdoppelt (von I48 auf 287,6 Tausend), während 
die Verwerfenden um fast $30 \mathrm{v}$. H. sich verminderte (von 342,I auf 242,4 Tausend.). Die Offentliche Meinung hatte einen (wenn auch nicht glänzenden) Sieg errungen.

II. (Die Öfentliche Meinung als Regierung.) Aber auch, wo kein Volksentscheid durch die Verfassung zugelassen oder geboten wird, spricht man oft aus, die Offentliche Meinung sei die politisch entscheidende Macht, oder wenigstens sie "regiere " neben der Regierung und der Volksvertretung und erweise sich zuweilen als beiden überlegen. "Ours is a government by public opinion" (Unsere Regierung ist eine Regierung durch die Offentliche Meinung) wird in Großbritannien wie in den Vereinigten Staaten oft ausgesprochen, obgleich beide große Staaten keine Volksabstimmung außer bei den nationalen Wahlen kennen, und zwar kommt in Amerika zu den Parlamentswahlen als oft noch wichtiger die Präsidentenwahl hinzu: beide sind nur Männerwahlen (außer sofern in einzelnen Staaten der Union das Frauenstimmrecht besteht) und beruhen nicht schlechthin auf allgemeinen und gleichen Wahlrechten der Männer. Hier muß also die Offentliche Meinung, wenn überhaupt, so auf andere Weise, in bestimmten einzelnen Fragen, zumal solchen, die nicht durch allgemeine Wahlen entschieden werden, erkennbar und erkannt werden. Welche Erkenntnisgründe tatsächlich unter heutigen Verhältnissen maßgebend sind, darüber kann man nicht zweifelhaft sein. Es ist in erster Linie die Presse, auf deren vielfache Stimmen der Staatsmann, der die Offentliche Meinung kennen lernen will, um ihr zu folgen, horcht - sie muß also dann einmütig sein, trotz des unablässigen Parteigezänkes? Es findet dabei natürlich eine differenzierende Schätzung der verschiedenen Preßorgane statt, sie werden mehr oder weniger geachtet, mehr oder weniger für treue Reflektoren der Offentlichen Meinung gehalten, wobei man wohl erwarten darf, daß Erfahrung und Urteilskraft die Schätzung bis zu einem gewissen Grade richtig machen können, wenn auch dem Irrtum hierin ein weiter Spielraum bleibt. Natürlich kommen nur, oder doch in erster Linie, die großen Zeitungen in Frage, und die großen sind die der Großstadt, schon als solche auch die am meisten gelesenen. Als Mittelpunkt des politischen, zumeist des wirtschaftlichen, und in vieler Hinsicht auch des geistigen Lebens überragt aber die $\mathrm{Ha} \mathrm{u} \mathrm{pt} \mathrm{-}$ stad $t$ die anderen Großstädte, darum in der Regel auch ihre Zeitungen oder wenigstens eine Zeitung. Ein gut Teil öffentlicher Meinung auch ist die Meinung der erlesenen Elemente, die sich in der Hauptstadt versammeln, begegnen, Konferenzen und Sitzungen halten, Gäste empfangen, an der Börse verkehren, in wissenschaftlichen Vereinen zusammenkommen und Reden halten, Briefe schreiben und 
unmittelbaren oder mittelbaren Einfluß auf Zeitungen oder auf die Zeitung ausüben, wenn sie auch gleichzeitig aus eben dieser Zeitung ein großes Stück ihrer eigenen Weisheit schöpfen, indem sie darin klar ausgesprochen finden, was sie unklar selber gedacht haben (haben wollen). Typisch für diese Verhältnisse ist die Weltstadt London und typisch ist - vollends "war "vor etwa 2 Menschenaltern die "Times « als Organ der britischen Offentlichen Meinung oder wie sie noch vor kurzem genannt wurde, als »Sprachrohr der herrschenden Klasse Englands». Wenn nun der Staatsmann so auf die Zeitungen, insbesondere auf die eine Zeitung achtet, so wird er bald bemerken, daß sie nicht immer, sehr oft nicht die Offentliche Meinung wiedergibt, daß sie aber auch in solchen Fällen stark auf die Offentliche Meinung wirkt, sie zuweilen rasch mit sich fortreißt, zuweilen entscheidet und sogar umschlagen macht oder wenigstens dazu hilft, wenn andere Umstände günstig sind ${ }^{1}$ ). Wenn also der Staatsmann teilweise, und zunächst vielleicht gänzlich, die Offentliche Meinung wie ein Fatum hinnimmt und die Zeitung, aus der sie ihm entgegentönt, wie eine selbständige Macht ehrt, der er unter Umständen sich zu unterwerfen habe; so wird er doch bald versuchen, eben $\mathrm{d} u \mathrm{rch}$ diese Zeitung auf die öffentliche Meinung Einfluß zu gewinnen und sie in seinem Sinne zu bestimmen. Das eben ist es, was in bezug auf die Times während des ganzen I9. Jahrhunderts und darüber hinaus englische leitende Staatsmänner, ganz besonders die Premier-Minister und die Staatssekretäre des Auswärtigen mit großem Erfolge sich haben angelegen sein lassen. Als Muster in dieser Hinsicht gilt Lord PALMERSTON. Er selber gab die Losung aus und das Programm für seine Tätigkeit in dieser Richtung, wenn er am II. Juni I829, in seiner ersten großen Staatsrede verkündete: „Es gibt in der Natur nur ei ne bewegende Kraft, den Geist . . . in politischen Dingen ist es die Offentliche Meinung; und wer sich dieser Kraft bemächtigen kann, wird mit ihr den Arm von Fleisch und Bein unterwerfen und seinen $Z$ wecken dienstbar machen. Diejenigen Staatsmänner, die es verstehen, sich die Leidenschaften, die Interessen und die Meinungen der Menschen zunutze zu machen, sind imstande, ein Übergewicht zu erlangen und einen entscheidenden Einfluß auf die menschlichen Geschicke auszuüben, außer allem Verhältnis zu der Kraft und den Hilfsquellen des Staates, den sie regieren." Nach LoTHAR Bucher (Der Parlamentarismus, S. 245) hat diese Rede den bis dahin unbeachteten Subaltern zum weltberühmten Staatsmann, zum Abgott der Offentlichen Meinung gemacht. PaLMERsTon selbst schrieb wenige

1) Nicht übel sagt der Franzose Toussener: „Die (öffentliche) Meinung ist die Königin der Welt und die Presse ist der Premierminister der Meinung". 
Tage nachher an WILLIAM TEMPLE (d. I4. Juni I829 bei BUlWER, Life of P., p. 305 Tauchn. ed.) über WeLLINGTON, der damals noch an der Spitze der Regierung stand, während PALMERSTon in der Opposition war: „In inneren Angelegenheiten hat er seine eigenen Meinungen und Wünsche der Notwendigkeit und der Offentlichen Meinung zum Opfer gebracht: er fand, $\mathrm{da} \mathrm{B}$ er die Regierung des Landes nicht weiterführen konnte, ohne die Katholiken-Frage (die Emanzipation) preiszugeben, und alsbald gab er in diesem Stücke nach. Die Offentliche Meinung hat auswärtige Angelegenheiten nicht berïhrt, diese haben bisher als carte blanche dem unerforschten Belieben der Regierung offen gelegen. Wenn sie je sich mit den auswärtigen Angelegenheiten befaßt, - und sie wird es sicherlich in der nächsten Session tun, - so wird der Herzog auch in diesem Stücke nachgeben und dadurch seine Macht behalten." Hier versteht also der schlaue Politiker die Offentliche Meinung noch als ein selbstständiges Wesen, dem der Sieger von Waterloo sich unterwerfen müsse, während es PALMERSTON zu gleicher Zeit offenbar erwog, durch welche Mittel der Proteus gefesselt werden könne, wie es ihm in seiner späteren Laufbahn in hohem Maße gelungen zu sein scheint.

12. (Staatsmänner und die Offentliche Meinung.) Er war nicht der Erste, der die öffentliche Meinung nach seinen $Z$ wecken zu gestalten verstand. Es gehört zum cäsarischen Regierungssystem, und soweit eine neuere Staatsregierung durch den Geist eines einzigen Mannes gelenkt wird - dann war sie immer am meisten erfolgreich - , sind ihre Methoden immer die des Cäsarismus gewesen. Schon CROMWELL hatte, zu einer Zeit als das Zeitungswesen noch in den Windeln lag, seinen Leibjournalisten, der im Mercurius politicus breite Auszüge aus den Elements of Law des Thomas HobBes abdruckte, um eine rein weltliche Staatstheorie und den Begriff der Souveränität den Ansprüchen der presbyterianischen wie der anglikanischen Geistlichkeit entgegenzusetzen (siehe Tönnies, Thomas Hobbes, 2. Aufl. S. 40). Auch sein Zeitgenosse RICHELIEU informierte, inspirierte, konzipierte und redigierte " (LÖBL a. a. O. 265). Daß FrIEDRICH II. sehr bewußt sich der Presse bediente, nicht nur um durch Flugschriften, eigene, wie die Trois lettres au public, und fremde, sondern auch durch Zeitungsartikel auf Freunde, Feinde und Neutrale zu wirken, ist in neueren Schriften oft dargestellt worden ${ }^{1}$ ). In weit höherem Maße noch gilt es von

\footnotetext{
1) .FRIFDricu D. GRosse war ein eifriger und geschickter Publizist, wußte die Spenersche Zeitung gut zu verwerten, vollführte in ihren Spalten manches diplomatische Kunststiickchen", L.OBI, a. a. O. Gut ist die Anekdote, die Bruniuber (Sammlung Göschen 400, S. 67) nach ZINKeISEN, Geschichte des osmanischen Reiches in Europa, mitteilt. Man vgl. auch über die im Text genannten drei Briefe«, J. G. Droysen in der Deutschen Rundschau Band 40 (1884).
} 
NAPOLEON BONAPARTE, der noch in seiner Frühzeit unter dem Direktorium den ihm ergebenen Zeitungen die Losung gab: „Immer mich, mich, mich nennen!" „Ausrufungszeichen hinter meinen Namen setzen!" und, je höher er stieg, um so sorgsamer die Presse seines wie des Auslandes, insbesondere Englands - die Times! überwachte und überwachen ließ, der sich nicht schämte, einen deutschen Buchhändler wegen einer Flugschrift zu erschießen, der sich auf alle Künste der Reklame und auch auf die nicht geringe Kunst verstand, die Aufmerksamkeit des Publikums in wichtigen und gefährlichen Momenten abzulenken, so wenn er im Jahre I8I2 das Journal de l'Empire und die Gazette de France anwies, ausführlich und unablässig den Streit über den Vorzug der französischen oder italienischen M usi k zu behandeln. - Auch BISMARCKs Verhalten und Verhältnis zur Presse ist des öfteren erörtert worden. In jungen wie in alten Tagen war er bekanntlich ein eifriger Mitarbeiter an Zeitungen, und als er auf dem Gipfel seiner Macht stand, war er auf das emsigste beflissen, durch den Mund der ihm gewogenen Zeitungen offiziös, aber auch durch offizielle und halboffizielle Kundgebungen auf die öffentliche Meinung $\mathrm{zu}$ wirken. Im Jahre $\mathrm{I} 848$ wurde die Leitung einer preußischen Zentralstelle für die "Beobachtung * der öffentlichen Meinung in der Presse dem Freiherrn EMm, von RrchthofEN übertragen; die erste Organisation dieses »literarischen Bureaus « hatte anfänglich nur einen informatorischen $Z$ weck: ,bis zu einer Führung der öffentlichen Meinung im Sinne der jeweiligen Regierungspolitik war das Institut noch nicht herangediehen" ("Ein preußisches Beamtenleben «, Deutsche Rundschau, April r883, S. 127). Übrigens galt es als Organ des gesamten Staatsministeriums und stand seit 1862 unter dem Ministerium des Innern. Erst durch den "Welfenfonds * war BISMARCK in der Lage, ein wirksames "Preßbureau " dem Deutschen Auswärtigen Amt anzugliedern, über dessen korrumpierenden Einfluß dann oft geklagt worden ist. Aber selbst während des Krieges $1870 / 7 \mathrm{I}$ erscheint, von heute aus gesehen, die Art, wie der Bundeskanzler sehr persönlich, mit seinem Obergehilfen LoTHAR BUCHER und dem Untergehilfen MORITZ Busch auf Monats- und Wochenschriften wie auf Tageszeitungen einwirkte, recht bescheiden und patriarchalisch. Aus den von Busch überlieferten Gesprächen und Weisungen erhalten wir ein lebendiges Bild davon. Bei weitem die meisten Zeitungsartikel, die er mitteilt, sind von BISMARCK unmittelbar inspiriert, einige von ihm diktiert, viele korrigiert. Was Busch in den "Tagebuchblättern " recht unterhaltend darüber berichtet, soll dartun, daß der Staatsmann ,,auch das Handwerk des Journalisten aus dem Grunde verstand" (I, 6). Vor dem Kriege, im 
März I870, wurde das Strafgesetzbuch für den Norddeutschen Bund beraten: der Reichstag war für Abschaffung der Todesstrafe. BUCHER muBte auf BISMARCKs Befehl einen Artikel schreiben, der nachweisen sollte, $\mathrm{da} B$ die Mehrheit des Reichstages die Offentliche Meinung und den Willen des Volkes nicht ausdrücke (S. I3). BISMARCK wandte ohne Bedenken den Kunstgriff an, Angriff oder Widerlegung zu verkleiden. „Fassen Sie es in eine römische Korrespondenz für die Kölnische Zeitung“ (S. 14). Gewisse Dinge sollen ,zunächst in ein Blatt, das der Regierung fernsteht" (I4), einen gelungenen Artikel soll Busch ,,breittreten und von den Blättern der Provinz wiederholen lassen" (25). Auf die Auswahl der Blätter, in die etwas zuerst "kommen" soll, wird großes Gewicht gelegt. Als der Krieg herannaht, wird das literarische Gewühl immer heftiger. Ein Gesandtschaftsbericht aus London meldet, daß Lord GRANVIILE gefragt habe, ob nicht von der Gesandtschaft die preußische Regierung gegen die britische aufgereizt werde. - BisMARCK hatte lebhafte Klagen über die Art, wie England die Neutralität verstehe, laut werden lassen. Es sei geantwortet worden, die Offentliche Meinung in Deutschland übe auf die Regierung EinfluB, wie die Presse der Regierung auf die öffentliche Meinung wirke; es mache eben in Deutschland große Erbitterung sich geltend usw. Der Bericht schloß: „England ist uns in vieler Hinsicht geneigt, will aber für jetzt neutral bleiben. Bestürmen wir die dortige öffentliche Meinung durch unsere offiziöse Presse weiterhin mit Klagen in dieser Angelegenheit, so wird das nichts nützen, könnte aber für die Zukunft Gefahren heraufbeschwören." Wie BISMARCK auf diese Warnung reagiert hat, erfahren wir nicht. Während des Krieges wird die Tätigkeit für die Presse, inund ausländische, durchaus als notwendige Begleitung der Kriegführung und Friedensvorbereitung aufgefa $B t$ und "Büschchen " hat unendlich viel zu tun, aber das ist auch alles. Und er behält doch Zeit, mancherlei Beobachtungen zu machen und Anekdoten in sein Tagebuch einzutragen. Interessant sind zuweilen BisMarcks Urteile über die Franzosen. Unmittelbar nach Sedan hatte er in Donchery zum General WIMPFFEN gesagt, er wisse recht wohl, daß die Anmaßung und Streitsucht der Franzosen und ihr Scheelsehen bei den Erfolgen der Nachbarvölker nicht von der arbeitenden und erwerbenden Bevölkerung ausgingen, sondern von den Journalisten und dem Pöbel; aber diese beherrschten und zwängen die öffentliche Meinung (I69). „Frankreich ist eine Nation von Nullen, eine Herde, sie haben Geld und Eleganz, aber keine Individuen, kein individuelles Selbstgefühl nur in der Masse". Bedeutsam ist, wie noch im September und in bezug auf den Gefangenen von Wilhelmshöhe Buscr einigen ,für die Denkart des Kanzlers charakteristischen Gedanken" in einem 
Artikel Ausdruck geben soll, nachdem die Nationalzeitung (damals sehr einflußreich) gemeint hatte, der Sieger sei vallzu ritterlich" gewesen. „Wir teilen diese Ansicht in keiner Weise. Allerdings ist die Öffentliche Meinung nur zu sehr geneigt, politische Verhältnisse und Ereignisse in der Weise von privatrechtlichen und privaten überhaupt aufzufassen, und unter anderem zu verlangen, daß bei Konflikten zwischen Staaten der Sieger sich mit dem Moralkodex in der Hand über den Besiegten zu Gericht setze, und ihn für das, was er gegen ihn, womöglich auch für das, was er gegen andere begangen, zur Strafe ziehe. Ein solches Verlangen ist aber völlig ungerechtfertigt; es stellen, heißt die Natur politischer Dinge, unter die die Begriffe Strafe, Iohn, Rache nicht gehören, gänzlich mißverstehen, ihm entsprechen, hieße das Wesen der Politik fälschen. Die Politik hat die Bestrafung etwaiger Versündigungen von Fürsten und Völkern gegen das Moralgesetz der göttlichen Vorsehung, dem Lenker der Schlachten zu überlassen. Sie hat weder die Befugnis, noch die Pflicht, das Richteramt zu üben, sie hat sich unter allen Umständen einzig und allein zu fragen: Was ist hierbei der Vorteil meines Landes und wie nehme ich diesen Vorteil am besten und fruchtbarsten wahr? ... die Politik hat nicht zu rächen, was geschehen ist, sondern zu sorgen, da $\beta$ es nicht wieder geschehe". Dies wird dann auf den besiegten und gefangenen Kaiser der Franzosen angewandt. Wie neuerdings bekannt geworden, hat der alte Kaiser WILHELM selber über die Unterredung, welche er mit NAPOLEON III. am Tage nach der Schlacht im Schlößchen Bellevue geführt hat, eine eigenhändige Aufzeichnung gemacht. Sie ist auch für unser Thema merkwürdig und möge hier im Originale mitgeteilt werden, da sie durch Übersetzung nur leiden würde ("Der Tag «, I92I Feb. 5): „Ego: Avant de vous quitter, Sire, j'ai encore un mot à dire. Je crois Vous connaître assez. et Vos vues politiques, pour me dire que Vous n'avez pas voulu cette guerre, mais que Vous avez été entraînés de la faire malgré Vous. $N$ (apoleon): Sire, Vous avez raison, mais l'opinion publique! Ego: Mais qui a fait l'opinion publique? C'est la marche du gouvernement et les principes qu'il suit, qui donnent l'opinion publique nommément par la presse; il ne faut que peu de jours de journalisme pour exciter l'opinion publique surtout quand on fait répandre que l'honneur national est froissé. C'est ce qu'a fait Votre Ministère! Dès que V. M. a choisi ce Ministère, je me suis dit que Vous jouerez et Votre dynastie et votre pays! N(apoleon): Ah! Vous n'avez pas tort!" Bekanntlich dachte BISMARCK - und wohl auch der König - an eine Wiedereinsetzung NAPOIEONS. LUDWIG BAMBERGER, der damals im UnterElsaß publizistisch tätig war, berichtete, er habe allerorten, zuletzt 
in einem Kreise politischer Freunde zu Karlsruhe Gelegenheit gehabt, zu konstatieren, da $B$ eine unter deutschen Auspizien vorgenommene Restauration des Napoleonismus dem öffentlichen Gewissen wie eine Monstrosität vorkomme. Man verkenne nicht die äußere und innere Haltlosigkeit der improvisierten republikanischen Regierung. „Aber ein Gefüh1 ${ }^{1}$ ), das stärker ist als alle praktischen Räsonnements, perhorresziert jene Lösung als eine moralische Unmöglichkeit." Dem Wunsche BAMBERGERs gemäß teilte Busch den Brief dem Kanzler mit (I, 242). Bismarck ,schickt mir ihn wieder. Das Wort »Gefühl «ist von ihm zweimal unterstrichen und mit einem Ausrufungszeichen versehen." Man muß sich zuweilen wundern, daß BISMARCK seine besten Gedanken nicht festgehalten und durchgesetzt hat. - BISMARCK besa $B$ an MORITZ BUSCH einen sehr ergebenen und durch Gewandtheit und Pfiffigkeit ungemein brauchbaren Diener, den er auch, nachdem er seine dienstliche Stellung infolge von Intrigen verlassen hatte, immer wieder einzuspannen und zum Artikelschreiben zu veranlassen wußte, so namentlich in der kritischen Zeit des Jahres 1877, wo BISMARCK die Ursache der Krisis ausführlich und wiederholt besprochen zu finden wünschte, und Busch ihm erklärte, die Grenzboten stünden ganz und unbedingt ,zu Ew. Durchlaucht Verfügung“ (II, 4I8). BISMARCK gibt ihm genaue Weisungen, wie er über die "Bonbonniere" (die Hofopposition) reden solle; in bezug auf deren evangelischen Teil möge er den Ausdruck gebrauchen: Bodensatz der Kreuzzeitungsgesellschaft und der inveterierten Herrenhausopposition. BuscH will alles allmählich in die Offentlichkeit bringen, deutlich, kräftig und vorsichtig. In seinem Artikel "Der Reichskanzler auf Urlaub «vom 19. IV. I877 erklärte er, die Krisis sei nur vertagt. Der Fürst werde seine Bedingungen stellen müssen, und man werde auf diese Bedingungen eingehen müssen. „Die Offentliche Meinung kann einiges dazu beitragen. Sie wird wohltun, wenn sie sich nicht mit dem dermaligen Stadium der Sache beruhigt, wenn sie sich vielmehr, deutlicher als bisher geschehen, die sehr ernste Hauptsache der fortschleichenden Krisis vergegenwärtigt, und wenn sie der gewonnenen Erkenntnis in der Presse Worte gibt, unablässig, nachhaltig, immer von neuem Worte gibt, und auf Abstellung der betreffenden krassen Mißverhältnisse dringt, mit dem selbst ein BISMARCK nicht in ersprießlicher Weise zu wirken vermag, geschweige denn einer der in den letzten Wochen als mögliche Nachfolger Bezeichneten, sei er auch noch so vornehm, noch so unabhängig und noch so talentvoll." Es wird ferner nach des Fürsten Anweisung erklärt, seine Gesundheit, sein Reichtum

1) So lese ich anstatt: ,im Gefühl"“.

Tönnies, Kritik. 
und ganz besonders sein Einfluß werde weit überschätzt. „Die Hauptschranke seines Einflusses aber ist - und bleibt vielleicht, wenn die öffentliche Meinung nicht die Augen auftut und sich kräftiger und nachhaltiger rührt als bis jetzt - das... Unwesen am Hofe, wo um eine gewisse hochgelegene Stelle der Bodensatz der Kreuzzeitungsgesellschaft und der inveterierten Herrenhausopposition mit dem ultramontanen Gifte aus den Kanälen Roms zusammengeflossen ist, und von wo aus der Politik des Kanzlers unaufhörlich VerdrieBlichkeit bereitet, bald der, bald jener Stein in den Weg gewälzt und durch immer neue Ermutigungen der Gegner der sonst wohl schon eingetretene Sieg aufgehalten wird." Die Bonbonniere der hohen Dame (der Kaiserin AUGUSTA) wird dann in allerdeutlichster Weise ans Licht gezogen. BUCHER sprach die Besorgnis aus, das Elixir wirke zu stark. Nach dem 5 ten Friktionsartikel, der die Überschrift »Friedensengel «trug und gegen die Königin VICTORIA, mittelbar auch gegen AUGUSTA gerichtet war, schrieb er: „Der Arzt (BISMARCK) findet, daß die verordneten Medikamente zu kräftig und viel $\mathrm{zu}$ schnell hintereinander angewandt worden seien. Eine längere und sanftere Sommerkur wäre besser gewesen." Der 6. und 7. (letzte) Friktionen-Artikel rührten von BUCHER selber her; sie richteten sich gegen den Hausminister voN SCHLEINITZ und gegen die Filiale der Bonbonniere in Karlsruhe, als deren Leiter die Professoren GEFFCKEN und MAX MÜLLER boshaft angegriffen wurden, ohne Nennung, aber mit durchsichtigster Andeutung der Namen. - BISMARCK war in jenen Jahren noch nicht fest in der öffentlichen Meinung. D. h. die Offentliche Meinung zu seinen Gunsten war noch nicht in einem soliden Aggregatzustand geronnen. In gewaltigen Blasen hatte sie ihn, nach den Erfolgen von I866 und I87I emporgehoben. Sie hatte sich verdichtet und war in FluB geraten; aber der Zusammenbruch der Gründerzeit und die große wirtschaftliche Krise, die ihr folgte, wirkten der Verdichtung entgegen. Man sprach von Reichsverdrossenheit, und ein Teil der Bourgeoisie fühlte sich durch den "Krieg in Sicht « und den fortgesetzten Militarismus, ein größerer durch die Fortdauer der Freihandelspolitik zurückgestoßen. Hier beschloß BISMARCK einzulenken. In Sachen des Kulturkampfes hatte er die liberalen Fraktionen und die Öfentliche Meinung auf seiner Seite. Das "Niederlegen der Waffen auf dem Fechtboden *, die Entlassung des Ministers FALK, mußten erkältend wirken. Um eine sichere Schutzzoll-Mehrheit zu gewinnen, mußte er dem Zentrum Zugeständnisse machen, die der Offentlichen Meinung zuwider waren, auch soweit sie die protektionistischen Liberalen vertrat. BISMARCKS Streben war fortwährend dahin gerichtet, der Offentlichen Meinung, die für ihn vorhanden war, eine feste und dauerhafte 
Gestalt zu geben; das konnte unter diesen Umständen nicht gelingen, auch das Sozialistengesetz, dem die Offentliche Meinung nur zögernd zugestimmt hatte, wirkte nicht dauernd in diesem Sinne. So lebte er im Anfange der 8oer Jahre in tieferer Verbitterung als zuvor. Das Bündnis mit Osterreich-Ungarn befriedigte allerdings die Offentliche Meinung, aber es machte die Stellung des Reichskanzlers im Innern nicht behaglicher. Seinen ehemaligen nationalliberalen Anhang hatte er sich zum großen Teile entfremdet, die Widerstände der Altpreußen und des Hofes wurden nicht geringer. Die Offentliche Meinung stand unter dem Eindrucke, daß BISMarck alt werde. Dagegen vermochte der Geist eines Busch wenig, sogar Buchers Geist nicht viel. Freilich, die Uberzeugung von den großen Leistungen des Fürsten in der auswärtigen Politik, von seinem Verdienst um die Einigung Deutschlands, verdichtete sich gleichzeitig und wurde schon mit dem Schimmer der Mythe umkleidet; aber über die Richtigkeit seiner inneren Politik blieben die Ansichten sehr geteilt. Er stand nun da als ein Anhänger der Konservativen und des Zentrums, diese - die "Schwarz-Blauen * - nicht als seine Anhänger; und die Nationalliberalen, die es wirklich waren und ihn immer, wenn auch mit einigen kritischen Vorbehalten, unterstützt hatten, wurden von ihm, obschon sie die freihändlerischen Sezessionisten ausgestoBen hatten, die ursprünglich doch auch entschiedene Bismarckianer waren, zu schlecht behandelt - van die Wand gedrückt " - um als seine Ritter und Herolde sich behaupten und ihren Einfluß verstärken zu können; die Partei kam immer mehr ins Gedränge und in Abnahme. Ohne Zweifel hätte BISMARck nur mit ihrer Hilfe, und wenn die Partei kräftig und zahlreich genug, also unzersplittert geblieben wäre, seine eigene Macht so zu sichern vermocht, daß der unerfahrene junge Kaiser unfähig gewesen wäre, sie zu stürzen. Dazu wäre aber auch ein vielseitigerer und verfeinerter Einfluß auf die öffentliche Meinung nötig gewesen, als BISMARCK sie durch die beiden Männer ausüben konnte. Diese waren nicht die geeigneten Persönlichkeiten, den Bismarck-Kultus, noch während er im Amte war, zu organisieren, und nichts Geringeres als dies wäre notwendig gewesen. Die Vertretung seines Namens und seiner Geltung in der Presse und Literatur wurde enger und kleinlicher, anstatt weiter und großzïgiger zu werden. So kam es, da $B$ erst nach seinem Abgange dem ersten Reichskanzler die Glorie allmählich zuwuchs. Die Öfentliche Meinung, in dem Sinne, daß er der »Säkularmensch «, der größte Mann des Jahrhunderts, der Schöpfer der deutschen Einheit und des neuen deutschen Reiches sei, der Mann, dem die Hohenzollern-Dynastie die deutsche Kaiserkrone zu verdanken habe, nahm festere Gestalt 
an, sie wurde bis I9I4 und blieb noch in den ersten Jahren des Weltkrieges in Deutschland unerschütterlich und der gewaltige Ruhm strahlte in die Welt hinaus. Alle Schatten verblichen, alle kleineren Sterne, auch der Stern des Monarchen, der ihm geleuchtet hatte, empfingen nur noch ihr Licht von seinem Namen. BISMARCK wurde Gegenstand einer religiösen Verehrung - durch die Öfentliche Meinung. Sie stieg mit dem Wachstum des Ansehens und der Macht des Deutschen Reiches. Den Untergang dieses Ansehens und dieser Macht wird die Verehrung kaum sehr lange überleben; denn der Mißerfolg senkt, wie der Erfolg hebt.

13. (Bismarcks Ansicht.) BrsMarcks Ansicht über die öffentliche Meinung möge schon in diesem Zusammenhange bemerkt werden. Im Jahre I868 oder I869 soll er zu HERMAN WAGENER gesagt haben: „Sie kennen unzweifelhaft den Ausspruch des alten NAPOLEON, daß drei schreiende Weiber mehr Iärm machen als tausend schweigende Männer. Man tut deshalb auch sehr unrecht, den schreienden Weibern der öffentlichen Meinung irgendeine größere Bedeutung beizulegen. Die wahre öffentliche Meinung ist die, welche sich aus gewissen politischen, religiösen und sozialen Vordersätzen in einfachster Fassung in der Tiefe des Volkslebens erzeugt und regt, und diese zu erkennen und zum Durchbruch zu bringen, das ist die eigentliche Begabung und Aufgabe des Staatsmannes. Ich möchte dieselbe die Unterströmung der öffentlichen Meinung nennen. Ich habe deshalb auch niemals mit den. eigentlichen Parlamentsschreiern gerechnet, und habe gerade um deswillen die Genugtuung gehabt, die öffentliche Meinung, auf welche ich Wert lege, in nachhaltiger Weise für mich zu gewinnen. Die Paulskirche in Frankfurt und das Unionsparlament in Erfurt waren in der Tat eine Versammlung ausgezeichneter Redner, und doch, was ist von denselben übriggeblieben? Versunken und vergessen, das ist des Sängers Fluch." Dazu hat der genannte langjährige Redakteur der Neuen Preußischen (Kreuz-) Zeitung die Anmerkung gemacht: ,Psychologisch sehr interessant ist es, daß der Kanzler, ähnlich wie NAPOLEON I., von dem Professor LEO behauptet, daß er selbst in dem Kanonendonner der Schlacht nach den Parlamentsreden in Paris gehorcht, den Parlamentarismus zwar praktisch mit großer Geringschätzung behandelt, nichtsdestoweniger aber die "öffentliche Meinung « wie kaum ein anderer auf das sorgfältigste studiert und seine größten Erfolge gerade seiner richtigen Diagnose der Volksstimmung und ihrer Strömungen verdankt. Freilich hat er dabei stets sowohl theoretisch wie praktisch den Grundsatz festgehalten, daß die Regierung als das Haupt des Volkskörpers und als der Ort, in welchem sich alle Staatsgedanken konzentrieren, der 
wichtigste und maßgebendste Teil des Volkskörpers sei und als Ausgangspunkt aller politischen Aktion die Aufgabe habe, die öffentliche Meinung zu leiten und zu korrigieren. Daher das große Gewicht, welches er auf die Presse und auf vollendete Tatsachen legt; daher auch die eiserne Konsequenz mit welcher er seine Pläne verfolgt. Er teilt, wie wir hören, und wie er dies in seinem vertrauten Kreise wiederholt ausgesprochen haben soll, die Ansicht des Paters BECKX (des Jesuitengenerals), welcher zu sagen pflegte: „Wenn der Wind sich dreht, drehen sich alle Wetterfahnen, und zwar um so schneller und entschiedener, je schärfer der Wind ist. " 1 ) Man erkennt aus diesen Äußerungen auch, daß der Staatsmann die Aggregatzustände der Offentlichen Meinung gekannt hat, wenn er auch kaum eine zureichende Vorstellung von ihrem Wesen, sofern es von Volksstimmungen und Gefühlen sich abhebt, besaß. Bei der Schärfe, womit er alle Stimmungs- und Gefühlspolitik verwarf, hätte ihm vorzugsweise darum zu tun sein müssen, eine urteilsfähige und sachlich urteilende Offentliche Meinung zu erziehen und für sich zu gewinnen, also für eine höhere politische Bildung des Publikums Sorge zu tragen. Darauf ist er aber niemals bedacht gewesen. Er hätte einen intellektuellen Generalstab um sich versammeln müssen, hätte den Gedanken, da $B$ Politik Sache der kühlen Berechnung, des wissenschaftlichen Denkens ist, systematisch pflegen, ausbauen, verbreiten müssen, um ihn selber der Offentlichen Meinung einzurammen und zu einem Gegenstande des öffentlichen Bewußtseins, d. h. eben der festen Offentlichen Meinung zu erheben. Auch wäre ersprießlich gewesen, die Wahrheit gegen den Irrtum abzuwägen, welche beide in dem von Bermiard (Aus d. Leben Th. v. B.'s, 6. Teil S. 304 nach BaUER, D. Krieg und die öffentliche Meinung, S. 47) aufbewahrten Bismarckschen Ausspruche enthalten sind: „, Man schießt nicht mit öffentlicher Meinung auf den Feind, sondern mit Pulver und Blei." Ein allgemeines Urteil über die Offentliche Meinung findet sich auch im III. Bande der "Gedanken und Erinnerungen «: ,Uber die Fehler, welche in der auswärtigen Politik begangen wurden, wird sich die öffentliche Meinung in der Regel erst klar, wenn sie auf die Geschichte eines Menschenalters zurückzublicken imstande ist, und die Achivi qui plectuntur sind nicht immer die unmittelbaren Zeitgenossen der fehlerhaften Handlungen" (S. I57).

14. B. (Konservative und reformative Parteiung.) Wenn wir nunmehr den zweiten Gegensatz der Parteien ins Auge fassen, so scheint dieser die wesentliche und ursprüngliche Scheidung der Meinungen;

1) Poschinger, Fürst Bismarck und dic Parlameutarier. Zweiter Band, S. IIr. 
die über öffentliche Angelegenheiten öffentlich geäußert werden, zu bezeichnen. Auf der einen Seite will man das Alte, auf der anderen das Neue, auf der einen will man erhalten, auf der anderen verändern. $\mathrm{Da} B$ dieser Gegensatz mit dem Gegensatz von Regierung und Opposition sich vielfach berüht, ist schon bemerkt worden. Aber er bezieht sich auch auf die Regierung, auf ihr System, ihre Methoden, ihre Grundsätze, daher auch auf die Verfassung, und im politischen Leben auf die Staatsform. So hat sich in Frankreich mehr als roo Jahre lang der Kampf der Meinungen, auch in der Literatur und der Tagespresse, gedreht um den Streitpunkt "Republik " oder "Monarchie " abgesehen von den Unterschieden und Gegensätzen innerhalb der monarchistischen wie innerhalb der republikanischen Richtungen. So war in den deutschen Staaten der Meinungskampf auf weiten Feldern entfaltet zwischen unbeschränkter und beschränkter, absoluter und konstitutioneller Monarchie, später - im Deutschen Reiche zwischen dem konstitutionellen und dem parlamentarischen System der Regierung. Neuerdings - seit Nov. I9I8 - auch hier: Monarchie $v$. Republik. Aber der vorwaltende Kampf der Meinungen bezog sich, schon vor dem I9. Jahrhundert, und vollends in dessen erster Hälfte, auf bürgerliche und politische Freiheit - und zwar wesentlich auf Bestreitung des rechtlichen und noch mehr tatsächlichen Vorranges des Adels im Staate, durch das reicher und selbstbewußter werdende Großbürgertum, in dessen Gefolge auch das kleinere Bürgertum wirkte. Grundsätzlich, und in der Regel auch wirklich, meinte dieses zugleich die Wünsche und Angelegenheiten der breiten Masse der großen Menge des "Volkes « - zu vertreten und geltend zu machen. So durch die Forderung der Gewerbefreiheit, der Freizügigkeit, des freien Arbeitsvertrages, der Auswanderungsfreiheit und vor allem auch der Religions- oder Gewissensfreiheit. Aber allmählich schob sich - von der Mitte des Jahrhunderts an, und gesteigert in dessen letztem Viertel - ein neuer Gegensatz von Erhaltung und Veränderung, von Altem und Neuem, hinein: der Kampf um die Gesellschafts ordnung, d.i. um die Grundlagen des Privatrechts. Die Arbeiterklasse tritt mit Rede und Schrift, mit Stimmzetteln, Arbeitseinstellungen und Demonstrationen auf den Plan wider die besitzende Klasse, am unmittelbarsten gerade gegen das Großbürgertum, aber zugleich auch gegen den "großen Grundbesitz ", der mehr und mehr in den Begriff der feindlichen und gehaßten "Bourgeoisie " hineingefaßt wird. Tatsächlich werden ebendadurch diese sonst entgegengesetzten Parteien bewogen oder doch angeregt, als erhaltende oder als (Gesellschafts-)Ordnungs-Partei sich zusammenzuschließen; wenigstens ist ihr Zusammenhalten gege n die "Feinde»der (Gesellschafts-) 
Ordnung eine Sache, die sich von selbst $z u$ verstehen pflegt und die sie einander gegenseitig als Pflicht predigen. Der Proze $B$ selber nimmt freilich in verschiedenen Ländern sehr verschiedene Formen an. In GroBbritannien ist das politische Herkommen und die Wahlentscheidung durch einfache Mehrheit auf das Zwei-Parteien-System eingestellt. Hier hat schon die Bildung einer radikalen, der noch nebelhaften Arbeiterpartei sich nähernden Parteigruppe, die immerhin schon das Schlagwort ihres gefeierten Hauptes (GladsTONEs) „Die Massen gegen die Klassen" auf ihre Fahne schrieb, eine ähnliche und zwar viel intensivere Wirkung gehabt: daB nämlich die durch $2 \mathrm{Jahr}$ hunderte als Aristokraten-Cliquen rivalisierenden, die Tories und die Whigs, zunächst 2 Jahrzehnte hindurch zusammengingen, endlich sogar zu einer Partei der "Unionisten « sich zusammenfügten. Es liegt in der Natur der Sache, daß die Gegenstände des Erhaltens und Neuerns vielfach sich verändern können, aber für die große politische Entwicklung, die während der letzten Jahrhunderte in Europa als Umwälzung der vom Mittelalter überkommenen Einrichtungen gewirkt hat, handelte es sich, bis zu dem noch immer schwankenden Auftreten des Proletariats, wesentlich um die Rivalität und den Klassenkampf zwischen dem alten und dem neuen Herrenstande, zwischen Grundherrentum und Kapital. Daß in diesem Streit die Offentliche Meinung vorzugsweise auf Seite des neuen Herrenstandes oder des Kapitals gestanden hat, ergibt sich aus dem Wesen der Offentlichen Meinung, insofern sie städtisch und modern und fortschrittlich gesinnt ist; sie wird in der Tat, wie die Wissenschaft, insbesondere die Naturwissenschaft, auf welche sie sich am liebsten stützt, von dieser emporstrebenden und emporkommenden Schicht getragen. Indessen ist das Verhältnis doch keineswegs so einfach und eindeutig, da $B$ es die Anwendung einer Schablone gestattete. Einmal sog die neue Bildung immer ihre Nahrung aus der alten, die Ubergänge sind mannigfach und auch Adlige sind unter den Vorkämpfern heilsamer oder so erscheinender Neuerungen, an ihrer Spitze zuweilen die Fürsten und ihr höfischer Anhang; in Deutschland war ein Jesuit unter den ersten Streitern gegen die Hexenprozesse, deren abergläubische Sinnwidrigkeit seitdem in die Offentliche Meinung übergegangen und darin fest verkapselt ist. Sodann darf nicht vergessen werden, da $B$ gerade die echte und höhere Bildung ihre selbständige Würde und Unabhängigkeit besitzt, die sie oft auch den neuen Elementen des Zeitgeistes gegenüber kritisch werden und beflissen sein läßt, den bloßen Schein zu durchdringen, um auch die andere Seite der Dinge kennen zu lernen. Endlich möge man sich erinnern, daß die Offentliche Meinung immer auch laudatrix temporis acti ist, daB sie gern die Schatten 
der "guten alten Zeit «den Úbeln und Verderbnissen der Gegenwart entgegenwirft und überdies eine ausgesprochene Vorliebe für die mittlere Linie hat. "In medio virtus " ist einer ihrer Wahlsprüche. Dennoch bleibt das Grundverhältnis geltend: die Öffentliche Meinung geht mit und entwickelt sich mit den Angriffen der Neuerer gegen die hergebrachten und srückständigen " Zustände, Sitten, Anschauungen; und diese Angriffe suchen ihren Hauptschauplatz in der Literatur, mehr und mehr und mit gewisseren Wirkungen, in der periodischen Literatur, in der Presse. Das Zeitungwesen hat neben seinem anfänglichen amtlichen und dem ebenso ursprünglichen bloßen Nachrichtenzweck ganz überwiegend eine liberal-fortschrittliche Tendenz gehabt. Die konservative Denkungsart war in der Defensive und konnte gegen den Fortschritt der liberalen Presse sich um so weniger wehren, da sich hinter diese mehr und mehr die großen Kapitalmächte, besonders die des Handels, der Banken und der Börse stellten. Daraus erklärt sich auch, daß wenigstens im deutschen Sprachgebiet die allgemeine Kritik des Zeitungwesens immer eine konservative und "reaktionäre " Färbung gehabt hat. . In diesem Sinne hat BISMARCK, bald nachdem er Minister geworden, sich ausgedrückt, wenn er von der »oppositionellen Presse «sagte, $\mathrm{da} ß$ sie zum großen Teil in Händen von Juden und unzufriedenen, ihren Beruf verfehlt habenden Leuten sich befinde. Unzählige Male ist dies Urteil in Deutschland wiederholt und abgewandelt worden; es ist ein beständiges Kampfmittel auf jener Seite, die ganze Presse als jüdisch verseucht, als verjudet $\mathrm{zu}$ brandmarken, womit unwillentlich zugegeben wird, daß die konservative Presse in ihrer Bedeutung mit der liberalen - die natürlich auch BISMARCK meinte, als er die oppositionelle nannte - nicht wetteifern könne; oder aber sie sei auch jüdisch "getauft ", was allerdings nicht selten der Fall gewesen ist. Darum bezeichnet auch TreiTschke (Politik II, 27) es einfach als Tatsache, daß „Juden heute bei uns die politische Presse beherrschen" und zwar als eine monströse Tatsache, weil der moderne Jude das Gegenteil dessen habe, was man politischen Sinn nennt: merkwürdig erscheint auch in dieser Hinsicht, daß die antisemitische Agitation, wenn sie neuerdings in Deutschland die Sozialdemokratie oder noch schärfer den neuen "Kommunismus» oder Bolschewismus anklagt, weil in ihnen das Judentum die führenden Rollen habe, nicht oder kaum auf dessen Tätigkeit in der Parteipresse dieser Richtungen Bezug nimmt: diese Parteipresse ist ja für die große »Offentlichkeit * so gut wie nicht vorhanden; als die Presse, welche ihnen ein Dorn im Auge ist, wird immer wieder die jüdisch-liberale oder jüdisch-demokratische Presse vorgeführt - eben wegen ihrer Mächtigkeit, ihres Geistes, 
ihrer Verbreitung. Gibt also diese die Offentliche Meinung wieder wie sie ist? oder wirkt sie so stark auf die öffentliche Meinung, daß sie sie bestimmt und mit sich fortreißt? Das eine wie das andere ist zuweilen der Fall, aber beides war viel häufiger - in deutschen Landen - zu jener Zeit, als noch Liberalismus das Glaubensbekenntnis fast der ganzen "gebildeten Welt « und diese weder von antiliberalen ("reaktionären «) Gedanken noch von antisemitischen Gefühlen anders als oberflächlich berïhrt war: so war die Lage der Dinge von etwa I830 bis um die Mitte des 8 . Jahrzehntes des Jahrhunderts. Seitdem hat die Offentliche Meinung in Deutschland kein ausgesprochenes Parteiprogramm mehr; war sie bis dahin "nationalliberal «mit entschiedener Betonung des »liberal «, so fiel nun der Ton, wenn sie überhaupt dies Beiwort sich noch gefallen ließ, ganz entschieden auf das "national « und zwar mit immer vermehrter Stärke, so daß endlich, in der Republik, eine Partei, deren Hauptträger die deutsch-nationale Bewegung von I8I5-I870 als demokratisch gehaßt und verfolgt hatten, sich als deutsch-nationale Volkspartei dem ahnungslosen Publikum empfehlen konnte. In der Tat hält jetzt die Offentliche Meinung, wenn nicht die konservative allein, so doch die »beiden Rechtsparteien " für die wahren und wirklichen "nationalen «Parteien. Allerdings ist die Offentliche Meinung dem "krassen " Antisemitismus nicht hold, dieser ist mehr auf ein dunkles Schleicherdasein angewiesen; auch sonst behält sie noch, mehr oder minder latent, starke liberale Bestandteile, die sich auch einem Teil der "starren Konservativen « aufdrängen; aber die Furcht und Abneigung vor sozialistischen Neuerungen führt nicht nur zu Verschmelzungen mit konservativen Gedankengängen, sondern macht auch sonst den Liberalismus verblassen und gewissermaßen zur Umkehr und Reue geneigt, als möchte er, wenn es möglich wäre, zurücknehmen und widerrufen, was er einst als Ideal erstrebt und als seine Errungenschaft gepriesen hatte. Wir werden hier in die Betrachtung zurückgelenkt, daß der alte Gegensatz: Adel - Bürgertum durch den neuen: "bürgerliche Parteien und Denkweisen « - "proletarische Parteien und Denkweisen « verdunkelt und teilweise verdrängt wird. In England stellen sich diese Verhältnisse etwas anders dar. Längst ist dort die Offentliche Meinung in allererster Linie national-englisch, imperialistisch, aristokratisch, konservativ gewesen (was sie bei uns zu werden seit 3-4 Jahrzehnten begonnen hatte); darum haben ihr alle großen inneren Reformen in langem Ringen allmählich abgewonnen oder aufgedrungen werden müssen. Da immer nur die 2 Hauptparteien für die Bildung der Regierung in Betracht kommen, und da die Offentliche Meinung in einigem Maße einen selbständigen Faktor neben den Partei-Organisationen für Entscheidung der Wahlen, 
von der die Regierung abhängt, ausmacht, so werben und wetteifern die beiden Parteien zunächst um die Gunst der Offentlichen Meinung. „Wenn die öffentliche Meinung in Tagesfragen sich geltend macht, so bleibt immer die Kritik in ihrer Nachbarschaft; in England ist sie kritikloser den Schlagwörtern preisgegeben, und kann sich um so mehr gehen lassen, da sich regelmäßig nur um die eine politische Hauptfrage die Aufregungen drehen: ja oder nein, die herrschende Partei am Ruder lassen oder die andere hinsetzen, wo dann die Stimmungen schnell entscheidend wirken." Nachdem Low (The governance of England, p. 8I) festgestellt hat, daß es sehr schwer ist, eine Regierung für irgend etwas, was sie in ihrer ministeriellen Arbeit getan hat, zur Rechenschaft zu ziehen, fährt er fort: „Der wirkliche Hemmschuh gegen einen $z \mathfrak{u}$ groben und schreienden Mißbrauch ministerieller Macht ist, ohne Zweifel, die heilsame Furcht vor der Offentlichen Meinung; aber diese Einschränkung wäre beinahe ebenso wirksam ohne den Beistand des Hauses der Gemeinen, der nicht darauf zurückwirkt, außer nach einer allgemeinen Wahl. Da diese also entscheidet über das Schicksal des Kabinetts, so muß das Kabinett sich natürlich angelegen sein lassen, nicht nur vor der öffentlichen Meinung zu bestehen, sondern sie auch unablässig und planmäßig zu bearbeiten". (TöNNIES, Der englische Staat und der deutsche Staat, S. 77.) Das gleiche geschieht aber durch die andere Partei, wie sich versteht: hier fällt eben der Kampf zwischen Regierung und Opposition zusammen mit dem Kampf der großen Parteien, und in einigem Maße ist, oder gebärdet sich doch, die jedesmalige Oppositionspartei immer als Reformpartei, wenn sie irgendwelche Neuerungen auf ihre Fahne schreibt, die der Offentlichen Meinung gefallen oder wofür diese - vielleicht durch die andere Partei oder wenigstens durch Freischärler, die aus ihr stammten - gewonnen wurde. Die regierende Partei findet Schwierigkeiten, diese Reform in Angriff zu nehmen, sie hat dringendere Aufgaben. Flugs nimmt die Oppositionspartei sie auf, als ob ihr nie um etwas mehr zu tun gewesen sei, möge sie sonst noch so sehr auf ihren "konservativen "Charakter pochen. Aber die Offentliche Meinung Englands ist Reformen grundsätzlich mehr ab-als zugeneigt; ihr ist vor allem immer darum zu tun, nicht nur das Reich zu vergrößern, den Markt für britische Waren zu erhalten und zu erweitern, sondern auch darum, die englische Verfassung als Musterverfassung, englische Gesetze und Rechte als im wesentlichen unübertrefflich, alles Ausländische als minderwertig darzustellen, als nicht einmal der Kenntnisnahme wert, außer sofern es sich um Nachbildungen, Nachahmungen der "Mutter der Parlamente" und ihrer wundersamen "verantwortlichen Regierung " handelt, deren 
wahrer aristokratischer Charakter längst von gewissenhaften Forschern britischen Namens enthüllt worden ist, ohne die Rede und Prahlerei von der wahren und echten Demolrratie - die allgemach und gleichen Schrittes mit der Burea ukr a ti e, also dem modernen Staat, wirkliche Fortschritte macht - zu erschüttern. Seit etwa 30 Jahren rücken auch in diesem mächtigsten Industriestaat die Fragen der sozialen Reform in den Vordergrund. Die Offentliche Meinung steht ihr dort mißmutig gegenüber. Sie ist nicht von ihrer in ne re n Notwendigkeit überzeugt, außer gelegentlich, wenn ein sensationeller Mißstand bekannt geworden ist, den sie schieunig zu vertilgen wünscht, hält es aber politisch für geboten, den Ansprüchen der Arbeiter weitgehende Einräumungen zu machen, teils um sie zu beschwichtigen, teils um sie an eine der beiden "respektabeln "Parteien zu fesseln. Im allgemeinen gilt noch, was vor etwa 25 Jahren BERNARD SHAw schrieb: „Die Offentliche Meinung steht dem Reformator ebenso feindlich gegenüber wie dem Verbrecher... In der Öffentlichkeit besteht nicht die Anschauung, daß jemand, der sein Brot auch ohne zu arbeiten findet, dafür $\mathrm{zu}$ arbeiten verpflichtet ist. Im Gegenteil: die Offentliche Meinung hat sich daran gewöhnt, tägliche Handarbeit als das Loos der verachteten Klassen anzusehen. Es ist das Streben aller, Vermögen zu erringen und dann nicht mehr zu arbeiten Selbst die Mitglieder der höheren Berufsarten stehen im Range unter dem unabhängigen Gentleman, der so genannt wird, weil er nicht von seiner eigenen Arbeit abhängt" (Sozialismus in England, herausgeg. von Sidney Webb. Deutsche Ausgabe von Kurelda, S. 130). Der aristokratische Charakter der Offentlichen Meinung wird hier durch den Dichter wohl etwas zu scharf betont, aber er ist ohne Zweifel in England viel ausgeprägter als etwa in Deutschland, zumal in Süddeutschland. Weit mächtiger ausgebildet ist dort das Bewußtsein des neuen Herrenstandes, der "middle-class *, die zwar mit einiger Ehrfurcht zur oberen Klasse emporschaut, aber deren politische Macht immer einzuschränken beflissen ist. Darum hat die Bekämpfung des Boden-Monopols von allen sozialen Reformgedanken am meisten Wurzel geschlagen. So gelangt am Schlusse einer Untersuchung der "Geschichte der englischen Bodenreformtheorien " (S. 222) NinhuUs zu der Feststellung, da B sich in allen Instanzen der Gesetzgebung sowie in der öffentlichen Meinung der Gedanke durchringe von der Notwendigkeit der Reform des Grundeigentums und der Inaugurierung einer Bodenpolitik, die den Interessen der Allgemeinheit und den wirtschaftlich Schwachen mehr als bisher entsprechen. In Deutschland ist die Offentliche Meinung mehr und mehr grundsätzlich der sozialen Reform, ja in einigem Maße dem 
Sozialismus geneigt geworden (in dem besonderen Kapitel über "Die Offentliche Meinung und die soziale Frage» wird darauf zurückzukommen sein): ein Erfolg der weiter und tiefer gehenden wissenschaftlichen Belehrung, namentlich von den Universitäten aus, wo von 1870-I900 und darïber hinaus, der "Kathedersozialismus " in einiger Blüte stand. Er hat auch einflußreiche Zeitungen erfaßt, nachdem er zunächst im Verein für Sozialpolitik sich kristallisiert hatte, einem ,,wissenschaftlichen Verein, der allerdings auch einen Einfluß auf die öffentliche Meinung ausüben will" (HERKNER, Die Arbeiterfrage ${ }^{6}$, II, I50). So hat sich ein stark modifizierter Liberalismus herausgebildet, der eine Portion Sozialismus in sich aufgesogen hat, wenngleich , an dem Privateigentum, an der kapitalistischen Unternehmung, an der Selbstbestimmung und Selbstverantwortung grundsätzlich": festhaltend (das. S. I67). Seit vielen Jahren dient die 》Frankfurter Zeitung «, neben der Kölnischen die bedeutendste Tageszeitung im Deutschen Reiche, diesem "Sozialliberalismus «, den schon SoNNEMANN ,nicht nur in der eigenen kleinen Partei (der süddeutschen Volkspartei) sondern in der öffentlichen Meinung überhaupt mächtig gefördert" hatte (das. S. I6o). Wenn aber ,,die sozialliberale Richtung in der praktischen Politik" am stärksten in England durchgedrungen ist (das. 158 ), so muB der Nachdruck durchaus auf der zweiten Hälfte des Wortes liegen, das vorwiegende Metall dieser englischen Denkweise ist immer noch der Freihandel, der, um sich zu erhalten; eine Legierung von sozialen Elementen sich gefallen läßt. Für die herrschende Denkweise und die Öfentliche Meinung in diesen Dingen ist es bedeutsam, daß eine eigentliche Arbeiterpresse in Großbritannien nicht aufkommen kann, obschon gerade unter Gelehrten und anderen Höhergebildeten sozialistische Lehrmeinungen nicht geringen Anhang haben. Kleine Wochenblätter mit sehr beschränktem Leserkreis hat es zwar schon lange gegeben; eine Tageszeitung der Arbeiterpartei kam erst kurz vor dem Weltkriege auf und ist in ihm rasch wieder untergegangen (neuerdings dann unter anderem Titel wieder aufgelebt; man hat Grund zu vermuten, da $B$ ihre Auflage auch jetzt noch nicht erheblich ist, obschon sich neuerdings Männer von hervorragendem Namen der Labour Party angeschlossen haben).

In Deutschland wird nun seit mehr als 40 Jahren (etwa seit 1878) der Liberalismus von beiden Seiten - von rechts und von links heftig angefochten und ins Gedränge gebracht, mit ihm die liberale Presse, die von der einen Seite überdies als Judenpresse der Geringschätzung und dem Verdacht preisgegeben wird. Besonders in die Landbevölkerung dringt diese Presse wenig mehr, die kleinen Ortszeitungen stehen zum größten Teil unter anderem Einfluß. Indessen 
wäre es durchaus ein Irrtum, zu meinen, daß die liberalistische Denkungsart in allen Stücken zurückgegangen sei und weiter zurückgehe. Sie bleibt immer die weit überwiegende Denkungsart der städtischen Bildung und in vielen Stücken, zumal solchen, die nicht unmittelbar der Tagespolitik unterliegen, verhält sich nach wie vor die ländliche Denkungsart $\mathrm{zu}$ dieser empfangend; ja in zunehmendem Grade; je mehr "die Stadt ins Land fortschreitet « und das geht unablässig vor sich. Am wenigsten können sich die konservativen Zeitungen diesen Einflüssen entziehen, die überdies, zum größeren Teil in der Großstadt geschrieben und ganz in der Großstadt gedruckt werden. Tatsächlich können sie nur innerhalb einer gewissen Grenze vom Liberalismus sich entfernen und ihm widersprechen, ohne die Öffentliche Meinung, und das ist dann auch die Meinung des größten Teils ihrer Leser, zu stoßen und zu kränken. Sie finden vielen Beifall, wenn sie die Vorzüge der Monarchie gegenüber der republikanischen Staatsform herausstreichen; aber sie können nicht dafür in die Schranken treten, den Absolutismus wiedereinzuführen, oder gar einen väterlichen Despotismus als Heilmittel empfehlen. Sie mögen das parlamentarische Regierungssystem, ja den ganzen Parlamentarismus verwerflich finden, aber sie werden doch nicht wagen, eine Regierung ohne Volksvertretung zu befürworten; und wenn sie für eine ständische oder Berufsvertretung sich aussprechen, so werden sie sicherlich alle Stände, alle Berufe irgendwie zur Geltung kommen lassen wollen. Sie mögen gelegentlich für Wiederherstellung der "Prügelstrafe « sich einsetzen; aber sie werden diese dann vorsichtig auf solche Untaten einschränken, denen gegenüber die Offentliche Meinung sich in so scharfer Empörung befindet, daß sie schon außerordentliche Maßnahmen zu erwägen geneigt ist; aber diese Zeitungen werden — in Deutschland - auch nicht zur Abschreckung der ärgsten Schieber und Wucherer die Strafe des Galgens, geschweige denn die des Vierteilens, Aufsradflechtens u. dgl. in Antrag bringen. Ebenso mögen sie allerhand Maßnahmen in Anregung bringen, um den Einfluß des Judentums einzudämmen, höhere Besteuerung des Börsenhandels, der Banken, auch etwa Hemmungen der Einwanderung von Israeliten aus dem Osten; aber sie werden nicht die russischen sog. Pogroms als nachahmenswert darstellen, nicht die Beschränkung der Juden auf gewisse Straßen der Städte, nicht die Bindung irgendwelcher politischer oder bürgerlicher Rechte an ein christliches Bekenntnis oder gar die Nachweisung eines njudenreinen "Stammbaumes befürworten. Einerseits werden wohl die meisten, und sicherlich die intelligentesten, konservativen Schriftsteller selber nicht von der Vortrefflichkeit oder der Ausführbarkeit solcher Vorschläge überzeugt sein; andererseits 
werden auch die beschränkten Eiferer es nicht wagen, damit ans Licht der Offentlichkeit zu treten: die Scheu vor dem »Fluch der Lächerlichkeit « wird sie davon abhalten oder auch die Aussicht auf eine $\mathrm{Zu}$ rechtweisung des Verlegers oder der Parteihäupter, denen die Leitung der Zeitung obliegt; denn diese müssen beflissen sein, die Offentliche Meinung nicht $\mathrm{zu}$ beleidigen und wissen, $\mathrm{da} B$ man behutsam mit ihr umgehen muß.

15. C. (Orthodoxe und heterodoxe Meinungen.) Wenn auch jenen Jahrhunderten, die wir als Mittelalter zu begreifen pflegen, die Ketzerei und Freigeisterei nicht fremd blieb, so sind doch diese erst seit der Zerspaltung der römischen Kirche und im Zusammenhange mit dem Fortschritt der wissenschaftlichen Eirkenntnis zu ebenbürtigen ja vielfach überlegenen Mächten neben der Religion und den Kirchen angewachsen. Auch die Offentliche Meinung, die in ihrer Entwicklung sich diesen mehr und mehr entgegengesetzt hat, ist eine neuzeitliche Erscheinung, gefördert durch die sich verallgemeinernden Künste des Lesens und Schreibens, durch die Vermehrung der Bücher und vollends durch die Ausbreitung der Zeitungen, dieser Scheidemünze der Literatur, die in jedes Haus, in jeden Winkel dringt, überall das Wissen mehrt, das Denken anregt, das Gespräch belebt, Wahres und Unwahres, Echtes und Falsches immer neu mitteilt, oft leidenschaftliche Gefühle und Wünsche entzündet, Stimmungen befestigt, Meinungen bildet, Gespräche fördert. Von den Vertretern des überlieferten Geistes, der alten Frömmigkeit, des schlichten Glaubens muBte die Zeitung als Feind empfunden werden. Der weltliche Charakter der Bildung, ihre Leichtigkeit und Leichtfertigkeit, die Flachheit der Aufklärung, der Materialismus der neuesten Weisheit des Tages, diese Merkmale, die schon die Literatur der Bücher, der Flugschriften und moralischen Wochenschriften bezeichneten, scheinen in der Tagespresse sich zu vollenden. Zunächst ist es der Geist des Protestantismus, der Geist von Wittenberg, Leipzig, Genf, der dem Anhänger der römischen Kirche aus der gesteigerten Tätigkeit des Buchdruckes entgegenweht ${ }^{1}$ ). Bald aber regt sich der Unglaube, die "materialistische "Naturwissenschaft, das Freidenkertum - eine Geistesrichtung, die den neuen Kirchen wie der alten Kirche verdächtig und verhaßt ist. Zugleich wächst das politische und soziale Interesse, das kirchliche und religiöse vermindert sich. Empor kam

1) Schon in der deutschen Reformationszeit fühlten die Verteidiger der alten Kirche sich im Nachteil. Sie hatten die Reichsstädte gegen sich, und die Reichsstädte hatten die Pressen. Dr. Eck mußte auf eigene Kosten drucken lassen. „Sie drucken in den Reichsstädten nichts wider den LtTHER, es nehme denn einer eine Anzahl Bücher. $\mathrm{Hab}$ in 6 Jahren ob 200 F1. verdruckt", schrieb Eck am I4. IV. I526 an Herzog WII,HEL,M. 
die Tagespresse mit der großen Revolution, und die Preßfreiheit bedeutete auch die Freiheit der Kritik gegen die Geistlichkeit und gegen den Glauben und Ritus der alleinseligmachenden Kirche. Die liberale Zeitung, Werkzeug der Protestanten, der Juden, der Freimaurer, war als solches auch eine Waffe, die sich gegen das Mittelalter und dessen ïberlebende geistige Gestalt, die Kirche, richtete. Die Offentliche Meinung wurde, auch über katholische Kreise sich ausbreitend, wenn nicht feindselig, so mindestens gleichgültig gegen die Segnungen und Flüche, die, vom päpstlichen Stuhl ausgehend, für den wahrhaft gläubigen Katholiken immer noch den Wert einer göttlichen Offenbarung hatten. Das war schon im Jahrhundert der Aufklärung, als noch die Wirkung von Büchern und Flugschriften überwog, der Fall, obgleich in dieser Arena die Jesuiten immer als gewandte und rücksichtslose Gegenfechter sich bewährten. „Die Hierarchie, der fast nur gelehrtes Wissen zu Gebote stand, verteidigte sich, da sie die Schriftsteller nicht mehr verbrennen konnte, durch Verbrennung ihrer Schriften. Aber diese Schriften enthielten die Offentliche Meinung von Frankreich" (HASE, Kirchengesch. ${ }^{7}$ S. 555 von der vorrevolutionären Philosophie in Frankreich). Durch Bekanntmachung aller "gefährlichen und verderblichen * Lehren, die den Jesuiten schuldgegeben wurden, war "die öffentliche Meinung gewonnen" (das. 556) und der Orden wurde als staatsgefährlich aus Frankreich verbannt (II64). Mit dem Empire, und vollends mit der Restauration, erfolgte bekanntlich eine glanzvolle Wicderherstellung der Kirche in Frankreich, nach ihrer völligen Zerrüttung durch die Revolution. Aber jede neue Revolution brachte ihr neue Erschütterungen. Ihre leidenschaftlichen Vorkämpfer sagten, wie der päpstliche Syllabus von 1864 , dem ganzen modernen Geiste den Krieg an und verklagten die Presse als dessen giftgeschwollene Trägerin. L,OUIS VEUILLOT, selber ein Journalist, schrieb darüber (um I860): „Der moderne Zeitgeist, dessen innerstes Wesen die Vertierung ist, hat nichts Todbringenderes geschaffen als dieses immer tätige Maschinenwerk, welches auf den Geist einwirkt durch die verschiedensten Düfte der Literatur, Kunst, Wissenschaft und durch den siegreichen Reiz der Frivolität. Sobald es ihn erfaßt hat, führt er ihn durch alle Temperaturen hindurch, dämpft ihn durch alle möglichen Dämpfe $a b$, verdunkelt ihn durch alle möglichen Rauchwolken, preßt ihn durch alle möglichen Walzen, stampft ihn in allen möglichen Mörsern und zieht ihn durch alle möglichen Hecheln, so daB am Ende nichts mehr übrig bleibt als Werg, auf welchem alle bösen Mächte keck schlummern dürfen." Um dieselbe Zeit gingen aus bayrisch-klerikalem Lager dic heftigsten Anklagen gegen die Presse hervor. So die Flugschrift des Dom-Kapitulars Molitor „Die 
Großmacht der Presse"; so mit noch größerer Wut JOSEF LUKas, dessen Büchlein „Die Presse, ein Stück moderner Versimpelung“, in konzentrierter Form alles enthält, was je gegen das Gift, die Lügenhaftigkeit, die Seichtheit, die Verjudung, den kapitalistischen Geschäftsbetrieb, die Reklame, die Korruption durch die Börse und die Industrie, über Verleumdungen und Verdächtigungen, den Widerspruch gegen den Geist des Christentums, die Wissenschaftsverflachung und die Sprachverderbnis, die politischen Schäden und endlich über „die allgemeine Versimpelung durch die Presse" gesagt werden konnte, vorher und nachher gesagt worden ist. Von MoLITOR zitiert LUKAS den Ausspruch, die Presse habe einen »entsetzlich gelungenen «Erfolg, „,durch welchen die Erkenntnis und das Gewissen der ganzen zivilisierten Welt irregeleitet und korrumpiert, durch welchen die $\mathrm{Zu}$ stände der irdischen Gesellschaft so aus allen Fugen gerissen worden sind, daß wir überall, wohin wir blicken, nur Haltlosigkeit und ein verzweifelndes Sichaufgeben, Trümmer und Verwüstung erblicken". Natïrlich lassen diese Autoren auch eine "gute" Presse gelten - die katholische -, aber sie kennen auch deren (zumal damals noch) geringe Bedeutung, sie erscheint ihnen als Ausnahme; auch wissen sie wohl, welche Vorzüge die »schlechte « Presse vor den Kaplanblättchen hat: LUCAS erzählt, daß der berühmte Theologe MöHLER mit Vorliebe die Allgemeine Zeitung las; als man ihm dies zum Vorwurf machte, antwortete er: er kenne gar wohl die schlimme Tendenz dieses Blattes, aber man müsse sich einmal einige Jahre durch die Gemeinheiten einer scheelsüchtigen Provinzialpresse durchgeschlagen haben, um die Wohltat einer anständigen Lektiire begreifen zu können, auch wenn diese nicht unseren Sternen folge. Seitdem ist nun freilich auf deutschem Boden auch ein stattliches katholisches Zeitungswesen in Anlehnung an die Zentrumspartei und ihre Organisationen herangewachsen. Während es um 1840 noch kein einflußreiches katholisches Organ in den Rheinlanden gab (BERGSTRÄSSER, Studien zur. Vorgeschichte der Zentrumspartei, S. I8gff. bei BAUER, Die öffentliche Meinung, S. 304 n.), so behaupten nunmehr seit Jahrzehnten die "Kölnische Volkszeitung " und der "Westfälische Merkur " neben anderen großen Zeitungen des Zentrums ihren Rang; die Zahl der Tageszeitungen, die 1890 erst 94 war, ist bis 1909 auf 278 gewachsen. Es wiederholt sich die alte Erfahrung, da $B$ die zuerst verabscheuten Waffen des Gegners angeeignet und nachgeahmt werden. Åhnlich ist die Entwicklung in anderen Ländern gewesen. Gleichwohl ist selbst in überwiegend und streng katholischen Ländern wie Österreich und Spanien die katholische Presse nur diejenige einer unter mehreren Parteien, und nicht leicht die einflußreichste - von Frankreich und 
Italien zu schweigen. Charakteristisch dafür ist, da $\beta$ die klerikalen Wortführer auch in jenen Ländern behaupten, »die "Presse sei in Händen von Freimaurern und Juden. Jene fühlen sich eben durchaus und überall in der Defensive, wenn sie auch von Zeit zu Zeit Vorstöße und Ausfälle wie aus einer belagerten Festung machen; sie ringen wider die Macht des Zeitgeistes.

I6. (Öffentliche Meinung beiderlei Sinnes im Verhältnis zur Presse.) Unsere Erörterung wird hier auf das Verhältnis von Presse und öffentlicher Meinung zurückgeführt. Es würde sich lohnen, was die neueren beachtenswerten Autoren über das Zeitungswesen Ähnliches und Verschiedenes in bezug auf diesen Gegenstand ausgesprochen haben, zu sammeln. Klare und deutliche Unterscheidung zwischen öffentlicher Meinung und der Offentlichen Meinung ist notwendig, um hier das Richtige vom Falschen zu trennen. Offentliche Meinung tritt in vielen Ausdrücken und Zeichen zutage, besonders stark und wirkungsvoll in der Literatur, die als periodisch regelmäßig erscheinende um so mehr in einheitlichem, bestimmtem Sinne sich geltend macht, daher am ein- und zudringlichsten in der Tagespresse. Offentliche Meinung so verstanden ist einem Kriegsschauplatz wohl zu vergleichen, wenn auch die Kämpfe nur zuweilen zum Handgemenge, zu Duellen und Mordanschlägen führen, in den romanischen Ländern nicht ganz selten. Das Publikum, insbesondere also das lesende, verhält sich zu diesen Meinungskämpfen als Zuschauer; freilich wie ein Zuschauer, der in einer hohen Proszeniumsloge sitzend nur die andere Hälfte der Bühne sieht, und zwar als solche die zu ihm gehörige, wie zur rechten Hemisphäre des Gehirnes das linke Auge gehört, zur linken das rechte. Dennoch nimmt der Broschüren- und Zeitungsleser immer an den Kämpfen teil, die sich ihm einseitig darstellen, nämlich wie seine Partei sie ihm darstellt, und so erscheint diese ihm immer als die rechthabende, daher in der Regel auch als die siegende. Leicht und oft wird auch die verfochtene Sache, weil als die richtige, so als die von allen redlichen und rechtschaffenen Leuten gebilligte empfohlen werden, die öffentlich vertretene Meinung, wenn nicht als die von allen, so doch von allen Vernünftigen, allen Vaterlandsfreunden, allen Wohlgesinnten oder allen Gescheiten geteilte Meinung, und diese Vorstellung geht namentlich in die Vorstellung der Offentlichen Meinung über. Zuweilen ist es wirklich so, daß die in einer bedeutenden und besonnenen $Z$ eitung ausgesprochene Meinung über eine Angelegenheit von öffentlichem Interesse die bestbegründete, die vernünftigste oder die durch den guten Geschmack, das richtige Gefühl am meisten gewährleistete Meinung ist; viel öfter freilich, dab die scheinbare Vernunft, die vorherrschende Denkungsart oder der modische Geschmack, 
das den Suggestionen des Tages unterliegende Gefühl ihr entgegenkommt - im einen wie im anderen Falle kann sie die allgemeine, die Offentliche Meinung schon sein oder werden. Wenn sie es wird, so schwerlich durch die kundgegebene Meinung eines Journals. Es müssen schon mehrere übereinstimmen und sie müssen die Grenzen der Parteigesinnung überschreiten, so da $B$ die sonst andersdenkenden Zeitungen fürchten müssen, Ansto $B$ zu erregen cder schon erregt zu haben bei ihren Lesern, so daß sie zum, wenn auch kunstreich verhüllten, Widerruf oder wenigstens zu erheblicher Abschwächung ihrer Gegenmeinung sich genötigt sehen. Das ist der die Widerstände brechende »Strom « der öffentlichen Meinung, der allerdings durch bedeutende Zeitungen, ja durch eine Zeitung, die von anderen nicht ignoriert werden kann, einen mächtigen Antrieb erhalten mag. Regelmäßig wird aber dieser Strom schon vorher vorhanden sein, und die Witterung des Preßorgans - es kann auch eine Wochen-, ja eine Monatsschrift sein - macht, $\mathrm{da} B$ es nun wie Aeolus den Wind aus seinem Schlauche blasen läßt, der eben geeignet ist, das ruhige Gewässer in Bewegung zu bringen: je nachdem einen ethischen, einen politischen oder ästhetischen Wind - aber heulen muß er; und zuweilen hat er alle Ursache dazu, auch ohne die Absicht, die ihn toben läßt. - Viel öfter aber ereignet es sich, daß ein großer Wind der Offentlichen Meinung, aufgeregt durch ein besonderes Ereignis, einen »Skandal « oder sonst einen "Fall «, sich erhebt, ohne daß die Zeitungen, anders als durch die von ihnen vermittelten Nachrichten (die aber auch auf anderen Wegen ins Publikum gelangen) dazu mitwirken. NaturgemäB wird dieser Wind auch die Herausgeber und Schriftsteller der Zeitungen ergreifen, aber wenn es ein ihnen widriger Wind ist, sie nur widerstrebend in seine Richtung mitfortreißen; als widrigen Wind empfinden sie ihn aber, wenn die Meinung, die er mit sich führt, den sonst von ihnen und von ihrer Partei vertretenen Grundsätzen und Ansichten entgegengerichtet ist. Selten werden sie wagen, sich dem Winde entgegenzuwerfen, er kann so stark sein, daß er sie umwirft. Sie werden doch lieber mit dem Winde gehen, wenn auch langsam und zögernd; zuweilen kann aber ein Sturm auch diesen Widerstand brechen, so daß sie, wenn auch unfreiwillig, sich getrieben fühlen.

\section{Dritter Abschnitt. Vulgäre Erscheinung der Öffentlichen Meinung.}

17. (Öffentliche Meinung und das Zeitungsgeschäft.) Der beständige Gegenstand der Beobachtung und Erörterung ist die öffentliche Meinung des Tages, an der nicht unterschieden zu werden pflegt, ob es die öffentliche Mein ung ist oder die Offentliche Meinung. Sehr oft. 
wird von der geteilten öffentlichen Meinung gesprochen, als ob ihre Einigkeit die normale Erscheinung wäre - was von der artikulierten Offentlichen Meinung allerdings gilt - ja, in der englischen Publizistik ist es üblich, von großen »Körpern « und von »Stücken «(Sektionen) öffentlicher Meinung zu reden, während sie unter Public Opinion, schlechthin die Öfentliche Meinung zu verstehen pflegt, wenn auch bedeutende Schriftsteller neuerdings zuweilen diese durch den Artikel auszeichnen, wohl auch ihn ergänzend durch die Worte »als ganze «1). Es ist für jene mannigfachen und verworrenen Stimmen des Tages nicht ein wesentliches Merkmal, durch die Schriftsteller des Tages vertreten zu werden; aber dies ist tatsächlich die große charakteristische Erscheinung des Zeitalters geworden. Ebenso ist es ihr normales Merkmal, da $B$ sie Meinungen, Ansichten, Gefühle und Bestrebungen von $\mathrm{Parteien}$ vertritt, mögen die Parteien organisiert oder unorganisiert, klein oder groß sein, mögen sie (ausnahmsweise) in ein und dasselbe Horn blasen oder (was die Regel) einander mit größerer oder geringerer Heftigkeit bekämpfen. Wenn die Schriftsteller - die Journalisten - die Ansichten und Gefühle, denen sie Ausdruck geben, selber teilen, so c-1eichtert ihnen das ohne $Z$ weifel ihre Aufgabe, und oft, vielleicht in den weitaus meisten Fällen wird es der Fall sein; nicht selten wird auch durch die Ubung im Aussprechen die Gesinnung selber entstehen oder wenigstens sich stärken und wachsen. Aber notwendig ist diese Ubereinstimmung offenbar nicht: der Soldschreiber folgt wie ein anderer Söldner der Fahne, die ihm Nahrung gibt und Beute in Aussicht stellt; er kann, wie er soll, und wenn er eine Gesinnung oder "Uberzeugung " hatte, so wird sie durch Mangel an Nahrung allmählich zusammenschrumpfen und verkümmern, ja er wird durch Erfahrung gewahr werden, da $B$ es ihm um so leichter wird, einer bestimmten - vorgeschriebenen - Ansicht Ausdruck zu geben, je weniger er selber eine Ansicht darüber »sich « gebildet hat, er braucht sie eben nicht für sich, sondern ausschließlich für die andern, nach außen hin und im Dienste einer ihm überlegenen Macht, seiner "Obrigkeit «. Unter allen, die über das Zeitungswesen neuerdings geschrieben haben, ist Ubereinstimmung, daß die Zeitung, zumal die große, wesentlich eine kapitalistische Unternehmung ist und geworden ist, deren unmittelbarer Hauptzweck also der ist, Gewinn aus dem Geschäfte zu erzielen. Folglich müssen nach diesem

1) Vgl. z. B. BRYCE: Modern democracies II, 253: „it must be understood that the public opinion of Australia as a whole, alarmed by the mischief which strikes were doing, and sympathizing with the desire of the wage-carners for a larger shave of the products of labour, was generally favourable to the experiment" (der "zwangsschiedsgerichte usw.). 
Zwecke die Schriftsteller sich richten, sich ihm anpassen - sie müssen aussprechen, was ihn fördert, verschweigen, was ihn hemmt; die Ansicht über das Interesse der Zeitung leitet den "Geist « ihrer Kundgebungen. Dies Interesse ist wesentlich bedingt durch das Gefallen oder Mißfallen a) des Leserkreises, b) der Abonnenten, c) der Inserenten. Der Leserkreis schließt die Abonnenten und Inserenten in der Regel in sich ein; was außerhalb dieser Gönner liegt, hat hauptsächlich darum Bedeutung, weil beide sich daraus ergänzen und vermehren; außerdem erhöht auch die Größe des Leserkreises den Ruf und das Ansehen der Zeitung. Die Höhe ihrer "Auflage« ist ein Zeichen davon, und diese ist teils durch den Absatz auf offenem Markte - den Einzelverkauf - teils (und - in Deutschland wenigstens - zum größeren Teil) durch die Abonnements bedingt. Diese sind wiederum ihrer großen Mehrzahl nach solche von Parteigenossen, die bestimmte Ansichten und Gesinnungen durch die von ihnen regelmäßig gelesene, gehaltene und etwa auch sonst unterstützte Zeitung vertreten $\mathrm{zu}$ sehen wünschen, die vihre "Zeitung mit Befriedigung lesen, wenn solche Meinungen darin $\mathrm{zu}$ offenem und starkem Ausdruck kommen, und sich entrüsten, wenn sie einen "Artikel «matt und nicht "gesinnungstïchtig " genug finden oder gar Zugeständnisse an den gegnerischen "Standpunkt « darin entdecken. Auch als Inserenten werden vorzugsweise, wenn auch keineswegs ausschließlich, Anhänger der durch die Zeitung vertretenen Meinungen sich geltend machen; manche unterstützen die Zeitung bewußt durch Inserate, weil sie die "gute Sache " damit fördern wollen; ja diese Absicht geht zuweilen über den eigentlichen $Z$ weck der Bekanntmachung ihrer Firma und ihrer Waren hinaus, wenigstens ist ihnen diese mittelbare Wirkung - die eben auch dem Geschäft zugute kommt - etwa ebenso wichtig wie die unmittelbare. Für das Zeitungsgeschäft aber darüber sind die Kenner der Sache einig - bedeuten die Inserate weit mehr als die Abonnements; mithin muß auf die Inserenten, wenn das nackte Gewinninteresse entscheidet, noch mehr Rücksicht genommen werden, als auf die Abonnenten. Und für jene wird in der Regel das Interesse des Geschäftsmanns wichtiger sein als das meistens wohl damit verbundene - des Parteimannes. Namentlich wird es sich negativ geltend machen: die Erbitterung über einen unmittelbaren oder mittelbaren materiellen Schaden wird viel heftiger sein und stärker sich geltend machen, als die Unzufriedenheit mit einer ideellen Verkehrtheit, einer Verirrung oder "Entgleisung «. Der Leiter einer Zeitung wird, nach dem Urteil des Verlegers und der anderen Hintermänner des Zeitungskapitales, seines Amtes übel gewaltet haben, wenn ein gewichtiger "großer " Inserent der Zeitung seine 
Anzeigen entzieht. Wiederum sind aber sehr oft die Inserenten keineswegs damit zufrieden, sich selber auf dem Rücken der Zeitung anzukündigen oder zu empfehlen; wertvoller sind schon die Annoncen vorn auf der Stirn oder auf der Brust, über oder mitten im gedankenvollen Text politischer Erörterung oder belletristischer Eirzählung. Auch von dorther aber merkt das Publikum die Absicht, es hört immer die Stimmen der Marktschreier und ein Teil des Publikums zumal das "gebrannte Kind " - ist mißtrauisch und scheut das Feuer. Besser nützt dem Absatz eine scheinbar uninteressierte Empfehlung, die Anpreisung durch einen scheinbar von dem Wert der Sache überzeugten Schriftsteller oder sogar durch die scheinbar streng sachlich urteilende Redaktion. Solche Urteile können angeführt ("zitiert «) werden, sie können auch mehr oder minder echt und unbefangen sein, wie es ohne $Z$ weifel manche Urteile über Bücher und andere Waren sind, die der Verleger oder Kaufmann zu deren Gunsten verwertet. Sie erfüllen aber meistens ebenso ihren $Z$ weck, wenn sie erfunden, gefälscht, bestellt sind. Noch besser wirken solche Urteile, wenn sie scheinbar nicht inseriert und bezahlt sind, sondern ausschließlich und unmittelbar vom Schreibtisch des Schriftstellers und sogar des Schriftleiters kommen, wenn der Leser sie mit demselben Vertrauen empfängt, womit er den gewohnten Leitartikel alle Tage in sich aufnimmt. Es ist daher die Aufgabe, den Leser zu täuschen und das ist auf mannigfache Art und Weise möglich. Die einfachste Methode ist die der versteckten Annonce; das Verstecken kann mehr oder weniger vollständig sein. Im Gegensatze zu anderen Fällen des sittlichen Lebens ist hier die Schamlosigkeit um so größer, je vollständiger die Verhüllung. Alle Beobachter sind darüber einig, da $B$ die französischen Zeitungen die verhüllte Annonce durchaus geflissentlich und regelmäßig pflegen. Unbekannt ist sie nirgends. Wenn sie trotz der Verhüllung erkennbar ist, so nimmt sie zuweilen raffiniertere Formen an, flieht z. B. aus dem Hauptteil der Zeitung und aus dem Handelsteil "unter den Strich «, wo sich in einer spannenden Novelle oder in einem witzigen (oder witzig sein sollenden) Feuilleton die "gelegentliche " Eirwähnung z. B. eines Automobil-Gummireifens "unauffällig « unterbringen läßt. Ubrigens ist seiner Natur nach der Handelsteil den Fremdkörpern des Geschäftsinteresses am meisten ausgesetzt. Kenner der Geheimnisse behaupten, daß die großen de utschen Zeitungen; „vor allem ihr Handelsteil, absolut unbestechlich sind" (FELDHaus, Das deutsche Zeitungswesen, U. B. 5875, S. 38). Bei den französischen sei die Bestechlichkeit eine offenkundige Tatsache; der Handelsteil werde ,ganz einfach an ein meistbietendes Bankhaus verkauft" und das Publikum sei so den Geschäftspraktiken irgendeiner 
Firma, die Geld verdienen will, ausgeliefert. Ja, die öffentliche Meinung in Frankreich billige das (FELDHAus das.). Die französische Zeitung lebt nicht, wie die der meisten anderen Länder, unmittelbar von ihren Inserenten; der Käufer und Leser verschmäht die Pakete von Beilagen mitzuerwerben und überläßt den Handelsfirmen, ohne seine Hilfe, ihre Waren bekannt zu machen. Um so mehr aber erscheint die versteckte Annonce, die kleine in den Text der Zeitung hineingeschmuggelte Reklame als eine Spezialität des französischen Geschäftes, wodurch es auf minder aufdringliche Art, die eben deshalb dem Franzosen wohl graziöser erscheint, sich zu empfehlen weiß.

I8. (Korruption.) Wie alle charakteristischen Erscheinungen des modernen Lebens, so zeigt die Tagespresse ihre schärfsten und freiesten Züge in den Kolonialländern, also am deutlichsten in dem größten und bedeutendsten von allen, den Vereinigten Staaten Amerikas. Die "Korruption" des Zeitungswesens ist hier nur ein hervorstechendes Merkmal der Korruption des öffentlichen Lebens überhaupt. Der Literatur des Landes, die zu einem großen Teile nur eine zusammengelesene und zusammengebundene Zeitung, ein "Magazin « oder ein geistiges Warenhaus darstellt, gereicht es zur Ehre, daß doch Stimmen in ihr laut werden, die das Geschwür der Korruption bloßlegen, und die also auch wagen, das Zeitungswesen so darzustellen, wie es ist. $\mathrm{Da} B$ es in erster Linie und durchaus Geschäft ist, hebt es vom europäischen Zeitungswesen längst nicht mehr ab. Dr. RoBERT BRUNHUBER, selber ein Journalist, wies darauf hin, daß die Gefahren des kapitalistischen Zeitungsbetriebes, einst von Männern wie LASSALLE verkündet, heute auch von Leuten erkannt und anerkannt werden, die auf dem Boden der kapitalistischen Wirtschaftsordnung stehen. Er führt unter anderen Belegen dafür einen Ausspruch THEODOR Barths an: „Der Gedanke der geistigen Beeinflussung des Publikums tritt zurück hinter der Frage: Wie kann aus dem Verkauf von bedrucktem Papier der größtmögliche Gewinn herausgeschlagen werden?" (Das deutsche Zeitungswesen, Sammlung Göschen 400, S. 30f.). Im großen Stile entwickelt sich dieser Preßkapitalismus durch das Zusammenkaufen vieler Zeitungen, so daß die schwächeren durch die stärkeren unterstützt und gehalten werden, und auch in diesem Gebiete etwas wie ein Monopol des bedruckten Papieres an die Stelle der Konkurrenz treten kann; es entsteht dadurch allmählich ein umgekehrtes Verhältnis zum Publikum und zu der sonst freier wachsenden öffentlichen Meinung: während die Konkurrenz sich in einigem Maße nach dieser richten muB, zwingt das Monopol ihr seine $\mathbf{n}$ Willen und seine Meinung auf, eben dadurch aber Willen und Meinungen des Spekulations-, sogar des Börsen- und Bankkapitals, in dessen 
Hände nach SchÄFfLES Ansicht zu seiner Zeit (er dachte wohl hauptsächlich an Osterreich) die eigentlich einflußreiche großstädtische Tagespresse gelangt war, der es, nach BRUNHUBERs Ausdruck, nicht darauf ankommt, die Idee durch den Profit töten zu lassen (1. c. S. 32). Aber, so paradox es scheint, das unmittelbare Geschäft der Presse ist für die Macht des Kapitals in der Presse, und durch die Presse auf die öffentliche Meinung, nicht die am meisten wirksame Kraft. Der Zeitungskapitalismus kann anderem Kapitalismus, sei es aus eigenem Interesse, sei es aus Grundsatz, den Zutritt verwehren, ja er kann ihn bekämpfen. Anders sieht die Sache aus, wenn dieser andere Kapitalismus sich der Zeitung bemächtigt als eines tauglichen oder tauglich $\mathrm{zu}$ machenden Mittels für seine $Z$ wecke; wenn also kein dringender Grund vorhanden ist, die Zeitung rentabel zu machen, sondern etwaige Zubußen durch die mittelbaren Vorteile, die solcher andere Kapitalismus aus dem Geschäfte zieht oder erwartet, wettgemacht werden. Das ist, was ein amerikanischer Schriftsteller, Herr JAMES EDWARD ROGERS (The american nerospaper S. 20I) "Verbandsherrschaft " (corporation control) nennt. „Die Verbände (d. h. vor allem die Trusts) sind von den Zeitungen angegriffen worden, die ihre Spalten gebraucht haben, um die öffentliche Meinung gegen sie einzunehmen. So erfolgreich sind Zeitungen in der Lage gewesen, gegen die großen Geschäftsinteressen des Landes einen Druck auszuïben, daß die Kapitalisten ihrer Selbsterhaltung wegen selber in das Zeitungsgeschäft sich begeben haben. Sie haben alte Zeitungen gekauft oder neue ins Leben gerufen. Es ist nur eine Wiederholung der Politik, wodurch zu allen Zeiten die vorwaltenden Interessen gezeigt haben, daß sie die Nützlichkeit der Presse als eines Mittels der Herrschaft zu würdigen wußten." Die Beispiele Napoleons, Bismarcks, Roosevelts werden dafür ins Feld geführt. „Ein fluichtiger Blick auf die Liste der Eigentümer unserer großen Zeitungen überzeugt davon, da $B$ sie besessen und beherrscht werden durch einige Millionäre, deren Interessen außerhalb ihrer liegen: Leute, denen Eisenbahnen, Bergwerke, Dampferlinien u. dgl. gehören. Die volle Bedeutung dieser Tatsache wird dem Leser zur Ėrwägung überlassen." Die hier angeklagte Eirscheinung ist neuerdings - wie es scheint, erst nach der Katastrophe von I9I8 auch in Deutschland offenbar geworden.

19. (Unabhängige Presse und Offentliche Meinung.) Folgendermaßen hat sich ein erfahrener und sehr angesehener amerikanischer Journalist, John Swinton, schon im Jahre I 895 (bei einem Festmahl der New-York PreßAssociation) ausgesprochen, um einen Trinkspruch auf "die unabhängige Presse zu beantworten: „Es gibt nichts desgleichen in Amerika wie eine unabhängige Presse, es wäre denn in 
Landstädten. Sie wissen es und ich weiß es. Es ist nicht einer unter euch, der wagen kann, einer ehrlichen Meinung Ausdruck zu geben. Wenn Sie es tun, so wissen Sie im voraus, da $B$ es niemals gedruckt wird. Ich erhalte $150 \S$ wöchentlich dafür, daß ich meine ehrlichen Meinungen von der Zeitung, mit welcher ich verbunden bin, fernhalte... Der Mann, der so töricht wäre, ehrliche Meinungen zu schreiben, fände sich auf die Straße gesetzt und müßte nach einem anderen Erwerb sich umsehen. Das Geschäft des New-Yorker Journalisten besteht darin, die Wahrheit $\mathrm{zu}$ verdrehen, dreist zu lügen, $\mathrm{zu}$ vertuschen, $\mathrm{zu}$ verunglimpfen, $\mathrm{zu}$ kriechen vor dem Götzen Mammon, Vaterland und Abstammung fürs tägliche Brot oder (was ungefähr dassẹlbe bedeutet) für sein Gehalt preiszugeben. Sie wissen das und ich weiß es; welche Narretei daher, auf eine sunabhängige Presse « $\mathrm{zu}$ toasten. Wir sind Werkzeuge und die Vasallen reicher Leute, die hinter der Szene stehen. Wir sind Marionetten. Sie ziehen an der Schnur und wir tanzen. Unsere Zeit, unsere Talente, unser Leben, unsere Aussichten, alles gehört anderen Leuten. Wir sind Prostituierte des Geistes." Diese furchtbare Anklage, die wie der Schmerzensschrei eines Mannes klingt, dessen Berufstätigkeit unter dem schweren Drucke eines ehrlichen Gewissens gelitten hat, findet sich wiedergegeben in LESTER F. WARDS »Pure Sociology «. Dieser Philosoph bemerkt dazu: „Die Zeitung ist schlechthin ein Organ der Täuschung. Jede hervorragende Zeitung ist Verteidiger irgendeines Interesses, und alles, was sie sagt, dient unmittelbar oder mittelbar (und am wirksamsten, wenn mittelbar) zur Förderung dieses Interesses. Es gibt in heutiger Zeit nichts dergleichen wie eine Zeitung, die ein Prinzip vertritt." - Im gleichen Jahre, als die Äußerung SwINTONs geschah, sprach J. W. JENks im American Journal of Sociology (Vol.I, No. 2) die Ansicht aus, der Einfluß der amerikanischen Presse auf die öffentliche Meinung sei verhältnismäßig - und im Vergleich mit England und Deutschland - gering; das Volk wisse, $\mathrm{da} B$ die Zeitungen nach Beweggründen persönlichẹn Gewinnes geleitet werden, und daß die Politik der Zeitung in weitem Maße bestimmt wird durch die Erwägung: wie wirken die ausgesprochenen Meinungen auf den Absatz und auf das Inseratengeschäft? Auch werde eine Zeitung sehr oft genötigt, ihre Behauptungen abzuändern, weil gefürchtet werde, daß der Einfluß auf die öffentliche Meinung ungünstig auf irgendwelches Geschäft wirken möge, woran der Besitzer der Zeitung beteiligt sei. „Wir werden niemals eine in ihren Kundgebungen über Probleme des öffentlichen Lebens durchaus unabhängige Zeitung haben, ehe wir eine Zeitung haben, die schlechthin unabhängig von ihrer Auflage und von ihrem Annoncengeschäft ist." 
In derselben wissenschaftlichen Zeitschrift warf im Jahre I909 ein sunabhängiger Journalist « aus Chicago die Frage auf: „,Ist eine ehrliche und vernünftige Tagespresse möglich?" Obgleich er eine verhältnismäBig günstige Ansicht über diese »Möglichkeit « hegt, so ist doch seine Darstellung der amerikanischen Wirklichkeit überwiegend grau in grau, und in den meisten Beziehungen darf die Tagespresse anderer Länder das $D e$ te sich sagen lassen. Was er anklagt, ist I. das "Fegen «, wie es in großen Zeitungen üblich sei; es nehme viele Formen an, nicht alle seien schlechterdings unmoralisch, aber alle beleidigend und unentschuldbar. Verstanden wird darunter die Effekthascherei im Suchen nach Aufsehen erregenden Neuigkeiten, das Aufbauschen irgendwelcher Vorkommnisse, insbesondere durch grobe Trivialisierung und Ubertreibung irgendwelcher von einem hervorragenden Manne öffentlich getanen Äußerungen, die Ausbeutung oberflächlicher Berichte, Behandlung von Gerüchten als Tatsachen, die "Vergelbung « wissenschaftlicher Gegenstände u. dgl. m., 2. die unehrliche Behandlung politischer, industrieller, sozialer und anderer bestrittener Gegenstände. „Es ist durchaus wahr, daß es keinen höheren und gerechteren Gerichtshof gibt, als die aufgeklärte öffentliche Meinung und keine bessere Regierung, als Regierung durch Debatte. Aber öffentliche Meinung kann nicht zur aufgeklärten werden, und Debatte kann nicht ersprießlich sein, wo in der Presse die Tatsachen umgekehrt, verdreht, unterdrückt, gauklerisch hin- und hergeworfen werden. Und es gibt Zeiten und Gelegenheiten - Feldzüge, Streiks, Verfolgungen - wo die Zeitungen, weit entfernt, unmittelbar oder mittelbar, für Rechtlichkeit, für Vernunft, für wesentliche Gerechtigkeit zu arbeiten, verzweifelte Anstrengungen zu machen scheinen, die ruhige Uberlegung zu verdunkeln und Verworrenheit schlimmer $\mathrm{zu}$ verwirren." In vielen amerikanischen Zeitungen sei kein Unterschied mehr zwischen dem Nachrichtenteil und den Leitartikeln; schon in jenem werden die Tatsachen "melodramatisiert ", d. h. mit phantastischem Stoff aufgepolstert. Aber auch 3. der Leitartikel hat seine schweren Gebrechen. Es wird gefehlt durch Tun und durch Unterlassen, durch Reden und durch Schweigen, und es ist schlimmer damit geworden. „Es gibt Zeitungen, die als die Sonderorgane besonderer Interessen, der Plutokratie, des Privilegs und des Monopols dienen, Zeitungen, von denen man keine oder geringe Rentabilität erwartet, sofern sie bloße Anhängsel für die Spekulation, für masende Finanz oder ausbeuterische, in den Formen des Rechtes sich bewegende Unternehmungen." Ehrliche Ėrörterung oder auch nur ehrliche Behandlung von Neuigkeiten könne natürlich von Zeitungen dieser Art niemals erwartet werden. Der Einfluß 
mächtiger Inserenten sei jedenfalls - in Amerika wie in England durch und durch verderblich. Dem Geiz des Publikums, das die Zeitungen allzu billig haben wolle, wird ein gut Teil Schuld beigemessen. Die offene und versteckte Unsittlichkeit des Annoncenteils ist ein Kapitel für sich. Aber allzuviele Zeitungen annoncieren sich selber auch in ihren Leitartikeln und machen Reklame für sich wie für alles mögliche, insbesondere auch für neue Romane - nach den Zeitungen zu urteilen gibt es jeden Monat mindestens ein Dutzend Meisterwerke! Die Phraseologie ist immer geschwollen, üppig, wortreich, geschmacklos. Schlimmer als die eigentliche gelbe Presse sind die gelben Streifen und die gelben Praktiken in der anständigen "weißen «Presse. Die Reinigung des Annoncenteils ist das schwierigste Stück in der herkulischen Aufgabe, ein wirklich sauberes Zeitungswesen herzustellen. A uf die Dauer würde aber hier, wie sonst, die Sauberkeit und Ehrlichkeit sich bezahlt machen. „Redakteure, die so bereit sind, der Öfentlichen Meinung Vertrauen zu schenken in politischen und wirtschaftlichen Streitfragen, sollten ihr aber auch vertrauen in bezug auf Anerkennung eines guten Journalismus." „Die Zeitungen, sogar die schlechtesten, haben so viel getan für moralische und politische Reform, bewußter und unbewußter, absichtlicher und unabsichtlicher Weise, daß sie wohl auch etwas für ihre eigene Hebung und Verbesserung tun könnten." - In der Tat ist man in den Vereinigten Staaten beflissen, durch besondere Anstalten die geistig-sittliche Ausbildung der Journalisten zu verbessern; Geldmittel wurden in Menge dafür aufgebracht. Der Soziologe E. A. Ross (Wisconsin) stellte vor kurzem - in der International Ethical Review, April 1920 - fest, es seien mehr als 40 Schulen und Kurse für Journalisten innerhalb der letzten I5 Jahre entstanden, und ... „die heimliche Preisgebung der Zeitung an die Geschäftsinteressen ist noch niemals so allgemein gewesen wie jetzt". Man darf sagen, daß wenigstens in den Staaten uiber den Wert oder Unwert ihrer Tagespresse die Offentliche Meinung in, einigem Maße dickflüssig geworden ist. $\mathrm{DaB}$ sie aber die Zeitungen und ihre Autoren oder Verleger oder anderen Interessenten zur Einkehr und Besserung veranlassen oder gar nötigen werde, ist mindestens in dem Verhältnis unwahrscheinlich, als die Offentliche Meinung des Tages durch eben dieselben Zeitungen "gemacht «wird. Mag jene dick-flüssige Meinung immer die Presse verneinen oder wenigstens ihr mit $Z_{\text {weifel }}$ und Mißtrauen gegenüberstehen - die luftige Offentliche Meinung bleibt von der Presse abhängig und läßt sich von ihr irreführen, betrügen, vergiften und verderben. Dies gilt freilich zunächst und vorzugsweise von der parteiischen Meinung, die also nur je einen Teil, wenn atch 
vielleicht den überwiegenden Teil, der öffentlichen Meinung in sich darstellt und kundgibt. Aber als überwiegender Teil kann sie auch die Offentliche Meinung werden, und das ist ein häufiger Fall im politischen Leben. Sei es, $d a ß$ die Presse einmal mit sich einig ist, oder $d a ß$ eine Parteimeinung auf schwachen Widerstand stöBt und sich als die maßgebende durchsetzt. Mit sich einig wird die Presse naturgemäß sein, wenn es um ihre eigenen Angelegenheiten, die man auch ihre Privilegien nennen kann, sich handelt - z. B. einem drohenden Gesetze gegenïber, das ein staatliches oder kommunales Inseratenmonopol einführen wollte. Einig wird sie auch sein, wenn eine hinlänglich starke öffentliche Meinung hinter ihr steht, von deren Strom sie getragen wird; so in offenbaren patriotischen Angelegenheiten. Diese Einmütigkeit hindert aber nicht, begünstigt vielmehr, daß ein großer 'Teil, ja vielleicht die gesamte öffentliche Meinung durch einen Teil der Presse und deren Hintermänner, seien es Minister oder Parteiführer, belogen und angeführt wird. Kein Publikum scheint so kritiklos wie das englische diesen Einflüssen sich hinzugeben; das amerikanische nimmt immerhin die Zeitungen weniger ernst. In einer artigen Satire beschrieb neulich GEÓRG BRANDEs den politischen Brüllaffen, der mit Vorliebe als sog. öffentliche Meinung in der Tagespresse auftrete, wo er dann nicht mehr über eine ... sondern wenn er Lord NORTHCLIFFE heißt, gar über mehrere Millionen von Stimmen verfügt. „Er bringt mit ihnen ein so fürchterliches Gebrüll hervor, daß kein Laut der Welt sich damit zu messen vermöchte, und Vernunft und gesunder Menschenverstand in panischem Schrecken die Flucht ergreifen." In einem Artikel, der wie eine Ahnung am I8. Juli I9I4 im "Nerw Statesman « erschien, wird berichtet, wie die Times durch NORTHCLIFFE ein gefährliches Beispiel des Feuilleton-Geistes geworden sei, des Geistes, der die Stunden nicht nach Glockenschlägen, sondern nach dem Fallen sensationeller Vorhänge zähle.

20. (Zusammenhang mit den Aggregatzuständen der Öffentlichen Meinung.) Wenn die T'agespresse naturgemä $B$ am stärksten auf die luftartige öffentliche Meinung des Tages wirkt und diese gleichsam vor sich her treibt, wenn sie nicht von ihr getrieben wird, so ist die SchluBfolgerung gegeben, $\mathrm{da} B$ die dichteren Gestalten in einem ähnlichen Zusammenhange und in Wechselwirkung mit anderer, soliderer Literatur stehen möchten; und dies ist wirklich der Fall. Es sind sich verengernde Kreise des lesenden Publikums, die Wochenblätter, Monatsschriften, Vierteljahrsschriften und Flugschriften, endlich sogar Bücher gewohnheitsmäßig lesen; und je enger der Kreis, um so mehr prägt er in sich einen wissenschaftlichen Typus aus, er repräsentiert um so mehr Sektoren der "Gelehrten- 
republik «, die in einem Lande und in der "Welt « gleichsam die höchste Instanz der Offentlichen Meinung darstellt. Die Meinung selber gewinnt an Solidität, also an Widerstandskraft, sie hat aber weniger das Bedürfnis, sich mit lautem Getöse kundzugeben. Man darf als Normalfall vorstellen, da $B$ die Meinungen dieser Kreise, und da $B$ folglich auch die Aggregatzustände der Meinung übereinstimmen; aber sie können auch auseinandergehen und einander widerstreiten. Die luftartige Offentliche Meinung ist es, die gewöhnlich als solche angesprochen wird; sie hält sich selber für die einzige und die wahre Offentliche Meinung und wird zumeist auch dafür gehalten. Man lebt in ihr, man atmet sie ein, man fühlt sie in der Haut wie Kälte und Wärme. Die dichteren Arten der Offentlichen Meinung liegen tiefer in Herz und Hirn, also in der Seele. Sie sind ihrem Wesen nach dauerhafter, sie überleben den Wechsel der Temperatur, sie bewirken aber auch den Umschlag des Wetters. Das gilt für das soziale wie für das individuelle Bewußtsein, es gilt für soziale Teilmeinungen, also für diejenigen einer Partei, wie für die Offentliche Meinung. Innerhalb einer Parteigesinnung und Bestrebung gibt ein gutes Beispiel ab der "Antisemitismus». Er ist für die sog. deutsch-nationale, ehemals deutsch-konservative Partei, mehr als eine flïchtige Tagesmeinung; die festen Uberzeugungen sehr vieler Mitglieder halten ihn im Flusse, und dieser Strom tritt bei Gelegenheit von öffentlichen Wahlen über seine Ufer. Aber er kann nicht eine feste Parteimeinung, nicht ein eigentlicher Punkt des Programms werden; vielmehr ist der feste Kern des Programms ihm entgegen. Dieser will und soll positivchristlich sein; das positive Christentum kann wenigstens geta ufte Juden nicht verwerfen. Auch ist die Parteikasse schwerlich stark genug, um die Beiträge solcher abzustoßen. Ferner ist es als Tatsache bekannt, da $B$ die einzige philosophische Begründung, die der preußische Konservativismus für sich gefunden hat, von dem getauften Juden STAHL, herrührt. Nur ein enger Kreis innerhalb der Partei denkt und wei $B$ solche Dinge. Aber er ist doch einflußreich genug, um unbesonnenen Meinungsflüssen und Meinungsblasen zu wehren. Ähnliche Beobachtungen lassen sich auch in der einheitlichen Offentlichen Meinung eines ganzen Landes machen. So war im Deutschen Reiche während der 3 Jahre I9I8-I92I die Offentliche Meinung des Tages ohne Zweifel jedesmal für Ablehnung der unerhörten $\mathrm{Zu-}$ mutungen, die von der sog. Entente an die Bewilligung des Waffenstillstandes, des Friedens und endlich zu mehreren Malen an die bloße Gunst der Festlegung des Maßes der aufgezwungenen Leistungen geknüpft wurden. Die zunächst latent bleibende, aber festere Offentliche Meinung wußte wohl, daß einer versklavten 
Nation, wie einem Manne, der unter die Räuber gefallen ist, nur die Wahl gestellt ist zwischen Verlust der Börse oder des Lebens, und daß von vielen Millionen, unter denen Frauen, Kinder und Greise die große Mehrheit bilden, nicht verlangt werden kann, daß sie den Tod der Schmach und Verarmung vorziehen. Dies Bewußtsein trat in den Beschlüssen der Nationalversammlung und des Reichstages ans Licht, und die Dissentierenden konnten die Verantwortung für ihr Nein leicht tragen, da sie nur diese Verantwortung zu tragen hatten. Im tieferen Grunde war die siegreiche Meinung auch ihre, wenngleich latent bleibende Meinung, und sie wäre früher oder später als die Offentliche Meinung zutage getreten, wenn sie nicht als unterliegende in der Opposition, sondern als verantwortliche an der Regierung gewesen wäre. Vielleicht wäre sie aber auch dann nur durch stahlharte Tatsachen bekehrbar oder zum Eingeständnis ihres Irrtums bewegbar gewesen. An diesen harten Tatsachen hätten die angeblichen Vorkämpfer des "Rechts «, der "Freiheit «, der "Zivilisation «, die alten Bundesgenossen des Zarismus, es sicherlich nicht fehlen lassen.

\section{Vierter Abschnitt. Höhere Erscheinungen der Öfentlichen Meinung.}

21. (Ausdrucksformen und Ausdrucksmittel der öffentlichen Meinung nach W. Bauer.) „Das ist eben die Art der öffentlichen Meinung, die sie vermutlich mit den meisten geistigen Mächten gemeinsam hat, daß sie nämlich dort, wo sie auf die Offentlichkeit als handelnde Kraft wirkt, gleichzeitig von ihr neue Antriebe empfängt. Sie birgt die verschiedensten Einzelkräfte in sich, die, sobald die öffentliche Meinung irgendwie zum Ausdruck kommt, frei werden und in verstärkender, bisweilen aber auch in abschwächender Weise auf sie Einfluß gewinnen. Alles, was sie hervorbringt und leistet, wirkt auf sie selber zurück, deshalb hat sie stets etwas Werbendes an sich. Wie mit Fangarmen greift sie nach neuen Anhängern, aber, indem sie solche erhascht, keimt in ihr schon der Same zu neuen Gestaltungen, denn jeder Neue reiht neue Gedankenteilchen an den alten Besitz. Deshalb gibt es auch keine Form, in der sich die öffentliche Meinung bewußt kundgibt, die nicht zugleich eine Werbung enthiclte. Ja, der Gradmesser für die Gewalt ihrer Äußerungen liegt geradezu in der Stärke ihrer Anziehungskraft, mit der sie sich ihr Gefolge gewinnt.

Diese auf Meinungswerbung angelegten Kundgebungen, die wir Publizistik nennen, weil es zu ihren Hauptzielen gehört, die Öffentlichkeit in Bewegung zu bringen und auf ihre Seite zu zichen, gedeihen natürlich am vorzüglichsten in unruhigen Zeiten. Um nun ihrer Anhänger sicher zu bleiben und neue heranzuzichen, gefällt sie sich, 
zu erscheinen, als ob der Inhalt ihrer Äußerungen die öffentliche Meinung selber sei. Dieser Deckmantel berückt oft auch spätere Kritiker, die ebenfalls die Erzeugnisse der Publizistik mit der öffentlichen Meinung identifizieren. Man darf eben nie aus den Augen lassen, $\mathrm{da} \beta$ alle diese agitatorischen Äußerungen bloß dem rationalen Teile der öffentlichen Meinung entsprechen und durch ihre offene oder verhüllte Werbeform ungebührlich überschätzt werden. Alle Agitation muß täuschen, muß die schwachen Seiten ihres Programms verdecken, die Irrtümer der Gegner absichtlich vergrößern, die Gegensätze, wo es sein muß, verschärfen oder abschwächen. Nicht der Wille zur Wahrheit, sondern die Absicht zu wirken, und zwar nach außen hin zu wirken, kennzeichnen das Wesen der Publizistik, womit nicht gesagt sein soll, daß ihre Erzeugnisse nicht bisweilen innerlich wahrer sein können als irgendeine wissenschaftliche Feststellung.

Publizistik und Publizistik ist nicht immer dasselbe. Auch hierin lassen sich genauere Unterschiede feststellen, die sowohl für die praktische wie auch für die historische Wertung von Belang sind. Um nämlich zu einem halbwegs sicheren Urteil zu gelangen, muß jedesmal untersucht werden, in welchem persönlichen Verhältnis der Publizist zu seinem Werke steht.

Das ursprünglichste und natürlichste ist es, wenn er sein eigenes Urteil, seine eigene Anschauung vertritt, ohne jede äußere Nebenabsicht, einzig und allein aus der inneren Notwendigkeit seiner Úberzeugung. $\mathrm{Da}$ er sich in der Beweisführung etwa den Meinungen der anderen in einem oder anderem Punkte anbequemt, verschlägt hierbei nichts oder wenig.

Einen anderen Charakter trägt die Publizistik, wenn sich nachweisen läßt, daß sie von vornherein, nicht bloß in der Anführung der Gründe, sondern in ihrer ganzen Absicht, in ihrem ganzen Aufbau, Antrieben von außen her gefolgt ist. Etwa um materieller Vorteile willen, um die Gunst eines Mächtigen zu gewinnen oder sei es auch nur, eine Eitelkeit oder persönlichen $\mathrm{Haß}$ zu befriedigen, derentwegen man die eigene wirkliche Gesinnung beugt und verhüllt.

Neben diesen beiden Arten agitatorischen Schaffens und mit diesen aufs engste verwoben, lassen sich jedoch noch weitere Unterschiede erkennen. Es ist nicht ganz gleichgültig, ob der Publizist mit seinem Schaffen nur an eine bestimmte Gelegenheit anknüpft, oder aber, ob er das Wirken auf die öffentliche Meinung zu seinem Gewerbe gemacht hat. Gerade diese letztere Erscheinung wirkt auch auf die Gestaltung der öffentlichen Meinung selbst zurück. Sie hängt aber auch mit politischen Verhältnissen zusammen, ist sie doch eine ständige Begleiterscheinung demokratischer Verfassungsformen." 
(WILHELM BAUER, Die öffentliche Meinung und ihre geschichtlichen Grundlagen. Ein Versuch. Tübingen, J. C. B. Mohr, I9I4, S. I53f.).

Diese Ausführungen sind vortrefflich, obgleich sie nicht zwischen öffentlicher Meinung und »der «Öffentlichen Meinung unterscheiden. Sie gelten für die eine wie für die andere, wenn auch zunächst und vorzugsweise nur für die öffentliche Mein u ng. Diese ist eine Mannigfaltigkeit von Agitation, die in der Publizistik aller Art ihre lebendigste Gestaltung findet, aber nicht die einzige. BAUER fährt fort (a.a.O.): „Bisher war nur von den Kundgebungen der öffentlichen Meinung im allgemeinen die Rede, nicht aber von den Ausdrucksmitteln, in denen diese sich äußern. Da sei denn gleich vorweggenommen, daß nichts, womit Mensch auf Menschen Eindruck zu machen vermag, in ihrem Bereiche fehlt. Die Gebärde, das Bild, die Sprache, die Schrift, die Tat, das sind so ungefähr die Grundformen, aber fast jede von ihnen kann noch weiter verstärkt und in ihrer Wirkung eindrucksreicher werden. Die Sprache wird es in der kunstvoll geformten Rede oder im Liede, die Schrift durch die Vervielfältigung im Druck, das Bild durch künstlerische Vervollkommnung, die Tat durch die Weihe idealer Ziele, durch Hingabe des Handelnden selbst. Diese Ausdrucksmittel existieren nicht für sich, sind nicht starr und unveränderlich, sondern werden von denselben Faktoren mitbestimmt, die für die Entstehung und Bildung einer öffentlichen Meinung selbst in Frage kommen. Deshalb läßt sich auch im allgemeinen kein absoluter Wertmaßstab ihrer Wirkungskraft aufstellen. Es gibt Zeiten und Völker, die dem Einflusse der Rede zugänglicher sind als dem gedruckten Worte, während andere sich ganz dem Eindrucke der mit beweglichen Lettern vervielfältigten Schrift hingeben. - In unserer im Zeichen der Technik stehenden Gegenwart läßt sich eine genaue Scheidung der Ausdrucksmittel fast überhaupt nicht mehr vornehmen. Sie alle fließen zusammen in die große Propagandaorganisation, wie sie heutzutage jede bedeutendere geistige Bewegung sich zu eigen macht" (das. S. I54f.).

BAUER stellt zunächst in einem großen Kapitel die "mündlichen Ausdrucksmittel " der öffentlichen Meinung dar, danı in einem größeren slie Ausdrucksmittel der öffentlichen Meinung in Schrift und Druck ". Dort wird die Rede und die Dichtung, besonders die lyrische, in ihren historisch bedeutsamen Wirkungen dargestellt; dann das religiös betonte Wort im Altertum, die Missions- und die Ërbauungspredigt im Mittelalter und neuerer Zeit, sodann die Staatsrede, Wahlrede, Kammerrede; die fortlebende Macht des gesprochenen Wortes in der Schule; das Gespräch, der Salon, der Verkehr überhaupt. Als besonders interessante Ausdrucksform wird noch das Drama 
vorgeführt und durch die Zeiten begleitet. „Der Beifall war zu einem Ausdrucksmittel politischer Meinungen geworden" (S. I87: im Frankreich vor I789). „Alles, was sich an religiösen, an politischen und nationalen, an gesellschaftlichen, ja sogar wissenschaftlichen, was sich an sittlichen Idealen in den Köpfen einer Zeit regt, spiegelt sich in der dramatischen Literatur wider" (I89). Wie der Beifall, so kann auch das Zischen und die Ablehnung eines Stückes zuweilen Ausdruck einer öffentlichen Meinung sein ${ }^{1}$ ). Schrift und Druck - so führt das 6. Kapitel aus - sind als Ausdrucksmittel nur graduell verschieden. Die Rede fließt in sie hiniiber, so auch der Dialog, der als Literaturgattung in der Antike, im Mittelalter und der Renaissance so große Bedeutung gewann; auch der Brief ist Ersatz der mündlichen Rede. Die agitatorische Schriftstellerei hat sich aber immer besonders gern der poetischen Formen bedient; stark hat in dieser Hinsicht das Spottlied, die Satire, gewirkt. Man hat die Göttliche Komödie übertreibend »eine große satirische Weissagung in Form einer Vision " genannt. In unruhigen Zeiten schaffen sich Unzufriedenheit und Spott iiberall Luft und Raum; auch die Mauern und Anschlagsäulen werden gesprächig. Immer wirkt die Verbreitung von Reden und Briefen auf die Bildung von Meinungen. Der Humanismus hat dem Brief zu einer ungeahnten Bliite verholfen. Auch politische Bedeutung heftet sich mehr und mehr daran, besonders an die Berichte der Gesandten, aber auch an Privatbriefe. Da trifft man auf eine der Wurzeln des Zeitungwesens. Flugschriften entstehen aus Briefen, wirklichen und fingierten. Durch Rundschreiben und Manifeste teilen die Träger geistlicher und weltlicher Macht die Beweggründe ihres Handelns mit. Wie die Kunst durch Bauten, Bildwerke, Denkmäler, so ziehen sie auch die Literatur in ihren Dienst, insbesondere die Historie: bald gab es offiziöse Geschichtsschreiber und die Wissenschaftlichkeit der Historie hat erst dadurch sich bewährt, daß sie aller (?) publizistischen Elemente sich entledigte. Auch von der

1) Die Bedeutung des Dramas als Mittel einer Agitation und Propaganda, daher auch für die öffentliche Meinung, würde eine Monographie erfordern, um völlig gewürdigt zu werden. Die Rolle, die dem Beaumarchais schen Lustspiel als einem Donnergrollen vor der großen Revolution zufiel, wird in späterem Zusammenhange gewürdigt werden. Es gibt aber manche andere interessante Beispiele. Je weniger die offenen Ausdrucksmittel geduldet werden, um so mehr werden die versteckten angewandt. In Rußland unter NIKolaI I. galten »Kunst, Literatur und Dichtung als mächtigste soziale Hebel «, Rußlands größter Kritiker BJELINSKI vertrat die Anschauung, daß dies zu ihrem Wesen gehöre. ,Es erschren (nach PYPIN) nicht seltsam, ein Schanspiel für die Verteidigung des Freihandels oder ein Gedicht zum Lobe einer gewissen Art von Steuern zu schreiben, noch daß man in einer Erzählung seine staatlichen Ansichten darlegte, während der Gegner in eincm Lustspiele dagegen stritt" (Hoztzsch, Rußland S. 63). Auch Schillers Jugenddramen tragen ja durchaus den Charakter von Anklageschriften gegen die Mächte seines Zeitalters. 
wissenschaftlichen Behandlung staatsrechtlicher, politischer, wirtschaftlicher Fragen unterscheidet sich die publizistische durch ihre tendenziöse Farbengebung, wie auch dadurch, daß sie immer Angelegenheiten ihrer Gegenwart aufgreift und zunächst nur auf diese zu wirken bestrebt ist. An Wendepunkten des geschichtlichen Daseins gedeiht diese Literatur am üppigsten, sie zieht und verrät ihre Herkunft aus dem Streit des Tages. BAUER geht in einem lehrreichen Uberblick die Literatur der F1 ugschrifte $\mathrm{n}$ in ihrer geschichtlichen Entwicklung von den hellenischen Ursprüngen des modernen Schrifttums her durch (S. 22I-262) und sagt dann über ihr Verhältnis zur öffentlichen Meinung, die Flugschrift trage nur insoweit kollektive Denkbestandteile an sich, als der Verfasser einer solchen Schrift die Meinungen und Meinungsrichtungen teile, die in seiner Umgebung zur Herrschaft gelangt sind. Erst durch Vergleichung aller gleichzeitig erschienenen Veröffentlichungen dieser Art könne das Pamphlet oder die Broschüre Quelle für die Erkenntnis der öffentlichen Meinung werden. „Erst indem man untersucht, welche Gedankengänge sich am öftesten wiederholen, wo diese an ältere anknüpfen, wie sie zu neuen weiterführen, wird man zu einem Ergebnis gelangen. In jedem Einzelfalle ist natürlich auch der Nachweis der Verbreitung der einzelnen Flugschrift von Bedeutung." Aber auch diese sei trügerisch. In den "gebildeten "Kreisen, als durch Wissen und gleichartige wirtschaftliche Bedingungen für sich abgesonderten, bilden sich Anschauungen und Vorurteile, ,die an sich vielleicht nur eine Minderheit hegt und teilt, die aber den Anschein gewinnen, als ob sie der Gesamtheit zu eigen seien, weil die an Ausdrucksmöglichkeiten ärmere Mehrheit (das gleiche gilt auch von anderen Minderheiten!) nicht zum Worte kommt oder sich doch nicht in entsprechender Weise verständlich zu machen imstande ist". So geht die Betrachtung auf die Zeitung über (Kap. 7), und auf die historische Entwicklung ihrer drei wesentlichen Merkmale Publizität, Periodizität, Aktualität. In welchem Verhältnisse steht die Zeitung zur öffentlichen Meinung? Das Nachrichtenblatt, das Parteiblatt, die politische Presse, die sich selbst Partei ist, werden unterschieden. Die Presse läßt die öffentliche Meinung auf sich wirken und formt sie auch ihrerseits. Die wirtschaftlichen Verhältnisse zwingen den Zeitungsunternehmer r. auf die Willensdispositionen seiner ständigen Leser und seiner Inserenten Rücksicht zu nehmen; 2. sich in den Mechanismus der großkapitalistischen Organisationen einzuordnen. Der Journalist muß wieder die Interessen des Unternehmers mit denen der Partei oder der Regierung ausgleichen und zugleich immer auf das Publikum achten. Bestimmte Analogien bestehen zwischen Presse und öffentlicher 
Meinung, aber keine Gleichheit. Die Wirkung und Bedeutung der Zeitung hatte schon im I7. Jahrhundert eine gewisse Blüte erreicht; erst die französische Revolution brachte eine wahre Zeitungsherrschaft, die sich im 19. Jahrhundert, zumal nachdem die Preßfreiheit durchgesetzt war, immer mehr steigerte. Nun ist die Presse frei, aber die Journalisten sind es nicht, das parteioffiziöse Joch lastet auf ihnen (Ausdruck BrunhuBERS). Außerdem legen die Unternehmerverbindungen mit ihren Rücksichten und Beziehungen der Preßfreiheit schwere Fesseln an. Die Großorganisation der Nachrichtenzufuhr macht den Inhalt der Zeitungen einförmig, insbesondere die Depeschenagenturen. Im Einzelfalle ist die Meinungsfreiheit eingeschränkter als je: die geistige Einkreisung der Parteien und Berufsverbände, der Mangel an Bildung, die Gleichgültigkeit gegen öffentliche Angelegenheiten schränken auch die Wirksamkeit der Presse ein. Ihre eigentliche Schwäche, die zugleich ihre Stärke ist, ruht in ihrer Herkunft aus der städtischen Kultur, besonders in ihrem großstädtischen Wesen. Es gibt auch, ,eine auf Traditionen sich aufbauende öffentliche Meinung, deren Wurzeln tiefer in den Gemütern ruhen, als die auf dem Neuigkeitenmarkt flüchtig eingetauschten Eingebungen" (S. 303). Diese also wehrt sich gegen die Zeitungseinflüsse, und sie ist besonders stark unter dem Landvolk, wo die Presse keine so bedeutende Rolle spielt. Eine besondere Aufgabe hat sie als Vermittlerin zwischen Volk und Regierung. Jenes sieht im Grundsatze der Öfentlichkeit die sicherste Gewähr bürgerlicher Freiheit. Aber die Zeitung repräsentiert nicht die ges a m te öffentliche Meinung und kann auch nicht in vollem Umfange Einfluß auf sie nehmen. Eine furchtbare Waffe besitzt sie durch das "Totschweigen ", das auch gegen das Auftreten politischer Persönlichkeiten, gegen die Bekanntmachung ernster wissenschaftlicher oder künstlerischer Werke sich richtet. Die Ansätze zur Vertrustung der Meinungsübermittelung machen Fortschritte und bald wird "Freigeist " heißen dürfen, wer sich dem Meinungsmonopol der Presse zu entziehen versucht. - An letzter Stelle betrachtet BAUER die "Tat " als Ausdrucksmittel der öffentlichen Meinung (Kap. 8) - vor allem die Politik und ihre zugleich furchtbarste und großartigste Erscheinungsform, den Krieg. Es gibt ein Widerspiel von Krieg und Publizistik; der Krieg ist der Tod jeglicher Phrase. Aber die öffentliche Meinung wirkt stark auf den Krieg, der Krieg auf die öffentliche Meinung. Das gleiche Wechselverhältnis auch sonst zwischen Tat und Meinung. Die Berufspolitiker sind die Journalisten der Tat: auch sie fragen nicht nach dem tatsächlichen Wert ihrer Vorschläge oder Anträge, sondern lenken ihre Blicke einzig auf die augenblickliche öffentliche Meinung. Damit 
werden persönliche und politische Momente in die Gesetzgebung und, was noch übler ist, in die innere Verwaltung oder gar in die Rechtsprechung gebracht. Wo »der rationale Teil der öffentlichen Meinung * zu herrschen beginnt, da offenbart er fast immer, da $B$ sein innerstes Wesen vorzüglich negativ wirkt; dadurch befördert sie oft den Fortschritt. Die moralisch stärkeren Autoritäten wehren sich im Kampfe gegen sie. Am bedeutendsten aber ist der Kampf des einzelnen Menschen, der durch sein Tun wirkt, gege n die öffentliche Meinung, die ihm früher oder später folgen muß, besonders also des großen Staatsmanns $\left.{ }^{1}\right)$.

22. (Ergänzungen.) Ich teile diesen Auszug aus der Schrift BAUERS mit, weil ich diese Kapitel als vorgetane Arbeit schätze und der Aufmerksamkeit derer empfehle, die das Wesen der öffentlichen Meinung erforschen wollen. Einige darin enthaltene Gedanken glaube ich durch meine Unterscheidungen $\mathrm{r}$. der Aggregatzustände der öffentlichen Meinung (wie der Meinungen überhaupt), 2. der öffentlichen Mein ung und »der "Offentlichen Meinung fester begründet zu haben. Ferner aber möchten zur Eirgänzung noch folgende Bemerkungen sich anknüpfen lassen:

I. BAUER hat selber darauf hingewiesen, daß er die »bildenden Künste als Ausdrucksmittel der öffentlichen Meinung übergangen habe. In Wahrheit ist die gesamte Publizistik, zumal deren niedere und am meisten verbreitete Gattung, nicht mehr denkbar ohne die "Illustration". Wie das Bild älter ist als die aus ihm entstandenen Schriftzeichen, so behält es auch seine Reize für die Welt der Leser, zumal für den weiblichen und jugendlichen Teil, der schaulustig, aber nicht denklustig ist. Ehemals den Monats- und Wochen-Zeitschriften vorbehalten, ist der Holzschnitt und Holzstich, mechanisch der unendlichen Vervielfältigung fähig, längst auch in die Tageszeitungen

1) Es ist ein Verdienst lebender deutscher Historiker, auf die Bedeutung von Flugschriften und Tagespresse als von Urkunden geistiger Bewegung, politischer Kontroversen, sozialer Futwicklungen hingewiesen und ihre Schüler veranla Bt zu haben, diese Urkunden, die dadurch mittelbar zur Geschichtsquelle wurden, zu studieren. Wir verdanken diesen Studien eine Reihe von brauchbaren Untersuchungen, z. B. Gustav Körner, Die norddeutsche Publizistik und die Reichsgründung im Jahre 18;o. OTro Bandmann, Die deutsche Presse und die Entwicklung der deutschen Frage 186.66 . IISA KULENkampir, Der erste vereinigte preußische Iandtag I 847 und die öffentliche Meinung Südwestdeutschlands. 'THEOdor SchelfFr, Die preußische Publizistik im Jahre 1859 unter dem Einfluß des italienischen Krieges. Ein Beitrag zur Geschichte der öfentlichen Meinung in Deutschland. ANnif Mirtis,stafedr, Der Krieg von 1859 , Bismarck und die öffentliche Meinung in Dentschland. Früher schon ist selbständig in diesem Gebiete gearbeitet worden, z. B. von EDUARD CaUkR, vber die Flugschriften Frienricus Dis Grossen aus der Zeit des 7 jährigen Krieges; H. vos Zwirninek-SUdrnuorst, Die öfentliche Meinung in Deutschland im Zeitalter Ludwigs XIV. in. a. m. 
eingedrungen, und jene müssen schon durch Farbendrucke sich auszeichnen, um ihren Rang zu behaupten. Wenn sonst in religiösen Darstellungen die »heilige Geschichte « oder Geschichten von Heiligen, wenn für Kinder Fabeln und Märchen immer jung und neu erscheinen, so verlangt der Sinn des modernen Menschen auch im Bilde das Wirkliche, das Bedeutende, das Neue, das Interessante, wenn möglich das "Pikante zu sehen. Das, womit die öffentliche Meinung sich beschäftigt, das will sie auch schauen und zwar möglichst rasch, sonst denkt sie schon an etwas anderes. Weniges Bedeutsameres prägt sich dauernd dem Gedächtnis ein, und wird in Monumenten verherrlicht: Personen und Sachen der Vergangenheit, die als gegenwärtige sich vorstellen und wirken; mehr und mehr wird aber die Ehre, die ihnen gezollt wird, konventionell und wird erledigt wie ein Geschäft; der typische heutige Mensch, der in der öffentlichen Meinung lebhaft mitwirkt, befaßt sich nicht gern dauernd damit. Auch will die charakteristische Richtung, "L'art pour l'art " nicht mehr die Kunst in den Dienst des Lebens, sei es der Religion oder anderer sozialer Willensgestalten ordnen, sondern sie zum reinen Spiele und zum Gegenstand der Schwelgerei und Neugier oder auch des edelsten Genusses machen. - Als wichtige Ausdrucksmittel der öffentlichen Meinung, besonders in politischen Angelegenheiten, möchte ich aber ferner erörtern: A. die Vereinsbildung. $\mathrm{Zu}$ dieser drängt alles gemeinsame "Meinen ", um so mehr, je mehr es als Wünschen und Wollen seiner selbst bewußt wird. Verein bedeutet verbundene Kräfte, verbundene Mittel, insbesondere also Geldmittel, eine gemeinsame Kasse, über die es eine einheitliche und geordnete Verfügung gibt. Besonders Vereine $\mathrm{zu}$ politischen Zwecken sind Ausdrücke eines öffentlichen Meinens; sogar geheime Gesellschaften und Verschwörungen können es sein, sofern sie einer gemeinsamen Gesinnung oder Bestrebung Ausdruck geben wollen und sollen. Offen oder geheim können Vereine für die Ausbreitung einer Denkungsart wirken und wühlen. In Vereinen wird geredet, beraten, beschlossen, sie können eine Strafgewalt über ihre Mitglieder in Anspruch nehmen und ausüben. Disziplin erhöht ihre Stoßkraft, stärkt ihren Zusammenhang. Ein tüchtiger Führer kann wie ein Feldherr wirken und heißt wohl auch General - merkwürdig genug gerade in religiösen Gesellschaften wie dem Jesuitenorden und der Heilsarmee. Wie die "Gesellschaft Jesu " für die römisch-katholische Religion und Kirche, so hat in den neueren Jahrhunderten für die öffentliche Meinung der Freimaurerorden, nebst seinen Abzweigungen, den Illuminaten u. a. gewirkt; und eine unmittelbare politische Bedeutung hatte in England frühzeitig der "Klub», der unmittelbar vor der großen Revolution nach Frankreich 
übertragen wurde; in diesen Klubs ,,sprach man laut und ohne $\mathrm{Zu}$ rückhaltung über die Menschenrechte, über die Vorzüge der Freiheit, uiber die großen Mißbräuche der ungleichen Lebenslage sich aus“ (Mém. de GEORGET bei BUCKIE II, 378). Die gewaltigste politische Bedeutung gewann dann der Klub der Jakobiner, der nach dem Ausdruck AULARDS, ebensosehr Dolmetsch als Führer der öffentlichen Meinung wurde (Etudes I, p. I25). In den romanischen Ländern hat das Maurertum als Ausdruck des Liberalismus und neuerdings des ausgesprochenen Antigermanismus noch im I9. und 20. Jahrhundert zunehmende Bedeutung gewonnen. G. MAIER (Ethische Umschau, Juni I9I5) meint, die politische Tätigkeit des Ordens in I talie n führe in weiten Kreisen zur Verkennung seiner ganzen Tendenz; die Führung der Kriegspolitik durch die Logen sei das erste Beispiel einer planmäßigen Beeinflussung der öffentlichen Meinung, wie sie früher von Frankreich und seinem Bonapartismus ausgegangen sei. - An die allgemeine Bedeutung von Vereinen für die heutige Politik möge hier nur erinnert werden: sie wirken ebenso regelmäßig auf Zersplitterung, wie gelegentlich auf Vereinigung der Gedanken und Wollungen. „Die Organisationen sind demnach sowohl ein wesentlicher Teil der gesellschaftlichen Denk- und Willenskraft, wie der Grundstock der gesellschaftlichen Denk- und Willensäußerungen, die man bald öffentliches Urteil, bald öffentliche Meinung, öffentliches Gewissen oder ähnlich nennt. $\mathrm{Da} B$ diese Urteile oder Meinungen jetzt sehr häufig mit merkwürdiger Bestimmtheit sich kundgeben und im Durchschnitte von den verschiedenen Interessen aus besehen, um manches sachgemäßer geworden sind und an Naivität verloren haben, das wird gleichfalls zum Teil den Organisationen und ihrer Sorge für das Ideologische zugeschrieben werden dürfen" (KLEIN, Die Organisation S. I77). B. Wie ein Verein sich periodisch versammelt, so kann er auch für seine Zwecke Versammlungen berufen, die zur Vermehrung seiner Mitgliederzahl und Mittel wirken sollen, oder aber sonst in allgemeiner oder besonderer Richtung bestimmte Gedanken eines Programmes zu vertreten geeignet scheinen. Hervorragende Bedeutung haben in den modernen Staaten die Wahlversammlungen, wie die Partei-Wahlvereine gewonnen. Sie heißen sich Organisationen und bedeuten eine Mechanisierung des politischen Willens durch die Parteihäupter, die in Amerika und in England gut durch den Ausdruck "Drahtzieher " (wire-pullers) bezeichnet werden. „Die Berufspolitiker arbeiteten (in den Vereinigten Staaten) unter der Leitung der managers und der wire-pullers, mit einem solchen Ensemble und mit einer so vollkommenen Gleichgültigkeit oder Bewußtlosigkeit gegenüber dem Guten und Bösen, da $B$ sie die Vorstellung eines automatisch und 
blind funktionierenden Mechanismus, einer Maschine hervorriefen. Die Wirkung schien so durchaus die gleiche, daß der Ausdruck Maschine der Organisation wie ein Spitzname angeheftet wurde, den sie bis auf diesen Tag trägt, indem er sogar dem Ausdruck caucus vorgezogen wird" (OSTROGORSkI, La démocratie et les partis politiques. Nouvelle ed. Paris I9I2, p. 365). Die Volksversammlung, die aber als Wählerversammlung (in Amerika primary) eine politisch höhere Bedeutung gewinnt, erweckt die Vorstellung eines einigen Willens, wenn sie durch den lauten Beifall, den sie einem Redner zollt, oder durch andere Zeichen ihre Stimmung und Meinung kundgibt. Sie nimmt einen mehr stürmischen oder mehr ruhigen Verlauf; mit Unrecht wird oft der Tumult für ihr ständiges Merkmal gehalten. Offentliche Meinung kann sich mit und ohne Lärm in ihr und durch sie geltend machen, aber als gemeinsamer Gedanke, gemeinsames Urteil eher, wenn sich Rede an Rede in gleichem Sinne anreiht und mit ruhiger aber entschiedener Zustimmung gehört wird. C. Wenn eine Versammlung und ihre Entschließungen nicht selten eine vorhandene starke Strömung des Meinens und Wollens dartun und beweisen sollen, so gibt es andere Demonstrationen, in denen solche Strömung sich unmittelbarer offenbart. Jedenfalls will sie sich öffentlich zeigen, und die einfachste Weise, weil sie zunächst nicht einmal der Worte bedarf, ist die, daß viele, die von ihr erfüllt sind und es zu zeigen wünschen, zusammen auf die Straße gehen oder auf dem Markte zusammenkommen, um ihr Wünschen und Meinen kundzutun, wofür das Tragen von Fahnen und Emblemen, das Singen von Liedern, vor allem aber die zahlreiche, wenn möglich massenhafte Teilnahme, die in jedem Teilnehmer das Bewußtsein seiner Kraft erhöht, natürliche Mittel und Formen sind. So wird der feierliche Gang, die "Prozession « eine beliebte Art des Demonstrierens, wie das Flaggenhissen, das Glockenläuten einer Volksstimmung und oft auch der darin enthaltenen öffentlichen Meinung Ausdruck gibt. D. Endlich sei hier noch des Ausdrucksmittels der Feste gedacht, zu denen sich Gleichgesinnte, Gleichdenkende vereinen, das Fest - Esse $n$ ist eine angenehme und beliebte Form und eine bequeme gemächliche Art darzutun, daß man "dazu gehört", was in der Regel auch bedeutet, $\mathrm{da} B$ man die vorgeschriebene politische Gesinnung hegt oder doch $\mathrm{zu}$ hegen scheinen will: wenn man z. B. den Träger der Krone und seinen Geburtstag feiert. Oder ein Einzelner, ein Fürst oder anderer Magnat, "gibt " Feste, sie sind eine Form der konventionellen Geselligkeit, die aus irgendwelchem Anlaß den Glanz einer Familie, eines Hofes, einer Partei oder Geistesrichtung, ja eines ganzen Volkes entfalten will. ,Sie (die Geselligkeit) wird benutzt, um Siege in den politischen 
und materiellen Interessenkämpfen, in Konkurrenzen und Wahlen vorzubereiten, durch Wahrung des Scheins von Reichtum sein Ansehen, den Kredit und die soziale Stellung zu behaupten, durch ein "großes Haus « und durch Fütterung von Schmarotzern sich Einfluß zu schaffen. Ersetzt doch die Geselligkeit den Markt und den Journalismus da, wo eine stupide Despotie einem ganzen Volke oder einer Volksschicht den Mund stopfen will." „Alle diese Momente erklären sich, wenn man sich die allgemeine Tatsache vergegenwärtigt, da $B$ die gesellig vereinigten Personen freie Tribunale der Wertschätzung und mitbestimmende Faktoren der öffentlichen Meinung sind" (Schaffle, Bau und Leben des sozialen Körpers IV, S. 99). - Die allgemeinste Bedeutung hat hierfür, besonders in deutschen Landen, das gemeinsame Trinken, der Festkommers, wozu ebenso wie zum Festessen, die Reden gehören, die in der Stimmung von yzur guten Stunde "Vereinigten einen um so stärkeren Widerhall finden, zumal wenn man schon zum $Z$ wecke einer bestimmten Kundgebung zusammengekommen ist. Oft wird der Festredner wallen aus der Seele gesprochen haben ", oft wird die in den Zeitungen oder sogar als besonderes Heft verbreitete Rede noch in weiten Kreisen derer "zünden ", die sie nur geistig vernehmen.

Im "Fest " kommt wohl am reinsten zum Ausdruck, was alle Ausdrucksmittel der öffentlichen Meinung miteinander gemein haben, da $B$ ihnen eine Tendenz innewohnt, den Menschen zu erheben: sie wenden sich an ihn als an ein Glied des "geehrten Publikums", sie wollen seinen Beifall, oder eine noch ausgesprochenere Mitwirkung, sie rechnen auf sein Urteil, also auf seine Bildung und zumeist auch auf seine gebildete richtige Denkungsart. In dem gemeinsten und allgemeinsten Mittel, der Zeitung, macht sich dies am wenigsten offenbar, aber es ist auch in ihr enthalten, auch sie schmeichelt dem Leser, sie wirbt um seine Zustimmung, wofern sie diese nicht als von selbst verständlich voraussetzt; indem sie eine Meinung öffentlich macht, versammelt sie gleichsam sich und ihre Leser zu einem Gerichtshof, der sein Urteil über eine Tagesfrage abgeben will, und der I eser wird, je mehr er sonst sich wichtig fühlt, auf seine Zustimmung Gewicht legen, oft sie auch durch ausdrückliche Zuschriften kundgeben, während er, wenn ausnahmsweise ihm "gegen den Strich" geht, was in einem I,eitartikel ausgesprochen wurde, wohl auch seine Entrüstung zu erkennen gibt, in der wirkungsvollsten Weise dadurch, $\mathrm{da} B$ er die Zeitung meinfach " abbestellt, und etwa auch seine Freunde überredet, ein Gleiches zu tun.

23. (Rückwirkungen - Mache - Analogien der Religion.) 2. Richtig weist BAUER oft darauf hin, daB die Ausdrucksmittel regelmäBig 
auf die öffentliche Meinung zurückwirken, da $B$ also Wechselwirkung zwischen Denkungsart und Ausdrücken besteht. Agitation und Propaganda wollen und sollen Meinungen und Wünsche - Forderungen, Ablehnungen - verbreiten und verstärken. So können sie unter günstigen Umständen bewirken, da $B$ aus einer Teilmeinung eine Gesamtmeinung, aus parteiischer öffentlicher Meinung also, die sich vielleicht anfangs nur schwach und zaghaft an die Offentlichkeit hervorwagte, die Öfentliche Meinung wird, wohl gar aus einer unterdrückten die herrschende Meinung. So können auch Meinungen, die einmal geherrscht und gegolten haben, die von der Offentlichen Meinung gehegt und getragen wurden, untergehen oder doch in einen verlorenen Winkel zurückgedrängt werden. Es ist zuweilen der Erfolg der gegnerischen öffentlichen Meinung, die gesiegt hat, zuweilen auch ein bloßes Absterben durch eine Art von Atrophie, die wiederum die Folge ungenügender Tätigkeit und Ubung ist. Im allgemeinen befestigt sich eine Meinung durch die Zeit, sie gewinnt die Kraft eines Vorurteils und erscheint als Selbstverständlichkeit: dies gilt für den einzelnen Menschen sowohl als für ganze Nationen und Gruppen von Nationen, die sich als Träger gleicher Kultur fühlen, zumal wenn sie diese für die höchste bisher erreichte halten. In dieser Hinsicht unterscheiden sich Meinung und Glaube nicht, aber Meinung wird durch Dauer und Alter dem Glauben ähnlicher. Beide werden Gegenstand der Überlieferung und gewinnen mit den Jahren eine gewisse Ehrwürdigkeit und Verklärung; freilich ist die Schätzung des Alters auch in dieser Hinsicht sehr verschieden, im gesellschaftlichen Zeitalter nimmt die Pietät $a b$ und die Kritik wird immer stärker und kühner; wenn auch immer neuer Autoritätsglaube sich entwickelt, so wird er doch auch immer von neuem bezweifelt und angefochten, und viele Meinungen werden wie Kleider so rasch abgelegt wie angezogen, sie werden auch wie der Zuschnitt von Kleidern zum Gegenstande der Mode. Wie durch eine veraltete Tracht, so kann man durch veraltete Meinungen auffallen, und das Auffallende, Sonderbare wird leicht belächelt; so neigt die Jugend immer dazu, über das Alter zu lächeln, und diese Neigung verneint die sonst wirksame Neigung, es zu ehren. - Also haben junge und neue Meinungen immer eine gewisse Stimmung der jungen Menschheit für sich, die als solche in einem gesellschaftlichen Zeitalter "mehr zu sagen " hat, und wenn sie einmal zu Worte kommt, laut, ja lärmend sich vernehmen läßt, und dies wird oft Ursache ihres Erfolges, zumal wenn ein allgemeines Durcheinanderschreien stattfindet und der Preis darauf gesetzt ist, die anderen Stimmen zu übertönen. Da kommen denn alle Ausdrucksmittel der öffentlichen Meinung zur Geltung, und 
indem der Erfolg sie stärkt, wird er Ursache neuer und größerer Erfolge.

3. Alle diese Ausdrucksmittel unterliegen der Mache. D. h. anstatt aus den Meinungen, Stimmungen, Affekten, die sie ausdrücken, unmittelbar und wirklich hervorzugehen, also natürlich zu sein, können sie künstlich werden, indem sie bewußterweise angewandt, gebraucht, vielleicht erfunden werden, um etwas auszudrücken, was vorhanden sein mag oder nicht vorhanden sein mag, wenn nur ein anders gearteter Zweck damit erreicht oder gefördert wird. Je entschiedener der $Z$ weck gewollt und verfolgt wird, je größer, unbedingter, wünschenswerter er erscheint, um so mehr ist in der Regel dem Strebenden "jedes Mittel recht «, desto rücksichtsloser, skrupelloser wird er in der Wahl seiner Mittel. Gleichgültiger daher vor allem gegen die Wahrheit. Unwahre Nachrichten dienen oft besser als wahre dem Interesse dessen, der sie verbreitet, und das Verschweigen und Unterdrücken der wahren kann vorzugsweise ersprießlich sein. Wenn die Tagespresse auf die auffallendste Weise in diesem Sinne gebraucht wird (worauf auch BAUER hinweist), so ist doch nicht weniger die öffentliche Rede, der Brief - auch der Privatbrief, wenn sein Inhalt bestimmt ist, öffentlich zu werden -, die Flugschrift, das Buch, ja auch das dichterische Werk, insbesondere das auf Sinne und Gedanken am stärksten wirkende Schauspiel, solcher Handhabung und Verwendung ausgesetzt; und je mehr der Kürwille, zumal in seiner geistigsten Form, als Bewußtheit, maßgebend wird im gesellschaftlichen Leben, um so mehr werden auch die Kämpfe der Meinungen mit solchen mechanischen Waffen geführt. Die "Erfindung", die gleichzeitig in der Technik ihre Triumphe feiert, bedeutet im geistigen Leben das Ersinnen von Mitteln, die Menschen zu täuschen oder sie auf irgendwelchen Weg zu führen, wo sie und ihre Gedanken unschädlich oder wo sie sogar sehr nützlich zu werden scheinen. Es ist das »Raffinement " der Zivilisation, das sich darin ergeht, und jeder Kämpfer drängt seinem Gegner die von ihm gebrauchten Waffen auf. Auch die Vereinsbildung, die Berufung von Versammlungen, die Demonstration und die Veranstaltung von Festen, dienen so nicht nur den Meinungen und Gesinnungen, denen sie Ausdruck geben, sondern auch den Absichten und Zwecken derer, für die der Schein oder das Offenbarwerden solcher Meinungen und Gesinnungen nützlich ist oder dafür gehalten wird; und eine solche oft gehegte Absicht, ein solcher mächtiger Zweck ist die Eroberung »der « Offentlichen Meinung, ihre Gewinnung für eine Idee oder eine Person, oder als Verwandlung einer ungünstigen in eine günstige Offentliche Meinung. - Hier wie überall entspricht der schroffe begriffliche Gegensatz nicht den ge- 
samten Errscheinungen der Wirklichkeit: die Übergänge des Natürlichen in das Künstliche sind vielfach; kunsthaft ist immer oder wird leicht die menschliche Praxis, wenn sie gekonnt wird - die Methode entspringt aus der Ưbung. Nur das Verhältnis des Subjektes zu seinem Mittel und das darin enthaltene Verhältnis von Mittel und Zweck biegt gleichsam die noch-natürliche Kunst in die Technik um. Technik im Kampfe heißt Taktik, Technik in Verfolgung irgendwelcher Zwecke Politik - Politik, Taktik, Technik sind erfinderisch, sie richten den menschlichen Geist auf die mechanischen Künste der Uberwindung von Widerständen, der Beschleunigung von Bewegungen, der Ordnung und Vermehrung von Kräften, der Umwandlung von Formen der Energie. Wie die (ökonomische) Technik im Kampfe mit der Natur, so führen Taktik und Politik die Menschen in ihren mannigfachen Kämpfen widereinander, so auch im Kampfe um die Öfentliche Meinung.

4. Nachdrücklich werde hier betont, daß die Ausdrucksmittel der Offentlichen Meinung auch die Ausdrucksmittel der Religion sind, und in der Regel früher der Religion als der ihrem Wesen nach älteren Kulturmacht dienen. Dies gilt von jeder Art der Kunst, von bildenden und redenden Künsten, von Architektur und Tonkunst in hervorragendster Weise, dazu kommt aber, zuweilen überwältigend, die öffentliche Rede, die Predigt, und hinzukommen alle Ausdrucksmittel der Schrift und des Druckes, das Buch, die Flugschrift, die Revue und endlich die Zeitung. Aber nicht minder wirken im Sinne der Religion, wie schon angedeutet wurde, der Verein und die Versammlung, die Prozession, das Fest und die Geselligkeit. Man möchte sagen, da $B$ die Öfentliche Meinung überall in den Bahnen wandelt, die ihr von der Religion vorgezeichnet wurden; wenn nicht den jüngeren proselytischen Religionen schon so vieles beigemischt wäre, was der Offentlichen Meinung wesensverwandt ist. So ist auch die Mache, die planmäßige, ja gewaltsame Propaganda eine Methode, deren sich die Apostel der Religion wie die der Offentlichen Meinung bedienen; und das Interesse mächtiger Personen, also der Fürsten, Staatsmänner und Eroberer, knüpft sich an die Ausbreitung politischer Lehren wie religiöser Dogmen, setzt sich daher für die eine wie für die andere Propaganda ein. Aber die großen Unterschiede zwischen Religion und Offentlicher Meinung treten uns entgegen, wenn wir auf der einen Seite uns die stillen Konventikel der Frommen, in denen die Gläubigkeit und Gottseligkeit sich recht eigentlich zu Hause fühlt, auf der anderen Seite die Stätten der Geselligkeit uns vorstellen, die für die Bildung der Öfentlichen Meinung im täglichen Leben hervorragende Bedeutung haben: das sind der "Salon" und das "Wirtshaus «; beide 
als Stelldichein-Plätze der räsonierenden, diskurrierenden, geistreich plaudernden und politisierenden "Welt " - der Salon typisch-französisch, aristokratisch mit bürgerlich aufgeklärter Denkungsart, das Wirtshaus von vornherein bürgerlich, demokratisch, zuerst als das "Kaffeehaus « in England wichtig für das soziale und politische Leben geworden; in Deutschland wird im I9. Jahrhundert der "Stammtisch" ein Brennpunkt des politischen Gespräches in kleinen, mittleren, aber sogar auch in großen Städten; uiberall das "Kannegießern « von mächtigen Wirkungen auf Gestaltung und Befestigung der öffentlichen Meinung, benannt nach der Figur eines geistreichen Lustspiels des Norwegers HolBERG, das den politisierenden Kleinbürger lächerlich macht.

24. (Verbindung, Verpflichtung.) Jede Art der Offentlichen Meinlung will, wie jede Art der Religion, diejenigen, die zu ihr gehören, verbinden, verpflichten. Alle ihre Ausdrucksmittel haben auch diesen Sinn, daß sie die Gesinnungen der Adepten einer »Meinungsschaft " auf die Probe stellen, wie fortwährend die Kirche und jede religiöse Gemeinde die Glieder ihrer Herde beobachtet, ob sie ihre Pflichten erfüllen - wenn diese Pflichten auch auf ein noch so geringes Mindestma $B$ eingeschränkt worden sind. So verlangt die öffentliche Meinung jedes Standes, jedes Kreises, jeder Partei, gewisse Leistungen von ihren Angehörigen, und, sofern die Gruppe eine gewisse Denkweise vertritt, gelegentlich eine Kundgebung, wenigstens die Nichtverleugnung dieser Denkweise. So wird etwa das Halten einer Zeitung oder Zeitschrift, das Kaufen einer Broschüre, eines Buches, die Zahlung für einen Verein, der Besuch einer Versammlung, die Teilnahme an einer Demonstration, vollends aber das Halten einer Rede, das Schreiben eines Artikels oder gar eines Buches, gewertet und nicht selten verlangt. Offenbar ist es leichter, die Äußerung einer Meinung vorzuschreiben, zu raten oder zu widerraten, zu loben oder zu tadeln, als das Hegen solcher Meinungen zu heischen oder zu verbieten; aber, wie früher erörtert, Hegen und Kundgeben wirken wechselseitig aufeinander. Die Kundgebung wird am erfolgreichsten empfohlen durch Hinweisung auf die günstigen Folgen, die sie für die gemeinsame Sache, mittelbar also auch für den Einzelnen, haben werden, auf die schlimmen Folgen, die sich aus anderen Meinungen und deren Duldung oder gar Ausbreitung für ihn und etwa für die Partei oder den Staat ergeben möchten. Was so dem gemeinen Wohle dient, wird der moralische Gerichtshof der öffentlichen Meinung immer begünstigen, was ihm entgegen ist, also auch abweichende Meinungen, als gefährlich, darum auch leicht als unsittlich abstempeln. Dadurch, daß sie immer praktische $Z_{\text {wecke im }}$ Auge hat, daB der Nutzen, nach SchirLiers Wort, 
ihr Idol ist, wird sie bewogen, die Meinungen selber, anstatt nach ihrem inneren Wert, ihrer Wahrheit oder Wahrscheinlichkeit, nach ihrer Heilsamkeit oder Schädlichkeit zu beurteilen, folglich auch am Wohle der Personen zu messen, solche und solche Meinungen vorzuschreiben als Mittel, um zu einem bestimmten Ziele zu gelangen, andere $\mathrm{zu}$ verwehren oder doch $\mathrm{zu}$ widerraten als Hemmungen auf dem Wege dahin, sei es in der Laufbahn zu einem persönlichen Glück, der Karriere, im Wettrennen und Wettbewerb, sei es in gemeinsamer Verfolgung eines Zweckes. Für die Wirkungen kommt es unmittelbar nur auf das Kundgeben an, und dies kann als Sache des Kürwillens in einem Sinne geschehen, der die gehegte Meinung schlechthin verneint; aber die Kundgebung wirkt auf den Gedanken zurück, besonders durch häufige Wiederholung, es findet eine Anpassung, ein Ausgleich statt: wie der ungläubige Geistliche durch häufiges Predigen gläubig wird, so ist es auch z. B. mit den politischen Meinungen. Der Beamte in einem monarchischen Staate mag republikanische Gesinnung hegen: durch Erziehung, Umgang, Lektüre mögen solche Meinungen sich stark in ihm befestigt haben; wenn er vorankommen will, muß er sie unterdrücken, ja er muß von Zeit zu Zeit monarchisch loyale Gefühle zu hegen scheinen; je mehr er Erfolg hat, desto mehr läßt das innere Widerstreben nach, das feste Gefüge seiner »ehemaligen * Uberzeugung wird aufgelockert, es löst sich zuletzt in Dunst und Nebel auf, ein neues Organ ist (wie sonst) allmählich durch die Funktion entstanden, er hat Verständnis gewonnen für den monarchischen Gedanken, so da $B$ dieser sich in seiner Seele ansiedeln konnte, um so sicherer, je mehr das alte "Vorurteil « dagegen Platz machte; und so in vielen ähnlichen Fällen, wo einer so oft etwas gesagt - im schlimmsten Falle geradezu "gelogen " - hat, da $B$ er es am Ende selber glaubt. Das ganze Gefüge des gesellschaftlichen Lebens nötigt zu solcher "Selbstverleugnung "fortwährend, am meisten natürlich den Geschäftsmann; den politischen wie den ökonomischen. Am Kaufmann ist es in der unmittelbarsten Weise wahrnehmbar, wie der $Z$ weck ihn veranlaßt, seine Meinungsäußerungen zu unterdrücken oder anzupassen. Auch verlangt von ihm die öffentliche Meinung seines Berufsstandes in erster Linie Klugheit und dadurch gewonnenen Erfolg; nicht anders vom Staatsmann die öffentliche Meinung sei ner Standesgenossen, der sich aber hier die eigentliche, die staatsbürgerliche Offentliche Meinung anschließt, denn hier ist das allgemeine Interesse am Erfolg und daru $\mathrm{m}$ an der Klugheit überwältigend. Insofern nun als di e Offentliche Meinung vorzugsweise auf das politische Leben, die politischen Führer, die Gesetzgebung, sich bezieht, so urteilt sie auch, wo sie ihr Wesen am reinsten ausdrückt, nach dem Erfolge, und verhält 
sich, bald dem geschehenen, bald dem erwarteten Erfolge nach, bejahend oder verneinend, bewundernd und verherrlichend oder verachtend und schmähend zu Personen und zu Begebenheiten. Sie verlangt daher Zustimmung insbesondere, wo ihr an einem zukünftigen Erfolge gelegen ist, weil sie die Einsicht verlangt, daß solcher Erffolg erstrebt werden müsse. Stark und deutlich tritt dies in einem Kriege hervor, wo eine ganze Nation lebhaft interessiert ist am siegreichen Ausgang, und folglich die Öffentliche Meinung solchen Eirfolg will. Sie legt dann allen Volksgenossen die Pflicht auf, nicht nur diesen Erfolg mitzuwollen (wozu kaum ein Druck notwendig ist) und ihn zu erhoffen, sondern auch zu denken und zu meinen, daß er eintreten werde, ihn nicht nur für wahrscheinlich, sondern so sehr als möglich für sicher und gewiß zu whalten " - wenigstens also keine widrige Meinung laut werden $\mathrm{zu}$ lassen, weil solche nachteilig, entmutigend, verstimmend auf die Volksgenossen, vielleicht sogar auf die Kämpfer, wirken würde; ausdrücklich wird dies Verhalten, wenn es auch aus reinster Überzeugung quillt und nichts als der unwillkürliche Ausdruck unwillkürlicher Gefühle und Gedanken ist, als eine Mache gebrandmarkt: die Angeklagten werden des Flaumachens, des Miesmachens bezichtigt, in der französischen Sprache als "Défaitistes", als ob sie die Niederlage herbeiwünschten und herbeizuführen beflissen wären; in Wahrheit geht der Verdacht leicht dazu über, auch hier wird der Wunsch als Vater des Gedankens ausgegeben, oder, wenn dies nicht einleuchtet, als der natürliche Sprößling - wer glaubt nicht an den Sieg, weil er ihn nicht wünscht « - wer wünscht den Sieg nicht, weil er nicht an ihn glaubt " - im zweiten Satze soll das "weil" zunächst einen Erkenntnisgrund bedeuten, d. h. man schlieBt aus dem Nichtglauben auf das Nichtwünschen; aber es wird auch ein ursächlicher Zusammenhang leicht hinzuverdacht, daß nämlich die Sünde des Unglaubens die größere Sünde des Verwünschens nach sich ziche. Die abweichende Meinung als Sünde zu verfemen, ist der echten Öffentlichen Meinung mit der Religion gemein; auch wenn beiden nur daran gelegen ist, $\mathrm{da} B$ solche abweichende Meinung nicht ausgesprochen, insonderheit nicht verbreitet ("propagiert «) werde, so geht doch die Schätzung, also die Verwerfung, 'unmittelbar auf die Hegung der Meinung, sie ist die materia peccans ", und der Richter ist beflissen, sie auf bösen Willen, auf Verstocktheit des Herzens, auf Verschliessung des Gemütes gegen die Wahrheit, zurückzuführen. - So wenn es um unmittelbare Strebensziele sich handelt, die der Offentlichen Meinung des Tages, aber oft auch der flüssigen Offentlichen Meinung angelegen sind. Etwas anderes ist es mit den Gegenständen, worauf die festgeronnene Offentliche Meinung sich bezieht. Wenn der Zeitgeist 
die Meinung zur Pflicht macht, daß die Folter eine Barbarei war oder $\mathrm{da} B$ eine Inquisition ein Schandmal der Menschheit bedeutet, so hält er zunächst für undenkbar, daß ein "moderner "Mensch das nicht einsehe; wer sich zum Verteidiger solcher Greuel aufwirft, möchte wohl gar sie wieder einführen oder solche Zeiten wieder herstellen, in denen sie geschehen konnten; und welche Beweggründe kann es dafür geben, als das eigene Interesse, das Interesse eines Standes oder einer Klasse, die zu herrschen und den freien Geist $\mathbf{z u}$ knechten wünscht oder ihre ehemalige Herrschaft wiederherzustellen trachtet? Auch hier vermischt sich im verneinenden und verdammenden Urteil das Aussprechen und das Fürwahrhalten solcher "unsinniger " und "abscheulicher " Meinungen. Das Verneinen und Verdammen, worin in solchen Fällen der Zeitgeist, d.h. die festgewordene Offentliche Meinung einig ist, geschieht in solchen Fällen teils im Affekt, aus überströmendem Gefühl und starker Überzeugung, teils aber - und das ist für die Öfentliche Meinung mehr charakteristisch - in bewußter Absicht, um solche für unrichtig und verderblich zu haltende Meinungen im Keime zu ersticken, sie als gemeingefährlich zu unterdrücken. Ist der Affekt besonders für die große Menge charakteristisch, so zeichnen sich durch überlegene Bewußtheit naturgemä $B$ die Führer aus, die sich aber für die Folgen und Wirkungen verantwortlich wissen, und als Intellektuelle im Denken geübter sind, wie im allgemeinen der bejahrtere Mann und der Meister jeder Kunst, jedes Handwerks.

25. (Führer der Öffentlichen Meinung.) Denn es gibt Führer der Öfentlichen Meinung, wie es Führer der Parteien gibt. Sie fallen zuweilen mit solchen zusammen, aber dann muß die Partei schon ein Ubergewicht haben, sie muß einem allgemeineren Gefühl und Drang Akzente verleihen, sie muB von einer siegreichen Propaganda getragen werden, und das wird sie nur, wenn ihr die Bedürfnisse der "Zeit «, die vorherrschenden Empfindungen und Eirfahrungen entgegenkommen, wenn ihre Formeln und Schlagworte unwiderstehlich wirken - dann wächst mit ihr die Öffentliche Meinung zu ihren Gunsten, die Offentliche Meinung nimmt selbst Partei. In diesem Sinne findet zwischen den großen starken Parteien des gebildeten Bewußtseins, der konservativen und der mutativen - varistokratischen " und "demokratischen ", autoritativen und freiheitlichen - ein offenbares Schwanken statt, eine rhythmische Bewegung, eine Pendelschwingung; wobei aber gleichzeitig durch die neueren Jahrhunderte ein Aufstieg des zweiten Gliedes der Alternative, der mutativen, demokratischen, freiheitlichen Politik und Gedankenrichtung stattgefunden hat und noch stattfindet. In allen Ländern Europas, ja 
auch in den Kolonialländern, läßt sich diese doppelte $Z$ wiefachheit erkennen.

Im Unterschiede von Religion, ja im Gegensatze zu ihr, so wurde gesagt, trage die Offentliche Meinung ein wissenschaftliches Gepräge. So hängt auch ihre freiere Gestaltung innig mit dem zunehmenden Einfluß wissenschaftlichen Denkens zusammen, wie dadurch die ganze Epoche, deren Beobachtung uns die Erkenntnis der Offentlichen Meinung an die Hand gibt - die Gegenwart in ihrem breitesten Sinne, oder die "Neuzeit « - stark und deutlich bezeichnet wird. So sind denn auch die Häupter des wissenschaftlichen Denkens, die Gelehrten als Lehrer, die natürlichen und wirklichen Führer der Offentlichen Meinung unmittelbar, aber mehr noch mittelbar, und immer in dem Maße, als ihr Denken, Forschen und Lehren sich erstreckt oder doch Bezug hat auf Fragen von allgemeiner Tragweite. von öffentlicher Bedeutung, daher

I. auf solche von allgemein-sozialem Charakter, der immer mit Problemen des wirtschaftlichen Lebens am engsten verknüpft ist;

2. auf solche von politischem,

3. auf solche von moralischem und in besonderer Weise geistige $\mathrm{m}$ Charakter.

Als Führer der öffentlichen Meinung innerhalb der Nationen stellen für die Neuzeit zunächst A. die Vertreter des alten Lehrstandes, stellt also die Geistlichkeit sich dar; ihr Einfluß ist noch in der ersten Hälfte der bezeichneten Epoche überwältigend, bleibt auch in der zweiten bedeutend. Ėr hängt naturgemä $B$ eng zusammen mit dem dauernden Gewicht, das die Religion für die Offentliche Meinung behält, deckt sich aber nicht damit, da auch ein religiöses und theologisches Laientum sich mehr und mehr geltend macht. Die Offentliche Meinung ist aber in den modernen Iändern, mehr oder weniger, im Laufe dieser Zeitspanne, den Einflüssen der Religion und Theologie überhaupt, daher denen des geistlichen Standes entglitten, sie hat sich sogar in weitem Umfange diesen Mächten entgegengestellt und ist - nach der hier zugrunde gelegten Begriffsbildung erst dadurch eigentliche Offentliche Meinung geworden. Der neue I chrstand entwickelt sich aus dem alten und entfernt sich mehr und mehr von dem alten. Zunächst in engster Fühlung und zum guten Teil identisch mit ihm: B. die Lehrer der Hochschulen. In geistig (d.h. der allgemeinen wissenschaftlichen Bildung nach) zurückgebliebenen Ländern, wie Spanien und England, bleiben sie bis in jüngste Zeit großen Teiles geistlichen Standes: freilich mit sehr verschiedener Wirkung, weil dort römisch-katholische, hier anglikanische 
(hin und wieder auch dissidentische) Geistlichkeit; dort schwacher, hier teilweise bedeutender Anteil an der neueren Wissenschaft. Sonst aber stellt die theologische Fakultät den Zusammenhang dar, und an sie schließt die andere dogmatische Fakultät, die juridische, vielfach sich an: beide vertreten die ïberlieferte Gestalt güitiger Wahrheit, die Vergangenheit. Hingegen die beiden jüngeren Fakultäten, die medizinische und die philosophische, sind mehr oder weniger mit dem Geiste der Zukunft erfüllt, sie wollen das Neue machen und darum das, was ist, bis in seine letzten Gründe erforschen.

Der Einfluß der Universitäten, und besonders der beiden durch die Naturforschung mitbestimmten Fakultäten, auf Gestaltung der Offentlichen Meinung ist in der Tat - zumal im deutschen Sprachgebiete - lebhaft gewesen. Hauptsächlich im protestantischen Deutschland hat sich dies bemerkbar gemacht. Deutsch und charakteristisch ist der Ausdruck "Aufkiärung ", und nach ihr wurde das I8. Jahrhundert genannt, nachdem schon der $\mathrm{Hu}$ manis mus vorzugsweise an deutschen Hochschulen die Stätten seiner Wirksamkeit gefunden hatte. Die Neubelebung des klassischen Altertums, zumal die Anlehnung an die griechischen Träger von Menschheitsidealen, hatte den Triumphen der Naturwissenschaft vorausgeleuchtet; jene konnte, auch im Geiste der beiden älteren Fakultäten, ertragen, ja gefördert werden. Die Naturwissenschaften aber, und eine von ihnen aus die Weltanschauung reformierende Philosophie, fanden in Deutschland früher als in anderen Ländern Eingang in die Hochschulen. Der Wettbewerb der Fürsten, und ihr Interesse, die neuen Erkenntnisse für sich nutzbar zu machen, trugen stark dazu bei. Viel geringer ist der Einfluß der englischen, der französischen, italienischen Universitäten auf die Bildung der modernen Offentlichen Meinung gewesen: im I8. Jahrhundert blieb überall oder wurde wiederum der geistliche Einfluß vorwaltend, sogar im I9., wenigstens in Großbritannien, während in Frankreich die Revolution diesen Einfluß immer von neuem lähmte und brach.

C. Auch der gesamte ïbrige Lehrstand - außer den Hochschullehrern - hat, wenn auch im ganzen weniger frei, also mehr im Banne der geistlichen und weltlichen Autoritäten bleibend, zum Teil doch im gleichen Sinne bedeutend gewirkt; vorzüglich die Lehrer an den Gymnasien ("Oberlehrer") und später den Realschulen; jene durch die Pflege der antiken Geistesschätze, diese durch Pflege der Naturwissenschaften und der lebenden Sprachen. Erst im Laufe des I9. Jahrhunderts ist auch der Volksschullehrerstand, zumal der städtische, insbesondere großstädtische, erstarkt, und hat, wenigstens innerhalb des Protestantismus, und in dessen Geiste, weiterhin aber 
auch für andere und modernere Ideen teils innerhalb seiner selbst, zum guten Teil aber auch in dem weiten Bereich seiner Lehrtätigkeit, an der Verbreitung neuerer Weltanschauung, und also der Offentlichen Meinung in bezug darauf, seinen Anteil genommen; zum guten Teil dadurch, $\mathrm{da} B$ er die von höheren Schichten des Lehrstandes schon wieder verlassenen oder schwach verteidigten Stellungen der Aufklärung noch behauptete oder neu besetzte; soweit ihm die mangelhafte Deckung seiner sozialen Lage oder seine mangelhafte Ausrüstung dies gestattete.

D. Wenn aber der gesamte Lehrstand unmittelbar und berufsmäBig hauptsächlich durch das lebendige Wort Gedanken und Meinungen ausbreitet, so gesellen sich ihm frühzeitig andere Redner und Prediger, die das Volk erregen und aufwiegeln oder dämpfen und beschwichtigen, die auf den Schlachtfeldern der Meinung in den vordersten Reihen fechten, und zwar überwiegend - gerade die freien Redner zum Unterschiede von den berufenen und besoldeten - zugunsten neuer, junger, ringender und reformatorischer oder sogar revolutionärer Ansichten und "Ideen \&. Ehemals auch diese fast ausschließlich religiös, aber vom religiösen Gebiete aus und mit theologischen Geräten auch den sozialen und politischen Acker pflügend, sind sie mehr und mehr, mit dem Wachstum der politischen Freiheiten, politische Volksredner und Agitatoren geworden. Die Tribüne wirkt im Volke, wie in einer beratenden und beschließenden Versammlung, zunächst für persönliche oder (in der Regel) von einer Partei gedeckte Ansichten, also Interessen; sie will diese empfehlen und für sie Stimmung machen; in einer Versammlung dieser Art, wenn es nicht eben eine Parteiversammlung ist (und auch dann gibt es wieder Parteien innerhalb der Partei) werden ihr geschlossene Parteiansichten und Parteiinteressen gegenüberstehen, so da $B$ Uberredungen und Bekehrungen selten vorkommen. Anders in offenen Volksversammlungen, wo die Menge zusammenströmt; hier wird der Redner, zumal wenn er über Stimm-Mittel und Beredsamkeit verfügt, um so mehr Beifall finden, Eindruck machen, Schwankende befestigen, auch Andersdenkende zu sich herüberziehen, je mehr er den Gefühlen, Stimmungen, Bedürfnissen einer solchen Menge entgegenkommt; er wird hier auch zum Handeln aufrufen, anfeuern und begeistern, oft zu ungestümen, leidenschaftlichen, verwegenen Taten und Untaten, sei es für reale oder für ideelle Ziele. Auch wenn eine solche Volksbewegung beschränkt bleibt auf Volksteile, die keine maßgebenden Meinungen zu bilden vermögen, so kann sie doch eine zeitliche Fernwirkung auf Umgestaltung der Offentlichen Meinung ausüben; teils durch das Gewicht ihrer Gründe, teils durch dic Furcht, welche sie erregt. 
E. Unter den Rednern und Redepolitikern ragt in allen modernen Ländern der Rechtsanwalt hervor, der durch die forensische Beredsamkeit geübt und vorbereitet, auch als freies Glied des Gelehrtenstandes und oft, als Mann von großem Einkommen, mit Vorliebe sich zum Volksführer und Staatsmanne aufwirft. Es war mehr eine zufällige als eine notwendige Erscheinung, da $B$ sie in auffallender Weise Vorkämpfer der liberalen Ideen, des Fortschritts und der Reformen, neuerdings daher oft auch des Sozialismus geworden sind. Es war hauptsächlich die Folge davon, da $B$ diese Richtungen, um die eherne Mauer der bestehenden Institutionen und Meinungen $\mathrm{zu}$ brechen, vorzugsweise der Anwälte bedurften, während die herrschenden Autoritäten die Sprache der Macht redeten, außerdem in der kirchlichen Geistlichkeit immer die Organe ihrer Denkungsart hatten, als Verteidiger der festen Stellungen von Thron und Altar. Nachdem in neueren Zeitläuften deren Einfluß stark gesunken und auch sonst die konservativen Gesinnungen aus ihrer Machtstellung herausgedrängt worden, sind sie ebenso genötigt, wenigstens a uch zu den Advokaten ihre Zuflucht zu nehmen und finden diese um so leichter bereit, weil jene Denkweisen auch sonst immer mehr darauf angewiesen sind, unter modernen politischen $\mathrm{Zu}$ ständen mit modernen Mitteln, also mit Schlagwörtern und agitatorischen Zündstoffen auf die öffentliche Meinung und auf die große Menge der Wählerschaften zu wirken; bei welchem Unterfangen sie naturgemäß bald ihre Gegner zu übertrumpfen sich bemühen und lernen. Die Herrschaft der Advokaten und Literaten, die AUGUSTE ComTE anklagte, wirkt nicht notwendig im Sinne reformatorischer oder gar revolutionärer Parteigesinnung, wenn sie auch im Dienste entgegengerichteter Meinungen vielleicht stärker einer sittlichen Auflösung dient, der nur mit organischen Mitteln gewehrt werden kann. - Der Arzt ist der andere gelehrte Stand, der wie der Anwalt frei im wirtschaftlichen Leben steht. Er ist in wissenschaftlicher Denkungsart bewandert auf einem Gebiete, das immer dem Wunderglauben und der Zauberei vorzugsweise offen gestanden hat und noch steht; er ist ein Vorkämpfer der Naturwissenschaft und als solcher, der jedes Haus betritt und meistens überall willkommen ist, geeignet, im Sinne eines vernünftigen männlichen Urteils $\mathrm{zu}$ wirken und Gespenster zu verscheuchen. Sein Einfluß hat die moderne Denkungsart gestalten und also die Offentliche Meinung bilden helfen. Wenn er unter besonderen Umständen auf die Seite vergangener oder vergehender Mächte und Gesinnungen sich stellt, so wird er einer zeitweiligen Strömung der Offentlichen Meinung untertan, anstatt sie zu beherrschen. Er gefährdet dadurch die soziale Grundlage seines geistigen 
Daseins und wird bald sich beklagen, daß er die von ihm gerufenen Geister nicht mehr los werde. Er will immer zum »denkenden besseren " Teile des Volkes gehören und das Bewußtsein hegen, daß er als Denkender und als Redender im Sinne der Aufklärung und Vernünftigkeit auf weitere Kreise wirke.

F. Aber (wie früher betont ward) - wenn nicht tiefer und stärker, so doch weiter und breiter, sind die Wirkungen - unmittelbare und mehr noch mittelbare - des gelesenen als des gesprochenen Wortes. Gerade für die Neuzeit, und daher auch für die Offentliche Meinung als soziale Macht in der Neuzeit, ist die Verallgemeinerung des Lesens durch die Buchdruckerkunst und die Ausbreitung der Volksschulbildung in hohem Grade charakteristisch geworden. Immer ist aber die Fähigkeit eines leichten, raschen und vielfachen Lesens, zumal des Lesens von Büchern wissenschaftlichen oder gar gelehrten Inhaltes, ungemein verschieden geblieben und beschränkt sich nach der sozialen Stellung, weil nach der Vorbildung und der geweckten Anteilnahme an Dingen und Fragen. In den meisten Ländern der heutigen Kultur wird die Fähigkeit des leichten geläufigen Lesens bei der großen Mehrheit von Frauen und Männern angetroffen; die Lesegewohnheiten beschränken sich auf eine Minderheit, wenn auch auf eine bedeutende, auch da, wo das Lesenkönnen allgemein oder fast allgemein geworden ist. Und in bezug darauf gelten die früher bezeichneten Unterschiede der Lebensalter, der Geschlechter, der Klassen und der Schichten innerhalb ihrer. Sehr stark heben sich die "Gebildeten « in dieser Hinsicht vom Volke ab, stark aber auch die Städter, und unter ihnen ganz besonders die Großstädter von den Landbewohnern. Auch für die Geschlechter gilt der Unterschied, wenn auch innerhalb der gebildeten Schicht, die allmählich tiefer ins Volk sich erstreckt, die Frauen im Lesen der schö nen Literatur regelmäßig den Männern voraus sind. Dies galt insbesondere in den protestantischen Ländern schon seit der Reformationszeit für das Lesen der Bibel und anderer Erbauungsbücher, während in katholischen erst das 19. Jahrhundert eine in tieferen Volksschichten andächtig gelesene religiöse Literatur hervorgebracht und mächtig gefördert hat, auch diese vorzugsweise für Frauen bestimmt und von Frauen geschätzt. Für die Offentliche Meinung kommt dies insoweit stark in Betracht, als die religiösen Meinungen einen Widerpart gegen die Offentliche Meinung darstellen, aber auch in sie übergehen. Der Natur der Sache nach haben auf die Offentliche Meinung als Meinung und Willen der gebildeten und daher hauptsächlich der bürgerlichen Klasse, vorzugsweise weltliche Schriften fortwährend gewirkt. 
Dieser Einfluß der Schrifts teller auf Gestaltung der Öfentlichen Meinung ist eine Wahrheit von ausschlaggebender Bedeutung. Er verzweigt sich von wenigen starken Hauptadern in unzählige Kapillargefäße. Seit dem I7. Jahrhundert, wo zuerst Philosophen ohne geistliche Gewänder, und sogar im Widerspruch gegen viele theologische Denkweisen, epochemachend auftraten - Hobbes, Descartes, Spinoza, LOCKE, LEIBNIZ, BAYLE und andere - hat dieser Einfluß unablässig zugenommen. Im I8. Jahrhundert erreichte er eine Höhe und Stärke, die ein bestimmender Faktor des politische n Lebens wurde, durch Voltaire, Rousseau, Montesquieu, Diderot und die Enzyklopädisten. Das Urteil TocQUEvILIES über den Einfluß der Schriftsteller auf die geistige Atmosphäre, aus der die Revolution hervorging, ist früher mitgeteilt worden (S. I46). Was dort der Historiker auf die politischen Theorien einschränkt, hat in Wahrheit eine viel allgemeinere Bedeutung. Auf allen Gebieten wurden die hergebrachten Meinungen tief erschüttert und zum großen Teile unheilbar zerstört. Die Offentliche Meinung, die daraus entstand und sich allmählich befestigte, ist das gemeinbürgerliche Bewußtsein, das schon unter der Fahne des aufgeklärten Absolutismus, der in Frankreich als solcher nur schwach zur Geltung kam, sich mächtig regte, das dann in der französischen Revolution zuerst sich selbständig betätigte, und das im Laufe des I9. Jahrhunderts, ungeachtet mehrerer lebhafter Erneuerungen, die der religiösen Denkungsart zuteil wurden, siegreich und durchdringend vorgewaltet hat. Dieser Fortgang geschah unter immer vermehrter Wirkung der Schriftsteller, indem sich zu den Buchschriftstellern und Flugschriftverfassern die Zeitungschriftsteller oft freilich dieselben Personen - gesellten, und ihnen, wenigstens was die Breite der Wirkungen betrifft, weit über den Kopf wuchsen. Jene Gegenströmungen aber haben auch eine da uernde Bedeutung. Wie in jedem Kriege und fortgesetzten Streit die Kämpfenden voneinander lernen und die Waffen, wodurch der Gegner sich ïberlegen erweist, selber ergreifen, so geschieht es auch in den Kämpfen der Weltanschauungen. Die Verdünnung des Buches und der Tagesschrift, der Gebrauch der Zeitungen, ist zuerst hauptsächlich Angriffswaffe der Neuernden, also der bürgerlichen und liberalen Denkungsart. Auch sie wird aber bald aufgegriffen und angewandt von der Gegenpartei, von den Verteidigern des alten, sonst als überwunden geltenden Bewußtseins. Je mehr nun diese Gegensätze im öffentlichen Leben und Schrifttum sich ausprägen, um so mehr tritt als Inhalt »der " Offentlichen Meinung hervor, was ihnen gemeinsam ist, wenn auch zunächst nur so gemeinsam ist, daß eine Stellung, die der neuen Denkungsart gehört, von ihren Gegnern nicht mehr angegriffen, 
sondern »eingeräumt " wird; die Einräumung geht sogar in vielen Fällen in Behauptung über. Solche Entwicklungen sind für das Verständnis gegenwärtiger Theorie besonderer Aufmerksamkeit wert. Dies Nachgeben und Aufgeben des Widerstandes läßt sich bei allen Aggregatzuständen der Offentlichen Meinung beobachten und ist für diese immer durchaus charakteristisch.

G. Den Schriftstellern im hier genannten Sinne pflegen nicht die Dichter beigezählt zu werden, obgleich sie fast ohne Ausnahme als Schriftsteller sich betätigen. Denn andererseits gehören die Dichter zu den vKünstlern", die sich zum Ziele setzen, Unwirkliches als wirklich erscheinen zu lassen, während die übrige Schriftstellerei irgendwie der außerwissenschaftlichen oder wissenschaftlichen Auffassung des Wirklichen dienen, es wiedergeben, darstellen will. Die Zusammenhänge und Berührungen sind aber mannigfach, so wie wiederum die des Schriftstellers mit dem Redner. Auch der Dichter kann als Redner wirken und insbesondere durch Vortrag seiner Dichtung große Wirkungen erzielen; eher aber läßt er andere im Spiele reden, legt den Spielenden seine Worte in den Mund, die sie also von der Bühne laut werden lassen. Der dramatische Dichter kann eher ncch als der erzählende ein Prophet und Führer der Offentlichen Meinung werden. Er wird es durch den Eindruck der sittlichen Urteile, die im Schauspiel lebendig zu Augen und Ohren sprechen. ScHILLER verherrlichte diese Gedanken als Jüngling in jenem Vortrag, worin er die Schaubühne als eine moralische Anstalt betrachtet. Er führt aus, die Unzulänglichkeit, die schwankende Eigenschaft der politischen Gesetze, welche dem Staat die Religion unentbehrlich mache, eben diese bestimme auch den sittlichen Einfluß der Bühne. „,Die Gerichtsbarkeit der Bühne fängt an, wo das Gebiet der weltlichen Gesetze sich endigt. Wenn die Gerechtigkeit für Gold verblendet und im Solde der Laster schwelgt, wenn die Frevel der Mächtigen ihrer Unmacht spotten, und Menschenfurcht den Arm der Obrigkeit bindet, übernimmt die Schaubühne Schwert und Wage und reißt die Laster vor einen schrecklichen Richterstuhl. Das ganze Reich der Phantasie und Geschichte, Vergangenheit und Zukunft, stehen ihrem Wink zu Gebot." Auch der großen Klasse von Toren halte die Schaubühne den Spiegel vor und beschäme die tausendfachen Formen derselben mit heilsamem Spott. „Aber ihr großer Wirkungskreis ist noch lange nicht geendigt. Die Schaubühne ist mehr als jede andere öffentliche Anstalt des Staats eine Schule der praktischen Weisheit, ein Wegweiser durch das bürgerliche I,eben, ein unfehlbarer Schlüssel zu den geheimsten Zugängen der menschlichen Seele." Nicht geringer als ihr Verdienst um die sittliche Bildung sei das um 
die ganze Aufklärung des Verstandes, in welcher höheren Sphäre der große Kopf, der feurige Patriot sie erst ganz zu gebrauchen wisse. „Die Schaubühne ist der gemeinschaftliche Kanal, in welchen von dem denkenden besseren Teile des Volkes das Licht der Weisheit herunterströmt und von da aus in milderen Strahlen durch den ganzen Staat sich verbreitet. Richtigere Begriffe, geläuterte Grundsätze, reinere Gefühle fließen von hier durch alle Adern des Volkes; der Nebel der Barbarei, des finsteren Aberglaubens verschwindet, die Nacht weicht dem siegenden Licht." Unter den vielen herrlichen Früchten der besseren Bühne will er dann in kurzen Worten die Duldung hervorheben und als noch zu erhoffende segensreiche Wirkungen die Verbesserung der Erziehung und die Zurechtweisung der Meinungen der Nation über Regierung und Regenten; die von der Schaubühne aus bewirkt werden könnte, wenn die Oberhäupter und Vormünder des Staats es verstünden. ScHILLER selbst, obschon er in seinen späteren Jahren die Freiheit ins Reich der Träume verwies, hat als "Dichter der Freiheit « in der deutschen Volksseele einen Platz erobert, den auch die Offentliche Meinung, je mehr sie selber für die "Freiheit « eingenommen war, ihm als gebührend zuerkannt hat; teils haben dazu die Werke seiner Jugend gewirkt, die von überschäumendem Trotz gegen "Tyrannen « und soziale Ubel erfüllt waren, und darin enthaltene Sprüche wie „Männerstolz vor Königsthronen“, ,IIch kann nicht Fürstendiener sein", "Sire, geben Sie Gedankenfreiheit", „Der Mensch ist frei, und wär' er in Ketten geboren" - teils das große Drama der Befreiung eines Volkes, das am Schlusse seiner Laufbahn lag, und die darin begegnenden starken Verse:

„Nein, eine Grenze hat Tyrannenmacht;
Wenn der Gedrückte nirgends Recht kann finden;
Wenn unerträglich wird die Last - greift er
Hinauf getrosten Mutes in den Himmel
Und holt herunter seine ew'gen Rechte
Die droben hangen unveräußerlich
Und unzerbrechlich wie die Sterne selbst - -

und

Wir wollen frei sein wie die Väter waren, Eher den Tod a!s in der Knechtschaft leben."

So hat er ohne Zweifel zur Schätzung der "Freiheit«, und also zum Aufstieg des politischen und religiösen Liberalismus in der ersten Hälfte des I9. Jahrhunderts, und darüber hinaus, mächtig beigetragen. Der allgemeine Eindruck seiner Persönlichkeit, eines sympathischen Idealismus, der an religiösen Enthusiasmus erinnerte, jener Eindruck, dem GozTHE die Worte gab:

Er glänzt uns vor, wie ein Komet entschwindend, Unendlich Licht mit seinem Licht verbindend" 
wirkte dazu mit und gab SchiLLERS Namen eine Verklärung, deren Spuren noch nicht gewichen sind. So ist der Dichter ein Führer des öffentlichen Geistes und der Offentlichen Meinung geworden.

Wie naturgemäß mit den Ausdrucksmitteln immer die Führung der Offentlichen Meinung zusammenhängt und weil neben Lehre, Rede, Schrift, Dichtung auch die ïbrige Kunst zu den Ausdrucksmitteln gehört, so werden auch die Künstler zuweilen, wenn nicht Führer so doch Begleiter der Offentlichen Meinung; in erster Linie etwa die Bühnenkünstler als Dolmetsche der dramatischen Dichtung; aber auch der anerkannte, ja bewunderte Maler, Bildhauer, Architekt und der Musiker wirken auf den Geschmack, den Genuß und dadurch mittelbar auf die Meinung, zunächst etwa nur von dem, was schön sei, aber das Schöne und das Gute berühren sich fortwährend, so daß nicht nur die ästhetische, sondern auch die ethische Offentliche Meinung von ihnen beeinflußt und mitbestimmt wird, in weiterer Folge daher wohl auch die politische. So haben die bildenden Künste und ihre Größen seit der Renaissance im Sinne der Lösung der neueren Denk- und Lebensweise vom asketischen Ideal mitgewirkt, was HEINE und andere die Emanzipation des Fleisches nannten; sogar die Baukunst wirkte leichter, heiterer, ja im Rokoko frivol, gegenüber der ernsten, düsteren und erhabenen Gothik. Indessen der sittliche Ernst, durch Wissenschaft und Philosophie vertieft, stellt auch in der Kunst dem Weltleben gegenüber von Zeit zu Zeit sich wieder her. Ihm unterwirft sich alsdann die Offentliche Meinung, indem sie den Künstlern die Palme zuerkennt, die sich im großen Stile als Meister bewährten und eine der religiösen Empfindung verwandte Stimmung der Seele hervorzurufen vermochten. Wenn der Künstler - welcher Art auch immer - den Erziehern des Menschengeschlechtes sich gesellt, so stellt er die Offentliche Meinung, den Zeitgeist auf sich ein und tritt alsbald in Wechselwirkung mit diesen Kräften, und der große Künstler wird immer in Harmonie mit dem großen Denker wirken auf die Offentliche Meinung des Jahrhunderts, auf die des Tages wirkt freilich der kleine Künstler wie der kleine Denker oft in viel auffallenderer, sogar in blendender oder berauschender Weise. 

Zweites Buch

Empirische Beobachtungen und Anwendungen 

V. Kapitel.

\section{Die Öffentliche Meinung und ihre Merkmale.}

\section{Erster Abschnitt. Soziologische Zusammenhänge der Öffentlichen Meinung.}

I. (Die Formen des sozialen Willens.) Ich habe den Begriff der Offentlichen Meinung dahin bestimmt, da $B$ er eine Form des sozialen Willens ausdrückt und zwar eines gesellschaftlichen Willens im Unterschiede von allen Formen des gemeinschaftlichen Willens. Die Lehre von den Formen des sozialen Willens werde hier nochmals zusammengefaßt. Unterschieden wurden je 6 Formen des gemeinschaftlichen und des gesellschaftlichen Willens, von denen 3 die einfachen oder elementaren, 3 die zusammengesetzten oder höheren Formen sind. Die Tafel dieser Kategorien ist:
A. (Gemeinschaft)
B. (Gesellschaft)

a) Verständnis, b) Brauch, c) Glaube;

aa) Eintracht, bb) Sitte, cc) Religion.

d) Vertrag, e) Satzung, f) Lehre;

dd) Konvention, ee) Gesetzgebung, ff) Offentliche Meinung.

Die mit einfachen Buchstaben $(\mathrm{a}-\mathrm{f})$ bezeichneten Formen sind die elementaren, die mit zwiefachen die zusammengesetztèn oder höheren Formen, die wir auch solche des Kollektivwillens genannt haben.

Alle diese Formen sind miteinander verwandt, hängen untereinander zusammen, gehen ineinander über. Die A-Formen sind ursprünglich und wesentlich geworden - sie entsprechen den Formen des individuellen Wesenwillens. Die B-Formen sind abgeleitet und wesentlich gemacht, sie entsprechen den Formen des individuellen Kürwillens. Die A-Formen des sozialen Wollens sind aber nicht selber notwendigerweise Ausdrücke von Wesenwillen, ebensowenig die B-Formen notwendigerweise Ausdrücke von Kürwillen. Wohl aber sind die individuellen Wesenwillen in entschiedener Weise an den A-Formen, die individuellen Kürwillen in entschiedener Weise an den B-Formen des sozialen Wollens beteiligt. Ubrigens aber müssen diese ganz aus sich selber, als gemeinschaftliche und als gesellschaftliche Formen erkannt und beurteilt werden. - Das 
Prinzip der linteilung ist die dreifache Natur der menschlichen Scele, die im vegetativen Leben beruht, im animalischen Leben sich betätigt, im mentalen und spezifisch menschlichen Leben als Geist sich vollendet. Diese Dreieinigkeiten müssen immer als Wechselwirkungen und Zusammenwirkungen begriffen werden.

Jede dieser fiormen verbindet menschliche Seelen und Willen; sie verbindet, indem sie auf das Tun und Handeln und - mittelbar oder unmittelbar - auf das Denken der Individuen wirkt, veranlassend, nötigend, anregend, also in dreifacher Weise auf ihren Willen. Die A-Formen entspringen überwiegend aus gemeinsamen Gefühlen, dic B-Formen überwiegend aus gemeinsamen Gedanken. Die B-Formen sind nur die srationalisierten" - reflektierten - d. i. durch menschliches Denken auf ihren Grund und ihren $Z$ weck bezogenen A-Formen, bleiben daher immer von diesen abhängig und in ihren Sphären. Sie sind gewissermaßen deren Nachahmungen, Nachbildungen, Eirsatzgestalten, die aber eben als Gebilde des menschlichen Denkens auch eine Kraft erlangen können, die in äußeren Wirkungen der Kraft jener Urgebilde weit überlegen wird. Die einen wie die anderen enthalten Imperative; aber die der B-Formen sind scharf begrenzt, bestimmt "formuliert «, hart und starr gestaltet, die der A-Formen hingegen schmiegsam weich, läßlich unbestimmt, lebendig bildsam. So läßt sich der Übergang wenigstens der einfachen A-Formen in die einfachen B-Formen mit einem ProzeB der Erstarrung vergleichen. So wird aus einem stillschweigenden losen Verständnis und Verständigung eine förmliche Abmachung, eine bestimmte Verabredung, ein Vertrag; so aus einem gefälligen, sinnigen, poesievollen Brauch eine harte Satzung; so aus einem frommen, hingegebenen, phantastisch-lebendigen Glauben eine trockene Lehre und ein starres Dogma. Die ausgesprochene Formel wird vollends befestigt - fixiert - durch die Schrift, sie wird in der Urkunde niedergelegt, geht in ein Buch über. Die Urkunde kann dann ihre eigene Würde empfangen, wie jeder Vertrag eine Weihe erhalten mag; ein Buch kann zur wheiligen Schrift" werden. Die Vernunft und das logische Denken treten in den Dienst des Glaubens und der Einbildungskraft. Aber eines 'Tages oder Jahrhunderts befreit sie sich von der Dienstbarkeit, sucht und findet ihre eigenen Wege.

2. (Die Entwicklung der sozialen Willensformen.) Die Entwicklung eines überwiegend gemeinschaftlichen Zeitalters zum Vorwalten der Gesellschaft wird vorzugsweise durch das Zurücktreten oder die Verwandlung der höheren A-Formen gegen und in die höheren B-Formen bezeichnet. Es ist die Rationalisierung des Geistes, der Fortschritt der Kultur zur Zivilisation, das Vorwalten des städtischen, 
großstädtischen Zusammenlebens mit Entwicklung des Handels, der Technik, der Wissenschaft. Aber auch innerhalb dieses großen Prozesses, in jedem Querschnitt durch die historische Entwicklung, erkennen wir die gleichen Unterschiede und Gegensätze, ein Mehr oder Weniger des älteren oder des neueren Geistes, eine Hinneigung in die spätere oder ein Beharren in der früheren Richtung, eine mehr oder minder vollkommene Verschmelzung, mehr oder minder ausgesprochene Herrschaft des einen oder des anderen Prinzips. Wenn wir nämlich die mannigfachen Weisen erforschen, worin Menschen durch gemeinsames und für sie verbindliches Wollen zusammenhängen, so finden wir, daß sich diese beziehen lassen auf ein

A. Zusammen-Wesen, B. Zusammen-Wohnen, C. Zusammen-Wirken. (Als Zusammen-Wesen werde hier das natürliche Gefühl der Zusammengehörigkeit in die Form eines Tätigkeitswortes gebracht.) Aus jeder dieser Hauptarten des Zusammen ergeben sich viele solche Weisen: I. des gegenseitigen Betragens, 2. des gemeinsamen Handelns, 3. der gleichen Gesinnung; also des in diesen Weisen sich ausprägenden, verbundenen und sich als verbindlich setzenden Willens. Jede betätigt und bewährt sich als gemeinsames Leben, gemeinsames Arbeiten, gemeinsames Denken.

3. (Zusammenhänge.) A. Das $Z$ usa m men-Wesen beruht in der naturgegebenen Verwandtschaft der Menschen, nach deren weitestem und engstem Sinne, so aber, daß es, je enger der Sinn, um so stärker in die Erscheinung tritt. Hier ist es das gemeinsame Leben, was vorwiegt und charakteristisch ist, gemeinsames Arbeiten und gemeinsames Denken sind davon abhängig. Wechselseitige Beziehung teils zueinander, teils zu lebendigen Ganzen (Familie, Geschlecht, Stamm, Volk) ergibt die Richtung. Das gemeinsame Leben bezeichnet den Ubergang zum in der Regel mit ihm verbundenen (B.) $Z$ us a m men-Wohnen, das gleichfalls ursprünglich zumeist in der Verwandtschaft, demnächst in Verhältnissen der Herrschaft und Untertanschaft gegründet ist, allgemein aber die von Verwandtschaft unterschiedene Nachbarschaft bezeichnet. Auch diese hat engere und weitere Bedeutung; auch aus ihr entspringt verbundener Wille um so leichter und stärker, je enger sie verstanden wird, je mehr ihr solcher Wille schon zugrunde liegt. Eine gewisse örtliche Nähe, die das allgemeine Merkmal der Nachbarschaft, ist für alle menschlichen Beziehungen, Verhältnisse, Verbindungen notwendig, wenn auch die Technik einer hochentwickelten Zivilisation die weitesten Entfernungen überbrückt und schon uns dem Ziele nähert,daß man von jeder bewohnten Stelle des Erdballs zu jeder anderen durch Drähte sprechen und durch Maschinen würde fliegen können. Die große Regel wird immer bleiben, 
daß die Wechselwirkung zwischen den Menschen, gesellschaftliche wie gemeinschaftliche, an die leichte, rasche und vielfache Erreichbarkeit von Gestalt und Stimme, also an die räumliche Nähe, die Nachbarschaft, wenngleich mehr oder weniger enge, geknüpft bleibt. Gemeinsame Beziehung auf den Boden - das Land, die Heimat prägt am lebendigsten im gemeinsamen Arbeiten, insbesondere im gemeinsamen Bebauen des Ackers, sich aus. So bedeutet sie den Ưbergang zum (C.) Zusammen-Wirken, das unmittelbar als gemeinsamer $\mathrm{Kampf}$ um den Boden, Verteidigung des besessenen Landes oder Eroberung des Grundes für Kinder und Nachfahren in die Erscheinung tritt, aber von der Kampfgenossenschaft ihr Wesen auf jede Art der Genossenschaft der Tätigkeit, des Sinnes und Geistes ausdehnt. Denn hier erfüllt sich am vollkommensten die Bedeutung des gemeinsamen Denkens: Plänemachens, Beratens, Beschließens, gegenseitiger Anregung, Förderung und Hilfe. Auch hieraus geht verbindender und verbindlicher Wille um so leichter und stärker hervor, je enger und inniger die Genossenschaft und Freundschaft, die gegenseitige Kenntnis und Anerkennung, je stärker daher der gemeinsame Geist, der sich darin ausprägt als Gesinnung und Bestrebung, in die Erscheinung tritt.

4. (Unterschiede der Individuen.) A. In bezug auf das $\mathrm{Z} \mathfrak{u}$ sammen-Wesen ist der tiefste Unterschied der Menschen, auch in allen psychologischen Wirkungen, der natürliche Unterschied des Geschlechtes: demgemäß die Individuen immer auseinanderstreben und gehen, aber auch immer zueinander hingezogen, aneinander gefesselt werden, und zwar so, daß das Weibliche das stärker Hinanziehende, das Männliche das stärker Fesselnde ist. Frauen fühlen und denken in vielen Stücken anders, und zwar ursprünglicher als Männer - Männer entfernen sich leichter und weiter von den Naturgrundlagen des Wesenwillens und der Gemeinschaft, weil sie eher und mehr mit Feinden und Fremden in Wechselwirkung treten, kämpfend und listend, strebend und handelnd. Also beharrt das weibliche Geschlecht mehr in den A-Formen, das männliche geht leichter über zu den B-Formen des sozialen Willens. Wie aber die Geschlechter auf das gemeinsame Leben, gemeinsame Arbeiten, gemeinsame Denken angewiesen sind, so sind auch diese Formen des sozialen (gleich den Formen des individualen) Willens nicht ohne einander und unabhängig voneinander zu denken. Dies gilt ebenso für die folgende Erörterung.

B. Der am tiefsten gehende Unterschied in bezug auf $Z$ us a m menwohnen ist derjenige, der durch die Vorstellungen Land und Stadt bezeichnet wird. Er ist dem zuvor bedeuteten Unterschiede wesens- 
verwandt. Auch das Land beharrt mehr in den A-Formen, die Stadt bildet die B-Formen des sozialen Willens aus. Aber die "Stadt «bleibt immer in einem gewissen $\mathrm{Maße}$ vom "Land * umfangen und abhängig, wie das männliche vom weiblichen Wesen. Sie befreit sich von ihrer Grundlage um so mehr, je ausgesprochener sie zur Großstadt wird diese aber dehnt sich auf das Land aus, strebt aber auch wieder zum Lande zurück - zumeist vergebens.

C. Im Zusammen-Wirken ist wiederum ein ähnlicher tiefer Unterschied erkennbar, der allgemein als Unterschied der Menge von ihren Häuptern, Unterschied also der großen Schichten eines Volkes angesprochen werden kann, von denen die eine die weitaus zahlreichere, aber an materiellem, politischem und geistigem Vermögen schwächere ist, die andere durch die entgegengesetzten Merkmale hervorragt. Wenn durch die Kluft zwischen Arm und Reich schon das gemeinsame Leben, durch die Kluft zwischen Arbeit und Kapital das gemeinsame Arbeiten, so wird vollends durch den Abstand zwischen dem Volk und den Gebildeten das gemeinsame Denken gehemmt und erschwert. Gleichwie aber die Geschlechter auf das gemeinsame Leben in Verwandtschaft, durch Ehe und Familie, sind Land und Stadt, sind Volk und Herren auf gemeinsames Leben, gemeinsames Arbeiten, gemeinsames Denken angewiesen: sie fordern einander zu ihrer Ergänzung. Insbesondere Land und Stadt auf das gemeinsame Arbeiten im Austausch friedlicher Nachbarschaft; Volk und Herren auf das gemeinsame Denken zur Erhaltung, Pflege und Vermehrung gemeinsamer Kulturwerte: ethischer, politischer, ästhetischer, im Geiste der Genossenschaft und Freundschaft, des volkstümlichen Verständnisses.

5. (Sekundäre Unterschiede.) In allen diesen Beziehungen gehen aber mehrere andere wichtige Unterschiede neben den genannten in gewissen Parallelitäten einher und vermischen sich mit ihnen.

In Zusammen-Wesen sind nicht nur die Geschlechter verschieden, sondern, wenn auch minder ausgeprägt und in beständigem Flusse, die Lebensalter. Eine gewisse $Z$ weiheit und möglicher Zwiespalt ist auch hier zwischen Jung und Alt, besonders zwischen Kindern oder geschlechtsunreifen und erwachsenen oder geschlechtsreifen Personen. Kinder gesellen sich Kindern, Jünglinge Jünglingen, Jungfrauen Jungfrauen, aber auch Altersgenossen verschiedenen Geschlechtes durch erwachende und sich steigernde Gefühle zueinander gezogen und getrieben; Männer mit Männern, Frauen mit Frauen, aber auch ganze Familien miteinander: miteinander zu spielen, zu tanzen, sich zu unterhalten; miteinander zu plaudern und zu schwatzen, Briefe zu wechseln, Gespräche und Verhandlungen 
zu führen. So sind auch die Gegensätze der Lebensalter immer als Möglichkeiten wirksam: daß Kinder und Ältere, Junge und Alte, Männer und Greise einander nicht verstehen und ihr Zusammenleben schwer belastet wird, wenn nicht die Kinder heranreifen, die Jungen sich losreißen und selbständig werden, die Greise abscheiden. Die Zwiespalte sind analog dem Zwiespalt zwischen weiblichem und männlichem Geiste.

Im $Z$ usa mmen - Wohnen unterscheiden sich ähnlich wie Land und Stadt schon das dichter zusammenwohnende Land von der dünn verstreuten Bevölkerung, daher das Landvolk der Ebene von dem des Gebirges, das der Marsch von dem der Geest und der Heide; ebenso hebt von der Landstadt - dem "Flecken " - die Großstadt, also auch die Großstadt von Land und kleinen Städten zusammen, vollends also die Hauptstadt von der "Provinz «, und die Weltstadt von allen anderen Städten sich ab. Ferner sind in den "gleichen Hinsichten ganze Gegenden oder Bezirke, unter deren klimatischen und kulturellen Einflüssen ganze Volksstämme voneinander verschieden. Auch diese Unterschiede gehen teilweise parallel mit dem Unterschiede von Land und Stadt, teilweise kreuzen sie sich mit ihm. Insbesondere aber heben juingere Ansiedlungen, zumal solche in fernen und neuen Gebieten, in denen mannigfache Individuen »aus aller Herren Ländern * begierig zusammenströmen, stark von alten Mutterländern sich $a b$, indem jene schon in ihrer ersten Anlage, auch wenn sie noch vorwiegend ländlich bleiben, einen städtischen, ja großstädtischen Charakter zu gewinnen anfangen und darin rasch fortschreiten.

Im $Z$ usammen - Wirken unterscheiden sich ähnlich wie Volk und Herren, verschiedene Tätigkeitsgruppen innerhalb des Volkes, verschiedene Stände innerhalb des Herrentums. Dort der Unterschied und Gegensatz des arbeitenden und des handeltreibenden Volkes, innerhalb des arbeitenden der des ackerbaulich und des handwerklich arbeitenden. In der Herrenschicht der Unterschied und Gegensatz des geistlichen und des weltlichen Herrenstandes, innerhalb des weltlichen der der älteren wesentlich mit der Grundherrschaft verknüpften und der jüngeren, wesentlich durch Kapital mächtigen Herrenschicht.

6. (Die Richtung auf Gesellschaft.) Vollkommener noch als in allen diesen Scheidungen erfüllen sich die hier dargelegten Begriffe, wenn auf der einen Seite die Teilnahme an irgendwelchem Inhalt des gemeinschaftlichen Zusammenlebens vorgestellt wird, auf der anderen die Entblößung davon, die schlichte Freiheit des Einzelmenschen, die sich von der jedesmal gedachten, oder sogar von aller Gemeinschaft schlechthin, abhebt oder sich über sie erhebt. Dies sisolierte Individuum» wird sodann begriffen als Urheber (Subjekt) neuer 
Verhältnisse und Verbindungen, deren es für seine $Z$ wecke bedarf, oder aber als Neubegründer und Umwandler der überlieferten alten, die aber dadurch erneuert werden, - daraus ergibt sich der Begriff der Gesellschaft und gesellschaftlichen Verhältnisse und Verbindungen.

In der Richtung auf Gesellschaft bewegen sich daher weniger als die jedesmal zweiten die jedesmal ersten, mehr also die jedesmal zweiten der angeführten $Z$ wiefachheiten.

Mithin:

die Männer mehr als die Frauen, die Städter mehr als die Dörfler, die Herren mehr als das Volk.

Ebenso ferner:

die reiferen Lebensalter mehr als die Kinder, aber die Jugend mehr als das Alter;

Und

die dichter Zusammenwohnenden mehr als die dünner $\mathrm{Zu}$ sammenwohnenden,

\section{Daher:}

die Anwohner des Meeres mehr als die Binnenländler, die Anwohner der Ströme oder anderer Verkehrsstraßen mehr als die davon Entfernten,

die Bewohner der Täler mehr als die der Gebirge,

die Ansiedler der Pflanzstätten (Kolonien) mehr als die Einwohner der Mutterländer.

\section{Ferner:}

die handeltreibenden mehr als die werktätigen Menschen, die dem Großhandel mehr als die dem Kleinhandel ergebenen, die Menschen des Geldhandels mehr als die des Warenhandels, die handwerklich arbeitenden mehr als die landwirtschaftlichen, die des feineren mehr als die des gröberen Handwerks, die selbständigen (Meister) mehr als die unselbständigen (Gesellen,)

der weltliche Herrenstand mehr als der geistliche Herrenstand, der höhere mehr als der niedere Klerus, der jüngere (kapitalistische) mehr als der ältere (grundherrliche) Herrenstand.

Die Analyse aber des gedachten Einzelmenschen lehrt ihn wiederum in mannigfacher Beziehung kennen: denn es steht

gegenüber dem Familienmenschen der Familienlose, gegenüber dem Einheimischen der Firemde, gegenüber dem Seßhaften der Reisende und Umherschweifende, gegenüber dem in seinem Denken Gebundenen der Freidenker. 
Wiederum gibt es in jeder dieser Beziehungen verschiedene Grade der Annäherung; und zu solcher Annäherung sind eben Männer mehr geneigt als Frauen, Städter mehr als Landleute, die Herren mehr als das Volk usw.

Dies tritt auch darin hervor, daß die Männer eher als die Frauen aus freien Stücken ein ehe- und familienloses Leben erwählen, das gleiche gilt für die Städter, vollends die Groß-, Haupt-, Weltstädtler, im Vergleich mit den Dörflern usw., für die Vornehmen und Gebildeten im Vergleich mit dem Volke usw. - Ebenso haben die Männer mehr Veranlassungen, Beweggründe und $Z$ wecke zum Reisen, werden also leichter als Fremde in der Fremde sein und mit Fremden Geschäftsund andere Beziehungen anknüpfen. Dasselbe gilt wiederum von Städtern im Vergleiche mit Landleuten, von Groß-im Vergleiche mit Kleinstädtern usw., von Herren im Vergleiche mit dem Volke; auch von Händlern und Kaufleuten mehr als von Handwerkern usw. Die Massenwanderungen des Volkes beweisen nicht gegen diese Tendenzen: sie sind zumeist durch Notstände hervorgerufen und nicht durch die $Z$ wecke der Individuen bestimmt. Vielmehr gilt allgemein, daß es sich hier um die Grade der Freiwilligkeit handelt, und die Freiwilligkeit stellt sich am reinsten dar als die Freiheit der Wahl, folglich im Begriffe des Kürwillens, der nicht sowohl unter einem Drucke (von außen) oder aus einfachem Beweggrunde (von innen) sich entschließt, als vielmehr um eines bestimmten Zieles willen seine Vorsätze faßt, seine Pläne schmiedet; insbesondere indem er sich Zwecke setzt wie Gewinn von Machtmitteln, und solchen Zwecken alles, was ihm zur Verfügung steht, mithin auch alle eigenen Handlungen dienstbar werden läßt.

Wir bemerken endlich auch, daß der freie Denker leichter und früher in Gestalt des Mannes als der Frau, des Städters als des Landmannes und vollends in Gestalt des Herren - des typischen Gebildeten - als des Mannes aus dem Volke auf die Bühne tritt. Und so läßt sich in allen jenen $Z$ wiefachheiten, die wir betrachtet haben, ein derartiger Unterschied feststellen.

7. (Individuelle Anlagen.) In alle spielt auch hinein die Mannigfaltigkeit der individuellen Anlage: Begabung und Neigung, deren Verursachung wiederum mannigfach mit den angezeigten Unterschieden zusammenhängt. Die Anlage des Menschen hängt in erster Linie von seiner Abstammung, also von den Anlagen seiner Eltern, diese wieder von denen ihrer Eltern, folglich jede einzelne von sehr vielen Kreuzungen ab. Aber die Fortpflanzung findet zumeist innerhalb eines engeren, mehr oder minder unter sich verwandten Kreises, eines Stammes, eines Volkes, oder zum mindesten einer Rasse statt. 
Unter regelmäßigen Umständen ist die Exogamie um so seltener, je größer der Kreis, innerhalb dessen die Endogamie beobachtet wird. Fruchtbare außereheliche Geschlechtsverbindungen zwischen Menschen verschiedener Rassen kommen nur unter anomalen Koloniezuständen häufiger vor, die auch neue Mischrassen erzeugen. Man bemerkt daher die psychischen Eigenschaften, wie die anthropologischen Merkmale, als solche, die einer Familie, einer Sippe, einem Stamme, einem Volke, einer Völkerfamilie und endlich einer Rasse deren Begriff freilich wacklig ist - gemeinsam sind. Bei den schwierigen Fragen, die sich daran knüpfen, zu verweilen, gehört nicht zum Gegenstande dieses Werkes. Es genügt uns, an die allgemein-menschliche Begabung zu erinnern, die als geistige Fähigkeit ein mehr oder minder starkes Vermögen der Entwicklung zur "Kultur « - die wir als den gemeinschaftlichen Urbegriff verstehen - und damit auch zur "Zivilisation «, der gesellschaftlichen Fortbildung und Rückbildung der Kultur, in sich schlieBt. Wie einzelne Menschen, so haben ganze Familien, Sippen, Stämme, Völker, Völkerfamilien, Rassen diese Fähigkeit in mehr oder minder ausgeprägter Weise, mehr oder minder hohem Grade, und die besondere Anlage zur Zivilisation ist von der allgemeinen Anlage zur Kultur erheblich verschieden. Je mehr man aber bei dieser Betrachtung ins Große geht - d. h. ganze Stämme, ganze Völker usw. ins Auge faßt - um so deutlicher tritt der Zusammenhang dieser Kollektiv-Psyche mit den allgemeinen Lebensbedingungen geographischer und wirtschaftlicher Art zutage. Denn durch diese ist es wiederum das Dasein der Mischrasse und die Tatsache, daß solche für die Zivilisation und Gesellschaft durchaus begabter ist als eine reine Rasse - diese begabter für Kultur und Gemeinschaft - wesentlich bedingt (Rasse wird hier allgemein verstanden als Abstammungsgruppe). So zog der üppige Boden SüdEnglands, der prachtvolle Themsestrom, die mannigfache Küste Abenteurer, Schiffer und Krieger an, führte zu mehreren Eroberungen und Ansiedlungen im Laufe weniger Jahrhunderte, folglich auch zu Blutmischungen, aus denen in der Oberschicht der "angelsächsische " Typus des aristokratischen Staatsmanns, Handelsmanns und Globetrotters erwuchs. So wiederholte sich der gleiche Prozeß auf viel größerer Stufenleiter in der Neuen Welt Nordamerikas. Die Küste, die Schiffahrt, das Meer, zusammenwirkend mit den plyysischen und mentalen Begabungen, die durch diese Gelegenheiten gezüchtet wurden, sind die Ursachen der ïberwältigenden Völkergrößen. So gelangt auch SOMBART, nach seiner meisterhaften, wenn auch in Einzelheiten anfechtbaren Charakteristik des jüdischen Geistes, zu dem Schlusse: „die Juden ein Wüstenvolk und ein Wandervolk" 
(Die Juden und das Wirtschaftsleben S. 404), ,ihre Kultur die spezifische Oasenkultur". Und den Schlüssel zu der Eigenart des Judentums und zu deren gewaltiger Wirksamkeit findet der geistvolle Soziologe in der Tatsache, „daß es ein orientalisches Volk ist, das in einer ihm völlig fremden klimatischen und volklichen Umgebung seine besten Kräfte verzehrt" (403), womit man freilich vergleichen muß, was er an anderer Stelle über die Anpassungsfähigkeit und Beweglichkeit der Juden ausführt (z. B. S. 423), die diese in sich, trotz und wegen ihrer Zerstreuung, gemeinschaftliche Menschenart zu einem Hauptträger der modernen gesellschaftlichen Zivilisation macht.

\section{Zweiter Abschnitt. Soziologische Wechselwirkungen.}

8. (Anwendung auf die Offentliche Meinung.) Die mannigfachen Erscheinungen und Einflüsse, die also auf die Entwicklung der gesellschaftlichen Zivilisation wirken und sie begleiten, müssen sich auch in den B-Formen des sozialen Willens und ihren Verhältnissen zu den A-Formen wiederfinden. Wenn Konvention sich wesentlich auf das allgemeine und also auf das wirtschaftliche, Gesetzgebung auf das politische Leben, so bezieht sich Offentliche Meinung wesentlich auf die ethische (und im Zusammenhange damit: die ästhetische) Seite des Zusammenlebens: also auf dessen „Geist «. Oder: während Konvention wesentlich Vorschrift (Empfehlung, Anordnung), Gesetzgebung Befehl (Ge- und Verbot), so ist Offentliche Meinung wesentlich Urteil. Es ergibt sich aber auch, daß diese Ausdrücke nahe miteinander verwandt sind und ineinander übergehen.

Als Regel darf aber aufgestellt werden: je mehr die Menschen auf bewußte Art denken und ihren Willen durch Absichten, Pläne, Begriffe bestimmt werden lassen, um so lebhafter ist ihre Teilnahme am gesellschaftlichen und öffentlichen Leben, ihre Mitwirkung in sozialen und politischen Angelegenheiten, um so stärker wirken sie auch mit zur Bildung von Konvention, Gesetzgebung, Offentlicher Meinung. Daher gilt auch dafür jene Stufenleiter, auf der die gesellschaftliche Richtung verschieden bedingter Individuen und Schichten gemessen wurde, nämlich daß:

die Männer mehr als die Frauen, die Städter mehr als die Landleute, die Großstädter mehr als die Kleinstädter, die Herren mehr als das Volk usw.

an Gestaltung der Offentlichen Meinung wie an Gestaltung der Konvention und an Gestaltung der Gesetzgebung beteiligt sind.

Während aber bei der Konvention die soziale Stellung entscheidend ist: sie ist vorzugsweise Sache der - sei es durch Geburt, 
durch Reichtum oder durch Rang - höchsten Schichten; während für die Gesetzgebung das politische Interesse den Ausschlag gibt: hier wirkt am stärksten der Zusammenhang des Privatinteresses mit den öffentlichen Angelegenheiten, daher die Geschäftsleute des Erwerbs und Handels - Grundbesitzer und Kapitalisten - um so mehr im Vordergrunde stehen, je bedeutender die "auf dem Spiele stehenden « Interessen, je tiefer die Gesetzgebung ins wirtschaftliche Leben einschneidet; so ist die Gestaltung der Öffentlichen Meinung hauptsächlich durch Wissen, Denken und Bildung bestimmt, so daß die Herrenschicht, die Städter und die Männer, als die durchschnittlich mehr Gebildeten, mehr Denkenden, mehr Wissenden, diejenigen sind, die in erster Linie als die Träger und Subjekte der Offentlichen Meinung betrachtet werden müssen; wobei aber immer der äußere und innere Zusammenhang dieser Gruppen mit jenen, die als Träger und Subjekte der Konvention und der Gesetzgebung bezeichnet wurden, im Auge behalten werde.

Es ergibt sich: je mehr die Bildung, insbesondere die politische Bildung, auf weitere Kreise sich ausdehnt und ausgebreitet wird, mithin je mehr sie auch die Frauen, die Landbewohner und das untere Volk, namentlich die Arbeiterklasse ergreift, um so größer wird die Mitwirkung dieser Schichten zur Offentlichen Meinung, um so mehr wird sie wirklich allgemein, zugleich aber wird sie als Einheit, als einmütige Offentliche Meinung um so unwahrscheinlicher. Vermag sie dennoch als solche aufzutreten und sich geltend zu machen, so wird ihre Macht und Bedeutung um so größer sein. Aber auch dann wird ihr von innen heraus Ton und Farbe gegeben werden: der Geist, der zur F ührung der öffentlichen Meinung taugt, wird als solcher hervortreten, der Geist, der der höhere, lebendigere, am meisten gebildete ist, oder zu sein scheint.

9. (Religion und Öffentliche Meinung.) Die sozialen Willensformen müssen betrachtet werden: einmal gleichsam horizontal, sofern sie in der gleichen Linie liegen; daher die Offentliche Meinung als der am meisten mentale Ausdruck eines sozialen Willens, dessen mehr vegetative Form die Konvention, dessen mehr animalische Form die Gesetzgebung ist. Sodann aber gleichsam vertikal, sofern sie mit den entsprechenden der anderen Linie - die gesellschaftlichen mit den gemeinschaftlichen - in der gleichen Ebene liegen. Begrifflich müssen sie wesentlich in ihrem linearen Zusammenhange betrachtet und die höhere aus der oder den niederen entwickelt werden; empirischhistorisch aber steht die vertikale Provenienz voran, die zugleich dadurch merkwürdig ist - wie die Herkunft des Kürwillens aus dem Wesenwillen -, daB die jüngere (B-)Form aus der älteren (A-)Form 
sich entwickelt und im Laufe ihrer Entwicklung ihr überlegen wird und mehr und mehr in Gegensatz zu ihr gerät, mehr und mehr in ihrem Gebiete der maßgebende soziale Wille wird. So verhält sich Konvention zu Eintracht, Gesetzgebung zu Sitte und Gewohnheitsrecht, so Offentliche Meinung zu Religion.

Im Sprachgebrauch wird Religion sowohl individuell als sozial verstanden. Der soziologische Sinn ist es, der uns hier beschäftigt. Er kommt zur Geltung, wenn man von einer herrschenden oder geltenden Religion, einer Volksreligion, Staatsreligion, von einer Gemeinde oder Kirche als Träger der Religion redet. Bekanntlich ist weder eine Religion noch eine "Konfession " als Gestalt einer Religion, weder eine Kirche, noch eine Sekte, an staatliche Grenzen gebunden. Auch sind die Bekenner einer Religion, zumal einer der großen Weltreligionen, so über den Erdball zerstreut, daß schwerlich ihr gemeinsames Wollen anders auf Einzelne einen Druck ausüben kann, als wiefern solcher in der Religion selber, dadurch, daß sie geglaubt und bekannt wird, enthalten ist. Und dieser Druck ist das Gebot des Gottes oder der Götter, deren Verehrung der Kern des Inhaltes der Religion und ihres Willens ist - auch wenn diese Götter noch lebende oder gestorbene Menschen sind -; das Gebot, das die Verehrer zu kennen glauben, als Ehrfurcht, Dienst, Kultus heischend, wie das Gebot jedes Herrn in mehr oder minder ausgeprägten Formen heischt. Auch wenn Religion in einem Verein, einer Gemeinde organisiert wirksam ist, so ist dies der notwendige erste Gegenstand des Gemeindewillens, der $Z$ weck des Vereins. Aber je mehr die Gemeinde oder der Verein in der Lage ist, sein Wollen zur Geltung zu bringen, um so mehr vermannigfacht sich dies Wollen. Und seine Kraft erhöht sich, wenn er selber, als "heilige Kirche « ein Gegenstand der Verehrung, ein Stück des Inhaltes der Religion wird. Desto leichter und vollkommener kann Religion sich vollenden als der ein ganzes Volksleben, eine Kultur durchdringende und erfüllende soziale Wille, als Gestalt des Volksgeistes selber, der allen einzelnen Ausdrücken ihres gemeinsamen Lebens, gemeinsamen Arbeitens, gemeinsamen Denkens ihre bestimmte Form verleiht. Dieser vernimmt und deutet überall und fortwährend die Stimme seines Gottes, er mißt an dessen Geboten und Verboten Wert und Unwert der menschlichen Handlungen, hüllt alle großen und öffentlichen Unternehmungen in ihr feierliches Gewand. Die Religion eines Landes oder Volkes ist also die Gesamtheit und Einheit vieler Glaubenssätze und wirkt ebenso nötigend und gebietend, wie Glaube überhaupt sozial wirkt. Über die Synonymik von Glauben und Meinen wurde in früherem Zusammenhange gesprochen. Religion ist der allgemeine 
und öffentliche Glaube, der eine Gemeinschaft-Verbundenheit zur Voraussetzung hat oder solche begründet und ausbildet.

Die Offentliche Meinung ist eine Macht, die sich ähnlich wie die Religion vorzugsweise als moralisches Urteil in einem Lande geltend macht, richtend, verdammend, "den Stab brechend ", mit Schmach und Schande bedeckend; aber auch freisprechend, ja belohnend, lobend, preisend, verherrlichend: Unwille und Wohlwollen. Hier wurde von den "Aggregatzuständen " der Meinung und so der Offentlichen Meinung gesprochen. Die Offentliche Meinung wird aber zumeist nur in ihrem luftartigen, flüchtigen Zustande angeschaut, wenn sie bei Gelegenheit eines — "Aufsehen erregenden " - Ereignisses mit ihrem Urteil auftritt, das oft nur eine dünne Haut hat, wie eine Seifenblase; aber es gibt auch - und sie sind uns vorzugsweise wichtig, weil daraus jene flüchtigen Urteile hervorzugehen pflegen - dauerhaftere Gestaltungen der Offentlichen Meinung in verschiedenen Graden der Flüssigkeit oder Festigkeit. Diese ihre Gestalten werden vorzugsweise durch Lehren bestimmt, die aus mannigfachen Ursachen Geltung gewinnen, als geltende umlaufen, gegeben und angenommen, besprochen und nachgesprochen, bewundert und geglaubt, allmählich für eine Menge, ein großes P ubli $\mathrm{kum}$ Gegenstand fester unerschütterlicher Úberzeugung werden. So ist eine zwischen Flüssigkeit und Festigkeit sich bewegende Gestalt der Offentlichen Meinung die Erscheinung eines sozialen Bewußtseins, die als "Zeitgeist « angesprochen wird und die ihrem Wesen nach international die Grenzen der Länder rasch überschreitet. Der Zeitgeist steht und fällt mit gewissen L,ehren. Je mehr das Publikum, das den Zeitgeist trägt, eine politisch oder wenigstens eine geistig und sittlich verbundene Gesamtheit bildet, um so mehr nähert sich seine gemeinsame Ansicht und Überzeugung der Offentlichen Meinung. $\mathrm{Da}$ aber eine Lehre nicht auftritt, verkündet, verbreitet wird, ohne anderen Lehren und Ansichten das Gebiet streitig zu machen, folglich auch nicht, ohne angefochten und von diesen, die sich wehren und verteidigen, bekämpft zu werden, so bedarf es einer gewissen Zeitspanne, um so längerer, je fester gewurzelt, je weiter verbreitet die zu verdrängenden Ansichten sind, damit eine ne ue Lehre in der öffentlichen Meinung erwogen und erörtert, viel längerer Zeit aber noch, damit sie dieser sozusagen ins Blut übergehe und ein fester Bestandteil der Offentlichen Meinung werde.

Je mehr aber dies der Fall, um so ähnlicher wird nach der FormSeite die Offentliche Meinung der Religion, oder doch einem religiösen Glauben, weil es diesem wesentlich ist, "fest \& zu sein, weil er in seinen ausgeprägten Gestalten als heilige Überzeugung unerschütter- 
lich ist und mit dem Gewissen als der gedankenhaftesten Form des Wesenwillens sich vermählt.

Die innere Verwandtschaft und Ähnlichkeit von Religion und Offentlicher Meinung - daß sie in derselben Ebene des mentalen sozialen Willens liegen - wird dadurch verdunkelt, daß der S prach gebrauch jener weit überwiegend einen festen, dieser fast ausschließlich einen luftartig-flüchtigen Inhalt gibt: man spricht von einer Religion in der Regel als von einem System der Glaubenssätze und der Kultusformen; von der Offentlichen Meinung fast nur als von einer gelegentlich in die Erscheinung tretenden Macht des gemeinsamen Bewußtseins. Der wissenschaftliche Begriff muß aber sowohl die Religion in ihren fluissigen und luftartigen Formen als die Offentliche Meinung in ihren verschiedenen Aggregatzuständen beobachten, und zunächst die festen Gestalten der Religion mit den festen der Offentlichen Meinung, die flüssigen mit den flüssigen usw. vergleichen. Dabei ist immer die Richtung der Entwicklung zu beobachten: ob der ProzeB auf Verdichtung oder auf Verdünnung geht; denn es gibt die dünneren Gestalten gleichsam vor und nach den dichteren. Wenn wir flüssige und luftartige Gestalten einer Religion behaupten, indem wir ihre feste Gestalt zum Ausgangspunkte nehmen, so meinen wir nicht, daß der Glaube der Personen, die ihr angehören, ins Wanken gerät, daß er sich, durch $Z$ weifel und kritische Lehren zersetzt, verflüssigt und verflüchtigt - sondern wir denken, $d a ß$ sie selbst als Wille, daß geglaubt werde, sich verwandelt, da $B$ sie sozusagen weich und mürbe wird und in Fluß gerät oder völlig in Dunst und Nebel sich auflöst. Offenbar steht aber die eine mit der anderen Entwicklung in Wechselwirkung. In Athen war ein ProzeB, wie er dem Anaxagoras, ja, wenn auch aus politischen Beweggründen, dem Sokrates gemacht wurde, 2-300 Jahre später schwerlich noch möglich. Die Stadtgemeinde, die Magistrate, die Priesterschaften nahmen die religiösen Zeremonien nicht mehr ernst und waren wenigstens mit äußerer Beobachtung der Formen zufrieden, weil jedermann wußte, daß kein vernünftiger Mensch noch an die Fabeln von Göttern und Heroen glaubte. ,Schon zu PLATons Zeit läßt das von ihm mit unnachahmlicher Plastik ausgeführte Bild des EUTHYPHRON nicht daran zweifeln, daß es einzelne Männer gab, die ehrlich beschränkten Sinnes alle alten Erzählungen von den Göttern für buchstäbliche Wahrheit nahmen, da $\beta$ diese aber dadurch auch leicht zum Gespötte der übrigen wurden" (L. SchmidT, Die Ethik der alten Griechen S. I45). In Rom wirkt es als charakteristisch für die Verdünnung, wenn erzählt wird, daß zwei A ug uren nicht ohne zu lachen einander begegnen konnten. In den neueren Jahrhunderten 
sind wir Zeugen des Vorganges, da $B$ die christliche Religion mit ihrer Dogmatik in einen Prozeß gerät, den man treffend die wSelbstzersetzung des Christentums * genannt hat. Die römisch-katholische Kirche freilich legt Wert darauf, unveränderlich zu scheinen und allem Modernisieren, auch dem theologischen, Widerstand zu leisten. Deutlicher ist die Aufweichung der protestantischen Kirchen, auch wo sie in Erhaltung ihrer Orthodoxie verharren. Diese selbst ist in Fluß geraten. Einige Bestandteile, die ehemals fest geglaubt wurden, haben sich gänzlich verflüchtigt, als: der persönlich und gelegentlich auf Erden auftretende Teufel, die wörtliche Inspiration der heiligen Schrift durch den Geist Gottes u. a.m. Das ganze System ist aufgeweicht durch die Deutungen, die ihm SchLEIERMACHER und später in ganz anderer Richtung RITSCHL gegeben haben, indem jener das "Gottesgefühl « zum absoluten Maßstabe nehmend die Dogmen daraufhin prüft, ob und wiefern sie dieses Gefühl ausdrücken; dieser die Metaphysik verwerfend, ja bekämpfend, sie nur als Ausdrücke eines gläubigen Gemeindebewußtseins gelten läßt und als Wahrheiten behauptet, obgleich als Wahrheiten anderen Sinnes - eine Erneuerung der Renaissance-Lehre von der doppelten Wahrheit. „Alles in allem genommen ist nun freilich diese "Dogmatik « keine Dogmatik mehr . . sondern nur Darstellung der christlichen Glaubensgedanken aus der Gesamtmacht des Christentums heraus und mit bald größerer, bald geringerer Angleichung an moderne Weltvorstellungen" (TRÖLTSCH in "Die Religion in Geschichte und Gegenwart" II, S. I09). Wenn sich so in vielen Eirscheinungen die Dissolution der Religion und ihrer Bekenntnisse beobachten läßt, so haben wir hingegen von ihrem Werden, ihrer Evolution, nur eine historische Erkenntnis, der aber die Beobachtung der Primitiven zur Hilfe kommen kann. Für den Kristallisationsproze $B$ des Christentums, wie für den des Buddhismus und den des Islâm, liegt der Ursprung deutlich erkennbar vor: die Bildung einer kleinen Gemeinde von Jüngern um die Lehre eines Meisters, dem eine übernatürliche Natur oder Weisheit, gottähnliche. oder göttliche Offenbarung zugeschrieben wird; die christliche Judengemeinde nimmt sich erweiternd und vermehrend Elemente griechischer Spekulation, die von Plato und weiter zurück vom Pythagoreismus stammten, in sich auf und gestaltet sie in Jahrhunderte durchdauernden Kämpfen und Entscheidungen zur Kirchenlehre, die so lange in Fluß bleibt, bis sie durch die großen Konzilien sich verhärtet, von denen das letzte - das Tridentinum - erst zu einer Zeit abschließend wirkt, als schon der Auflösungsprozeß begonnen, ja zu tiefstgehenden Spaltungen geführt hat. - Daß Religion auch im staus nascens fortwährend auftaucht, innerhalb und außerhalb 
der vom Christentum umschriebenen Bezirke, lehrt jede Beobachtung des Volkslebens, zumal in Ländern und Gegenden, wo die religiöse Erregbarkeit noch stark ist. Der Dichter Gerhard HauptmanN hat einen "Narren in Christo " beschrieben; in England und Schottland sind solche Narren fast eine allsonntägliche Erscheinung; nicht minder häufig sind die Wunderpropheten und ihr Anhang in den Vereinigten Staaten - ein weiblicher Prophet dieser Art (Mrs. EDDy) hat es zum Bau von Kirchen für ihre neue, aber sehr elementare Frömmigkeit gebracht. In Rußland erheben sich unablässig solche Blasen, die neuesten Zeitläufe sind ihnen ohne Zweifel günstig gewesen. Einen luftartigen Zustand der Religion bemerkt man überhaupt an dem in einem Volke herrschenden »Aberglauben «, der zum Teil von der eigentlichen und offiziellen Religion gutgeheißen und gefördert, zum Teil mit Gleichgültigkeit betrachtet, vielfach aber auch von ihr bestritten und bekämpft wird, zumal als Bestandteil und Rest einer ehemaligen überwundenen und unterdrückten Religion. Er kann nichtsdestoweniger allgemein verbreitet und sehr stark, insofern der echten Religion gleichartig sein, ja unter Umständen bei bestimmten Gelegenheiten - ihr an Kraft überlegen.

Dem gewöhnlichen Sinne des Sprachgebrauches gemäß wird also Religion der Offentlichen Meinung um so ähnlicher, je mehr sie (die Religion) als Gegenwirkung der herrschenden Denkungsart gegen bestimmte einzelne Vorgänge und Handlungen, mithin auch gegen die Personen, die darin tun oder leiden, sich offenbart und aufgefaßt wird; ebenso wird die Offentliche Meinungder Religion (in deren vorwaltendem Sinne) um so ähnlicher, je mehr jene als eine festgeronnene Denkweise, als ein Stück "Weltanschauung " erscheint und erkannt wird. Der gemeinsame und neutrale Begriff möge als der des Offentlichen Urteils gelten, welches die in einem Volke herrschende, mehr oder minder bestimmte, günstige oder ungünstige, bejahende oder verneinende Ansicht ist, wie sie zu Menschen, Erreignissen, Taten und Untaten, zu Gesetzen und Verordnungen, zu Ansichten und Lehren selber, zu wirklichen und möglichen "Fragen «in "göttlichen «und "menschlichen " Dingen, zur "Welt « schlechthin - eben als Weltanschauung - sich stellt und verhält. Ein anderer neutraler Begriff ist der des Imperativs, das Gebot, solche Vorstellungen, Meinungen, Ansichten, solche Lehren anzuerkennen und für wahr zu halten, das Verbot zu widersprechen und anders zu denken, vollends andere Meinungen kundzugeben. Jeder Wille, also auch jeder soziale Wille, bejaht und behauptet sich selber, verneint die gegen ihn gerichteten Willen und deren Tätigkeiten - also auch (und vollends) der Wille einer Gesamtheit, einer Verbindung, die widerstrebenden Willen ihrer Mitglieder - das gehört 
zum Wesen des Mitsicheinigseins: der Eintracht wie der Konvention, der Sitte wie der Gesetzgebung, der Religion wie der Offentlichen Meinung.

I0. (Gemeinsame und unterscheidende Merkmale.) Religion beruht und wurzelt in den Tiefen des Volkslebens, daher des Familienwesens, der gemeinsamen Abstammung, der Erkennung und Ehrung von Vater und Mutter und gemeinsamer Ahnen. Daher auch in gemeinsamen Erlebnisser, gemeinsamen Gefühlen und Vorstellungen, die fortgepflanzt werden durch die Generationen, dem Glauben nach immer bestätigt durch neue Erfahrungen. Dunkel und geheimnisvoll im Verkehr mit den Unsichtbaren, Mächtigen, sucht sie das Wahre, Richtige, Heilsame durch Anrufung der Götter in Preis und Dank, durch Zeichendeutung, Orakel, Lose, Opfer oder aus heiligen Büchern zu gewinnen, wie es hergebracht und von alters her geheiligt; darum ist $Z$ weifel an dem Werte solchen Brauches, an der Wirksamkeit des Gebetes und Opfers Frevel und Kränkung jener ïbernatürlichen, immer als nahe und gegenwärtig und in der Natur lebendig tätig empfundenen und gedachten Mächte. Religion steigt von den unteren, allgemeinen Schichten der Frommen empor zu den besonderen, oberen, seien sie Priester oder Vornehme, Künstler oder Schriftgelehrte, in deren Geiste sie sich verfeinert und veredelt durch die Pflege der Uherlieferung und des Gedankens, der in Dichtungen und anderen Werken der Phantasie und Firinnerung niederschlägt. Man vergleiche etwa mit den im a!ten Hellas herrschenden Religionen, dem rohen Götterdienst, wie er noch in den homerischen Eipen uns entgegentritt, die erhabenen Chorlieder eines Aeschylos, die tiefen Gedanken des Herakleitos oder der Pythagoräer, die Kunst des Pheidias und des Praxiteles. Man vergleiche ebenso mit dem katholischen Volksglauben etwa des r3. Jahrhunderts den Dichter der Divina Commedia und die Denkgebilde eines Albertus Magnus, Thomas Aquinas und Duns Scotus. In der gesamten Geistlichkeit, sofern und je mehr sie dem Studium obliegt, sublimiert sich die Volksreligion. Dies fiihrt in der abendländischen Kirche zunächst zur Verhöhung und Verschärfung des mönchischen Ideales, bald aber eben dadurch zu einer Krise der Lebensanschauung und Et thik, indem sich die laxere Ansicht von der strengeren scheidet. Das eine wie das andere ist Folge des Wachstums und zunehmenden Einflusses der Städte. Wenn das mönchische Ideal, unterhalb dessen für die große Menge der Landbewohner und Krieger die christliche Lehre nur ein neuer Wunderglaube und die Anbetung neuer ausländischer Götter bedeutete, neben denen die alten Volksgötter zu armen Teufeln hinabsanken wenn jener weltverneinende Gedanke zuerst die Geistlichkeit, dann 
auch im Gefolge der Kreuzzüge den Stand der Ritter ergriffen und erhoben hatte, so ging er mit den Bettelorden - den Orden der Philosophen - auf das Bürgertum über, an dem er seine Kraft bewährte, aber auch zerbrach. Die asketische Lebensrichtung, die immer nur ringend, in der Erwartung des baldigen Weltendes, sich behaupten konnte, wurde als Unwahrheit offenbar: die Sittenlosigkeit der Klöster - wie der Weltgeistlichkeit - spottete der frommen Gelïbde, die Reformen mißlangen. Die Moral der Neuzeit wird, je mehr diese sich auf ihre eigenen Füße stellt und von der alten Religion sich unabhängig macht, um so mehr in letzter Instanz durch die Offentliche Meinung bestimmt, wenngleich diese zunächst ein neureligiöses Gewand anzieht und von Zeit zu Zeit, auch nachdem es stark verblichen ist, aufs neue sich damit bekleidet. Veränderungen schreiten unablässig fort und zwar, wenn auch mit starken Unterbrechungen, überwiegend in der gleichen Richtung: die Offentliche Meinung wird immer mehr sie selber und wird mächtiger, indem die Macht der Religion sich vermindert. Nur die moderne Offentliche Meinung können wir hier erkennen und beurteilen, wie sie bis heute geworden ist, ohne ihre kommende Entwicklung vorauszusagen und vorauszuwissen. Insonderheit wissen wir nicht, wie sie sich inskünftig etwa zur Religion verhalten wird, sei es zu einer oder mehreren überlieferten oder $z \mathfrak{u}$ einer ganz jungen und frischen, wie im Altertum, im römischen Reiche der juidisch-hellenistische Glaube der Nazarener war, der allmählich die Philosophen für sich gewann und dadurch eine wissenschaftlich-moralische Autorität erwarb.

II. (Moral der Religion und Moral der Öffentlichen Meinung.) Wir denken hier an die wirklich geibte und gedachte Moral, an das vorherrschende Urteil, wie es sich öffentlich kundgibt, an die Offentliche Meinung als ethischen Richter. Feststehen dürfte etwa folgendes. Die Öffentliche Meinung beurteilt den Menschen nach seinen Handlungen, sie fragt nicht so viel nach seiner Denkungsart, wenigstens nicht nach seinem Glauben; es ist ihr merkwürdig, aber nicht ein Greuel, wenn er ungläubig oder wenn er gläubiger Jude, gläubiger Moslem oder Buddhist ist. Das finstere Heidentum gibt es für sie nicht. Was ihr Eindruck macht, ist die Tüchtigkeit, der tüchtige Mensch, was ihr am meisten mißfällt, die Nichtsnutzigkeit, der Tunichtgut. Sie unterscheidet freilich das spezifisch Unmoralische als nichtsw ürdig und böse, aber das spezifisch Moralische und Unmoralische steht in ihrer Wertung nicht mehr schlechthin im Vordergrunde, wie es für das Urteil, das durch Sitte und vollends durch Religion gebunden ist, der Fall. Die Tüchtigkeit kann allerdings durch eine besonders auffallende Nichtswürdigkeit verdunkelt 
werden; aber die Nichtswürdigkeit selber, oder was dafür gehalten wurde, wird verdunkelt durch den großen Erfolg, den Glanz des Namens, die unbestrittene Geltung. So kommt an den "großen Mann « das spezifisch moralische Urteil nicht heran, die Größe wird angestaunt und bannt den Blick. Typisch dafür ist das Urteil über den "großen " NAPOLEON, wie es - bei seinen Zeitgenossen noch durch vielfachen $\mathrm{HaB}$ und Unwillen, auch durch sittliche Entrüstung getrübt - für die Nachwelt sich festgesetzt hat. Die Ideale des Rittertums wirken stark nach in der Offentlichen Meinung: einem siegreichen Feldherrn weiht sie immer noch lieber ihre Lorbeeren als einem Dichter oder anderen Künstler, wenn auch dessen Augenblickserfolg ebenso groß sein mag. Und doch verabscheut die Offentliche Meinung das Blutvergießen und die Grausamkeit, sieht auch das ganze kriegerische Wesen - den "Militarismus" - wesentlich als ein "notwendiges Ubel « an. Ebenso betrachtet die Offentliche Meinung den Krieg - ungeachtet alles Chauvinismus und Imperialismus, der durch die Länder am meisten rast, die andere am heftigsten als militaristische anklagen -, nur wenn er in notwendiger Verteidigung geführt wird, als »berechtigt «. Sie verurteilt eine auf Krieg abzielende Politik und setzt sich immer für den "Völkerfrieden " ein, in erster Linie aus wirtschaftlichen Gründen, wegen der ungeheuren Zerstörungen von Gütern, Zerrüttungen der Finanzen, die der große Krieg mit sich bringt, aber auch aus Gründen der Humanität, also aus sittlichen Gründen. Die Humanität ist beständige Forderung der Offentlichen Meinung, und sie legt großen Wert darauf, dadurch mit der Lehre des Christentums, nämlich dem Gebot der Nächstenliebe sich zu berühren. Es wäre ihr nicht unwillkommen, die Ansprüche der Religion auf diesen Punkt der Ubereinstimmung einzuschränken. Während aber die christliche Nächstenliebe sich am liebsten als Barmherzigkeit (Carität) und sogar mit der Richtung auf Feindesliebe betätigen will, so ist die moderne Humanität mehr passiv und charakterisiert sich am reinsten als D uld ung (Toleranz) und insbesondere als Duldung fremder, wenn auch anstößiger und für schädlich gehaltener Meinungen, zumal solcher von religiösem Charakter, und als Duldung beliebiger Religionsübung. "Jeder mag auf seine Fasson selig werden", das ist ihre Losung, die auf den Füirsten sich zurückführt, von dem KANT sagte, daß er ,zuerst das menschliche Geschlecht der Unmündigkeit wenigstens von seiten der Regierung entschlug". Dieser Geist der Offentlichen Meinung hat seinen bewußten Träger am Freimaurerorden gefunden, der aber die Humanität auch in einem weiteren Sinne ausdeutet und befördern will. In bezug auf die Religion aber ist gerade die Toleranz das wesentliche Merk- 
mal, wodurch die weltliche Offentliche Meinung von der geistlichpriesterlichen Gesinnung sich abhebt, die in den großen christlichen Konfessionen, wie in den historischen Religionen vorwaltet. Denn diese ist unduldsam, weil sie nur ihre Lehre für wahr und heilsam, alle Irrlehre aber für Verrat und Abfall, für Verderben am Seelenheil erkennt. Sofern sie Einfluß hat auf die politische Macht und Regierung, wird sie immer diese bewegen wollen, solche schädliche und gefährliche Doktrinen zu unterdrücken, ihre Prediger zu bestrafen und die Verbreitung zu untersagen. Die Offentliche Meinung ist in der Regel duldsam in bezug auf religiöse Vorstellungen, aber sie ist in den Gebieten, worauf sie größeren Wert legt, ebenso unduldsam wie irgendeine Religion.

Keineswegs ist in allen Fragen der Ethik die Offentliche Meinung im Gegensatz zur Religion. Aber die Akzente liegen anders, zum Teil so sehr, da $B$ ein offenbarer Widerspruch herausspringt. Beide bleiben in einigem Maße abhängig vom Natürlich-Ursprünglichen, das die einträchtige Volksgesinnung heischt und heiligt, und vom UberliefertenHergebrachten, das die Sitte und das Gesetz einschärfen, z. B. in bezug auf die Einehe, die Verwerfung inzestuöser Ehen wie der Polygynie oder Polyandrie. Aber verschiedene Akzente liegen schon auf den Tugenden der Wahrhaftigkeit, Treue und Ehrlichkeit, die aus dem ursprünglichen Schatze des Volksbewußtseins und Volksgewissens geschöpft, ihren eigentlichen Sinn immer hatten als Regeln für das Verhalten zu den Brüdern, Genossen, Kameraden, als Ausfluß einer gemeinschaftlichen Gesinnung. In der Religion werden sie überschattet von den viel höheren Pflichten des Dienstes an den Göttern, der Ehrfurcht vor den Priestern, des Glaubens an die Wahrheit und Weisheit ihrer Vorschriften - der Gottesfurcht und des Gehorsams. Die Offentliche Meinung beruht zwar auf den gleichen Grundlagen, aber in eine gesellschaftliche Umgebung, eine Welt von Ungenossen und Fremden gestellt, wird sie duldsam gegen Verletzungen der Wahrhaftigkeit, Treue und Ehrlichkeit, so lange als diese Verletzungen nicht in strafbare Handlungen übergehen, die als "Verbrechen" im Einklange mit dem Gesetz die Öfentliche Meinung in der Regel verwehrt. Andere Verstöße dieser Art sind zu alltäglich und zu sehr durch den "Kampf ums Dasein «aufgenötigt, als daß die Offentliche Meinung sich viel darum bekümmern könnte und wollte; sie müssen schon kolossal sein, um eine starke Entrüstung hervorzurufen, und dann wird auch Verfolgung und Bestrafung gefordert. Diese Betrachtung führt darauf, festzustellen, daß überhaupt innerhalb der gesamten Sittlichkeit für die Religion die Gesinnung, für die Offentliche Meinung die Tat im Vordergrunde steht, daher für jene die 
Moralität, für diese die Legalität der Handlungen dasjenige ist, worauf am meisten Gewicht gelegt wird. Die Religion will die Seelen beherrschen und macht darauf Anspruch, die innerste Gesinnung, ob sie dem Gotte wohlgefällig sei oder nicht, zu erforschen; dem dient auch eine Einrichtung wie die Beichte. Die Offentliche Meinung bält sich an die Erscheinung, an das Offenbare und Offenkundige, daher auch leicht an den bloßen Schein und läßt sich oft durch den Schein täuschen. Sie will auch im Sittlichen das Vorgeschriebene, das Regelmäßige, das Korrekte. Sie ist läßlich und nachsichtig in bezug auf die Ausschweifungen des Egoismus in Handel und Verkehr, wenn nur die Gesetze nicht offen übertreten werden, oder sogar dann, wenn es nur nicht "publik « wird, und 》das Zuchthaus nur mit dem Ärmel gestreift «wurde. In Kolonialländern treten jene Ausschweifungen am grellsten zutage. Auch die Öffentliche Meinung entfaltet an diesen spezifisch modernen Stätten ihre Macht in der lautesten und freiesten Weise. Ein englischer Sozialpolitiker, Lord WELBY, sagt von dem Geist der Vereinigten Staaten: ,Die Offentliche Meinung ist gelinde oder, um das allergeringste zu sagen, stumpf (lenient, or to say the least, indolent) in ihrer Haltung gegen gewissenloses Trachten nach Reichtum. Allzu oft geht man über Unrechttun leicht hinweg indem man es "Geschäft " nennt. Das Ergebnis ist Mangel an Vertrauen in die Rechtschaffenheit derer, die große industrielle Unternehmungen leiten. Folglich ist das Land von vornherein zur Beunruhigung geneigt, und wenn üble oder fragwürdige Zeiten kommen, so entartet dieser Mangel an Vertrauen leicht in Angst und panischen Schrecken" (Contemp. Revierw, Dez. 1907).

12. (Ordnung, Recht, Moral.) Wir mögen wiederum die drei Gebiete unterscheiden, in denen das Zusammenleben der Menschen der Regelung durch kollektiven Willen unterliegt, indem als Ordnung der Inbegriff von Normen bezeichnet wird, die das L,eben im allgemeinen bändigen und das Kulturleben aus der Wildheit herausheben sollen; als Recht die Gesamtheit der Regeln, deren Betätigung und Durchführung einem förmlichen Gericht unterliegt; als Moral endlich höhere Forderungen und Verwehrungen, die aus der Idee eines schönen und edlen menschlichen Lebens sich ergeben. Religion und Offentliche Meinung beziehen sich auf alle drei, aber in der Moral finden sie ihr eigentliches und besonderes Gebiet, zugleich gehen sie darin am weitesten auseinander. Sie unterscheiden sich überhaupt durch das $\mathrm{MaB}$ des Eirnstes und der Strenge, womit sie ihre Regeln betonen und sanktionieren: im allgemeinen ist Religion darin der Offentlichen Meinung weit überlegen, aber dies tritt in bezug auf die allgemeine Ordnung des I,ebens, als die am meisten ä uße re Regelung, am 
wenigsten in bezug auf die Moral, als die am meisten innere Regelung, am meisten zutage. Die Religion vertritt eine strenge Moral, die Offentliche Meinung eine laxe Moral. Der Unterschied ist auch, aber in viel minderem Maße, in bezug auf das Recht und am wenigsten in bezug auf die Ordnung erkennbar. - In allen diesen Beziehungen verhalten sich sowohl Religion als Offentliche Meinung I. wünschend und verwünschend, billigend und mißbilligend, lobend und tadelnd, bewundernd und verachtend, 2 . heischend und hemmend, ge- und verbietend, fordernd und verwehrend, 3. richtend und vergeltend, also freisprechend und verurteilend, belohnend und bestrafend. Und zwar macht die erste Art der Normierung ebenso vorwiegend im Gebiete Ordnung, wie die zweite vorwiegend im Gebiete Recht, die dritte vorwiegend im Gebiete Moral sich geltend. Dies zu erläutern mögen noch folgende Bemerkungen dienen:

A. Für die herrschende, besonders die in einem Lande herrschende Religion, wie für die (herrschende) Offentliche Meinung gibt es bewegende Vorstellungen des Normalen und Gesunden, die sich steigern zu Ideen des Vollkommenen, zu Idealen. Beide werden bezeichnet durch Worte wie Kultur, Gesittung, Veredlung, denen sowohl Religion als Offentliche Meinung günstig sind, wenn auch Religion in der Regel den idealen Zustand in die Vergangenheit, Offentliche Meinung in die Zukunft verlegt. So ist für jüdische wie für christliche Religion der Mythus vom Sündenfall ebenso charakteristisch, wie für den hellenischen Götterglauben die Mär vom goldenen Zeitalter. Dagegen hat die Offentliche Meinung immer die Neigung, an den Fortschritt, an die allmähliche Vervollkommnung des Menschen als an die Tatsache der Erfahrung sich zu halten; sie sieht in der Wildheit und Roheit nicht einen Zustand des Abfalles und der Entartung, sondern den ursprünglichen Zustand der Menschheit. Nach diesen Maßstäben richtet sich die Schätzung, welche beide a) Menschen, b) Institutionen, c) Vorstellungen angedeihen lassen. Gelobt und bewundert, getadelt und verachtet werden solche nicht bloß unter dem Gesichtspunkte der Moral, sondern auch, und zumeist, unter demjenigen der Ordnung. Menschen wünscht die Religion als fromm und friedlich gesinnte, sanftmütig und barmherzig, demütig und gehorsam, darum auch als tapfer und aufopfernd, wenn es gilt für die Hausaltäre, für die heimischen Götter und Heiligtümer zu streiten; aber in gewöhnlichen Zeitläufen entspricht die Frau dem Ideal mehr als der Mann; die Offentliche Meinung verherrlicht überhaupt eher den schaffenden, arbeitenden, kämpfenden Mann. Das Ideal ist dort der Heilige, hier der Held; aber der Ritter, wenn helfend und edel, für eine gute Sache streitend, wird dort wie hier bewundert. Institutionen wünscht 
und lobt die Religion vorzugsweise als althergebrachte, bewährte, geweihte, zumal solche, die sich der Einsetzung durch eine Gottheit oder einen gottbegnadeten Menschen erfreuen. Die Öfentliche Meinung mißt hingegen die Institutionen an ihrem Ideale der Vernunft und der wissenschaftlichen Geltung, daher des Nutzens und

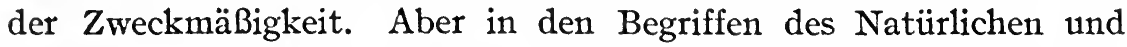
Gesunden begegnen sich beide, die Idee des Naturrechts ist der Religion und der Öfentlichen Meinung in den neueren Zeitläufen gemeinsam gewesen. Dies führt uns zu den Vorstellungen, und es ergibt sich von selbst, daß die Religion religiöse, die Offentliche Meinung wissenschaftliche Vorstellungen am meisten wünscht und verherrlicht; dort werden irreligiöse, gottlose, hier unwissenschaftliche und abergläubische verabscheut: jene erregen mehr Schande, diese mehr Spott. Aber auch hier ist das Auseinandergehen nicht so weit, $\mathrm{da} B$ nicht manche Berührungspunkte blieben: die Religion sucht durch ihren Dolmetsch, die Theologie, Fühlung mit den Wissenschaften, am liebsten mit der Königin der Wissenschaften, der Philosophie, zumal mit deren Krone, der Metaphysik, weil diese ihrerseits und zwar eben unter dem Einfluß der Religion und ihrer Theologie den Ubergang vom Natürlichen zum Ubernatürlichen finden will. Aber die Offentliche Meinung steht ihrem Wesen nach, das auf Wirkliches und Praktisches, auf die Erfahrung gerichtet ist, auch diesen Versuchen der "Apologetik " ablehnend gegenüber; ja sie fühlt sich dadurch herausgefordert. Eher läßt sie die Religion in ihrer Einfalt, als schlichten kindlichen Glauben und als Sitte oder sogar als Staatseinrichtung gelten und ist sogar bereit, sie in diesem Sinne zu schützen.

B. Auch in der Sphäre des Rechts verhalten sich Religion und OffentlicheMeinung auf die dreifacheWeise (wünschend, heischend, richtend) und in der dreifachen Beziehung: auf Menschen, Institutionen, Vorstellungen. Aber hier steht die jedesmal zweite Weise und die zweite Bezichung voran, und diese müssen unterstrichen werden. Auch die Menschen sollen "von Rechts wegen "so und so sein: die "Rechtsordnung * wïnscht sie "rechtschaffen « und gerecht, ganz besonders ihre eigenen bestellten Hüter, die Richter; sie gebietet und verbietet ihnen, den Gesetzen gemäß (zuwider) zu handeln und zu richten; sie richtet selber in den ordentlichen Gerichten die Ubertretungen und stellt sich mit $Z$ wangsgewalt wieder her, wo sie verletzt wurde. Aber die Institutionen sind das eigentliche Gebiet der Rechtsordnung; in diesen verkörpert sich ihr Geist, und zwar zunächst, indem sie sie durch eine Idee beherrscht, z. B. durch die Idee der Monarchie oder durch die Idee der Republik oder durch die Idee einer gemischten Verfassung, der konstitutionellen Monarchic. Ebenso will die Rechts- 
ordnung die Idee der Gemeinschaft oder die Idee der Gesellschaft oder eine Mischung beider verwirklichen (wenn auch unter anderen Namen). Aber die wirklichen Institutionen sind es, in denen die Rechtsordnung vorzugsweise heischend und hemmend, ge- und verbietend, fordernd und verwehrend auftritt, mit einem Worte: Gehorsam und regelmäßige Tätigkeit verlangend. In keinem $Z$ weige tritt dies so bestimmt hervor, wie in den Institutionen des Heer wese $\mathrm{ns}$, in denen 》des Dienstes ewig gleichgestellte Uhr « maßgebend ist. Aber so sind alle staatlichen, gemeindlichen und privaten Institutionen, mehr oder minder scharf, von Heischungen und Hemmungen durchwirkt. Überall aber macht sich die Rechtsordnung auch rich tend innerhalb der Institutionen geltend: neben den 》ordentlichen " Gerichten gibt es mannigfache außerordentliche, als geistliche Gerichte, Ehrengerichte, Standesgerichte und Standgerichte, Kriegsgerichte, Handels- und Gewerbegerichte, Disziplinargerichte, Volksgerichte - öffentliche und heimliche - usw. Alle wollen Recht finden und Recht sprechen, wenn auch verschiedenes Recht und in verschiedener Weise: Recht und Richter sind untrennbar voneinander. Die starken Einflüsse, mit denen zu allen Zeiten die Religionen auf das gesamte Recht gewirkt haben, sind bekannt und offenbar, sie verkörpern sich auch heute noch in lebendigen Einrichtungen und in tiefwurzelnden Vorstellungen. Familie, Gemeinde, Kirche sind die großen Bereiche dieses Zusammenhanges. Aber mehr und mehr hat in den neueren Jahrhunderten, wie in der Spätzeit der Antike, besonders im Römischen Reich, die Öfentliche Meinung mit der wissenschaftlichen Denkungsart, der Ratio, sich an die Stelle der Religion geschoben und ist die ausschlaggebende geistige Macht für Rechtsbildung und Rechtserhaltung geworden. Die Offentliche Meinung fordert Abschaffung alter, Herstellung neuer Gesetze - der Gesetzgeber muß ihr folgen und sich anbequemen. Die großen Bereiche der Offentlichen Meinung, worauf sie ihre Postulate vorzugsweise bezieht, sind Individuum - Gesellschaft-Staat. Im alten Recht, das in der Religion seine höchste Instanz hat, liegt Gemeinschaft und die natürlichwesentliche Gebundenheit der Individuen wie der Gruppen zugrunde. Im neuen Recht wird gemäß der rationalistischen Offentlichen Meinung die Freiheit der Individuen und ihre freiwillig zweckmäßige Selbstbindung zugrunde gelegt und gelten als die allein natürlichen oder naturrechtmäßigen Bindungen.

C. Betrachten wir endlich auch die Moral oder die sittliche Ordnung des menschlichen Zusammenlebens unter dem dreifachen Gesichtspunkte. Auch sie, und sie vollends, hat ihre Ideen und Ideale und wünscht deren Verwirklichung, lobt und verherrlicht, tadelt 
und verachtet also Menschen, Institutionen, Vorstellungen, je nachdem sie dem sich nähern oder davon entfernt sind und sogar widrig sich dazu verhalten. Sie verhält sich auch heischend zu ihnen, gebietet und verbietet solches und solches Verhalten der Menschen, solche und solche Beschaffenheit der Institutionen und der Vorstellungen. Aber sie erfüllt sich erst - wie früher betont wurde -, wenn sie richtend auftritt: sie will richten, und zwar in letzter, in höchster Instanz, wenn sie auch unfähig ist, ihre Sprüche anders zu vollziehen als durch sich selber; sie erwartet nicht, wie die Recht sprechenden Gerichte es in der Regel tun, den Beistand einer anderen, zwingenden Gewalt. Sie richtet auch über Institutionen, sogar über den Staat (so wenig sie ihn entbehren kann und will), wenn er als von ih re $m$ Geiste verlassen, als feindselig, so den Christen als "heidnischer " Staat sich darstellt. Und so richtet sie auch über gerichtliche Erkenntnisse und Urteile, billigt und unterstützt sie oder verurteilt sie als ungerecht. Sie meint dann vorzugsweise die darin ausgeprägten Vorstellungen und Gedanken, denn auf diese bezieht sich ihre Jurisdiktion am unmittelbarsten, wenngleich richterliche Erkenntnisse auch als Willenshandlungen der Menschen erscheinen, die dafür verantwortlich sind; aber die Beurteilung dieser Menschen ist für solchen Fall offenbar sekundär, es wird oft oder sogar in der Regel zugegeben, da $B$ diese subjektiv in gutem Glauben waren; der gerichtliche Spruch wird als solcher, als Gedankengebilde, nach seinem moralischen Wert beurteilt. Das Urteil kann in einem gegebenen Umkreise höchst mannigfach und sehr verschieden begrïndet sein, ob Einzelne es fällen, ob ganze Gruppen oder die Gesamtheit. Nur dann wird man annehmen dürfen, da $B$ die sittliche Ordnung eines Volkes dahinter stehe, wenn feststehende Grundsätze sich darin kundgeben, die man als Inhalt des wirklichen Volksgewissens oder doch eines übereinstimmenden moralischen Bewußtseins zu deuten berechtigt ist, nicht aber, wenn bloße Gehässigkeit, blinde Feindschaft, zumal die einer Nation gegen eine andere, sich darin ausspricht. In den Vorstellungen und Gedanken, eigenen sowohl als fremden, hat dies gemeinsame Denken und Wollen seinen eigensten Gegenstand, worin es sich reflektiert, und zwar wünschend, heischend, zumal aber richtend. So bricht es »den Stab « über Ideen, die ihm falsch, töricht, verderblich und unheilvoll scheinen, wie etwa heute die Ideen des "Bolschewismus «, lange Zeit des Sozialismus schlechthin, heute noch wenigstens des als seine Spielart oder Entart aufgefaßten "Kommunismusa, vollends des Anarchismus und Syndikalismus, Namen und Vorstellungen, die aber niemals so tief unter die Oberfläche des öffentlichen BewuBtseins gedrungen sind, wie heute die 
Vorstellungswelt Sowjet-Rußlands. Erst außerhalb des politischen Gebietes tritt das moralische Urteil in die ihm gehörige Sphäre. Und diese begrenzt sich am schärfsten als die der geschlechtlichen Sittlichkeit nebst allen Lebenserscheinungen, die davon abhängen. In dem ganzen Gebiete (der Moral) liegt klar zutage, daß die Ideen, die Forderungen, die Urteile, ganz hauptsächlich durch die Religion und die Offentliche Meinung bestimmt werden: dem Inhalte nach verwerfen beide ein selbstsüchtiges, eigennütziges, unsoziales Verhalten, aber die Religion grundsätzlich, die Offentliche Meinung nur, wenn es durch Übermaß und besonders, wenn es gewalttätig sich bemerklich macht. Die Religion fordert (in ihren ausgeprägten Gestaltungen) Entsagung, Askese, darum macht sie jezuweilen Armut, Gehorsam, Keuschheit durch Geluibde zur Pflicht. Die Offentliche Meinung hat für alle diese Tugenden keinen Sinn. Sie setzt immer ein bewegtes gesellschaftliches Leben und einen Verkehr zwischen Menschen, die einander innerlich fremd sind und bleiben, voraus. Darum ist ihr (s. oben) die Legalität und die ihr verwandte äußere formale Korrektheit, der Anstand, wertvoller als die eigentliche Moralität, wenigstens als die aus der Gesinnung fließende; und wo sie auf diese Wert legt, da appelliert sie an das wohlverstandene Selbstinteresse, ïberhaupt immer an die Einsicht. In bezug auf Ehrlichkeit ist ihr Wahrspruch, daß Ehrlichkeit die beste Politik sei, überhaupt ist ihr an dem Zusammenfallen des sozialen mit dem individuellen Interesse alles gelegen. Darum ist sie aber auch gegen Unehrlichkeit als die irrende Verfolgung des eigenen Interesses nachsichtig, und wendet sich mit viel mehr Schärfe gegen Roheit und Gewalttat als die Zeichen eines unzivilisierten, zurïckgebliebenen Menschentums. Die Religion (die christliche) erblickt in den Sünden dieser Art die unbekehrte, unwiedergeborene Natur der Menschen, die für sie bleibend und unveränderlich ist, außer durch Gnade, d. i. durch innere Erleuchtung, die dem Gläubigen, sei es allein aus dem Glauben oder aus dem Schatz der guten Werke, den die Heiligen angehäuft haben, zuteil wird. „Sich unter Verzicht auf das kreatürliche Selbst auf dem Höhepunkt der sittlichen Leistung aus der eigenen Hand in die Gottes zu übergeben, um in Gottes Kraft das Göttliche zu wirken, das die Kreatur aus eigener Kraft nur mit untilgbarer Befleckung durch die kreatürliche Selbstsucht wirken kann, das ist der Kernpunkt der christlichen Religion und Ethik" (nach TröLTSCH, Religion in Geschichte und Gegenwart II, I47I): will sagen etwas, das für die Offentliche Meinung schlechthin unverständlich, oder soweit sie es verstehen mag, unassimilierbar ist. Sie wird sicherlich in keinem Lande der gegenwärtigen Zivilisation den 
Wert eines Menschen danach beurteilen, ob der Mensch auf sein kreatürliches Selbst verzichtet hat, oder den einer menschlichen Handlung danach, ob sie darauf ausgehe, in Gottes Kraft das Göttliche zu wirken. Vielmehr fragt sie bei der Bewertung des Menschen zuerst danach, ob er vtaugt «, die Tüchtigkeit steht ihr am höchsten und als Tüchtigkeit zuerst die Klugheit, sodann fragt sie, ob er und was er »bedeutet «, der bedeutende Mensch ist es, der ihr gefällt, auf den sie "Wert legt «. Endlich - und das ist für ihre Schätzung entscheidend - fragt sie nach der Wirkung, nach dem Erfolge. Der Erfolg tilgt für die Öfentliche Meinung alle Flecken, der Sieg verscheucht die Schatten einer Kriegführung, die sich farbiger Mietsoldaten im europäischen Kriege, die sich einer ebenso antivölkerrechtlichen Aushungerungsmethode bedient hat. So wertet die Öfentliche Meinung, wo sie ganz frei ihre Wege wandelt, bei einer Handlung zu allererst die Leistung, und. als solche die Gescheitheit eines Gedankens, Planes, Entwurfes, insbesondere einer Erfindung; denn sie ist auf den Fortschritt der Menschheit eingestellt und findet diesen am meisten ausgeprägt in Vermehrung und Verbesserung der Mittel des Lebens, in Erleichterungen und Förderungen des Tausches und Verkehrs über den Erdball hin, in allen Neugestaltungen der Technik, wobei die nicht minder gewaltige Technik der Destruktion gern über der Technik der Produktion vergessen wird. Verallgemeinert wird diese Schätzung durch den Bezug auf das gemeine Wohl, am liebsten das der Menschheit, aber auch das eines engeren Kreises, wie der "Nation " - die sich zuweilen mit der Menschheit identifiziert oder doch für ihren Eixtrakt oder gleichsam ihre Quintessenz hält, und dies hat typische Bedeutung für das Urteil. Uberhaupt aber ist der Sieg die Handlung, die am entschiedensten der Offentlichen Meinung gefällt. Auch Religion - und zwar je mehr sie ursprünglich und natürlich ist, um so unumwundener - feiert und verherrlicht den kriegerischen Helden und den Sieg; das I eben der Gemeinschaft ist dadurch bedingt. Aber die Offentliche Meinung richtet ihre Aufmerksamkeit unmittelbarer und stärker auf den Gewinn, den Ertrag, den Vorteil des Sieges, die Religion mehr auf seine Schönheit, seinen Glanz und seinen Ruhm, und bei der Heldentat krönt sie am liebsten die Aufopferung, darum den Heldentod noch über das Heldenleben; die Öfentliche Meinung eher umgekehrt.

13. (Empirische Merkmale der ephemeren Öffentlichen Meinung.) Die Vorstellung der Offentlichen Meinung wird hier von ihrem Begriff abgelöst, sie wird in ihrer alltäglichen, dem Sprachgebrauch zugrunde liegenden Ërscheinung, also in ihrem luftigen oder gasförmigen $\mathrm{Zu}$ stande betrachtet. Wir finden an ihr folgende Charaktere ausgeprägt: I. Sie ist sehr veränderlich. Rasch wie sie entsteht, vergeht sie auch, 
und zwar zunächst darum, weil sie ihre Gegenstände wechselt. Die öffentliche Aufmerksamkeit verweilt nicht lange bei einem Gegenstande, sie springt von selber ab oder wird abgelenkt. Dies bezeichnet vor allem die großstädtische Offentliche Meinung, wie sie in diesem ihrem Charakter immer durch $\mathrm{Paris}$ am deutlichsten charakterisiert wird. Paris fühlt sich als Hauptstadt der Welt, wie einst Rom es war. Und der römische Dichter mahnt

\section{... Nec si quid turbida Roma}

Elevet, accedas, nec te quaesiveris extral -

eine Mahnung, die der Denkende immer gegenüber den Wirbelwinden der Offentlichen Meinung sich wiederholen wird. Ihre Veränderlichkeit bedingt, daß sie oft und plötzlich umschlägt. Was macht sie umschlagen? Zuerst und vor allem eine Tatsache, ein Ereignis, ein Erfolg. So in bezug auf eine Persönlichkeit. „Mußt Ruhm gewinnen, da werden sich die Leute gleich anders besinnen." Sodann aber auch oft eine Bewegung, eine Agitation, zumal wenn ihr die Begebenheiten zur Hilfe kommen. Ein klassisches Beispiel: der Sieg der Anti-Corn-LawLeague in England wird uns in späterem Zusammenhange begegnen. Die Offentliche Meinung ist 2. hastig - schnell fertig mit dem Wort, wie die Jugend, ja oft weist sie die Züge eines Kindes auf und dann nicht leicht die eines artigen Kindes. Die Geschwindigkeit und Hast ist um so mehr natürlich und notwendig, je mehr die Offentliche Meinung in der Großstadt, zumal der Hauptstadt, sich bildet, wo ein Eindruck den anderen verjagt. Auch wenn man die Teilnahme der eigentlichen großen Volksmenge außer acht läßt, und etwa nur die Gestaltung des maßgebenden Urteils, zumal in politischen Angelegenheiten, ins Auge faßt, so stellen eben hier schon die'Gebildeten eine "Menge" dar und weisen daher die Merkmale auf, die sich an dieser beobachten lassen. Ein solches Merkmal ist vor anderen die leichte, also rasche Erregbarkeit, daher rührend, daß die Erregung sich leicht und rasch fortpflanzt, und $\mathrm{da} B$ sie durch gegenseitige Mitteilung in jedem Erregten verstärkt wird. Dies wird bei jeder Volksmenge beobachtet, sobald die Individuen in leibliche Nähe miteinander kommen: je größer der Haufen, um so sicherer fühlt sich jeder in ihm, um so mehr ermutigen alle den Einzelnen und verstärken seine Leidenschaft. Die Bildung erleichtert es, sich ungeachtet leiblicher Ferne, im Geiste einig $z \mathfrak{u}$ fühlen mit vielen anderen, von denen man weiß oder meint und erwartet, da $B$ sie Gesinnungsgenossen sind, da $B$ daher ein bestimmtes Erlebnis, der Eindruck eines Ereignisses bei ihnen die gleichen Empfindungen hervorrufen werde wie bei mir selber. Und dieser Gedanke wirkt um so stärker auf die eigene Gemütsbewegung zurück, je mehr er zu vermuten Grund hat, daß "alle " gleichzeitig 
von dem elektrischen Schlag durchzuckt werden, wie es in der Großstadt der Fall ist, wo ein Gerücht oder eine Tatsache "wie ein Lauffeuer " sich verbreitet, wo zum wenigsten die Morgen- oder Abendzeitung an allen Ecken und Enden der Stadt gleichzeitig die Neuigkeit aufflammen läßt, wenn nicht "Extrablätter «schon um einige Stunden vorausgerannt sind und die Kunde dann mündlich oder von Hand zu Hand weitergetragen wurde. Die Gelegenheiten, ssich auszusprechen «, fehlen nicht, obschon der Großstädter zumeist als Fremder unter Fremden lebt; man trifft doch Bekannte, auf der Eisenbahn, der Straßenbahn, im Kontor oder Bureau, oder in Sprechzimmern, auf dem Markte, den Plätzen oder in den Straßen, man besucht seine Freunde, man kommt auch mit Unbekannten ins Gespräch, wenn das Bedürfnis der Rede stark genug ist. In der Regel ist dann jeder "auch der Ansicht", sie wird von allen "ordentlichen Leuten "geteilt. Der geschwinde und regelmäßige Verkehr macht ein ganzes Land einer Großstadt ähnlich, zumal alle großen Städte zusammengenommen ; binnen 24 Stunden wissen alle die große Neuigkeit, und jeder der daran teilnimmt, wird auf gleiche Art erschïttert und wirkt mit seiner gebildeten Meinung in gleicher Weise auf die allgemeine Meinung zurück. - Die Offentliche Meinung ist 3. oberflächlich - dies folgt aus ihrer Hast und Beweglichkeit. Sie urteilt nach dem Schein und läßt sich durch den ersten Eindruck bestimmen. Dieser Eindruck kann der richtige, ja der allein mögliche sein - unter der Voraussetzung, da $\beta$ die Nachrichten, worauf er sich gründet, wahr und richtig sind. Sehr oft ist aber das nicht der Fall. "Gelogen wie gedruckt ", "Gelogen wie telegraphiert "sind Ausdrücke, die das I9. Jahrhundert, das auch die Offentliche Meinung emporblïhen sah, erfunden hat. Aber es ist viel seltener direkte Lï̈ge, als Ungenauigkeit, Entstellung, Ausgeben einer Vermutung als Wirklichkeit oder hohe Wahrscheinlichkeit, Ergänzung, Aufbauschung, Ubertreibung, was telegraphierte oder gedruckte Nachrichten unzuverlässig macht. Der durchschnittliche gebildete Leser und Staatsbürger weiß dies entweder gar nicht oder vergißt es doch immer wieder. Er bildet sein Urteil, ohne die Gründe $z \mathfrak{u}$ untersuchen. Berichtigungen werden übersehen oder dringen nicht unter die Oberhaut des Bewußtseins. Die Offentliche Meinung ist also 4. leichtgläubig und unkritisch - am meisten, wenn eine wirkliche oder angebliche Sache ihren vorgefaßten Gedanken und Ansichten entgegenkommt, die gleichsam darauf warten, ihre Nahrung zu bekommen, die ihnen sogar dann schmeckt, wenn sie an und für sich für die Subjekte der Meinung unerfreulich ist, um so mehr also, wenn auch Wünsche durch sie befriedigt werden, und je lebhafter der Wunsch, je größer die Ungeduld, um so 
leichtgläubiger ist die Offentliche Meinung. Sie ist 5. von Vorurteilen erfüllt - diese entspringen aus der flïssigen, vollends aus der festen Offentlichen Meinung: aus den entschiedenen Gesinnungen und Willensmeinungen, den herrschenden Überzeugungen und damit verbundenen Gefühlen. Diese sind regelmäßig um so weniger wandelbar, je mehr sie auf Überlieferung beruhen, je mehr der Mensch sie "mit der Muttermilch eingesogen «, d. h. sie aus seiner frühesten und stätigsten Umgebung empfangen hat, je mehr sie ihm daher als natürlich und von selbst verständlich erscheinen. Darum ist das jedesmalige einzelne Urteil sehr oft eine bloße Folgerung aus einem Vorurteil, und dieses wehrt sich dann gegen anders gerichtete Gedanken und Gründe. Darin ist ein Widerspruch gegen das erste Merkmal, die Veränderlichkeit, enthalten. Die Offentliche Meinung hat auch 6. ihre Beharrlichkeit und ihren Eigensinn. Sie kommt wohl vorübergehend auf andere Gedanken und gibt sich dem Augenblicke hin, aber sie kehrt auch elastisch in die ihr gewohntere, erwünschtere Lage zurück. Um so eher und gewisser, je zäher ihr Vorurteil in bezug auf die Sache oder die Persönlichkeit. Sie ist aber 7. besonders zähe in bezug auf Persönlichkeiten - viel zäher als in bezug auf Sachen. Denn hier hat das Gefühl - Begeisterung oder Abscheu - freieren Spielraum und knüpft sich unmittelbar an die Empfindung des Guten oder Bösen, des Erwünschten und des Unerwünschten, welches von der Person ausgeht oder auszugehen scheint. Je mehr sich diese Gefühle befestigen, um so mehr wird die Offentliche Meinung der Religion wieder ähnlich, wenn auch die Gegenstände der Verehrung (oder der Furcht) ganz und gar verschieden sind von den sonst gepflogenen Gegenständen des Glaubens. Menschen werden "vergöttert « (oder im Gegenteil, wovon nunmehr abgesehen werde, vverteufelt «). Die Neigung dazu, nämlich zur Vergötterung, ist nach dem Tode der Personen um so größer (die umgekehrte geringer). Wenn aber die ursprüngliche und echte religiöse Stimmung solche Tote fortwalten und fortwirken läßt, und eben darum ihrem abgeschiedenen Geiste opfert, um ihn zu versöhnen und seine Hilfe in Not und Gefahr heranzurufen, so wird die Offentliche Meinung nicht leicht so weit von ihrer Basis, der wissenschaftlichen Denkungsart, sich entfernen. Die Vergötterung eines abgeschiedenen Helden kleidet sich allerdings in die Form des Wunsches, beharrt aber auch bei dem sich ohnmächtig wissenden Wunsche: "wenn doch der Held noch unter uns wäre " oder "gewesen wäre «, und in den rationalen Gedanken: die Dinge hätten einen ganz anderen, einen besseren Verlauf genommen, wenn er noch als Feldherr oder als Staatsmann an der Spitze gestanden hätte. 8. So steht die Offentliche Meinung des Tages unter den Eindrücken des Tages, ist daher 
in der Regel aufgeregt und oft leidenschaftlich bewegt. Sie entspricht daher selten der Idee, die wir von der Offentlichen Meinung als der mentalen Form des sozialen Kürwillens gebildet haben. Aber sie selber betrachtet den Affekt, von dem sie beherrscht wird, als etwas ihr Fremdes und macht als Urteil auf Wahrheit und Geltung Anspruch. Dies mit um so mehr Grund und Recht, je mehr sie Ausdruck einer flüssigen oder sogar festen Öfentlichen Meinung ist; denn in diesen Aggregatzuständen haben die Erregungen sich "gesetzt ", es sind vabgekühlte "Zustände, in denen die Vernunft waltet oder doch $\mathrm{zu}$ walten meint. Dadurch ist keineswegs ausgeschlossen, daß der Affekt auch darin sich geltend mache. Eine feste "Uberzeugung " und entschiedene Meinung, die etwa dem Denkenden als schlechthin selbstverständlich erscheint, wird oft "sich auf keinen Streit einlassen « und etwa über entgegengerichtete Meinungen als Torheit und Aberglauben lächeln; sie richtet damit zugleich über sie und verurteilt sie. Das ist auch dem Wesen der Offentlichen Meinung, wie es sich in ihrer Festigkeit zu erkennen gibt, gemä $B$. Sie ist erhaben über den Streit des Tages und bleibt als die gemeinsame Überzeugung der "Intellektuellen « - der Gelehrtenrepublik - oft in dessen Hintergrunde wirksam. Oft stellt sie sich verneinend den herrschenden Meinungen des Augenblicks entgegen, aber sie ist auch immer in Gefahr, von diesen fortgerissen zu werden. Alsbald wird auch die Leidenschaft sich ihrer bemächtigen, wenn wir auch diese nur der Mehrzahl von Individuen, die gerade Träger der Offentlichen Meinung sind, zuschreiben, und die feste Offentliche Meinung selber, von ihnen unabhängig, als freie Vernunft und objektive Wahrheit über den Dingen schwebend denken, die sich dann etwa auf einen engeren Kreis von Subjekten zurückzieht, die unerschüttert durch den Sturm als Piloten auf dem Schiffe stehen und von ihren eigenen Gedanken, ihrem Vorsatz und Ziel tiefer bewegt werden als von aller äußeren Umgebung. In diesem Sinne bleibt die echte Offentliche Meinung als die vernünftige "Weltanschauung « über den Parteien und ihrem vielfältigen $Z_{\text {weck. Die }}$ Offentliche Meinung des Tages bleibt immer unter dem Einflusse der festen und der flüssigen Öfentlichen Meinung, wenn diese Abhängigkeit auch oft verdunkelt wird, ja den Widerspruch und Gegensatz nicht ausschließt. So ist gemäß den Idcen, die in der festen oder der flïssigen Offentlichen Meinung von Ordnung, Recht, Moral sich ausgeprägt finden, auch die luftartige Offentliche Meinung, 9. grundsätzlich für Eirhaltung dieser sozialen Willensmächte, wenn sie auch oft deren Wesen nur mangelháft erkennt, und sich leicht durch gegenwärtige Affekte wider sie erregen läßt, vielleicht ohne die Tragweite der 
gerade in ihr vorwaltenden Gedanken $z \mathfrak{u}$ ahnen. Insbesondere ist nach unseren Begriffen - die Moral das eigentliche Gebiet der Offentlichen Meinung, worin sie auch in ihren diffusen Formen fortwährend sich bewegt. Sie wird immer ihré Verbeugungen vor der Moral machen, wenn sie auch oft den Verbeugungen ähnlich sehen, wodurch das heuchelnde Laster vor der Tugend sich angenehm machen will; und wenn auch ihre Ansicht des Moralischen immer durch das Interesse - das gemeinsame Interesse, das Parteiinteresse, oder für "die Offentliche Meinung das öffentliche oder nationale Interesse, endlich etwa ein Menschheitinteresse - gefärbt und oft verfälscht wird. Die Feldzeichen der Moral kann sie in ihren Kämpfen nicht entbehren und sie ergreift sie, wo immer sie ihr am Wege liegen. Sie liegen aber am Wege als "Schlagworte" und so ist es ro. die Verwendung von Schlagworten, wodurch die Offentliche Meinung des Tages sich kennzeichnet. „Die Mutter des Schlagworts ist immer und immer wieder die Leidenschaft, der Kampf und die Entzweiung der Geister. Man prïfe Worte (ich würde sagen "Wörter «) wie Freisinn, Fortschritt, Kleiner Mann, Proletarier, Preßfreiheit, Weltpolitik, Revanche, Kubismus oder Naturalismus, sie alle sind oder waren umtobt von Streit und $Z$ wist. Jedes von ihnen wird zu einer Art Geßlerhut, den die vordringende Partei als Symbol ihrer Macht aufrichtet. Wie der Eroberer auf den Zinnen der erkämpften Festung zum Zeichen des Erfolges seine Fahne hißt, so sind auch Schlagworte nichts anderes als Standarten jener Gedankenmächte, die eben an Gelände gewonnen haben $\left.{ }^{1}\right) .{ }^{\text {" }}$

II. Wenn es demnach zunächst die Partei ist, die das Schlagwort ergreift, es weiter trägt und unter seinem Zeichen kämpft, auch oft ihre Siege erringt, so zeigt sich hier, wie in vielen Beziehungen, das Publikum, Subjekt der Offentlichen Meinung, als eine verallgemeinerte Partei, insbesondere als die siegreich gewordene Partei. Da sind es nun offenbar gewisse Ansichten der Ordnung, des Rechtes, der Moral, die sich in Konvention, in Gesetzgebung, und endlich entscheidend in Offentlicher Meinung durchsetzen und alsdann normgebend werden, so daß sie selber als Normen sich geltend machen können. Sie kristallisieren sich in Schlagwörtern, aber daraus folgt nicht, daß sie nicht mit lauterer und starker Überzeugung für wahr gehalten werden, daß nicht eine wahre Offentliche Meinung für ihre Gegenstände sich ausgebildet hat und eine unwiderstehliche Macht geworden ist. Sie mußten sich verbreiten, sie mußten ausgebreitet werden. $\mathrm{Ob}$ ihre Propheten und Verkünder in bewußter Weise eigene

1) WILHELM BAUER, ,Das Schlagwort als sozialpsyschische und geistesgeschichtliche Erscheinung" (Histor. Zeitschr., 3 F. 26. Bd.). Eine durchdachte Studie. S. ob. Seite 62. 
Interessen, Klasseninteressen, Sekteninteressen verfolgten oder nicht, ist für den Erfolg nicht von wesentlicher Bedeutung. Auch das Schlagwort kann in gutem Glauben angewandt und um seiner selbst, seiner Bedeutung willen geschätzt werden, so nahe auch die Versuchung liegen mag, es als bloßes Gerät zur Erzielung bestimmter Wirkungen zu gebrauchen. Daß der Redner weiß: es zündet, beweist nicht gegen seine eigene UUberzeugung von dem Wert und der Richtigkeit darin enthaltener Idee. Vielleicht verfährt er in unbesonnener, leichtfertiger Weise, wenn er töricht auf die Gutheit der Menge baut und sich verstockt gegen die Erkenntnis ihrer wirklichen Beschaffenheit. Sein Glaube kann gleichwohl einer religiösen Ưberzeugung gleichartig und gleichwertig sein. Darum ist es so oft unrichtig und durch Vorurteile eingegeben, wenn den Volksführern als Demagogen zur Last gelegt wird, daß sie gewissenlos die Menge aufreizen und mit Schlagwörtern um sich werfen. Es kann allerdings, und wird sehr oft, der gewissenlose Agitator, der nur das Seine sucht, oder nur bestellte und bezahlte Arbeit leistet, also im Dienste anderer redet und arbeitet, viel größere Erfolge erzielen als der ehrliche Enthusiast und Schwärmer. Aus historischer Ferne, daher in objektiver Gestalt angesehen, sind aber die einen wie die anderen Erscheinungsformen der Ausbreitung einer Idee, eines Glaubens, einer Meinung, zufällig und gleichgültig. $D a ß$ sie sich ausbreiten ist es, was mit soziologischer Notwendigkeit sich erfüllt. Und diese Erfüllung ist in letzter Linie immer die Folge der Ausbreitung einer Kraft, der Veränderung eines Kräfteverhältnisses, einer Wandlung in den Zuständen sozialer Macht. Sehr deutlich ist dies an den Schlagwörtern, die den Gedankengehalt des rationalen Naturrechts, also der Úberzeugung des Jahrhunderts der Aufklärung verkörperten und in der französischen Revolution siegreich wurden. "Freiheit und Gleichheit hört man schallen." Der Minister NECKER, ein wohlmeinender Reformator aus der Schule der aufgeklärten Autokratie, schrieb darüber im Jahre I792, als ob nur selbstsüchtige Absichten der "Drahtzieher « zugrunde gelegen hätten. Er sagt, es sei nicht schwer, das öffentliche Urteil zu lenken, wenigstens nicht so schwer wie eine gute Staatsverfassung zu machen. Der Nationalversammlung oder ihren Leitern sei in der Tat die Erfüllung der ersten Aufgabe besser als die der anderen gelungen. „Besonders die Meinung des Volkes ist leicht zu unterjochen: es genügt, die kleine Zahl seiner vorherrschenden Leidenschaften zu kennen, und durch einen wirklichen Knoten, oder durch Illusionen, damit die Vorstellungen zu verbinden, womit man sie erfüllen will. Die Menschen, die einer höheren Klasse angehören, lassen sich oft auf dieselbe Weise leiten, so sehr fühlen sie sich geschmeichelt, die unwillkürlichen 
Erregungen ihrer Seele mit den schönen Namen des Gedankens, der Reflexion, der Úberlegung geehrt zu sehen. Darum hieß es auf kluge Art der Verfassung dienen, daß man dies Werk an 2 Prinzipien, an 2 Wörter anknüpfte: die Gleichheit und die Freiheit"1). - In der Sprache selbst prägt sich die Offentliche Meinung deutlich aus. Nicht nur der Inhalt, sondern der Klang der Worte drückt oft die Affekte aus, die sich an die Vorstellungen heften, denen diese Worte dienen. So ist ein Wort wie Freiheit seines Zaubers immer sicher, so sind Wörter wie Wucher, Verbrechen, Mord und die entsprechenden Personenbezeichnungen, so in jüngster Zeit Kriegsgewinnler und Schieber, mit einem Makel behaftet, den die Offentliche Meinung immer von neuem in Aussprüchen, Anekdoten, Satiren ausbreitet.

I2. Die große Schwäche des Klebens an Wörtern haftet allerdings nicht nur der Öffentlichen Meinung des Tages, sondern auch der dauernden und festen, wie dem vulgären Denken überhaupt, an. Schnell fertig wie die "Jugend « ist sie mit dem Wort, und je mehr sie sich darauf verbissen hat, um so schwerer belehrbar. Die Bildung, die Intellektualität, tritt allerdings in ihr zutage, aber eine mittelmäßige, die des durchschnittlichen Urteils. Dies Niveau ist natürlich sehr verschieden in verschiedenen Kreisen, Gruppen, Nationen. Die Deutschen rühmen sich mit gutem Grunde einer verhältnismäßig hohen durchschnittlichen Bildung. Aber diese Bildung ist nicht auch politische Bildung. Die politische Bildung ist schwach, weil das politische Interesse $z u$ wenig entwickelt ist. Auch Männer von starker allgemeiner Bildung durchschauen selten die Dunstwolke ihrer Partei. Die nationale Gesinnung ist lebhaft genug, aber die Einsicht in das, was durch das gemeinsame nationale Interesse gefordert wird, ist matt, und die Verwechslung des nationalen Interesses mit dem Parteioder eigentlicher, dem Klasseninteresse, gerade bei denen, die jenes auf ihr Banner schreiben, alltäglich. „Tief und ernstlich denkende Menschen haben gegen das Publikum einen schweren Stand" - das gilt in besonderer Weise für die Politik, wo das Publikum, ob mit

1) Du pouvoir executif dans les grands Etats II, 266. WILHELM BAUER, der in seinem schätzenswerten gclehrten Buche ,Die öffentliche Meinung und ihre geschichtlichen Grundlagen", S. I2I, den ersten Satz dieser NECKERschen Auslassung zitiert, hat sie nicht richtig verstanden. Er will damit belegen, daß das Wesen und die Wirkungsweise der Offentlichen Meinung damals im großen und ganzen erkannt worden war. Aber NeCKER unterscheidet offenbar die Öfentliche Meinung, die er auch sonst den „Menschen, die einer höheren Klasse angehören", zuschreibt und immer feierlich mit ihrem Namen O. P. nennt, von der "Opinion du Peuple", schon durch die Majuskel (die das Zitat BAUERs nicht wiedergibt), deutet er an, da $\beta$ er hier (als Peuple) die große Menge, das Volk im Unterschiede von der Bourgeoisie meint; welche Entgegensetzung eben damals reif geworden war. NECKER versteht immer als Opinion publique die Meinungen der Bourgeoisie. 
sich einig oder nicht, jedenfalls mit der größten Zuversicht und Heftigkeit seine oft kenntnislosen und törichten Urteile oder Vorurteile dem Denkenden entgegenhält, entgegenschleudert. So hat dieser oft genug Grund, über die Dummheit der Offentlichen Meinung sich zu beschweren und sich zu empören. Die Offentliche Meinung ist dumm, wenn sie nach dem Schein, wenn auf Grund oberflächlicher Kenntnis, einer tendenziös ausgestreuten oder geradeswegs gefälschten Nachricht, aufGrund vorgefaßter, schlecht begründeterMeinungen, wenn das Publikum gemäß dem Schlendrian seiner gewohnten Vorstellungen und Einbildungen sich ein Urteil anmaßt über Dinge und Fragen, die ein scharfes Nachdenken, sorgfältige Prüfung, Kenntnis verborgener Tatsachen und Beweggründe, die überhaupt einen überdurchschnittlichen Verstand erfordern, um auch nur verstanden $z u$ werden.

14. (Gefühlspolitik der Öffentlichen Meinung.) So bleibt die wirkliche Öfentliche Meinung als Durchschnittsmeinung vieler, wenn auch zumeist leidlich gebildeter und gut unterrichteter Menschen - ein Durchschnitt, woran die Frauen nur geringen Anteil haben in politischen Dingen und Fragen, wo sie am entschiedensten als soziale Macht hervortritt, am meisten hinter ihrem Begriff, der ein wohlerwogenes Urteil verlangt, zurück. Gefühlspolitik ist der Tummelplatz der Offentlichen Meinung. Diese kann oft wundervoll mit einer planmäßigen Verstandespolitik zusammentreffen. Sie kann ihr die wertvolle Unterstuitzung der Begeisterung, ja der Leidenschaft, die Ingredienzen der sittlichen Entrüstung oder der moralischen Uberzeugung, die dem Politiker als solchem vielleicht gänzlich fremd sind, verleihen, die aber der Politiker für sich verwenden kann, um seinen Handlungen eine Rechtfertigung und Weihe zu geben, ja ihnen den Schimmer der Tugend und etwa auch den Glanz einer religiösen Sendung zu verleihen. Folglich gehört es zur staatsmännischen Kunst, die Offentliche Meinung in diesem Sinne zu lenken oder ihr, wenn sie schon die nützliche Richtung gewonnen hat, gehörigen Nachdruck und Nachschub zu geben, sie zu fördern und zu erheben und vorallem - zu verbreiten. Es ist bekannt, wie die Politik und Diplomatie Großbritanniens es versteht, das Instrument der Offentlichen Meinung zu spielen und ihm jenen religiös-moralischen "Gesang \& zu entlocken, der unter diesem Namen (cant) eine seltsame Berühmtheit erworben hat, um so merkwürdiger, da diese 'Töne dem I Lande ohne Musik" entstammen. Dem klugen Politiker, der "britische Interessen "vertritt, klingen auch die schrillen Mißtöne angenehm im Ohr, wenn sie nur mit diesen Interessen harmonieren und wenn sie nur fortissimo gesungen werden. Und doch ist gerade die britische Offentliche Meinung verhältnismäBigstark mitdemBewußtsein 
des politischen Nutzens, eben der britischen Interessen erfüllt, sie wird nicht nur getäuscht, sie täuscht auch sich selber, wenn sie den unedlen Bestrebungen der Eroberungspolitik edle Beweggründe unterschiebt. Das ist freilich auch nicht etwas dem Engländer Eigentümliches, wenngleich er es besser versteht als andere: „la politique cache toujours ses buts égoistes sous le masque des actions généreuses" (DAscovicI, La question du Bosphore, p. 243). Die Offentliche Meinung ist allerdings und der Regel nach moralischer als die Politik, und wenn jene ganz ihre eigenen Wege geht, so mag sie auch jezuweilen einer niederträchtigen Politik, die unter Umständen (und oft, wenn sie glaubt ganz besonders klug zu sein), sehr schädliche Wirkungen hat, Zügel anlegen, ja ihr Steine des Anstoßes in den Weg legen, über die sie nicht hinwegkommt. In der Regel aber gibt sie dem Schlagwort, der berauschenden Phrase besinnungslos sich hin und gefällt sich in der Illusion, als wären die vorgegebenen Beweggründe die wirklichen Beweggründe des Handelns. Treffend sagt W. Schu ÜTER (Verf. des "Deutschen Tatdenkens «): „Die Masse bringt von sich aus mit ihrer Uberproduktion von Gesinnung und ihrer Unterproduktion von Sachlichkeit keinen durchgreifenden Führungsplan auf" (Gewissen, 8. VIII. I92I). Für die "Masse" gilt hier das Wort Macchiavelis (an den dort angeknüpft wird): „Nel mondo non è se non volgo").

Die Politik will und soll vor allem klug sein - Klugheit ist geistige Weitsichtigkeit, Voraussehen kommender Ereignisse und ihrer Wirkungen, der Wirkungen eigenen Handelns und Unterlassens, der Gegenzüge gegen die eigenen Schachzüge. Der kluge Staatsmann will das Interesse seines Landes wahrnehmen, will seinen Staat vor Schaden bewahren und ihm Vorteile erwerben, seine Lage verbessern und sichern. Je entschlossener er dieses Ziel ins Auge faßt, um so mehr wird er zu Schlußfolgerungen über das, was ersprießlich, ja notwendig ist, gelangen, die von der großen Menge eines gebildeten Publikums nicht erkannt und nicht verstanden werden, er wird also gegen den Strom der Offentlichen Meinung und ihrer Gefühlspolitik kämpfen müssen. Eine streng verstandesmäßige, von wissenschaftlichem Denken geleitete Staatskunst wird der immer unreifen Offentlichen Meinung in auswärtigen Angelegenheiten immer als schwächlich, ängstlich, ja zuweilen als nachgiebig und feige erscheinen; eine solche Staatskunst wird bereit sein, um wichtiger Ziele willen, zumal wenn es sich um die Selbsterhaltung, um die Lebensmöglichkeiten des Vaterlandes handelt, große Opfer zu bringen, ja diese Willigkeit ist geradezu charakteristisch für einen höchst bewußten Kürwillen, der den endlichen Vorteil und Gewinn rücksichtslos zu seinem Ziele setzt. Solchen Opfern wird sich, zumal wenn die un- 
mittelbare Notwendigkeit nicht in die Augen fällt, die Offentliche Meinung eines Landes regelmäßig widersetzen, sie wird dagegen protestieren, als mit der "Ehre "des Reiches unvereinbar. Man stelle sich vor, ein deutscher Staatsmann hätte in diesem Sinne, um Frankreich $\mathrm{zu}$ versöhnen oder wenigstens seinen kriegerischen Willen $\mathbf{z u}$ parieren und das Bündnis mit dem Zarismus zu brechen, den Verzicht auf die Reichslande oder auch nur auf die französisch sprechenden Teile von Lothringen angeregt und angebahnt! Die Annexion selber hat bekanntlich BISMARCK nicht in dem Umfange, wie sie wirklich wurde, gewollt; er dürfte sich mit ähnlichen Erwägungen getragen haben, wie I 866 in Nikolsburg. Er fühlte sich genötigt, den strategischen Gründen nachzugeben, er hätte aber auch einen sehr schweren Stand gegen die Offentliche Meinung gehabt, die - mit guten historisch-moralischen Gründen - die Wiedergewinnung der in den traurigsten Zeiten verlorenen deutschen Lande stürmisch und dringend verlangte, wie jeder, der jene Zeit denkend durchlebt hat, sich dessen lebhafter erinnern wird, als es etwa der Publizistik des Jahres zu entnehmen wäre. Der Staatsmann ist, wie jeder andere Geschäftsmann, geneigt, über moralische Empfindungen sich hinwegzusetzen, wie es die unbedingte Zielbewußtheit gebietet; wie schwer oder leicht es ihm werden möge, die Widerstände seiner eigenen Seele zu besiegen, schwerer wird in der Regel die Uberwindung der objektiven Macht sein, die in Gestalt der Offentlichen Meinung, zumal wenn diese mit dem allgemeinen Volksempfinden zusammenfällt, ihm gegenüberstehen $\left.\operatorname{mag}^{1}\right)$. Er muß versuchen, diesen Widerstand aufzuweichen und zu biegen - im Sinne der Zweckmäßigkeit die Offentliche Meinung bearbeiten, sie zu politisieren versuchen; wenn aber dies im gegebenen Falle unter Umständen höchst nützlich ist, so kann es doch durch die Maxime, die ihm zugrunde liegt - die Schwächung moralischer Gefühle - so schädlich wirken, daß der Nutzen mehr als wettgemacht wird. Vollends gilt dies, wenn der Entschlu $B$ gefaßt würde, solchen moralischen Widerstand zu brechen oder ihn als gleichgültig zu behandeln, seiner zu spotten; allzuoft

1) G. MAIER in seiner Ethischen Umschau (Mai 1915) betont, wie sehr durch die Offentliche Meinung, „,welche sich mit Hilfe der modernen Verkehrsmittel ungeahnt rasch und plötzlich verbreiten läßt", die Staatsmänner heute beeinflußt werden. Vielleicht erkläre sich daraus die Tatsache, $\mathrm{da} B$ der Beruf des Staatsmannes ein weniger bestimmender geworden sei und daß geniale Staatsmänner seltener geworden. Die Mitbestimmung „der Völker" enthalte eine ungeheure Gefahr, weil sie eine mehr oder weniger zufällige, anarchische sei, an meisten bestimmbar durch die Presse, deren fortgesetzter Suggestion sogar der Deukende und Gebildete nicht zu widerstehen vermöge. Er knüpft daran Vorschläge, für eine Reform der Presse durch ihre eigene Berufsorganisation. In gleichem Sinne sind von manchen Seiten neucrdings Bestrebungen rege geworden. 
wird sich dies bitterlich rächen und diese Gefahr muß die Staatsklugheit im Auge behalten, auch wenn sie selber solche moralische Bedenken nicht achtet, ja sie verlachen zu dürfen meint. In der Regel wird die Gefühlspolitik derOffentlichen Meinung nicht wisse n, was sie will; sie ist oft erfüllt von Widersprüchen, ihre Logik ist weibliche Logik. So ist sie etwa dem Kriege abgeneigt, mit allem natürlichen und sittlichen Widerwillen, den dies Schreckgespenst erregen kann; aber mit aller Entschiedenheit pocht sie auf die nationale Ehre, die Nachgiebigkeit verbiete, vollends empört sie sich gegen die Idee, etwa durch Landabtretungen die Gunst des Feindes zu "erkaufen «; als schmählichen Handel wird sie diese Zumutung von sich weisen. Ein klassisches Beispiel des Verhängnisses, das an solcher Politik hängt, liegt auch vor in der Weigerung der Magyaren, Rumänien diejenigen Einräumungen zu machen, die geeignet gewesen wären, aus dem feindseligen Nachbar einen Bundesgenossen zu machen; noch nach Ausbruch des Weltkrieges wäre es an der Zeit gewesen, als nach dem Tode des Königs CAROL sogar die Neutralität nicht mehr sicher war. Graf CZERNIN hat als Gesandter in Ubereinstimmung mit dem deutschen Gesandten die Ansicht vertreten, daß Ungarn ein territoriales Opfer bringen solle, um Rumäniens Eingreifen zu ermöglichen. Ungarn wies den Gedanken von der Schwelle seines Hauses: „,wer immer es versuchen sollte, auch nur einen Quadratmeter ungarischen Bodens zu nehmen, auf den wird geschossen", schrieb STEFan Tisza, der als Staatsmann nicht zu den geringsten der Profession gehörte. „Aber dieser Widerstand war keine Spezialität TrszAs, denn wer immer von den ungarischen Politikern an der Spitze des Kabinetts gestanden wäre, hätte denselben Standpunkt verfochten" (CZERNIN, Im Weltkriege, S. I40). Denn jeder hätte unter dem Hochdruck der Offentlichen Meinung gestanden. Mit überlegener Einsicht hätte ein Staatsmann rücksichtslosen Willen und Willens kraft verbinden müssen, um zu tun, was unzweifelhaft politisch richtig war, und die Gefahr des nationalen Unwillens auf sich nehmen müssen. Jede Politik enthält freilich, wie jeder Handel, ein aleatorisches Moment; ist und bedeutet ein Stück Spekulation. Auch der besonnenste Staatsmann muß unter Umständen etwas wagen, er muß vor allem wagen derOffentlichen Meinung zu trotzen und sie eines besseren zu belehren. Sie ist immer belehrbar - durch den Erfolg. Der Erfolg blendet sie und läßt sie mit großer Geschwindigkeit umlernen und vergessen. Sie bekundet dadurch ihre Oberflächlichkeit, und daß sie vom Durchschnittsmenschen abstammt. Mit dem Umlernen ist regelmäßig ein Vergessen verbunden; sie weiß dann nicht mehr, wie sie früher gedacht und geurteilt hat. Individuen bekennen dies zuweilen offen und öffentlich, 
ja sie rühmen sich wohl ihrer gewonnenen besseren Einsicht, wie der Fromme stolz ist auf seine Bekehrung. Die Offentliche Meinung will immer weise gewesen sein und es auch heute sein, sie verleugnet daher in der Regel ihren früheren wStandpunkt «; das ist die Haltung des Philisters, am Ende "will es niemand gewesen sein «. In lebhaften Farben schildert den Umschwung der politischen Stimmung beim gebildeten Publikum Rhein-Hessens Franz STAudinger (Kulturgrundlagen der Politik I, S. 29): es habe I866 eine gegen Preußen geradezu fanatische feindselige Stimmung geherrscht. „In der Stadt (Darmstadt) war alles Wut gegen Preußen und Bismarck.“ - „Plötzlich aber hieß es: das 8. Armeekorps zieht sich zurück, die Preußen kommen." „Und dann hieß es: es gibt Frieden. Die Gymnasiasten kehrten nach der Hauptstadt zurück. Und war die Welt auf den Kopf gestellt? BisMARCK war nun auf einmal ein großer Mann, kein Lumpenhund mehr. Alles bewunderte ihn ..." „... in vielen, sehr vielen Fällen waren es ganz dieselben Menschen, die vorher gegen Preußen gewütet hatten." STAUdINGER gibt das Rätsel auf, warum in diesem Falle die Menschen den Erfolg anbeteten und in so vielen anderen Fällen gerade durch den Errfolg des Gegners um so hartnäckiger an ihre alte Fahne geschmiedet werden. Er hat gewiß recht, daß die Lösung nicht einfach ist, nicht in einer patriotischen oder einer demokratischen Phrase erledigt werden kann. Ein Stück der Lösung liegt in der Natur der Offentlichen Meinung, und zwar eben in dem, was sie vonVolksgefühl, Volksstimmung und Willen, die mehr oder weniger einen religiösen Charakter haben, unterscheidet; denn, sofern dieser wirksam ist, bringt er auch die Treue zur Geltung und hängt weniger von den zufälligen Erreignissen und Erfolgen des Tages ab. Die Öfentliche Meinung ist um so mehr geneigt, »den Mantel nach dem Winde zu hängen", je mehr sie sich von dem echten Volksgefühl unterscheidet.

\section{Ka pitel.}

\section{Allgemeine Inhalte der Öffentlichen Meinung in ihren neuzeitlichen Gestaltungen.}

Wir betrachten nunmehr in den 3 mit römischen Ziffern zu bezeichnenden Gebieten - dem sozialen und ökonomischen (I), dem politischen und rechtlichen (II), dem geistigen und sittlichen (III) - nacheinander

a) die feste

b) die flüssige

c) die luftartige

Offentliche Meinung in einigen charakteristischen Inhalten und Beispielen, mit gelegentlichen Bezügen auf einzelne Länder, umihre allgemeine moderne Gestaltung zu erkennen. 


\section{Erster Abschnitt. (I) Das soziale und ökonomische Gebiet.}

I. (I a: In der festen Öffentlichen Meinung.) Die Idee des sozialen Lebens, worauf die Offentliche Meinung sich am tiefsten festgelegt (fixiert) hat, ist die Idee der persönlichen Freiheit; sie macht diese als Ideal geltend. Dabei ist es zunächst das Wort, das sozusagen angebetet wird; die Vorstellungen, die mit dem Worte verknüpft sind, bleiben zumeist in der Schwebe. Aber das Schlag wort wirkt mit um so größerer Gewalt, je mannigfacher und je unbestimmter die daran hängenden Gedanken sind: "Freiheit, die ich meine* jeder "meint " und liebt die Art der Freiheit, deren er bedarf. Vor allem im Gegensatz zum Sklavenstande und dem Zustande des Gefangenen, sodann als die vielverzweigte Freiheit des Tuns und Lassens, also des Handelns: man will nicht behindert, nicht gehemmt sein in Verfolgung seiner $Z$ wecke, seines Glückes, und die Offentliche Meinung wünscht und gönnt diese Freiheit jedem Individuum als Glied »der "Gesellschaft, soweit als sie mit der Freiheit aller übrigen zusammen bestehen kann, gemäß der berühmten Formel KAN'rs. Demgemäß wäre der vollkommene soziale Zustand die allgemeine gleiche Freiheit, gehemmt ausschließlich durch die Gesellschaft, deren Wille als Recht den Staat zu seinem Träger hat, so daß es nur diese allge meinen Vorschriften in "Gesetzen "gibt, die eines jeden Freiheit binden, indem sie die ihm gelassene Freiheit schützen. Daraus fließt insbesondere die Forderung eines möglichst hohen Maßes von wirtschaftlicher Freiheit: Freiheit des Handelns im engeren Sinne und Freiheit der Arbeit; ferner die Freiheit der Verbindung zu beliebigen, nicht um der allgemeinen Freiheit willen verbotenen $Z$ wecken. Dieser Grundgedanke wird von der Offentlichen Meinung aller modernen Länder mehr oder weniger stark festgehalten, wenngleich er überall gewisse Einräumungen zu machen sich genötigt fand, und namentlich während des Weltkrieges in den kriegführenden und sogar in den neutralen Ländern seine Waffen strecken mußte; dies wurde doch allgemein als ein Notstand empfunden und gedacht, nach dessen Überwindung die Offentliche Meinung, wenngleich durch "sozialistische« Meinungen längst erschüttert, die Wiederherstellung der wirtschaftlichen Freiheit, insbesondere der Freiheit des Kaufens und Verkaufens, als dringende Forderung stellt. Die Handelsfreiheit soll wenigstens die Regel bleiben, wenn auch viele Ausnahmen zugelassen werden müssen. Am festesten steht dies Ideal noch in den Vereinigten Staaten von Amerika. Auch in England bleibt es, oder blieb doch noch bis vor $\mathrm{I}-2$ Jahrzehnten, auf dem Grunde der vorherrschenden Denkungsart. „Die politische Offentliche Meinung 
Englands hat es mit gewohnter Kunst verstanden, sich mit diesem Gang der Dinge (den Wirkungen des Freihandels auf die Landwirtschaft) abzufinden", K. OLDENBERG in ScHMOLLERS Jahrbuch XLIII, S. 876, wo dann darauf hingewiesen wird, wie diese Weisheit auf Deutschland abgefärbt habe; im ganzen sei - bis in die neueste Zeit - auch hier die Offentliche Meinung durchaus auf die englische Tonart gestimmt gewesen, bei unverkennbarem Einfluß englischer Lehrbüicher. Ich behaupte, daß auch ohne solche Einflüsse die öffentliche Aufmerksamkeit immer durch den Glanz der Großindustrie, die Vermehrung des Reichtums, die verbesserte Lebenshaltung der Arbeiterklasse, zu stark gefesselt wurde, als da $\beta$ die aufsteigenden Besorgnisse einzelner viel Gewicht hätten erhalten können. Letzten Endes stand und steht die Bevölkerungsfrage im Vordergrunde, wenn nicht des Denkens, so doch eines ahnenden Gefühles. Das Laisser faire hat drüben noch die Macht eines kaum bestrittenen Dogmas der Offentlichen Meinung, während es in den europäischen Staaten, namentlich in Frankreich und in England, die Häresie neben sich dulden muß und allmählich auf sich Einfluß gewinnen läßt, wenn auch das Dogma seine gleichsam festliche Geltung behält. Nur in Deutschland - um von den übrigen Staaten Europas zu schweigen - hat es diese beinahe verloren, nachdem hier die wissenschaftliche Kritik am stärksten an seiner Zersetzung gearbeitet hat. Einen reinen Ausdruck findet es iiberall noch in der Lehre von der "Heiligkeit « des Eigentums, einen Ausdruck, an dem auch die religiöse Formel bemerkenswert ist. Die Offentliche Meinung hält das individuelle Eigentum und dessen grundsätzliche Unantastbarkeit durch den Staat für etwas schlechthin Natürliches und Notwendiges. So nennt Bryce an erster Stelle unter den 6 Lehrmeinungen, auf die man zu stoßen pflege, wenn man sozusagen einen Schacht abteufe im a merika nische $\mathrm{n} G e$ iste, die, da $B$ gewisse Rechte des Menschen, zum Beispiel sein Recht, zu genießen, was er erworben hat, ursprünglich und heilig seien; und an letzter, da $B$ die Funktionen der Regierungen auf ein Mindestma $\beta$ beschränkt werden sollten : ,,je weniger Regierung, um so besser". Für diesen Grundsatz des Gehenlassens ist, nach BRYCE, der Grund des Gefühles ungemein stark in Amerika, ,wurzelnd in Charakter und Gewohnheiten der Rasse, und sich zu ergeben scheinend aus jener Behauptung individueller Freiheit, die in solchen ehrwürdigen (revered) Urkunden niedergelegt wurde, wie in der Erklärung der Unabhängigkeit und in den älteren Verfassungen der Einzelstaaten". Mehr als die Urkunden dürfte für diesen Individualismus die Tatsache wirken, da $B$ in dem weiträumigen Koloniallande Menschen aus allen Gegenden und Winkeln des Erdballes zusammenlaufen, von denen jeder nur sein Glück zu suchen 
und zu machen beflissen ist. Fremde, die mit Fremden sich zu vertragen und zusammenzuleben angewiesen sind - der Charakter des heimatlosen Wandervolkes, der mehr und mehr auch den alten Ländern sich mitteilt, ist den Bewohnern der Vereinigten Staaten von Anfang an in hohem Grade eigen gewesen: die "Freiheit « ist ihnen Lebensbedingung und bleibt mit der Freiheit der Wildnis oder der Wüste innerlich verwandt.

Anders als mit der Freiheit verhält es sich mit der, wie GoETHE einmal sie auszeichnet, "öblichen "Gleichheit. Sie gehört zwar in der französischen Formel mit jener zusammen, auch der Amerikaner bekennt sich theoretisch zur Gleichheit alles dessen, was Menschenantlitz trägt. Während aber Freiheit mit Enthusiasmus und Liebe verkündet wird, so geschieht die Hinzufügung der Gleichheit mehr pflichtmäßig, nicht ohne inneres Widerstreben. Denn die Offentliche Meinung ist gegen Verwirklichung der Gleichheit im sozialen Leben ebenso eingenommen, wie sie deren Möglichkeit verneint. Jene (die Verwirklichung) trägt den Geruch kommunistischer Lehren an sich, die als falsch und unheilvoll abgelehnt werden, gegen diese (die Möglichkeit) richtet sich die Hinweisung auf die offenbare Verschiedenheit der natürlichen Anlagen in Fähigkeiten und Neigungen, die noch schärfer als bei Individuen, bei verschiedenen Volksstämmen, vollends bei ganzen Völkern und gar Rassen hervortrete. Dieselbe gesellschaftliche Entwicklung, die das »Ideal «der Gleichheit bei einer großen Kolonialnation am höchsten erblïhen lie $B$, bewirkte, $\mathrm{da} B$ in eben dieser Nation die Verschiedenheit des Vermögens und der Lebenshaltung in die äußersten Dimensionen gesteigert wurde, und, noch ehe dies geschah, ein Zusammenleben verschiedener Rassen, die sogar durch die Hautfarbe voneinander abstechen, notwendig erschien, von denen die eine zunächst mehr als ein Jahrhundert lang im Stande der persönlichen Unfreiheit (Sklaverei) gehalten wurde, um nach deren Aufhebung um so bitterer die persönliche Ungleich heit zunächst in sozialer, bald auch in politischer Beziehung kosten zu müssen. Die Offentliche Meinung Amerikas, die von allen Kennern als besonders machtvoll dargestellt wird, nimmt hieran nicht nur keinen AnstoB, sondern verlangt sie vielmehr und mißbilligt stark die gelegentlich vorkommenden Ausnahmen, wenn auch in Einzelheiten das Urteil anders in den südlichen als in den Nordstaaten sich gestaltet. Dennoch hat die "Gleichheit « in den Vereinigten Staaten, und ebenso in den übrigen Ländern moderner Kultur, eine Bedeutung, die von der Offentlichen Meinung anerkannt, ja gefördert wird. Zunächst ist sie ein anderer Ausdruck für die allgemeine persönliche Freiheit: in diesem Sinne ist sie überall, zuletzt in den vom Geiste der neuzeitlichen Bildung am längsten unberührt 
gebliebenen Ländern, in Rußland und eben in Amerika, durchgedrungen. Ferner aber will sic den Sinn haben, da $B$ der Vorzug eines angeborenen Standes, erblicher Würde und darauf sich berufende Ansprüche schlechthin geleugnet werden. Die Vereinigten Staaten, und ebenso die anderen Kolonialländer, kennen weder einen hohen noch einen niederen, weder einen persönlichen noch einen erblichen "Adel «, und die Offentliche Meinung dieser Länder würde dem Versuch, solche Einrichtung zu schaffen, den Widerstand der Mißbilligung und des Gelächters entgegensetzen. Dies ist Ergebnis des in Europa Jahrhunderte hindurch fortgesetzten Klassenkampfes zwischen dem alten Herrenstande und dem sich verdichtenden Nationalbewußtsein des Bürgerstandes, insbesondere des Großbürgertums (der »Bourgeoisie»), das sich zum neuen Herrenstand entwickelte. Die Offentliche Meinung der europäischen Haupt-Kulturstaaten duldet noch den Adel, strebt aber nach Ausgleichung mit ihm, und verwirft alle Ansprüche, die er auf besondere Vorzüge als geschlossener Stand geltend macht; sie besteht darauf, daß nur Verdienst und Fähigkeit, nicht Geburt und angeborener Rang entscheidende Geltung haben dürfe. Fast alles in diesem Gebiete greift in das Gebiet des Rechtes und der Politik hinüber, wird daher unter (II) wiederum erörtert. Nur in der "Geselligkeit «, und der Gesellschaft ihres Sinnes, gönnt die Öfentliche Meinung dem Adel noch seine hervorragende Stellung, zumal dem hohen Adel und schenkt ihm ein persönliches Interesse, woran besonders die Frauen auch der bürgerlichen Schichten teilnehmen. Dies Interesse gilt dem Glanz der Familien, und dieser ist wesentlich bedingt durch Reichtum, besonders durch großes Grundeigentum, sammelt sich aber melhr und mehr auf den Reichtum schlechthin, je mehr dieser in einzelnen Personen sich steigert; und so kann es auch gleichsam auf den Adel werzichten ", wie in den Vereinigten Staaten und sonst in Ländern modernster Gesellschaft. Wenn in Spanien der Adel noch eine Verachtung der bürgerlichen Errwerbstätigkeit zur Schau trägt, so würde die Offentliche Meinung in anderen Ländern dies verurteilen, am ausgesprochensten gerade in England, wo die Bewunderung des Glanzes und gesellschaftlichen Ranges der adligen Familien am offensten zutage tritt. Ein Amerikaner sagt, er habe einige ganz vorzügliche Männer und Frauen in der englischen Aristokratie angetroffen, freilich ebenso vorzügliche unter den Großkaufleuten und Fabrikherren: ,ebenso echte Verfeinerung, mehr Rücksicht auf die Empfindungen anderer, und wenn nicht gerade ein Lord oder eine Lady des Weges kam, ebensoviel angeborene Würde“. „In Gegenwart der Aristokratie jedoch, fallen sie alle geistig auf ihre Hände und Kniee" (BADEAU, Aristocracy in England, I885, S. I53). In der Offentlichen Meinung Englands sind 
allerdings ein Lord und eine Lady so etwas wie höhere Wesen. BADEAU nennt das Kriechen des gemeinen Engländers vor einem Lord eines der Wunder unserer Zeit. Es gebe nichts, was ihm gleiche, bei irgendeiner zivilisierten Nation auf dem Erdball. „Weder der Bauer Frankreichs oder Spaniens, noch der gemeine Soldat Deutschlands, noch der Lazzaroni von Neapel, ja nicht einmal der befreite russische Leibeigene offenbart in Gegenwart eines gesellschaftlich Höheren jene UUberzeugung vom Dasein einer Kaste (derer, die "besser " seien als er selber), welche den gebildeten Briten der Mittelklasse bezeichnet." Es ist in der Tat etwas von religiöser Ehrfurcht im englischen Snobbism; die Offentliche Meinung innerlich entwickelterer Kulturen stellt sich kälter zu den angeborenen sozialen Unterschieden und fühlt sich beinahe verpflichtet, sie zu verneinen, wie es 1848 in den Anträgen auf "Abschaffung «des Adels in Deutschland und in Preußen hervortrat und auch in der neuen, noch (I9I9) fortwirkenden Revolution stark zur Geltung gelangt; wie denn die neue Verfassung vom II.VIII. I9I9 in ihrem Art. Io9 erklärt: „Adelsbezeichnungen gelten nur als Teil des Namens und dürfen nicht mehr verliehen werden" ein Satz, den die gegenwärtige Öfentliche Meinung, wenn auch vielleicht mit einem süßsauren Gesichte, nicht umhin kann, gutzuheißen, oder den sie wenigstens nicht geradeswegs abzulehnen wagt.

2. (I b: In der flüssigen Öffentlichen Meinung.) Einen bedeutenden Fall der flüssigen Offentlichen Meinung im Gebiete des allgemeinen sozialen und wirtschaftlichen Lebens sehe ich in Schätzung der "Arbeit «. Wenn noch SchrLLER allgemein »der Hände Fleiß als des Bürgers Ehre pries, während den König seine "Würde» ehre, so dauerte im I9. Jahrhundert dieser altbürgerliche Stolz gegenuiber dem "müßigen Junker und Pfaffen "zwar fort, er geht aber allmählich in eine Verherrlichung der bloßen kommerziellen und industriellen Erwerbstätigkeit über, die durch den Namen der Arbeit ausgezeichnet wird, während die eigentliche körperliche und Handarbeit ebenso herabgesetzt wurde, wie sie tatsächlich in der sozialen Stufenleiter durch die große Vermehrung einer lebenslänglichen Lohnarbeiterklasse sank. In jenem Sinne war es typisch, wenn GUSTAV FREYTAG, nach Anleitung von JULIAN SCHMIDT, im Roman das Volk bei seiner "Arbeit « aufsuchen wollte, nämlich im Kontor. Die Geringschätzung der Handarbeit trat um jene Zeit (I860) und noch lange nachher bald in dem herablassenden Bedauern zutage, womit von "Fabrikarbeitern " gesprochen wurde, bald darin, daß der gebildete Bürger sich lieber Brauereibesitzer als Bierbrauer, lieber Marchand Tailleur als Schneidermeister, lieber Schuhwarenfabrikant als Schuhmachermeister nannte, welche Neigung auch heute dauert, 
so $\mathrm{da} B$ selbst eine so wissenschaftliche Berufsarbeit wie die des Apothekers sich gern hinter dem "Apothekenbesitzer " versteckt. Indessen ist doch die Schätzung der gemeinen wie aller Arbeit während der letzten Jahrzehnte erheblich in FluB gekommen, und zwar ist sie "höher " geworden. $\mathrm{Zu}$ einem Teile hat dazu das neu erwachende Selbstbewußtsein des alten Handwerks, soweit es noch Charakter hat, gewirkt; weit stärker aber die eigentlich sogenannte Arbeiterbewegung, weil sie eben der herabgedrückten, aber zugleich emporkommenden Lohnarbeit Verbesserung ihrer Lage, politische Geltung und damit auch erhöhte Wertschätzung erzwang. Dafür werde auf die besondere Erörterung über die Offentliche Meinung und die soziale Frage hingewiesen.

Ein anderes Gebiet, worin die Flüssigkeit der Offentlichen Meinung sich beobachten läßt, ist die Frauenfrage und Frauenbewegung. Auch hier handelt es sich um ein Problem der Gleichheit und Ausgleichung. Die Arbeitsteil ung zwischen Mann und Frau ist ein uraltes Erbstück der Gesittung: die Frau nach innen gewandt, der Mann nach außen. Die häusliche Bestimmung und Beschränkung der Frau und des Mädchens ist durch Herkommen vorgeschrieben, durch Religion geheiligt. Die Offentliche Meinung stand noch vor 2 Menschenaltern fast durchaus unter diesem EinfluB und faßte sich in die Formel: "Die Frau gehört ins Haus «. Aber sie ist seitdem stark in FluB gekommen, unter dem Drucke der wirklichen und wirtschaftlichen Entwicklung. Ein weites Gebiet der Erwerbstätigkeit hat sie der Frau schon eingeräumt. Wir denken hier nicht zunächst an die Frau der Arbeiterklasse, sondern an die der "gebildeten "Schichten, die der Offentlichen Meinung so viel näher steht, wenn auch eine dünne Oberschicht in den alten Lebensformen und Ideen verharren kann. Die weibliche Berufswahl erscheint schon als etwas Normales, beinahe Notwendiges. Das Dichterwort, ,der Mann muß hinaus ins feindliche Leben", hat zwar noch vollere Geltung als ehemals gewonnen, aber in enger begrenzter Weise gilt es auch für die Frau: auch sie muß wirken und streben und pflanzen und schaffen, wenn sie auch noch selten am ,erlisten, erraffen", am "wetten und wagen, das Glück zu erjagen", unmittelbar teilnimmt. In den Vereinigten Staaten läßt die Offentliche Meinung zu, ja verlangt zuweilen, daß die Frau Rechtsanwalt und Richter werde; nirgends verwehrt sie ihr noch, ärztliche Tätigkeit aller Art auszuüben; und im allgemeinen ist das Frauen-Studium, das vor 30 Jahren noch als eine Freiheit galt, die allenfalls der von den Banden der Sitte sich befreienden Russin in der demokratischen Schweiz gegönnt ward, von allen Hochschulen zögernd zugelassen worden, - man 
kann sagen, daß sie dem Drängen der Offentlichen Meinung haben nachgeben müssen, die in diesem Stücke schon eine erhebliche Festigkeit gewonnen hat, wenngleich sie in bezug auf die Abgrenzung der weiblichen Berufe sich noch im Flusse befindet.

3. (Ic: In der luftartigen Öffentlichen Meinung.) Die Öfentliche Meinung des Tages, wie wir ihre luftartige Gestalt lieber nennen wollen, ist zum guten Teil durch ihre flüssige, mehr noch durch ihre feste Gestalt bedingt, und erscheint als deren Anwendung auf besondere Fälle und Gelegenheiten. Waren es im I8. Jahrhundert die Reste des Feudalismus, die Leibeigenschafts-, Hörigkeits-, Erbuntertänigkeits-Verhältnisse im eigenen Iande und der britische Sklavenhandel, worüber die Offentliche Meinung etwa Deutschlands und Frankreichs sich empörte, so blieb noch im I9. die Negersklaverei in Amerika, die Leibeigenschaft in Rußland, denen sie das Verlangen nach Befreiung entgegensetzte, und zwar im Bunde mit anderen Mächten erfolgreich; seitdem sind in dieser Beziehung nur einzelne Ausnahmen, wie der Sklavenhandel der Araber in Afrika, die Reste von Sklaverei in Südamerika und Westindien, als Gegenstände gelegentlichen Unwillens übrig geblieben. Dazu kommen aber, soweit sie in auffallenden Tatsachen offenbar werden, die mannigfachen Umgehungen des Verbots der Sklaverei, in denen der Europäer in den Kolonien einheimische oder eingeführte Arbeitskraft an Scholle und Frohnde zu fesseln sucht. So wirkte auf die Offentliche Meinung in England die Einschleppung indischer und chinesischer Arbeiter in die Goldgruben zu Transvaal, unter Kontrakten, die ihnen ein Mindestmaß persönlicher Freiheit ließen (,,indentured labour"). Empörender noch war die Aufdeckung der Kongo-Greuel und des Verfahrens der englischen Erwerbsgesellschaften in Putumayo (Peru) gegen die Indianer. - Als Kränkungen der sozialen Gleichheit werden in neuerer Zeit selten noch Uber= griffe des Adels gegen das Bürgertum, viel weniger solche des Adels und des Bürgertums gegen die Arbeiterklasse von der Offentlichen Meinung aufgefaßt; wohl aber die gelegentlich vorkommenden Ausschreitungen der Militärgewalt gegen "Zivilisten «, Äuerungen des in der Offentlichen Meinung nicht beliebten »Militarismus «. Solche traten in den letzten Jahren vor dem Weltkriege in auffallender Weise sowohl in Frankreich und in England als im Deutschen Reiche zutage. In Frankreich zuerst und vor allem der Fall DrEyfus. So lange als man glaubte, es handle sich um Verrat, den ein jüdischer Offizier zugunsten des verhaßten Feindesgeübt habe, stand die Offentliche Meinung zu der Verurteilung und grausamen Strafe. Nachdem aber enthüllt war, daß eine betrügerische Intrige der auf die Reste 
Aligemeine INhal,te usw. - Das Soziale und ÖKONomische Gebiet. 265

des alten Herrenstandes sich stützenden Militärpartei zugrunde lag, da schlug die Offentliche Meinung um, und zwar in so entschiedener Weise, daß die Bildung eines republikanisch-demokratischen Blocks die unmittelbare Folge war, der sich zur Trennung der Kirche vom Staate verband und eine antimilitaristische Politik einleitete. Dennoch blieben auch, nachdem DREyfus in wiederaufgenommenem Verfahren (I906) endlich freigesprochen war, neue grobe Ausschreitungen des Militarismus in Frankreich nicht aus. Im Jahre 1907 geschah eine aufständische Bewegung der Weinbauern in Montpellier, im Jahre IgII eine ebensolche in der Champagne. Beidemal fand die radikale Regierung, an deren Spitze Herr CLÉMENCEAU stand, sich veranlaßt, die Bewegungen durch Soldate n niederzuschlagen, und als in Südfrankreich diese teilweise meuterten und sich zu den Aufständischen hielten, ließ er die Meuternden durch Kürassiere niederreiten. In beiden Fällen stand die Offentliche Meinung diesem schneidigen Militarismus entgegen, da die Klagen und Beschwerden der Winzer als berechtigt anerkannt wurden. Anders war es freilich, als im Oktober I9Io der Ministerpräsident BRIAND gegen den Streik der Eisenbahnarbeiter sich anschickte, den gesamten Eisenbahndienst zu militarisieren: jeder Bedienstete der Eisenbahnen erhielt die Einberufung zu einer militärischen Ubung und wurde also der militärischen Gerichtsbarkeit unterstellt, so daß Enthaltung von der Arbeit militärische Gehorsamsverweigerung wurde. Diesmal billigte die Offentliche Meinung Frankreichs diese sehr weitgehende Betätigung eines politischen Militarismus - es handelte sich um ein dringendes Verkehrsinteresse, und der Militarismus richtete sich gegen Proletarier! - In England brachte das Jahr des Weltkrieges selber, unmittelbar vor dessen Ausbruch, ein Muster des allerschwersten Militarismus als Ungehorsam der kriegerischen Macht gegen die bürgerliche Regierung. In der irischen Provinz Ulster war ein freiwilliges und gesetzwidriges Heer entstanden, das auch die ausdrückliche Bestimmung sich gab, einem bevorstehenden unwillkommenen Gesetz Widerstand zu leisten. Natïrlich beschloß die Regierung, dieser Insurrektion durch eine militärisch-maritime Kraftentfaltung zu begegnen; sie tat dies ihrer von selbst verständlichen Pflicht gemäB, die öffentliche Ruhe aufrecht zu erhalten (während es sich in Frankreich um rein bürgerliche Bewegungen handelte, denen gegenüber die bürgerliche Polizeigewalt zunächst hätte genügen müssen, wenn man zugleich sich bemüht hätte, die Ursachen der Unzufriedenheiten abzustellen!). Den in Irland stationierten Landstreitkräften hatte der Kricgsminister besondere und eingehende Befehle erteilt. Alles war vorbereitet, 
um die sämtlichen 20-25000 Mann, die in Irland standen, in Ulster zu konzentrieren und nötigenfalls noch eine Division aus England hinüberzuwerfen. Es handelte sich um eine militärische Operation großen Stiles. Und siehe da - „die Auflehnung des Heeres wurde zur Wirklichkeit", so drückte die große Zeitschrift Quarterly Review sich aus. „Da war", - heißt es in diesem Bericht weiter - „keine Erörterung mehr nötig; es war unmittelbar deutlich, daß das Heer als Ganzes mit General Gough und seinen Offizieren es war, wovon die Gehorsamsverweigerung ausging, und daß jeder Versuch, sie zu bestrafen und mit der Zwangspolitik fortzufahren, den unmittelbaren und vollständigen Austritt von fast dem ganzen Offizierkorps der Linie zur unmittelbaren Folge haben würde, wahrscheinlich sogar auch den der Hauptmasse der Landwehr ... die Regierung tat das einzige, was sie unter den obwaltenden Umständen tun konnte, sie kapitulierte..." Im Jahre I907 hatte CLÁMENCEAU in der französischen Kammer ausgerufen, das schwerste Unglïck für das Land würde sein, wenn die Regierung kapitulieren würde vor einer disziplinlosen Soldateska! Soweit kam es in der Tat in der alten Heimat des Militarismus nicht. Aber in England, dem Musterlande parlamentarischer "verantwortlicher " Regierung und bürgerlicher Freiheit, geschah diese Kapitulation! Sie ist uns hier merkwürdig hauptsächlich wegen der Haltung der Offentlichen Meinung. Sie stand in diesem schreienden Falle des Versagens der bürgerlichen Autorität, der durch den "Volkswillen «eingesetzten Behörde, nicht einmütig auf deren Seite, ja im eigentlichen England unzweifelhaft überwiegend auf Seiten des widerspenstigen Militärs! Aber sie würde einhellig und mit Getöse verneinen, daß darin eine Erscheinung des Militarismus schlimmster antibürgerlicher Art vorliege. Solche Erscheinungen würden natürlich in Theorie und Worten unablässig bekämpft und an den Pranger. gestellt - wenn sie anderswo, insbesondere in dem verhaßten und gefürchteten Deutschen Reich, sich ereigneten, wie es, in einem weit schwächeren Fall, einige Monate zuvor im Elsaß geschehen war. Hier war es zuerst die bekannt gewordene grobe Taktlosigkeit eines Offiziers, alsdann die Übergriffe der Militärbehörden bei Bekämpfung von Unruhen in der Stadt $Z$ abern, die den unmittelbaren Unwillen der deutschen Offentlichen Meinung, zugleich aber den künstlich geschürten derjenigen in den Nachbarländern erregte, die gegenüber dem viel ärger zutage getretenen Militarismus des eigenen Landes ruhig und duldsam gewesen war, ja ihn ermutigt hatte. Die Offentliche Meinung auch der neutralen Länder gab in dieser Sache, und nachher, während der Kriegsjahre, in den Anklagen gegen den ausschließlich pre ußische n Militarismus ihre ganze Luftigkeit und Windigkeit 


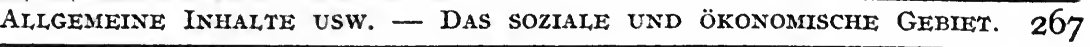

kund, vermöge deren sie gedankenlos jedem äußeren Druck sich preisgibt.

Von einer anderen Seite betrachten wir aber die Öffentliche Meinung des Tages, wo sie, zunächst sittlich erregt, empört oder entrüstet über einen gegebenen einzelnen Fall, in einer neuen Gestalt aufsteigt und von solchen einzelnen Urteilen aus allmählich sich verdichtet, um nachher flüssige und endlich feste Gestalt zu gewinnen. In dieser Hinsicht sind die gesellschaftlichen S ka ndale, insbesondere Skandalprozesse, die auch durch Dauer die öffentliche Aufmerksamkeit fesseln, oft von historischer Bedeutsamkeit. Typisch dafür ist die "Halsbandgeschichte", die NAPOLEON eine der 3 Ursachen der französischen Revolution genannt haben soll. „Das Entsetzliche war, daß im Publikum das moralisch Unglaubliche glaublich gefunden und mit großer Bereitwilligkeit aufgenommen wurde" (NIEBUHR, Gesch. des Zeitalters der Revolution, I, S. I5I). Der Hof, der Adel und die hohe Geistlichkeit, alle Mächte die äußerlich noch über der schon entwickelten bürgerlichen Gesellschaft standen, waren bloßgestellt, ja entehrt. Ein langwieriger Prozeß wurde vor dem Parlament von Paris geführt. „Und eben dieser war es, welcher die öffentliche Meinung ganz außerordentlich erregte" (WAHL, Vorgesch. der franz.Revolut. I, S.3I9). Es war daher gleichgültig, wer verurteilt, wer freigesprochen wurde; gleichgültig, daß ein Teil des Publikums für die Königin aus dem Hause Ósterreich, ein Teil wider sie, ein Teil für den Herzog-Kardinal, ein Teil gegen ihn Partei nahm; entscheidend war der Eindruck, daß die ganze hohe Gesellschaft verrottet sei, sie hatte sich verächtlich und lächerlich gemacht. Ähnlich haben in neuerer Zeit manchmal Skandale und Prozesse zuungunsten der vornehmen Welt gewirkt; so besonders englische Ehebruchs- und Ehescheidungsprozesse. Das Publikum - vorzugsweise »bürgerlich "gesinnt - verallgemeinert immer: "so lebt man in der Gesellschaft, die sich die gute nennt". "Das ist High Life" - und so wird der Glaube an die Rechtschaffenheit derer, die den Vorzug des Ranges und des Reichtums genießen, untergraben, die Offentliche Meinung bricht den Stab über sie. Zumeist ist es die geschlechtliche Sittlichkeit, deren gröbere oder feinere Verletzungen das öffentliche Ärgernis geben; aber zuweilen machen auch andere Laster und Verfehlungen in ähnlicher Weise peinliches Aufsehen und bringen die Offentliche Meinung gegen einzelne, besonders auch dann gegen die höheren Schichten auf, weil diese überhaupt am schärfsten beobachtet werden, weil ihre Privatangelegenheiten als solche schon das öffentliche Interesse auf sich ziehen. So war es in Deutschland der SpielerprozeB der sog. Harmlosen, der im Jahre I904 einen gewaltigen Lärm erregte und das Ansehen der 
adligen Kavallerie-Offiziere tief schädigte. Ähnlich wirkten zuungunsten des "Militarismus « und jener Schichten, die vorzugsweise als dessen Träger gelten, der Fall Brüsewitz und der Fall Zabern. Nachdem die Meinung so durch Jahre hindurch sich verdichtet hatte, und auch der Druck der feindlichen Anklagen nicht ohne Wirkung geblieben war, brachte endlich der Zusammenbruch der deutschen Sieghoffnungen im Oktober Igr8 die Offentliche Meinung in FluB, so daß sie - momentan - wirklich von der Schädlichkeit des preuBisch-deutschen Militarismus überzeugt wurde, dem sie lange gläubig, oder aus Vernunftgründen, durchdrungen von seiner Notwendigkeit wegen der Lage des Deutschen Reiches, gehuldigt hatte. In den republikanischen Ländern, wie in den Vereinigten Staaten und Frankreich, reiht sich Skandal an Skandal, die allgemeine Käuflichkeit, Bestechlichkeit, Nichtswürdigkeit in Geldangelegenheiten grell beleuchtend, insbesondere die tiefe Verderbnis der gewerbsmäBigen Politiker, die unter dem Namen des Volkswohles nichts als ihren wirtschaftlichen Vorteil verfolgen. Die Öfentliche Meinung des Tages ist in unablässiger Erregung über solche Fälle; aber diese Dünste verdichten sich nie zu einer Anklage gegen Staatsform und Verfassung; diese gelten vielmehr für unübertrefflich und in allen wesentlichen Bestandteilen richtig; die rationalistische Gedankenbewegung, von der überhaupt die Offentliche Meinung getragen wird, ist in Einrichtung dieser Formen zur Ruhe gekommen, die Offentliche Meinung selber hat in bezug darauf einen Grad der Festigkeit erreicht, den nicht leicht eine entgegengerichtete Strömung erschüttert, wenn sie je sich bilden sollte. Diese Betrachtung geht in die Ansicht der Offentlichen Meinung auf dem politischen Gebiete über. Sie dient hier nur, um verständlich zu machen, da $B$ die Unzufriedenheiten der Offentlichen Meinung wegen der Erscheinungen des sozialen, insbesondere auch des wirtschaftlichen Lebens, in jenen Ländern keinen politischen Charakter annehmen, vielmehr höchstens in die Forderungen innerer Reformen zusammenlaufen.

\section{Zweiter Abschnitt. Das politische und rechtliche Gebiet.}

4. (II a: In der festen Öffentlichen Meinung.) Die wenigen festen Bestandteile der Offentlichen Meinung im politischen Gebiete beziehen sich zumeist auf die Staats-Formen. Mit vollkommener Sicherheit verwirft sie alles, was ihr als mittelalterlich, mithin als barbarisch gilt. Vor allem daher die Priesterherrschaft und die geistlichen Staaten. Es wird allgemein als zugestanden und als selbstverständlich angenommen, $\mathrm{da} ß$ solche niemals, getaugt 
haben, da $B$ überhaupt der klerikale Einfluß im Staatsleben, und alles, was durch das Wort "Theokratie " bezeichnet wird, durchaus vom Ubel sei. Ebenso, aber minder allgemein, wenigstens in manchen Ländern von minder fester Geltung, ist die Verneinung und Verwerfung der Herrschaft des Adels als eines erblich für die führenden Stellungen und Tätigkeiten begabten und vorzugsweise berufenen Standes. In England hat tatsächlich der Adel auch politisch noch eine bevorrechtete Stellung, die von der Offentlichen Meinung geduldet wird, was die gerade in der "Mittelklasse " herrschende Ehrfurcht vor hohen Geburtstiteln erleichtert; auch in anderen Ländern sind noch bedeutende Reste solcher politischen Sonderrechte vorhanden, aber z. B. in Preußen minder bedeutsam, weil Preußen nur Teilstaat des Deutschen Reiches ist. Sie waren - vor dem zerstörenden Weltkriege - um so besser gesichert, je weniger entwickelt die Offentliche Meinung in dem Lande, je mächtiger hingegen noch die Religion, als Trägerin der Ubberlieferung und geheiligter Einrichtungen, war. Ferner gehört auch zu diesen verschmähten und in die Rumpelkammer der Vergangenheit zurïckgestellten politischen Einrichtungen der mit Unrecht von der Offentlichen Meinung für mittelalterlich gehaltene fürstliche Absolutismus, der allerdings in mittelalterlichen Glaubensideen seine starke Stütze hatte. Unter gehässigen Namen wie Despotie, Autokratie, persönliches Regiment, werden auch seine Reste nicht sowohl kritisiert, als ohne Prüfung verworfen; sie sind der Offentlichen Meinung gegenüber unmöglich, sind "gerichtet «. So ist denn auch die politische Offentliche Meinung in bezug auf Staatsform und Verfassung um so fester, je weiter diese von der absoluten Monarchie entfernt sind, also in demokratischen Republiken. Ganz besonders in den Vereinigten Staaten von Amerika ist sie schlechthin durchdrungen und erfüllt von der Vortrefflichkeit und Musterhaftigkeit ihrer Einrichtungen (»our institutions»), also von ihrer politischen Uberlegenheit über die meisten Staaten Europas, ungeachtet aller Verderbnis ("corruption"), die am Marke dieser jungen Mischnationalität frißt. Diese Überzeugung und Selbstgefälligkeit ist durchaus ein fester Bestandteil der "amerikanischen " Offentlichen Meinung. Wird sie aber als theoretische Ansicht, daß diese Staatsform die schlechthin beste sei, aufgcfaßt, so würde ich ihren Aggregatzustand immerhin als tropfbar-flüssig bezeichnen, wenn auch die Tropfen dick und schwer sind: will sagen, daß der typische gebildete Amerikaner einer unbefangenen Würdigung anderer politischer Systeme schwerlich fähig ist, aber doch nicht leugnen wird, daB, wenn nicht die beste, so doch die für ein gegebenes Land am meisten geeignete Staatsform Gegenstand verschiedener Meinungen sein ka n n. 
Als einen festen Bestandteil der Öfentlichen Meinung in allen Ländern der heutigen Zivilisation darf man noch die Ansicht betrachten, $\mathrm{da} B$ der Staat sein Wesen darin hat, eine Einrichtung zum Nutzen und Vorteil der Individuen zu sein. Indessen ist auch diese Ansicht am reinsten und bewußtesten ausgebildet in den neuzeitlichen Republiken, deren Typus die Vereinigten Staaten als Union und Einzelstaaten darstellen. In den Monarchien versucht noch die Idee eines in sich beruhenden Ganzen, das durch die Monarchie oder doch durch die Dynastie symbolisiert werde, sich zu erhalten. Sind diese Monarchien zugleich verhältnismäßig reine Nationalstaaten, so verbindet sich damit leicht die Idee einer von Natur zusammengehörigen Volksgesamtheit, deren äußere Form nur der Staat sei. Die Theorie bestimmt solche Gesamtheiten, wenn sie doch als Verbindungen gedacht werden, deren Wesen durch Denken und Wollen ihrer Subjekte, in letzter Linie also der Individuen, gesetzt wird, als 》Gemeinschaft «im Gegensatz zur "Gesellschaft ", die den ausschließlich als Mittel für die individuellen Zwecke vorgestellten und konstruierten Verein bezeichnet. Die Öfentliche Meinung verschmäht jene Begriffe, als mit Metaphysik oder gar Mystik behaftet; sie will klar und flach denken, darum ist ihr nur der gesellschaftliche Begriff zugänglich. Dieser ist in den Vereinigten Staaten auf der Höhe; aber auch in England ist er um so tiefer und fester in der Offentlichen Meinung verwurzelt, je vollkommener daselbst »die « Gesellschaft, als die stillschweigende Konvention der durch Geburt und Reichtum oder nur durch Reichtum regierenden Schichten das politische Übergewicht über das Volk behauptet. JAMES BRYCE berichtet im 98. Kapitel seines Werkes über Amerika, dem er die Uberschrift » Laisser faire « gibt, über ein Gespräch, das er mit einem philosophierenden Europäer über den Gegenstand geführt habe. Dieser hatte ihn gebeten, der amerikanischen "Theorie des Staates « ein Kapitel zu widmen. BRYCE antwortete: die Amerikaner haben keine "Theorie des Staates". „In England und in Amerika gleicherweise vermißt man einen ganzen Kreis und ein System von Gedanken und Empfindungen, die unter den Nationen des europäischen Kontinents machtvoll gewesen sind. Für diese Nationen ist der Staat eine große moralische Macht, die Gesamtheit der Weisheit, des Gewissens, der Kraft des Volkes, jedoch weit größer als die Summe der Individuen, die das Volk bilden, weil jene Macht auf bewußte und wissenschaftliche Art, gewissermaßen also durch ein Naturgesetz, organisiert ist für $Z$ wecke, die das Volk nur undeutlich begreift, und weil er der Erbe einer tiefgewurzelten Ehrfurcht und einer fast despotischen Autorität ist. Es haftet ein Anflug von Mystizismus an dieser Vorstellung, der die Verwandlung willkürlicher in Volksvertretungs- 
Regierung überlebt hat und beinahe an die Heiligkeit, welche die mittelalterliche Kirche zu umgeben pflegte, erinnert." Auch in England sei dem Staat und Staatsdienst ein gewisses $\mathrm{MaB}$ von Einfluß und Achtung geblieben; wenn auch niemand dem Staat als solchem eine besondere Weisheit zuschreibe, niemand die Beamten als eine Oberschicht ansehe, so wohne dem Staate doch Würde bei, und die Menschen seien stolz darauf, ihm zu dienen. Nichts dergleichen in Amerika: ,sogar die Würde des Staates ist verschwunden“. „Er scheint in Wirklichkeit weniger als die Individuen, die unter ihm leben“. „Der Staat ist nichts als ein Name für die Gesetzgebungs- und VerwaltungsMaschinerie, wodurch gewisse Geschäfte der Einwohner erledigt werden." „Er hat nicht mehr Gewissen oder moralische Bestimmung oder Anspruch auf Ehrfurcht und Achtung als eine Handelsgesellschaft zum Behuf der Unternehmung einer Eisenbahn oder eines Bergwerkes." „Die Nation ist nichts weiter als soundso viele Individuen." In diesen und verwandten Sätzen prägt sich die vollkommene gesellschaftliche Ansicht des Staates aus, zu der in allen Iändern die Offentliche Meinung ihre entschiedene Neigung bekundet, auch da, wo sie sich in diesem Sinne nicht durchaus befestigt hat. In Frankreich geht sie mit der Úberzeugung, da $\beta$ die Republik die beste, ja die "einzig wahre Staatsform darstellt, Hand in Hand, obgleich dort der Sozialis m us immerhin tieferen Einfluß auf die Offentliche Meinung gewonnen hat als in den Vereinigten Staaten: der Sozialismus, dessen Idee sich zwar mit jener gesellschaftlichen Ansicht des Staates verträgt, aber doch auch andere und zwar entgegengesetzte Elemente in sich enthält. - Im niedergetretenen Deutschland, dem der Zusammenbruch seiner Macht Veranlassung geworden ist, auf die Eirneuerung und Vollendung seines nationalen BewuBtseins bedacht zu sein, tut sich zugleich eine Vertiefung des sozialen Denkens in dem fast einmütigen Verlangen nach 》Gemeinschaft « kund, der von einem lebhaft fließenden Strom der Offentlichen Meinung getragen wird.

5. (II b: In der flüssigen Öffentlichen Meinung.) Was die Staatsform betrifft, so wurde schon ausgesprochen, daß im allgemeinen in den europäischen Hauptländern die öffentliche Meinung nur einig und fest ist in Verwerfung des Absolutismus und der Theokratie, ubrigens aber in jedem Lande - unter normalen Verhältnissen - den bestehenden Zustand als den, wenn auch nicht schlechthin, so doch für das eigene Land am meisten geeigneten zu behaupten geneigt ist. In den meisten dieser Länder hielt sie bis an die Schwelle des Weltkrieges eine mehr oder minder eingeschränkte Monarchie für zweckmäßig, und als Regel auch das Gelten einer geschriebenen Verfassung für notwendig, um das 
Staatsrecht, besonders die Rechte der "Krone " und die der "Volksvertretung " oder des Volkes schlechthin, gegeneinander, in bestimmten Formen darzustellen. Aber diese Meinungen befanden sich im Flusse: mehr und mehr war ein »konstitutionelles "Königtum als die sich von selbst verstehende Art der Monarchie in den Hintergrund getreten, und die Frage war insbesondere im Deutschen Reich und in den deutschen Einzelstaaten geworden, ob "parla mentarische" Regierung oder nicht. Die Offentliche Meinung befand sich seit geraumer Zeit im Übergange zur Bejahung dieses Systems. Dazu wirkte besonders der Druck der Arbeiterbewegung und die Ausbreitung der sozialdemokratischen Ansichten im Volke, aber auch die Kritik, die gerade in den weitesten Kreisen der Bildung und des Besitzes an dem zufälligen Träger der "Kaiserkrone " und vollends an dem zu erwartenden Nachfolger geübt wurde, trug stark dazu bei: das "persönliche Regiment" wird nicht auf so entschiedene Weise von der Offentlichen Meinung gemißbilligt, wie der maßgebende Einfluß unverantwortlicher Freunde des Monarchen, die unter dem Namen der "Kamarilla "Gegenstand eines mit Grauen vermischten Unwillens sind. Je mehr ferner die im "Bund der Landwirte" neu organisierte konservative Partei-Anschauung nach Osten schaute, weil sie in "Ostelbien " zu Hause war, und, nach preußisch-dynastischer Überlieferung, in der Autokratie des Zarismus den festesten Hort politischer Autoritätsprinzipien zu erkennen meinte, um so mehr blickte alles, was dieser Denkungsart entgegen war - und also die Offentliche Meinung -, nach Westen und den "westlichen Demokratien ", ob sie die Formen der Monarchie abgestreift hatten oder nicht. Das alte Vorbild politischer "Erbweisheit ", England, erschien auch in der neuen Gestalt, die seine Verfassung im I9. Jahrhundert angenommen hatte, als Muster eines "Landes, das sich selbst regiert «; in Wirklichkeit wurde und wird es durch eine, trotz aller Parteiung, nach außen hin fest zusammenhaltende, in der Ausbeutung der Weltteile die Bedingung der eigenen Macht und Pracht erkennende aristokratisch, mehr noch (und in rasch zunehimender Weise) plutokratisch orientierte Bourgeoisie erfolgreich beherrscht. Eben darum galt es immer dem reichen Bürgertum in allen Ländern als Land

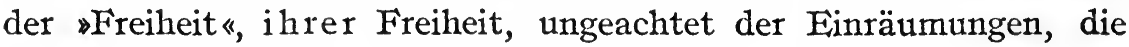
den Ansprüchen der Arbeiterklasse gemacht wurden und obschon diese in dem noch "freieren "Lande, den Vereinigten Staaten von Amerika, beinahe fehlten; daß solche unter europäischen Verhältnissen schlechthin notwendig waren, hatte die Öfentliche Meinung auch z. B. in Frankreich und im Deutschen Reiche erkannt. Zur Verflüssigung der Meinung in dieser Hinsicht trugen dann die 5I Monate 
des Weltkrieges, die wie sonst $5 \mathrm{I}$ Jahre wirkten, um so mächtiger in Deutschland bei, je ungewisser der endliche Erfolg, je wahrscheinlicher endlich sogar der völlige Mißerfolg dieser ungeheuren Kraftprobe wurde. Je mehr Schuld an dem mangelhaften und endlich an dem Mißerfolg, der politischen Leitung vor dem Ausbruch und während des Verlaufes zugeschrieben ward, um so mehr wurde die Offentliche Meinung aufnahmefähig für die große Reform der scheinbaren Verwandlung des Obrigkeitsstaates in einen Volksstaat, der "Parlamentarisierung « und "Demokratisierung « der Verfassungen im Reiche und in den Staaten. Auf das Verhältnis der Offentlichen Meinung zur ferneren Entwicklung wird die Betrachtung unter IIc zurückkommen.

Die flüssige Offentliche Meinung ist der Bearbeitung zugänglich, wie Eisenerze, wenn sie in Fluß gebracht werden; und auch fest gewordene Vorurteile und Ansichten lassen sich erschüttern und aufweichen, wenn gehörige Kraft daran gewandt wird. Hier ist der Ort, eines Falles aus dem I9. Jahrhundert Erwähnung zu tun, der zwar zunächst für Großbritannien, mittelbar aber sozusagen für den ganzen Erdball starke Bedeutung hatte, wo es einem planmäßigen, 7 Jahre lang unermüdlich mit großem Aufwande an materiellen und geistigen Kosten geführten Feldzug der Agitation und Werbung gelang, die Offentliche Meinung anderen Sinnes zu machen als sie bis dahin seit langer Zeit gewesen war. Es handelte sich um eine Frage, an der damals, gleichwie es jetzt der Fall ist, unermeßliche wirtschaftlich-finanzielle Interessen hingen, die Frage der Handelspolitik; die Bewegung setzte sich zum Ziele, die Offentliche Meinung zu gewinnen, um mit ihrer Hilfe die Schutzzölle, insbesondere die Kornzölle, abzuschaffen, und dies gelang! Dies Gelingen war um so schwerer, da es galt, das ganze politische Schwergewicht der regierenden Familien Englands zu überwinden, die damals (1839-46) noch unumschränkter als heute das britische Staatswesen und die Offentliche Meinung des Landes in den Zügeln hielten. Die gegen sie, und also gegen die Klasse der Großgrundbesitzer, gerichtete Bewegung hatte 2 Führer, die nichts von dem ererbten Einfluß, dem Prestige, besaßen, wodurch diese Aristokratie $I^{1 / 2}$ Jahrhunderte lang ihrem Lande wie dem Auslande zu suggerieren wußte, daß England das Land der politischen "Freiheit" sei; es war eben das Land ihrer Freiheit und Macht. Von jenen Führern, die daran zu rütteln wagten, stammte der eine, RICHARD CoBDEN, aus einer bescheidenen kinderreichen Landwirtsfamilie, der andere, JoHn BRIGHT, gehörte der stillen Gemeinde der "Freunde» (Quäker) an; beide waren Kaufleute, Fabrikanten, Vertreter der emporkommenden Mittelklasse, die bis I 832 zum großen'Teile überhaupt 
keine politischen Rechte im Lande der Freiheit besessen hatte. Der Erfolg ihres Sturmlaufs gegen eine Hochburg der Aristokratie ist aus unserem Gesichtspunkt besonders dadurch merkwürdig, da $B$ er eine vollständige Ablenkung des Stromes der Öfentlichen Meinung bewirkte, die dann ein volles Menschenalter hindurch der Lehre vom allein reich und glücklich machenden Freihandel treugeblieben ist, um dann aber schwerfällig und langsam in ihr altes Bette zurückzukehren. Jene Freihandelslehre, so nüchtern wirtschaftlich sie ist, so materialistisch und nationalegoistisch sie von ihren $\mathrm{Kri}$ tikern verstanden $\mathrm{zu}$ werden pflegt, hatte und hat bei den genannten Führern und unter ihren bewußtesten Anhängern einen religiös-humanitären Anstrich, und wenn man sich mit deren Persönlichkeiten bekannt macht, so findet man keinen Grund, an der Ehrlichkeit und Aufrichtigkeit zu zweifeln, womit sie geltend machten, der Freihandel werde sich als die hohe Straße bewähren, die $z u$ einem dauernden Friedenszustande in Europa, und über die Erde hin, führe. Auf die mannigfachen Mittel, wodurch diese Männer die Offentliche Meinung für ihren $Z$ weck planmäßig und wirksam bearbeitet haben, werden wir in anderem Zusammenhange zurückkommen.

In Wahrheit will die Offentliche Meinung immer eine unparteiische, nicht durch Interessen bestimmte Meinung sein, sie behauptet das, wofür sie eintritt, als das Richtige, das durch Vernunft Gebotene, durch Wissenschaft Empfohlene, auf die besten Autoritäten Gestiitzte oder: im Sinne des allgemeinen Wohles Notwendige, eine bessere Zukunft Sichernde. Dadurch rechtfertigt sie vor sich und der Welt ihre Wandlungen, ihren oft so plötzlichen Umschwung, der an den Wechsel der Mode in bezug auf Kleidung, Möbel u. dg1. erinnert. Gleichwie dieser Wechsel sich als ein veränderter Geschmack einführt und, so lange als die Mode dauert, der jedesmalige Geschmack der gute Geschmack sein will, ja geradezu ein ästhetisches Gewand anzieht, so will das, was in der Politik "en vogue " ist, auch für wahr und richtig gelten, ohne daß die Offentliche Meinung über die wirklichen Ursachen ihrer Veränderungen zum Bewußtsein kommt. Wenn diese in dem bezeichneten englischen Falle Erfolg einer starken Agitation war, so wirkte doch unterhalb und mit dieser Agitation der Umstand, daß die Großindustrie, besonders die Baumwollspinnerei und Weberei, in dieser Zeit zunehmende Bedeutung gewann, die sich allmählich dem allgemeinen Bewußtsein mitteilte und ein wohlfeileres Brot als im Interesse des Ausfuhrhandels gelegen erscheinen ließ; besonders, wenn es gelänge, das Freihandels-Dogma auch in anderen Ländern siegreich zu machen, d. i. deren Widerstand gegen die britische Ware zu brechen. Aber es 
kamen äußere Umstände und Ereignisse hinzu: die seit langem in der Arbeiterklasse gärende, im Chartismus sich kundgebende Stimmung und die furchtbare Hungersnot als Folge von Kartoffelkrankheit in Irland, dazu die schlechten Weizenernten auch in Großbritannien 1845 und I 846 und die Furcht vor unmittelbarer Hungersnot; wie begründet sie war, lehrt die Tatsache, daß 1848 weniger als 5 Millionen Zentner Weizen und Weizenmehl eingeführt wurden, I 845 aber fast I 8 Millionen und überdies I5 Millionen Zentner Mais für Irland. Die harte Not und Notwendigkeit wirkt eben auch auf die Offentliche Meinung in entscheidender Weise. In den modernen Volkswirtschaften und Staaten steht sie immer abwechselnd unter dem Einfluß des ökonomischen Aufschwunges und der Handelskrise. So wirkte im Deutschen Reiche die schwere Krisis 1875 und folgender Jahre im umgekehrten Sinne: als Bekehrung vom Freihandel zum Schutzzoll. Und auch hier war es die rasch emporgekommene Großindustrie, besonders die Eisenindustrie, die ihren Untergang befürchtete, woraus die neue Strömung hervorging, die sich selber noch 1875 als "gege n den Strom «(Flugschrift VON KARDORFFS) gerichtet erkannt hatte. Seitdem ist eine Wandlung der Öfentlichen Meinung nur zugunsten von Handelsverträgen eingetreten, wiederum unter dem Einfluß einer Mißernte und einer beginnenden Handelskrise (I $891 / 92$ ), die Handelsverträge selber sind aber mehr und mehr protektionistisch geworden, und in der Schutzzollpolitik ist der Agrarschutz in den Vordergrund getreten, dessen Wirkungen die Offentliche Meinung in den Jahren des Weltkrieges als "Rettung « begrüßen zu dürfen meinte; der Ausgang des Krieges wird auch in diesem Bezuge zum Umlernen zwingen. Ohnehin treffen sich grundsätzliche Freihändler, wie BRENTANO, und Verteidiger der Schutzzollpolitik, wie H. DELBRÜck, in der Ansicht, daß wir - nach dem Kriege - ,einer neuen Freihandelsperiode entgegengehen", die sogar ,ganz von selber kommen werde", meinte DELBRÜCK im August 1918. „Könnte man die öffentliche Meinung schon heute von der Richtigkeit dieses Gedankenganges überzeugen und den allgemeinen Freihandel als Friedensprogramm proklamieren, so würden wir uns damit in der ganzen Welt eine mächtige Bundesgenossenschaft gewinnen, die dem Frieden sehr zustatten kommen würde $\left.{ }^{1}\right)$. “ - Daß die Offentliche Meinung, wie immer verursacht, oft als eine Art von Modewechsel auftritt, lehren am besten Beispiele aus dem typischen Modelande, Frankreich. So ist seit I87I der Revanche-Gedanke stärker und schwächer an der Mode gewesen, stärker in Verbindung mit monarchischen oder cäsaristischen (die

2) PreuB. Jahrb., Sept. 1918. S. 397. 
Boulange) Ideen, schwächer mit dem Erstarken der Republik, stärker mit der Schwärmerei für die Armee und dem Antisemitismus (der Fall DREYFUS), schwächer mit dem Zusammenbruch des Betrugfeldzuges und der wachsenden Furcht vor dem Kriege; stärker mit dem entschiedenen Auftreten des Deutschen Reiches im Wettbewert um Weltmacht, schwächer mit dem Erstarken des alten Rivalen, Englands, in entscheidender Stärke aber endlich, als England sich des nicht mehr gefürchteten Rivalen gnädig annahm und sogar die wenn auch latent bleibende - Bundesgenossenschaft des Zaren sich gefallen ließ, ja umwarb, um das Deutsche Reich bei nächster Gelegenheit zu erdrosseln. Ubrigens ist in Frankreich die Offentliche Meinung des Tages, bestimmt durch Skandale und Skandalprozesse, stärker als irgendwo, und verdichtet sich leichter so, daß sie in eine fließende Bewegung gerät; um freilich ebenso rasch wie der neueste "cri de Paris « wieder zu verdunsten.

6. (II c: In der luftartigen Öffentlichen Meinung.) Die Öfentliche Meinung des Tages in politischen Angelegenheiten ist die am meisten auffallende, ja sich aufdrängende Erscheinung der Offentlichen Meinung überhaupt; sie wird daher sehr oft für die Offentliche Meinung schlechthin gehalten und als solche angesprochen. Freilich findet dabei regelmäßig die Vermischung und Verwechslung der Offentlichen Meinung, die gleichsam als einheitliche Gesamtperson gedacht wird, mit der öffentlichen Meinung als Gesamtheit der Äußerungen verschiedener Meinungen statt. An diese letztere wird zunächst und vorzugsweise gedacht, wenn »die Presse als Organ oder als Instrument der öffentlichen Meinung dargestellt wird; man betrachtet und würdigt dann die Aufregung der Gemüter als solche, auch wenn sie in einem wüsten Durcheinander des Geschreies sich kundgibt.

Ohne Zweifel ist die Tagespresse das bedeutendste $\gg$ Ausdrucksmittel « der Offentlichen Meinung a uch als einheitlichen sozialen Willens. Nur in diesem Sinne werde sie hier betrachtet. Die Voraussetzung ist, daß die Offentliche Meinung vorher und unabhängig von der Tagespresse feststeht, daß sie durch das Bekanntwerden einer Tatsache, eines Ereignisses mit naturgesetzlicher Notwendigkeit sich bildet und dann, wie durch viele andere Mittel, so auch durch die Tageszeitungen ganz eigentlich "zutage tritt«. In diesem Falle werden die Zeitungen einmütig sein, oder sie sind wenigstens »auf denselben Ton gestimmt «; Parteiansichten, die sonst von ihnen verfochten werden, treten zurück, sie unterwerfen sich und dienen der Öffentlichen Meinung. Diese hat in solchen Fällen etwas von einem Sturm, ja zuweilen von einem Orkan an sich, der in 
einer bestimmten Richtung alles vor sich herjagt, alle Widerstände bricht, und durch seine Druckwirkung auf die Gehirne der Menschen ihr Reden und Schreiben, also auch die Ausdrücke, die es in der "gedruckten Kolumne" findet, eindeutig bestimmt. Die Offentliche Meinung dieses Sinnes ist auch in jeder großen und allgemeinen Volkserregung enthalten, wie sie etwa der Ausbruch oder der Ausgang eines Krieges hervorruft. Aber hier überwiegt die leidenschaftliche Empfindung, die auch an der Offentlichen Meinung immer ihren starken Anteil hat; aber während jene in unklarer Aufwallung, im Brausen und Zischen ihr Genüge hat, so strebt wenigstens die Offentliche Meinung immer nach klarem und gemessenem Urteil. Am ehesten ist sie in dieser Beziehung "mit sich einig ", wenn es sich um die Beurteilung von Erreignissen und Personen handelt, die eine bestimmte moralische Erscheinung darbieten, sei es, da $B$ diese ein allgemeines Gefallen oder ein allgemeines Mißfallen auf sich ziehe. $\mathrm{Da} B$ »das Moralische sich immer von selbst versteht «, wird bei solchen Gelegenheiten offenbar. Politisch macht hier die Offentliche Meinung sich geltend insofern, als es um politische Ereignisse oder auch nur um politische Personen sich handelt; denn noch in anderer Weise als sonst allgemein bekannte und berühmte Menschen, ziehen diese die allgemeine Aufmerksamkeit auf sich; das öffentliche Wohl ist mit ihrer Handlungsweise verknüpft. Daher machen gewisse Rechtsstreitigkeiten, die ein besonderes Licht auf ihr Privatleben werfen, z. B. Eheirrungen und Scheidungsprozesse, nicht selten solche Personen "unmöglich " in der Offentlichen Meinung, die sie verurteilt. In England trägt die Offentlichkeit solcher Prozesse wesentlich dazu bei. So erging es dem Politiker DILKE I886 und dem Vorkämpfer Iriands PARNELI I89o. Aber das eigentliche politische Urteil der Offentlichen Meinung tritt viel deutlicher zutage, wo es sich um politische Verfehlungen handelt, die als solche zunächst mehr von der intellektuellen als von der moralischen Seite kritisiert werden. In dieser Hinsicht sind die Reden des deutschen Kaisers WILHELM DES ZWFITEN, im eigenen Lande oft heftig erörtert und scharf gemißbilligt worden. So ließ sich - und das war wohl der Gipfelpunkt solcher Kritik - eine ungewöhnliche Einmütigkeit der Offentlichen Meinung feststellen, als am 28. Oktober I908 eine englische Zeitung über eine Unterredung mit dem Kaiser berichtete, die vor kurzem stattgefunden habe und vollkommen beglaubigt sei. Jeder politisch Denkende, der diese Mitteilungen las, war entsetzt über den Mangel an politischem Verstand und Takt, den die Äußerungen des so hoch gestellten Mannes verrieten. Nur wer die Eindrücke unmittelbar erlebt hat, konnte damals der Offentlichen Meinung 
gleichsam ins Antlitz schauen; da gab es in Wahrheit keine Parteien mehr, sondern nur ein allgemeines Schütteln des Kopfes sowohl über den Inhalt der Aussprüche als über die Tatsache, daß ihre Veröffentlichung zugelassen worden sei. Der Widerhall, den die umlaufenden Urteile in der Tagespresse fanden, war verhältnismäßig schwach natürlich, weil die Person des Monarchen strafrechtlich vor der öffentlichen Kritik geschützt ist. Doch nannte sogar eine streng konservativ-monarchische Pastorenzeitung die Veröffentlichung einen Schlag gegen die Vertrauenswürdigkeit der deutschen Politik. Stärker und deutlicher trat die allgemeine Unzufriedenheit in der Verhandlung des Reichstags am 9. November zutage. Von allen Parteien lagen Anfragen vor, die Auskunft und Verantwortung verlangten. Von keiner Partei wurde der grobe Mißgriff des Kaisers in Schutz genommen. Der konservative Redner nannte es »erfreulich", daß das deutsche Volk in schweren Augenblicken nach einheitlicher Verständigung dränge. Ein Redner der damaligen (liberalen) Volkspartei wies darauf hin, daß auch aus Bundesratskreisen niemand die Haltung des Monarchen als richtig bezeichnet habe. - Wenn sich bei dieser Gelegenheit die Offentliche Meinung des Tages in ihrer Stärke zeigte, so offenbarte sie doch zugleich ihre Schwäche. Flüchtig und windig wie sie ist, war sie bald wiederum in Nichts aufgelöst; obschon sie anfangs sich verdichten $\mathrm{zu}$ wollen schien $\mathrm{zu}$ einer einhelligen Stimmung und Kundgebung gegen das persönliche Regiment und die eitlen Wahnvorstellungen eines sonst redlichen, aber seiner Aufgabe, wie er sie verstand, durchaus nicht gewachsenen Mannes. Der Reichstag hätte damals beflissen sein sollen, diese Verdichtung zu befördern; er hätte dann wenigstens eine flüssige Offentliche Meinung hinter sich gehabt, wenn er auf verfassungsmäßige Einschränkung der Rechte des Kaisers gedrungen hätte. $\mathrm{DaB}$ aber der Reichstag nicht handelte, hatte wiederum eine seiner Ursachen darin, $\mathrm{daB}$ die Offentliche Meinung, wie sie am reinsten wohl durch die nationalliberale Partei dargestellt wurde, zu konservativ war, zu große Furcht vor »demokratischen « Neuerungen hatte, die doch das Lebensinteresse der Nation gerade angesichts der Persönlichkeit des Monarchen, - man mochte sonst wie immer über ihren Wert denken, - gebieterisch forderte. Es kam hinzu, daß die Offentliche Meinung, erfolgreich bearbeitet durch einen Flottenverein, der sich in mehr als 3600 Ortsausschüssen seit 1898 über das ganze Reich ausgebreitet hatte, die Vermehrung der deutschen Hochseeflotte stark begünstigte und in der Person des Kaisers den Herold dieser Flotten- und Weltpolitik erblickte und, ungeachtet aller Bedenken gegen die Art seines Auftretens, feierte. - In jener 
Reichstagssitzung sagte ein Abgeordneter: tiefgehende Erschütterung, Bestürzung und Zorn erfülle das ganze deutsche Volk. Dies war, wie bei solchen Gelegenheiten üblich, stark übertrieben. Die große Menge des Volkes, wie sie in kleinen Städten und Dörfern ihrer Arbeit, ihren Geschäften nachgeht, wird von solchen Begebenheiten kaum berührt. Man muß an solchen Tagen in Eisenbahnwagen dritter oder gar vierter Klasse reisen, um sich zu überzeugen, daß die Wogen der Erregung nicht sehr weit ins Binnenland spülen. Auch ist von dieser Erschütterung und Bestürzung das politische Urteil wohl zu unterscheiden, nach welchem die Öfentliche Meinung wenigstens strebt als nach ihrem eigenen charakteristischen Merkmal, sofern sie darauf Anspruch macht, die Politik mitzubestimmen, ja selber zu "regieren «. Mit diesem Anspruch, und in nicht geringem Umfange mit seiner Erfüllung, ist nun die Öffentliche Meinung in jüngster Zeit immer offenbarer aufgetreten; wir finden daher Grund, der Offentlichen Meinung als politischer Macht einen besonderen Abschnitt zu widmen.

\section{Dritter Abschnitt. Das geistige und sittliche Gebiet.}

7. (III a: In der festen Öffentlichen Meinung.) Im geistigen und sittlichen Gebiete ist der Grundzug der Offentlichen Meinung, der sich in ihrer festen Gestalt am stärksten ausprägt, die Vernünftigkeit. Das Streben danach ist, wenn auch in einer rhythmischen Bewegung, während der verflossenen 4-500 Jahre neuzeitlicher Entwicklung immer stärker und immer erfolgreicher geworden. Es gefällt sich selbst als Streben nach dem Lichte der Erkenntnis und der Freiheit. In diesem Sinne stellt sich die Neuzeit als Zeitalter der "Aufklärung" dem "finsteren Mittelalter " (den "dark ages «) bewußt entgegen. Das allgemeine Merkmal dieser Finsternis, von der Seite der Vorstellung und Meinung, ist der Aberglaube. Ihn zu bekämpfen ist die Aufklärung, der Rationalismus, unablässig beflissen. Ausgeprägtes Merkmal des Aberglaubens ist die Meinung, daß es in der wirklichen und wahrnehmbaren Welt "Geister « gebe - der Gespensterglaube, ein uralter, ja in der naturwüchsigen Gestalt menschlicher Vorstellungen ursprünglicher Bestandteil des Volksbewußtseins, der auch heute noch in der großen Mehrheit des Menschentums fortdauert und das Grundelement der positiven Religionen als sozialer Willensmächte bildet. Innerhalb des Christentums ist er am lebendigsten geblieben in der orthodoxen (griechisch-katholischen) Kirche. Aber auch in der römisch-katholischen Kirche genießt er stärkeren Schutzes und besserer Pflege als in den protestantischen Kirchen, und innerhalb dieser mehr in den kirchlich streng als in den 
freier gesinnten Kreisen; auch diesen aber ist er innerlich nicht so fremd geworden, wie der kleinen Minderheit derer, die streng wissenschaftlich zu denken gewohnt sind. Und doch tauchen auch in diesen immer von neuem die $Z$ weifel auf, ob nicht doch setwas daran sei ", ob nicht ein Hineinragen der "Geisterwelt « in die nüchterne Wirklichkeit des Tages unter Umständen wirklich stattfinde: - Zweifel, die als solche zum Wesen des wissenschaftlichen Denkens gehören, insofern als es jeder echten Erfahrung sich offen halten will und muß. Seine kräftigste Stütze behält der Gespensterglaube an dem Verlangen der menschlichen Seele nach individueller Fortdauer und dem entsprechenden Wunsche, daß ein besonderes Leben der abgeschiedenen geliebten Personen nicht nur als ungewisser Glaube, sondern als gewisse Tatsache möge festgestellt werden. Als Glaube, wenn auch in verschiedenen Formen, ein Bestandteil des religiösen Glaubens der Völker, besonders auch des christlichen Glaubens. Als angebliche Erfahrung findet er dort am meisten Boden, wo der religiöse Glaube mit der Aufklärung kämpft und wo diese ungenügend ernährt wird, wie es in Großbritannien, und in seinen ehemaligen sowohl als jetzigen Kolonien (Amerika, Australien) bekanntlich der Fall ist. Entschiedener als in diesen Ländern lehnt in Deutschland, in Holland, Skandinavien und Frankreich die Offentliche Meinung bisher noch den "Spiritismus" ab.

Wenn nun der allgemeine Geisterglaube nicht unmittelbar der Religion angehört, so gilt dies hingegen innerhalb der christlichen Weltanschauung durchaus vom Glauben an das Dasein des Te ufels. Im I7. Jahrhundert noch durchaus herrschend, sogar innerhalb der protestantischen Kirchen mehr als in der römisch-katholischen gepflegt, ist er vor dem Lichte des philosophischen I8. Jahrhunderts erblaßt und im I9. fast verschwunden. Er gehört zwar noch zur geltenden Dogmatik der alten Kirche, ein vereinzelter Professor der katholischen Theologie weiß wohl gar den Ort der Hölle als des Wohnsitzes, worin der Satan - mit seinen vielen Unterteufeln, seiner "GroBmutter " und den ihm anheimgefallenen Seelen - hause, zu beschreiben; auch die protestantische Orthodoxie hat diesen wichtigen Bestandteil ihres Systems niemals schlechthin aufgegeben, und ein achtungswerter deutscher Gelehrter des I9. Jahrhunderts will gar den "Leibhaftigen «zähnefletschend mit leiblichen Augen gesehen haben. Aber lebendig ist der Teufelsglaube nicht mehr. Er wird nicht mehr ernst genommen, man lächelt über ihn; ob mit Recht oder mit Unrecht, bleibe hier dahingestellt, nur an Feststellung der Tatsache ist uns gelegen, daß die Öfentliche Meinung ihn nicht kennt und sein Dasein leugnet. 
Mit dem Teufelsglauben ist der Glaube an bösen Zauber, daher an die Hexerei, innig verwandt. Frauen sind $\mathrm{zu}$ vielen Tausenden als Hexen, die mit dem Teufel buhlten, angeklagt und verurteilt worden; hochgebildete Männer, gelehrte Juristen in deutschen Landen waren als ihre Richter noch vor 200 Jahren fest überzeugt, da $B$ diese armen, zumeist geisteskranken Weiber in der Walpurgisnacht auf dem Besen zum Blocksberg ritten; ähnliche Meinungen herrschten über sie in anderen Ländern. Die Ausbildung des Hexenprozesses war zu ihrer Zeit eine Errungenschaft juridischer Weisheit, die der Theologie zur Hilfe kam; in den protestantischen, neueren Jahrhunderten und in protestantischen Ländern, wurde Sorgfalt und Scharfsinn besonders darauf angewandt. $\mathrm{Da} \beta$ die Tatsachen, insbesondere die Unzucht der Dämonen (Succubi und Incubi) mit Menschen, fest geglaubt wurden, ist ebenso gewiß, wie es den heutigen Menschen durchweg unverständlich, ja unglaubhaft geworden ist. Die gesamte Zauberei ist ein Stück der echten, uralten Volksreligionen, die das Christentum bekämpfte, nicht indem es ihre Wirklichkeit anfocht, sondern indem es sie zum Verbrechen machte, als Abfall vom wahren Gott, Anbetung heidnischer Götzen und böser Dämonen, oder ihres Hauptes, des "Beelzebub*.

Die Zauberei selber, der nicht nur Frauen, sondern auch männliche Hexenmeister oblagen, erschien als etwas verhältnismäßig Natürliches, so lange als "Wunder "überhaupt, also übernatürliche Ereignisse, zwar als ungewöhnlich und selten, aber doch als durchaus möglich und wirklich galten. ,Gewiß gibt es in der Geschichte der letzten 3 Jahrhunderte keine Umwälzung, welche auffallender und an einer größeren Menge bedeutsamer Forschungen reicher wäre, als jene, welche in der Schätzung des Wunderbaren eingetreten ist. Gegenwärtig nehmen fast alle Gebildeten die Errzählung von einem in ihren Tagen stattgehabten Wunder mit einem vollkommenen und sogar spöttischen Unglauben auf, der sie aller Prüfung der Gewißheit überhebt. Mögen sie auch ganz und gar außerstande sein, eine genügende Eirklärung der stattgehabten Erscheinungen $z u$ geben, so fällt es deswegen ihnen doch nimmer auch nur im Traume ein, sie einer übernatürlichen Ursache zuzuschreiben, weil eine solche Voraussetzung, nach ihrer Ansicht, ganz und gar außerhalb des Bereiches einer vernünftigen Erörterung liegt. Und doch gab es vor wenigen Jahrhunderten keine Ėrklärungsweise, der sich das menschliche Gemüt bereitwilliger bei jedem auffallenden Ereignisse zugewandt hätte. Eine Wundergeschichte wurde damals allgemein als vollkommen glaubhaft, wahrscheinlich und gewöhnlich aufgenommen. Is gab kaum ein Dorf oder eine Kirche, die nicht zu irgendeiner Zeit der Schauplatz einer 
übernatürlichen Kundgebung gewesen wäre. Man hielt dafür, daß die Mächte des Lichtes und die der Finsternis sichtbarlich um die Meisterschaft kämpften. Heilige Wundertaten, übernatürliche Heilungen, überraschende Urteilssprüche, Gesichte, Weissagungen und Wunder jeder Art bezeugten die Tätigkeit des einen, während Hexerei und Magie mit all ihren begleitenden Schrecken die augenscheinlichen Kundgebungen der anderen waren."

Indem W. H. LECKY, der das I. Kapitel seiner History of the rise and influence of the spirit of Rationalism in Europe mit diesen Sätzen eröffnet, fernerhin darstellt, daß die Welt das, was einst so allgemein und so fest geglaubt ward, ganz und gar aufgegeben habe, fährt er fort: wenn eine so vollständige Umwandlung in der öffentlichen Mein ung Platz greife, so könne sie nur von einer oder der anderen von 2 Ursachen sich herschreiben. Sie könne das Ergebnis einer Untersuchung sein, wodurch die Frage so erledigt sei, daß es als feste Wahrheit von allen Aufgeklärten angenommen werde, auch von denen, die gar nicht imstande seien, die Begründung nachzuprüfen. Oder aber sie sei durch den sogenannten Zeitgeist bewirkt, also die Folge einer allmählichen, unmerklichen, aber tiefen Umgestaltung der vorwaltenden Geistesrichtung - und dies treffe offenbar für die Verwerfung der Hexerei zu, während ein Beispiel der ersten Art etwa das Verstummen des Widerspruchs gegen das kopernikanische System oder gegen die Lehre vom Kreislauf des Blutes sei. Wir finden hier in scharfsinniger Weise unterschieden, was eine so starke Veränderung und Befestigung der allgemeinen Denkweise bewirken kann. Hinzuzufügen ist, daß die herrschende Überzeugung von der Richtigkeit einer wissenschaftlichen Ansicht als solche noch keine Öfentliche Meinung begründet, sondern erst dann, wenn entweder die Nichtannahme dieser Ansicht moralisch verurteilt wird - und dies ist offenbar der Fall bei allem, was sie (die Offentliche Meinung) als finsteren Wahn, als rohen Aberglauben u. dgl. bezeichnet - oder aber die Ansicht selber als moralisch wertvoll, als eine Quelle der Verbesserung und des Fortschrittes der Menschheit oder der Kultur empfohlen wird. Der hier gemeinten Verdammnis unterliegt z. B. der neuerdings (von Herrn JohanNes Schlaf) gewagte Versuch, die Richtigkeit der heliozentrischen Erklärung des Planetensystems durch scheinbare Beweisgründe zu erschüttern, nicht; und ebensowenig gehört die Lehre des Kopernikus oder Harveys zu denjenigen Stücken der wissenschaftlichen Erkenntnis, denen "man « eine besondere moralische Bedeutung beizulegen pflegt; es sei denn insofern, als sie die allgemeine Vermehrung des Wissens bezeichnen. 
Aligemeine Inhalte usw. - Das geistige und sittifiche Gebiet usw. 283

Die Verwandlung der Denkungsart, auch in dem so eingeschränkten Sinne, erstreckt sich noch weiter. In den bisher erwähnten Stücken ist ein schroffer Gegensatz zwischen Religion (in ihrer überlieferten Gestalt) und der nunmehr seit etwa 2 Jahrhunderten allmählich festgewordenen Offentlichen Meinung. Was die Religion zur Pflicht macht, erklärt die Offentliche Meinung für unsittlich und verabscheuenswert, was jener als schwere Sünde erscheint - z. B. einem verfolgten Ketzer Schutz und Obdach gewähren - erscheint der Offentlichen Meinung als gute Tat, ja als allgemein menschliche Pflicht. In anderen Stücken tritt der Gegensatz dadurch zutage, daß gegen Gesinnungen und Gedanken, welche Religion nicht dulden kann und will, Offentliche Meinung sich zum mindesten gleichgültig verhält, $\mathrm{da} B$ sie in Glaubensfragen $D u l d u n g$ verlangt, während Religion unduldsam ist. So war noch für den großen Reformator Calvin der Zweifel an der Gottheit Christi und die Leugnung der Trinität ein schweres Verbrechen, das mit dem Feuertode bestraft werden mußte; bekanntlich hat auch der sanfte MELANCHTHON dies gebilligt. Man vergleiche damit, wie sich selbst in Ländern und Gegenden, die noch stark unter geistlichem Einflusse stehen, die Offentliche Meinung heute, und schon seit roo Jahren, dazu verhält. Sogar die Leugnung des Daseins einer Gottheit überhaupt, wenigstens eines persönlichen Gottes, wird sie zwar nicht ausdrücklich billigen die Offentliche Meinung nimmt wohl dieses Dasein an, ohne ihm aber eine übernatürliche Wirkung, also Eingriffe in die Naturgesetze zuzuschreiben, man darf sagen, daß sie heute dem "Deismus «huldigt — aber sie wird schlimmsten Falles bedauernswerte Irrtümer darin finden. Eine gewisse Einigkeit besteht hingegen noch zwischen Religion und Öfentlicher Meinung in bezug auf Ablehnung des sog. "Materialis mus «. Der Religion ist diese Ablehnung im höchsten Grade ernst, da sie ganz und gar auf der Annahme immaterieller und doch wirklicher, ja unter Umständen wahrnehmbarer "Geister « beruht. Die Offentliche Meinung dagegen pflegt mit dem Worte einen unklaren Begriff (oder mehrere) $z u$ verbinden. Bald denkt sie wesentlich an materielle und fleischliche Genüsse und deren Minderwertigkeit gegenüber edleren geistigen Genüssen und bringt die Vorliebe für jene mit einer rohen Weltanschauung in Verbindung, die alles leugnet, was nicht greifbar ist, und wohl gar seelische Vorgänge als schlechthin unwirklich gering schätzt. Bald meint sie die Gleichgültigkeit gegen mideale " Bestrebungen und die AusschlieBlichkeit des Interesses für Geld und Gelderwerb, welche Verhaltungsweisen wiederum mit einer beschränkten und äuBerlichen Denkungsart in Zusammenhang gebracht werden, während sie tatsächlich ebensogut mit einer religiösen und 
theologischen wie mit einer wissenschaftlichen Denkweise sich verträgt, wenngleich sie, aus anderen Ursachen, parallel mit dieser zugenommen und sich ausgebreitet hat. In diesem Sinne klagt auch die OffentlicheMeinung die materialistischeRichtung unserer Zeit heftig an, während die Vertreter der Religion den Vertretern jener vorrücken, daß eben der von ihnen so gleichmütig aufgenommene, ja begünstigte "Abfall vom Glauben " diesen Materialismus notwendigerweise hervorbringe und verschulde. Und in Zugeständnissen an diese Vorwürfe zeigt sich, z. T. in Deutschland, mehr in den kleineren protestantischen Ländern, vollends aber in England, in den Vereinigten Staaten usw. die Offentliche Meinung wenigstens soweit noch unter dem Einflusse der Religion, $\mathrm{da} \beta$ sie den "Atheismus « mit gleichem Abscheu betrachtet und mit einem so wirksamen Banne belegt, daß diejenigen, die im Ernste nicht verhehlen können, da $\beta$ sie die Vorstellungen von einem Gotte für ebenso unbegründet halten, wie die überwundenen Vorstellungen von Göttern, doch aus Scheu vor diesem Banne es vorziehen, den Atheismus nicht offen zu bekennen, sondern sich unter anderem Namen (Agnostiker, Konfessionslose, Monisten) dem Publiko vorzustellen.

Der feste Grundsatz der Duldung erhöht sich selber als Forderung der "Gewissensfreiheit ", und findet auch in dieser Form die entschiedene Zustimmung der Offentlichen Meinung. Es wird darunter insbesondere verstanden das Recht, religiöse Ansichten und Überzeugungen beliebiger Art nicht nur zu hegen, sondern auch kundzugeben, so da $\beta$ sie eigentlich nur einen besonderen Ausdruck der Rede- und der Preßfreiheit darstellt. Aber die Gewissensfreiheit stellt sich insbesondere dem Glaubenszwang entgegen, sie nennt sich daher auch, wie in der berühmten Anrede des Marquis POSA an den König Phrı.IPP, "Gedankenfreiheit «, obschon Gewissen und Gedanken ihrem Wesen nach nicht gezwungen werden können, so daß in Wahrheit immer nur jene Freiheiten, für die Religion etwa namentlich die Freiheit des Kultus als besonderer Form der Gottesverehrung in Frage kommt; diese aber ist eigentlich eine politische Angelegenheit. Ubrigens aber ist das Verhältnis derOffentlichen Meinung zur Toleranz in zwiefacher Hinsicht merkwürdig. Einmal behält in manchen Erscheinungsformen die Offentliche Meinung immer etwas von einer herrschenden Religion, ist daher tatsächlich und im Widerspruch zu ihrem Wesen oft auch religiös intolerant, indem sie eine bestimmte Form der Religion oder des Kirchentums begünstigt, andere mit Geringschätzung bedenkt. So ist in ausgesprochener Weise die Öfentliche Meinung in England beschaffen gewesen, wo sie, ganz offenbar nicht aus religiösen oder theologischen Gründen, nur die „Kirche von England « als respektabel gelten ließ, außerdem etwa der römisch-katholischen ịhren Rang zuerkannte, aber 
über jede Art von Dissent die Nase rümpfte, weil er mit einem plebejischen Geruch behaftet war. Dies innere Verhältnis der Offentlichen Meinung zur wetablierten» Kirche und hingegen zur "Kapelle « besteht auch noch, aber es ist, infolge zunehmender Gleichgültigkeit gegen Religion überhaupt einerseits, zunehmenden Reichtums vieler Methodisten, Independenten, Quäker usw. andererseits, sehr verdünnt und flüssig geworden; man wird es kaum noch als einen festen Bestandteil der englischen Offentlichen Meinung schätzen können. - Ferner aber ist die Offentliche Meinung als sozialer Wille auch eine Kraft, die ihre eigenen Anhänger bindet und verpflichtet; den Grundsatz der Duldung wendet sie wohl auf religiöse Meinungsverschiedenheiten an, denen sie geringe Bedeutung beimißt, aber keineswegs auf andere, insbesondere nicht auf politische, worin sie am meisten als in ihrem eigenen Gebiete schaltet. Vielmehr verlangt die Offentliche Meinung von jedem, der auf eine führende Stellung in der Gesellschaft oder im Staat Anspruch macht, Bekenntnis zu den »richtigen " (»korrekten «) Meinungen oder wenigstens Vermeiden des Widerspruchs dagegen und ächtet also die Kundgebung entgegenstehender, ungehöriger Ansichten. Sie kann in dieser Hinsicht außerordentlich starke Wirkungen ausüben, nicht nur unmittelbar, indem sie selber lobt und tadelt, verherrlicht oder den Stab bricht, sondern auch mittelbar, durch Wechselwirkung mit ihren eigenen Trägern, insbesondere solchen, die Gesetze geben und deren Vollziehung leiten, mit den Machthabern in der Gesellschaft und im Staate. Wie es in jedem sozialen Kreise "eine "öffentliche Meinung gibt, die mehr oder minder heischend oder verwehrend auch in bezug auf Meinungsäußerungen sich geltend macht, so verlangt "die" Offentliche Meinung von allen Hochgestellten, daß sie jedenfalls kein Årgernis geben, mindestens also schweigen, von den Höchstgestellten aber geradezu, wenigstens bei gewissen Gelegenheiten, den Ausdruck derjenigen Meinungen, die ihr selber, der Offentlichen Meinung, als die angemessenengelten, daher in einer monarchischen Regierung königstreuer, in traditionell republikanischen solcher, die der "Freiheit « den Vorzug geben, womit nicht gesagt wird, daß ein Würdenträger auch die Freiheit habe, seine Meinung zugunsten eines persönlichen Regiments kundzugeben oder gar Propaganda dafür zu machen. In dieser Betrachtung ist aber die der Offentlichen Mcinung des Tages (IIIc) vorweggenommen. Als ein fester Bestandteil der Offentlichen Meinung in geistiger Hinsicht, zumal der in deutschen Landen herrschenden, darf die Hochschätzung der "Bildung « bezeichnet werden, die zugleich ein wesentliches Stück in dem hier vorgelegten Begriff der Offentlichen Meinung darstellt. Sogar in England hat sie die gesetzliche 
Einführung eines, wenn auch mangelhaft durchgesetzten, Volksschulwesens $\mathrm{zu}$ bewirken vermocht, in anderen I,ändern arbeitet sie noch daran. Sie betrachtet die Ausbreitung des Analphabetismus als eine Schande, dessen Mindestmaß als eine Ehre des dadurch charakterisierten Landes. Die wissenschaftlichen Leistungen des de utschen Volkes standen in der Offentlichen Meinung aller Länder hoch, bis es im Weltkriege der englischen Propaganda gelang, die deutsche Nation als eine Nation von Barbaren, als Hunnen, zu brandmarken.

Den Unterschied fester und flüssiger Offentlicher Meinung kann man deutlich an den gangbaren Urteilen über Hauptfragen des Rechts und der Sittlichkeit beobachten. Feste Öfentliche Meinung gibt es vorzugsweise in bezug auf Strafprozeß, Strafarten, Strafvollzug. Ein Hauptstiick des alten Strafprozesses, wie er im späteren Mittelalter ausgebildet, in der Neuzeit überlebte, war das strenge Beweisverfahren mit der peinlichen Frage, der sog. Tortur. Die Einmütigkeit, womit diese verworfen und als ein Denkmal finsterer Zeiten betrachtet wird, ist ein fester Bestandteil der Offentlichen Meinung in allen Ländern gegenwärtiger Kultur. Das gleiche kann man von den qualifizierten Todesstrafen sagen; wenn sich je eine Stimme dafür erheben sollte, das Vierteilen, das Flechten aufs Rad, das Schleifen bis zur Richtstätte wieder einzuführen, so würde eine solche Stimme rasch durch allgemeine Empörung, durch den Unwillen der Öfentlichen Meinung, erstickt werden. Flüssig hingegen ist die Offentliche Meinung in betreff der noch übrigen Reste von Leib- und Lebensstrafen. Die Todesstrafe wird von ihr überwiegend gebilligt, die Prügelstrafe überwiegend gemißbilligt. In beiden Fällen ist aber, wenigstens in Deutschland, das Gefüge der Offentlichen Meinung ziemlich locker, die Offentliche Meinung nähert sich dem öffentlichen $Z$ weifel, sie fühlt sich unsicher. Das gleiche gilt im allgemeinen von der Art des Strafvollzuges. Die Offentliche Meinung ist zunächst stolz auf die moderne Humanität und die Verbesserung der Gefängnisse, sie empfindet von Zeit zu Zeit einen heilsamen Schauder, wenn sie an die scheußlichen Verließe der Vergangenheit, wie sie etwa in Rußland noch vorhanden sind, erinnert wird. Auf der anderen Seite aber ist sie auch ziemlich stark gegen den »Humanitätsdusel « eingenommen, indem sie fürchtet, daß durch zu gute Behandlung, zu milde, vielleicht gar willkommene Strafen, das Verbrecher- und das Landstreichertum ermutigt werden, oder daß die Verbrecher und Vagabunden es "besser " haben als manche ehrliche Leute, oder endlich weil die Genugtuung ausbleibt, die dem Schuldigen die verdiente Strafe angedeihen lassen will: die Offentliche Meinung, da $\beta$ die ewige Weltordnung, der sie einen unbestimmten Glauben 
nicht versagt, irgendwie zu kurz komme und unterstützt werden müsse.

8. (III b: In der flüssigen Öffentlichen Meinung.) Im $\mathrm{Zu}-$ sammenhange damit steht es, daß die Offentliche Meinung mit einiger Festigkeit auf schärfste Bestrafung von Roheitsverbrechen, besonders sexuellen, dringt; der Einwand, da $B$ die Urheber solcher Missetaten oft geistig mangelhafte, kaum zurechnungsfähige Individuen sind, pflegt abgelehnt $\mathrm{zu}$ werden; das Publikum glaubt mit den meisten juristischen Richtern, daß da entweder Simulation oder eine weichliche, mitleidige Beurteilung zugrunde liege; oder es verlangt, da $B$ die Unzurechnungsfähigen erst recht dauernd unschädlich gemacht werden sollen. Andererseits gibt es, wenigstens in Deutschland, eine flüssige Offentliche Meinung zugunsten einer schonenden und vorwiegend erzieherischen Behandlung $j$ ugendlicher Verbrecher: die Einführung der bedingten Verurteilung (oder vorläufigen "Begnadigung «) fand ebenso, wie die Gesetzgebung für $Z$ wangs- oder (später sog.) Fürsorge-Erziehung, und die Versuche der Einführung von "Jugendgerichten "den Beifall der Offentlichen Meinung, worin sich, bei diesen wie manchen anderen neueren Gelegenheiten, weibliche Einflüsse geltend und erkennbar machten. In einer Schrift über die Entwicklung des deutschen Jugendgerichts (von HERBER'T RUSCHEWEYH, Kieler Inaugural-Diss. I9I8) werden im 4. Abschnitt „die Reformforderungen in der deutschen Jugendgerichtsbewegung" ererörtert und, nach allgemeinen Bemerkungen, die Forderungen der Fra uen an die Spitze gestellt. Bezeichnend dafür, daß die Offentliche Meinung, nachdem sie zunächst nur durch einzelne Fälle in Erregung gesetzt wurde, in Flu $B$ kommt, ist die Entstehung einer besonders sog. "Bewegung " für oder wider eine Sache, besonders zugunsten von gesetzgeberischen Neuerungen.

Mit dem Privatrecht und seinen Schäden beschäftigt sich die Offentliche Meinung verhältnismäßig wenig, ob sie gleich zu seiner neueren Gestaltung auf entschiedene Weise mitgewirkt hat. Auf ihre festen Bestandteile in dieser Hinsicht wird unser IX. Kapitel: "Die Offentliche Meinung und die soziale Frage zurückkommen. Der Teil des Privatrechts, dem sie am ehesten ihre Aufmerksamkeit widmet, ist derjenige, worin Recht und Moral am unmittelbarsten sich berühren, nämlich das Fa milienrecht. Aber auch hier kann höchstens von einer flüssigen Öfentlichen Meinung gesprochen werden, außer insofern, als sie die monogamische Ehe und die selbständige Einzelfamilie als wesentliche und notwendige Einrichtungen bejaht: in dieser Hinsicht besitzt sie allerdings eine Festigkeit, die den mannigfachen Anfechtungen gegenüber, die in der Literatur und in losen Reden zugunsten der 
Geschlechtsfreiheit und allgemeiner Staatserziehung seit geraumer Zeit auftauchen, fast unerschüttert geblieben ist. Hingegen kann man sagen, $\mathrm{daB}$ gegenüber dem im deutschen BGB. festgelegten Eherecht die Offentliche Meinung in Deutschland einigermaßen im Flusse ist zugunsten der erleichterten Ehescheidung. Besonders ist sie geneigt, kinderlosen Ehen die Scheidung auf Grund gegenseitiger Einwilligung zu gestatten. Auch wird es stark bemängelt, daß gesetzeskundige und vermögensmächtige Personen durch geschickte Anwälte leicht eine Umgehung des strengeren Eherechts zu bewirken vermögen: Fälle von dieser Art erregen von Zeit zu Zeit öffentliches Ärgernis. Ǔbrigens wendet sich die "Frauenbewegung " auch in Deutschland gegen einige Grundlagen des Eherechts, wie es im BGB. vorliegt, zumal gegen die androkratischen und patriarchalischen Bestandteile darin, besonders im ehelichen Güterrecht. Diese Bewegung ist aber bisher nicht stark genug gewesen, um der Offentlichen Meinung ihre Richtung mitzuteilen, an deren Bildung in Deutschland die Männer in so viel höherem Grade mitwirken als die Frauen. Mehr Erfolg haben diese, wenn sie auf bessere rechtliche Stellung der außerehelich geborenen Kinder dringen; hier kommt ihnen die Humanität der Männer entgegen, von denen doch nur eine kleine Minderheit durch das Dasein solcher Kinder beeinträchtigt wird, und auch diese werden aus Furcht vor der Meinung sich nicht öffentlich dazu bekennen. So hat, nach MARIanNe Weber (Ehefrau und Mutter S. 325), sogar in Frankreich eine Klärung des sittlichen Bewußtseins begonnen. Die von französischen Frauen eingeleitete Agitation für die Zulässigkeit der Vaterschaftsklage, meinte die treffliche Schriftstellerin (I907), könne auf die Dauer nicht wirkungslos bleiben; wie denn - offenbar ein ähnlicher Erfolg der Frauen in der Offentlichen Meinung - schon im Jahre 1884, bei Wiedereinführung der Ehescheidung, "das Privileg des Mannes zur ehelichen Untreue beseitigt wurde "(WEBEK 1. c.). Was das dem Familienrecht so eng verknüpfte Erbrecht betrifft, so ist die Offentliche Meinung zwar durchaus für dessen Erhaltung, begünstigt aber nicht das Intestat-Erbrecht in entfernte Grade, ist vielmehr dem Eintritt eines staatlichen Erbrechts, ebenso wie hoher Erbschaftssteuern, sogar bei Vererbung von Eltern auf Kinder, durchaus zugänglich; wie die Tatsache beweist, daß solche in hochkapitalistischen Staaten, wie England, Hamburg, Lüibeck, ohne starken Widerspruch eingeführt werden konnten, und wie auch in den Jahren I908/9 die Offentliche Meinung in Deutschland einem entsprechenden Gesetzentwurf günstig gestimmt war.

In bezug auf eigentlich moralische Fragen ist die Offentliche Meinung im allgemeinen dünnflüssig. Im Gegensatz zum religiösen 
Glauben, der feste sittliche Grundsätze $\mathrm{zu}$ verfechten pflegt, weil sie durch Autorität, sei es eines Religionsstifters, eines Propheten, eines Buches oder einer Priesterschaft geheiligt sind; wobei in der Regel Ubereinstimmung mit der Sitte, die den festgefügten Bau überlieferter Handlungsweisen und überlieferter Anschauungen bewahren will. Die Offentliche Meinung huldigt, je mehr sie sich von der Religion entfernt, ja ihr entgegenwirkt, um so mehr einer laxen Moral: nicht nur kasuistisch, wie die übrigens durchaus in Religion und Kirchentum wurzelnde Theorie und Praxis der Jesuiten, sondern gedanklich, grundsätzlich. Hier sind nicht die Systeme der Philosophen gemeint, die allerdings auch auf die Sittenlehre der Öffentlichen Meinung einwirken - sogar dem Rigorismus eines KAN'T und Fichte widmet sie eine gewisse Ehrfurcht - , sondern die wirklich gang und gäbe Denkungsart der gebildeten Welt. Deren Beschaffenheit tritt am deutlichsten in den Fragen der geschlechtlichen Sittlichkeit zutage, die überhaupt für die Sittlichkeit charakteristisch sind. Mit einiger Strenge richtet die Öfentliche Meinung nur den Ehebruch der Frau, und auch diesem gegenüber ist sie nachsichtig, so lange bis er sich zum öffentlichen Årgernis, zum Skandal, auswächst. Ebenso duldsam ist die Offentliche Meinung gegen die Ausschweifungen der männlichen Jugend, daher wird die Prostitutio n zwar als schweres soziales Ubel anerkannt, auch ihre gesundheitlichen Gefahren drücken auf das allgemeine Bewußtsein, aber die sittlichen Folgen und Begleiterscheinungen werden kaum wahrgenommen und selten erörtert. Strenge überwacht wird dagegen die Reinheit der weiblichen Jugend mittlerer und höherer gesellschaftlicher Schichten. Fehltritte, die hier begegnen, finden ebenso wenig Gnade vor der Offentlichen Meinung wie vor der religiösen Moral. Aber jene heftet ihr Mißfallen noch mehr an das äußerlich, das gesellschaftlich Anstößige, als diese. Daher gilt auch der "Makel der Geburt» nur noch innerhalb der höheren Schicht, während er ehemals vom ehrlichen Handwerk und Bürgertum ausschloß. - Auch in anderen Gebieten der Sittlichkeit läßt sich die Flüssigkeit der Offentlichen Meinung beobachten. Sie schätzt den -Altruismus \& als Mitleid und Barmherzigkeit hoch, und feiert gern den bleibenden Wert der christlichen Lehre wegen der Vorschrift "Liebe deinen Nächsten als dich selbst «, während ihr die Feindesliebe und das Segnen derer, die uns fluchen, nicht einmal theoretisch einleuchtet. Die Offentliche Meinung schätzt aber gleichzeitig, und in Grunde weit mehr, den vernünftigen Egoismus, besonders auch das Eirwerbsstreben, wenigstens wenn es in maßvollen Grenzen gehalten wird. Hoch steht ihr der mit gutem Geschmack verwaltete Reichtum, zumal der selbsterworbene, wenn er auch mit weitgehender Wohltätigkeit 
und "Liberalität "verbunden ist. Eine gewisse charakterlose Weichheit und Mürbheit ist dadurch der Offentlichen Meinung namentlich in Ländern eigen, wo auch die Religion an diesen platten und flachen Widersprïchen nicht nur ihr Genüge hat, sondern darin sich mit Behagen ergeht, wie in England und den Vereinigten Staaten so offensichtlich der Fall ist. Der Mann, der nach dem satirischen Spruch GrILLPARZERs heute Bettler beglïckt, die er gestern zu Bettlern gemacht hat, ist in diesen plutokratischen Ländern ein ganz besonders angesehener Mann. Viel weniger Sinn als für Wohltätigkeit hat die Offentliche Meinung in allen modernen Ländern für die Tugend der Ge rechtig keit, wenn sie auch vom Richter verlangt wird. Uberhaupt hängt sie sehr an der Vergeltung im Strafrecht und an der Herrschaft des formalen Rechts, scheut aber die Anwendung eines sittlichen Begriffs der Gerechtigkeit auf Begründung des Eigentums, besonders des »ehrlichen «d. h. mit dem Strafgesetz verträglichen Erwerbes, und des großen Eigentums an Kapital und Boden. - Noch weniger schätzt die Öffentliche Meinung praktisch die Wahrhaftigkeit. Sie nimmt keinen oder geringen Ansto $B$ daran, daß sogar versprechende Eide als leere Worte empfunden tnd behandelt werden, daß geistliche Personen öffentlich verpflichtet werden, zu Unglaublichem und wahrscheinlich Nichtgeglaubtem sich zu bekennen. Der Konflikt zwischen Religion und der Offentlichen Meinung bleibt in diesen Dingen, infolge der Energie und äußeren Macht der Religion, und der Schlaffheit der Offentlichen Meinung, versteckt und hat geringe Wirkungen. Besonders lax ist die Öfentliche Meinung auch gegenüber der Unwahrhaftigkeit des Politikers. Daß dieser, um Wahlstimmen zu gewinnen, seine Aussagen und angeblichen Úberzeugungen der Gelegenheit anpaßt und rasch wandelt, erscheint ihr beinahe als selbstverständlich oder sogar als Pflicht vom Standpunkte der Partei aus.

Wenn die Hochschätzung der intellektuellen Bildung als fester Bestandteil der Öfentlichen Meinung zumal in Deutschland, bezeichnet wurde, so sind dagegen die meisten anderen Schätzungen des Unterrichtswesens flüssig. Die Würdigung der klassischen Bildung, also des Unterrichts in den alten Sprachen, wirkt noch in die Modernität hinein, aber stark aufgeweicht, während sich dieVoranstellung der Realien, also auch der Realschulbildung, mehr und mehr verdichtet. Jene wird konventionell, diese entspricht der allgemeinen Richtung der Offentlichen Meinung auf das Nützliche und Vernünftige, das "Reelle». So ist sie von Bewunderung erfüllt für alle Fortschritte der Technik, und begünstigt daher auch die technischen Hochschulen, wie die technische Fortbildung des Handwerkers und Fabrikarbeiters. Innerlich gleichgültig, wenn nicht sogar feindlich, gegen die Religion, vielmehr die 
Religionen, hegt sie doch schwere Bedenken gegen deren "Abschaffung ", daher auch gegen die Ausscheidung des Unterrichts in »der «, d. i. in irgendwelcher Religion, welche Ausscheidung ihr als ein Vorspiel solcher Abschaffung erscheint. Sie fürchtet nicht nur, daß die gemeine Sittlichkeit dadurch Einbuße erleidet, sondern sie sieht um so mehr eine Erschütterung der gesellschaftlichen Ordnung darin, da die Parteien, deren ausgesprochenes Streben auf eine solche Erschütterung abzielt, auch den Religionsunterricht in den Schulen abzuschaffen wünschen.

9. (III c: In der luftförmigen Öffentlichen Meinung.) Die Offentliche Meinung des Tages in sittlichen und geistigen Angelegenheiten ist die Erscheinungsform der Öfentlichen Meinung, die am häufigsten und schärfsten die Aufmerksamkeit auf sich zieht, daher auch oft verallgemeinert wird, als ob in ihr das Wesen der Offentlichen Meinung sich erschöpfe. Denn hier tritt sie als Sittenrichter auf, und da sie diese Funktion auch in allgemeinsozialen und besonders in politischen Angelegenheiten ausübt, so scheint dieselbe schlechthin für sie charakteristisch zu sein. Eben daher aber wird hier leicht "die "Offentliche Meinung mit einer öffentlichen Meinung (vgl. Buch I, Kap. III, 4. Abschnitt, S. 40) verwechselt, wie sie als das gemeinsame geltende und verbindliche Urteil in jedem sozialen Kreise, zumal solchen von gemeinschaftlicher Art, sich bildet, lobt oder tadelt, ehrt oder verdammt, bestimmte Handlungsweisen, aber auch Denkweisen, d. i. Bekenntnisse zur Pflicht macht. Als Gericht wirkt diese vorzugsweise negativ, wie ein Strafgericht; der "Gerichtshof der Offentlichen Meinung " kann auch freisprechen und sogar den Angeklagten mit Glanz und Ruhm aus der Untersuchung hervorgehen lassen; in der Regel aber tritt er in seine Tätigkeit ein, um ein mißbilligendes, verwerfendes Urteil zu fällen, wodurch das "Ansehen « des Schuldigen vermindert wird. Jede Privatperson unterliegt so in ihrem Kreise einer öffentlichen Meinung, deren Urteilssprüche mehr oder minder Bedeutung und Gewicht für ihre Stellung » in der Gesellschaft « haben. Dies ist aber in erhöhtem Maße der Fall bei Personen "von Stande", zumal wenn ihr Stand durch solches Urteil erschüttert wird; daher in allen aristokratischen und exklusiven Kreisen, die besonderen Wert auf ihre eigentümliche Ehre legen. Die Minderung dieser Ehre hat sogar regelmäßig den Verlust des Standes selber zur Folge. So ist der Offizier, den die Meinung seiner Kameraden als feig brandmarkt, weil er etwa dem Vorurteil des Standes in bezug auf "Satisfaktion " nicht gerecht wird, dadurch in seinem Stande " unmöglich " geworden. Ebenso wird, wer sein Ehrenwort gebrochen hat, im Offizierkorps wie in der studen- 
tischen Verbindung mit Ausstoßung bestraft und wird von der öffentlichen Meinung eines solchen Kreises verurteilt. In einigem Maße stellen auch die Frauen der guten Gesellschaft in jedem Orte oder in einer Landschaft einen solchen Kreis dar, der insbesondere über Verstöße ihrer eigenen Angehörigen gegen die Frauenehre zu richten sich berufen fühlt. Jede öffentliche Meinung dieser Art - mit Ausnahme etwa derjenigen in den untersten sozialen Schichten, unter Vagabunden und Verbrechern, wenn anders man auch da »eine« öffentliche Meinung finden will, - ist gemeint, wenn im Deutschen Reichsstrafgesetzbuch (§ I86) die Behauptung oder Verbreitung einer Tatsache mit Strafe bedroht wird, welche einen »anderen "verächtlich zu machen oder in der öffentlichen Meinung herabzuwürdigen geeignet ist, und ebenso (§ I87) mit schwererer Strafe Behauptung oder Verbreitung einer unwahren Tatsache, welche den anderen "verächtlich zu machen oder in der öffentlichen Meinung herabzuwürdigen oder dessen Kredit zu gefährden geeignet ist « (vgl. auch § I89). Jede öffentliche Meinung eines Standes oder eines Ortes kann so durch Aufnahme einer über mich behaupteten Tatsache bewogen werden, mich geringer als bisher zu schätzen oder sogar mich zu verabscheuen. "Die« Öffentliche Meinung schlechthin, also etwa die des ganzen Landes, wird sich darum nicht kümmern, außer wenn ich eine öffentlich bekannte Person bin: "die "Offentliche Meinung ist aber auch »eine« öffentliche Meinung. Solche Fälle nun, daß die Öfentliche Meinung über einen oder mehrere Menschen gleichsam zu Gerichte sitzt, begegnen im heutigen öffentlichen Leben alle Tage; auch wenn sonst unbekannte Personen erst durch ihre Handlungen bekannt werden oder geworden sind, wie bei "sensationellen « Prozessen, insbesondere Strafprozessen. Fälle dieser Art sind schon erwähnt worden, wo das "Verdikt"der Offentlichen Meinung auch politische Bedeutung gewonnen hat. Aber in der Regel handelt es sich hier nur um moralische Wirkungen: auch der strafrechtlich Freigesprochene oder Leichtbestrafte kann moralisch, auf Grund der durch den Prozeß über ihn bekannt gewordenen Tatsachen, verurteilt, ja verfehmt werden. Nicht minder als die in einem Prozesse bloßgelegten Tatsachen kann aber irgendeine Tatsache, die von einem öffentlich bekannten Mann in den Zeitungen berichtet wird, ihn in der Offentlichen Meinung des Landes herabsetzen oder gar vernichten. So wirkte etwa im November I9I8 das Bekanntwerden der Tatsache, daß WILHELM DER ZWEITE nach Holland entflohen war, - zumal nachdem berichtet ward, daß diese Flucht schon vor Monaten sei vorbereitet worden - in entscheidender Weise zu seinen Ungunsten. Ebenso wurde die hohe Meinung, worin der General LUDENDORFF als 
Feldherr gestanden hatte, erheblich vermindert, als das deutsche Publikum allmählich Klarheit darüber gewann, daß er fortwährend einen starken politischen Einfluß ausgeübt, ja so etwas wie eine Diktatur sich angemaßt habe - nachdem die Folgen sich als Unheil herausgestellt hatten. Dieser Fall ist auch darum bemerkenswert, weil es sich hier nur gleichsam um eine Herabsetzung der Temperatur handelte, bewirkt durch an sich verzeihliche Mißgriffe, von denen man nicht bezweifelt, daB sie in gutem Glauben geschahen; also nicht um unmittelbar moralisch genierende Tatsachen.

\section{Vierter Abschnitt. Urteile der Moralphilosophen über die allgemeinen Inhalte.}

io. (Locke, Hobbes, Mandeville, Helvetius, Smith.) Offentliche Meinung dieses Sinnes hat oft die Aufmerksamkeit der Moral philoso phen in Anspruch genommen. So unterscheidet L OCKE (Essay concerning human understanding Book II, Ch. 28 § 7, Io, I2) drei Arten von Gesetzen oder Sittenregeln, worauf die Menschen im allgemeinen ihre Handlungen beziehen, um danach zu beurteilen, ob sie srichtig " oder "sschief « seien : I. das göttliche Gesetz, 2. das bürgerliche Gesetz, 3. das Gesetz der Meinung oder des Rufes (reputation) - die Ubersetzung von TH. SchulTZE (Leipzig, Reclam) sagt hier dem Sinn gemäß „Gesetz der öffentlichen Meinung «. LOCKE erörtert dies in seiner weitläufigen Weise, um zu schließen : ,Also ist das Maß dessen, was irgendwo als Tugend und als Laster benannt und geschätzt wird, dies Gefallen oder Mißfallen, Lob oder Tadel, wie sie, durch eine geheime und stillschweigende Einmütigkeit, in den verschiedenen Gesellschaften, Schichten und Vereinen (tribes and clubs) von Menschen in der Welt sich bilden; woher es kommt, daß verschiedene Handlungen Ehre oder Schande unter ihnen finden, je nach dem Urteil, nach den Regeln oder der Mode (fashion) des Ortes". Fernerhin betont er, daß die Rücksicht auf diese Urteile der stärkste Beweggrund für die Menschen sei, sich ihnen anzubequemen. Anderen Strafen, göttlichen oder menschlichen, hoffe man sich zu entziehen; ,aber niemand entgeht der Strafe ihres Tadels und Mißfallens, der gegen die Mode und Meinung der Gesellschaft, an die er sich hält und der er sich empfohlen halten will, verstößt" $\left.{ }^{\prime}\right)$. Viel stärker und schärfer, zugleich in klassischer Knappheit, denkt auch in diesem Stücke

1) Die Wiedergabe bei WUNDT Ethik ${ }^{3}$, I, 400 ist nicht riclitig, wenn es darin heißt, LOCKE lasse das natiurliche, auf der Grundlage der allgemeinen Iust- und Schmerzempfindungen und des Reflexionsvermögens empirisch entstandene Sittengebot dem bürgerlichen Gesetz und dem Gesetz der öffentlichen Meinung überlegen sein: denn er identifiziert vielmehr das natiurliche Sittengebot nit dem Gesetz der öffentlichen Meinung. 
Lockes Vorgänger, Thomas HobBEs, wenn er (The Elements of Law natural and politic, Ch. 8) von der Macht des Menschen spricht und von der Ehre als Anerkennung solcher Macht durch andere, ferner von den "ehrenvollen «Zeichen, nach denen Anerkennung, daß jemand mehr Macht habe als sein Mitbewerber, sich richte; endlich dann von den Zeichen der Ehre selber, je nachdem sie der Niedere dem Höheren oder der Höhere dem Niederen angedeihen läßt (ausführlicher in Leviathan Ch. ro, wo es dann einfach heißt: „Ehre besteht nur in der Meinung von Macht"). Geistreich handelt auch MANDEVILLE: (Fable of the Bees, Dialogue II) von der uiberwältigenden Macht der "Meinung der Leute «, insbesondere der »Meinung der Standesgenossen " über das Gemüt der Menschen, und von der "Erfindung der Ehre" als der weitaus größeren Leistung gegenüber der Erfindung der Tugend, da sie das edelste und stärkste Band der Gesellschaft geschaffen habe. Wie sein Vorgänger LAROCHEFOUCAULD, und unter dem Einflusse des HobBes, will auch MANDEviLLE ${ }^{1}$ ) alles Löbliche auf das Trachten nach Lob und die Furcht vor Tadel zurückführen. „Der wirkliche Gegenstand des Stolzes oder der Eitelkeit ist die Meinung anderer"; Beifall und Bewunderung am liebsten in der ganzen Welt, am liebsten in alle Zukunft, sei es, wonach der strebe, der am meisten von Stolz und Eitelkeit erfüllt sei $^{2}$ ). MANDEVILLE weiß aber auch, daß der Beifall des Publikums keineswegs ausschließlich, ja nicht einmal vorzugsweise, Tugenden und sittlich als wertvoll anerkannten Eigenschaften gezollt wird, sondern oft weit mehr dem Reichtum, Prunk, der hohen Geburt, dem Geist und geistigen Leistungen und allem was glänzt, auch dem Betragen mehr, sofern es sich den in jedem Kreise herrschenden Ehrbegriffen und Vorstellungen von Anstand und Schicklichkeit anpaßt als, sofern es religiösen oder anderen sittlichen Schätzungen entspricht; ja, mehr die Eleganz und Feinheit des äußeren Benehmens als wirklich tugendhafte Handlungen preist. So ist die Meinung der Leute, so auch die Offentliche Meinung, selber an einem sittlichen Maßstabe gemessen, von sehr zweifelhaftem Werte, aber darum nicht weniger mächtig und einflußreich. Die Philoscphen der Aufklärung haben miteinander gemein, daß sie die denkende Bewußtheit als Beweggrund menschlichen Handelns schärfer betonen als eine richtige Psychologie gestattet, aber daß eine mehr oder minder bewußte Rücksicht auf die Meinung der Leute für Menschen, die im öffentlichen Leben stehen, auf die Offentliche Meinung, ein ungemein starkes Motiv auch desjenigen Handelns ist, das gut genannt wird, ist eine offenbare Wahr-

1) SakmanN, Bernard Mandeville (Freiburg i. B. I897), S. 123.

2) The Fable of the Bees (Dialogue II), Vol. II, p. 52 ed. Edinbourgh 1772. 
heit; auch, was schon PLATo so scharf hervorgehoben hat, daß zumeist in dieser Hinsicht die schei n ba re Tugend die gleiche, ja oft eine viel stärkere Wirkung auslöst als die wirkliche. - In Anlehnung an MANDEVILLE und dessen Vorgänger entwickelt HeLvÉTrus den Gedanken, da $B$ der Nutzen der Gesellschaft und des Gemeinwesens allein bestimme, was gut und schlecht sei, und $d a B$ in den umlaufenden Meinungen das Gefühl für diesen Nutzen sich ausdrücke. Er unterscheidet dabei die Urteile des Publikums von denjenigen besonderer Gesellschaften; von diesen werde ganz besonders hochgeschätzt, was man den guten Ton und die gute Sitte nenne; das große Publikum könne diese nicht gleich hoch schätzen, und umgekehrt; ebenso sei es, aus dem Grunde der verschiedenen Interessen, mit der Bewunderung, die das Publikum einem Menschen zolle, und derjenigen, die von besonderen Gesellschaften ausgehe. Der große Mann, zumal wenn er bescheiden sei, verzichte gern auf den Beifall der besonderen Gesellschaften; er fühle, daß ihre Schätzung nur beweisen könnte, daß seine Gedanken den ihren ähnlich seien, und diese Ähnlichkeit sei oft wenig schmeichelhaft; die öffentliche Würdigung sei für ihn allein des Wünschens und Strebens wert, weil sie immer ein Geschenk der öffentlichen Dankbarkeit und folglich Beweis eines wirklichen Verdienstes sei. „In der Tat, wie gleichgültig immer man sich stellen möge gegen die öffentliche Meinung (quelqu' indifférence qu'on affecte pour l'opinion publique), jeder sucht sich selbst zu schätzen, und hält sich um so mehr für schätzenswert, je allgemeiner er sich geschätzt sieht $\left.{ }^{1}\right)^{\prime \prime}$. Der geistreiche Schriftsteller unterscheidet also sehr deutlich zwischen dem, was wir »eine« öffentliche Meinung nennen, und "der "Offentlichen Meinung als der Meinung des allgemeinen Publikums, so da $\beta$ die Vorstellung des allgemein Geschätztwerdens für ihn übergeht in die des Ruhmes, oder wenigstens der Berühmtheit bei den Zeitgenossen. Er gibt (am Schlusse des Kapitels) folgende Merkmale des wahren Verdienstes, auch wenn es noch nicht durch die Feuerprobe des Publikums gegangen sei, und des Geistes, der die allgemeine Schätzung wirklich verdiene: I. daß der Träger solchen Verdienstes und Geistes sich zu den Leuten, die durch das Publikum und durch die Nationen des Auslandes am meisten geschätzt würden, am meisten hingezogen fühle, 2 . da $B \mathrm{er}$, nach einem Worte Crceros, gelobt werde von einem Menschen, der selber schon gelobt wird, 3. wenn er endlich die Schätzung derjenigen erlange, die, in Werken oder großen Stellungen, schon große Begabungen haben glänzen lassen; ,,i hre Schätzung für ihn setzt eine

1) De l'esprit, Amsterdam u. Leipzig 1759, I, p. 125. (Discours II, Ch. 10.) 
große Ähnlichkeit zwischen ihren Ideen und den seinen voraus; und diese Ähnlichkeit kann, wenn auch nicht als ein vollkommener Beweis, so doch als eine hinlänglich große Wahrscheinlichkeit dafür angesehen werden, daß er, wenn er ebenso wie sie den Blicken des Publikums sich ausgesetzt hätte, gleich ihnen einen Anteil an dessen Achtung gewonnen hätte". - Interessant ist wiederum, daß HEIVÉrTrus das Publikum als das des eigenen Landes versteht und die Nationen des Auslandes davon unterscheidet: der richtige Gedanke liegt zugrunde.

Auch ADAm Smith (The theory of moral sentiments) verlegt den sittlichen Wert in das Urteil der Umgebung, und zwar in das des unparteiischen Zuschauers, das auf unwillkürlicher Sympathie beruhe; er betrachtet diese hauptsächlich in bezug auf die Beweggründe der Handlungen, nachdem auch Hume vor ihm als Merkmal der sittlichen Handlung das angenehme Gefühl der Billigung bezeichnet hatte, das sie in der Seele des uninteressierten Zuschauers auslöse. AdAM Smrтh bemüht sich um die Analyse der Bedingungen, unter denen eine Handlung gebilligt werde, ihm liegt daran, die Rückwirkung der Urteile über andere auf das Gewissen als Urteil über uns selbst darzustellen. Er erörtert die Selbstschätzung, inwiefern sie selber die Sympathie des Zuschauers erwecke, und unterscheidet in dieser Hinsicht das berechtigte Selbstbewußtsein sowohl als die ausschweifende Selbstbewunderung von den Fehlern ("Lastern«) des Stolzes und der Eitelkeit. Er schildert diese Fehler nach ihren unterscheidenden Merkmalen. Der Stolze fühle sich nicht immer wohl in der Gesellschaft von seinesgleichen und noch weniger in derjenigen von Höhergestellten. Der Eitle hingegen suche eben diese, und scheine zu denken, daß von ihrem Glanze etwas auf ihre Umgebung ïberstrahle. „Er liebt es, zu den Tafeln der Großen hinzugezogen zu werden und noch mehr, gegen andere Leute den intimen Verkehr, dessen er dort gewürdigt werde, herauszustreichen. Er gesellt sich, so viel er kann, mit Leuten nach der Mode: jenen, von denen man annimmt, $\mathrm{da} B$ sie die öffentliche Meinung leiten (who are supposed to direct the public opinion), mit den Witzigen, mit den Gelehrten, mit den Populären; und er meidet die Gesellschaft seiner besten Freunde, sobald als der sehr ungewisse Strom der öffentlichen Gunst gegen sie zu laufen' scheint" (II, II9). Hier wird die (wirkliche) öffentliche Meinung offenbar nicht verstanden als wesentlich moralischen Inhaltes, sie wird von den ,Gefühlen des angenommenen unparteiischen $\mathrm{Zu}$ schauers", die man auch die ideelle öffentliche Meinung nennen könnte, unterschieden; Rücksicht auf diese ist gleich dem Sinn für Schicklichkeit, der hauptsächlich und beinahe ausschließlich der allgemeinen 
Hilfstugend, der Selbstbeherrschung, zur Empfehlung gereiche (II, I30).

I I. (Neuere Moralphilosophen.) Von neueren Moralphilosophen sagt ganz im Sinne von ADAM Smith GuSTAV RÜMELIN: „Der gewaltigeTrieb, in der Vorstellung Anderer Anerkennung und Geltung zu finden, unterwirft uns und unsere Handlungsweise dem Urteil und sittlichen Bewußtsein der Gesellschaft." Der sittliche Maßstab der Menge sei reiner und strenger als der sittliche Durchschnittswert des Einzelnen erwarten ließe. „Weil es unserer Eitelkeit und Selbstliebe lästig wäre, den anderen uns selbst gleich oder gar höher zu stellen, so legen wir für die Wertschätzung anderer einen strengeren $\mathrm{MaBstab}$ an als für uns selbst, und aus der Massenwirkung dieser Tadelsucht und Selbsttäuschung ergibt sich für das Ganze die heilsame und hochbedeutende Tatsache, *da $B$ die Offentliche Meinung immer sittlich höher steht als die Gesellschaft selbst*." Diese Autorität aber, die dem Einzelnen aus der öffentlichen Ordnung, Sitte und Meinung zuströme, verfahre schon ihrer Natur nach blind und ohne Kritik. „Wie die Flagge eines Schiffs die gute wie die schlechte Ware deckt, so nimmt sie neben den ewigen Grundlagen sittlicher Ordnung auch die vorübergehenden Strömungen des öffentlichen Meinens, die Vorurteile, den Aberglauben, den Priesterbetrug, die Sonderinteressen herrschender Klassen unter ihre Flügel. In anderen Dingen, und zwar gerade in solchen, die ein Zeitalter am lebhaftesten beschäftigen, gerät sie selbst ins Schwanken und die öffentliche Meinung spaltet sich in die Meinungen der Parteien" (Reden u. Aufsätze N.F. S. 24f.). Harald HöFFDING, der sich diese Betrachtung RÜMELINS zu eigen macht, nennt die öffentliche Meinung ein Mittelglied zwischen dem positiven Recht und der ethischen Überzeugung, oder den intellektuellen Ausdruck der positiven Moralität, etwas wie eine moralische Polizei, die durch ihr Lob und ihren Tadel mächtigen Einfluß ausübe. Sie sei auf ihre Weise ebenso wie die Rechtsorganisation, deren gründliche Methoden ihr aber nicht zu Gebote stehen, eine Art Naturordnung, welche Schranken und Bedingungen aufrichte; sie übe eine Kontrolle aus, die nicht zu entbehren sei. Ihre Schranken zu erkennen, sei sie nicht geneigt; sie glaube sich im Besitz der Allwissenheit und werde intolerant, schere alle über einen Kamm, werde oft von Standes-, Rassen-, Partei- und Religionsvorurteilen beherrscht (Ethik, Deutsche Ausgabe ${ }^{2}$, S. 533-535). Auch Friedrich PaUlsen kommt in den späteren Auflagen seines Systems der Ethik (7. u. 8. Aufl. II, 327ff.) auf die öffentliche Meinung zu sprechen. Sie sei die Summe alles dessen, was man in der Gesellschaft über alles, was die Aufmerksamkeit auf sich zieht, redet und hört, meint und urteilt. „All dies Hören- 
sagen bildet gleichsam eine Nebelwand, auf der die Dinge und Personen, die vorüberziehen, einen vergrößerten und oft ins Groteske verzerrten Schattenriß ihrer Gestalt werfen, zum Erstaunen oder Gelächter der Vorübergehenden." Weiter heißt es dann, die Bedeutung dieses Gerichtshofs der öffentlichen Meinung liege offenbar darin, daß er die geltenden Anschauungen von dem, was löblich und tadelnswert, schön und häßlich, gut und schlecht ist, allen Abweichungen gegenüber aufrecht erhalte und durchsetze. Sie wirke als eine Art Sittenpolizei (vgl. HöFFDrng: aber Polizei ist etwas anderes als ein Gerichtshof!), ihre Strafmittel seien die dem Staat und der Kirche entfallenen: Verweis, Minderung der Achtung, endlich der Bann, d.h. die Ausschließung aus der Gesellschaft. Gelegentlich spende sie auch Belohnungen: Beifallklatschen ${ }^{1}$ ), Bewunderung, Ruhm. PAULSEN erörtert dann noch die Schwächen »dieses Gerichtshofs «: Mangel an geordnetem Verfahren, Mangel an sachkundigem Urteil. Dazu komme, daß die öffentliche Meinung die gemeine Meinung, die Meinung des Durchschnittsmenschen sei; sie begrüße alles Große, Ungewöhnliche, über die Durchschnittsfassung Hinausgehende mit Widerspruch und Hohngelächter. Hier liege der Grund, daß alle großen und kraftvollen Geister das Urteil der öffentlichen Meinung gering schätzten. - Man bemerkt, daß HöFFDING nur an die öffentliche Meinung irgendwelcher Umgebung als Kritik der sittlichen Werte denkt, PAULSEN aber an das vorherrschende Urteil des Publikums überhaupt - des Publikums, d. h. irgendeines Publikums. Beide beschäftigen sich nicht mit der besonderen politischen Bedeutung der öffentlichen Meinung, weder als einer mannigfachen noch als einer einheitlichen Potenz. Für beide gibt es die Offentliche Meinung nur als besonderen Fall meiner " öffentlichen Meinung, diese ist es, die sie im Auge haben, also eine sehr allgemeine und darum auch sehr primitive Erscheinung, ganz im Gegensatz zu der Auffassung, welche die Offentliche Meinung als eine ausgeprägt neuzeitliche, an die heutigen Lebensbedingungen geknüpfte Macht des Zusammenlebens versteht. In jenem Sinne spricht auch HERBERT SPENCER von wilden Volksstämmen, die ihre friedliche Lebensweise ohne andere Regierung außer derjenigen von öffentlicher Meinung und Sitte führen (Princ. of Sociology I, p. 719). Die Zusammenstellung mit der Sitte und mit der Mode (fashion) ist für diese Auffassung bezeichnend. Sitte und Mode, obgleich innerlich nahe verwandt, sind ganz verschiedene Arten des sozialen Willens. Sitte ist konservativ, Mode mutativ; Sitte Element der Vererbung, Mode

1) Im Texte steht: Beifall, Klatschen. Ich vermute einen Druckfehler. 
der Anpassung; Sitte will, daB man ihr treu bleibe, auch nachdem sie ihren ursprünglichen Sinn verloren hat, Mode will überhaupt keinen Sinn haben, sie ist wechselnde Laune, die keine Treue verlangt, sondern raschen Gehorsam; Sitte beruht in "Eintracht « der Lebensformen, Mode ist durchaus konventionell. In der konventionellen Gesellschaft liegen auch die Wurzeln der Offentlichen Meinung, sowohl als mannigfachen wie als einheitlichen Willens, während Offentliche Meinung, die sich an die Sitte anschließt, für jede Ge me in schaft charakteristisch ist, daher in der gegenwärtigen Theorie als eingeschlossen im sozialen Willen, der als Religion seine ausgeprägte Gestalt hat, verstanden wird.

\section{Kapitel.}

\section{Madht und Machtfaktoren der Öffentlichen Meinung.}

\section{Erster Abschnitt. Die Macht.}

I. (Neuerungen.) Es ist eine Tatsache, der alle bedeutenden Geschichtsschreiber ihre Anerkennung zollen, da $B$ die Offentliche Meinung, wie sie von ihnen in Ubereinstimmung mit der gegenwärtigen Theorie verstanden wird, bei allen großen Veränderungen in Kirche und Staat, in der Gesetzgebung, Justiz und Verwaltung, von denen die neueren Jahrhunderte erfüllt sind, eine bedeutsame Rolle gespielt, ihre Macht zur Geltung gebracht habe. Dies ergibt sich schon aus dem, was über die Aggregatzustände der Offentlichen Meinung ausgesprochen wurde. In ihren wichtigsten Ansprüchen und Leistungen kann eben die Offentliche Meinung schlechthin als der moderne Geist, der subjektive "Geist der Neuzeit «, begriffen werden, der zumeist allmählich, zuweilen stoßweise und plötzlich, sich entwickelt und immer stärker, immer erfolgreicher an der Vernichtung und Untergrabung überlieferter Anschauungen wie hergebrachter Institutionen arbeitet. Merkwürdig ist dabei vor allem, daß die Offentliche Meinung des Tages keineswegs im allgemeinen Neuerungen geneigt ist, viel eher stemmt sie sich dagegen und besteht darauf, daß das Hergebrachte wertvoll und richtig, oder doch im gegebenen Falle zweckmäßig sei, und jedenfalls einen guten Sinn habe. So sind alle die großen Veränderungen der Ansichten, des Rechts, der Staatsverfassungen zunächst von Wenigen befürwortet worden oder von Schichten, die nicht als die maßgebenden unmittelbar an der Gestaltung der Offentlichen Meinung beteiligt waren. Daher ist 
es ein langer historischer Prozeß gewesen, der die Offentliche Meinung zuerst in Fluß gebracht, dann sogar befestigt hat, zugunsten der Gewerbefreiheit, des freien Geldverkehrs, der Freizügigkeit, der Koalitionsfreiheit, der Versammlungsfreiheit, zugunsten der Verfassungen, der Wahlrechte und ihrer Ausdehnung, gegen das heimliche und schriftliche Prozeßverfahren, gegen Hexenprozesse und Folter, für Schwurgerichte und freie Beweiswürdigung; vollends in einer späteren Phase der Entwicklung für die Einmischung des Staats und seiner Gesetzgebung in den freien Arbeitsvertrag, für die Bedingtheit des Privateigentums an Boden und Kapital, also für die Zulässigkeit und Zweckmäßigkeit sozialistischer Neuerungen als gesetzgeberischer Beschränkungen des Eigentumsrechts. Die Widerstände versammelten sich regelmäßig und am wirksamsten in irgendwelchem religiöse n Motive, wie denn die Religion durchaus eine konservative Macht ist, mithin auch die Offentliche Meinung des Tages, so lange und sofern sie von der Religion umfangen bleibt. Es wird sich also immer um eine Umwandlung, Umgestaltung der Offentlichen Meinung handeln, wodurch sie zugleich entbunden und auf ihre eigenen Füße gestellt wird. Immer ist die Aufgabe der Neuerer gewesen, wenn sie nicht schon im Namen einer festen oder wenigstens flüssigen Öfentlichen Meinung auftraten, diese oder wenigstens unmittelbar die flüchtige Offentliche Meinung des Tages für sich $\mathrm{zu}$ gewinnen, also die Meinungen $\mathrm{zu}$ bearbeiten, sie, wo es nötig und möglich schien, umzustimmen. Sei es, daß einzelne "Propheten « mit bewußtem Willen dies unternehmen, von wenigen Anhängern unterstützt, oder $\mathrm{da} B$ diese, als ihre Jünger und Apostel, die Botschaft von der heilsamen Wahrheit, die der Meister gebracht habe, in die Welt verkünden, oder daß Dritte sich zu ihrem Vorteil der Sache bemächtigen, ihn und sein Gefolge unterstützen, selber offen oder verborgen die neuen Meinungen fördern und begünstigen - immer wird der Gang der Dinge um so langsamer und schwieriger sein, je stärker das Heer der überlieferten Ansichten, der damit verknüpften Gefühle und Interessen, je zäher also das Vorurteil und der Selbsterhaltungstrieb der alten Ordnung dawider steht. In diesem Sinne kann man das Sichdurchringen der neuen Ideen mannigfach beobachten. Auch wenn sie selber religiös sind, ja oft um so mehr, steht ihnen die Religion, die überlieferte, geltende, überwiegend geglaubte, als eine Festung, die zu erobern ist, entgegen. Indessen, wie religiöse mit religiösen, so kämpfen auch außerreligiöse mit außerreligiösen. Auch hier ist die Offentliche Meinung zunächst für die überlieferten, alten, festgewurzelten Ideen, sie weicht nur allmählich immer wiederholten Angriffen, wenn auch zuweilen, unter dem Druck ungeheurer Erreignisse, ein plötzlicher Ruck 
entsteht, der die langsam ausgehöhlte fallen läßt. Immer ist eine neue Offentliche Meinung zur Stelle, wie in einer politischen Revolution die neuen Träger der souveränen Gewalt, nachdem die alten abgesetzt sind oder abgedankt haben.

2. (Das Moment der Öffentlichen Meirung.) Die Macht der Offentlichen Meinung ist, wie das Gleichnis anzeigt, um so stärker, je höher der Grad ihrer Festigkeit und zugleich die Energie, mit der sie in Bewegung gesetzt wird: beide zusammen, die Masse mit dem Faktor der Geschwindigkeit, machen das Moment der Offentlichen Meinung. Die Festigkeit allein entscheidet die passive und negative Macht des Widerstandes gegen Angriffe, die Energie ist für den Angriff selber, also für die aktiven und positiven Wirkungen wesentlich.

In diesen Eigenschaften, die ihre Kraft bedingen, ist die Offentliche Meinung mit der Religion gleichartig. $\mathrm{DaB}$ aber, wie früher bemerkt wurde, die Religion vorzugsweise im festen, die Offentliche Meinung zumeist in ihrem flüchtigen Aggregatzustande betrachtet wird, rührt auch davon her, daß wir durch ein halbes Jahrtausend den Kampf zwischen Religion und Offentlicher Meinung beobachten; einen Kampf, worin sich die Religion notwendig und wesentlich in der Defensive befindet, während die Offentliche Meinung die Macht ist, die ihr das Gebiet streitig macht und immer vergrößertes Gelände ihr abgewonnen hat. Darum hat die Religion insbesondere durch ihre Festigkeit, als fester Glaube, ihre Widerstandsfähigkeit bewährt, es liegt in der Tat nahe, sie mit einer starken, sich selbst für uneinnehmbar haltenden Festung zu vergleichen, die als ganze selten angegriffen wird; um so mehr aber ihre zahlreich gebauten Vorwerke, gegen die von Zeit zu Zeit, mit größerem oder minderem Erfolge, ein Sturm der Offentlichen Meinung sich erhebt. In der Regel, und namentlich in den früheren Phasen werden wir auch in diesen Bewegungen ein starkes religiöses Element finden, wodurch sie sich verstärken, solange und sofern die gesamte populäre Denkungsart noch religiöse Färbung trägt. Die Offentliche Meinung offenbart sich zunächst in der Negative, der Kritik, der Ablehnung,Verwerfung, Herabwürdigung, Lächerlichmachung überlieferter, durch die Religion bisher geheiligter Vorstellungen, Lehrsätze, Vorschriften, "Dogmen " und "Riten«. Daran beteiligen sich insgemein die Andersdenkenden, mögen sie dabei ihre eigene, andersgeartete Religion oder Konfession ins Gefecht führen, oder diese im Hintergrunde behalten, oder insgeheim sogar verleugnen. Wenn wir die letzten $4^{1 / 2}$ Jahrliunderte überblicken, in denen diese Kämpfe so lebhaft gewesen sind, so finden wir, daß in der größeren Hälfte dieser Zeit die Offentliche Meinung noch kein Dasein für sich gehabt hat, $\mathrm{daB}$ sie olne religiöse Gewandung sich 
nicht sehen lassen durfte; ihr besonderes Dasein aber erkennen wir hinter dieser Gewandung, und zwar vorzüglich daran, da $B$ sie einmütig auftritt, ohne daß Einmütigkeit in den religiösen Fragen, die umstritten werden, als wirklich oder wahrscheinlich vorauszusetzen wäre.

3. (Verhältnis zur Kirche um die Wende der Neuzeit.) Eine solche Einmütigkeit wird nun am leichtesten sich einstellen in bezug auf Gegenstände von moralischer Bedeutung, insofern als in einem Volke hinlänglich gleichartige Normen gelten und also das Urteil über bestimmte Verstöße gegen solche sich von selbst $\mathrm{zu}$ verstehen scheint, weil Empfindungen des Unwillens und des Wunsches, Mißbilligung kundzugeben, ja zu strafen, allgemein und notwendig entstehen. Nun ist immer für eine herrschende Schicht der gute Ruf von ganz besonderem Werte, er trägt erheblich bei zu ihrem Ansehen und ihrem EinfluB, wenn auch beide zunächst auf Macht und Gewalt, diese aber zum guten Teil auf Uberlieferung, also auf den Glauben an die Erhabenheit und Würde der Herrscher sich stützen; welcher Glaube wiederum als religiöser Glaube seine Weihe und feste Gestalt empfängt. Gilt dies mittelbar für den weltlichen, so gilt es ganz unmittelbar und also um so stärker für den geistlichen Herrenstand. Beide aber können, trotz des beharrenden Glaubens an den Stand als solchen und an die Ämter, die er bekleidet, durch das Verhalten seiner individuellen Träger sich in Verruf bringen, so daß auch Macht, Ansehen, Einfluß schweren Schaden davon leidet. „,Keine Gesellschaftsklasse ist so sehr auf die öffentliche Achtung angewiesen wie der Klerus: darauf beruht seine innere und äußere Macht. Versteht er nicht zu imponieren, so versteht er nicht zu regieren." (LORENZ u. Scherer, Gesch. des Elsaß I, I42)ํㅣㅇ. Das Imponieren freilich mußte um so besser gelingen, wenn die Würden des weltlichen Adels mit der geistlichen Aristokratie gepaart waren, wie es in ausgedehntem Maße immer mehr im I5. Jahrhundert üblich geworden war, da das bischöfliche Amt regelmäßig dem Adel vorbehalten blieb und oft auch landesherrliche Funktionen in sich schloß. Auch ist es weniger diese Verweltlichung der Kirche, die mehr innerhalb ihrer selbst Anstoß erregte, als der anstößige Lebenswandel der allzu massenhaft auftretenden niederen Geistlichkeit gewesen, allzu oft verbunden mit auffallender Unwissenheit dieses bisherigen

1) $\mathrm{Da} ß$ die 》Renaissance in Italien literarisch dahin wirkte, das Ansehen des geistlichen Wesens und damit auch des geistlichen Standes zu untergraben, ist offenbar. Uber die „Stellung des Papsttums zur öffentlichen Meinung“ handelt BURckHARDT ausführlich (Kultur der Renaissance, I, 97ff., 265), ebenso über die schmachvolle Nachrede, die man (schon im 13. Jahrhundert) den bloßen Pfründnern, Chorherren und Mönchen gewidmet hat (II, 23off.). 
Lehrstandes, was allmählich "die öffentliche Meinung " gegen sie empört hat ${ }^{1}$ ); das aber war schon damals vorzugsweise die, wenn auch noch durchaus religiös gefärbte, Bildung der Städte, woran auch ein Teil des niederen Adels tätigen Anteil nahm. Bis dahin um die Wende des I5. zum I6. Jahrhundert - war die gemeinsame Religion der Völker, die als Erben des weströmischen Reiches dessen Kultur fortsetzten, indem sie ihre eigene ausgestalteten, das Christentum der römisch-katholischen Kirche. Nachdem beide - Religion und Kirche - manche Erschütterungen bestanden hatten, geschah es im I6. Jahrhundert, daß ein tiefer Riß sich öffnete, der seitdem nicht wieder geheilt worden ist, und Teile jener Völker, auch innerhalb der meisten, als protestantische von denen, die der alten Kirche wenigstens äußerlich treu geblieben sind, abhebt. Die Fortschritte der "Reformation "laufen parallel und sind vielfach verwoben mit den Fortschritten des städtischen Wesens, also des Handels und der von ihm abhängigen industriellen Arbeit. Mit ihnen aber steigt auch die Erkenntnis der wirklichen Welt und das Streben, sie durch Erkenntnis zu beherrschen, wenn man auch zunächst mit dem Wissen, das aus dem Altertum überliefert war, sich begnügen muß. Dies Studium schließt unmittelbar an die Gelehrsamkeit der Schulen, die Kleriker und Rechtsgelehrte zu bilden bestimmt war, sich an, als älterer Humanismus noch in Fühlung damit bleibend, als jüngerer in heftiger Opposition dagegen, die sich als Spott und Verachtung kundgibt. Die Angriffe richten sich wider die ganzen Stände: die Geistlichkeit und die Doctores, aber mit der größeren Leidenschaft und Erbitterung gegen jene, die gerade auch im Punkte der Bildung am meisten der Kritik ausgesetzt war. Die Angriffe waren bestimmt, auf die große Menge der Gebildeten oder Bildungsdurstigen zu wirken; darum kleideten sie sich am liebsten in das Gewand des Witzes, der Satire; wie Thomas MURNER zu jener Zeit sagte: „Wer dem Ungelehrten will schreiben, der muß spassen viel." Holzschnitt und Buchdruck waren schon als die technischen Mittel der Vervielfältigung der Späße wie des Einstes zur Verfügung; sie waren auf den lebhafteren Verkehr der größeren Städte, woran auch das Landvolk der Umgebung teilnahm, berechnet. Aber auch an die Gelehrten, auch in deren eigener Sprache

1) „Ys war so weit gekommen, daß die Verfassung des geistlichen Standes die öfentliche Moral beleidigte" . . .,der Zustand der in wilder Ehe lebenden Priester ... erregte Mitleiden und Verachtung". (RANKF, Deutsche Geschichte im Zeitalter der Reformation I, 251.) Eir führt des Humanisten WIMPnitr.ING Ausspruch vom scandalum odium murmur populi in omnem clerum an und fügt hinzu: ,Unzählige Aussprüche in diesem Sinn waren im Umlauf; die Flugschriften jener Zeit sind voll davon." Als gemeinsamen Charakter der hervorleuchtendsten Eirscheinungen der Literatur um die Wende des Jahrhunderts bezeichnet RANkE den der Opposition. 
und Denkweise, wandte sich die Bosheit der Kritik gegen den gelehrten Stand - dies war der Charakter und darin beruhte die Wirkung der „Episteln unberühmter Männer", worin es so grell zutage trat, daß „der ehemals hochgeehrteste Stand", die Geistlichen, in der öffentlichen Meinung, ,immer tiefer sank und seinen Boden in stetiger Abnahme mehr und mehr verlor". So lange als es noch wesentlich um eine Bewegung in der Gelehrtenwelt und deren Ausbreitung sich handelte, stand unangefochten an ihrer Spitze ein Schriftsteller und Theologe europäischen Ansehens wie der Niederdeutsche ERASMUS, „der erste große Autor der Opposition in modernem Sinne", wie ihn RANKE (Deutsche Geschichte im Zeitalter der Reformation I, 260), ,der erste große Vertreter und Prediger der rein humanistischen Bildung in Deutschland", wie ihn PAULSEN (Gesch. des gelehrten Unterrichts ${ }^{3}$ I,67) genannt hat. Sein ,L,ob der Torheit“",brachte eine unbeschreibliche Wirkung hervor": ,noch bei Lebzeiten des ERASmus sind 27 Auflagen davon erschienen; in alle Sprachen ist es übersetzt worden: es hat wesentlich dazu beigetragen, den $*$ Geist des Jahrhunderts* in seiner antiklerikalischen Richtung zu befestigen" (RANkE 1. c. 263). „So ward er allmählich der berühmteste Mann in Europa: die öffentliche Meinung, der er Weg bahnte vor ihr her, schmückte ihn mit ihren schönsten Kränzen (ib. 265). Ein Prediger wie JoHAN GEILER vON KEISERSPERG, der die erregte Kritik des Volkes mit der Autorität seines Wortes bekräftigte (LORENZ u. SCHERER, 1. c. I53); ein Schriftsteller wie der Dichter des Narrenschiffs, SEBASTIAN BRANT, der „mit kühnem Freimut den Trägern der kirchlichen und der weltlichen Gewalt ihre Gebrechen vorhält, mit schneidender Schärfe gegen die Verkehrtheiten und Laster, wo und wie immer sie sich zeigen, zu Felde zieht" (JANSSEN, Gesch. d. deutschen Volkes I, I7/I8, 304), haben mit vielen Geringeren, und mit dem begünstigenden Einfluß der Zeitverhältnisse, die eine immer zunehmende Unzufriedenheit etwa I467-I5I7 nährten, dahin zusammengewirkt, etwas wie eine dem deutschen Volke gemeinsame Offentliche Meinung hervorzubringen, die der Reformation die Wege ebnete. So meinte schon Christran Garve, keine Begebenheit habe vielleicht die Macht der öffentlichen Meinung in dem Sinne, den er dem Worte gebe (er war einer ihrer frühesten Theoretiker) deutlicher gezeigt als die Reformation. „Es hatte sich eine öffentliche Meinung gebildet, daß eine Änderung in der Lehre, den Gebräuchen, und vornehmlich in der Hierarchie der Kirche vorgehen müsse; und selbst über viele Punkte des neu zu errichtenden Systems war man im Stillen zu einer Entscheidung und Einstimmigkeit gekommen. Daher der unerwartete Beifall, welchen der Mann in der Welt fand, der diese gemeinschaftlichen Urteile Vieler in seinen 
Schriften gleichsam nur sammelte und kundmachte. Er wurde der Vereinigungspunkt, um den sich die schon vorhandene Partei sammelte, wodurch ihre Größe sichtbar wurde, er war aber nicht der Stifter derselben" (Versuche über versch. Gegenstände der Moral, V, 30I) Bei einem neueren Autor finden wir dargéstellt, wie die ,nationalen Humanisten, HUTTEN voran" um LUTHER sich drängten und ihn als ihren Bundesgenossen begrüßten, wie HuTres auch den mächtigen Reichsritter SÄCKINGEN gewann, und so die drei bis dahin getrennten Richtungen der Opposition, die theologische, die humanistische und die politische ,zu einem großen Strom verschmolzen“. „Zum erstenmal wurde die Presse eine Macht im Leben des deutschen Volkes" (KÄMMEL, Der Werdegang des deutschen Volkes II., S. 7). Dabei ist aber noch nicht der revolutionären Bewegungen in der Bauernschaft und in den Unterschichten der Städte gedacht worden, die geraume Zeit vor LUTHER in lebhaftester Gärung waren, aber die Verkündung der *evangelischen Freiheit « um so lieber willkommen hießen, da sie längst im stillen der Schwärmerei huldigten, die durch alle Ketzereien hindurchgehend, im Husitentum neu belebt, eine vollkommene Erneuerung christlicher Gemeinschaft und des allgemeinen Priestertums verlangten, um der erwarteten Wiederkunft des Herrn und dem Aufgang des rooojährigen Reiches entgegenzugehen. Diese Schwarmgeisterei bildete den Generalbaß in der Harmonie der Offentlichen Meinung; sie ist durch und durch religiös, aber widerkirchlich religiös und eben dadurch auch weltlich-praktisch gerichtet. Nur kurze Zeit klangen alle diese Instrumente zusammen, und diese Zeit war eben die des Auftretens LUTHERS, darum horchten, so mannigfach auch ihre Motive waren, alle ,Ritter, Bürger und Bauern, Kleriker und Laien, Gelehrte und Ungelehrte deutscher Nation, hoch auf, als ihnen die lang erwartete Stimme des Befreiers, das ersehnteWort der Erlösung ans Ohr schlug" (F. v. BEZOLD, Gesch. d. deutschen Reformation, 244). Aber, wie es regelmäßig und gesetzmäßig geschieht, auf diesen Gipfel gelangt, erweckte das Getöse auch den Widerstand, die Reaktion bahnt sich an, die alten Gewalten sammeln ihre Streitkräfte - LUTHER verfiel dem Bann und der Reichsacht. Hausrath, sein protestantischer Biograph, berichtet, wie unter Hadrians Papsttum der Aberglaube beider Parteien mit einem mißgeborenen Kalbe sich deutend beschäftigte. „Es gab nur noch eine Liebe und einen $\mathrm{HaB}$; kam ein Ungeheuer zur Welt, so mußte es LuTHer bedeuten oder die Klerisei, wo man früher an den "Türk oder 'Tartar" gedacht hätte. Das war die Stimmung in Deutschland unter Hadrian VI., und dieser Umschlag der öffentlichen Meinung war das Werk eines einzigen Mannes" (L.UTHER, I, 572). Aber nicht umgeschlagen war die Offentliche Meinung, 
die Spaltung ist von nun an das, was sie in Fragen der Religion und des Kirchentums bezeichnet. Sie geht der Spaltung der Länder und Städte, der Territorien in katholische und protestantische, später in lutherische und reformierte, voran, in welchen Spaltungen dann die ganze Bewegung erstarrte und verging. - Ein amerikanisch-deutscher Literaturhistoriker, der das tragische Schauspiel der deutschen Entwicklung von der Reformationszeit bis in den 30 jährigen Krieg schildert, bricht in die Worte aus: „Wie anders wäre der Gang der Ereignisse gewesen, wenn zu jener Zeit ein umfassendes nationales Bewußtsein, eine starke Öfentliche Meinung in Deutschland vorhanden gewesen wäre!" (Kuno Francke, Social forces in German literature, p. I39). Und er wiederholt (ib. 20 Seiten nachher), die Hauptursache, warum die Bewegung ins Stocken geriet und die idealistische Strömung der deutschen Literatur hemmte, sei darin zu finden, daß ein starker nationaler Wille, eine aufgeklärte Öfentliche Meinung im Deutschland des I6. Jahrhunderts gefehlt habe.

4. (Die Wucherfrage.) Ganz auffallend tritt uns die Einmütigkeit der Offentlichen Meinung entgegen in Fragen von wirtschaftlicher und politischer Art, die ehemals streng von der Religion aus betrachtet wurden, jetzt aber gänzlich außerhalb ihres Bereiches fallen, auch wenn sie etwa noch eine moralische Seite darbieten, die sonst ausschließlich vom religiösen Standpunkt beurteilt wurde, nunmehr aber einem rein weltlichen und rationalen Urteil unterliegt. Eine solche Frage ist die des zinsbaren Darlehns. Bis über das Jahr I60o hinaus, und mindestens seit I200, galt der Satz von der pravitas usuraria: daß alles eigentliche Zinsennehmen eine Sünde sei, gemäß dem Herrenwort Mutuum date, nihil inde sperantes. Es war ein religiös begründetes, theologisch-kanonisches Verbot, das eine weitschichtige gelehrte Literatur hervorrief, eine sehr große Rolle in der Beichtpraxis spielte und als schlechthin gewissenbindend galt. Heute geht, unabhängig vom religiösen Bekenntnis, die allgemeine Überzeugung dahin, daß es kaum etwas Harmloseres, Unschuldigeres, Natürlicheres geben könne, als bei Gewährung eines Darlehens Zinsen dafür auszubedingen; während die Gewährung eines zinsfreien Darlehens - in der Regel auf kleine Beträge beschränkt - entweder als Ausdruck besonderen Wohlwollens gegen Freunde und Verwandte gilt, oder als eine Wohltätigkeit, deren Luxus reiche Personen sich gönnen, sei es aus gutem Herzen, oder weil sie darin einen besonderen Genuß ihrer Reichtumsmacht empfinden. Die Verwerfung und Verurteilung des "Wuchers « ist die gleiche geblieben; aber während damals - für den Standpunkt des römisch-katholischen Christentums - alles Zinsnehmen als Wucher gebrandmarkt wurde - weshalb auch jene Norm des kano- 
nischen Rechts als "Wucherverbot " bekannt ist -, so wird heute darunter teils alle mit Ausbeutung fremder Notlage, fremden Leichtsinnes u. dgl. verbundene Annahme oder Bedingung übermäßiger Zinsen genannt, teils die damit verwandte Erzielung und Erraffung auffallend hohen Handels- und Unternehmergewinnes, zumal wenn Schliche und Tücken dafür angewandt werden, um Gesetze zu umgehen oder auf die Gefahr nicht abschreckender Strafen hin offen zu ïbertreten. In der entschiedenen Mißbilligung solcher Praktiken gehen ebenso, wie im Abscheu gegen Diebstahl und Betrug die Moral der Religion und die Moral der Offentlichen Meinung einig; um so auffallendex erscheint das weite Auseinandergehen, wenn die historische Bedeutung des Wucherverbotes ins Auge gefaßt wird. Sie hängt damit zusammen, da $B$ überhaupt das wirtschaftliche Erwerbsleben in erster Linie unter den Gesichtspunkt von Gut und Böse gebracht wurde, und daß die Arbeit für besser galt als Handel und Geschäft; nachdem diese überwiegend und herrschend geworden sind, haben sie nicht geradehin das Verhältnis umzukehren vermocht, wohl aber bewirkt, daß sie nur ausnahmsweise unter moralische Beurteilung fallen; im allgemeinen genügt die Rechtlichkeit und Ehrlichkeit, deren Wesen man darein setzt, $\mathrm{da} B$ I. das positive Recht wenigstens soweit beobachtet wird, als es allgemein geltenden moralischen Vorstellungen Ausdruck gibt, 2. auch ein natürliches Recht Anerkennung findet, das darin gefunden wird, da $B$ sehr weitgesteckte Grenzen des Verhältnisses von Leistung und Gegenleistung nicht überschritten werden. Während nun die Offentliche Meinung als Sprecherin jener moralischen Vorstellungen auch sehr hohen Handels- und Unternehmergewinn in der Regel mehr bewundert als verurteilt, so ist es anders in bezug auf "Kriegsgewinne" - gegen diese macht sie mit Heftigkeit geltend, daß es häßlich ist, in einer Zeit, da das Volk leidet und seine Jugend sterben oder verstümmelt oder in Gefangenschaft schmachtend sehen muß, sich zu bereichern und zu mästen, zumal wenn dies durch die Not des Volkes geschieht, wie bei einigen Arten dieser Handelsgeschäfte offensichtlich der Fall ist oder doch so, daß die öffentliche Not dadurch gesteigert wird. Nun begegneten freilich diese Anklagen sich mit dem Odium, worin der Kapitalismus überhaupt in weiten Kreisen des Volkes gefallen ist, als Ursprung des Mehrwertes, des arbeitlosen und auf Ausbeutung fremder Arbeit beruhenden Einkommens. Die Offentliche Meinung nimmt bisher an dieser Gesamtverurteilung des werbenden Kapitals nicht Teil, sie will vielmehr durch Preisgabe der "Auswüchse «, des sillegitimen «Handels, des neuen Reichtums, den die verhängnisvolle Kriegskonjunktur hervorbringe, den "reellen « Handelsund Fabrikationsgewinn retten, sie betrachtet als Regel, daß der 
Gewinn durch das persönliche Verdienst der "Unternehmer " erzielt werde, und daß er zugleich dem allgemeinen Besten, insbesondere gerade zum Besten der Besitzlosen, denen sie "Arbeit geben «, diene; denn nur die Aussicht auf Gewinn kann sie dazu bestimmen, diesen sogar im Vorschuß - Lohn zu zahlen. Auch abgesehen davon, daß im Unternehmergewinn ein Lohn enthalten ist, der als Vergütung für Leistungen, die für die Entstehung des Produktes wesentlich waren, zu denken ist, gilt doch der Gewinn, also auch der des reinen Handels, als "verdient «, weil erworben durch eigene kluge Tätigkeit, durch Fleiß und Eifer, und weil das Ergebnis, die Versorgung des Marktes, gemeinnützig sei. Auf ein solches Verdienst kann nun freilich der bloße Leihkapitalist keinen Anspruch machen. In Wahrheit gilt, wenn auch die Nationalökonomen allerhand Theorien zur Erklärung des Kapitalzinses, die zum Teil zugleich dessen Rechtfertigung enthalten wollen, vorbringen, der Kapitalzins als selbstverständlich. „Es wird ganz so Eigenschaft des Geldes, Wert zu schaffen, Zins abzuwerfen, wie die eines Birnbaumes, Birnen zu tragen“ (K. MARX, Kapital III, 378). „In dem zinstragenden Kapital ist aber die Vorstellung vom Kapitalfetisch vollendet, die Vorstellung, die dem aufgehäuften Arbeitsprodukt, und noch dazu fixiert als Geld, die Kraft zuschreibt, durch eine eingeborne geheime Qualität, als reiner Automat, in geometrischer Progression Mehrwert zu erzeugen ...." (ib. 385). Es ist sicherlich der größte Triumph der Offentlichen Meinung, daß sie in diesem Sinne sich durchzusetzen vermocht hat, ihre Macht kann sich nicht deutlicher beweisen, als dadurch, daß sie keinen Widerstand und Widerspruch mehr zu gewärtigen hat, daß insbesondere auch die Religion ihr durchaus hat nachgeben müssen, wie es dadurch geschehen ist, $\mathrm{da} B$ im Jahre $\mathrm{I} 830$ die Poenitentiaria Romana den Beichtvätern Anweisung erteilte, die Zinsnehmer nicht mehr zu beunruhigen (Roscher, I ${ }^{22}, 573$ ). Die Geschichte des Wucherverbots ist die Geschichte eines allmählichen Zurückweichens mit immer vermehrten Einräumungen, deren bedeutendste sich noch heute in der Einschiebung des Wortes Interessen, das in mehreren Hauptsprachen das herrschende Wort für Zins geworden ist, dem Gedächtnis eingeprägt hat; denn dies Wort sollte ursprünglich einen anderen Begriff, den Begriff einer erlaubten Vergütung, im Gegensatz zur verruchten des Zinses, bezeichnen. Die Offentliche Meinung ließ sich diese Einräumung gefallen und sprach unter dem Namen des Interesses den Zins frei, nachdem in Wirklichkeit beide längst identisch geworden waren. Auch darin tut ihr entscheidender Sieg sich kund, daß die modernen philosophischen Werke über Ethik der Fragwürdigkeit des Zinsnehmens überhaupt keine Erwähnung mehr tun. Und es ist 
sogar eine Neigung deutlich wahrnehmbar, die Selbstverständlichkeit des Zinses auf den ganzen Kapitalgewinn auszudehnen, wenn er nur nicht durch eforme Höhe AnstoB erregt; diese aber wird auch dem Zinsfuß nicht gegönnt, ja gilt sogar als verbrecherisch.

5. (Kirche und Staat.) Ein drittes Beispiel der Macht der Offentlichen Meinung, wie sie im Gegensatz zur Religion sich entfaltet hat, wählen wir aus dem politischen Gebiete. Es betrifft die Idee des Gemeinwesens selber. Für die Religion, so lange sie die herrschende Geistesmacht war, verstand es sich, daß die Kirche das höchste, das wahre, das von Gott selber gestiftete, also über menschliche Kritik erhabene Gemeinwesen wäre. Die Offentliche Meinung hingegen steht auf seiten des Staates. Sie bekämpft die Hierarchie, die Theokratie, die Machtansprüche der Kirchen, die Intoleranz und den Jesuitismus, ja auch das Staatskirchentum; sie neigt dazu, im Staate allein die sittliche Macht anzuerkennen, welche die Kirchen für sich in Anspruch nehmen. Sie begrüßte den Kampf der preußischen und badischen Gesetzgebung gegen die Úbergriffe der Kirche, die Verbannung der Jesuiten aus dem Deutschen Reiche als "Kulturkampf «, sie klagte die Verkündung der Unfehlbarkeit des Papstes in dogmatischen Fragen an als eine Verhöhnung der gesunden Vernunft, eine Kriegserklärung gegen den Staat, wodurch der konfessionelle Friede gestört werde. Der Gebrauch der Wörter "Pfaffen " und "Pfaffenherrschaft ", oft in Verbindung mit dem Worte "mittelalterlich «, gibt der Offentlichen Meinung in dieser Hinsicht bezeichnenden Ausdruck: das Wort Pfaff, ursprünglich eine ehrenvolle Bezeichnung des geistlichen Standes, ist längst zum Schimpfwort geworden. Im übrigen ist das Verhalten der Offentlichen Meinung, wenigstens in Deutschland, vollends etwa in England, nicht schlechthin feindlich gegen die Kirchen, sondern duldsam, mit dem Zugeständnis, da $B$ sie einen gewissen moralischen Wert haben, wenn sie nur dem Staate sich unterordnen und keiner Ubergriffe in dessen Gebiet sich schuldig machen. Anders ist es in den romanischen I,ändern. Besonders in Frankreich steht die Offentliche Meinung stark unter dem Einfluß des Freimaurer-Ordens, und dieser huldigt, außer, $\mathrm{da} B$ er einen heftigen republikanischen Chauvinismus, dem die Offentliche Meinung genau folgt, vertritt, Vor,TAIREschen Uberlieferungen, deren Stichwort das Ecrasez l'infame. Nur unter dem Druck einer starken antikirchlichen Offentlichen Meinung war die Trennung der Kirche vom Staat möglich, die im Jahre 1905 ausgesprochen wurde, nachdem schon vorher mit rücksichtsloser Härte gegen die geistlichen Korporationen und ihre Schule verfahren war. In dem fortdauernden Kampfe ist es aber ohne Zweifel der Kirche zugute gekommen, daß dic Offentliche Meinung in den folgenden Jahren abgelenkt wurde ind zwar auf ein 
Gesichtsfeld, das gerade in Frankreich ihr von altersher teuer ist: das der nationalen Gloire und Bereicherung: die Eroberung Marokkos, die Entente cordiale mit England, die dadurch und durch Englands Versöhnung mit dem Zarismus der Aussicht sich eröffnende Wiedereroberung des Elsaß und der abgetrennten Teile Lothringens diese Dinge traten mit erhöhter Stärke ins öffentliche Bewußtsein; die leidenschaftliche Wut der Eifersucht und Rachsucht gegen das immer mächtiger emporsteigende deutsche Nachbarreich verdunkelte alle anderen Empfindungen. Die Kirche gab dazu wie immer ihren Segen; Kirche und Offentliche Meinung schlossen einen Waffenstillstand auf Grund des gegebenen Zustandes. Ähnlich wirkte in Preußen, und mittelbar im ïbrigen Deutschen Reich, der verstärkte Gegensatz gegen die Sozialdemokratie im letzten Viertel des I9. Jahrhunderts zur Abschwächung des Kulturkampfes: die Waffen wurden auf dem Fechtboden niedergelegt, weil der Staat sie für anderen Gebrauch nötig hatte, und die Offentliche Meinung gab ihre Zustimmung dazu. Überhaupt läßt sich beobachten, daß fast das ganze Jahrhundert hindurch, die Stoßkraft der Offentlichen Meinung wie die der gesamten liberalen Denkungsart, der sie den am meisten geistigen Ausdruck gibt, erheblich vermindert wird durch das Emporkommen des Radikalismus und Sozialismus, weil gegen diese Mächte auch, und oft am meisten, der Liberalismus sich wehren muß und daher nicht selten mit den konservativen Gesinnungsmächten sich zu vertragen und sogar zu verbünden geneigt wird. Sehr bedeutende Bestandteile der liberalen Meinung sind feste Offentliche Meinung geworden; im Widerstand gegen "hierarchische Gelïste « wirkt sie bestimmend und maßgebend; wo es nicht oder nicht mehr der Fall ist, da muß der Liberalismus kämpfen um seine Geltung und, um als öffentliche Meinung zu wirken, sich nach Bundesgenossen umsehen; daher wirbt er um konservative Gunst, wenn es gegen links, und um radikale Gunst, wenn es gegen rechts zu kämpfen geboten scheint. Das Werben ist es eigentlich, was die unartikulierte öffentliche Meinung bezeichnet, Werben und Kämpfen. Im allgemeinen hat sie, wenn sie einen so hohen Grad von Dichtigkeit gewinnt, daß sie als artikulierte wirken kann, dies einem Eindruck und Antrieb zu verdanken, der plötzlich "die weitesten Kreise " ergreift und nun mit größerer oder geringerer Heftigkeit "die» Offentliche Meinung in Bewegung setzt: als ein heftiger Wind, ja als Sturm, ersetzt sie dann durch Energie, was ihrer Masse fehlt; ihr Moment kann durch diesen Impetus gewaltig und zermaimend wirken. So erhob sich ein Sturm der Offentlichen Meinung Deutschlands, als jene Daily Telegraph-Enthüllung geschehen war, die das persönliche Ansehen des Kaisers tief erschütterte und damit eine der Wurzeln des monarchischen 
Bewußtseins angriff. Auf eine Einschränkung der monarchischen Gewalt, Abschaffung des persönlichen Regimentes hatte die liberale Meinung immer hingearbeitet; in bezug auf den zweiten Punkt waren sogar die nationalliberale und die fortschrittliche Richtung miteinander einig; auch das Zentrum fand daran keinen Gefallen; die sozialdemokratische Partei, soweit sie schon für die öffentliche Meinung in Betracht kam, war der monarchischen Institution ebenso wie ihrem persönlichen Träger abgeneigt. Aber auch die entschiedensten Verfechter der Institution sahen auf diesen Träger mit starken Zweifeln, wenn nicht mit offener Geringschätzung. So bedurfte es in diesem Falle keines eigentlichen Werbens und Kämpfens, um den Sturm zu entfesseln. Oft aber ist die Entstehung der Offentlichen Meinung des Tages und ihrer Kraft einem langwierigen Bohren zu verdanken, einer "Agitation ", die das Erdreich des zumeist in Sitte und Religion verwurzelten Bewußtseins allmählich auflockert und es bereit macht zum Empfange und zur Förderung des eingestreuten Samens.

\section{Zweiter Abschnitt. Die Machtfaktoren.}

6. (Übergänge der Aggregatzustände.) In der Regel wird man finden, $\mathrm{da} B$ die luftartige $O$ ffentliche Meinung $I$. aus der flüssigen und 2. durch deren Vermittlung aus der festen Offentlichen Meinung in einem Prozeß entsteht, den wir mit der Schmelzung und Verdunstung vergleichen mögen. Beide sind Wirkungen der Zufuhr von Wärme, d. i. von Bewegung, die den molekularen Bau eines Körpers zersetzt. Solche Wirkung übt auf die menschliche Seele die Gemütsbewegung oder Erregung, die ebenso ganze Mengen, wie den einzelnen Menschen ergreift. Bei dem Einzelnen stellt sie sich ein, wenn seine persönlichen Werte und Güter angegriffen und bedroht, vermindert und verschwächt, aber auch, wenn sie begünstigt und gefördert, vermehrt und verstärkt werden. Es ist in der Regel wohl heute die feste Meinung und Überzeugung eines gebildeten Mannes, daß Sklaverei durchaus und unter allen Umständen verwerflich und schändlich sei; zuweilen ist es aber nur eine flüssige Meinung, deren Gerinnen verhindert wird durch gewisse Eindrücke, die er aus der Lektüre von der Minderwertigkeit der schwarzen Rasse, von der Notwendigkeit, in tropischen Ländern Arbeitszwang auszuüben usw. gewonnen hat; oder der Abscheu, den eine Zeitungsnachricht von der Bestialität farbiger Soldaten, deren die Fntente-Politik zur Zivilisierung der barbarischen Deutschen sich bedient, hat schmelzend auf sein BewuBtsein gewirkt. Nun aber wird ihm die briefliche Kunde, daß sein Sohn auf einer Reise in die Gewalt eines Negerstammes geraten und in die Sklaverei verkauft 
worden ist. Wenn er das gleiche gehört hätte von einem jungen Türken oder Engländer, so wäre der Fluß seiner Meinung kaum davon berührt worden. Da sie ihn selbst angeht, so treibt die Kunde Blasen, die in die Höhe steigen. Sein Kummer läßt den leidenschaftlichen Wunsch und die Meinung entstehen, daß die Sklaverei und die Reste des Sklavenhandels von den europäischen Nationen mit aller Macht unterdrückt werden sollten. - So auch die Offentliche Meinung. Es war im Jahrzehnt I 860-I870 eine ziemlich feste Offentliche Meinung, durch Wissenschaft und Presse genährt, daß die vollkommene wirtschaftliche Freiheit, ohne hemmende Staatseinmischungen, für das Gesamtwohl, auch für die Arbeiterklasse, das heilsamste System sei, daß diese nur durch Selbsthilfe, namentlich durch Sparsamkeit.und Einschränkung ihrer Vermehrung sich helfen könne, übrigens werde die Vermehrung des Kapitals auch den Lohnfonds allmählich erhöhen. Durch die Arbeiterbewegung und den dieser entgegenkommenden Kathedersozialismus geriet diese Offentliche Meinung in den Fluß der Diskussion, die mit nicht geringer Heftigkeit und Wärme geführt wurde. Dann aber wurde die Sozialdemokratie drohend. Die Vermehrung ihrer Anhänger erregte die Gemüter; eine schwere, lang sich hinschleppende wirtschaftliche Krisis ließ die Lage der Arbeiterklasse, zumal der Arbeitslosen, in trübstem Lichte erscheinen; die Monarchie und die Religion wurden von einer rücksichtslosen Agitation in Reden und Schriften angefochten, mit ihnen schien die Sicherheit des Eigentums zu wanken. Die Offentliche Meinung verlangte Repression, aber sie bekehrte sich gleichzeitig unter dem Drucke der Furcht zum Aufgeben des Laisser faire-Prinzips, zu der Erkenntnis, daß durch Gesetze, durch Reformen der Arbeiterklasse von Staats wegen geholfen werden müsse. Die beiden Attentate auf den mehr als achtzigjährigen Kaiser, im Sommer I 878, obgleich Taten Wahnwitziger ohne wirklichen politischen Hintergrund, wirkten in höchstem Maße aufregend und entscheidend, zunächst ausschließlich im Sinne des Ausnahmegesetzes, bald aber auch so, $\mathrm{daB}$ die kaiserliche Botschaft, die ein praktisches Christentum ankündigte, willkommen war: die Furcht gab den Ausschlag und drängte die theoretischen Bedenken in den Hintergrund.

Eine feste Meinung oder Úberzeugung geht nicht leicht unmittelbar in den gasförmigen Zustand über, sie muß erst in Fluß geraten sein. Jemand hat die heutzutage normale Ansicht in sich befestigt, daß Geistererscheinungen nichts Wirkliches sind, sondern auf Täuschungen und Einbildungen beruhen. Durch vielfache Erzählungen und Versicherungen gläubiger Spiritisten gerät aber seine Meinung sachte in Fluß. Da wird die Zauberei eines seiner bisherigen Freunde als Betrug entlarvt. Nun "empört « er sich gegen den "Unfug « - »seht ihr, 
wie recht ich hatte " - seine Meinung zittert in den Lüften, so wie sie durch das Erlebnis erregt wurde; ihrem allgemeinen Inhalt nach gewinnt sie den vorigen Grad der Festigkeit. Ganz das gleiche begegnet der Offentlichen Meinung, die leicht in Fluß und Zweifel gebracht wird durch Reden und Schriften, durch erschütternde Begebenheiten gerade in bezug auf übersinnliche Dinge besitzt sie in der Regel nur einen geringen Grad von Festigkeit, aber mit lebhafter Genugtuung, mit einem Gefühl der Sättigung nimmt sie es wahr, wenn ein »eklatanter « Fall bekannt wird, durch den ihre »eigentliche « Ansicht, daß es mit allen solchen angeblichen Erfahrungen nichts auf sich habe, Bestätigung empfängt. - Je weniger fest eine Meinung ist, um so leichter gerät sie ins Wanken, ja wenn mannigfache Elemente auf sie wirken, in Zerrüttung. Eine flüssige Meinung wird leicht, wenigstens Stücke von ihr werden durch widrigen Wind in entgegengesetzte Richtung getrieben, oder sie teilt sich nach verschiedenem Gefälle. Kommt dann eine Erregung hinzu, die dem Stücke, das in die andere Richtung treibt, begegnet, so hat sich das Individuum oder das Publikum eine neue Meinung gebildet, ist anderen Sinnes geworden: ein Beispiel wurde schon angeführt. Es ergibt sich zugleich, warum die Offentliche Meinung in ihrem luftartigen Zustande so selten mit sich einig ist, und, um es vorübergehend zu sein, eines starken I $\mathrm{m} p$ ulses bedarf. Normal ist die Auflösung in verschiedene Meinungen, ja es darf die Regel gebildet werden: je loser der Aggregatzustand, um so mehr wird die artikulierte Offentliche Meinung der unartikulierten ähnlich, und umgekehrt: je fester der Aggregatzustand, um so einiger ist mit sich die Offentliche Meinung. Immer ist die Einigkeit am größten nach außen hin, gegen den Feind oder den Gegner; daher dauernd in gewissen wesentlichen Beziehungen. Die Öfentliche Meinung ist hier wie eine Mater oder umgibt sich mit einer Mauer wie eine Feste, mit einem Panzer wie ein Kriegsschiff; die Einigkeit entsteht plötzlich im Augenblicke der Gefahr: es wird notwendig, zu kämpfen, sich zu wehren; um der Abwehr willen zum Angriff überzugehen. Möge es sich dabei um einen wirklichen "Verteidigungskrieg " handeln oder nur der Schein eines solchen erregt sein und in Wirklichkeit ein räuberischer Angriffskrieg gegeben sein, der aus Handelseifersucht entsprungen ist - um Volksstimmung und öffentliche Meinung für die Sache zu gewinnen und zu einigen, täuscht aber die Regierung eines solchen Staates den Verteidigungskrieg vor, oder wenn dies gar zu unwahrscheinlich ist, sogar den ritterlichen Krieg, um einer kleinen Nation gegen Räuber und Mörder zu helfen; dies wirkt eben auf die Offentliche Meinung stark, und sie wird rasch hinabgedrückt auf das Niveau der allgemeinen impulsiven Volksstimmung; 
oder diese wird von der Offentlichen Meinung mit fortgerissen. Möge die Stimmung bis zum gegebenen Augenblicke noch so zerrissen, noch so sehr von innerer Feindseligkeit erfüllt gewesen sein, sie einigt sich leicht und rasch in der Überzeugung von der Ruchlosigkeit des ohnehin gehaßten und gefürchteten Feindes; Schimpfwörter, mit denen man ihn anspuckt, tragen dazu bei, auch den Zorn einer rohen Menge gegen ihn zu entfesseln. Ebenso hat aber die Offentliche Meinung eines Landes ihre Gegnerschaft im Inneren, und wird unter ähnlichen Umständen gegen diese einig. Am ehesten gegen die Regierung des Staates, deren Druck immer von allen gefühlt wird, deren Gründe oft nicht gekannt, öfter nicht verstanden, aber auch, obgleich gekannt und verstanden, gemißbilligt werden, zumal weil und sofern der Staat selber auch (und vielleicht sogar am meisten) von den Intellektuellen und Gebildeten des Landes als ein fremdes Wesen empfunden und gedacht wird, vor dessen Mißhandlungen man auf der Hut sein, dessen Übergriffen man vorbeugen müsse. Diese grundsätzliche Kritik steigert sich, wenn die Bildung und wissenschaftliche Denkungsart meint, daß die Regierung von veralteten Anschauungen sich leiten lasse und ehemalige Zustände und Einrichtungen, deren man froh ist, ledig geworden $\mathrm{zu}$ sein, wieder heraufzuführen unternehme; das Schlagwort "Reaktion ", zumal wenn das Prädikat "finster " hinzugefügt wird, genügt dann, um sie anzuklagen und zu richten. Wenn der liberale Kammerredner oder Volksversammlungsredner oder die liberale Zeitung diese Ausdrücke hinwirft, zugleich etwa die Worte "Pfaff « und "Junker «, so geschieht es in der Rechnung auf Beifall außerhalb ihrer engeren Parteikreise, es enthält eine Berufung an die Offentliche Meinung, man weiß, daß auch der etwa konservativ wählende Oberlehrer oder Amtsrichter, ja der städtische Pfarrer in der Regel so etwas nicht will und also insoweit auf der liberalen Seite steht. Die große Brauchbarkeit der Schlagwörter besteht eben darin, daß sie die Offentliche Meinung gleichsam auf den Kopf schlagen und betäuben.

7. (Eindrücke.) Übrigens wird die Offentliche Meinung des Tages in auffallender Weise durch Eindrücke bestimmt. In Deutschland wie in Osterreich, war sie von dem Wert, ja der Notwendigkeit der Mo narchie noch im Oktober 1918 ziemlich fest überzeugt. Durch den Zusammenbruch der Heere, den Verrat des österreichischen, die Fahnenflucht des deutschen Kaisers, das iiberraschende, fast vollständige und beinahe ohne Widerstand sich erfüllende Gelingen der Staatsumwälzung, geriet sie stark in Fluß und nahm eine entschiedene Neigung zur Republik an, dies kam auch vor und in den Wahlen zur Nationalversammlung, deren Berufung die Offentliche Meinung 
stïrmisch verlangt hatte, zum Ausdruck; die Bildung der Koalitionsregierung entsprach der Meinung, daß nunmehr nichts anderes möglich sei, und $\mathrm{da} \beta$ man, wenn nicht die demokratische Republik gutheißen, so doch sich mit ihr abfinden und ssich auf den Boden der gegebenen Tatsachen stellen « solle. Wäre es nun der neuen Regierung gelungen was nach Lage der Dinge unmöglich war - einen erträglichen Frieden abzuschließen, eine ausreichende Volksernährung sicherzustellen, die Wucherer und Schieber, die von der Offentlichen Meinung längst aufs Korn genommen waren, schwer zu bestrafen und an den Pranger zu stellen, überhaupt nach der furchtbaren Niederlage durch 20 fache Ubermacht erträgliche Zustände herzustellen, so hätte sicherlich die Offentliche Meinung in der Richtung auf den Republikanismus sich befestigt, sie hätte den sozialdemokratischen Präsidenten aus dem Handwerkerstande, so großes Unbehagen er ihr verursachte, geschluckt, und hätte die Losung ausgegeben, $\mathrm{da} B$ es zunächst keine andere Aufgabe gebe, als denen, die einmal die politische Macht besaßen, nach Kräften beim mühevollen Wiederaufbau zu helfen. Das wäre auf alle Fälle das Gebot eines weisen politischen Bewußtseins gewesen. Aber unter dem Druck einer schwülen Atmosphäre, inmitten allgemeiner Erschlaffung, Abstumpfung, Entsittlichung wurden die Gemüter der Besonnenen in andere Richtung getrieben. Das Bewußtsein tiefen Elends, der wirtschaftlichen Verarmung, der geistigen Verkümmerung, der moralischen Demütigung, das bei hinlänglichem und klarem Denken schon in jenem November hätte vorhanden sein müssen, bedurfte erst einer langwierigen Erfahrung, immer neuer Eindrücke, um sich zu vertiefen und auszubreiten. Und, wie es in solchen Fällen geschieht, war rasch eine ursächliche Verbindung hergestellt: das Elend - die neue Regierung; Wohlstand und Macht - die alte Regierung. Die Offentliche Meinung des Tages nahm wieder eine monarchistische Färbung an, um so leichter, da sie in ihren alten Strom zurïcklenkte, die noch vor kurzem heilig gehaltene nationale Gesinnung, die nur durch die Ereignisse eine Erschütterung erfahren hatte. Es würde neue trübe oder gar düstere Erffahrung dazu gehören, um wieder die entgegengesetzte Meinung hochzubringen. Diese Phasen der Schwankung hat bekanntlich die Offentliche Meinung Frankreichs mehr als Ioo Jahre lang durchgemacht, bis sie einstweilen - ob endlich? bei dem "Glauben an " die Republik sich beruhigt hat. Ihre religiöse Beglaubigung hat die monarchische Staatsform überall in Europa beinahe völlig verloren; der Cäsarismus hat sie kaum genossen; sie überlebt fast nur noch in der Denkungsart von Frauen und mit politischem Bewußtsein verbunden bei den Männern der alten Aristokratie und des höheren Beamtentums. Die Offentliche Meinung Deutsch- 
lands huldigte und huldigt heute in einigem Maße wieder, dem "Vernunft-Monarchismus «, und eben dies Wort ist für das Wesen der Offentlichen Meinung charakteristisch. Die Vernunft ist immer beweglicher als das Gefühl; der Kürwille veränderlicher als der Wesenwille. Dieser hat ein natürliches Beharrungsvermögen, jener flattert und flackert hin und her, auf der Suche nach neuen Mitteln zur Erleichterung, Beschleunigung, Verbesserung des Lebens zur fliehenden, unerreichbaren Glïckseligkeit. Und die Offentliche Meinung des Tages urteilt in gar vielen Fällen oberflächlich, urteilt nach dem Schein, nach der unmittelbaren Erfahrung, nach Eindrücken. "Unter dieser Regierung herrscht eine wirtschaftliche Krisis - wir müssen nach einer anderen Regierung streben." Die andere Regierung tritt auf, es bleibt alles beim alten - "vielleicht war die frühere Regierung doch vorzuziehen.« Der Eindruck, die Erfahrung, deren Wirkungen auf die Empfindung, und durch die Empfindung auf das Denken, diese sind also die entscheidenden Faktoren für die Entstehung der Offentlichen Meinung des Tages, sofern sie etwas anderes ist als bloße Erscheinungsform einer flüssigen oder sogar festen Offentlichen Meinung. Darum müssen dort die für solche Eindrücke empfänglichen Seelen vorhanden sein, solche die geneigt sind und fähig, oder doch für fähig und berufen gelten, eine Meinung sich zu »bilden «. Das sind aber die modernen, die auf Kürwillen eingestellten, die gesellschaftlichen Menschen, daher vorzugsweise die Gebildeten in der Großstadt; überhaupt aber die Menschen je nach ihren naturalen und kulturalen Beschaffenheiten und Anlagen, in den früher angezeigten Relationen mehr oder weniger.

Die erste Bedingung ist die Lebhaftigkeit des Verkehrs. Aus ihr entspringt die Entwicklung und Beschleunigung des Denkens und Urteilens. In erster Linie sind es Geschäfte aller Art, die dem Menschen die Zunge lösen, ihn beredt machen; das sind hauptsächlich A. Tausch- und Handelsgeschäfte, B. politische, d. h. im allgemeinen auf gemeinsame Angelegenheiten bezügliche Geschäfte und Verhandlungen nach außen und nach innen. Beide Arten machen häufige und möglichst rasche Ortsbewegung notwendig: innerhalb einer Großstadt kommen die Menschen für beide Arten fortwährend von der Peripherie aus im Zentrum (der City) zusammen, aber auch alle Punkte der Peripherie stehen in Verkehr miteinander und haben viele engere Nebenzentren der Zusammenkünfte:Läden, Markthallen Wirtshäuser, Theater und andere Schaustätten, Versammlungssäle und Vereinsräume - alles was im Zentrum dichter, mannigfacher, prächtiger anzutreffen ist; hier vor allem die Börse als mächtige Anziehung für das Gewerbe des Kaufmanns und alle, die durch irgendwelche Handelsgeschäfte Gewinn zu erzielen oder Verluste 
wiedergutzumachen hoffen; aber auch auf den Marktplätzen und Straßen, in den Eisenbahnwagen, Straßenbahnen, Omnibussen finden solche Begegnungen statt, die zum Abschluß von Verhandlungen und Geschäften führen. Überall ist das Gespräch, wodurch die Menschen Abreden und Abmachungen treffen, heute neben dem natürlicheren Nahgespräch das Ferngespräch, das viele persönliche Zusammenkünfte erspart und weit über die Grenzen einer Stadt, ja eines Landes hinaus vermittelnd, fördernd, erleichternd trotz vieler Hemmungen wirkt. Im Gespräch kommen gemeinsame wie verschiedene Meinungen zutage, die von den unmittelbaren Gegenständen auf mittelbare, mehr oder minder damit zusammenhängende übergehen, am ehesten auf die Begebenheiten des 'Tages und Vortages, auf erhoffte oder drohende Ereignisse, auf Persönlichkeiten, die gerade im Mittelpunkte des Interesses stehen. Auch mit ganz fremden, die der Zufall zusammenfiihrt, zumal auf Reisen, kommt man ins Gespräch; in der Regel setzt aber das Gespräch irgendwelche Beziehungen und Verhältnisse gemeinschaftlicher oder gesellschaftlicher Art voraus; unter Umständen machen auch feindliche Beziehungen und Verhältnisse, mögen ihnen jene positiven zugrunde liegen oder nicht, Gespräche notwendig - einen Gedankenaustausch, der sich in der Regel streng und hart an den Gegenstand und Zweck halten wird. Solche Gespräche sind im politischen Verkehr am ehesten anzutreffen, der zum guten Teil ein Verkehr zwischen offenen oder geheimen Feinden ist, nicht selten sogar, wenn diese Feinde sich Bundesgenossen nennen. Sonst aber geht auch ein freundliches Gespräch, zumal wenn es geschäftlichen Charakter hat, leicht in ein feindliches, einen (mehr oder minder scharfen) "Wortwechsel «über. Das gilt auch vom gelehrten und gebildeten Gespräch; sachliche Gespräche und Disputationen werden leicht "persönlich « und führen zu Ausdrücken der Geringschätzung, des Hasses und der Verachtung. Auch im politischen Verkehr von Freunden und Parteigenossen treten die Gegensätze und Meinungsverschiedenheiten zutage. Unabhängig davon aber, und sogar vorzugsweise durch den Widerstand, worauf die Meinungsäußerung trifft, wird die Bildung der Meinung und des Urteils gefördert, die freie Aussprache entfesselt. Das ist besonders wichtig für das politische Leben, es ist um so lebhafter, je mehr in ihm die Debatte vorherrscht.

8. (Debatte.) Die Debatte wird mehr oder weniger heftig, leidenschaftlich, oft mit Erbitterung und Wut geführt und der Kampf der Worte geht zuweilen sogar in ernsthaften beratenden Versammlungen in Handgreiflichkeiten roher Art über und setzt sich in Straßenkämpfen, ja in Bürgerkriegen fort. Solchen pathologischen Eirscheinungen gegenüber ist die geordnete Debatte in parlamen- 
tarischen Formen, unter mäßigendem, rügendem, ja strafendem Vorsitz der normale und physiologische Ausdruck eines reifen staatlichen, gemeindlichen, korporativen Zusammenlebens. „Kampflosigkeit", so urteilt der konservative Clemens Theodor Perthes (Politische Zustände und Personen in Deutschland zur Zeit der französischen Herrschaft. Das südliche und westliche Deutschland, S. 5), ,deutet in der Nation, wie in dem Einzelnen nicht auf Frieden, sondern auf Schwäche und Stumpfsinn. Uberall und zu jeder Zeit ringt nicht allein das Gute mit dem Bösen, das Berechtigte mit dem Unberechtigten, sondern auch das Berechtigte mit dem Berechtigten, um inmitten mächtig drängender Kräfte seinen Platz zu behaupten oder zu gewinnen. Eine Fülle von Gegensätzen, eine große Mannigfaltigkeit von Kräften, Richtungen, Interessen war durch das deutsche Mittelalter hervorgearbeitet; sie alle hatten das Recht auf Gel :ung und bedurften der gesonderten Vertretung. Eine politische Parteienbildung war in dem Gange der Dinge begründet; wie durch einen Naturprozeß wuchsen Parteien hervor und wirkten mit der vollen Kraft jugendlicher Unmittelbarkeit. Oft genug freilich wurde das politische Ringen mit dem Schwerte ausgefochten... Die Form des Kampfes gehörte dem Geiste des Mittelalters an, die Gegensätze der politischen Strömungen aber und deren Geltendmachung durch kräftige Parteien waren damals, wie zu jeder Zeit, nicht nur Kennzeichen, sondern auch Wurzel und Frucht eines bedeutenden politischen Lebens. " Im gleichen Sinne preist WALTER BAGEHOT (Der Ursprung der Nationen. Deutsche Ausg., Leipzig I874) das Zeitalter der »Erörterungen « und ein auf Erörterung beruhendes Staatswesen : nichts erhöhe die Intelligenz so sehr wie intellektuelle Erörterung und nichts erhöhe diese so sehr wie eine Regierungsform, die danach strebe und darauf angewiesen sei, eine intellektuelle Atmosphäre zu erzeugen; solche Regierung trage mächtig zum Wachstum einer Fähigkeit bei, die er "Lebhaftigkeit verbunden mit Mäßigung «nennt, und wodurch die Engländer, wie er meint, im praktischen Leben alle anderen Nationen übertreffen.

9. (Staatsreden, Gespräche, Briefe.) Wenn die öffentliche Versammlung und der große Kreis von Zuhörern, den der Redner wie der Schauspieler sich wünscht "um ihn gewisser zu erschüttern «, die Lebhaftigkeit der Rede anregt, so sorgt die Geschäftsordnung der Versammlung und mit ihr das Präsidium für Mäßigung, wenn auch oft mit geringem Erfolg. Von Zeit zu Zeit aber erhebt sich in politischen Versammlungen, sei es denen gesetzgebender Körperschaften oder in freiberufenen, die große Staatsrede, die den Hörer fesselt und einen tiefen, nachhaltigen Eindruck auf ihn macht, zu einer mächtigen, die politische Offentliche Meinung mitbestimmenden 
Bedeutung. Diegünstigsten Vorbedingungen dafür hat ein führender Staatsmann, wenn er Vertrauen genieBt, wenn er nicht nur in der Versammlung selber, sondern weithin im ganzen Lande und darüber hinaus (insbesondere auch bei den Landsleuten im Auslande) Widerhall findet, wenn er auch über die Mittel verfügt, sich vernehmbar zu machen; in Frankreich beschließt die Kammer zuweilen, eine solche Rede durch öffentlichen Anschlag im Lande zu verbreiten. In Deutschland wurden I870-I89o die Reden BISMARCKs, in England zu gleicher Zeit diejenigen Gladstones und DisRafiris mit Spannung, Andacht und Bewunderung gehört und gelesen. Aber einen Resonanzboden, wie den der französischen Volksseele, hat keiner jener Redner je gefunden. Diese kriegerische Nation, der Miles gloriosus der Geschichte, liebt die Trompetentöne und den Trommelwirbel auch in der Rede; ihre rasche Leidenschaft drückt sich in einer nüchternen, durchsichtigen, an schlagenden Wörtern reichen Sprache aus, geschaffen, um "Eindruck « zu machen auf eine weiche, weibliche Haut, wie sie dort den Männern von eherner Stirn eigen ist. Der Appell eines Redners an ihre Eitelkeit, an ihren Sinn für die Mode, ihre Lust am Neuen und am Spielzeug, am Putz und am Parfüm, wird niemals verloren sein. Echt französisch ist gedacht, was GabriEl Hanotaux, ein hervorragender Historiker und Politiker, nach dem Erscheinen der letzten Bände von EMILE OLLIVIERs „L'empire libéral" schrieb (Figaro, 29. Aug. I9I3): ,Unter einem Regime der Meinung muß man überzeugen und, um zu überzeugen, muß man sprechen. Das hauptsächliche Urteil über eine Persönlichkeit des heutigen öffentlichen Lebens ist stets: "er spricht gut; er hat gut gesprochen «. Das Wort genügt für alles, es entscheidet alles, zerschneidet alles, deckt alles." Er führt dann aus, der Redner wolle überzeugen, wolle gefallen, er wolle das letzte Wort haben: um dies Dreifache zu erreichen, müsse sein Vorgehen notwendigerweise offen, gefällig und warm sein - genau die umgekehrten Eigenschaften seien aber die des Diplomaten und des Geschäftsmannes. Gewiß richtig. Wie aber, wenn der Diplomat und Geschäftsmann den Offenherzigen, den Gefallenwollenden, den von edler Leidenschaft Erfüllten zu spielen weiß? Oder ist etwa das Komödiantentum dem Staatsmann und anderen Leuten, die bestimmte Zwecke im Auge haben, fremd? - "Der Vortrag macht des Redners Glück «, möge der.Vortrag echter oder geheuchelter Empfindung entspringen. Ein hinreißender Redner kann die Menge umstimmen, eine gebildete Menge eher als eine ungebildete; denn je geringer die Bildung, desto mehr horcht ein Mann nur auf das, was seinen Vorstellungen, Meinungen, Gefühlen entgegenkommt, sie stärkt und fördert, um so weniger ist er fähig und geneigt, 
Beweisgründe und Beweggründe auf sich wirken zu lassen, die seinen "Vorurteilen" entgegengerichtet sind. Darum beruht in der Wirkung auf die Gefühle, in der Rechnung auf das, was die Zuhörer hören wollen, die Macht des eigentlichen Volksredners in der Volksversammlung; dagegen wird in engeren Kreisen, in Vereinen und ihren Versammlungen, in Ausschuß- und Komitee-»Sitzungen «, auch der schwächere Redner durch die Stärke seiner Argumente Eindruck machen und Erfolge haben. Dort wird mehr die Stentorstimme, die Energie und Rücksichtslosigkeit des Ausdrucks, die tönende Phrase, hier eher die Feinheit der Unterscheidung, der schlagende Witz, der freundliche Humor, die Planmäßigkeit des Gedankens entscheidend auf die Seelen wirken. Hier wie dort macht sich oft der Machtzauber (das Prestige) der Persönlichkeit geltend, auch durch Eigenschaften außerhalb der Rednergabe: durch den großen Namen und Ruhm, der »ihm vorangeht «; schöne und simponierende" Gestalt und Miene, Anmut und Würde, Liebenswürdigkeit und finsterer Ernst, - man denke an ROBESPIERRE - diese Zaubermittel wirken, je für sich oder zusammen, um den Taten und Worten eines Mannes Gewicht zu geben, um ihn selber in der öffentlichen Meinung zu heben freilich auch, ihn zu senken, wenn er verdächtig wird, wenn die Mutmaßung um sich greift, daß er mit solchen Mitteln betrügen wolle, $\mathrm{da} B$ er nur das Seine suche, seine Macht und Herrschaft begründen wolle - und ach, wie nahe liegt dies! ${ }^{1}$ )

Aber Persönlichkeiten größeren oder kleineren Kalibers wirken im neueren öffentlichen Leben, ja schon seit vielen Jahrhunderten, mehr und öfter durch das geschriebene als durch das gesprochene Wort. Zunächst wird das Gespräch ergänzt, auch ersetzt durch den Briefwechse1. In unendlichen Mengen schwirren heute Briefe und was ihnen verwandt ist, hin und her, am meisten innerhalb eines Landes, noch intensiver in engeren Gebieten, aber auch über die Grenzen von allen Orten, zu allen Orten des Erdballes, wenn nicht Notstände, wie Krieg und Aufruhr, es verhindern. In der Regel betrifft der Brief nur Privatangelegenheiten zwischen Einzelpersonen oder Familien; darunter hebt der Geschäftsbrief sich ab durch die Tragweite der wirtschaftlichen, meistens pekuniären Interessen, denen er dient. Aber es gibt auch Briefe in Angelegenheiten der Wissenschaft, der Künste, und Briefe über öffentliche Angelegenheiten. Solcher schriftlicher Gedankenaustausch zwischen politisch tätigen,

1) So nannten schon beim Fest des Höchsten Wesens feindliche Stimmen RoBEsPIERRE den Papst der Revolution. „Es hieß so viel", sagt BARERE (Mémoires I, 202), „als ihm, wie MAHOMET, das Szepter und die Tiere geben. Es war auch das Prognostikon seines Falles in der öffentlichen Meinung." 
zumal wenn einflußreichen, Personen, kann auch für die Bildung der Offentlichen Meinung Bedeutung gewinnen. Ist der Briefschreiber eine Persönlichkeit von hohem Range oder hoher Stellung, so macht eine briefliche Außerung von ihm um so mehr Eindruck, der Brief wird im Vertrauen oder auch ganz offen mitgeteilt, der Eindruck, den er macht, verbreitet sich; zuweilen ist er eben dafür bestimmt. Es gibt Rundschreiben, die umlaufen und uiberall eine gleiche oder doch möglichst ähnliche Wirkung auslösen sollen. Dazu kommt dann der "Offene Brief «, der sich an viele, wohl gar an Alle, wenigstens an alle Bewohner eines Landes wendet. Ein solcher offener Brief eines Königs an seine "Untertanen " gestaltete im Jahre 1846 durch den Widerspruch und Unwillen, den er hervorrief, das schleswig-holsteinische Nationalbewußtsein, die bewußt deutsche, also antidänische Offentliche Meinung, die sich in Hunderten von Adressen und Petitionen, in stürmischen Volksversammlungen, in Protesten der holsteinischen und der schleswigschen Ständeversammlung kundgab. „Nur das Vertrauen, daß die Stände sich durch die Beschränkung ihres Petitionsrechts nicht abhalten lassen würden, die Rechte des Landes, zugleich besonnen und entschieden zư verteidigen, vermochte die aufgeregte öffentliche Meinung vor Ausschreitungen zu bewahren" (ScHLEIDEN, Erinnerungen eines Schleswig-Holsteiners II, S. I53). Ein Brief war es auch, wodurch BISMARCK seinen Entschluß, zu einer schutzzöllnerischen Handelspolitik überzugehen, am I5. Dez. I 878 öffentlich machte, freilich ein Brief, den er als Reichskanzler an den Bundesrat richtete; der Grundgedanke, der gesamten inländischen Produktion einen Vorzug auf dem heimischen Markte zu gewähren, hatte damals schon in der öffentlichen Meinung, nach dem sie durch eine schwere Krisis, durch den Unwillen, den die Gründerzeit erregt hatte, vorbereitet war, Boden gewonnen; die Autorität des Fürsten BISMARCK gab ihr nunmehr die gewaltigste Förderung und brachte sie in FluB.

\section{Kapite1. \\ Die Öffentliche Meinung als Faktor des Staatslebens.}

\section{Erster Abschnitt. Insgemein und in Amerika.}

r. (Die Anerkennung der Tatsache.) Die Macht der Offentlichen Meinung ist dadurch auf die vollkommenste Art eine feststehende Tatsache geworden, daß sie als ein Faktor des Staatslebens anerkannt wird. Dies geschieht bald dadurch, da $B$ sie neben dem Parlament eines 
Landes genannt wird, als eine Instanz, von deren Billigung oder Mißbilligung der Erfolg einer Maßnahme der Regierung, daher oft auch das Bestehen und die Dauer einer Regierung abhänge. Nicht selten werden in diesem Sinne auch die Presse und die Offentliche Meinung zusammengenannt, obschon andererseits die Presse selber als ein Ausdruck oder als ein Organ, in neuerer Zeit als das bedeutendste Organ der Offentlichen Meinung gilt. Es wird dann eben die Presse ihrer selbständigen Bedeutung und Macht wegen herausgehoben und den übrigen Äußerungen der Öffentlichen Meinung, wie sie in Tagesgesprächen, in Volksversammlungen und deren Entschließungen, in Vereinen, in Petitionen, Demonstrationen, literarischen Publikationen, Theatervorstellungen usw. zutage treten, an die Seite gestellt. So ist auch nicht selten von Parlament, Presse und Offentlicher Meinung als einer dreigliedrigen Organisation des »Volkes " oder des Publikums die Rede, und zwar zuweilen so, daß die Offentliche Meinung als die letzte entscheidende Instanz gilt, weil sie, wenn einmütig, die Haltung der Presse maßgebend bestimme, und weil auch das Parlament ihr nicht dauernd widerstehen könne, denn, sobald das Parlament erneuert wird, sei es im regelmäßigen Verlauf oder nach geschehener Auflösung, so werden die Neuwahlen ihr Gepräge erhalten durch die Offentliche Meinung. Daher werden in England, wo die parlamentarische Tradition die älteste ist, die Nachwahlen mit besonderer Aufmerksamkeit beobachtet: wenn die Wählerschaft eines Kreises eine andere Mehrheit als die gewohnte, oder auch nur als die der letzten vorhergehenden Wahl aufweist, so wird dies als ein Zeichen veränderter oder doch in bestimmtem Sinne sich kundgebender Offentlicher Meinung aufgenommen. In manchen Darstellungen wird daher die Offentliche Meinung als souverän, als der eigentliche, wahre Souverän eines wirklich modernen Staates dargestellt, also insbesondere eines demokratischen Staates, wo dann die Meinung der Mehrheit als die Offentliche Meinung, und diese als erklärter "Volkswille» erscheint. Wenn wir hingegen streng unterscheiden zwischen öffentlicher Meinung und Volksstimmung, der Öfentlichen Meinung und dem Volkswillen, so wird doch anerkannt, daß die so benannten Erscheinungen ineinander übergehen, und daß die Offentliche Meinung auf die Volksstimmung, daher auch auf den Volkswillen sehr oft entscheidenden Einfluß ausübt, aber auch umgekehrt: so daß zuweilen die Erscheinungen voneinander sich nicht unterscheiden lassen.

2. (Vereinigte Staaten.) In keinem Lande ist demnach diese Oberherrlichkeit der Öffentlichen Meinung so zu erwarten wie in den Vereinigten Staaten von Nordamerika. In keinem und von keinem 
wird sie auch so geflissentlich hervorgehoben. Alle Darsteller des amerikanischen Staatslebens stimmen in dieser Hinsicht völlig überein. Der große Washington hatte in seiner Lebewohl-Ansprache (Farewell-Adress) die Losung dafür in den Worten gegeben: „Im Verhältnis wie der Aufbau (the structure) einer Regierung der öffentlichen Meinung Kraft verleiht, ist es von wesentlicher Bedeutung, daß die Offentliche Meinung aufgeklärt sei." Unter den Kennern des großen Bundesstaats ragt durch eingehendste Kenntnis, politischen Verstand und unbestrittene Autorität hervor JAMES (jetzt Viscount) BRYCE, Verfasser des älteren Werkes The american commonwealth und des neueren Modern Democracies. Er hat einen ganzen Abschnitt des erstgenannten Werkes (Part IV) der Offentlichen Meinung gewidmet und ist in mehreren Kapiteln des jüngeren darauf zurïckgekommen. Dort stellt er nach einleitenden Kapiteln über das Wesen der Offentlichen Meinung und Regierung durch die Offentliche Meinung (welche Kapitel hier übergangen werden) dar (Chap.LXXVIII), wie die Offentliche Meinung in Amerika herrsche. Es sei von allen Experimenten, die Amerika gemacht habe, dasjenige, welches am meisten Aufmerksamkeit verdiene, weil die Lösung des Problems: einem System nahezukommen, worin der Wille des Volkes unmittelbar und beständig auf seine vollziehenden und gesetzgebenden Geschäftsführer wirke, von allen früheren Lösungen abweiche; Amerika habe mehr Kühnheit im Vertrauen auf die Offentliche Meinung in ihrer Anerkennung und Wirksammachung gezeigt, als bisher irgendwo sonst geschehen sei. ,Sich hinwegsetzend über Präsidenten und Staatsgouverneure, über den Kongre $\boldsymbol{B}$ und über die Legislaturen der Einzelstaaten, über Konventionen und über die unermeßliche Maschinerie des Parteiwesens, steht die Offentliche Meinung in den Vereinigten Staaten da, als die große Quelle der Macht, als die Herrin von Dienern, die vor ihr zittern" (II, 267). Diese vollere und unmittelbarere Herrschaft der Offentlichen Meinung in den Verenigten Staaten leitet BRyce aus der Tatsache ab, da $B$ von drei möglichen Systemen der Volksherrschaft - das erste sei die Herrschaft der Vollversammlung der Bürger, das andere das Repräsentativsystem - das dritte sich durchgesetzt habe, das als ein Versuch, das erste auf ein großes Land anzuwenden oder als Modifikation des anderen verstanden werden könne; in diesem dritten System habe nicht eine Kammer, sondern das Volk selbst die entscheidende Gewalt; jene bestehe zwar fort, werde aber für so kurze Frist gewählt und begegne so vielen Hemmungen, da $B$ viel von ihrer Macht und Würde dahin sei; die Abgeordneten werden nicht als weise und starke Männer, gewählt, um zu regieren, vorgestellt, sondern als Delegierte mit begrenztem Mandat, das in kurzen Intervallen 
erneuert wird. Die wirkliche Regierung durch die Offentliche Meinung sei da vorhanden, wo die Wünsche und Ansichten des Volkes vorwalten, selbst ehe sie durch die regelmäßigen gesetzlich bestimmten Organe hindurchgegangen sind, und ohne da $\beta$ dies Hindurchgehen notwendig wäre. Er vergleicht diese Herrschaft mit der Herrschaft eines unbeschränkten Monarchen oder Despoten. Solche letzte und höchste Instanz sei im amerikanischen Staatsleben um so mehr notwendig, weil das ganze Verfassungswesen mit seinen einander hemmenden Faktoren und Gewalten fortwährenden Konfliktstoff in sich berge, so daß die Maschinerie immer in Gefahr sei, zum Stillstand zu kommen. Da sei nun aber der Herr und Meister stets bei der Hand: die Offentliche Meinung wirft ihr Gewicht in die eine oder die andere Wagschale, und das ist entscheidend. Zeigt die Meinung selber kein entschiedenes Ubergewicht, so ,ist es ohne $Z$ weifel schwer, bis die nächste Wahl stattfindet, zu bestimmen, welcher von vielen disharmonischen Rufen wirklich die vorwaltende Stimme ist"; diese Schwierigkeit müsse in einem großen Lande, wo häufige Plebiszite unmöglich, ertragen werden. Die Bemühungen der Bildner der Verfassung, dem Volkswillen seine zerstörende Gewalt zu nehmen, indem sie ihn in viele kleine Kanäle leiteten, haben, meint BRYCE, gerade den Erfolg gehabt, die Offentliche Meinung über die regelmäßigen und gesetzlich bestimmten Organe der Regierung zu erheben. Jedes dieser Organe sei zu klein, um die Offentliche Meinung zu gestalten, $\mathrm{zu}$ eng, um sie auszudrücken, $\mathrm{zu}$ schwach, um ihr Wirksamkeit zu verleihen. „Sie herrscht als eine durchdringende und ungreifbare Macht, gleich dem Äther, der durch alle Dinge hindurchgeht. Sie bindet alle Teile des verwickelten Systems zusammen, und gibt ihnen jegliche Einheit des Geistes und der Tätigkeit, die sie besitzen" (27I). Und auch aus einem anderen Grunde sei die Meinung der großen Nation ein gewichtigerer Faktor in der Regierung der Vereinigten Staaten, als er irgendwo in Europa sei. In Europa mache die herrschende Oberschicht die Offentliche Meinung ebenso, wie sie die Verwaltung leite und die Gesetzgebung in Händen habe. Davon sei in Amerika nicht die Rede. Die Mitglieder der gesetzgebenden Körperschaften seien geistig kaum über dem Durchschnitt ihrer Wähler. Keine Klasse könne darauf Anspruch machen, mehr als eine andere der Ursprung von Ideen zu sein und politische Lehrmeinungen für die Menge aufzubauen. Man kann in Amerika nicht von den Klassen an die Massen appellieren.

3. (Die Organe der Öffentlichen Meinung in Amerika.) Als von selbst verständlich bezeichnet $\mathrm{BRYCE}, \mathrm{da} B$ unter den Organen der öffentlichen Meinung die Presse, insbesondere die Zeitungspresse, obenan steht. Zeitungen seien auf drei Arten einflußreich: 
als Erzähler, als Anwälte und als Wetterhähne. In der dritten Eigenschaft, wo sie der Offentlichen Meinung als Zeiger und Spiegel diene, finde die Tagespresse am meisten Aufmerksamkeit: ,die Leute, die im öffentlichen Leben stehen, fühlen, daB sie, indem sie ihr sich ergeben zeigen, die Offentliche Meinung gleichsam versöhnen und ihrer Befehle gewärtig sind“. „Wenn man der Gottheit seinen Kultus widmet, lernt man dem Priester sich fügen." Mehr als Parteiblätter sind in dieser Hinsicht unabhängige oder halbunabhängige Zeitungen von Bedeutung, nämlich I. einige Großstadtblätter, die zwar in der Regel eine Partei unterstützen, aber ihr den Rücken wenden, wenn sie glauben, daß es an der Zeit ist; 2 . Blätter, die hauptsächlich Nachrichten geben und nur je nach Umständen eine oder die andere Partei unterstützen; 3. unpolitische Blätter, worunter weitaus die wichtigsten in Amerika die religiösen Wochenblätter sind. Wenn diese sich gelegentlich, wie bei einer Präsidentenwahl, auf Politik einlassen, so ist ihre Macht bedeutend, weil sie einen moralischen Standpunkt einnehmen und weil sie Sonntags herauskommen. - Als ein Organ, dieOffentliche Meinung aufzufangen, zu messen und bekannt zu machen, das in Europa fast unbekannt sei, bezeichnet BRYCE die Methode, private Äußerungen hervorragender Persönlichkeiten zu zitieren. Manchmal geschieht dies dadurch, $\mathrm{da} B$ man einen Privatbrief bekannt macht, der nicht an die Zeitung gerichtet war, sondern an einen Freund, der aber weiß, welche Bestimmung er hat. Manchmal wird angekündigt, wie der Hervorragende bei der nächsten Wahl zu stimmen gedenkt. Ahnlich, aber noch schärfer, wirkt das Interview, das nicht selten bestellt wird. Den Zeitungen helfen diese Mittel, dem Ausdruck und zugleich der Gestaltung der Offentlichen Meinung dienstbar zu sein, was ihnen im ganzen besser gelingt als z. B. in England. Danach wird oft einen Politiker, der eine Zeitlang auf Reisen gewesen ist, das Gespräch mit 4-5 leitenden Männern besser über die vorherrschende Stimmung unterrichten als alle Zeitungslektuire. Versammlungen spielen im öffentlichen Leben der Vereinigten Staaten eine geringere Rolle als in England. Die Häufigkeit der Wahlen erleichtert es dort am meisten, der öffentlichen Meinung den Puls zu fühlen; auch aus Nebenwahlen in den Einzelstaaten werden oft Schlüsse gezogen. Stark ist die Wirksamkeit von Ver einen: sie stacheln die Aufmerksamkeit, rufen Erörterung hervor, formulieren Grundsätze, entwerfen Pläne, machen ihre Mitglieder kühn und reizen sie, bringen den Eindruck einer sich ausbreitenden Bewegung hervor, welcher Eindruck bei einem mitfühlenden und empfindsamen Volke ein wesentlicher Faktor des Erfolges ist. Der Schein der Stärke sammelt Rekruten und erhöht das Selbstvertrauen 
auch der Veteranen. - Die Einflüsse, welche für das Leben in Städten charakteristisch sind, wirken bei der so viel dïnneren Bevölkerung in Amerika viel weniger als in Europa, aber die Tendenzen der Meinung sind leichter zu fassen, weil die Klassenunterschiede viel geringer sind, der Verkehr leichter und die Parteizugehörigkeit bestimmter. Dennoch bleibt auch hier dem Irrtum weiter Spielraum. Und doch regiert die Offentliche Meinung? Ein Souverän ist darum nicht weniger Souverän, weil seine Befehle zuweilen falsch verstanden oder unrichtig wiedergegeben werden. „In Amerika lauscht jeder auf sie. Diejenigen, denen die Führung der Geschäfte des Landes obliegt, gehorchen nach ihrem besten Wissen und Verstehen. Sie handeln nicht, wie es in Europa bisher üblich war, nach ihren eigenen Ansichten und erwarten, daß das Volk diese billige; sie steuern den Kurs, von dem sie glauben, daß das Volk im Augenblicke ihn wünscht."

4. (Faktoren der Öffentlichen Meinung.) BRYCE untersucht nun ferner die Potenzen, wodurch die Offentliche Meinung in Amerika bestimmt werde, und zwar in erster Linie den Volkscharakter, denn die Offentliche Meinung eines Volkes sei noch unmittelbarer als seine politischen Einrichtungen Reflex und Ausdruck seines Charakters. Was er aber als den Volkscharakter versteht, soll wesentlich nur von den eingeborenen Amerikanern, nicht von der jüngeren europäischen Einwanderung, geschweige von den Negern des Südens gelten. Die Amerikaner, sagt er, sind gutherzig, hilfreich zueinander, nachsichtig, wenn auch zuweilen jähzornig, hegen großen Abscheu gegen Grausamkeit. Sie haben guten Humor und nehmen die Dinge nicht übermäßig ernst. Sanguinisch und duldsam, glauben sie an ihren Stern und geben sich gern Hoffnungen hin. Unbegrenzten Glauben haben sie an das, was sie das $\gg$ Volk « nennen und an ein demokratisches Regierungssystem, mit dem Vertrauen, daß Wahrheit und Gerechtigkeit darin sich durchsetzen, auch wenn zunächst nur von einer Minderheit vertreten. Daraus folgt die Neigung, etwas für richtig und gut zu halten, weil es die Mehrheit auf seiner Seite hat. Eine, wenn auch oberflächliche Volksbildung ist allgemein verbreitet. Der Stand der Moral ist (abgesehen von dem Pöbel einiger Großstädte und von den Negern des Südens) ziemlich hoch, besonders im Verhalten gegen Frauen und Kinder, überhaupt im Familienleben. Sie sind im ganzen ein religiöses Volk. Religion und moralisches Gefühl verleihen allen philanthropischen und Reformbestrebungen Eifer und Nachdruck. Aber sie sind nicht willig, Autoritäten anzuerkennen. Der Einzelne pocht auf sein eigenes unabhängiges Urteil. Zumal in der Politik, die jeder praktische Mann zu verstehen meint, so gut wie jeder andere. An der Gemeindepolitik, worin man sich selbst regiert, wird auch die 
große Politik gemessen. Es gibt wenig Leute, die "Zeit « haben, auch hat der Bürger keine Zeit über politische Probleme nachzudenken, wenngleich die Pflicht, sich damit zu beschäftigen, von jedem anerkannt wird. Das Geschäft geht vor. Der Mangel an ernstem und ausdauerndem Denken macht sich nicht nur in der Politik bemerklich; man bemerkt ihn sogar mehr in bezug auf wirtschaftliche und soziale Fragen. Die Denkweise des Handeltreibenden überwiegt, sie lehnt abstraktes und subtiles Denken ab und ist durch Gründe schwer zu überzeugen, weil ihre Ansichten in der Regel durch lokale oder Parteiverhältnisse im Vorwege gebildet und festgewurzelt sind. Gleichwohl sind Phantasie und Affekte leicht zu erregen, und ihre Empfänglichkeit für Idealismus übertrifft die der Engländer und Franzosen. Wenig seßhaft, teilweise geradezu nomadisch, sind sie doch sehr gesellig und weniger reserviert als der gebildete Engländer, darum leichter zu organisieren, aber auch der Veränderung und Abwechslung geneigt (sie haben geringe spezifische Wärme). Nichts hat bei ihnen so viel Erfolg wie der Erfolg. Die Stimmungen wechseln nicht selten wie eine Sturmflut und hohle Ebbe. Und doch sind sie in gewisser Weise auch ein konservatives Volk. Sie hängen an Gewohnheiten, an gesetzlichen und theologischen Bräuchen und Formeln; ihr Prosperieren befördert die konservative Gesinnung. So rasch sie in der Annahme und Einführung praktischer Neuerungen, so sehr sie vielfach auch dem Experimentieren in der Politik geneigt sind, so haben sie doch den praktischen Verstand, der den Wert des Dauerhaften und Soliden in den Institutionen zu schätzen weiß.

5. (Einfluß von Klassen.) In einem besonderen Kapitel betrachtet der Forscher die Gewohnheiten und Tendenzen der Hauptschichten des amerikanischen Volkes in ihrem Einfluß auf die öffentliche Meinung. Der Landwirt, noch in einigem Maße der wichtigste Typus, weist z. T. die Merkmale auf, die ihn in allen Ländern bezeichnen; aber er ist mehr ein Geschäftsmann als in Europa. Er fühlt und vertritt eben sein Berufs- und Klasseninteresse im Kampfe gegen Monopole und Kapitalismus, insbesondere gegen die Eisenbahngesellschaften im Westen. Die Landarbeiter bilden keine Klasse für sich. Auch Krämer und Handwerker an den kleineren Plätzen sind in ihren Interessen mit den Landwirten eng verbunden, lesen aber mehr Zeitungen, lernen mehr aus Gesprächen, haben mehr städtische Bildung, interessieren sich mehr für Handelspolitik, und eher im Sinne des Protektionismus, sonst selten von Berufs wegen für eine der Parteien eingenommen. Die I,ohnarbeiter sind im ganzen (wie bekannt) besser gestellt als in Europa. Ungeachtet ihres kleinbürgerlichen Gepräges hat aber das Klassenbewußtsein neuerdings stark zugenommen. Die 
Arbeit als solche ist bisher in den Parlamenten der Union wie in denen der Staaten noch kaum vertreten, wenn auch manche Mitglieder dieser Körperschaften ihr Leben als Arbeiter begonnen haben. Lebhaft macht sich oft die Stimmung gegen Einwanderung wohlfeiler Arbeitskräfte geltend, besonders in den Pacifik-Staaten gegen Einfuhr aus China und Japan. Übrigens unterscheidet sich die Klasse der industriellen Arbeiter politisch nicht wesentlich von den Kleinbürgern und Landwirten. Unter den jüngeren Einwanderern machen sich die religiösen Sympathien (besonders der Katholiken), die Abneigung gegen Bierverbote (bei den Deutschen) und der $\mathrm{Haß}$ gegen England (bei den Iren) bemerkbar. Die Großbürger - Klasse gebraucht die Politik vorzugsweise für ihre eigenen $Z$ wecke, insbesondere defensiv und im Sinne des Laisser faire; sie besitzen aber die Mittel, um die öffentliche Meinung und den Gang der Dinge zu beeinflussen. Auch ihr mittelbarer Einfluß, besonders in Finanzfragen und durch Herrschaft über die Eisenbahnen, ist bedeutend und hemmt rasche Veränderungen. Unter den freien Berufen sind die $J$ uriste $n$ weitaus am meisten politisch tätig und wirksam. Ihre Leistung besteht hauptsächlich darin, die öffentliche Meinung von der technischen Seite zu erziehen und die Fragen dem Volke mundgerecht zu machen. Der Einfluß der Schriftsteller ist nicht gering durch Wochen- und Monatsschriften, ebenso und unmittelbarer der der Lehrer, zumal der Universitätslehrer: sie wirken dahin, die politische Denkungsart ernster zu gestalten, den Gesichtskreis unter den Reichen zu erweitern, ihren Patriotismus zugleich zu dämpfen und zu erheben. Die Musensitze gehören heute zu den stärksten Kräften, die für den Fortschritt wirken und eine gesunde Offentliche Meinung in den Vereinigten Staaten bilden helfen; Wert der Lehrkräfte und Zahl der Studierenden nehmen fortwährend zu. - Scharfe Klassenscheidungen gibt es in den Vereinigten Staaten nicht. Namentlich gibt es keine Schicht, deren eigentliche Tätigkeit darin besteht, die öffentliche Meinung zu gestalten und zu leiten; am wenigsten fühlen die Politiker sich dazu berufen. Sie werden von der Offentlichen Meinung geleitet, anstatt sie zu leiten. Noch weniger gibt es eine regierende Klasse. Auch die beiden großen Parteien scheiden sich nicht nach Klassen. Allerdings sind neuerdings durch die großen Streiks und durch die politische Agitation, die sie begleitete, neue Elemente von Klassengefühlen und Klasseninteressen auf die Bühne getreten. Die Stärke der Nation liegt aber in der Fähigkeit politischen Denkens und vaterländischen Interesses bei der großen Menge.

6. (Wirksamkeit.) Nachdem in einem Folgekapitel (82) noch die Unterschiede im Geiste des Ostens, des Westens, des Südens innerhalb des großen Reiches, und die Färbungen der Offentlichen Meinung durch 
die in jeder Gegend vorherrschenden Einflüsse erörtert worden, wird von BRYCE die Frage aufgeworfen: wie wirkt sie? und in 3 Fragen unterschieden: $\mathrm{I}$. wer bildet sie, die Wenigen oder die Vielen? 2. wie sucht sie die Gesetzesmaschinerie zu ergreifen und zu benutzen, die von den Verfassungen (des Bundes und der Staaten) dargeboten wird? 3. welche Mittel hat sie außer diesen, auf den Gang der Dinge zu wirken? - Diese Fragen, zumal die erste, werden dadurch geklärt, daß man in bezug auf politische Bildung drei Schichten unterscheidet: $I$. die der praktischen Politiker, an deren Spitze die Parteiführer stehen, 2. die der politisch Interessierten, 3. die der verhältnismäßig Gleichgültigen, die höchstens zur Wahlurne gehen oder sich ziehen lassen. Die erste Schicht ist in Amerika durchaus gering, auch die dritte kleiner als in England, wird nur durch Neueingewanderte und Neger erheblich. In der zweiten Schicht wird die Offentliche Meinung der Vereinigten Staaten sowohl gebildet als auf die Probe gestellt, sowohl geschaffen als gestaltet. Luft und Wärme der Politik strahlen nicht, wie in England, von einem Zentrum aus, durchdringen vielmehr die ganze Atmosphäre und sind nicht viel intensiver in der inneren Sphäre der praktischen Politiker als anderswo. Die fortwährenden Wahlen nötigen den gewöhnlichen Bürger, an den öffentlichen Angelegenheiten einen tätigen Anteil zu nehmen. Er hält sich für ebenso kompetent wie seinen Vertreter und den Beamten. So gilt für Amerika, daß die Offentliche Meinung nicht gemacht wird, sondern wächst. In irgendwelchen Bewegungen ist die Rolle der individuellen Führer minder bedeutend als in England. Reden und Leitartikel wirken weniger, der Gang der Eireignisse mehr auf die Denkungsart des Amerikaners als des Europäers. Jene erste und innere Schicht von Denkern, Schriftstellern, Rednern, ist zwar auch in Amerika, zumal in den Großstädten, nicht gering an Zahl, aber sie sind isoliert und unorganisiert, sie bilden keine Klasse. Das Machen und Führen der öffentlichen Meinung ist mehr Sache von Liebhabern (Amateurs), die darin zuweilen Großes leisten, aber es ist weniger zusammenhängend, weniger überwältigend, wirkt weniger rasch auf die Masse der Bürger als es z. B. in England der Fall ist. - Wie kann man nun durch die Offentliche Meinung Einfluß auf die Gestaltung der Dinge zu erlangen hoffen? Einfach ist es, wenn sie in den Bahnen einer Partei verläuft, wie aber, wenn außerhalb? Zuvörderst ist Organisation unerläßlich, dann aber stehen 3 Wege offen. Man kann versuchen, für die Sache, den Zweck, den man fördern will, eine der großen Parteien zu gewinnen - der sicherste aber auch der schwierigste Weg. Die Partei hat ihre feste Dogmatik. 2. eine neue Partei bilden. Kostspielig und mühsam, nur anwendbar, wenn man nicht der 
Lächerlichkeit verfallen will, wo es sich um eine Sache von offenbar großer Bedeutung handelt, dann freilich wirkt es als Reklame und kann zersetzend auf die alten Parteien wirken, auch wenn es sonst keinen Erfolg hat. Endlich 3. die Sache in der Schwebe halten und sie den Parteien anbieten als Preis, der für Unterstützung im Wahlkampfe zu zahlen wäre - ein häufiges Verfahren, wirksam und verhältnismäßig leicht anwendbar. Die Möglichkeit, daß es eingeschlagen wird, wirkt als eine Hemmung auf die Parteien, indem es sie abhält von Gesetzgebung, die ein Stück wachsender öffentlicher Meinung reizen und zur Absplitterung veranlassen könnte; es macht sie also duldsamer gegen Abweichungen vom orthodoxen Programm, als sonst die Parteidisziplin zulassen würde. - Allgemein gilt natürlich, daß Rücksicht auf die Offentliche Meinung und ihren Erfolg bei den nächsten Wahlen mächtig wirkt auf die Gesetzgeber und Regierungen. Wie Strafrecht und Gerichtsbarkeit neben ihrer vergeltenden eine vorbeugende Wirkung haben, so macht auch eine gesunde und wachsame Offentliche Meinung sich dadurch geltend, daß sie törichte oder korrupte Gesetzgebung sowohl als unredliche Verwaltung zu verhüten in der Lage ist. Die Zeichen werden auch hier zuweilen irrig gedeutet. Aber es gibt ziemlich sichere Zeichen, dazu gehört die Art, wie Personen von anerkannt gemäßigter Denkweise sich aussprechen und die von den weniger parteigebundenen Zeitungen eingenommene Stellung. Bald merken dann auch einige der Parteiorgane, wie der Wind weht. Wenn es in den Wählerschaften immer unsichere Elemente gibt, die leicht den Ausschlag geben, so sind das oft auch solche, die unlauteren Einflüssen zugänglich sind, aber in Amerika darf es eher als in England für ein Zeichen unabhängigen Urteils und das Abschwenken von einer Partei zur andern für begründet durch ernsten und sachlichen Dissens oder durch Unzufriedenheit mit den Personen gelten. Als Gegengewicht gegen die Parteischeidung wirken die mannigfachen "Bewegungen " für oder wider eine Sache, die in den Vereinigten Staaten alle Kräfte anspannen, um ihren Meinungen Ausdruck und Verbreitung zu geben. Die Parteien befassen sich wenig mit Lehrmeinungen. Nur vor wichtigen Wahlen, die eine Frage entscheiden sollen, versucht jede von ihrem Standpunkt aus, die politischen Ansichten zur Reife und Klärung zu bringen. Die Geschäftigkeit der Offentlichen Meinung ist weniger stetig als in Europa, sie kümmert sich nur stoßweise intensiv um die Politik. Amerika leidet unter einer Art von Wechselfieber, in jedem 4. Jahre erleidet das Land mit bevorstehender Präsidentenwahl einen Anfall. Übrigens hat die Politik es nicht eilig, sie macht viel Iärm, ohne viel vorwärts zu kommen; 
mehr als die Maschinerie der Regierung hilft dazu der praktische Verstand und ehrliche Patriotismus von Männern unabhängiger Denkungsart, die sich den Parteidogmen nicht gefangen geben.

7. (Mehrheit und Menge.) Die Tyrannei der Mehrheit, die man oft den Demokratien zur Last legt, macht sich nach BRYCE in den Vereinigten Staaten wenig fühlbar: sowohl in der Gesetzgebung der Union und der Staaten, als in der Tätigkeit der Offentlichen Meinung. Was diese betrifft, so war es anders in der ersten Hälfte des I9. Jahrhunderts: TocQUEviLLE sagte damals, er kenne kein Land, wo im allgemeinen weniger Unabhängigkeit des Geistes und echte Freiheit der Erörterung anzutreffen sei als in Amerika. Der Bürgerkrieg hat mit der Bigotterie und dem Fanatismus aufgeräumt, die bis dahin vorherrschten. Nicht sowohl Tyrannei der Mehrheit, als ein gewisser Servilismus der Minderheit macht sich geltend. Aus dem Dogma, daß die Mehrheit entscheiden soll, quillt leicht ein anderes, wenn es auch zumeist unterbewußt bleibt, daß nämlich die Mehrheit immer im Rechte sei; aus beiden wiederum entsprießt das Gefühl, $\mathrm{da} B$ es umsonst ist, der Mehrheit Opposition zu machen oder sie auch nur zu kritisieren. BRYCE nennt dies den $" F$ atalismus der Menge». Die schrankenlose Freiheit der Diskussion wirke dazu mit, wie Unterdrückung den Widerstand reizt; wer von der Menge verurteilt oder totgeschwiegen werde, könne an kein höheres Gericht Berufung einlegen. Ebenso wirke der feste Glaube, den die Amerikaner haben an die Gesundheit ihrer Institutionen und an die Zukunft ihres Landes. Man hat gesagt, sie halten sich für Gegenstände einer besonderen Fürsorge der göttlichen Vorsehung. Die Amerikaner fühlen sich bei ihrer freiwilligen Unterwerfung unter den Willen der Offentlichen Meinung unzweifelhaft wohl. Sie kann um so geschwinder und um so vollständiger ihren Willen durchsetzen, sie gewinnt überdies dadurch eine Festigkeit, die den ganzen politischen Körper stärkt. Fragen, über welche die Massen sich entschieden haben, scheiden aus der praiktischen Erörterung aus. Der Streit beschränkt sich auf Nebenfragen; wie wild er hier auch tobe, er stört die große und schwere Masse der Úbereinstimmung ebensowenig, als ein Sturm die Tiefen des Ozeans aufrührt.

8. (Schätzung der Öffentlichen Meinung.) Als offenbare Schwäche einer Regierung durch die Offentliche Meinung bezeichnet BRYCE die Schwierigkeit, diese mit Sicherheit zu erkennen; denn es gibt vicle unechte Nachahmungen. Wahlen sind die große Probe, aber Wahlen sind schon ïberzahlreich in den Vercinigten Staaten. Das Referendum wäre mühsam und kostspielig schon in den größeren Einzelstaaten, geschweige in der Union. Die Offentliche Meinung ist 
mehr geeignet, Wünsche auszudrücken, als praktische Entwürfe daraus zu gestalten - sie weist auf $Z$ wecke hin, aber ist minder geeignet, die Mittel dafür zu prüfen und auszuwählen, sie schwächt vielmehr die dafür geschaffenen Organe. Die Parlamentarier haben wenig Geschick für konstruktive Gesetzgebung. Die Offentliche Meinung selber ist langsam und schwerfällig in der Art wie sie große praktische Probleme behandelt: sie faßt sie ins Auge, redet unaufhörlich darüber, beklagt sich, $\mathrm{da} B$ der Kongre $B$ sie nicht löse, ärgert sich, daß sie nicht von selber sich lösen. Sie bleiben ungelöst. Das bedächtige und zögernde Auftreten der Offentlichen Meinung hat freilich auch seine guten Seiten. Es ergibt sich schon durch die Größe des Gebiets, und in der Tat wirkt die Offentliche Meinung in den Einzelstaaten zuweilen hastig und hemmungslos, während in der Gesamtnation ihre Qualitäten einander mehr gegenseitig aufheben. Ihre große Aufgabe der Gesetzgebung und Verwaltung gegenüber ist Kritik. Diese Funktion wird sehr erschwert durch das amerikanische System vielfach geschiedener und einander kreuzender Kompetenzen. Zuweilen irrt das Publikum umher wie ein brïllender Löwe, suchend, wen es verschlinge, und findet keinen, den es für den Skandal verantwortlich machen kann. Und überdies ist die Offentliche Meinung zwar in großen Sachen rasch und voll Eifers, in geringeren aber sorglos, und immer zur Nachsicht geneigt. Daran ist auch schuld, daß gerade die tatkräftigen Naturen durch ihre Privatinteressen sich völlig in Anspruch genommen finden, und daß der fatalistische Optimismus sie oft gleichgültig macht. "Die Sache wird schon zurecht kommen"damit tröstet man sich. Der eine glaubt, nicht mehr berufen zu sein, sich einzumischen, als der andere. Auch der praktische Staatsmann scheut sich davor, etwas Neues anzuregen, weil er fürchtet, es möge der Offentlichen Meinung mißfallen. So ist die enorme Macht der Offentlichen Meinung sowohl eine Gefahr für das Volk selber wie für seine Führer. Die einen wie die anderen werden mit übermäßigem Vertrauen zu ihrer eigenen Weisheit und Tugend, zu ihrer Freiheit angefuillt. Andererseits ist die Gesundheit der Offentlichen Meinung und die von ihr geïbte Kontrolle die starke Seite des amerikanischen Systems. „Die Offentliche Meinung ist eine Art von atmosphärischer Luft, frisch, scharf und getränkt mit Sonnenschein, wie die der amerikanischen Städte, und dies Sonnenlicht tötet viele der schädlichen Keime, die da ausgebrütet werden, wo Politiker zusammenkommen. Der Genius der allgemeinen Offentlichkeit hat überwiegend heilsame Ergebnisse.“ „Die Meinung einer ganzen Nation ist, wenn sie zum Ausdruck gelangt, die berufenste Autorität, die Endzwecke der nationalen Politik zu bestimmen." Die Herrschaft der Offentlichen Meinung 
in Amerika kontrastiert vorteilhaft mit einer Demokratie, die ausschlieBlich auf Mehrheiten gegründet, in der Praxis hastig, gewaltsam, tyrannisch wäre. Auf jene wirken allmählich Beredsamkeit, Bildung, Weisheit, Ansehen der Erfahrung und der Persönlichkeit. So wird durch die Offentliche Meinung die Demokratie duldsam und vernünftig, es wird minder wahrscheinlich, daß sie durch Klassenscheidungen verbittert und geplagt wird. In Amerika ist es nicht nur die Gewohnheit des Wählens, sondern die erfrischende Seeluft der ganzen Atmosphäre des öffentlichen Lebens und die Art, wie man Nachrichten empfängt und bespricht, wie man beide Seiten hört und beurteilt, was die Einsicht des durchschnittlichen Bürgers gestaltet. Er atmet die Offentliche Meinung, wie er sie bilden hilft, und beides hebt, entwickelt, erzieht ihn. Es gibt ihm eine Empfindung persönlicher Verantwortlichkeit, stärker, weil beständiger als es in den "freien Ländern "Europas vorhanden ist, wo er seine Macht einer gesetzgebenden Körperschaft anvertraut. Er hat ein Gefühl von Eigentumsrecht an der Regierung, und damit eine Art von Unabhängigkeit sowohl des Benehmens wie des Geistes, das stark absticht gegen die Untertänigkeit der unteren Klassen in der alten Welt. Der eingeborene Amerikaner ist politisch geduldig, geneigt, es zuerst mit sanften Mitteln zu versuchen und zu erwarten, $\mathrm{da} B$ die anderen sich der Gewalt der Offentlichen Meinung, die sie selber anerkennen, auch beugen werden. In keinem Lande nimmt eine geschlagene Minderheit ihre Niederlage so gut auf. Beweisend dafür ist auch der erzieherische Einfluß der Offentlichen Meinung auf den Einwanderer. Die geistige Luft, die er atmet, verwandelt ihn unmerklich; das gilt sogar von den Iren, trotz ihrer Abneigung gegen England. Die Amerikaner haben einen unbegrenzten Glauben an freie Untersuchung und völlig freie Aussprache. Die unermeßliche Macht der Offentlichen Meinung ermöglicht ihnen, ihrer eigenen Ansicht nach, mit wenig Regierung auszukommen. Klasseninteressen, wenn sie auch auf die Gesetzgebung zu wirken suchen, werden gemildert durch die nationale Offentliche Meinung. Sie gestattet weder, daß die Armen durch die Reichen bedrückt werden, noch das Umgekehrte, was die demokratische Verfassung so leicht machen würde. Die Ehrlichkeit und der gesunde Menschenverstand des Staatsbürgertums verhindert es. Gesetzgebung, die zunächst vielleicht plausibel scheint, wird durch die Kritik der Offentlichen Meinung oft mit Erfolg unter Trommelfeuer genommen. Unzählige Beförderungen weiß sie zu verhindern, wenn sie auch nicht die Setzung der richtigen Männer auf die richtigen Plätze zu sichern in der Lage ist. DaB in den Südstaaten schamlose Patronage herrschte, besonders in den 20 Jahren nach dem Bürgerkriege, hängt mit dem Charakter der Offentlichen 
Meinung dort zusammen, die ganz von den Weißen gemacht, der republikanischen Partei feindlich war, so daß diese, während sie die Posten zu vergeben hatte, auf die Offentliche Meinung keine Rücksicht nahm. Diese war bisher so gut wie ganz die Meinung der kleinen Sklavenhalter, der Aristokratie von Grundeigentümern gewesen und als solche heftig und unduldsam gegen die Abolitionisten und den Norden. Das humane Verhalten der siegreichen Nordstaaten, das nicht den Politikern, sondern dem Volksganzen gutzuschreiben ist, hat sie umgestimmt und beinahe ausgeglichen mit der Meinung des Nordens und des Westens. - Die alles unterwerfende Macht der öffentlichen Stimme verhindert die Amerikaner nicht, große Männer anzuerkennen und zu ehren. Sie haben einen Hunger nach solchen und sind durchaus willig, sich zu begeistern. Und wenn auch die Bekämpfung einzelner Personen noch oft mit Erbitterung geschieht, so läßt sich doch bemerken, daß die Offentliche Meinung mäßiger, weicher und sicherlich duldsamer wird. Gerade ihre Stärke trägt dazu bei: sie achtet sich selber zu hoch, um zu wünschen, irgendeine Stimme zum Schweigen zu bringen.

9. (Kritik I.) Der Leser findet hier (2.-8.) im Auszuge (von mir übersetzt) wiedergegeben, was der 4. Abschnitt des BRYCEschen Werkes auf II6 Seiten dargestellt hat. Was darin zur allgemeinen Theorie der Offentlichen Meinung enthalten ist, wird in späterem Zusammenhange ausführlicher erörtert werden. Hier werde nur die Schilderung der Offentlichen Meinung in den Vereinigten Staaten ins Auge gefaßt und einer Prüfung unterzogen. Ihr Verfasser ist ein Gelehrter und Denker von Rang, der die Vereinigten Staaten nicht nur aus Büchern, sondern mehr durch eigene Beobachtung und Erfahrung kennt. Er verhehlt nicht die Schattenseiten des amerikanischen Lebens, zumal des öffentlichen Lebens und des Parteiensystems, dessen Verderbnisse er mit aller Schärfe anklagt - teils in dem dritten Abschnitt, der dem Parteiwesen gewidmet ist, teils in besonderen Kapiteln, so in dem ror. über die wahren Mängel der amerikanischen Demokratie und im I22. über die Zukunft der politischen Institutionen. Aber unverkennbar gibt sich doch in dem ganzen Werke der Freund und Bewunderer des amerikanischen Gemeinwesens und der Gesellschaft, worin es wurzelt, kund. Es ist zum Teil eine Apologie, die aber nur ungern zugesteht, daß eine Apologie irgendwie notwendig sei. Es ist das Buch eines schottischen Liberalen, der in einer demokratischen Verfassung und im fessellosen öffentlichen Leben die einzige eines fortgeschrittenen und gebildeten Volkes würdige Art des Zusammenlebens sieht. Also findet er in einem gewissen Maße in der 
amerikanischen Demokratie sein Ideal verkörpert. Und da er doch die schweren Schäden des Staatslebens nicht wegleugnen kann oder will, so ist es die Herrschaft der "gesunden « Offentlichen Meinung, ihre Uberlegenheit auch über den Präsidenten, über den Kongreß und vollends über die Regierungen der Einzelstaaten, was ihn tröstet und beruhigt, was ihm das sehr günstige Vorurteil, womit er den amerikanischen Boden betreten hat, rettet und ihn mit vollkommener Zuversicht in die Zukunft der Vereinigten Staaten schauen läßt. Die Macht des Kongresses, will sagen, des Parlaments, das weder an Mut, noch an Tatkraft und Weisheit, darum auch nicht an Ansehen gewinne, scheine, im Vergleiche mit der Macht der Offentlichen Meintung, eher abzunehmen (II, 907). Der Präsident sei in manchen Beziehungen besser geeignet als das Parlament, die Offentliche Meinung sowoll zu beeinflussen als in sich darzustellen (ib. 908). Diese wisse wohl, daß die "Maschine" - so wird das System der organisierten Parteien allgemein genannt - der gründlichen Reinigung bedürfe, aber das letzte Menschenalter lasse auch eine zwar langsame aber stetige Besserung in dieser Hinsicht erkennen (9Io). Die drei großen Vorzüge, die Amerika vor Europa habe - I. Abwesenheit von Klassenscheidung und Klassenhaß, 2. Verbreitung des Wohlstandes über eine unermeBliche Schicht kleiner Eigentümer, 3. Abwesenheit des chronischen Pauperismus und wirtschaftlicher Not, auch in Zeiten der Depression, wo die unentwickelten Gebiete des Westens so etwas wie ein Sicherheitsventil darbieten - diese Vorzüge bleiben. Freilich, es hängen auch Wolken über der Zukunft und das amerikanische Schiff hat einen Nebelberg vor sich: die zunehmende Verdichtung der Bevölkerung, abnehmende Fruchtbarkeit des Bodens. Aber auch gegen die drohenden Übel, wodurch die Zustände denen Europas ähnlicher werden, insbesondere gegen die Kämpfe zwischen Kapital und Arbeit, wird sich die Ordnungsliebe, die freiheitliche Sitte, die dadurch begünstigte Mäßigung und Selbstbeherrschung, die glückiiche Verteilung des Grundeigentums, der einschränkende und versöhnende Einfluß der Religion bewähren ( $9 \mathrm{I}_{4} \mathrm{f}$.).

Io. (Kritik II.) Die Methode, die Bryce bei seinem Studium des Geistes der Vereinigten Staaten anwendet, ist überwiegend empiristisch-induktiv. Aber hier und da geht er auch von allgemeinen Sätzen aus, um davon die Erscheinungen, wie sie zu erwarten seien und wirklich vorgefunden werden, abzuleiten (deduktive Methode). So in dem Kapitcl (85) über den Fatalismus der Menge. Jene drei Sätze, daß die Mehrheit entscheiden müsse, daß die Mehrheit im Recht sei, daß es vergeblich sei, ihr Widerstand zu leisten, gewinnt er auf diese Weise. Er geht von der Voraussetzung aus, daß 
die aristokratische Struktur einer Gesellschaft aufgelöst ist, daß die alten Gruppen verschwunden sind, daß die Menschen sich mehr als Mitglieder einer Nation als einer Klasse, einer Familie oder Gemeinde innerhalb einer Nation fühlen, $d a ß$ ein nivellierender Proze $B$ den Vorzug der Geburt und des Ranges zerstört hat, daß großes Grundeigentum nicht mehr vorhanden ist, $\mathrm{da} B$ viele Personen der sonst unteren Klasse zu Eigentum gelangt sind, daß Wissen leicht zugänglich und die Fähigkeit, es zu gebrauchen, nicht mehr auf die Wenigen beschränkt ist. „Unter solchen Bedingungen sozialer Gleichheit wird die Gewohnheit intellektuellen Befehles und individuellen Selbstvertrauens aus der führenden Klasse verschwunden sein, die den Typus des Nationalcharakters schafft, und wird nirgends in der Nation vorhanden sein." BRYCE setzt ferner voraus, daß politische Gleichheit Hand in Hand mit diesem Nivellement gegangen ist. Dadurch und wenn alles der Entscheidung der Mehrheit uiberlassen wird, wird unvermeidlich auch das Selbstvertrauen des starken Mannes und sein Bewußtsein individueller Kraft sinken, weil auch er fühlt, $\mathrm{da} \beta$ er nur einer unter vielen ist, und $\mathrm{da} B$ er, wenn überhaupt, nur dadurch etwas erreichen kann, daß er die Persönlichkeit seines Nachbars als in jedem Zoll seiner eigenen gleichwertig anerkennt. Es wird ferner vorausgesetzt, daß diese Entwicklung stattfindet in einem enorm großen und volkreichen Lande, wo der Einfluß, den einer privatim durch seinen Geist oder seinen Reichtum ausüben kann, sich beschränkt auf den kleinen Kreis seiner Stadt oder Nachbarschaft. In der unermeßlichen geschäftigen Menge mit ihrem Geschrei durcheinanderwirbelnder Stimmen, das er aus der Nähe vernimmt, scheint sein eigenes Sein verloren. Eir hat das Bewußtsein seiner Nichtigkeit, das uns überwältigt, wenn wir nachts die Milchstraße am Himmel anschauen, und wissen, daß schon von dem nächsten Fixstern aus unser Planet unsichtbar ist. In einem so beschaffenen Lande dürfe man erwarten, gewisse Gefühle und Denkweisen in den Seelen der Menschen herrschend $\mathrm{zu}$ finden. Und als solche bezeichnet BRYCE die genannten drei Sätze. Er hat gewisse Merkmale der amerikanischen Gesellschaft und ihres Staates richtig geschildert. Aber diese sind, wenn auch zum Teil minder ausgeprägt, die Merkmale jeder modernen Gesellschaft, jedes modernen Staates. An einigen davon nimmt freilich gerade Großbritannien am wenigsten teil, und naturgemäß denkt der Schotte zunächst an die Unterschiede der Vereinigten Staaten von diesem seinem Vaterlande. Die Tendenzen zur sozialen Gleichheit sind hier viel schwächer entwickelt, auch die förmliche politische Gleichheit war, zumal als BRYCE schrieb (vor I9II), noch sehr mangelhaft, da eine gesetzgebende Körperschaft, die aus erblichen 
Großen und aus Bischöfen besteht, noch jedes Gesetz, das im Hause der Gemeinen beschlossen war, zu Fall bringen konnte. Auch ist Großbritannien, mit den Vereinigten Staaten verglichen, ein kleines Land, dessen Kräfte und Gedanken in einer ungeheuren Hauptstadt konzentriert sind, das die heutigen Verkehrsmittel in fortwährendem raschen Austausch seiner Bewohner erhalten. Was die Ausdehnung des Gebietes betrifft, so konnte nur das ehemalige Rußland mit den Vereinigten Staaten verglichen werden. Alle großen europäischen Länder, wenn auch Rußland bisher am wenigsten, und mehrere kleine, unterliegen sonst den gleichen Lebensbedingungen, die besonders während der 2. Hälfte des I9. Jahrhunderts unsäglich verschärft sich herausgestellt haben: den Umständen, die ich als die Entwicklung von Gemeinschaft zu Gesellschaft zu begreifen versuche.

Ich habe unterschiedlich dargestellt (»Individuum und Welt «,Weltwirtsch. Archiv I, I), wie die freien Individuen und der $\gg$ Individualismus «, den sie vertreten, also auch die gesellschaftlichen Vereinigungen, die daraus hervorgehen, I. in, 2. aus, 3. neben den gemeinschaftlichen Zusammenhängen und Verbänden sich entwickeln. Kolonien, die einen günstigen Boden finden, gehen einerseits schon aus diesen Individualisierungen und ihren Gesellschaften (die auch im Gemeinschaftsgewande auftreten, wic religiöse Sekten) hervor, andererseits machen sie die gleichen Entwicklungen stark beschleunigt und mit geringeren Hemmungen durch. Freilich steht bei Ackerbaukolonien die Natur des Ackerbaues, die den gemeinschaftlichen Typen so viel günstiger ist, entgegen. Aber dieser Widerstand pflegt durch Neuheit und Fremdheit des Bodens, durch den Mangel an Überlieferung, durch die Gebildetheit des Individualismus der Ansiedler, bald überwunden zu werden. So zeigen die Vereinigten Staaten, ungeachtet des so viel breiteren Raumes, den noch die landwirtschaftliche Basis in ihnen einnimmt, trotz des so viel geringeren Teiles der gesamten Bevölkerung, der in großen Städten wohnt, und allgemein der viel geringeren Dichtigkeit der Bevölkerung - verglichen mit den führenden Ländern der alten Welt - sie weisen gleichwohl die Züge der fortgeschrittenen und entfesselten "Gesellschaft «, nicht nur innerhalb ihrer Großstädte, sondern im Gesamtcharakter des Landes, schärfer als irgendwo ausgeprägt auf. A. I nnerha1b der Gemeinschaften - und als solche sind es religiöse Gemeinden, "freie Kirchen «, die für Neu-England wie für andere Siedelungsländer am meisten Bedeutung in sich trugen - entwickelt sich auf dem jungen Boden der einzelne Mann mit seiner Kraft, seinem Verstand, seinem Selbstvertrauen, um so leichter und rascher, da schon die Auswanderung ursprünglich ein "Abenteuer ist, das Tapferkcit und Wagemut, ja 
rücksichtslose Entschlossenheit fordert; von vornherein ist Kampf gegen die rohe Natur, zumeist auch gegen feindliche Urbewohner, geboten, der diese Eigenschaften weiter fördert. Auch ist es die Beschaffenheit, besonders der geringe Umfang und die Zerstreuung, der politischen und religiösen Verbände - der township und der Chapel - was das Hervortreten und die freie Bewegung tatkräftiger Individuen erleichtert. Geistig bindet die Heimat mehr als die Fremde, und die Kolonie bleibt lange, und immer für die Neuankömmlinge, eine Fremde. B. A us den Gemeinschaften befreit sich der einzelne Mensch um so leichter, da ihre herrschaftliche Gestaltung von vornherein schwächer ist oder - gegenüber einer für minderwertig geschätzten Rasse - die absolute Form der Herrschaft über Sklaven angenommen hat. Während sonst die Herrschaft auch die Herren nicht nur moralisch, sondern auch rechtlich verbindet, so fällt in der Sklaverei die rechtliche Bindung weg. Was aber die genossenschaftlichen Bindungen betrifft, so ergibt sich ihre Schwäche aus dem gesamten Charakter des kolonialen Wirtschaftslebens, das primitive Merkmale mit spätentwickelten, solche der Ursprünge mit solchen der Auflösung verknüpft. Die mittlere (und mittelalterliche) Phase, die in ausgebildeter Markgenossenschaft und im Zunftwesen ihren Ausdruck hat, ist in ihm am wenigsten vertreten, oder erliegt bald den Lebensbedingungen, die $z \mathfrak{u}$ scharfem Wettbewerb reizen, wie die durch das Mißverhältnis zwischen der Roheit des Landes und den Kulturbedürfnissen der Einwanderer angeregte Lebhaftigkeit des Verkehrs und Austausches, und die durch die Notwendigkeit der Einfuhr aus der alten Welt hervorgerufene Richtung auf Ausfuhr von Produkten. Auch auf dem politischen Gebiete sind die Voraussetzungen des Individualismus durchaus gegeben. Gerade hier wurzelt das Gemeinschaftliche durchaus in Überlieferung und Bodenständigkeit; das historische Bewußtsein wird ihm eine starke Stütze. Das Leben der Kolonie ist unhistorisch, es gestaltet die Anfänge neu, aber mit dem ausgebildeten rationalistischen Bewußtsein; die Basis des "natürlichen Rechts《 ist hier vorhanden. „Das ganze Staatsgebäude ist neu, für eine unvordenkliche Überlieferung also gar kein Platz. Alle Institute sind vor den Augen der Staatsgenossen selber gepflanzt und herangewachsen: ein Gefühl der Ehrfurcht können sie daher nicht gebieten" (Roscher, Kolonien" S. 9I). - In geistiger Beziehung wirken diese Lebensbedingungen und Einrichtungen dahin, einer nüchternen, prosaischen, auf das unmittelbar Nützliche gerichteten Denkungsart den Boden zu bereiten. Nur scheinbar, oder nur in geringem Maße, wirkt dem die Frömmigkeit, die oft zu den Veranlassungen der Auswanderung gehörte, entgegen. Sie 
nimmt bald den Charakter an, den man längst mit gutem Grunde der englisch-schottischen Religiosität zugeschrieben hat, den Charakter des kalten Aberglaubens, wenn sie diesen Charakter nicht schon mitbringt. Auch hier eine Vermischung des ursprünglichen Opfer- und Gebetwesens, das für irgendwelche Wagnisse die Hilfe der Götter in Anspruch nimmt, mit dem späten Ritualismus erstarrter Konventionen. Zugleich führt die Mischung verschiedener Religionsformen wenn auch (in Amerika) keineswegs zur Fusion, so doch zum Ausgleich und inneren Indifferentismus. Ebenso wird das individuelle und allgemein-menschliche Bewußtsein durch das Zusammenleben und Zusammenwirken der Menschen, die verschiedenen Ländern entstammen, gefördert. Eine seichte Gebildetheit gibt dem allgemeinen geistigen Leben sein Gepräge. Wenn diese schon in England mit einer außerordentlichen Verbreitung grober Unwissenheit sich vereinbar erweist, so muß dies vollends in einem Koloniallande zutage treten, das seine Sprache ganz und seine Sitten und Denkungsart zum größten Teile aus Großbritannien entlehnt hat. Der Ausgleich des Geisteslebens zwischen Männern, Frauen und Kindern trägt dazu nicht unerheblich bei. $\mathrm{Da} B$ auch aus der Familie sich die Individuen emanzipieren, ist einer der auffallendsten Züge des Koloniallebens die Emanzipation der Frauen, auch wo sie nicht zur politischen Gleichberechtigung fortschreitet, eine ausgeprägte Erscheinung, die der Kinder ging dem entschiedenen Befürworter des Individualismus, Herbert Spencer, zu weit. Jene, die Freiheit der Frauen, wird auch begünstigt durch ihre relative Seltenheit in Einwanderungsgebieten, die ihren Wert und ihre Selbstschätzung erhöht. C. Neben allen Gemeinschaften ist es auf dem ökonomischen Gebiete die umwälzende Kraft des Handels, die im Zusammenhange mit den bisher betrachteten Tendenzen und Voraussetzungen im Kolonialleben rascher und entscheidender, als sonst im modernen Gesellschaftswesen, den Ausschlag gibt. Handel bedeutet in seinem Fortschreiten und seiner Vergrößerung Kapitalismus, und dem Kapitalismus ist nichts willkommener als der freie und junge Boden der Kolonien, wenn auch die am meisten für ihn charakteristische industrielle Produktion zunächst großen Hemmnissen begegnet. Das Widersprechende im Beieinandersein des primitiven und des hochmodernen Wesens tritt auch hier zutage. Dem ist zuzuschreiben, da $B$ der Kapitalismus in diesem neuen Lande nicht nur äußerlich fessellos sich entfaltet, sondern auch in seinem inneren Wesen groteske Züge, bis zum Zerrbilde aufweist; es fehlen die Hemmungen des Heimat- und Gemeinschaftsgeistes, oft auch die des Verständnisses, das zwischen Kompatrioten das Zusammenleben trotz des Gegensatzes der Klassen 
erleichtert. So ist auch der Staat der einer gemischten und künstlich gebildeten Nation, die im wesentlichen nur geeinigt ist durch das gemeinsame Bedürfnis des Schutzes der Person und des Eigentums, so daß der Staat nur als Gehilfe und Wächter der Gesellschaft erscheint. „In Amerika“, erklärt BRYCE (II, 588), ,ist sogar die Würde des Staates (die ihm in England noch geblieben sei) verschwunden. Er scheint tatsächlich weniger als die Individuen, welche unter ihm leben. Das Volk, d. h. die ungeheure Menge der Menschen, die das Land bewohnen, flößt Achtung oder sogar Ehrfurcht ein, von dem Organismus weiß man nichts. Der Staat ist nichts als ein Name für die Gesetzgebungs- und Verwaltungsmaschinerie, die gewisse Geschäfte der Einwohner erledigen. Ihm wird nicht mehr Bewußtsein, geschweige eine moralische Mission oder ein Rechtsanspruch auf Ehrfurcht und Achtung, zugeschrieben als einer Aktiengesellschaft für den Betrieb einer Eisenbahn oder eines Bergwerks; und diejenigen, die ihn vertreten, werden öffentlich und im Privatleben mit genau ebenso geringer Eirgebenheit behandelt." Unter solchen Umständen wird auch das Staatsleben, der Staatsdienst und das Amt in ausschließender Weise als ein Geschäft empfunden und betrachtet werden, ein Geschäft, das der Privatmann, der sich damit befaßt, so vorteilhaft als möglich für sich zu gestalten und auszubeuten beflissen ist. Und die Offentliche Meinung?, wird nicht auch dieser Ausdruck des nationalen Willens gleichsam gepachtet werden von Unternehmern, die hinlänglich gerissen (smart) sind, sich auf dies Geschäft zu verstehen? Wird nicht dieser gesellschaftliche Geist neben allem gemeinschaftlichen Geist, aus den Bedürfnissen der Interessen der Individuen sich herausbilden? Werden nicht dieselben Spekulanten und Streber, die das politische Leben beherrschen und ihren Zwecken anpassen, auch dieses "Oberherrn " sich zu bemächtigen wissen? Sollte nicht die Offentliche Meinung zum Geschäft werden wie alles andere?

II. (Kritik III.) Die Ansicht Bryces geht dahin, daß in Amerika die Offentliche Meinung wirklich die Willensmeinung der großen Mehrheit des Volkes sei. „Die Offentliche Meinung Deutschlands, Italiens, Frankreichs und Englands ist wesentlich die Meinung der Klasse gewesen, die schwarze Röcke trägt und in guten Häusern wohnt, wenn sie auch in den zwei zuletzt genannten Ländern während der letzten Jahre in zunehmender Weise durch die Meinung der sozial niedrigeren Schichten beeinflußt worden ist. Wenn auch die Mitglieder des britischen Parlaments jetzt der Masse ihrer Wähler gehorchen, sobald diese einen bestimmten Wunsch kundgibt, so ist doch der Einfluß, der am stetigsten auf sie wirkt und durch sie hindurchgeht, die Meinung einer Klasse oder von Klassen, und nicht die 
der ganzen Nation. Die Klasse, zu der die große Mehrheit der Mitglieder beider Häuser gehört (nämlich die Grundbesitzer und die Personen der freien Berufe und der höheren Schichten des Handels) ist die Klasse, welche hauptsächlich gestaltet und ausdrückt, was man die Offentliche Meinung nennt." In Amerika sei das anders (s. ob. 2.). Man könne hier nicht von den Klassen an die Massen Berufung einlegen. „Was der Unternehmer denkt, denken auch seine Arbeiter (es sei denn in Fragen, die sich besonders auf die Arbeit und ihre Interessen beziehen). Was der Großkaufmann empfindet, empfindet ebenso der Krämer und die ärmeren Kunden. Die Scheidungen der Meinung sind vertikal und nicht horizontal." Die Tatsache, welche der Gelehrte hier ausdrücken will, könnte auch dahin gedeutet werden, $\mathrm{da} B$ der Übergang der Meinungen aus den oberen Schichten in die unteren in der Neuen Welt sich leichter und widerstandsloser vollziehe als in der Alten Welt, daB eben dadurch die wirkliche Ver allge meiner ung der Offentlichen Meinung öfter geschehe und darum auch mehr für unerläßlich gehalten werde, als in den Ländern Europas, insbesondere in England, der Fall sei. Hier, in einer durch und durch aristokratischen sozialen Verfassung, die auch den wesentlichen Inhalt der Politik, trotz demokratischer Formen, bestimme, genüge es, wenn die öffentliche Meinung der Oberschicht sich geltend mache; die der unteren komme wenig in Betracht, möge sie sich jener anschließen oder ihr widersetzen. Offenbar meint Herr BRYCE dies, wenn er hervorhebt, in England und Frankreich sei die Offentliche Meinung während der letzten Jahre in zunehmender Weise durch die Meinung der sozial niedrigeren Schichten beeinflußt worden. Er irrt sich gröblich (wie der Brite fast immer irrt, wenn er über Deutschland urteilt) in der Ansicht, daß dies hier weniger oder gar nicht der Fall sei. Durch das Dasein eines breiten Bauernstandes und damit eng zusammenhängenden Handwerkerstandes sind beide Länder, Frankreich und Deutschland, im soziale n Sinne demokratischer konstituiert als England, und in Deutschland macht gerade in diesen mittleren Schichten der hohe Stand der Volksbildung sich erkennbar, der auch politisch bedeutende Wirkungen ausübt; so ist nur aus ihm die außerordentliche Stärke der Arbeiterbewegung, und die Kraft des politischen Verstandes erklärbar, der in ihr sich Geltung verschafft hat. Gewi $\beta$ ist, da $B$ in Deutschland, und wahrscheinlich ebenso in den übrigen europäischen Hauptländern, die Offentliche Meinung, schon wegen des Anteils, den die Arbeiterklasse an ihrer Bildung hat, den Wust und Greuel politischer Korruption nicht dulden würde - sagen wir lieber, vor I9I4 nicht geduldet hätte - der in den Vereinigten Staaten seit Jahrzehnten wuchert und aller Reformversuche spottet. 
BRYCE selber erklärt, nachdem er die Schilderung der Wahlmaschinerie, des Beutesystems, der Bestechungsmethoden in gesetzgebenden und kommunalen Körperschaften geschildert hat, der Leser werde sich zuweilen an das England unter Sir ROBERT WALPOLE, zuweilen an Rußland unter Zar NIcolaus I. gemahnt finden. Mancher werde daraus den irrigen Schluß ziehen, es könne in Amerika wenig öffentliche Meinung in der Politik wirksam sein und ,die leitenden Geister, die in allen Ländern die Meinung gestalten und leiten, hätten in Amerika dieser Funktion entsagt und ließen die Politiker ihre eigenen Wege gehen" (II, 239). Er gesteht, hier liege das Kardinalproblem der amerikanischen Politik. Wo dies politische Leben alles durchdringe, könne da die praktische Politik auf einem niedrigeren Niveau sich befinden als die Offentliche Meinung? „Wie kann ein Volk, das grobe Ubel duldet, ein reines Volk sein?" Diese Fragen zu beantworten, sei die schwerste Aufgabe, der ein Schilderer der Vereinigten Staaten sich gegenübergestellt finden könne. Um sie zu lösen, will BRYCE das Verhalten der amerikanischen Offentlichen Meinung zu jenen Erscheinungen des öffentlichen Lebens objektiv darzustellen versuchen, indem er es an dessen auffallende Merkmale anknüpft. Er erörtert also I. die Korruption. Das meiste davon sehen die Leute nicht; sie sehen wenig und glauben noch weniger. Die umlaufenden Anschuldigungen werden dem Parteistreit und Parteiha $B$ zugeschrieben; oder man hält sich daran, daß doch wenig sich beweisen lasse; oder man meint, die Politiker haben ihre besondere Moral, mit der nicht zu rechten sei. Gebildete Leute sagen: ,es sind nur die Politiker; was kann man erwarten von den Politikern?" Kurz: viele bilden sich keine zureichende Vorstellung von dem Ubel und die es tun, regen sich nicht sehr darïber auf. 2. Wahlbetrug. Erregt eher Entrüstung als Bestechung, aber mit Maßen, denn man ist niemals überrascht, davon zu hören. Man versucht, durch Gesetzgebung Abhilfe zu schaffen. Wird aber der Wahlbetrug gegen Neger geübt, so erfährt er kaum Mißbilligung, sogar im Norden nicht. 3. Die Maschine (das Caucus-Wesen). Der Ärger darüber ist oft vermischt mit Amüsement. Der Boss ist so etwas wie ein Spaß, wenn auch ein recht kostspieliger. „Es ist eine Art von Fatalismus in ihrer Ansicht der Demokratie. Wenn in einem freien Lande etwas besteht, so hat es ein Recht, zu bestehen, denn es besteht mit Genehmigung des Volkes, von dem man annehmen kann, daß es sich beruhigt bei dem, was es nicht vertilgt. 4. Das Beute-System und die Günstlingswirtschaft in der Patronage wird gelinde beurteilt, weil man meint, die Abwechslung entspreche der Gleichheit und verhindere Beamtenaristokratie. Freilich: es ist schwer zu verstehen, warum die 
Praxis der Politiker so gelinde beurteilt wird. „Kein gewöhnlicher Bürger, geschweige ein Mann von sozialer Bedeutung und höherer Bildung würde in seinem privaten Verhalten tun, was viele Politiker mit wenig Furcht vor Schande tun," und ohne daß ihre Laufbahn dadurch gestört würde. „Europa bietet einen ähnlichen Kontrast zwischen dem Ton des öffentlichen und dem des Privatlebens." Der Beobachter knüpft hieran eine interessante Anmerkung ïber die öffentliche Moral in England. „Die Engländer haben zwei sittliche Maßstäbe für das öffentliche Leben : einen konventionellen oder idealen, und einen praktischen (wirklichen).“ „Der konventionelle findet Ausdruck nicht bloß auf der Kanzel, sondern auch in den Reden der Politiker und in den Leitartikeln von Journalisten. Er behandelt, von der Voraussetzung aus, daß der normale britische Staatsmann ein patriotischer, uninteressierter, wahrheitliebender und großdenkender Mann sei, jede Verfehlung als eine Abweichung von einer durchaus festen Linie der Pflicht, ein Vorkommnis, das schlechthin eine Ausnahme darstelle und den Schuldigen des Vertrauens auch seiner eigenen Partei unwürdig mache, aber den im allgemeinen so edlen Ton des britischen politischen Lebens nicht berühre. Ganz anders die praktische Moral (the actual morality), wie man sie in den Foyers der gesetzgebenden Kammern, oder den Rauchzimmern der politischen Klubs, oder in den Ausschußräumen bei den Wahlhandlungen kennen lernt. Sie betrachtet (oder betrachtete noch vor kurzem) die Bestechung von Wählern nur als ein Vergehen, wenn Entdeckung folgte; sie nimmt als selbstverständlich an, da $B$ ein Minister von seiner Patronage Gebrauch machen wird, um seine Partei oder sich selber zu stärken; sie lächelt über Wahlversprechungen, wie die Götter lächelten über die Schwüre der Liebenden; sie verteidigt den Mißbrauch parlamentarischer Regeln; sie duldet $Z$ weideutigkeiten und irreführende Behauptungen, die von einem Beamten ausgehen, sogar dann, wenn sie nicht die Entschuldigung staatlicher Notwendigkeit für sich haben. Nach dieser wirklichen Richtschnur beurteilen die Engländer einander tatsächlich; und wer unter diesen Normalstand nicht sinkt, braucht die konventionelle Idealität von Presse und Kanzel nicht zu fürchten." Dieser Tatbestand, meint BRYCE, sei vielleicht auf eine Tendenz zurückzuführen, die in allen Berufen zutage trete; auch pflege jedes Land scine eigenen Staatsmänner nach einer wirklichen Richtschnur, die des Auslandes nach der konventionellen zu beurteilen (für njedes Land « muB man hier lesen "Eingland " und hin und wieder wohl auch ein anderes I and). Aber Amerika? Ess beurteile seine eigenen Mängel insofern milde, als es sich nach der bisherigen Praxis abschätze, d.h. man sei über gewisse politische 
Laster weniger entsetzt, weil diese Laster alltäglich seien, als nach dem allgemeinen Ton zu erwarten wäre. „Aber weit entfernt, die Dinge nach Art der Engländer zu verhüllen, eine strenge Norm zu verkünden und unerbittlich auf das Ausland, gelinde auf die eigenen Landsleute anzuwenden, gibt man in Amerika der Offentlichkeit aller Art einen ungemein freien Lauf und gestattet Schriftstellern und Rednern, die Fehler ihrer Politiker in greller, um nicht zu sagen, in übertriebener Färbung darzustellen." Das habe seine Schattenseiten. „Es ist fast $\mathrm{zu}$ wenig Vorspiegelung (of make-believe) bei den Amerikanern in ihrer Publizistik wie in ihrer privaten Unterhaltung, und ihr Widerwille gegen Humbug, Heuchelei und was sie den englischen Pharisäismus nennen, neigt nicht nur zur Laxheit, sondern hat sie in den Augen der Alten Welt ihrer wirklichen moralischen Empfindlichkeit Unbill widerfahren lassen. Gewohnt, unablässigen Lippendienst einer Tugend gezollt $\mathrm{zu}$ sehen, deren praktische Ausübung man nicht beabsichtigt, nehmen die Europäer (d. h. die Engländer!) naturgemä $\beta$ an, da $\beta$ die Dinge in den Vereinigten Staaten noch um etliche Schattierungen dunkler sind als sie geschildert werden und deuten Freimütigkeit als Zynismus. Würde die amerikanische Politik nach dem wirklichen und nicht nach dem konventionellen Maßstabe europäischer Länder (d.h. Großbritanniens!) beurteilt, so würde der Kontrast zwischen den Untugenden der Politiker und den Tugenden des Volkes weniger auffallend sein." Man hört aus dieser gesamten Erörterung des Bewunderers amerikanischer Kultur die Verlegenheit heraus, der er in ihrem Eingang unverhohlenen Ausdruck gibt, um sie nachher mit Flei $\beta$ zu übertäuben. Er leugnet zuerst, daß die führenden Geister, denen er hier auch für Amerika zugesteht, daß sie die öffentliche Meinung gestalten und leiten, die Politiker ihre eigenen Wege gehen lassen. Er sagt dann (zwei Seiten nachher), daß gerade die Gebildeten sich damit trösten, von den Politikern könne man nichts Besseres erwarten. Er schildert in dem folgenden großen Abschnitt (dessen wesentlichen Inhalt wir mitgeteilt haben), die Offentliche Meinung als den eigentlichen Souverän in Amerika, als den immer wachsamen Hüter und Herrscher, und zugleich als die über alle Schichten ausgebreitete Gesinnung - und hier? auch hier ist sie ihm stärker und tätiger als irgendwo, aber - um solche Kleinigkeiten, wie die Korruption im öffentlichen Leben, kümmert sie sich wenig, das meiste sieht sie einfach nicht, das wenige, was sie sieht, glaubt sie meistens nicht. „Der Seelenzustand des Durchschnittsmenschen ist eher ein Zustand der Mattigkeit als der Schwieligkeit (callousness)." In der Hauptsache kann und will BRYCE die Tatsache nicht leugnen, daß die Offentliche Meinung im politischen 
Leben die gröbsten Verstöße gegen sonst gültige sittliche Grundsätze duldet und leicht nimmt, daß man ohne Scham und Rückhalt solche Dinge öffentlich erörtert, ohne auch nur die Vorstellung der Mühe wert zu halten, als ob man auf Besserung ernstlich bedacht sei. Er sucht diesen Tatbestand dadurch zu beschönigen, da $B$ er sagt: ,in England ist's im Grunde nicht viel besser, aber man macht wenigstens immer seine Verbeugung vor der Tugend, man macht ihr in Gestalt der heuchlerischen Rede sein Kompliment; die Amerikaner verstehen sich darauf nicht".

12. (Andere Auffassungen - Ostrogorski.) Man begreift demgemäB, daB es über das Verhältnis der Offentlichen Meinung in den Vereinigten Staaten zu den politischen Zuständen andere Auffassungen gibt. Eine große Schilderung der englischen und amerikanischen -Demokratie", wie sie in der Organisation ihrer politischen Parteien sich ausdrückt, hat in einem bedeutenden Werke OSTROGORSKI gegeben, zu dessen englischer Ausgabe der Verfasser des „American Commonwealth" eine empfehlende Vorrede geschrieben hat. Vor BRYCES eigener Darstellung zeichnet sich OSTROGORSKI dadurch aus, $\mathrm{da} B$ er, obschon sich selber als Demokraten bekennend, den amerikanischen Zuständen keine sentimentale Beschönigung zuteil werden läßt, sondern nur beflissen ist, zu schildern, was ist. Er entwickelt auf mehreren Seiten (Democracy and the organisation of political parties II, 384-390), wie die Offentliche Meinung durch die "Maschine " beschwind elt wird (how public opinion is hoodwinked by the Machine). Die Maschine kann Leute von Charakter nicht gebrauchen; ja zuweilen muß sie der Vorsicht halber, ,,notorische Banditen " in Anspruch nehmen, weil diese zu viel wissen und sonst zu Verrätern würden; jedenfalls müssen die Kandidaten - möge es sich um ein Gemeinderatsmitglied, einen Abgeordneten zum KongreB, oder sogar um den Gouverneur eines Staates handeln - dem unteren Ende ihrer respektiven sozialen Sphäre angehören. ,,Sie der Gesamtpartei, einschließlich deren anständige und unabhängige Teile, aufzunötigen, erfordert oft eine höhere Strategie und eine besondere 'Taktik, wodurch der perverse Scharfsinn der Häupter der Maschine selbst, des Boss und des geschäftsführenden Ausschusses auf die Probe gestellt wird. Die Aufgabe besteht darin, die Karten geschickt zu mischen, besonders auch die verschiedenen Wahlen durcheinander zu bringen. So handelt es sich bei einer Gemeindewahl niemals um die gute Verwaltung der Stadt, um Straßenpflaster und Entwässerung, sondern um Schutzzölle, um Cuba, um die Philippinen. Das allgemeine Geschick der Partei im Staate und im Reiche steht auf dem Spicl. Da darf man nicht kleinlich sein und die Partei, die glorreiche Partei, für die 
Verfehlungen irgendwelcher Mitglieder büßen lassen. Ihre Niederlage würde wohl gar finanziellen Ruin bedeuten; was liegt da an dem einzelnen Mann? es ist die Flagge, der man folgen muß. Gerade im gegebenen Augenblick kommt alles darauf an, es ist ein Fall von force majeure, der es schlechthin gebieterisch verlangt, $\mathrm{da} B$ man für die Parteiliste eintrete und sogar einen "gelben Hund " mit in den Kauf nehme! - Dabei werden auch falsche Karten ins Spiel gebracht. Auf der einen Seite gilt es, durch Zierrat zu täuschen: anständige, aber charakterschwache, leicht zu lenkende Persönlichkeiten an die Spitze zu bringen, als Delegierte, aber auch als Kandidaten, z. B. für einen Bürgermeisterposten - ein solcher Ehrenmann an der Spitze muß dann eine ganze Reihe von Leuten decken, die es nicht sind. Andererseits aber werden die Wähler beschwindelt durch Aufstellung von ,dummies" - das sind Kandidaturen von Leuten, die in einem noch viel schlechteren Ruf stehen als die eigentlich gewollten. Eine solche allerübelste Kandidatur ruft natürlich Unwillen und Entrüstung hervor. Dann macht die Maschine ihre Verbeugung vor der Offentlichen Meinung, gibt willig nach und zieht die Kandidatur zurück, um mit derjenigen aufzuwarten, die sie von Anfang an gewollt hat. Das Publikum nimmt alsdann diesen Mann als das kleinere von zwei Ubeln mit einer wahren Erleichterung auf und gratuliert sich zu dem neuen Beweis, der für die Allmacht der freien Meinung in einer Demokratie gegeben sei, da schon ihr Wink genüge, um zu bewirken, daß die politischen Banditen ihre Köpfe verstecken. Bei dieser Finte ist der Schuft, der den dummy spielt, im Vernehmen, er verzichtet dann »freiwillig «. Zuweilen wird aber auch eine anständige Persönlichkeit als dummy verwandt, $d . h$. seine Kandidatur ist nicht ernst gemeint, soll aber einen guten Eindruck machen; im letzten Augenblick wird sie durch eine echte Maschinen-Kandidatur ersetzt. Oft wird sogar die Rolle des dummy von der Maschine der Gegenpartei eingespielt. Wenn diese schlechte Aussichten hat, so tut sie der scheinbar von ihr bekämpften Partei den Gefallen, nur Kandidaten aufzustellen, deren Ablehnung durch die Wählerschaft sicher ist; $Z$ weck: einen Anteil an der "Beute" zu gewinnen. Z. B. es wäre Stimmung vorhanden, aus Widerwillen gegen die Korruption der Republikaner einen Demokraten zu wählen, wenn es ein anständiger Mann ist. Die demokratische Maschine hat aber zu wenig Aussicht, sie zieht es vor, mit ihrer Gegnerin unter einer Decke zu spielen (wofür diese natürlich an anderer Stelle sich ebenso gefällig erweisen muß). Was tut sie? sie stellt einen anständigen Mann auf, der aber bekannt ist als Befürworter einer Sache, die für die Gegenpartei unmöglich ist - manche, die sonst gern für einen Demokraten stimmen würden, 
werden sicherlich nicht für einen solchen stimmen, der z. B. für freie Silberprägung eintritt u. dg1. Auch in anderer Weise kolludieren die gegnerischen Maschinen häufig; sie verschachern einander die Stimmen und tauschen sie aus, leisten einander "Liebesdienste». Wird eine Parteimaschine von Reformern angegriffen, so fühlt sich die Gegenpartei nicht selten solidarisch mit ihr; es handelt sich darum, das Regime und das Beutesystem zu retten, die Heiligtümer der Politiker. Bleibt aber eine Maschine auf sich selber angewiesen, so predigt sie den Frieden in der Partei, sie ist zu Opfern bereit, gibt Mißstände zu und ist scheinbar emsig, sie abzustellen. „Je nach Lage der Dinge macht sie die Opfer größer oder kleiner; dem Zerberus der Offentlichen Meinung schmeißt sie etliche Wahlstellen in den Rachen, die hochanständigen Personen zugedacht werden, ... ist das Ungeheuer wild und zeigt scharfe $Z$ ähne, so werden ihm einige Brocken mehr zugeworfen." Je größer die Gefährdung, um so ausgesprochener die Nachgiebigkeit. „Wenn die Offentliche Meinung besonders nachdrücklich sich für eine bestimmte Kandidatur erklärt, so beeilt sich die Maschine, diese anzunehmen.“ „Die Anpassungswilligkeit der Maschine ist unter solchen Umständen grenzenlos; sie ist imstande, um die Offentliche Meinung irrezuführen, ihre Haut zu wechseln, durchaus anständig $z \mathfrak{u}$ werden und scheinbar nur um das Gemeinwohl besorgt zu sein; ja sie hißt wohl selber die Fahne der »Reform", predigt den Kreuzzug gegen die Korruption der Politiker, " zumal gegen diejenigen in der Maschine der Gegenpartei. „Alles dieses dauert so lange als nötig, bis der Sturm sich gelegt hat; nachher geht es wieder nach der alten Weise. Die versprochenen Reformen sind abgetan; der Form halber werden einige Gesetzentwürfe eingebracht, oder wenn sie durchgehen, so wurden sie vorher in der Kommission so ihrer Lebenskraft beraubt, $\mathrm{da} B$ es totgeborene Kinder sind. Die Verbeugungen vor der Ehrlichkeit und die Reuakte, zu denen die Maschine sich verstanden hatte, sind für sie nichts als Komödien, womit sie den friedlichen Genuß der Macht unterbricht. Außer in solchen kritischen Perioden kümmert sie sich wenig darum, was anständige Leute von ihren Taten und Missetaten denken; sie rechnet auf die Gleichgültigkeit und die Apathie der großen Masse der Wähler; sie ist überzeugt, daß die Partei, welcher Art Leute sie auch in die Stellungen bringen möge, wins Geleise rollen « wird, und die Eirfahrung widerspricht dem selten; in ruhigen Zeiten kann sie die Kandidaturen nach ihrem Gefallen schieben, und das ist genug, sie zur Herrin der Lage zu machen. Also die Offentliche Meinung zum besten habend, mit ihr fechtend, oder sie einfach ignorierend, wenn es angeht, weiß die Maschine doch immer ihr weis zu machen, sie (die Maschine) habe 
eigentlich gar keine Macht und müsse unbedingt tun, was das "Volk * will. Und das »Volk «macht sich diese Auffassung mit vieler Selbstgefälligkeit zu eigen, es weiß zwar, $\mathrm{da} B$ die Politiker voller Listen und Kniffe sind, aber es hat Vertrauen zu seiner eigenen Stärke, ein hochsinniges Vertrauen, auf Grund dessen es nicht sowohl mit Entrüstung, als mit nachsichtiger Verachtung für die Politiker erfüllt ist, die von seiner Gnade abhängig sind." Im Anschlu $B$ an diese Ausführung weist OsTROGORSKI noch darauf hin, daß dies Hinterslichtführen der Offentlichen Meinung in wirkungsvoller Weise unterstützt werde durch die Parteipresse. An späterer Stelle seines Buches führt Ostrogorskr aus, daß von Zeit zu Zeit doch die Geduld des Publikums sich erschöpfe, ja daß schließlich jede Maschine von ihrem Schicksal ereilt werde, wie jeder Straßenräuber auf dem Schaffot zu enden pflege - freilich, wie jedem Straßenräuber ein frischer folge, so werde auch jede verkrachte Maschine bald, sei es durch denselben oder einen anderen Boss, wieder zusammengeflickt. Man fühle sich zuweilen erinnert an das Wort vom "Despotismus, gemäßigt durch Meuchelmord", aber es gehe in Wirklichkeit friedlich her, wenn das Volk einmal in seinem Zorne sich erhebe. Dann führe das souveräne Volk seine Streiche ohne Erbarmen und unterschiedlos, Schuldige und Unschuldige werden gerichtet. Terror läuft durch die Reihen der Politiker, die mächtigsten unter ihnen, die Häuptlinge der Bosses, an deren Lächeln noch den Tag zuvor Staatsgouverneure und Gesetzgeber hingen, müssen ins Gras beißen. „Die Macht der Offentlichen Meinung, von der man annimmt, daß sie in den Vereinigten Staaten auf jedem und auf allem schwer lastet, wie die Moira der Alten, erreicht schließlich einmal die Politiker, aber es geschieht mehr oder weniger von ungefähr, während jede regelmäßige Verantwortlichkeit ausgeschlossen ist. Die Autorität, die von der Offentlichen Meinung über die Maschine ausgeuibt wird, ist die Autorität des Richters Lynch folglich beschränkt sich die Ergebenheit und Unterwürfigkeit, womit die Maschine genötigt ist, die Offentliche Meinung zu behandeln, ausschließlich auf das Risiko, dem sie ausgesetzt ist, den Lynch zu wecken, der in der Brust des Publikums schlummert." „Allerdings pflegt die Maschine der Offentlichen Meinung große Aufmerksamkeit zu schenken." Wo immer es möglich ist, ohne großes Opfer die Offentliche Meinung zufrieden zu stellen, tut die Maschine es gerne. „Aber es steht nicht oft in ihrer Macht, denn wollte sie immer nach den Interessen des Publikums sich richten, so würde sie ihre eigenen Aussichten zugrunde richten. Würde sie nur anständige Leute in die Ämter bringen, so würden diese nicht willens sein, ihr zu dienen; gäbe sie es auf, Wahlrechte, Gesetze, Schutz für irgendwelche 
Körperschaften feil zu halten, wo würde sie das Geld hernehmen, das sie für ihren Unterhalt und für die enormen Ausgaben ihrer Propaganda in einer Großstadt oder einem Staat nötig hat? So ist schon durch die Macht der Verhältnisse der Boss gezwungen, über die Meinung anständiger und aufgeklärter Leute sich hinwegzusetzen. Der im allgemeinen apathische und träge Zustand der Offentlichen Meinung setzt ihn in den Stand, ihr in 9 von Io Fällen ungestraft zu trotzen; die Schwierigkeit ist, über den Io. Fall hinwegzulkommen. $\mathrm{Zu}$ diesem Behuf schlagen sie die Offentliche Meinung an, um die Annäherung des schlimmen Punktes zu künden. So lange sie ihn nicht für nahe halten, treiben sie ihre Praktiken, ohne sich Schranken zu setzen, ja finden zuweilen ein wüstes Vergnügen darin, der Offentlichen Meinung offen Trotz zu bieten; ihre Frechheit kommt ihnen dann, angesichts der drohenden Gefahr, wie eine Art von Heroismus vor. Sie geben nur nach, wenn sie gar nicht anders können. Wenn die politische Lage auf eine bestimmte Frage sich verengt, die in ausgesprochener Weise der Offentlichen Meinung vorgelegt ist, so daß diese in einer bestimmten Richtung sich bewegen muB, so steht das Wetterglas für die Maschine niedrig. Wenn sie nun noch die Wahl hat zwischen Niederlage oder Unterwerfung unter die Forderungen der Offentlichen Meinung, so gibt die Maschine nach. Aber oft versucht sie trotzdem noch, die Oberhand zu bekommen, und nur, wenn sie geschlagen ist, bessert sie sich. Dann stellt sie vorzügliche Kandidaten bei den Wahlen auf, nimmt eine demütige, ja kriechende Haltung ein, und übt sich so lange in Tugendhaftigkeit, bis die Offentliche Meinung wieder einschlummert. Im großen und ganzen ist die Autorität der Offentlichen Meinung nur eine schwache und nachgiebige Hemmung gegen die Machinationen der Maschine; nur teilweise Einschränkungen vermag sie ihrer Macht aufzuerlege ${ }^{1}$ ) (S. 420). Dies Urteil bewährt sich in Anwendung auf die einzelnen Erscheinungen. Ungeheuerliche Mißbräuche, die mit den Urversammlungen (primaries) verbunden waren und sind, haben zum Einschreiten der Gesetzgebung geführt, eine gewisse polizeiliche Aufsicht ist ihnen zuteil geworden, die AuBerlichkeiten ihrer Einberufung und Leitung sind besser als sie es zuvor waren, geordnet worden; aber was hinter den Kulissen vorgeht und die primaries zur Komödie macht, liegt außerhalb des Bereiches der Gesetzgebung. So sind denn die Eirgebnisse nicht erheblich gewesen. „Im allgemeinen bleiben die Betrügereien, die in den Urversammlungen begangen werden, ungestraft, trotz des

1) Vgl. Lord WELBY, über die Offentliche Meinung in den Vereinigten Staaten, (oben S. 239.) 
Gesetzes." Die Behörden - Wahlbeamte, die selber in diesen Versammlungen ernannt werden, vielleicht unter Mitwirkung ebenderselben Leute, die fortgesetzt Betrügereien sich zu schulden kommen lassen - hätten wohl ihre Pflicht getan, wenn sie von der Offentlichen Meinung unterstützt oder ermutigt wären, aber die Missetaten der Urversammlungen sind nicht so beschaffen, da $B$ sie ihren Zorn erregen; jedenfalls ist dieser Zorn niemals von langer Dauer - tags darauf ergeht man sich in sittlicher Entrüstung über die Politiker, dann geht man wieder an seine Geschäfte. „Das ist das Geheimnis der Wirkungslosigkeit und man möchte fast sagen, der Nutzlosigkeit aller dieser Gesetze zum Schutze der Urversammlungen. Die Offentliche Meinung, oder wenigstens ein erheblicher Teil von ihr, hat im Laufe der letzten Jahre (vor I902) die Wichtigkeit, ja die gebieterische Notwendigkeit, die Urversammlungen $z u$ säubern, sich vergegenwärtigt, indem sie Gesetze gegen die Ubeltäter verlangte; aber sie hat noch nicht den Willen und die Tatkraft erworben, aus diesen Gesetzen eine Wirklichkeit zu machen. Günstigsten Falles ist sie noch in der Phase des Video meliora proboque, deteriora sequor." Anderen Reformversuchen, insonderheit in der Gemeindeverwaltung, ist es nicht besser ergangen. In den Jahren I882-85 wurde in Brooklyn, Boston und New York, nachher noch in mehreren anderen großen Städten, das System der "Gemeinde-Diktatur e eingeführt und mit entschiedener Gunst aufgenommen; es war ein Versuch, den Teufel der Korruption mit dem Beelzebub des Cäsarismus auszutreiben - die bekannte Sackgasse der Demokratie. „Es gab nichts Neues oder Amerika Auszeichnendes, um diesen Absolutismus zu mäßigen oder zu regulieren, außer der Macht der Offentlichen Meinung, die in den Vereinigten Staaten stärker als anderswo ist": alles kam darauf an, daß es gelänge, Männer von hervorragenden Eigenschaften an die Spitze zu bringen. „Aber das Parteisystem behielt nach wie vor die Schlüssel zu allen öffentlichen Stellungen in Händen. Die Neuigkeit des Systems und das Wesen, das davon gemacht wurde, hatten bewirkt, $\mathrm{da} B$ die Offentliche Meinung in ziemlich vielen amerikanischen Großstädten mit einem Sprung erwachte und Säuberungen in den Gemeindehaushalten durchsetzte, Aber es hatte nur eine bleibende Wirkung, die aber gar viele amerikanische Bürger zu schätzen wußten: es sparte ihnen die Mühe, sich selber zu regieren, und wiegte sie in die Täuschung, eine wirksame Art von Regierung erfunden zu haben, die von selber arbeite. Die Zentralisation, die auf Kosten der Gemeinderäte geschah, entzog diesen auch manche Befugnisse, die den Staatsgesetzgebungen, ja dem Staatsgouverneur übertragen wurden - d. h. Körperschaften und Beamten, die am meisten dem Parteidruck ausgesetzt waren, vor dem jene 
Kompetenzen gerade gerettet werden sollten. Andere Reformversuche sind ebenso erfolgarm gewesen. So die Einführung des australischen Listensystems und die Legalisierung der Parteien. Die Politiker verstanden es, die guten Gedanken, die dieser Reform zugrunde lagen, auf den Nullpunkt herunterzubringen. Sie lieferten damit ein schlagendes Beispiel ihrer gewohnheitsmäßigen Taktik, ihrer Gepflogenheit, die von der Offentlichen Meinung verlangten Reformen einzufangen, der Allmacht der Offentlichen Meinung, ,vor der in den Vereinigten Staaten alle zittern, alle bis in den Staub sich demütigen", scheinbar sich zu unterwerfen. „Sie gaben ihr nicht die Sache selbst, sondern den Namen der Sache, wie ein Spielzeug, das man Kindern gibt, um sie ruhig zu halten." So habe das australische System, weit entfernt, das "Wähler-Monopol « der Maschine zu brechen, es vielmehr befestigt. Man hat sich, nach dem Ausdrucke eines Fürsprechs solcher Reformversuche (GoodNow), wie Leute, die sich im Nebel verirrt haben, in einem Kreise bewegt. Gleichwohl ist der Glaube an die geheimnisvolle Macht der Offentlichen Meinung unerschüttert; man spricht davon mit einer Art von religiöser Ekstase, und so ist der Glaube an die Offentliche Meinung selber eine mystische Potenz und wiegt in einigem $\mathrm{Maße}$ sogar die Unzulänglichkeit ihres Einflusses auf. Wenn der Bürger auch keinen Finger rührt, um Mißbräuche zu bekämpfen, so bleibt er doch überzeugt, $\mathrm{da} B$ er es jederzeit kann, und diese Uberzeugung nährt in ihm den Funken, aus dem die Flamme des Unwillens sich erheben kann, um Licht und Wärme zu verbreiten (S. 596).

13. (Andere Zeugnisse.) Die außerordentlich hohe, ja gebietende Stellung, die der Offentlichen Meinung in den Vereinigten Staaten eigen sei, wird von vielen anderen Schriftstellern hervorgehoben. So widmet MÜNSTERBERG ein Kapitel seines Werkes ("Die Amerikaner", 2 Bände, Berlin 1904) der Offentlichen Meinung. Er wagt, der Parallele Ausdruck zu geben (I, 224 ,Man könnte sagen“): ,das Parteileben mit allen seinen Wahlen und Åmtern und Programmen ist im Grunde doch nur das Unterhaus der Nation, die Offentliche Meinung ist das Oberhaus, und das wirkliche öffentliche Leben wird von beiden Häusern gemeinsam geleitet." Ja er spitzt diese Vergleichung noch folgendermaßen zu (,In gewissem Sinne könnte man sagen“): ,das Parteileben bringt das Wollen der Nation zu quantitativem Ausdruck, die Offentliche Meinung zu qualitativem". Doch müsse jede Situation sich in scharfe Gegensätze spalten, damit eine numerische Feststellung der Anhänger und der Gegner möglich werde, der innere Reichtum der Frage werde da zerstört zugunsten einer Abstraktion, die schematisch jede Bewegung als Diagonale in einem Parallelogramm verschieden 
gerichteter Kräfte auffasse; Hauptvorzug sei, daß die Diskussion in jeder Wahl ein vorläufiges Ende finde. Im Oberhaus dagegen, in der Offentlichen Meinung stehe die mannigfache Wirklichkeit auf der Tagesordnung, keine zahlenmäßige Abstimmung könnte da fördern, in der Welt der Qualitäten gebe es keine Gegensätze, sondern nur Abstufungen und Übergänge, keine Anhänger und Gegner, sondern nur Verschiedenheiten ... vor allem in der sittlichen Energie und sittlichen Reinheit. Das Ziel sei aber nicht eigentlich politisch, sondern in allen Gebieten reformierend zu wirken und das öffentliche Schaffen den Idealen der Nation anzupassen; die Offentliche Meinung sei die über den Parteien wirksame moralische Einheit der Nation. „Hier müssen nur die wahrhaft besten Männer der Nation in den Vordergrund treten, nicht mit Programmen und nicht mit Parteireden, und doch mit der stillen Kraft, der alle Parteien sich schließlich beugen müssen und eine öffentliche Meinung muß sich herausbilden und organisieren," die z. B. ein Präsidenten-Veto fordere, eine Kandidatenliste durchstreiche, eine Partei in der Gesetzgebung zerspalte und unablässig beide Parteien gleichzeitig zwinge, trotz allen Sträubens den Parteivorteil hinter der reiferen sittlichen Forderung zurücktreten zu lassen. Das könne sie nur leisten, weil sie alle Wesenheiten des typischen Amerikaners enthalte. Dieser Typus sei freilich nicht in einem numerischen Durchschnitt $\mathrm{zu}$ finden; um ihn $\mathrm{zu}$ charakterisieren, schildert MÜNSTERBERG einen "Freund «, der „mit allen seinen guten und schlechten Eigenschaften die Sprache der öffentlichen Meinung spricht". Dieser Freund ist nun allerdings (eben dieser Darstellung gemäß) nicht ein durchschnittlicher Einwohner, wohl aber der durchschnittliche wohlhabende und wohlmeinende Bürger der Vereinigten Staaten, der es sich leisten kann ,,mit Fehlern und Schwächen Geduld und Nachsicht", aber „für niedrige Gesinnung und Ehrlosigkeit unnachsichtliche Empörung und Verachtung" (S. 230) nicht nur zu hegen, sondern kundzutun. Auch der unversiegliche $\mathrm{Humor}$, den MÜNSTERBERG das Antiseptikum der amerikanischen Politik nennt, weil er in deutlichem Gegensatz zum Parteileben stehe, ist charakterstisch für den satten und behäbigen Geschäftsmann, der zwar ,mit vollen Händen für Bibliotheken und Universitäten gibt" aber „nicht leugnet, daß in ihm selber ein Zug zum Lebensgenuß und zur Oberflächlichkeit steckt" (S. 228). Hinweisung auf diesen "Humor", womit dieselben Parteiführer, die ihre Geschäfte mit plebejischem Eirnste treiben (,,philisterhaft humorlos"), wie das souveräne Volk es verlange, im sozialen Kreise „,spöttisch, ja selbst zynisch" über den Parteien zu stehen scheinen, darf nach MÜNSTERBERG auch bei der flïchtigsten Charakterisierung der 
Offentlichen Meinung niemals fehlen (230). MÜNSTERBERG hebt dann die Mitwirkung und den energischen Einfluß der Frauen auf die amerikanische Offentliche Meinung hervor, besonders auf ihre moralische Betätigung:, ,jede Reformbewegung, die an sittliche Gründe appelliert, ist durch die öffentliche Frauenmeinung gefördert und gestärkt worden" (232); ferner in Ubbereinstimmung mit BRYCE, daß die Offentliche Meinung nicht durch Klassengegensätze zerspalten sei, $\mathrm{da} B$ sie im ganzen mit überraschender Einheitlichkeit sich entwickle. Freilich ,die Anregungen für die öffentliche Meinung kommen aus dem Kreis der Gebildeten und Besitzenden"..., , aber von da aus dringen sie dann schnell unpersönlich in weitere und weitere Kreise". „Der Mann auf der Straße trägt sie fort, und wenn sie der rechte Ausdruck des typischen Amerikanertums waren, so nimmt der Schlichteste sie mit derselben Frische auf wie der Gebildetste, der Fabrikarbeiter ebensogut wie der Fabrikbesitzer, der Bauer so gut wie der Bankier. Wer an die Gewissenhaftigkeit, an die Sittlichkeit, an den Patriotismus, an die Gemeinnützigkeit, an den Geist des Fortschritts und der Ordnung, des Edelmuts und der Menschenliebe beim Amerikaner appelliert, der findet keine Klassen, keine Gegensätze, sondern nur die eine öffentliche Meinung, deren Träger sich nach der Intensität ihres sittlichen selbstlosen Wollens abstufen" (233). Das von BRYCE wenigstens berührte Problem, wie es möglich sei, daß diese edle Offentliche Meinung das ungeheuerliche, durch und durch korrupte Treiben der Politiker nicht nur ertrage und dulde, sondern offenbar durch ihre Nachsicht befördere, wirft MÜNSTERBERG (so weit ich sehe) nicht auf.

14. (Amerikanische Ansicht.) BRYCE und MÜNSTERBERG, der Schotte und der Deutsche, sind beide Enthusiasten für Amerika. Das tritt auch in ihrer Verherrlichung der amerikanischen Offentlichen Meinung zutage. Ostrogorski, der ein Adoptiv-Amerikaner ist und dem politischen Leben des I andes das eingehendste Studium gewidmet hat, dämpft diese Auffassung erheblich; und seine Darstellung ist innerlich wahrscheinlicher. Wir werden finden, da $B$ sie auch durch angelsächsische Amerikaner, deren Stimme wert ist, gehört zu werden, ihrem wesentlichen Gehalte nach bestätigt wird. So widmet in seinen „Principles of Sociology" F. H. Giddings der Offentlichen Meinung eine streng theoretische Prüfung, die ihn auf Grund der Kenntnis seines Iandes keineswegs zu unbedingter Anerkennung ihres Wertes, ebensowenig wie zum Preise ihrer Allmacht führt. Giddings unterscheidet ochte Offentliche Meinung von falscher (ohne über diese sich des näheren auszulassen) und definiert jene als das Urteil einer selbstbewußten Gemeinschaft über irgendeinen Gegenstand von allgemeinem Interesse. In politisch organisierten Gesellschaften sei 
sie abhängig von der Aufrechterhaltung einer liberalen und verfassungsmäßigen Regierung, aber auch von allgemeiner Verbreitung der Bildung und von Beziehungen der Gerechtigkeit und Sympathie zwischen Wohlhabenden und Armen, daB offener Ausdruck der Gesinnungen die natürliche Gewohnheit aller Klassen sein kann. Es sei mehr der Geist als die Form des Republikanismus erforderlich. „Echte Offentliche Meinung ist höher entwickelt in England als in Frankreich" (auch jene Beziehungen der Gerechtigkeit und Sympathie??). „Verhängnisvoll für sie ist die halb-kriminelle Demokratie, welche amerikanische Großstädte entehrt und mißregiert hat" (139). „Indessen, “ fährt er fort, ,,wie republikanisch auch eine Gemeinschaft sein möge und wie einsichtig ihre Mitglieder, in einigem Maße wird ihre öffentliche Meinung immer durch einige führende Geister gestaltet. In der Ortsgemeinde (Amerikas) sind diese jetzt nicht immer mehr der Geistliche, der Gutsherr und der Arzt, die in der letzten Generation noch das Denken auf dem Lande bei uns leiteten. An vielen Plätzen sind sie verdunkelt worden durch den Geschäftsmann - nicht immer zum Besseren". Die Presse sei erst seit der Anti-Sklaverei-Agitation ein wichtiges Organ der Offentlichen Meinung in den Vereinigten Staaten geworden. Ihr Einfluß sei aber nicht so unbegrenzt, wie man oft behaupte. Und doch leugnet ein anderer amerikanischer Publizist, Prof. HADLEY, auf Grund dieses Einflusses, daß es eine allgemeine (universal) Offentliche Meinung in den Vereinigten Staaten gebe; vielmehr bilde das Publikum jeder großen Zeitung eine öffentliche Meinung für sich. „Die Tatsachen, Ansichten, Beweggründe, die den Lesern der einen dieser Zeitungen vertraut sind, sind denen der anderen fremd. Jede Gruppe denkt, daß ihre Meinungen ein wirkliches Verständnis der Bedürfnisse des Volkes bedeuten, und daB die Ansichten der anderen Gruppen die Beweisgründe selbstsüchtiger Heuchler darstellen, doppelt verabscheuenswert, weil sie die Form einer Berufung an das öffentliche Interesse annehmen." Und an anderer Stelle macht derselbe angesehene Gelehrte das Publikum selber für den ,gelben Journalismus" verantwortlich. ,Wenn dem Publikum mehr um Sensationen als um Tatsachen zu tun ist, mehr um Aufregung als um Einsicht, so müssen natürlich seine Meinungen auf falschen Angaben und oft auf gefährlichen beruhen, und seine Schlußfolgerungen werden unweise und unverantwortlich sein. Und so lange als die Offentliche Meinung unweise oder unverantwortlich ist, so wird auch die Regierung des Landes schlecht sein $\left.{ }^{1}\right) . "$

1) Die erste Stelle in "Standards of public morality“, p. 13, 16; die zweite aus einem Artikel in The youth's companion; beide Stellen dem Büchlein von JAMES EDWARD ROGERS (s. o.) entlehnt. 
Offenbar anerkennt hier der Autor das Publikum der gelben Presse als ein so großes, daß er (im Gegensatz zu seinem früheren Ausspruch) dessen Meinung als "die" Offentliche Meinung gelten lassen muB. ROGERS macht sich in dem Büchlein "The american newspaper" (Chicago I909) HADLEys SchluBfolgerungen zu eigen. Wir haben schon früher (S. I83) auf seine Darlegungen Bezug genommen.

15. (Schlußfolgerungen.) Wir dürfen zu dem Schlusse kommen, da $B$ die Offentliche Meinung als politischer Faktor in den Vereinigten Staaten nicht so sehr verschieden ist von ihrer Bedeutung in anderen Ländern. Sie ist ein mächtiger Faktor neben den anderen mächtigen Faktoren, ein politischer Faktor, der aus der Gesellschaft hervorgeht und sie, nämlich "die « Gesellschaft, die Gesamtheit der maßgebenden Schichten, repräsentiert. Sie ist, dort wie überall, die Meinung der Vertreter von Bildung und Besitz; nur daß hier ein stärkerer Nachdruck auf dem Besitz liegt, so da $B$ ein sehr großes Vermögen oder wenigstens ein sehr großes Einkommen dazu gehört, in dieser Hinsicht »dazu zu gehören «; während eine mäßige Bildung dafür genügt, die dank der formalen Demokratie sehr weit verbreitet ist. Das gegensätzliche Nebeneinander wirklicher Plutokratie und förmlicher Demokratie muß sich auch in der Offentlichen Meinung reflektieren. Sie ist sehr weit ausgebreitet; nur die Farbigen (Neger, Mischlinge, Indianer) und die jungen Zuwüchse der Einwanderer, haben keinen Teil an ihr; deren Meinungen und Gesinnungen zählen nicht. Andere stehen in zweiter Reihe; das gilt mehr oder minder von allen unenglischen Amerikanern, besonders von den zahlreichen und in einzelnen Persönlichkeiten zuweilen von der Offentlichen Meinung anerkannten, in ihr zur Geltung gelangten Deutsch-Amerikanern. Die Art, wie die Offentliche Meinung sie während des Weltkrieges als "Bindestrich-Amerikaner" brandmarkte, war dafür bezeichnend. Die Offentliche Meinung der Vereinigten Staaten ist angelsächsisch. Wir denken hier immer nur an die flüchtige Tagesmeinung, die man in der Regel als die Offentliche Meinung versteht. Aber die hat eben ihre festen Wurzeln, und diese sfeste" Offentliche Meinung gilt es zu erkennen, um die flüssige und die luftartige zu begreifen. Jene ist noch heute wesentlich puritanisch; $d . h$. sie ist in ihrem Ursprunge kleinbürgerlich eng, beschränkt religiös - aber sie trägt diesen Ursprung zur Schau, ohne wirklich noch darin befangen zu sein, ohne daran zu glauben. Sie ist äußerlich fromm, innerlich durchaus weltlichflach, weltlich im Sinne jener Aufklärung, die im Mittelalter nur Finsternis sah. Sie kennt die alte Welt, daher die Grundlagen ihrer eigenen Kultur, nur mangelhaft, lebt daher viel mehr in dẹr Gegenwart und in Zukunftsvorstellungen, die ausschließlich durch die 
Gegenwart bestimmt sind, als die Offentliche Meinung etwa in Deutschland und England, von der GoETHES Wort gilt: „Wir alle leben vom Vergangenen und gehen am Vergangenen zugrunde". Was wir hier von der Offentlichen Meinung der Vereinigten Staaten sagen, das wird sonst wohl vom "Geist « der Amerikaner gesagt; aber die Offentliche Meinung, wie wir sie verstehen, ist ja der wesentliche Ausdruck des Geistes einer Nation. Ein tief klaffender Widerspruch geht durch ihn hindurch: das späte Endprodukt der $\mathrm{I}^{1} / 2$ Jahrtausend hindurch genährten Bildung Europas, woran er durch seine unehrwürdigen Kirchen, wie durch die kargen Spuren von Kunstübung, die ihn umgeben, erinnert wird, ist er in seinem Bewußtsein ganz jung und neu, also durchaus "rationalistisch " und zwar im Sinne einer Vernunft, die sich am liebsten mit den Mitteln für äußere $Z$ wecke beschäftigt. Der amerikanische Geist ist, wie weidlich bekannt, schlechthin auf Bereicherung, auf ehrenhaftes oder nicht ehrenhaftes Geldmachen erpicht, und dies billigt, ja begünstigt die Offentliche Meinung, indem sie den Reichtum bewundert, wenn sie auch zugleich von ihm verlangt, $\mathrm{da} B$ er sich in großzügiger Wohltätigkeit, insbesondere in Spenden für öffentlich anerkannte Bildungszwecke äußere. In entschiedener Weise ist überhaupt die Offentliche Meinung für alles Große eingenommen; auch in dieser Beziehung die fortgeschrittene Trägerin der modernen Zivilisation. $\mathrm{Da} B$ sie diese unbedingt bejaht, bezeichnet die amerikanische mehr als irgendeine europäische Offentliche Meinung. Die Unterscheidung von Zivilisation und Kultur, die neuerdings fast eine Welle in der flüssigen Offentlichen Meinung des Deutschtums geworden ist, ist der amerikanischen durchaus unverständlich. Die amerikanische Offentliche Meinung ist individualistisch und gesellschaftlich, Höheres und Tieferes ist ihr unbekannt. Mehr als irgendwo, außer aber in Australien, gilt der Ausspruch ADAm Smirhs von der amerikanischen Gesellschaft, daß in ihr jedermann ein Kaufmann ist; daher ist für die amerikanische Offentliche Meinung die eigentliche Lebensaufgabe des Menschen, ein gutes Geschäft zu machen; und dies muB sich auch ins Jenseits erstrecken. Politisch bedeutet es die Geringschätzung des Staats; die als Errungenschaft des Fortschritts der Zivilisation gepriesene $\mathrm{F}$ reiheit wird vorzugsweise als wirtschaftliche Freiheit verstanden; sfreie Bahn dem Tüchtigen" will man allerdings, aber die Tüchtigkeit wird vorzugsweise als smartness, a's Schlauheit und Rücksichtslosigkeit des Sichgeltendmachens verstanden. Die Offentliche Meinung freilich wird dies nicht ausdrücklich gelten lassen, sie wird immer ein moralisches Gewand anziehen; aber sie zeigt ihre Blöße in der Beugung vor dem Erfolg, die leicht in Anbetung der Erfolgreichen übergeht. Die Verehrung der "Freiheit* 
hat sich fast ein Jahrhundert lang mit der Negersklaverei vertragen. Sie verträgt sich auch heute noch mit Erscheinungsformen der Lohnsklaverei, die in Europa die Offentliche Meinung nicht mehr dulden würde. Die Vereinigten Staaten sind das gelobte Land des Kapitalismus und der Bourgeoisie; die Offentliche Meinung dort hält diesen Zustand nicht nur für schlechthin normal, sondern für einen Musterzustand und für den höchsten Gipfel menschheitlichen Fortschritts. Sie steht insbesondere den dort aufs höchste gepflegten Fortschritten der Technik durchaus unkritisch gegenüber. Indessen läßt sich gewahren, daß diese selbstgewisse Offentliche Meinung neuerdings an Festigkeit verliert; an manchen Stellen ist sie in FluB geraten. Die Erscheinungen der Korruption, die Auswïchse der Geldmacht, sind so schreiend, daß die Offentliche Meinung ihr Ohr nicht davor verschließen kann. Der Einfluß eines bedeutenden Schriftstellers, des Kaliforniers HENRY GEORGE, hat sich seit einem Menschenalter bemerkbar gemacht und ist in der Stille gewachsen. Mit ihm zersetzen europäische sozialistische und philosophische Strömungen die amerikanische Offentliche Meinung. Indessen mußte sie wiederum in ihrem rohen und unwissenden Dünkel bestärkt werden durch die englische Propaganda während des Weltkrieges. Diese stellte Deutschland als das Land der Hunnen dar, dessen Regierung auf nichts als Raub, Mord und Brandstiftung bedacht, die Weltherrschaft erobert hätte, wenn nicht das edle England der von ihm so heiß geliebten französischen Republik und dem armen kleinen Belgien, wie dem großen, in unnahbarer Kulturhöhe schwebenden Reiche des Zaren großmütig und selbstlos zur Hilfe gekommen wäre. Die leichtgläubige Offentliche Meinung des oberflächlich gebildeten Koloniallandes schluckte alles. Sie offenbarte ihre ganze Nichtigkeit und Nichtswürdigkeit. - Immerhin sind in der festen Offentlichen Meinung der Vereinigten Staaten auch Bestandteile von echterem Gehalt. Daß eine republikanische Verfassung und die Demokratie die angemessenen Formen des modernen Staates sind, läßt sich theoretisch durch starke Gründe verteidigen, auch wenn man zugibt, daß die Tatsachen des amerikanischen politischen Lebens abschreckend sind. Wie stark aber diese Überzeugung ist, läßt sich daran ermessen, $\mathrm{da} B$ die beiden großen Parteien einander als die republikanische und die demokratische gegenüberstehen; da jeder wei $\beta$, da $\beta$ die republikanische auch Demokratie, die demokratische auch Republik will, so da $B$ der Gegensatz einen ganz anderen Sinn, nämlich (ursprünglich) den des Zentralismus und des Föderalismus hat. Jene Einmütigkeit bedeutet eine mächtige Ursache der Stärke der Offentlichen Meinung, denn auch die große Menge, wie sehr sie 
sich sonst den Interessen der herrschenden Klasse entgegenstemmen möge, ist mit ihr im Glauben an Republik und Demokratie einig. Sie ist nur monarchisch gesinnt, wo die Monarchie als Überlieferung geschätzt wird und wenigstens einem großen Teil des arbeitenden Volkes, z. B. den Bauern ihre besondere Gunst erweist, oder wo sie die Menge durch kriegerischen Glanz und Sieg an sich gefesselt hat. Die industrielle Arbeiterschaft ist von der großstädtischen Aufklärung mehr oder weniger tief erfaßt und daher grundsätzlich republikanisch gesinnt. Infolgedessen ist die Herrschaft der großbürgerlichen oder kapitalistischen Klasse in einer Republik viel besser gesichert als in einer Monarchie, wie auch immer die Monarchie sich zu den Ansprüchen der Arbeiterklasse verhalten möge. In den Vereinigten Staaten hat aber ohnehin jene Klasse eine gewisse Universalität, die sonst ihrem Wesen fremder bleibt. Uberall repräsentiert sie das »Bürgertum «als dessen stärkstes Element; und am Bürgertum haben gewissermaßen alle Teil; wenn auch die Vorstellung von ihm in der französischen Sprache sich in den bourgeois und den citoyen spaltet, so bleibt es doch der Ausdruck des normalen Menschentums im heutigen Staate; in Amerika aber weit mehr als anderswo: r. weil Amerika keine Ritterschaft, keine Aristokratie (der Geburt) kennt, also der sonst vorhandene Gegensatz von Adel und Bürgertum fehlt, 2. weil auch eine breite Schicht der Arbeiterklasse, dank ihrer relativen Seltenheit im Koloniallande, verhältnismäßig gutes Einkommen genießt, daher kleinbürgerlich lebt und kleinbürgerlich fühlt; dazu kommt, daß bei den Chancen, die die Weiträumigkeit und die rasche Entwicklung durch den immer frischen Zustrom von Einwanderern bietet, der Tüchtige und Mutige sozusagen noch den Marschallstab in seinem Tornister trägt; er fühlt sich nicht, wie der Proletarier in den alten Ländern, hoffnungslos an sein Los gekettet. Aus diesen Ursachen kann der von BRYCE beschriebene Schein entstehen, als wäre die Offentliche Meinung in Amerika schlechthin allgemein: sie ist in der Tat allgemeiner, d. h. weniger durch Klassengegensätze eingeschränkt als in irgendeinem Lande Europas (um so mehr jedoch durch Rassengegensätze; von den coloured people ist hier charakteristischer Weise nicht die Rede, wenn auch BRYCE einmal betont, daß sie an Bildung der Offentlichen Meinung keinen Anteil haben). Ein starkes Moment der Einigkeit liegt aber in der Abhängigkeit eines Koloniallandes vom Mutterlande. Und so mannigfach auch die Bestandteile der amerikanischen Einwohnerschaft sind, sie empfindet als ihr Mutterland Großbritannien, wie denn die geistige Bildung ihren Hauptsitz immer in den Neuengland-Staaten gehabt hat. „In diesem Kreise (der englisch sprechenden Welt), der wohl über die Hälfte der 
weißen Völkerrassen umfaßt, besitzt die englische Sprache ein absolutes Monopol ...“ (dieses Monopol) ,hält die Offentliche Meinung der Vereinigten Staaten in einer festen Abhängigkeit von England, die fast so stark ist, als wären die Staaten eine britische Provinz" (Prof. PAUL, Carus ( $\dagger$ ) "Neutrale Stimmen *, Leipzig I9I6, S. 23) ${ }^{1}$ ).

16. (Nachträge zu BRYCE.) Es wurde darauf hingewiesen, da $B$ BRYCE in seinem neuen Werke über moderne Demokratien auch die Offentliche Meinung in Amerika von neuem erörtert. Die Lehre von der öffentlichen Meinung geht durch die beiden Bände hindurch. Den Hauptinhalt des Werkes bildet die Schilderung von 6 demokratischen Staatsverfassungen: als solche werden die der Vereinigten Staaten, der Schweiz, Frankreichs, Canadas, Australiens und Neuseelands dargestellt (PartII). Voraus geht eine allgemeine Abhandlung über demokratisches Staatsrecht (Part I) und den Schluß (Part III) bilden Reflexionen - in 23 Kapiteln -, die sich teils auf die Beobachtungen an jenen 6 Republiken (als solche gelten dem Verfasser auch die Dominions) zurückbeziehen, teils die demokratischen Erfahrungen überall betreffen, teils endlich die Ergebnisse eines systematischen Studiums und der Vergleichung mit anderen Staatsformen enthalten. Die öffentliche Meinung wird im einleitenden ersten Abschnitt durch ein besonderes (das letzte) Kapitel betrachtet, die Offentliche Meinung in den Vereinigten Staaten wiederum durch ein besonderes Kapitel, und auch der dritte Hauptabschnitt kommt auf ihre Wichtigkeit und Macht zurück. Vieles wird hier wiederholt und weitergesponnen, was dem Leser des Commonwealth bekannt ist, und soweit es nicht reine Theorie enthält, hier mitgeteilt wurde. „Es gibt keinen besseren Prüfstein für die Vortrefflichkeit einer demokratischen Regierung als die Stärke der Offentlichen Meinung als herrschender Macht", mit diesem Satze beginnt das Kapitel über die Offentliche Meinung in Amerika. Der Gedankengang schreitet dann in folgender Bahn fort: Das politische Interesse ist weit

1) Graf BERNSTORFr, ehemaliger deutscher Botschafter in Washington, sagte vor dem Untersuchungsausschuß in Berlin am $x_{4}$. November 19r9: „Jeder, der die Verhältnisse in Amerika kennt, wei $B, \mathrm{da} B$ ein Präsident nichts unternehmen kann, was nicht mit der Ansicht der Offentlichen Meinung übereinstimmt. Er kann diese Offentliche Meiuung wohl beeinflussen und hemmen, er kann aber nichts gege n sie tun. Anfangs war die amerikanische Meinung gegen uns unfreundlich, sie nahm fïr die Entente Partei. Wir standen nicht einer nicht vertrauenswürdigen Perso n gegenüber, sondern der alisgesprochenen Ansicht des amerikanischen Volkes, und infolgedessen handelte es sich nicht darum, ob Wrr,SoN zuverlässig war, oder nicht, sondern darum, da $B$ das amerikanische Volk diesen Wunsch ausgesprochen hatte." Im Anschluß daran bezeichnete der ehemalige Vizekanzler HeI,YPERICH seine "Auffassung dahin, daß Wusos von der amerikanischen Geschäftswelt und der Offentlichen Meinung getrieben worden sei. Die Auslegung war ohne Zweifel richtig. Denn die Geschäftswelt hatte eben die Offentliche Meinung in ihrer Tasche. 
verbreitet, und es gibt über die meisten Fragen eine erhebliche Übereinstimmung, wodurch die Klüfte zwischen den Parteiansichten verengt werden. Dafür dienen auch die Erfahrungen des Weltkrieges zur Bestätigung. Deutsche und Iren stehen freilich in bezug auf äußere Politik nicht im allgemeinen Strome. Aber die lösenden und assimilierenden Kräfte der Schule, der Kameradschaft, des ganzen sozialen Milieus sind in Amerika stärker als irgendwo; auch religiöse Unterschiede bedeuten wenig. $\mathrm{Da} B$ die Scheidungen der Denkungsart vertikal, nicht horizontal verlaufen (s. ob.) wird wiederholt. Ebenso wenig als über Religion denken in der Regel über Politik Unternehmer und Arbeiter wegen ihrer verschiedenen Klassenlage verschieden. So bewegt sich auch in den wichtigsten Fragen die Offentliche Meinung nicht in Parteikanälen; gelegentliche Heftigkeit des Parteistreites darf darüber nicht täuschen. Die allgemeine politische Bildung ist verhältnismäßig hoch; der Einfluß der Universitäten darauf während der letzten 40 Jahre mächtig gewachsen, die Zahl der Promovierten wohl zehnmal so groß (im Verhältnis zur Volkszahl) als irgendwo auf dem europäischen Festland und zweimal so groß als in Großbritannien. (Ein sonderbares Kriterium - daß diese Promotionen größeren Bildungswert haben als etwa unser Abiturientenexamen wird BRYCE nicht zu behaupten wagen!) Die Presse übt, mit allen ihren Fehlern, auch guten Einfluß auf Meinungsbildung; das Lesen ist allgemein, hervorragende Leute lassen sich gern sinterviewen * und geben dadurch ihre Ansichten kund, die immer Eindruck machen. Leitartikel der Zeitungen bedeuten nicht so viel wie in England und Frankreich, die Zeitungen werden überhaupt nicht so ernst genommen, und die bedeutenden Journalisten gelangen selten zu politischer Machtstellung; auch ist ihre Gunst oder Ungunst weniger maßgebend für die Geltung eines Staatsmannes. Der Parteicharakter der Zeitungen ist auch weniger ausgeprägt, die eigene Partei wird oft scharf kritisiert. Keine einzelne Zeitung hat einen EinfluB, wie ihn einzelne Zeitungen in England, Frankreich, Italien, Australien, Argentinien haben. Die Entfernungen sind zu groß, die neue Zeitung veraltet, bis sie im Lande herumkommt. Durch Bekämpfung der Korruption, wie auch durch ihre Haltung im Weltkriege, habe sich die amerikanische Presse verdient gemacht (!). - Den charakteristischen Typus des Durchschnitts-Amerikaners als Subjekts der Offentlichen Meinung bildet für BRYCE der einheimische Bauer in den nördlichen, speziell den mittleren westlichen und nordwestlichen Staaten, mit dem er den Krämer und Handwerker der kleineren Städte zu einer Art von zusammengesetzter Photographie zusammenlegen will; dieser amerikanische Mensch zeichne durch Stolz auf sein Vaterland und 
durch vaterländisches Pflichtgefühl sich aus; sein Denken bewege sich in einem engen Kreise, lasse sich politisch leicht täuschen und für eine Partei gewinnen, ermangele aber nicht der Menschenkenntnis und wisse die guten Eigenschaften eines tüchtigen Staatsmannes zu schätzen. In normalen Zeiten nachsichtig und duldsam, keineswegs wie die meisten Europäer meinen, materialistisch, sondern freigebig wie kein anderes Volk $\mathrm{zu}$ wohltätigen und gemeinnützigen Zwecken; der Klassengegensatz werde durch ein höheres gemeinsames Nationalbewußtsein überragt. Als Urteil und Gefühl der großen Nation trete dies in den verschiedenen Reformbewegungen zutage: das eben sei die wahre Herrschaft der Offentlichen Meinung, die nur mangelhaft in der Volksvertretung sich ausdrücke, auch aus dem sorgfältigsten Studium der Presse nicht leicht sich eruieren lasse, und doch in Wahrheit eine Kraft, ungreifbar wie der Wind, die alle zu erkennen und der fast alle $z u$ gehorchen wünschen. BRYCE schildert das Keimen und langsame Wachstum jener Reformbewegungen seit dem Bürgerkriege. So sei auch die Bewegung zugunsten des Friedens und wider den alten aggressiven Geist stetig gewachsen. „Von den unselbstischen Beweggründen, die Amerika in den Weltkrieg brachten, um zu verteidigen, was es für eine gerechte Sache hielt, braucht man nicht zu reden" (1!). Die Offentliche Meinung hat die Ausdehnung der Zentrale über die Einzelstaaten begünstigt, zuletzt (I920) durch Ausdehnung des Frauenstimmrechts ïber das ganze Reich, während sonst die Wahlrechte immer den Staaten vorbehalten blieben. Auch hat sich der philanthropische Impuls in die soziale Gesetzgebung übertragen, um die Lage der Armen zu verbessern, nicht auf Grund von kollektivistischen Theorien importiert aus Deutschland durch die Schüler von MARX, sondern aus der Gesinnung menschlicher Brüderlichkeit (!). Wichtiger sind drei politische Strömungen, die unter sich nahe verbunden sind: I. Haß der Geldmacht, besonders der monopolistischen, 2. Widerwille gegen die Parteimaschinerie, 3. Unwille über die Korruption und Mißverwaltung der großen Städte. „Diese 3 Quellen des Ubels sind im Geiste von Bürgern, die durch Gemeinsinn und Tatkraft sich auszeichnen, als 3 Häupter der Hydra miteinander verknüpft, die gleichzeitig abgehauen werden müssen, wenn das Ungeheuer vertilgt werden soll.“ „Es ist versucht worden auf gesetzgeberischem Wege, und mißlungen, denn die gesetzgebenden Körperschaften werden korrumpiert durch die Geldmacht und beherrscht durch die Maschine." Und doch - so fragen wir - ist die Offentliche Meinung allmächtig? Doch bleibt sie rein und unverdorben? - Es genügt die Fragen aufzuwerfen und auf die Darstellungen Ostrogorskis zurückzuverweisen; auch dürften die groben Illusionen des schottischen 
Gelehrten durch die Zeichen, mit denen sie hier an 4 Stellen begleitet wurden, hinlänglich gerichtet sein. Gleichwohl bleibt aus seiner gründlichen Kenntnis des Landes sehr viel zu lernen, auch in bezug auf die öffentliche Meinung.

\section{Zweiter Abschnitt. Die Öffentliche Meinung in England.}

I7. (Grundzüge.) Weil die öffentliche Meinung tatsächlich überall die nach Verallgemeinerung strebende bürgerliche Denkungsart ist, so hat sie im "alten Lande" - das ist eben England für die Amerikaner - ein anderes Gesicht. Hier tritt viel deutlicher zutage, daß die öffentliche Meinung zunächst als bürgerliche Denkungsart im Gegensatz zur adlich-kirchlichen, daher zur offiziellen Religion als politisch maßgebender Macht sich entwickelt hat. Ja, England ist typisch dafür, daß sie in dieser Weise sich entwickelt, während sie selber noch gewissermaßen ganz Religion ist oder doch erfüllt von religiösen Meinungen und Vorurteilen. In der "puritanischen Rebellion «, die den König enthauptete, wurde zuerst diese weltlichbürgerliche Denkungsart eine Weile siegreich - sie selber noch ganz eingehüllt in religiöse Anschauungen, ja im Sinne des subjektiven Ernstes viel religiöser als die von ihr überwundene Kirche. Aber sie trägt die entscheidenden Merkmale der Offentlichen Meinung insofern an sich, als sie auch auf Rationalität Anspruch macht, und gerade an die innerpolitischen Verhältnisse hauptsächlich diesen Maßstab anlegt. Dies geschieht in ausgesprochenerer Weise als durch den Puritanismus, durch die Laiengemeinden und ihre Vertretungen, so auch durch die Generalversammlung der schottischen Kirk, eben darum, weil sie den Anspruch erheben, auch das politische und das Privatleben nach christlichen Grundsätzen zu ordnen. „In der Generalversammlung war es, daß die neue Kraft der Offentlichen Meinung (the nere force of public opinion) gesetzgebende und verwaltende Gestalt annahm", sagt von der Zeit, als JAkOB V. (der Erste von England) noch König von Schottland allein war, JoHN RICHARD GreEN (Hist. of the English People III, 67). An den Versuchen, diese Kraft $\mathrm{zu}$ unterdrücken oder $\mathrm{zu}$ beschneiden, erschöpfte JАков seine monarchischen Hilfsmittel; durch einen Tendenzprozeß gegen presbyterianische Geistliche I606 - den Linlithgow-Prozeß - brachte er die Offentliche Meinung des Landes in einer Weise gegen sich auf, die noch an seinem Nachfolger, ein Menschenalter später, sich rächte. Die Offentliche Meinung Schottlands wirkte ansteckend auf diejenige Englands, der presbyterianische Pietismus verband sich mit dem puritanischen, die Monarchie zu zerstören. KARL I. hatte schon bald nachdem er den Thron bestieg, die Gunst der Offentlichen Meinung 
eingebüBt; R. GARDINER spricht (History of England VI, 9) von seinen Bemühungen, sie durch eine kühne und wie er hoffte, erfolgreiche auswärtige Politik zu versöhnen, während der Minister Buckingham zu gleicher Zeit sich vorwerfen lassen mußte, daß er eben an solcher Bemühung (die öffentliche Meinung mit sich auszusöhnen), es fehlen lasse (ib.). GARDINER, der den staatsmännischen Fähigkeiten STRAFFordS gerecht wird, hebt hervor, wie dieser (im Jahre I640) alle schwachen Punkte des parlamentarischen Systems erkannte, ohne irgendeine von dessen starken Seiten zu sehen. „Er hatte keinen Glauben, daß eine bessere Organisation aus der chaotischen öffentlichen Meinung seiner Tage hervorgehen könne" (IX, II9). Als aber CroMweli, mit starker Hand den Staat wiederherstellte, kannte er wohl die Tragkraft der Offentlichen Meinung und wußte, daß sie nicht durch Frömmigkeit allein ernährt werden konnte. Er berief sich nachdrücklich auf die weltlichen Interessen und behauptete die bürgerliche Gewalt tatkräftig gegen die Ubergriffe der Geistlichkeit. Obgleich es noch viele Katholiken im Lande gab - besonders unter dem Adel und in den unteren Schichten - und sonst die religiösen Richtungen sehr geteilt waren, so war doch die (gemeinbürgerliche) Offentliche Meinung so gut wie einig in der Ablehnung des Papismus (No Popery) und in der Forderung der Gewissensfreiheit, die jede Richtung für sich stellte. Der Protektor stellte sich als Vorkämpfer für beide dar, legte aber der Gewissensfreiheit den Sinn einer weitgehenden Duldung - sogar für Juden und Quäker - unter, obschon der Puritanismus so unduldsam war wie irgendeine Kirche, während er als Staatsmann allen Denominationen die Einmischung ihrer geistlichen Vorurteile in politische Angelegenheiten bestritt und abwehrte, die fast alle in Anspruch nahmen. Sein wirkliches System war die Militärdiktatur, seine Macht war die Macht des Schwertes. Aber der General und das Heer waren weit entfernt davon, ihre Stellung als eine revolutionäre zu betrachten. „Obwohl sie auf keinen formalen Grund zu ihrer Rechtfertigung sich berufen konnten, so waren doch ihre Maßregeln seit Einrichtung der Republik bis dahin wesentlich zur Aufrechterhaltung der Rechte des Landes auf Vertretung und Selbstregierung bestimmt; und die Offentliche Meinung war einigermaßen mit dem Heere gegangen, sowohl in ihrem Verlangen nach einer vollständigen und wirksamen Körperschaft von Vertretern, als in ihrem Widerstand gegen den Plan, wodurch das Rumpfparlament halb England seines Wahlrechtes berauben wollte" (Grien, 1.c. 279/80). Sie ging auch weiter mit Olivir: sein Wunsch, eine geordnete Verwaltung (settlement) einzurichten, war ,nicht nur gestärkt worden durch die Triebkraft der Offentlichen 
Meinung, sondern zugleich durch das dringende Bedürfnis jedes Tages" (ib. 286). „Nie hatte der Ruf eines englischen Herrschers höher gestanden" (30I). Aber diese Höhe war von kurzer Dauer. CROMWELL mußte noch erleben, daß die Woge der Opposition gegen sein Regiment stündlicîstieg, daß der "Strom der Meinung* immer stärker sich gegen ihn kehrte. „Der gemäßigte Monarchist reichte dem Kavalier die Hand, der stetige Presbyterianer schloß dem gemäßigten Monarchisten sich an und ihre Reihen wurden schließlich gefüllt durch die Gründer der Republik selber“ (ib. 305). „Papist und Ungläubiger, Mystiker und Ritualist, Latitudinarier (liberale Theologen) und Presbyterianer, alle waren feindlich" (ib.). Die schwächliche Gestalt des zweiten Protektors gab der Begeisterung für die Republik den Rest und für eine Weile der Meinung für die Restauration des legitimen Königtums das entschiedene Übergewicht. Der neue König (KARL II.) sagte bei seiner Landung: „Es ist meine eigene Schuld, da $B$ ich nicht früher gekommen bin; denn ich finde niemand, der mir nicht sagt, daß er sich immer gesehnt habe nach meiner Rückkehr." „Mit ihr - der Restauration - beginnt das moderne England" (GREEN, ib. 327). Die rationalistischen Elemente treten in den Vordergrund des öffentlichen Geistes. Aber den stärksten Rückhalt gab ihnen noch der Schauder vor der Rückkehr des Papsttums, obschon die mächtigste Partei, die der Whigs, diese nicht so sehr aus religiösen Gründen fürchtete, wie aus Angst um die Klosterländereien (abbey lands), die durch die "Reformation "den Magnaten zugefallen waren und manche Krautjunker oder Händler erst zu Magnaten gemacht hatten. Diese Einmütigkeit kehrte sich in entscheidender Weise gegen den letzten Stuart-König, der sich durch seine Toleranz-Verordnungen auch die torystische Geistlichkeit, die sonst passiven Gehorsam predigte, zu Feinden machte; und diese Stimmung konnte sogar einen großen Teil des Dissent, der doch aus jenen Verordnungen Befreiung gewann, mit sich fortreißen. JAKOB wollte ein Parlament berufen, das die Toleranz-Verordnung gesetzlich machen sollte; zu diesem Behuf setzte er eine Kommission ein, um die inkorporierten Städte in seinem Sinne zu reformieren. Katholische und dissentierende Bürger sollten Anhänger der Duldung in das nächste Haus der Gemeinen wählen. „Indessen“, sagt RAwson GARDINER ( $A$ students history, II, 64I), ,so stark war die Offentliche Meinung gegen den König, daß sogar diese neuen Mitglieder, die ausdrücklich gewählt waren, für die Kandidaten des Königs zu stimmen, als unzuverlässig erschienen und deswegen der Gedanke, ein neues Parlament einzuberufen, einstweilen fallen gelassen wurde." - Die "glorreiche" Revolution begründete die englische Oligarchie, als 
Herrschaft einer Bourgeoisie, worin der große Grundbesitz, also der Adel und sein linker Arm, die Kirche, noch auf lange hin das ausgesprochene Übergewicht besaßen. Während in den Hauptländern des Kontinents die Monarchie die Stände überwand und in den Dienst des einheitlichen Staatsgedankens zwang, entwickelte sich in England ein planmäßigeres ständisches Regiment, als sonst irgendwo vorhanden gewesen war, wenn auch in monarchischen Formen und auf ökonomisch modernisierter Grundlage. Die Offentliche Meinung des Landes stand ganz unter seinem Einflusse. Mehr und mehr versammelte sie sich in der Hauptstadt, deren Geist aber mit den nahen Universitäten in starker Wechselwirkung blieb. Eine neue Heimstätte fand sie in den "Kaffeehäusern ", wo literarische und politische Angelegenheiten einer täglich frischen und angeregten Erörterung unterzogen wurden. Die kecke und dreiste Kritik, die sich hier Luft machte, erhöhte das Bewußtsein der bürgerlichen Freiheit, das zu gleicher Zeit in Schriftstellern wie LOCKE, AdDISON, STEELE sich Bahn brach. Die Offentliche Meinung wurde unter den Bann des Zauberwortes *Freiheit "gebracht. Die mehr privatrechtliche als öffentlichrechtliche Tyrannei der "Squirearchy" erschien gegenüber dem Absolutismus, der in Frankreich so glänzend sich entfaltete, als Freiheit des Volkes und machte auch auf die unzufriedenen Elemente des Auslandes diesen Eindruck. Als solche fanden sich zunächst wiederum die sonst einander widerstrebenden Schichten zusammen: die adligen, die um ihre beschnittenen alten Freiheiten rangen und durch Einschränkung der Monarchie sie wiederzugewinnen hofften, und die bürgerlichen, die solche Freiheiten neu erobern wollten. Diese Einigkeit wurde zwar durch die Schrecken der französischen Revolution und des napoleonischen Despotismus gesprengt; aber das bürgerliche Bewußtsein erstarkte doch überall so sehr, daß nach einem Menschenalter - dem ersten des I9. Jahrhunderts - die Offentliche Meinung in Frankreich, wie in Deutschland und den Nebenländern, auf England als das Musterland eines Verfassungsstaates blickte. Dies mußte das Selbstbewußtsein, womit die Offentliche Meinung Englands ohnehin sich zu gefallen gewohnt war, bedeutend verstärken. In der Tat war längst der nationale Dünkel, womit der Engländer auf andere Nationen geringschätzend hinabzublicken pflegt $^{1}$ ), durch ungeheure

1) RAWSON GARDINER, der tüchtigste unter den englischen Historikern im 19.Jahrh, spricht (H.o.E. VII, 358) von der Notwendigkeit, dic im Jahre I634 für England offenbar geworden sei, angesichts der holländischen Ubermacht zur See und der unter RICHELIEU wachsenden französischen Seemacht, eine des Namens werte Flotte zu besitzen, und dem Anspruch KArL.S I. auf Mare clausum. .Ungeheuerlich wie dieser Anspruch war, traf er zu stark (appealed too strongly) auf die englische Verachtung von A usländern, um ohne Widerhall in englischen Herzen zu bleiben!" - 
Eroberungen in allen Weltteilen mächtig gewachsen. Er war mehr und mehr der Hochmut einer zur Weltherrschaft sich für berufen haltenden Nation geworden. Zunächst der Stolz des eigentlichen Engländers gegenüber den unterworfenen oder angegliederten $\mathrm{Na}$ tionen - den Walisern, den Iren und den Schotten - seines Inselreichs, ist er zum unbedingten Anspruch auf Uberlegenheit und deren Anerkennung im Verhältnis zu den vEingeborenen " (natives) aller fremden Länder geworden; und daran nehmen naturgemä $B$ alle bewußten ¿Briten " der maßgebenden Schichten teil. So hat ein fester Bestandteil der britischen Offentlichen Meinung tiefe Wurzeln geschlagen. Durch schwere Kriege, die Englands Aristokratie mit seinen geworbenen und gepreßten Mannschaften $z \mathfrak{u}$ Wasser und $z \mathfrak{u}$ Lande führte, besonders durch den mehr als roojährigen Kampf gegen den französischen Nebenbuhler, konnte sich dies Bewußtsein um so mehr verstärken, da es nur durch den Abfall der Kolonien, aus denen die Vereinigten Staaten entstanden, einen Rückschlag erfuhr; sonst vermochte der unermeßlich wachsende Reichtum Englands immer, den Endsieg zu gewinnen; die Bedeutung der Seeherrschaft für die Weltherrschaft stellte sich allzu klar an den Tag. So hat sich die Meinung, eine Nation höherer Art, das »auserwählte Volk «zu sein, in einen Glauben verdichtet, das "Dogma eines Vierteljahrtausends ", wie ein deutscher Gelehrter (Prof. Dibelius) es genannt hat, ist daraus erwachsen.

18. (Reformbill - Freihande1.) Bestimmend wurden diese festen Bestandteile für die Offentliche Meinung des I8. und I9. Jahrhunderts, wie sie es im 20. noch sind. Um I750 aber treten sie in einen gewissen Gegensatz gegeneinander: die Machtpolitik wurde wieder schärfer betont, das Verlangen nach politischer Freiheit regte sich in den bürgerlichen Schichten, besonders der jüngeren, vom Parlament ausgeschlossenen Städte und Flecken als Forderung der Reform wider die herrschenden Familien: die jüngere, durch das Wachstum der Industrie rasch. emporgekommene Schicht der Fabrikanten meldete ihre Ansprüche an, nachdem der Handel auch politisch immer mehr in den Vordergrund getreten war. Bezeichnend dafür ist schon die Verehrung, die dem älteren PirT gezollt wurde. „Es war nicht eine Popularität in der gesamten Nation, von der die Mehrheit zu jener Zeit weder lesen noch schreiben, ebensowenig eine politische Erörterung verstehen konnte. PITTS begeisterte Verehrer waren zu finden unter den Kaufleuten und Geschäftsinhabern der Städte", die an der Sittenlosigkeit und Korruption der feinen Gesellschaft keinen Teil hatten - so setzte „der große Commoner « seine Macht, als auf popularer Unterstützung beruhend, der Macht, wie sie bisher 
auf parlamentarische Konnexionen gegründet war, entgegen (R. GARDINER, $A$ students history III, 75I). Der geistvolle SEELEY nennt ihn „,den ersten Minister der Offentlichen Meinung" (Introd. to pol. science, S. 238). So bildete sich allmählich, auch durch die Wirksamkeit seines Sohnes, dann infolge der Revolution, des großen Krieges, der Reaktion, der Teuerung, endlich der französischen Juli-Revolution, der starke Strom der Offentlichen Meinung, der die Reformbill 1832 zum Gesetz erhob $^{1}$ ). Obschon die politische Freiheit der Bürger bis dahin überaus mangelhaft, ja illusorisch gewesen war; obschon sie es für die große Menge blieb, auch nach den Erweiterungen des Wahlrechts durch die Gesetze von I874 und I885, so blieben doch über das Schlagwort der Freiheit und die Meinung, da $B$ man in England mehr als irgend wo außer etwa in den Vereinigten Staaten - diese Freiheit genieße, die Parteien einig; sie bewährte sich als festes, trotz vielfacher scharfer Kritik von Gelehrten im eigenen Lande, unerschüttertes Stück der heimischen Offentlichen Meinung, die auch nach wie vor im Auslande nachgebetet wurde. In dem Schlagwort vermischt sich der Stolz auf politische mit der Behauptung unübertrefflicher bürgerlicher Freiheiten, an die keine Staatsgewalt rühren dürfe. Auch diese Uberzeugung bleibt noch ziemlich fest, obschon man allmählich, während des I9. und 20. Jahrhunderts, dem Schulzwang, der Einkommensteuer, den Fabrikgesetzen und anderen Ausdehnungen der Polizeigewalt, sodann trotz heftigerWiderstände dem Versicherungszwang - während des Weltkrieges sogar der "Konskription «, d. i. dem System, das wir allgemeine Wehrpflicht nennen, und $\operatorname{der} Z$ wangswirtschaft in bezug auf Lebensmittel, Bebauung des Bodens u. a. sich hat unterwerfen müssen. Der moderne Staat mit sei ne r charakteristischen Freiheit und Gleichheit war noch in der ersten Hälfte des I9. Jahrhunderts durchaus schwach entwickelt in England; erst mit der Katholiken-Emanzipation I 828 begann der Begriff des Staatsbürgers wirksam zu werden, und diese erste Bresche in die Mauer des Anglikanismus zu legen, war eine unendlich mühsame Arbeit; wenn sie gelungen sein werde, sagte damals ein Lord LONSDALE, so werde der ungeteilte Enthusiasmus des Landes in den Kanal der Reform strömen. LECKY, der dies erzählt, bemerkt dazu, viele Jahre lang sei die Offentliche Meinung auf die Katholikenfrage konzentriert gewesen, und die Erfahrung lehre, da $B$ die Stärke der Offentlichen Meinung, die notwendig sei, um

1) Das alte, ,auf den verrotteten Flecken und umfangreichen Bestechungen beruhende" Unterhaus hatte als vermeintliches Bollwerk der politischen Freiheit die öffentliche Meinung - anderer Länder für sich; die des eigenen Landes keineswegs immer. „Namentlich in dem 23 jährigen Kriege gegen die französische Republik und NAPOL,EoN ist die öfentliche Meinung öfter verzweifelt und hat von der... Regierung die Herstellung des Friedens gefordert." DFLBRECK, Regierung und Volkswille, S. I2. 
eine große organische Veränderung in England durchzubringen, niemals gleichzeitig ins Leben gerufen werden kann über zwei ganz verschiedene Fragen (Democracy and liberty I, S. I7). Schon im Jahre I827 nannte die Westminster Review den Erfolg das vielleicht denkwürdigste Ereignis des Jahrhunderts, ,, als Beweis für die wachsende Kraft und Kultur der Offentlichen Meinung". Andere Stücke der Offentlichen Meinung sind zwar im Flusse geblieben, haben aber doch einen hohen Grad von Zähigkeit und Konsistenz gewonnen. Von dieser Art ist der Glaube - wie wir hier wiederum sagen dïrfen an den Freihande1, der zunächst als ein Sieg über die Offentliche Meinung, als Begründung einer neuen Offentlichen Meinung um die Mitte des I9. Jahrhunderts entstanden war, und in diesen Hinsichten das merkwürdige Beispiel der Wirkungen einer planmäßig geleiteten und durchgeführten Propaganda darstellt. Deren Gelingen war sehr schwer, und zuerst durchaus unwahrscheinlich, denn es galt, das ganze politische Schwergewicht der oberen Zehntausend zu überwinden, die zu jener Zeit noch fast unumschränkt das britische Staatswesen beherrschten. Die gegen sie, gegen die Klasse der Großgrundbesitzer - Nobility, Gentry und Kirche - gerichtete Bewegung hatte, wie früher erwähnt, zwei Führer, die nicht zu jenen Familien gehörten. Unter ihrem Einfluß, und dann freilich noch mehr unter dem Einfluß des unermeßlichen Aufschwunges, den der britische Welthandel im folgenden Menschenalter nahm, wurde die Lehre vom allein wohlhabend und irdisch glïcklich machenden Freihandel ein Evangelium, das als solches allen Völkern gepredigt werden wollte. Dies hätte wahrscheinlich auch dann keinen entscheidenden Erfolg gehabt, wenn der COBDEN-Club ïber die gleichen Agitationsmittel verfügt hätte, mit denen es COBDEN und BRIGHT gelungen war, die Offentliche Meinung ihres eigenen Landes zu bekehren. Diese Mittel zu betrachten, hat darum ein theoretisches Interesse, weil sie auch heute in solchen Bewegungen angewandt werden, wenn sie auch kaum jemals wieder $\mathrm{zu}$ so systematischem Zusammenwirken gebracht worden sind. An erste Stelle und in ihren Mittelpunkt stellte sich ein Verein, die berühmte Anti-Corn-Lare-League, die ihren Hauptsitz in Manchester hatte und ihre $Z$ weige über das ganze Land hin ausbreitete. Das zweite Mittel stellten Vorträge dar, die zuerst in den Städten Englands, dann in denen Schottlands, und, nachdem im Verlauf von 4 Jahren ein starker Anhang in den Städten gewonnen war, auch auf dem Lande gehalten wurden; oft in Verbindung mit dem dritten Mittel: großen Volksversammlungen, die nicht selten, weil Räume vorenthalten wurden, unter freiem Himmel tagten, wobei Lastwagen als Rednertribünen dienten. Immer hatten die 
Versammlungen, so sehr als möglich einstimmig, die vorher abgefaßten Entschließungen für schleunige Abschaffung der Getreidezölle anzunehmen. Es war der Natur der Sache nach schwerer, die Pächter und Landarbeiter zu überzeugen, als die Handwerker und Krämer oder gar die Kaufleute und Fabrikherren. Auch wurde erst im 4. Jahre damit begonnen, es erwies sich aber schon als ein großer Gewinn, die allgemeine Aufmerksamkeit auf den Gegenstand zu lenken, und jenen ländlichen Schichten die Erwägung immer wieder nahe $z u$ bringen, ob ihr Interesse das gleiche sei wie das der Grundeigentümer, den $Z$ weifel daran $z u$ wecken und wach $z u$ erhalten. Das 4. Hauptmittel der Werbung bildeten die Druckschriften. Von Anfang an hatte die Liga ein eigenes Wochenblättchen, das, wie COBDEN sagte, jede Silbe von seinen und seiner Freunde Reden 20000 Menschen in allen Kirchspielen des Reiches mitteilte. Aber noch mehr Wirkung schrieb man der Verteilung und Versendung von Flugschriften zu. Diese geschah in immer zunehmendem Umfange. Am Schlusse des 4. Jahres der Liga meldete der Jahresbericht, daß 500 Personen angestellt waren für die Verteilung der Flugschriften von Haus zu Haus, 5 Millionen Exemplare waren an Wähler in England und Schottland versandt worden, und insgesamt - denn die Zahl der Wähler war damals noch verhältnismäßig gering - mehr als 9 Millionen. Das 5. Mittel, zugleich bestimmt, wie mehrere andere Veranstaltungen, die Finanzen der Liga zu verbessern - als sie 3 Jahre bestanden hatte, waren roo0oo $£$ aufgewandt, und noch schienen die Korngesetze unbeweglicher als je - ein Mittel also, um zugleich Geld zu machen, waren $\gg$ Bazare , damals noch etwas Neues und ein Gespött der Gegner. Ein 6. Mittel: De monstratione n und öffentliche Aufzüge. Viel Aufsehen machte der Marsch von 500 Delegierten, wohlgekleideten und wohlhabenden Herren, vor das Haus der Gemeinen, im Februar 1842, als die Krisis in der Herstellung von baumwollenen Waren ihren Höhepunkt erreicht hatte. Der Premierminister Sir RoberT PEEL, derselbe, der 4 Jahre später die Abschaffung der Korngesetze selber in Antrag brachte, wurde, als er in seinem Wagen ihnen begegnete, mit Zurufen wie vNieder mit dem Monopol ", "Gib Brot", "Sofortige Abschaffung ", begrüßt. Das 7. Mittel setzte schon eine eigene Tätigkeit gewonnener Anhänger voraus. Es bestand in Veranlassung von Petitionen an das Parlament: diese hatten um so mehr Bedeutung, weil sie das einzige Mittel der noch nicht wahlberechtigten Menge waren, ihre Wïnsche und Beschwerden unmittelbar vernehmbar zu machen. Natürlich gab es Gegen-Petitionen; aber CoBden und BrignT blieben mit den Zahlen, die sie aufweisen konnten, weit überlegen. Das 8. Mittel bestand 
darin, die Zahl der Parlamentswähler, auf die man rechnen konnte, auf Grund des geltenden Wahlrechtes, dessen Erweiterung damals jenseits aller Erwartungen war, zu vermehren. Dies konnte schon in weitem Umfange dadurch geschehen, da $B$ man die sehr vernachlässigten Wählerlisten vollständiger machte; dann aber geschah es auf unmittelbare Art, indem man zu Wählern machte, die es bisher nicht waren. Nach dem Reformgesetz von 1832 hatten Männer das Wahlrecht, die ein freies Grundeigentum im Werte von $40 \mathrm{Sh}$. jährlichen Ertrages ihr eigen nannten. Diese ließen sich schaffen. In den drei hauptsächlichsten industriellen Grafschaften waren schon Anfang I845 auf diese Weise 4-5000 neue Wähler in die Listen eingetragen worden. Das 9. Mittel endlich war dasjenige, welches allein den schließlichen Erfolg unmittelbar bewirken konnte: die Tätigkeit im Parlament selber, d. h. wesentlich im Hause der Gemeinen. Die Wirkung aber hatte um so mehr den vorherigen starken Erfolg in der öffentlichen Meinung zur Voraussetzung, da, selbst nachdem die Mehrheit im Unterhause gesichert war, der Widerstand des Hauses der Lords als des Bollwerkes der großen Grundeigentümer, schwer überwindbar gewesen wäre, wenn es nicht vor dem unsichtbaren Bundesgenossen - eben der Offentlichen Meinung - die Waffen zu strecken sich genötigt gesehen hätte. Kurz vor dem entscheidenden Erfolge schilderte CoBDEN am 27. Februar I846 im Parlament den Stand der Dinge, wie er sich ihm darstellte. Er leugnete, daß die Gegner irgendwelche Wahrscheinlichkeit hätten, im Falle einer Auflösung, die Mehrheit zu gewinnen. Aber selbst, wenn es gelänge, ,was würde eine Mehrheit von 20-30, die aus minderwertigen Wahlkreisen (pocket boroughs and nomination counties) gewonnen wäre, beginnen angesichts einer Minderheit, die aus den Großstädten hervorginge? Sie würden entsetzt zurückschrecken vor der Lage, in der sie sich befänden. Die so zustande kommende Mehrheit würde keinen Tag fortfahren ihre Ansichten zu vertreten, nachdem sie ein so unermeßliches moralisches Ubergewicht der Offentlichen Meinung, wie es wirklich vorhanden ist, vorgefunden hätten". COBDENS Biograph bemerkt dazu: ,kein Versuch wurde damals oder später gemacht, seine schlagende Feststellung des Zustandes, worin das öffentliche Bewußtsein sich befinde, abzuschwächen. Sogar der Premierminister (Sir R. PEEI) war nicht gefaßt auf eine so überwältigende Kraft der Offentlichen Meinung" (MORLEY, Life of R. Cobden, pop.ed.S. 357). Und wenige Tage, nachdem die Abschaffung zum Gesetz erhoben war, am 2. Juli I846, sprach JoHN BRIGHT im Rate der Liga, zu dem Antrag, deren Tätigkeit nunmehr, da der Erfolg gesichert, abzubrechen, u. a.: „Wir haben das Volk dieses Landes den Wert eines großen 
Prinzips gelehrt... Sie haben gelernt, da $B$ in der Offentlichen Meinung eine Macht vorhanden ist, viel größer als diejenige, die in irgendeiner besonderen Staatsform enthalten sein kann; daß, obschon wir in diesem Reiche ein System der Regierung besitzen, das demokratisch (popular) und ein repräsentatives genannt wird - ein System, das ziemlich plump konstruiert ist und nur mit vielen knirschenden Reibungsgeräuschen funktioniert _ , da $B$ doch, unter dem Impuls eines großen Prinzips, mit großer Mühe und mit großen Opfern, alle diese Hindernisse überwunden werden, so da $B$ aus einer Maschine, die ausdrücklich ersonnen ist, das Gegenteil zu bewirken, am Ende doch Gerechtigkeit und Freiheit für die Nation herauskommt ...." Lothar BUChER (der langjährige Sekretär BisMarcks) hat um das Verständnis der öffentlichen Meinung sich Verdienste erworben. Er weiß, daB sie ein Proteus ist, wegen des Unbestimmten, Unbestimmbaren ihres Inhaltes fast nie $z u$ fassen und festzustellen. Er sagt ("Der Parlamentarismus wie er ist «S. 243), in England pflege man (um das Jahr I854) zwei typische Fälle anzuführen, um das Wesen der öffentlichen Meinung zu beleuchten: das Reformgesetz von 1832 und die Aufhebung der Getreidezölle. Bucher wendet ein : „Aber in jedem dieser Fälle existierten doch zwei sehr bestimmte, sehr tätige und einander gerade entgegengesetzte öffentliche Meinungen. Wie hätte es sonst so langer hartnäckiger Kämpfe bedurft?" Auch meint er, es könne, gerade was das Ergebnis von 1846 angehe, nicht gelten, daß öffentliche Meinung sei, was die Mehrheit meine. Denn, während die Reformbill auch die Unterstützung der Arbeiter gehabt habe, so habe der Aufhebung der Getreidezölle diese gefehlt, weil die damals noch bestehenden Vereine der Chartisten in den schutzzöllnerischen Grundsätzen mehr Verwandtes mit ihren eigenen sozialistischen Theorien oder Wünschen gefunden haben als in dem (später sogenannten) Manchestertum. Es ist Bucher nicht klar geworden, daB ïberhaupt und regelmäBig die Offentliche Meinung in Wirklichkeit Willensmeinung des geistig regsten, finanziell stärksten, literarisch einflußreichsten Teiles einer Nation, der als solcher die andersdenkenden Teile zu überschatten vermag, ist und bedeutet: nur unter diesem Gesichtspunkte wird man ihre Macht richtig würdigen ${ }^{\mathbf{l}}$ ).

1) ..Die öffentliche Meinung erzwang den Rücktritt von NoRTu (1782), unterstützte den König bei Entlassung des Koalitionsministeriums (1783) und gab dem jingeren PITT eine Mehrheit im Parlament von 1784 , die ihn von den Intrigen des Hofes unabhängig machte. Dies Erwachen der Offentlichen Meinung war nicht von Daver; aber als das 18 . Jahrhundert zu Ende ging, wurde das Haus der Gemeinen unabhängiger; die gröberen Formen der Korruption verschwanden mit Iord Norru." Assos, Law and Custom of the Constitution, 2. cd., II, 37. Ausdrücklich sagt dieser Kenner der englischen Staatsgeschichte, im 18 . Jahrhundert sei das Haus der Gemeinen nicht "representative of Public Opinion" gewesen; ib. 137. 
I9. (Die Öffentliche Meinung im neuesten England.) In der Uberzeugung von dem Heil und Kulturfortschritt des Freihandels blieb die Offentliche Meinung 30 Jahre lang unerschüttert. Seitdem ist allmählich wieder eine Gegenströmung erstarkt, die jene feste Burg zu unterwühlen vermochte. Noch einmal konnte die liberale Partei nebst ihrem Anhängsel, der Arbeiterpartei, im Jahre I906, mit diesem Stützpunkt einen gewaltigen Wahlsieg gewinnen. Erst der Weltkrieg hat auch auf diese Gedankengänge so zersetzend gewirkt, daß die "Tarifreform «, wie die schutzzöllnerische Politik sich verschämt nennt, die Oberhand gewonnen zu haben scheint. Die Abschließung des britischen Weltreichs soll versucht werden. Die große Frage ist, ob es gelingen wird, die inzwischen so stark angewachsene, so viel besser organisierte. industrielle Arbeiterklasse mit neuen Getreidezöllen zu versöhnen. Sie ist zwar nach wie vor kein wesentlich bestimmender Faktor der Offentlichen Meinung, aber durch das allgemeine Wahlrecht ist sie nicht nur unmittelbar politisch wirksam, sondern hat auch Einfluß auf jene gewonnen; wenn auch immer noch schwächeren als sie etwa in Deutschland besitzt. Die Offentliche Meinung in England findet sich zurückgezwungen auf den Gedankengang, den Sir ROBERT PEEL, im Jahre 1842 , also lange vor seiner Bekehrung zu CoBDENs Ansichten entwickelte, da er sagte, es sei für die Wohlfahrt aller Klassen seines Landes unendlich wichtig, dafür zu sorgen, da $B$ der Bedarf an Getreide hauptsächlich aus dem einheimischen Ackerbau gedeckt werde; es lohne sich, einen etwas höheren Betrag dafür zu zahlen, gleichsam als eine Versicherungsprämie gegen das Unheil, „das sich ergeben würde, wenn wir ganz oder zum großen Teile für unsere Zufuhr vom Auslande abhängig würden". Bekanntlich ist Großbritannien jetzt ungefähr für vier Fünftel seines Bedarfes an Brotkorn auf überseeische Einfuhr angewiesen. - Wandelbarer als in den großen Hauptfragen der inneren Politik hat sich die Offentliche Meinung Englands zu wiederholten Malen in Angelegenheiten der auswärtigen Politik erwiesen. Die auswärtige Politik ist bis in die neueste Zeit die besondere Domäne der regierenden Familien des Landes geblieben. Sie hatte darum bis vor kurzem ihre eigentliche Heimstätte im Oberhause. Der Sekretär des Auswärtigen Amtes ist fast immer ein Mitglied dieses Hauses, also ein Peer; es war eine Ausnahme, daß Sir EDWARD GREY, der einer der vornehmsten Familien der Oligarchie angehört, es nicht war (er wurde erst bei seinem Abgange in diesen Rang befördert). Auch um die Mitte des I9. Jahrhunderts wurde eine sehr aktivistische auswärtige Politik durch einen Commoner geführt, aber dieser Commoner war Lord PALMERSTON, der als irischer Peer für das Unterhaus wählbar war. Merkwürdig ist nun, wie um 
die Zeit, als PaLMERSTONs Einmischungspolitik in ihrer Blüte stand, die Offentliche Meinung, die kurz zuvor noch COBDEN und BRIGHT ihr "Hosianna * zugerufen hatte, über dieselben Männer ihr »Kreuziget ertönen ließ. Die Offentliche Meinung war dahin bearbeitet worden, den Krimkrieg für einen notwendigen und gerechten Krieg zu erklären - COBDEN und BRIGHT verurteilten diesen Krieg innerhalb und außerhalb des Parlamentes in der entschiedensten und rücksichtslosesten Weise. „Die britische Nation“, schrieb Lord PaLMERSTON in einem Privatbriefe, ,ist einmütig in dieser Angelegenheit; ich sage einmütig, denn ich bin nicht gesonnen, COBDEN, BRIGHT und Compagnie für etwas zu rechnen." Um so auffallender wird nun der rasche Umschwung der Offentlichen Meinung, obgleich der Ausgang auch dieses Krieges für England günstig war. Der neueste Biograph John Brights, CH. Trevelyan, stellt die Tatsache fest: „Während BRIGHT und COBDEN (denn in diesem Kampfe ging BRIGHT voran), so lange der Krimkrieg dauerte, sich kaum vernehmbar machen konnten - nachdem der Krieg vorüber war, fanden sie Glauben." Und er schreibt es ihrem Einflusse $z u$, da $B$ bei mehreren späteren Gelegenheiten, wo England scheinbaren Grund hatte, sich einzumischen, wie im Jahre I864, diese Einmischung unterblieben sei. Nach einem Ausspruche GLADsTonss habe man den Krimkrieg nach seinem Abschlusse in einen Abgrund des Odiums gestürzt, und der Geschichtsschreiber WALPOLE meint, es sei schwer zu bestimmen, ob die Gründe für jenen Krieg oder die Dauer seiner Ergebnisse das gewesen sei, was am wenigsten zur Größe des Ringens in angemessenem Verhältnisse stand. - Eine Wiederholung dieses Spektakels hat der Burenkrieg I899-1903 dargeboten. Wiederum war die öffentliche Meinung so gut wie einmütig: die wenigen Pro-Boers, die auf das Ungerechte und Unedle dieses Angriffskrieges hinwiesen, wurden verachtet und niedergeschrieen. Nachdem der Krieg »siegreich unter furchtbaren Greueln beendet war, konnten wenige sich der Einsicht entziehen, daß jene die Wahrheit gesprochen hatten; den Burenkrieg öffentlich zu verteidigen, erschien bald als ein Wagnis. Der Ausfall der Parlamentswahlen im Januar I906 wurde allgemein auch als Verurteilung der gewaltsamen Erstickung jener südafrikanischen Republiken, und der schwach verhüllten Sklaverei, wodurch die sieger die Ausbeutung der Goldgruben des Transvaal sich zu sichern wünschten, aufgefaßt. - Die Offentliche Meinung wird auch in England oft als die in der Politik entscheidende Macht dargestellt. In Wirklichkeit ist sie hier wie überall ein Faktor, dessen Einfluß und Stärke je nach Umständen und je nach seiner eigenen Beschaffenheit verschieden ist. Der Grad seiner Festigkeit ist der 
Grad seiner Stärke. Je fester die Offentliche Meinung, desto weniger vermag ein anderer Faktor des politischen Lebens sich gegen sie zu behaupten; je flüssiger und gar luftartiger, um so eher. Denn um so leichter kann sie bearbeitet, umgestaltet, ja umgeweht werden; sie läßt sich nicht nur täuschen, irreführen, fälschen, sie kann auch, wie eine allgemeine Erörterung zeigen wird, gemacht (fabriziert) werden.

\section{Dritter Abschnitt. Die Öffentliche Meinung im französischen Staat.}

20. (NECKER und die große Revolution.) JAKOB NECKER, der in der ersten Phase der großen französischen Revolution eine sehr bedeutende Rolle gespielt hat, eröffnet seine im Jahre I797 erschienenen Betrachtungen über diese Revolution mit dem Satze, die Epoche einer großen politischen Umwälzung sei niemals die Zeit, die man wählen müsse, ihre Geschichte zu schreiben; welchen Satz er zu begründen unternimmt. Er wolle sich hauptsächlich angelegen sein lassen, ihren moralischen Fortgang zu schildern. „Ich habe eine große Stellung innegehabt in der Regierung und beim König, wenige Jahre vor und nach Einberufung der General-Stände; ich war folglich in einer Lage, worin man die Vorläufer einer Revolution, wenn es deren wirkliche oder ausgesprochene gibt, entdecken kann. Hiermit gebe ich wieder, was ich gesehen habe. Zuvörderst die große Kraft der Offentlichen Meinung. Sie hatte mich außerordentlich betroffen; und nicht erst nach ihren Triumphen sage ich das; denn ich habe mich über den Gegenstand verbreitet in meinem Werke über die Administration der Finanzen, verfaßt unmittelbar nachdem ich das Ministerium verlassen hatte, im Jahre I78r." Er gibt dann einen Uberblick über die Geschichte der Offentlichen Meinung während der letzten Jahrhunderte ${ }^{1}$ ). „LUDwIG XIV. hatte lange Zeit nur die Gunst der Offentlichen Meinung erfahren, und er fürchtete sich nicht davor, sie in Ansehen $z \mathfrak{u}$ bringen. Sie fügte $z \mathfrak{u}$ dem Ruhme des Monarchen eine größere Solennität; und da sie ausschließlich mit ihm sich beschäftigte, so glaubte er, im Vertrauen auf seine persönliche Größe, daß die Könige, zu allen Zeiten, ihre Meister und ihre Lenker bleiben könnten. Er täuschte sich. Die Bewegung der Geister, die Eifersucht der Talente, das leidenschaftliche Verlangen nach Lob, diese ganze neue Erregung der Geister, als deren belebendes Gestirn LUDWIG erschien, erwarb auf unmerkliche Art eine Kraft, die ihr

1) TREITschke nennt den Ausspruch NAPOLEONS DES Dritren sehr richtig, in diesem Lande der Zentralisation habe die Offentliche Meinung ohne Unterla $B$ alles, das Gute wie das Böse, dem Haupte der Regierung zugeschrieben (Hist. u. pol. A ufsätze 5, Dritter Band, S. 60). 
eigentümlich wurde; und als dieser große Monarch seinen Ausgang nahm, da entwickelten sich die Gedanken und die Gefühle, die er belebt hatte, unabhängiger geworden, in verschiedenen Gestalten. Man hatte sich daran gewöhnt, empfunden zu werden, bemerkt $\mathrm{zu}$ werden, und man suchte in der Gesellschaft die Errmutigungen und die Belohnungen, die man nicht mehr am Hofe fand. In der Hauptstadt richtete daher die Offentliche Meinung ihre Herrschaft auf; und bald verteilte sie dort Preise und Kronen, die man in Parallele brachte mit den Belohnungen, über welche die Könige verfügten. Der Regent, LuDwIG XV. und sein Enkel, jeder in der Weise seines Geistes und seines Charakters, fühlten sich oft erschüttert durch diese immer zunehmende Autorität, und nicht ohne Widerstreben sahen sowohl sie selber als ihre Minister sich in einer Art von Notlage, mit ihr zu verhandeln. Gern hätte man ihr überlassen, als souveräne Herrin zu entscheiden über Geschmack und Geist, über Beredsamkeit und angenehme Talente; aber seit langem hatte die Offentliche Meinung diese Grenzlinie überschritten, und sobald als der Stand der Dinge die Blicke auf sich zog, scheute sie sich nicht, mit Kühnheit sowohl gegen die Regierung als gegen ihre Maßregeln sich auszusprechen. Die ernsthaften Bücher vermehrten sich, und die Verfasser gaben sich, vom Zeitgeist geleitet, Erörterungen hin über die Rechte des Volkes oder über die Pflichten der Staatsverwaltung. Und während noch, unter LUDwIG XIV., der beriihmte FENELON einige allegorische Lektionen im Exil hatte büßen müssen, die überdies gemildert waren durch die Gewandtheit des Hofmanns und durch den Reiz einer harmonischen und poetischen Sprache, so erlebte man in unseren Tagen, da $B$ eine ganze Menge von Schriftstellern ohne Gefahr, und oft in einem barbarischen Stil, die wichtigsten Fragen der politischen Okonomie aus dem Grunde behandelten und überdies ungestraft die Fehler der Minister und die Irrtümer oder die Sorglosigkeit der höchsten Stelle tadelnd beurteilten. Sie wurden gleichwohl gelesen und sie hatten in allen Schichten ihre Anhänger und Parteigänger." NECKER ist dann, in Schilderung der unmittelbaren Vorgeschichte wie des Verlaufes der Revolution selber, unablässig beflissen, das Verhältnis der Offentlichen Meinung zu den Ereignissen und den Einfluß zu beobachten, den sie darauf gehabt habe. So in Darstellung des Kampfes zwischen der Regierung und dem Parlament von Paris: das Schwanken BRIENNEs, der Fehler, den er gemacht habe, einen Streit mit dem höchsten Gerichtshof anzufangen, in einem Augenblicke, wo die Regierung die Stütze der Offentlichen Meinung verloren hatte. „Die Warnungen, welche BRIFNNE empfangen hatte über die Macht der Offentlichen Meinung und die Fügsamkeit, die er 
selber gegen sie gezeigt hatte, indem er seinen Steuerplänen so rasch entsagte, machten ihn doch nicht von seinem gewagten Gange abwendig", er faßte den Plan, die Gerichtshöfe in ihren Lebenswurzeln anzugreifen, auf die offenbare Gefahr hin, die Nation mit ihrer Sache zu verbinden (I, 34). Das Parlament von Paris hatte schon im August $I 787$ die Berufung der Generalstände verlangt. „Die Offentliche Meinung, welche ihm seinen Weg gewiesen, belebte sich, durch ein so bedeutendes Zugeständnis erregt, mehr und mehr, und die Generalstände wurden des Feldgeschrei, worin Paris und die Provinzen sich einigten." „Die Regierung versuchte diesem allgemeinen Votum Widerstand zu leisten, dann gab sie ihm allmählich nach" (4I). Auf BRIENNEs Sturz folgte NECKERs eigenes zweites Ministerium (anno I788). Er nennt sich berufen durch die Offentliche Meinung, unterstuitzt von dieser in der Leitung der Finanzen. Er verteidigt sich gegen die Vorwürfe, die man ihm gemacht hat, weil er den Monarchen nicht bewogen habe, von Einberufung der Stände Abstand zu nehmen. „Keine Illusion, kein Prestige hätte die Offentliche Meinung geblendet, und rasch hätte sie ihr Gericht gehalten über den, der aus unbedachtem Ehrgeiz seine Wissenschaft und seine Kräfte allein an die Stelle der A ufklärung (lumières) einer ganzen Nation und ihrer Allmacht hätte setzen wollen“ (52). „Die Berufung der Vertreter der Nation war beschlossen, der Monarch hatte die Verpflichtung übernommen, und die Offentliche Meinung stand aufrecht da, um ihn zu nötigen, sein Versprechen zu halten" (70). NECKER entwickelt, wie seit der letzten Ständeversammlung (von I6I4) alles anders geworden sei: die Sitten, die Geistesverfassung, die Gefühle der Furcht oder des Respektes vor der königlichen Macht, das Maß der Kenntnisse, Natur und Ausdehnung des Reichtums; ,und vor allem, eine Autorität hatte sich erhoben, die vor zwei Jahrhunderten nicht vorhanden war, und mit der man notwendigerweise verhandeln mußte, die Autorität der Offentlichen Meinung" (77). Eingehend und scharfsinnig erörtert er die Verhältnisse zwischen den drei Ständen und den siegesgewissen Aufstieg des Tiers, der sich am Io. Juni zuerst als Aktiv-Versammlung, bald nachher als Nationalversammlung konstituierte. Der Adel trug sich mit Plänen, dem entgegenzutreten, er setzte sich dem Verdacht aus, daß er den König bewegen wolle, eine Versammlung aufzulösen, worin der dritte Stand mit so vieler Kraft sich geltend machte. „Die Verblendung war außerordentlich. Wie hätte der König, der eben der Allmacht der Offentlichen Meinung gehorcht hatte, indem er eine Nationalversammlung einberief, so rasch eine genügende Autorität erwerben sollen, um dieser selbigen Macht im Augenblicke ihrer größten Energie entgegenzutreten, im 
Augenblicke, wo sie gehalten wurde durch die Vereinigung der Vertreter der Nation, im Augenblicke, wo alle Hoffnungen noch in ihrer ersten Glut entzündet waren ?" (242). NECKER gab LUDWIG den Rat, die §Königliche Sitzung "(am I4. Juli) zu halten. Er begründet diesen Rat u. a. wie folgt: „Der Monarch mußte, indem er mit Pomp sich den Generalständen zeigte, auf eine bestimmtere und ausgedehntere Art, als er bisher getan, seine Interessen für das öffentliche Wohl und seine besonderen Neigungen zugunsten des Volkes kundgeben; er mußte es sowohl, um der Nation Vertrauen einzuflößen in die wahren Gefühle seines Herzens, als auch, um seinen liberalen Gesinnungen ein Gepräge der Echtheit zu geben, das den Auslegungen der Verleumdung zu trotzen vermöchte; er mußte es ferner, um seiner Autorität neue Parteigänger und neue Freunde zu gewinnen und um mit Vorteil gegen die Anstrengungen einer Partei zu kämpfen, die dadurch, daß sie der Offentlichen Meinung den Hof machte, sich zu ihrem Meister machen wollte und Gesetze in ihrem Namen zu geben wünschte" (258). NECKER beruft sich darauf, daß er alles getan habe, um der Regierung die Stütze der Offentlichen Meinung zu erhalten. „Ich riet ganz genau, was hier zu gewinnen notwendig war, und nichts mehr als das. Man durfte sich auf mich verlassen für eine solche Würdigung; und sicherlich, ich kannte sie besser, diese Offentliche Meinung, ich kannte sie besser als die Hofschranzen, die seit langer Zeit mit ihr auf gespanntem Fuße lebten" (283). Er wollte sogleich nach der Séance royale zurücktreten; der König und die Königin überredeten ihn, davon Abstand zu nehmen. Er wollte nun um so bewußter sich auf den dritten Stand stützen, der sein Bleiben gefordert hatte; er erklärte diesem, daß er nicht lange mehr bleiben werde, wenn sie fortführen, sich von der Regierung zu trennen, und wenn sie sich weigerten, mit ihr die Mittel der Versöhnung zu suchen, die den inneren Frieden sichern und den Generalständen einen regelmäßigen Fortgang geben konnten (3I2). Die Vertreter des Tiers machten ihm große Versprechungen; und NECKER meint, sie hätten diese vielleicht gehalten, wenn nicht der Hof, üblen Ratgebern folgend, Maßregeln ergriffen hätte, die notwendigerweise den Argwohn nähren und Mißtrauen säen mußten. „Der König hatte inzwischen, da er mit solcher Entschiedenheit in mich drang, ihm zur Seite zu bleiben, mich überzeugt, daB er, durch den 23. Juni gewarnt vor der Angriffs- und Widerstandskraft der Offentlichen Meinung, meine Hilfe in Anspruch nahm, um eine so wertvolle Bundesgenossin und so gefährliche Feindin wiederzugewinnen" (3I3). NECKER hielt um diese Zeit sich selber für fähig, den Abgeordneten des dritten Standes diese Macht streitig zu machen. 
Am I4. Juli geschah sein Sturz, zugleich mit Entlassung von drei anderen Ministern, die damals die öffentliche Gunst für sich hatten, zugleich mit Entsendung von Regimentern nach Versailles. In Paris und anderen Großstädten wurde eine Bürgerwehr zur Verteidigung der Freiheit ins Leben gerufen, die später so berufene Nationalgarde. ,So wurde fast in einem Augenblick das Lebensprinzip der königlichen Autorität zerstört; denn eine Autorität ist nichts ohne die Kraft; die ihr als Stütze dient... (Ergebnis des unpolitischen Verhaltens unbesonnener Ratgeber des Monarchen). Niemals war ein Augenblick schlechter gewählt, um der Offentlichen Meinung zu spotten und zu versuchen, ihr die Stirn zu bieten. Niemals war sie wachsamer, niemals kraftvoller und ihrer Macht gewisser gewesen. Man erwartete mit immer wachsender Teilnahme die Verhandlungen einer solennen Versammlung, die in ihren Händen das Geschick Frankreichs zu halten schien" (II, I3). „Ein einziger Tag kann die Ideen zerstören, die den menschlichen Größen als Pfeiler dienen; ein einziger Tag kann den gewaltigen Koloß der Meinung, in welche Höhe auch die Zeit ihn erhoben hat, umstürzen" (II, 25). Die Geschichte wird den ersten Ständen, insbesondere dem Adel, nicht verzeihen. „Sie wird ihnen vorwerfen, nicht bemerkt $z \mathfrak{u}$ haben, daß die Vergangenheit auf keine Weise der Gegenwart glich, und daß Geistlichkeit, Adel, Dritter Stand, Hof, die Großen, die königliche Autorität, die Verteilung des Reichtums, die Verbreitung der Aufklärung, kurz der Nationalcharakter und die Offentliche Meinung, daß alles das verändert war seit 200 Jahren" (II, 39). Im ferneren Verlaufe seiner Erzählung, die bis zur Einführung der Verfassung des Jahres III (I795) geht, über welche NECKER den Stab bricht, spricht er weniger und mit schwächeren Akzenten von der Offentlichen Meinung, hin und wieder von ihrer "Erschlaffung (II, 235, III, 352). Aber bei seiner erbitterten Schilderung des Konvents und der Terreur bemerkt er, daß trotz der Schliche und der Unverschämtheit, womit das Komitee des Salut Public (der "Wohlfahrtsausschuß «) sich in Gunst zu setzen bemüht war, die Offentliche Meinung nicht gezögert habe, in durchschlagender Weise sich auszusprechen; ,ein allgemeiner Schrei ließ sich vernehmen und zwang die Versammlung, den Schleier zu zerreißen, den sie auf Mißbräuche der Gewalt hatte werfen wollen, zu denen sie so lange als ruhiger Zuschauer sich verhalten hatte" (III, 82). In den letzten Abschnitten des Werkes, die ganz theoretisch sind, begegnen manche allgemeine Anmerkungen über die Offentliche Meinung, worauf in späterem Zusammenhange zurückzukommen sein wird.

2I. (MIRABEAU, SIEYES u. a.) Auch bei anderen Zeitgenossen der großen Revolution finden wir die Bedeutung, welche die Offentliche 
Meinung in ihr und schon vor ihr, als Vorbereitung, gewonnen habe, vielfach gewürdigt. Vorzüglich merkwürdig ist, wie NECKERS überlegener Gegner MIRABEAU nicht minder eifrig beflissen ist, die Offentliche Meinung zu erkennen und in seine politischen Rechnungen einzustellen. Seine kleinen Denkschriften für den Hof sind angefüllt mit Hinweisungen auf die Bedeutung der Offentlichen Meinung und mit Entwürfen, in einem für die Monarchie günstigen Sinne auf sie einzuwirken. „Ich habe oft gesagt, " heißt es in der 20. dieser Denkschriften (vom 24. August I790), „daß man die Art des Regierens ändern müsse, wenn die Regierung nicht melır dieselbe ist. Die Offentliche Meinung hat alles zerstört, die Offentliche Meinung muß wiederherstellen. Man kann die Offentliche Meinung nicht entscheidend bestimmen (déterminer) außer durch Führer der Meinung; man wird in Zukunft nicht über die große Menge verfügen können, außer durch die Popularität einzelner Männer," und in der 2I. (I. Nov. I790), wo er NECKER scharf kritisiert, heißt es u. a.: „Er beherrscht nicht mehr die Offentliche Meinung“; in der 23. (7. Nov.): „Man hat oft gesagt, und ich scheue mich nicht, es zu wiederholen, daß die Offentliche Meinung das einzige Bereich (ressort) ist, das der Regierung bleibt, $\mathrm{da} B$ der einzige Minister, der seines Platzes würdig, derjenige ist, der sich auf den Boden der Tatsachen stellt und vermöge der Mittel, die noch in seiner Macht sind, diese Meinung zunächst zu leiten, nachher zu meistern versteht: durch Anstellung der gescheitesten Männer und durch alle Werkzeuge des Einflusses." Als ein des Erfolges beinahe sicheres Mittel dieser Art empfiehlt er eine offiziöse, sehr billig zu verkaufende Zeitung (qui sans porter le cachet suspect du ministère, servit pourtant son ouvrage). Die 29. Schrift handelt von den Mitteln, die Verfassung zu berichtigen, unter Eirhaltung aller derjenigen Bestandteile, die der Nation und dem Monarchen nützlich seien. Auch dafür hänge alles von der richtigen Leitung der Offentlichen Meinung ab. Man müsse die Provinzen durch geschickte Leute bereisen lassen; ,ihre Korrespondenz würde das Thermometer der Meinung in jedem Departement und in jeder wichtigen Gemeinde anzeigen, würde erkennen lassen, welche Bürger es sind, auf deren Stimmen es ankommt" usw. „Es ist unnötig, zu bemerken, daß dieser Gang sehr langsam sein muß, weil die Offentliche Meinung in einer Zeit der Revolution außerordentlich vorsichtig behandelt werden muß, da man sie sammeln muß, ehe man sie stärkt, und ihr vielmehr beistehen, als sie aufregen muB..." "Je nachdem die Offentliche Meinung der Nationalversammlung günstig oder entgegen wäre, würde man handeln, um den Gang der Dinge zu beschleunigen oder zu verlangsamen..." Nicht solle man die Versammlung durch 
die Offentliche Meinung fortjagen lassen, das würde alles verderben; ,es ist vielmehr nützlich, daß sie so lange bleibt, bis die Unzufriedenheit sehr ausgeprägt ist, wenn man will, daß diese Meinung Einfluß gewinne auf die Wahl des zweiten gesetzgebenden Körpers und auf die Antriebe, die er aus den Provinzen empfangen wird, auf die Befugnisse, die ihm gegeben werden sollen, auf die Art, wie er sie erfüllen wird..." In der 36. Denkschrift (24. Dez. I790) triumphiert MIRABEAU über den Rücktritt des Ministeriums, ,ich halte sie für fortgeschickt durch den absolutesten aller Tyrannen, die Offentliche Meinung, und durch die gebieterische Notwendigkeit." Die 47. Denkschrift, die umfangreichste (ein „Abriß der Lage Frankreichs und der Mittel, die öffentliche Freiheit mit der königlichen Autorität zu versöhnen") gibt einen systematischen Plan zur Rettung der Gesellschaft, wie Mrrabeau sie dachte. Er zählt eine Menge Hindernisse auf, an erster Stelle die Unentschlossenheit des Königs, an zehnter die Richtung, welche die Offentliche Meinung unmerklich einschlage nach dem Parteigeist hin; in der Ausführung nennt er es eins der schlimmsten: „,Das ärgste Ubel wäre ohne $Z$ weifel, wenn die Offentliche Meinung entschieden einen solchen Kurs einschlïge; denn welches Mittel bliebe dann? Wie sollte man die Bürger lenken, die weder hören noch aufgeklärt werden wollten? Die übertriebenen Werke gegen die Revolution, z. B. das von CALONNE, sind durchaus geeignet, ein solches Resultat hervorzubringen, und das beweist, daß man, wenn man versucht, durch Schriften auf die Meinung der Provinzen einzuwirken, sich die größte Mühe geben muß, sie hinlänglich mit Patriotismus zu tränken, die Versammlung mehr zu loben als zu kritisieren, die Aufmerksamkeit des Volkes ausschließlich auf die Dekrete zu lenken, die offensichtlich dem Interesse aller entgegen sind." Und er fügt sehr charakteristisch hinzu: „die allergrößte Geschicklichkeit, die größten Begabungen sind notwendig, damit dies Mittel des Erfolges nicht eine neue Gefahr werde." Eingehende Vorschriften gibt alsdann der kluge Politiker, wie man das Ansehen der Versammlung untergraben könne, wie man auf sie selber, wie auf die Meinung in den Provinzen, wie auf Paris wirken müsse . . . „Es wird oft vorkommen, $\mathrm{da} B$ die Journalisten, deren Schriften man dirigieren kann, nicht genügen werden, um die Offentliche Meinung zu bestimmen; besondere Werke werden da notwendig sein ..." „Die meisten verwaltenden Körperschaften des Reiches werden viel weniger irregeführt durch die Offentliche Meinung als daß sie schwach ihr gegenüber sind: sie möchten dem Volke Widerstand leisten, vielleicht sogar sich beschweren über die Versammlung; aber sie haben dazu weder die Kraft noch die Freiheit..." Der Plan enthält dann Anweisungen, wie die 
beiden Chefs eines einzurichtenden Atelier de Police täglich von Herrn DE Montmarin einen Bericht über den Etat de Paris einreichen sollen, darin über die Nationalversammlung, die Jakobiner, deren Häupter, über den Klub von I789, über den monarchischen Klub, über öffentliche Plätze, Kaffees, Theater, Klubs, Promenaden, über M. DE LAFAYETTE, die Nationalgarde, ... Arbeiter, Geistliche, Journalisten ..., den König, die Königin, die Offentliche Meinung usw. Ebenso will er ein Atelier des Ouvrages, d. h. ein Bücher-Preßbureau einrichten, und führt die früher angedeuteten Gedanken aus, Emissäre zur Berichterstattung über das ganze Land zu senden: die "Reisenden ersten Ranges " sollen zunächst beobachten: I. den gegenwärtigen Stand der öffentlichen Meinung über die Revolution und über die Verfassung; 2. welche Leute am meisten Einfluß auf diese Meinung haben; 3. welche Tendenz in den neuen Verwaltungskörperschaften, den Wahlkörpern und den Gerichtshöfen zu bemerken sei? Und zum ersten Punkte will er untersucht wissen: a) wie die Offentliche Meinung über die Revolution im allgemeinen, über ihre Notwendigkeit und ihre Wohltaten denke, wie über die Dauer der Verfassung und über ihre Fehler, wie endlich über die allgemeine und vorbehaltlose Billigung aller Dekrete (gemeint sind offenbar die des Königs) und über die Unvollkommenheit und sogar die Mißbräuche einiger neuer Gesetze?. b) in betreff eines jeden dieser Punkte, aus welchen Elementen die Offentliche Meinung bestehe, d.h. aus welcher Klasse der Bürger sie gebildet sei? c) in welchem Verhältnisse die Mehrheit zur Minderheit stehe; z. B. ob die der Offentlichen Meinung entgegengerichtete Meinung ein Drittel oder ein Viertel oder weichen anderen Bruchteil der Gesamtheit für sich habe? Ob man von Mehrheit oder Minderheit rede, es wird bezeichnet werden müssen, in welchen Verhältnissen darin Adel, Geistlichkeit, die alte Beamtenschaft, die Hofleute, die Militärs, die wohlhabenden Bürger, die Kaufleute, die Handwerker und die Bauern, die Bewohner der Städte und die des flachen Landes vertreten sind? - Zum zweiten Punkte will der Staatsmann, daß ermittelt werde: a) welche Leute am meisten teilgehabt haben an der Revolution und ihren Kredit eingebüßt haben, b) welche in diesem Augenblicke am meisten Popularität genießen unter den Patrioten? c) welche am meisten Einfluß auf die Unzufriedenen des Klerus, auf die Unzufriedenen des Adels, auf die Unzufriedenen der Gemeinen und auf diejenigen haben, die, obwohl sie die Revolution lieben und die Verfassung annehmen, gleichwohl mit einer Menge von Dekreten der Versammlung unzufrieden sind. „Es wird notwendig sein, insbesondere alle diejenigen Dekrete zu bemerken, mit denen man am wenigsten zufrieden ist; die Beweggründe 
anzuzeigen, die man anführt für die Beschwerden darüber; und das genaue Verhältnis zwischen denen, die solche sich gefallen lassen und denen, die eine Abänderung wünschen; d) man muß, wenn man von einflußreichen Leuten redet, diejenigen, die da fähig sind, Werke $z \mathbf{u}$ verfassen, die Meinung $\mathbf{z u}$ gestalten, $\mathbf{z u}$ propagieren und $\mathbf{z u}$ dirigieren, von denen unterscheiden, die da nur durch ihren Eifer und durch ihr Betragen die Volksgunst erworben haben; e) man muß den Charakter jedes einflußreichen Menschen schildern, sein Alter, seinen Stand, seine Sitten, seine Talente, Vermögen, Passionen, Rechtschaffenheit, Fehler, Klugheit, Beziehungen sowohl in den Provinzen als in Paris, seine geheimen Ansichten, sein Interesse, seine Hoffnungen und seine Bedürfnisse ermitteln. $\mathrm{Zu}$ 3. sollen die Kundschafter auf folgende Fragen antworten: a) welches ist die Meinung jedes Mitgliedes der Körperschaften über alle Gegenstände der öffentlichen Meinung? b) wie steht es mit ihrer Popularität und ihrem Einflusse? c) beobachten sie als Körperschaften genau die Dekrete der Nationalversammlung, oder übertreten sie diese, sei es aus Unkenntnis oder aus anderen Gründen? d) sind sie zufrieden mit der Abhängigkeit, worin die Nationalversammlung sie hält, oder wünschen sie, ihre Befugnisse zu vermehren? e) sind alle Körperschaften des gleichen Departements einmuitig, oder sind sie einander entgegen und in bezug auf welche Punkte? f) stehen sie in Beziehungen mit den verwaltenden Körperschaften anderer Departements? g) von welchen Mißlichkeiten fühlen sie sich am meisten getroffen in den neuen Gesetzen? h) welchen Einfluß hat jede dieser Körperschaften auf die öffentliche Meinung? i) welche sind die einflußreichsten Mitglieder, sei es in bezug auf ihre Körperschaften oder auf die öffentliche Meinung? - Z weimal wöchentlich soll über alle diese Fragen Bericht erstattet werden und außerdem noch eine Reihe von Einzelfragen beantwortet werden, an deren Spitze steht: ,welche ist die öffentliche Meinung über die Intentionen Ihrer Majestäten?, über die Art ihres Verweilens in Paris?, über die Notwendigkeit der monarchischen Regierung?, welchen Eindruck glaubt man, daß eine Reise des Königs in die Provinzen hervorbringen würde? Es folgen solche Einzelfragen über die Nationalversammlung, über Journalisten, über das Heer, die Nationalgarden, die Jakobiner und andere Klubs, die Anarchie, die Steuern, das Ministerium (welches ist die öffentliche Meinung über das Ministerium und über jeden einzelnen Minister?), über Paris, über die Assignaten, die Güter der Geistlichkeit, die Verfassung im allgemeinen, die Bildung der neuen gesetzgebenden Körperschaft, deren Macht, und über einzelne Begebenheiten. Aus diesen Instruktionen könnte vielleicht auch heute ein Staatsmann 
lernen. Sie zeigen, wie MrRabeau nicht nur die Macht und Bedeutung der öffentlichen Meinung kannte, sondern auch die Aufgabe erkannte, sie $z u$ lenken und $z u$ bestimmen, und $\mathrm{da} B$ er die Methoden scharf in Erwägung gezogen hatte, den Proteus zu bezwingen. Auch für die Geschichte der Theorie sind diese Gedanken beachtenswert, im gehörigen Zusammenhange wird darauf zurückzukommen sein. Noch einen dritten berühmten und mitwirksamen Zeitgenossen der großen Revolution vernehmen wir hier, der dem Genius der Offentlichen Meinung seine Huldigungen dargebracht hat: den Abbé SIÉYès. In der anonymen Schrift aus dem Jahre VIII „Des opinions politiques du citoyen Siéyès et de sa vie comme homme public" heißt es (p. Io), der Jünger LOCKES, CoNDILLACs und BonNETs habe sich frei gemacht von jeder Art abergläubischer Ideen und Empfindungen und sei erstaunt gewesen, als er die Welt kennen lernte, zu finden, da $B$ sie in dieser Hinsicht weiter fortgeschritten war, als er vermutet hatte. „Der Mangel an Gleichgewicht, der sich bemerken ließ $z$ wischen der Offentlichen Meinung und der Meinung der Leute seines Standes, war auf einen Punkt gekommen, daß eine nahe Explosion ihm unausweichlich schien. Was für eine soziale Ordnung, sagte er oft, wo man die Fortdauer des 14 . Jahrhunderts mitten in den Fortschritten des I8. erblickt!“ - So heißt es in jener Flugschrift „Was ist der dritte Stand ?", die als eine schmetternde Trompete in die Morgendämmerung der Revolution hinaustönte: „Die Bürgschaft der öffentlichen Freiheit kann nur da sein, wo die wirkliche Kraft ist. Wir können nur frei sein mit dem Volke und durch das Volk ..." „Wenn eine Erwägung von dieser Wichtigkeit für den Leichtsinn und den engen Egoismus der meisten französischen Köpfe zu hoch ist, so werden sie doch wenigstens nicht umhin können, von den Veränderungen, die sich in der öffentlichen Meinung ereignet haben, überrascht zu sein. Die Herrschaft der Vernunft dehnt sich alle Tage weiter aus; sie macht mehr und mehr die Wiedergewinnung der angemaßten Rechte notwendig; früher oder später wird es geboten sein, da $B$ alle Klassen sich in die Schranken des Gesellschaftsvertrages einschließen..." (3. ed., p. 10). Natürlich war SIEyEs ein Vorkämpfer der PreBfreiheit. In einer Rede vor der Nationalversammlung sprach er sich dahin aus: ,Sehet die Wirkungen der Presse: sie verwandelt sich in eine fruchtbare Quelle nationaler Wohlfahrt; sie wird die Schildwache und die wahre Schutzwehr der öffentlichen Freiheit; es ist wahrlich die Schuld der Regierungen, wenn sie es nicht verstanden haben, wenn sie nicht den Willen gehabt haben, alle Früchte daraus zu gewinnen, die sie ihnen verhieß. Will man Mißbräuche reformieren? Sie wird euch die Wege bereiten, wird sozusagen wegfegen diese Menge von Hemmnissen, 
welche die Unwissenheit, das persönliche Interesse, die Arglist auf eurer Straße aufrichten werden. Im Fackelglanz der öffentlichen Meinung müssen alle Feinde der Nation und der Gleichheit, die von selber auch die Feinde der Aufklärung sind, sich beeilen, von ihren schändlichen Anschlägen abzusehen" usw. In den Verhandlungen der Constituante wie in den parallel laufenden und allmählich immer einflußreicher werdenden des Klubs der Jakobiner waren die Berufungen auf die Offentliche Meinung naturgemäß häufig. Hervorragend betätigte sich in beiden ROBESPIERRE. "Ich wiederhole es, “" sagte er am I3. Juni I792 im Klub, ,das Mittel, um die Freiheit zu retten, ist Aufklärung der öffentlichen Meinung, das Mittel sie zugrunde zu richten ist: Verleumdung unter ihre eifrigsten Verteidiger zu säen" - ROBESPIERRE zollte der Offentlichen Meinung eine abgöttische Verehrung, sie war für ihn das wahre Etre suprême: sie, d. h. was er dafür hielt, die Meinung seiner weiteren Anhängerschaft, die er während der Terreur durch den Klub beherrschte; nach dem Ausdruck AUlARDS war dieser ebenso sehr der Dolmetsch als der Regulator der Offentlichen Meinung! $\left.{ }^{1}\right)$ Noch in seiner letzten Rede bei den Jakobinern, am 8. Thermidor (I794) spricht ROBESPIERRE von dem, was er auf die Gefahr hin, die Offentliche Meinung zu beleidigen, getan habe um der heiligsten Interessen des Vaterlandes willen. Und als zwei Tage später der Konvent über den Klub triumphiert hatte und der scheußliche BARERE im Namen des Wohlfahrtsausschusses Bericht erstattete, da hob dieser besonders den verhängnisvollen EinfluB hervor, den ROBESPIERRE durch seine despotische Herrschaft im Klub auf die öffentliche Meinung gewonnen habe. „Wenn sich ein Mann auf despotische Weise des Willens, der Verhandlungen und der Bewegungen der zahlreichsten und berühmtesten populären Gesellschaft bemächtigt, wird er unvermerkt der Beherrscher der Offentlichen Meinung, und die Offentliche Meinung, welche allein das Recht hat, ein freies Volk zu regieren, hat dann ihre Herrschaft verloren" (Hist. parlémentaire XXXIV, p. $77 \mathrm{ff}$. bei ZINKEISEN, Der Jakobiner-Klub II, 932).

Auch von minder bedeutenden Politikern jener Zeit gibt es viele Zeugnisse ihrer Aufmerksamkeit auf die Offentliche Meinung, auch schon der Versuche, sie im eigenen Sinne zu stimmen und zu bestimmen. Die 2 Bände der Korrespondenz MrRabeaus mit dem Grafen DE LA MARCK sind reich an Zeugnissen davon. Am meisten bemerkenswert dürften folgende sein. In dem Entwurf einer Denkschrift über die Annahme der Verfassung durch den König - diesen

1) Etudes et leçons sur la révolution francaise, I, I25. 
Entwurf hatte MARIE ANTOINETTE von LA MARCK sich ausgebeten, um ihn in den ersten Tagen des September I79I dem Könige vorzulegen; Verfasser war LA MARCKs Sekretär PELIL̀NE - heißt es u.a: „Man hat gemeint, um das Dasein der gegenwärtigen Revolution zu sichern, alle Veränderungen (der Verfassung) langsamen und gesetzlichen Formen unterwerfen zu müssen; man hat sogar den beiden nächsten Legislaturen jede Revision untersagt; man hat dabei aber nicht bedacht, wie wenig der französische Geist in diese Langsamkeiten sich schickt; man hat ebensowenig bemerkt, daß, in einer Zeit der Revolution, die Offentliche Meinung ein unwiderstehlicher, reißender Strom wird zugunsten der Parteicliquen (des factieux), die es verstehen, sie hervorzurufen ..." Trotz schwerster Bedenken spricht der Verfasser sich für Annahme der Verfassung aus und über den Ton, worin die Akte abgefaßt werden müsse, sagt er: „Der König muß in der ersten Redewendung sagen, da $B$ er die Urkunde der Verfassung mit aller Aufmerksamkeit, die ein so wichtiger Gegenstand fordert, geprüft; daß er das Ganze und alle Einzelheiten in sich aufgenommen habe und beides in unwiderruflicher Weise annehme; er wird des weiteren sagen können, daß er in dieser Vetfassung die Ausdrücke der Mehrheit der französischen Nation anerkennt; und da $B$ selbst wenn diese Verfassung noch unvollkommen wäre, das öffentliche Wohl verlangt, da $ß$ der gegenwärtigen Revolution eine Grenze gesetzt werde, sowie dem gesetzlichen Interregnum, das ihre unvermeidbare Folge gewesen ist. Der König wird zeigen, daß er nicht erst diesen Augenblick abgewartet hat, um aus der öffentlichen Meinung die Regel für sein Verhalten zu gestalten, so bald er geglaubt hat, da $\beta$ diese Meinung ihm ein Mittel mehr anzeigte, zum Heile der Nation mitzuwirken." - Graf VERGONNES, NECKERS zeitweiliger Kollege, verklagte diesen beim Könige in einem vertraulichen Bericht abgedruckt in Soulavies Mémoires historiques IV, 206-2I3-und sagt darin u.a.: „Wenn Herrn N E C K E R S öffentliche Mein ung das Ubergewicht erhielte, so müßte Ew. Majestät sich darauf gefaßt machen, befehlen zu sehen, die sonst gehorchen, und gehorchen zu sehen, die sonst befehlen." BLaNc (Hist. de la rev. fr. II, 52.) findet in dieser Außerung ein Zeichen durchdringenden Scharfblicks.

22. (GEORG FORSTER.) Der Enthusiasmus der Revolution teilte sich, wie bekannt, auch Ausländern mit, zumal solchen, die an ihrem Herde lebten. War Necker frei von Illusionen und durch und durch bürgerlicher Aristokrat, und den (von ihm selber geleiteten) Anfängen der Revolution hold, so blieb dagegen GEORG Forster der Liebe treu, um derentwillen er sich zum Einwohner von Paris und zum französischen Bürger gemacht hatte. In seinen "Parisischen Umrissen 4, 
die er im November und Dezember I793, also mitten in der Schreckenszeit, an seine Frau Therese (geb. HEyNE später Frau HUBER) geschrieben und bekannt gegeben hat (sie wurden zuerst in der Zeitschrift "Friedens-Präliminarien " gedruckt), um ,die Sache, die er zu der seinigen gemacht hatte, vor sich und anderen zu rechtfertigen" (PERTHES, Politische Zustände und Personen S. I04), zeigt er sich ganz und gar erfüllt von dem Gedanken (den später GARVE dahin formte), daß in allen Perioden, welche die Revolution durchschritten, und in welchen sie nach der Reihe ihre eigenen früheren Werke und deren Baumeister zugrunde gerichtet habe, so wie sie damit anfing, die alte Verfassung des Reichs und deren Verteidiger zu stürzen - sie immer der öffentlichen Mein ung nachgekommen sei; woher es auch komme, daß sie bisher unaufhaltsam und unwiderstehlich gewesen sei. Im ersten dieser Briefe meint FORSTER, in der öffentlichen Meinung bestehe die größte Stärke des Revolutionsheeres, sie und ihre Einflüsse seien Dinge, wovon man vor der Revolution keinen richtigen, wenigstens keinen vollständigen Begriff gehabt haben möge. Das neulich erlassene Dekret des Konvents, da $B$ die Regierung in Frankreich bis zum Frieden revolutionär bleiben solle, sei der eigentlichste Ausdruck der öffentlichen Meinung, daß die Revolution sich so lange fortwälzen müsse, bis ihre bewegende Kraft ganz aufgewendet sein werde. In ihr habe der Wille des Volkes seine höchste Beweglichkeit erlangt, und die große Lichtmasse der Vernunft werfe ihre Strahlen in der von ihm verstatteten Richtung. Er will sich "mathematisch" so über sie ausdrücken: „Unsere öffentliche Meinung ist das Produkt der Empfänglichkeit des Volkes, vermehrt mit dem Aggregat aller bisherigen Revolutionsbewegungen." „Wer einen anschaulichen Begriff davon hat, oder auch nur aus der Geschichte und Anthropologie weiß, wie beweglich und empfänglich die französische Nation ist; und wer dann berechnet, in welchem Grade die Ereignisse der 4 letzten Jahre diese Reizbarkeit erhöhen und das Teilnehmen an den öffentlichen Angelegenheiten schärfen mußten: dem wird es schwerlich entgehen, da $B$ die Macht einer auf diese moralische Beschaffenheit geimpften öffentlichen Meinung Wunder tun kann." Er entschuldigt sich im dritten Briefe, daß er seinen Freund immer wieder ,von unserer öffentlichen Meinung" unterhalte; ,allein sie ist das Werkzeug der Revolution und zugleich ihre Seele". Seit mehr als 6 Jahren (also noch in den letzten Zeiten der Monarchie) habe sie allmählich sich verwandelt und die großen Ereignisse eines nach dem anderen hervorgerufen: „denn die Größe der Hauptstadt, die in ihr konzentrierte Masse von Kenntnissen, Geschmack, Witz und Einbildungskraft; das daselbst immer schärfer 
ätzende Bedürfnis eines epikuräisch kitzelnden Unterrichts; die Losgebundenheit von Vorurteilen in den oberen, und mehr oder weniger auch in den mittleren und niederen Ständen; die ungezwungene Mischung in Gesellschaften; die stets gegen den Hof strebende Macht der Parlamente; die durch die Freiwerdung von Amerika, und Frankreichs Anteil daran, in Umlauf gekommenen Ideen zur Regierung, Verfassung und Republikanismus; die Abhängigkeit der im Ubermaß genießenden Klasse von der ihren Begierden dienstbaren, die sich dadurch immer mehr emanzipierte; das böse Gewissen des Hofes und der Administration, die einem Staatsbankrott entgegen sahen; endlich die dadurch entstandene Straflosigkeit der politischen Broschürenschreiber, die zu Hunderten jetzt die Wunden des Staats sondierten, und mit grenzenloser Keckheit und Quacksalberweisheit ihren Wundbalsam darauf $z \mathfrak{u}$ streichen sich erkühnten: - dies alles bahnte der Denkfreiheit und der Willensfreiheit dergestalt den Weg, daß schon eine geraume Zeit vor der Revolution eine entschiedene öffentliche Meinung durch ganz Paris, und aus diesem Mittelpunkt über das ganze Frankreich, beinahe unumschränkt regierte." Nach dieser ebenso knappen wie geistvollen Schilderung des Zustandes der französischen Volksseele, aus dem die Revolution geboren wurde, stellt er in wenigen Sätzen auch deren Geschichte bis zur Stunde, da er schrieb, dar: man dürfe als ausgemacht annehmen, da $B$ die Offentliche Meinung in einer jeden dieser Epochen sich entschieden geäußert, und zugleich vor den Hauptereignissen derselben einen besonderen Charakter angenommen habe. „Der sanfte Tod des Priestertums". heißt es einige Seiten nachher, ,und seiner Hierarchie in Frankreich ist der redendste Beweis von der Macht der öffentlichen Meinung." Als letzte und mächtigste Wirkung der Revolution und der ihr innewohnenden Kraft der Offentlichen Meinung bezeichnet ForsTER dann - seine Irrtümer sind hier, wie sonst die Irrtümer edler stürmischer Geister, merkwürdig -, daß sie der Habsucht, der Gewinnsucht, dem Geize, mit einem Worte, der ärgsten Knechtschaft, zu welcher der Mensch hinabsinken könnte, der Abhängigkeit von leblosen Dingen, einen tödlichen Streich versetzt habe. Einmal spricht er in der Sprache NEckers vom KoloB, an anderen Stellen vom Strom der öffentlichen Meinung. Paris gebe den Ton an, nicht bloß wegen seiner Bevölkerung und Größe, sondern weil der Umlauf des Handels, der Ideen, der Menschen selbst, im Lande noch unbedeutend sei. „Bei uns ist Paris der einzige Maßstab der Vollkommenheit, der Stolz der Nation, der Polarstern der Republik. Hier allein ist Bewegung und Leben, hier Neuheit, Erfindung, I,icht und Erkenntnis. Paris ist der Kommunikationspunkt zwischen allen übrigen Städten, 
zwischen allen Departements der Republik; alles fließt hier zusammen, um erst von hier aus nach den Provinzen zurückzuströmen. Die Gesetze des Geschmackes und der Mode werden seit einem Jahrhundert in Paris gegeben und promulgiert. Frankreich gehorchte ihnen wie Göttersprüchen; und.ohne daß wir es verlangten (FORSTER fühlt sich als Franzose und spricht als solcher) huldigte ihnen Europa. Noch jetzt wird ihre Oberherrschaft jenseits unserer Grenzen anerkannt, wie schon die bloße Existenz eurer Modejournale beweisen muß; aber im Bezirke der Republik selbst gebietet jetzt Paris auf eine weit wirksamere Art: durch die Kraft der Offentlichen Meinung." Man werde zugeben müssen, daß die außerordentliche Verbreitung wissenschaftlicher Begriffe und Resultate in Paris der Grund von jener großen Empfänglichkeit seiner Einwohner für Revolutionsideen geworden sei: „Die Neugier der Pariser ist viele Grade feiner und unterscheidender als in irgendeinem Winkel des ganzen Landes; und ihre Ausbildung durch den Umgang mit unterrichteten Leuten, und durch die Ubung, im Schauspiel attische Feinheiten zu empfinden, ïbertrifft, im ganzen genommen, alles, was man sich vorstellen kann, ehe man hier gewesen ist und mit eigenen Augen gesehen hat." Durch die 5 Revolutionsjahre sei dies noch viel auffallender geworden. „Des Morgens sieht man alle Hökerinnen auf der Straße über ihren Kohlenfeuern sitzen und die Zeitungen lesen; des Abends hört man in den Volksgesellschaften, in den Sektionsversammlungen Wasserträger, Schuhknechte und Karrentreiber von den Angelegenheiten ihres Landes und von den Maßregeln des Augenblickes mit einer Bestimmtheit sprechen, die nur aus der einfachen Richtigkeit und Klarheit allgemein verbreiteter Grundbegriffe entspringen kann." FORSTER täuscht sich nicht darüber, daß oft die Stimme der Pariser für die Stimme des ganzen Volkes gegolten habe; aber, so meint er, das ganze Volk habe dieser Stimme Beifall gegeben, und alle Versuche, die Departements mit Paris zu entzweien, seien jederzeit mißlungen.

23. (Frau voN STAËL.) Ich untersuche hier nicht, ob und wie weit Forster die Rolle und die Kraft der Offentlichen Meinung in der von ihm bewunderten großen Revolution richtig dargestellt habe. Aber man wird sich der Erkenntnis nicht entziehen, daß er sie mit ungemeiner Lebendigkeit aufgefaßt und in blendender Sprache geschildert hat; auch daß man durch diese zeitgenössische Abbildung in das wogende Leben der Hauptstadt, die damals wohl die Hauptstadt der Welt heißen durfte, hineingeführt und gleichsam untergetaucht wird, daß man den Puls der öffentlichen Meinung schlagen fühlt, der immer in den Großstädten, zumal den zentralen, am lebhaftesten sich regt, darf man zum Lobe des Mannes sagen, der freilich 
keineswegs ein deutscher Patriot, aber einer der besten deutschen Schriftsteller gewesen ist. Seinen Scharfsinn tut ForsTER auch darin kund, daß er erkennt, in Deutschland gebe es noch keine öffentliche Meinung in dem von ihm gemeinten politischen Sinne, und es könne keine geben, ,, wenn das Volk nicht zugleich losgelassen sein wird"; aber ,es dort loslassen, diese ungemessene unberechnete Kraft auch in Deutschland in Bewegung setzen, das könnte jetzt nur der Feind des Menschengeschlechtes wünschen". Klar erkennt er auch den Unterschied des französischen Lebens darin, daß es in Paris konzentriert sei. „Paris ... ist die Quelle der öffentlichen Meinung, das Herz der Republik und der Revolution.“ „Paris empfindet, denkt, genießt und verdaut für das ganze Land." - DaB FORSTER durch NECKER stark beeinflußt worden ist, halte ich für wahrscheinlich, wenngleich mir bisher keine Hinweisung darauf begegnet ist. Dieser Einflu $B$ versteht sich von selbst bei der geistreichen Tochter NeCKERS, die selber in jungen Jahren Zeugin der Ereignisse gewesen war. Frau von STAËL zeigt sich in ihren Considérations sur les principaux évènements de la révolution francaise fortwährend beflissen, der $\mathrm{Be}-$ deutung der öffentlichen Meinung als bewegender Kraft des politischen Lebens gerecht $z u$ werden. Freilich verfällt sie dabei in Irrtümer: so wenn sie darauf hinweist, daß im I8. Jahrhundert (in Wirklichkeit viel früher) die aristokratischen Körperschaften die ersten gewesen seien, welche die königliche Macht angriffen; „nicht daß sie den Thron umstürzen wollten, aber sie waren getrieben durch die Offentliche Meinung “; ,diese wirkt eben auf die Menschen, ohne daß sie es merken, und oft sogar gegen ihr Interesse" (I, 43). (In Wirklichkeit handelte es sich da um einen sehr bewußten und sehr heftigen Interessenkampf des Adels gegen die absolute Monarchie.) Von Maurepas, dem ersten Premier-Minister Ludwigs XVI., sagt die Baronin, er habe sich derartig von der Offentlichen Meinung, ohne es zu wissen, gezogen gesehen, daß die erste Handlung, die er dem Könige vorschlug, die Wiederherstellung der "Parlamente«, jener I3 höchsten Gerichtshöfe des Landes, war (49). „,Diese neue Macht (eben die Offentliche Meinung) gewann von Tag zu Tag vermehrte Kraft, und die Nation befreite sich sozusagen durch sich selber" (52). Während des ersten Ministeriums NeCKers sei die Meinung noch nicht durch den Parteigeist verdorben gewesen (62). Es sei das Kreditbedürfnis, was die Regierungen genötigt habe, die öffentliche Mcinung in acht zu nehmen (d ménager l'opinion publique); ,und ebenso wie der Handel die Nationen zivilisiert hat, so hat der Kredit, der eine seiner Folgen ist, irgendwclche Verfassungsformen notwendig gemacht, um die Offentlichkeit in den Finanzen zu sichern und die eingegangenen 
Verpflichtungen zu gewährleisten" (66). Die Veröffentlichung des Standes der Finanzen - NECKERs große Neuerung - habe auch den wichtigen Nutzen gehabt, ihm die Stütze der Offentlichen Meinung zu sichern bei den mannigfachen Einschränkungen, die zu bewirken notwendig war (72). Nur diese zwei Mittel habe es damals gegeben, um die öffentliche Meinung, die sich schon stark über die Staatsgeschäfte im allgemeinen aufregte, zu befriedigen: die Provinzialverwaltungen und die Offentlichkeit der Finanzen (86). Die Tochter bezeugt, nächst seinen religiösen Pflichten sei ihrem Vater die Offentliche Meinung das gewesen, was ihn am meisten beschäftigte; ,er opferte Vermögen, Ehre, alles, was die Ehrgeizigen erstreben, der Wertschätzung der Nation; und diese Volksstimme, damals noch nicht zerrüttet (altérée) hatte für ihn etwas Göttliches" (98). Bei der Verehrung, die NECKER gezollt wurde, insbesondere bei seinem ersten Rücktritt (I78I), verweilt natürlich die Tochter besonders gern. Unter LUDWIG XIV. wäre so etwas einem in Ungnade gefallenen Minister gegenüber nicht möglich gewesen. „Dieser neue Geist der Unabhängigkeit hätte einen Staatsmann über die Macht der Offentlichen Meinung belehren müssen", aber die Minister begingen Fehler über Fehler (106). CaLONNE mußte es büßen, daß die Offentliche Meinung immer größer wurde und der Geist der Unabhängigkeit in allen Klassen zutage trat. Er glaubte sich auf die Offentliche Meinung stützen zu können gegen das Parlament, aber sie war ebenso sehr gegen ihn wie gegen das Parlament selber (rI2f.). Dagegen blieb sie NECKER treu. Als ihn die lettre de cachet erreicht hatte, die ihn 40 Meilen von Paris verbannen sollte, da, verwandelte die Offentliche Meinung die Verfolgung in einen Triumph" (II6). Durch das Versprechen der Generalstände feierte die Offentliche Meinung selber ihren Triumph, den sie sich nicht durch die von BRIENNE gesetzte Frist von 5 Jahren verschieben ließ (I26). Sie zwang den Hof, den Erzbischof fortzuschicken und NECKER zurückzuberufen (I55). MARIE ANTOINETTE betrachtete ihn während seines zweiten Ministeriums immer als ernannt von der Offentlichen Meinung - obgleich sie ihn während des ersten protegiert hatte (I59). Die Offentliche Meinung war, teils durch die Maßregeln des Erzbischofs, teils durch die eigene Kraft des dritten Standes, „vollkommen darauf vorbereitet, daß dieser in den Generalständen von 1789 mehr Einfluß gewann als in den früheren Versammlungen" (I70). Das Verhalten der Privilegierten (Könige, Ade1, Priester) um diese Zeit, in der Literatur und in der Politik, erklärt sich Frau von STAEL daraus, daß sie ihre Vorteile durchaus wahren wollten, aber zugleich auf die Ehre Anspruch machten, gleichgültig dagegen zu sein; „und die Geschicktesten 
schmeichelten sich, die Offentliche Meinung einzuschläfern, damit sie ihnen nicht streitig mache, was sie sich die Miene gaben, gering zu schätzen" (I82). Auch dies Urteil ist offenbar unrichtig. - Die Baronin verfaßte das Werk in den ersten Jahren der Restauration; es war I8I6 abgeschlossen. Sie war begeistert für die englische Verfassung, die auch ihres Vaters Ideal war. So meint sie, die »echte « Offentliche Meinung, diejenige nämlich, die oberhalb der Faktionen schwebe, sei seit 27 Jahren (also seit 1789 ) die gleiche in Frankreich und jede andere Richtung könne als künstliche nur einen augenblicklichen Einfluß haben (207); man habe damals (1789) eben nur die Trennung der gesetzgebenden und der vollziehenden Gewalt gewollt und nicht daran gedacht, den Thron umzustürzen. Aber auch der am meisten energische Wille der neueren Zeit, derjenige BonaparTEs, hätte er sich auf dem Throne befunden, wäre zerschellt gegen die Offentliche Meinung im Augenblicke der Eröffnung der Etats Généraux (209). „Als NAPOLEON den Despotismus in Frankreich aufgerichtet hat, waren die Umstände diesem Vorhaben günstig; man war der Unruhen müde, man hatte Furcht vor den schrecklichen Ubeln, die man erlitten hatte, weil die Rückkehr derselben Faktionen sie von neuem herbeiführen konnte; überdies war der Enthusiasmus des Publikums dem kriegerischen Ruhm zugewandt; der Krieg der Revolution hatte den Nationalstolz erhoben. Dagegen unter LUDWIG XVI. knüpfte sich die Offentliche Meinung ausschließlich an rein philosophische Interessen (offenbar zu viel gesagt); sie war gestaltet worden durch die Bücher, welche eine große Zahl von Verbesserungen für die Ordnungen des bürgerlichen Lebens, der Verwaltung und der Gerichte in Vorschlag brachten; man lebte seit langer Zeit in tiefem Frieden; der Krieg war sogar aus der Mode gekommen seit LudwIG XIV. Die ganze Bewegung der Geister bestand in dem Wunsche, politische Rechte auszuiben, und die ganze Geschicklichkeit eines Staatsmanns gründete sich auf die Kunst, zu dieser Meinung das richtige Verhältnis zu gewinnen" (de ménager cette opinion) (210). - Auch der I4. Juli — die Eirstürmung der Bastille - macht die geistreiche Dame, die als 23jähriges Mädchen das Erreignis aus der Nähe erlebte, in ihrem Urteil nicht irre; mit dẹr Bewegung jener Zeit fühlte sie, ungeachtet allen Unwetters das folgte, doch sich in Sympathie verbunden. „Der Tag“, sagt sie, ,, hatte, trotz scheußlicher Morde, die der Pöbel beging, "Größe«; die Bewegung war national, keine Faktion, weder des In- noch des Auslandes, konnte einen solchen Enthusiasmus erregen. Ganz Frankreich teilte ihn ... die ehrenwertesten Namen: Bail.LY, LA FAyetTte, LALLI, wurden von der Offentlichen Meinung ausgerufen; man verlie $B$ das 
Schweigen eines Landes, das von einem Hofe regiert wurde, um das Geräusch der freiwilligen Beifallsrufe aller Bürger zu vernehmen. Die Geister waren erregt, aber es war noch nichts als Gutes in den Seelen ..." (24I). Ihr Urteil über die Nationalversammlung, der sie nachrühmt, daß sie eine vornehme Gleichgültigkeit gegen die Angriffe ihrer Gegner, ,,wofür die Offentliche Meinung sie richte“, gezeigt habe, faßt sie dahin zusammen: hätte sie damit eine gerechte Strenge gegen alle Schriften und alle Aufläufe, die zur Unordnung reizten, verbunden; hätte sie sich gesagt, da $B$ in dem Augenblicke, wo eine Partei mächtig wird, sie zu allererst die Ihren zurückdrängen (réprimer) muB, so hätte sie mit so vieler Tatkraft und Weisheit.regiert, da $B$ das Werk von Jahrhunderten vielleicht in 2 Jahren sich erfüllt hätte." Liebenswürdige Fata morgana! - Im Jahre I79o sei die Nationalversammlung der Offentlichen Meinung noch so sicher gewesen, daß die Versammlung es liebte, sich mit Soldaten des Vaterlandes zu umgeben (376).

24. (NIEBUHR, TOCQUEVIlle, ANTON SPRINGer.) Kaum ein anderer noch hat iber die Begebenheiten der Revolution in den zwei folgenden Menschenaltern so bedeutsam geurteilt, wie der deutsche Historiker NIEBUHR und der französische Historiker TocQUEVILLE - beide ersten Ranges als staatsmännische Kenner der Geschichte. NIEBuHR hat im Sommer I829 Vorlesungen über die Geschichte der letzten 40 Jahre in Bonn gehalten (sie sind in 2 Bänden, nach Heften, als Geschichte des Zeitalters der Revolution, von seinem Sohne herausgegeben worden: Hamburg I845). Er führt seine Vorträge damit ein, daß er die darzustellende Zeit größtenteils selbst erlebt habe und unter Verhältnissen, die es ihm möglich machten, mehr als viele andere von den Begebenheiten $z u$ erfahren. Er war dreizehn Jahre alt, als an der Seine die Trompete erscholl, gehört also wirklich noch zu den Zeitgenossen der Revolutionszeit. NIEBUHR nimmt oft auf die allgemeine, die herrschende Meinung Bezug, auch unter anderen Ausdrücken: so, wenn er erwähnt (I, I04), daß die hohe Geistlichkeit sich durch Vernachlässigung ihrer Pflichten ganz in Dekonsideration "gebracht hatte; er spricht aber auch ausdrücklich von der Offentlichen Meinung: sie sei bei dem Vorgehen TERrays und Maupeous gegen das Parlament, so entschieden gegen die Regierung" gewesen, daß nur einige Leute von der philosophischen Partei sich für das neue, von MAUPEOU eingesetzte Parlament erklärten, unter denen VolTAIRE war (I34); sie habe - in der ersten Zeit der Regierung LudwIGs XVI. - in ganz Frankreich zwei Männer der höchsten Stände: TURgot und MALESHERBES, als die besten der Nation genannt, und sie seien es gewesen (I37); die Offentliche Meinung habe in Frankreich eine freundliche Stimmung gegen das wfreie 
England verbreitet, die dem Handelsvertrage PIrTs entgegenkam (II7). NIEBUHR, der keine hohe Meinung von NECKER hat, hebt hervor, $\mathrm{da} B$ er schon bei seiner ersten Ernennung (I776) in der öffentlichen Meinung, „die schon etwas vom Revolutionären hatte", sehr hoch gestanden habe. Damals aber habe die Offentliche Meinung Krieg gegen England gewollt (I43). - Merkwürdig ist nun, wie in der geistvollen Erzählung, die NIEBUHR von dem späteren Verlauf der Dinge gibt, die Rede nicht mehr von der Offentlichen Meinung ist; man darf darin den Ausdruck der Tatsache sehen, daß sie in den ungeheuren Wirrungen der Kriege, der Schreckensregierungen, des napoleonischen Despotismus betäubt und gedämpft, oder wie NECKER sich ausdrückte, erschlafft war: ein Vorgang, dessen Analogie wir im 20. Jahrhundert erlebt haben und erleben. Was zutage trat, war, wie schon Forster erkannte, die Meinung von Paris, und diese machte mit tyrannischen Mitteln zuerst der Jakobiner-Klub, später NAPOLEON. - TOCQUEVILLE geb. I805, der unter den Eindrücken des Kaiserreichs, wenn auch nur als Zeuge von dessen Untergang, und unter denen der Restauration aufgewachsen war, schildert in einem besonderen Kapitel seines tiefen Werkes L'ancien régime et la révolution, wie Frankreich von allen Staaten Europas derjenige gewesen sei, dessen Hauptstadt das größte Ubergewicht über die Provinzen erlangt hatte und folglich das übrige Reich am vollständigsten absorbierte. Schon I740 habe MoNTESQUIEU einem seiner Freunde geschrieben, da $B$ es in Frankreich ein Paris und einzelne entfernte Provinzen gebe, die zu verschlingen Paris noch nicht Zeit gehabt habe. Als Bestätigung führt TocQuEvilıE an, daß es im I6. Jahrhundert und im Anfange des I7. in den Provinzen sehr bedeutende Buchdruckereien an Orten gegeben habe, wo sie seitdem verschwunden seien. „Und doch unterliegt es keinem Zweifel, daß im I8. Jahrhundert unendlich mehr Bücher aller Art gedruckt wurden als im I6.; aber alles Leben des Geistes hatte sich nach Paris, dem Zentrum des Landes gewandt. Paris hatte die Provinzen verschlungen" (deutsche Übers. S. 83, 85). TocQuevilLE will damit nicht leugnen, daß die Offentliche Meinung über das ganze Land hin zu einer gewaltigen Woge angeschwollen war. Wenn er darstellt, wie gegen die Mitte des I8. Jahrhunderts die Schriftsteller zu großer politischer Macht gelangten, wie die Religionsverachtung unter den Franzosen dieser Zeit eine allgemeine und herrschende Leidenschaft geworden sei (Buch III, Kap. I u. 2), so behauptet er nicht, daß diese Einflïsse ausschließlich von Paris ausgegangen seien; vielmehr schreibt er einen großen Teil der Wirkungen dem Verfalle des religiösen Glaubens und dem Stummwerden der gallikanischen Kirche zu, die ehemals so fruchtbar an hochbegabten Rednern 
gewesen war: ,Leute, die noch am alten Glauben festhielten, fürchteten die einzigen zu sein, die ihm treu blieben, und da sie die Absonderung mehr als den Irrtum fürchteten, so gesellten sie sich zu der Menge, ohne wie diese zu denken. Was nur die Ansicht eines Teiles der Nation noch war, schien auf solche Weise die Meinung aller zu sein, und dünkte eben deshalb denjenigen unwiderstehlich, die ihr diesen trügerischen Anschein gaben" (das. S. I82). Im Anschluß daran schildert er die Bewegung für wirtschaftliche Freiheit, die von den Economistes ausgehend, das ganze Land und gerade die wohlhabenden und gebildeten Ackerbauer am meisten ergriff. Diese Bewegung war den eigentlichen politischen Freiheiten nicht geneigt. „Selbst TURGOT, dessen Seelengröße, dessen hochbegabter Geist, ihm eine abgesonderte Stellung inmitten aller anderen anweist, hat keinen größeren Hang zu politischer Freiheit, wenigstens entsteht bei ihm die Neigung dazu erst, als die Offentliche Meinung sie ihm einflöBt" (r87). TURGOT selber hatte die Bedeutung dieser Macht erkannt. TOCQUEVILLE führt aus einer Denkschrift, die jener 1775 dem Könige einsandte, an, wie er seinen Vorschlag, jährlich eine repräsentative - beratende Versammlung einzuberufen, begrïndet habe in den Worten: „Dadurch würde die königliche Gewalt aufgeklärt werden, ohne gehemmt zu sein, und die Offentliche Meinung wäre dann ohne alle Gefahr befriedigt. Denn diese Versammlung hätte keine Gewalt, sich notwendigen Maßregeln zu widersetzen..." TOCQUEVILLE meint dazu, man habe den Bereich einer Maßregel und den Geist seiner Zeit nicht in höherem Grade verkennen können (I69). „Der König“, so drückt er in einem späteren Kapitel sich aus (Buch III, Kap. 4), worin er schildert, wie LUDWIGs XVI. Zeit im Wohlstande die blühendste der alten Monarchie gewesen sei, ,führte zwar noch immer die Sprache des Herrn und Gebieters, aber er gehorchte selber einer Offentlichen Meinung, die ihn täglich leitete oder mit sich fortriß; die er stets berücksichtigte, fürchtete, der er unablässig schmeichelte; unumschränkt dem Buchstaben des Gesetzes nach, war er bei dessen Vollziehung von Schranken umgeben“" Zur Bestätigung führt er an, daß schon I784 NECKER in einer öffentlichen Urkunde dies als eine unbestrittene Tatsache behauptet habe: „Den meisten Fremden fällt es schwer, sich eine Vorstellung von der Macht zu bilden, die in Frankreich die Offentliche Meinung ausübt; sie begreifen kaum, daß es eine unsichtbare Macht gebe, die ihre Herrschaft bis in die Behausung des Königs erstreckt. Das ist aber dennoch wahr" (204f.). TocQuEVILLE knüpft diese Sätze an die Betrachtung, daß die französische Nation in ihren oberen Klassen bereits die aufgeklärteste und freieste des Kontinents gewesen sei, in deren Schoße jeder auf seine Weise 
Reichtümer sammeln und nach Belieben mit dem erworbenen Gute schalten durfte. Was aber diese Offentliche Meinung, wie mehr oder minder jede, bezeichnete, war, daß die gebildeten und vermögenden Schichten darin einig waren, und zwar stand damals der Adel durchaus in der vordersten Reihe ${ }^{1}$ ). „In dieser ersten Epoche der Revolution, wo der Krieg noch nicht erklärt ist zwischen den Klassen, ist die Sprache der Adligen im ganzen ähnlich derjenigen der anderen Klassen; sie unterscheidet sich nur darin, daß sie weiter geht und einen höheren Ton anschlägt" (Chap. inéd. de l'ouvrage L'ancien régime et la révolution: Oeuvres VIII, 98). „Die Opposition des Klerus war nicht minder entschieden, wenn auch behutsamer." „Überall, wo die Stände sich zum Widerstand vereinen, sieht man die Geistlichen sich einstellen (das. S. IOO). Die Regierung wehrt sich, indem sie (unter anderem) mit großen Kosten viele kleine Schriften zu ihrer Verteidigung veröffentlichen läßt. „Aber man liest ihre Verteidigung nicht, und man nährt sich an Iooo Flugschriften, die sie angreifen" (das. I06). Bald aber - nachdem die Einberufung der Generalstände erfolgt war - trat der Umschwung ein: die Sprecher des tiers, sich als Vertreter von 26 Millionen fühlend, wie SIÉẎ̀s sich ausdrückte, wenden sich gegen die 200000 »Privilegierten «. „Die Aristokratie erkannte mit Erstaunen in den Ideen, deren man sich bediente, um sie zu schlagen, ihre eigenen Ideen.“ „Die Begriffe, mit deren Hilfe man sich bemühte, sie zu vernichten, bildeten den Grundbestand ihres eigenen Gedankens.“ „Was die Unterhaltung ihres Geistes in ihren Mußestunden gewesen war, daraus wurden schreckliche Waffen, gegen sie gerichtet" (das. I27). TocQUEVILLE führt dann aus, wie die Verdoppelung des tiers und die gemeinsame Abstimmung notwendig diesem das Úbergewicht verleihen mußten: „er hatte für sich den Strom der öffentlichen Gunst, die anderen hatten ihn gegen sich" (I3I). An einer späteren Stelle, wo er Bemerkungen über die konstituierende Versammlung macht, gibt TocQUEVILLE eine Stelle aus der zeitgenössischen Correspondance des députés de l'Anjou wieder, worin es heißt: ,Ungeachtet aller Verworrenheit (alle Welt redet dort gleichzeitig, man regt sich ziellos auf, man weiß nicht, welcher Form man folgen soll; man kennt einander nicht) ist die Versammlung schon allmächtig durch die Einheit ihrer Gefühle und den Strom der Meinung, der sie trägt und den sie empfindet unter ihren Füßen" (I79).

ANTON SPRINGer widmet in seinen Vorlesungen über "Die Geschichte des Revolutionszeitalters I789-I848《 (Prag I849) der

1) .Ce fut la noblesse qui entra la premiere et le plus hardiment dans la lutte commune contre le pouvoir absolu du roi", Tocguevil,I.,. Chap. inédits de l'ouvrage L'ancien régime (Oeuvres VIII, p. 97). 
»literarischen Opposition " eine geistreiche Betrachtung, die er dahin zusammenfaßt: „,So weit war die öffentliche Meinung in Frankreich gekommen: was bisher bestanden, als Macht und Gewalt gegolten, es war durch die Literatur zerbröckelt, in seine Bestandteile aufgelöst worden. Der innere Volksgeist war bereits vollständig revolutionär und lange konnte es nicht dauern, daß er auch die öffentlichen $Z$ ustände mit in dasselbe Geleise nachzog“ (S. 79), und ,Die öffentliche Meinung hatte sich bereits zu stark ausgesprochen, zu nachdrücklich auf die Widersprïche im alten Staatsleben hingewiesen, als daß sie nicht selbst bei den Machthabern am Throne Beachtung gefunden hätte" (S. 88). - Tiefe Einblicke in den Geist und die innere Geschichte der Revolution gewinnt man aus den von ADOLF SchmidT herausgegebenen "Tableaux (Leipzig I867-I870, Vol. I-3), wo - nach den eigenem Worten des Herausgebers (Pariser Zustände, Jan. I874, I, p. VII) - es möglich ist, das Innenleben der Revolution zu belauschen, den täglichen Pulsschlag der öffentlichen Meinung, die Stimmungen und Strebungen der Bürger aller Parteien und aller Klassen usw.

25. (Die Öffentliche Meinung Frankreichs in neuerer Zeit.) „Was war das für ein neues, was für ein seltsames Wort, das Wort 》öffentliche Meinung *, das ein Minister zum ersten Male in die Ohren eines absoluten Monarchen erschallen lieB?" In diesen Worten gibt Lours BLANC den Eindruck wieder, den er von der Entdeckung dieser neuzeitlichen Macht empfangen hat (Hist. de la révol. française II, 52). Er weiß wohl, daB sie nicht mit den Stimmungen und Bestrebungen der großen Menge, insbesondere der Arbeiterklasse, deren Anwalt er sein will, zusammenfällt. Er spricht nicht ausdrücklich aus, läßt aber durchblicken, daß die Offentliche Meinung der Terreur feindlich war und $\mathrm{daB}$ sie daraus für die Vorbereitung der Gegenrevolution Nahrung $\operatorname{sog}^{1}$ ). In Wahrheit haben NECKER und seine Tochter Recht, wenn sie als die echte Offentliche Meinung in bezug auf das Verfassungswesen während der Revolutionszeit und weit über diese hinaus - die Anerkenntnis der beschränkten Monarchie, des konstitutionellen Königtums, behaupten. Damit verband sich aber das Interesse für eine tatkräftige auswärtige Politik, für den Ruhm der französischen Waffen und die Eroberung: ein so starkes Interesse, daß es sogar das Emporkommen einer cäsarischen und unbeschränkten Monarchie

1) Richtig bemerkt auch der englische Historiker Hor, IAND ROSE: "TALI,IER und die anderen Jakobiner, welche ROBESPIERRE durch den Staatsstreich des Io. Thermidor stürzten, dachten nicht daran, mit Milde zu regieren. Es war die Kraft der nun endlich freigesetzten Offentlichen Meinung, was sie zur Mäßigung zurückfegte, und die Leidenschaft des französischen Wesens versprach diese in Royalismus um. zugestalten." (Pitt and Napoleon, p. 37.) 
nicht nur duldete, sondern begrüßte. Immer wieder setzt sich oder wenigstens ihren Schein die Offentliche Meinung durch: im konstitutionellen Gebahren der letzten Jahre NAPOLEONS und der Ioo Tage, in der Charte LuDwIGs XVIII., vor allem im Bürgerkönigtum, ${ }^{1}$ ) und in der raschen Restauration nach dessen Sturz durch den Februar I848, dem dann der neue Cäsarismus, mehr getragen von der Bauernschaft als von der Offentlichen Meinung, folgte, die aber schließlich das Empire libéral durchsetzte. „Bis 1860 wurden keine sehr heftige Klagen laut. Aber von I86o an befriedigte die äußere und volkswirtschaftliche Politik NAPOLEONs III. die öffentliche Meinung so wenig, daß er selbst die Notwendigkeit fühlte, den Liberalen einige Zugeständnisse $z \mathfrak{u}$ machen ..." LEBON, Staatsrecht der franz. Rep. (Hdb. d. ö. Rechts IV, Abt. 6) p. I7. Auch in der dritten Republik hat die Offentliche Meinung lange Zeit - bis an die Schwelle des neuen Jahrhunderts - mit der republikanischen Staatsform sich nicht ausgesöhnt; nur die Furcht vor der vollkommenen Reaktion durch Armee und Kirche, hielt die Bourgeoisie bei der Stange, während der Einfluß der Arbeiterklasse gleichzeitig immer stärker wurde, wenn er auch bisher nicht vermocht hat, den bourgeoisen Charakter der Republik erheblich zu modifizieren.

Die Offentliche Meinung Frankreichs hat an den Traditionen des Militarismus, also des kriegerischen Ruhmes und der Eroberung festgehalten, die in der französischen Volksseele immer ihren Widerhall gefunden haben. Diese Stimmungen und Neigungen, durch den Befreiungskrieg gegen England mächtig angeregt, von König FRANZ I. gepflegt, von LUDWIG XIV. auf den höchsten Grad gesteigert, waren doch vorzugsweise auf den Adel und die ihm unmittelbar anhängenden Schichten beschränkt geblieben, bis die Revolution und NAPOLEON sie national $\mathrm{zu}$ machen wußten. Sie teilten sich dem ganzen Volke mit; zu ihrem Hüter wurde die Bourgeoisie, die in ihren höheren Schichten den Idealen des Rittertums zu huldigen für ihre Pflicht hielt. „Immer haben die Helden Frankreichs durch den Mut und die Todesverachtung, durch den unwiderstehlichen Schwung und die siegreiche Expansion, durch die Seelengröße und den ritterlichen Geist, durch die Hingebung an das Vaterland oder an die Menschheit, die Liebe zur "Freiheit " zur »Aufklärung», zum "Fortschritt — durch solche Eigenschaften und Ideen haben sie die schlichte und unwillkürliche Phantasie des Volkes verführt" (FOUIllEE, Psychologie du peuple francais p. 387); wozu man hinzufügen darf, daß die rednerische Phrase dabei immer mächtig mitgewirkt hat. Die Offentliche Meinung

2) Vgl. Exkurs über dic Juli-Revolution S. 401 . 
Frankreichs ist chauvinistisch. Darum konnte sie das Emporkommen Preußens nicht ertragen. Sie forderte Rache für Waterloo und erhob sich mit dem Schrei nach dem linken Rheinufer I840; Rache für Sadowa, d.h. für eine Niederlage, die Frankreich unmittelbar gar nicht, mittelbar wenig berührte; das besiegte Osterreich war ihm seit Jahrhunderten der Feind. Ein englischer Historiker, der angesehenste der Epoche (RAwson GaRdINER, A students history of England III. 964) urteilt so: „Indem die Franzosen eifersïchtig wurden auf den Erfolg Preußens, brach der Kaiser NAPOLEON I870 einen Streit vom Zaune mit dem König von Preußen.". Dies ist ebenso historische Wahrheit - wenn auch BISMARCK verstanden hatte, den Gegner in seinem Netze zu fangen - wie es historische Wahrheit ist, daß Frankreichs kriegerischer Geist nicht geruht hat, bis sein verbündetes Zarenreich zum entscheidenden Angriff bereit war (I9I4). In auffallendster Weise trat der militaristische Charakter der französischen Offentlichen Meinung hervor in der DREYFusAffaire. Die Verbrecher, die es wagten, mittels gefälschter Urkunden die Verurteilung $\mathbf{z u}$ bewirken, wußten, daß sie die Offentliche Meinung hinter sich hatten. Die Regierung, die so lange sich weigerte, die chose jugée wieder aufnehmen zu lassen, wußte, daß die Offentliche Meinung von der Wiederaufnahme nichts wissen wollte. Wenn es zuletzt gelang, die volle Freisprechung des Verurteilten und Schwerbestraften $z \mathfrak{u}$ erwirken, so ist die Offentliche Meinung nicht zu seinen Gunsten umgeschlagen, sondern sie wurde durch die Wucht der enthüllten Tatsachen gelähmt; sie war ohnmächtig. Während weniger Jahre schwieg der rachedurstige Militarismus; kaum rührte sich einmal (im Jahre r905) die deutsche Macht in einer Richtung, die der französischen Machterweiterung entgegentrat, so war der Chauvinismus wieder auf dem Posten und hat ihn seitdem nicht wieder verlassen.

26. (Die Friedensbedingungen 187r.) HIPPOLYTE TAINE, einer der stärksten und schönsten Geister im Frankreich des I9. Jahrhunderts, schrieb am 9. Oktober 1870 über , die Offentliche Meinung in Deutschland und die Friedensbedingungen" (Studien, deutsche Übers. S. 2Io ff). Er wollte jene aufklären über die wirkliche Offentliche Meinung in Frankreich. „Der Kaiser spielte Würfel um die Wiederherstellung seiner persönlichen Macht. Die Kammern, die er ernannt hatte, waren gefügig; mehrere Journalisten, die den Krieg predigten, waren von eigennützigen Motiven bewegt oder liebten effekthaschende Phrasen. Ihr Geschrei hat die Deutschen betrogen und täuscht sie noch. Der verworrene Lärm, der von der Straße ausgeht, verhinderte, daß ein anderes Wort gehört wurde, und zwar ein ernstes und aufrichtiges, die schwache, 
traurige und allgemeine Stimme der öffentlichen Meinung"... Er beruft sich auf das, was er - nach Ausbruch des Krieges - in allen Kreisen und in den verschiedenen Schichten der Gesellschaft habe sagen hören. „Man zürnte den Abgeordneten, die den Mund THIERS' geschlossen hatten; man war entrüstet über die geheimen Manöver, durch die man die Straßenkläffer gewann, um die Offentliche Meinung unter ihrem Geschrei zu ersticken." „Unglïcklicherweise hat bei uns die Offentliche Meinung nicht wie in England einen unmittelbaren und zwingenden Einflu $\beta$ auf die öffentlichen Angelegenheiten: sie äußert sich nur in Gesprächen, sie macht sich erst spät geltend. Die Fremden, die sich an die Kammern und die Zeitungen halten, kennen von unserem Lande nur die öffentliche Schaustellung und ... kennen gar nicht oder verkennen die wahren Gefühle der Nation“ . . „,Außer den Feldzügen in der Krim und in Italien hat die Offentliche Meinung alle seine (NAPOLEONS III.) Kriege als kostbare und gefährliche Paraden betrachtet, die zum Nutzen der Dynastie und zum Schaden der Nation erfunden und wie eine schlechte Oper veranstaltet wurden, um Lärm zu verursachen und die Menge zu zerstreuen. Heißt das, $\mathrm{da} B$ die Nation Beifall gespendet hat? Sie hat sie geduldet, aus Mangel an Pfeifen, um sie zum Stillschweigen zu bringen, indem sie die Achseln zuckte, sich die Ohren verstopfte, und zwar mit einer so starken Mißbilligung, daß sich von diesem Augenblick an die Opposition wieder gebildet hat und der Kaiser den Boden unter seinen Füßen schwanken fühlte und dann alles auf eine Karte setzte." Wie es scheint, hat TAINE eine unrichtige Ansicht von der öffentlichen Meinung. Er schreibt ihr eine schwache und traurige Stimme zu. Was er meint, ist die viel tiefer liegende, unartikulierte (mit CARL YLE zu reden) Stimme der großen Menge des Volkes, und innerhalb dieser Menge wiederum die der älteren Leute, die nicht so leicht und rasch wie die Jugend, von einem aus der Hauptstadt und von höheren Schichten aus erhobenen Geschrei der Stimmungsmache sich fortreißen lassen. Bezeichnend für TAINEs Auffassung ist, daß er sich darauf beruft, er habe viermal das ganze Frankreich durchreist und überall mit den Arbeitern und noch mehr mit den Bauern gesprochen, habe ganze Monate hindurch in verschiedenen Dörfern gewohnt, immer und überall habe er dieselben Ideen getroffen. (Nämlich Gedanken an ihren Grundbesitz, an die Zukunft, an ihre Wertpapiere, an ihren steigenden Wohlstand, dem gegenüber ihr Gütchen durch die Hypothek und den Wucher fast nicht mehr sich bedrückt fühle.) Was das Bürgertum, die Industriellen, die Kaufleute, die Menschen von freier Profession und die ganze Klasse derer, die einen "Rock « tragen und Kapital besitzen, betreffe, so sei bekanntlich der Reichtum 
ungemein angewachsen und damit auch das Bedürfnis nach Komfort. Ihren Geist dürfe man nicht mit dem Geist jener Generation vergleichen, die zu Beginn des I9. Jahrhunderts lebte, „damals als das Heer die große Karriere bedeutete und der beständige Krieg jedem Ehrgeiz grenzenlose Perspektiven eröffnete". Zu gleicher Zeit sieht aber TAINE voraus: wenn die Deutschen ihre Forderungen (Elsaß und Lothringen) durchsetzen sollten, so würde sich für ein Jahrhundert oder wenigstens ein halbes Jahrhundert eine Perspektive von Metzeleien eröffnen; das gebe zu denken, auch für Sieger, „,das Glück wechselt" - die Ungerechtigkeit sei eine unverwüstliche Kriegssaat; ,,in dieser Hinsicht spricht, wenn das Herz schweigt, die Geschichte laut genug". TAINE erkannte nicht, da $B$ schon I866-I870 alle jene Franzosen, die an der nationalen Elhre und der Tradition des Ruhmes mit ganzer Leidenschaft hingen - und diese Gefühle hatten sich von der writterlichen und feudalen Klasse", die TAINE als heute veraltet und von der Herrschaft ausgeschlossen bezeichnet, über die gesamte höhere Bourgeoisie und ihre Bildung ausgebreitet - da $B$ alle diese Wortführer und Träger der Offentlichen Meinung schon in dem rivalisierenden Emporkommen Preußens eine kränkende Ungerechtigkeit erblickten und daß sie den Sieg dieser Nebenbuhler auch ohne die Annexionen schwerlich bald verschmerzt hätten. (Demnach wäre ohne $Z$ weifel von seiten des neuen deutschen Reiches nur eine auf Versöhnung und Bündnis gerichtete Politik gute und richtige Politik gewesen!) Interessant ist es, mit TAINES Ansicht diejenige eines nicht minder berühmten deutschen Historikers $z \mathfrak{u}$ vergleichen. HEINRICH VON TREITSCHKE schrieb I87I: „Ich wüßte nicht, wann jemals die öffentliche Meinung Europas eine so versteckte Ungerechtigkeit gezeigt hätte, wie im Verlaufe dieses Krieges, vornehmlich seit dem Sturze NAPOLEONS III. Eine friedfertige Nation wird von einem unruhigen Nachbarn, der sie seit Jahrhunderten mißhandelt und verhöhnt hat, ohne jeden Vorwand angegriffen; sie erhebt sich in herrlichem Einmut, zerschmettert den Dränger in zwanzig Schlachten und fordert schließlich mit erstaunlicher Mäßigung als den Preis unerhörter Siege eine Landschaft, die ihr einst frevelhaft geraubt worden, die ihr angehört durch Geschichte und Sprache, die ihr unentbehrlich ist, wenn die Wiederkehr des Friedensbruches verhindert werden soll ... Und in einem solchen Kampfe, wo Recht, Mäßigung, Menschlichkeit ausschließlich auf der Seite des Angegriffenen erscheint, nimmt die öffentliche Meinung fast des gesamten Auslandes laut oder heimlich Partei für den Angreifer; sie übernimmt die Mitschuld an seinem Verbrechen, ermöglicht ihm durch ihren Beistand die Fortsetzung des Krieges" (Hist. u. polit. Aufsätze, III, 575). 
27. (Exkurs.) (Die Juli-Revolution.), ,So riß die Gewalt der öffentlichen Meinung, die für Erhaltung der Monarchie, Erhöhung einer neuen Dynastie, für die Bestätigung der Revolution zugleich und ihre Beschließung war, alle Gedanken unwillkürlich dieses Weges; ihre Schwerkraft hielt den revolutionären Elementen selbst in dem Stadthaus, dem Herde der Demagogie, wo sich bereits die Anwandlungen regten, ein wenig Pariser Commune zu spielen, ein niederziehendes Gewicht" (Gervinus, Geschichte des I9. Jahrh., VIIIb, S. 469). ,So festigte sich unter dem Gewicht der öffentlichen Meinung der Orleanismus auf dem Stadthause dem republikanischen Gedanken gegenüber; im Palais Bourbon befestigte er sich in denselben Stunden den letzten Versuchen und Versuchungen des Bourbonismus gegenüber" (S. 47I). Dann über die Flucht der königlichen Familie: „Die Dauphine war in einer fast krampfhaften Aufregung. Wie mußte ihr auch zumute sein, wenn sie auf dieses Geleite der Kommissäre sah, die selbst ohne jeden Schutz nichts neben und hinter sich hatten als die moralische Macht der öffentlichen Meinung" (S. 534). Gervinus nennt die Hauptstadt ,die große Fabrik der Meinungen“" ${ }^{1}$ und charakterisiert die Handlungsweise der Dynastie dahin, daß sie bei ihrer Verletzung der Verfassung selbst alle Ventile der öffentlichen Meinung zerbrochen, alle Mittel des gesetzlichen Widerstandes abgeschnitten habe (S. 587). Nach AlFRED STERN nahm auch die öffentliche Meinung des englischen Volkes mit einer Wucht, deren Gewalt keinen Widerstand zulieB, für die ,glorreiche Revolution des Nachbarlandes Partei" (Gesch. Europas IV, S. 46).

\section{Vierter Abschnitt. Die Offentliche Meinung im deutschen Staat.}

28. (Allgemeines.) Es wurde ein Ausspruch Forsters angeführt und gebilligt, wonach um die Zeit der französischen Revolution eine politische Offentliche Meinung in Deutschland nicht möglich war. Nämlich nicht in dem Sinne, wie sie in Frankreich, und vorher schon in England, auf die Gesetzgebung und das übrige politische Leben einwirkte. In der Tat wären die Bedingungen dafür eher im Deutschland des 16. als in dem des 18 . Jahrhunderts gegeben gewesen: es gab damals mehr deutschen Staat als in der Zeit KLopstocks, I,Essings, Schillers und Goethes. So ist denn auch oft von der Offentlichen Meinung als einer Macht in Zeitalter der Reformation gesprochen worden. Schon GARVE, dessen vortreffliche Studie "Uber die öffentliche Meinunge uns schon mehrmals beschäftigt hat, spricht sich dahin aus,

1) Offenbar ein entlehnter Ausdruck, da Grovinus selber ihn in Anführungszeichen setzt. Woher?

I o a i es, Kritik. 
keine Begebenheit habe vielleicht die Macht der öffentlichen Meinung (in dem Sinne, den er dem Worte gebe) deutlicher gezeigt als die Reformation. „Der, welcher glaubt, daß die Predigten und Schriften LutHERS die Veränderung in den religiösen Begriffen der Menschen zuerst hervorgebracht haben, welche sich von seiner Zeit herschreibt - daß er der Urheber der Reformation sei; der schlägt die Kraft eines Mannes $\mathrm{zu}$ hoch an und verkennt die Kraft der Wahrheit. Nein, eben weil schon vor LUTHER, in mehreren christlichen Ländern, eine große Anzahl von Menschen so dachte wie er, die Ungereimtheiten bemerkte, welche er ins Licht setzte, sich von denjenigen Mißbräuchen gedrückt fühlte, gegen die er sich erhob, und die Wahrheiten, welche er laut predigte, wenigstens dunkel ahndete: eben deswegen war sein Anhang so groß und die Ausbreitung der Reformation gleich in den ersten Jahren seiner Erscheinung so schnell. Es hatte sich eine öffentliche Mein ung gebildet, daß eine Anderung in der Lehre, den Gebräuchen, und vornehmlich in der Hierarchie der Kirche vorgehen müsse; und selbst über viele Punkte des neu zu errichtenden Systems war man im stillen $\mathrm{zu}$ einer Entscheidung und Einstimmigkeit gekommen. Daher der unerwartete Beifall, welchen der Mann in der Welt fand, der diese gemeinschaftlichen Urteile vieler in seinen Schriften gleichsam nur sammelte und kundmachte. Er wurde der Vereinigungspunkt, um den sich die schon vorhandene Partei sammelte, wodurch ihre Größe sichtbar wurde; er war aber nicht der Stifter derselben." Gleichwohl wird man nur mit Vorbehalt von der Offentlichen Meinung als einheitlicher Macht im öffentlichen Leben jener Zeit reden dürfen. Es fehlte der Zusammenhang und Verkehr, auch das Leben der Städte hatte noch fast ganz und gar lokalen Charakter und wanderte nur schwer und langsam von einem Orte zum andern. Auch beruhten die herrschenden Stimmungen gegen die Kirche, die Klöster und die Pfaffen, mehr in dumpfen und unklaren Gefühlen, unterstützt durch Ahnungen und Prophezeiungen der Schwarmgeister, als da $B$ eine scharfe und bestimmte Willensmeinung auf Erneuerung und Entweltlichung des Kirchenwesens gerichtet war. Die gesamte Vorstellungswelt des Volkes wurzelte noch im Glauben und Aberglauben, also in der Überlieferung. Nur eine Minderheit, in erster Linie die Geistlichkeit selber, und von Laien fast nur Adel und wohlhabendere Bürger, waren des Lesens und des Schreibens kundig. Es gab keine Zeitungen und keine telegraphischen Depeschen. Allgemeiner als Druckschriften wirkten noch Bilder, man denke an die Biblia Pauperum; der Holzschnitt machte die Anschauung des Heiligen, wie des Verhaßten und Mißachteten volkstümlich. Gelesen wurden natürlich vorzugsweise fromme Schriften, von denen freilich manche 
die Verderbnis der Welt und der Kirche anklagten und nicht nur $\mathrm{BuBe}$, sondern auch politische Eingriffe verlangten. Allerdings war die erregte Gesamtstimmung, durch zunehmende Teurung genährt, gegen Kaufleute und Wucherer ebenso heftig wie gegen Mönche und Weltgeistliche, zum Teil auch gegen Adel und Fürsten gerichtet, etwas der Offentlichen Meinung Ähnliches, und man darf sagen, daß die Offentliche Meinung der deutschen Nation eben damals in den Anfängen ihrer Entwicklung stand. Aber man war noch ,,viel zu ausschließlich auf den allgemeinen Zustand der Gesellschaft gerichtet und auf die moralische Reformation des Volkes, als da $B$ man dem Tatsächlichen, den Handlungen viele Achtsamkeit hätte schenken können, wären sie auch bedeutender gewesen als sie waren" (GERVINUS, Gesch. d. deutschen Dichtung II, 29I). „Wo irgendeine Seite des Lebens so gewaltig alles verschlingt, wie in der Reformationszeit das Moralische und Religiöse, da muß jede andere Seite notwendigerweise verhältnismäßig darunter leiden" (das. 453, wiederholt von SCHMOLLER, Zur Gesch. der nationalökonomischen Ansichten in Deutschland während der Reformationsperiode: Tüb. Zeitschr. für d. ges. Staatswissensch. I860, S. 470). Man darf auch sagen: die Offentliche Meinung war noch die Religion, sie beruhte ganz in der Uberlieferung und im Glauben, auch wo sie auf Neuerungen drang, wollte sie nichts als Rettung und Wiederherstellung des Alten, Echten; ihre Ubereinstimmung in wesentlichen Punkten war daher natürlich, insoweit als überall die unmittelbare Erfahrung, der Augenschein, Zerstörung dieses Alten, Echten offenbar machte; sie bedurfte verhältnismäßig wenig der Verständigung zwischen den einander fernen Orten, wenig der überallhin sich erstreckenden Propaganda, um universal und stark zu werden, wie schon seit Beginn des 15 . Jahrhunderts, und zwar besonders in deutschen Landen, das Verlangen nach Reform der Kirche an Haupt und Gliedern geworden war. Im stillen war die Ketzerei überall verbreitet; sie nahm so für sich das echte und ursprüngliche Christentum in Anspruch; der Husitismus hatte ihr Mut gemacht, die altevangelischen Gemeinden standen miteinander in heimlichem aber tiefem Verständnis, das immer nahe an einer Verschwörung war; unter mannigfachen Namen und mit dem gemeinsamen Hang zur Mystik und zu intensiver Frommheit begegneten sie sich und kannten sie einander. Für ihre Religiosität war die Verwerfung der Kirche und der Widerwille gegen die Priester selbstverständliche Sache; dafür bedurfte es keiner Belehrung und Aufregung. Weil aber der Boden so bereitet war, darum schlugen LUThers Flugschriften, schlug die Kunde von seinem mutigen Auftreten so mächtig ein, und bewirkten allerdings, daß zeitweilig eine 
Gemeinsamkeit des Denkens und Wollens in Deutschland entstand, die man füglich als die Offentliche Meinung ansprechen kann. Überhaupt tritt deren Wesen um so mehr hervor, je mehr sich die Aufmerksamkeit weltlichen Angelegenheiten zuwendet, die bald auch den politischen Willen auf den Plan rufen. So war es der Fall bei den wirtschaftlichen Nöten, an deren Beurteilung eben auch LUTHER mit seinen Anklagen wider den Wucher so lebhaften Anteil nahm. „Was war natürlicher", meint SchmolLER (a. a. O. S. 505), indem er darstellt, wie die Kaufleute ihren Vorteil auch in der Geldentwertung fanden, ,als daß die öffentliche Meinung den Grund von all dem in den großen Handelsgesellschaften suchte, daß man sie der Monopole und der willkürlichen künstlichen Teuerung beschuldigte?" Die nächste Folge der Preisveränderung, da sie ja nur eine künstliche sein sollte, ,war der Wunsch der öffentlichen Meinung und der Versuch der Gesetzgebung, sie mit Gewalt zu beschränken und zurückzuhalten" (das. 5II). Das volkswirtschaftliche Gebiet ist offenbar dasjenige gewesen, auf dem sich die Offentliche Meinung am frühesten und freiesten entfalten konnte, weil der Gegenstand jedem Haushalter naheliegt und weil alles, was es an Verkehr gab, gerade diese Erörterung befördern mußte: nächst dem Wetter ist die teure Zeit, die Sorge ums tägliche Brot der sich unmittelbar darbietende Gegenstand des Gespräches, zwischen Fremden wie zwischen Freunden. Und wo die Tatsachen reden, gehen die Ansichten nicht weit auseinander: das erleben wir heute (I9I9/20) wie man es damals erlebt hat. Überdies wirkten $\mathrm{zu}$ jener Zeit noch das kirchliche Wucherverbot und das religiöse Mißtrauen gegen den Handel, die Abneigung der Christen gegen die Juden und die Furcht vor den Türken zusammen, um die natürliche Unzufriedenheit mit den bestehenden Zuständen zu verstärken. Religion geht hier unmerklich in die Offentliche Meinung ïber. Ganz langsam hat sich diese sozusagen auf ihre eigenen Füße gestellt. Der naturwissenschaftliche Historiker FRIEDRICH VON HELLWALD meint in besonderem Bezuge auf Deutschland, es habe „mit Ende des I6. Jahrhunderts die öffentliche Meinung in Europa ganz leise begonnen, eine Macht zu werden, der sich auch die Herrscher nimmer völlig zu entziehen vermochten"; er will dadurch erklären, $\mathrm{da} B$ in den großen Kämpfen zwischen Österreich und dem emporkommenden Preußenkönige die Völker (wie die Literatur jener Periode beweise) im allgemeinen hinter ihren Fürsten standen (Kulturgeschichte $^{3}$ II, 520). Schwerer wiegt die Ansicht LEOPOLD RANKES: „Nicht erst heutzutage hat die öffentliche Meinung Einfluß in der Welt bekommen; in allen Jahrhunderten *des ne ueren Europas* hat sie ein wichtiges Lebenselement ausgemacht"(Werke, Bd. 37, S. 87). 
Auch RANKE denkt dabei an Deutschland mindestens ebenso wie an die im I7. und I8. Jahrhundert voranschreitenden Staaten. Deutschland, ökonomisch und politisch zurückgedrängt, behauptete und steigerte bald seine Bedeutung für das geistige Leben. Die deutschen Universitäten vor allem, unter ihrem Einflusse manche Höfe und Städte, nährten die philosophisch-wissenschaftliche Denkungsart, die für einmütige Gestaltung der öffentlichen Meinung maßgebend wurde. Weil sie keinem einheitlichen deutschen Staat gegenüberstand, so mußte sie sich begnügen, in jedem Territorium auf die Neuerungen zu dringen, die der Zeitgeist verlangte. Im I7. Jahrhundert vorbereitet, wurde so die Aufklärung im I8. recht eigentlich Sache der öffentlichen Meinung, in Deutschland mehr als irgendwo. Ihre Einmütigkeit tritt dadurch am hellsten zutage, daß nicht nur die protestantische, sondern auch die katholische Geistlichkeit in und mit diesem Strome schwamm. Diese Entwicklung ist oft durch Meistergriffel geschildert worden; auch wenn man die öffentliche Meinung nicht ausdrücklich nennt, so schildert man sie doch. „Man wollte vor allem geistig weiter. Der Verstand war es, von dem man alles Heil erwartete. Verstandesmäßig war zunächst die Betonung des Natürlichen ..., verstandesmäßig anfangs auch die bürgerliche Bekämpfung der gesellschaftlichen Unsitten der galanten Welt." „Man faßt die Aufklärung « falsch auf, wenn man in ihr nur ein geistiges Vorwärtsstreben sieht: ebenso wichtig ist der durch sie bedingte moralische Fortschritt" (STEInhausen, Gesch. der deutschen Kultur, S. 639, 64I). In der Tat hat gerade die öffentliche Meinung, wie sie im I8. Jahrhundert in Deutschland sich bildete, einen ausgeprägt moralischen Charakter: sie beurteilt kritisch die ïberlieferten und gegenwärtigen Einrichtungen, sie verhält sich zu vielen bisher durch Herkommen und Glauben geheiligten verneinend; und zwar vorzugsweise aus moralischen Gründen, indem sie den Maßstab der humanen Gesittung, der natürlichen Freiheit, des vernünftigen Rechts daran legt. Besonders stark wirkt dahin die allgemein anerkannte, vielgepflegte, insbesondere den Beamten auf Hochschulen, und durch umfangreiche Literatur, mitgeteilte philosophische I ehre des "Naturrechts", sowohl als natürliches Privatrecht wie als allgemeines Staatsrecht. Mehr und mehr hatte sich in dieser Lehre, im Gegensatz zu ihrem früheren ständischen Charakter, die Stabilierung der unbeschränkten Souveränität des Staates, repräsentiert (in der Regel) durch den Fürsten, herausgestellt, und zwar in Absicht auf eine weise "Policierung", die Ordnung der gesellschaftlichen Verhältnisse nach Gesichtspunkten der sozialen Zweckmäßigkeit oder der Wohlfahrt. Von der zweiten Hälfte des I7. Jahrhunderts her, 
unter dem Einflusse des Thomas HoBbes, durch Autoren wie Puffendorf, Thomasius, Chr. Wolff, bis über die Mitte des I8. hinaus, war dieser Vorzug des Polizeistaates, der Wert einer aufgeklärten Selbstherrschaft allmählich beinahe ein fester Bestandteil der Offentlichen Meinung geworden. Er wurde dann erschüttert durch englische und diese vermittelnde französische Einflüsse (LOCKE, MONTESQUIEU), so daß Verfassung und beschränkte Monarchie bald gegen den "Despotismus " ausgespielt wurden. Dies stand offenbar im Zusammenhang mit dem gleichzeitig sich ausbreitenden Ideal der wirtschaft lichen Freiheit; obgleich die Physiokratie durchaus den $¥$ Freihandel im Absolutismus« predigte. Freiheit wurde mehr und mehr die Losung; auch die "löbliche" Gleichheit, nach GozTHEs Wort, wurde ihr gern gesellt, als die beiden Schlagworte von jenseits der Vogesen herübertönten. Aber auf diese Jugendträume, denen die gesamte Bildung sich hingab, fiel bald ein Mehltau durch die Schreckenszeit, den Prozeß des Königs, die Revolutionskriege. Vollends die napoleonische Unterdrückung wirkte wie Eiseskälte scheidend auf die öffentliche Meinung: wenn sie weite Kreise für sich gewann und noch einmal den Absolutismus in seiner rationalsten Gestalt als Cäsarismus emporleuchten ließ, so wandten sich edlere Gemüter mit Schauder von der ganzen Modernität $a b$, die darin verkörpert war, um in die Vergangenheit, in das sonst verachtete Mittelalter zurückzutauchen: die "Romantik "wurde auch in der politischen Denkungsart Mode. Bald, und überwiegend das I9. Jahrhundert hindurch, wurde doch an der Idee eines konstitutio nelle n Königtums festgehalten; sie hat sich als ein festes Stück der Offentlichen Meinung erwiesen, und hat sich als solches auch zur gegenwärtigen Zeit (I9I9/20), nachdem seit einem Jahre das Reich und die Einzelstaaten in Republiken verwandelt worden sind, wesentlich erhalten. Wenn auch diese Umwandlung durch das nur mittelmäßige Ansehen und die schwachen Sympathien, deren die Persönlichkeit des Kaisers, ebenso wie die Persönlichkeiten mancher Einzelmonarchen sich erfreuten, erleichtert worden ist, so ist sie andererseits eng verknüpft mit dem unglückseligen Ausgange des Weltkrieges und erscheint der Offentlichen Meinung, sofern diese noch die Meinung der alten herrschenden Schichten ist, als das Werk törichter oder verbrecherischer Schwärmer und Verräter, in Verbindung mit ausländischen Machinationen und Bestechungsgeldern. Durch den Kontrast werden die Zustände der "alten Regierung « in helleres Licht gehoben, als worin sie sonst, belastet durch anerkannte schwere Irrtümer, erscheinen würden. Die Republik ist das Banner des Proletariats, darum schon scheinen alle Meinungen, die mit den Angelegenheiten des Kapitals 
und des Grundbesitzes verknüpft sind, um das Banner der Monarchie sich sammeln zu sollen, obschon offenbar noch keine Möglichkeit vorhanden ist, es zu entfalten. Wenn dieser Zustand länger als ein Menschenalter dauern sollte, so wird voraussichtlich die Offentliche Meinung sich an die republikanische Verfassung gewöhnen und mit ihr aussöhnen; sollte sich sogar herausstellen, daß sie der Erhaltung der bestehenden Gesellschaftsordnung eher günstig als nachteilig wirken wird, so wird sie den Umsturz der Staatsordnung nicht nur verschmerzen, sondern als Fortschritt preisen. So ist die Entwicklung in Frankreich während der letzten Jahrzehnte des I9. Jahrhunderts gewesen; und die Republik der Vereinigten Staaten ist noch das festeste Bollwerk der Bourgeoisie und ihres Privateigentums.

29. (PERThes über die deutsche Staatsgesinnung.) CLEMENS THEODOR PERTHES hat in durchaus lehrreicher Weise ,das deutsche Staatsleben vor der Revolution" (nämlich vor der französischen und ihren Wirkungen auf das Deutsche Reich) dargestellt. Der zweite Teil dieser Schrift handelt von den staatbildenden Kräften im deutschen Volke vor der Revolution, und darin der Erste Abschnitt von der Staatsgesinnung des deutschen Volkes. Als solche erscheint zunächst der politische Gehorsam und die politische Treue, als deren Mutter aber die Gewohnheit, die in keinem politischen Zusammenleben zu entbehren sei. ,Solange Geist und Leben den bestehenden Formen innewohnt, bilden daher Gewohnheitstreue und Gewohnheitsgehorsam eine große politische Macht, welche in den Formen die Träger des inneren Lebens und hierdurch dieses selbst schützt und bewahrt. Wenn aber die bestehenden Einrichtungen ihres früheren Gehalts beraubt sind, so tritt der Teil des Volkes, welcher die lebensleeren Formen mit gleich zäher Gewohnheit des Gehorsams und der Treue wie früher die belebten festhält, durchaus in den Hintergrund, da in ihm kein eigener Wille und keine eigene Tat sich findet. Nichts als die vis inertiae hatte auch in Deutschland dieser Teil des Volkes gegen Ausgang des vorigen Jahrhunderts denen entgegenzusetzen, welche, getrieben vom guten oder bösen Prinzip, entschlossen waren, statt das Leben ihrer Vorfahren zu wiederholen, selbst zu leben und wollend und handelnd in die politische Umbildung einzugreifen, zu welcher der Gang der Geschichte drängte. Weit bedeutender für die Zukunft Deutschlands als die Gewohnheitstreue und der Gewohnheitsgehorsam war daher die Gesinnung innerhalb des deutschen Volkes, welche, sich entbindend von der Macht des Hergebrachten, den bestehenden politischen Formen entgegentrat. In ihrer historischen Entwicklung und in ihrer Erscheinung seit der zweiten Hälfte des vorigen Jahrhunderts bedarf sie einer näheren Betrachtung" (202). PERTHES 
schildert dann in einem Ersten Kapitel (203-227) die politische Opposition in Deutschland bis zum Ausbruch des Dreißigjährigen Krieges. Die von ihm ausführlich dargestellte Ansicht der Reformatoren über die Stellung der Untertanen zur Obrigkeit in weltlichen Verhältnissen sei tief in die Volksgesinnung eingedrungen und klinge vielfach wieder in den beiden am meisten gelesenen Volksschriftstellern der ersten Hälfte des I6. Jahrhunderts; Hans SAchs und Johann FischarT. Nachdem die Versuche der Ritter und der Bauern, Befreiung von dem auf ihnen lastenden Drucke mit den Waffen zu erkämpfen, durch die Siege der Fürsten gescheitert waren, sei die Opposition dieser beiden Schichten aus der deutschen Geschichte verschwunden. Auch die Städte, vielfach in diese Kämpfe verwickelt, büßten den Landesherren gegenüber jede Möglichkeit ein, ihrem Widerstreben gegen die Hemmungen des städtischen Lebens Geltung zu verschaffen. Nur die Opposition der Fürsten gegen die Reichsgewalt blieb, und zwar schließlich nur die der evangelischen, da die katholischen sich an den Kaiser anschlossen. Diese Opposition führte zum großen Kriege. Im Zweiten Kapitel dieses Abschnittes zeichnet PerThes die Umbildung der politischen Opposition in Deutschland vom Ende des 30jährigen Krieges bis zur Mitte des I8. Jahrhunderts. Nur Trümmer der alten Stände, die sich nun in schrofferer Abgeschlossenheit als zuvor gegenüberstanden, überlebten den Westfälischen Frieden. Für die Landesherren war nicht nur der religiöse, sondern auch der politische Grund zur Opposition weggefallen. Die Deutschen fanden sich nur noch als Individuen nebeneinander, und ausschließlich die Opposition der Individuen kommt noch in Frage. In den Städten mischten sich die Individuen: zu dem eigentlich städtischen Leben hatte sich ein Leben in Wissenschaft und Kunst gesellt; dazu kamen die von einsamen Burgen in die Städte ziehenden Ritter, die sich mehrenden Beamten, die Elemente der Höfe. „Aus ihrem gegenseitigen Verhalten zueinander und aus der Wechselwirkung, welche sie untereinander übten, wuchs sehr allmählich und unbemerkt ein neues, der früheren Zeit unbekannt gebliebenes geistiges Sein hervor, welches, da ein treffenderer Ausdruck fehlt, als soziales Leben bezeichnet werden mag." Nach meinen Begriffen würde ich eben dies als »die Gesellschaft «bezeichnen, in dem eingeschränkteren Sinne der Oberschicht, der maßgebenden Kreise, wie ihn auch PERTHES versteht, wenn er weiter sagt: ,Alle, deren Lebenstätigkeit durch die von ihrem Berufe gestellten Anforderungen in körperlicher Arbeit verzehrt ward, waren daher ausgeschlossen; alle dagegen, deren Beruf eine vorwiegend geistige Tätigkeit verlangte oder gestattete, eingeschlossen. Die Bauern, Handwerker, Krämer standen außerhalb, 
die Gutsbesitzer, die allmählich hervortretenden Fabrikanten und die Kaufleute innerhalb" der Gesellschaft. In Wirklichkeit vollzog sich dieser Prozeß, den man seinem Ziele gemä $B$ die Ausbildung eines Gesellschafts- und Staatsbürgertums - der "Bourgeoisie" nennen darf, in allen Ländern, wenn er auch in dem großen Gebiete des Deutschtums zunächst weit mehr auf territorialer als auf nationaler Grundlage geschah. Eine ausgeprägte Form habe zwar, fährt PERTHES fort, der soziale Sinn nicht gewonnen, aber die Macht, womit die Einzelnen ergriffen und festgehalten wurden, sei doch nicht ausschließlich innerer Natur gewesen. „Vielmehr bildete derselbe in seiner *Konvenienz* eine Norm aus, welche so stark, ja stärker als ein Gesetz es vermocht hätte, den Kreis umgrenzte, innerhalb dessen die Einzelnen sich bewegen durften. Das Organ ferner zur Wirksamkeit nach außen, welches für den Rittersinn in dem Fehderechte, für den Bürgersinn in dem städtischen Rechte lag, war für den sozialen Sinn die *öffentliche Meinung*, eine Tat des sozialen Lebens, welche mitbestimmend in die Zeitverhältnisse eingriff. Weil die Kraft, durch welche die wirkenden Organe des sozialen Lebens, die Konvenienz nämlich und die öffentliche Meinung, hervorgetrieben war, in einem dunklen und unbestimmten Gefühl lag, so konnte auch den politischen Zuständen gegenüber das soziale Leben weder eine mit besonnener Einsicht fest abgegrenzte Aufgabe sich stellen, noch die unbestimmten und schwankenden Aufgaben, welche es sich setzte, in einer geordneten, sich seines Zieles bewuBten Weise verfolgen. Weil ferner das soziale Leben einer äußeren Erscheinungsform entbehrte und ein vorwiegend Inneres blieb, so konnte es selbst körperlos, nicht berührt und erregt werden durch den realen Druck, welchen menschliche Willkür oder ertötende Einrichtungen in den staatlichen Verhältnissen ausübten. Aber so oft politische Handlungen oder Einrichtungen auf ein ihnen zugrunde liegendes Prinzip hinwiesen, welches mit der durch die Konvenienz des sozialen Lebens festgestellten Auffassungsweise in Widerspruch stand, fühlte sich das soziale Leben verwundet und dic öffentliche Meinung begann den Kampf nicht gegen einzelne politische Übelstände, sondern gegen das Prinzip, aus dem sie sich wirklich oder vermeintlich ableiteten. Handlungen schreiender Ungerechtigkeit, härteste Bedrückung Einzelner kamen dann sehr gelegen, um an ihnen das Unheilbringende des bekämpften Prinzips anschaulich zu machen.*

„Da das soziale Leben durch die Wechselwirkung, welche die Einzelnen als Einzelne aufeinander übten, sich gebildet hatte und deshalb unter seinen Angehörigen keinen Unterschied der Art nach anerkennen konnte, so wurde, wenn auch nur sehr allmählich, die 
Gleichheit aller seiner Elemente die Basis, auf welcher die das soziale Leben beherrschende Geistesrichtung ruhte. In den schroffsten Widerspruch gegen dieselbe trat die neue Stellung, welche das deutsche Fürstentum und die Nachkommen der alten Ritterschaft seit dem Ende des Dreißigjährigen Krieges in immer wachsendem Umfang für sich in Anspruch nahmen. Der prätendierten Stellung beider gegenüber erhob sich die Offentliche Meinung tief gereizt zu dem noch jetzt nicht beendeten Kampf." In wesentlicher Ubereinstimmung mit PERTHES sagt auch TREITSChkE: „Jene mittleren Schichten der Gesellschaft, welche die neue Bildung tragen, rückten dermaßen in den Vordergrund des nationalen Lebens, da $B$ Deutschland vor allen anderen Völkern ein Land des Mittelstandes wurde; ihr sittliches Urteil und ihr Kunstgeschmack bestimmten die öffentliche Meinung" (D. G. I, 88).

30. (Wirkungen der Revolution, Freiherr vom STEIN.) So mußte die Revolution im Nachbarlande mächtig zur Gestaltung und Stärkung dieser Gedankenelemente, also zur Verdichtung der politischen Offentlichen Meinung in Deutschland wirken.

„Denn wer leugnet es wohl, daB hoch sich das Herz ihm erhoben

Ihm die freiere Brust mit reineren Pulsen geschlagen,

Als sich der erste Glanz der neuen Sonne heranhob,

Als man hörte vom Rechte der Menschen, das allen gemein sei,

Von der begeisternden Freiheit und von der löblichen Gleichheit!

Schauten nicht alle Völker in jenen drängenden Tagen

Nach der Hauptstadt der Welt, die es schon so lange gewesen,

Und jetzt mehr als je den herrlichen Namen verdiente?

Waren nicht jener Männer, der ersten Verkünder der Botschaft

Namen den höchsten gleich, die unter die Sterne gesetzt sind?

Wuchs nicht jeglichem Menschen der Mut und der Geist und die Sprache?

Da war jedem die Zunge gelöst; es sprachen die Greise,

Männer und Jünglinge laut voll hohen Sinns und Gefühles."

(,Hermann und Dorothea, Klio: Das Zeitalter".).

Diese Stimmungen und Meinungen konnten nicht ohne Einfluß auf die politischen Leitungen bleiben. In den einzelnen deutschen Territorien und Staaten, zumal solchen, wo sie schon vor der Revolutionszeit als gebildeter Zeitgeist sich geregt hatten, tritt dies im letzten Jahrzehnt des I8. und im ersten des I9. Jahrhunderts mehr und mehr zutage. Freilich erwartete und erhoffte man noch in überwiegender Weise das Heil von den erleuchteten Leitern des Staates, mehr schon von den Staatsmännern, die es ihrem Berufe nach waren, als von den Fürsten. Um so mehr richtete sich die Mißbilligung gegen solche Staatsmänner, die für unfähig, unaufgeklärt und unwissend galten, so daß man ihnen die Schuld am öffentlichen Unglïck gab, 
wo es sich eingestellt hatte, wie I806 in Preußen. Schon vor der Katastrophe sah der Freiherr voM STEIN sie herannahen. Er entwarf am 27. April eine „Darstellung der fehlerhaften Organisation des Kabinetts und der Notwendigkeit der Bildung einer Ministerialkonferenz", die er am Io. Mai als Denkschrift zuerst der Königin LuISE und dann dem Könige ïberreichte. Sie enthielt die heftigsten Anklagen gegen die Personen der Geheimen Kabinettsräte BEyME und LOMBARD und des von diesen abhängigen Ministers von HAUGwirz. Diese unverantwortliche Camarilla, aus untauglichen Menschen bestehend, mache und entscheide alles - hingegen ,denen obersten Staatsbeamten bleibt die Verantwortlichkeit der Anträge, der Ausführung, die Unterwerfung unter die öffentliche Meinung". „Die neueren Ereignisse“, heißt es dann weiter, ,wo wir feierlich sanktionierte Verträge im Augenblick der Erfüllung umgangen und bald darauf umgestoßen sahen, sind ein fürchterlich belehrendes Beispiel, wie notwendig es ist, Personen $z u$ ändern, wenn man $M a B$ regeln ändern will. Die neue Staatsverwaltung kann auch nur durch die Entfernung der Mitglieder der alten Zutrauen erlangen, da diese in der öffentlichen Meinung tief gesunken, und zum Teil mit Verachtung gebrandmarkt sind" (G. H. PERTZ, Das Leben des Ministers Freihr. voM STEIN I, 338) ${ }^{1}$ ). Nach seiner Absetzung und nach der furchtbaren Niederlage schrieb STEIN im Juni 1807 einen neuen "Verwaltungsplan ", der an jenen Versuch, die Kabinettsherrschaft zu stürzen, sich anschloß. Er spricht darin seine Überzeugung voi der Vortrefflichkeit zweckmäßig gebildeter "Stände " aus, die er als ein kräftiges Mittel ansehe, die Regierung durch die Kenntnisse und das Ansehen aller gebildeten Klassen zu verstärken, sie alle durch Úberzeugung, Teilnahme und Mitwirkung bei den Nationalangelegenheiten an den Staat zu knüpfen..., *und ein gut gebildetes Organ der öfentlichen Meinung zu erhalte ${ }^{*}$, die man jetzt aus Äußerungen einzelner Männer oder einzelner Gesellschaften vergeblich zu erraten bemüht ist" (ib. 427). Er beruft sich hicr auf seine "Diensterfahrung " und wir haben ein Zeugnis vor uns, daß er als

1) Auch Prinz I,ours Fiskinand gehörte zu dem Kreise, dessen Bestreben dahin ging, die Kabinettsregierung in ein wirkliches Staatsministerium umzugestalten. Der Mittelpunkt dieses Kreises war SrEIN. „Das Ereignis ist von der allergrößten Wichtigkeit für unsere innere Geschichte; es ist der Anfang zur Bildung einer öfentlichen Meinung in den Fragen innerer Politik, der Anfang zur Bildung einer politischen Partei in Preußen." Paur, Bair.,Eu, Prinz Louis Ferdinand, "Deutsche Rundschaux, Band XLV, 5, S. 221. .. Der König warf aber den Bittstellern vor, daß sie selbst durch ihr Verhalten die öffentliche Meinung irreführten und das so notwendige Vertrauen zur Regierung schwächten, tadelte den herrschenden Parteigeist, der den Verfall des Vaterlandes herbeiführen werde, und verbat sich übrigens für die Zukunft asehr bestimmt derartige Eingabeu." Das., S. 223. 
Minister sich hat angelegen sein lassen, die öffentliche Meinung in politischen Fragen $z \mathfrak{u}$ erkennen und $\mathbf{z u}$ beachten. Nach seinem zweiten Rücktritt schrieb er im März I8Io eine Denkschrift über den Geist, worin das Unterrichtswesen Österreichs geleitet werden sollte. Er klagt darin über den gewaltsamen Zustand der Dinge in Deutschland. „Ein eiserner Druck lähmt alle auf politische oder historische Gegenstände angewandte Geistestätigkeit, *es gibt keine öffent liche Meynung mehr*, die sich aus denen frey ausgesprochenen, sich wechselseitig bekämpfenden Urteilen der Menschen bildet, und es darf sich nur die Stimme der Schmeichelei und des Beifalls erheben, die der Wahrheit, der freimütigen Beurteilung, des Unwillens über Unterdrückung und zugefügte Schmach muß schweigen" (PERTZ II, 424). Und doch tröstet sich der Verfassser: „,Die Meinung bekämpft siegreich die Gewalt, die Herrschaft NAPOLEONS steht in Widerspruch mit der öffentlichen Meinung, mit der Vernunft, sowohl mit denen eigennützigen als mit denen edelsten Gefühlen des Menschen, dem Gefühl für Recht, für Wahrheit und Freiheit." Die päpstliche Herrschaft sei im I2. und I3. Jahrhundert fester gegründet gewesen als die NAPOLEONS, ,sie beruhte in einem religiösen Zeitalter; auf religiösen Ideen ... und dennoch unterlag diese Macht der öffentlichen Meinung" (ib. 427). Wenn man erwarten dürfe, daß die liberalen und edleren Grundsätze wieder die Herrschaft erhalten und in das Leben treten, ,so werden die Nationen und die Regenten um so dringender aufgefordert, durch Leitung der Literatur und der Erziehung dahin zu wirken, daß die.öffentliche Meinung kräftig und rein erhalten, und die Künste der Verführung des Unterdrückers vereitelt werden" (428). Er spricht dann von der Anzahl der Schriftsteller, die in Deutschland größer sei als in irgendeinem anderen europäischen Lande, da die große Menge von Lehrern und jungen Leuten, die sich den Wissenschaften widmen, in ihrem Beruf, oft auch in dem Wunsch, ihre wirtschaftliche Lage zu verbessern, eine Veranlassung zu schriftstellerischen Arbeiten finde. „Diese Zahlen versinnlichen einigermaßen die Größe des Einflusses der Gelehrten und der Literatur auf die öffentliche Meinung, und wie wichtig es ist, einen solchen kräftigen Hebel zu ergreifen, und seine Anwendung nicht dem Zufall oder einer feindseligen Hand zu überlassen" (430). „Osterreich sollte also die deutschen Gelehrten mehr benutzen, um auf die öffentliche Meinung in Deutschland zu wirken, dieses würde geschehen, wenn es eine große Achtung für die Wissenschaft äußerte, dem Umlauf der Ideen weniger Hindernisse in den Weg legte; ausgezeichnete Gelehrte, besonders solche, die für die gute Sache schreiben; belohnte, öffentliche literarische Blätter sich zu eigen machte, seine 
wissenschaftlichen Anstalten verbesserte und dem in Deutschland herrschenden Vorurteil entgegenwirkte, als halte es die Fortschritte des menschlichen Geistes zurück und lähme dessen Kraft durch die ängstliche Vormundschaft, die es über ihn ausübt" (ib.). STEIN läßt sich dann aus über die Erziehung als das andere kräftige Mittel zur Leitung des gegenwärtigen und Veredlung des zukünftigen Geschlechts. In seinen "Staatswissenschaftlichen Betrachtungen ", die er um dieselbe Zeit geschrieben hat, kiagt er, daß dem Geist des Zeitalters eine bestimmte Richtung fehle. „Die Schriftsteller der Nation haben zum Teil allen Abwechslungen der äußeren Verhältnisse sich knechtisch hingegeben, die öffentliche Meinung war.geführt, nur sehr wenige haben feste Grundsätze aufgestellt und sind diesen und der Wahrheit und dem Recht getren geblieben" (446). Auch in diesen Aphorismen kommt er darauf zurück, Osterreich sollte die deutschen Gelehrten mehr benutzen, um auf die öffentliche Meinung in Deutschland zu wirken (452). $\mathrm{Zu}$ gleicher Zeit schloß er seine „Prüfung des HARDENBERGschen Finanzplans" mit den Worten: „Auf die Opinion ist im Preußischen wenig Rücksicht $\mathrm{zu}$ nehmen. Hier herrscht ein tief eingewurzelter Egoismus, halbe Bildung, Ungebundenheit vereinigt mit der nordischen Gemütslosigkeit und Roheit. Diese verwilderte öffentliche Meinung muß durch ernsthafte Strafmittel berichtiget und nicht durch Schonung und Nachgiebigkeit noch mehr irregeleitet werden" (49I). Und in einer beigefügten Denkschrift, die besonders die Zweckmäßigkeit eines Papiergeldes in der damaligen Lage des preußischen Staates erörtert, wiederholt der berühmte Staatsmann fast wörtlich seine Brünner Ausführungen über die Aufgabe der Regenten, durch Leitung der Literatur und der Erziehung dahin zu wirken, da $B$ die öffentliche Meinung rein und kräftig erhalten werde (502). In einem Schreiben an GENTZ aus dem Jahre I8II bestätigt STrEIN dessen Ansicht, daß die Ursache des Falles im Wert und Kredit des österreichischen Papiergeldes, in einer verwilderten öffentlichen Meinung“ liege, deren „Berichtigung nicht allein die Angelegenheit der Regierung, sondern der Verständigen, Vermöglichen, Angesehenen der ganzen Nation sei" (556f.). Mit diesen und so mit der öffentlichen Meinung, wie sie allerdings im übrigen Deutschland lebendiger war als im damaligen Preußen, hatte sich der Minister im Einklange gewußt, als er für den erleichterten Besitz und den freien Gebrauch des Grundeigentums und also für Aufhebung der Ėrbuntertänigkeit eintrat. Die naturrechtliche Idee von der Freiheit als dem Rechte des Menschen und Bürgers hatte eine mächtige Verstärkung erfahren durch die physiokratische, von АDAM SмIтn in gefälligen Formen dringender gemachte Befürwortung der wirtschaftlichen 
Freiheit. Auch STEIN stand unter diesen Einflüssen: er verklagte damals die Leibeigenschaft als im Widerspruch mit den ursprünglichen und unveräußerlichen Rechten der Menschheit, und die willkürliche Entsetzung von Bauernhöfen verschaffe den Berechtigten wenig Vorteil, halte aber die Verpflichteten in einem fortdauernden Zustand von Unmündigkeit, und sein unterhabendes Land, Gebäude und Inventarium bleibe von einer elenden Beschaffenheit, da es ihm nicht eigentümlich gehöre und aller Reiz fehle, es zu verbessern und Kapital anzuhäufen (II, 29). Seine tiefere Einsicht, die ihn von dem starken Strom der Meinung unabhängig machte (,der Grundsatz der möglichsten wirtschaftlichen Freiheit hatte damals die Herrschaft" v. D. GolTz, Die länd1. Arbeiterklasse S. 90) bewährte aber der Freiherr, wenn er alsbald, im Gegensatz zu Vorschlägen der Kommission, erklärte, nur eine gesetzliche Einschränkung der freien Disposition über das Eigentum werde bleiben müssen, diejenige nämlich, welche dem Eigennutz des Reicheren und Gebildeteren Grenzen setze, und das Einziehen des Bauernlandes zum Vorwerksland verhindere. Dies werde um so nötiger sein, als der im $\S$ I erlaubte freie Güterverkehr die Veränderungen mit der Herrschaft vervielfältigen, und der steigende Kaufwert die neuen Besitzer immer mehr reizen werde, ihren Vorteil zu suchen (II, 20). - Nachdem STEIN, um desto kräftiger gegen NAPOLEON zu wirken, in die Dienste des Zaren getreten war, überreichte er diesem am I3. September I8I2 Bemerkungen über die politische und militärische Lage Deutschlands von dem österreichischen Hauptmann voN PFUEL, (in französischer Sprache): an die Darstellung der Hauptländer schließt sich ein kleiner Aufsatz über die Opinion publique, dessen Eingang hier verdeutscht werde: „Ungeachtet der abweichenden Verhältnisse, die den öffentlichen Geist in den verschiedenen Teilen Deutschlands beeinflussen, bemerkt man doch eine gewisse Gleichförmigkeit in der Art, die Dinge zu betrachten und über die Ereignisse nachzudenken, die sich vorbereiten. Diese Gleichförmigkeit stellt eine wohl ausgeprägte Offentliche Meinung her" - diese sei, wie dann eingehend ausgeführt wird, durchaus auf Seite Rußlands, trotz aller Anstrengungen der Franzosen, sie auf ihre Seite zu ziehen. - Uber die deutsche Bundesakte, die am 8. Juni I8I5 unterzeichnet wurde, urteilte STEIN, wie bekannt, von einer so fehlerhaften Verfassung lasse sich nur ein sehr schwacher Einfluß auf das öffentliche Glïck Deutschlands erwarten: ,und man muß hoffen, daß die despotischen Grundsätze, von denen mehrere Kabinette sich noch nicht losmachen können, nach und nach durch die öffentliche Meinung, die Freiheit der Presse und das Beispiel zerstört werden, welches mehrere Fürsten, besonders Preußen, geben zu wollen 
scheinen, indem sie ihren Untertanen eine weise und wohltätige Verfassung erteilen" (IV, 446). Die große Bedeutung, die STEIN der Offentlichen Meinung beilegte, erhellt auch aus seinen staatsmännischen Maßnahmen und Anregungen, ihr eine bestimmte und erwünschte Richtung $\mathrm{zu}$ geben, sie also $\mathrm{zu}$ »bearbeiten ", worauf an anderer Stelle zurückzukommen sein wird.

3I. (Die Öffentliche Meinung bis I 848, die Burschenschaft.) Nach der Revolution und ihren Wirkungen in Deutschland waren es die Befreiungskriege, die dem deutschen Volke ein gemeinsames und erhöhtes nationales Bewußtsein gaben, das zunächst überwiegend religiös und romantisch gestimmt, mehr und mehr doch eine politische Ziele erstrebende öffentliche Meinung wurde. Als der verhängnisvolle, von stumpfen Ansichten beherrschte Wiener Kongreß tagte, da regte sie sich überall, ohne von Fürsten und Diplomaten der Beachtung gewürdigt zu werden. „Die Offentliche Meinung in Deutschland, von den preußischen Staatsmännern, besonders HumboLD'T und GNEISENAU, warm befürwortet, sprach sich energisch für die Rückgabe der in früheren Jahrhunderten dem Reiche entrissenen Gebiete Elsa $B$ und Lothringen aus" (SPRINGER, Gesch. d. Revolutionszeitalters S. 359). Bekanntlich war es die englische Welt- und Gewaltpolitik, die diesen Akt der ausgleichenden Gerechtigkeit verhinderte, obgleich oder vielmehr weil er die Ruhe Europas besser als irgendeine andere der gegen NAPOLEONS Reich zielenden Maßregeln gesichert hätte. Die Offentliche Meinung mußte wachsen mit der zunehmenden Bedeutung des Bürgertums und seines Liberalismus; dieser aber gewann um so mehr Energie, je mehr er gedrückt wurde und sich durch die Fortdauer des absolutistischen Regimentes betrogen fand. Dazu wirkte aber hauptsächlich, da $B$ nunmehr auch die größeren Teile des Adels, die sonst, auf Wiederherstellung ihrer ständischen Rechte erpicht, mit der Bourgeoisie zusammen, nach Repräsentativverfassungen gestrebt hatten, in Furcht vor der Revolution, deren Schrecken im Nachbarlande zutage getreten waren, um Thron und Altar sich scharten. Die Offentliche Meinung entwickelte sich als Opposition des dritten Standes gegen die Restaurationspolitik. Ihr nächstes, mit Inbrunst ersehntes Ziel war die staatliche Ei in heit Deutschlands, deren Herstellung von den 39 nun ganz souverän gewordenen Fürsten als Kränkung ihrer Rechte empfunden und verabscheut wurde. Ihr reihte sich der Finthusiasmus der gebildeten Jugend an, der die Erneuerung des deutschen Kaisertums in romantischer Verklärung sah; aber langsam rang sich auch das kommerzielle und industrielle Interesse des Bürgertums zum Streben nach einem gemeinsam-einheitlichen Wirtschaftsgebiet durch, das dem gleichen Recht, der gleichen Münze, 
gleichem $\mathrm{MaB}$ und Gewicht unterliegen und dem freien Binnenhandel offenstehen solle; wo dieser Gedanke einmal Wurzel gefaßt hatte, erwärmte er auch den trockensten Geschäftsmann für ein einiges Deutschland. Aber zunächst war diese Vorstellung eine Schwärmerei, die an den Universitäten ihren Herd hatte. An einzelnen Stellen entartete die Schwärmerei in politischen Wahn. „Der $\mathrm{HaB}$, mit welchem die öffentliche Meinung KOTZEBUE verfolgte, gestaltete sich (bei dem Studenten SAND) zu der fixen Idee, durch die Ermordung KotzebuES mit Aufopferung seines eigenen Lebens das Vaterland zu retten" (Springer, 1. c. 393). Die Tat war allerdings ein Flammenzeichen. Darum versuchten die "Karlsbader Beschlüsse" I8I9 dies Feuer im Keime $z u$ ersticken, als die Bundesregierungen sich gegeneinander verpflichteten, „Universitäts- und andere Lehrer, die ... durch Verbreitung verderblicher, der öffentlichen Ordnung und Ruhe feindseliger, oder die Grundlagen der bestehenden Staatseinrichtungen untergrabender Lehren ihre Unfähigkeit zur Verwaltung des ihnen anvertrauten wichtigen Amtes unverkennbar an den Tag gelegt haben, von den Universitäten und sonstigen Lehranstalten zu entfernen." Es folgte (in § 3) eine ausdrückliche Ächtung des ,unter dem Namen der allgemeinen Burschenschaft bekannten Vereins“". Von den Universitäten sagt FRIEDRICH PAULSEN, sie seien seit dem I8. Jahrhundert die Stätten, von denen die Nation die großen Impulse ihres Lebens erwarte. „Sie sind ... die Bildungsstätten für die führenden Klassen, die Stätten wo die "öffentliche Meinung "für das nächste Menschenalter zuerst Gestalt gewinnt" (Richtlinien der jüngsten Bewegung, S. 88). Nächst den Universitäten faßten die Beschlüsse den Mißbrauch der Presse scharf ins Auge, alle Druckschriften außer Büchern von mehr als 20 Bogen wurden - zunächst für 5 Jahre - einer strengen Zensur unterworfen; endlich wurden strenge Maßregeln gegen revolutionäre Umtriebe und demagogische Verbindungen einer Zentral-Untersuchungs-Kommission zur Pflicht gemacht. Die Karlsbader Beschlüsse, urteilt TREITSCHKE, verwirrten und verwüsteten die öffentliche Meinung von Grund aus (D. G. II, 573), und, als die Demagogenverfolgung zu rasen begonnen hatte, sei die ohnehin verstimmte öffentliche Meinung in hellem Zorne aufgebraust, als der Herausgeber des Rheinischen Merkurs (JOSEF GöRRES) . . . vom preußischen Staate ausgestoßen und von seinen alten Todfeinden, den Franzosen .... mit unverhohlener Schadenfreude großmütig beschützt wurde (ib. 579). STEIN, der ungeachtet seiner immer heftiger gewordenen Abneigung gegen „das fratzenhafte und zum Teil auch verbrecherische ... Treiben mehrerer dünkelvoller Gelehrten" offen gestand, daß ihm die Karlsbader Maßregeln mißfielen, bezeichnete 
als Lehre der "Demagogen", diese seien das Resultat einer Adelsverschwörung gegen die Volksfreiheit $(\mathrm{V}, 452)$. Diese Ansicht und die damit verbundene Verurteilung war offenbar die Antwort der Offentlichen Meinung des Tages, die allmählich sich verdichtete. $\mathrm{Zu}$ den Zeugnissen ihrer Entwicklung gehört die immer lebhafter werdende theoretische Beschäftigung mit der öffentlichen Meinung; ihren Spuren werden wir später nachgehen. Darin gab sich zugleich ihre Schätzung und das Verlangen nach freier Meinungsäußerung, insbesondere literarischer, also nach Preßfreiheit, kund, die schon lange auf dem, wenn auch noch ungestalteten, Programm des politischen Liberalismus gestanden hatte. Eine Sturmflut der öffentlichen Meinung erregten mehrere hervorstechende Begebenheiten: auf den hannöverschen Verfassungsbruch und die Eidesverweigerung der "Göttinger Sieben « ist in früherem Zusammenhange schon Bezug genommen worden (III). Diese gesamte Richtung schritt, bis sie im Jahre 1848 siegreich wurde, über zwei große Stufen vor: die erste war die der französischen Juli-Revolution gewesen, die sehr stark auf Deutschland zurückwirkte, die andere wurde die des preußischen Thronwechsels (I840), an den sich die liberalen Hoffnungen knüpften, obgleich sich bald herausstellte, daß der gekrönte Romantiker viel weniger modern dachte, als sein nüchterner und beschränkter Vater. Die Offentliche Meinung erstarkte im jungen Deutschland und der sog. Linken der Hegelianer, so da $\beta$ der jugendliche Weltstürmer FRIEDRICH ENGELS, der auch diese Veste einzunehmen gedachte, im Vorwort seines Aufsehen erregenden Buches "Die Lage der arbeitenden Klasse in England « zu schreiben wagte, die Mittelklasse oder Bourgeoisie sei in Frankreich und England direkt, in Deutschland als öffentliche Meinung « indirekt im Besitze der Staatsmacht (Ausg. I892, p. XXXII). Endlich erhob sich dann die Offentliche Meinung und die Klasse, in deren Namen sie sich äußerte, gegen den Absolutismus, der unter FRIEDRICH WILHELM IV., wie unter anderen deutschen Monarchen die Reste des Feudalismus liebevoll unter seine Fittiche genommen hatte: die Revolution von 1848 hob also auch die Macht der Offentlichen Meinung rasch und bedeutsam empor. Es war die in den tiefsten Hintergrund gedrängte Bundesversammlung, die am 18. Mai erklärte, die deutschen Regierungen und sie als deren gemeinschaftliches Organ, ,,aufrichtig huldigend dem neuen Geiste der Zeit", reichten den Nationalvertretern die Hand zum Willkomm; sie hätte auch sagen können, daß sie der Offentlichen Meinung, die über sie längst den Stab gebrochen hatte, die Schlüssel der eroberten Stadt entgegenbringe. So wurde der Preußische Vereinigte Landtag von der Flutwelle der Offentlichen Meinung getragen und wurde sich 
dessen bewußt, so schwach auch der Liberalismus in ihm vertreten war. Die Offentliche Meinung jener Zeit hatte in manchen Stücken auch einen konservativen Charakter, besonders in religiösen Fragen. Der Minister EICHHORN berief sich darauf bei Beratung des Antrages auf Ånderung der ständischen Gesetzgebung und Erweiterung der Rechte der Dissidenten (20. Mai I847). Dazu sagte der schlesische städtische Abgeordnete Tschinke: „Ich glaube, daß wir die öffentliche Meinung gern hören und achten, ich glaube, daß sie keinem von uns gleichgültig ist, und zwar um so weniger, als sie nach vielen Kämpfen endlich sich Geltung errungen hat, als sie gottlob auch in unserem Staat bereits das Richteramt ausuibt. Nichtsdestoweniger, glaube ich, werden wir uns dem Herrn Minister zu Dank verpflichtet fühlen, daß er von seiner Seite der öffentlichen Meinung eine Anerkennung gezollt hat... Ich meinerseits muß bekennen, $\mathrm{da} B$ ich vernommen habe, $\mathrm{da} B$ die öffentliche Meinung mit den Ständen des preußischen Reiches und ihrem Wirken bisher zufrieden war, daß die Stimmen da draußen sich beifällig geäußert haben ... über die feste aber gemäße Stellung, die die preußischen Stände bis jetzt eingenommen haben, daß sie sich beifällig geäußert haben über die drei Grundpfeiler, die wir uns erkoren haben zur Richtschnur: Recht und Pflicht und Humanität."

32. (Die Paulskirche.) Nachdem das Vorparlament den Grundsatz der Volkssouveränität aufgestellt hatte, bedeutete die deutsche Nationalversammlung, die am I8. Mai in der Paulskirche zusammentrat, einen unbestrittenen Triumph des schwarz-rot-goldenen Einheitsgedankens, den die Offentliche Meinung einmütig zu dem ihren gemacht hatte. Der Abgeordnete für Köln, RAvEAux, berief sich (am 27. Mai) auf die Gesinnungen, die der größere Teil Deutschlands hege. „Jeder, der widerspricht, wird der öffentlichen Meinung widersprechen, und diese öffentliche Meinung, sie spricht sich nicht bloß hier in diesem Saale, sondern auch in der Presse aus." In der großen Debatte über die provisorische Zentralgewalt sagte am 2I. Juni Herr voN AUERSWALD, er sei viel in verschiedenen Teilen Deutschlands herumgereist und wisse, daß man ïberall denke, es müsse der öffentlichen Meinung, die in der Paulskirche repräsentiert werde, Rechnung getragen werden. Und in der langen Aussprache über Standesunterschiede, Adel, Titel und Orden, sprach am I. August Morirz MOHI, die Worte: „Die öffentliche Meinung ist zu aufgeklärt, um noch Geburtsunterschiede zu wollen; die Bildung und das Rechtsgefühl sind zu mächtig, um vor der Tatsache herkömmlicher Kastenvorzüge sich zu beugen." Und in der gleichen Frage erklärte MORITz HARTMANN (aus Böhmen): „der Adel ist eigentlich in der öffentlichen 
Meinung getötet, und gegen etwas Lebloses zu Felde zu ziehen, gibt das Ansehen eines Don Quixote". In der Paulskirche nahm die Galerie einen sehr lebhaften Anteil an den Verhandlungen und gab zu manchen Klagen, auch zu Beschränkungen der Offentlichkeit Anlaß. Dazu bemerkte am I. September WIESNER von Wien treffend, in England sei die Gegenwart des Publikums durch ein altes Gesetz verboten. „Die Macht der Offentlichen Meinung hat aber so sehr gesiegt, da $B$ man über das alte Gesetz wegschritt." Eir hätte wohl hinzufügen mögen, daß eine mächtige Offentliche Meinung in betreff einer solchen Sache in Deutschland schwerlich zu finden sei. Hingegen behauptete EISENMANN von Würzburg am I4. September, als es sich um den traurigen Waffenstillstand von Malmö handelte, wohl mit Recht, es herrsche allenthalben in Deutschland die größte Aufregung gegen die Annahme: nicht nur die Demokraten oder die roten Republikaner, sondern alle konstitutionellen Vereine von München bis an den Rhein, seien darüber einig. Der Volksvertreter müsse den Mut haben, einer gemachten Offentlichen Meinung zu trotzen, wenn es das Wohl seines Vaterlandes fordere. „Wenn man sich aber überzeugt, $\mathrm{da} B$ die große Mehrheit des Volkes einen entschiedenen Entschlu $B$ fordert, wenn man sich überzeugt, da $B$ man durch Nachgeben der Nationalversammlung das notwendige Vertrauen raubt, da $B$ man ihren moralischen Einfluß vernichtet und so die letzte Stütze ruiniert, auf der vielleicht noch die deutsche Ordnung sich halten kann, daun ist es unsere Pflicht, die öffentliche Meinung zu hören." Er riet deshalb, man möge das Verzeichnis aller Adressen und Petitionen über den Gegenstand hören, ehe man ein endliches Urteil fälle. Dies geschah am folgenden Tage durch den Sekretär Srmson. Und dazu sagte ROBERT BLUM am I6.: , Man weist hin auf dic Offentliche Meinung; ihr Ausspruch liegt nahe genug, wenn von 67 Eingaben 66 sich in einem und demselben Sinne aussprechen." - Interessant ist auch die Bemerkung, die am 22. September in der langen Debatte über das Schulwesen FRIEDRICH (von Bamberg) machte: „In früherer Zeit", sagte er, ,waren die Schullehrer bescheidener in ihren Anforderungen; allmählich sind sie mutiger geworden, je mehr sie sich der Gunst der öffentlichen Meinung versichert halten konnten" . . . Diese Gunst hatte auch über die Nationalversammlung wie ein weicher Frühlingsregen sich ergossen; bald aber trat Dürre ein. Als im Oktober der Ausspruch der Times in der Versammlung berichtet wurde - die Nationalversammlung sei ein Schatten und der Reichsverweser sei ein Schatten dieses Schattens -, da war in Wahrheit auch in Deutschland selber das Vertrauen schon gewichen, die Meinung erlahmt. Bald folgte die Reaktion in Preußen; die Frage des 
Verhältnisses zu Österreich trat zu gleicher Zeit in den Vordergrund. Am 6. Januar I849 sprach LöwE (von Calbe) sich dahin aus, die Geschichte werde ihr Urteil über diese Versammlung dahin aussprechen, daß der größte Scharfsinn, der ganze Aufwand des Geistes dafür dagewesen sei, wie man sich die Verhältnisse so zurechtlegen könne, „da $\beta$ man keinen Entschluß zu fassen braucht, da $\beta$ nichts geschieht!“ „So stehen wir auch heute den preußischen Verhältnissen gegenüber." Als er das letztemal geredet habe, sei alles noch in der blauen Zukunft verborgen gewesen, „damals war Furcht vor dem großen Kampfe, der entbrennen könnte zwischen Volk und Krone, und man wagte damals noch nicht, über die öffentliche Meinung so mit Stiefeln und Sporen fortzugehen, wie das in der letzten Zeit Sitte geworden". Am II. Januar begann aber WILHELM JORDAN eine seiner dichterischen Reden mit den Worten: „Der Politiker, sagt man, soll Ehrfurcht haben vor der öffentlichen Meinung." In den letzten Wochen, da die österreichische Frage entladungsreif in den Zenit hinaufgerückt sei und alle Federn und Druckerpressen beschäftige, sei es ihm sehr schwer geworden, jenes Gebot zu erfüllen; den Fanatismus der Phrase gegen die nüchterne Notwendigkeit und die Rücksichtslosigkeit der politischen Phantasie gegen die Gewalt der handgreiflichen Dinge: ,alles das haben wir in reichem Maße entfaltet gesehen auf dem Felde der öffentlichen Meinung". Der zum Präsidenten des Reichsministerrats gewählte Herr voN GAGERN verteidigte sich am I3. Januar gegen den Vorwurf, er trage Mitschuld daran, daß die theoretische Richtung auf Bildung einer tabula rasa für die Konstituierung Deutschlands nicht habe mit Erfolg angeschlagen werden können. Er gedenke mit hoher Achtung der Erhebung des Volkes, welche das Vorparlament hervorrief, habe aber der Wirksamkeit des Vorparlaments niemals eine andere Berechtigung vindiziert, als die eines entschiedenen und unzweideutigen Ausdrucks der öffentlichen Meinung, mittels einer freiwilligen Versammlung, die das Vertrauen der Nation sich erworben hatte, und die auf Grund dieses Vertrauens Aussprüche tat, die sich allgemein Geltung verschafften. Er spricht dann von der Veranlassung der Revolution in Berlin, die er in dem Streben nach einer Gesamtvertretung des preußischen Staats an Stelle der von der öffentlichen Meinung für ungenügend erachteten Institutionen erblicken will. Auch für die Herstellung des starken Bundesstaates, also der deutschen Einheit, werde die allein praktische Idee sich in der öffentlichen Meinung weiter Bahn brechen. Es war die große Staatsrede zugunsten des Erbkaisertums, die auf der Rechten und im Zentrum sehr starken Beifall erntete, während auf der Linken Unruhe und heftiges Zischen 
antwortete. Eingehend erörterte am I7. Januar der Heidelberger Historiker HAGEN, warum die Dynastie Hohenzollern den Wünschen, Hoffnungen und Bestrebungen des deutschen Volkes niemals entgegengekommen sei; man könne nicht glauben, daß die absolutistische Richtung der preußischen Regierung mit dem März auf einmal verschwunden sei, einer Regierung, ,,welche von der öffentlichen Meinung seit 33 Jahren immer aufgefordert worden ist, eine konstitutionelle Regierungsform $\mathrm{zu}$ geben, welche aber niemals diesem Wunsche Gehör geliehen hat", bis sie dazu gezwungen wurde. In einem Teile von Deutschland wenigstens sei die öffentliche Meinung gegen Preußen. Der Redner kritisiert mit Schärfe die verschiedenen Vorschläge des Erb- wie des Wahlkaisertums, und des Direktoriums. Er stimme für einen verantwortlichen und zeitweiligen Präsidenten. Ob ein solcher die Macht habe, Deutschland zu regieren? Die Machtfrage sei allerdings von größter Bedeutung. „Sie wissen, meine Herren, wir hatten auch einmal eine Macht, obwohl uns weiter nichts zu Gebote stand als die Offentliche Meinung; aber sie ist es, welche immer und ewig die meiste Macht gibt." Er schließt mit dem Wunsche, daß ein neues Parlament gewählt werde, welches entschieden die Offentliche Meinung repräsentiere. „Meine Herren, der Geist der deutschen Freiheit ist fähig, Armeen aus der Erde zu stampfen." Der Darmstädter Schulz beantragte die erste Einnennung des Oberhaupts auf nur ein Jahr und berief sich zur Begründung zuerst auf den schwankenden Zustand der öffentlichen Meinung in Deutschland, namentlich, da $B$ über die Oberhauptsfrage die Meinung höchst geteilt sei. Bassermann, der beredt für das Eirbkaisertum eintrat, bekannte zugleich seinen Glauben an eine deutsche Zukunft, die politische Zukunft beruhe aber auf der Zukunft der Parteien, und das Leben der Parteien beruhe auf der öffentlichen Meinung, er achte die öffentliche Meinung zu sehr, als daB er nicht glaube, einiges beitragen zu müssen zu ihrer Aufklärung und Berichtigung. Der Kölner REICHENSPERgER bestritt mit dem Erbkaisertum zugleich den Wert der öffentlichen Meinung. Ihr Gewicht gehöre zu den Argumenten, die man vorzugsweise für den preußischen Eirbkaiser anführe. „Man sagt, dieselbe habe sich auf clas entschiedenste für den Plan ausgesprochen und müsse schon für sich allein maßgebend sein." Er bezweifle das, wolle aber auch daran erinnern, wie diese sogenannte öffentliche Meinung in der dänischen Waffenstillstandssache so plötzlich zu Falle gekommen sei; erinnern wolle er an die neuliche wilde Jagd auf das Ministerium Brandenburg, erinnern, wie diese öffentliche Meinung, nachdem sie in Frankreich vor wenigen Monaten noch erst der Republik zugejauchzt, in den letzten Tagen eine Verschwörung von 6 Millionen 
Franzosen gegen CAVAIGNAC organisierte, und warum?, ,weil er, wie selbst seine Gegner zugeben, der honetteste unter den Republikanern ist". Wenn es sich wirklich begeben sollte oder könnte, daß Herrn BASSERMANNS erblicher Kaiser so aller Sympathien bar dastünde, so wurzellos in der öffentlichen Meinung wie LAMARTrNe in Frankreich, so sähe es wahrlich schlecht aus um diesen Kaiser, trotz aller Erblichkeit und äußeren Macht. In den sich anschließenden endlosen Debatten über Reichsoberhaupt und Reichsrat führte der Demokrat WILHELM ZIMMERMANN (von Stuttgart) als Ausspruch eines berühmten Staatsmannes, den er sich zu eigen machte, an: „Wenn auch die physische, die Militärmacht noch so gering wäre, die Offentliche Meinung, die eine Regierung für sich hat, wird diese kleine Militärmacht verhundertfachen." Am I. Februar aber sagte der Freiherr von VINCKE, der das absolute Veto des Oberhauptes in Verfassungsfragen verteidigte, nachdem er seine Ansicht ïber die Revolution ausgesprochen: ,und wenn die Offentliche Meinung wirklich die Macht ist, wofür wir sie halten, so wird ihre Wirksamkeit sich auch geltend machen in der Verfassung und wird Sie schützen davor, eine Revolution notwendig zu finden; und wenn Sie der Offentlichen Meinung, wie Sie es getan haben und täglich tun, auf den Thron verholfen haben in Europa, so haben wir keine Revolution zu scheuen; aber auch wahrlich nicht, daß das absolute Veto imstande sein wird, der Offentlichen Meinung, wenn sie eine wahrhafte Gewalt geworden ist, einen wirksamen Damm entgegenzusetzen, und Sie haben daher keine Ursache, gegen das absolute Veto zu stimmen“ . . . ,sollte überhaupt eine Anderung der Regierungsform in der öffentlichen Meinung notwendig erscheinen, und die ungeheure Mehrheit konsequent sich dafür aussprechen, so bin ich der Ansicht, daß die Offentliche Meinung allein hinreichende Macht haben wird, ihren Zweck zu erreichen, und daß nicht das Wort eines Fürsten ihr einen Damm wird entgegenstellen können." Der Berliner NEUWERCK bestritt am I3. Februar diese Ansicht. Die deutsche Geschichte beweise das Gegenteil. „War das etwa die moralische Macht, welche im März die Revolution hervorrief? Nein, es war eine ganz ehrliche, materielle, bewaffnete Macht. War das etwa die öffentliche Meinung, welche alle Fürsten und Regierungen mit einem Schlage nötigte, sich auf den Kopf zu stellen?" In derselben Sitzung meinte aber ein anderes Mitglied der Linken, RODINGER (von Stuttgart), in pathetischem Idealismus: „Gibt es aber ein Mittel, die öffentliche vernünftige Meinung, den öffentlichen Geist, den Volksgeist, ja man kann in gewissem Sinne wohl sagen, den Weltgeist, zuzuziehen zur Entwicklung des Menschen... gibt es ein solches Mittel, den Krieg unmöglich zu machen, und 
unmöglich zu machen die Revolution; so, denke ich, müssen wir zugreifen und dürfen nicht die Abweisung an die hinfällige Hoffnung knüpfen, daß wir auf dem bisherigen Wege auskommen können." Wie viele hinfällige Hoffnungen hat der Weltgeist versinken sehen auf unserer Erde, seit diese guten Worte gesprochen wurden! - In der Debatte über öffentliche oder geheime Wahl verteidigte RIESSER (Hamburg) am 27. Februar jene, u. a. mit den Worten, die sich gegen den Vorwurf wandten, man wolle doch in anderen Akten des Staatslebens nicht die volle Offentlichkeit: ,jede politische Handlung soll in dem Augenblicke, wo sie zur Tat wird, nach den Regierungsgrundsätzen, zu denen wir uns alle einstimmig bekennen, vor das Licht der Offentlichkeit, vor den Richterstuhl der Offentlichen Meinung treten". Er berief sich dann mehrfach auf die öffentliche Meinung in England, der das allge meine Wahlrecht nicht entspreche, in England, dessen Kraft und Heil darin liege, daß es auf dem Boden seiner Verfassung ohne gewaltsame Umwälzung die Reformen, deren es bedarf, und die sich allmählich in der öffentlichen Meinung Bahn brechen, erhalten kann. REICHENSPERGER sprach gegen das direkte Wahlrecht, das in der Regel die Offentliche Meinung nur an ihrer Oberfläche fasse, wie sich in Frankreich zeige, ,diejenigen, welche vor etwa $3 / 4$ Jahren sozusagen auf den Schultern der Urwähler unter Ovationen in die Deputiertenkammer getragen worden sind, sie müssen sich jetzt krampfhaft an ihren Stühlen festhalten, um von den Fluten der Offentlichen Meinung nicht hinweggespült zu werden" ... schließlich, ,wenn man dies stete Hin- und Herfluten der öffentlichen Meinung, die heute nach dieser, morgen nach jener Seite sich wirft, müde ist, wird der Ruf Ordnung um jeden Preis von einem Ende des Kontinents zum andern ertönen, und dann vielleicht gar der Säbel nicht bloß dem allgemeinen, sondern allem Stimmrecht überhaupt ein Ende machen." Wenn am i9. März, in der dritten Lesung der Verfassung, EISENMANN es sleider wahr « nannte, daß gar wenige Männer die Kraft haben, unberührt von jedem "Windzug " der öffentlichen Meinung der einmal gefaßten Uberzeugung treu zu bleiben, so versicherte am 20. ZITTELBahlingen, er treibe keinen "Götzendienst " mit dem, was man gewöhnlich die öffentliche Meinung zu nennen pflege; die beiden Gleichnisse vertragen sich freilich schlecht mitcinander. Am folgenden Tage erklärte RIESSER es für vollkommen richtig, „daß wir für die Durchführung unseres Beschlusses und für die Annahme der Kaiserwürde auf die Offentliche Meinung sowohl in Preußen als im übrigen Deutschland rechnen“. Weiterhin aber erklärt er: „Wenn wir von der öffentlichen Meinung reden, so meinen wir nicht die Revolution, sondern wir meinen das feste Bewußtsein, das dauernde Wollen und 
Streben eines Volkes, das sich nicht in einzelnen gewaltsamen Taten ausläßt, sondern fest und stetig dem Fortschritt der Menschheit und der Geschichte folgend, im Geiste des Volkes lebt", wozu Stimmen auf der Rechten riefen "Sehr gut *. Wenn aber am 28. März die Kaiserwahl mit 290 gegen 248 Stimmen (die sich der Wahl enthielten) geschah, so zeigte dies Ergebnis deutlich genug, daß es eine einheitliche und starke Offentliche Meinung (der vermutlich auch FRIEDRICH WILHELM nicht widerstanden hätte) über die Frage in Deutschland nicht gab - ein Jahr früher wäre sie wahrscheinlich vorhanden gewesen, aber eher im entgegengesetzten Sinne. Am 23. April sprach WELCKER für die Erhaltung der neuen Verfassung, die zu gleicher Zeit massenhaft durch Eingaben politischer Vereine gefordert wurde; er nannte sie den einzigen Faden, der aus dem Labyrinth der Gegenwart hinausführe. „Rechts und links dürfen Sie die Männer fragen: wo ist das neue Heil? Alles vereint sich in dem Gefühl: nur hier ist Heil und Rettung, weil ein anderes nicht möglich ist. Das ist die Bürgschaft der Dauer, der Kraft und des Wachstums jener öffentlichen Meinung“ ... „dazu die ganze Stärke des vaterländischen Gefühls aller würdigen Deutschen für die Einheit und Ehre des Vaterlandes, “ was der Redner mit einem glühenden Appell zum Schluß ausführte.

33. (Preußens Revolution.) Ich habe hier die bedeutendsten Aussprüche zusammengestellt, die in der Paulskirche über die öffentliche Meinung laut geworden sind; fast ohne Ausnahme wird sie darin als eine einheitliche Macht vorgestellt, als die Macht des Zeit- und Volksgeistes, deren die Nationalversammlung in ihrem gemeinsamen Streben für die Einheit und Freiheit Deutschlands, wie verschieden diese Begriffe auch gedeutet wurden, sich gewiß fühlte, wenn auch die entschieden liberalen Elemente sich am zuversichtlichsten auf sie beriefen. Minder lebhaft noch als in der deutschen, machte sich in der verhängnisvoll mit ihr konkurrierenden preußischen Nationalversammlung die öffentliche Meinung geltend, und das ist bezeichnend für den großen Unterschied zwischen beiden. Die Paulskirche wollte einen deutschen Staat schaffen, sie hatte keinen Staat hinter sich, sondern einen Bund von 2 großen, einigen mittleren und vielen kleinen Staaten; eine Bundesverfassung und eine Bundesversammlung, die von der Offentlichen Meinung längst gerichtet waren; diese hätte es begrüßt und unterstützt, wenn von Anfang an die Frankfurter Nationalversammlung als Vertretung des souveränen deutschen Volkes sich und ihre Verfassung ausdrücklich an die Stelle des bestehenden durch den Wiener Kongre $\beta$ hergestellten Monstrums von Bund gesetzt, und erklärt hätte: das deutsche Reich, das wir ins Leben rufen sollen und wollen, ist mit dem Deutschen Bunde 
unvereinbar; weil jenes leben will, muß dieser fallen. Die Nationalversammlung, die sonst in ihrer ersten Phase, getragen von der Offentlichen Meinung und einem allgemeinen Enthusiasmus, große Entschlossenheit zeigte, war doch zu einer solchen offenen Erklärung gegen das alte System unfähig; sie beriet die Verfassung noch, als es nichts mehr zu verfassen gab, Formen, denen der Inhalt fehlte. Die Offentliche Meinung Deutschlands war nicht nachhaltig und stark genug, den Verfall ihres Werkes, der deutschen Revolution, aufzuhalten. In Preußen war die öffentliche Meinung von vornherein zweideutig und mit innerem Widerspruch behaftet; sie wollte zugleich die deutsche Einheit und den preuBischen Staat; FRIEDRICH WILHELM der Vierte meinte, ihr gerecht zu werden, wenn er am 2I. März in dem Aufruf "an mein Volk und an die deutsche Nation «die salten deutschen Farben annahm " und »das Aufgehen Preußens in Deutschland "verhieB; und er wäre ihr gerecht geworden, wenn auch nur für die Dauer jener Tage, wenn seinen Worten sogleich Taten gefolgt wären. Statt dessen versuchte er, durch Taten wie den Kaiserritt und dazu gesprochene Worte sich ferner, an die Spitze derselben Freiheitsbewegung zu stellen, deren größtes Hindernis seine Regierung bis dahin gewesen war" (AD. STAHR). Darïber erhob sich eine so starke Entrüstung im ganzen übrigen Deutschland, daß mit seinem König auch das preußische Volk sich gekränkt fühlte. Der Hallische Löwe, H. LEO, der im Sinne der Reaktion die Signatura Temporis schrieb, sagt darüber S. 39: „Ein sehr wohltätiger Rückschlag war gewonnen auf die öffentliche Meinung in Preußen selbst ... gerade infolge dieser Vorgänge schlug die patriotische Empfindung Preußens wieder ihre ersten jungen Wurzeln, nachdem die alten in der wilden Glut der letzten revolutionären Aktionen vor 2 Tagen verdorrt schienen" (STAHR, S. 137). Zunächst wandte sich die Offentliche Meinung in Preußen um so entschiedener der "Freiheit"zu. „Das stolze Wort, womit der Minister Hansemann einer Deputation der Kölner Radikalen in den ersten Tagen seines Ministeriums erklärte: „die Bildung des Ministeriums sei an und für sich die beste Garantie dafür, da $B$ alles vernünftigerweise $\mathrm{zu}$ Verlangende gewährt werden würde", fand lauten Widerhall in der öffentlichen Meinung (STAHR I8I). STAHr, dem wir eine lebendige und lichtvolle Schilderung der preußischen Revolution, unmittelbar unter ihren Eindrücken entstanden, verdanken, macht darauf aufmerksam (I87), daß ein merkwürdiger Umschwung der öffentlichen Meinung in bezug auf die Berufung des Vereinigten Landtages zutage trat: bis zum Morgen des 18 . März rief alle Welt in und außer Preußen nach schleuniger Versammlung dieses einzigen, wenn auch noch so unvollkommenen, 
bestehenden Organes der Nationalvertretung ... noch am Mittage dieses kritischen Tages wurde die Verkündung der beschleunigten Einberufung ... mit Jubel begrüßt. „Und noch waren kaum die äußerlichen Spuren des unmittelbar darauf folgenden Revolutionskampfes beseitigt, da erhoben sich schon von allen Seiten dringend und laut die Stimmen des Protestes gegen die eben noch ersehnte Maßregel.“ „Die Frankfurter Wahlen traten gegen die preußischen in der öffentlichen Meinung des Landes auf eine bedauernswerte Weise in den Hintergrund" (2I9). In Sachen der Rückberufung des Prinzen von Preußen siegte die Regierung. „Aber dieser Sieg war eine Niederlage in der öffentlichen Meinung" (23I). Als das Ministerium HANSEMANN-AUERSWALD als Ministerium der Tat die Revolution förmlich anerkannte, hieß es allgemein, dies Ministerium ,sei die äußerste Konzession, welche die Krone an die öffentliche Meinung zu machen gedenke" (329). Bald regte sich mächtig: die Reaktion. Es bildete sich eine Liga der Aristokratie. Die Offentliche Meinung unterschätzte offenbar deren $\mathrm{Kraft}$, wenn sie dieselbe für unschädlich und ohnmächtig hielt (40I). Die Gegenrevolution verfügte außerdem auch über das Heer und die Bureaukratie. „Aber noch wagte man nicht, diese Waffen zu gebrauchen. Denn noch stand die Offentliche Meinung im Bunde mit der Märzrevolution ... es war der Verblendung der ultrademokratischen Partei vorbehalten, die öffentliche Meinung in ihren Sympathien für die Revolution zu erschüttern ..." (425f.). Bald ,hatten die offenbaren Versuche, republikanisch-sozialistische Theorien zur Geltung zu bringen, die öffentliche Meinung alarmiert ..." (437). Die Ermattung und Wandlung der deutschen öffentlichen Meinung (494), die auch die Idee deutscher Einheit verblassen ließ, fiel nicht zufällig mit ihrer Entkräftung in Preußen zusammen. Als das Ministerium BRANDENBURG gebildet war, dessen Seele der Freiherr voN MANTEUfFEL war, da hielt jede Partei es rätlicher, die andere zum Angriffe $\mathrm{zu}$ provozieren, denn jede von beiden fürchtete, da $B$ sich die Offentliche Meinung gegen den Angreifer etrklären würde (647).

Der Ministerpräsident CAMPhaUSEN hatte in der I4. Sitzung der preußischen konstituierenden Versammlung, am I4. Juni I848, ausgesprochen, es sei, als er berufen wurde, das Land wie nach einem eben überstandenen Sturme, von einem wogenden Wellenschlag bewegt gewesen. Zwei Wege habe es gegeben, um es $\mathrm{zu}$ beruhigen. Der eine: sofort alle Konsequenzen des eingetretenen Zustandes mit Schnelligkeit und Energie ohne Scheu vor willkürlichem Eingreifen zu ziehen, gewissermaßen als eine revolutionäre Regierung aufzutreten und dem Volke einerseits den unverkümmerten Genuß der ihm zugesagten Rechte und Freiheiten zu sichern, um sich dadurch 
andererseits seine Zustimmung zu den kräftigsten Maßregeln für Ordnung und Ruhe gewiß zu machen. Diesen Weg habe das Ministerium, auch wenn es ihn hätte einschlagen können, unter keinen Umständen einschlagen wollen. „Den zweiten Weg, den des gesetzlichen Übergangs, sind wir gegangen, und er war nicht leicht. Es wurde uns dadurch die Aufgabe gestellt, unsere Stärke, unsere exekutive Gewalt beinahe ausschließlich in der öffentlichen Meinung zu suchen; wir mußten mit der Offentlichen Meinung regieren, die zu jeder Zeit, an jedem Orte und im voraus zu erkennen, ungemein schwierig ist, die nicht selten nach vollendeten Tatsachen eine andere zu sein scheint als vorher." In diesen Worten lag eingeschlossen, daß die Methoden einer revolutionären Regierung die öffentliche Meinung vor den Kopf gestoßen hätten. Wenn dies richtig, so folgt daraus doch nicht, daß sie unzweckmäßig gewesen wären, daß der Beweis ihrer Zweckmäßigkeit nicht auch die Offentliche Meinung überzeugt und mit sich fortgerissen hätte. Wenige Tage nach jener Rede hatte HaNSEManN aufgehört, an der Spitze zu stehen. Auch unter seinem Nachfolger AUERswald sprach - am 4. Juli - der Minister des Inneren KüHLWETTER, über die Frage des Reorganisation Posens sich dahin aus, die Regierung werde mit Dank jede Aufklärung entgegennehmen, ,namentlich solche, die nicht von Behörden herkommt, sondern aus der öffentlichen, auf Vernunft und Kenntnis der Sache gegründeten Meinung hergenommen wird, und diese öffentliche Meinung kann wohl nicht besser hergestellt werden als durch die Vertreter, die aus dem Vertrauen des Volkes hervorgegangen sind, um seine Interessen hier wahrzunehmen." Beinahe schon ihren letzten Widerhall fand die revolutionär gestimmte Offentliche Meinung jener Tage in den Oktober-Verhandlungen über Abschaffung des Adels und der Orden und Ehrenzeichen. In dieser zweiten Frage sprach der nationalökonomische Professor BAumstark. Er stellte in Frage, ob die ,sittliche Kraft unserer Zeit" in Beziehung auf das Ordenswesen erwiesen sei. „Lassen Sie die sittliche Kraft der Gegenwart uns nicht an solchen Dingen erproben, woran sich ihre Schwäche zeigt. Hätten wir nicht einen besseren Maßstab als diesen, so stünde es schlecht. Die öffentliche Meinung hat indessen über den Ordensunfug längst entschieden, und zwar in solcher Weise, daß nach meiner Ansicht ein Ausspruch in der Staatsverfassung über den Ordenskram nicht nötig ist. Das Ubel wird durch die Zeit selbst geheilt werden, die es verachtete." Die MANTEUFFer und General WRANGel standen schon vor der Tür. Die 98. Sitzung der Nationalversammlung fand (am 27. November 1848 ) in Brandenburg statt. Darin leitete Dr. DANE ein Schreiben von 13 liberalen Abgeordneten, die an der Sitzung teilnahmen, 
mit der persönlichen Erklärung eines gedämpften Protestes ein, worin er sagte: „Wir haben im Vertrauen auf die Gerechtigkeit unserer Sache das Urteil der öffentlichen Meinung anheimstellen wollen."

34. (Die Reaktion, BISMARCKS Kampf gegen die Offentliche Meinung.) Die Offentliche Meinung hatte sich um diese Zeit wohl noch nicht völlig von der Revolution abgewandt. Es geschah erst im Laufe des Jahres I849, als auch die Frankfurter Versammlung immer mehr sich als ohnmächtig erwies; insbesondere dürfte das Fehlschlagen der Kaiserhoffnungen dazu beigetragen haben. Am 30. Mai dieses Jahres erließ König FrIEDRICH WILHELM die Verordnung über das Wahlrecht in 3 Klassen auf Grund des Art. r05, der unter dem 5. Dezember I848 oktroyierten Verfassung, obschon dieser Artikel auch nach dem Urteil konservativer Juristen dafür keine genügende Rechtsbasis gewährte. Am I2. August I849 unterbreitete das Ministerium der auf Grund dieser Verordnung gewählten Kammer eine längere Denkschrift zu deren Rechtfertigung („Der Offentlichkeit glaubte man eine, wenn nicht bessere, so doch wenigstens ausführlichere Begründung schuldig zu sein" als die im Immediatbericht an den König enthaltene: H. v. GERLACH, „Die Geschichte des preußischen Wahlrechts" S. I2). Vom öffentlichen Wahlverfahren heißt es darin (A1. 9): "Gerade bei diesem Verfahren werden Wahlumtriebe, Bestechungen und sonstige Unlauterkeiten am wenigsten verborgen bleiben. Die öffentliche Meinung wird sie richten und die Prüfung der Wahlverhandlungen ihre Wirkung vereiteln." Also auch damals noch, auch von der ausgesprochen reaktionären Regierung wurde der Offentlichen Meinung eine Huldigung zuteil, wenn auch nur in einer Sache von minderer politischer Bedeutung. Wie die Regierung um diese Zeit sonst von der Offentlichen Meinung dachte, das hatte in derselben II. Kammer schon am 2I. April I849 der Ministerpräsident Graf BRANDENBURG durch jene Rede verraten, die in dem berufenen dreimaligen "Niemals! " endete, womit der Preuße die Reichsverfassung ablehnte; er sagte darin: „Es ist hier vielfach die Rede von der öffentlichen Meinung gewesen (u. a. hatte ein Abg. LöHER darauf hingewiesen, es gebe auch im Auslande die gefürchteten Kommunistenvereine, ,die Revolutionäre haben sich sogar durch das ganze Land nach Art von geheimen Orden organisiert; dennoch haben sie wenig Einfluß: die Offentliche Meinung hält diesen in Schach')... Ich erkenne diese Macht an in vollem Maße ... ich erkenne sie aber an in der Art, wie das Schiffsvolk die Macht der Elemente auf hoher See anerkennt, indem es sich nicht den Winden und den Strömungen hingibt und auf diese Weise herrenlos auf der See treibt - denn auf diese Weise wird das Schiff nie den rettenden 
Port erreichen" usw. Auf derbere Art sprach sich wenige Monate später, am 6. September, der Abg. von BISMARCK-SchÖNHAUSEN aus, als er seine Zustimmung zum sog. Drei-Königs-Vertrage mit dem Wunsche begleitete, den er bei der Gelegenheit nicht unterdrücken könne, „da $\mathrm{B}$ es das letztemal sein möge, daß die Errungenschaften des preußischen Schwertes mit freigebiger Hand weggegeben werden, um die nimmersatten Anforderungen eines Phanto ms zu befriedigen, welches unter dem fingierten Namen von Zeitgeist oder öffentlicher Meinung die Vernunft der Fürsten und Völker mit seinem Geschrei betäubt, bis jeder sich vor dem Schatten des anderen fürchtet und alle vergessen, daß unter der Löwenhaut des Gespenstes ein Wesen steckt von zwar lärmender, aber wenig furchtbarer Natur." Wenn BISMARCK als konservativer Landedelmann, der er im Grunde seines Herzens immer blieb, auch in seiner späteren großen Laufbahn die öffentliche Meinung bald $\mathrm{HaB}$, bald Verachtung fühlen ließ, so wußte er doch als Staatsmann ihre Macht zu würdigen, ihre Bedeutung zu schätzen. Hier mögen zuvörderst für das eine wie das andere Belege aus den "Gedanken und Erinnerungen" gegeben werden. Einmal spricht er (I, IIO) von der a ngeblichen öffentlichen Meinung des englischen Volkes, von ihr im Bunde bald mit dem Prinzen ALBERT, bald mit Lord PaLMERSTON; von diesen Hilfen sei - um das Jahr I86odurch die "Wochenblattspartei « und den BethmanN-HolLwEGschen Kreis die Gestaltung der deutschen Zustände mit Sicherheit vorausgesagt (soll heißen: als von diesen Hilfen zu erwarten), die später auf den Schlachtfeldern erkämpft worden sei. Ebenso spricht er (im Anfang des 6. Kapitels I, I22) mit Ironie von dem Beifall der öffentlichen Meinung von Paris und London: die geistig hervorragende Residenz Weimar sei nicht frei von dem Alp gewesen, der bis zur Gegenwart auf unserem Nationalgefühl gelastet habe: daß ein Franzose und vollends ein Engländer durch seine Nationalität und Geburt ein vornehmeres Wesen sei als der Deutsche, und da $B$ jener Beifall ein authentischeres Zeugnis des eigenen Wertes bilde als unser eigenes BewuBtsein. Diese Kritik gilt der Prinzessin Augusta, deren "persönliche Politik «, nachdem sie Königin und Kaiserin geworden, von dem Staatsmann als eine Hemmung seiner Macht und der Staatsraison empfunden und bekämpft wurde. In der Konfliktszeit hatte BiSMARCK unablässig wie gegen höfische und parlamentarische Feindseligkeiten, so gegen die Offentliche Meinung sich zu wehren und schien oft ihrer zu spotten ${ }^{1}$ ). Sehr großes Aufsehen machte es, als am 5. Juni 1863

1) Im November I 864 schrieb A. v. Gurscirmid an H. v. TREITscirke von BISMARCK: . Wenn er sich nur abgewöhnen wollte, die öffentliche Meinung unnötiger Weise zu brüskieren!" (,Von Kieler Professoren", herausgeg. v. Dr. M. I,IRPMANN, S. 343.) 
der damalige Kronprinz in Danzig erklärte, er habe von den Anordnungen, die eben zur Beschränkung der Presse erlassen waren, nichts gewußt und habe keinen Teil an den Ratschlägen gehabt, die dazu führten. Der König war empört. Der Kronprinz schrieb am 3. September an BisMARCK, der König wisse nunmehr, daß er, der Prinz, der entschiedene Gegner des Ministeriums sei. Er reichte eine Denkschrift ein, um sein Verhalten zu begründen und zu rechtfertigen. BISMARCK teilt die Randbemerkungen mit, die er dazu gemacht habe. In einer von diesen heißt es, die Stellung, welche S. Kgl. H. gege n die Krone genommen habe, sei im Lande bekannt genug und werde von jedem Hausvater im Lande, welcher Partei er auch angehören möge, gemißbilligt als ein Lossagen von der väterlichen Autorität, deren Verkennung das Gefühl und das Herkommen verletze. „Sr. Kg1. H. konnte nicht schwerer in der öffentlichen Meinung geschadet werden als durch Publikation dieser mémoires" (I, 325). BISMARCK irrte sich ohne Zweifel, wenn er dies wirklich glaubte, was man aber mit Grund bezweifeln mag. Der gebildete Hausvater hat es damals so wenig wie jetzt unschicklich und unehrerbietig gefunden, da $B$ ein 32 jähriger Sohn eine von der des Vaters abweichende politische Ansicht hegt und geltend macht; um so weniger wenn der Hausvater die Ansicht des Sohnes teilt, wie es in den Schichten, die vorzugsweise die Offentliche Meinung bilden, damals wirklich der Fall war. In seiner auswärtigen Politik dachte der preußische Ministerpräsident damals (I863) noch an eine dualistische Spitze Deutschlands; unter ihr, meinte er in den »G. u. E.«, würde unsere innere verfassungsmäßige Entwicklung von der Versumpfung in bundestägiger Reaktion, und von der einseitigen Förderung absolutistischer Zwecke in den einzelnen Staaten nicht notwendig bedroht worden sein; die Eifersucht der beiden Großstaaten wäre der Schutz der Verfassungen gewesen. „Preußen, Osterreich und die Mittelstaaten würden bei dualistischer Spitze auf Wettbewerb um die öffentliche Meinung in der Gesamtnation wie in den einzelnen Staaten angewiesen geblieben sein, und die daraus entspringenden Friktionen würden unser öffentliches Leben vor ähnlichen Erstarrungen bewahrt haben, wie sie auf die Zeiten der Mainzer Untersuchungskommission folgten" (I, 333). Und weiterhin: (Österreich und Preußen, sobald sie einig, leichtfertig anzugreifen, war keine der anderen Mächte geneigt). „Solange Preußen allein, wenn auch in Verbindung mit dem stärksten. Ausdruck der öffentlichen Meinung des deutschen Volkes, einschließlich der Mittelstaaten, die Sache in der Hand hatte, kam sie nicht vorwärts und führte zu Abschlüssen, wie dem Waffenstillstand von Malmö und der Olmützer Konvention." Man habe aber in Wien Preußen unrichtig eingeschätzt. 
liit dem Wechsel im Charakter der obersten Leitung (durch die Thronfolge König WILHELMS) habe man $\mathrm{zu}$ wenig gerechnet , und $\mathrm{zu}$ viel mit dem Einfluß, den man durch die a ngebliche öffentliche Meinung, wie sie durch Preß-Agenten und Subsidien erzeugt wurde, auf Berliner Entschließungen früher hatte ausüben können, und durch Vermittlung fürstlicher Verwandten und Korrespondenzen des königlichen Hauses auch ferner auszuiuben bereit und imstande war" (I, 336). In dem Gespräch, das am 22. August 1864 der König und BISMarck mit Franz JOSEPH und seinem Minister RECHBERG führten, kam der österreichische Kaiser auf die Schwierigkeit zu sprechen, der öffentlichen Meinung in Osterreich gegenüber ganz ohne Äquivalent aus der gegenwärtigen Situation hinauszugehen, wenn Preußen einen so großen Gewinn wie Schleswig-Holstein mache (I, 345). BISMARCK hatte seinen Vorsatz, diese Herzogtümer in Preußen einzuverleiben, schon früher ziemlich unverhohlen ausgesprochen. An seinen Nachfolger als Botschafter in Paris, den Grafen RoBERT V. D. Golitz, hatte er zu Weihnachten I863 u. a. geschrieben: ,Sie glauben, da $B$ in der odeutschen öffentlichen Meinung «ammern, Zeitungen etc. irgendetwas steckt, was uns in einer Unions- oder Hegemoniepolitik stützen und helfen könnte. Ich halte das für einen radikalen Irrtum, für ein Phantasiegebilde. Unsere Stärkung kaun nicht aus Kammern- und Preßpolitik, sondern nur aus waffenmäßiger Großmachtpolitik hervorgehen..." (II, 4). Und zurückblickend sagt er: „Als die Situation, welche ich absolut glaubte, vermeiden $\mathrm{zu}$ müssen, betrachtete ich diejenige, welche in der öffentlichen Meinung von unseren Gegnern als Programm aufgestellt war, d. h. den Kampf und Krieg Preußens für die Errichtung eines neuen Großherzogtums, durchzufechten an der Spitze der Zeitungen, der Vereine, der Freischaren und der Bundesstaaten außer Osterreich, und ohne die Sicherheit, daß die Bundesregierungen die Sache auf jede Gefahr hin durchführen würden. Dabei hatte die in dieser Richtung entwickelte öffentliche Meinung, auch der Präsident LUDWIG VON GERIAACH, ein kindliches Vertrauen zu dem Beistande, den England den isolierten Preußen leisten würde ... Ich habe nie in der Überzeugung geschwankt, daß Preußen, gestützt nur auf die Waffen und Genossen von I848, öffentliche Meinung, Landtage, Vereine, Freischaren und die kleinen Kontingente in ihrer damaligen Verfassung, sich auf ein hoffnungsloses Beginnen eingelassen und unter den großen Mächten nur Feinde gefunden hätte, auch in Lingland" (II, 9-Io). Beim Könige sei für seinen Standpunkt, daB er okein Recht auf Holstein « habe, die Vergegenwärtigung der Mißbilligung wirksam gewesen, die er, wenn er den Augustenburger aufgab, bei seiner Gemahlin, bei dem kronprinzlichen 
Paare, bei verschiedenen Dynastien und bei denen zu erwarten hatte, welche damals in seiner Auffassung die Offentliche Meinung Deutschlands bildeten (I2). „Die öffentliche Meinung war in den gebildeten Mittelständen Deutschlands ohne $Z$ weifel augustenburgisch, in derselben Urteilslosigkeit, welche sich frïher den Polonismus.und später die künstliche Begeisterung für die battenbergische Bulgarei als deutsches Nationalinteresse unterschieben lieB. Die Mache der Presse war in diesen beiden etwas analogen Lagen betrübend erfolgreich und die öffentliche Dummheit für ihre Wirkung so empfänglich wie immer" (das.). Der berühmte Staatsmann verrät hier selber etwas von jener Urteilsschwäche, die bei ihm aus der Mißachtung sittlicher Ideen entsprang. Er sah den ungeheuren Unterschied nicht, da $B$ in der schleswig-holsteinischen Frage die Überzeugung zugrunde lag, $\mathrm{da} B$ ein gutes monarchisches Recht mit der Forderung des Nationalgefühls zusammentraf, und daß eben die Gerechtigkeit die Trennung Schleswig-Holsteins von Dänemark innerlich notwendig mache. Seine Geringschätzung solcher Erwägungen und Beweggründe kontrastiert seltsam mit seiner oft wiederholten Versicherung, da $B$ die Liebe und Treue $\mathrm{zu}$ seinem hohenzollernschen Herrscherhause für seine Politik das Leitmotiv gewesen sei. „Mein Respekt vor der sog. öffentlichen Meinung“ (so fährt er a. a. O. fort), „das heißt, vor dem Lärm der Redner und den Zeitungen, war niemals groß gewesen, wurde aber in betreff der auswärtigen Politik in den beiden oben verglichenen Fällen (es war von 3 Fällen die Rede, gemeint ist wohl die Augustenburgerei und die Polenbegeisterung) noch erheblich herabgedrückt" (das.). Am I. Juni I865 hielt BISMARCK eine Rede für den außerordentlichen Geldbedarf der - preußischen! - Marine; einige Stellen daraus teilt er in den G. u. E. II, S. I8ff. mit. „Es hat wohl keine Frage die Offentliche Meinung in Deutschland in den letzten 20 Jahren so einstimmig interessiert, wie gerade die Flottenfrage. Wir haben gesehen, daß die Vereine, die Presse, die Landtage ihren Sympathien Ausdruck gaben, diese Sympathien haben sich in Sammlung von verhältnismäßig recht bedeutenden Beträgen betätigt." Da es besonders die liberalen Parteien gewesen seien, die dabei tätig waren, so habe er geglaubt, mit der Vorlage diesen eine rechte Freude zu machen. Daß die Vorlage abgelehnt wurde, erfüllte ihn noch beim Rückblick mit Zorn: Parteihaß, Unehrlichkeit, Vaterlandslosigkeit macht er aus diesem geringen Anla $B$ den Parlamentariern zum Vorwurf. Indessen war damals nicht daran zu denken, daß die preußische Marine gegen die französische etwas bedeuten könne, und der Krieg gegen Frankreich lag in der Iuft; ihm galten nach Begrïndung des Norddeutschen Bundes alle diplomatischen Sorgen 
und Erwägungen. „In der öffentlichen Meinung Italiens konnte ich auf sicheren Anhalt nicht rechnen, nach der Haltung der italienischen Politik während des Krieges, nicht bloß auf Grund der persönlichen Freundschaft VICTOR EMANUELs für LOUIS NAPOLEON, sondern auch nach Maßgabe der durch Garibaldi im Namen der öffentlichen Meinung Italiens bekundeten Parteinahme. Der Bund Italiens mit Frankreich und Osterreich lag nicht bloß nach meiner Befürchtung, sondern nach der öffentlichen Meinung in Europa nicht außerhalb der Wahrscheinlichkeit" (II, 53f.). Daß BISMARCK den Wert und die Macht der Offentlichen Meinung auch für sich und sein Wirken zu würdigen wußte, bewies seine Bemühung um "Indemnität «, wofür König WILHELM kein Verständnis hatte, dieser sah darin ein Eingeständnis begangenen Unrechts. Der Umschlag der Offentlichen Meinung, der sich in Deutschland nach dem Ausgange des deutschen Bürgerkrieges vollzog, ist in der Tat eines der auffallendsten Beispiele der Wirkungen, die der Erfolg auf die Offentliche Meinung ausübt. BISMARCK ist bekanntlich dieses durch 1870 und die Begründung des neuen Reiches gesteigerten Erfolges niemals völlig froh geworden, er wußte nicht, mit denen, die ihm wahrhaft und als gläubige Jünger anhingen - das waren aber, zumal nach I87I die Wortführer der Offentlichen Meinung -, sich in ein dauerndes freundschaftliches Verhältnis zu setzen, vielmehr machte er aus seinen Freunden $Z$ weifler oder Gegner, aus seinen Gegnern nicht Freunde, aber laue Gefolgsmänner; ernster als sie es wohl verdienten, nahm er die Widerstände bei Hofe, und diesen gegenüber brauchte er auch die Offentliche Meinung. So schrieb er am 8. Juni 1877 an den Geheimrat TIEDEMANN, als der König den ehemaligen Unterstaatssekretär vON GRUNER, einen Günstling der Königin, zum Wirklichen Geheimen Rat ohne Gegenzeichnung ernannt hatte, u. a.: „Die öffentliche Meinung und der Landtag würden kaum annehmen, daß das Staatsministerium diese Auszeichnung seines notorischen Gegners gewünscht habe" usw. (II, 199). Als er vor der Wahl stand zwischen Osterreich-Ungarn und RuBland (1879) hielt BISMARCK die Verbindung mit Rußland zunächst noch für materiell stärker. "Sie hatte mir früher auch für sicherer gegolten, weil ich die traditionelle dynastische Freundschaft, die Gemeinsamkeit des monarchischen Erhaltungstriebes und die Abwesenheit aller eingeborenen Gegensätze in der Politik für sicherer hielt als die wandelbaren Eindrücke der öffentlichen Meinung der ungarischen, slavischen und katholischen Bevölkerung der habsburgischen Monarchie" (II, 234). Dennoch entschied er sich für Osterreich und legte großen Wert darauf, daß dies Bündnis zzicmlich bei allen Parteien populär « war (236). „,Wir müssen und können der 
österreichisch-ungarischen Monarchie das Bündnis ehrlich halten; es entspricht unseren Interessen, den historischen Traditionen Deutschlands und der öffentlichen Meinung unseres. Volkes" (257). BISMARCK wies auch mit großem Nachdruck auf diese hin in seinem Schreiben an Lord SALISBURy vom 22. November I887. „Es wäre widersinnig, anzunehmen, heißt es darin, daß die Regierung einer Nation von 50 Millionen Einwohnern - bei dem Maße von Zivilisation und der Macht der Offentlichen Meinung, wie sie in Deutschland vorhanden ist - diesem Lande die Leiden, welche ein jeder große, auch ein siegreicher Krieg im Gefolge hat, auferlegen würde, ohne der Nation genügende schwerwiegende und schlagende Beweise zu geben, um die Offentliche Meinung von der Notwendigkeit des Krieges zu überzeugen." So ließ er auch den 2. WILHELM in dessen erster Thronrede am 25. Juni I888 zum Deutschen Reichstage sagen, er halte an dem Bündnis in deutscher Treue fest, ,nicht bloß, weil es geschlossen ist, sondern weil ich in diesem defensiven Bunde eine Grundlage des europäischen Gleichgewichts erblicke, sowie ein Vermächtnis der deutschen Geschichte, dessen Inhalt heute von der gesamten Offentlichen Meinung des gesamten deutschen Volkes getragen wird und dem herkömmlichen europäischen Völkerrecht entspricht, wie es bis I866 in unbestrittener Geltung war".

35. (Die Öffentliche Meinung unter WILHELM II.) In dem Kampfe, der dann zwischen dem alten Reichskanzler und dem jungen Kaiser sich entspann, hatte jener die Offentliche Meinung auf seiner Seite so darf man sagen, obwohl in einem solchen Falle niemals von einer einstimmigen oder auch nur von einer überwältigend starken Übereinstimmung die Rede sein kann. Mehr Autorität als Majorität fällt da ins Gewicht. BISMARCK verstand es dann bekanntlich, diese Gunst zu hegen und durch unablässige heftige Kritik der Politik seines Nachfolgers warm $z u$ erhalten. Treffend sagt Hammans, der damals Preßreferent im Auswärtigen Amt wurde: „,Da die Wirkungen auf die öffentliche Meinung, die von selbst und ohne besondere Nachhilfe von der Macht der Persönlichkeit BIsMarcks ausstrahlten, weggefallen waren, mußte nun die Tagespresse sorgfältiger beobachtet und die Vertretung nationaler und amtlicher Interessen in ihr planmäßig gepflegt werden ..." Die Offentliche Meinung umzustimmen, gelang natürlich nicht; eine gewisse Neigung dazu brachte für kurze Zeit des Freiherm von Marschali, "Flucht in die Offentlichkeit " hervor: Der Staatssckretär des Auswärtigen Amtes mußte fliehen vor der politischen Polizei, und diese Institution des preußischen Staates hatte die BISMARCKsche Fronde hinter sich. Das Unglück des Deutschen Reiches, inmitten seiner glänzenden wirtschaftlichen 
Entwicklung, ging seinen verhängnisschweren Weg. Die Weltpolitik, die BISMARCK nur zögernd sich hatte regen lassen, entfaltete ihre Schwingen. Sie hatte mit der Begeisterung für eine große Flotte, mit der Uberzeugung, daß Kolonien schlechthin notwendig seien, die Offentliche Meinung auf ihrer Seite. Der Kaiser selbst wurde ihr beredter Anwalt, ihr gewandter Agitator. So weit er in seinen Reden einer gemäßigten Ausdrucksweise beflissen war, konnte er eben dadurch die Offentliche Meinung mit sich versöhnen. Sie mit sich versöhnen hieß in diesem Falle, sie an sich fesseln. Er machte sich zum Vorkämpfer und Herold der Offentlichen Meinung. Die Offentliche Meinung war auch für ein festes und entschiedenes Auftreten dem Auslande gegenüber; weil es so viel billiger war, glaubte sie dadurch noch mehr als durch gesteigerte Rüstungen den Frieden zu sichern. Sie verkannte die ungeheuren Gefahren der Einkreisung ebenso wie sie die Unmöglichkeit einsah, eine Kriegsflotte $z u$ bauen, die der englischen wirklich ebenbürtig gewesen wäre. Sie leistete den Staatsmännern, die, in berechtigtem Stolz auf die deutsche Leistungsfähigkeit und getragen von mächtigen Interessenkörpern, die politische Notwendigkeit der Welt-, Kolonial- und Flottenpolitik vertraten, keinen Widerstand, sondern lieh ihnen Unterstützung, die von patriotischen Hochgefühlen geheischt wurde. Freilich verstanden diese Staatsmänner auch, die Offentliche Meinung für ihre Gedanken und Pläne zu gewinnen. Die Begründung und Ausbreitung des "Flottenvereins «, den zu fördern bald ein wohlfeiles Mittel war, den Ruf einsichtiger und hoher nationaler Gesinnung, also auch Belohnungen dafür, zu erwerben, war ein ebenso wirksames Mittel, wie einst die Bildung der Anti-Corn-Lar-League für ihre Zwecke gewesen war. So hat der Admiral Tirpitz, wie H. DEI.BRǗck (,,BISMARCks Erbe“ S. 200) sich ausdrückt, nach langer, ebenso kunstvoller wie erfolgreicher Bearbeitung der Offentlichen Meinung das Werk hochgebracht. Mit diesem Werke stieg die Offentliche Meinung Deutschlands in jene Höhe, in der sie auch während des furchtbaren Weltkrieges sich zu halten vermochte, aus der nur eine noch schrecklichere Katastrophe sie herabgestürzt hat. Wir erinnern uns des jüngst (aus dem dritten Pande G. u. F..) bekannt gewordenen Bismarck-Wortes (s. ob. S. 165), $\mathrm{da} B$ die Achivi qui plectuntur nicht immer die unmittelbaren Zeitgenossen der fehlerhaften Handlingen sind. - Wir lernen auch aus dem mit so vieler Spannung erwarteten Bande, daB WIIHFLM II. schon als Prinz mit der Offentlichen Meinung zu rechnen wuBte: in seinem Schreiben, das ihn wegen der WALDERSFi-Versammlung rechtfertigen wollte, heiBt es, er habe den Hofprediger STÖCKER trotz seiner anerkennenswerten Leistungen für Monarchie und Christentum 
"gerade wegen der öffentlichen Meinung " in der von ihm beabsichtigten Missionsvereinigung zurückgestellt (G. u. E. III, S. IO). Gleichwohl ermahnt ihn BISMARCK - in seiner ziemlich gestrengen Antwort - um im Regieren die nötige freie Hand zu haben (es gäbe Zeiten des Liberalismus und Zeiten der Reaktion, auch der Gewaltherrschaft), müsse verhütet werden, daß der Prinz ,schon als Thronfolger von der öffentlichen Meinung zu einer Parteirichtung gerechnet werde; das sichere Mißlingen ihrer Unternehmungen könne von Vereinsmitgliedern um so leichter getragen werden, da jeder nachher den anderen anklage; einen Thronfolger als Protektor aber treffe es schwerer in der öffentlichen Meinung" (S. I9, 2I). Nach diesen Außerungen scheint dem berühmten Staatsmann die Offentliche Meinung von entscheidender Bedeutung; andererseits rügt er es, daß der Großherzog von Baden in dem Herkommen aufgewachsen sei, daß das Streben nach Popularität und das "Rechnung tragen * jeder Regung der öffentlichen Meinung gegenüber das Fundament der modernen Regierungskunst sei (S. 30). Auf Lours PHILIPPE als Vorbild konstitutioneller Monarchen gehe diese Denkungsart zurïck. Ihn selber verläßt jedoch die Rücksicht auf jene verhängnisvolle Macht keineswegs. Auch der letzte Satz im Entwurf seines Abschiedsgesuches lautet: (er würde es schon vor Jahr und Tag dem Kaiser unterbreitet haben, wenn er nicht den Eindruck gehabt hätte, daß es S. M. erwünscht wäre, die Erfahrungen und Fähigkeiten eines treuen Dieners seiner Vorfahren $z u$ benützen) „Nachdem ich sicher bin, daß Eure Majestät derselben nicht bedürfen, darf ich aus dem öffentlichen Leben zurücktreten, ohne zu befürchten, daß mein Entschluß von der öffentlichen Meinung als unzeitig verurteilt werde" (S. IOO). 
Drittes Buch

Besondere Fälle der Öffentlichen Meinung 

IX. Kapitel.

\section{Die Öffentliche Meinung und die soziale Frage.}

\section{Erster Abschnitt. Das allgemeine Verhältnis.}

I. (Grundlagen.) Die soziale Frage ist, ihrem Kerne nach, eine Rechtsfrage, die das Verhältnis zwischen öffentlichem Recht und Privatrecht betrifft. In dem Mittelpunkt steht die Frage des Privateigentums, seines Inhaltes, seiner Ausdehnung oder Beschränkung. Religion - als ihr historischer Typus wird hier die der römischkatholischen Kirche betrachtet - ist keineswegs für unbedingtes und schrankenloses Privateigentum. Ihre Lehren knüpfen zunächst an die Tatsachen des Bodeneigentums an, wo die Rechte der Gemeinde, der Sippe, der Kirche denen des Einzelnen vorausgehen und sie bedingen. Sie behaupten die Rechtspflicht des Almosens und oft den moralischen Vorzug der Armut. Ebenso verlangen sie nicht unbedingte persönliche Freiheit, sondern, ohne gerade völlige Knechtschaft gutzuheißen, lassen sie den Einzelmenschen durch seinen angeborenen oder erworbenen Stand bedingt sein und "heiligen « diesen Stand als Stück der überlieferten und von Gott gesetzten Ordnung, als deren Wesen immer Gemeinschaft, in ihren Ausprägungen als patriarchalisch-herrschaftliche oder brüderlich genossenschaftliche Gliederung, erkannt wird. So ist Religion untrennbar verbunden mit der "Patrimonial-Feudal-Innungszeit" (nach SchafFles Ausdruck) und ist beflissen, diese zu verteidigen und $\mathrm{zu}$ erhalten. Ihr steht mit Verkündung der "Gesellschaft «, in der sich die freien Eigentümer begegnen und zusammenfinden, die Offentliche Meinung gegenüber. „Auf den höchsten Kulturstufen setzt endlich die Macht der "öffentlichen Meinung ", von den Ideen allgemeiner Menschenliebe und demokratischer Gleichheit beherrscht, die völlige Aufhebung aller unkündbaren oder gar angeborenen Knechtschaftsverhältnisse durch" (ROSChER). In gleicher Weise setzt sie das freie und unbeschränkte Eigentum durch, es scheint ihr allein natürlich und dem Naturrecht gemäß, zumal, wenn es gedacht wird als auf eigene Arbeit gegründet. Jene Ideen haben freilich selber zunächst religiöse Färbung, insbesondere die des Protestantismus, getragen, zumal 
des antikirchlich-individualistischen, aber allmählich verbleicht diese Farbe an der Sonne der Wissenschaft und Aufklärung, indem diese immer mehr die Offentliche Meinung erleuchtet. Wir erörtern hier aber nicht, wie diese liberalen Ideen in die sozialistischen übergehen und in ihnen umgebogen werden, denn indem die Offentliche Meinung als gegebene historische Erscheinung betrachtet wird, bleibt sie von jener ursprünglichen wbürgerlichen "Gestalt des Liberalismus beherrscht. Auch der wchristliche "Sozialismus vermag über sie wenig; wenn dieser als Politik der katholischen Kirche sich geltend macht, so tritt hier unmittelbar »Religion " als Gegenbild der Offentlichen Meinung in Wirksamkeit, gegen welche sie freilich große Mühe hat, sich zu behaupten und auch $\mathrm{zu}$ Anpassungen und Einräumungen genötigt ist, weil eben die Offentliche Meinung die stärkere Macht im öffentlichen Leben geworden ist. Insbesondere hat sie in den bestehenden Einrichtungen sich ausgeprägt, denen Religion und Kirche nicht nur nicht sich entziehen können, sondern die sie immer auch in einigem Maße $\mathrm{zu}$ wahren und $\mathrm{zu}$ ssanktionieren * angewiesen sind. - Die wirkliche Gestaltung des Privatrechts in allen modernen Staaten beruht ganz und gar auf den Grundlagen der persönlichen Freiheit und des freien Eigentums. Die persönliche Freiheit ist ein Gegenstand der festen Offentlichen Meinung. Hörigkeit, Leibeigenschaft, vollends Sklaverei gelten als Schandmale eines überwundenen, durch Bildung und Humanität nicht erhellten Zeitalters. Versuche, sie wiederherzustellen, werden von der Offentlichen Meinung nicht nur gemißbilligt, sondern begegnen sittlicher Entrüstung und heftigem Unwillen. Wenn sie dennoch gewagt werden, so müssen sie sich in andere Namen einhüllen und die Offentliche Meinung zu täuschen versuchen, was unter Umständen - wenn es sich auf weit entfernte Gegenden bezieht - wohl gelingen kann (man erinnere sich der ,indentured labour"). Weniger fest und eher flüssig zu nennen ist das Postulat der Freiheit des Eigentums in dem Sinne, daß damit die Freiheit des Erwerbs, der Veräußerung, der Verpfändung, das (subjektive) Recht des Gebrauches und des Mißbrauches verknüpft ist; wenngleich der Mißbrauch als solcher Bedenken erregt. Das bürgerliche Bewußtsein, das in der Offentlichen Meinung sich spiegelt, erkennt in der Befreiung des Eigentums von den vielfachen hemmenden Schranken, die es ehemals umgaben, eine der großen Errungenschaften der Neuzeit und Aufklärung. Es findet darin eine hohe Forderung der Gerechtigkeit verwirklicht, aber zugleich rühmt es die Nützlichkeit und $Z$ weckmäßigkeit der Befreiung, die sich in Vermehrung des Nationalvermögens, in glänzenden neuen Erfindungen, in Zunahme und Beschleunigung des 
Verkehrs und in einem Aufschwung aller Gewerbe und Künste bewähre.

Indessen haben doch manche Umstände sich vereinigt, ein vollkommenes Gerinnen dieser Offentlichen Meinung zu verhindern. Das Entstehen großen privaten Reichtums wird auch von vielen Gebildeten als Verminderung und Zurücksetzung ihrer selbst und ihres Verdienstes empfunden. Die Quellen dieses Reichtums sind oft als unlauter, ja schmutzig bekannt. Wucher, wie maßlose Spekulationsgewinne, Gründertum und Protzentum begegnen allgemeiner Mißbilligung. Ebenso wird hilflose Armut und Not, das Elend, worin ehrbare und arbeitsame Familien schmachten, mit Schauder und Mitleid wahrgenommen. Die Ungerechtigkeit, die darin liegt, daß einige allzuviel, viele allzuwenig haben, wird beklagt. Wohltätigkeit, die dem Übel abzuhelfen beflissen ist, wird gelobt, aber auch als unzureichend empfunden. Religion spricht noch stärker zu ihren Gunsten als Offentliche Meinung. Auch stellen sich die Vertreter des Christentums, zumal des römisch-katholischen, niemals rückhaltlos auf die Seite der Verherrlichung des freien Eigentums und der wirtschaftlichen Freiheiten, so wenig wie sie sonst die Fortschritte der Neuzeit ohne weiteres anerkennen, die vielmehr oft von ihnen heftig angefochten werden. - Gleichwohl ist der Strom der Offentlichen Meinung stark genug gewesen, um Bewegungen, die in entgegengesetzter Richtung versucht wurden, ungemein zu erschweren. Solches der Offentlichen Meinung trotzende Streben enthalten die sozialistischen und kommunistischen Lehren und ihre Vertretung durch Gelehrte wie durch Führer der Arbeiterklasse. Von diesen Bemühungen, gegen den Strom zu schwimmen, ist das I9. Jahrhundert erfüllt gewesen. Und sie haben das Gefüge der ihnen feindlichen Offentlichen Meinung immerhin allmählich zu erschüttern vermocht. Viele Schwimmer sind in den Wellen versunken, aber etliche haben sich gerettet und dem ungeheuren Druck, der auf ihnen lastete, siegreich widerstanden. Die antisozialistische Offentliche Meinung ist als solche auch heute noch vorhanden und stark. Aber ihre Kraft hat sich merklich vermindert. Bewirkt und erreicht hat die unablässige Kritik der für die Offentliche Meinung unantastbaren "Gesellschaftsordnung ", daß alle sie betreffenden Fragen in sehr lebhaften Fluß gekommen sind, und daß eben dadurch jener Strom der Offentlichen Meinung sich geteilt und verdünnt hat.

2. (Sozialistische Lehren.) Solange wie sie sich bloßen Theorien der "Gütergemeinschaft" gegenüber sieht, lehnt die Offentliche Meinung den Sozialismus und Kommunismus als wohlgemeinte, aber 
ganz und gar unpraktische «Schwärmereien«ab. Denn I. die Gütergemeinschaft widerstrebe der menschlichen Natur. Schon bei Kindern lasse sich der angeborene Sinn für das Eigentum beobachten. 2. die Gütergemeinschaft würde den untüchtigen und faulen Mitgliedern der Gesellschaft zugute kommen und wohl auch gefallen, die tüchtigen und fleißigen müßten sich dagegen empören, sie würden den Lohn ihres Fleißes und ihrer Leistungen in Anspruch nehmen und genießen wollen; 3. die Gütergemeinschaft müßte aus diesen und aus vielen anderen Ursachen $\mathrm{zu}$ unablässigem Zank und Streit führen. Häufiger aber wird anstatt der Gütergemeinschaft (Kommunismus) als Sozialismus die künstliche Gleichmachung der Vermögen und Einkommen, das "Aufteilen « verstanden. Dagegen richtet die Offentliche Meinung den Einwand, die Gleichheit würde sich nur kurze Zeit halten können, der alte Zustand werde bald wieder hergestellt sein. Oder aber, es wird geltend gemacht, solche Verteilung werde niemanden glücklicher machen, vielmehr werde aus einer Gesellschaft, in der wenigstens Viele ein gutes Auskommen genössen, eine Gesellschaft von Habenichtsen werden. Die Anekdote aus dem Jahre I848, daß der Baron Rothschild einem Frankfurter Arbeiter gesagt habe: „Ihr wollt teilen? jeder soll gleich viel haben? ich bin einverstanden, ich besitze 30 Millionen Taler, es gibt 30 Millionen Deutsche - hier haben Sie Ihren Taler" - bezeichnet den damaligen Stand der Offentlichen Meinung, der noch lange, vielleicht bis heute, wenn auch sehr abgeschwächt, fortgedauert hat. Immer besteht eine starke Neigung; so unpraktische Ideale lächerlich zu machen. Der erfahrene Mann, der die Welt kennt, der Praktiker, der »etwas vor sich gebracht hat «, wird von der Offentlichen Meinung vorgezogen, sie wird immer geneigt sein, ihm Recht zu geben. Eir aber spottet über die Narren und "Weltverbesserer *. - Bei etwas näherer Bekanntschaft mit den Ideen einer allgemeinen Arbeitspflicht, einer »Organisation der Arbeit « wird der Unwille laut über den "Tod aller Freiheit», und die unerträgliche Tyrannei der Staatsgewalt, über den Zuchthausstaat und wohl gar "ein von inappellabeln Demagogen regiertes Zuchthaus», welches Bismarcksche Wort Roscher in seiner Kritik des Sozialismus des öfteren zitiert hat. - Wenn aber die Verfechter des Sozialismus und Kommunismus geltend machen, es handle sich um den sozialen Fortschritt, der natürlich nur unter großen Schwierigkeiten sich vollziehen könne, es sei eine sittliche Aufgabe, die Freiheit der Individuen mit den Rechten der Gemeinschaft zu versöhnen u. dgl., so erklärt die Offentliche Meinung dagegen, die Gütergemeinschaft gehöre rohen Völkern und Zeiten an. „Erst in demselben Verhältnisse, wie sich hernach der Wohlstand und die Bildung entwickelten, pflegte sich, 
zugleich als Wirkung und Ursache, das Privateigentum schärfer auszubilden" (ROSCHER).

Anders verhält sich die Offentliche Meinung, wenn konkretere Anklagen gegen die bestehende Verteilung der Güter erfolgen. Ihre Ubel werden nicht geleugnet; aber ihnen gegenüber wird der Arbeiter zunächst auf Selbsthilfe hingewiesen. Die erste Selbsthilfe, die man ihm empfiehlt, ist die Sparsamkeit. $\mathrm{Da}$ jeder seines Glückes Schmied, daß der ehrliche, rechtschaffene und fleißige Mann, auch wenn er »mit nichts « anfängt, es zu etwas bringen könne, ist eine Grundlehre des bürgerlichen Bewußtseins und also der Offentlichen Meinung. Sparsamkeit aber gilt als das Mindeste, was man von dem Arbeiter, der oft bei günstiger Lage des Betriebes, worin er tätig ist, oder bei günstiger allgemeiner Konjunktur hohen Lohn verdiene, erwarten und verlangen müsse. Als eine Hauptursache des unleugbaren Elends vieler Arbeiter gilt aber, außer, daß er seinen Mehrerwerb leichtsinnig zu verjubeln pflege, ganz besonders die verfrühte Eheschließung und unbedachte Erzeugung vieler Kinder. Dieser Beweisgrund hat in der Offentlichen Meinung etwa von $1800-1880$, aber auch darüber hinaus, eine ungemein starke Zugkraft gehabt; die Offentliche Meinung war davon durchdrungen und stützte sich auf die Urteile der berühmtesten Nationalökonomen und Sozialphilosophen. An deren Spitze stand durch allgemeines Ansehen und tiefreichenden Einfluß der Schotte John STUART MILL: er wollte die Offentliche Meinung selber zu einer wirksamen Macht erheben gegen die Tendenzen der zu starken Vermehrung; sie werde dereinst genügende Fortschritte machen, um eine den Verhältnissen nicht entsprechende Zahl von Kindern sittlich ebenso tadelnswert zu finden, wie jede andere Art von sinnlicher Unmäßigkeit, z. B. Trunksucht. Im gleichen Sinne lehrte Roscher, ein Hauptmoment zur Bestimmung der Lohnhöhe liege in der Hand des Arbeiterstandes selbst; es setze freilich einen hohen Grad von Einsicht und Sclbstbeherrschung der unteren Klassen voraus, wenn die Sachwertsteigerung des Arbeitslohnes eine Vermehrung, nicht der Arbeiterzahl, sondern des Arbeiterwohlstandes bewirken solle. - Allgemein aber pflegte (und pflegt auch heute noch vielfach) die Oifentliche Meinung sich dahin zusammenzufassen, $\mathrm{daB}$ die Arbeiter selber schuld seien, wenn es ihnen schlecht gehe. Besonders fand (und findet) dies auch Anwendung auf die traurigste Lage des Angebots der Arbeitskraft den Mangel an Nachfrage, die Arbeitslosigkeit. Die Offentliche Meinung setzte als deren allgemeine Ursache dic "Arbeitsscheu *, nebst Trunkfälligkeit, Neigung zum Landstreichen, mangelnden Sinn fürs Familienleben, kurz Lasterhaftigkeit voraus, und hat sich in 
bezug auf die wirklichen Hauptursachen erst allmählich und unzulänglich belehren lassen ${ }^{1}$ ). - Was die großen Einkommen betrifft, so unterscheidet die Offentliche Meinung deren Bewertung nach ihrem Ursprunge: wenn sie lediglich als Früchte eines ererbten Vermögens und als müßige Rieseneinkommen gelten, so werden sie mit Mißbehagen betrachtet, zumal wenn eine üppige, auffallende, protzenhafte Lebensweise damit verbunden ist, die als solche schon der öffentlichen Zensur unterliegt. Anders, wenn ein großes Einkommen für verdient oder für das Eirgebnis eines "sauer erworbenen "Vermögens gehalten wird; es erscheint dadurch um so mehr als gerechtfertigt und wird auch gern bewundert, je mehr es in Liberalität, großartiger Wohltätigkeit, Unterstützung von Kunst und Wissenschaft, patriotischen Betätigungen sich kundgibt. Tätige, fleißige Geschäftsmänner gelten nun im allgemeinen als Eirwerber ihres Vermögens und Einkommens. Im I8. Jahrhundert wurde die aufgeklärte Meinung vorzugsweise dem großen $\mathrm{Kaufmann}$ hold, zumal dem überseeischen: „Güter zu suchen geht er, doch an sein Schiff hänget das Gute sich an." Wir hören von poetischen Verherrlichungen des Handels, die seit der zweiten Hälfte des I7. Jahrhunderts häufiger geworden seien (SoMBART, Kapitalismus ${ }^{2}$ II, I, S. 32). Als Widerhall dieser Denkungsart dürfen wir auch verstehen, was GoETHE in Meisters Lehrjahren dem Kaufmann Werner in den Mund legt: „Wo gibt es nun noch einen rechtmäßigeren Erwerb, eine billigere Eroberung als den Handel?"

3. (Der Handel.) In Deutschland hatte sich in dieser Hinsicht ein großer Umschwung vollzogen seit der Reformationszeit, wo die Offentliche Meinung noch ganz in der Religion befangen, in MARTIN LUTHER ihren wirkungsvollsten Sprecher fand, der mit grellen Farben die unter den Kaufleuten vorhandenen ,böse Griff und Tïcke des Geizes, des Eigennutzes und der Büberei" schilderte und die Preissteigerer, Einkäufer und Monopolisten als ,„öfentliche Diebe, Räuber und Wucherer" brandmarkte; die Raubritter seien geringere Räuber als die Kaufleute, sintemal die Kaufleute täglich die ganze Welt rauben, wo ein Räuber im Jahr einmal oder zwei einen oder zwei beraubt" (nach JANSSEN, Gesch. d. deutschen Volks II, S. 420f.).

1) Uber die ersten Jahre nach der Julirevolution und in bezug auf die Pfalz, bemerkt H. . TREITSCHKE, die Offentliche Meinung habe vor der neuen Erscheinung des Massenelends noch ganz hilflos gestanden und die Auswanderung als ein wirksames soziales Heilmittel gepriesen. (D. G. IV, 25r.) MARX behauptet in ciner seiner rhetorisch leidenschaftlichen Wendungen, schon während der „Manufakturperiode", mit der Entwicklung der kapitalistischen Produktion habe die Offentliche Meinung von Europa den letzten Rest von Schamgefühl und Gewissen eingebüßt (Kapital I, 4, S. 724). Seine Beweisgründe sind spezifisch englischen Erfahrungen entlehnt. 
Solche Töne, die noch von dem altchristlichen, im Mittelalter beharrenden Widerwillen gegen den Handel herrühren, sind in den folgenden Jahrhunderten immer leiser geworden, wenn auch niemals verstummt. Die Offentliche Meinung ist auch in 19. Jahrhundert geneigt geblieben, den Handel $z u$ verherrlichen ${ }^{1}$ ), mehr aber noch wandte sie ihre Gunst dem industriellen Unternehmer zu, zumal in den Fällen, wo er den Erfinder oder den erfolgreichen Ingenieur oder beide in seiner Person vereinigte. Vor allem wird seine Tatkraft, sein Wagemut, seine Beharrlichkeit, kurz der "Unternehmungsgeist " hoch gepriesen und die "Hauptleute der Industrie», wenigstens die erfolgreichen, begleitet ein ähnlicher Beifall, wie die Führer eines siegreichen Heeres. Die Reste der Abneigung gegen Wucher und Plusmacherei, die vorzugsweise auf dem Lande, in konservativ und klerikal beeinflußten Kreisen bleiben, richten sich - in Deutschland, Frankreich und anderen Ländern - am liebsten gegen die Juden, als eine volksfremde Gruppe, deren wachsender Reichtum mit Mißvergnügen betrachtet und gern auf unlautere Handlungsweisen zurückgeführt wird. Mehr und mehr hat aber die Offentliche Meinung mit den Angriffen, die von sozialistischer Seite, also im Interesse der neuen industriellen Arbeiterklasse, gegen den "Kapitalismus " und damit gegen die "Ausbeutung " der Arbeitskraft durch das "profithungrige Kapital " gerichtet wurden, sich auseinandersetzen müssen und konnte gewissen Wirkungen dieser starken Strömungen sich nicht entziehen. Sie ist immer zu bedeutenden Einräumungen bereit gewesen, und hat, wie sie die "Auswüchse " des Handels im Börsenspiel, Grundstückschacher, Kettenhandel verurteilt, so auch die "Mißstände völlig anerkannt, die das Maschinenwesen, die Fabrikindustrie, der Großbetrieb im Gefolge haben. Und so hat sich eine entschiedene Wandlung vollzogen von jenem Standpunkt des Gehenlassens, der alle Einmischung des Staates in den freien Verkehr für schädlich hält ${ }^{2}$ ), zur entschiedenen Befürwortung einer sozialen Gesetzgebung, namentlich zum Schutze der Frauen, Kinder und jugendlichen Personen, in hygienischem und in sittlichem Interesse. Mit dieser Einräumung war lange eine um so entschiedenere Ablehnung

1) Nach KI.EIN (Die Organisationen, S. 47) habe im letzten Drittel des 18 . Jahrhunderts die Offentliche Meinung begonnen, sich gegen die Aktiengesellschaften aufzulehnen. Er bezicht sich dann auf das Verbot durch den französischen Konvent 1793. Die Abneigung war gegen die Assoziation, nicht gegen den Handel gerichtet.

$\left.{ }^{2}\right)$, Bis zu Anfang des 8. Jahrzehnts (des XIX. Jahrh.) herrschte in Wissenschaft und bffentlicher Meinung eine Auffassung vor, die dem Staate nur einen Rechtsund Machtzweck beilegte und glaubte, daB alles wirtschaftliche Leben am besten sich selbst zu überlassen sei." G. K. ANros, Geschichte d. preuß. Fabrikgesetzgebung。 I891, S. VIII. 
des auf erwachsene Männer - die Normalarbeiter - auszudehnenden Schutzes verbunden. Besonders scharf und deutlich machte sich diese Unterscheidung in England geltend und konnte sich dort bis gegen Ende des I9. Jahrhunderts behaupten, nachdem schon in dessen Anfang die Aufdeckung der Greuel in Frauen- und Kinderarbeit, besonders in der jungen Baumwollenindustrie, eine gelinde Empörung zur Folge gehabt hatte, die denn auch schwache gesetzgeberische Maßnahmen zu bewirken vermochte, unterstützt durch ein Parteiinteresse, das den industriellen Emporkömmlingen abhold war. Die soziale Frage, als Zweifel an dem Werte der modernen Gesellschaftsordnung und Eigentumsordnung, blieb gerade in England lange außerhalb des Gesichtskreises der Offentlichen Meinung, die sozialistischen Gedanken wurden als unsinnige Projekte (wild schemes) vorgestellt. Während der letzzten 30 Jahre (I890-I920) haben sie jedoch unerbittlich sich weiter vorgeschoben und das Ernstgenommenwerden erzwungen. Dies ist eine allgemeine Erscheinung in den alten Kulturländern, so daß hier eine gewisse Indifferenz der Offentlichen Meinung gegenüber den Theorien eingetreten ist; wie immer der goldenen Mittelstraße (dem juste-milieu) geneigt, will sie das Gute des Individualismus mit dem Guten des Sozialismus verbinden und die übelen Seiten beider vermeiden, oder: der Staatstätigkeit zum allgemeinen Besten ihr Recht lassen, aber auch der individuellen Selbstverantwortung freien Spielraum gewähren; wenn in wirtschaftlicher Hinsicht niemals schlechthin das laisser faire gegolten hat - am meisten immerhin, trotz der Fabrikgesetzgebung, in Großbritannien - so hat sich die Wage neuerdings immer mehr einer gemäßigten Sozialreform zugeneigt, weil diese zugleich als Vorbeugung gegen die ssoziale Revolution", überhaupt gegen innere Unruhen, die von "Fabrikarbeitern " und von "großstädtischem Pöbel « immer befürchtet werden, geschätzt wird. Dagegen hat sich die Anerkennung der Selbsthilfe, die bei theoretischen Urteilen lange im Vordergrunde stand, erheblich abgeschwächt; vielmehr knüpften sich daran Besorgnisse, als anstatt der individuellen die kollektive und organisierte Selbsthilfe in den Vordergrund trat: vor der Macht der ogewerkschaftlichen "Verbindungen, weil die Meinung ist, daß sie Streiks anzetteln und dem Unternehmer streitig machen, Herr im eigenen Hause zu sein; vor der "genossenschaftlichen * Organisation, weil sie den Ruin des Mittelstandes bedeute. Die Stellung der Offentlichen Meinung zu diesen beiden Arten der Selbsthilfe, in denen sie die Verwandtschaft mit sozialistischen Ideen wittert, erfordert eine nähere Beleuchtung. 


\section{Zweiter Abschnitt. Die besonderen Probleme.}

4. (Das Koalitionsrecht.) Die Offentliche Meinung sah zunächst scheel zu allen Verbindungen der Arbeiter, die den Zweck setzten, bessere Arbeitsbedingungen zu erobern. Sie betrachtete den freien Arbeitsvertrag als eine große Errungenschaft des Geistes der Aufklärung gegenüber allen Arten von unfreier Arbeit und sah das Wesen des freien Arbeitsvertrages in der individuellen Vereinbarung zwischen den Parteien, nämlich dem, der die Arbeit "gebe«, d. h. die Verdienstgelegenheit gewähre, und dem, der sie nehme, wobei jeder, wie sonst bei einem rechten Tausch, im eigenen Interesse handle. "Zusammenrottungen « erschienen als Beschränkungen der Freiheit, also als Störungen des Marktes, wie alle Verabredungen über Preise, die den freien Wettbewerb unterbinden. In dem Lande, das zuerst die große Industrie sich entfalten sah, haben auch zuerst die "Gewerkvereine" (Trade Unions) die öffentliche Aufmerksamkeit in Anspruch genommen. Bis 1824 war die Koalition «schlechthin verboten. Die Strenge der Gesetze gegen sie wurde verschärft durch die Angst vor Jakobinern und geheimen Gesellschaften, die unter den Eindrücken der französischen Revolution die Gemüter beherrschte; das Gesetz von I8oo bedrohte alle Verabredungen, Versammlungen und Vereine von Lohnarbeitern zum $Z$ wecke, eine Lohnaufbesserung herbeizuführen, mit Zuchthausstrafe (Koalitionen der Arbeitgeber nur mit Geldstrafe). Die Aufhebung dieser Gesetze geschah fast unversehens, sie wurde, nach dem Ausdrucke BRENTANOs, durch das Parlament hindurchgeschmuggelt, die Offentliche Meinung wurde ihrer erst gewahr, als die Folgen sich bemerklich machten, und unterstützte es, daß im folgenden Jahre (I825) soviel wie möglich davon zurückgezogen wurde. Die Gewerkvereine blieben verfemt. „In den 30 er und 4 oer Jahren des I9. Jahrhunderts litten die Gewerkvereine unter der äußersten Ungunst seitens der öffentlichen Meinung und der Gesetzgebung" (BRENTANO HWS ${ }^{3}$ IV, II26). Sie steigerte sich durch das Auftreten der Chartisten und der christlichen Sozialisten, die als deren unheilvolle Gönner galten; vollends aber durch vorkommende Fälle von Koalitionszwang, der bis zu verbrecherischen Gewaltsamkeiten verschärft wurde. Der öffentliche Unwille stieg auf den höchsten Gipfel, als gewisse Vorgänge von äußerster Roheit bekannt wurden, die sich in Sheffield zugetragen hatten (1866). Wenige Jahre vorher war durch den Bericht eines Ausschusses, den die Gesellschaft zur Beförderung der Sozialwissenschaften eingesetzt hatte, ,der erste systematische Versuch gemacht worden, die Gewerkvereine gerecht zu beurteilen“. „Allein die den 
Arbeitgebern so genehme Beurteilungsweise ließ sich aus der Offentlichen Meinung nicht so leicht verdrängen" (das.). In einigem Maße gelang dies aber durch den Bericht der parlamentarischen (königlichen) Kommission, die, eben infolge der Erregung gegen die Gewerkvereine, zur Untersuchung ihres Wesens und Tuns berufen wurde. Der Kontrast war sehr auffallend, in den sich die ermittelte Wahrheit zu dem losen, verallgemeinernden Gerede, die Tatsachen zu den Gerüchten, stellten. Auffallend und beschämend. In solchen Fällen muß sich die Offentliche Meinung bequemen. Niemand kann wagen, die ehemals so beliebten Lästerungen zu wiederholen, ohne sich dem Vorwurf der Unwissenheit auszusetzen; und die Untersuchung anfechten, macht den, der ihre Methoden nicht nachzuprüfen vermag, lächerlich. Es trat aus diesen Ursachen eine tiefgehende Veränderung, die nicht eben als ein Umschwung zugunsten der Arbeiter-Fachvereine gedeutet werden sollte, sondern lieber als ein Verstummen, und in der Folge als ein reserviertes, abwartendes Verhalten ${ }^{1}$ ). Im Laufe der Jahrzehnte ist dieses aber mehr und mehr in eine gewisse Sympathie übergegangen. Die Größe der Organisation, ihrer Finanzkraft und pekuniären Leistungen zieht Bewunderung auf sich, es wird anerkannt, daß sie das Verhältnis zwischen Kapital und Arbeit regelmäßiger und ordentlicher gemacht haben, daß ihre Führer nicht, wie man ehemals wähnte, zu Streiks aufwiegeln, sondern eher vor solchen warnen und als Finanzminister der großen "amalgamierten "Unionen und Kartelle vorsichtig erwägen, ob der Erfolg die Kosten lohnen werde. Daher wurde mit großem Mißfallen bemerkt, daß die Autorität der Führer bei den großen Massen sich verminderte, daß diese ungezügelt ihre eigenen Wege suchten und gingen, wie es bei den großen Ausständen der Transportarbeiter in den Jahren IgII-I3 offensichtlich der Fall war. Man sah hierin fremde Einflüsse, besonders solche der französischen Syndikalisten, wirksam werden, und konnte um so mehr schätzen, daß ein gut geführtes Gewerkschaftswesen als ein Bollwerk gegen die soziale Revolution sich bewähre. Auch die großen internationalen Kongresse, an denen die Häupter der Gewerkschaften neben denen der Sozialisten teilnahmen, machten in dieser Zuversicht nicht irre, weil man wußte, daß der englische Trade Unionism durchaus den rechten Flïgel in diesen Arbeiterparlamenten darstelle,

1) ,Von diesen Berichten der Kommission datiert ein neues Stadium in der Stellungnahme der Offentlichen Meinung gegenüber den Trade Unions, die sich insbesondere auch in den Leitartikeln der Presse wiederspiegelt. Auch große Unternehmer wie BRASSEY äußerten sich öffentlich dahin, daß die Gewerkschaften erzieherisch auf die Arbeiter einwirkten, und da $B$ ihre Tätigkeit die Kosten der Produktion nicht erhöhe, sondern vermindere." KULEMANN, Gewerkschaftsbewegung (I900) S. I6. 
und sich auf praktische, unmittelbare Ziele beschränke, deren Erreichbarkeit die Offentliche Meinung zugestanden hat, indem sie eben dadurch das kapitalistische Privateigentum und die ganze darauf beruhende Gesellschaftsordnung zu retten hofft. Andere Momente haben in England dazu beigetragen, das Odium, welches so lange auf den Arbeiterverbindungen lastete, zu beheben. Vor allem zeigt sich die Wechselwirkung zwischen Offentlicher Meinung und Gesetzgebung. Noch im Jahre I866 hatte das Obergericht entschieden, $\mathrm{da} B$ Trade Unions ungesetzliche Verbindungen seien. Erst im Gesetze von I87I gab ihnen ein neues Gesetz vollständigen Schutz für ihr Vermögen; aber noch wurde ein besonderes Strafgesetz daran gehängt, um ihre Aussichten, in Lohnstreitigkeiten zu siegen, wesentlich zu verschlechtern. Fünf Jahre später wurde das Ausnahmegesetz aufgehoben. Die Offentliche Meinung, die also sich zu größeren Einräumungen gedrängt sah und diese Gesetzgebung zuließ, sah sich dann wieder dem Einflusse ausgesetzt, den die Sicherung der Rechtslage zugunsten der Gewerkvereine ausüben mußte. Einzelne Vertreter der Arbeit betraten die heiligen Hallen des Hauses der Gemeinen. Die unlängst noch als verbrecherisch geschmähten Vereine wurden von den herrschenden Klassen als regelmäßiges Glied der bestehenden Gesellschaftsorganisation rezipiert (BRENTANO). Dies war freilich mehr Schein als Wirklichkeit $\left.{ }^{1}\right)$. Die schwere und schleichende Krise, die gegen Ende der 7oer Jahre gipfelte und nach einer kurzen Hebung auch die Mitte der 8oer erfüllte, streute auch den Samen sozialistischer Lehren, der Glaube an den sozialen Frieden wurde tief erschüttert, das Unbehagen, von dem auch der denkende Teil der Gebildeten sich ergriffen zeigte, machte das Vertrauen rasch wieder wankend, das man in die Arbeiterorganisationen gesetzt hatte. Die Offentliche Meinung fühlte sich völlig unsicher. Auf der einen Seite gewann das Gefühl der Furcht die Oberhand, auf der anderen die Gefühle des Mitleids mit dem greller in die Erscheinung tretenden Elend der Schichten, die nicht in Gewerkvereinen organisiert waren. Bei dem Ausstand der Streichholzmacherinnen 1888 wie bei dem großen Hafenstreik 1889 trat dies zutage: ,nichts kann den Fortschritt, den die Gewerkvereinsbewegung in der öffentlichen Meinung

1) Bei allem „Wohlwollen" hielt bis weit über 1870 hinaus ,,jeder Gebildete es für ausgemacht, da $B$ der Trade Unionism als Mittel, die Iage des Arbeiters zu verbessern, agegen die politische Ökonomiex sei. Dieser Eindruck rïhte nicht sowohl von einer ausdrücklichen Erklärung der Nationalökonomen, als von der allgemeinen Ansicht des Arbeitslohnes her, die eine aufgeklärte Offentliche Meinung von jenen empfangen hatte" (Theorie des Lohnfonds, in Verbindung mit den Theorien der Akkumulation und des Bevölkerungswachstums), S. u. B. WéBB, Industrial Democracy II, S. 603 . 
gemacht hatte, besser zeigen, als daß nunmehr Damen der vornehmsten Kreise ihre bisherigen kostspieligen Lieblingsversuche zur Besserung des Lohnes der weiblichen Arbeiter ... verließen und sich an die Spitze einer Bewegung zur Organisation der weiblichen Arbeiter in Gewerkvereinen stellten" (BRENTANO). Zu gleicher Zeit lenkte der Ausstand der Hafenarbeiter (1889) die Aufmerksamkeit auf die Zustände des Ostens von London, die schon einige Jahre frïher der "Schmerzensschrei " $(A$ bitter cry) und die Untersuchung über das Schwitz-System von anderer Seite grell beleuchtet hatte. Der Ausstand wurde wesentlich durch die laute Sympathie des Publikums gewonnen, ebenso 2 Jahre später der Streik der Omnibus-Bediensteten. Im Jahre I900 erklärte WERNER SOMBART, indem er von den Eroberungen der Gewerkvereine auf dem Gebiete des öffentlichen Lebens in England sprach, es habe sich tatsächlich alles zu ihren Gunsten gewandt: „Staatsbehörden, städtische Behörden, Gerichte, Presse, öffentliche Meinung wetteifern untereinander, um der Arbeiterbewegung bei jeder Gelegenheit, die sich bietet, ihre Reverenz zu machen" ("Dennoch! «S. 20). Bezeichnend ist es, daß der nächste starke Angriff gegen diese gewonnenen Stellungen in der Weise geschah, daß er aus dem rechtlichen Stande der Gewerkvereine die Konsequenzen $\mathrm{zu}$ ihren Ungunsten $\mathrm{zu}$ ziehen unternahm. Dies geschah durch die Haftbarmachung des Eisenbahnerverbandes für Schaden, der durch Streikposten verursacht sei (die Taff. Vale Decision I9or) und - gewissermaßen im entgegengesetzten Sinne durch das OsBORNE-Urteil (Dez. I909), das ihnen, eben weil sie bloße Zweckvereine seien, das Recht nahm, sich parlamentarisch vertreten zu lassen. Die Offentliche Meinung, deren Sympathie infolge der Ausbreitung imperialistischer Ideen und Gefühle, der Agitation für Schutzzölle und gegen ausländischen, besonders deutschen Wettbewerb, stark abgeflaut war, zeigte sich sehr geneigt, dem letzten Urteil ihren Beifall zu geben, nachdem das erstere durch eine von der neuen liberalen Regierung durchgesetzte Akte unwirksam gemacht worden war (Trades Disputes Act 1906). Guten Teils erklärt sich dies daraus, daß die Offentliche Meinung zu dem ganzen ungeheuren Eirfolg der von der neuen Arbeiterpartei unterstuitzten, liberalen Herrenpartei, ein schiefes Gesicht machte; in anderer Weise als es auch sonst regelmäßig und naturgemäß durch die Vertreter der überwundenen Meinung geschieht, die nicht in Anspruch nehmen kann, die Offentliche Meinung zu sein. Diesmal fühlte sich, wie niemals zuvor, das eigentliche und alte England durch Wales, Schottland und Irland geschlagen; zugleich die Respektabilität durch Vertretungen des Pöbels oder derer, die mit ihm paktierten; die Kirche 
von England durch die "Kapelle», d.h. die Nicht-Konformisten, durch Sekten, über die man die Nase zu rümpfen gewohnt war, wie Methodisten und Quäker. Dies Verhalten der Offentlichen Meinung machte sich auch bei den zwei Neuwahlen des Jahres I9Io bemerkbar und bewirkte, obgleich die Mehrheit im Hause erheblich vermindert blieb, daß im eigentlichen England die Mehrheit der Wähler und der Gewählten wieder sich zum konservativ-unionistischen Programm bekannte. Willkommen mußte unter diesen Umständen der Offentlichen Meinung sein, daß sich innerhalb der Gewerkschaftswelt Erscheinungen zeigten, auf die sie als hochgefährlich hinweisen konnte: dahin gehörte die schon erwähnte Unbotmäßigkeit der Leute ihren Führern gegenüber, und die Spuren des französischen Syndikalismus, die bei Gelegenheit des Kongresses zu Sheffield rgro und in den folgenden Jahren bei Massenstreiks (auf die zurückzukommen sein wird) zutage treten. Auch SombarT schreibt in bezug auf die jünste Entwicklung (Sozialismus und soziale Bewegung 6. Aufl. S. 276), seit einer Reihe von Jahren sei die Stimmung in England zuungunsten der Gewerkvereine umgeschlagen. „Das Unternehmertum ist in seiner überwiegenden Mehrheit, wie es scheint, gewillt, die Tyrannei der Gewerkvereine zu brechen, die "öffentliche Meinung", d.h. im wesentlichen die Welt der Philister, bekommt ebenfalls Angst vor der immer mehr erstarkenden Macht der Trade Unions und fürchtet vor allem, deren Politik könne die Leistungsfähigkeit der englischen Industrie und damit ihre Konkurrenzfähigkeit herabsetzen"'1).

Im Deutschen Reiche haben die "Gewerkschaften" nicht die gleiche historische Bedeutung für die Arbeiterbewegung gehabt wie in England. Daher entbehrt auch ihre Entwicklung der großen dramatischen Momente. Sie ist erst im Gefolge der geistigen und politischen Bewegung eingetreten, vorzugsweise als Wirkung des großen Einflusses, den die sozialdemokratische Partei auf die Massen der industriellen Lohnarbeiter gewann. Bis dahin, d.h. bis tief in das letzte Viertel des Jahrhunderts, hatte die Offentliche Meinung geringe Veranlassung, den Fachvereinen erhebliche Aufmerksamkeit zu widmen; seitdem aber geschah es teils im Zusammenhange mit Streiks, teils mit der genannten Partei; beide Gegenstände bleiben der Betrachtung noch vorbehalten. Die Folge beider $\mathrm{Zu}$ sammenhänge war aber ein überwiegend ungünstiges Urteil, indem man sie, wenigstens die sog. freien Gewerkschaften bald als aufrührerische Verbindungen anklagte, bald ihre Tyrannei gegen die

1) Ich würde sagen: „glaubt ... habe herabgesetzt und geschädigt!“ 
eigenen Mitglieder, vollends gegen Streikbrecher, den "Terrorismus «, womit sie (sagte man) ihren Willen geltend machen, schalt. SombarT (1. c. S. 48 ) stellt dar, wie sich $1878-1890$ die polizeiliche Unterdrückung gleichermaßen gegen die politische Partei und gegen die Gewerkschaften richtete. Dann trat die Bewegung 1890 in eine neue Phase ihrer Entwicklung. Auch der Kampf gegen sie veränderte sich. „An die Stelle der brutalen Unterdrückung trat die schikanöse Drangsalierung, an die Stelle der Keulenschläge traten die Nadelstiche. Aber daran lassen es Verwaltungs- und Gerichtsbehörden, Unternehmertum und öffentliche Meinung nicht fehlen." Seitdem ist die Offentliche Meinung allerdings enthaltsamer geworden. Sie hat ein gewisses Verständnis für das Gewerkschaftswesen gewonnen, hat sich hin und wieder darauf besonnen, da $B$ sie ehemals für diese "Selbsthilfe " eingenommen war, als diese freilich noch in schwachen Anfängen steckte; so kann sie wenigstens den nicht-sozialdemokratischen Gewerkvereinen einige Achtung und Sympathie nicht versagen, und läßt sich den »klerikalen «Einfluß in dieser Sphäre gefallen. Vollends gefallen ihr die jüngsten sog. wirtschaftsfriedlichen Vereine und ähnliche Bildungen, die eine nationale und patriotische Gesinnung in den Vordergrund stellen, alle Kampfmittel, besonders die Niederlegung der Arbeit, grundsätzlich verwerfen und die (von der ältesten Gruppe deutscher Gewerkvereine ehemals vertretene, dann aber aufgegebene) Lehre von der wesentlichen Harmonie zwischen Kapital und Arbeit aufs neue geltend machen. Freilich sind diese sämtlichen Formen des vom Odium der politischen Partei freien Gewerkschaftswesens an Zahl und Bedeutung bisher unbedeutend geblieben. Wenn aber das Aburteilen über die Sache selber an Schroffheit verloren hat, so ist dies der Beachtung und Aufklärung zu verdanken, die ihr deutsche Gelehrte gewidmet haben, unter denen BRENTANo an der Spitze steht. Der Verein für Sozialpolitik und, nachdem dieser seinen politischen Charakter eingebüßt hatte, die vom Freiherrn vON BERLEPSCH gegründete Gesellschaft für Soziale Reform haben dazu mitgewirkt. In ihrem Geiste lehrte auch SOMBART, wenn er (Pfingsten Ig0o im Vorwort der genannten Schrift "Dennoch») schrieb, der eigentliche $Z$ weck (seiner Vorträge, die in dieser Schrift wiedergegeben wurden) sei der, durch Klärung des Urteils Stimmung zugunsten der Gewerkschaftsbewegung zu machen. „Bei den Arbeitern, soweit es hier noch nötig ist; vor allem aber in den Kreisen der Gebildeten, deren Stellungnahme auch in sozialen Fragen deshalb keineswegs bedeutungslos ist, weil sie ein gut Teil der sog. "öffentlichen Meinung «bilden, und diese gerade für die Erfolge der Gewerkschaftsbewegung ein nicht zu unterschätzender Bundesgenosse ist" (1. c. p. VI). 
Frankreich ist das Mutterland des utopischen Sozialismus, ist aber lange ein unfruchtbarer Boden geblieben für alle praktischen Bestrebungen und einheitlichen Organisationen der Arbeiterklasse, sei es auf politischem oder auf wirtschaftlichem Gebiete. Den Vereinen der Arbeiter zur Wahrung und Förderung ihrer Interessen standen Gesetz und Offentliche Meinung gleichermaßen entgegen. Beide auf dem Boden der Revolution, die nichts bestehen lassen wollte als das Individuum und den Staat, die eine und unteilbare Republik. Dieser extreme "Individualismus « war natürlich ebenso den Unternehmerverbänden wie den Arbeitervereinen abgeneigt, aber die Macht der Bourgeoisie in Gesetzgebung und Offentlicher Meinung: zeigt sich darin, daß jene viel früher als diese geduldet wurden. Erst nach I87I konnte die politische und gewerkschaftliche Arbeiterbewegung ihr Haupt etwas höher erheben. Noch auf dem zweiten freien ArbeiterkongreB (in Lyon 1876 ) warnte man vor Streiks, und der Comtist Finance hob die Bedeutung der Offentlichen Meinung. hervor, die bei allen Bestrebungen der Arbeiter geschont und gewonnen werden müsse (M. v. D. OsTEN, Die Fachvereine und die soziale Bewegung: Frankreich: Schmollers Jahrbuch I89. S. I060). Erst das Gesetz vom 2I. März I884 brach mit der revolutionären (berlieferung ${ }^{1}$ ). Das Gesetz von I79I und der Satz des Code criminel, der alles, was die $₫$ Freiheit der Arbeit \& beeinträchtige, unter Strafe stellte, wurden gleichzeitig aufgehoben. Den Fachvereinen wurde gesetzliche Anerkennung zuteil, ihr rechtliches Dasein wurde geregelt. ,Welcher Umschwung der Anschauungen ist damit angedeutet, wie mußten sich die sozialen Verhältnisse geändert haben, damit in dem den Kultus der freien Persönlichkeit auf die Spitze treibenden Frankreich ein solches Gesetz möglich wurde!" (v. D. OsTEN, 1. c. S. rogo). In der Tat, eine neue Strömung hatte in der Offentlichen Meinung die Macht gewonnen. Indessen ist sie, ungeachtet dieser Zugeständnisse, in den Gedankenbahnen der großen Revolution und ihres Ruhmes geblieben. Daraus ist auch der Syndikalismus hervorgegangen, der zwar als rebellische Form des Klassenkampfes nicht von der Offentlichen Meinung gebilligt wird, aber doch wegen seiner heroischen Geste und seiner verwegenen Anwendung der großen Prinzipien (Freiheit, Gleichheit, Brüderlichkeit) mehr Gnade vor ihr gefunden hat als andere und rationellere Bestrebungen. Hier,

\footnotetext{
1) Das Gesetz von 1874 zum Schutze jugendlicher und weiblicher Arbciter ist lange "eit hindurch sehr lückenhaft zur Ausführung gebracht. „Der Arbeiterstand bekundete zunächst Gleichgültigkeit, die Unternehmerschaft zum Teil hartnäckige Gegnerschaft; die öfentliche Meinung war ïber den Gegenstand wenig geklärt, man erblickte in dem Gesetz vielfach mehr einen Versuch unangebrachter Einmischung in Privatverhältnisse als eine sozialpolitische Maßnabme." Mataja HWSt ${ }^{3}$ I S. 668.
} 
wie überall macht sich überdies bemerkbar, daß mehr und mehr auch die Meinung des Proletariats auf die Offentliche Meinung Einfluß gewinnt und in ihren Richtungen wenigstens hier und da eine Ablenkung $\mathrm{zu}$ erzwingen vermag.

In Italien ist die ökonomische Organisation der Industriearbeiter, noch ausgesprochener als in Deutschland, im Gefolge der politischen Bewegung erfolgt, hat aber mehr als dort auf die Landarbeiter übergegriffen. Nachdem sie, was sehr spät erfolgt ist, rechtliche Freiheit erworben hatte, hat die Offentliche Meinung ihr keinen erheblichen Widerstand mehr geleistet. Ja, SOMBART schreibt der Offentlichen Meinung eine wesentliche Mitwirkung zu dem Ergebnisse $\mathrm{zu}, \mathrm{da} B$ der Bourgeoisie in Italien mit dem Jahre 1890 ein verändertes Verhalten aufgezwungen wurde. „Immerhin ist es nicht uninteressant, zu konstatieren, wie auch in Italien die Bourgeoisie bis zu dem Augenblicke, wo der Druck der Arbeiterschaft und mit ih m die Offentliche Mein ung ihr ein verändertes Verhalten abzwingen, und der Gesetzgebung Fesseln schmiedet, mit denen sie versucht, die Arbeiter zu bändigen." (Archiv für soziale Gesetzgebung VI, S. 2Io.)

Für die Schweiz nennt Herkner unter den Gründen, aus denen er meinte (im Jahre I909), daß der schweizerischen Bewegung noch schwere Zeiten bevorstehen, den Umstand, daß ,die zahlreichen Streikunruhen die öffentliche Meinung den Gewerkschaften manchenorts entfremdet haben" (HVSt". IV, S. I202).

In den Vereinigten Staaten habe, sagt MÜNSTERBERG (Die Amerikaner I, 469), "die Nation " $z \mathfrak{u}$ der stetig fortschreitenden Organisation der Arbeit im wesentlichen die Rolle des interessierten aber neutralen Zuschauers gespielt. MÜNSTERBERG unterscheidet fein zwischen dem Verhalten bei dem konkreten Fall eines direkten Konfliktes (wo die Sympathie der "Nation « fast regelmäßig auf der Seite der Arbeiter sei) und hingegen, wenn die "Gesetzgebung « in Frage komme, also der begriffliche Gegensatz von Arbeit und Kapital ins Bewußtsein trete (hier neige die "Nation " umgekehrt zur Sympathie mit dem Kapital); dies gilt natürlich auch gegenüber dem Dasein und Wirken der Gewerkvereine. Der geistreiche Kenner der Vereinigten Staaten schildert ferner, wie der Riesenausstand in den Anthrazitkohlengebieten von Pennsylvania I902 die Kapitalistengruppe in allzu unerfreulichem Lichte gezeigt habe, und als ihre Vertreter sich nicht entblödeten, auch den Präsidenten der Vereinigten Staaten in brüsker Weise über die Rechte des Eigentums aufzuklären, da begann man, die geläufigen Anschauungen mehr und mehr zu revidieren." „Die Offentliche Meinung wurde sich in wachsendem Maße klar, daß jene ganz großen Gesellschaften denn doch nicht mehr 
Privatgesellschaften im gewöhnlichen Sinne des Wortes seien, da B ein Stahltrust oder ein Kohlentrust im Gefüge des Staatslebens nicht diejenige Freiheit beanspruchen kann, die der Besitzer eines Krämerladens für seinen winzigen Betrieb erwarten darf." Insbesondere sei die Úberzeugung gewachsen, daß dem Arbeiter das moralische Recht zustehe, bei der Leitung des Betriebes ein entscheidendes Wort mitzusprechen. „Und so hat sich denn langsam in der öffentlichen Meinung die Ansicht durchgerungen, daß Gewaltsamkeit von seiten der Arbeiter, und Weigerung der Arbeitgeber, mit den Gewerkvereinen zu verhandeln, in gleichem Maße verdammenswert sind... Die öffentliche Meinung verlangt, daß, nachdem nun einmal sich historisch die Organisation in Gewerkvereinen vollzogen hat, eine Verhandlung zwischen den Delegierten beider Seiten alle Streitpunkte $z u$ beseitigen erstrebe, und daB, wo eine Einigung nicht erfolgt, ein Schiedsgericht in Kraft trete, dem beide Seiten sich unbedingt unterordnen" (1. c. S. 487). Gerade in dieser Richtung sei die Offentliche Meinung energisch vorgegangen. Schon im Jahre I90r habe eine Konferenz der führenden Kapitals- und Arbeitsvertreter eine ständige Behörde eingesetzt, um Streitigkeiten zwischen Arbeitgebern und Gewerkvereinen auszugleichen.

5. (Genossenschaftswesen.) Als Selbsthilfe der Arbeiterklasse und Versuch, den Umklammerungen des Kapitalismus sich zu entwinden, ist in neuester Zeit in allen Ländern das Ge nossenschafts wesen mehr und mehr bedeutsam geworden, namentlich durch die Konsumvereine und deren Großeinkaufsgesellschaften, die auch als Organisationen der Arbeit Kraft gewinnen, wenn sie zur Eigenproduktion gewisser Verbrauchsgegenstände übergehen. In England und Schottland, wo deren äußere Entwicklung am frühesten und weitesten fortgeschritten ist, hat ihnen auch die Offentliche Meinung längst eine gewisse Beachtung und sogar Sympathie geschenkt. $\mathrm{Da}$ in diesen Ländern die Mittelstandsschicht des Kleinhandels zwar stark an Zahl, aber - außer dem Kleinhandel mit geistigen Getränken - schwach an sozialer und politischer Bedeutung ist, so konnte deren Widerstand und Unzufriedenheit diese Entwicklung nur wenig hemmen. In anderen Ländern haben sich diese Hemmungen viel stärker bemerkbar gemacht. Die Offentliche Meinung, im Grundsatz der Selbsthilfe der Armen geneigt, ist andererseits auch sehr für die "Ërhalturg des Mittelstandes " eingenommen, schon weil sie selber auf dessen Denkungsart und Bildung beruht - in England nennt die Bourgeoisie sich sclber die Mittelklasse -, und weil sie überall der Maxime „In medio virtus" huldigt. Bis in die jüngste Zeit wurde, insbesondere in Deutschland, den Konsumvereinen wenig 
Beachtung geschenkt. Nur in wenigen Großstädten hatten sie einige Bedeutung gewonnen. Man ließ sie gewähren und war nicht unzufrieden damit, daß sie dem Lose der Armen einige Erleichterung brächten. Erst als gegen Ende des Jahrhunderts aus der Arbeiterbewegung ein mächtiger Aufschwung des Genossenschaftswesens sich erhob, fühlte in weiterem Umfange die bürgerliche Schicht des Kleinhandels um so mehr sich bedroht, da sie zu gleicher Zeit gegen die neuen Warenhäuser sich wehren mußte; das Ziel ihrer Wünsche, besonders gefördert durch das hinter ihnen stehende Kapital (die Großkrämer, die nicht sowohl durch große Läden, als durch viele kleine ihr Geschäft machen), ging dahin, Warenhäuser und Konsumvereine müßten durch Steuern erdrosselt werden. Dem Publikum waren die Warenhäuser wegen ihrer niedrigen Preise und anderer Annehmlichkeiten lieb geworden; gegen die Konsumvereine wendet es sich nicht aus Wettbewerbseifersucht, unterstïtzt diese aber durch die Verurteilung der "sozialdemokratischen" Konsumvereine. Die fliissige Offentliche Meinung zeigt sich hier bisher in ihrer ganzen Blödigkeit und ihrem tauben Eigensinn. Wären diese Konsumvereine sozialdemokratisch, so hätte sie alle Ursache, diese Wendung der "Umsturzpartei "von der Verfolgung entfernter Ziele und der Hingebung an fatalistische Theorien zu praktischer Selbsthilfe und zur Anpassung an den "Gegenwartsstaat « willkommen zu heißen. Anstatt dessen genügt das odiose Beiwort, sie gegen solche redliche Versuche einzunehmen (mit den "redlichen Pionieren «im Auslande wird natürlich, wenn man von ihnen hört, sympathisiert). Zur Rede gestellt aber, wird die Offentliche Meinung geltend machen, daß doch offenbar und eingeständlich diese neuen Konsumvereine es darauf abgesehen haben, durch ihr Anwachsen und ihre Eigenproduktion allmählich die kapitalistische Welt aus den Angeln zu heben. Daß dies nicht geduldet werden müsse, scheint sich von selbst zu verstehen. (Etwas anderes ist es, wenn aus der eigenen Mitte oder wenn von einer anderen politischen Richtung her vor unbesonnenen Fortschritten, vor Wegen, die in den Sumpf führen, gewarnt wird und dagegen strenge Grundsätze vorsichtiger Geschäftsführung eingeschärft werden; jedoch vermischt sich naturgemäß dieser Gesichtspunkt mit der allgemeinen Abneigung der Offentlichen Meinung), ferner wird dann die Personalunion ins Gesichtsfeld gerückt. Die meisten Leiter dieser Arbeiterkonsumvereine sind tatsächlich Sozialdemokraten. Die meisten Leiter der größeren Banken sind tatsächlich Nationalliberale. Man redet um deswillen nicht von nationalliberalen Banken, aber die andere Tatsache scheint Grund genug, von sozialdemokratischen Konsumvereinen zu reden. Gegen diese Bezeichnung, die 
als eine Bezichtigung wirken soll, hilft es wenig, da $B$ das deutsche Gesetz den Genossenschaften jede politische Betätigung verwehrt. Noch weniger helfen die grundsätzlichen, oft wiederholten Erklärungen und Versicherungen, da $B$ die Konsumvereine politisch schlechthin neutral sind und sein wollen; daB es eine innere Lebensbedingung für sie sei, diese Neutralität aufrecht zu erhalten und zu schützen. Die Offentliche Meinung sagt unerschüttert: "sozialdemokratische Konsumvereine«. Die Schädigung des Mittelstandes, die als solche für unerfreulich gilt, erscheint in um so schlimmerem Lichte, wenn sie von sozialdemokratischen Organisationen ausgeht. - Das Konsumvereinswesen hat, ungeachtet so heftiger Widerstände, gegen Ende des alten und im Laufe des neuen Jahrhunderts, in Deutschland und in anderen Ländern (besonders auch in der Schweiz und in Skandinavien) einen mächtigen Aufschwung genommen. Wenn eben dieser auch die heftigen Anklagen und die abgünstigen Urteile verursacht hat, so leitet er doch zugleich hinüber zu einer besseren Erkenntnis. Diese zu vermitteln, ist, wie in allen Dingen, die Wissenschaft berufen, die in diesem Gebiete, wie überall, mit der politischen Theorie und Praxis sich nahe berührt. Da läßt nun ein Fortschritt, wenigstens der Aufmerksamkeit und, in der sozialen Frage, der Beachtung sich wahrnehmen, die der Erscheinung heute gewidmet wird, wenn sie mit derjenigen verglichen wird, die ihr noch vor wenigen Jahrzehnten zuteil wurde. HUBER, der erste und verdienstvolle deutsche Förderer der Sache, sprach noch (1857 im ersten Bande des Staatswörterbuchs) - hauptsächlich mit Bezug auf das gesamte Assoziationswesen der Arbeiter in England - von der gehässigsten Opposition der mammonistischen Privatindustrie und der ihr dienstbaren Presse, bei fast gänzlicher Ignorierung von seiten der Offentlichen Meinung und dem durch diese widrigen Umstände mitverursachten Scheitern von Hunderten solcher Assoziationsversuche. Der Rechtshistoriker O. GrERkE aber wußte, Io Jahre später, im ersten Bande seines berühmten Genossenschaftsrechts (I 868 ), schon die verschiedenen Arten der "Personalgenossenschaft für wirtschaftliche $Z$ wecke « und unter ihnen besonders die wirtschaftlichen Distributivgenossenschaften von den Produktivgenossenschaften zu unterscheiden; jene aber zerfallen ihm in Konsumvereine und Wohnungsgenossenschaften. Uber beide spricht er mit vollkommener Kenntnis der damals vorhandenen Tatsachen. Die Rechtsgelehrten haben natürlich auch später insoweit mit diesen sich beschäftigt, als die Gesetzgebung sich darauf bezogen hat, also besondere Rechtssätze darauf angewandt werden müssen; aber auch nicht weiter. Das BGB. und das gleichzeitig (r. Januar I900) in Kraft getretene deutsche Handelsgesetzbuch 
gehen daran vorbei. - Auch die Nationalökonomen haben sich bis vor kurzem nur obenhin darum bekümmert. RAU tut der Konsumvereine in seiner »Volkswirtschaftspolitik «keine Erwähnung; ROSCHER gleichfalls nicht in seinen "Grundlagen der Nationalökonomie" (der Begriff ist also für ihn bedeutungslos); hingegen in der "Nationalökonomie des Handels und Gewerbfleißes « widmet er unter dem allgemeinen Kapitel "Genossenschaftliche Neubildungen der Gewerbefreiheit " den Produktivgenossenschaften einen Abschnitt und bringt in diese auch die Rochdale Equitable Pioneers Society, offenbar nur, um den Satz anzubringen (der auch in seiner "Politik "wiederkehrt), daß nichts so, wie ihre "glorreiche Geschichte" die giftige Irrlehre des Sozialismus von der Hoffnungslosigkeit des Sparens für Arbeiter in helles Licht setze. Hingegen im fünften Bande des "Systems der Volkswirtschaft «, wo das zweite Buch die „Anstalten, die Armut zu verhüten", erörtert, will das dritte Kapitel dieses Buches die Konsumvereine behandeln und geht hauptsächlich auf die englischen ein, sieht aber (I894) richtig voraus, daß die gesetzliche Zulassung (1889) von Genossenschaften mit beschränkter Haftung im Deutschen Reich „die Vereine gewiß sehr heben wird“. In den neueren Lehrbüchern von CONRAD und PHILIPPOvich zeigt sich dann ein erheblicher Fortschritt. ConRad behandelt die Konsumvereine in seiner "Volkswirtschaftspolitik " als eine Erscheinung der "Arbeiterfrage " und diese als ein Kapitel seines Abschnittes II, der ïberschrieben ist „Die stoffveredelnden Gewerbe" (als ob die Konsumvereine für die Landwirtschaft grundsätzlich ohne Bedeutung wären, was ein Kenner der Landwirtschaft und seines Genossenschaftswesens wie CoNRAD am wenigsten meinen konnte!). Hingegen PhILIPPOVICH weist ihnen in der "Allge meinen Volkswirtschaftslehre« ihren Platz an, wo er im zweiten Abschnitt seines zweiten Buches ("Produktion und Erwerb») die Organisation der Produktion und des Erwerbes darstellt und an erster Stelle die $\gg$ Formen der Unternehmung « erörtert. Hier unterscheidet er Einzelunternehmung, gesellschaftliche Unternehmungsformen und öffentliche Unternehmungen, und widmet, nach einem Paragraphen (63) über die Aktiengesellschaften, 5 solche $(64-68)$ den "Genossenschaften «; darin aber kommen den Konsumvereinen nur 4 Zeilen zugute, und bei der Sonderbehandlung der Genossenschaften in Deutschland nennt er dessen Genossenschaftsbewegung ,fast ausschließlich ein Mittel der Vervollkommnung wirtschaftlicher Technik in den mittleren Klassen der Bevölkerung, die, wenig begütert, durch Konsumvereine kleine Ersparungen zu machen hoffen, und sodann eine Stütze des gewerblichen und landwirtschaftlichen Kleinbesitzes" ( ${ }^{8}$, S. I8I). 
Auch SCHMOLLER behandelt in seiner "Allgemeinen Volkswirtschaftslehre" (I, 525) die Konsumvereine auf einer halben Seite. Wenn er aber in ihre Definition aufnimmt, „daß sie einen Gewinn erzielen wollen", und dann auch von Verteilung des "Gewinnes « nach den Ankäufen spricht, wenn er ferner zu den Verwaltungsgrundsätzen zählt: ,,möglichst, wenn das Gesetz es erlaubt, Verkauf auch an Nichtmitglieder, um sie zum Eintritt zu locken" - so verkennt er ihr Wesen durchaus. Er fällt hinter ROSCHER zurück, der zwar gegenüber einem Konsumvereine, der auch an Nichtmitglieder verkauft, die Gewerbesteuer für begründet erklärt, dann aber hinzufügt: „,Sonst aber hat der sog. Gewinn der Konsumvereine ja nur den Charakter einer Ersparnis" (er setzt es als bekannt voraus). Dieser Unterschied ist sehr oft, und in verschiedenen Ländern mit gleicher Schärfe, betont worden, so noch neuerdings durch den schwedischen Genossenschafter ANDERs ORNE, der die Terminologie einer Kommunalsteuervorlage als völlig unrichtig bekämpft, weil sie von kooperativen ^Nahrungsgeschäften «spreche; diese Bezeichnung (näringsföretag im Schwedischen) setze eine Absicht, Gewinn zu erzielen, voraus. „Eine solche Absicht liegt nicht vor bei kooperativen Geschäften, kommt jedenfalls nicht in Frage bei der wichtigsten Gruppe unter ihnen, den Konsumvereinen. Diese haben zum Zwecke eine Ausgabeersparnis, nicht einen Gewinn" (Hur bör kooperationen beskattas? Stockholm I9I7, S. I6). Was aber den Verkauf auch an Nichtmitglieder betrifft, so ist er, wo gesetzlich erlaubt, eine Praxis unbedeutender Vereine, die von den Verbänden und den Leitern der Gesamtbewegung unablässig und eindringlich bekämpft wird, auch mit sichtlichem Erfolge: so in Schweden, in Norwegen, in der Schweiz usw. Durchaus unrichtig ist es, diesen Mißbrauch als Verwaltungsgrundsatz $z u$ bezeichnen, wie Schmoller tut. Eben die Bekämpfung ist Verwaltungsgrundsatz. - Auch bei AdolPH WAGNER wird man, obschon er mit allen Bestrebungen der Arbeit gegen das Kapital lebhaft sympathisierte, keine Würdigung des Konsumgenossenschaftswesens erwarten. Er war zu sehr Staatsmann - Staatssozialist - um der Selbsthilfe der Arbeiter, außer wo sie unmittelbar auf Gestaltung des Arbeitslohnes wirkt, sonderliche Bedeutung beizumessen. - So ist die Verbreitung einer richtigen Erkenntnis fast ausschlieBlich solchen Schriftstellern vorbehalten, die der Sache ihre besondere Teilnahme widmen, ihr besondere Förderung persönlich angedeihen lassen - derer aber ist keine große Zahl, und sie gelten mehr oder weniger, zumeist mit gutem Grunde, als Sozialisten, und dies wird leicht zum AnlaB, die Bezeichnung der zahlreichsten Gattung von Konsumvereinen als "sozialdemokratisch " für bestätigt zu halten. In Wahrheit ist gerade die 
Teilnahme ausgesprochen sozialdemokratischer Theoretiker für diese Gestalt der Arbeiterbewegung und vollends die der Partei als solcher, durchaus lau, zum Teil offenbar, weil sie Ablenkung von den großen politischen Zielen besorgen, deren Erreichung diese bescheidenen Fortschritte überflüssig machen soll; sodann aber auch, weil die strenge Lehre den davon gehegten Erwartungen entgegen ist. So $\mathrm{da} B$ die sog. anarchistischen, mit ProudHons Theorien verwandten Doktrinen, die jedoch in England, Deutschland, Skandinavien sehr geringen Anhang haben, sich durch die tatsächlichen Erfolge mehr befriedigt fuihlen und auch wirklich diese befördert haben. Andererseits ist es kein Zufall, daß ein entschiedener Gegner des Sozialismus, ein Mann, der mit dem gesamten Liberalismus seiner Zeit das "Gehenlassen "(laisser faire) vertrat, HERMAN SchulZE aus Delitzsch, der praktische Begründer der Konsumvereine in Deutschland ist (STAUDINGER, Die Konsumgenossenschaft S.66). Wie aber STAUDINGER zeigt (das. S. 6I), betrachtet eben dieser um die Sache so verdiente Mann die Organisation der Konsumenten nur als Handelsgeschäft, das mit seinen "Kunden « arbeitet, und die Eigenproduktion für die organisierten Konsumenten nur als Marktproduktion. - Wenn also bei den Nationalökonomen und Sozialpolitikern wenig Verständnis für diese höchst bedeutsame, einer großen Entwicklung fähige Sache angetroffen wird, so dürfen wir noch weniger davon bei den Philosophen erwarten, obgleich diese, soweit sie sich mit Problemen der Ethik befassen, und vollends, wenn sie dadurch auf die politische Theorie geführt werden, nicht umhin können, der sozialen Frage einige Aufmerksamkeit zu schenken. F. STAUDINGER, der hervorragendste Vorkämpfer des Arbeitergenossenschaftswesens, steht auch als Ethiker, der in einer Reihe von Schriften dessen grundsätzliche Bedeutung unterstrichen hat, ziemlich allein. STAUDINGER hat am eingehendsten in seinen "Kulturgrundlagen der Politik" (Jena I9I4) zu beweisen sich angelegen sein lassen, daß es ohne Genossenschaftsbildung heute keine nach oben führende Kulturpolitik geben könne, daß aber für Kulturpolitik im Sinne der Gemeinschaft zu wirken, höchste ethische Aufgabe sei. Auch bei anderen neueren Ethikern finden wir in der Regel - wenigstens bei den deutschen eine scharfe Beurteilung des Kapitalismus, also der heute durchaus vorherrschenden sozialen Lebensbedingungen. So bei PAULSEN und bei WUNDT, deren umfangreiche Werke durch Reihen von Auflagen bekunden, $d a ß$ sie zeitgemä $B$ gewirkt haben und noch wirken. PAULSEN, der in seinem "System der Ethik " 7. 11. 8. Auflage I906) das vierte Buch den Formen des Gemeinschaftslebens und den großen dritten Abschnitt darin dem wirtschaftlichen Leben und der 
Gesellschaft widmet, behandelt in einem langen Kapitel dieses Abschnitts "Sozialismus und soziale Reform «; er schreibt darin (II, S. 487) dem Genossenschaftswesen die Absicht zu, den Kleinbetrieb zu erhalten und lebensfähig zu machen (es wirke aber doch zugleich im Sinne der inneren Sozialisierung der Produktion und der produktiven Kräfte); dann führt ihn die Betrachtung der sozialen Reform auf die "Organisation der Arbeiter ", und er spricht von Gewerkvereinen, Arbeiterausschüssen, Geschäftsbeteiligung, von diesen auch als einer „Übergangsform zu einer Produktionsgenossenschaft" (das. S. 528): das ist alles. WUNDT erwähnt als die sittlichen Lebensgebiete zuerst die einzelne Persönlichkeit, sodann »die Gesellschaft «, unid zwar I. die Familie, 2. die Gesellschaftsklassen, 3. die Vereine und Verbände (Ethik II, $292 \mathrm{ff}$.). Der "Berufsverband " führe zumeist vorzugsweise den Namen der Genossenschaft: diejenige Gattung von Berufsverbänden habe die größte Bedeutung gewonnen - und dies sei für Charakter und Richtung der sozialen Bewegungen der Gegenwart bemerkenswert - die an sich die allerloseste Form der Vereinigung sei: die Koalition; als solche werden dann in einigen Sätzen die Gewerkvereine und Gewerkschaften der Arbeiter und die Kartelle der Unternehmer besprochen. Nichts weiter. Wenn also diese beiden berïhmten Ethiker tatsächlich das Konsumgenossenschaftswesen nicht zu kennen scheinen, so spiegelt sich doch dessen Fortschritt bei einem dritten - in der Grundrichtung mit beiden verwandten Autor, dem Dänen HARALD HÖFFDING, dessen Ethik in Skandinavien und durch die deutsche Ausgabe auch in Deutschland Ansehen und Einfluß besitzt. Während er nämlich in der ersten deutschen Ausgabe (I888) gleichfalls nur von Gewerkvereinen, Gewinnbeteiligungen und Produktivgenossenschaften als Formen der freien Assoziation von Arbeitern handelt, um am Schlusse des Abschnittes zu sagen (S. 290), es könnten noch verschiedene andere Arten erwähnt werden, ,welche jede ihren Wert haben" (,So die Konsumvereine, die Baugenossenschaften, die Versicherungsvereine u. a.") - in der zweiten Auflage dieser deutschen Ausgabe (I9OI) werden die Konsumvereine besser gewürdigt, hauptsächlich auch, weil sie - in Ëngland und in der Schweiz - mächtig zur Entwicklung des Solidaritätsgefühls beigetragen haben, und weil sie ,,Redlichkeit und Uneigennützigkeit, Klugheit und Energie, demokratische Gesinnung und Fähigkeit zur Selbstverwaltung" erfordern. Sie seien neben den Gewerkvereinen die wichtigste Schule für die Arbeiterklasse geworden wie auch das wichtigste Mittel für soziale Organisation dieser Klasse, "die seit der Aufhebung der I eibeigenschaft und der Zünfte als eine chaotische Masse dastand" (S. 383). 
Wie immer Führer und Geführte in Wechselwirkung miteinander stehen, so auch Führer und Geführte der Offentlichen Meinung. Die hier dargestellte Haltung jener $z \mathfrak{u}$ einer so wichtigen sozialen Erscheinung ist nur dadurch zu erklären, daß sie von der Offentlichen Meinung so gut wie nichts empfingen; es geht aber daraus auch hervor, da $\beta$ diese von ihren Führern sehr wenig empfing. Wenn fast alle hier genannten einflußreichen Schriftsteller von dem Wesenskern oder dem unterscheidenden Merkmal der Konsumgenossenschaft nichts erkannt hatten - $\mathrm{da} B$ sie keinen Gewinn machen und kein Kapital bilden will um zukünftigen Gewinnes willen -, so kann es nicht wunder nehmen, wenn die Offentliche Meinung nichts davon wei $\beta$ und, man darf sagen, nichts davon wissen will, sondern im günstigsten Falle den Konsumvereinen einen Platz neben den für normaler geltenden Kleinhandelsbetrieben einräumt und sie in der Besteuerung diesen gleichgestellt sein läßt. Wenn man die Stellung, welche die Gewerkschaften in der Offentlichen Meinung sich erobert haben, damit vergleicht, so fällt $z \mathfrak{u}$ deren Gunsten ins Gewicht, daB sie mehr und mehr als nicht mehr vernichtbare Macht sich dargestellt haben, was man von den Konsumvereinen noch nicht sagen kann, am ehesten von der Bedeutung sagen mag, die sie in Großbritannien und in der Schweiz erlangt haben.

\section{Dritter Abschnitt. Verhältnis zu Sozialdemokratie und Arbeiterbewegung.}

6. (Die Sozialdemokratie.) Um so mehr gilt aber von der politischen Partei, die den Sozialismus zugleich mit der Demokratie sich zum Ziele gesetzt hat, da $B$ sie als Macht sich Beachtung und dadurch in einigem Maße auch Achtung erzwungen hat. Wir nehmen hier die deutsche Sozialdemokratie als Muster, denn nur, oder doch am frühesten und stärksten, im Deutschen Reiche hat diese aus dem Geiste des I9. Jahrhunderts entsprungene Partei historischen Rang erworben. Während ihrer ganzen Entwicklung ist sie von der Offentlichen Meinung verneint worden, wenn auch vor 40 Jahren (I878) viel entschiedener, als es heute (I9I8) der Fall ist. Hier ist der typische Fall, daß »die "Offentliche Meinung als Einmütigkeit der sonst entgegengesetzten und feindlichen Parteien sich darstellt, der konservativen und der liberalen; wenn jene mehr die politische Richtung ablehnen und verdammen - mit Hinweisung darauf, daß die liberale ihr verwandt sei -, so diese um so heftiger die ökonomisch-soziale Richtung - wiederum mit Hinweisung, daß diese falsche Tendenz mit gewissen Neigungen der konservativen Parteien sich begegne. Wie aber die Offentliche Meinung den sozialdemokratischen Geist 
schlechthin verwirft und verabscheut, offenbart sich auch darin, da $B$ die Liberalen ängstlich beflissen sein müssen, den Schein verwandter politischer Bestrebung, die Konservativen ebenso den Schein verwandten sozialen Geistes, abzuwehren. Vieles Charakteristische enthielten in dieser Beziehung die Verhandlungen des Reichstages, als er im Jahre 1878 die Vorlage über die ,gemeingefährlichen Bestrebungen" der Sozialdemokratie beriet. So erklärte damals Fürst BISMARCK, er halte für richtig, was er vor kurzem in einem Artikel der "Nationalzeitung "gefunden, da $B$ die Wähler aller Abgeordneten, also auch des Zentrums und der Fortschrittspartei, mit alleiniger Ausnahme der Sozialdemokraten, von ihren Abgeordneten erwartet haben, daB sie der Regierung gegen Beseitigung dieser Gefahr beistehen würden. Es war allerdings nicht buchstäblich richtig; denn die Wähler des Zentrums waren noch zu feindlich gegen die Regierung gestimmt, solange sie, wie WINDTHORST in dieser Verhandlung sich aussprach, ,ihres Glaubens wegen verfolgt würden", aber sie kamen eben für die Offentliche Meinung damals wenig in Betracht, die Offentliche Meinung wurde allerdings durch jene Außerung charakterisiert. BISMARCK machte sie sich zu eigen, um die Notwendigkeit der Gruppe, die später als »die Kartellparteien " bekannt war, für sich und seine Politik daraus abzuleiten. In diesem Sinne antwortete ihm am folgenden Tage Herr von BENNIGSEN. Er sagte, der Reichskanzler habe in einer offenen, unumwundenen Weise die Gleichberechtigung der liberalen und konservativen Elemente auf dem Gebiet unseres politischen L,ebens anerkannt, und dies sei wertvoll gerade in der jetzigen Zeitlage, je schwieriger die Verhältnisse seien, ,,wenn wir gemeinsam eine so große Gefahr bekämpfen sollen, wie die sozialdemokratische Bewegung", um so mehr werde man verlangen können, $\mathrm{da} B$ sich Staatsmänner und Parteien berühren. Man nannte diese BENNIGSENsche Rede eine staatsmännische Rede; sie war ein Echo der Offentlichen Meinung ${ }^{1}$ ).

1) Im Jahre 1874 schilderte A. SCHÄFFLE den „,verworrenen Zustand der öffentlichen Meinung", bei dem das Eirste, was not tue, sei: die präzise Kenntnis vom Wesen und Ziel der sozialistischen Neugestaltung, insbesondere die Zerstreuung der einlullenden falschen Vorstellungen und die Vernichtung der sich selbst täuschenden Ignoranz - in folgendem Satze, dem ersten seiner ",Quintessenz des Sozialismus", als deren Absicht er bezeichnet, richtige Kenntnisse auf diesem Felde zu fördern: ,'Seit den letzten Wahlen zum Deutschen Reichstag (1874) spukt das srote Gespenst \& bis in die letzte Bierstube. Aber merkwürdig, nicht bloß in der Welt der Kannegießer, sondern weit hinauf in die Reihen der $\gg$ besitzenden und gebildeten Klassen «... ist der Kern und das Ziel der sozialistischen Propaganda noch fast unbekannt" usf. Die 1894 erschienene Schrift von OTrO PRANGE, „Das rote Gespenst", betrachtet in ihrem ersten Kapitel , las rote Gespenst und die öfentliche Meinung". Und 1889 erklärte G. v. Schur.ze - GaEvernatz: „Die öffentliche Meinung ....irrt, wenn sie in den Umsturzparteien das unabwendbare Gespenst der Zukunft sicht, demgegenüber man nichts kann, als das Gewissen salvieren ..." 
Sehr deutlich sprach sich auch damals und während der folgenden Jahrzehnte die Offentliche Meinung aus, wenn sie die sozialdemokratische Partei als Umsturzpartei « bezeichnete und alle übrigen Parteien ihr gegenüber als Ordnungsparteien oder gar schlechthin als die Ordnungspartei. Das Gothaer Programm (vom Mai I875) erklärte zwar, daß die sozialistische Arbeiterpartei Deutschlands „mit allen gesetzlichen Mitteln" den freien Staat und die sozialistische Gesellschaft usw. erstrebe. Um diesen Wortlaut kümmerten sich aber unter ihren Gegnern wenige. Dennoch war es für diese eine Genugtuung, daß zwei Jahre nach Erla $\beta$ des Sozialistengesetzes der Wydener Kongre $B$ die Streichung des Wortes "gesetzlichen « beschloß, und die Parteileitung in einem Manifest u. a. erklärte: „Will es nicht biegen von oben herab, so muß es brechen von unten hinauf." In einer Schrift über „die rote Internationale“ schrieb der Regierungsassessor Dr. ZACHER (I884), die Partei habe sich nun als Revolutionspartei zu erkennen gegeben (S. 23). Wenn sie sich aber trotzdem nach außen hin immer wieder als friedliebende Reformpartei aufzuspielen suche, so sei das nichts weiter, als ein taktisches Manöver, um der Offentlichen Meinung gegenüber den Schein der Gesetzlichkeit $\mathrm{zu}$ wahren und schwankende Elemente nicht abzuschrecken. In dieser Angabe ist die Erkenntnis enthalten, daß die Offentliche Meinung Gesetzlichkeit will, und zugleich der (begründete) Verdacht kundgegeben, daß die Offentliche Meinung sich durch den Schein täuschen lasse. In den Verhandlungen von 1878 sagte auch der geistreiche Zentrumsführer WINDTHORST, indem er das Ausnahmegesetz als verwerflich hinstellte, das Einzige, was er den Sozialdemokraten absolut verbiete und verbieten wolle, sei, $\mathrm{da} B$ sie die Ideen, über die sie diskutieren, und die sie nach seinem Willen frei diskutieren möchten, mit Gewalt durchführen wollen (,,wenn es so gemeint ist, dann stehen wir Schulter an Schulter gegen Sie"). Eir unterstrich damit die Einhelligkeit der Offentlichen Meinung in dieser Beziehung, von einem Standpunkte aus, für den Religion und nicht öffentliche Meinung den maßgebenden Grundsatz bedeutet.

Wenn aber darin beschlossen scheint, daß sie eine friedliche und gesetzlich vorgehende Partei wenigstens zu dulden und nicht mit Gewalt zu unterdrücken gesonnen sei, so war (und ist noch heute, wenn auch vermindert) die Offentliche Meinung doch gegen die Sache, gegen die Ideen dieser Partei in schärfster Weise eingenommen. Selbst dann noch, wenn die ursprünglichen Vorstellungen von Kommunismus, vom Aufteilen oder von Gütergemeinschaft verblichen sind, und insbesondere das Schlagwort "Sozialismus « aufgehört hat, 
Schauder zu erregen. Die Auffassung neigt dann dahin, nicht so selır die Scheußlichkeit, wie die Unmöglichkeit solcher Endziele hervorzuheben, daher in der Hinweisung auf "sozialistische Utopien « das zweite Wort schärfer zu betonen. Wenn der eigentliche Sinn des Wortes "Utopie " oder gar sein Ursprung wenigen, die es im Munde führen, bekannt ist, so verbindet sich doch stark damit die Vorstellung von etwas Sinnlosem, Törichtem, ja Kindischem, durch dessen Verfolgung also man sich lächerlich mache; und der „Fluch der Lächerlichkeit « wirkt in der öffentlichen Meinung wie ein Bannfluch. Alle Pfeile, die auf ein so geächtetes Ziel gerichtet werden, vereinigen sich in den Angriffen auf den " $Z$ ukunftsstaat $«$. Die Offentliche Meinung betrachtet dies Gebilde der Phantasie bald als etwas Furchtbares, als das "große Zuchthaus», bald als etwas so Unsinniges, daß es, in die Wirklichkeit ïbersetzt, rasch in sich zusammenstürzen müßte. Nach dem Fall des Ausnahmegesetzes (I890) kamen der allgemeinen Überzeugung, da $\beta$ die Sozialdemokratie nunmehr mit "geistigen Waffen « überwunden werden müsse, nach jenen beiden Richtungen entgegen die von dem namhaften Politiker EUGEN RICHTER verfaßten Flugschriften ,Die Irrlehren der Sozialdemokratie“ und ,Sozialdemokratische Zukunftsbilder". Obgleich dieser gewandte und kenntnisreiche Mann nur ein schwaches und zusammenschmelzendes Parteigefolge hatte, so wurde ihm doch lebhafter Beifall von allen Seiten außerhalb der Sozialdemokratie zuteil, der lebhafteste von seinen eigensten politischen Gegnern, den Konservativen. So wurde das erste kleine Heft in mehr als 80000 Exemplaren verbreitet, von dem anderen wurde im März 1892 das 206. bis 210. Tauserd gedruckt, die Zukunftsbilder" verdankten ihren größeren Eirfolg offenbar der novellistisch erzählenden Form, worin das Schicksal einer Familie am Tage mnach dem Umsturz" und binnen weniger Wochen nachher auf mergreifende Art « dargestellt wurde. Die :Zukunftsbilder "wollten "frei nach BEBEL " entworfen sein; dem lag zugrunde, daß A. BEBEL unter dem Banne des Ausnahmegesetzes ein Buch über "die Frau "verfaßt hatte, das auch außerhalb seiner Partei weithin gelesen wurde; er hatte darin seine persönlichen Ansichten über die Lage der Frau in der kommenden Gesellschaft entwickelt und zu diesem Behuf sich eine Vorstellung von der Zukunftsgesellschaft (den Ausdruck "Zukunftsstaat « meidet er ängstlich) gebildet, die von seinen eigenen Genossen stark angefochten wurde, aber der gegnerischen Kritik um so reicheren Stoff bot, ihren Witz und Spott daran zu üben; außer der RICH'ERschen erschien noch eine Reihe von Flugschriften im letzten Jahrzelnt des Jahrhunderts, die alle sich der Widerlegung BeBbis widmeten.

Tonaies, Kritik. 
Wenn aber die Gedanken an den Zukunftsstaat als Hoffnungen und Schwärmerei doch etwas Harmloses an sich zu haben scheinen, das zwar töricht, aber nicht verdammenswert sein möchte, so erregen hingegen Unwillen und Empörung jene Irrlehren, die gegen die befestigten und geheiligten Institutionen des sozialen Lebens gerichtet sind. Als solche wird auch »die " Religion geachtet, und wenn auch das Zeitalter sich gewöhnt hat, das Nebeneinander ganz verschiedener und einander gegenseitig für verderblichen Wahn erachtender Religionen oder Konfessionen und Sekten als unabänderlich anzusehen; wenn auch $-z$. T. infolgedessen - die Offentliche Meinung ziemlich gleichgültig gegen diese Unterschiede und Unterscheidungslehren, ja überwiegend freidenkerisch geworden ist: so gilt ihr doch ein Angriff auf »die "Religion, auf alle Religion und Religiosität als staatsgefährlich, zumal wenn er in Verbindung mit Angriffen auf andere Institutionen, die dem modernen Menschen näher am Herzen liegen, insbesondere also auf das "Eigentum ", gebracht wird. Obgleich nun die deutsche sozialdemokratische Partei Religion für Privatsache erklärt, also keine programmatische Stellung $\mathrm{zu}$ ihr einnimmt, so hatten doch gar manche Äußerungen ihrer Anhänger, auch einiger Führer, der Vorstellung Nahrung gegeben, daß die Partei als solche atheistisch sei, und die Bezeichnung als "Privatsache" wurde oft dahin gedeutet, $\mathrm{da} B$ sie eine Geringschätzung und Herabsetzung in sich schließe. Die "Begründung « des Sozialistengesetzes konnte auf Verständnis und Zustimmung der Offentlichen Meinung rechnen, wenn sie als Folge der sozialdemokratischen Agitation u. a. hinstellte: „Die sittlichen und religiösen Uberzeugungen, welche die Gesellschaft zusammenhalten, werden erschüttert"; wenngleich es ihr schwer gefallen wäre, diese religiösen Überzeugungen der heutigen Gesellschaft genauer zu beschreiben. In der Generaldebatte konnte BEBEL, nachdem er "ausdrücklich erklärt « hatte, daß die Sozialdemokratie nicht verlange, daß ihre Anhänger in religiösen Dingen eine bestimmte Meinung haben müssen, mit Recht fragen: „Wer hat denn aber diese atheistischen Lehren, die Ihnen so viel Sorge und Verdruß machen, wissenschaftlich und philosophisch begründet?" und die Frage dahin beantworten, es seien Männer der Wissenschaft, die mit ihren sonstigen Anschauungen im bürgerlichen Leben, und meist in der liberalen Partei, gestanden haben. Und am folgenden Tage war HÄNEL ehrlich genug, der Behauptung gegenüber, die sozialdemokratische Agitation gehe aus auf die Untergrabung der Religion, einzugestehen: „Die Richtung gegen die religöse Stimmung, wahrhaftig, sie stammt nicht aus der sozialdemokratischen Agitation ... sie stammt von uns, sie stammt aus unserer Literatur, 
sie stammt vor allen Dingen auch aus dem Verhältnis unserer gebildeten Klassen zu den verschiedenen Kirchen, in denen sie eingeboren sind." - Indessen die Offentliche Meinung verlangt nicht eine besondere Ehrfurcht vor den Kirchen, deren Mannigfaltigkeit und Streit ihr anstößig ist, sie ist mehr für eine unkirchliche Religion und will wenigstens den Gottesglauben nicht angetastet wissen, ohne da $B$ sie Eingriffe der Götter in den Verlauf der Natur anzunehmen geneigt wäre: sie setzt den Deismus fort, der im I7. Jahrhundert aufkam und im I8. zu den Vernunftideen der "natürlichen "Religion gerechnet wurde. Weil ihr ebenso wie das Dasein Gottes auch das Dasein der menschlichen Seele über allem Zweifel steht, so ist ihr der sog. Materialismus gleich dem Atheismus zuwider, und es gehört eine besondere Dreistigkeit dazu, die leicht als ein freches Trotzen gegen die Offentliche Meinung erscheint, sich zu diesem »Materialismus « zu bekennen, der jedoch von vielen als Eirgebnis und letztes Wort der neueren Naturwissenschaft geschätzt wird, besonders seitdem diese die Abstammung des Menschen von niederen Organismen in ihr Bereich gezogen und, wie man glaubt, bewiesen hat; denn damit scheint das Besondere, der göttliche Adel des Menschentums, preisgegeben zu werden. Uberdies, und in nahem Zusammenhange damit, wird dann diese philosophische Ansicht als die Wurzel einer Willensrichtung aufgefaßt, die ausschließlich auf sinnliche Genüsse gerichtet sei, und wohl gar, weil ja der Glaube an ein zukünftiges Leben nicht vorhanden, also nicht hemmend wirke, in der Äußerung sich zusammenfasse: "Lasset uns essen und trinken, denn morgen sind wir tot." In der Verhandlung von I878 zitierte der Abgeordnete voN KLEISTRETzOW diesen bekannten Lebensgrundsatz und meinte, dazu müßten die Sozialdemokraten kommen, denn „die Sozialdemokraten wollen ein glückliches, reiches Leben mit einem AbschluB in dieser Welt erreichen." Herr voN KLEIST gab in der gleichen Rede den Worten HÄNELS seine volle Anerkennung, wonach die gebildeten Klassen, die Besitzenden, gegenwärtig in „Materialismus und Unglauben“ versunken seien. Wenn man auch die Behauptung der Tatsache nicht als Inhalt der Offentlichen Meinung bezeichnen darf, so ist doch für diese charakteristisch, da $B$ der stockkonservative und der fortschrittlich-freisinnige Abgeordnete in der Mißbilligung des "Materialismus und Unglaubens " sich zusammenfanden, wenn auch ohne Zweifel die beiden Schlagworte für den einen eine andere Bedeutung hatten als für den anderen. - Im Gegensatz zum Materialismus billigt die Offentliche Meinung den sIdealismus", ohne aber dabei an dessen philosophische Bedeutung, die sie schwerlich kennt, zu denken, es wäre denn in dem Sinne eines Glaubens an das "Geistige «, das »Höhere «, 
an "Ideale «, womit alsbald der Übergang in die sittliche Bedeutung vollzogen wird. Wenn nun gleichzeitig den Sozialdemokraten die "Leugnung aller Ideale "vorgeworfen und die törichte, unpraktische Schwärmerei für das unmögliche Ideal des Zukunftstaates und der Gütergemeinschaft zur Last gelegt wird, so stört dieser Widerspruch die öffentliche Meinung keineswegs. Jeder Tadel hat seine Zeit und seinen Ort. Ja, die öffentliche Meinung kann auch den Tadel in ein Lob wenden, und z. B. den Idealismus, die Aufopferung und Begeisterung, die von Sozialdemokraten für ihre Partei betätigt werden, den Mitgliedern anderer Parteien als Muster darstellen; ebenso wird wohl die Hingebung, die der organisierte Arbeiter seinem Gewerkverein bewähre, anerkannt und als exemplarisch gewürdigt. - Hingegen richtet sich wieder die volle Wucht des Unwillens gegen die von sozialistischen Schriftstellern ausgehenden »Angriffe auf die Ehe « und die "Verherrlichung der freien Liebe «. Wenn auch nicht geradezu geltend gemacht wird, $\mathrm{da} B$ die Partei als solche Weibergemeinschaft als das Stück ihres Kommunismus predige, dem, nach W. Roscher, alle konsequenteren Sozialisten so nahe stehen wie der Gütergemeinschaft, so ist doch die Meinung, daß jenes Ideal eines lediglich moralischen Bundes zwischen den Geschlechtern in der Wirklichkeit kaum auf etwas anderes als auf Weibergemeinschaft hinauskommen werde. Wie stark der Abscheu dagegen in jener Phase, die dem Erlaß des Sozialistengesetzes vorausging, die öffentliche Meinung in Anspruch nahm, davon zeugt u. a. die Reihe der Zitate in einem I876 erschienenen Buche (Die Sozialdemokratie. Nach ihrem Wesen und ihrer Agitation quellenmäßig dargestellt. Von RICHARD Schuster, S. 226-234), die danach angetan waren, den ruhigen Bürger schaudern $\mathrm{zu}$ machen. Dagegen ist es nun auffallend, daß zwei Jahre später, in der großen Gerichtsverhandlung, wie man wohl die Beratung des Ausnahmegesetzes nennen kann, diese Anklage auch von den heftigsten Anklägern kaum gestreift worden ist. Diese Unterlassung zeigt den Unterschied der öffentlichen Meinung von der Tätigkeit öffentlicher Politiker. Diese mochten es für bedenklich halten, gerade in diesem Punkte die Kritik bestehender Zustände, insbesondere solcher, die in den höheren Schichten der Gesellschaft angetroffen werden, herauszufordern.

Die Offentliche Meinung, immer beflissen, sich an einfache, elementare Formeln zu halten, machte auch von jeher die sozialdemokratische Partei dafür verantwortlich, daß sie »das Eigentum "aufheben wolle. Treffend sagt das genannte Buch von I876: „Vom Kampf der Sozialdemokratie gegen das Eigentum redet wohl jedermann, aber nicht alle haben es zu klaren Vorstellungen hinsichtlich 
dieses Punktes gebracht." Der Verfasser will dann einiges zur Aufklärung darüber beitragen. In der oft genannten Beratung von 1878 wurde auch bei dieser Seite verhältnismäßig wenig verweilt. Wahrscheinlich aus der Ursache nicht, weil keine volle Einmütigkeit zwischen den Parteien darüber vorhanden war, die naturgemäß reiner in die Erscheinung trat gegenüber den Ideen zu gewaltsamem Umsturz, dem "Hochverrat ", wie Herr vON KLEIST, ohne Widerspruch zu finden, die Bestrebungen der Sozialdemokraten brandmarkte, ebenso aber auch gegenüber dem Materialismus und Atheismus. Angriffen gegen das große Grundeigentum hätten die Liberalen sich nicht völlig versagen können. Angriffe gegen das kapitalistische Eigentum waren den Konservativen (damals noch) nicht unbedingt zuwider. Da nun aber der Sozialismus hauptsächlich gegen den "Kapitalismus « sich richtet und in den Zuständen der Industrie seine Wurzeln hat, so fühlten sich hier auch die Liberalen auf den Kampfplatz gerufen, obgleich das Ausnahmegesetz in den konservativen Parteien seine eigentlichen Träger hatte, wie auch dadurch sich bestätigte, daß die Neuwahlen nach der Auflösung des Reichstages I 878 im Vergleiche mit den Wahlen des Vorjahres die Zahlen der für beide konservative Parteien abgegebenen gültigen Stimmen von 977766 ( $=17,6$ von Ioo gültigen Stimmen) auf I 525270 (=26,2 v. H.) vermehrte $^{1}$ ), wodurch die Zah1 der Abgeordneten dieser beiden Parteien von $78(=19,7)$ auf $\operatorname{Ir} 6(=29,3)$ erhöht wurde. Durch dieselben Neuwahlen fiel die Zah1 der für die damaligen drei liberalen Parteien (liberale, nationalliberale und Fortschrittspartei, ohne die "süddeutsche Volkspartei «) abgegebenen Stimmen von 2 I50 850 auf I 960 999, d. i. von 38,8 auf 33,7 v. H. und die Zahl der Abgeordneten von 176 auf 135 , d. i. von 44,3 auf 33,9 v. H. Der Liberalismus war eben schon durch das Verlangen der Offentlichen Meinung nach dem Ausnahmegesetz ${ }^{2}$ ) ins Gedränge gekommen, während gleichzeitig der Umschwung in der Handelspolitik ihn so unterwühlte, da $B$ er für drei Jahrzehnte aus dem vordersten Graben herausgedrängt wurde. Außerlich trat das auch in der Zerspaltung der bis dahin so stolzen und starken nationalliberalen Partei zutage, wenngleich sie noch geschlossen für das Ausnahmegesetz stimmte. Die liberalen Hauptredner in der Beratung waren HäNEL, BAMBERGER, BENNIGSEN. HÄNEL behandelte die Frage ideologisch. Er wollte dic Heftigkeit

1) Zugrundegelegt sind die entscheidenden Wahlen: Stat. Jahrb. f. d. D. R., Erster Jahrgang 1880, S. I4 If.

2) Auch in dem Artikel ",Sozialdemokratie" des HWS ${ }^{3}$ Bd. VII, S. $58_{4}$ heiBt es, nachdem von den beiden Attentaten die Rede gewesen: „Aber die öffentliche Meinung machte ungerechterweise die Sozialdemokraten dafür verantwortlich, und so kam (Oktober 1878) das Ausuahmegesetz . . zustande." 
und Roheit der Agitation auf dem Boden des gemeinen Rechts eindämmen, den Forderungen der Offentlichen Meinung also entgegenkommen, verwarf aber das "Partei- und Tendenzgesetz «. Ganz anders BAMBERGER: dieser gescheite Mann wand sich in so unbestimmten Redeformen, daß HÄNEL, der sich als ,Anhänger seiner geistreichen Redeweise" bekannte, erklären mußte, er sei absolut nicht imstande, zu erkennen, was Herr BAMBERGER denn eigentlich im letzten Sinne und im letzten Ziele wirklich wolle. In Wahrheit hatte aber der (damals noch) nationalliberale Abgeordnete für das Gesetz gesprochen, indem er in sophistischer Weise begründete, er glaube nicht, daß es sich um ein Ausnahmegesetz »dieser Art « handle (in dem Sinne nämlich, da $B$ nur eine besondere Kategorie von Personen von demselben getroffen werde). Er läßt sich dann aber dahin aus, $\mathrm{da} B$ er für unentbehrlich halte, das Wort ssozialistisch " (außer sozialdemokratisch und kommunistisch) in das Gesetz hineinzunehmen. Er machte, wenn auch in zweideutiger Sprache, kein Hehl daraus, $\mathrm{da} B$ er auch Katheder- und Staatssozialisten der Verfolgung auszusetzen wünschte; denn "das Ubel « habe seine Wurzel auch in den Denkweisen, die von den verschiedensten Seiten aus der Nation heraus gefördert worden seien. Man könne religiös und monarchisch gesinnt sein und doch »die Theorien "vertreten, von denen er gesprochen habe (,,daß das Kapital an und für sich ein Fluch und ein Unglück sei und abgeschafft werden müsse" (!!); von manchen werde nicht gegen das Eigentum im allgemeinen, sondern gegen das römische Eigentum polemisiert, von anderen zwar nicht das unbewegliche Eigentum, sondern das sog. Kapital angegriffen, ,auf welches überhaupt alle Schmach, Vorwürfe und Entrüstung herabgerufen wird"). Das Gift, das in die deutsche Nation hineingetragen worden sei, bestehe darin, daß jede Partikel der Nation gegen die andere in wildester Weise aufgehetzt wurde, weil man immer dem betreffenden Teile sagte: der andere Teil lebt auf deine Kosten; wenn es mit gerechten Dingen zuginge, würdest du an seiner Stelle oder teilweise an seiner Stelle sein, und es ist nur böser Wille der Gesetzgebung, wenn dies nicht geschieht. Durch die krause Erörterung leuchtet doch unverkennbar heraus, daß BAMBERGER den Kapitalismus vor gefährdender Kritik schützen wollte. Das war aber nicht der vorwaltende Gesichtspunkt der Offentlichen Meinung. Sie war keineswegs gesonnen, die schriftstellerische Freiheit der Gelehrten oder gar die wissenschaftliche Lehre der Hochschulen zu beschränken, vielmehr hätte die Erkenntnis, daß dies eine Folge, vielleicht sogar eine beabsichtigte Folge des Ausnahmegesetzes sein werde (tatsächlich ergab es sich als notwendige Wirkung), die Offentliche Meinung irre machen 
können an der Verfemung jener, „gemeingefährlichen Bestrebungen“. Kein Wunder, wenn der eigentliche Führer der nationalliberalen Partei, der auch nach der Sezession es blieb, zugleich ein Führer der gebildeten politischen Meinung, sich ganz anders aussprach. Herr vON BENNIGSEN, der wenige Monate vorher mit schlagenden Gründen und beredten Worten die Vorlage der verbündeten Regierungen verworfen hatte, fand sich nun - nicht am wenigsten durch die Offentliche Meinung, der gegenüber er seine Partei zu retten beflissen war in der Notlage, die neue, gleichgeartete Vorlage zu verteidigen. Er nannte das Gesetz ein "Spezialgesetz « und versuchte es als im Vergleich mit dem Frühjahrsentwurf »besser « darzustellen: wohl nicht unter die Absicht des Gesetzgebers, wohl aber unter den Wortlaut seien damals wissenschaftliche Untersuchungen, humanitäre Zwecke, praktische Förderung von Arbeiterinteressen ebensowohl wie revolutionäre, direkt auf den Umsturz hingehende Agitationen gefallen. Nunmehr aber werde nicht die Sozialdemokratie als solche unter Verfolgung gestellt, nicht ihre Bestrebungen als solche würden verfolgt, am allerwenigsten werde eine bestimmte Klasse der $\mathrm{Be}$ völkerung als solche getroffen (!!). Er führte dann aus: niemand werde so vermessen sein, zu glauben, daß mit der - ,,ich will es mit dem hergebrachten Kunstausdruck bezeichnen" - k a pitalistische $n$ Produktionsweise der heutigen Zeit die letzte Form gefunden sei, welche die wirtschaftliche Produktion annehmen könne und annehmen werde; und niemand werde behaupten wollen, wenn im Laufe der weiteren Entwicklung der Menschheit eine andere Grundlage für die Froduktionsweise gewonnen werde als die heutige, da $B$ dann diejenige Form des Privatrechts, also auch des Eigentums, welche gerade dieser kapitalistischen Produktionsform entspreche, dieselbe bleiben werde, ja, auch nur bleiben könne. ,Meine Herren, wenn vor unsern Augen ... der Schleier weggezogen würde, der uns die späteste Zukunft verhüllt, wenn die alsdann herrschenden Formen des wirtschaftlichen Lebens und Zusammenseins und die Gestaltungen von Staats- und Privatrecht unserem Blicke sich zeigten - sie würden uns gewiß sehr wunderbar und fremdartig erscheinen, viel wunderbarer und fremdartiger möglicherweise noch, als derartige Erscheinungen in früheren Jahrtausenden." Wer wolle so vermessen sein, zu sagen, er könne den Gang der wirtschaftlichen und Rechtsentwicklung für Jahrhunderte, Jahrtausende voraussehen? Und als Folgerung aus diesen Betrachtungen spricht er dann aus: „Nein, m. H., wissenschaftliche Erörterungen abzuschneiden, selbst wenn sie unwillkommen sein mögen für die bestehenden Institutionen, das darf ein menschlicher Gesetzgeber nicht wagen. Würde er es wagen, 
es würde ihm doch niemals gelingen" usw. Ähnlich würde es liegen hinsichtlich aller derjenigen Versuche, vielleicht weitgehenden Versuche, die Lage der arbeitenden Bevölkerung zu verbessern, oder, um es wirtschaftlich bestimmter auszudrücken, den Anteil, den die arbeitende Klasse im ganzen an dem Produktionsergebnis habe, zu steigern: darauf können wissenschaftliche Untersuchungen, darauf könne die Gesetzgebung bis zu einem gewissen Grade einwirken. Nur der revolutionäre Charakter, den die ganze sozialdemokratische Bewegung angenommen habe, erscheine als so gefährlich, und nur der müsse getroffen werden. Nachdem der Parteiführer dies noch in eingehender Weise erörtert hat, faßt er sich dahin zusammen, das seien die Gründe, ,,aus denen wir gegenüber dieser veränderten... Vorlage, angesichts einer so entschieden hervorgetretenen $\mathrm{Kund}$ gebung der Offentlichen Meinung unseres Volkes, uns der Aufgabe nicht entziehen, mit der Regierung und den Parteien zusammen, die diesen Boden für den richtigen halten, gesetzgeberisch tätig zu sein." Daran schließt sich dann der Ausdruck des Vertrauens, daß der Reichskanzler keine reaktionäre Politik einleiten wolle, daß er vielmehr die Gleichberechtigung der liberalen und der konservativen Elemente auf dem Gebiete unseres politischen Lebens anerkenne. - Selten hat wohl ein einflußreicher Politiker so gute theoretische Einsicht mit so völliger Blindheit in bezug auf Ausführung und Wirkungen eines Polizeigesetzes verbunden, das allerdings dazu geschaffen war, eine bestimmte Klasse der Bevölkerung als solche zu treffen.

7. (Wandlungen der Öffentlichen Meinung.) Das Gesetz bedeutete einen vollkommenen Sieg der Offentlichen Meinung über die noch junge und mutwillige Partei. Sie lag eine zeitlang zerschmettert am Boden. Allmählich aber vermochte sie sich zu erholen und dem Gesetze zu trotzen. Und als nach I2jähriger Wirksamkeit es nicht erneuert wurde, da hat die Freiheit, im Verein mit anderen Ursachen, der Partei zu einer so glänzenden äußeren Entwicklung verholfen, da $B$ diese im Jahre 1878 als das vollkommene politische Verderben des Deutschen Reiches gegolten hätte. Aber mit zunehmender Ausdehnung und Macht hat die Sache der Sozialdemokratie zwar nicht über die Offentliche Meinung gesiegt, aber sie doch in einigem Maße überwunden. Manche alte Vorwürfe und Anklagen sind verstummt oder doch selten und unwirksam geworden; sie werden wie abgelegte Kleider nur noch von bescheidenen Geistern, und wie alte Moden in Krähwinkel und Schöppenstedt getragen. Die Wandlung tritt deutlich zutage, wenn man mit der Rede eines Parteiführers wie BENNIGSEN, der damals natürlich die vornehmste Zeitung seiner Partei tätiges 
Geleite gab, vergleicht, was die Kölnische Zeitung 20 Jahre später (I898) schrieb, z. B. im April des Jahres: „Nie mand gla ubt, daß die Sozialdemokraten im Ernst daran denken, auf die Straße hinabzusteigen und durch eine Revolution Staat und Gesellschaft umzuwälzen", eine Betrachtung, die im Oktober des gleichen Jahres mehrfach in derselben Zeitung ausgeführt wurde, und im Januar I9oo war von einer geschäftigen und vordringlichen Menschenklasse die Rede, bei der die Erscheinung des Hasses und der Angst vor der Sozialdemokratie nicht selten ins Pathologische umschlage. Im September desselben Jahres schrieb in den Preußischen Jahrbïchern, worin einst die mächtige Stimme HeINRICI voN Treitschkes über den Sozialismus und seine Gönner, den Sozialismus und den Meuchelmord ertönte, Hans DelBRÜCK, heute sei zweifellos unter den deutschen Parteien die minteressanteste " die Sozialdemokratie, die anderen seien alle mehr oder weniger im Stadium der Versteinerung. Und THEODOR Mommsen konnte im Dezember I902 wagen, der öffentlichen Meinung die Worte ins Gesicht zu schleudern, jene sei zur Zeit die einzige große Partei, die Anspruch habe auf politische Achtung. Man stelle sich vor, diese Worte wären 1878 gesprochen worden! Offenbar hatte der Strom der Offentlichen Meinung, gegen den die Anhänger wirklich oder scheinbar revolutionärer Ansichten immer schwimmen müssen, sich geteilt und war durch das Zerfließen in mehrere Richtungen erheblich dünner und schwächer geworden. Die Ursachen dieser merkwürdigen und wichtigen Tatsache sind mannigfach: wir versuchen sie ihrer Bedeutung gemäß zu ordnen.

I. Die wachsende Macht der Partei war zunächst geeignet, sie furchtbarer und gefährlicher erscheinen zu lassen. So hatte sie wirklich bis 1878 fast ausschlieBlich gewirkt. Das Wachstum unterhielt und befruchtete die Vorstellung, daß das schädliche Gewächs noch ausgerottet werden könne und, solange es Zeit sei, vertilgt werden müsse. Aber die Zahlen der Reichstagwähler, die sogar unter dem Druck des Gesetzes bedeutend gestiegen waren, und der Verzicht auf das Gesetz durch die Nach-BISMARCKsche Regierung, ließen keinem Zweifel Raum, daß dies mißlungen war. Nun begann die zunehmende Macht eine entgegengesetzte Wirkung auszuïben; mit steigender Beachtung erzwang sic auch ein gewisses $\mathrm{Ma} B$ von Achtung, das bei näherer Kenntnis und vermehrter Gewöhnung oft auch eine feindliche Sache auf sich zieht, wenn sie Eigenschaften aufweist, die sonst als achtungswürdig gelten. In dieser Richtung konnte nun die Offentliche Meinung sich der Iirkenntnis nicht entziehen, da $B$ in der vielgeschmähten Partei eine vortreffliche Organisation, eine gute Disziplin herrsche, da $B$ - ganz besonders unter der Verfolgung - viel Aufopferung und 
Begeisterung, ein echter Idealismus, zutage getreten sei und dauernd sich bewähre; da $B$ die Partei und die Gewerkschaft eine nicht geringe Bildungs- und Erziehungsarbeit leiste, daß dem Alkoholismus und anderen Lastern nicht ohne Erfolg entgegengewirkt werde; da $B$ ihre Presse von manchen Übeln frei sei, die in den meisten anderen Zeitungen widerwärtig auftreten. Vor allem aber wirft eine anerkannte Macht die Frage auf, ob man sie nicht für sich nutzen könne, ob nicht ein Bündnis mit ihr ersprießlich sei? Die Offentliche Meinung hat sich dagegen gesträubt, sie verneinte die Bündnisfähigkeit der »Umsturzpartei «; und doch mußte diese im heftigen Kampfe der anderen Parteien wider einander jezuweilen als das "kleinere Übel " erscheinen; mindestens aber mußte ihre freiwillige Hilfe im Wahlkampfe willkommen geheißen werden. Da dies öfter vorkam, so konnte es nicht ausbleiben, daß jene Entschiedenheit der Öfentlichen Meinung geschwächt wurde.

2. Dazu trug nun ferner bei, das Fortschreiten der sozialen Reform, das auf Anerkennung derselben Übel und Mängel vorhandener Gesellschaftsordnung beruhte, die auch die verrufene Partei sich anheischig machte, zu beseitigen. Die aller "Sozialpolitik" abholde Lehre vom volkswirtschaftlich allein richtigen Gehen- und Geschehenlassen war niemals sehr fest gewurzelt, wenn auch die Offentliche Meinung sie angenommen hatte. Die Preisgebung dieses Dogmas erfolgte zwar langsam, aber stetig. In dieser Hinsicht, wie in so mancher, bezog die Öffentliche Meinung noch oder wieder ihre Nahrung von der Religion; "wieder ", indem mit der großen Umkehr vom Liberalismus, die eine Folge der Weltkrise von 1875 und der Folgejahre war, auch die Frömmigkeit wieder mehr gepflegt und geehrt wurde. Dies geschah wohl mit ausdrücklicher Berufung auf das Beispiel des Fürsten BIsMarck und auf den vom ehrwürdigen Kaiser, nach seiner Verwundung getanen Ausspruch „dem Volke muß die Religion erhalten werden": Das Stocken des sog. Kulturkampfes wurde vielfach als eine Folgerung empfunden. Die Kaiserliche Botschaft vom I7. November I88I, womit die Zwangsversicherungs-Gesetzgebung eingeleitet wurde, berief sich ausdrücklich darauf, in der Fürsorge für die Hilfsbedürftigen die rechten Mittel und Wege zu finden, sei ,eine schwierige, aber auch eine der höchsten Aufgaben jedes Gemeinwesens, welches auf den sittlichen Fundamenten des christlichen Volkslebens" stehe. Diese Worte konnten darauf rechnen, einen starken Widerhall zu finden, wenn auch kaum einen nachhaltigen. Die christlich-sozialen "Parteien ", evangelische wie katholische, blieben unbedeutend. In den beiden Erlassen des Kaisers Wilhelm II., vom 4. Februar I890, welche die zweite Phase der 
Sozialreform im Deutschen Reiche einleiteten, wird der Entschluß kundgegeben, die fernere Entwicklung unserer Gesetzgebung in der gleichen Richtung zu fördern, in welcher ,Mein in Gott ruhender Großvater sich der Fürsorge für den wirtschaftlich schwächeren Teil des Volkes im Geiste christlicher Sittenlehre angenommen hat". Es wird nur darauf als auf eine historische Tatsache Bezug genommen. Und der Urheber dieser Erlasse erklärte, wenige Jahre später, christlich-sozial für »Unsinn«. In Wahrheit hat sich die Erkenntnis der Notwendigkeit umfassender Sozialreform in der Offentlichen Meinung nicht aus Gründen des Christentums oder aus religiösen überhaupt, sondern aus politischen Gründen, festgesetzt, abgesehen von den Gefühlen des Mitleids und der Scham, die bei solcher Erkenntnis mitwirken. Die politischen Gründe sind teils in der Erwägung enthalten, daß die Sozialdemokratie um so wirksamer bekämpft werden könne, wenn man ihre »berechtigten Forderungen « so weit wie möglich erfülle; teils beziehen sie sich auf die Wehrtüchtigkeit, sind also militärischer und national-patriotischer Art, teils endlich erwarten sie eine allgemeine Verbesserung der Gesamtkultur von einer Hebung des "vierten Standes « und seiner Eingliederung in die gleichberechtigte Staatsbürgerschaft. Als berechtigte Forderungen aber erscheinen vorzüglich alle jene, die durch Rücksichten der Hygiene und der Moral gerechtfertigt werden, daher - wie schon in den ältesten Daten der Fabrikgesetzgebung - solche zugunsten der Frauen, insbesondere verheirateter Frauen und Mütter, der Kinder und jugendlichen Personen; dazu kommen dann andere Gesichtspunkte, die dafür sprechen, dem Arbeiter ein »menschenwürdiges Dasein " zu sichern: angemessenes Lohneinkommen, Einschränkung der Arbeitszeit, um Muße und Unterhaltung zu gewähren, Beschaffung von Obdach für die Obdachlosen, anständige Wohnung für Familien, besonders für kinderreiche, Bekämpfung des Schlafstellenwesens und vieler anderer Übelstände, die teils den Groß- und Industriestädten eigentümlich, teils mit besonderen $Z$ weigen der Arbeit und Dienstleistung verbunden sind - allen sozialen Reformen dieser Art, die das gegebene Grundverhältnis zwischen Kapital und Arbeit nicht wesentlich verändern, ist die Offentliche Meinung mehr und mehr geneigt geworden, nachdem diese Schäden deutlicher zutage getreten und immer öfter erörtert worden sind.

3. Indem in dieser Hinsicht, neben und ïber den christlichsozialen Bestrebungen, eine weltliche und wissenschaftliche Richtung, die zunächst als Katheder-Sozialismus angeklagt oder verspottet wurde, steigenden Einfluß auf die Jugend, dadurch auch auf das Beamtentum in Staaten und Gemeinden gewonnen hatte, mußte 
dies allmählich auch die öffentliche Meinung in bezug auf die Sozialdemokratie aufklären und verdünnen. Wesentlich trug dazu bei ein so erhabenes Beispiel, wie es der junge Kaiser durch seine FebruarErlasse und durch die Berufung einer internationalen Arbeiterschutzkonferenz zu geben kühn genug war, wenn auch die Wirkung stark vermindert wurde dadurch, daß es mit der Trennung von dem weltberühmten Reichskanzler verbunden war, für den die Offentliche Meinung entschieden Partei nahm gegen den Kaiser. Vollends wurde dann die Wirkling abgeschwächt durch die Entlassung des preußischen Handelsministers VON BERLEPSCH im Juni I896, die als eine Abkehr von der Sozialreform verstanden werden mußte, wie denn diese auch in anderen Tatsachen um die Mitte des letzten Jahrzehntes wiederum war es in einer Zeit wirtschaftlicher Krisenstimmung sich offenbarte. Gleichwohl war die sozialreformerische Stimmung so stark geworden, $\mathrm{da} B$ sie sich nicht wieder unterdrücken lieB: sie äuBerte sich a) in der Begründung einer Gesellschaft für soziale Reform, an deren Spitze die Autorität des genannten ehemaligen Ministers sich stellte, b) darin, da $B$ der Verein für Sozialpolitik, der inzwischen seinen ursprünglichen Charakter eingebüßt hatte, doch jener Stimmung und daraus hervorgehender wissenschaftlicher Arbeit wenigstens wieder freiere Bahn gewährte, c) in der Begründung neuer sozialpolitischer und die Kenntnis der Tatsachen des sozialen Lebens in der Arbeiterbewegung fördernder Zeitschriften, wie des 》Sozialpolitischen Zentralblatts», der "Blätter für soziale Praxis», des "Archivs für soziale Gesetzgebung und Statistik«, der "Hilfe« usw., d) darin, daß eine neue, wenn auch schwach bleibende Partei unter Leitung eines bedeutenden Mannes sich bildete, die nationale Ziele mit sozialen verbinden wollte, von ihrer Mutter, der evangelischsozialen Richtung, durch politischen Geist sich scharf unterscheidend, e) da $B$ die freisinnige Partei, die mehr oder minder rein den alten wirtschaftlichen Liberalismus vertreten hatte, und so freilich den auf Selbsthilfe beruhenden Organisationen gewerkschaftlicher und genossenschaftlicher Art grundsätzlich keinen Widerspruch entgegensetzen konnte, nunmehr auch die Unentbehrlichkeit der 》Staatshilfe" anzuerkennen genötigt war. Sie war dazu genötigt unter dem Drucke der Offentlichen Meinung und, daß sie es tat, wirkte in gleichem Sinne auf die öffentliche Meinung zurïck. Ebenso die damit in Verbindung stehende, nur dadurch mögliche Aufsaugung einer kleinen "nationalsozialen " Parteigruppe. Wenn diese auf unmittelbare politische Betätigung verzichtet und sich darauf beschränkt hätte, aufklärend und belehrend $\mathrm{zu}$ wirken, so wäre freilich ihr Einfluß gerade auf die öffentliche Meinung weit stärker und nachhaltiger geworden, f) wie 
in allen Wandlungen vorherrschender Denkungsart, so macht sich auch in diesem Falle der Aufstieg einer neuen Generation geltend, die, wie stark auch durch die vorhergehende ältere bestimmt, zugleich neuen Ideen und neuen Idealen huldigt. Daß die liberalen Gedanken verblaßten und die entsprechenden Neuerungen der inneren Politik sich nicht zu bewähren schienen, kam zwar überwiegend konservativen, aber doch $z \mathfrak{u}$ einem guten Teile auch sozialistischen Gesinnungen zugute. So etwas wie "soziales Empfinden «, ein sympathisches Verständnis für die Leiden der unteren Gesellschaftsschichten und ihre Versuche, sich davon zu befreien, wurde ebenso wie vermehrte Kenntnis der Tatsachen des sozialen Lebens und der sozialen Entwicklung, mehr und mehr den Gebildeten zur Pflicht gemacht.

4. Nicht geringen Einfluß darauf hat auch der vermehrte Druck des Kapitalismus auf das mittlere Bürgertum und die in ihm beruhende Beamtenschaft ausgeiibt. Wenngleich diese Schichten selber am Kapitalismus beteiligt sind und mit ihm stark zusammenhängen, so fühlen sie doch mehr und mehr ihre Ohnmacht gegenüber dem kartellierten und syndizierten "Großkapital «. Und dazu trägt wieder bedeutend bei das Wachstum einer in ihnen beruhenden Kategorie von Angestellten " der Industrie und des Handels, die allmählich erkennen müssen, daB ihre Anstellung nicht mehr eine Stufe, sondern eine lebenslängliche Berufsstellung ist. Es gibt eine Angestelltenbewegung und bedeutende Anfänge einer gewerkschaftlichen Vereinigung, wovon I878, als dieser "neue Mittelstand " noch nicht in nennenswertem Umfange vorhanden war, keine Rede sein konnte. Im gleichen Sinne dürfte die zunehmende Erwerbstätigkeit der Frauen, besonders diejenige junger Mädchen des gebildeten Mittelstandes, gewirkt haben. Und im Zusammenhange mit allen diesen Momenten steht, wenn auch praktisch nur im Gegensatze zu einer besonderen Kategorie des Kapitals, dem der Hausbesitzer und HausHypothekengläubiger, die Bewegung für "Bodenreform «, die immer weitere Kreise der Mieter, als der Konsumenten der Wohnungsware, und des städtischen Beamtentums zur Erkenntnis über den wesentlichen Antagonismus der kapitalistischen Gesellschaft drängt. In England, wo das absolute und riesenhaft ausgedehnte Eigentum am Boden noch immer die feste Grundlage einer aristokratischen Gesellschaftsverfassung bildet, hat diese Bewegung eben so ticfe Wurzein wie in den Vereinigten Staaten und anderen Kolonialländern, wo die unbegrenzte Spekulation mehr und mehr dieser wesentlichen Basis aller freien Arbeit sich bemächtigt hat und HFNRY GEORGE mit großem Erfolge ihr eine theoretische Form verlich. Daß sie auch in Deutschland zu einer erheblichen Bedeutung herangewachsen ist, 
war hauptsächlich dem sittlichen Ernst und Eifer ADOLF DAMASchKËs $\mathrm{zu}$ verdanken, der sich der Unterstuitzung von Politikern und Sozialökonomen, unter denen ADOL,PH WAGNER hervorragt, erfreute, und mit Beredsamkeit und Geschick die Offentliche Meinung wenn nicht völlig für die Sache zu erobern und zu befestigen, so doch in lebhaften Fluß des Strebens zu setzen verstanden hat.

5. Durch das Wachstum und die Vermehrung der Aktiengesellschaften, durch das Aufkommen der Kartelle, durch die Herrschaft der Spekulation und die Krisen, die sie im Gefolge hat, gelangte es mehr und mehr zum allgemeinen Bewußtsein, daß nicht sowohl, oder doch nicht allein, wie die umlaufende Lehre und Rechtfertigung des Kapitalismus behauptet, die Tüchtigkeit und der Geist individueller Unternehmer, sondern in erster Linie das unpersönliche $\mathrm{Ka}$ pital Träger des Systems ist, daB in ihm schon die Arbeit gesellschaftlich organisiert worden ist, aber nicht zum Vorteil der Gesamtheit und des Staates, sondern zum Vorteil der zumeist anonymen Eigentümer des Kapitals, und daB die Verstaatlichung, auch wenn sie nach wie vor Produktion oder Verkehr in der Absicht auf Gewinn betreibt, diesen Gewinn doch irgendwie dem allgemeinen Nutzen dienstbar macht.

6. Endlich mußte zur Milderung des öffentlichen Urteils über die Sozialdemokratie auch der Umstand beitragen, daß sie selber milder wurde. Dadurch, da $B$ ihre Vertretung in den Staaten und Gemeinden, wie im Reiche, wuchs, war sie genötigt, den praktischen Aufgaben sich mehr zu nähern und deren Schwierigkeiten kennen zu lernen; bei ernsten Naturen mußte der Sinn für Verantwortung der Politik dadurch gehoben werden. Auch die Presse ging mehr und mehr von Deklamationen zu sachlichen Erwägungen über, die auch früher nicht gefehlt hatten, aber leichter übersehen werden konnten. Im gleichen Sinne haben die außerpolitischen Organisationen auf die Politik zurïckgewirkt. Damit hing wieder die tatsächliche Verbesserung der Lage der arbeitenden Klasse nahe zusammen, die in erster Linie der ungeheuren Vermehrung des deutschen Nationalwohlstandes, infolge der Ausdehnung seiner großen Industrien und seines Außenhandels, sodann der Sozialreform selber, endlich den eigenen Bestrebungen der Arbeiterschaft zu verdanken war. Nun mündete aber diese Veränderung und Verbesserung auch in einer "Mauserung " der Partei, die unter dieser Bezeichnung schon vor dem Ausnahmegesetz oft erwartet wurde und die öffentliche Aufmerksamkeit stark auf sich zog. Wenn das - nach dem Falle des Sozialistengesetzes vereinbarte - Programm der Partei eine Verschärfung und Verhärtung des theoretischen Standpunktes in 
sich schloB, so machte sich wenige Jahre später das Verlangen nach einer "Revision " dieser Grundsätze geltend, und wenn sie auch nicht durchdrang, so blieb doch ein starker, den "Revoluzern " und "Radikalinskis " sehr kritisch gegenüberstehender Flügel, der in den gewerkschaftlichen und genossenschaftlichen Kreisen seine stärksten Stützen hatte, und für Besonnenheit und praktische politische Tätigkeit unablässig eintrat.

Von den alten Vorwürfen gegen die Partei erwies sich als der zäheste und nachhaltigste derjenige, der ihr den Mangel an Patriotismus, die "Vaterlandslosigkeit « Schuld gab. In der militärfeindlichen Gesinnung wurde eine Gefahr für das Heer erblickt, die Anklage wegen Internationalität verstärkte sich um so mehr, je schärfer die Gegensätze zwischen dem Deutschen Reich und anderen Großmächten sich zuspitzten, was um die Wende des Jahrhunderts und dann während des neuen Jahrhunderts in wachsendem Maße geschehen ist. Das Wort des Kaisers wider die wvaterlandslosen Gesellen "(I895) fand in der öffentlichen Meinung einen lebhaften Widerhall. Gesetzgeberische Versuche, die als "kleine Sozialistengesetze" die Partei von neuem ins Herz treffen sollten, scheiterten zwar an den Verhältnissen der Parteien und auch an der verdünnten Offentlichen Meinung, um so mehr aber fand der Gedanke Anklang, durch andere Mittel die Ausbreitung einzudämmen. So fand der "Reichsverband gegen die Sozialdemokratie «, im Mai 1904 begründet, einen fruchtbaren Boden für seine mit mannigfachen Mitteln in lebhaftester Weise betriebene Agitation. Er erblickte seine Aufgabe lediglich in der Bekämpfung der internationalen ,volks- und vaterlandsfeindlichen Sozialdemokratie und in der Aufklärung der großen Masse der Arbeiterschaft durch Wort und Schrift". In den Aufrufen wurde mit Vorliebe der Ausdruck, gemeinsames Vorgehen gegen den roten Feind" gebraucht, er wollte alle sbürgerlichen " oder "staatserhaltenden " Parteien vereinigen. Durch den (im Grunde undeutschen) Gebrauch des Wortes "bürgerlich», der journalistisch auf beiden Seiten gepflegt wurde, war ein neues Symbol geschaffen, das die politisch Gläubigen von den Ketzern schied. Wie dann das Verhalten der Ketzer am 4. Aúgust I9I4 gewirkt hat, wird an späterer Stelle betrachtet werden.

8. (Der Sozialismus in anderen Ländern.) Hier möge noch ein Blick auf die Stellung der Offentlichen Meinung zur Sozialdemokratie und zur politischen Verwirklichung der sozialistischen Lehren in anderen Ländern geworfen werden. In Frankreich, dem Mutterlande sozialistischer und kommunistischer I,ehren, ist die Bildung einer sozialdemokratischen Partei und ihr entsprechender Kammerfraktion 
vielen Hemmungen begegnet und erst in der dritten Republik spät vollendet worden. Die Offentliche Meinung, eingeschworen auf die Prinzipien von $I 789$, hält die Freiheit, Gleichheit und Brüderlichkeit, vor allem durch die republikanische Verfassung, dann auch durch das Suffrage universel, für gewährt und gesichert; und da die Unverletzlichkeit des Eigentums schon während der Revolution unter die „Rechte des Menschen und Bürgers", die nicht veräußerlich sind, aufgenommen war, so konnte dadurch der natürliche Abscheu der besitzenden Klasse, um so mehr natürlich, da in ihr die Bauern und Kleinbürger noch eine sehr breite Schicht bildeten, gegen eigentumsfeindliche Bestrebungen nur befestigt und gesteigert werden. Nachdem die Niederwerfung der Pariser Kommune geschehen war, erhielt sich die Einigkeit der auf dem Boden der großen Revolution stehenden republikanisch gesinnten Klassen um so besser, je schwerer sie durch die lange noch vorwaltenden Tendenzen der Restauration bedroht waren. Um so weniger aber konnte die Bildung einer einheitlichen Sozialistenpartei gelingen, und solange diese fehlte, hatte die Offentliche Meinung keinen Grund, iiber die umlaufenden mannigfachen Lehren sozialistischen Charakters sich aufzuregen. Nachdem aber die Partei einmütig und stark geworden ist, sind ihre parlamentarischen Erfolge mit Fortschritten in der öffentlichen Meinung Hand in Hand gegangen, und beide hat sie wesentlich dem Geiste, der Beredtsamkeit und Redlichkeit ihres bedeutenden Hauptes JEAN JAURÈS verdankt. Sein Einfluß vermochte sogar dem in der Offentlichen Meinung Frankreichs so stark verankerten Chauvinismus und dem »konstanten Faktor «, den für die französische Politik die Feindschaft gegen Deutschland bildete, in einigem Maße entgegenzuwirken. Insbesondere erschien dann in dem Streite des Freimaurertums, das in Frankreich so hohe politische Bedeutung hat, gegen den Klerus und die römische Kurie, die sozialistische Partei nur als ein kampfentschlossener Flügel des radikalen Blocks, der auch sonst in Abwehr der Reaktion nicht zu entbehren wäre. Dieser Flügel vermochte dann sogar, kurz vor Ausbruch des Weltkrieges, in der Deputiertenkammer und im Senat die Einkommensteuer durchzusetzen, gegen welche die Offentliche Meinung Frankreichs so lange sich gesträubt und mit dem Erfolge, daß viele Ministerien dadurch zugrunde gingen, gerungen hatte. ADOLPH WAGNER schrieb schon (Finanzwissensch. 3. Teil, Ergänzungsheft S. I44) zu Anfang des Jahres I8g6 über den BourGEOrs-DoumERschen Entwurf, es sei ,unwahrscheinlich, daß er, selbst mehr oder weniger abgeändert, Gesetzeskraft erlange, gegenüber dem Widerstand, welchen er in der öffentlichen Meinung, in der Presse, vor allem in den Kammern bereits gefunden hat", und alsbald konnte er 
berichten, da $B$ die Budgetkommission den Einkommensteuerentwurf mit 28 gegen 5 Stimmen abgelehnt und die Regierung aufgefordert habe, einen anderen Entwurf, der die Lasten in gerechterer Weise verteile, vorzulegen; zu gleicher Zeit sei im Senat gewarnt worden vor der "sozialistischen"Steuerpolitik des radikalen Ministeriums. Die Furcht vor der öffentlichen Meinung wirkte offenbar auf die Entscheidungen beider Kammern. „Als der (Doumersche) Entwurf veröffentlicht wurde, brach ein wahrer Sturm der Entrüstung los ... Man behandelte den Vorschlag als das Produkt eines Wahnsinnigen. Alle nationalen und politischen Leidenschaften wurden gegen ihn entfesselt. Man sah in dem Entwurf eine Gefahr für die Freiheit, für den Besitz, für die Arbeit; er schlage dem génie du peuple français ins Gesicht" (TrolTSCH, Supplementbd. II zur I. Aufl. des HWSt. S. 312). Gewisse Anschauungen, meinte AdolPH WAGNER (I896), spielen in Frankreich noch heute eine ähnliche Rolle, wie in der Periode der ersten Revolution (dies ist in der Tat, wie oben ausgesprochen, das allgemeine Merkmal der öffentlichen Meinung in Frankreich) ... so die Bedenken gegen das »inquisitorische" Eindringen in die persönlichen und in die Einkommen- und Vermögensverhältnisse bei einer ordentlichen direkten Einkommensteuer, ein dem französischen Nationalcharakter vielfacher Behauptung nach unerträgliches Verfahren (A. WAGNER, Finanzwissenschaft III, I., S. 425). Es war also nichts Geringes, daB der Finanzminister CarlLAUX im Jahre I9I4 beide Kammern dazu vermochte, trotz dieses Widerwillens sein Einkommensteuergesetz - den zwölften Entwurf seit r887 - wirklich anzunehmen. Offenbar war dieser Widerstand zugleich mit demjenigen gegen die dreijährige Dienstzeit schlaff geworden unter dem Einflusse des wieder erstarkten Chauvinismus, der als die politische Religion der Franzosen immer wieder der öffentlichen Meinung sich überlegen erweist. - Ubrigens finden wir das Verhältnis der öffentlichen Meinung in Frankreich zur sozialen Frage gut charakterisiert in einem Pariser Briefe von F. SchotrthöFER, der am I6. Juni 1898 in der "Sozialen Praxis " gedruckt wurde. Es heißt darin, der französische "Liberalismus « - der ist dort mehr als in einem anderen Lande das Bekenntnis der Offentlichen Meinung - sei wirtschaftspolitisch schon zum intensivsten Schutzsystem übergegangen, seine theoretische Bekchrung zur Staatsintervention auf sozialem Gebiete scheine nur eine Frage der Zeit zu sein (in der Tat hat seitdem der Arbeiterschutz e einige Fortschritte gemacht, besonders in bezug auf Begrenzung der Arbeitszeit!). Freilich einen konsequenten Staatssozialismus nach deutschem Muster wird er nie inaugurieren. Dazu enthält er zu viel Unternehmerinteressen in sich, dazu fehlen in 
Frankreich ïberhaupt die allgemeinen Voraussetzungen. Man hat immer mit der weiter vorgeschrittenen Demokratisierung und mit der Kleinbürgerlichkeit des Landes $\mathbf{z u}$ rechnen, und nie $\mathbf{z u}$ vergessen, $\mathrm{da} B$ die französische Nation heute in einer starken Dezentralisation des politischen Lebens, in einer Verminderung der zentralen Staatsgewalt eine der notwendigsten Reformen erblickt und darum vor neuen Staatseingriffen etwas zurückschreckt. Der gemäßigte Liberalismus ist aber einer der Hauptträger dieser Ideen, und seine Sozialreform richtet sich darum weit mehr dahin, die unteren Klassen zu seiner eigenen Lebens- und Gesellschaftsauffassung heraufzuziehen, mehr im Arbeiter die private Initiative $z u$ wecken, als den positiven Arbeiterschutz oder die obligatorischen Versicherungen zu entwickeln, denen er nur den unbedingt notwendigen Raum zugesteht". Wenn hieraus $z u$ entnehmen ist, da $B$ die Offentliche Meinung die gewerkund genossenschaftliche Organisation der Arbeit mit einer gewissen Gunst bedenkt, so darf man doch nicht wähnen, daß diese Gunst mehr als theoretisch und akademisch ist. Der Brief schließt mit Erwähnung eines schönen Spruches, den Herr WALDECK-RousSEAU damals vor kurzem verkündet hatte: „Il faudra que le capital travaille et que le travail possède". Die Lösung der sozialen Frage durch diese liebenswürdige Phrase dürfte der Offentlichen Meinung Frankreichs völlig eingeleuchtet haben! - Wenn die politische Bewegung und Partei sich Achtung in der Offentlichen Meinung erworben hatte, so war dies wohl fast ausschließlich der bedeutenden und lauteren Persönlichkeit, dem Geist und der Beredsamkeit des einen Mannes JEAN JAURÈs zu verdanken; dennoch machte die Wut des Chauvinismus kurzen Prozeß mit diesem Manne, als er sich tatkräftig ihr entgegenwarf, und die Offentliche Meinung hat es ertragen, da $B$ der Mörder (bisher) 4 Jahre lang (I9I4-I9I8) straffrei geblieben ist!

In England ist bekanntlich die Bildung einer Arbeiterpartei langsam und spät erfolgt, und diese hat im Parlament noch nicht gewagt, sich grundsätzlich als Gegnerin des Kapitalismus und sei ner Parteien zu bekennen. Dies beruht darin, da $B$ in keinem anderen Staate Grundvermögen und Kapitalvermögen, ungeachtet ihrer wesentlichen Gegensätze, eine so befestigte, zugleich verbundene und - durch den Wechsel der Parteien - getrennte Herrschaft aufzurichten verstanden haben, wie in Großbritannien; eine Herrschaft, die der (wiederum mehr als irgendwo sonst) noch im Schoße der Religion ruhenden öffentlichen Meinung als schlechthin notwendig und durch die göttliche Weltordnung bestimmt erscheint. Diesem System entspricht auch die Technik der Wahlen mit ihren vielen kleinen, das Gewicht der örtlichen Größen sichernden Wahlkreisen 
und vor allem mit der Regel einfacher Mehrheiten, der gegenüber jede dritte Partei so lange ohne alle Aussicht ist, bis sie die Aussicht auf eine einfache Mehrheit hat, während sie als Minderheit nur wirkt, wie die ungültigen Stimmen in Wahlsystemen, die eine vollkommene Mehrheit verlangen. In einem Beispiel ausgedrückt: wenn in einem Wahlkreis die konservative Partei ein geringes Ubergewicht über die liberale Partei hat, so bewirken die Stimmen einer dritten Partei nichts weiter, ais da $\beta$ jene siegt, $d . h$. sie können das nicht verhindern, während sie bei der (früheren) deutschen und bei der französischen Wahltechnik eine zweite Wahl bewirken und dann für die liberale Partei den Ausschlag geben können. - Indessen hat sich doch in der zweiten Hälfte des I9. Jahrhunderts eine tiefgehende Wandlung im inneren politischen Leben Großbritanniens vollzogen. Deren nächste Ursache ist die A usdehnung des Wahlrechts gewesen, wodurch die herrschenden Parteien genötigt wurden, mehr und mehr die Bedürfnisse und Wünsche der großen Masse sich angelegen sein zu lassen, deren Wirkung jene Ausdehnung selber gewesen war. In diesem Sinne sind die beiden alten Parteien gleichermaßen "demokratisch" geworden; zu gleicher Zeit aber haben diese beiden alten Parteien in der Weise sich neu gebildet, daß gewichtige Teile der Linken (die Whigs und andere "Unionisten ", vorzugsweise Schutzzöllner) mit ihren alten Gegnern, den Torys, zunächst sich verbunden, dann sogar sich verschmolzen haben, während der Rest, eine kleine Minderheit der Aristokratie und Plutokratie, nunmehr mit besserem Recht sich als Volkspartei darstellt, da er nicht nur die breiten mittel- und kleinbürgerlichen Schichten, die teils als solche der Nebenländer (Schottland und Wales), teils als die "Kapelle" (Nonconformists) sich charakterisieren, unter seiner Fahne versammelt, sondern auch durch das Bekenntnis zum Freihandel und durch entschiedene, insbesondere dem großen Grundbesitz entgegengerichtete soziale Reformen, die industrielle Arbeiterschaft an sich fesselt. Und diese neue liberale Partei ging aus den Wahlen der Jahre rgo6 und rgro siegreich hervor, so daß dem Herkommen gemä $\beta$ aus ihr die Regierung sich bildete. Während nun bis dahin der Wechsel der Regierungen selber - das Schwingen des Pendels - der Offentlichen Meinung als normal galt und grundsätzlich die cine Partei als ebenso berechtigt wie die andere, so da $B$ die jedesmalige Regierung, ebenso wie die vorkommenden Koalitionsregierungen, gleichsam von der Offentlichen Meinung ihre Salbung empfing, wie sehr auch die geschlagene Minderheit sie in Presse, Parlament und Agitation bekämpfte, - so war im neuen Jahrhundert der völlig neue Zustand eingetreten, da $B$ die Offentliche Meinung die Regierung als solche 
verneinte, und ihr Dasein nur duldete, obgleich es als ein revolutionäres verabscheut wurde. Das war der Zustand I906-I9r4: die Offentliche Meinung, die im eigentlichen England und in dessen Großbürgertum - mit großem Grundbesitz oder ohne solchen ihren eigentlichen Herd hat, war empört über die plebejische, revolutionäre, irenfreundliche, die Verfassung zerstörende, die erworbenen Rechte in Frage stellende Regierung. Sie betrachtete sie nicht mit freundlicheren Augen, als wenn sie wirklich aus einer Mehrheit der Arbeiterklasse hervorgegangen, als wenn sie - sozialdemokratisch gewesen wäre. Charakteristisch dafür war es, daß die Regierung vergebens versuchte, eine große Londoner Morgenzeitung ihrer Richtung ins Leben zu rufen. Heller aber noch wurde diese Lage der Dinge beleuchtet durch die Vorgänge der Jahre IgIr und I9I4. Im Jahre IgII geschah es, daß der Ministerpräsident im Hause der Gemeinen als Verräter begrüßt und ein anderer Minister durch das Werfen harter Gegenstände an seine Sterblichkeit erinnert wurde, obgleich beide persönlich zu den "respektabelen Personen «gehörten die Täter hätten es nicht gewagt, wenn sie nicht Grund gehabt hätten, auf Verständnis oder wenigstens auf Nachsicht der Offentlichen Meinung $z u$ rechnen. Im Jahre IgI4 geschah es, daB in einem Teile Irlands die Rebellion gegen ein rechtsgültig beschlossenes Gesetz von englischer Seite planmäßig organisiert wurde, und daß die Offiziere englischer Regimenter, die bestimmt wurden, der Rebellion entgegenzutreten, den Gehorsam verweigerten; in dem bald nachher, infolge des Weltkrieges, gebildeten Koalitionsministerium erhielt der Urheber jener Rebellion einen Sitz! Alle diese Vorgänge waren nur möglich, weil die Öffentliche Meinung auf Seite der Rebellion und ihres Urhebers, auf Seite der ungehorsamen Offiziere stand. Die Regierung war in der Tat gegen die Offentliche Meinung ohnmächtig. Man mag nach diesen Tatsachen schätzen, wie sich die Offentliche Meinung zu einer starken Arbeiterpartei und gar zu einer aus dieser gebildeten Regierung verhalten würde.

Scheinbar fast ohne Zusammenhang mit dem in bezug auf die wesentlichen Grundlagen des sozialen und politischen Lebens streng konservativen Charakter der britischen Offentlichen Meinung ist nun aber die Erscheinung, daß diese sich doch während des letzten Drittels des I9. Jahrhunderts von einer ausgeprägt windividualistischen " zu einer in der Oberfläche "kollektivistischen " Richtung bekehrt hat. Den Gang dieser Wandlung schildert ausführlich ein besonderes Buch des Juristen A. V. DICEY „Lectures on the relation between law and public opinion in England" (I905). Wir wollen es an dieser Stelle behandeln - anstatt bei Errörterung des Verhältnisses zwischen 
öffentlicher Meinung und dem Sozialismus als solchem - weil es durchaus die Wechselwirkung zwischen der Gesetzgebung und der öffentlichen Meinung zum Gegenstande hat. Wenn dabei alles Gewicht auf Entstehung der "kollektivistischen "Strömung gelegt wird, so liegt doch eine Einteilung zugrunde, die den ganzen Verlauf des I9. Jahrhunderts in drei Abschnitte zerlegt, so daß nacheinander die drei Gestaltungen des Gedankens zur Geltung kommen, die der konservativen, der liberalen und der sozialistischen Parteiung zugrunde liegen. DrCEy bezeichnet den ersten Abschnitt als die Periode des alten Toryismus oder der gesetzgeberischen Ruhestimmung (I800 bis I830); sie enthält neben reaktionären Gesetzen auch humanitäre Reformen (sehr bescheidene) wie das Gesetz von I802 zum Schutze der Gesundheit und Sittlichkeit. Der zweite Abschnitt ist die Periode des Benthamismus oder Individualismus (I825-I870), der eine sehr eingehende Darstellung gewidmet wird. Die Gesetzgebung dieser Zeit wird bezeichnet durch $\mathbf{I}$. den Úbergang der politischen Macht auf die Mittelklasse, 2. durch humaneres Strafrecht, Tierschutz, Sklavenbefreiung, 3. ganz besonders durch Ausdehnung der individuellen Freiheit, namentlich mit Bezug auf Verträge und Assoziationen, 4. durch Schutz der Personen im formalen Recht, besonders im Strafprozeß. Aber in dieser Ära der Bliite des Liberalismus beginnt schon der Gegensatz zwischen Individualismus und Kollektivismus in die Erscheinung zu treten; namentlich durch die Fabrikgesetzgebung, als deren treibende Kraft in erster Linie die toryistische Philanthropie christlich-sozialen Anstrichs geschildert wird: idealer Repräsentant Lord ASHLEY (dessen späterer Name SHAFTESBURY war). Darin trat zutage, $\mathrm{da} B$ die gemeinsame Gegnerschaft auch Tendenzen, die selber einander feindlich sind, vereinigt. Die von den Torys ausgehende Gesetzgebung trägt ein kollektivistisches Gepräge. „Der Eirfolg der Fabrikgesetze gab, nicht nur in der Welt der Arbeit, sondern in vielen anderen Lebenssphären, Anschauungen Gewähr, die, wenn sie nicht geradezu sozialistisch waren, wenigstens doch in der Richtung auf Sozialismus oder Kollektivismus lagen" (S. 239). Aber erst nach I870 kommt diese Richtung zum Durchbruch, so daß ihre Periode durch das letzte Drittel des Jahrhunderts (I865-I900) bezeichnet wird und darüber hinausgeht. Ihr Hauptinhalt möge als bekannt vorausgesetzt werden. DICEY stellt als den "wesentlichen und grundfesten * Unterschied zwischen der Gesetzgebung, welche die Âra des Individualismus und derjenigen, welche die des Kollektivismus bezeichne, dar, daß sie in verschiedenen, wenn auch nicht schlechthin miteinander unverträglichen, Weisen, das Verhältnis zwischen dem Menschen und dem Staat aufzufassen, beruhe und ihnen 
Ausdruck gebe. „Die Liberalen der Benthamschen Schule haben vorzugsweise und $\mathrm{zu}$ ausschließlich die Menschen betrachtet als gesonderte Personen, von denen jede durch ihre eigenen Anstrengungen ihr eigenes Glïck und Wohl bewirken muß; und haben die Ansicht vertreten, daß das Gedeihen einer Gemeinschaft - z. B. der englischen Nation - weiter nichts bedeutet als das Gedeihen oder die Wohlfahrt aller oder der Mehrzahl ihrer Mitglieder. Sie haben ferner angenommen, und sicherlich nicht ohne Grund, da $B$, wenn das wahre Interesse eines Menschen wohl verstanden werde, seine wahre Wohlfahrt die wahre Wohlfahrt des Staates bedeute. Darum haben die Liberalen während der Zeit, als ihr Einfluß vorherrschend war, eine Gesetzgebung befördert, die eines jeden Bürgers Freiheit, Tatkraft und Unabhängigkeit steigern sollte, ihn über sein wahres Interesse belehren und in ihm die Empfindung seiner eigenen individuellen Verantwortlichkeit für die Wirkungen seines eigenen persönlichen Verhaltens, sei es für ihn selber oder für seine Nächsten, verschärfen sollte. Die Kollektivisten hingegen haben die Menschen hauptsächlich, und zu ausschließlich, betrachtet, nicht sowohl als isolierte Individuen, sondern als Wesen, die ihrer eigentlichen Natur nach Bürger und Teile des großen Organismus - des Staates - seien, dessen Glieder sie sind. Reformer, deren Aufmerksamkeit dermaßen durch die soziale Seite der menschlichen Natur in Anspruch genommen wurde, haben geglaubt, oder vielmehr gefühlt, daß das Glück eines jeden Bürgers von der Wohlfahrt der Nation abhänge, und haben geltend gemacht, daß die Wohlfahrt der Nation sicher der einzige Weg sei, das Glück jedes individuellen Bürgers zu befördern. Daher haben die Kollektivisten eine Gesetzgebung begünstigt, welche die Kraft der sozialen und sympathischen Gefühle jedes Menschen steigern, seine Empfindung der Verantwortlichkeit der Gesellschaft oder des Staates für die Wohlfahrt und das Glück jedes einzelnen Bürgers schärfen sollte." Die Kraft des Kollektivismus sei (,wir fühlen es alle instinktiv") noch nicht erschöpft; allem Anschein nach noch nicht einmal abnehmend. Der Verfasser bezieht sich dann auf eine frühere Ausführung in seiner zweiten Vorlesung, daß die Offentliche Meinung viel weniger durch die Kraft des Beweises als durch den Druck der Umstände bestimmt werde: die Umstände aber, die das Wachstum des Kollektivismus begünstigt haben, seien noch fortwährend da, und ihre Macht über die Anschauungen und Gefühle des Publikums sei offenbar. „Gesetze wiederum gehören (wie gleichfalls früher gezeigt worden) $\mathrm{zu}$ den mächtigsten unter den vielen Ursachen, die gesetzgeberische Meinung erzeugen; die Gesetzgebung des Kollektivismus hat nunmehr (1905) einige 25 oder 30 Jahre gedauert und hat selber dazu beigetragen, die 
moralische und intellektuelle Atmosphäre zu schaffen, worin sozialistische Ideen blühen und wuchern. So wahr ist dies, da $B$ moderne Individualisten selber zumeist in einigen Stücken Sozialisten sind. Die innere Logik der Dinge führt daher zur Ausdehnung und Entwicklung der Gesetzgebung, die das Gepräge des Kollektivismus trägt" (S. 30I). - Der gelehrte Jurist hat eine bedeutsame Wandlung der Offentlichen Meinung richtig erkannt. Daß er aber deren Beweggründe, und folglich auch ihre Tiefe, richtig schätze, darf bezweifelt werden. Allerdings sind die Ansichten führender Denker anders geworden, und Lehrsätze über das Verhältnis zwischen Staat und Individuum werden auch in England jetzt öfter als vor 60 Jahren in dem von DICEY kollektivistisch genannten Sinne kundgegeben. Man mag auch sagen, daß diese nicht ohne allen Einfluß auf Gestaltung der öffentlichen Meinung geblieben sind. Entscheidenden Einfluß haben sie schwerlich ausgeübt. Die Offentliche Meinung Englands ist, wie gesagt wurde, in bezug auf die wesentlichen Grundlagen des sozialen und politischen Lebens streng konservativ. Sie ist durchdrungen von der Überzengung, daß die englische Nation bei weitem die erste der Welt, religiös gesproche11, daß sie die auserwählte sei, daher zur Herrschaft über alle andern vorausbestimmt. Verschiedenheit der Ansichten über innere Politik tritt dagegen zurück; die Offentliche Meinung Englands hält ihre Erobererblicke immer nach außen gerichtet, und in dieser Spannung ist ihr die Unübertrefflichkeit und Vorbildlichkeit der eigenen Zustände wie der eigenen Verfassung und Gesetzgebung eine vor aller Prüfung feststehende Glaubenssache. Scheinbar hat die Offentliche Meinung von der Gleichgültigkeit gegen die Kolonien, die so weit ging, daß Äußerungen von Politikern, man könne nichts Besseres tun, als sie aufgeben, geduldet wurden, zum Imperialismus sich bekehrt; in Wahrheit ist sie immer imperialistisch gewesen; mitten in jener Zeit wurde die auswärtige Politik durch Palmerston beherrscht, den man Lord FEUERBRAND nannte, weil er stets bereit war, die Kriegsfackel in ein fremdes Land zu schleudern, wenn das geringste britische Interesse auf dem Spicle zu stehen schien. Der französische Sozialökonom BASTiat beklagte sich bitterlich gegen COBDEN über PALMERSTONs ,taquinerie“ (Necksucht, d. h. ununterbrochen herausforderndes Wesen). „Nichts, was ihr gleichkam, ist je in unserer Politik gesehen worden, weder vor- noch nachher", schrieb I879, als der neue Imperialismus noch in der Wiege lag, JoIn MORLEy im Leben Condens (zum Jahre I850). Und doch weiß Escomt, der Geschichtsschreiber von Downing Street, von dem Machtzauber beim Volke (d.h. natürlich bei der Mittelklasse) und bei den Vornehmen zu erzählen, den das Auswärtige Amt 
unter dem PALMERSTONschen Regiment erworben hatte (,,the popular and fashionable prestige acquired under the Palmerstonian regime by the Foreign Office". Escotr, The story of British diplomacy 379). PALMERSTON S Zauberformel war, daß England für »etwas \& gelten sollte in den Ratsversammlungen Europas; dies »etwas», sagt der sehr korrekt englisch denkende EscoTr, bedeutete, in der Wirkung: alles". „Die Nation liebte PaLMERsTons lebensvolle Politik (spirited policy)". Auf die Kolonien kam damals wenig an; der Gegensatz gegen die russische Machtpolitik im Balkan, gegen die französische im Mittelmeer, beherrschte alles. - So groß der Triumph CoBDENs in und mit der Offentlichen Meinung gewesen war, in der auswärtigen Politik erlitten er und BRIGHT Niederlage auf Niederlage. Die gewaltige "Bewährung " des Freihandels durch den Aufschwung des englischen Geschäftes und Reichtums I850-I870 schützte sie nicht davor, als unpraktische Friedensschwärmer zu gelten. Seitdem ist die Offentliche Meinung mehr und mehr zur "Tarif-Reform *, d. h. zum Schutzzollsystem zurückbekehrt worden. Aber diese Bewegung geht ebensowenig tief, wie die mit ihr verwandte $\mathrm{zu}$ "kollektivistischen Anschauungen. Es sind unwillige Einräumungen an die Not der Umstände; in einem Falle der böse Deutsche, im anderen der böse Arbeiter, ist es, der das Verlassen der ygesunden «englischen Ideen zu erzwingen scheint ${ }^{1}$ ). Und im stillen denkt man immer, daß es doch nur zeitweilig geschehe. Charakteristisch dafür ist DICEy selber, der bei aller Gerechtigkeit, die er dem Sozialismus widerfahren läßt, seinen heimlichen Widerwillen dagegen, als Sprecher der englischen Herrenschicht, nicht verhehlen kann, indem er des öfteren von jenen Tendenzen als von einer Zeiterscheinung redet, die ihm wie eine Laune und wie eine Mode vorkomme; er glaubt nicht, $\mathrm{da} B$ sie bald sich erschöpfen werde, aber er hält es offenbar nicht für ausgeschlossen, daß eine Periode entgegengesetzter Denkungsart wiederkehren werde. „Es mag gestattet sein, zu mutmaßen," heißt es in einer Anmerkung (S. 30I), „,daß, wenn je der Fortschritt sozialistischer Gesetzgebung aufgehalten werden sollte, diese Hemmung nicht sowohl dem Einfluß des Denkens, als irgendeinem offenbaren Tatbestande, der die öffentliche Aufmerksamkeit auf sich ziehen wird, zu verdanken sein mag; z. B. dem Wachstum der staatlichen Besteuerung als der gewöhnlichen, wenn nicht unausweichlichen Begleiterscheinung einer sozialistischen Politik." $\mathrm{DaB}$ überhaupt das individualistische, in Wahrheit gesellschaftliche, kapitalistische Wirtschaftssystem allmählich untergehen könne,

1) Im Weltkriege ist es zutage getreten, wie stark auch heute noch die Formeln und Phrasen der Freiheit wirkten, während sie zu gleicher Zeit mit Füßen getreten wurden. 
dem Großbritannien und Größerbritannien zweifellos ihre Größe und Macht verdanken, vermag ein normales angelsächsisches Hirn nicht zu denken. Und doch verwechselt DrCEy eine Bewegung, die in den Köpfen der Intellektuellen - einer in Großbritannien besonders schmalen Schicht - in der wissenschaftlichen Literatur und in der fortwährend auf die Bedürfnisse und Unzufriedenheiten der Masse zugeschnittenen praktischen Politik mächtig geworden ist, mit der Bewegung der öffentlichen Meinung, die so viel langsamer ihre trägen Fluten einherwälzt. Auch in Großbritannien wirken die »Intellektuellen " allmählich und zuweilen stark auf die öffentliche Meinung, sie gehören zu ihren Führern; aber ihr Einfluß ist, verglichen mit dem Einflusse der Zeitungen und Parteiführer, der Romanschriftsteller und Musikhallen, viel zu gering, als $\mathrm{da} B$ man die unter jenen vorherrschende Meinung mit der Offentlichen Meinung identifizieren dürfte. Man darf sagen, daB, ungeachtet der von Dicey richtig gezeichneten Umwandlung der Denkungsart in gelehrten Kreisen, die Offentliche Meinung in England noch entschieden mindividualistisch und gesellschaftlich ist, in dem Sinne, den der ökonomisch-politische Liberalismus ausprägt.

Was das Verhältnis der Offentlichen Meinung in den Vereinigte $n$ Sta a te n zum politischen Sozialismus betrifft, so dürfte in der Hauptsache noch heute ein charakteristischer Ausspruch von BRYCE gelten, der im Jahre I905 schrieb: . . , ,die sozialistische Propaganda und die Arbeiterparteien, welche furchtsame Leute in europäischen Ländern beunruhigen, beunruhigen niemand in den Vereinigten Staaten, zum Teil vielleicht, weil so viel Glaube an die gesunde Vernunft der Massen herrscht, zum Teil aber, weil ein so großer Teil der Bevölkerung weder aus Unternehmern noch aus Arbeitern besteht, sondern aus Landwirten, denen der Boden gehört, den sie bebauen", freilich sei ihm von allen seinen Freunden gesagt worden, daß die ruhige Zufriedenheit, womit die amerikanische Offentliche Meinung der Zukunft entgegensehe und durch den Fortschritt kollektivistischer Ideen sich den Blick nicht trïben lasse, nicht für dauernd und unerschütterlich gelten dürfe. Er aber werde immer von neuem durch den tiefgewurzelten Optimismus, der in den Staaten herrsche, überrascht, durch ihr ungeheures Selbstvertrauen. Die seitdem vergangenen Jahre, besonders die Wirkungen der Krise von I907 und folgenden Jahren, dürften aber den Freunden Bryces recht geben. Max Schipper, hält das Werk von Myers über die großen amerikanischen Vermögen, soweit es einer schon vielverbreiteten Volksstimmung nicht nur der Arbeiter, sondern auch der Farmerklasse Ausdruck gebe, für ein Sturmzeichen, ,das dem bequemen 
kapitalistischen Gehenlassen der bisherigen amerikanischen Wirtschaftsund Sozialpolitik zur Warnung dienen sollte" (Neue Rundschau, April I916, S. 449). Freilich, auch die Farmer bilden nur einen schwachen Faktor für das Werden der öffentlichen Meinung; und soweit es der Fall ist, denken sie ganz überwiegend "gemeinbürgerlich " (kapitalistisch).

9. (Streiks und Aussperrungen.) Ich betrachte nunmehr noch die luftartige Gestalt der Offentlichen Meinung, worin sie ihr Wesen erst rein entfaltet. Sie sitzt zu Gericht über die Ereignisse, über die Verhaltungsweisen der Bürger, der Regierungen, der Arbeiter, ihre Richtersprïche steigen wie Blasen empor, scheinbar nach Stimmungen und Launen, daher selten berechenbar, oft in derselben Frage, über den gleichen Gegenstand wechselnd, ja entgegengesetzt - der Begriff der Offentlichen Meinung in diesem Sinne würde sich erst erfüllen, wenn sie ihre Urteile bewußterweise, in Absicht auf gewisse Zwecke, der jedesmaligen Lage der Dinge anpaßte; davon bleiben indessen die Erscheinungen noch weit entfernt, die Gefühle, Sympathien und Antipathien geben in der Regel den Ausschlag. Naturgemäß ist diese, bei bestimmten Gelegenheitsursachen sich äußernde Form des sozialen Willens in hohem Maße bedingt durch die gleichzeitige flüssige Gestalt der Offentlichen Meinung und vollends durch deren dauernde und feste Gestalt. So auch in der sozialen Frage. Als die britische Regierung indentured labour, d. h. die Sklaverei, in die Goldgruben des Transvaal einführte, da empörte sich die Offentliche Meinung dagegen, so sehr sie sonst jene erobernde Regierung unterstützte. Ebenso entrüstet sich regelmäßig die Offentliche Meinung über alles, was als "mittelalterliche Barbarei " auftritt oder ihr so dargestellt wird; im Bereiche der sozialen Frage daher über Mißhandlungen von Dienstboten und Arbeitern, wie sie auf dem Lande vorkommen, wie über anderen auffallenden Mißbrauch der Obmacht der Arbeitgeber, z. B. Truck. - Ferner sind die jedesmaligen Urteile der Offentlichen Meinung abhängig von ihrer vorherrschenden Strömung oder flïssigen Gestalt, daher gegen alles. Revolutionäre, insbesondere gegen öffentliche Unruhen, Krawalle, Putsche; werden bei solchen Gelegenheiten oft die "armen verführten « Massen bedauert, so wendet sich der Unwille um so heftiger gegen die Führer und Verführer. Die immer wiederkehrenden Anklagen gegen diese, daß sie sich von den "Arbeitergroschen " "mästen «, die Verdachtsäußerungen, daß sie in ihrem selbstischen Interesse zu Streiks aufreizen, verdichten sich $\mathrm{zu}$ einem flüssigen Aggregatzustand, so daß die Offentliche Meinung, auch wenn sie die Arbeiterbewegung als solche dulden gelernt hat, ihr doch die Führer versagt, zumal wenn diese als ordentlich bezahlte Beamte ihrer Organisationen 
sich vorstellen. Indessen ist diese Strömung sichtlich schwächer geworden, je mehr die Organisation und Führung unter dem Drucke der wirtschaftlichen Verhältnisse sich verallgemeinert hat; es sind mehr einzelne auffallende Fälle, worüber die Offentliche Meinung sich aufregt. Ein solcher Fall war die BEBELsche Villa: die Tatsache, $\mathrm{da} B$ der hervorragende Politiker in Zürich, wo seine Tochter verheiratet lebte, eine Villa besaß, von der er einen Teil zur Sommerfrische bewohnte, während sie sonst vermietet war, schien mit dem Stande eines Arbeiterführers schlechthin unverträglich und ein Beweis zu sein, daß dieser in der Regel es sich wohl sein und das Elend der Massen auf sich beruhen lasse. - Wie die rohen und kindischen Attentate auf den greisen Monarchen, der sich allgemeiner Hochachtung erfreute, auf die öffentliche Meinung im Deutschen Reiche wirkten, ist schon erwähnt worden. Ebenso wie hier zur Sozialdemokratie, verhielt sie sich in den Vereinigten Staaten zu den Anarchisten, als 8 Jahre später ein blutiger Zusammenstoß zwischen diesen und der Polizei in Chicago geschah. „Aber jetzt wandte sich die öffentliche Meinung mit Heftigkeit gegen die Anarchisten" (G. AdLER HWSt. ${ }^{3}$ I, S. 460). Es folgten die bekannten (ungesetzlichen) Hinrichtungen. Ähnlich war es in Frankreich nach der Ermordung CARNots: ,die aufflammende Reaktion der bis in den innersten Nerv erregten Gesellschaft fegte wie ein Sturmwind den Anarchismus hinweg" (das. S. 462). - Was aber die Sozialdemokratie betrifft, so ist noch in lebendigster Erinnerung, wie der 4. August I9I4 auf die öffentliche Meinung in Deutschland gewirkt hat. Wie mit einem Schlage war die Anklage der vaterlandslosen oder gar vaterlandsfeindlichen Gesinnung zu Boden geworfen. Freigesprochen und gereinigt stand die verfemte Partei da, glänzend hatte sich das Wort bewährt, das Io Jahre zuvor (am 7. März I904) BEBEL im Reichstage gesprochen hatte: ,Meine Herren, Sie können künftig keinen siegreichen Krieg ohne uns schlagen. Wenn Sie siegen, siegen Sie mit uns und nicht gegen uns, ohne unsere Hilfe können Sie nicht mehr auskommen": worauf die mächtigen Worte über die ,Verteidigung unseres deutschen Bodens" folgten, Worte, die derselbe Volksführer noch am Io. Dezember des gleichen Jahres in gesteigerten Formen wiederholte. Bemerkenswert ist aber, daß diese und manche ähnliche Kundgebungen hervorragender Sozialdemokraten auf die öffentliche Meinung nur geringen Eindruck machten und die festgewurzelten Vorurteile nicht zu erschüttern vermochten (vgl. Eiduard DAvid, Sozialdemokratische Briefe über Vaterlandsliebe I-VI in der Wochenschrift "Die neue Gesellschaft « I905).

Die regelmäßig sich wiederholenden Vorgänge im Gebiete der sozialen Frage, worüber die Offentliche Meinung sich aufregt, sind aber 
die großen Arbeiterausstände. In der Regel ist das Urteil nur eine Folgerung aus der allgemeinen Schätzung der Arbeiterbewegung und des Sozialismus - die flüssige Offentliche Meinung verdunstet darin. In der früheren Phase - bis etwa I880 - lag noch zumeist die Auffassung zugrunde, daß ein Streik nicht nur unsittlich, sondern auch unrechtmäßig sei, so etwas wie eine Empörung von Dienern gegen ihren Herrn oder doch von Abhängigen gegen ihren Brotgeber, zum mindesten aber wurde Undankbarkeit und überdies Torheit darin gefunden, der armen unwissenden, verführten Masse jedoch weniger als den Führern und Verführern die Schuld gegeben. HERkNER schrieb noch in der ersten Auflage seiner Arbeiterfrage (I894) S. 24, 52, in Deutschland spiegele die Offentliche Meinung die Stimmung der durch die Streiks gereizten Arbeitgeber wider. Immerhin fand die um I885 von einem preußischen Minister kundgegebene Auffassung, hinter jedem Streik lauere die "Hydra der Revolution", nur einen schwachen Widerhall; man hatte den Eindruck der Unkenntnis und Ubbertreibung, die eher schade als nütze. Es war eben um die Zeit der Wende zur allgemeiner werdenden Einsicht, daß es sich jedenfalls um den Gebrauch eines Rechtes handle, das als solches geachtet werden müsse, wenn auch im einzelnen Falle die sittliche Berechtigung fehlen möge. Die im kaiserlichen Februar-Erlaß I89o enthaltene Verkündung der 》Gleichberechtigung der Arbeiter " mußte einen starken Eindruck machen. Seitdem nimmt nur noch zu den ganz großen Ausständen die Offentliche Meinung in entschiedener Weise Stellung, und zwar überwiegend verneinende, hauptsächlich wegen des Schadens für die Volkswirtschaft, der Gefahren für die öffentliche Ruhe. In England ist, wie die ganze Entwicklung, so auch diese um einige Jahrzehnte früher. Die Streiks erscheinen hier so stark im Zusammenhange mit den Gewerkvereinen, daß das Verhalten der Offentlichen Meinung zu jenen in der Hauptsache immer aus dem Verhalten zu diesen abgeleitet werden kann (Ablehnung, zuletzt gesteigert, bis gegen I870, Sympathie bis etwa I900, seitdem wieder Umschwung in entgegengesetzter Richtung). In Frankreich wird alles auf die politische Revolution bezogen. Wie die Offentliche Meinung diese in ihrem bürgerlichen Charakter bejaht, so will sie auch ihre Errungenschaften - vor allem das freie und gesicherte Eigentum gegen die soziale Revolution schützen. Die größeren Streiks werden als Vorbereitungen zu dieser oder als ihre Vorspiele empfunden und aufgefaßt. Nur das politische Interesse der Parteiführer, ihre Arbeiterfreundlichkeit zu beweisen, wirkt einigermaßen entgegen. DieOffentliche Meinung wird fast nie für die Arbeiter Partei nehmen, wohl aber, wie überall, Vergleichen und Vermittlungen ihre Gunst schenken. 
Im Zusammenhange damit die Tatsache, daß gewonnene Streiks seltener als in anderen Ländern vorkommen. Auch das Gesetz von I892 über das Einigungsverfahren hat geringen Eirfolg gehabt, weil die Unternehmer sich immer, auch bei geratenen Vergleichen, überlegen wissen. - Im allgemeinen wird man sagen dürfen, daß folgende Bedingungen die Offentliche Meinung geneigt machen, ausständige Arbeiter mehr oder weniger zu unterstützen: I. wenn auffallend schlechte Lohn- oder andere Arbeitsverhältnisse offenkundig vorliegen, 2. wenn kein Kontraktbruch vorliegt, sondern 》ordnungsmäßige Kündigung«, 3. wenn das Publikum aus anderen Gründen gegen die Betriebe ihrer Unternehmer und Leiter eingenommen ist, 4. wenn Vermittlung und Schiedsgericht angebahnt wurden, aber an dem Widerstand der Unternehmer gescheitert sind, 5. wenn keine "Begehrlichkeit " - nach höheren Löhnen - entdeckt werden kann, sondern die Arbeiter offenbar im Stande der Verteidigung gegen Verschlechterung ihrer Lage sind (Abwehrstreiks), 6. wenn der scheinbare Streik in Wirklichkeit als eine Aussperrung sich darstellt und so aufgefaßt wird ${ }^{1}$ ), 7. wenn die Arbeiter sich eines ruhigen Verhaltens befleißigen, zu keinen Klagen über "Terrorismus * Veranlassung geben, 8. wenn der Ausstand gute Aussichten auf Erfolg hat, und wenn er einen siegreichen Verlauf zu nehmen scheint. - Jede dieser Bedingungen kann allein genügen, um ein bejahendes Verhalten der Offentlichen Meinung $z \mathfrak{u}$ einem Ausstande $z u$ bewirken, wahrscheinlicher wird es, wenn mehrere zusammenkommen, am wahrscheinlichsten, wenn alle gegeben sind, was aber wiederum an sich selbst das am wenigsten wahrscheinliche ist. $\mathrm{Zu} \mathrm{I}$. wirkt besonders stark mit, wenn Frauen und Kinder als die wausgebeuteten " Personen erscheinen. Dies ist in auffallender Weise der Fall in der Heimindustrie, die als solche schon leicht als offenbares Elend in die Erscheinung tritt. So war es bei dem Ausstand der Streichholzarbeiterinnen (match girls) I888 in London. „Ohne Kasse, ohne Organisation, schien der Streik hoffnungslos. Aber durch die unermüdliche Tatkraft von Frau Besant und Herrn Herbert Burrows wurde die Offentliche Meinung in einer nie vorher bekundeten Weise aufgebracht... nach hartnäckigem Widerstand, der zwei Wochen dauerte, wurden die Unternehmer durch den bloßen Druck der öffentlichen Stimmung genötigt, ihren Arbeiterinnen einige Zugeständnisse zu machen“ (S. u. B. WEBB, History of Trade Unionism 388). „Es war eine neue Erfahrung für die Schwachen, gerade wegen ihrer Schwäche Eirfolg

1) .Nicht zu vergessen ist ..., daß die öffentliche Meiuung viel leichter Sympathien empfindet für die »armen * Arbeiter, als für den »reichen "Arbeitgeber." A. WEBER, Der Kampf zwischen Kapital und Arbeit, S. 485 . 
zu haben, vermöge der Dazwischenkunft des Publikums" (das. 389). Ähnlich geschah es in Deutschland mit dem Konfektionsarbeiterinnenstreik I896. „Unter dem Druck der öffentlichen Meinung kam es in Berlin noch zu einem Versuch der Verständigung“ ... „Ohne $Z_{\text {weifel }}$ hätten die großen Herren viel kürzeren Prozeß gemacht (als es durch die teilweisen Einräumungen geschah) ... wenn nicht die öffentliche Meinung, wie sie sich in Parlamenten, Presse, öffentlichen Versammlungen und hilfreichen Veranstaltungen mit überwältigender Deutlichkeit äußerte, eine gewisse Rücksicht verlangt hätte" (OLDENBERG, HWSt. ${ }^{3}$ I, S. 940 f.). Als ein gutes Mittel, um die Offentliche Meinung für eine Sache der Arbeit zu gewinnen, erwiesen sich die Ausstellungen der Heimarbeit, bei denen der Kontrast zwischen Leistung und Lohn schreiend zutage trat. 2. Der deutsche Kaiser war Sprecher der Offentlichen Meinung, als er am I4. Mai 1889 die Deputation der Bergarbeiter empfing, die ihm erklärte: „Wir fordern, was wir von unseren Vätern ererbt haben, nämlich die achtstündige Schicht." Der Gedanke dieser Sendung war aus einer Lage der Dinge entsprungen, welche „durch die sich verschärfenden Gegensätze und die Wucht der öffentlichen Meinung auf der einen, die Aspirationen der Dortmunder Häuptlinge auf der anderen Seite" bedingt war (OlDENBERG in Schmollers Jahrbuch XIV, S. 932; vorher daselbst): „Nicht nur die allgemeine Parteinahme des durch den drohenden industriellen Stillstand erschreckten Publikums für die streikenden Bergleute, nicht nur die einmütige Arbeiterfreundlichkeit der gesamten, freilich auch von parteitaktischen Nebenrücksichten geleiteten Tagespresse bis tief in das eigene nationalliberale Lager hinein... reizte die Arbeitgeber aufs empfindlichste." Ebenso aber sprach der Kaiser im Namen der Offentlichen Meinung, wenn er seinem Willkommsgruß hinzufügte: ,Ihr habt euch aber ins Unrecht gesetzt, denn die Bewegung ist eine ungesetzliche, schon deshalb, weil die I4tägige Kündigungsfrist nicht innegehalten wurde, nach deren Ablauf die Arbeiter gesetzlich berechtigt gewesen wären, die Arbeit einzustellen. Infolgedessen seid ihr kontraktbrüchig." Offenbar wäre die Bedeutung des kaiserlichen Empfanges viel höher gewesen, wenn dieser Vorwurf nicht hätte erhoben werden können. „, Es scheint mir deshalb auch", schrieb OLDENBERG (a. a. O. S. 93I Note I), ,nicht unglaubwürdig, wenn berichtet wird, die den Vertragsbruch scharf betonenden Worte des Kaisers hätten vielfachen Anstoß und die Empfindung bei Bergleuten erregt, das kann der Kaiser nicht gesagt haben«. Treffend nennt OLDENBERG den Standpunkt, den die Mehrzahl der Arbeitgeber eingenommen hatte, die Wiederaufnahme der Arbeit zu verlangen, ehe man sich auf Verhandlungen einlasse, 
„für den der Verhältnisse Kundigen“ eine „formalistische Ubertreibung". Solcher Verhältnisse kundig ist eben die Offentliche Meinung fast nie, die nach einfachen Formeln und Schlagworten urteilt. 3. Hier liegt wohl der häufigste und leichteste Grund zur Parteinahme für ausständige Arbeiter. Daher so oft die üble Lage der Grubenherren: als Käufer der Kohlen steht ihnen nicht nur das gesamte Publikum, sondern insbesondere auch alle an Kohlen-verbrauchenden Industrien beteiligten Personen, mithin sehr bedeutende Unternehmerkreise, gegenüber. Wenn alle Abnehmer an billigen Kohlenpreisen interessiert sind und die Grubenherren geltend machen können, daß jeder Streik die Ware verteuere, so überwiegt doch die Meinung, $\mathrm{da} B$ ihre Gewinne auch bei verhältnismäßig niedrigen Preisen sehr hoch seien und daß ihnen demgemäß die Schmälerung szu gönnen "sei. Sehr leicht entsteht dann auch der Verdacht, daß jene selber den Streik hervorgerufen hätten, um einen Vorwand zur Erhöhung der Kohlenpreise zu gewinnen. OLDENBERG (S. 960) hält diesen Verdacht wohl mit Recht im Falle von 1889 für unbegründet, hebt aber hervor, der objektive Zusammenhang von Streik und folgender Kohlenteuerung werde auch von unbefangenen Interessenten nicht geleugnet. Derselbe Gewährsmann berichtet (im HWSt. ${ }^{3}$ I, 945) über die Wiederholung der Katastrophe im Jahre I905, ,des größten Streiks, den Deutschland erlebt hat": „Die öffentliche Meinung nahm mit seltener Einmütigkeit gegen die Arbeitgeber Partei, deren Konto ohnehin vom Kohlensyndikat und den Zechenstillegungen her schwer belastet war", und fügt hinzu, wichtiger als die finanzielle, sei die politische Hilfe gewesen, die die Offentliche Meinung den Bergleuten brachte (Berggesetznovelle der preußischen Regierung $\left.)^{1}\right)$. - So war es auch in den Vereinigten Staaten (vgl. ob.) „der große Kohlenstreik, der die "Nation « wie nie zuvor zum Nachdenken anregte und das Problem mit allen seinen Gefahren in voller Beleuchtung zeigte" (MüNSTERBERG, 1. c. 484). Åhnlich liegt es aber auch bei den Verkehrsinstituten: gerade weil das Publikum hier unmittelbar unter dem Stillstand leidet, und weil es selber oft über Willkür und (wie es leicht glaubt) Öberteuerung durch die "Gesellschaften " (oder gar durch den Staat) seufzt, so ist es geneigt, die Schuld an einem Ausstande weniger bei den Arbeitern als bei den Betriebsleitern zu sehen. In Stuttgart scheiterte I900 ein Straßenbahnerstreik , trotz energischer Unterstïtzung durch Magistrat und öffentliche Meinung" mit der nicht unbescheidenen Forderung des Neunstundentages und anderer Verbesserungen (OLDENBERG, 1. c. 944). Auch den Meistern der Nahrungsmittelgewerbe ist

1) Vgl. auch A. WEBr:R, Der Kampf zwischen Kapital und Arbeit, S. 466. 
bekanntlich das Publikum im allgemeinen »nicht grün «. Der Teilerfolg eines I4tägigen Ausstandes von 3500 Berliner Bäckern und Konditoren im Mai I904, und eines zweiten Berliner Bäckerstreiks im Frühjahr I907, ,,ist der Sympathie des konsumierenden Publikums zu verdanken" (OLDENBERG, S. 948), zu dem freilich auch die große Menge der Arbeiterklasse selber gehört. 4. Der Vermittlung wird immer die Offentliche Meinung geneigt sein, zumal wenn sie von bedeutender Seite, Regierungen, Oberbeamten, allgemein angesehenen Privatpersonen ausgeht. Wenn daher die Unternehmer ablehnen und bedingungslose Unterwerfung fordern, so entfremden sie sich leicht die Offentliche Meinung. Die Streikgeschichte Englands, des "klassischen Landes der Ausstände«, weist manche solche Fälle auf. Oft genug ist aber die Parteinahme gegen die Arbeiter zu stark, um nachzugeben, wenn sie auch erschüttert wird. So war es im Hamburger Hafenstreik 1895/96, wo der Arbeitgeber-Verband den , unglücklichen Schiedsgerichtsvorschlag, mit dem man den Arbeitgebern so unzeitgemä $B$ in den Arm gefallen sei und der der Arbeiterschaft erst die Ansicht von einem vermeintlichen Rechte beigebracht habe", verwarf; daß die öffentliche Meinung sich nicht dagegen zu erheben wagte, bewies das Schweigen des Bürgerschaft-Parlaments. 5. Schon zu einer Zeit, ,als noch die öffentliche Meinung ohne weiteres Ausstände als an sich unberechtigt erklärte" ${ }^{1}$ ), kam es in England vor (1828!), daß der Widerstand der Teppicharbeiter in Kidderminster gegen eine Lohnherabsetzung von I7 v. H. ,die Sympathie und Unterstützung Vieler, die nicht zu ihrer Klasse gehörten, fand" (WEBB, $H$. of Trade Unionism S. IOo). Von dem Verhältnis der Offentlichen Meinung zu den Arbeitern in den Vereinigten Staaten sagt MÜNSTERBERG allgemein: ,Man will ihnen wohl, solange sie sich verteidigen. Werden sie wirklich zu Angreifern, so schlägt die Stimmung um" (a. a. O. S. 488). 6. Der Unterschied von Streiks und Aussperrungen spielt für die Offentliche Meinung eine beträchtliche Rolle; die geringere Sympathie, die im Falle jener, gegen diejenige, die ihnen zuteil wird, wenn eine offenbare Aussperrung vorliegt, ist nur die Steigerung des Vorzuges von Abwehr, gegen Angriffstreiks. Bündig erklärte BIERMER (I895) über den Unterschied von Streik und Aussperrung (lock out): materielle Bedeutung habe er nur insoweit, ,als die Beurteilung der Streitigkeit seitens der Parteien und der öffentlichen Meinung in Frage kommt" (HWSt. ${ }^{1}$ Supplm. I, S. Io6). In einer späteren Abhandlung (HWSt. ${ }^{3}$ II, S. 250: I909) sagt derselbe Gewährsmann: „Die Parteien haben der öffentlichen Meinung gegenüber

1) Nosirz, H. v., Das Aufsteigen des Arbeiterstandes in England (Jena 1900) S. 548. Der Verf. fügt hinzu, dieser falsche Standpunkt sei gegenwärtig überwunden. 
ein natürliches Interesse, die Verantwortung für den Streit der Gegenseite zuzuschieben. Das gelingt dem Unternehmertum leichter als dem schwerfälligen Apparat einer Arbeiterkoalition." Keineswegs ist es aber die Schwerfälligkeit hauptsächlich, sondern vielmelır die viel geringere Gunst, der die Arbeiterschaft von vornherein begegnet, und ihre geringere Fähigkeit, die öffentliche Meinung in ihrem Sinne zu beeinflussen. Wenis daher BIERMER ferner sagt (das. S. 254): „An und für sich liegt es nicht im Interesse der Unternelimer, in Arbeitsstreitigkeiten die Initiative zu ergreifen. Sie haben heutzutage mehr als die Arbeiter Rücksicht zu nehmen auf die Stellung der öffentlichen Meinung, die vielfach ohne genaue Kenntnis der dem Konflikt zugrunde liegenden Ursachen dem passiven Teile der Kämpfenden ihre Sympathie zuzuwenden geneigt ist, also den verurteilt, von dem, oberflächlich betrachtet, die den Frieden störende Aktion ausgeht" - so ist das nur insoweit richtig, als die Unternehmer nicht in der Lage sind, die "Schuld auf die Arbeiter abzuwälzen, ja sogar die Aussperrung als einen Streik erscheinen zu lassen, was doch oft mit einigem Geldaufwand gelingt. So war es im Kampfe der Krimmitzschauer Textilarbeiter um den Zehnstundentag (I903), der ,,von beiden Seiten mit einer Erbitterung geführt wurde, die ihn zu einem Merkstein in der deutschen Sozialgeschichte gemacht hat" (OlDENBFRG). - Zur Bestätigung seien noch die Bemerkungen BERNSTEINS angeführt (Der Streik, S. 50): „Bei der großen Rolle, die fast mehr noch als bei anderen Kämpfen, beim Streik der mora lisrhe Faktor spielt, sind Unternehmer wie Arbeiter unter Umständen sehr darauf bedacht, die Gegenpartei als die angreifende erscheinen zu lassen, und wenden demgemä $\beta$ allerhand taktische Mittel an, dies Ergebnis herbeizuführen. Umgekehrt wird aber auch mancher Angriffsstreik unternommen, der faktisch der Abwelır eines von der anderen Seite vorbereiteten Angriffs gilt, und manchmal mischen sich Angriff und Abwehr in solcher Weise, daß es schwer hält, herauszufinden, welches Moment vorwiegt. Das gleiche ist beiläufig auch im Verhältnis von Streik und Arbeitssperre der Fall. Englische Gewerkschaften haben sogar eine fast abergläubische Vorstellung von dem Unterschied, den es ausmacht, ob ihre großen Kämpfe als Streiks oder als Abwehr von Aussperrungen geführt werden $\left.{ }^{1}\right)$." Die

1) Ein gutes Beispiel bietet auch die Sperre, die $\mathrm{nach}$ dem großen Streik von 1880 über eine Menge von einheimischen Bergleuten im Ruhrkohlenrevier verhängt wurde, was beinahe einen Viederausbruch des allgemeinen Ausstandes zur Folge gehabt hätte, .,dessen Abwendung nur durch dringendes Abraten einiger sozialdemokratischer Reichstagsabgeordneter, durch starken moralischen Druck der öfentlichen Meinung auf die Arbeitgeber, und durch die amtlich beglaubigte \%usicherung gelang, die Ausgesperten wieder aufzunehmen". (OLDENBERG a. a. O., S. 948.)

Tonnies. Kritik. 
Ånnlichkeit der Fälle eines großen Krieges springt hier in die Augen, "Verteidigungskrieg « ist die Losung. Keine Seite will die angreifende gewesen sein. Ebenso in großen inneren Konflikten, wie dem deutschen »Kulturkampf «. Immer die gleiche Rücksicht auf die Offentliche Meinung, die Furcht vor ihrem verdammenden Urteil, das Buhlen um ihre Gunst. 7. Wie wichtig und wertvoll für die Streikenden ein gesetzliches, ruhiges Verhalten ist, ergibt jeder Bericht über einen großen Ausstand in Büchern und in der zeitgenössischen Presse. Wenn dies in den wenigen Fällen, wo ein Ausstand mit Hilfe der Offentlichen Meinung gewonnen wurde, besonders hervorgehoben zu werden pflegt, so ist eine Wirkung immer ebenso sicher, wie umgekehrt das öffentliche Mißfallen am meisten durch Gewalttätigkeiten, ïberhaupt durch Nötigungen gegen "Arbeitswillige ", vollends durch Aufruhrszenen erregt wird. Die Entrüstung darüber tritt so oft auf, wie andererseits die Ausdauer, Zähigkeit und Opferbereitschaft bewundert wird. 8. Es gilt endlich, wie bei jedem Kampf, da $B$ in der Regel die siegreiche Sache nicht nur den Göttern am besten gefällt, sondern auch den Beifall des Publikums gewinnt. Haben doch sogar hervorragende Gelehrte einen Streik darum als »frivol « bezeichnet, weil er geringe Aussicht auf Erfolg gehabt habe. Der gute Errfolg gilt in der Regel als Beweisgrund für die Güte der Sache. Je moderner und gesellschaftlicher die geistige Bildung in einem Lande, desto mehr wird dieser Gesichtspunkt bestimmend wirken, um so mehr wird auch die große Menge an Bildung der öffentlichen Meinung beteiligt sein.

Treffend bemerkt BIERMER ( $\mathrm{HWSt}^{3}$ I, S. I008), ein unbedingter Verlaß auf die Unterstützung streikender Arbeiter von seiten des Publikums sei nicht vorhanden. „Wenn auch die öffentliche Meinung, wie sie sich wenigstens in den angesehensten Preßorganen äußert, gleichsam als eine Art höherer Instanz zu richten und $\mathrm{zu}$ entscheiden das Recht für sich in Anspruch nimmt, so kann sie natürlich nicht als eine in jedem Falle billig und neutral urteilende Instanz angesehen werden. Es ist eine Eigentümlichkeit der sog. 》öffentlichen Meinung ", daß sie im Wiederholungsfalle, durch die nicht endenwollende Kette der Streitigkeiten degoutiert und übermüdet, die bisher verfochtene Richtung aufgibt und zu einer gegenteiligen Auffassung umschwenkt, sich selbst aber von jeder Schuld und Verantwortung freispricht." Dagegen schreibt ein nationalliberaler Politiker (Hugo BötTrger, Die Industrie und der Staat r9ro, S. 235): die deutsche Arbeiterschaft werde ja wohl so bald noch nicht auf den Streik als Mittel der Verbesserung ihrer Lage verzichten, obwohl das Mittel häufig genug versagt habe. „Aber sie wird allmählich von der 
Uberschätzung dieses Mittels geheilt werden, namentlich dann, wenn auch die öffentliche Meinung, die heute ihre Argumente mehr aus der Tiefe des Gemüts als aus der Kenntnis der realen Verhältnisse schöpft *und fast blindlings für die Arbeiter Partei zu ergreifen pflegt,* besser über die Ursachen der Arbeitskämpfe unterrichtet sein wird. Dann werden die organisierten Arbeiter sich nicht mehr auf diesen Rückhalt verlassen können, und sie müssen dann die sachlichen Interessen den politischen voranstellen. Die öffentliche Meinung, die Kommunen und der Staat haben bei diesen Kämpfen die Rechte und Pflichten der Neutralen; wer einer Partei Waffen zuträgt in Gestalt von Streikfonds oder Sympathiekundgebungen, tritt selbst in den Kampfzustand ein und wird über kurz oder lang an den Kriegskosten beteiligt werden." Anders urteilt H. v. Nostiz (a. a. O. S. 548), freilich unmittelbar nur mit Bezug auf England, indem er sagt, es „komme vor", daß nicht bloß eine Anzahl Angehöriger der oberen Stände, sondern die Offentliche Meinung ïberhaupt sich auf Seite der Ausständigen stelle, wie es insbesondere bei dem Dockerstreik 1889 geschehen sei. Eine solche allgemeine Parteinahme sei aber nur der Ausnahmefall, ... was von der Offentlichen Meinung und den oberen Ständen verlangt werden dürfe, sei Unparteilichkeit als Regel. Der Ausnahmefall ist schwerlich häufiger in Deutschland als in England, jedenfalls dort wie hier Ausnahmefall. Beide Autoren scheinen nicht zu erwägen, da $B$ auch der Richter unparteiisch und neutral sein will und soll, und daß doch ein gerechter Richter einer von zwei Parteien rechtzugeben pflegt. Die Offentliche Meinung aber wird regelmäßig als eine Art von moralischem Gerichtshof angerufen. $\mathrm{DaB}$ sie als solche gerecht zu urteilen sich befleißigt, ist wenigstens nicht ausgeschlossen; wie weit es ihr gelingen mag, ist eine andere Frage. Nach der Natur der Offentlichen Meinung ist sicherlich eher ihre Voreingenommenheit gegen die Arbeiter zu vermuten, wie denn alle Beobachter übereinstimmen, da $B$ diese in den früheren Zeiten, d. i. bis weit über die Mitte des 19. Jahrhunderts linaus, durchaus vorwaltete, gemäß der hergebrachten und ehemals ganz natürlichen Auffassung, da $B$ Gesellen (in England "Diener") ihren Meistern zu gehorchen, also die ihnen aufgetragene Arbeit zu leisten hätten. Von der veränderten Auffassung wird noch zu reden sein. Richtig ist, was, nach Herrn v. Nos'riz' Angabe, im amtlichen Bericht über den Ausstand der Londoner Hafenarbeiter (I889) zu lesen steht, da B die Streitfragen in der Regel zu schwierig sind und zu tief für eine sachliche Beurteilung durch die Allgemeinheit liegen. HERkNER meinte noch 1896 (Die Arbeiterfrage $^{2}$, S. Ior), die Offentliche Meinung, „die ursprünglich den 
Arbeiterorganisationen durchaus abhold war," sei dabei bestimmt worden, und werde in vielen Streiks noch bestimmt, durch ,grobe Selbstsucht der Besitzenden, Weigerung, den Arbeiter praktisch als gleichberechtigten Kontrahenten beim Arbeitsvertrage anzuerkennen, individualistische Abneigung gegen kooperative Gestaltungen, irrige ökonomische Theorien, Vorherrschaft der kapitalistischen Interessen in der bürgerlichen Tagespresse und im politischen Leben". Keine dieser Feinde der Gewerkvereine befinde sich im Vorrücken, der größte Teil wanke oder sei schon in die Flucht geschlagen.

10. (Veränderungen des Urteils.) $\mathrm{Da}$ die Dinge in der Regel zu tief für eine sachliche Beurteilung durch die Allgemeinheit liegen, gilt allerdings für die meisten Fragen, die vor das "Forum " der Offentlichen Meinung kommen. So läßt sich überhaupt in ihrem Verhalten zur sozialen Frage im ganzen und in ihren Einzelheiten das Wesen der Offentlichen Meinung wohl erforschen und erkennen. Besonders geben gerade die Ausstände Gelegenheit zur "Bearbeitung " der Öfentlichen Meinung, die denn auch von beiden Seiten geschieht, und zwar neuerdings - während der letzten 30 Jahre - offenbar in stark zunehmendem Maße. Ein gutes Beispiel gab hierfür der damals vor kurzem organisierte Arbeitgeberverband von Hamburg-Altona im großen Hafenarbeiterausstand, der 1896 ausbrach. „Wenn aber die Unternehmerschaft die Gunst der Behörden in höchstem Maße genoß ... so hatte sie doch, wie sie wohl wußte, sich um die Gunst der Offentlichen Meinung gebracht (durch Ablehnung des Schiedsgerichts). Diese galt es wieder zu gewinnen. Die Reeder hatten von Anfang an behauptet, daß die Schauerleute hohe Löhne verdienten. Schon am 30. November veröffentlichte die Amerika-Linie eine Lohnliste über Kohlenakkordarbeiter, die, mit lauter Jahreslöhnen von 2-3000 M. figurierend, wohl danach angetan war, Unkundige zu frappieren... Auszüge aus Lohnbüchern anderer Stauereibetriebe folgten, während und nach den Tagen des Schiedsgerichtsvorschlages" usw. (TöNnIES, Der Hamburger Streik von I8.96/97" im Archiv für soziale Gesetzgebung und Statistik Bd. X, H. 5, S. 702). Daraufhin erklärte der Staatssekretär BöTriger am 3. und ro. Dezember im Reichstage: Hunderttausende, ja vielleicht Millionen von deutschen Arbeitern würden sich danach sehnen, gleich günstige Erwerbsverhältnisse zu haben ... „nachdem die Hamburger Lohnlisten gedruckt vorliegen, werden Sie ... gar nicht anders können, als zugeben, daß der Stand der Lohnhöhe in Hamburg für den gesamten deutschen Arbeiterstand ein beneidenswerter ist." Der Staatssekretär fand im Reichstage „lebhafte, allseitige Zustimmung“, natürlich um so mehr im großen Publikum. Auf Grund des späteren 
Berichtes der Senatskommission urteilte E. Francke (Schmoliters Jahrbuch XXII, 3, S. 949), die Erhebung habe unumstößlich festgestellt, daß aus diesen Maximallöhnen Einzelner (!) ein Schluß auf die Verhältnisse der großen Mehrzahl der Arbeiter nicht gezogen werden dürfe, und daß insofern die Veröffentlichung der Lohnlisten ein ganz schiefes Bild über die Lage der Hamburger Hafenarbeiter geliefert habe. Näheres ist dort und in meinem Aufsatze »Die Enquête über Zustände der Arbeit im Hamburger Hafen « im Archiv XII, S. $308 \mathrm{ff}$. nachzulesen, wo es heißt: „Das Urteil über das Listenmanöver kann hiernach dem Leser überlassen bleiben." Aber das Listenmanöver hatte seine Wirkung auf die öffentliche Meinung geübt. In ähnlicher Weise pflegen vorkommende Gesetzwidrigkeiten vausgeschlachtet « $z u$ werden, während von der Gegenseite natürlich diese verkleinert und entschuldigt werden, ebenso stellt die Arbeiterpresse und stellen Reden und Flugblätter die Lage der Arbeiter in grellen Farben dar, klagen die Ungerechtigkeit und Habgier, wohl auch das üppige Leben der Unternehmer,-die Parteilichkeit der Behörden heftig an; zumeist in unmittelbarer Verteidigung ihres Standpunkts und Verfahrens, neuerdings aber auch mehr planmäßig, in der Absicht, die öffentliche Meinung für sich zu gewinnen ${ }^{1}$ ). - Ubrigens konnten die Veränderungen der Urteile über Gewerkschaften und über die sozialdemokratische Partei nicht ohne Einfluß auf die Äußerungen der Offentlichen Meinung bei Gelegenheit großer Ausstände bleiben. SCHMOLLER meint sogar, auch die schlecht geleiteten, oft von einem Haufen junger Leute vom Zaun gebrochenen, den ruhigen älteren Arbeitern oktroyierten und zunächst erfolglosen Ausstände hätten doch für den Arbeiterstand auf die Dauer insofern Früchte getragen, als die Offentliche Meinung a ufger üttelt, die Arbeiter selbst durch Erfahrung klüger, die Führer geschulter, die Unternehmer vorsichtiger und $\mathrm{zu}$ Kompromissen geneigter wurden, als auch diese Streiks doch später häufig zur Abstellung vieler Mißbräuche führten (Allgem. Volkswirtschaftslehre II, S. 407). Diese "Aufrüttelung " hätte kaum erhebliche Wirkungen gehabt, wenn ihr nicht eine Belehrung vorausgegangen wäre. Das Publikum hat den Streik richtiger zu beurteilen gelernt; es hat gelernt, $d a B$ er an und für sich keine ungesetzliche Handlung, da $B$ er vielmehr der Gebrauch eines durch die Gesetzgebung anerkannten Rechtes ist; da $B$ es so etwas wie Ausbeutung der Arbeitskraft und ihrer Träger gibt, daß deren Erhaltung

1) Demnach meint Ad. Weber (Der Kampf zwischen Kapital und Arbeit, S. 465), indem er hervorbebt, da $\mathrm{B}$ die Arbeiter sehr viel Wert darauf legen, die Offentliche Meinung für sich zu gewinnen, sie seien in dem Punkte „offenbar viel klüger und diplomatischer als die Unternehmer". 
und Schonung im allgemeinen, ganz besonders auch im nationalen und staatlichen Interesse liegt. Wenn die Offentliche Meinung den Belehrungen sozialistischer Schriftsteller wenig zugänglich ist - bekanntlich fürchtete (vor dem Weltkriege) das gebildete Publikum dieBerührung mit sozialdemokratischen Zeitungen wie eine ansteckende Krankheit - so hat um so mehr die unermüdliche und mutige Aufklärung geleistet, die (z. B.) von einem Manne wie LUJO BRENTANo ausgegangen ist; sein Einfluß rinnt durch viele Kanäle. - Mit dem Verständnis für die Sache ist der Sinn für Vermittlung und Ausgleich, also für Schiedsgerichte, Einigungsämter u. dgl., gewachsen; so daB nunmehr die von den meisten Großunternehmern noch festgehaltene Ansicht, ein Streik müsse mit bedingungsloser Unterwerfung der Streikenden, also mit Niederzwingung und Triumph der "Herren" enden, der Offentlichen Meinung gegenüber als veraltet gelten darf. Schon im Jahre I889 machte ein Geh. Regierungsrat UlRICH Vorschläge bekannt (in ConRads Jahrbüchern N. F. Bd. I9), was im Falle der Weigerung einer Partei (der Fall, daß beide Teile sich weigern, werde selten vorkommen), der Entscheidung eines Schiedsgerichts sich zu fügen, geschehen müsse. Er meint, bei Weigerung des Arbeitgebers könne durch das Gesetz den Arbeitern das Recht zugesprochen werden, ohne Einhaltung der Kündigungszeit, indem angenommen würde, daß die Kündigung durch Anrufen des Schiedsgerichts (gemeint ist, daß es vor Streik oder Aussperrung angerufen wäre) erfolgt sei, in den Ausstand zu treten, und es könnten dem weigerlichenArbeitgeber alle öffentlichen Kosten, welche durch den Ausstand entständen, aufgelegt werden. „Es würde das wohl genügen, in Verbindung mit dem Druck der öffentlichen Meinung, um auch den hartnäckigsten Arbeitgeber mürbe zu machen. "Ebenso würde im Falle, daß Arbeiter sich weigern (was bekanntlich sehr viel seltener vorkommt) ,außer dem Druck der öffentlichen Meinung“ genügen, wenn die Staatsregierung im Verwaltungswege jede Unterstützung der ausstehenden Arbeiter z. B. durch Geldsammlungen verhinderte, dagegen dem Arbeitgeber, der sich der Entscheidung fügen wollte, in jeder Beziehung ihre Hilfe angedeihen ließe. Wenn hier die Öfentliche Meinung - wohl nicht ihre Macht, aber ihre Einsicht und Unparteilichkeit - überschätzt werden dürfte, ebenso, wie zu gleicher Zeit v. SCHULZE-GAEVERnitz die Anstalten zur Erhaltung und Sicherung des »sozialen Friedens « in Großbritannien überschätzte, so ist doch nicht verkennbar, da $B$ die Offentliche Meinung für den Gedanken, durch Schiedsgerichte und Einigungsämter Ausständen und Aussperrungen vorzubeugen, ausgesprochene Arbeitsstreitigkeiten durch die gleichen Mittel rasch zu beenden, gewonnen ist, wenn sie auch - 
ähnlich wie beim Völkerfrieden - noch keine Wege sieht, solche Schiedssprüche obligatorisch zu machen und ihre Geltung zu erzwingen. Wie verhält sich die Offentliche Meinung zur Erledigung von Arbeitsstreitigkeiten durch Schiedsgerichte, insbesondere zu dem Gedanken obligatorischer Schiedsgerichte? Im allgemeinen ohne Zweifel günstig, wie immer zur Vermittlung und Vorbeugung. Aber zu dem wirksamsten Prinzip, dem des $Z$ wanges, hat sie in Europa noch kaum Gelegenheit gehabt, Stellung zu nehmen. Es liegt außerhalb ihres Gesichtskreises. In bezug auf Australien sagt ganz neuerdings (Modern Democracies I92I, Vol. II, p. 253) JAMES BRYCE, die Offentliche Meinung Australiens (,,in ihrer Ganzheit") sei im allgemeinen dem Experiment der obligatorischen Schiedsgerichte günstig gestimmt gewesen. Er schreibt die Tatsache einerseits der Beunruhigung über das Streikunheil, andererseits der Sympathie mit dem Streben der Lohnarbeiter, ihre Lage zu verbessern, zu. Ähnlich beurteilt BRYCE auch die Offentliche Meinung auf Neuseeland: sie scheine der Erhaltung des Gesetzes, das ein Schlichtungsverfahren obligatorisch macht, günstig zu sein (ib. p. 337).

Im allgemeinen kann man sagen, daß die Öfentliche Meinung I. von der Notwendigkeit und Unwiderruflichkeit der Koalitionsfreiheit - wenigstens für industrielle Arbeiter - überzeugt ist; daß sie im Deutschen Reiche ihrer Durchführung, wie sie jüngst vermöge Aufhebung des § I53 GO. geschah, keinen nennenswerten Widerspruch entgegensetzte, ist allerdings Folge der Kriegsstimmungen gewesen, bleibt aber um nichts weniger bedeutungsvoll. 2. Wenn in Frankreich die Egalité als Prinzip und Schlagwort vergöttert wird, ohne daß man immer geneigt ist, Folgerungen aus ihr zugunsten der Arbeiter zu ziehen, so hat in der öffentlichen Meinung Englands wie des Deutschen Reiches die gesetzliche „Gleichberechtigung der Arbeiter", die bekanntlich auch der zweite kaiserliche Februarerlaß (I890) vertrat, allmählich sich festgesetzt. - Beide Grundsätze gehören ihrem Wesen nach der bestehenden liberalen Rechts- und Gesellschaftsordnung an, aber diese hat erst nach und nach ihren Platz in der öffentlichen Meinung erobert, insofern als sie der überlieferten, durch Religion geheiligten, in Gemeinschaftsvorstellungen beruhenden Ordnung widersprach. Wenn nun ebenso eine gesetzliche Vertretung politischer Grundsätze und Forderungen, also das Auftreten und "positive Mitarbeiten « in gesetzgebenden Körperschaften nicht nur als erlaubt, sondern in einigem Maße als wünschenswert zu gelten, sich durchgesetzt hat, so wehrt sich die Offentliche Meinung um so mehr wider die Vermischung ökonomischer und politischer Mittel. Sie will, daß gegen die wirtschaftliche Umwälzung durch Gesetze alle "bürgerlichen 
Parteien « geschlossen Front machen, sie empört sich gegen den Gedanken, daß die Arbeiter durch allgemeine Arbeitseinstellung politische Veränderungen $\mathrm{zu}$ erzwingen versuchen. Interessant ist in dieser Hinsicht, wie JEAN JAURÈs die leidenschaftliche Befürwortung des Generalstreiks, die, damals noch innerhalb seiner Partei lärmend, bald in den Syndikalismus überging, abwehrt, indem er die Bedingungen des, wie er dartut, höchst unwahrscheinlichen Gelingens erörtert. Es genüge nicht, daß das Proletariat begeistert sei, auch nicht, $\mathrm{da} B$ es seinem eigenen inneren Antriebe gehorche. „Es ist überdies erforderlich, daß es einem beträchtlichen Bruchteile der öffentlichen Meinung bewiesen hätte, daß seine Forderungen berechtigt sind und unmittelbar sich verwirklichen lassen. Jeder allgemeine Ausstand wird notwendigerweise eine Störung in den ökonomischen Verhältnissen hervorrufen; er wird viele Gewohnheiten kränken oder sogar viele Interessen aufrühren. Die Offentliche Meinung des gesamten Landes - und selbst die Meinung desjenigen sehr wichtigen Teiles der Lohnarbeiter aller Art, der nicht in die Bewegung eingetreten sein wird - wird sich daher kraftvoll kundgeben gegen diejenigen, die man verantwortlich machen wird für die Verlängerung des Konfliktes. Nun aber wird die Offentliche Meinung nicht die Kapitalistenklasse verantwortlich machen, und nur dann sich in überwältigender Stärke gegen sie kehren, wenn durch eine glïhende und sachliche Propaganda die Billigkeit der Arbeiterforderungen und die praktische Möglichkeit, sie zu befriedigen, ihr unmittelbar bewiesen sein werden ... Und, da keine Kraft, auch keine revolutionäre, gegen die Offentliche Meinung des ganzen Landes aufkommen kann, so würde die Arbeiterklasse eine sehr ausgedehnte Niederlage erleiden" (Etudes socialistes $5^{\text {me }} e ́ d$. I902, S. IoIf.).

\section{Kapite1. \\ Die Öffentliche Meinung und der Weltkrieg.}

\section{Erster Abschnitt. Vor dem Weltkriege.}

I. (Vor dem Weltkriege in Deutschland.) Die Öfentliche Meinụng im Deutschen Reiche war auf einen nahen Krieg wenig vorbereitet. Sie wußte wohl, daß der kommende Krieg groß und furchtbar sein werde, aber sie fürchtete ihn verhältnismäßig wenig, weil sie ein gewisses Vertrauen hegte, daß er den Nachbarmächten ebenso furchtbar erscheine, und daß es gelingen werde, ihn abzuwenden, wie es mehr als einmal in den Jahrzehnten seit dem Frankfurter Frieden 
gelungen war. Denn man wußte, daß das Reichsoberhaupt lebhaft wünschte, den Frieden zu erhalten und daß auch unter den maßgebenden Ministern keiner war, der eine zum Kriege reizende Politik vertreten oder geltend gemacht hätte. Ganz besonders traf dies zu für den letzten Reichskanzler des Friedens, Herrn von BeThManNHoLLwEG. Die Offentliche Meinung war allerdings auf Deutschlands Großmachtstellung stolz und wußte, daß diese Neid, Eifersucht, $\mathrm{Ha} B$ bei den alten und neuen Feinden erregte. Sie begrïßte jeden Schritt der Machtbeton ung, weil sie richtig schätzte, daß nur die Furcht vor einem gewaltigen Gegner die bei anderen Völkern vorhandenen Neigungen, den Frieden $z u$ brechen, zurückhalten könne. Sie wußte wohl, daß Österreich-Ungarn kein sehr starker, wenn auch ein zuverlässiger Bundesgenosse war; aber sie hielt das Deutsche Reich für so mächtig vermöge seines Landheeres, daß die "Monarchie « durch die Gewißheit der »Nibelungentreue "von Fall zu Fall hinlänglich geschützt sein werde, um den offenbaren Bestrebungen Rußlands, durch die Balkanstaaten, insbesondere durch Serbien, Österreich zu unterwühlen, standzuhalten. Dies hatte sich, bei Gelegenheit des kühnen ÄHRENTHALschen Schrittes, Bosnien und die Herzegowina in das Reich einzuverleiben, bewährt, und der Erfolg stärkte, wie immer, die Offentliche Meinung. In seiner großen durchdachten Rede, die der Reichskanzler, Herr von BeThMANN-Hol, WEg, am 7. April I9I3 zur Militärvorlage gehalten hat, erinnerte er daran, was auch die Offentliche Meinung wußte, aber gern verga $B$, da $B$, soweit menschliche Voraussicht reiche, kein europäischer Krieg entbrennen werde, in den nicht auch wir Deutsche verwickelt sein würden. Er wies darauf hin, da $B$ die Ereignisse auf dem Balkan ,das Verhältnis der Großmächte zueinander nicht nur nahe und empfindlich berühren, sondern auch verhängnisvoll stören können". Auch mit dem Dreibund, und gerade als die nach Osten und Westen vorgeschobene Macht des Dreibundes, bleibe das Deutsche Reich eingekeilt zwischen die slavische Welt und die Franzosen. „Wir müssen darauf gefaßt sein, uns nach zwei Seiten unserer Haut wehren zu müssen." Das war der lautere Ausdruck der Offentlichen Meinung in Deutschland vor dem Kriege. BETHMANN warnte zugleich die Kabinette der Großmächte in der Form, da $B$ er, als er seine Meinung aussprach, die Chancen, da $B$ sie den Mittelpunkt kriegerischer Aspirationen bilden würden, seien nicht gestiegen, sondern gesunken. „Von den Dimensionen eines Weltbrandes, von dem Elend und der Zerstörung, die er über die Völker bringen würde, kann sich kein Mensch eine Vorstellung machen. Alle Kriege der Vergangenheit werden wahrscheinlich ein Kinderspiel dagegen sein. Kein verantwortlicher Staatsmann wird gesonnen sein, 
leichtfertig die Lunte an das Pulver zu legen. Die Neigung dazu hat abgenommen. Zugenommen aber hat die Macht der Offentlichen Mein ung, und innerhalb der öffentlichen Meinung der Druck derer, die sich am lautesten gebärden. Das pflegen, je demokratischer die Einrichtungen sind, in leidenschaftlich erregten Zeiten (um so mehr) nicht Majoritäten sondern Minoritäten zu sein." Es bezog sich auf Frankreich, der Minister meinte hier offenbar die sunartikulierte" öffentliche Meinung der Presse, die gerade in Frankreich trotz heftigster Gegensätze innerhalb ihrer in dem einen Punkte eindeutig war. BETHMANN-HOLLWEG hat kurz vor dem Eintritt der Katastrophe an den Botschafter in London über die Kriegsbläserei des russischen Kriegsministers geschrieben, deren ,Rüickwirkungen auf die deutsche öffentliche Meinung" ihm unverkennbar und bedenklich schienen ("Die deutschen Dokumente" I, Nr.3). Seien es bisher nur die extremsten Kreise unter den Alldeutschen und Militaristen gewesen, welche Rußland die planvolle Vorbereitung eines baldigen Angriffskrieges auf uns zuschoben, so „beginnen sich jetzt auch ruhigere Politiker dieser Ansicht zuzuneigen"; auch der Kaiser habe sich schon ganz in diese Gedankengänge eingelebt und es sei der Ausbruch eines neuen »Rüstungsfiebers « $z \mathfrak{u}$ befürchten. Maßnahmen, wie die Mehrindienststellung von Auslandskreuzern, die Armierung und Bemannung der Schlachtschiffe usw., die sonst als notwendige Folge allmählicher ruhiger Entwicklung in die Erscheinung treten würden, könnten verhängnisvoll wirken, wenn sie ,panikartig unter dem Druck einer aufgeregten und von Kriegsbesorgnis erfüllten öffentlichen Meinung“" vorgenommen würden. In seinen nach dem Kriege verfaßten "Betrachtungen " macht der Staatsmann die Bemerkung: „Wo Differenzen zwischen der Marine und der politischen Leitung sich andeuteten, trat die Offentliche Meinung fast ohne Ausnahme auf die Seite der ersteren. Erwägung der internationalen Kräfteverhältnisse galt leicht als schwachmütige Rücksichtnahme auf das Ausland" (S. IOI). Wie wir früher gesehen haben, ist dies ganz und gar charakteristisch für die Offentliche Meinung. Es fehlte ihr freilich hier, wie in der Regel, nicht ein Begriff: die "Seegeltung " als Vollendung der Macht, das Meer als die Quelle der Völkergröße, war von hervorragenden Gelehrten ihr vorgestellt worden, das Vorbild Großbritanniens wirkte in leuchtender Größe; auch sog die Flottenbegeisterung fortwährend ihre Nahrung aus den mächtigen Interessen der Großindustrie, die bei ihrem Kampfe um Absatz auf dem Weltmarkte und um einen "Platz an der Sonne ", nämlich um Anteil am Kolonialbesitz in fremden Weltteilen, eine Macht hinter sich haben mußte und wollte - aber diese durchaus natürlichen und in sich 
berechtigten Bestrebungen und Ideen sahen nicht die Konsequenzen und Gefahren, sie erkannten nicht die Notwendigkeit, um der Sicherung und Sicherheit willen Opfer zu bringen - eine oberste Regel der politischen Klugheit. Durch vermehrte und verstärkte Rüstungen allein wähnten sie den Gefahren der Lage zu begegnen, oder sogar ihnen vorzubeugen, und sahen nicht, was der Staatsmann sehen $m u B$, $\mathrm{da} B$ solche auch die Gefahr näher bringen. Nur eine kleine Minderheit - und diese war nicht die der Flottenschwärmer - innerhalb der Zivilbevölkerung sah dem kommenden Kriege gleichmütig, ja zuweilen mit Genugtuung entgegen; sie hatte das Verdienst, auf die Feindseligkeiten der Feinde immer von neuem scharf aufmerksam zu machen, aber sie bemerkte nicht oder bekümmerte sich nicht, daß die Art, wie sie es tat, besonders der Ton ihrer Presse, der dem der Nachbarn wenig nachgab, dazu diente, diese Feindseligkeiten $\mathrm{zu}$ verschärfen und $\mathrm{zu}$ vermehren. Das wollte nicht nur die große Menge des deutschen Volkes nicht, auch die Mehrheit der Gebildeten, die eigentliche Trägerin der Öfentlichen Meinung, war davon weit entfernt; sie erkannte die Größe und Nähe der Gefahr nicht, sie vertraute dem allgemeinen Friedensbedürfnis, das ja in Wahrheit einer Friedensnotwendigkeit entsprach - und zog dabei Rußland und die "unartigen Kinder " auf dem Balkan nicht gehörig in Rechnung $\left.{ }^{1}\right)$. Die wesentliche Gefühlspolitik der Offentlichen Meinung trat ganz besonders im Verhältnis zu England zutage. Die klare Einsicht, daß auch um sehr hohen Preis ein gutes Verhältnis zu dieser Weltmacht - neben der damals die Vereinigten Staaten noch nicht in Betracht kamen - gesucht werden müsse, da $B$ dies eine Lebensfrage für das Deutsche Reich sei, woran dessen ganze Zukunft hing, fehlte. Nicht ohne Grund wird die deutsche Diplomatie der Jahre I89o bis 1904 angeklagt, die sicherlich nicht durch ïberlegene Klugheit sich ausgezeichnet hat; aber es ist recht fragwürdig, was sie gegen eine leidenschaftlich erregte, von den Hochgefühlen der BISMARCKschen Ära noch erfüllte Offentliche Meinung durchzusetzen vermocht hätte. Nicht zu übersehen sei es - meint bei Eirörterung des Verhältnisses zu Eingland G. von JAGOw, Ursachen und Ausbruch des Weltkrieges S. 34 -, daß die Offentliche Meinung jenseits und diesseits des Kanals durch verschiedene $Z$ wischenfälle (KRÜGER-'Telegramm, Burenkrieg, Rededuell Bürow-Chamberlain, Hetze einzelner Preßorgane) einem

1) Treffend stellt der belgische Gesandte BEYINS noch in seinem ausfïhrlichen Bericht vom 24. VI. 1913 fest, daß der Kaiser durch die friedliche Tendenz seiner Politik während der letzten Jahre (nach der Daily Telegraph-Sache) wiederum größeres Ansehen gewonnen, und daß er sich den Wïnschen der Offentlichen Meinung angepaßt habe, in dem er le guardien de la paix war: Scuwhotuggr, Der lehlspruch $\nabla$.

Versailles, S. 188. 
Bündnis immer ungünstiger geworden war. Es war das Unglück Deutschlands, daß seine Offentliche Meinung an BISMARCK einen Führer gehabt hatte, dem sie fast unbedingt vertraute; von diesem Bande losgelassen, wähnte sie sich jedem möglichen anderen Führer überlegen - dem deutschen Kaiser, der sich für berufen, sogar vom Himmel geweiht hielt, es zu sein, mit gutem Grunde - und gab sich lieber der Leitung eines im bunten Gauklergewande Klugheit durch Dreistigkeit übertrumpfenden Journalisten hin, der angeblich und scheinbar die BISMARCKsche Tradition bewahrte. So entstand der sonderbare Widerspruch, daß dieselbe Offentliche Meinung, die durchaus gegen den Kaiser eingenommen war und ihm kein politisches Urteil zutraute, mit höchster Begeisterung auf die politisch mangelhaft erwogenen Flottenvergrößerungsgedanken des Kaisers und seiner damaligen "Handlanger " einging und bei jeder kritischen Gelegenheit dem gewaltigen Seenachbar fletschende Zähne zeigte, anstatt durch freundliche Mienen um seine Gunst $z u$ werben. So habe - sagt Herr von ECKARDSTEIN, Lebenserinnerungen und politische Denkwürdigkeiten II, S. 4I - Graf BüLow schon in der Samoa-Angelegenheit ,sich nicht nur dem Kaiser, sondern auch fast der gesamten öffentlichen Meinung Deutschlands gegenüber in einer sehr schwierigen Lage“ befunden; und ,nur unter dem Druck der künstlich verhetzten öffentlichen Meinung schritt man zu neuen Verhandlungen mit dem englischen Kabinett auf der Basis, da $B$ Deutschland den Hauptteil der Samoa-Gruppe erhalten sollte" (das. S. 43). So instruierte auch der Botschafter Graf HATZFELDT den Botschaftsrat dahin, es müßten (von England) hinreichende Kompensationen zugestanden werden, um die Verständigung ,,vor unserer öffentlichen Meinung rechtfertigen zu können" und da für eine Kombination der beiden Fragen Samoa und Togo die "Arbitrage "des Königs von Schweden vorgesehen war: „Wir müßten jedenfalls unserer öffentlichen Meinung gegenüber den größten Wert auf Beibehaltung der Arbitrage legen" (S. 49). Auch bei der ferneren Verhandlung wollte HATZFELDT als feststehend betrachtet wissen, „daß unsere öffentliche Meinung durch ... Verzicht auf Samoa auf das tiefste erregt und ... auch durch Gewährung großer kolonialer Kompensationen durch England nicht beruhigt werden würde"; er ließ Chamberlain sagen, daß er einen Ausgleich auf der Basis erstrebe, ,welche uns die Möglichkeit bieten würde, bei der weiteren Entwicklung unserer freundschaftlichen Beziehungen zu England auf die bereitwillige Unterstützung unserer öffentlichen Meinung zu rechnen“" (S. 63). Der so schrieb und dachte, war ein geschickter Diplomat, aber er war nicht der I eiter der auswärtigen Politik, noch weniger 
der Gesamtpolitik; dieser war noch der greise Fürst HoHENLOHE, oder - der Kaiser: weder der eine noch der andere war imstande, die Offentliche Meinung Deutschlands zu politisieren, wie es gerade in bezug auf das Verhältnis zu England mit aller Tatkraft hätte versucht werden müssen. So versetzte der Burenkrieg, der wohlbegründete moralische Entrüstung fast in allen Volksschichten auslöste, auch die Offentliche Meinung in einen Zustand der Raserei, der sie sehr geneigt machte, die Ansicht von Hofgeneralen, daß es ,jetzt Zeit für uns sei, gegen England loszuschlagen" zu billigen und zu unterstützen - es gab keine Autorität, die dem Publikum mit Aussicht auf Erfolg sagen konnte, daß die politische Klugheit gebicte, sich jeder Einmischung in die Händel Englands mit seinen Vasallen (denn zu diesen gehörten schon damals Transvaal und die südafrikanische Republik) zu enthalten; daß die Idee, Englands Weltherrschaft zu brechen, etwas sei, was - wie auch immer die Zukunft Europas sich gestalten möge - für u ns, denen der Zweifrontenkrieg bevorstand, die wir zwischen die zwei großen Militärmächte eingekeilt, nur den schweren Nationalitätenstaat Österreich-Ungarn und ein wie im Grunde jedermann wuBte - durchaus unzuverlässiges Italien in unserem Gefolge hatten, da $B$ dieser Gedanke für uns schlechthin ein Noli me tangere, darstellen müsse. Tatsächlich wurde die Offentliche Meinung zwischen Sorgen und Zuversicht hin- und hergerissen, und ihre Sorgen, wenn sie rege waren, zwischen Rußland auf der einen, England auf der anderen Seite; daß diese beiden Mächte sich die Hände reichen würden, hielt man, bis es 1907 geschah, für unmöglich, wie der geistig nicht normale Staatssekretär von Hor,STEIN diese Vermutung immer für "naiv " erklärt hatte. Der einzige feste Punkt in der auswärtigen Politik war für die Offentliche Meinung wie für die regierenden Personen das Festhalten am "Dreibund «, insbesondere an Oiterreich-Ungarn, das wegen seiner deutschen Bestandteile als stammverwandt empfunden wurde; das Wort von der Nibelungentreue gab diesem guten Willen eine heroische Klangfarbe. Anders war das Verhältnis zu Italien, dem Eirbfeinde des auch mit ihm sverbündeten "Osterreich. „Unsere öffentliche Meinung nahm, besonders auch im Hinblick auf die räuberische Art des italienischen Vorgehens, zum überwiegenden Teil lebhaft Partei gegen Italien" (J AGOW, 1. c. S. 47). Die elementare politische Klugheit gebot hingegen freundliche Neutralität, und unsere Regierung handelte demgemäB. - So hatte sich mehr und mehr lie Lage zugespitzt. Es war nicht eine Spitze, sondern viele, die alle als Pfeile gegen das Herz des deutschen Reiches gerichtet waren. Die Offentliche Meinung stand dem ohne gehöriges, ohne hinlänglich tiefgehendes Verständnis, und folglich völlig ratlos 
gegenüber. Sie fand das sog. Ultimatum Österreich-Ungarns an Serbien "zu scharf ", wie es auch BETHMANN-Hol, WEG und JAGOW fanden. Aber wir alle hatten auch die dumpfe Empfindung, daß jede mildere Behandlung den großserbischen Größenwahn und seine blinde Wut nur ermutigt, und daß Rußland dahinter mit Genugtuung sich ins Fäustchen gelacht hätte. Zur entschiedenen Friedensliebe und Friedenspolitik des Kaisers und seiner damaligen verantwortlichen Ratgeber hatte die Offentliche Meinung Deutschlands ein unbedingtes und gerechtes Vertrauen; die Person des Monarchen, ohnehin mehr mit Nachsicht als mit Bewunderung angesehen, verlor sogar dadurch etwas von dem Nimbus seiner Würde, daß man ihn als einen Führer im Kriege noch weniger als im Frieden sich vorstellen konnte und mochte. Fest stand aber für die Offentliche Meinung wie für die offizielle Politik und deren Leiter die Notwendigkeit der Bündnistreue zu Österreich-Ungarn, für jene mehr aus moralischen, für diese durchaus aus praktischen Gründen, wenn auch die Nibelungentreue laut verkündet wurde. „Wir müssen und können der österreichischungarischen Monarchie das Bündnis ehrlich halten; es entspricht unsern Interessen, den historischen Traditionen Deutschlands und der öffentlichen Meinung unseres Volkes" (BISMARCK, Gedanken und Erinnerungen II, S. 257).

2. (Vor dem Weltkriege in England.) Die Offentliche Meinung Englands ist ohne $Z$ weifel politisch geschulter und politisch klüger als die deutsche. Wenn die allgemeine Bildung dort ohne Zweifel tiefer steht und ihre Verbreitung geringer ist, so kommt das der politischen Bildung in denjenigen Kreisen, die auf die Gestaltung der Offentlichen Meinung entscheidenden Einfluß üben, eher zugute, als $\mathrm{da} \beta$ es sie mindert. Denn es hängt unlösbar damit zusammen: I. daß die Offentliche Meinung ihre Zellkerne in geschlosseneren Kreisen hat, 2. da $B$ die Aufmerksamkeit der Intellektuellen, die am meisten zur Gestaltung der Offentlichen Meinung wirken, sich mehr auf die politischen Probleme versammelt und verdichtet. Beide Ursachen tragen dazu bei, daß die Offentliche Meinung Großbritanniens mehr feste und flüssige Bestandteile in bezug auf politische Fragen enthält, als die Offentliche Meinung anderer Länder. Dies hat jedoch seinen hauptsächlichen Grund in der geschlossenen und gewaltigen Überlieferung des Landes, in der Kontinuität und Konzinnität seiner Entwicklung und dem ungeheuren Machtzauber (dem Prestige), den die Insel kraft ihrer Erfolge in der Weltbeherrschung so ausübt, daB sie - wenigstens am hellen Tage einer Friedensära - wie die Sonne alle anderen Sterne verdunkelt. Die Geschlossenheit der für die Meinung maßgebenden Kreise ist nur ein anderer Ausdruck der Tatsache 
daß die sregierenden Familien «, ungeachtet aller demokratischen Formen und Redensarten, das Heft fest in ihren Händen behalten. Und die Intensität des politischen Interesses dieser Kreise ist zum guten Teile eine Folge des außerordentlichen Wertes, den sie auf ihren Reichtum und auf dessen Erhaltung legen. Außerdem ist sie eine Folge der Mentalität der Frauen, die dem männlichen Geiste viel näher und verwandter ist und am Urteil über Politik lebhafteren Anteil nimmt. In meiner Schrift „Der englische Staat und der deutsche Staat" (I9I7) hatte ich geschrieben: „Wenn die Offentliche Meinung in Deutschland wie in England großen politischen Einfluß in sich trägt, so dürfte dort - in Deutschland - ihr chronischer, in England dagegen der akute Charakter stärkere Bedeutung haben; dieser Unterschied läßt sich am einfachsten deutlich machen dadurch, da $B$ man beide aufs Lesen bezieht: in Deutschland behält das Buch noch eine verhältnismäßig größere Geltung; in England ist es weit mehr die Zeitung, wonach die Ansichten sich richten." (S. 276.) Auch amerikanische Beurteiler (und in ihrem Sinne Lord BRYCE) heben hervor, daB die Zeitung in den Vereinigten Staaten mindere Geltung habe als in England, und $d a ß$ es auch davon herrühre, daß das Leben dort sozusagen in extensiver Kultur liegt; für Großbritannien wird das Denken alle Tage frisch wie der Frühstücksspeck und wie das Roastbeef des abendlichen dinner in London zubereitet, wenn auch die nahe gelegenen gleichsam offiziellen Universitätsstädte Oxford und Cambridge immer einige Ingredienzien dazu liefern. Nun muß aber auch hervorgehoben werden - was in der genannten Darstellung übersehen wurde -, daß auch die Rückwirkung des Publikums auf die Presse stärker und bewußter ist, als irgendwo, insbesondere durch die unentgeltliche Mitarbeit benannter und unbenannter, angesehener und unbekannter Männer und Frauen an den Zeitungen durch die ,Letters to the Editor", mit deren Bedeutung und Einfluß sich die ,Stimmen aus dem Publikum" in unseren Blättern nicht entfernt vergleichen können. - Der berufene Erfolg, den das Zusammenwirken von Nationalcharakter, insularer Beschränktheit, historischer Erfahrung, Weltmacht und aristokratischer Regierungsgrundlage und Methoden in der britischen Seele gehabt hat, ist die vollkommene Steifheit und Sicherheit eines Nationalstolzes, für den alles Ausländische minderwertig und leicht ein wenig lächerlich ist. Dieser Nationalstolz ist auch das beharrende Grundelement der britischen Offentlichen Meinung. Auf ihm beruhen ihre festen politischen Bestandteile, und auch die flüssigen sind von ihm eingedämmt; er erhebt sich oft in wunderlichen Blasen. Als die festen oder wenigstens flüssigen Bestandteile des britischen politischen Bewußtseins seien hier aufgezählt: 
I. die Lehre von den britischen Interessen: da $B$ sie für alle politischen Fragen entscheidendes Gewicht haben: sie werden je nach Bedarf auch Lebensinteressen * genannt. So denken auch andere Nationen über ihre Interessen, jede denkt so auf ihre Weise. Aber der Brite denkt so und zieht mit intuitiver, bedenkenfreier Sicherheit die Folgerungen daraus. Er bewährt darin seine politische Reife und Kraft, daß sie ihm über aller Gefühlspolitik, daher auch über aller Parteipolitik steht. Darin beruht die Kontinuität der auswärtigen Politik, trotz der Pendelschwingung der Regierungen und obgleich hier wie anderswo die traditionelle Machtpolitik ihre Hauptstütze in der konservativen Partei hat, auch vom Oberhause aus am bewußtesten getrieben wird, ja gleich dem Hosenbandorden als zur Prärogative der Lords gehörig angesehen wurde. Es war sehr ungewöhnlich, daß in Sir EDWARD GREY ein Mann an die Spitze des Foreign Office trat, der nicht dem Peers-Hause angehörte, und noch ungewöhnlicher, daB er K. G. (Knight of the Garter) wurde. Überraschungen in der Form, die gleich den Uberraschungen in der Sache auf die öffentliche Meinung einen tiefen Eindruck gemacht haben. Als sachliche Überraschung wirkte es, trotz allem, was man in dieser Hinsicht gewohnt war, daß das Kabinett der Pro-Boers und LittleEnglanders - denn als deren Partei wollte die übergroße Mehrheit der Wähler dem unverschämten Imperialismus der Tories, der dem Lande im Burenkriege unerwartet teuer geworden war, Halt gebieten die imperialistische Politik der LANSDOWNe und ChamberLaIN unentwegt fortsetzte und ihr sogar bald eine schärfere Spitze verlieh. Die Herren AsquiTh - zuerst war ein wirklicher Mann des Friedens, Herr Campbeli-Bannerman, an die Spitze getreten - Grey und Haldane waren die Präsidenten jener Liberal (Imperialist) League, die von Joe Chamberlain als "Imperialism in brackets" heftig verspottet worden war. Dieser Imperialismus in Klammern war aber gerade das, was die Offentliche Meinung und ihr gehorsamster Diener, Sir EDWARD GREY, schätzten und begehrten. Sie wollten allerdings den Imperialismus, aber er sollte eingeklemmt werden in die Klammern der Friedensliebe und des Eintretens für die Rechte der schwächeren und kleineren Staaten, mit anderen Worten in die Klammern der Scham und der Heuchelei, die zusammen die verschämte Heuchelei, den cant charakterisieren. Dies war also richtig auf die Offentliche Meinung berechnet, die hier, wie so oft, das Widersprechende in sich zu vereinigen beflissen war: den Imperialismus und den Pazifismus, was für England zugleich dem europäischen Kontinent gegenüber die Maxime bedeutete Bclla gerant alii! In vollkommener Úbereinstimmung befanden sich Regierung und Offentliche Meinung durch 
das Bestreben, den Gegensatz zwischen Frankreich und Deutschland von neuem anzufachen, d. h. die chauvinistische Revanchestimmung der Pariser zu ermutigen und zugleich das Deutsche Reich als Friedensstörer hinzustellen. Der Sympathie der britischen Offentlichen Meinung wurden die Franzosen versichert, selbst wenn es um eine so sichtlich faule Sache, wie die von ihnen in Anspruch genommene Eroberung von Marokko war, zum Kriege mit Deutschland käme. Sir EDWARD GREY sprach diesen seinen Wunsch schon im Beginn der ersten Marokko-Krise dergestalt gegen die Botschafter beider Länder aus, da $\beta$ er als seinen "Glauben « bezeichnete, die britische öffentliche Meinung werde über die materielle Unterstützung "Frankreichs einig werden. Die liberale und der Erhaltung des Friedens günstige „Partei, welche die Mehrheit in der französischen Kammer hatte, wurde gefürchtet von unserem Auswärtigen Amt und von der Times, die sich verbündeten mit allem, was am wenigsten liberal und am wenigsten dem Frieden geneigt war in der französischen öffentlichen Meinung" - dies das klassische Zeugnis des ausgezeichneten englischen Gelehrten Bertrand RusseiL (,,The policy of the Entente" I9I6, p. (16) ${ }^{1}$ ). Derselbe Autor, der übrigens die Ansicht vertritt, daß die deutsche Regierung weit mehr zu tadeln sei als die britische, sowohl für den Kriegsausbruch als für die Art der Kriegführung, ist gleichwohl offen genug, zu erklären: ,Was unser Auswärtiges Amt beunruhigte, war nicht die Furcht vor Krieg zwischen Frankreich und Deutschland, sondern die Furcht, da $B$ sie zu einer Verständigung gelangen möchten, die für unsere Interessen nachteilig wäre" (p. 29) und: „Ist es überraschend, wenn Deutschland, eingedenk, da $B$ wir vor kurzem (I9I2) uns geweigert hatten, Neutralität zu versprechen, wenn Deutschland angegriffen würde, erkennend, da $B$ wir offenbar bange waren vor freundlichen Beziehungen zwischen Frankreich und Deutschland und nicht uns scheuten, mit Krieg zu drohen (wie Herr I, LOYD GEOKGE im Juli I9I I tat), zu der Schlußfolgerung kam, daß wir eine Kraftprobe zwischen Deutschland und der Entente wünscliten?" (p. 3I). RUSSELl meint, was die ungeheure Mehrheit der Engländer angehe, so sei es das Gegenteil der Wahrheit, aber das Auswärtige

1) Der belgische Gesandte in London schrieb am 23. Juni 1906: „Der Standpunkt der Oftentlichen Meinung ist festgelegt. Die englische Presse hat sich in Angriffen gegen den Kaiser, seine Regierung und sein Volk derart ausgetobt, da $B$ das Publi. kum miBtrauisch bleibt. Deutschland ist der große Nebenbuhler auf dem Weltinarkte, als Militär. und in \%ukunft vielleicht auch als Scemacht." Am 8. Februar 1907 schreibt derselbe die furch Purcht und Eifersucht hervorgerufene antideutsche Stimmung habe noch nichts von ihrer Stärke eingebïßt; dic Uffentliche Meinung scheine von dem deutschen Wahlergebnis (das der Regierung verhältuismäßig günstig war) enttäuscht. 
Amt und die Times hätten die Sachen so geführt, ,d a $B$ die $D$ e utschen zu keiner anderen Schlußfolgerung kommen konnten." Die Furcht vor guten Beziehungen zwischen Frankreich und Deutschland sei der uneingestandene Beweggrund der ganzen englischen Politik gewesen (p. 36), und obgleich diesmal (IgII) noch, trotz der herausfordernden Rede LLOYD GEORGE's, die diplomatische Frage erledigt wurde, ,so blieben doch die schlimmen Wirkungen auf die Offentliche Meinung“ (p. 37). „Die Engländer, die Herrn Lrovd GEORGE für einen echten Friedensfreund hielten, waren überzeugt, $\mathrm{da} B$ er schwerwiegende geheime Gründe für seinen Vorstoß gehabt haben müsse; der Panther "von Agadir erinnerte sie an die Kaiserrede zu Tanger von I905, und sie kamen zu der entschiedenen Ansicht, daß die deutsche Politik, dreist und aggressiv immer die internationale Lage störe, immer bei der Hand sei, die Welt in Krieg zu stürzen; irregeführt durch die Times, blieben die Engländer in Unwissenheit über die deutsche Sache und erfuhren nicht, daB sie und die Franzosen die wirklichen Angreifer gewesen waren." - Aber die Offentliche Meinung Englands war nicht nur von Furcht vor Deutschland, die sich in Gespensterfurcht vor einer Invasion verdichtete, angefuillt; es war auch der $\mathrm{HaB}$, die Eifersucht in ihr rege, sie hegte den ehrlichen Wunsch, dem Deutschen Reich mitsamt seiner Industrie und seiner Flotte den Garaus zu machen. Wenn dies auch nur von Heißspornen ausgesprochen wurde, so verbreiteten sich doch immer mehr jene Gefühle und erhoben sich zur hohen Politik. Das hing zusammen mit dem anderen Grundsatz, der in der britischen Offentlichen Meinung, soweit sie politische Gedanken hegt, feststeht, das ist 2. der Grundsatz des europäischen Gleichgewichts, der balance of power. Es muB Verwunderung erregen, daß eine Nation, die sich gern ihres untheoretischen Charakters rühmt, in der Politik einer so grauen Theorie huldigt, ebenso wie das Volk der Vereinigten Staaten der MONROEDoctrin, die aber dadurch sich auszeichnet, daß sie ehrlich das amerikanische Interesse zur Begründung geltend macht, während die englische Offentliche Meinung hier, wie immer, die Humanität und, wenn möglich, die Vorsehung ins Gefecht führt, die freilich auch den britischen Interessen immerdar zur Hilfe kommen. Ein freidenkender und zugleich frommer Engländer, JoHN BRIGHT, nannte jene Lehre vom Gleichgewicht ein Idol, dem zahllose Opfer gebracht worden seien. Treffend ist diese Charakteristik auch dadurch, daß sie auf einen religiösen Aberglauben als die trübe Quelle hinweist, aus der die Verehrung dieses Idols fließt. In der Tat ist der kritiklose Glaube hier wie sonst ein Element der Stärke. Wenn ein Staatsmann die Formel ausspricht, so kann er darauf rechnen, daß ihm nachgesprochen, 
da $B$ ihm geglaubt wird. ${ }^{1}$ ) - Ein Grundsatz von ziemlich fester Beschaffenheit war ferner auch 3. der»Zwei-Mächte-Standard « geworden, des Inhaltes, daß es für Großbritannien notwendig sei, immer den beiden nächst ihm größten Seemächten, auch wenn sie verbunden wären, überlegen $\mathrm{zu}$ bleiben. Ein schlechthin kriegerischer, militaristischer Grundsatz, der jede Macht, auch wenn sie wie Frankreich seit I904 verbündet und in Wirklichkeit abhängig war, als möglichen Feind betrachtet. Er ist gleichbedeutend mit dem nicht so gern eingestandenen der vollkommenen Herrschaft Großbritanniens über die Meere „Rule Britannia, rule the waves". Als Maxime des britischen, politischen Handelns geht er durch die letzten 3 Jahrhunderte hindurch. Ihm ist vor allem die Aufrechterhaltung des Beuterechtes zur See zu verdanken, obwohl sie längst auch von britischen Völkerrechtslehrern als schlechthin barbarisch charakterisiert worden ist. So muB es 4 . als ein wenigstens flüssiges Stück der Offentlichen Meinung in England betrachtet werden, $\mathrm{da} B$ dies angebliche Recht nicht aufgegeben werden dürfe. Allerdings regten sich kurz vor dem Weltkriege Stimmen, die es als eine Schande bezeichneten und zugleich das Interesse der gewaltigen britischen Handelsflotte, von der auch die Ernährung des Inselreiches abhängig sei, geltend machten, um die Abschaffung als ratsam erscheinen zu lassen. Bezeichnend aber ist, daß eine radikale und sozialistische Wochenschrift, der Nere Statesman, am I6. Mai I9I4 einen Artikel von 3 Spalten brachte, um das Seebeuterecht zu verteidigen! - Als ein flüssiges Element möchte ich auch bezeichnen 5. die Ansicht, daß der Schein immer aufrecht erhalten werden müsse, als verabscheue die britische Offentliche Meinung den Krieg schlechthin aus moralischen und religiösen Beweggründen, und daß doch ebensolche Beweggründe die Teilnahme an Kriegen und die ihnen folgenden Annexionen und Vernichtungen anderer Mächte notwendig machen und rechtfertigen. Denn - in den Worten des Schweden STEFFEN - es ist „der Instinkt des Engländers, sich stets einzubilden, daß er streng moralisch handle, wenn er tatsächlich mit allen zweckdienlichen oder nötigen Mitteln seine krassen Machtinteressen fördert". Darum wird die Offentliche Meinung einen Krieg

1) Ein englischer Gelehrter, Ph. H. W-d, der als einer der scharfsinnigsten volkswirtschaftlichen Denker Englands bezeichnet wird, schrieb am ro. September 1914 an den Schweden Gustav F. STEFren u. a., nachdem er seine glühende Hoffnung ausgesprochen, daß die Allierten siegen würden: „Und schließlich hoffe ich, $\mathrm{da} B$ jener widerwärtige Götze, den man das seuropäische Gleichgewicht * nennt, gestürzt werden wird. Dicses "Gleichgewicht « bedeutet, da $B$ man überall Explosivstoffe umberliegen hat, die durch $Z$ ündschnüre verbunden sind - nur um die Leute abzuschrecken, da $B$ sie nicht brennende Streichhölzer wegwerfen! Wir haben jetzt gesehen, wie vortrefflich das System wirkt." STEFren, Krieg und Kultur. Aus dem Schwedischen, S. 36 . 
nur billigen, wenn sie die Ưberzeugung gewonnen hat, daß es ein vgerechter und notwendiger Krieg* ( $a$ just and necessary war) sei die Billigung wird aber nicht etwa auf den Verteidigungskrieg eingeschränkt - welcher englische Krieg wäre ein solcher? - Innerhalb dieser Elemente und mehr oder weniger durch sie gefördert, war die Abneigung gegen Deutschland ins Ungeheuerliche angewachsen. Ein liberaler Staatsmann (ROSEBERY) sprach von dem furchtbaren Gegner, „der uns bewegt, wie das Meer die schwachen Teile eines Küstenlandes". So erklärt sich, nach HELFFERICH, der englische Kampf gegen das Bagdadbahn-Projekt in der Hauptsache daraus, $\mathrm{da} B$ die britischen Staatsmänner und die britische Offentliche Meinung in dieser Bahn einen außerhalb der britischen Kontrolle stehenden Zugang zum Persischen Golf und die Möglichkeit einer deutschen Festsetzung an dessen Küsten, darin aber eine Bedrohung Indiens erblickten (Vorgeschichte des Weltkrieges S. 50). Mit wenigen Ausnahmen arbeitete die gesamte einflußreiche Presse in dieser Richtung, sie malte den Teufel des Krieges alle Tage an die Wand. Von England aus ist die Behauptung, daß die Gewinninteressen von Waffen- und Panzerplattenfabriken dahinter gestanden haben - eine Behauptung, die auch auf Deutschland und Frankreich angewandt wurde - mit der größten Bestimmtheit und dem geringsten Widerstand ausgesprochen worden; in England erhielt die schmutzige kriegstreiberische Presse ihren Namen als «gelbe Presse». Ihre Aufgabe und ihre Leistung war, die Offentliche Meinung vorzubereiten und bei jedem wirklichen oder möglichen Konflikt die Schuld auf das Volk zu wälzen, das bald nachher mit dem Schimpfworte "Hunnen" bedacht wurde. „Es ist klar,“ schrieb am 24. Mai I907 der belgische Gesandte in London, Graf LALAING, „daß das amtliche England im stillen eine deutschlandfeindliche Politik befolgt, die auf eine Isolierung Deutschlands abzielt, und daß König EDUARD es nicht verschmäht hat, seinen persönlichen Einfluß in den Dienst dieser Idee zu stellen; aber es ist sicherlich sehr gefährlich, die Offentliche Meinung in so offenkundiger Weise zu vergiften, wie es die unverantwortliche Presse tut, von der hier die Rede ist." Und im gleichen Sinne schrieb am 30. Mai der belgische Gesandte in Berlin, daß das Mißtrauen durch die persönlichen Bemühungen des Königs von England genährt werde. „,Die Presse tut das ihrige dazu, indem sie jeden Erfolg der äußeren Politik Englands als auf das Endziel gerichtet hinstellt, Deutschland $\mathrm{zu}$ isolieren. Wer wollte wagen, $\mathrm{zu}$ behaupten, daß sie sich in diesem Punkte irrt?" - Z wei Monate vor der Katastrophe schilderte sehr lebendig ein englischer Schriftsteller, von Berlin aus, den Zustand und die Mache der britischen Offentlichen Meinung (The New Statesman 
vom 30. Mai I9I4). Der englische Journalist in Berlin sei am wenigsten zu tadeln für die Verhetzung. Er sei ein geplagtes Individuum und habe wenig Zeit, das Land wirklich kennen $\mathrm{zu}$ lernen, noch weniger, die Wahrheit seiner Neuigkeiten kritisch zu prüfen. „Er weiß überdies, was man in England von ihm erwartet. Vor kurzem sprach ich mit einem Korrespondenten der von Paris gekommen war und nunmehr von Berlin aus nach London schreiben sollte. Er fühlte den Wechsel als eine Erlösung. In Paris, sagte er, war man gar zu sehr beschränkt. Man durfte weder schimpfen, noch kritisieren, nicht einmal auf offenbare Ubelstände hinweisen. "Das wäre schädlich für die Ententer, so lautete die Weisung aus London. In Berlin habe man freie Hand. Je mehr Geschichten von Deutschlands niederträchtigen Ambitionen, von brutalen Schutzmännern, von Soldatenmißhandlungen oder von Beamtendummheiten, um so besser ..." „Kein Gerücht ist zu abgeschmackt, berichtet zu werden, keine Geschichte zu unbedeutend, so lange sie darzutun geeignet ist, was für Narren oder Schurken diese Deutschen sind." - Dieser Schriftsteller sieht die Sache noch ziemlich arglos an; er scheint nichts zu wissen von dem ,Boykott alles Deutschen durch die weltumspannende Organisation der Presse, die in diesen Jahrzehnten uns nicht nur geschäftlich, sondern auch kulturell und menschlich in Verruf zu bringen suchte und fast alle Schlagworte des Weltkrieges von langer Hand her vorbereitete“. „Es ist die aufsteigende Welle in Lande der public opinion, die den Staatsmännern, die einen anderen Weg gehen möchten, schon uubequem werden könnte, denjenigen aber, der sich ihrer bemächtigt, mit starkem Ruck in die Höhe tragen wird."1) „Es wird eine zukünftige Aufgabe der Geschichte sein, festzustellen, welche Rolle diese Presse, der Zeitungskonzern des Lord NORTHCLIFFE mit seinem Gefolge abhängiger Organe in der Provinz und im ganzen englischen Kolonialreich, das Bureau REUTER und die Associated Press, der Temps und Matin für die Vorbereitung einer antideutschen und kriegerischen Atmosphäre gespielt haben“2). Diese Maschine, urteilt ONCKEN, greife in den nächsten Jahren so sicher und regelmäBig ineinander, da $B$ man nicht von einem regellosen Uberflutetwerden der Staatskunst durch die »öffentliche Meinung , sondern eher von einem zielbewußten politischen Willen sprechen möchte, der, von oben nach unten durclisickernd, als eine lebende Energie von unabsehbaren Wirkungen sich immer weiter potenziert.

1) Hermans Oncken, Die Vorgeschichte des Krieges, „Deutschland und der Weltkrieg"2, S. 542.

2) Dazu ist mindestens noch die Novoje Vremja zu zählen, die eine Filiale der NorTHCLIFF-Presse für das Zarenteich geworden war. 
Damit ist in einem etwas verwegenen Gleichnis zutreffend ausgedrückt, wie die englische Politik allmählich die englische Offentliche Meinung in die Vorstellung hineingeknetet hat (um ein anderes Gleichnis zu gebrauchen), daß Seite an Seite mit dem Zarismus zu kämpfen, für Recht, Freiheit, Zivilisation kämpfen heißt, weil jedenfalls gegen Deutschtum kämpfen so viel als die Barbarei, die Niedertracht, den Militarismus kämpfen heiße. Das war unbedingt keine leichte Sache. $\mathrm{Da}$ sie gelang, muß als ein Meisterstück der hohen politischen Betrugskunst und Taschenspielerei gewürdigt werden. Es hieß so viel als die Offentliche Meinung auf den möglichen Fall eines Krieges, wie der Weltkrieg tatsächlich war, von langer Hand vorbereiten. Dieser mögliche Fall war mit dem Augenblicke der Entente mit Frankreich gegeben, auch ohne daB es noch einer besonderen Entente mit Rußland bedurft hätte. Denn daß in einem ernsten deutsch-französischen Konflikt, wie sehr er von Frankreich oder sogar von Rußland eingefädelt werden mochte, Deutschland beflissen sein mußte, um diesen Zweifrontenkrieg zu bestehen, sich die Offensive gegen Frankreich zu sichern, stand strategisch fest; der Fall war damit gegeben, und es galt mithin, selbst unter den ungünstigsten Umständen einen solchen Koalitionskrieg als einen gerechten und notwendigen Krieg erscheinen zu lassen.

Die ungünstigsten Umstände traten ein: ein VorstoB - nicht einmal direkt von Rußland, das allenfalls noch als Kulturstaat, verglichen mit dem barbarischen Deutschland, dem britischen Philister, der, nach Houston STEWART CHAMBERLAIN, unkundig ist wie die Kaffern, eingebildet werden mochte; sondern von einem Schützling Rußlands, von Serbien, einem jungen Staate, dem sich alle möglichen Eigenschaften, nur nicht die der Gesittung, andichten ließen. Die Kunde von dem scheußlichen Doppelmorde, dem ein fürstliches Ehepaar am 27. Juni I9I4 zum Opfer fiel, konnte nur Entsetzen und Empörung, Mitleid mit unschuldigen Kindern, die ihrer Eltern beraubt waren, auslösen; auch fühlte man wohl, daß das Ereignis eine politische Bedeutung hatte - für Österreich. Es ist bezeichnend, daß eine Wochenschrift wie der New Statesman, die einen hochstehenden Teil der britischen Intelligenz repräsentierte und an der öffentlichen Meinung mitzuwirken berufen war; in der ersten Nummer nach dem Morde, am 4. Juli, am Schlusse eines Artikels über die Aussichten Osterreich-Ungarns, darauf hinweist, daß der Erzherzog den Trialismus begünstigt habe und der größte Freund der serbokroatischen Rasse gewesen sei, zugleich freilich der entschiedenste Gegner des Gedankens, sie der Monarchie zu entziehen. „So erklärt es sich, daß der slavophilste Fürst, der je dem österreichischen Thron 
nahe kam, durch einen slavischen Parteigänger ermordet wurde." Sodann wird in einer allgemeinen Betrachtung ïber politischen Meuchelmord ein menschliches Mitgefühl mit den Mördern, ob sie schon geistig entartet und moralisch einäugig sein möchten, ausgedrückt. Von Gefahr für den Weltfrieden, Gefahr für England keine Andeutung. In der folgenden Nummer (July II) geschieht der Sache überhaupt keine Errwähnung. Am I8. Juli wird über das Ende HARTWIGs gesprochen, der ,mit Isvolsky die Führerschaft des aggressiven und pro-russischen Panslavismus in der heutigen diplomatischen Welt geteilt" und eine entscheidende Rolle bei der Bildung des Balkanbundes gebildet, habe; ,,er wurde bald das Orakel der Staatsmänner König PETERs und machte Serbien zu Rußlands verläBlichstem diplomatischen Pfande"; er bildete (als der Balkankrieg ausbrach) den Brennpunkt aller der aggressiven Einflüsse auf der russisch-serbischen Seite in dem akuten Konflikt mit OsterreichUngarn." Erst am 25. erscheint ein Artikel über ,die neue österreichische Panik", worin ausgeführt wird, daß Osterreich nicht auf Unterstützung durch Bulgarien und die Türkei rechnen könne und daß Serbien nicht ohne Freunde sein würde, diplomatischer Druck auf Osterreich werde sich nicht auf seine Bundesgenossen beschränken. Vom Weltkrieg noch keine Ahnung. Erst am I. August wird gleicl auf der ersten Seite die Katastrophe als höchst bedrohlich angekündigt. Dabei ein vernünftiges Urteil: ein Verhängnis, wie in der antiken Tragödie. „Denn niemand ist auf greifbare Art im Unrecht - außer etwa Serbien, und auch Serbien ist mehr zu tadeln wegen der Mittel, die es gebraucht hat, als wegen des Zieles, nach dem es strebte." Es sei Serbiens Unglïck, nicht seine Schuld, daß dessen Erreichung das Dasein Österreichs bedrohen muB. „Und wer kann Rußland tadeln, wenn es ablehnt, die junge slavische Nation vernichten zu lassen? wer Deutschland, wenn es ablehnt, die Wahrscheinlichkeit, eine triumphierende russische Armee an seinen Grenzen zu sehen, sich gefallen zu lassen, wer Frankreich, wenn es seinem so eng verbundenen Bundesgenossen zu Hilfe kommt?" Hier aber sei die Kette zu Ende. Für Italien und für Großbritannien gebe es keine solchen bindenden Verpflichtungen. ,Ja, beide sind nicht im mindesten geneigt, die Seite zu unterstützen, an die sie dem Namen nach gebunden sind." „, In Italien scheint die Offentliche Meinung im ganzen durchaus ohne Sympathie, wenn nicht geradezu feindlich gegen Osterreich zu scin; und das gleiche darf von der britischen Meinung so weit als es solche überhaupt gibt - im Verhältnis zu Rußland gesagt werden." Und in einem Artikel über die Beziehungen zwischen den Großmächten heißt es, Berlin habe während der gegenwärtigen 
Krisis gearbeitet, Wien zu mäßigen; aber der schwache Punkt sei gewesen, daß Deutschland, was immer Österreich-Ungarn tun möge, nicht zulassen könne, daß es vernichtet werde. Der Ausgangspunkt der Krise sei ein durchaus echter Konflikt der Interessen. ÖsterreichUngarn konnte nicht umhin, dem serbischen Irredentismus Halt zu gebieten, bei Strafe selber zerstückelt zu werden. „Wie immer man über die Einzelheiten der Note denken möge, ihr Ursprung war Selbstverteidigung." „Rußlands Einmischung, wenn ÖsterreichUngarn schon im Kriegszustande mit einem anderen Staate (z. B. Serbien) wäre, würde Deutschland zwingen (would compel Germany) gemäß den Satzungen des Dreibundes, Osterreich-Ungarn zu Hilfe zu kommen." „Das wiederum würde Frankreich zwingen usw.“ Das Vereinigte Königreich sei an dem Ringen auf dreifache Weise interessiert: I. durch den Wunsch, das europäische Gleichgewicht zu erhalten, 2. durch die Verbindlichkeiten der Tripel-Entente, 3. durch das spezielle Interesse, das einige ihm zuschreiben für das Schicksal Frankreichs und die fortgesetzte Neutralität der Niederlande, insbesondere des Hafens von Antwerpen. „Keins von diesen Dingen ist ein bloßer Fetisch, aber keins ist auch jenseit des Zweifels. Gegen I. wird darauf hingewiesen, daß Europa nicht mehr die Welt ist; „zwei aufsteigende Mächte, die Vereinigten Staaten und Japan, stehen draußen und ihre relative Bedeutung würde angesichts eines durch Krieg ruinierten Europas noch größer werden als sie ist". Auch der 2. Punkt habe seine Kehrseite, aber das dritte Argument sei dem Fetisch am nächsten. Die Entwicklung von Deutschland und Rußland mache die Frage des Gleichgewichts für die Zukunft zu einer Frage zwischen diesen beiden Mächten. „Es ist eine Frage, worin unsere Politik, in die schwächere Wagschale unser Gewicht zu legen, uns fast mit Gewißheit - wenn nicht heute, so morgen - auf Deutschlands Seite führen muß." Diesem verständigen Artikel folgt eine für Deutschland durchaus sympathische Korrespondenz aus Berlin, die am Schlusse darauf hinweist, die Krise habe offenbar gemacht, daß das Deutsche Reich weit davon entfernt sei, die Eroberungspläne zu hegen, welche die Chauvinisten Großbritanniens und anderer Nationen ihm zuschreiben. - Und nun vergleiche man das vom 8. August datierende Heft dieser Zeitschrift. Die Teilnahme Großbritanniens war Tatsache geworden. Auf der Frontseite herrscht zwar noch ein gemäßigtes Urteil. Den unmittelbaren Tadel für den Ausbruch des Krieges wolle man nicht versuchen, zwischen Deutschland, Rußland und Österreich zu verteilen. Aber es scheine klar, daß die deutsche Regierung, ob hauptsächlich aus Furcht vor Rußland, $o b$ aus Treue gegen Österreich oder aus einem weniger ehrenvollen 
Beweggrunde, sich nicht angestrengt habe, den britischen Bemühungen, den austro-serbischen $Z$ wist zu schlichten (sto arrarge «), zu helfen. Ferner wird vorgeworfen, daß man in Berlin die britische Neutralität habe erkaufen wollen und $\mathrm{da} B$ Deutschland sich durch Uberschreitung der belgischen Grenze ins Unrecht gesetzt habe. Nun aber die Register, die im ferneren Texte gezogen werden! Die Fiktion, da $B$ Belgien entscheidende Ursache für Englands Eintritt gewesen sei, tritt hier in ihre vollen Rechte. Alles Vertrauen und alle Achtung hätte man sonst eingebüßt usw. Dann aber der Pariser Brief von einem ROBERT DELI, „der französische Gesichtspunkt" hat die Schriftleitung ihn ïberschrieben. Er enthält die groben Verzerrungen der Wahrheit, die dreisten Anschuldigungen, die dann allmählich auch in das allgemeine Bewußtsein der Engländer und von da in das der Amerikaner hinübergedrückt worden sind - Hohenzollern-Tyrannei und der ganze Schwindel! -

Sir EDWARD GREY war kein weiser Mann und keineswegs ein Staatsmann von mehr als mittelmäßigem Range. Aber er konnte nicht umhin, die Lage der Dinge von Anfang an zu durchschauen. Er mußte wissen, daß der serbische Vorsto $B$ von Rußland gefördert, wenn nicht angestiftet war; daß Osterreich sehr kräftig darauf reagieren mußte; daß der Krieg dadurch sehr wahrscheinlich würde, der Krieg, so wie er wirklich kam. Das Problem war von Anfang an, die Offentliche Meinung Englands für Englands Eintritt in den Welt₹rieg zu gewinnen. Fest stand zunächst: sie war nicht für Serbien, und als Vorkämpfer der serbischen Meuchelmörder das Deutsche Reich niederzuringen, das schien keine erfreuliche Aufgabe. „Ich hasse die Idee eines Krieges zwischen den Großmächten und da $B$ irgendeine von ihnen in einen Krieg gezerrt werden sollte durch Serbien wäre verabscheuenswürdig", sagte er am 20. Juli zum deutschen Botschafter und berichtete darüber an den Geschäftsträger in Berlin (The British Diplomatie Correspondence No. I). Inzwischen wurde der britische Botschafter in Petersburg von seinem französischen Kollegen und von Herrn SASSONorf bedrängt, die Regierung Seiner Britannischen Majestät möge sich vollkommen solidarisch mit der französischen und der russischen Regierung erklären. Dagegen habe er, so berichtet er, Buchanan am 24. (Nr. 6) gesagt, direkte britische Interessen in Serbien seien gleich Null, und ein Krieg wegen dieses Landes würde niemals von der britischen Offentlichen Meinung gebilligt (sanctioned) werden. GREY antwortete darauf mit voller Zustimmung: „Ich denke nicht, daß die hiesige Offentliche Meinung unsern Eintritt in einen Krieg über einen serbischen Streit billigen würde oder sollte. Die Entwicklung anderer Fragen kann uns 
aber, wenn der Krieg ausbricht, in ihn hineinziehen, und ich bin deshalb beflissen, ihn zu verhüten" (Nr. 24). Sir EDward wußte natürlich genau, daß die anderen Fragen nur Vorwände sein würden, die er suchen müsse, weil der Eintritt Deutschlands an Österreichs Seite unvermeidlich war, und weil Großbritannien jede nfalls gegen Deutschland Partei ergreifen würde. $\mathrm{Da} B$ er dies wußte, geht aus oft wiederholten Äußerungen, die in das "Blaubuch « übergegangen sind, deutlich genug hervor. So schreibt er am 29. an den Botschafter in Berlin: er habe dem deutschen Botschafter - Lichnowsky gesagt, die britische Einmischung komme nicht in Frage, wenn Deutschland nicht dabei wäre, oder sogar nicht einmal, wenn Frankreich nicht dabei wäre. Aber wir wïßten sehr wohl, daß, wenn die Sache so ausliefe, daß wir dächten, britische In teresse $n$ verlangten von uns die Einmischung, daß wir dann sofort uns einmischen mïßten, und die Entscheidung werde sehr schleunig geschehen müssen, ebenso wie die Entscheidungen der anderen Mächte. Er warnte noch ausdrücklich den Vertreter Deutschlands davor, zu vermuten, daß England nicht eingreifen werde, er solle sich durch den freundschaftlichen Ton ihrer Unterhaltung nicht irreführen lassen (Nr. 89). Diese Warnung teilte er alsbald dem französischen Botschafter СамвоN mit. „Aber", so berichtet er selbst seinem Botschafter in Paris, ,ich fuhr fort, ihm auch zu sagen, daß unsere Offentliche Meinung die gegenwärtige Schwierigkeit von einem ganz anderen Gesichtspunkte aus betrachte als demjenigen, den sie vor einigen Jahren während der Marokko-Schwierigkeit einnahm. Im Falle von Marokko handelte es sich um einen Streit, worin Frankreich unmittelbar interessiert war, und worin es zutage trat, da $\beta$ Deutschland, in einem Versuch, Frankreich an die Wand zu drücken, Frankreich einen Zwist aufnötigte über eine Frage, die Gegenstand eines speziellen Verständnisses zwischen Frankreich und uns war (ein echter GREY! die Algeciras-Konferenz war also etwas völlig Gleichgültiges, Wert- und Folgenloses in seinen Augen!). Im gegenwärtigen Falle handle es sich um einen Streit zwischen Österreich und Serbien, worin wir uns nicht berufen fühlten, Hand anzulegen. Selbst wenn es eine Frage zwischen Osterreich und Rußland würde, dürften wir uns nicht berufen fühlen, die Hand hineinzustecken. Es wäre dann eine Frage der Überlegenheit zwischen Germanen und Slawen - ein Ringen um die Überlegenheit auf dem Balkan; und es sei immer unsere Idee gewesen, es zu vermeiden, in einen Krieg über eine Balkanfrage hineingezogen zu werden. Wenn Deutschland hineingezogen würde und Frankreich hineingezogen würde, so hätten wir noch keine Entschlüsse gefaßt, was wir tun würden; es wäre ein Fall, den wir zu überlegen haben würden. 
Frankreich würde dann in einen Streit hineingezogen, der nicht sein eigener wäre, aber worin, dem Bündnis (mit Rußland) zufolge, seine Ehre und sein Interesse es verpflichteten, teilzunehmen. Wir seien frei von Verpflichtungen und wir würden zu entscheiden haben, was die britischen Interessen von uns verlangen würden. Ich hielte es für notwendig, das zu sagen, weil, wie er wisse, wir alle Vorsichtsmaßregeln in bezug auf unsere Flotte träfen, und ich eben daran sei, Fürst Lichnowsky zu warnen, nicht darauf $z u$ rechnen, daß wir zur Seite stehen würden, aber es wäre nicht schicklich, daß ich Herrn САмвол sollte irregeführt werden lassen zu der Annahme, als bedeute dies, $\mathrm{da} B$ wir beschlossen hätten, wie wir handeln würden in einem Falle, von dem ich noch hoffe, daß er nicht wirklich werden würde." Am folgenden Tage (d. 30.) erinnerte der französische Botschafter GREY an den Briefwechsel, den sie vor 2 Jahren miteinander geführt hatten, „worin wir übereinkamen, wenn der europäische Friede ernstlich bedroht wäre, zu erörtern, was wir tun wollten" (Nr. I05). Es war ein leicht verschleiertes Versprechen bewaffneter Hilfe. GREY brauchte nicht daran erinnert $z u$ werden, aber er wußte auch, daß er diesen Briefwechsel vor seinem Parlament geheim gehalten hatte, und er fühlte sich keineswegs sicher, ob er die Mehrheit für sich haben werde, wenn er daraufhin Englands Teilnahme an einem serbischrussischen Krieg fordern würde. Die Offentliche Meinung war zweifellos stark dagegen eingenommen. ,Für Petersburg und Paris“ - so schreibt M. Pokrowskr in der Wochenschrift Prawda vom 23. Februar I9I9 auf Grund der von der Sowjet-Regierung gefundenen Aktenstïcke - ,war in diesem Moment (in den letzten Tagen des Juli I9r4) die englische "öffentliche Meinung" der interessanteste Kranke, und diesem Kranken fühlte man unentwegt und beinahe mehrmals täglich den Puls." Nachdem BENCKENDORFF (der russische Botschafter in London) am 27. hoffnungsvoll sich ausgesprochen hatte, wegen der schon 2 Tage früher beschlossenen Flottenvorbereitungen, und weil die Sprache Greys viel klarer und merklich fester geworden sei, wird er am 30. bedenklich: die Lage sei in den Augen des Parlaments noch nicht so weit geklärt, daß GREx ohne Gefahr schon offen auftreten könnte. Und am 3I. stellt er fest, daß das englische Publikum, und sogar das Parlament, die Frage als eine spezifisch-slawische betrachte. So hatte eben die Times sie dargestellt und dabei ,die französischen, englischen und europäischen Interessen sehr taktlos verschwiegen“. „Ich bitte Sie (Sassonow), in Betracht zu ziehen, da $B$ die Regierung nicht auftreten kann, ohne die Offentliche Meinung vorbereitet zu haben." Und es folgte ein noch weniger günstiges -Bulletin《 aus London: „Heute wurde konstatiert, da B das Parlament 
im gegenwärtigen Moment keine bestimmte Haltung billigen könne, $\mathrm{da} B$ die serbische Sache in den Augen der Öffentlichen Meinung keine Bedeutung habe, und daß alle Finanz-, Handels- und IndustrieCentralen Nord-Englands gegen den Krieg seien. Einige Stunden später fürchtete er sogar, daß eine übereilte Beurteilung der Haltung Englands „GREX paralysieren würde“; es gelte aber, seinen Einfluß wiederherzustellen. Treffend bemerkt der Russe, dies zeige, wie schwerfällig die Offentliche Meinung Englands in jenem Moment auf den österreichisch-russisch-serbischen Konflikt reagierte. Er führt noch als höchst charakteristisch das Telegramm des IsvoLSKY (den JAURES kurz vorher als den Schurken bezeichnete, der den Krieg gewollt und durchgesetzt habe) vom 2. August an, worin dieser triumphierend folgenden Klimax mitteilt: I. die Deutschen überschreiten schon in kleinen Abteilungen die französische Grenze - dies wird der Regierung die Möglichkeit geben, vor den Kammern zu erklären, auf Frankreich sei ein Úberfall verübt worden, 2. deutsche Truppen haben Luxemburg betreten - dieser Umstand werde als sehr vorteilhaft für Frankreich betrachtet, denn er werde unvermeidlich England zu einer energischeren Handlungsweise veranlassen, 3. es sind Anzeichen vorhanden, daß Deutschland im Begriff steht, auch die belgische Neutralität zu verletzen. „Das wird noch fühlbarer für England sein. Der Präsident des Conseil telegraphierte sofort nach London und beauftragte CAMBON, die Aufmerksamkeit GREYs darauf zu lenken" ("Deutschland schuldig?" S. 205-208). Und so geschah es. GREY hielt seine aufstachelnde Rede im Unterhaus am 3. August noch ohne durchschlagenden Erfolg. Diesen gab erst Belgien. Der New Statesman hatte am I3. Juni (IgI4) geschrieben: „Es ist eine richtige Verallgemeinerung, zu sagen, daß, ungeachtet der Öffentlichkeit unseres demokratischen Zeitalters, das englische Volk in lächerlicher Weise schlecht unterrichtet ist über alle Fragen der auswärtigen Politik. Die vielen wissen nichts, und die wenigen, welche wissen, hüten ihre Geheimnisse mit der Berufseifersucht eines römischen Augur. Überdies ist das allgemeine Publikum gleichgiiltig gegen seine Unwissenheit." Dieselbe vortreffliche Zeitschrift beantwortete am 24. Oktober die Frage: Warum gingen wir in den Krieg? dahin: ,Wie auch immer Sir EDWARD GREYs persönliche Wünsche gewesen sein mögen, er könnte nicht das Kabinett, noch weniger das ganze Land mit sich fortgerissen haben, wenn nicht die deutsche Armee den Fuß nach Belgien gesetzt hätte. Es ist möglich, daß später die Offentliche Meinung zu einer Politik der Einmischung bekehrt worden wäre durch den Anblick eines Frankreich, das unter der gepanzerten Faust gelegen hätte, aber dies ist durchaus hypothetisch." Die historische 
Tatsache steht sogar fest, daß erst durch Belgien die Mehrheit des Kabinetts für den Krieg gewonnen wurde. Der Minister LLOYD GEORGE hat in einem Gespräch, das im März I9I5 bekannt gemacht wurde, gemeint, noch am I. August hätte eine Abstimmung der Wähler von Großbritannien eine Mehrheit von $95: 5$ gegen den Krieg ergeben, am 4. August umgekehrt eine Mehrheit von $99:$ I dafür. „Die Revolution in der Offentlichen Meinung war ausschließlich dem Angriff auf ein kleines und unbeschütztes Land, das ihm kein Unrecht getan hatte, zuzuschreiben." Er, LLOYD GEORGE, hätte sonst nicht der Kriegserklärung zugestimmt, und er glaube das gleiche sagen zu können für die meisten seiner Kollegen. - Gleichwohl hatte bekanntlich GREY sich geweigert (am r. August), Neutralität zuzusichern gegen das Versprechen, die belgische Neutralität unangetastet zu lassen, oder gegen irgendein Versprechen. „Alles, was ich sagen kann, “ hatte er geantwortet, ,ist, daß unsere Haltung in hohem Maße durch die hiesige Offentliche Meinung bestimmt sein wird, und da $B$ die Neutralität Belgiens sehr starke Bedeutung für die hiesige Offentliche Meinung haben wird“ (Nr. I23). - „Wenn Worte etwas bedeuten," bemerkt dazu der EARL OF LOREBURN (How the war came? p. 238), „so bedeutet dies, daß Sir EDwARD nicht um der Rettung Belgiens willen unser Land zur Neutralität verpflichten wollte." „Er mag im Rechte gewesen sein,“ fügt er hinzu, ,aber es war nicht belgischen Interessen zu Liebe, daß er sich weigerte." Wenngleich konservativ-realpolitische Publizisten längst die Vorstellung als lächerlich gebrandmarkt haben, daß England lediglich, oder auch nur hauptsächlich, um eines anderen Staates willen - dessen Rettung nicht einmal versucht wurde - sich in einen ungeheuren Krieg begeben, so wird doch die britische Offentliche Meinung daran festhalten, daß nur ein so edler Beweggrund die Friedensliebe des britischen Bürgers zu überwinden vermocht hat.

3. (Vor dem Weltkriege in Frankreich ${ }^{1}$ ).) Die Offentliche Meinung Frankreichs war und ist Chauvinismus, nämlich eine ungemessene und unmeßbare Nationaleitelkeit und Begierde nach Ruhm. Aber nicht nur der Chauvinismus, auch das normale Nationalgefühl und der gerechte Stolz eines krieg- und sieggewohnten Volkes war tief gekränkt worden durch die Niederlagen von 1870 und durch den Frankfurter Frieden. So war es natürlich, daß die Generation, die dies erlitten hatte, nach Vergeltung lechzte. Aber diese Generation war um die Jahrhundertwende fast versunken, andere Interessen

1) Mit Geist und Kenntnis findet man die Vorkriegshaltung der "Westmächte * in Politik und Meinung dargestellt in dem Buche .,Schwedische Stimmen zum Weltkriege". S. 97 ff. 
und Kämpfe waren in den Vordergrund des öffentlichen Bewußtseins getreten. Die Auffrischung durch das russische Bündnis war mehr von moralischer als von unmittelbar politischer Bedeutung, und zunächst wurde dieses mehr als Sicherung und Wiederherstellung des Gleichgewichts gegen die BISMARCKsche Hegemonie in Europa gedacht. Frankreich dachte nicht daran, Rußland gegen Japan zu helfen, obwohl es sehr geneigt war, gegen England, das ihm I898 eine Demütigung beigebracht hatte, die nicht viel geringer war als SedanFrankfurt, zugunsten der Buren-Republiken zu intervenieren. Das Blatt wandte sich erst, als England Miene machte, die Vernichtung des Deutschen Reiches ins Auge zu fassen. Ein durch verbrecherische Liederlichkeit europäisch verrufener König hegte und pflegte diesen Gedanken mit sportmäßigem Leichtsinn. Noch am II. Juli I903 schrieb der belgische Gesandte aus Paris: „Was man hier heiß begehrt, ist die Erhaltung des Friedens: Ägypten und Faschoda, ebenso wie Elsaß-Lothringen, sind Fragen, die das französische Publikum zu vergessen beginnt." Aber der Gesandte in Berlin schrieb am gleichen Tage, die gemeinsame Abneigung gegen das aufstrebende Deutschland habe im letzten Grunde Frankreich und England zueinander geführt. Die kritischen Jahre waren I904, das die französisch-englische Entente, und I905, das die erste Marokko-Krise brachte. Am 24. Oktober dieses zweiten Jahres stellt der belgische Gesandte in Paris fest, der nationale Chauvinismus sei dort wieder erwacht. Um dieselbe Zeit schrieb der Gesandte desselben Landes von Berlin aus, der engliśche $\mathrm{Ha} B$ gegen Deutschland entspringe einzig und allein dem Neide auf die Entwicklung der deutschen Marine, des deutschen Handels und der deutschen Industrie. - Treffend bemerkt OnckeN (a. a. O. S. 58I), die öffentliche Meinung Frankreichs und Englands sei damals in wechselseitigen und sich steigernden elektrischen Kontakt eingetreten. Das Jahr IgII - die zweite Marokko-Krise obgleich der Erfolg Frankreichs, eine Demütigung Deutschlands offenbares Eirgebnis waren, bewirkte dort eine erheblich vermehrte Ladung und Spannung. Ein Rundbericht des Brüsseler auswärtigen Ministeriums vom 28. Oktober I9I2 gibt dem britischen Quos ego die Rede LIOyd GEORGEs ist gemeint - die Schuld, daß in der französischen öffentlichen Meinung ein Umschwung jener Art sich eingestellt habe, wie er nur bei einem so leicht zu beeinflussenden Volke wie dem französischen möglich sei. „Diese Umformung in der Einstellung der öffentlichen Meinung ist auffallend. Wenn man sagen wollte, da $\mathrm{B}$ die französische Nation in ihrer Gesamtheit kriegslustig geworden sei, so hieße das vielleicht zu weit gehen. Der Landmann, der Bürger, der Kaufmann, der Industrielle und der Geschäftsmann 
wissen, was ein $Z$ usammensto $ß$ sie kosten würde; bei der allgemeinen Wehrpflicht muß jeder für die Seinigen zittern. Gleichwohl ist man dahin gelangt, dem Lande das Vertrauen in den Erfolg zu geben; man muß ferner mit der stürmischen Jugend, den militärischen Kreisen und den Leuten rechnen, die nichts zu verlieren haben." Doch wohl auch mit denen, die viel zu gewinnen hofften! Der Bericht schildert dann die ausgedehnten Kundgebungen, an denen der Großfürst Nikolaus nebst Gemahlin teilnahm, die sich an die Grenzen des Gebietes begaben, um die abgetretenen Provinzen zu begrüßen, und fährt dann fort: ,Alles dies erregt die Offentliche Meinung, die von der militärischen Uberlegenheit und einem zukünftigen französischen Siege um so mehr überzeugt ist, da die Regierung unaufhörlich militärische Flugzeuge in Bestellung gibt. ... Die Offentliche Meinung, die I870 NAPOLEON III. die Hand geführt hat, und die wiederum nervös und reizbar geworden ist, wird eines Tages unter diesem Gesichtspunkte "recommencer l'histoire" und die beiden Regierungen jählings vor eine Lage stellen können, aus der es keinen anderen Ausweg gibt als den Appell an die Waffen." (SCHWERTFEGER, S. I62f.). Auch im folgenden Jahre, dem letzten vollen Friedensjahre, betont der belgische Gesandte GuILLAUME von Paris aus, mit Unrecht werde von den französischen Zeitungen die kriegerische Haltung der französischen Regierung als Antwort auf die deutscherseits ergriffenen Maßregeln dargestellt; viele ihrer Maßregeln seien nur das Ergebnis seit langer Zeit gepflogener Studien. Und derselbe schreibt am 3. März: „Von meiner Stelle aus kann ich die öffentliche Meinung Deutschlands schwer ergründen; aber ich stelle alle Tage fest, wie die Offentliche Meinung in Frankreich alle Tage mißtrauischer und chauvinistischer wird." Etwas später wiederholt er, sie werde mehr und mehr chauvinistisch und unbesonnen. Und doch deuten viele Zeichen darauf hin, daß auch diejenigen französischen Kreise, in denen die öffentliche Meinung zu Hause ist und zubereitet wird, mehr mit dem Feuer spielten, als daß sie das europäische Wohngebäude in Brand zu stecken wünschten. Man fürchtete das Abenteuer und schnte sich zugleich nach dem ungeheuren Nervenkitzel, den es mitsichbringen würde, wenn es dem heißgeliebten Freunde, dem Zarismus, gefallen sollte, es heraufzubeschwören. Für diesen war es seit dem Februar I9I4, wenn nicht früher, beschlossene Sache, - er wußte, daß Marianne ihm gehorchen würde, wie sie gehorchte, als er die Wiedereinführung der (nunmehr allgemeinen und nur für kurze Dauer erträglichen) dreijährigen Dienstzeit in Frankreich verlangte. Die Machinationen der offiziösen, ja halb-offiziellen russischen Presse in den Frühlingsmonaten sind alle darauf berechnet, Frankreich 
vorzubereiten, Frankreich $z u$ binden und $z u$ fesseln $\left.{ }^{1}\right)$. Sie waren alle auf den Ton gestimmt, den am I3. Juni die Birscherwija Wjedomosti mit der Úberschrift anschlug: „RuBland ist bereit, Frankreich $\mathrm{m} u ß$ es auch sein". Der Zarismus war ungeduldig, der Zarismus befahl. Lieber wäre ihm gewesen, wenn ein deutsch-französischer Streitfall, ein neuer Marokko- $Z$ wist, sich hätte vom Zaune brechen lassen, weil er dann der englischen Hilfe sich unmittelbar sicherer gefühlt hätte, und dieser sich zu versichern, war das Ziel der russischen Politik. Ein solcher Fall war aber nicht sehr wahrscheinlich. Von Serbien aus konnte der Tanz alle Tage beginnen. Herr von HarTwig hatte dafür gesorgt. Der belgische Gesandte in Paris schrieb am 24. Juni, also noch 4 Tage vor dem Meuchelmord: „Frankreich und Rußland spielen in Wahrheit gegenwärtig ein sehr gefährliches Spiel; sie arbeiten auf einen Bluff hin, der die verhängnisvollsten Wirkungen zeitigen könnte." Diesen Bericht machte das Brüsseler Ministerium für ein Rundschreiben sich zu eigen, das am 3. Juli, also am 5. Tage nach dem Meuchelmord erlassen wurde und fügt hinzu: „Sie steigern sich wechselseitig auf dem Wege der Rüstungen bis zum äußersten" und bei Ankündigung des Bluffs einschaltet ,,hauptsächlich RuBland“ (SchWERTFEGER, S. 206f.). Die zarische Regierung brannte auf Aktion, es handelte sich für sie um nichts Geringeres als um die Krönung der SToLyPINschen Reaktion, um die Rettung der - nunmehr konstitutionell verbrämten - Autokratie durch einen glorreichen, siegreichen Krieg, der insbesondere bestimmt war, das Ziel der Jahrhunderte, "Zargrad" (Konstantinopel) in den Rachen des heiligen Rußland zu bringen. „Auf dem Wege zu den Meerengen“, schreibt in richtiger Erkenntnis und auf Grund der Akten des Petersburger Auswärtigen Amtes M. Pokrowskr, „ergaben sich zwei Hindernisse. Das erste war die reservierte Haltung Englands in der Frage, das zweite das ängstliche Verhalten der französischen Offentlichen Meinung, d.h. der französischen Bourgeoisie, zu Kriegsabenteuern. Es gab ein Mittel, das zweite Hindernis zu be seitigen, dieses Mittel war der Krieg mit Deutschland. Wenn Deutschland in den Krieg verwickelt wurde, erhielt die russische Diplomatie ein sicheres, ohne Versagen wirkendes Mittel, die Befürchtungen der Pariser Bankiers zu überwinden." Die unmittelbare Unterlage für diese innerlich höchst wahrscheinliche Ansicht bietet dem Russen ein Bericht des russischen Botschafters in Paris Isvolsky

1) Vgl. die Nachweisungen, in „Deutschland schuldig?”, S. I86ff. S. TönNies, „Die Schuldfrage. Rußlauds Urheberschaft nach Zeugnissen aus dem Jahre I914." 2. Aufl. (Berlin, Strilke.) „Germany's guilt disproved" (C. L. von LANGerhuysen, Amsterdam 1919), p. 6-48. 
aus dem September IgI2 (der Briefwechsel CAMBon-GrEy folgte im November des gleichen Jahres!). Außerungen des damaligen französischen Ministerpräsidenten POINCARÉ werden darin wiedergegeben. Danach würde, auch wenn durch diese oder jene Ereignisse, z. B. einen Uberfall Ósterreichs auf Serbien Rußland „gezwungen « würde, aus seiner passiven Lage herauszutreten, Frankreich energische diplomatische Unterstützung gewähren; aber die französische Regierung wäre nicht in der Lage, vom Parlament oder von der Offentlichen Mein ung die Ermächtigung für irgendwelche aktiven militärischen Maßnahmen zu erhalten. De utschlands Eintreten für Osterreich werde aber die friedliche Gesinnung Frankreichs sofort ändern; er sei überzeugt, daß in diesem Falle das Parlament und die Offentliche Meinung die Entschlossenheit der Regierung, Rußland bewaffnete Unterstützung zuteil werden $\mathrm{zu}$ lassen, ausnahmslos billigen werde. Die Chancen Rußland-Frankreichs im Falle eines allgemeinen Zusammenstoßes wurden von den Sachverständigen siiberaus optimistisch « beurteilt. Dieser Brief nimmt schon ausdrücklich Bezug auf die »bereits früher " (also längst vor dem November-Briefwechsel) zwischen dem französischen und dem englischen Marinestab getroffenen Vereinbarungen; so sei auch der eben gefaßte Beschlu $B$, das dritte französische Geschwader aus Brest nach Toulon zu verlegen, „im Einverständnis mit England " getroffen worden. Für die Offentliche Meinung in Frankreich kam in der Tat auf dies Einverständnis mit England alles an. Wenn aber Herr Pokrowskr diese Offentliche Meinung einfach mit der Meinung der Pariser Bankiers gleichsetzt, so erweist er diesen offenbar zu viele Ehre. Richtig dürfte aber sein, $\mathrm{d} a ß$ die hohe Finanz einen außerordentlich großen Einfluß auf die öffentliche Meinung in Paris und dadurch in Frankreich hat. Naturgemä $B$ war sie nicht unbedingt für den Krieg, aber die Hauptströmung der öffentlichen Meinung: Gelegenheit zu suchen, um mit der Sicherheit englischer Hilfe Rußland beizustehen, dem Deutschen Reich einen tödlichen Schlag zu versetzen, war viel zu stark, als daß die Bankiers hätten sich ihr entgegenwerfen können und wollen; überdies wirkte auf sie sehr stark das Interesse der von Rußland verschluckten Milliarden. Bei alledem war die französische Offentliche Meinung und durch sie die französische Politik nur ein Spielball in den Händen der ïberaus geschickten und völlig skrupellosen russischen Diplomatie. Am 24. Juli I9I4 sagte der französische Botschafter PAlélogur zu Herm SAssónow: ,Vergessen Sie nicht, da $B$ meine Regierung eine Regierung der Offentlichen Meinung ist, und daß sie euch nur dann wirksam unterstützen kann, wenn sie die Meinung für sich hat. Eindlich denken Sie an die englische Offentliche 
Meinung!" (Revue des deux mondes, Bd. I5. I. I92I). Der offenbare Sinn dieser Mahnung ist offenbar identisch mit demjenigen der Äußerungen PoINCARÉS gegen Isvolsky, die PoKrowskr mitteilt. ,,Sorgen Sie dafür, daß Deutschland eingreift, und es wird sicher eingreifen, wenn Rußland gegen Österreich-Ungarn so vorgeht, daß es für dieses Reich um Verteidigung sich handelt; ihr müBt also euch bemühen, den casus foederis für Deutschland herbeizuführen, ihr dürft euch also nicht darauf beschränken, Serbien diplomatisch, nicht einmal darauf, es militärisch zu unterstützen, sondern ihr müßt, ohne Osterreich direkt den Krieg zu erklären, es so bedrohen, daß Deutschland sich mitbedroht fühlt, daß Deutschland Grund zur Besorgnis hat, ihr möchtet mit eurer Mobilmachung rascher fertig werden, als ihm lieb ist, daß also der Angriff von Deutschland auszugehen scheint. Nur dann wird die französische Offentliche Meinung sicher auf den Köder anbeißen!“ „Und denken Sie an die englische Offentliche Meinung!" Parallelstelle zu dem Satze Pokrowskrs („,Deutschland schuldig?" S. I94): „Und nun kann man sich das Vergnügen der zarischen Diplomatie vorstellen, als es sich fast zu gleicher Zeit herausstellte, daß der Krieg mit Deutschland auch das beste Mittel bildete, das englische Eis zum Schmelzen zu bringen." Der Franzose sah es voraus - diese Bedeutung hatte die Mahnung PALÉologues.

4. (Vor dem Weltkriege in Rußland $\left.{ }^{1}\right)$.) Der Rumäne DAscovicI nannte noch I9I5 Rußland ein Land, wo die Offentliche Meinung fast nichts bedeute (un pays où l'opinion publique ne compte presque rien: La question du Bosphore, p. 246). Ganz in gleichem Sinne urteilt ein im Auslande bewanderter Deutscher KARL FEDERN (Die Politik des Dreiverbandes und der Krieg, S. 69; die Schrift war vorher in englischer Sprache erschienen). Er bezieht sich darauf, was Sir EDWARD GREY am 24. Juli an den britischen Botschafter in Paris geschrieben habe, daß Rußland durch die Offentliche Meinung gezwungen sein würde, einzugreifen, falls Österreich Serbien angreifen sollte. Dies gibt freilich GREY nicht als seine Meinung, sondern als eine Außerung CAmbons, aber es tritt auch in mehreren späteren Depeschen zutage, da $B$ die britischen Diplomaten sich dies Argument gern zu eigen machten. Dazu bemerkt FEDERN: „Also die öffentliche Meinung in RuBland ist schuld! Als ob die öffentliche Meinung in Rußland irgend etwas zu sagen hätte! Oder vielmehr, als ob, wenn die öffentliche Meinung in RuBland irgendwelche Macht hätte, die gegenwärtige (damalige von I9I6) Regierung, das ganze gegenwärtige

1) Vgl. hierüber besonders auch die Flugschrift von THEOdor SchiEmanN, „Wie die Presse unserer Feinde den Krieg vorbereitet und erzwungen hat", Berlin I919. 
Regierungssystem auch nur einen Tag länger Bestand haben könnte! Und wenn es eine öffentliche Meinung in diesem Sinne in RuBland gäbe, die das Drängen der russischen Regierung zum Kriege entschuldigen konnte, wieviel mehr müßte dann die öffentliche Meinung in Osterreich - die wirklich bestand und den Krieg gegen Serbien forderte - die österreichische Regierung rechtfertigen! Diese Berufung auf die russische öffentliche Meinung ist grotesk. Die russische öffentliche Meinung ist nichts weiter als eine Gliederpuppe, die hervorgeholt und künstlich bewegt wird, wenn die russische Regierung die Verantwortung für irgendeinen Schritt nicht selbst nach außen hin übernehmen will, die aber ganz unfähig ist, von selber irgend etwas $z u$ verlangen oder gar zu erreichen. So oft die wirkliche Offentliche Meinung in Rußland einen Wunsch zu äußern versucht, mit dem die Regierung nicht einverstanden ist, wird die betreffende Zeitung bestraft oder unterdrückt; wenn sie ihre Stimme in einer Versammlung $\mathrm{zu}$ erheben wagt, wird sie von Kosaken niedergetreten. Die »öffentliche Meinung in Rußland, auf die Herr Sassónow und Sir EDward GREY sich berufen, bedeutet nichts weiter als Zeitungsartikel, die die russische Regierung bestellt oder doch zu drucken gestattet hat; die russische öffentliche Meinung ist von der russischen Regierung abliängig, nicht aber die russische Regierung von ihr. Sir EDward GrEy wei $B$ dies natürlich sehr genau, aber der englische Zeitungsleser weiß es nicht. Die Mehrzahl der englischen Zeitungsleser ist über die $\mathrm{Zu}$ stände fremder Länder so wenig unterrichtet, daß man ihnen solche Märchen leicht aufbinden kann, und da er (der Durchschnittszeitungsleser) wei $\beta$, da $B$ in seinem Lande die öffentliche Meinung eine Macht ist, so ist er gerne zu glauben bereit, $\mathrm{da} B$ dies auch in Rußland der Fall sei, und daB die russische Regierung dadurch sehr gegen ihren Willen gezwungen würde, einzugreifen, wie ungern sie auch den Weltfrieden stören mochte. So wird die Fiktion einer »öffentlichen Meinung in Rußland als ein Mittel verwendet, die öffentliche Meinung in England irrezuführen." - Das Vorhandensein der Offentlichen Meinung im zarischen Rußland wird hier nirgends bezweifelt, aber ihre Macht wird geleugnet. Als gewi $B$ darf man annehmen, da $B$ die Offentliche Meinung damals (und viel mehr noch neuerdings) einen engeren Zirkel repräsentierte als in einem anderen großen Lande, gemä $B$ der so viel geringeren städtischen, zumal großstädtischen Bevölkerung, gemä $\beta$ ihrer weiten Zcrstreutheit in einem Gebiet mit geringen Verkehrsmitteln, gemä $\beta$ dem niedrigen Stande der allgemeinen Volksbildung, der schon die Fähigkeit, vollends die Gewohnheit, des Lesens als eine Ausnahme erscheinen läßt. Viele Jahre vor dem Weltkriege ist schon oft von Kennern des russischen Volkes oder 
solchen, die es zu sein meinten, versichert worden, die Volksstimmung sei den Deutschen feindlich, und als nähere Ursache pflegte die Vereitlung des Friedens von St. Stefano durch Bismarck und der Berliner Congreß geltend gemacht zu werden. Später ist bald im allgemeinen die "friedliche Durchdringung " der russischen Volkswirtschaft mit deutschem Kapital, bald mit besonderem Nachdruck die Ungunst des Handelsvertrages, in dem Rußland schmählich benachteiligt worden sei, angeführt worden. Und - so meint Graf E. REVEnTlow (Politische Vorgeschichte des großen Krieges, S. 310) gerade der Umstand, daß man die Deutschen als Techniker, als Verwalter oder als kaufmännische Berater brauchte, erhöhte den $\mathrm{HaB}$ und den Glauben an die Legende, Rußland werde durch die Deutschen ausgesogen. Der konservative Schriftsteller fügt hinzu, der Deutsche werde in Rußland "vielfach " mit dem Juden identifiziert, und darauf führe sich der $\mathrm{HaB}$ gegen die Deutschen »wesentlich mit « zurück. Wieviel nun von diesem $\mathrm{Haß}$ ein wirklich verbreitetes Volksgefühl, wie viel "öffentliche Meinung "Moskauer und Petersburger Intellektueller, Politiker und Journalisten, wie viel endlich bloße Mache gewesen ist, das zu ent- und $z \mathfrak{u}$ unterscheiden würde eine sehr tiefgehende Kenntnis dieser schwer zu kennenden Nation voraussetzen. Tatsache dürfte aber sein, daß die prahlerische Schwärmerei, in Verbindung mit dem »orthodoxen "Bekenntnis, eine Stimmung war, die verschiedene Schichten des russischen Volkes miteinander gemein hatten, und woraus eine öffentliche Meinung ihre Nahrung ziehen konnte, wenn die auswärtige Politik des Zarismus irgendwie auf Widerstand stieß, wie solcher Widerstand von Osterreich-Ungarn und folglich auch von Deutschland her, naturnotwendig war.

Wenn man Einfluß und Macht der Presse in RuBland abschätzen will, so muß man allerdings ihre geringe Freiheit und die geringe Verbreitung der Bildung in Rechnung stellen, andererseits aber auch, daß die politische Opposition, je weniger sie andere gangbare Wege fand, um so mehr sich in den Zeitungen Luft $\mathrm{zu}$ machen beflissen war. Gewandte und beredte Schriftsteller konnten mehr als irgendwo durch Zeitungen - erlaubte oder verbotene - die Offentliche Meinung beherrschen. So wird von AL. HERzEns Zeitschrift Kolokol (Glocke), die in London gedruckt wurde, gesagt, daß sie die Offentliche Meinung Rußlands jahrelang verkörperte, mindestens beherrschte (HOETZSCH, Rußland, S. 63). Das war etwa der Fall bis die Bauernbefreiung in den Hintergrund trat. Nachher ging „Herzens Stellung in der russischen öffentlichen Meinung, die seine dem Polenaufstand freundliche Haltung vernichtet hatte", auf KATKov über, der, in den Moskauer Nachrichten als Wortführer eines auf der Slavophilie sich 
aufbauenden aggressiven Nationalismus" sich geltend machte und unermeßlichen Einfluß gewann (das. S. 66). - Daß der Panslawis mus das Element war, auf dessen Wirken und, wenn es erwünscht war, Explosion die hinterlistige russische Staatskunst immer rechnen konnte, geht auch aus der jüngst (Herbst I92I) bekannt gewordenen Äußerung Sassónows an Isvolsky vom I8. Juni I9I2 hervor; sie bezog sich auf eine Uneigennützigkeitserklärung der Großmächte, mit der sie zwischen Italien und der Türkei vermitteln wollten: „Die Unterzeichnung (eines solchen Aktes) wïrde sowohl von der russischen Offentlichen Meinung als auch von den slawischen Staaten so aufgefaßt werden, als ob Rußland auf seine Jahrhunderte alte Politik auf dem Balkan verzichtete“ (vgl. Graf PourTalÈs ,Neues über die Ententediplomatie vor dem Weltkriege“, Preuß. Jahrbücher, September I92I).

Unmittelbar vor der Katastrophe sprach in einem vielbemerkten Briefe an den Herausgeber der "Preußischen Jahrbücher "ein russischer Gelehrter, der, ,ganz und gar von deutscher Bildung durchdrungen“" wußte, was er und die Welt dem Deutschtum verdanken, über die Ursachen dieser Antipathien sich aus. Die Mißstimmung gegen die Deutschen sei in jedermanns Seele und Munde, ,und selten dünkt es mir, war die Offentliche Meinung einstimmiger"; als ein »Resonator " dieser Offentlichen Meinung wünscht der "Kernrusse« zu gelten. Eir sucht die Ursprünge der Feindseligkeit - in der Politik Perers des "Großen", weil dieser unbarmherzig und gewaltsam das alte Russentum ausgerottet habe und ,die Russen in Deutsche verwandeln wollte". Dann aber wird die nächste Ursache doch in die unmittelbare Vergangenheit, keineswegs in irgendwelche Schuld Rußlands und des Zarismus verlegt. Der letzte Handelsvertrag, unter dem Drucke des unglïcklichen Japan-Krieges und der inneren Verwirrung geschlossen, sei nur dem deutschen Ackerbau und der deutschen Industrie zugute gekommen. „Zwölf Jahre lang war Rußland ein Tributär Deutschlands, und die Offentliche Meinung erhebt im voraus ihre warnende Sprache, daß die Regierung die früheren Fehler nicht wiederholen dürfe. [Wenige Zeilen vorher versichert der logische Schriftsteller, das Land (der 'Tributär Deutschlands) wachse - gerade seit 1904, also während der bewußten I2 Jahre - materiell und geistig auf eine geradezu staunenerregende Weise ... die Agrarreform STolypins fange an, ihre Früchte zu tragen und der Bauer sei der früheren Not entromen; die Industrie maclie solche Fortschritte, $\mathrm{da} B$ es an Rohmaterialien fehle und diese entwickelte Industrie könne sogar den inneren Verbrauch nicht befriedigen; die Wunden des japanischen Krieges und der Revolution seien geheilt. Und dafür 
sollte das schuldige Deutschland büßen!] Zur Bekräftigung fügt der Schriftsteller hinzu: ,Man darf nicht vergessen, daß in dem letzten Dezennium die Offentliche Meinung eine ganz andere Rolle spielt als ro Jahre zuvor; sie ist $z \mathfrak{u}$ einem reellen politischen Moment gewachsen." Der Brief läuft in eine sehr dünn verhüllte Drohung mit demnächstigen Kriege aus: ,wir sind entschlossen, die uns gebïhrende Stellung uns zu verschaffen", „man entzieht sich sogar einer bitteren Notwendigkeit nicht, wenn sie wirklich notwendig wird". Der Adressat, Professor H. DELBRÜCK, verstand seinen Schüler richtig: „Sie kündigen uns den Krieg an." In Wahrheit war das ganze Halbjahr, das im Doppelmorde von Serajevo seinen Abschluß fand, von diesen Ankündigungen und Drohungen des Krieges erfüllt' ${ }^{1}$ ), und der deutsche Staatssekretär im Auswärtigen Amte, Herr voN JAGow, hatte alle Ursache, am I4. Mai warnend darauf hinzuweisen, natürlich steht da für ihn die Presse im Vordergrunde. „Zweifellos hat sich die seit langem in einem Teil der russischen Presse herrschende deutschfeindliche Bewegung in letzter Zeit immer mehr verschärft und auf den verschiedensten Gebieten zu einer fast systematischen Kampagne gegen uns geführt...“ „In unserer nervösen Zeit mit den Einwirkungen der Presse auf die Psyche des Volkes ist das ein Spielen mit dem Feuer." Er sprach die Hoffnung aus, daß es den Bemühungen der beiden Regierungen gelingen werde, diesen gefährlichen Strömungen einen Damm entgegenzusetzen. Keine 7 Wochen vergingen, da erhob sich mit wildem Brausen die Sturmflut. Die serbische Woge des Panslawismus schlug in das Fahrzeug des europäischen Friedens.

Weniger als sonst kann man in solchem Falle die wahre Offentliche Meinung durch die Zeitungen ermitteln. Die Offentliche Meinung zwingt die Presse, sittliche Entrüstung kundzugeben. Ihr wahres Gesicht zeigt sie erst wieder, wenn die Folgen und Folgerungen zutage treten. Die Offentliche Meinung verwirft regelmäßig den politischen Mord, kann aber oft nicht umhin, mit seinen Wirkungen zufrieden $z \mathfrak{u}$ sein. $\mathrm{Ob}$ sie in Rußland damit zufrieden war, daß der österreichisch-serbische Konflikt zur hellen Flamme wurde, wird man nur mit Mühe noch aus mannigfachen Spuren jener Tage ermitteln können, aber in hohem Grade wahrscheinlich ist es. Die Offentliche Meinung Rußlands war (und ist sicherlich im Grunde noch) der Panslawismus, sei es in der milderen Form, daß die heilige Mutter ihre Balkan-Kinder unbedingt schützen, ihnen Hilfe gewähren müsse, oder in der herberen, daß die allslawische

1) Vgl. meine Schrift, „Die Schuldfrage“. 2. Aufl. Berlin, SrILKE 1919. 
Sache die Vernichtung der Türkei und die Zertrümmerung ÖsterreichUngarns fordere. Gleichwohl scheint ihr der Fürstenmord nicht unmittelbar willkommen gewesen zu sein, weil er zunächst doch als eine schlechte Sache erschien und eine freudige Mitwirkung der verbündeten Mächte, insbesondere Englands, an einem Kriege, der im Sinne der Mörder zu führen wäre, zweifelhaft erscheinen mußte. Noch am 25. Juli berichtet der deutsche Botschafter nach Berlin: „Die hiesige (St. Petersburger) öffentliche Meinung hat sich bis jetzt dem österreichisch-serbischen Konflikt gegenüber merkwürdig gleichgültig gezeigt." Er fügt freilich hinzu: „Dies dürfte sich allerdings. wie schon die heutige Presse zeigt, in den nächsten Tagen ändern" (Die deutschen Dokumente, Nr. 204), aber in seinen Erinnerungen wiederholt Graf Pourtalìs (Am Scheideweg zwischen Krieg und Frieden, S. 16), in Petersburg sei die Stimmung am 25. Juli noch ganz ruhig gewesen. „Von einer besonderen Erregung infolge des serbischen Ultimatums war im Publikum nichts zu merken." In den nationalistischen Zeitungen habe man natürlich scharfe Angriffe gegen Osterreich-Ungarn gefunden, ein überraschend vernünftiger Standpunkt sei aber in dem Kadettenorgan »Rjetsch «zum Ausdruck gekommen. „Jedenfalls", so folgert der Botschafter, ,ist es in diesem Augenblicke nicht die Offentliche Meinung gewesen, welche die russische Regierung zu einem aggressiven Auftreten gegen OsterreichUngarn gedrängt hat." Nur eine kleine Gruppe sei bestrebt gewesen, dem Konflikt gleich von vornherein einen scharfen Charakter zu geben. Die Offentliche Meinung des Landes freilich mochte doch hinter dieser kleinen Gruppe stehen; sie ließ sich wahrscheinlich eher in Moskau als in St. Petersburg beobachten und erkennen. Der deutsche Kaiser telegraphierte am 28. Juli an den Zaren, nachdem er auf das Monarcheninteresse hingewiesen, und daß die Politik dabei keine Rolle spiele: „Andererseits verstehe ich vollkommen, wie schwierig es für Dich und Deine Regierung ist, den Strömungen eurer öffentlichen Meinung entgegenzutreten." In merkwürdigem Gegensatz zu dieser Äußerung faßte man in Petersburg das monarchische Interesse auf. Graf PourTalìs findet es bemerkenswert, da $B$ in dem Gespräch, das er am 30. Juli etwa II Uhr vormittags mit SAssónow führte, dieser zum zweiten Male auf die Gefahren hingewiesen habe, die-der russischen Dynastie erwachsen würden, wenn die russische Politik den österreichisch-ungarischen Forderungen gegenüber nicht fest bleibe. „Man könnte aus dieser Außerung schließen, daß die öffentliche Meinung Rußlands in hohem Maße erregt war und, auf die Gefahr eines Krieges hin, die Regierung zu einer schroffen Haltung gegen Österreich-Ungarn und Deutschland gedrängt habe." Das 
sei, betont Graf PourTalìs, in Wirklichkeit nicht der Fall gewesen. Eine gewisse Aufregung sei allerdings durch die Preßhetze entstanden, auch seien die Kundgebungen in Zunahme gewesen. „Das große Publikum verhielt sich aber im ganzen erstaunlich ruhig. Von Kriegsbegeisterung war nicht das geringste $\mathrm{zu}$ bemerken, viel eher konnte man Anzeichen lebhafter Besorgnis wahrnehmen, daß es zum Kriege kommen könnte." Während des Balkankrieges sei die Aufregung viel größer gewesen. „Manche Anzeichen lassen es aber nicht ausgeschlossen erscheinen, daß sich in der russischen Regierung Elemente befanden, die in einem Kriege eine willkommene Ablenkung erblickten gegenüber mannigfachen Zeichen von Unzufriedenheit und Gärung, die sich in der letzten Zeit im Volke bemerkbar gemacht hatten." Graf PourTalìs dürfte diese Zeichen richtig gedeutet haben. Am 6. Februar (IgI4) hatte die Reichs-Duma der Regierung ein entschiedenes Mißtrauensvotum wegen der Verfechtung offenbar gesetzwidriger Maßregeln erteilt, indem sie darin eine Bestätigung dafür sah, daß die Regierung selbst ein System gesetzwidriger Maßregeln organisiert hatte. Am I9. März, nachdem der erste der Kriegsministerartikel der St. Petersburger Börsenzeitung vorausgegangen war, erließ der Zar ein merkwürdiges Reskript an den Ministerpräsidenten, worin es heißt, die ,,weitere Festigung" der Staats- und Gesellschaftsordnung müsse die allererste Sorge der Regierung bilden, und er, der Zar, erwarte vom Ministerpräsidenten, daß dieser unablässig im Auge behalte, daß das große Bildnis des russischen Staates nicht durch persönliche Erwägungen verdunkelt werden und das Wohl des Volkes mit seinen Überlieferungen und historischen Grundfesten, auf denen RuBland wuchs und erstarkte, völlig fremden, grundlosen Bestrebungen nicht zum Opfer gebracht werden dürfe.

Am 9. April nahm die Duma mit I66 Stimmen der Oktobristen und der Opposition gegen 64 der Rechten eine von den Oktobristen eingebrachte Tagesordnung an, worin es $\mathfrak{u}$. a. hie $B$, es sei klar zutage getreten, daß das Ministerium des Innern fortfahre, die Offentliche Meinung $\mathrm{zu}$ verachten und die Interessen der breiten Masse zu ignorieren. Auch der Handelsminister wurde auf schärfste Weise angegriffen. Und während zu gleicher Zeit die bewilligten Rüstungsausgaben ins Ungemessene wuchsen, besonders diejenigen für Wiederherstellung der Flotte, wurde am I7. Mai durch die Oktobristen der Antrag gestellt, mehrere Kapitel des Etats um die Gesamtsumme von 768 ooo Rubel zu kürzen, um gegen die Nichterfüllung der von der Duma I9I3 ausgesprochenen Wünsche, sowie gegen die allgemeine Politik des Ministeriums des Innern $\mathrm{zu}$ protestieren. Mit einer 
Mehrheit von I86 gegen 95 Stimmen wurde eine Ubergangsforme1 angenommen, die $\mathrm{u}$. a. besagte: „Da das Ministerium des Inneren systematisch die Wünsche der gesetzgebenden Faktoren ignoriert, hält die Duma es für nutzlos, irgendwelche neue Wünsche auszusprechen. Sie findet, daß die Politik des Ministeriuns des Inneren die Unzufriedenheit der breiten Massen der Bevölkerung hervorruft, zur Verstärkung regierungsfeindlicher Strömungen beiträgt und die Durchführung des in Allerhöchsten Manifesten offenbarten Kaiserlichen Willens hindert. Dies schwächt die Macht Rußlands und bedroht das Reich mit unübersehbarem Schaden. Die Duma richtet die Aufmerksamkeit der Regierung auf die Gefahren einer derartigen Politik." Am 3. Juni erfolgte, wiederum unter Teilnahme der Oktobristen, ein ebensolcher Vorstoß gegen das Unterrichtsministerium, wie er im April gegen das Ministerium des Innern geschehen war, auch mit entsprechender Begründung und zugleich als Protest gegen die allgemeine Politik des Ministeriums. Die Weigerung des Unterrichtsministeriums, mit der Offentlichen Meinung zu rechnen, wird ausdrücklich angeklagt. Wenige Tage später erschien der schon erwähnte zweite Kriegsministerartikel, der ausdrücklich bestimmt war, Frankreich zu drängen, wenn er mit dem in fetten Lettern gedruckten Worten schlo $B$ : „RuBland ist bereit, und es hofft, daß Frankreich es gleichfalls sein wird." Am 23. Juni lief die englische Flotte in Kronstadt ein. An demselben Tage, unmittelbar vor ihrer Vertagung, nahm die Duma noch in geheimer Sitzung eine ganze Reihe von Rüstungsvorlagen (zu Wasser und zu Lande) an, deren letzte und bedeutsamste ein Verbot der Pferdeausfuhr über die europäische und die Schwarze-MeerGrenze. Ein solches Verbot erfolgt bekanntlich immer erst, wenn ein Kriegszustand schon vorhanden ist oder doch unmittelbar bevorsteht. Am 28. Juni geschah der Doppelmord. - Die Regierung der Staatsstreiche und der Gegenrevolution war durch die Energie und den Verstand STolypins geschaffen und getragen worden. STOLyPIN wurde am I4. September I9I I ermordet. Mit ihm hatte jene Regicrung allen Halt verloren. In der 4. Duma, die im Herbst r9I2 gewählt war, bildeten die Oktobristen - die Anhänger eines streng monarchischen Konstitutionalismus, den deutschen Nationalliberalen vergleichbar - mehr noch als in der dritten das Zünglein an der Wage. STOLYPIN hatte sie zu beherrschen verstanden und konnte einigermaßen auf sie rechnen, wenn sie auch seine Verfassungsbrüche nicht billigten. Ihr Kongre $B$ im November I9I3 sprach sich für scharfe Opposition gegen die Regierung aus. Sie verlangten IgI4 sämtliche Präsidentensitze der Duma. Sofern die Offentliche Meinung in RuBland eine Wirklichkeit war, stand sie ohne Zweifel hinter der 
vereinigten Opposition der Oktobristen und der sog. Kadetten. Die Regierung bewegte sich auf einem glatten und sehr dünnen Eise. Der Einbruch konnte alle Tage erfolgen. Sie mußte ihn fürchten, denn das Wasser unter ihr war tief. Sie hatte das dringende Verlangen, festes Land zu erreichen, Erdboden unter ihren Füßen zu haben. Das feste Land war der Panslawismus, der Eirdboden der Militarismus. Die Vorbereitung zum Kriege im ersten Halbjahr I9I4, die scharfe Betonung der unmittelbaren Bereitschaft, die drängende, heischende, ja befehlende Art, in der die Heeresfolge Frankreichs verlangt wurde, korrespondiert vollkommen dem Notgefühl der gegenrevolutionären, ihrer Schuld und ihrer inneren Haltlosigkeit bewußten Regierung. Nur durch den Appell an die Vaterlandsliebe, und vollends an die Liebe $z u$ den südslawischen "Brüdern «, den lieben Kindern der Balkanhalbinsel, insbesondere der Serben, deren hoffnungsvolle Angriffe auf das verhaßte Österreich unablässig und planmäßig ermutigt und gefördert wurden, nur durch diese Ablenkung aller Stimmungen und der Offentlichen Meinung nach außen hin, konnte eine solche Regierung die ihr entgleitenden Zügel wieder in die Hände bekommen und ihre Führerschaft behaupten. Daher war ihr der Anlaß, der Fürstenmord, wenn sie ihn nicht geradezu herbeigeführt, gerufen, bestellt hat, zum mindesten eine höchst willkommene Gelegenheit, das erlösende Wort C'est la guerre zu sprechen. „Serbiens Land der Verheißung liegt im Gebiet des heutigen Osterreich-Ungarn", schrieb am 6. Mai I9I3 SAssónow an Herrn von HARTwig, und „für Serbien werden wir alles tun“, ließ sogar der friedliche Zar am 2. Februar I9I4 dem König von Serbien durch den Ministerpräsidenten PASchrTsch sagen. „Es ist auf der einen Seite der slawische Ehrgeiz, der die Verantwortung für diesen Zustand der Dinge trägt; andererseits muß man die Gründe für die herausfordernde Haltung Rußlands und seiner Armeen in den innerpolitischen Fragen suchen: die russische Umsturzpartei erhofft von einem auswärtigen Kriege die Befreiung von der Monarchie; die Monarchisten, im Gegensatz, erwarten von demselben Kriege das Ende der Revolution. Man muß auch das Bedürfnis in Betracht ziehen, eine müßige und zahlreiche Armee zu beschäftigen, den Ehrgeiz ihrer Generale zu befriedigen und die Aufmerksamkeit der Liberalen, welche Verfassungsänderungen verlangen, auf die auswärtige Politik abzulenken." So hatte am 22. November I887 Fürst Bismarck an den Marquis von SALISBURY geschrieben. So war es in der Hauptsache auch noch 19r4, wenngleich die extreme Gruppe der "Bolschewisten ", den Lehren des Pazifismus huldigend, den auswärtigen Krieg verwünschte; einig waren sich darüber, daß er einen unerträglichen Zustand beenden werde, die konterrevolutionäre 
Regierung und die Opposition der Duma, die aus den Kadetten und wenigstens der Mehrheit der Oktobristen bestand, während Kleinrussen, Polen, Mohammedaner und andere allogene oder andersgläubige Gruppen, in der Staatsstreich-Duma schwach vertreten, auch sonst sich passiv verhielten, da sie vom russischen Sieg ebensoviel zu fürchten wie von der russischen Niederlage zu hoffen hatten. Die Großrussen erwarteten einen raschen Sieg, mit Hilfe der Franzosen und ganz besonders mit der Flottenhilfe Großbritanniens: die Regierung erhoffte davon Eroberung und Befestigung der Autokratie, die echtrussischen Leute sogar mit Beseitigung der konstitutionellen Formen; die Opposition hingegen erwartete eine Modernisierung des russischen Staates, Mitregierung der Bourgeoisie, ungeheuren wirtschaftlichen Aufschwung durch Vertilgung der pénétration pacifique - einmütig war man in der Absicht, der deutschen Industrie und der deutschen Macht einen tödlichen Schlag zu versetzen, einmütig in dem Streben nach den Meerengen und nach Konstantinopel. Für die Offentliche Meinung, sofern sie die nüchterne besonnene politische Denkungsart zugleich mit dem nationalen Idealismus in sich verkörperte, war dies Endziel die Hauptsache. Offenbar mit Rücksicht darauf veranstaltete die Regierung jene "besondere Beratung" am 2I. Februar I9I4, worin von mehreren autoritativen Seiten die Verwirklichung des Ideals waller Russen" - die Eroberung von "Zargrad" - als bedingt durch einen europäischen Krieg und zugleich als unmittelbar ins Auge zu fassendes Ziel festgestellt wurde. Die Regierung der Sassónow und Suchomlinow wußte sich verloren gegenüber der Offentlichen Meinung, die eine Fortführung der Revolution, eine Erneuerung ihrer Errungenschaften forderte, gegenüber der Mehrheit der Duma, die ihr ein Mißtrauensvotum über das andere erteilte, gegenüber der Zerfahrenheit eines Hofes, an dem die Geisterschau eines GrIGORY RASPUTIN die Geister beherrschte, während im Hintergrunde die Partei der Großfürsten den $₫$ Krieg um jeden Preis» zu schüren nicht abließ.

5. (Vor dem Weltkriege in anderen Ländern.) Die Offentliche Meinung aller Länder war an dem Entsetzen über den Doppelmord und an der angstvollen Beobachtung der Folgen naturgemäß stark beteiligt. Für Osterreich-Ungarn wird man noch weniger als für RuBland eine einheitliche und gleichartige Stimmung und Denkungsart behaupten können; nicht beim Volke, noch weniger in der Regel beim gebildeten Publikum. Es gab vercinzelt Reichsstaatsmänner; noch mehr vercinzelt war die Reichs-Offentliche Meinung. Die Staatsmänner waren in der Regel austrozentrisch oder magyarozentrisch, die Offentliche Meinung noch ausschlieBlicher das 
eine oder das andere. In jedem der beiden Staaten war das eine oder das andere Interesse maßgebend. Es gab wohl auch eine tschechische, eine kroatische Offentliche Meinung, aber sie stellten keine politischen Mächte dar. Die österreichische und die ungarische Offentliche Meinung gingen in mehreren Stücken zusammen, so in bezug auf die Dynastie, wenn auch zunächst nur wegen der Person des Kaisers und Königs; in den meisten Stïcken gingen sie auseinander. Um so schwerer fiel die Einmütigkeit ins Gewicht, womit die beiden Nationen sich dafür erklärten, der serbischen Feindseligkeit mit der größten denkbaren Schärfe zu begegnen. Beide wußten, daß die Großmachtstellung des Reiches auf ihrer Verbundenheit beruhte, und daß sie getrennt ohnmächtig würden; beide legten folglich auf die Erhaltung dieser Großmachtstellung den allergrößten Wert; beide erkannten die Gefahr ihrer gänzlichen Zerstörung durch die großserbischen und panslawistischen Bestrebungen, hinter denen der Zarismus und sein Kosakentum lauerten. Anfänglich war gerade Tisza für eine mildere Tonart. Graf BERCHTOLD (der österreichische) betrachtete ihn (den ungarischen Minister) als ,retardierendes Moment" (Die deutschen Dokumente, Nr. I9), aber am I4. Juli (Nr. 49) besuchte TiszA den deutschen Botschafter, um ihm zu sagen, er habe bisher immer zur Vorsicht ermahnt, aber jeder Tag habe ihn nach der Richtung hin mehr bestärkt, daß die Monarchie zu einem energischen Entschlusse kommen müsse, um ihre Lebenskraft $\mathrm{zu}$ beweisen und den unhaltbaren $\mathrm{Zu}$ ständen im Südosten ein Ende zu machen. Er habe sich schwer entschlossen, zum Kriege (gegen Serbien) zu raten, sei aber jetzt fest von dessen Notwendigkeit überzeugt, und werde mit aller Kraft für die Größe der Monarchie einstehen. Es kann nicht zweifelhaft sein, daß die Offentliche Meinung seines Landes den Minister zu dieser Entschlossenheit gedrängt hat. Der magyarische Nationalismus war ebenso leidenschaftlich und scharf wie der serbische; in seiner Handelspolitik war er mehr als der österreichische (der ohnehin schwächer und milder war) gegen Serbien feindlich gewesen. Und immer wieder bewährt sich das Wort des CoRNELIUs TAciTus: Oderunt homines quos laeserunt, eine Mischung von gutem und bösem Gewissen, nebst einigen Ingredienzen von Übung (im Kränken) und Schadenfreude ergeben die Beweggründe. $\mathrm{DaB}$ die magyarische Offentliche Meinung sonderlich von Gefühlen und wenig durch Einsicht bestimmt war, ist an anderer Stelle (vgl. S. 256) an einem guten Beispiel dargestellt worden. Der Mangel an geschlossener Einheit der beiden Reichshälften hat auch während des Krieges, zumal als er seinem unseligen Ende sich näherte, verhängnisvoll in der öffentlichen Meinung wie in der Regierung der "Monarchie», die eben ihr 
Wesen in der Untertanschaft unter das Haus Habsburg hatte, sich geltend gemacht.

„So austrophobim allgemeinen die it alien ische öffentliche Meinung ist, so serbophil hat sie sich bisher immer gezeigt.“ „Ganz abgesehen davon, daß die Politik der Regierung in Italien nicht unwesentlich von den Stimmungen der öffentlichen Meinung abhängt, so beherrscht die Auffassung (eine territoriale Ausbreitung der österreichisch-ungarischen Monarchie, selbst eine Ausdehnung ihres Einflusses im Balkan werde in Italien perhorresziert und darüber die in Wirklichkeit für Italien viel größere slavische Gefahr verkannt) doch auch die Köpfe der Mehrzahl der italienischen Staatsmänner." Diese Sätze finden sich in einem Schreiben des Staatssekretärs voN JAGow an den Botschafter in Wien vom I5. Juli I9I4. Das Schreiben zeugt nicht nur von Kenntnis Italiens, die Herr voN JAGOw als Botschafter in Rom erworben hatte, sondern auch von staatsmännischer Einsicht. JAGow sieht klar voraus, daß Italiens Parteinahme für Serbien die russische Aktionslust wesentlich ermutigen werde, und $\mathrm{da} \beta$ Italien mit Grund bei jeder Veränderung im Balkan zugunsten der Donaumonarchie ein Recht auf Kompensationen in Anspruch nehme; als einzige vollwertige Kompensation werde aber in Italien die Gewinnung des Trento erachtet werden. „Dieser Bissen wäre allerdings so fett, daß damit auch der austrophoben öffentlichen Meinung der Mund gestopft werden könnte." Durchaus treffend wird weiter gesagt, es sei zwar ein solches Opfer sehr schwer mit den Gefühlen des Herrschers wie des Volkes in Osterreich vereinbar, aber es frage sich, welchen Wert die Haltung Italiens für die österreichische Politik habe, welchen Preis man dafür zahlen wolle, und ob der Preis im Verhältnis zu dem anderwärts erstrebten Gewinn stehe. Gleichwohl will er nur der Beurteilung des Botschafters selber, seiner Kenntnis der in Wien vorhandenen Dispositionen anheimgeben, ob bei einem vertraulichen Gespräch mit dem österreichischen Minister die Frage des Trento auch nur erwähnt werden könne! Offenbar mußte die Bundesgenossenschaft immer sehr behutsam angefaßt werden; angesichts der ungeheuren Gefahren wäre aber eine entschlossenere Haltung, ja eine bestimmte Weisung allerdings angezeigt gewesen. Vortrefflich wird in der "Ethischen Umschau "von Gustav MAIER-Zürich, Nr. I vom November IgI ,'Tripolis und die offentliche Meinung in Italien" dargestellt. „Gewisse Geistesbewegungen" - heißt es da - „werden durch die Kraft der Massensuggestion bis zu cinem Punkt gesteigert, wo die vernünftige Meinung des Einzelnen vollständig verschwindet, und der Irrtum, gleich einem unsichtbaren Fluidum, epidemisch ansteckend in der I,uft schwebt." Wie früher durch die Religion, 
so werde heute durch große nationale Fragen die Seele der Völker derartig erhitzt, daß zeitweise jede ruhige Besinnung verloren gehe. Der Krieg, der diese Stimmung in Italien bewirkte, war der Krieg um die Erroberung eines Stückes der Türkei in Afrika. - Eine ähnliche üble Rolle wie Italien hat für die unglücklichen Mittelmächte der heimliche Bundesgenosse Rumänien gespielt. Treue ist in der großen Politik ein scheinbarer Wert, der bei Gelegenheiten zur Schau getragen wird, aber sich als nichtig erweist, sobald er dem Feuer der Wahrheit auch nur nahekommt. Schon im Winter I9I3/I4 hat der König aus dem Hause Hohenzollern dem österreichischen Gesandten gesagt, er werde seine Politik nicht gegen die Offentliche Meinung seines Landes führen können (D. D. Nr. 39). Und in dem Memorandum der österreichisch-ungarischen Regierung, das nach langen Vorbereitungen unmittelbar vor dem Morde von Serajevo fertiggestellt und nach Berlin gesandt wurde, heißt es, die russisch-französische Aktion habe in Rumänien schon während der Balkankrise mit voller Intensität eingesetzt und habe die Offentliche Meinung durch erstaunliche Verdrehungskünste und durch geschickte Anfachung der unter der Oberfläche stets fortglimmenden großrumänischen Idee in eine feindselige Stimmung gegen die Monarchie hineingetrieben und die auswärtige Politik Rumäniens zu einer mit seinen Bundespflichten gegenüber Österreich-Ungarn kaum in Einklang stehenden militärischen Kooperation mit Serbien veranlaßt. Diese Aktion werde mit allem Nachdruck und mit so eindrucksvollen und demonstrativen Mitteln, wie dem Besuch des Zaren am rumänischen Hofe, fortgesetzt. „Parallel damit vollzog sich ein immer tiefer gehender Umschwung in der rumänischen öffentlichen Meinung, und es kann heute nicht daran gezweifelt werden, daß viele Kreise der Armee, der Intelligenz und des Volkes für eine neue Orientierung Rumäniens gewonnen sind, für eine Politik des Anschlusses an RuBland, die sich die "Befreiung der Brüder jenseits der Karpathen" zum Ziele zu setzen hätte." Dennoch meint Graf Czernin, der Rumänien kannte, wenn BRATIANU nicht die Offentliche Meinung seines Landes durch zwei Jahre gegen Österreich hätte aufpeitschen lassen, und schließlich seine russische Grenze nicht von allen Truppen entblößt, so wäre das russische Ultimatum vom August I9I6 wirkungslos geblieben (Im Weltkriege, S. 357). - In bezug auf Serbien schreibt ein einsichtsvoller serbischer Diplomat, wie ihm im Herbst I9r3, als er zum letztenmal in Belgrad war, der Größenwahn auffallend gewesen sei, der den Hof, die Regierung und ,die unreife öffent liche Meinung in Serbien" ergriffen hatte (Boghitschewitsch, Kriegsursachen, S. 77). 
Uber die Offentliche Meinung in den neutralen Ländern, zu denen ja auch die Vereinigten Staaten bis zum 3. Februar I9I7 gehörten, möge nur folgendes bemerkt werden. Nur in dem kleinen Dänemark war sie schon vor dem Weltkriege ausgesprochen und aus offenbaren Gründen, deutschfeindlich, hingegen in Schweden um so mehr germanophil geworden, je mehr der russische Imperialismus die Freiheiten Finlands erwürgte und seine Expansion über die Ostsee ausdehnte, was eine schwere Bedrohung Skandinaviens in sich schloB, die aber außer in Finland nur in Schweden $\mathrm{zu}$ deutlichem und starkem Bewußtsein gelangte. Was mit mehr oder weniger Grund über die Unbeliebtheit der Deutschen in anderen Ländern ausgesagt worden ist, mag dem Betragen vieler Reisender und besonders mancher Handlungskommis zugeschrieben werden, aber Klagen dieser Art werden zwischen Nachbarn immer laut und sind im allgemeinen nur Begleiterscheinungen der Größe, die das Deutsche Reich vermöge seiner politischen Macht und mehr vermöge der Leistungen seiner großen Industrie in Europa und auf dem Erdball gewonnen hatte. Größe gebiert immer $\mathrm{HaB}$ und Eifersucht, zumal wenn sie die Kleinen überwältigt. Kein Völkerhaß ist dem vergleichbar, der die Engländer traf, als sie den Burenrepubliken den Garaus machten. In den Folgejahren hat England verstanden, den $\mathrm{HaB}$ auf Deutschland abzuwälzen, dessen Last es selber jahrelang empfunden hatte. Wenn aber in bezug auf die Rivalität zwischen Deutschland und England, in bezug auf den Rachedurst, der den Chauvinismus der Franzosen beseelte, ja sogar in bezug auf die Bekämpfung des Deutschtums durch den Panslavismus und die antiösterreichischen Tendenzen des italienischen Nationalismus, in der öffentlichen Meinung der neutralen Länder nur eine schwache Teilnahme, ja sogar eine weitgehende Gleichgültigkeit erwartet werden muB und als Tatsache gelten darf, so kommt bei den Vereinigten Staaten und vollends für andere exotische Länder, eine vollkommene Unkenntnis und Unwissenheit hinzu, die zu jedem Urteil über diese Fragen der europäischen Politik von vornherein unfähig machte. Bezeichnend clafür ist, daß in der New-Yorker Evening Post, einer Zeitung, die etwa den Rang der Frankfurter Zeitung in Anspruch nehmen kann, während des ersten Halbjahrs I9I4 von europäischen Dingen überhaupt keine Rede ist, außer da $B$ hin und wieder die Angelegenheiten Irlands und einige andere Vorgänge des britischen politischen Lebens berührt werden! - Die vollkommene Unwissenheit des amerikanischen Publikums war die logische Prämisse seiner Stellungnahme während des Krieges. 


\section{Zweiter Abschnitt. Die Öffentliche Meinung während des Weltkrieges. ${ }^{1}$ )}

6. (Im allgemeinen.) In der Regel wird die öffentliche Meinung in einem Lande, das sich im Kriegszustande befindet, darüber einig sein, da $B$ der Krieg dem eigenen Lande aufgezwungen, daß er ein Verteidigungskrieg oder, wie die englische Formel lautet, ein gerechter und notwendiger Kriég sei. Die Volksstimmung ist kriegerisch, ist von $\mathrm{Haß}$ und Zorn gegen den Feind oder die Feinde erfüllt, zumeist auch von patriotischer Begeisterung, von Hoffnung auf ein baldiges und glückliches Ende, von Zuversicht in den endlichen ruhmvollen Sieg. An anderen Stellen ist schon darauf hingewiesen worden, daß die Offentliche Meinung in solcher kritischen Lage ihr Wesen deutlicher als sonst offenbart: nämlich als soziale Willensmacht, die eine bestimmte Art $\mathrm{zu}$ denken und $\mathrm{zu}$ urteilen heischt und gebietet, und gegen Andersdenkende unduldsam ist. Wie für die Religion, wird für die Offentliche Meinung der Zweifel Sünde - Zweifel an der eigenen Stärke, Zweifel am endlichen Siege, Zweifel an der Nichtswürdigkeit und Schuld des Feindes. Zunächst werden die Außerungen solcher Zweifel verwehrt wegen ihrer schädlichen Wirkung auf die Stimmung; als Miesmacher, Flaumacher, Défaitisten werden solche Zweifler beschuldigt, durch ihr Verhalten den Mut der Kämpfer und der Heimbevölkerung zu schwächen und eben dadurch auch die Aussichten des Triumphes zu mindern. Alsbald aber gilt auch die Denkungsart selber, auch wenn sie nur durch Schweigen, durch gedrückte Stimmung und zögernde Teilnahme an patriotischen Kundgebungen sich verraten mag, als tadelnswert, ja als verächtlich und schlechthin vom Übel. Die leidenschaftliche Erregung, die der Krieg notwendig bewirkt, vergrößert die Gefahren und macht entschlossener zur Tat, um ihnen zu wehren. Die Offentliche Meinung findet leicht, daß die Regierung versäume, die notwendigen Maßregeln zu ergreifen, diese wird manches tun, weil sie es für notwendig hält, sie wird wirkliche Verräter, wo sie diese gewahr wird, mit fester Hand packen, sie wird auch manches tun nur zur Beruhigung der Offentlichen Meinung. So war es wohl, als in England dem hervorragenden Gelehrten Bertrand Russel, der über die Politik der Entente Ansichten vertrat, die das britische Interesse nicht verleugneten, aber

1) .Wie aber alles Reden ein Urteilen in sich begreift, so legt die öffentliche Meinung nirgends ihre Schwäche an Kritik und Sachkunde so offen bloß, wie gerade im Kriege. All das Fürchten, Hoffen und Zittern, das die Menschen in solchen Zeiten erfaßt und durchrüttelt, das herrscht auch über ihr Denken und lockt dieses Denken von starrer Logik und kühler Überlegung ins Reich der Gefühle und Leidenschaften." W. BAUER, Der Krieg und die öffentliche Meinung (1915), S. I3. 
der korrekten nationalen Selbstgerechtigkeit nicht entsprachen, als diesem wissenschaftlichen Manne verboten wurde, außerhalb eines gewissen inneren Kreises öffentlich zu reden. Die Zeitung Manchester Guardian, die selber eines maßvolleren Urteils sich befleißigte, als sonst üblich war, bemerkte zu dieser Maßregelung: „Bei uns (in England) hat die akademische Welt wenig Gewicht; in Amerika und allgemein in Ländern, wo das Volk an die Wichtigkeit der Bildung glaubt, ist sie ein ernstlicher Faktor in Gestaltung der öffentlichen Meinung."

Die Gestaltung der öffentlichen Meinung im Kriege unterliegt naturgemäß der Sorge der Regierung und der Heeresleitung. Zunächst ist ihnen an der Stimmung im Heere - sie ist die "Moral — - und um dieser willen an der Volksstimmung überhaupt gelegen. Diese muß hochgehalten, muß immer von neuem aufgefrischt werden. Kein besseres Mittel gibt es dafür als Siegesnachrichten und, um die Siegesnachrichten wahrscheinlich zu machen, kein besseres Mittel als den wirklichen Sieg. Leicht wird aber, wegen des Wertes der Siegesnachricht, der wirkliche Sieg vergrößert, die wirkliche Niederlage - deren Nachricht naturgemäß die entgegengesetzte Wirkung auslöst - verkleinert oder verschleiert; und von der Leichtfertigkeit oder doch minderen Gewissenhaftigkeit in bezug auf die Wahrheit führt bald ein weiterer Schritt zum Entschlusse der bewußten Täuschung, der Lüge. Die Kriegsgeschichte aller Zeiten ist davon erfüllt; durch Unverfrorenheit im Lügen haben von je die Russen sich hervorgetan. Mit der unmittelbaren Wirkung auf die große Menge ist der Zweck aller solcher Künste erfüllt. Die Offentliche Meinung kann nicht lange über die Unwahrheiten solcher Darstellungen getäuscht werden. Man studiert Kriegskarten, man vergleicht, man erhält private Berichte, man liest feindliche oder neutrale Zeitungen, man unterstuitzt vielleicht das Bestreben, die große Menge in Unkenntnis zu erhalten. Aber Regierung und Heeresleitung wollen auch die Offentliche Meinung nicht sich selber überlassen, auch wenn sie allen Grund haben, ihrer patriotischen Gesinnung zu vertrauen, sie sind nichtsdestoweniger bemüht, dieser fortwährend die ihnen genehme Richtung zu geben, und zwar wird sich leicht ein Zwiespalt zwischen den beiden Mächten, der zivilen und der militärischen ergeben, wenn etwa jene die Offentliche Meinung zum Frieden geneigt zu machen für notwendig hält, diese unablässig die Fortsetzung des Krieges verlangt und als aussichtsreich darstellt. Vorteilhafter ist offenbar, wenn die öffentliche Meinung in einem und im gleichen Sinne bearbeitet wird, und zwar kann der einheitlich friedliche oder der einheitlich kriegerische Einflu $B$ angezeigt sein, je nach der wirklichen, oft nur den Wenigen, die an der Spitze stehen, bekannten Kriegslage. 
7. (In Deutschland während des Weltkrieges.) In Deutschland war, angesichts einer ungeheuren Überzahl von Feinden, die sich fortwährend vermehrte und verstärkte, eine maßvolle und vorsichtige Haltung geboten, die sich vor anderen der Reichskanzler v. BETHMANNHOLLWEG angelegen sein ließ, wodurch er von vornherein einen schweren Stand hatte gegen die eines raschen und vollkommenen Sieges gewärtige Offentliche Meinung, die über Art und Ausdehnung des Mißerfolges an der Marne, der den ursprünglichen Feldzugsplan als gescheitert anzusehen nötigte, getäuscht worden war $\left.{ }^{1}\right)$. Den Vertretern der Presse wurde am 3. August gesagt: „Wir werden nicht immer alles sagen können, aber was wir Ihnen sagen werden, ist wahr." In den deutschen Heeresberichten dürfte in Wahrheit nichts geradezu Unwahres gestanden haben, aber der Zeuge vor Gericht muB nicht ohne guten Grund schwören, nichts zu verschweigen Das Verschweigen und Verschleiern machte die Berichterstattung über den großen Rückzug im September durchaus unwahr, wie das Schweigen über verlorene Schiffe den Bericht über die ehrenvolle Leistung des großen Seegefechts im Skagerrak. Politisch war das eine wie das andere ein Fehler, schon weil es doch bekannt werden mußte und das Vertrauen erschütterte, aber auch, weil das deutsche Volk nicht wie ein Kind behandelt werden durfte. Es mußte auch die bittere Wahrheit ertragen, da es so viele Bitternisse willig ertrug, die durch falsche Siegeszuversicht nicht versüßt wurden. Die politische Führung hatte in diesem so viel schwereren Kriege nicht den ungeheuren Machtzauber für sich, den schon im Jahre I870 Graf BISMARCK geltend machen konnte, der ihn verführte, auch in rein militärische Fragen sich hineinzumischen; so war es das Schicksal des Deutschen Reiches, daß seine Leitung ausschlieBlich militaristisch wurde, die fast ungehemmte Diktatur des Generals LUDENDORFF, der dann auch die Behandlung der Offentlichen Meinung zu seinen Aufgaben zählte und nur durch starke Getränke sie wach zu erhalten und aufpeitschen zu sollen meinte. Von Anfang her stand wie in allen anderen Ländern, so auch in Deutschland die öffentliche Meinungsäußerung unter einer strengen Zensur. Natürlich waren ihre Funktionen unzulänglich und erregten viele Unzufriedenheiten.

1) Treffend urteilte H. DEIBRück nach der Katastrophe (Deutsche Allg. Zeitung, 27. VII. 1919): „Die öffentliche Meinung geht notwendigerweise mit dem Soldaten.“ „Soldaten aber sind und müssen ihrer Natur nach optimistisch und zuversichtlich sein." Der Kaiser habe nicht die Kraft gehabt, BeTHManN-Holi.weg zu halten -, ,,dem geschlossenen Ansturm der öffentlichen Meinung der Majorität des Reichstages und der Obersten Heeresleitung gab er nach." Man dürfe auch nicht vergessen, wie schwierig die Position der Michaelis und HertuING gewesen sei, gegenüber der patriotisch erregten öffentlichen Meinung. 
Schon im Februar I9I5 erkannte die Oberste Heeresleitung als ihre Aufgabe, den selbständigen Pressedienst des Generalstabes zu einer Oberzensur auszuweiten und eine Art von Pressestrategie einzurichten. „Eine Führung der Offentlichen Meinung erwartete die Oberste Heeresleitung nur durch weitgehende Aufklärung und freiwillige Mitarbeit der Presse (Nrcolar, Nachrichtendienst, Presse und Volksstimmung im Weltkrieg, Berlin I920, S. 75). So trat im August I9I5 das Kriegspresseamt ins Leben, worin die Oberzensurstelle die 2. Abteilung bildete. In dem Werke des Oberstleutnants NicoraI wird natürlich die Tätigkeit des Kriegspresseamtes nicht nur verteidigt, sondern in glänzendes Licht gesetzt. „Politische Aufgaben wollte und sollte das Kriegspresseamt nicht tragen, trug sie aber tatsächlich durch das Zurücktreten der politischen Stellen hinter die Oberzensurstelle und hinter die treibende Kraft des Kriegspresseamts, besonders in der Frage der Beeinflussung der Volksstimmung und der Auslandspropaganda", S. 89. Nachdem die Oberste Heeresleitung an den Generalfeldmarschall und an General LUDENDORFF übergegangen war, bemühten diese sich mit aller ihrer Tatkraft, dem Reichskanzler „die Notwendigkeit einheitlicher Presseleitung und einer Aufklärung der öffentlichen Meinung" vorzustellen und eine bei der Reichskanzlei zu errichtende Zentralstelle durchzusetzen, die für ein einheitliches Vorgehen sämtlicher Pressestellen, sowie auch dafür verantwortlich sein sollte, daß bei größeren Ereignissen rechtzeitig weitblickende Weisungen erteilt und Maßnahmen verabredet würden. Im Scheitern dieses Planes sieht der General LUDENDORFF die Hauptursache des Verhängnisses; es habe an einheitlichem Siegeswillen gefehlt, der bei den feindlichen Nationen vorhanden gewesen sei. Durchaus treffend bemerkt dazu H. DELBRÜCK (LUdENDORFF, Tirpitz, FAlKenhayn S. I7): „Man faßt sich an den Kopf, wenn man solche Gedankengänge liest. Jeder Satz eine Absurdität oder ein historisches Falsum. Es ist durchaus unrichtig, $\mathrm{da} B$ das englische Volk geschlossen hinter dem Vernichtungswillen der Regierung LIOYD GEORGE gestanden habe. Sehr bedeutende Teile sowohl der demokratischen Linken wie der Konservativen waren einem Verständigungsfrieden geneigt, und sind nur (?) durch die von der Vaterlandspartei und General LUDDENDORFF in Deutschland repräsentierte Gewaltpolitik verhindert worden, sich geltend zu machen. Nicht anders war es in Amerika, und sogar, wenn auch in schwächerem Maße, in Frankreich... Wie hätte das (deutsche) Volk zu noch höheren Leistungen aufgepeitscht werden können? Mit einer von der Regierung geleiteten Presse (meint LudEndorfF). Welche Vorstellung vom Wesen der Presse, von Regierungseinflüssen 
und von der Natur eines Volkes, das eben darin seine Freiheit sieht, $\mathrm{da} B$ jeder Einzelne aus eigenem freien Willen dem Vaterlande dient! Gewi $B$ hat auch die Regierung Einfluß auf die Presse und durch die Presse auf das Volk. Aber dieser Einfluß ist begrenzt, und die Erfahrung gerade dieser Jahre hat uns gelehrt, daß solche Beeinflussung oft viel mehr Schaden als Nutzen gestiftet. Die Produktionen des LUDENDORFFschen Kriegspresseamts wie das Walten der Zensur, haben uns oft genug mit einer Art von Schauder erfüllt. Dies deutsche Volk, von dem ein Drittel der Sozialdemokratie anhing, ein anderes Drittel unter dem Einfluß der katholischen Kirche stand, bildet General LUDENDORFF sich ein, hätte durch offiziöse Zeitungen zu einer anderen Gesinnung erzogen werden können. Nun erst gar für welche Zwecke!" (nämlich imperialistische) usw. Man hätte nun meinen sollen, daß der Obersten Heeresleitung ihr Vorhaben nach Beseitigung des Reichskanzlers BETHMANN gelungen wäre. Beim Reichskanzler MichaELIs wurde der Antrag auf Herbeiführung einer Leitung der Offentlichen Meinung erneuert (NICOLAI, S. I05). Dieser entschloß sich, die Stelle eines Pressechefs in der Reichskanzlei zu schaffen (das. S. 94), d. h. den Geboten LUDENDORFFs zu willfahren. „Anfang September nahm sie ihre Tätigkeit auf, die Anfang Oktober mit dem Amtsantritt des Grafen HERTLING wieder beendet wurde" (das.). Dieser Regierung gegenüber erweiterte sich die Forderung der Obersten Heeresleitung zu der nach einem Propagandaminister, bestimmt, den militärischen Kampf politisch zu unterstützen und die in ihm erzielten Erfolge politisch auszuwerten“ (S. 95). „Die Regierung des Grafen HERTLING stimmte der Forderung an sich zu, bei der Durchführung versagte sie noch mehr als die früheren." Noch Ende Juni I9I8 trug sie sich mit "Vorarbeiten ", um die $\mathrm{Zu}$ sammenfassung sämtlicher, zur führenden Einwirkung auf die Offentliche Meinung des In- und Auslandes bestimmten amtlichen Einrichtungen ins Werk zu setzen. „Die bureaukratische Behandlung, wo die Oberste Heeresleitung Taten verlangt hatte, wirkte wie Hohn" (S. 96). Daß LUDENDORFF in gutem Glauben und von reinem Eifer für die Sache beseelt war, unterliegt keinem Zweifel. Auch war eine einheitliche Direktion im Sinne ungebrochener Tatkraft nicht ganz so aussichts- und wertlos, wie DELBRÜCK sie erscheinen läßt. Aber an den elementaren Tatsachen der Stärkeverhältnisse, an dem Scheitern des U-Bootkrieges, an dem Sinken der moralischen Kraft durch die fortgesetzte Unterernährung konnte keine solche Direktion etwas ändern. Auch Lord NoRTHCLIFFE, auf dessen Wirken als Propagandaminister die Oberste Heeresleitung sich berief, wäre gänzlich ohnmächtig gewesen, wenn die Erfolge des U-Bootkrieges 
vom April I9I7 sich 2-3 Monate lang auch nur auf gleicher Höhe gehalten hätten, geschweige, wenn sie noch gesteigert worden wären! Die Oberste Heeresleitung hat offenbar einen Unterschied zwischen Volksstimmung und der Offentlichen Meinung nicht gekannt. Sie wollte auf die Volksstimmung einwirken und konnte im günstigsten Falle die Offentliche Meinung erreichen, die im Grunde solcher Einwirkung kaum bedurfte. Durch Zeitungsartikel wird die eigentliche Volksmenge in Stadt und Land wenig beeinflußt, die Volksstimmung beruht auf dem Wohl- oder Ubelbefinden des Volkes, und dies ist durch den Ernährungszustand wesentlich bedingt. Die Offentliche Meinung ${ }^{1}$ ) erkannte wohl, daß eine letzte Energie eingesetzt werden mußte, um auch nur zu einem erträglichen Frieden zu gelangen, aber sie konnte diese letzte Energie nur aus dem Vorrate des Volkes schöpfen, und der war so gut wie erschöpft. Allerdings wirkten auch der Zusammenbruch Bulgariens und Osterreichs, der auch dem Volke nicht verborgen bleiben konnte, in einer Weise niederdrückend, die durch keine Zeitungsartikel hätte ausgeglichen werden können; es wirkte auch verhängnisvoll der Wahn der Weltrevolution, der durch den von aller politischen Einsicht »unabhängigen «Flügel der deutschen sozialdemokratischen Partei genährt wurde; aber diese Wirkungen traten eben darum in so schlimmer Weise ein, weil die Volksseele, zumal die der städtischen Einwohner und eines großen Teiles der erschöpften Kämpfer, ganz und gar mürbe geworden war. Die englische und französische war es auch; aber sie hatten die Mannschaft, die Munition und die Fourage eines reichen und frisch auf den Kampfplatz tretenden Hundert-Millionen-Volkes hinter sich - Deutschland hatte, nur noch, mehr als es selbst zerbrochene Stützen neben sich. Was der Oberst Nicolar im 6. Abschnitt des zweiten Teiles seiner Schrift über die Volksstimmung sagt, ist ohne alle Kenntnis der Volkspsychologie geschrieben, es hat genau den Wert, wie der Eifer des Geistlichen, der von der Kanzel Glauben und Gottesfurcht predigt, als zum ewigen Heile notwendig, und durch seinen Eifer die Erfüllung wahrscheinlicher zu machen vermeint; in diesem Sinne sind die Ausführungen von dem Gedanken durchzogen: „Wir brauchten die starke Stimmung, wie wir sie im ersten Teil des Krieges hatten." So sbraucht auch der kranke Greis die Kraft und das Lebensgefühl des Jünglings, um das zu leisten, was dieser ehemals geleistet hat.

1) Die, nach dem Ausdrucke des Prof. von Schulzz.Garvernitz (Schmollers Jahrbuch. XIII, S. 418), ,bei uns zur Zeit" - in Wahrheit gilt es so gut wie überall und immer - „auschlieBlich cine öffentliche Meinung der oberen Klassen” ist (wo man jedoch das Wort sobere nicht in engem Sinne ausdeuten darf). 
8. (In England während des Weltkrieges.) In einem Umfange, wie es niemals erhört war, hat im Weltkriege eine Propaganda stattgefunden, ein Werben um die Offentliche Meinung des neutralen Auslandes, das in erster Linie mit den Mitteln der Zeitungspresse, aber ferner auch durch Bildwerke, durch Films, durch Bücher und Flugschriften und fast mit allen denkbaren Methoden geschah, man nannte es wohl einen Wettbewerb um die Seele des fremden Volkes, es war in der Tat nicht allein auf die Offentliche Meinung, sondern zugleich auf die Gefühle der gesamten Volksmenge berechnet. Es ist eine oft erörterte und sichere Tatsache, daß Deutschland und seine Bundesgenossen in diesem nicht sonderlich edlen Wettstreit von Anbeginn sich im Nachteil befunden haben. Die Feinde zeichneten sich nicht nur durch größere Geschicklichkeit, Rücksichtslosigkeit, Ubung in Bestechungskünsten u. dg1. aus, sie hatten vor allem den Vorteil ungehinderten Verkehrs und der Kabelstränge, die das überseeische Nachrichtenwesen beherrschen, und der englische Feind überdies den unermeßlichen Vorzug der Sprache, zumal für die Vereinigten Staaten von Amerika, deren Kern eine Gruppe seiner ehemaligen Kolonien bildet.

Die Offentliche Meinung Englands war zunächst der Teilnahme am Kriege nicht sehr geneigt. Gewisse feste Bestandteile ihres Credo sträubten sich dagegen, als Anwälte der Balkan-Meuchelmörder und im Namen des Zarismus zur Vernichtung Deutschlands sich anzuschicken. Es gab zwar eine starke aristokratische Gruppe, repräsentiert durch ein Tageblatt wie die Morning Post, eine Wochenschrift wie die Saturday Review, eine Monatsschrift wie die National Review, die längst das Germaniam esse delendam auf ihr Banner geschrieben hatte, der also der Krieg unter allen Umständen willkommen war, wenn erwartet werden durfte, daß der russische steam roller bald vor den Toren der preußisch-deutschen Hauptstadt stehen würde. Diese Gruppe agitierte zwar seit langem in diesem Sinne und hatte Einfluß auf die öffentliche Meinung in Großbritannien, wie auch jenseits des Ozeans, gewonnen, aber sie war nicht die Offentliche Meinung. „Warum gingen wir in den Krieg?" fragte am 24. Oktober I9r4 der „New Statesman", die Zeitschrift der Fabian Society, die also auf einer höheren Warte steht als die vulgäre Publizistik. Nach vielen Umschweifen wird behauptet, die Verteidigung Belgiens sei der wirksame Beweggrund gewesen, der Englands Eintritt in den Kampf bestimmte. Für die Offentliche Meinung war dies ohne $Z$ weifel richtig; sie konnte sich nicht nur beruhigen, sondern erheben in dem Gedanken, daß nur ein edles Motiv die friedfertige britische Nation - die sonst wohl notgedrungen in Afrika und in Asien Kriege führt - an die 
Seite des russisch-serbischen Barbarentums bringen konnte. „Lord BEACONSFIELD soll von Gladstone gesagt haben, daB er stets seine Politik mit falschen Karten im Rockärmel spiele, und daß er überdies fest überzeugt sei, der Heilige Geist habe sie ihm hineingeschoben. England konnte nicht Holland seiner Flotte, Frankreich seines Handels und seiner Kolonien und die Buren ihrer Gold- und Diamantenminen berauben ohne ein frommes Gebet zum Himmel und einen edlen ethischen Grund auf den Lippen." So ein amerikanischer Theologe, T. C. HALL in einem kleinen Hefte über ,,The English yellow press" (aus der „New York Sun" vom I7. Januar I9I5). Ein anderer amerikanischer Schriftsteller, Prof. KunO FRANCKE, schrieb um dieselbe Zeit „Die sittliche Entrüstung der heutigen englischen Regierung über die deutsche Invasion Belgiens würde mehr Eindruck machen, wenn man sich sicher fühlen dürfte, daß im Falle einer französischen Invasion die gleiche sittliche Entrüstung und darauffolgende Kriegserklärung gegen Frankreich zutage getreten wäre" (The Germanistic society of Chicago, Nr. 5). Die britische Regierung wußte, daß sie die Vorstellung, Belgien sei der Grund zum Kriege, als "Schmieröl für die Offentliche Meinung" brauchte, um einen Ausdruck, den ich einmal aus dem Munde MAX WEBERs hörte, anzuwenden. Heute wird im Ernst kein britischer Politiker die Fabel aufwärmen. Wenn aber die englische Offentliche Meinung und ihre Führer sich hätten genügen lassen an dieser Legende und ihrer sorgsamen Pflege, so hätte die Göttin der Wahrheit mit nachsichtigem Lächeln auf sie hinabgeschaut $\left.{ }^{1}\right)$. Aber mit Schaudern wendet sie sich $a b$ von den Methoden, mit denen die öffentliche Meinung verhetzt und vergiftet wurde, nicht nur innerhalb des Landes, das diesen Angriffskrieg des Zarismus und seiner Bundesgenossen führte, sondern über den ganzen Erdball hin. „Die Amerikaner ärgern sich, daß sie schlecht unterrichtet werden über den Krieg ..." (es ist von Anfang an nicht besser gewesen). „Behaupten sie jetzt im Ernste, zu glauben, da $B$ der deutsche Kaiser den Krieg hervorrief, oder da $B$ der Kronprinz ihn in den Krieg hineinnötigte, oder daB LIEBKNECHT mit 600 Sozialisten auf den Straßen Berlins erschossen wurde, oder da $B$ die russische Dampfwalze binnen 6 Wochen in Berlin sein wird, oder da $B$ Deutschland nur eine historische Erinnerung ist, aber da $B$ belgische Kinder, denen beide Hände abgehackt wurden, herumlaufen, da $B$ der Kronprinz getötet, der Kaiser wahnsinnig geworden, daß Breslau

1) Herr v. Bethmann Hollweg klagte mit gutem Grunde am 26. August 19r5 Mr. Asquith an, daß er durch Verschweigen eines sehr wichtigen Umstandes bei den Neutralitäts verhandlungen mit HALDANE (,if war should be forced upon Germany") die Offentliche Meinung in England auf unverantwortliche Weise irregeführt habe. (Sechs Kriegsreden des Reichskanzlers, S. 49.) 
genommen, Krakau verbrannt worden ist? - Und doch werden alle diese Lïgen und tausend mehr mit gelehriger Unterwürfigkeit aus den Händen einer Londoner Presse entgegengenommen, deren schreiendes Gelb und grenzenlose Fähigkeit zum Aufschneiden eine der schandbarsten Neuheiten dieser traurigen neuen Ära in der englischen Geschichte ist ...“ „... wir empfangen unsere Meinungen und die angeblichen Tatsachen aus den gleichen besudelten Quellen". So Thomas C. HalL in der genannten Flugschrift. Der Lïgen- und Verleumdungsfeldzug ist ein historisches Faktum. In ihm, und zum guten Teil durch ihn, hat Großbritannien im Weltkriege den "Sieg * davongetragen $\left.^{1}\right)$. Denn gerade, da $\beta$ der Boden Amerikas und mit ihm der nicht übermäßig starke Geist seines Präsidenten so zubereitet war, bewirkte die sonst nicht hinlänglich motivierte innere Einstellung der Offentlichen Meinung drüben, die von den wirklichen Zusammenhängen der europäischen Dinge eine mangelhafte Vorstellung hatte und durch die systematische Lüge in Wahn und $\mathrm{HaB}$ hineingęzogen wurde. Ein dritter amerikanischer Autor, PHILIPP FRANCIS, der nach dem Kriege schrieb, sagt treffend darüber: „Daß die Deutschen in dieser Beziehung von den Briten vollkommen matt gesetzt wurden, führt sich nicht auf Mangel an Bemühungen ihrerseits zurück, sondern auf die überlegene Geschicklichkeit und die längere Berufserfahrung der Briten." Er spricht dann ausführlich über die Greuelpropaganda und die furchtbaren, ja allerschlimmsten Greuel der britischen Kriegführung, den Aushungerungskrieg; er zitiert den Ausspruch BERNARD SHAws: „Ich trage kein Verlangen danach, ein Kind zu töten, aber wenn ich ein Kind töten müßte, so würde ich es lieber mit einer Bombe oder einem Torpedo töten, als es zu Tode zu hungern." Er vergleicht dann die deutsche und die britische Methode, von denen jene nur darauf abgezielt habe, das Volk der Vereinigten Staaten für eine strenge Neutralität, diese, es für Eintritt in den Krieg zu stimmen. „Nach ihrer rationalen Art beriefen sich die deutschen Propagandisten auf die Vernunft, zuweilen mit richtiger, zuweilen mit falscher Logik, aber immer mit dem Versuche, die Offentliche Meinung durch logisches Räsonieren zu beeinflussen. Die Briten waren klüger, sie appellierten an Gemütserregungen." Das sei von je her und immer das System der britischen Propaganda gewesen, ,indem man die wirklichen Motive dieses fortwährenden Kriegserregers . . . hinter dem Heucheln

1) „England ließ sofort die Kabel zerschneiden, welche uns mit den überseeischen Ländern verbanden ...., es zerstörte die drahtlose Telegraphie, um seiner Presse die Alleinherrschaft über die Geister in aller Welt zu sichern." K. BücHER, Unsere Sache und die Tagespresse, S. 3. Vgl. HETrNER, Englands Weltherrschaft und der Krieg VI, 2, Kabel, Funkentelegraphie und Nachrichtenwesen (von Dr. ScHMTTHHENNER), S. $138 \mathrm{ff}$. 
beleidigter Unschuld und der angeblichen Verteidigung erhabener Prinzipien, allgemeiner Rechte und Freiheiten ... verbarg." Die offenbare Tatsache ist, $\mathrm{da} B$ diese Pressestrategie, obgleich man ïberall die englischen Methoden und die wichtigsten Tatsachen kannte, die $\mathrm{zu}$ ihrer Beleuchtung erfordert werden, einen fast vollständigen Erfolg gehabt hat. Es wurde beinahe ein fester Bestandteil der Offentlichen Meinung nicht nur unter den feindlichen Nationen, von denen mehrere ohne jeden auch nur scheinbar gerechtfertigten Kriegsgrund der großen Verschwörung sich anschlossen, sondern auch unter den meisten derer, die dauernd neutral blieben: I. daß vom Deutschen Reich und von Osterreich-Ungarn der Weltkrieg aus schierer Machtbegierde begonnen und planmäßig vorbereitet worden sei, da $B$ insbesondere Deutschland allein schuldig an diesem großen Unheil sei, 2. daß die Verletzung der Neutralität Luxemburgs und zumal Belgiens durch den Notstand, worin sich Deutschland befand, in keiner Weise gerechtfertigt oder auch nur entschuldigt werde, sondern ein kriegerisches Vorgehen sei, dessen sich engelreine Mächte, wie Großbritannien, Frankreich, Rußland und Serbien niemals schuldig gemacht haben, 3. da $\mathrm{B}$ überhaupt der sanften und humanen Kriegführung dieser zivilisierten Staaten die Kriegführung der Deutschen als die einer schlechthin wilden oder doch gänzlich barbarischen Nation gegenüberstehe. Diesen frechen Blödsinn charakterisiert Тн. C. HALI mit dem Satze: „Kann ein Amerikaner von gesundem Menschenverstand mit Geduld zuhören, wenn die Londoner Presse uns belehren will, daß ein Heer, zusammengesetzt aus der Blüte von Deutschlands gebildeter Jugend, worin Gelehrte von Weltruf als gemeine Soldaten und Unteroffiziere dienen, ... eine Horde von Barbaren sei, verglichen mit einer Armee von Turkos, Sikhs, dem Auswurf von London, Gurkhas, Kosaken, Tartaren vom Amur-Strome, Japanern, tunesischen Arabern und Negern aus der Sahara? Und daß das Schicksal der Zivilisation abhängt von dem Siege der ungebildeten und trunksüchtigen Bauernschaft Rußlands unter dem Befehl der korrupten, anmaßenden und brutalen Autokratie, deren leitender Geist der Großfürst NicolaI NicoLAJEWITSCH ist?" - 4. daß in entsprechender Weise die Behandlung der Kriegsgefangenen auf jener Seite zart und rücksichtsvoll, auf dieser schlechthin roh und menschenunwürdig gewesen ist.

Wie schreiend auch der Widerspruch dieser Anschuldigungen mit aller festgestellten Wahrheit und inneren Wahrscheinlichkeit, - die Offentliche Meinung der I,änder, um nicht zu sagen sder Welt «, hat diese Widersprüche und Lïgen willig geschluckt und mit besonderem Behagen daran gekaut, nachdem das Deutsche Reich und seine Verbündeten 
dem humanen Aushungerungskrieg erlegen waren. Zur Charakteristik der Offentlichen Meinung ist es wichtig, diese Tatsachen festzulegen. Sie werden allerdings $\mathrm{zu}$ einem Teile durch die "Kriegspsychose" erklärt und entschuldigt; und daß die häßlichen Methoden der Lüge und Verleumdung - dazu gehört auch »das Bild als Verleumder», wie es der Dichter Ferdinand Avenarius in einer Flugschrift des DüRER-Bundes unwiderleglich dargestellt hat -, daß diese Methoden angewandt wurden, mag als ein Stück des modernen Krieges und seines Raffinements gewertet werden; auch auf deutscher Seite ist ohne $Z$ weifel in dieser Hinsicht vieles unternommen worden, was vor einem strengen ethischen Urteil nicht besteht; wie auch sonst der Radikalismus der Kriegführung von allen Seiten geübt worden ist und Ursachen hat, die allgemeiner Natur sind und in einem zukünftigen Kriege noch furchtbarer zutage treten werden. Die Tatsachen sind uns hier nur wichtig zur Charakteristik der Offentlichen Meinung. Naturgemä $B$ steht sie in einem kriegführenden Lande, je ernster die Kriegsnot, um so mehr unter dem Drucke des Affektes; und zum Affekt kam im Weltkriege in allen beteiligten Ländern, mehr oder minder scharf, überall aber mit gewollter Strenge, die Zensur. Leidenschaftlich erregt war die Offentliche Meinung mit der Volksstimmung; Gedanken, die sie dämpfen oder gar hätten umstimmen können, wurden mit vielen Künsten durch die Zensur ihr ferngehalten; die vrichtigen " Gedanken führte eine offiziöse Presse, führten die Kriegsberichte, führten bestellte Broschüren und Bücher ihr zu. Daß es gelang, den Engländern und den Amerikanern die gröbsten Unwahrheiten und Unwahrscheinlichkeiten zu suggerieren, muß zum Teil dem Bildungsstande der Gebildeten in diesen Ländern und ihrem ganz besonders in bezug auf Dinge des europäischen Kontinents engen Gesichtskreis zur Last gelegt werden; zum Teil rührt es her von wirklichen Greueln, die der große Krieg, und der moderne technisch »veredelte " Krieg in um so höherem Grade, mitsichbringt; aber der größte Teil der Schuld daran ist doch absichtlicher künstlicher Mache zuzuschreiben, einer Politik, die schlechthin skrupellos in der Wahl ihrer Mittel war, und die man nach dem Florentiner Staatsschreiben zu benennen pflegt, obgleich MACHIAVELLI wohl von Gift und Dolch, aber kaum etwas von systematischer Vergiftung der Offentlichen Meinung und moralischem Meuchelmord als Mitteln einer gewissenlosen Politik gewußt hat. ${ }^{\text {) }}$

1) In der Schrift von PAUL DEHN, »England und die Presse $\measuredangle$, ist der Versuch gemacht worden, durch die Gruppierung charakteristischer Bruchstücke, den Feldzug der Londoner Presse gegen Deutschland vor und während des Weltkrieges von r91 $_{4}-\mathrm{r}_{5}$ darzulegen. Unter der Utberschrift: „Ist die Presse bestechlich?" werden auch über 
9. (Frankreich während des Weltkrieges.) Der französische Geist weist eine Parallele zum Wesen der luftartigen Offentlichen Meinung insofern auf, als beide der Idee nach rational, logisch, nüchtern urteilend sind, in Wirklichkeit aber von heftigen, sinnlich-übersinnlichen Leidenschaften inspiriert sich zeigen. So bedurfte die französische Offentliche Meinung der Vorstellung, daß Deutschland das friedenliebende, friedensinnende Frankreich überfallen und aus eitel Bosheit und Machtbegierde ihm, wie dem unschuldigen Belgien den Krieg ins Land getragen habe. Obgleich Frankreich seit 44 Jahren den Rachekrieg geplant hatte, und sich in dieser Idee, die verlorenen Landesteile mit Gewalt zurückzuerobern, moralisch völlig gerechtfertigt fühlte, so $\mathrm{da} B$ der Offentlichen Meinung jeder Krieg, der zur Vernichtung Deutschlands die Aussicht darbot, willkommen sein mußte, und wie der russische Botschafter BENCKENDORFF an seinen Minister aus London schrieb - am I2./25. Februar I9I3 - „von allen Mächten Frankreich allein diejenige war, die, um nicht $z \mathfrak{u}$ sagen, daß sie den Krieg wolle, ihn ohne großes Bedauern sehen würde" [schon damals bei Gelegenheit der Balkanverhandlungen in London, wo, nach dem

die Pariser Zeitungen artige Tatsachen und Aussprüche mitgeteilt. So habe JAUR ÈS gesagt: „Unsere Presse ist verfault bis in die Wurzeln. Der Journalismus in unserm Lande ist schlimmer als die Prostitution; denn er umgibt sich mit einem Mantel von Moral und Wohlanständigkeit und es wirkt draußen ... wie ein Ausdruck der Meinung der Besten Frankreichs, und ist doch nichts anderes als der Ausdruck einer perfiden und geldgierigen Spekulantenclique." EMIIE Verhatren habe die Presse einen Schandfleck der französischen Kultur genannt, AUGuste RodiN ihr das. Prädikat „verabscheuungswürdig" gegeben. (Nach der Voss. Ztg. v. 20. X. 1914.) Ein durchaus glaubwürdiger Kenner der englischen Presse ist der Philosoph und Mathematiker BERTRAND RUSSEL, ; er schreibt (Roads to freedom, p. I47ff.): „Die Masse der Bevölkerung eines Landes kann angeleitet werden, jedes andere Land $z u$ lieben oder zu hassen, nach dem Wunsche der Zeitungsbesitzer, der oft ummittelbar oder mittelbar unter dem Einflusse des Willens der Finanzgrößen steht. So lange als Feindschaft $z$ wischen England und Rußland erwünscht war, waren unsere Zeitungen voll von der grausamen Behandlung russischer politischer Gefangener, von der Unterdrückung Finlands und Polens u. dgl. Nachdem die auswärtige Politik eine Schwenkung gemacht hat, sind diese Notizen aus den bedeutenderen Zeitungen verschwunden, wir hören statt dessen von den Missetaten Deutschlands." - Eine gute Ubersicht über die Organisationen der Preßarbeit in den kriegführenden Ländern gibt Eı,rzBACHER: „Die Presse als Werkzeug der auswärtigen Politik", Jena I918. Die deutsche Praxis ist durch Deutsche mit scharfen Akzenten kritisiert worden, so vor allem von K. BUCher, ,Unsere Sache und die Tagespresse." „Die deutsche Tagespresse und die Kritik"; neuerdings in einem kleinen Heft von PAUr, RACHE: „Wir sind allzumal Sünder", Berlin s. a. (1919). Aber auch darin heißt es: „Wir können dem Gegner den Ruhm neidlos lassen, daß er auf dem Gebiete der Verhetzung alles das, was wir nach der Richtung hin geleistet haben, tief in den Schatten stellte“... "so mag das daran liegen, da $B$ wir uns vielleicht doch scheuten, gar zu skrupellos vorzugehen." - Für den ganzen Gegenstand ist auch die Darstellung, ,.Krieg und Presse - auf Grund amtlicher Quellen" im 2. Band des Werkes „Deutschland und der Weltkrieg", 2. Aufl., I9r6 und die noch heute sehr lesenswerte Darstellung im 4. Abschnitt über Vorgeschichte usw. des Krieges von HERMANN ONCKEN zu vergleichen. 
gleichen Bericht, der französische Botschafter offenbar gierig auf das verlösende kriegerische Wort der Russen gewartet hat: BENCKENDORFF sagt ausdrücklich, daß Frankreich sich durchaus keine Reserve auferlegt habe. „Si peu, il ne faut pas s'y tromper, que qu'elle qu'ait été la modération prudente quoique jamais énigmatique de $M$. Cambon en séance - c'est en réalité sur moi (den russischen Botschafter) qu'il se réglait plus que sur ses propres inspirations. Au contraire, en récapitulant tous ses entretiens avec moi les paroles échangées ${ }^{1}$ ), en y ajoutant l'attitude de $M$. Poincaré - il me vient l'idée qui ressemble à une conviction, que de toutes les Puissances c'est la France seule, qui pour ne pas dire qu'elle veut la guerre, la verrait sans grand regret." Frankreich, das Frankreich des leidenschaftlichen Nationalgefühls, wünschte den Krieg, es brannte auf den Krieg, er war ihm mindestens seit I9II zu jeder Zeit willkommen, da es sich auch der Hilfe Englands, außer derjenigen Rußlands, sicher fühlte. RuBland bereitete den Krieg planmäßig vor und wollte ihn zwischen Serbien und Österreich ausbrechen lassen; es fühlte sich im Jahre I9I3 noch nicht fertig und bereit, wohl aber im Jahre I9I4 - wenn die Brandfackel von Serajevo nicht gezündet hätte, so wäre ohne allen $Z$ weifel noch im gleichen Jahre eine andere noch feurigere geworfen worden. England "wünschte" und "wollte "keinen Krieg, aber es sah ihn kommen, da es genau wußte, daß seine Bundesgenossen ihn wünschten und wollten, und war entschlossen, die Vernichtung des Deutschen Reiches - nicht etwa unmittelbar sich zum Ziele zu setzen - welcher Frevel! - aber auf jede Weise und unbedingt zu begünstigen, wenn eine weise Vorsehung sie beschlossen haben sollte. - Für die Haltung des französischen Geistes und der französischen Politik ist sehr bezeichnend die Erklärung, welche Herr POINCARÉ - damals Ministerpräsident - vor dem Balkankriege dem Russen Sassónow gegeben hat (Deutschland schuldig, S. I43), „daß es die Offentliche Meinung Frankreichs der Regierung der Republik nicht gestatte, wegen Fragen, die nur den Balkan betreffen, kriegerische Aktionen zu unternehmen, *wenn Deutschland teil nahmlos bliebe* und nicht aus eigener Initiative den casus foederis provoziere. In letzterem Falle könne Rußland natürlich auf volle und genaue Erfüllung der Verpflichtungen rechnen, zu welchen Frankreich sich Rußland gegenüber gebunden habe. Ganz im gleichen Sinne berichtete Isvolsky an SAssónow am 30. August/I2. September einmal und nochmals am 4./I7. November I9I2. Ein klares Kriegsprogramm, ein deutlicher Plan. Auf dem Balkan soll es losgeheñ,

1) Der Text in „Deutschland schuldig?", Anlage Io, scheint hier lückenhaft. 
Osterreich soll gereizt werden, Deutschland soll sich Osterreich zur Seite stellen - alles übrige ergibt sich von selbst. Am 22./23. November I9i2 geschah der berufene Briefwechsel zwischen Herrn Paur, CAmbon und Sir EDWARD GREY. Die französische Offentliche Meinung sah dem Kriege, wie Graf BENCKENDORFF in dem gleichen Bericht vom I2./25. Februar IgI3 sich ausdrückt, mit der meisten "Philosophie * entgegen; sie habe, mit Recht oder mit Unrecht, vollständiges Vertrauen zur eigenen Armee. - Und doch - der Uberfall! doch die Legende! doch gerade der greise CLEMENCEAU, der typische Herold des Rachekrieges, am meisten erpicht darauf, die alleinige Schuld am Ausbruche des Krieges auf diejenige Macht zu schieben, der Rußland nicht einmal Zeit gelassen hatte, den casus foederis für gegeben zu erachten, sie war durch die zarische Gesamtmobilmachung unmittelbar vor die Frage der notgedrungenen Abwehr und Verteidigung gestellt. Dieselbe Offentliche Meinung, die den Krieg herbeigesehnt hatte, bedurfte in ihrem selbstgefälligen Wahn des Parfüms eines unschuldigen Bewußtseins - um die Volksstimmung mit sich fortzureißen. In diesem Sinne wurde die Preßarbeit während des Krieges im Inund Auslande betrieben. „Die Franzosen selbst weiß man gemäß ihrer heißbliitigen und nicht allzu sachlichenArt, auch in den schwersten Lagen immer wieder durch ein blendendes Schlagwort oder durch die Fata Morgana einer Hoffnung zu neuen Opfern aufzupeitschen ... die Völker des Auslandes sucht man für das edle und ritterliche Frankreich, das Land der Freiheit, des Lichts und der Schönheit zu gewinnen, und gegen dessen barbarische Gegner, die dickköpfigen Sauerkrautfresser, die geistlosen, rohen und tierischen boches einzunehmen." Eitzbacher (Die Presse als Werkzeug der auswärtigen Politik, S. 32), dem diese Sätze entlehnt sind, faßt seine Ansicht, warum der auswärtige Dienst Frankreichs die Offentliche Meinung fremder Länder durch das Mittel der Presse so gut zu bearbeiten verstehe, dahin zusammen: „Für wen die öffentliche Meinung des eigenen Volkes höchste Instanz ist, der denkt auch daran, wie viel von der Stimmung anderer Völker abhängt. Jeder französische Minister und jeder Vertreter Frankreichs im Auslande betrachtet es als selbstverständlich, da $B$ für die auswärtigen Beziehungen Frankreichs heute alles auf die Gesinnung der Völker (d.h. der guten Gesellschaft, die das Publikum bildet) ankommt, und weiß, wie man die Presse zu diesem $Z$ wecke verwendet. Namentlich, wenn er selbst dem Presseberuf angehört hat, wird er im Ausland wie in der Heimat bei jeder Maßregel deren Rückwirkungen auf die öffentliche Meinung beachten. Die am eigenen Volk erworbene Schulung kommt ihm bei fremden Völkern zugute" (das. S. 34). Vorbedingung dieses 
Erfolges war aber die Tatsache, daß die Freiheit der Presse und jeder öffentlichen Meinungsäußerung in keinem Staate so eingeschnürt war, wie im republikanischen Frankreich. „In Paris“ - so führte schon Herr v. BETHMANN-HolLWEG am 28. Mai I9I5 aus - ,herrscht allein der Terror der Zensur.“ „Keine Verlustlisten erscheinen, kein deutscher, kein österreichisch-ungarischer Generalstabsbericht darf abgedruckt werden; die ausgetauschten schwerverwundeten Invaliden werden von ihren Angehörigen abgesperrt. Eine wahre Angst vor der Wahrheit scheint die Regierenden zu beherrschen. So kommt es, daß, nach zuverlässigsten Beobachtungen in breitesten Volksschichten, noch heute keine Kenntnis von den schweren Niederlagen der Russen, auch nur im vorigen Jahre, besteht, daß man weiter glaubt an die russische Dampfwalze, die auf Berlin losgeht usw." - (Sechs Kriegsreden, S. 33.)

I0. (Rußland während des Weltkrieges.) Die russische öffentliche Meinung - sofern eine solche als vorhanden vorgestellt werden darf - war eine scharfe Aufsicht und Kontrolle gewöhnt, aber die Niederlagen konnten ihr nicht verborgen bleiben. Sie schob die Schuld zunächst auf die korrupte Großfürstenwirtschaft und den Hof, außer auf den Mangel an Munition, dem England abhelfen mußte, sie rüstete sich allmählich, unter dem Beistande der englischen Botschaft, zu dem Entschlusse, die Friedenspartei am Hofe zunächst durch Beseitigung des gesundbetenden Mönches, sodann des Zaren selber, über den Haufen zu werfen. In der Hauptsache abhängig von Frankreich, und mittelbar von England, war sie mit beiden einig in den Schlagworten: gegen den preußischen Militarismus, für den zukünftigen Weltfrieden, für die Befreiung der kleinen Nationen usw. Gleichwohl finden wir nicht, daB die Schuld am Kriege auf das Deutsche Reich geschoben wurde: diese allzu schreiende Unwahrheit hat das Land nicht auszusprechen gewagt, das sich vollkommen der Tatsache bewußt war, den Krieg ganz eigentlich durch seine Mobilmachung angefangen zu haben. Indem Rußland diese Urheberschaft des Krieges zu rechtfertigen versucht, gesteht es sie ein. In dem zarischen Manifest, das sogleich im Anfange ans Licht trat, heißt es: „Heute obliegt es uns, für ein ungerecht angegriffenes, verwandtes Land (Serbien) einzutreten und die Ehre, die Würde und Integrität Rußlands, sowie seinen Platz unter den anderen Großmächten zu wahren. Wir glauben unerschütterlich daran, daß alle unsere treuen Untertanen einig und opferfreudig sich zum Schutze unserer russischen Erde erheben werden." Natürlich muß man, wenn man aus irgendwelchem Grunde oder Scheingrunde Krieg anfängt, die eigene Erde zu schützen bemüht sein - nur in diesem Sinne wird behauptet, daß 
es sich um einen Verteidigungskrieg handle. Ebenso sagte der Präsident der Duma in der Sitzung vom 8. August IgI4 nicht, daß Deutschland den Krieg angefangen habe, sondern, indem er versichert, da $B$ oRußland « den Krieg nicht wollte, daß dem srussischen Volke Eroberungspläne fremd seien, fährt er fort: „aber dem Schicksal selbst gefiel es, uns in kriegerische Taten hineinzureißen. Das Los ist gefallen usw." NrColaus Suchanoff, der in einer kleinen Schrift „Die russische Linke und der Krieg“, die I9I7 bei EUGEN DIEDERICHS deutsch erschien, dies mitteilt, fügt hinzu: „In demselben Sinne faßte auch die öffentliche Meinung den Krieg auf, soweit diese Meinung in den bei der neuen Lage der Dinge noch erhalten gebliebenen Organen der Tagespresse zum Ausdruck kommen konnte." Er zeigt aber weiter, wie die Ideologie des Krieges bald über diese Grenzen hinausgeschritten sei, daß fast unmerklich der Krieg gemäß der Auslegung der "patriotischen « Presse aus einem Verteidigungs- in einen Befreiungskrieg sich verwandelte. Der "Germanismus " sei dargestellt worden, als ob das heilige Rußland unter seinem Joch wie unter einer Fremdherrschaft seufze und stöhne, und wie als "Frage der Unabhängigkeit Rußlands « die Meerengenfrage aufgestellt worden sei, wie auch dabei die »deutschen Greuel « herhalten mußten, und wie endlich ,der liberale Imperialismus, der bisher der Tradition entsprechend unter einer dichten Schicht von Feigenblättern schamhaft sich verborgen gehalten, plötzlich durch die Kriegsereignisse stürmisch nach außen gedrängt worden" sei (S. 98). Von einem Vertreter dieser Ideen (MURAwIEFF) sagt der sozialdemokratische Verfasser, daß er, nachdem er alle Kriegsmotive als unhaltbar abgewiesen, „bei der zerbrochenen Schale des Panslawismus“ stehen bleibe, ,für die er dann künstliche Stützen und Ornamente im Stile der Modernen entdeckte" (S. 45).

\section{Dritter Abschnitt. Die Öffentliche Meinung nach dem Weltkriege.}

II. (Im allgemeinen und in Deutschland.) Seit dem Ende des Weltkrieges ist die öffentliche Meinung in den beteiligt gewesenen Ländern beider Welten, mit der gesamten Volksstimmung dieser Iänder und auch mehrerer neutral gebliebener, in einem Zustande der Gärung. Die ungeheuren Erregungen zittern mächtig nach, ein Aufatmen nach den gewaltsamen Anstrengungen und schweren Entbehrungen findet statt, man versucht, sich $\mathrm{zu}$ besinnen, und erkennt allmählich den ungeheuren Umfang der Zerstörungen, die das Unheil bewirkt hat, eine gewisse Unlust und Unkraft, gepaart mit Hoffnungslosigkeit, tritt zutage, die gewohnten Geleise des 
vormaligen täglichen Arbeitslebens wiederum zu befahren. Die längst gelockerten Bande sfrommer Scheu "scheinen völlig aufgelöst zu sein, es macht sich ein Zustand erkennbar, den ein geistreicher Beobachter als den der moralischen Verlausung kennzeichnete. Eine leidenschaftliche Neigung zum Tanze machte sich nicht weniger bei den überwundenen als bei den »siegreichen "Völkern geltend. Und die Offentliche Meinung? Auch sie ergab sich dem Tanzvergnügen, sie bewegte sich und bewegt sich bis zur Stunde schaukelnd hin und her, bewegt hauptsächlich durch die Ungewißheit der Zukunft, den unbefriedigenden Zustand der Gegenwart, den Rückblick auf eine Vergangenheit, in der die Möglichkeiten einer ungestörten Beharrung vorhanden gewesen $\mathrm{zu}$ sein scheinen, obgleich sie in Wirklichkeit ausgeschlossen waren.

Ubrigens ist natürlich die Gedankenbildung der Offentlichen Meinung in jedem Lande sehr verschieden, je nachdem es aus dem Unheil und dem Wirrsal herausgekommen ist. In dem einen beherrscht die Traurigkeit und der Ernst, in dem anderen Freude und Heiterkeit die vernünftige Denkungsart. In dem einen ist $z \mathfrak{u}$ den Schrecken und Schäden des Vae victis die Veränderung der Staatsform mit mannigfachen Neuerungen hinzugekommen. So in dem mit Füßen getretenen, verleumderisch beschimpften, verstümmelten Deutschen Reich. Durch die Revolution, einen Umschlag, der sämtliche Kronen und Krönchen, die sich bisher als die Träger des deutschen Staatswillens gefühlt hatten, auf die Erde rollen ließ, war die Offentliche Meinung betäubt ratlos, hilflos. So stark auch der Eindruck war, der Eindruck der furchtbaren, schwer begriffenen Erkenntnis, daß der Krieg verloren, war noch stärker und verdunkelte in einigem Maße jenen. Uberdies war das Mißtrauen gegen die Arbeiterklasse, die Abneigung gegen die Sozialdemokratie durch die national-patriotische Haltung jener, durch die Bewilligung der Kriegskredite, wozu die große Mehrheit der Partei dauernd sich verstanden hatte, erheblich gedämpft worden. Unter diesen Eindrücken hatte die Offentliche Meinung Deutschlands sich - wie für anderes Entgegenkommen - so für die Abschaffung des ohnehin längst zum Gegenstande der Scham gewordenen Klassenwahlrechts im Staate Preußen entschieden, und hätte die Verkündung, $\mathrm{da} B$ in Zukunft das Reichstagswahlrecht auf Preußen, ja auf alle Einzelstaaten Anwendung finden solle, wenn nicht mit Genugtuung, so doch mit dem Bewußtsein einer inneren Notwendigkeit empfangen. Nun kam die Revolution mit einer noch viel weiter gehenden Gleichheit der Individuen und ihrer politischen Rechte. Die Offentliche Meinung nahm dies zweifelnd und resigniert, aber ohne erheblichen Widerstand, entgegen. Stark mußte dazu mitwirken, daß gerade die gebildeten 
Frauen das ihnen in den Schoß gefallene Wahlrecht als ein Kompliment empfanden und willkommen hießen, und daß gerade sie, die wohl am meisten um die verschwundenen Dekorationen der Monarchien und Höfe trauerten, mit allem Eifer in eine gegenrevolutionäre Strömung hinabzutauchen bereit waren. Zunächst hatte die Offentliche Meinung genug politische Einsicht, um unmittelbar jede Regierung, wenn sie nur eine "feste " und durch überwiegende Zustimmung des Volkes beglaubigte Regierung sei, der Fortdauer des diktatorischen Zustandes einer Herrschaft von sog. Volksbeauftragten vorzuziehen, wenngleich diese Diktatur sich tatsächlich in sehr gemäßigten Formen bewegte. Daher war der Ruf nach der "Nationalversammlung « einmütig, und jener Besinnungslose, der erklärte, nur über seine Leiche gehe der Weg dahin, machte sich vor der Offentlichen Meinung schlechthin lächerlich. So wurden dann auch die Beratungen über die neue Verfassung und die Beschlüsse tiefgehender Neuerungen mit Ruhe und Geduld, ja im Durchschnitt nicht ohne Hoffnung, da $B$ "manches Gute" daraus sich ergeben werde, aufgenommen; die Mitwirkung einer Persönlichkeit, die so hoch in der Offentlichen Meinung stand wie diejenige FrIEDRICH NAUMANNS, wirkte in dieser Hinsicht ohne $Z_{\text {weifel günstig. Erschüttert wurde die Offentliche Meinung }}$ erst wieder durch das Ungeheuer des Versailler Friedens und seines Korollars, des Friedens von St. Germain; ein Übergewicht war in der Offentlichen Meinung wohl noch entschiedener als in der damaligen Regierung gegen die bejahende, in Verzweiflung beruhende Entscheidung der Nationalversammlung, also für Verwerfung der aufgezwungenen Bedingungen, insbesondere des scheußlichen Eingeständnisses der alleinigen Schuld am Weltkriege - trotz des schauderhaften Risikos der Erneuerung des Krieges ohne Hoffnung und Kraft, das schlimmer als die Streckfolter der "peinlichen Frage s wirken sollte und mußte. Seitdem hat mehr und mehr, neben dem Unwillen über diese Friedensbedingungen, neben der Meinung, da $B$ zu große Nachgiebigkeit gegen die Feinde geübt werde, neben der Empörung über das Verhalten der Besatzungstruppen - insonders die "schwarze Schmach" - und dem damit immer mehr sich vertiefenden Bewußtsein der Erniedrigung des Vaterlandes - die zunehmende Teuerung und die vollkommene Zerrüttung der Finanzen des Reiches wie aller öffentlichen Körperschaften, die Gedanken der Offentlichen Meinung in Anspruch genommen; im Zusammenhange damit, ohne daß dieser Zusammenhang in der Regel klar erkannt wurde, die Geldentwertung, namentlich die hinschwindende Geltung der deutschen Mark im Auslande, die "Valuta", die seitdem in aller Munde ist. Nur noch die brennende Frage "Oberschlesien ", die ebenso 
sehr eine Lebensfrage ist, konnte mit ihr in Wettbewerb treten. Die parteiische Anklage, daß dieser üble Zustand der Sozialdemokratie, der Revolution, der neuen Regierung zugeschrieben werden müsse, hat anfangs in der öffentlichen Meinung nur wenig Boden gefunden, hat aber unter dem Druck planmäßiger, unablässiger, mit großen Mitteln rücksichtslos arbeitender Agitation, die zum guten Teil besonders die Anstachelung judenfeindlicher Gesinnungen sich angelegen sein ließ und mit diesem rohen Verfahren am erfolgreichsten war, mehr und mehr sich ausgebreitet und fortgesetzt. Die Offentliche Meinung ist in ihren für Deutschland normalen Zustand zurückgekehrt, Ausdruck des bürgerlichen, insonders des hochbürgerlichen, Bewußtseins (der vornehmen Bourgeoisie) zu sein, das als Attraktionszentrum und durch seine Macht über die Presse, wie durch andere materielle Kräfte, für weite Kreise maßgebend ist. Es kommt hinzu, daß für die gemeine Denkungsart die Schlußfolgerung: mit der ehemaligen Regierung war ein glücklicher Zustand, mit der gegenwärtigen Regierung ist ein unglücklicher Zustand verbunden - also ist die gegenwärtige Regierung verantwortlich für die gegenwärtigen Übel - unmittelbar einleuchtend zu sein pflegt. So ist denn im allgemeinen der abnorme Zustand eingetreten, daß die Offentliche Meinung gegen die Regierung und - wenn auch mit geringerer Entschiedenheit - gegen die neueingeführte Staatsform, die sich in den schwarz-rot-goldenen Farben symbolisiert, in Empörung sich befindet und, wenn auch verhohlen, auf eine Restauration, also auf den Umsturz hinarbeitet. Gleichwohl kann sie nicht umhin, mit den aufgeworfenen Problemen sich zu beschäftigen, und kann sich der Erkenntnis nicht entziehen, $\mathrm{da} B$ diese Probleme irgendwie durch Faktoren bewirkt worden sind, die dauernder und wesentlicher sind, als die jeweiligen Regierungen. So vor allem das Problem der sozialen Frage, das alsbald in der deutschen und österreichischen Staatsveränderung mit dem Schlagwort „Sozialisierung « auf die Bühne trat. Die Offentliche Meinung verhält sich im allgemeinen skeptisch dazu, sie hält die Initiative des Unternehmers und das Streben nach Gewinn für unerläßlich zum Gedeihen der Volkswirtschaft, sie bezweifelt oder leugnet gänzlich die von Anwälten der Sozialisierung verkündete größere Produktivität solchen Arbeitssystemes; ferner wurde auf die Gefahren hingewiesen, daß vermehrtes Staatseigentum von den feindlichen Regierungen als Pfand für ihre Schadenersatzansprüche mit Beschlag belegt würde. Andererseits war und ist in die öffentliche Meinung ein gut Teil sozialistischer Denkungsart übergegangen; ein Prozeß, der sich langsam vor dem Weltkriege entwickelt hatte, nahm ein beschleunigtes Moment an; äußerlich trat es darin zutage, daß viele- 
Intellektuelle, auch Universitätsprofessoren, der bisher geächteten Partei beitraten. So hat denn auch in Deutschland die Offentliche Meinung halb mit Resignation, halb mit Zustimmung und Hoffnung in die Betrachtung sich ergeben, da $\beta$ ein neues soziales« Zeitalter angebrochen sei, daß die neuen Rechte und Ansprïche des werktätigen Volkes, dessen intellektuelle Kraft durch den Zuzug der "Angestellten "so erheblich gewonnen hat, unwiderruflich festgelegt sind, da $B$ also die Fragen der Gemeinwirtschaft, Planwirtschaft und allmählicher Umgestaltung aus der Richtung auf Gewinn in die Richtung auf Bedarfsdeckung nicht mehr mit einem grundsätzlichen und doktrinären Nein beantwortet werden können, sondern Fragen der

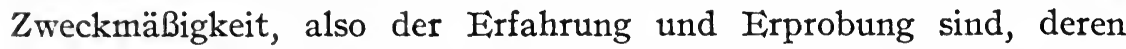
Lösung aber durch die gegenwärtigen Nöte durchaus erschwert werde, so da $B$ ihre Vertagung geboten sei. Einen starken Druck hat dabei zuungunsten des Kapitalismus und seines Handels die Erscheinung des Kriegs- und des Revolutionsgewinnlertums geübt, die abstoßenden Gestalten des neuen Reichtums und die empörenden Eirscheinungen der Gewinnsucht, denen die rasche Verarmung höher gebildeter und in ihrem Vertrauen auf die Stabilität der Volkswirtschaft, des Staats- und Hypothekenkredits traurig betrogener Schichten gegenübersteht. Hingegen haben wieder zugunsten des Kapitalismus und freien Handels die Erfahrungen der Kriegszwangswirtschaft, die dadurch anscheinend begünstigten Erscheinungen des Schleichhandels und das Versagen des Anreizes auf die Produktionsfähigkeiten insbesondere der landwirtschaftlichen Betriebe gewirkt; mehr als alles andere jedoch das Gespenst des "Bolschewismus", der in Rußland seit dem Herbst I9I7 mit schonungsloser Gewalt durchgeführten "Diktatur des Proletariats «, deren volkswirtschaftliche Leistungen in Deutschland nicht durch den Namen des Kommunismus, den die Anhänger der »dritten Internationale sich beilegten, an öffentlicher Gunst gewannen; denn mit dem Worte ist von lange her die Vorstellung einer besinnungslos utopistischen Schwärmerei unlöslich verbunden, wenn nicht die noch roheren der Aufteilung, der Weibergemeinschaft $u$. dgl. Jedenfalls werden die Erlebnisse dieses Kommunismus im ehemaligen Zarenreiche mit Begierde und Spannung verfolgt, soweit es die dünn gesäten Berichte zulassen. Und mit Genugtuung erfährt man, daß der Kapitalismus und die freie Unternehmung wieder zurückgerufen werden, um den unerträglich gewordenen Zuständen, dem fortschreitenden Rückgange der Industrie abzuhelfen; mit Schaudern hört man die Schilderungen der Leiden, denen sogar deutsche Anhänger des Systems, die in ihrer Torheit sich verlocken ließen, das kommunistische Paradies zu erproben, ausgesetzt 
waren. Die Offentliche Meinung ist ebenso einig über die Unmöglichkeit des Sozialismus nach russischem Muster, wie über die ungeheuren Gefahren, die der europäischen, also auch der deutschen Gesittung durch seine Ausbreitung, ja schon durch die Propaganda der Weltrevolution "drohen. Immer von neuem glaubt man, auf Grund oberflächlicher Nachrichten, den Zusammenbruch der Sowjetregierung erwarten $z \mathfrak{u}$ sollen; ohne $\mathrm{da} B$ in der Regel die Frage aufgeworfen wird, ob denn ein anderes Regiment wirklich dem deutschen Interesse günstiger sein werde oder nicht etwa viel ungünstiger? Die Offentliche Meinung steht in dieser Hinsicht, wie in so mancher, ohne sich dessen bewußt zu werden, oft unter dem Einfluß der Interessen des Handels, die sich selber regelmäßig mit den Interessen der Volkswirtschaft identifizieren, obgleich sie nur zu einem Teil damit zusammenfallen, und ohne daB andere, geistigere und moralisch wichtigere Interessen dagegen abgewogen werden. Im ganzen ist sie eines wohlerwogenen Urteils über große politische und ethische Lebensfragen nur in mangelhafter Weise fähig, und zumeist nur, indem sie der Autorität großer Führer sich fügt, die in neuerer Zeit verhängnisvoll selten geworden ist. Indessen beharrt die Offentliche Meinung in ihrer gerade für den deutschen Geist schon hergebrachten und der Überlieferung gemä $\beta$ hohen Schätzung der Volksbildung und Volkserziehung, - und sie verkennt nicht, da $B$ den Bestrebungen dafür durch die soziale und politische Hebung des Proletariats eine freiere Bahn gebrochen wurde. In diesem Sinne ist die Teilnahme am "Volkshochschulwesen " gerade nach der Staatsveränderung allgemeiner geworden und in einigem Maße sogar vertieft worden; während man freilich eingestehen muß, daß mit diesen Mitteln, so wenig wie sonst durch verbesserte Bildung des Verstandes, der offenbaren Entsittlichung des Volkes bisher keineswegs gewehrt worden ist. Allgemeiner erhebt sich der Gedanke, daß mit der modernen Kultur die gesamte Weltanschauung in eine schwere Krisis eingetreten ist. Charakteristisch dafür ist der von vielen Seiten laut werdende Ruf nach erneuter "Gemeinschaft " und die Tatsache, daß der begriffliche Gegensatz „Gemeinschaft und Gesellschaft "fast plötzlich in das allgemeine Bewußtsein überzugehen begonnen hat. So ist die Offentliche Meinung auch genötigt, mit der religiösen Krisis sich zu beschäftigen, die seit Jahrhunderten angewachsen, in einer so kritischen Zeit wie ein gähnender Abgrund zutage tritt. So sehr die Offentliche Meinung der Geister- und Gespensterseherei, der Bildung mystagogischer Sekten und Konventikel ablehnend gegenübersteht, sie kann der in allen sozialen Schichten zutage tretenden Neigung, auf solchen Abwegen Trost, Beruhigung, Zerstreuung zu suchen, nur 
mühsam wehren. Darin wie in einer wütenden Vergnïgungssucht und Verschwendung offenbart sich nicht minder die vorherrschende Verzweiflung, wie die Gedankenlosigkeit und Verwilderung der Gemüter.

I2. (In Frankreich.) Wie zuvor bedeutet wurde, und wie mannigfach bezeugt ist, werden die gleichen Erscheinungen auch in den anderen Ländern Europas, die durch den Weltkrieg hindurchgegangen sind, beobachtet. Auch in den siegreichen, die zwischen Triumph und Trauer hin- und hergeworfen werden. In Frankreich überwiegt das Triumphgefühl und mit ihm die fortdauernde Besorgnis, da $B$ der zu Boden geschlagene Gegner, dessen Überlegenheit auch der "Sieg « nicht verkennen ließ, von neuem sich erheben werde, und die Entschlossenheit, mit allen Gewaltmitteln ihn daran zu verhindern. Mit dieser Furcht und dem sie begleitenden unerbittlichen $\mathrm{HaB}$ verbindet sich, wie sonst bei dem Gallier, der nüchterne geschäftliche Sinn, der in dem Satze "Le Boche paiera tout" seine sprechende Formel fand. Die Fähigkeit des Boche, alles zu bezahlen, was der Franzmann verlangen würde, stand zunächst für das doktrinäre und rasch urteilende Bewußtsein dieser Nation fest. Neuerdings sind freilich recht ernste $Z$ weifel daran aufgekommen. „Die gesamte öffentliche Meinung, die Handels- und Industriewelt, selbst die Berufspolitiker, beschäftigen sich seit Wochen mit der eventuellen Zahlungsunfähigkeit Deutschlands. Den AnstoB dazu gaben ohne Zweifel die Alarmartikel des englischen Professors Keynes, der früher als Deutschenfreund verhaßt und verachtet war, dann aber durch das Eintreffen seiner bisherigen Prophezeiungen in den Mittelpunkt des öffentlichen Interesses trat. Sein Name ist heute in aller Munde, Freund wie Feind nimmt Stellung, seine Ideen und Beweisführungen werden leidenschaftlich diskutiert, vielfach angegriffen, nie widerlegt, von der überwiegenden Mehrzahl gutgeheißen." So schreibt ein Pariser Vertreter des Hamburgischen Correspondenten am 22. September I92I. Wahrscheinlich schreibt er der Pariser Offentlichen Meinung, die in Frankreich immer den Ton angibt und das Konzert sicherer beherrscht als diejenige irgendeiner anderen Hauptstadt irgendeines anderen Landes, mehr Vernünftigkeit und Besonnenheit $\mathrm{zu}$, als sie besitzt, wenn auch in den Zeitungen einmal eine Laune und die nie schlummernde Furcht zum Ausdruck gelangt. Die Franzosen sind bekanntlich - zu einem guten Teil - ausgezeichnete Mathematiker und Mechaniker; der Mechanismus ist auch im geistigen Wesen, im moralischen, im politischen, ihr Idol. Aber sie sind zugleich so sehr Phantasten, so ganz von Einbildungen beseelt, wenn eine herrschende Leidenschaft sie erfüllt, daß sie gerade in diesen 
Gebieten, wo die genaue Berechenbarkeit nicht möglich ist, unverwandt und unbekehrbar an das Perpetuum mobile glauben und für dessen Verwirklichung ihren Geist und Willen vergeuden. „Der wesentliche Zug unseres Geistes in diesem Gebiete" (dem des sozialen Lebens), sagt in Selbsterkenntnis ALFRED FouILLÉE (Psychologie $d u$ peuple trançais, Paris I898, S. 204), ,das ist der Glaube an die Allmacht des Staates und der Regierung...“ „Mit Unrecht personifizieren wir allzu voreilig die Gesellschaft in einem einzigen Menschen oder in einer Gruppe von Menschen, die uns regiert. Infolge dessen wird unser durchaus berechtigter Glaube an die soziale Kraft ein durchaus unberechtigter Glaube an einen künstlichen Mechanismus. Anstatt des politischen Sinnes wie oft haben wir nichts als den Fanatismus der Politik.“ „Wir glauben, daß es genügt, Prinzipien zu verkünden, um die Folgerungen daraus $z \mathfrak{u}$ verwirklichen, genügt, die Verfassung mit einem Zauberschlage zu verändern, um auch Sitten und Gesetze zu verwandeln, Dekrete zu improvisieren, um den Gang der Zeit zu beschleunigen ...“ „Unsere Vernunft, die vernünftelt bis zur Unvernunft, begreift schlecht die dunklen und tiefen Notwendigkeiten der Natur und des Lebens“... , wir ahnen nicht die Macht der Zeit und denken ausschließlich an die Kraft des menschlichen Willens, und nicht einmal des ausdauernden Willens, sondern des impulsiven, ungeduldigen Willens, der da ausruft: "Alles oder nichts." $\mathrm{Zu}$ gleicher Zeit führen wir das Gefühl (le sentiment) in die Politik - wo es übrigens als eine sehr wirkliche Kraft allerdings seine Rolle spielt, die um so größer wird, in dem Maße, als die Offentliche Meinung mehr und mehr die Welt regiert." Und gerade, daß die Offentliche Meinung ihrem Wesen nach Vernunft ist, $\mathrm{da} B$ sie räsonniert und räsonniert, und doch so ganz und gar im Banne der heftigsten Leidenschaft eingeschlossen ist, ist zugleich für sie und für den französischen Geist bezeichnend, der zuerst der Offentlichen Meinung die Bahn eröffnet hat, die Bahn einer über ihr eigenes Wesen völlig unklaren, aus Freiheitsenthusiasmus in Despotismus, aus Despotismus in Restauration, aus Restauration in neue Umwälzungen sich stürzenden Revolution, die schließlich in einer ausgesprochenen Herrschaft der hohen Finanz und in einer Verschwörung auf Tod und Leben mit - dem Zarismus als dem Hüter der europäischen Zivilisation ihre vorläufige Endschaft gefunden hat.

13. (In England.) Auch Großbritannien, der eigentliche Gewinner, soweit in Europa von einem Gewinner die Rede sein kann, wird seines Triumphes und der Vernichtung des Deutschen Reiches, nach der es so lange sich gesehnt hat, um derenwillen es gleichfalls dem Zarismus die Bruderhand reichte, nicht froh. Es erkennt, daß der 
deutsche Geist, der deutsche Fleiß, auch ihm unentbehrlich ist, und es wei $B$, da $B$ zum Gedeihen von Geist und Flei $B$ Freiheit gehört, da $B$ Sklavenarbeit zumal für moderne Betriebe keineswegs ein geeignetes System darstellt. Ein englischer Brief schilderte die Lage der Dinge im Sommer I9I9, als die Triumphstimmung noch auf der Höhe war, dahin, daß die wirklichen Gedanken der Denkenden nicht bei den Siegesfeiern, sondern bei dem iublen Zustande der Finanzen, bei der Zügellosigkeit von Kriegsgewinnlern und bei der um sich greifenden Arbeitlosigkeit verweilten. Seitdem ist diese immer schlimmer in die Erscheinung getreten, Riesenausstände ließen eine tiefe Unzufriedenheit der Bergleute, der Transportarbeiter, und anderer großer Massen des werktätigen Volkes erkennen, das Irlandproblem hat immer furchtbarere Gestalt angenommen, Irland ohne Ulster kann es wagen, seine Anerkennung als eines souveränen Staates zu verlangen. Die Fortsetzung der Hungerblokade über den Waffenstillstand und die erklärte Ohnmacht der Mittelmächte hinaus ist in weiten Kreisen auch von denen als unmenschlich und schandbar empfunden worden, die sonst mit der Aushungerung von "Hunnen einverstanden waren; die kostspielige und vergebliche Unterstïtzung der russischen Gegenrevolution erschien auch denen als eine Torheit, die von Antipathie und Furcht vor dem Bolschewismus erfüllt waren; so wenig wie der Ausgang des Weltkrieges sonst, konnte sie Ehre und Ansehen der Nation heben oder retten. Ahnlich wirkt als ein Mene mene tekel upharsin der lange fortdauernde Krieg in Mesopotamien, der Sieg der schon nicht mehr in die politische Rechnung einbezogenen Türken über die ententefrommen Griechen, endlich für die englische Weltmacht insonders bedrohlich der glimmende Aufstand in Indien, dessèn Feuer früher oder später in helle Flammen ausschlagen muß. Noch tröstet sich England mit seinem unerschütterlichen guten Gewissen, es gibt keine Nation, die so sehr das Talent des guten Gewissens hätte. Aber dies Gewissen, das durch grobe Täuschungen ernährt wurde, kann auf die Dauer seine Ruhe sich nicht erhalten. Es ist zu viel gesunder Menschenverstand und zu viel Humanität im englischen Geiste, wenn auch beide zurückgedrängt wurden, als da $B$ nicht allgemach das ungeheure Unrecht, das seine verzerrten Gestalten dem deutschen (und deutsch-österreichischen) Volke angetan haben, zur Erkenntnis und zur Geltung kommen sollte. Mächtig erhebt sich eine mehr und mehr von den Trägern wissenschaftlicher Bildung gestützte "Partei der Arbeit", so daß schon im größten Ernste deren Fähigkeit, zur Regierung zu gelangen, erörtert wird: es wäre die erste in echterem Sinne demokratische Regierung Großbritanniens. Ihre intelligenteste Gruppe, die Independent 
Labour Party, hat vom Anbeginn klar gesehen, ,wie der Krieg kam“: in einer kleinen Flugschrift, die diese Frage behandelt, findet man den schlechthin wahren Satz: „Niemand, der sämtliche Urkunden durchforscht, kann einen Augenblick zweifeln, daß Rußland vom ersten Tage an auf Krieg lossteuerte" (The Nerw Statesman, 27. Februar I9I5). Diesen Satz wird die Offentliche Meinung Englands anerkennen und sich zu eigen machen müssen, um zur Gerechtigkeit und Wahrhaftigkeit, die sie wertzuschätzen immer in Anspruch genommen hat, zurückzukehren.

I4. (In den übrigen Ländern.) Von der Offentlichen Meinung nach dem Weltkriege in den übrigen Ländern wagen wir nur wenig zu sagen, außer, daß viele Zeichen darauf deuten, ihre Entwicklung nehme einen ähnlichen Lauf wie in England. Die "Welt « hängt bekanntlich heute zu eng zusammen, als daß nicht Unglïck, Unzufriedenheit, Unbehagen iiberallhin sich ausbreiten sollte. Offenbar haben die Gewaltfriedensschlïsse, das erpreßte unwahre Schuldbekenntnis, bei den Denkenden aller Länder Entrüstung hervorgerufen. Der Torso des Völkerbundes ist zum Gespött geworden; die ehrlichen Freunde des Weltfriedens erwarten mehr Schaden als Nutzen für ihre Sache von ihm. Sogar die Vereinigten Staaten Amerikas, die außerhalb dieses Gebildes stehend, dennoch des politischen Ubergewichts sich bewußt sind, das der durch ihre Teilnahme entschiedene Weltkrieg ihnen gegeben hat, werden angesichts der Zerrïttung Europas, auf dessen wirtschaftliche und geistige Leistungen sie einstweilen noch angewiesen sind, dieser ihrer Machtstellung nicht froh. Mit den besonnenen und einsichtigen Politikern aller Länder müssen auch die ihren eine gründliche Revision jener Verträge wünschen und erstreben, die, von aller politischen Einsicht verlassen, lediglich dem wahnsinnigen Rachedurst derer, die als Besiegte zu Siegern wurden, ihre Entstehung verdanken. Gesetzt, es sei wahr, daß »die Offentliche Meinung der Welt" diesen Ausgang als einen gerechten Ausgang gewünscht hat - die Offentliche Meinung der Welt hegt über seine Folgen keine $Z$ weifel mehr. Diese Folgen wären auch bei einem entgegengesetzten Ende nicht wesentlich verschieden gewesen - zugegeben; aber diese Vermutung bietet so wenig eine Entlastung dar, wie etwa die Richter des Kapitäns DREYFus dadurch entlastet werden, $\mathrm{da} ß$ man annehmen mag, radikal gesinnte und freimaurerische französische Richter hätten unter gleichen Umständen einen royalistischen Hauptmann ebenso parteiisch und ungerecht beurteilt. - Von einer russischen öffentlichen Meinung kann heute weniger als je die Rede sein. Ihre intellektuellen Träger sind getötet oder verjagt oder mundtot gemacht; nicht nur die andersdenkende Tagespresse, sondern 
jede öffentliche Kundgebung von Gesinnungen und Meinungen wird schonungsloser als von den grausamsten zaristischen Regierungen unterdrückt; alles Geistige ist zerrissen und zersplittert, das Exil in Paris und in Berlin verhält sich stumpf und als ohnmächtiger $\mathrm{Zu}$ schauer zu dem Gange der Dinge in dem weiten Lande, dessen fernerer Verlauf aber sicherlich eine unabsehbare Weltbedeutung haben wird. Unter den übrigen Nationen Europas, zumal denen germanischer Abstammung, aber auch unter den denkenden Gliedern der italienischen, der spanischen Nation, ja auch Czecho-Slovakiens, um von Irland, Finland u. a. zu schweigen, wird die Offentliche Meinung mehr und mehr zu der Erkenntnis sich durchringen, daß die Rettung deutschen Geistes, deutscher Wissenschaft und Kunst ihre eigene Rettung ist, da $B$ daher das Verderben der deutschen Volkswirtschaft und des deutschen Staatswesens sie in einen Abgrund hinabstürzen würde, der tiefer und hoffnungsloser wäre als der Abgrund, in den ehemals die Kulturen Griechenlands, Vorderasiens, Nordafrikas und Italiens versunken sind.

\section{Kapite1.}

\section{Die Zukunft der Öffentlichen Meinung.}

I. (Verhältnis zur Religion.) Die Zukunft der Offentlichen Meinung ist die Zukunft der Kultur. Es unterliegt keinem Zweifel, daß die Macht der Offentlichen Meinung fortwährend zunimmt und ferner zunehmen wird. Ebenso ist es gewiß, daß sie immer mehr von unten her beeinflußt, verändert, zuweilen aufgewuihlt wird. Es leuchtet ein, welche Möglichkeiten diese Entwicklung in sich trägt: manche wird man gutheißen, manche wird der voraussehend Urteilende übel nennen, wie schon jetzt das Urteil des Historikers und Ethikers über Heil und Unheil, das aus den Wirkungen der Offentlichen Meinung erwächst, nach beiden Seiten schwankt. Wenn man den Gang der menschlichen Gesittung ins Auge faßt, im Sinne einer Veredlung des Menschen, von der einige Spuren im Laufe der uns bekannten Geschichte erkennbar sind, so wird diese in den zukünftigen Jahrhunderten wesentlich bedingt sein durch den Grad der Festigkeit, den die Offentliche Meinung in bezug auf sittliche Fragen gewinnen wird, und durch den Inhalt ihres Bewußtseins über solche Probleme.

Wenn auch in ihren wirklichen Eischeinungen die Offentliche Meinung vielfach mit religiösen Beweggründen vermischt auftritt, so steht doch im ganzen ihre Ausbildung und Macht im umgekehrten 
Verhältnis zur Bedeutung der Religion im öffentlichen Leben. Die christliche Religion hat in den neueren Jahrhunderten verloren, was die Offentliche Meinung gewonnen hat. Dort Abnahme, hier Zunahme der Kraft und des Einflusses. Mehr Gegensatz der Offentlichen Meinung gegen die ältere, festere und stärkere Gestaltung des Christentums, die der römischen Kirche, als gegen die jüngere, losere und schwächere des Protestantismus, mit der sie vielfach, zumal in England und in den Vereinigten Staaten, engere Fühlung behält, insonderheit mit deren dissidentischen, spezifisch bürgerlichen Elementen. Der Verfall der christlichen Religionsformen jeder Art wird, ungeachtet vieler edler Kräfte, die sich ihrer Erhaltung widmen, fortschreiten, die Selbstzersetzung des Christentums ist im Werke und kann in ihrem gesetzmäßigen Fortschreiten nicht dauernd gehemmt werden. Wird also Irreligiosität und mit ihr völliger Verfall der Sitten eintreten?

Die Sittlichkeit steht zur Religiosität in vielen engen und starken Beziehungen, sie ist nicht wesentlich durch Religiosität, noch weniger durch eine bestimmte Art der Religion oder gar durch ein Bekenntnis, einen dogmatischen Glauben bedingt. Die Offentliche Meinung ist aber - nicht nur in England und den Vereinigten Staaten - für Religiosität: sie versteht darunter den sittlichen Ernst und die Beziehung der Güter des Lebens auf Ewigkeitswerte. Sie nennt eine solche Gesinnung auch Idealismus und stellt sich in scharfen Gegensatz zum "Materialismus«, dessen Deutung in theoretischem oder praktischem Sinne unklar schwebend gelassen wird, wenn nur seine Verwerflichkeit und Falschheit feststeht. Darum ist auch die Offentliche Meinung - insbesondere in Deutschland - einem freisinnig verstandenen Christentum als der historischen Form eines sittlichen Idealismus, der Nächstenliebe, Sanftmut, Aufopferung fordere, bisher günstig gewesen, ja geneigt, in ihm die vollendete Gestalt der Religiosität anzuerkennen. Aber der Wert und die Bedeutung, die irgendwelchem Glauben beigelegt werden, nehmen sichtlich $a b$, und die Ideenassoziation Christentum-Ethik ist im Laufe der letzten Jahrzehnte - wenn Beobachtung und Lebenserfahrung nicht trügen lockerer geworden. In dieser Hinsicht hat das Verhalten der christlichen Nationen zu einander, insbesondere die christliche Liebe, womit das protestantische England und das protestantische Amerika das gleichfalls überwiegend protestantische Deutschland behandelt haben, tief erschütternd gewirkt; außer dem Weltkriege selbst, da der Krieg als solcher dem Christen eine vertraute Erscheinung ist. Immerhin hat sein Wüten dem Ansehen des Christentums unermeBlich Eintrag getan: viele gute und gläubige Christen verteidigen einen gerechten 
Verteidigungskrieg, aber kaum wird einer wagen, das Verhalten guter Christen, z. B. anglikanischer Geistlicher zum Baralong-Morde oder einiger deutscher Pastoren $\mathrm{zu}$ den beklagenswerten Methoden, die deutscherseits nur als völkerrechtliche Repressalien gegen die Hungerblokade gerechtfertigt waren, und ähnliche Erfahrungen als Christentum in Anspruch zu nehmen. Wenn aber der Heroismus, die Aufopferung und Entsagung der Männer und Frauen, die im Kriege sich betätigt haben, gepriesen werden, so kann doch weder eine Nation noch eine Religion solche Leistungen und Eigenschaften wesentlich für sich allein in Anspruch nehmen. Das Lob gebührt dem Menschentum, nicht dem Christentum.

Der Rückzug auf die christliche Moral ist nur eine Verschleierung des Standpunktes, auf den die Offentliche Meinung unter dem Einfluß der Aufklärung, und vollends unter denen der verbundenen naturwissenschaftlichen und historischen Erkenntnisse des I9. Jahrhunderts, sich gestellt hat; er kommt einer Preisgebung des christlichen Glaubens gleich. Das ist ein tragisches Ereignis im Völkerleben, für das der christliche Glaube nicht nur als Weg zum ewigen Heil, sondern auch als Anerkennung metaphysischer Wahrheiten gegolten hat, denen gegenüber alle Vernunft und Wissenschaft zu wesenlosen Schatten verbleichen - sollten. Aufgehalten und verzögert ist dieser soziologische Prozeß hauptsächlich durch die Konventionalität der guten Gesellschaft, die durch die französischen Revolutionen und ihre Folgen in Angste geraten war, und deren höhere Schichten insbesondere in den Burgen der Kirche Schutz suchten; gehemmt aber wurde er auch durch die monarchische Staatsform und die Regierungen, die ihr dienten. Diese Hemmung ist jetzt in Deutschland, in Osterreich, in Rußland und in den neuen Nationalstaaten weggefallen, wie früher in Frankreich, in Portugal; die Religiosität, auch das Christentum, kann in republikanischen Staaten so gut wie in monarchischen gedeihen, die Kirchen können ihre Positionen behaupten, aber die bewußte Förderung sei es des Scheines oder der Wirklichkeit religiöser Vorstellungen und religiöser Zeremonien durch die höchste oder allerhöchste Stelle ist weggefallen. Auch jene Konventionalität wird dadurch aufgelockert; mehr aber leidet sie durch die zunehmende soziale Bedeutung der Schichten, die an ihr keinen 'Teil haben und nicht gewillt sind, sich dadurch beengen zu lassen; die zwar geringere Einsicht in die Zusammenhänge der Dinge, schwächeres Wissen besitzen, die aber ein stärkeres Bedürfnis nach Aufrichtigkeit und Wahrhaftigkeit in Lebensfragen empfinden, die auch von ihnen als heilige anerkannt werden. Immer mehr nehmen Elemente solcher Herkunft an Gestaltung der Offentlichen Meinung teil. Je mehr diese 
Teilnahme wirksam wird, um so weniger wird die Offentliche Meinung in dieser Hinsicht durch politische Rücksichten irgendwelcher Art gebunden sein. „Ohne das Band zu kennen, kann man es nicht lösen"1). Nun aber lernt das Volk selber das Band kennen.

2. (Mögliche Entwicklungen.) Mehrere Entwicklungen sind möglich. Vielleicht ist eine revolutionäre auch in diesem Gebiete am meisten wahrscheinlich. Sie hat schon einmal stattgefunden, als fanatisierte evangelische Horden die Bilder stürmten und die herrlichen Glasfenster gotischer Kirchen zertrümmerten. Die grandiose Einheit der römisch-katholischen Kirche hätte sich durch Reformen und Kompromisse erhalten lassen; es wäre insbesondere für die politische Entwicklung Deutschlands unendlich heilsamer gewesen. Daß es nicht geschah, hatte tiefe innere Ursachen. Solche werden auch die künftige Entwicklung als notwendige bestimmen. Die endliche Krisis des Christentums wird tiefer sein, als die Krisis der Kirche im I6. Jahrhundert war. Sie wird die Welt stärker erschüttern.

Denkbar ist auch eine andere Entwicklung. Die Verallgemeinerung des freigeistigen Bewußtseins, seine Erhebung in der öffentlichen Meinung, die Vertiefung seiner Lehren durch die Beziehung auf die Ewigkeit und Unendlichkeit des Seins, auf die Unerforschlichkeit des Wesens der Dinge, kann die Offentliche Meinung selber zur Religiosität werden lassen. Sie kann aus sich heraus die Religion des Heiligen Geistes gestalten: die universale Menschheitsreligion als die Erfüllung und Vollkommenheit aller bisherigen Weltreligionen, die schon Priester des I3. Jahrhunderts ahnungsvoll kommen sahen. Ein großer Sieg und Triumph des Christentums wäre es, wenn es diese seine Aufhebung und Vollendung aus sich heraus zu gestalten vermöchte; eine Selbsterkenntnis und Selbstüberwindung der Offentlichen Meinung, wenn sie in diesem Sinne das Christentum in sich aufzunehmen und sich seiner anzunehmen vermöchte, nicht mehr es zu glauben und zu bekennen, sondern es auszugestalten in seiner reinsten und echtesten Absicht, der Absicht einer Veredlung des Menschentums.

Es ist fast schon ein feststehendes Urteil der Offentlichen Meinung geworden, daß eine Beherrschung der Volkswirtschaft, eine entschiedene Gegenwirkung gegen die Herrschaft des Kapitals in ihr, $\mathrm{da} B$ also die Erhebung der Arbeit - zunächst wenigstens zum mitbestimmenden Faktor - Voraussetzung dieser Verbesserung des Volksgeistes ist: die soziale Reform. Die Offentliche Meinung wagt noch nicht, den "Sozialismus« $z u$ bejahen, aber sie wagt auch nicht mehr, ihn zu verneinen. Sie scheut zurück vor dem Wort, dessen Sinn mit

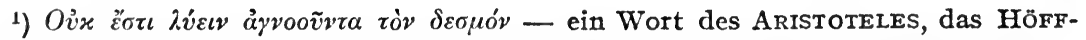
DING dem ersten Kapitel seiner Religionsphilosophie als Motto vorgesetzt hat. 
Zwang, Bureaukratie, Schematismus allzu eng verschmolzen ist, noch mehr vor dem Wort "Kommunismus «, das neterdings durch wilde Bewegungen in Gebrauch und in Verruf gekommen ist; das Wort, dem sie - wenigstens im Deutschen - den Vorzug gibt, ist schon genannt worden, das Wort "Gemeinschaft «. Die Volksgemeinschaft ist im Weltkriege, sowohl durch das, was sie leistete, als durch ihr Mangeln, zum Gegenstande eines Bewußtseins geworden, das sie zugleich als Wirklichkeit und als moralische Notwendigkeit erkennt. Und es wird erkannt, daß sie ihren Kern nicht in irgendwelchen Vorstellungen, Theorien und Lehren, sondern in Tatsachen hat, vor allem in der Gesundheit des Familienlebens, des Herdes der echten Sittlichkeit, den das beste öffentliche Erziehungswesen wohl umhegen und verbessern, aber nicht ersetzen kann. Je mehr die Offentliche Meinung sich auf diesen Gedanken versammelt, um so mehr wird sie die mannigfachsten Kräfte, die verschiedenen Weltanschauungen und Parteien zu einem Ziele vereinigen können; wie denn schon jetzt in der Richtung auf maßvoll durchführbare Reformen des Arbeiterrechtes, auf Bodenreform, Wohnungsreform, auf Bekämpfung des Alkoholismus, der Geschlechtskrankheiten und der Tuberkulose, im Sinne der sozialen Hygiene überhaupt, zu der auch die Hygiene der Ehe und der Fortpflanzung gehört, wie im Genossenschaftswesen, das den Kapitalismus von innen heraus heilen will, wahre Menschen- und Volksfreunde längst einander die Hände reichen, ohne nach den Bescheinigungen ihres richtigen und übereinstimmenden Glaubensbekenntnisses zu fragen. Da ist der Heilige Geist des Wahren, Schönen und Guten mitten unter ihnen, der Parakletos, der berufen ist, alle zu stärken und zu fördern. Zu ihm können auch diejenigen sich bekennen, denen ein anderer Glaubensinhalt noch wichtiger ist und erscheint, aber er wird eines Tages »die "Religion derer sein, die nur eine organisch vertiefte Vernunft, welche sich als Gewissen ihre Normen gibt, zum Lenken ihres Denkens und Wollens zu machen entschlossen sind; die Offentliche Meinung wird das soziale Gewissen, wie Religion es immer gewesen ist: sie wird selber die endliche Religion, in dem Maße, wie sie sich mit ethischem Inhalt erfüllt und diesen zu läutern sich angelegen sein läßt.

So ist die Zukunft der Offentlichen Meinung und also die Zukunft der Kultur von der Zukunft der Wissenschaft abhängig. Sofern der wissenschaftliche Geist von der Flamme der Wahrhaftigkeit durchleuchtet und erwärmt wird, trachtet er auch nach dem Schönen und Guten, nach der Einheit des Schönen und Guten. Zum Schönen und Guten gehört in erster Linie die Pietät - der Sinn der Ehrfurcht vor allem Edlen, das gewesen ist, das gesucht wurde, das verloren ging; 
ein großer Gewinn für die Veredlung des Menschentums wäre es, wenn die Offentliche Meinung gelehrt werden könnte, die Pietät und Ehrfurcht zu pflegen, wie auch GoETHE als eine Aufgabe, die mit Erziehung des Menschengeschlechts aufgegeben ist, erkannt und verkündet hat.

Die Wissenschaft wird ferner wie bisher zur Zersetzung und Zerstörung dienen. Der Geist der Wahrheit trägt in seinem Arme nicht die Friedenspalme, sondern das Schwert. Aber er führt auch den Pflug, er hat schon vielen Boden urbar gemacht, und je mehr seine Geltung anerkannt wird, um so mehr wird er zu bauen vermögen. Und was gut gebaut wird, das dauert; so wird neues Leben aus den Ruinen erbliihen.

3. (Die Reform der Presse.) Nicht nach unseren Wünschen und Hoffnungen richtet sich die Zukunft, wohl aber, wenn auch in engbegrenzter Weise, nach unserem Tun und Wirken, das zum Teil unseren Wünschen und Hoffnungen folgt. Wir können alle mitwirken an Gestaltung der Zukunft, wir - Männer und Frauen des gelehrten Standes - sind sonderlich berufen, mitzuwirken an der Zukunftsgestaltung der Offentlichen Meinung.

$\mathrm{Da}$ die Offentliche Meinung eine Form des geistigen Lebens einer Nation - wir denken hier zunächst an unsere eigene, an die de utsche Nation - so wirken auf sie alle Elemente dieses geistigen Lebens, unter denen wir die Wissenschaft voranstellen, weil ihr die Offentliche Meinung am nächsten steht. Auch alle echte $\mathrm{Kunst}$, die den Geschmack bildet, das Gemüt erhebt und läutert, darum besonders die schöne Literatur, sofern sie wahrhaft schön und edel ist, kann zur Erziehung der Offentlichen Meinung beitragen. Fast alle Elemente werden heute vermittelt durch periodische Druckschriften mit dem Wesen der Tagespresse ist die Vorstellung, die wir von der Offentlichen Meinung haben, so eng verknüpft, daß Reform und Zukunft der Offentlichen Meinung unabtrennbar scheint von Reform und Zukunft der Zeitungen. Im früheren Texte dieses Werkes ist auf die Anklagen hingewiesen worden, die gegen die Presse neuerdings und seit langer Zeit laut geworden sind, auch ist einiger Vorschläge und Wünsche Erwähnung geschehen, die auf ihre Verbesserung ausgehen. Zum Schluß werde hier auf einen Gedanken aufmerksam gemacht, den die Erfahrungen des Weltkrieges in der Seele eines deutschen Amerikaners wachgerufen haben, die unter der ungeheuren Last von Unwahrheit und rohem Gebaren der englisch-amerikanischen Zeitungen dieser Jahre schwer gelitten hat. Herr Ferdinand HANSEN ruft seine amerikanischen Mitbürger auf zur Stiftung eines Fonds von Iooo Millionen Dollars, um wSicherheitsventile" im öffentlichen Leben der Vereinigten Staaten ,gegen die selbstsüchtige Macht des 
Goldes“ zu schaffen. „Eine völlig unabhängige Tageszeitung sollte in jeder Stadt gegründet und durch erfahrene, hochgebildete und gewissenhafte Männer, die besten Köpfe, die das Land hervorbringt, geleitet werden, in Verbindung mit Körperschaften pädagogischer Richtung. Sie möge den Titel führen »der Staatsbürger».“ „Alle anerkannten Parteien würden darin freien Raum haben, dem Gange der Ereignisse $z u$ folgen und sie nach ihren Grundsätzen auszudeuten. Die Stimmen des Volkes würden unmittelbaren Ausdruck finden. Die Leitartikel des "Staatsbürgers» würden so leidenschaftslos, so unparteiisch und objektiv sein, $\mathrm{da} B$ ihre Botschaften oder Meinungen bald mit vollkommenem Glauben, mit größter Achtung und mit Vertrauen empfangen würden. Die Zeitung würde ihren eigenen Kabeldienst haben, frei von den Lïgendrähten und den vergifteten internationalen Brunnen der REUTER, HAVAS, NORTHCLIFFE und der gelben finanz-imperialistischen Presse. Diese sind die gemeinsamen Feinde des Menschengeschlechts und sie müssen entlarvt und vernichtet werden, ehe ein wirklicher dauernder Friede und guter Wille in der Welt herrschen kann" (übersetzt aus der Handschrift des amerikanischen Originals). Die Zeitung soll von dem Einkommen aus Inseraten - HANSEN nennt es das Krebsgeschwür am Herzen alles Journalismus - , durch ihre hohe Auflage unabhängig sein, die ihr der Umstand, da $B$ sie die Zeitungen verschiedener Parteirichtungen überflüssig mache, sichern werde. „Nur den zuverlässigsten Firmen, nur ehrenwerten Inseraten würde Raum gegeben werden.“ „Natürlich wären die lasterhaften und gemeinschädlichen Züge des ModetorheitJournalismus mit größter Strenge ausgeschlossen, insbesondere der unsittliche Mord- und Totschlag-Sensationalismus, die schandbaren Verletzungen der Heiligkeit des Privatlebens usw." ${ }^{1}$ )

Die Grundgedanken dieser Unternehmung, die auf amerikanische Verhältnisse näher angewandt werden - haben ihren Wert auch für uns in Deutschland. $\mathrm{DaB}$ sie verwirklicht werden, glauben wir nicht. Aber sie sind wertvoll als Kritik dessen, was im Felde des Zeitungswesens wirklich ist. Am meisten Aussicht dürfte, wenigstens in Deutschland, eine Reform der Presse von innen her, durch sie selber, d. h. durch ihre ernstesten und am meisten gebildeten Repräsentanten haben. Die Notwendigkeit einer solchen Reform sollte selber als öffentliche Meinung in Fluß kommen, und sie wäre ein wirksames, vielleicht das wirksamste Mittel zur Selbsterziehung der Offentlichen Meinung.

1) Vgl. auch die jüngst erschienene Schrift „Zur Frage der PreBreform" von KARL BÜCHER. Tübingen 1922. 


\section{Namenverzeidhnis.}

Addison 365.

Adelung 9.

Adler 49r.

Aehrenthal 505.

Aeschylos 235.

Albert Prinzgemahl 429.

Albertus Magnus 235.

Anaxagoras 232.

Ansor 371.

Anton 445.

Aquinas 235.

Aristoteles 572 .

Ashley 485.

Asquith 5I2, 55 I.

Auerswald 4r8, $426 \mathrm{f}$.

Augusta v. Preußen 162, 429.

Aulard 197, 384.

A venarius 554 .

Badeau 26If.

Bagehot 318 .

Bailleu 44I.

Bailly 391.

Bamberger r6of., $469 \mathrm{f}$.

Bandmann 195.

Barth I 82 .

Bassermann 42If.

Bastiat 487 .

Bauer 62, I65, I76, I89ff., I99, 20I, 250, 252, 544.

Baumstark 427 .

Bayle 2 I 2.

Beaconsfield 55I.

Beaumarchais 192.

Bebel 465f., 49r.

Beckx I65.

Benckendorff $523,555 \mathrm{ff}$.

Bennigsen $463,469,47 \mathrm{If}$.

Berchtold 540 .

Bergsträsser $\mathrm{I} 76$.

Berlepsch 452, 476.

Bernhardi 165.

Bernstein 497 .

Bernstorff 359 .

Besant 493.

Bethmann-Hollweg, M. A. 429.
Bethmann-Hollweg, Th. 505f., 5IO, 546, 548, 55 I, $55^{8}$.

Beyens 507, 516, 526.

Beyme 4II.

Bezold 305.

Biermer $496 \mathrm{ff}$.

Bismarck 158 ff., 168,183 , 195, 255, 257, 319, 32I, $37 \mathrm{I}, 398, \quad 429 \mathrm{ff} ., \quad 442$, $463,474,476,507 \mathrm{f}$., 510, 532, 546 .

Bjelinski 192 .

Blanc 385, 396.

Blum 4I9.

Boghitschewitsch 542 .

Böhm-Bawerk 130 .

Bonnet 383 .

Bossuet I44.

Böttger 498.

Bötticher 500 .

Bourgeois 480.

Brandenburg 42I, 426, 428 .

Brandes 187.

Brant, Seb. 304.

Brassey 448.

Bratianu 542.

Brentano 275, 447 ff., 452, 502.

Briand 265.

Brienne $375,390$.

Bright 273, 368 ff., 488, 5 I 4.

Brunhuber $157,182 \mathrm{f}$., 194 .

Brüsewitz I4I, 269.

Bryce 79f., I79, 259, 270, 323 ff., $35^{8 f f ., ~} 489,503$, 5 II.

Buchanan 521 .

Bucher Io, $156,158 \mathrm{f}$., I62f., $37 \mathrm{r}$.

Bücher $148,552,555,575$.

Buckingham 363 .

Buckle 197.

Bülow $507 \mathrm{f}$.

Bulwer 157 .

Burckhardt 302.

Burrows 493.

Busch I 58 ff.
Caillaux $48 \mathrm{I}$.

Calonne 380, 390.

Calvin 283.

Cambon 522 ff., 529f., 557 .

Campbell-Bannermann 5I2.

Camphausen 426 .

Carlyle 399.

Carnot 49I.

Carol v. Rumänien 256, 542.

Carus 359.

Cauer 195.

Cavaignac 422.

Chamberlain, H. St. 5 I 8.

Chamberlain, Joe. 507f., 5 I 2.

Cicero 295.

Clemenceau 265 f., 557.

Clifford 47.

Cobden 273, 368 ff., 487 f.

Comte 2 Io.

Condillac 383 .

Conrad $45^{8}$.

Cromwell 157,363 .

Czernin 256, 542.

Damaschke 478 .

Dane $427 \mathrm{f}$.

Dante 65, 192, 235.

Dascovici 254, 530.

David 49I.

Dehn 554 f.

Delbrück $275,435,473$, $534,546 \mathrm{ff}$.

Dell $52 \mathrm{r}$.

Descartes 212.

Dibelius 366 .

Dicey $484 \mathrm{ff}$.

Diderot 212.

Dilke 277.

Disraeli 3 r9.

Doumer 480 .

Dreyfus 264f., 398, 568.

Droysen 157 .

Eck 174 .

Eckardstein 508.

Eddy 234.

Eduard VII. 5 I6. 
Eichhorn 418.

Eisenmann 419, 423.

Eltzbacher 555, 557 .

Engels 417 .

Erasmus 304 .

Escott $487 \mathrm{f}$.

Euripides ro6.

Falk I62.

Federn 530f.

Fenelon 375.

Fichte 289.

Fick 3 .

Finance 453.

Fischart 408.

Forster $3^{8} 5$ ff., 393, 4 or.

Fouillée $397,566$.

Francis 552.

Francke, Ernst 50r.

Francke, Kuno 306, 551.

Frank 130.

Frantz 152.

Franz I. 397.

Franz Joseph 43I, 540.

Friedrich 4 ro.

Friedrich II. 86, I44, I57, I95, 237.

Friedr. Chr. v. Augustenburg 147.

Friedr. Wilh. III. 4 II, 4 I 7 .

Friedr. Wilh. IV. 4 I 7, 424 f., 428.

Freytag 262.

Gagern 420.

Galilei 3 .

Gardiner $363 \mathrm{ff} ., 398$.

Garve 304, 386, 40 orf.

Garibaldi 433.

Geffcken 162.

Geiler 304.

Gentz 413.

George 357, 477 .

Georget 197.

Gerlach, H. v. 428 .

Gerlach, I. v. 43 .

Gervinus 401, 403.

Giddings VIf., 353.

Gierke 457.

Gladstone 167, 319, 373. 551.

Gneisenau 4 I5.

Goethe I48f., 214,260 , $356,401,406,410,444$, 574.

Goltz, Rob. v. d. 43 r. Tönnles, Kritik.
Goltz, Th. v. d. 4r4.

Goodnow 35r.

Goschen 521 .

Gough 266.

Granville 159.

Green $362 \mathrm{ff}$.

Grey 372, 512f., $521 \mathrm{ff} .$, 529 ff., 557.

Grillparzer 290.

Grimm 9, 13.

Gruner 433.

Guillaume $526 \mathrm{ff}$.

Gustav Adolf 143 .

Gutschmid, A. v. 429.

Hadley $354 \mathrm{f}$.

Hadrian VI. 305.

Haering $\mathrm{V}$.

Hagen 421.

Haldane 51 2, $55 \mathrm{r}$.

Hall $55 \mathrm{Iff}$.

Hammann 434.

Hänel $467 \mathrm{ff}$.

Hansemann $425 \mathrm{ff}$.

Hansen $574 \mathrm{f}$.

Hardenberg 4r3.

Hartmann 4 r 8.

Hartwig 519, 528, $53^{8}$.

Harvey 282.

Hase 175 .

Haugwitz 4 Ir.

Hauptmann 234.

Hausrath 305.

Haussonville r26f.

Hatzfeldt 508 .

Hegel 77.

Heine 86, 2 I 5.

Helfferich 359,5 r6.

Hellwald 404 .

Helvétius $295 \mathrm{f}$.

Heraklit 235.

Herkner I 72, 454, 492, $499 \mathrm{ff}$.

Hertling 546, $54^{8}$.

Herzen 532.

Hettner $55^{2}$.

Heyne 9.

Hobbes 16, 74, I04, I 57, 212, 293 f., 406.

Hoetzsch 192, 532.

Höffding 297f., 46r, 572.

Hohenlohe 509.

Hohlfeld 132.

Holberg I 43, 203.

Holland I 5 .

Holm I $43 \mathrm{f}$.

Holstein 509.
Huber 457 .

Hume 296.

Hutten 305.

Ihering 73 .

Isvolsky $518,524,528 \mathrm{ff}$., 533,556 .

Jagow 507, 509f., 534, 54 r.

Jakob I. 362,364 .

Jakob II. III.

Janssen 304, 444.

Jaurés $480,482,524,555$. 564 .

Jenks 184 .

Jordan 132, 420.

Joseph II. I44.

Kämmel 305.

Kant $13,237,258,289$.

Karl I. 362, 365 .

Karl II. 364 .

Karl X. I40.

Kardorff 275 .

Katkov 532.

Kern 68f.

Keynes 565 .

Klein 197, 445.

Kleist-Retzow 467, 469.

Klopstock $40 \mathrm{Or}$.

Kopernikus 282.

Körner 195.

Kotzebue $4^{16} 6$.

Krüger 507 .

Kühlwetter 427 .

Kulemann 448 .

Kulenkampff 195 .

Kurella I 7 I.

Lactantius I2.

Lafayette $38 \mathrm{r}, 39 \mathrm{r}$.

Lalli 39r.

Lalaing $513,516$.

Lamartine 422.

La Marck $384 \mathrm{f}$.

Lansdowne 5 I 2 .

La Rochefoucauld 294.

Lassalle 182 .

Lebon 397.

Leiky 282,367 .

Leibniz 8, 212.

Leo 164,425 .

Lessing $40 \mathrm{r}$.

Lessius 62

Lichnowsky $522 \mathrm{f}$.

Liepmann 429. 
Lloyd George 5r3f., 525f., Murray Io. 547.

Locke 21 2, 293, 365, 383, 406.

Löbl 132, 136f., I57.

Löher 428 .

Löwe 420.

Lombard 4 Ir.

Lonsdale 367 .

Loreburn 525 .

Lorenz 302, 304.

Irouis Ferdinand $4 \mathrm{Ir}$.

Louis Napoléon 433.

Iouis Philippe I40, 397, 436 .

Low 170.

Ludendorff $546 \mathrm{ff}$.

Ludwig XIV. 374 ff., 385 , 390 f., 397.

Ludwig XV. 375 .

Ludwig XVI. 375, 389, 392, 394.

Ludwig XVIII. 397.

Lukas 176 .

Luise v. Preußen $4 \mathrm{Ir}$.

Luther I 4, 304f., $402 \mathrm{ff} ., 444$.

Macchiavelli I42f., 254, 554.

Maier I97, 255, 54 If.

Maistre 65.

Malesherbes 392.

Mandeville 294.

Manteuffel $426 \mathrm{f}$.

Marie Antoinette 385,390 .

Marschall 434.

Marx V, 64, 308, 36r, 444.

Mataja 453.

Maupeou 392.

Maurepas 389.

Melanchthon 283 .

Michaelis 546,548 .

Mill 443.

Mittelstaedt I95.

Mirabeau $379 \mathrm{ff}$.

Mohl 4 I8.

Möhler I 76 .

Molitor I $75 \mathrm{f}$.

Mommsen 473.

Monmarin $38 \mathrm{r}$.

Montesqieu 212, 393, 406.

Morley 370,487 .

Müller I 62 .

Mïusterberg $35 \mathrm{Iff}$, $454 \mathrm{f}$., $495 \mathrm{f}$.

Murawieff 559 .

Murner 303.
Myer $489 f$.

Napoléon I. I I7, I39, I53, I58, I64, I83, 237, 367, $391,393,397,406,412$, $4 \mathrm{I}_{4} \mathrm{f}$.

Napoleon III. 374, $397 \mathrm{ff}$., 527.

Naumann $476,56 r$.

Necker $251 \mathrm{f}$., $374 \mathrm{ff}$., 385 , $3^{8} 7,389 f ., 393,396$.

Neuwerck 422.

Nicolai $547 \mathrm{ff}$.

Nicolai Nicolajewitsch 553 .

Niebuhr 267, $392 \mathrm{ff}$.

Niehuus $17 \mathbf{r}$.

Nikolaus I. 342 .

Nikolaus 535f., 538, 542.

North 371 .

Northcliffe $187,517,548 \mathrm{f}$., 575.

Nostiz 496, 499.

Oerne 459.

Oldenberg $259,494 \mathrm{ff}$.

Oldenburg-Januschau $\mathbf{I}_{4} \mathbf{r}$.

Oncken 5I7, 526, 555 .

Osborne 450 .

Osten, v. d. 453.

Ostrogorski I 98, $345 \mathrm{ff} ., 353$, $36 r$.

Paléologue $529 \mathrm{f}$.

Palm 158.

Palmerston I56f., $372 \mathrm{f}$., $429,487$.

Parnell 277.

Paschitsch 538 .

Paulsen 297f., 304, 416, 46of.

Peel 369f., 372.

Pertz 4 IIf.

Perthes 318, 386, $407 \mathrm{ff}$.

Peter d. Gr. v. Rußland 533.

Peter v. Serbien 519, 538.

Pfuel 4I4.

Pheidias 235.

Philipp von Orléans 375 .

Philippovich $45^{8}$.

Pitt d. Ä. 366, 393.

Pitt d. J. 37 I.

Platon 232f, 295.

Poincaré $529 \mathrm{f}$., 556.

Pokrowski 523, 528ff.

Poschinger 165 .
Pourtalès 533, $535 \mathrm{f}$.

Prange 463.

Praxit les 235 .

Proudhon 460.

Puffendorf 406.

Raché 555.

Ranke 303f., $404 \mathrm{f}$.

Rasputin 539, $55^{8}$.

Rau $45^{8}$.

Raveaux 4 I8.

Rechberg 43r.

Reichensperger 42I, 423 .

Reuter 517.

Reventlow 532.

Richelieu $157,365$.

Richter 465 .

Richthofen ${ }_{5} 5$.

Riesser 423.

Ritschl 233.

Robespierre 320, 384, 396.

Rodin 555.

Rödinger $422 \mathrm{f}$.

Rogers I 83, 354f.

Roosevelt I83.

Roscher I44, 308, 338, 439, $442 f ., 458,468$.

Rose 396 .

Rosebery 5 r6.

Roß 186.

Rothschild 442 .

Rousseau 74, 212.

Rümelin 297.

Ruscheweyh 287 .

Russel 127. 513f., 544f., 555.

Sachs 408.

Sassonow 521, 523, 529, 531, $533,535,538$ f., 556 .

Säckingen 305 .

Sakmann 294.

Salisbury 434 .

Sand 4 I 6.

Schäffle I83, I98f., 439. 463.

Scheffer 195.

Scherer 302, 304.

Schiemann 530.

Schiller 83, I92, $203 f$., 2 I 3 ff., 262, 284,40 r.

Schippel $489 \mathrm{f}$.

Schlaf 282 .

Schleiden 32 I.

Schleiermacher 233.

Schleinitz 162.

Schlosser I 40. 
Schlüter 254 .

Schmidt, Ad. 396.

Schmidt, Jul. 262.

Schmidt, L. 232.

Schmitthenner 552 .

Schmoller 403f., 459, 501.

Schopenhauer ro 4 .

Schotthöfer $48 \mathrm{r}$.

Schubert 7 r.

Schultze 293.

Schulz I21.

Schulze-Delitzsch 460 .

Schulze-Gaevernitz 463 , $502,549$.

Schuster $468 \mathrm{f}$.

Schwertfeger 507, $527 \mathrm{f}$.

Scotus 235.

Seeley 567 .

Shaw I71, 552.

Siéyès 383 ff., 395 .

Simson 4 I9.

Smith 296f., 356, 4 I3.

Sokrates 232.

Sombart 97, 227f., 444, 450 ff., 454 .

Soulavie 385 .

Spencer 298, 339.

Spinoza 212.

Springer $395 \mathrm{f}$, 4 I $5 \mathrm{f}$.

Staël 388ff., 396.

Stahl r 88 .

Stahr 425.

Staudinger 257, 460 .

Steele 365 .

Steffen 515.

Stein 4 roff.

Steinhausen 405 .

Stern 140, 40r.

Stöcker $435 \mathrm{f}$.
Stolypin 138, 528, 533, Wagener 164. 537 .

Strafford 363 .

Suchanoff 559 .

Suchomlinow 537, 539.

Swinton $183 \mathrm{f}$.

Tacitus 540.

Taine $398 \mathrm{ff}$.

Tallier 396.

Tarde V.

Temple I 57.

Terray 392.

Thomasius 406.

Tiedemann 433 .

Tirpitz 435 .

Tisza 256,540 .

Tocqueville $65,146,212$, $331,392 \mathrm{ff}$.

Tönnies 27, 67, I57, I70, 337, 50of., 5II, 528, 534 .

Toussenel I 56 .

Treitschke I39f., I68, 374, $400,410,416,429,444$, 473.

Trevelyan 373 .

Troeltsch 233, 244, 48 r.

Tschinke 418 .

Turgot $147,392,394$.

Ulrich 502 .

Vergonnes 385 .

Verhaeren 555 .

Veuillot 175 .

Victor Emanuel 433.

Victoria 162.

Vincke 422.

Voltaire 2r2, 309, 392.
Wagner $459,478,480 f$.

Wahl 267.

Waldeck-Rousseau 482 .

Waldersee 435 .

Walpole $34^{2}, 373$.

Ward 184 .

Washington 323 .

Webb r30, r 7 r, 449, 493, 496 .

Weber, Ad. 493, 495, 5or.

Weber, Marianne 288.

Weber, Max 132, 136, 55 I.

Weigand 13 .

Welby 239, 349.

Welcker 424 .

Wellington 157 .

Westphal 7 .

Wiesner 419.

Wilhelm I. I60, 312, 433 , 474 f., $49 \mathrm{r}$.

Wilhelm II. $\mathrm{r}_{4} \mathrm{r}, \mathrm{r}_{3}, 272$, 277 f., 292 f., 3rof., 3r4, 406,434 ff., 474 ff., 507 ff., 5I4, 535, 546, 55 I.

Wilmanns 7 .

Wilson 359, 552 .

Wimpffen $\mathrm{I} 59$.

Wimpheling 303 .

Windthorst $463 \mathrm{f}$.

Wolff 406.

Wrangel 427 .

Wundt 293, $460 f$.

Zacher 464 .

Zedler 12.

Zimmermann 422 .

Zinkeisen 157 .

Zittel 423.

Zwiedinek-Siidenhorst 195 . 


\section{Sadverzeidnis.}

Aberglaube 16, 234, 279ff., | Burenkrieg 373, 507, 509, Fakultäten ror ff., 208. $312 \mathrm{f} ., 339,514$.

Absolutismus 75, II I, I 43 ff. 269, 27I, 406, 4I 7 .

Adel 29, I09f., I20, I66f., 26If., 269, 302f.

Agitation 23, 45, 62 f., rgof., 3 II.

Angestelltenbewegung 477, 563.

Anti-Corn-Law-League 246, $368,435$.

Arbeit II8f., 262, 307. $526,543,55 \mathrm{I}$.

Burschenschaft $4 \mathrm{I} 6$.

Cäsarismus $153,157$.

Chauvinismus $309,397 \mathrm{f}$., 482.

Christentum 29, 38, 57, 233, 235f., 289, 403, 570 ff.

Dänemark I43, 432, 543 .

Daily Telegraph 277, 310, 507.

Debatte 133,317 f.

Demokratie I 53, 269, $345 \mathrm{ff}$., 357.

Demonstration 198.

Deutsche Rundschau 158.

Deutschland I09, II2, I40, 157 ff., I 67 ff., I 7 I ff., 208, 259, 262, $266 \mathrm{ff}$., $27 \mathrm{Iff}$., 275 ff., 286, 288, 292 f., $304 \mathrm{ff}$., $309 \mathrm{ff}$., $34 \mathrm{I}, 40 \mathrm{Iff}$., 45 I f., 477 f., 504 ff., 5 I 3 f., 5 I 6 ff., 532 ff., 543,547 ff., $560 \mathrm{ff}$.

Deutschnationale Volks. partei I69, I88.

Bagdadbahn 516.

Bauern II8f.

Befreiungskriege 139 .

Begriff 18,60 .

Bild I $95 \mathrm{f}$.

Belgien 52I, 524f., 550f., 553.

Bevölkerungsbewegung 127 443.

Bildung 85 f., r67, I74, $252,285,290,341$.

Birschewija Wjedomosti 528.

Bodenreform I71, 477f., 573.

Bolschewismus 563,567 .

Börse $95 \mathrm{f}$.

Bourgeoisie 26r, 272, 328, $358,417$.

Buddhismus 38, 57, 233.

Bulgarien 5I9, 549.

Bund der Landwirte 272.

Einkommensteuer 480 ff.

Eintracht $66 \mathrm{ff}$.

Elsaß-Lothringen 255, 310, $400,4 \mathrm{I} 5,526 \mathrm{f} ., 555$.

England I rof., I56f., I67, r69ff., I96, 208, 227, 253f., 259, 26r, 265f., 27 Iff., 284 ff., 290, 309, 322, $336 \mathrm{f}$, 339, 34I, 343, 345 , $354,362 \mathrm{ff} ., 4 \mathrm{I} 7,446 \mathrm{f}$., $456,462,482$ ff., $492 \mathrm{f}$., 496, 506ff., 5 Ioff., 543, 547,550 ff., $566 \mathrm{ff}$.

Entente 276, 310, 398, 5 I $7 \mathrm{f}$., $526,535,539,542,55^{8}, 566$.
Familie 66, 287, 573 .

Finland 543,569 .

Flotte 432, 435, 506, 508, 526.

Flottenverein 278, 435 .

Frankfurter Zeitung 172 .

Frankreich IIof., I39f., . $\mathrm{I} 59 \mathrm{f}$, I $66, \mathrm{I} 75, \mathrm{I} 8 \mathrm{I}, \mathrm{I} 92$, r97f., 208, 25 If., 264 ff., 27I, 275 f., 309f., 315, $34 \mathrm{I}, 354,365 \mathrm{f} ., 374 \mathrm{ff}$., 40I, 406, 4IO, 4I7, 453, 479 ff., 49 Iff., 506,5 I3, 5I6ff., 525 ff., 543, 547, $55 \mathrm{I}, 555 \mathrm{ff} ., 565$.

Frauenarbeit $445,475,477$, 493.

Frauenfrage $263 f ., 288,339$, $353,465,56 \mathrm{I}$.

Freihandel 15, 172, $258 \mathrm{f}$, 273 ff., 312, 366ff., 406, 488.

Freiheit 64f., 139, 166, 214, $258 \mathrm{ff} ., 367,406,410,439$.

Freimaurer I75, 196f., 237 . 309,480 .

Friede zu Frankfurt r 59 f., $525 \mathrm{f}$.

Friede von Versailles $188 \mathrm{f}$., $56 \mathrm{I}, 568$.

Ehe 238,287 f., 289, 468, 573. Führer 3 If., 36 ff., 206f., $462,489 f ., 564$.

Fürst I rof., 142, 144 .
Gazette de France $148,158$. Gefühl 4, 12 f., 19, 2 I, 4I, 44 . Geistlichkeit 30, I09f., I2O, I75, $207 \mathrm{f}$., $302 \mathrm{ff}$.

Gelehrte 89, I0I f., I06, 2 I2. Gemeinschaft 21, 44, 80, 9If., 2Igff., 242, 270 , $337,439,564$.

Genossenschaften 446,455 ff $476,479,573$.

Gesellschaft 2I, 80, 92, 200, 219ff., 242, 270, 337, $408,439,564$. 
Gesetzgebung 74 ff., I 51 .

Gewerkschaften 446,45 If., 474, 476, 479.

Gewissensfreiheit I24, 284 .

Gewohnheit 5If., 54, 64, $67 \mathrm{ff} ., 86,407$.

Glaube I5ff., 2 Iff., $38 \mathrm{ff}$., $52,64,56 \mathrm{f}, 3 \mathrm{O}, \mathrm{II}_{4} \mathrm{f}$., I 20 ff., 280,302 .

Gleichheit 260, 336, 406, 410, 442, 492, 503.

Gottheit I 5, 38f., 70, 92, II 5 f., I 22, 283 .

Großstadt $246 f$.

Grundbesitz I18, I66f.

Häresie I5, 29, 38, Iogf., I22, $283 \mathrm{f}$.

Hamburgischer Korrespondent 565 .

Handel 29, 95 f., 98, 307 ff., 339, $444 \mathrm{ff} ., 563 \mathrm{f}$.

Handwerk 29.

Heterodoxie I I4f., I 74 .

Hexenprozesse 167, 281.

Humanismus 208.

Hungerblockade 567 .

Indien 567.

Irland 265 f., 275, 567, 569 . Islam $38,57,233$.

Italien I97, 302, 433, 454. 509, 519, 533, 54r, 569.

Jakobinerklub 197, 384, 393. Jesuiten I 75, I96, 289, 309 . Journal de l'Empire 158. Journalisten $178 \mathrm{ff}$.

Journal officiel 148 .

Juden 38 , I68f., I73, I75, I 88,227 f., 233, 445, 532, 562.

Jurisprudenz 26 , rorf.

\section{Kamarilla 272.}

Kapital II8f., I66f., I79ff. Kapitalismus 307, 470f., $478,563$.

Kathedersozialismus $\mathbf{1 7 2}$, $312,470 \mathrm{f}$.

Katholische Presse I $76 \mathrm{f}$.

Katholizismus 29, $174 \mathrm{ff}$, 233, $279,363 \mathrm{f}$.

Kaufmann 96f., 204, 444. Kinematograph $83 \mathrm{f}$.

Kirche 22, 57, rogf., I $21 \mathrm{ff}$.,
I 74ff., 303 ff., 402 ff., 439, Menge 25, 27, 3I, 37, I20, $570,572$.

Klassen 28, 30, 327 f., 335 , $34 \mathrm{I}, 353,360$.

Klassenkampf $28 \mathrm{ff}$., $6 \mathrm{r}$, I08f., I66f. s. Arbeiterbewegung.

Koalitionsrecht 447 ff., 503 . Kölnische Volkszeitung 176 .

Kölnische Zeitung 172, 473.

Kollektivwille 66 ff., 8o, 2 r9.

Kolonien 264, 337 ff., 435 , 487 f., 506.

Kompromiß I33.

Konservative Partei 272.

Konservativismus 64 , I I $2 \mathrm{ff}$., I66f.

Konstantinopel 528, 539 .

Konsumverein $455 \mathrm{ff}$. siehe Genossenschaft.

Konvention $7 \mathrm{r}$ ff., 228, 409 .

Krieg 42, 98, I 25 f., 205, 237, $256,313,504 \mathrm{ff}$. 5 I 5 f., 544 f., 570 .

Kriegspresseamt $547 \mathrm{f}$.

Krimkrieg 373.

Kritik I6, I2 If.

Künstler 25, 2 I $3 \mathrm{ff}$.

Kürwille $18,27,34,40 \mathrm{f}$, $44,46,60,63,7 x, 78$, 105, 20I, 219, 254, 3I6.

Kultur 8o, 227, 356.

Kulturkampf I62, 309f., 463.

Kunst 89, r95f., 574 .

Labour party I72, $567 f$.

Land $28 \mathrm{f}$., II $9 \mathrm{f}$.

Laisser faire $259,3 \times 2,328$, 445.

Lehre 53, $56 \mathrm{ff} ., 60 \mathrm{ff} ., 231$.

Lehrer 208f., 328, 4ז6.

Liberalismus $6 \mathrm{I}$, I $12 \mathrm{ff}$., I $66 \mathrm{ff} ., 2$ I, 3 I of., 476 .

Manchester Guardian 545.

Marokko 310, 513, 522, 526.

Maschine $198,342,345 \mathrm{ff}$.

Materialismus $283 \mathrm{f}$.

Matin 517.

Medizin 26, 102.

Mehrwert 307.

Meinungsäußerung 23, 32 ff., $45,49,8 \mathrm{r}, 203 \mathrm{f}$.

Meinungskämpfe 89 , гоo, 177.
$319,335$.

Militarismus I4I, $264 \mathrm{ff}$.

Mode $40 \mathrm{f}$., $72 \mathrm{f}$., 200, 274 , 293, 296, 299, 388.

Monarchismus $65,166,27 \mathrm{x}$, 3 I $_{4}$ ff., 358, 396, 406, $42 \mathrm{I}$.

Moral 236ff., $242 \mathrm{ff} ., 288 \mathrm{ff}$.

Nachrichten $94 \mathrm{ff}$.

Nachrichtenfälschung 98.

Nationalgefübl 429, 5IIf.

National Review 14.

Nationalversammlung 56r.

Nationalzeitung 106, 463 .

New Statesman 74, I87, 5 I 5 ff., 524, 550, 568.

New-York Evening Post 543.

Niederlande 520, $55 \mathrm{I}$.

Novoje Vremja $5 \mathrm{I} 7$.

Offentliche Meinung $77 \mathrm{f}$., I29, I3I ff., 177.

eine ö. M. I $29 \mathrm{f}$., I $37 \mathrm{ff}$.

die O. M. I 3 Iff., I $_{37}$ ff., I $_{54}$, I 77 ff., 219,229 ff., 236 ff.,

Österreich-Ungarn 163 , 256, 4I 2 f., 43I, 433f., $505,509 \mathrm{f}$, $5 \mathrm{r} 8 \mathrm{ff} ., 534 \mathrm{ff}$., $538 \mathrm{ff} ., 549,553,556$.

Oligarchie $\mathbf{I} \mathbf{I}$.

Opposition ro8, I 50 f.

Ordnung $239 \mathrm{ff}$.,

Orthodoxie $\mathrm{II}_{4} \mathrm{f}$., I $74 \mathrm{ff}$.

Paris 246, 388f., 393, 4Io.

Parlament 322.

Parlamentarismus 272.

Parteien $35 \mathrm{ff} ., 40,43,62 \mathrm{ff}$., 99, I08ff., I 52, I 79, 250, 290, 318f., 329f., 345 ff., 357.

Parteiregierung I50, 153.

Paulskirche I64, 4 I $8 \mathrm{ff}$.

Politik 160, 165, $252 \mathrm{ff}$, $279,435,524,566$.

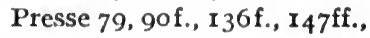
I $55, \quad 158, \quad 168, \quad 172 \mathrm{f}$., 175 ff., r $93,255,276,322$, $324 \mathrm{f}$., $348 \mathrm{ff}$., $354,360 \mathrm{f}$., 516f., 527, 531f., 534, 546 ff., 550 ff., 557 f., 562 , $574 \mathrm{f}$. 30off., 371, 374, 544 . 
Preßfreiheit I25, 127, 129, Revolution, deutsche 1918| Sozialpolitik, Verein für I49, 175, 383 .

Preußen 257, 424, 560 . II 2 f., I I 5, I 29, I 53, 31 4 f., $549,560 \mathrm{ff}$.

Priester 22, 30, 70, 9If., I I6f. Rumänien 256, 542.

Privateigentum 76, II 2 , I I $9,259,439,466$.

Produktivgenossenschaft $45^{8}$.

Proletariat 76, III, II 8 , I28, I66, I69.

Propaganda $79 \mathrm{f}, 104,357$, 368.

Protestantismus $29, \mathrm{I} 74 \mathrm{ff}$., 232.

Prozesse 267, 292.

Publizistik r9o.

Rassen 355, 358.

Rationalismus 282 .

Recht 68f., 74f., 239ff., 24 Iff., 290,457 .

Erbrecht 288.

Gewohnheitsrecht 68 .

Naturrecht 6r.

Privatrecht 76, II2, 166, $287,440,47$ I.

Staatsrecht 74 .

Strafrecht I 47, 286f., 290.

Völkerrecht 74, 515 .

Rechtsanwalt 2 ro.

Redefreiheit I26, 149.

Redner 93, 209, $318 \mathrm{ff}$.

Referendum I $53 \mathrm{ff}$.

Reformation 25, 100, 109,

Privateigentum $76, I 12, I 19$, $439,466$.

I 24, I 74, 303ff., $402 \mathrm{ff}$., $444,472$.

Reformbill IIx, 366ff.

Regierung I08ff., I42, I $47 \mathrm{ff}$., 314.

Regiment $108 \mathrm{ff}$.

Reichstag 278.

Religion $21 \mathrm{f} ., 29,32,38 \mathrm{ff}$., 59f., 65, 69ff., $152 \mathrm{f}$., 202, 23off., $283,289 \mathrm{f}$., 300 ff., $466 \mathrm{f} ., 474,564$, $569 \mathrm{ff}$.

Republiki66, 3I4f., 357,397.

Resolution 47.

Revolution, engl. 1688 I I of.

- franz. I789 IIO, I39, I92, 25 If., 267,365 , 374 ff., 406, 4 Io.

- - I830 139, 401, 417.

-deutsche I $84^{8} 424 \mathrm{ff} ., 433$.

Rußland III, 276, 433, 488,505 ff., 518, 530 ff., $542 \mathrm{f}$., 545, 555f., 558f., 568 .

Samoa 508.

Satzung 53 .

Sitte 67 ff., 73 f., $289,297 \mathrm{ff}$. Sittlichkeit 289, 560, 564f., 570, 573 .

Skandale 267,276 .

Sklaverei 260, 264, 3IIf., $338,354,357,373,439$, 490.

Schlagwort 62f., 250 ff., 258, 3 I 4 .

Schleswig-Holstein 32I, $43 \mathrm{If}$.

Schottland I Io.

Schriftsteller 88, 146, 2 I Iff., 328.

Schuldfrage $14 \mathrm{I}, 5 \mathrm{O}_{4} \mathrm{ff} .9$ $55^{8}, 56 \mathrm{r}, 568$.

Schulwesen 286.

Schutzzoll 32 I s. Freihandel.

Schweden 543 s. Skandinavien.

Schweiz I54f., 454, 457, 462.

Sekten IIO, I2I.

Serajewo $5 \mathrm{r} 8 \mathrm{f} ., 535,537 \mathrm{ff}$. , 556.

Serbien 505, 510, $518 \mathrm{ff}$., 534 ff., $538,542,556,558$.

Skandinavien 457,569 .

Sozialdemokratie 64 , Ir3, 3Ioff., 45I, 456f., $462 \mathrm{ff}$., $49 \mathrm{Iff} ., 548,560,562 \mathrm{f}$.

Soziale Frage 439ff., 562.

Soziale Gesetzgebung 76, $36 \mathrm{r}, 367,445,474 \mathrm{f}$.

Soziale Reform I7If., 446, $474 \mathrm{ff} ., 478,572 \mathrm{f}$.

Gesellschaft für Soziale Reform 452, 476.

Sozialisierung 562 .

Sozialismus II $\mathrm{f}$., $44 \mathrm{rff}$., $489 \mathrm{f} ., 572 \mathrm{f}$.

Sozialismus, christlicher, $439,474 \mathrm{f}$.

Sozialistengesetz 163,312 , ${ }_{4} 6{ }_{4} \mathrm{ff}$.
I 72, 452, 476 .

Sowjet-Rebublik 76 , IIIf., 563f., $568 \mathrm{f}$.

Spanien 208, 261, 569.

Sprache $45,82$.

Staat $43,57,75 \mathrm{f}$, I IO, I 22 ff., 268 ff., 309 ff., 340, $367,486 \mathrm{f}$.

Staat und Gesellschaft 75 ff.

Staatsanzeiger $\mathbf{I}_{4} 8$.

Staatsmann $96 \mathrm{f}$., $\quad 156 \mathrm{ff}$. 204, 255 ff., 277, 319.

Stadt 28f., 67, roo, ro3, II 9 .

Stand $28,376 \mathrm{ff}$.

Strafgesetzbuch 130, I59, 292.

Tag, Der 106.

Technik 290, 357.

Temps 517.

Test Act III.

Theater 82f., I5O.

Theokratie 269, 27 I.

Theologie 26, 38, 70, IOI.

Times 130, $156,158,187$, 419, $513 \mathrm{f}$.

Tory I67, 169f., 483,485 .

Trade Unions 447 ff., $492 \mathrm{f}$.

Trust $454 \mathrm{f}$.

Türkei 519, 533, 535, 567 .

Ubereinstimmung $25 f$., 44 .

Utberlieferung $9 \mathrm{If}$.

Unabhängige Sozialdemokratische Partei 549.

Universitäten 207 f., 4 I6.

Unternehmer $307 \mathrm{f}$., 445 .

Vaterlandspartei 127, 547 .

Verein $43,47 \mathrm{f}$., 57, r96f., 325.

Vereinigte Staaten $182 \mathrm{ff}$., 227, 259ff., 269f., 272, 290, $322 \mathrm{ff}$., $454 \mathrm{f}$., 477 , 48gf., 49I, 495, 5I4, 543, 547, 549, 554f., 568, $574 \mathrm{f}$.

Verfassung II8f., 27If.

Verkehr I03, 3I6f.

Versammlung $133 \mathrm{ff} ., \mathrm{I}_{97} \mathrm{f}$., 209.

Volksherrschaft $323 \mathrm{f}$.

Volksstimmung I53f., 257, 313f., 322, 544f., 449, 554 . 
Wahlen 35 f., I 53, I55, 322, $44,46,5$ If., 7 I, I05, 2 I9. $\mid$ Zabern I4I, 266, 268. $325,329 \mathrm{ff} ., 342 \mathrm{ff}$.

Wahlrecht $153,361,367$, Westfälischer Merkur I 76. $423,428,482 \mathrm{f}$., $560 \mathrm{f}$.

Weltanschauung 564 .

Weltkrieg 125, 258, $272 \mathrm{f}$., Wien I26f.

357, 36o, 367, 398, 406, Wissenschaft $2 \mathrm{If}$., $38 \mathrm{f}$., 57 . 435, 488, 49r, 5r $8 \mathrm{ff} .$, Wohltätigkeit 289f., 352, $540 \mathrm{f} ., 546,570,573 \mathrm{f}$. $356,439$.

Zeitung 84 , $90 \mathrm{f} ., 94 \mathrm{ff}$., 99f., 104, 136, I48, I $58 \mathrm{f}$., I 74, I 77 ff., I93f., I99. Zensur I $25 \mathrm{ff} ., 147,546 \mathrm{ff}$., $55^{8}$.

Wesenwille $7,17 \mathrm{ff} ., 27,4 \mathrm{I}$, Wucher $306 \mathrm{ff}$.

Zentrum 463 f., $54^{8}$.

Zins $306 \mathrm{ff}$.

Zivilisation $80,227,356$. 
Druck der Spamerschen Buchdruckerei in I,eipzig. 
Lehrbuch der Geschichtsphilosophie. Von Dr. Georg Mehlis, Professor an der Universität Freiburg i. Br. I9I5.

Preis M. 20.-; gebunden M. 23.-

Psychologie der Weltanschauungen. Von Dr. phil. Karl Jaspers, ord. Professor der Philosophie an der Universität Heidelberg. $Z$ weite, durchgesehene Auflage. Erscheint im Sommer 1922

Der Gegenstand der Psychologie. Eine Einführung in das Wesen der empirischen Wissenschaft. Von Paul Häberlin, ordentlicher Professor an der Universität Bern. 1921. Preis M. 48.-

\section{Psychologie der Zusammenhänge und Be-} ziehungen. Von Dr. med. Vera Strasser in Zürich. I92I.

Preis M. 96.-; gebunden M. I ro.-

\section{Naturgeschichte der Seele und ihres Bewußt-}

Werdens. Eine Elementarpsychologie. Von Dr. Eugen Bleuler, o. Professor der Psychiatrie an der Universität Zürich. Mit 4 Textabbildungen. 1921. Preis M. 66.-; gebunden M. 78.-

Intelligenzprüfungen an Menschenaffen. von Wolfgang Köhler. $Z$ weite, durchgesehene Auflage der ,Intelligenzprüfungen an Anthropoiden I“", aus den Abhandlungen der PreuB. Akademie der Wissenschaften, Jahrgang 19I7, physikalisch-mathem. Klasse, Nr. I. Mit 7 Tafeln und I9 Skizzen. I921.

Preis M. 66.—; gebunden M. 78.-

Psychologische Forschung. Zeitschrift für Psychologie und ihre Grenzwissenschaften. Herausgegeben von K. Koffka in Gießen, W. Köhler in Berlin, M. Wertheimer in Berlin, K. Goldstein in Frankfurt a. M., H. Gruhle in Heidelberg. Erscheint in zwanglosen, einzeln berechneten Heften, die zu Bänden von 20-30 Bogen vereinigt werden. 
Sozial-Idealismus. Neue Richtlinien sozialer Erziehung. Von Paul Natorp. $Z$ weite, unveränderte Auflage (unveränderter Neudruck). I922.

Preis M. 90.-

Genossenschaftliche Erziehung als Grundlage zum Neubau des Volkstums und des Menschentums. Thesen nebst Einleitung. Von Paul Natorp. I920.

Preis M. $5 \cdot 50$

\section{Aufsätze zur deutschen Revolution. Von Hans von Hentig. I9I9. \\ Preis M. 2.60}

Der Friede von Versailles. Wirtschafts- und sozialpolitische Ausblicke. Von Adolf Braun. I9I9.

\section{Der Friedensvertrag und Deutschlands Stel-} lung in der Weltwirtschaft. Beiträge von Moritz Julius

Bonn-Berlin, Hans Bredow-Berlin, Heinrich Dade-Berlin, August EulerFrankfurt a. M., Franz Eulenburg-Kiel, Ernst Francke-Diessen, Emil Guggenheimer-Berlin, Walther Jung-Berlin, Herbert Kraus-Königsberg, Alfred Lansburgh - Berlin, Franz Lusensky - Berlin, Albrecht Macco-Köln, Carl Scholz-Berlin, Peter Stubmann-Hamburg, Georg de Thierry-Berlin, Walther Vogel-Berlin. Herausgegeben von der Deutschen Weltwirtschaftlichen Gesellschaft, E. V. Mit einer Übersichtskarte. I921. Preis M. 28.-

Das Völkerrecht. Systematisch dargestellt, von Dr. Franz von Liszt, o. ö. Professor der Rechte der Universität Berlin. $Z$ wölfte Auflage. Von Prof. Dr. Max Fleischmann, Halle a. S. In Vorbereitung.

Das neue Arbeitsrecht. Systematische Einführung von Professor Dr. jur. Walter Kaskel in Berlin. Vierte, unveränderte Auflage. 1922.

Gebunden Preis M. 96.- 


\title{
Friedrich Engels \\ Eine Biographie von Gustav Mayer
}

\author{
Eirster Band:
}

\section{Friedrich Engels in seiner Frühzeit (1820-185I)}

Mit einem Bildnis. I920. Preis M. 22.-; gebunden M. 26.80

Eirgänzungsband:

\section{Friedrich Engels / Schriften der Frühzeit}

Aufsätze, Korrespondenzen, Briefe, Dichtungen aus den Jahren 1838-1844 nebst einigen Karikaturen und einem unbekannten Jugendbildnis des

Verfassers. I920. Preis M. 26.-; gebunden M. 38.-

Aus den zahlreichen Besprechungen:

... diese Mayersche Biographie erschließt uns Quellen, die bisher nicht sprudelten, und gibt uns ein plastisches und gut abgerundetes Bild aus der Frühzeit des deutschen Sozialismus . . . „Der Tag“"

... Mayer ist kein Biograph im Sinne trockener Historie, er ist vielmehr Porträtist. Er gibt uns von seinem Helden nicht bloß zu hören, sondern er läßt ihn uns auch sehen, er ist kein Nekrologist, sondern er macht lebendig . . .

"Vorwärts"

...Wenn dies Werk in erster Linie die Geschichtschreibung des neuzeitlichen Sozialismus um eine Arbeit bereichert, an der fortan niemand wird vorbeigehen dürfen, so ist es zugleich eine in hohem Grade fesselnde Schilderung der Entwicklung des politischen Geistes im Deutschland des Vormärz.

"Berliner Tageblatt"

Feinheit und Tiefe der Auffassung bei hervorragender Sachkenntnis, psychologischer und historischer Takt, weiteste Durchdringung des zeitgeschichtlichen Hintergrundes, insbesondere vorzügliche Beherrschung der Hegelschen Philosophie und ihrer Ausläufer, dazu eine ungemein lebensvolle, durchsichtige und gebändigte Darstellung rücken dieses Buch wissenschaftlich wie literarisch in erste Reihe der historiographischen Neuerscheinungen der letzten Jahre.

„Der neue Merkur"

... Wie Engels, der spätere Kommunist und Verbündete von Karl Marx, aus einer durchaus konservativ gerichteten, wohlhabenden bergischen Familie hervor- und hinauswuchs, das ist ein menschlich und sozialpsychologisch gleichbedeutsamer Vorgang, der in seiner seelischen Kompliziertheit und in seinen geschichtlichen Folgen die Ausführlichkeit vollauf rechtfertigt, mit der G. Mayer in diesem ersten Band die Frühzeit, die Lehr- und Wanderjahre scines Helden darstellt ...

Die menschlichen und die literarisch-politischen Urkunden der Frühzeit sind die farbige Illustration und bestätigende Dokumentierung der Mayerschen Darstellung ... „Deutsche Revue'“ 
Das neue deutsche Wirtschaftsrecht. Eine systematische Übersicht über die Entwicklung des Privatrechts und der benachbarten Rechtsgebiete seit Ausbruch des Weltkrieges. Von Dr. Arthur Nußbaum, a. o. Professor an der Universität Berlin. 1920. Preis M. 16.-

Die volkswirtschaftliche Bilanz und eine neue Theorie der Wechselkurse. Die Theorie der reinen Papierwährung. Von Edmund Herzfelder. I9I9.

Preis M. 24.-; gebunden M. 26.40

\section{Die Verkehrsmittel in Volks- und Staatswirt-} schaft. Von Dr. Emil Sax, o. ö. Professor der politischen Ökonomie i. R. Zweite, neubearbeitete Auflage.

Erster Band: Allgemeine Verkehrslehre. I9I8. Preis M. I0.Zweiter Band: Land- und Wasserstraßen, Post, Telegraph, Telephon. I920.

Preis M. 48.-; gebunden M. 66.-

Dritter (SchluB-) Band: Eisenbahnen. Erscheint im Mai 1922.

Der Kapitalzins. Kritische Studien. Von Dr. Emil Sax, o. ö. Professor der politischen Ökonomie i. R. I9I6. Preis M. 6.-

Die Seehafenpolitik der deutschen Eisenbahnen und die Rohstoffversorgung. Von Dr. Erwin

v. Beckerath, Privatdozent an der Universität Leipzig. I9r8.

Preis M. II.-

Das Seefracht-Tarifwesen. Von Dr. Kurt Giese, Oberregierungsrat in Hamburg. 1919. Preis M. 34.-; gebunden M. 40.-

Die Reichseisenbahnen. Gedanken und Vorschläge zur Finanzwirtschaft und Organisation des deutschen Verkehrswesens. Von Regierungsrat R. Quaatz in Köln. I9I9. Preis M. 2.40. 
Lehrbuch der Geschichtsphilosophie. Von Dr.Georg Mehlis, Professor an der Universität Freiburg i. Br. I9I5.

7. Preis M. 20.-; gebunden M. 23.-

Psychologie der Weltanschauungen. von Dr. phil, Karl Jaspers, ord. Professor der Philosophie an der Universität Heidel-

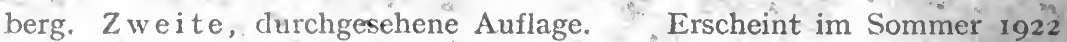

Der Gegenstand der Psychologie. Eine Einführing in das Wesen der empirischen Wissenschaft. Von Paul Häberlin, ordentlicher Professor an der Universität Bern. I921.

Preis M. 48 . -

Psychologie der Zusammenhänge und Beziehungen. Von Dr. med. Vera Strasser in Zürich. Ig21. Preís M. 96.-; gebunden. M. Iro.- -

\section{Naturgeschichte der Seele und ihres Bewußt-} Werdens. Eine Elementarpsychologie. Von Dr. Eugen Bleuler, o. Professor der Psychiatrie an der Universität Zürich. Mit 4 Textabbildungen. I921. Preis M. 66.-; gebunden M. 78.-

Intelligenzprüfungen an Menschenaffen. Von Wolfgang Köhler. $Z_{w}$ ite, durchgesehene Auflage der ,Intelligenzprüfungen an Anthropoiden I", aus den Abhandlungen der Preuß. Akademie der Wissenschaften, Jahrgang I9I7, physikalisch-mathem. Klasse, Nr. I. Mit 7 Tafeln und I9 Skizzen. I9zI.

Preis M. 66. ; gebunden M. $78 .-$

Psychologische Forschung. Zeitschrift für Psychologie und ihre Grenzwissenschaften. Herausgegeben von K. Koffka in Gießen, W. Köhler in Berlin, M. Wertheimer in Berlin, K. Goldstein in Frankfurt a. M., H. Gruhle in Heidelberg. Erscheint in zwanglosen, einzeln berechueten Heften, die zu Bänden von $20-30$ Bogen vereinigt werden. 



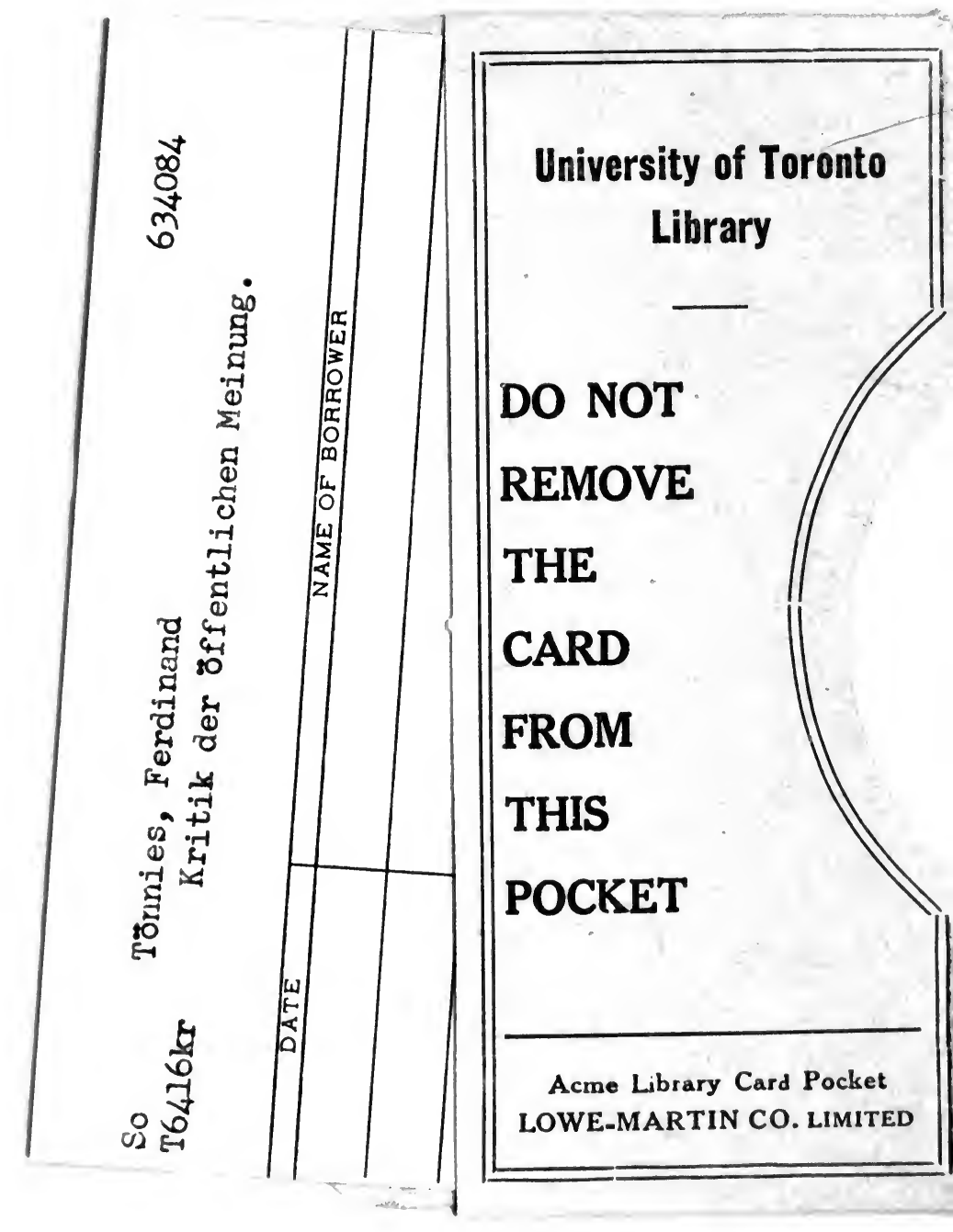


